\title{
Doris Schweitzer
}

\section{Juridische Soziologien}

Recht und Gesellschaft von

1814 bis in die 1920er Jahre 
Schriftenreihe

Theorie und Geschichte der Soziologie

herausgegeben von

Prof. Dr. Hans Braun und Prof. Dr. Uta Gerhardt

Band 4 
Doris Schweitzer

\section{Juridische Soziologien}

Recht und Gesellschaft von

1814 bis in die 1920er Jahre

\section{Nomos}


Die Veröffentlichung der Druckausgabe sowie die Open Access-Veröffentlichung der elektronischen Fassung wurden ermöglicht mit Unterstützung durch die Deutsche Forschungsgemeinschaft (DFG).

Die Deutsche Nationalbibliothek verzeichnet diese Publikation in der Deutschen Nationalbibliografie; detaillierte bibliografische Daten sind im Internet über http://dnb.d-nb.de abrufbar.

Zugl.: Justus-Liebig-Universität Gießen, Habil., 2020

1. Auflage 2021

(c) Doris Schweitzer

Publiziert von

Nomos Verlagsgesellschaft mbH \& Co. KG

Waldseestraße 3-5 | 76530 Baden-Baden

www.nomos.de

Gesamtherstellung:

Nomos Verlagsgesellschaft mbH \& Co. KG

Waldseestraße 3-5| 76530 Baden-Baden

ISBN (Print): 978-3-8487-6878-3

ISBN (ePDF): 978-3-7489-0973-6

DOI: https://doi.org/10.5771/9783748909736

\section{(9) $(9 \Theta$}

Dieses Werk ist lizenziert unter einer Creative Commons Namensnennung

- Nicht kommerziell - Keine Bearbeitungen 4.0 International Lizenz. 


\section{Inhaltsverzeichnis}

Einleitung

$\$ 1$. Auf der Suche nach der Gesellschaft im Recht: Methodologische Überlegungen

I. Die soziologiegeschichtliche Perspektive: Gesellschaft als „epistemisches Ding“

1. Das „epistemische Ding“ Rheinbergers

2. Soziologiegeschichte als Geschichte des epistemischen

Dings, Gesellschaft

2.1 Soziologiegeschichte als Objektgeschichte

2.2 Objektgeschichte und Gesellschaftstheorie

II. Rechtssoziologische Orientierungen: Das epistemische Dispositiv der Rechtswissenschaft

1. Dispositivanalyse, epistemisches Dispositiv und Recht

1.1 L'urgence

1.2 Das epistemische Dispositiv der Rechtswissenschaften

1.3 Problematisierung

2. Recht und Autonomie

3. Recht, Wahrheit und Normativität

4. Recht und Soziologie

5. Recht und Macht

6. Erschließungsebene

Erster Teil. Von der Gesellschaft im Recht zum Recht der Gesellschaft: Juridische Adressierungen des Sozialen

\2. Die Entdeckung der Gesellschaft im Privatrecht: Das Repräsentationsdispositiv der Historischen Rechtsschule (1814ca. 1860er Jahre)

I. L'urgence: Die drohende Kodifikation (Anton Friedrich Justus Thibaut)

II. Die Entdeckung des Volksgeistes im Recht (Friedrich Carl von Savigny) 
1. Die Umdeutung der Kodifikation in ein epistemisches Problem

1.1 Die Rechtsentstehung im Volksgeist 79

1.2 Organologische Volksgeistlehre 81

1.3 Von der politischen zur epistemischen Frage 84

2. Epistemische Folgen I: Die Rechtstheorie der Volksgeistlehre

2.1 Rechtswissenschaft als „Wissenschaft der Wirklichkeit“ 87

2.2 Die Reinigung des Rechtsbegriffs

2.3 Die Autonomisierung des Rechts und der

Rechtswissenschaft

Autonomisierung in der geschichtlichen Entwicklung

Die Bestimmung der rechtswissenschaftlichen Methode

Die rechtserzeugende Kraft der Rechtswissenschaft 97

2.4 Recht und Repräsentation

Repräsentation I: Recht als Repräsentation des

unsichtbaren Volksgeistes

Repräsentation II: Der Privatrechtswissenschaftler als

Gesellschaftswissenschaftler

3. Epistemische Folgen II: Dogmatisch-methodische Praktiken der Volksgeistlehre

3.1 Historische Wissenschaftspraktiken

3.2 Die dogmatisch-methodische Arbeit: Der Volksgeist in den rechtswissenschaftlichen Praktiken und Techniken Volksgeist und Systemerkenntnis: Induktion - Deduktion - Rekonstruktion

Der methodische Weg: Volksgeist, Auslegung und Sinnverstehen

III. Der Volksgeist im rechtstheoretischen „Feld der Gegnerschaft“:

Die Problematisierung des Rechts angesichts der vorausgesetzten gesellschaftlichen Wirklichkeit

1. Recht als „lebendes Recht“

1.1 Der lebendige Charakter des historisch gewachsenen Rechts

1.2 Das Scheitern des normativen Rechtsbegriffs: Der Rückzug der naturrechtlich-rechtsphilosophischen Kritik

Von der Kritik zur Arbeitsteilung: de lege lata und de lege ferenda

Kongruenzen zwischen Historischer Rechtsschule und Rechtsphilosophie 
2. „Lebendes Recht“ und Repräsentation der gesellschaftlichen Wirklichkeit

2.1 Missrepräsentationen I: Eigenes versus fremdes Recht, gegenwärtiges Volksrecht versus Juristenrecht (Beseler)

2.2 Missrepräsentationen II: Die „Bedürfnisse der Zeit“ und das Recht der Gegenwart

2.3 Nichtrepräsentierbarkeit des lebenden Rechts: Die Unmöglichkeit der Rechtswissenschaft (Kirchmann)

2.4 Politische Repräsentationsprobleme: Römisch-liberales versus germanisch-soziales Recht

3. „Lebendes Recht“ als Repräsentationsproblem

IV. Der Volksgeist in der Rechtsdogmatik: Die Problematisierung der Eigenart und des Werts der Rechtswissenschaft

1. Die Eigenart der Jurisprudenz angesichts des „lebenden Rechts": Produktive Jurisprudenz (Georg Friedrich Puchta) 145

1.1 Das Recht der Wissenschaft

1.2 Die Korrekturen der juristischen Logik durch den Volksgeist

2. Der „Wert“ der Jurisprudenz für das Leben: Die Konstruktionsjurisprudenz (Rudolph von Jhering)

2.1 Innen und Außen des Rechtsorganismus: Logik und Leben

2.2 Die juristische Technik

3. Rechtsdogmatik und Leben

V. Das epistemische Dispositiv der Repräsentation

1. Recht und Repräsentation

2. Recht und Politik

3. Die Entdeckung der Gesellschaft im Recht

\$3. Auf dem Weg zur Entdeckung des Rechts der Gesellschaft: Jherings Zweckdenken im Recht

I. Rudolph von Jherings Entdeckung des „Rechts der Gesellschaft"

1. L'urgence: Die Ungerechtigkeit der juristischen Konstruktion

1.1 Kritik am Wert der juristischen Konstruktion

1.2 Auf der Suche nach dem wahren Ursprung des Rechts

1.3 Das Ringen um Gerechtigkeit

2. Die Entdeckung des Rechts der Gesellschaft: Der Zweck im Recht 
2.1 Die treibende Kraft des Zwecks im Recht 187

2.2 Die Gesellschaft und ihr Recht 190

2.3 Das Recht der Gesellschaft: Norm und Zwang 193

2.4 Das Spannungsverhältnis zwischen Gesellschaft und Individuum: Die „sociale Mechanik“ 198

2.5 Die funktionale Rechtsanalyse 201

3. Die Neuverortung der Rechtswissenschaft 204

3.1 Rechtswissenschaft als Teil der

Gesellschaftswissenschaft 204

3.2 Die Rechtswissenschaft in der Gesellschaftswissenschaft 206

3.3 Die Kritik an der „Begriffsjurisprudenz“ 207

3.4 Rechtswissenschaft und gesellschaftliche Entwicklung 210

II. Die ambivalente Rezeption des Zwecks (ca. 1880-1900) 212

1. Der Erfolg des Zwecks außerhalb der Privatrechtswissenschaft

1.1 Der Zweck in der Philosophie und in den Sozialwissenschaften

Der Zweck in der Ethik

Der Zweck und die Kulturwissenschaften

Der Zweck in den Sozialwissenschaften

1.2 Der Zweck in den Staats- und Strafrechtswissenschaften

Der Zweck in der Staatslehre

Der Zweck im Strafrecht

1.3 Der Zweck in der Rechtsphilosophie

Rechtspositivismus (Bergbohm)

Neuhegelianismus (Berolzheimer)

Neukantianismus (Stammler, Lask)

Der rechtsphilosophische Zweck

2. Die Ablehnung des Zwecks im Fachdiskurs der Privatrechtswissenschaften

\$4. Zweck-Dispositiv I: Die soziale Aufgabe des Privatrechts und das gesellschaftsfunktionale Zweckdispositiv (ca. 1880er-1900)

I. L'urgence: Die zu bewältigende Kodifikation des Privatrechts

1. Eine kurze Geschichte der Kodifikation des BGBs

2. Kodifikation als Bestandsaufnahme

3. Die Verabschiedung des Gewohnheitsrechts

II. Die Kritik des Entwurfs des BGBs im Namen der „sozialen Aufgabe“ 
1. Die Diffusität des Sozialen: „Soziale Aufgabe“, „Sozialpolitik“, „Soziale Frage“ etc.

2. Der "kleine Windscheid“

2.1 Römisch-individualistisches versus deutsch-soziales Recht

2.2 Die soziale Aufgabe und die Rechtswissenschaft

III. Der Zweck des Rechts: Die Sicherung der gesellschaftlichen Ordnung

1. Die gefährdete Gesellschaft

2. Die Aufwertung des Zweckgedankens

3. Recht als gesellschaftlicher Ordnungsfaktor

IV. Epistemische Folgen I: Theorie der Gesellschaft, Rechtstheorie und Gesetzgebungstechnik

1. Die Theorie der Gesellschaft und die soziale Aufgabe

2. Privatrechtstheorie als Gesellschaftstheorie: BGB und Spezialgesetzgebung

V. Epistemische Folgen II: Wahrheit, Gesellschaftswissenschaft und Autonomie der Rechtswissenschaft

1. Die Wahrheit in der Gesetzgebung: Die soziale Aufgabe des BGBs jenseits der Politik

2. Rechtswissenschaft und Gesellschaftswissenschaft

VI. Zusammenfassung: Der gesellschaftsfunktionale Zweck im Privatrecht

\$5. Zweck-Dispositiv II: Das Problem der Normativität des Rechts im Methodenstreit als normatives Zweckdispositiv (ca. 1900-1920er)

I. L'urgence: Die Anmaßungen der Begriffsjurisprudenz

1. Eine kurze Geschichte der Genese des Methodenstreits

1.1 Die schwelende Kritik an der dogmatischen Rechtswissenschaft

1.2 Vom Streit um die Rechtsdogmatik zum Methodenstreit

1.3 Gemeinsame Polemik gegen die Begriffsjurisprudenz

2. Die Gefahren der Begriffsjurisprudenz

2.1 Der Streit um die Wissenschaftlichkeit

2.2 Das Problem der Rechtssicherheit

2.3 Die drohende Ungerechtigkeit der Begriffsjurisprudenz

II. Die erneute Suche nach dem Lebensbezug des Rechts: Das Recht der Gesellschaft 
III. Epistemische Folgen I: Der Streit um die richtige juristische Methode

1. „Soziologische Methoden“ der Rechtswissenschaft

1.1 Soziologische Kausalwissenschaft als

Gerechtigkeitswissenschaft: Ernst Fuchs

1.2 Wertungsgrundlage und Kulturwerte: Die soziologische Verankerung des juristischen Urteils (Gmelin, Wüstendörfer)

2. Wertungen in den Interessenabwägungen

3. Die Problematisierung der Normativität des Rechts

IV. Epistemische Folgen II: Die Rolle der Soziologie angesichts des Wesens der Rechtswissenschaft

1. Die Rolle der Soziologie in der Rechtswissenschaft

1.1 Rechtswissenschaft als Soziologie

1.2 Soziologie des Rechts als „wissenschaftliche Grundlage“ der Jurisprudenz

1.3 Ergänzung der Rechtswissenschaft durch die Soziologie

1.4 Rechtssoziologie als "Zwischenwissenschaft“

1.5 Der ,juristische Werturteilstreit“: Soziologie, Norm und Werturteil

2. Das Wesen der Rechtswissenschaft

2.1 Rechtswissenschaft als Sozialwissenschaft, Kulturwissenschaft oder Normwissenschaft

2.2 Konkurrenzproblem „Soziologie“

2.3 Die Relativierung der, Gesellschaft ${ }^{\star}$

2.4 Die Sicherung der Autonomie der Rechtswissenschaft

Zweiter Teil. Juridische Soziologien: Soziologische Adressierungen des Rechts in der entstehenden Soziologie

\$6. Émile Durkheim und das Repräsentationsdispositiv

I. Die juristischen Vorläufer der Soziologie und die Gewohnheitsrechtslehre

1. Jhering und die positiven Moralwissenschaften in Deutschland

2. Montesquieus Beitrag zur Gründung der Soziologie

3. Die Anerkennung der Gewohnheitsrechtslehre als Voraussetzung der Soziologie 
II. Recht als Repräsentation: Arbeitsteilung, Recht und soziale Solidarität

1. Recht als Repräsentation der Solidaritätsform 406

2. Die Gewohnheitsrechtslehre in der Arbeitsteilung 410

III. Rechtsentstehungslehre und soziologische Methode 413

1. Der forschungspragmatische Rekurs auf das Recht in den Regeln

2. Die Rechtsentstehungslehre in den Regeln 418

IV. Die Kehrseite des Repräsentationsdispositivs 418

1. Durkheim und die Historische Rechtsschule 419

1.1 Konvergenzen mit dem juristischen

Repräsentationsdispositiv

1.2 Abweichungen vom juristischen

Repräsentationsdispositiv

Recht und Rechtssystem

421

Recht und "lebendes Recht"

424

Die Bedürfnisse der Zeit

425

2. Durkheims funktionale Perspektive jenseits des gesellschaftsfunktionalen Zweckdispositivs

3. Durkheims Ablehnung der Problemlagen des normativen Zweckdispositivs

4. Die Indexthese als Kehrseite des Repräsentationsdispositivs

V. Der Verlust des Rechts im Repräsentationsgedanken

\$7. Ferdinand Tönnies und das gesellschaftsfunktionale Zweckdispositiv

I. Die geistesgeschichtliche Fundierung von Gemeinschaft und Gesellschaft in der Rechtsphilosophie

1. Naturrecht versus Historische Rechtsschule

1.1 Die Ursprünge der Grundbegriffe in Naturrecht und Historischer Rechtsschule

1.2 Der Konflikt zwischen Naturrecht und Historischer Rechtsschule

2. Die juristischen Vorläufer der Soziologie: Jhering als „Erneuerer des Naturrechts“

II. Die gegenstandsbezogene Fundierung der Soziologie im Recht

1. Die sachlich gebotenen Orientierung am Recht

1.1 Rechtsverhältnisse als soziale Verhältnisse

1.2 Recht als soziale Ordnung 
2. Die wissenschaftstheoretisch gebotene Orientierung am

Recht

2.1 Naturrecht als rationale Wissenschaft

2.2 Rechtsbegriffe und soziologische Begriffe

III. Soziologie als Rechtsphilosophie: gemeinschaftliches Naturrecht

1. Das Natürliche im Recht

2. Der Entwurf eines gemeinschaftlichen Naturrechts

3. Die Wertfreiheit der Soziologie als Rechtsphilosophie

IV. Tönnies' soziologische Problematisierung des Rechts im Lichte des gesellschaftsfunktionalen Zweckdispositivs

1. Die Ablehnung des Repräsentationsgedankens

2. Die Problemlosigkeit der Normativität des Rechts

2.1 Die Kritik am Freirecht

2.2 Wissenschaftstheoretische Bestimmungen von Soziologie und Rechtswissenschaft: Jenseits des Konkurrenzproblems

3. Tönnies und die Problematisierungsweise des gesellschaftsfunktionalen Zweckdispositivs

V. Die Anschlussschwierigkeiten an Tönnies' soziologischer Adressierung des Rechts

\8. Max Weber und das normative Zweckdispositiv

I. Webers Auseinandersetzung mit dem Recht in der „Wissenschaftslehre"

II. Wider die Prämissen des Repräsentationsdispositivs: Roscher und Knies und die Kritik an der Historischen Rechtsschule

1. Von der Kritik an der Historischen Schule der Nationalökonomie...

2. ... zur Kritik des Repräsentationsgedankens der Historischen Rechtsschule

III. Das Ringen um die Verhältnisbestimmung von Soziologie und Rechtswissenschaft

1. Objektivitäts-Aufsatz: Idealtypus und rechtsdogmatische Begriffsbildung

2. Objektive Möglichkeit und adäquate Verursachung: Juristisch-soziologische Zurechnungslehren

3. Die Stammler-Kritik: Die Abwehr der rechtswissenschaftlichen Bestimmung des Sozialen 
4. Der Kategorien-Aufsatz: Die Konkurrenz zur Rechtsdogmatik

4.1 Die kategoriale Orientierung an normativen Ordnungen

4.2 Die „Idealtypik“ der juristischen Begriffsbildung

4.3 Die Notwendigkeit der Abgrenzung zur Rechtsdogmatik

5. Die Lösung des Problems der Werturteilsfreiheit: Der Sinn der Werte in den normativen Wissenschaften

6. Zusammenfassung: Webers wissenschaftslogische Bestimmung der Rechtsdogmatik

IV. Webers Bestimmungen der Rechtsdogmatik und das epistemische Dispositiv der Privatrechtswissenschaft

1. Recht und Ordnung: Webers Abkehr vom gesellschaftsfunktionalen Zweckdispositiv

2. Rechtsdogmatik und Begriffsjurisprudenz: Webers Positionierung im normativen Zweckdispositiv

Schluss 


\section{Einleitung}

In der gegenwärtigen Soziologie spielt das Recht so gut wie keine Rolle. ${ }^{1}$ Die soziologische Theorie ist - wie Alfons Bora mit Blick auf die Rechtssoziologie feststellt - der Rechtspraxis gegenüber weithin sprachlos (Bora 2016: 261). Weder steht derzeit eine soziologisch gehaltvolle responsive Außenbeobachtung des Rechts zur Verfügung (ebd.). Noch lässt sich die Soziologie aktuell in ihrer Theoriebildung von einem gegenwärtig forcierten Wandel rechtlicher Grundkategorien, juristischer Selbstreflexionen oder gesetzgeberischer Neuregulierungen irritieren.

Das gilt selbst dann, wenn es um ähnliche Problemstellungen geht. So ist beispielsweise in den derzeit in der Soziologie vieldiskutierten Ansätzen des Neuen Materialismus bzw. des „material turn“ (die zugegebenermaßen sehr different sind, vgl. Lemke 2017) ein rechtlicher Fluchtpunkt erkennbar. Als Kritik der exkludierenden Strukturen des klassischen Anthropozentrismus wird eine Anerkennung der agency der Dinge und Objekte gefordert. Dabei wird insbesondere geltend gemacht, dass in Folge der Trennung von Natur und Kultur (Latour 1995) den Dingen in der Moderne jegliche Rechte abgesprochen wurden - und zwar entgegen den vorherigen Epochen, in denen der Akteursstatus auch nicht-menschlicher Entitäten als rechtlich relevant anerkannt war. Das zeigen etwa die mittelalterlichen Tierprozesse oder die Rechtsfigur des „deodand“ (vgl. Bennett 2010: 9; s. bereits Kelsen 1941). Legitimer Inhaber von Rechten ist in der modernen Rechtskonzeption nur der Mensch, Rechte erscheinen als menschliche subjektive Rechte. Dem wird in kritischer Absicht die Forderung entgegengehalten, den Dingen eigenständige Rechte zu verleihen. Das Parlament wird zum Parlament der Dinge (Latour 2001a), und dem Gesellschaftsvertrag wird - wie etwa von Michel Serres - der Naturvertrag entgegengehalten (Serres 1994a).

In der Rechtswissenschaft wiederum steht die Frage des rechtlichen Status von Dingen und Objekten schon seit längerem zur Debatte (vgl. Beck 2013). Zunehmend werden subjektive Rechte auch anderen Entitäten zugesprochen: Flüsse und Affen haben bereits durch Gesetzgebung und Rechtsprechung solche Rechte erhalten (z.B. Whanganui-River, Orang-

1 Dies zeigt sich auch in der Randständigkeit der Rechtssoziologie innerhalb der Soziologie. 
Utan); in der EU wird der Gesetzesvorschlag diskutiert, Roboter als „elektronische Personen" mit subjektiven Rechten auszustatten (Europäisches Parlament 2017); und in der Rechtsphilosophie und Rechtswissenschaft wird angesichts eines konkreten ökologischen und v.a. technischen Wandels (z.B. Umweltverschmutzung, smart homes, Gentechnik, Digitalisierung) zunehmend über die Rechtsfähigkeit von Pflanzen (z.B. Stone 1974), intelligenten Automaten (z.B. Kersten 2017) und anderen elektronischen Aktanten diskutiert (etwa Teubner 2006; Gruber 2014). Auch wenn hier in beiden Diskussionsfeldern das Recht der Dinge zur Debatte steht, gibt es keine Korrespondenz: Weder wird in der Rechtswissenschaft etwa auf den gewandelten Handlungsbegriff Latours rekurriert, noch stellt man sich in der Soziologie die Frage, ob nicht bereits eine spezifische agency der Dinge anerkannt ist, auf die die Kritik zu reagieren hat.

Die Liste der Beispiele, in denen es Konvergenzen zwischen soziologischen und juristischen Problemlagen gibt, ließe sich leicht fortsetzen. Man denke etwa an die biotechnische Regulierung und die Debatten um die Biopolitik, die Entstehung und den Wandel des Umweltschutzrechtes und die soziologischen Diskussionen um Nachhaltigkeit, soziale Ungleichheiten und das neue AGG (Allgemeine Gleichbehandlungsgesetz), die Umstellung vom Gefahren- auf den Risikodiskurs etc. Daher stellt sich die Frage: Warum sagen in der Soziologie heute Erkenntnisse des Rechts oder über das Recht wenig über die Gesellschaft aus, obwohl paradoxerweise das Recht nach wie vor als zentraler Garant jeglicher sozialer Ordnung angesehen wird (vgl. Luhmann 2008; Tamanaha 1995)?2 Warum liegt hier eine riesige Menge an leicht zugänglichem Datenmaterial brach (neue Gesetze und Gesetzesmaterialien, Urteile, juristische Fachdebatten, Problematisierung des Rechts in den Zeitungen etc.), selbst wenn es in soziologischen Untersuchungen um Materien geht, die unzweifelhaft einen starken Rechtsbezug aufweisen? Letztlich kann man nur feststellen: Der Zugang zum Recht bereitet der Soziologie - und zwar nicht nur der allgemeinen soziologischen Theorie, sondern sogar der Rechtssoziologie ${ }^{3}-$ große

2 Als einzige nennenswerte Ausnahme wären hier die security studies und die entsprechenden Untersuchungen aus dem Bereich der Gouvernementalitätsstudien zu nennen, die aus dem Wandel im v.a. straf- und polizeirechtlichen Bereich gesellschaftstheoretische Rückschlüsse ziehen. Zur Problematik der Verhältnisbestimmung von Recht und Gesellschaft in den Gouvernementalitätsstudien vgl. u. \1.II.3-4.

3 Es gehört zum viel beklagten Topos in der Diskussion um die Frage nach der Zukunft der Rechtssoziologie, dass das Recht aus der Rechtssoziologie verschwindet (vgl. Luhmann 2008: 2). 
Schwierigkeiten (vgl. statt vieler Riles 2005). Recht und Soziologie stehen in einem problematischen Verhältnis zueinander.

Diese Situation erscheint vor allem vor einem soziologiegeschichtlichen Hintergrund bemerkenswert. In der entstehenden Soziologie, d.h. in den ersten Entwürfen der Soziologie und den Auseinandersetzungen über das Proprium soziologischer Untersuchungen bis hin zu ihrer Konsolidierung in der Weimarer Republik als eigenständige Disziplin, gehört das Recht nicht nur unzweifelhaft in den Gegenstandsbereich der Soziologie (zu Émile Durkheim, Ferdinand Tönnies und Max Weber s. $\$ \mathbb{S}$ 6-8; daneben exemplarisch auch Eisler 1903: 153ff.; Achelis 1908: 102ff.; Brinkmann 1919: 81ff.). Vielmehr hat die Auseinandersetzung mit dem Recht eine theoriekonstitutive Funktion, werden doch im Recht gesellschafts- und sozialtheoretische Implikationen gesucht (vgl. Schweitzer 2018b).

Auf einer solchen Suche nach der, Gesellschaft im Recht' wird man fündig, da die Genese der Soziologie von vielen Autoren im engen Zusammenhang mit der Entwicklung des Rechtsdenkens gesehen wird. Das zeigt sich exemplarisch an der weitverbreiteten Frage nach der Rolle des Naturrechtsdenkens (vgl. $\$ 7 . V$ ), betrifft aber ebenso die Bestimmung des Verhältnisses zur Historischen Rechtsschule (neben Durkheim, Tönnies und Weber vgl. Below 1926; Oppenheimer 2015 [1929] sowie in der geisteswissenschaftlichen Tradition v.a. Jerusalem 1930: 15f.) bzw. später zum funktionalen bzw. teleologischen (Rechts-)Denken (prominent hier natürlich Stammler, s.u.). Es gab also so etwas wie die ,Entdeckung' der Gesellschaft im Recht, mit der sich die sich konsolidierende Soziologie auseinandersetzt und an die sie - in positiver wie in negativer Weise - anschließt. ${ }^{4}$

In der Folge verliert die Soziologie jedoch ihr Interesse am Recht, wie schon Talcott Parsons feststellte: „After the brilliant start by Durkheim and Max Weber about the turn of the century, it is something of a mystery why the social sciences and particularly, perhaps, sociology have shown little interest in the study of law and legal systems." (Parsons 1977: 11) Trotz großer Nähe zum Recht ist zugleich eine Entfremdung der Soziologie zu erkennen (vgl. Gephart 1993a: 10), und genau darin liegt das Mysterium, von dem Parsons spricht.

Der Zugang zu der Frage nach den Gründen für das weitverbreitete soziologische Desinteresse am Recht oder an rechtlichen Phänomenen erfolgt in der vorliegenden Arbeit über die historisch-genealogische Analyse.

4 Damit ist nicht gemeint, dass die Gesellschaft im spezifischen Sinne der Soziologie in der Rechtswissenschaft „entdeckt“ wurde, sehr wohl aber, dass die Rechtswissenschaft zum Entdeckungszusammenhang gehört (s. $\$ 1$ 1.I.1). 
Diese Gründe werden dabei nicht in der Geistesgeschichte der Moderne (vgl. Parsons 1977) bzw. in den späteren theoretischen Entwicklungen der Soziologie gesucht (so etwa Schelsky 1980a bzgl. Gehlen, Dahrendorf, Habermas und Luhmann; Gephart 1993a bzgl. Mead, Schütz und Wilson). Vielmehr resultieren die gegenwärtigen Schwierigkeiten der Soziologie mit dem Recht - so die These dieser Arbeit - aus der Art und Weise, wie in der sich konsolidierenden soziologischen Disziplin das Verhältnis von Gesellschaft und Recht problematisiert wird - und zwar nicht als rein soziologieinternes Problem, sondern gerade im Verhältnis zur Rechtswissenschaft. Denn es zeigt sich: Es handelt sich um eine Problemstellung, die ebenso die Privatrechtswissenschaft in Deutschland betrifft. Gerade dort werden im 19. und Anfang des 20. Jahrhunderts über die Entdeckung der Gesellschaft im Recht Problematisierungsweisen des Verhältnisses von Recht und Gesellschaft entwickelt, die nicht nur die Rechtstheorie, sondern ebenso die Rechtsdogmatik wie -methodik betreffen ( $\$ S \$ 2-5)$. Diese Problematisierungsweisen werden Eingang in die entstehende Soziologie finden, wie paradigmatisch an den Soziologieentwürfen von Émile Durkheim, Max Weber und Ferdinand Tönnies gezeigt wird ( $\$ \$$ 6-8). Aus dieser Nähe zum Recht - den juridischen Soziologien von Durkheim, Tönnies und Weber - resultiert in der Gründungsphase der Soziologie zugleich die Notwendigkeit der Abgrenzung zu den Rechtswissenschaften. Dabei werden Anschlüsse, aber auch Verschiebungen gegenüber dem rechtswissenschaftsinternen Diskurs gewählt, die letztlich zum Verlust des Rechts für die Soziologie führen. Daher gilt es den Punkt der Problematisierung des Verhältnisses von Recht und Gesellschaft zu identifizieren, will man hier eine Abzweigung nehmen und das Recht für die Soziologie wieder adressierbar machen. 


\section{$\$ 1$. Auf der Suche nach der Gesellschaft im Recht: Methodologische Überlegungen}

Im Zentrum der Untersuchung steht die Frage, wie und in welcher Form die Entdeckung der Gesellschaft im deutschen Privatrecht des 19. Jahrhunderts die entstehende Soziologie beeinflusste. Diese Fragestellung enthält ein Spannungsverhältnis. Denn sie kombiniert eine soziologiegeschichtliche mit einer rechtssoziologischen Perspektive, und beide bestimmen das Verhältnis von Recht und Gesellschaft auf jeweils widersprechende Weise:

Auf der einen Seite wird im Rahmen einer Geschichte der Soziologie die Frage untersucht, an welche Gesellschaftskonzeptionen die entstehende Soziologie Anschlüsse suchte und damit Problemlagen generierte, die auch heute noch für die soziologische Theorie relevant sind. Ziel einer solchen disziplinengeschichtlichen Selbstreflexion ist der veränderte Blick auf die Gegenwart (vgl. Peter 2001: 11ff.). Es geht also darum, mit Foucault gesprochen, eine „Geschichte der Gegenwart“ zu schreiben (Foucault 2009b: 43). Will man verstehen, warum die gegenwärtige Soziologie mit dem Recht ein Problem hat, so muss man die historische Analyse ausgehend von dieser gegenwärtigen Problematik der Verhältnisbestimmung von Soziologie und Recht betreiben. ${ }^{5}$

Sucht man dabei den Ort der Produktion des wissenschaftlichen Gegenstandes ,Gesellschaft' in der Privatrechtswissenschaft, wird eine Art Vorgängigkeitsverhältnis des Rechts gegenüber der Gesellschaft proklamiert. Das setzt eine Form der Eigenständigkeit des Rechts voraus. Denn Recht wird nicht als gesellschaftliches Phänomen untersucht, sondern als etwas, das das epistemische Ding, Gesellschaft ${ }^{\star}$ konstituiert und damit das Denken über Gesellschaft zuallererst geprägt hat. Die paradigmatischen Perspektiven der Rechtssoziologie werden also verschoben: In der „Soziologie des Rechts" wird das Recht in erster Linie als gesellschaftliches Phänomen beschrieben, es wird in der Gesellschaft verortet und aus gesellschaftstheo-

5 Daher zielt die vorliegende Arbeit auch nicht auf die Erschließung neuer Quellen, sondern auf die soziologisch informierte Analyse jenes bereits in der Rechtsgeschichte auf umfassende Weise erforschten Komplexes der Historischen Rechtsschule und ihrer Kritik, der wissenschaftlichen Diskussion um den Erlass des BGBs sowie der juristischen Methodendebatte Anfang des 20. Jahrhunderts, um sie auf ihre „soziologischen Rationalitäten im Recht“ (Schweitzer 2015b) hin zu untersuchen. 
retischer Perspektive auf seine Funktionen für die Gesellschaft und seine Funktionsweisen innerhalb der Gesellschaft hin untersucht bzw. problematisiert (vgl. Schelsky 1970; Tamanaha 2006; Röhl 1987: 575ff. m.w.N.). Gefragt wird nach dem Recht in der Gesellschaft. ${ }^{6}$ Demgegenüber untersucht die „soziologische Jurisprudenz“ die Einflüsse der gesellschaftlichen Sphäre im Prozess der Herstellung des Rechts. ${ }^{7}$ Einsatzpunkt solcher zumeist rechtskritischen Ansätze ist die Konfrontation des juristischen Ideals mit der Realität. ${ }^{8}$ In einem gewissen Sinne wird also nach der Gesellschaft im Recht gefragt - allerdings als etwas, das von außen eindringt und die rechtlichen Abgrenzungsbemühungen unterwandert ${ }^{9}$ bzw. aus juristischer

6 Hierzu sind nicht nur die gesellschaftstheoretischen „Haupttheorien“ (Merton) zu zählen (etwa Luhmann 1993; Habermas 1992a), sondern ebenso die gegenwärtigen Ansätze, die Recht zunehmend als soziale Praxis verstehen (vgl. Kahn 1999; Banakar 2000; Morlok et al. 2000; Wrase 2010) bzw. parallel zu den Entwicklungen in der Soziologie die performativen, operationalen und medialen Existenzweisen in den Vordergrund rücken (vgl. Scheffer 2014). Selbst wenn es dabei dann nicht um den Entwurf neuer soziologischer Großtheorien geht, wird Recht als soziales bzw. kulturelles Phänomen verstanden, das sich den neuen Erklärungsansätzen für kontingente gesellschaftliche bzw. kulturelle Phänomene zu stellen hat.

7 Bereits Eugen Ehrlich, einer der renommiertesten Vertreter der Freirechtsschule (vgl. u. $\$ 5$ ), legte den Fokus auf die Herstellung des Rechts. Seine Überlegungen zum „lebenden Recht" hatten nachhaltigen Einfluss und wurden im englischsprachigen Raum zum Ausgangspunkt der law in action-Bewegung (vgl. Cotterrell 2009).

8 Im Bereich der Justizforschung hat eine Reihe von Untersuchungen der richterlichen Urteilsfindung auf die Distanz der Darstellung zur Herstellung des Urteils hingewiesen (Lautmann 2011). Die Studien gelangen zu dem Ergebnis, dass politische Ideologien (etwa Frank 1973; Hannover, Hannover-Drück 1987; Graf 1988), Rücksicht auf existierende Macht- und Ungleichheitsstrukturen wie insbesondere Klassen- oder Schichtmerkmale (vgl. Peters 1973; Rottleuthner 1973a; Mikinovic, Stangl 1978), Geschlechtszugehörigkeit (etwa Geißler, Marißen 1988; Legnaro, Aengenheister 1999), karrierepragmatische Gründe (Posner 1993), sonstige Grundüberzeugungen (Segal, Spaeth 2002) und Gemeinplätze (vgl. Sisk et al. 1998) das richterliche Urteil (mit-)bestimmen. Die Urteile basieren diesen Studien zufolge auf außerrechtlichen und damit illegitimen Entscheidungsgründen. Diesem explizit kritischen Gestus, der in den Rechtswissenschaften vielfach auf Widerstand gestoßen ist, schreibt man eine entscheidende Rolle für Probleme der Entwicklung der Rechtssoziologie zu. Gegenwärtige Untersuchungen aus dem Bereich der Justizforschung haben sich von einem solchen Gestus verabschiedet (vgl. etwa Stegmaier 2009; Berndt 2010; Kranenpohl 2010; Latour 2010).

9 Die Soziologie steht „vor den Toren der Jurisprudenz“, wie Rüdiger Lautmann in der Hochphase der bundesrepublikanischen Rechtssoziologie in den 1970er Jahren proklamierte (Lautmann 1971); zur Geschichte der Rechtssoziologie in Deutschland vgl. Wrase 2006 m.w.N. 
Sicht konsequenterweise zur Forderung nach der Soziologisierung der Rechtswissenschaft führt (vgl. Lautmann 1971: 7; Rottleuthner 1973b; kritisch Schelsky 1980b). ${ }^{10}$

Im Folgenden geht es aber weder um die Frage der Funktion des Rechts für die Gesellschaft, noch um die gesellschaftlichen Einflüsse auf das Recht oder der Relevanz außerjuridischen Wissens im Recht. Vielmehr wird das Recht als Ort der Produktion der Gesellschaft adressiert: Gesellschaft wird im und durch Recht hergestellt. ${ }^{11} \mathrm{Um}$ dies in soziologiegeschichtlicher Perspektive analysieren zu können, wird die Gesellschaft als „epistemisches Ding“ (Rheinberger) des Rechts analysiert (I.).

Auf der anderen Seite handelt es sich bei der Gesellschaft um ein besonderes Objekt. Sie stellt einen Totalitätszusammenhang dar, der alle sozialen Phänomene, also auch das Recht, umfasst. Die Soziologie muss davon ausgehen, dass das „Recht der Gesellschaft“ (Luhmann 1993) ein Teil der Gesellschaft ist und nicht vice versa. Gesellschaft geht - aus soziologischer Sicht - dem Recht voraus. Andernfalls wäre das Recht etwas, was sich dem soziologischen Blick entzieht (vgl. Krasmann 2015). Auch die Annahme der Ausdifferenzierung des Rechts ändert nichts an diesem (methodologischen) Vorgängigkeitsverhältnis, das im Widerspruch zur erwähnten Vorgängigkeit des Rechts in der soziologiegeschichtlichen Perspektive steht. Denn selbst wenn das Recht in der Moderne gemäß der funktionalen Differenzierung eine Form der Autonomie erlangt, die etwa äußere Einflüsse nur bedingt zulässt - sei es als relative bzw. relationale Autonomie (vgl. Buckel 2007) - oder als autopoietisches System operativ geschlossen ist und nur über strukturelle Koppelungen den Umwelteinflüssen ausgesetzt

10 Für diese Forderung wird zumeist auf empirische soziologische Erkenntnisse abgestellt. Rechtssoziologie wird insofern anwendungsorientiert gedacht, wobei der Soziologie nicht selten die Rolle einer zuarbeitenden „Hilfswissenschaft“ zugeschrieben wird - selbst wenn dies als „Ehrentitel“ gemeint ist (Rehbinder 2003: 8; zur Kritik statt vieler Machura 2001). Gesellschaft im Recht bedeutet in diesem Zusammenhang die Verwendung empirischen soziologischen Wissens für rechtliche Problemstellungen.

11 Bruno Latour hat in seinem Entwurf einer alternativen Rechtssoziologie jüngst eine solche Neujustierung des Verhältnisses von Recht und Gesellschaft versucht: Das Recht wird selbst zu einem der Mittel „for producing the social defined as association, for arranging and contextualizing it" (Latour 2010: 264; s.a. Latour 2013, 2014). Allerdings muss man m.E. diesen Entwurf als gescheitert bezeichnen, da er den Weg ins Recht für die Rechtssoziologie letztlich versperrt (zu einer umfassenden Kritik vgl. Schweitzer 2016). 
erscheint, ${ }^{12}$ so ermöglicht diese Perspektive auf das Recht zwar die Annahme eines (wie auch immer definierten) Eigensinns des Rechts. Allerdings handelt es sich um soziologische Fremdbeschreibungen, die von einem strukturellen und nicht von einem inhaltlichen Eigensinn des Rechts gegenüber der Gesellschaft (und anderen Subsystemen) ausgehen.

Man könnte also vermuten, dass in der rechtssoziologischen Perspektive eine genuin juridische Beschreibung der Gesellschaft, die unser Denken über Gesellschaft zuallererst formt, zwangsläufig aus dem Blick gerät. Einem solchen Ergebnis hat jedoch gerade Luhmann mit seinem Entwurf der autopoietischen Systemtheorie widersprochen: Die gesellschaftliche Binnendifferenzierung führt dazu, dass eine Reihe von funktionalen Subsystemen existiert, welche weder hierarchisiert noch über eine spezifische Kommunikationsform zusammengeführt werden können. Das bedeutet, dass es keinen übergeordneten Standpunkt mehr gibt, der einen Zusammenhang über eine gemeinsame Referenz ermöglicht: „Keine Thematisierung von Gesellschaft erreicht mithin eine volle Welttransparenz." (Luhmann 2006: 882) Jedes Subsystem bildet seinem Code entsprechende Selbstbeschreibungen. Dazu gehört eine je spezifische Sicht auf die Gesellschaft: Es existiert eine Vielzahl von zum Teil konkurrierenden Deutungen der Gesellschaft - und so auch eine genuin juridische Beobachtung der Gesellschaft, die als Beobachtung der Beobachtung soziologisch analysiert werden könnte.

Die Selbstbeschreibungen bilden sich bei Luhmann in der Form von Semantiken aus. Die Semantik ist der gesellschaftlichen Struktur jedoch prinzipiell nachgelagert (kritisch hierzu Stäheli 1998, 2000: 184ff.; Opitz 2012: 94ff.). Selbstbeobachtungen und Selbstbeschreibungen „müssen voraussetzen, dass das System schon vorliegt, sind also nie konstitutive, sondern immer nachträgliche Operationen, die es mit einem bereits hoch selektiv formierten Gedächtnis zu tun haben“ (Luhmann 2006: 883). Die Herausbildung des gesellschaftlichen Subsystems Recht bildet somit einen death point of no return für die juridische Beobachtung der Gesellschaft zumindest ist weder ein stufenweiser Akt der Ausdifferenzierung noch eine etwaige Entdifferenzierung auf der Ebene der Semantik in der Systemtheorie nach Luhmann denkbar (vgl. Teubner 1987). Würde er die Semantiken als strukturbildend begreifen, müsste er die Idee des autopoietischen Systems aufgeben.

12 Diese Annahme korreliert mit dem starren Autonomiebegriff des späteren Luhmann in Das Recht der Gesellschaft, wenn er dort Autopoiesis mit Autonomie gleichsetzt (Luhmann 1993: 65). 
Der Schwachpunkt dieser Konzeption zeigt sich insbesondere in der historischen Perspektive: Denn was wäre, wenn gerade die Semantik der Gesellschaft eine entscheidende Rolle in der Autonomisierung des Rechts spielte und damit als machtvoller Diskurs fungierte, der die Ausdifferenzierung vorantrieb? Und insbesondere mit Blick auf das Privatrecht: Was bedeutet es für die Theorieanlage der Systemtheorie, wenn Anfang des 19. Jahrhunderts gerade die Entscheidung, das Recht nicht zu kodifizieren, bei der Ausdifferenzierung maßgeblich gewesen wäre, da sie den Weg in die Normativität des Rechts für die Rechtswissenschaften eröffnete? ${ }^{13}$ Denn dann hätte sich die Herausbildung und Autonomisierung des systembestimmenden Codes ,Recht/Unrecht' im modernen Recht nicht über die Positivierung, sondern erst über die Problematisierung des Verhältnisses von Recht und Gesellschaft in den Privatrechtswissenschaften vollzogen. ${ }^{14}$ Aber auch ganz prinzipiell kann man mit Blick auf das Verhältnis von Recht und Soziologie danach fragen, was es bedeutet, wenn die Rechtsquellenlehre Anfang des 19. Jahrhunderts nicht wie für Luhmann die Divergenz zwischen Rechtswissenschaft und Soziologie begründet, sondern als ein Baustein zur Herausbildung der Soziologie angesehen wird. ${ }^{15}$ Müsste man dann nicht davon ausgehen, dass die Idee der Gesellschaft, aber

13 Bestritten wird in historischer Hinsicht, dass die Positivierung des Rechts in dem großen Sprung vom Recht vorneuzeitlicher Hochkulturen zum modernen Recht des 19. Jahrhunderts Zielrichtung der Selbstabschließung des Rechts als System war (vgl. Luhmann 1970; 2008: 166ff.). Dieser Prozess ist sehr viel komplizierter angelegt, als Luhmanns historisch grob gezeichneten Ausführungen nahelegen.

14 Luhmann geht demgegenüber davon aus, dass der Nährboden der Vollpositivierung des Rechts, d.h. der Autonomisierung, im öffentlichen Recht bzw. in atypischen Sondergebieten wie Arbeits- oder Wohnungsrecht zu suchen sei (Luhmann 2008: 201). Das verwundert wenig, da in diesen Rechtsmaterien die Steuerungsperspektive, aber auch die funktionale Sicht, wie sie in Luhmanns normativem Rechtsverständnis eingelagert ist, eine zentrale Stelle einnimmt. Damit kann er jedoch aus historischer Sicht gerade nicht erklären, wie die Vorstellung des Rechts (und der Gesellschaft) überhaupt erst normativiert wurde, d.h. also die seiner Theorie vorgelagerte Koppelung des Rechts an die Normativität bewerkstelligt wurde. Genau diese Frage steht im Folgenden im Zentrum der Analyse des Rechts.

15 Gerade die Rechtsquellenlehre trug nach Luhmann zu der Ausdifferenzierung zwischen Rechtswissenschaft und Soziologie bei (Luhmann 2008: 207). Denn sie markiert den notwendigen Unterschied in der Perspektive der beiden Disziplinen: Für die Soziologie ist die zentrale Vorstellung einer ,Rechtsquelle` nicht annehmbar (Luhmann 1973), die in ihrer juristischen Form soziologische (Entstehungsgrund des Rechts), ethische (Prinzipien, nach denen man das Recht zu handhaben habe, Geltungsgrund) sowie rechtstheoretischen (Erkenntnisgrund) Erwägungen vermischt (vgl. Ross 1929: 167f., 291). Für die kausale Perspektive, 
auch die Idee der funktional differenzierten Gesellschaft selbst ihre Ursprünge (auch) im Recht hätte? Und zeitigte es nicht Folgen für die Theorie, wenn man zeigen kann, dass diese juristischen Semantiken von Anfang an umstritten waren, und auch heute noch sind, und gerade hier Machteffekte eingelagert sind, die die ambivalente Stellung des Rechts (und der Soziologie) zur Macht betreffen? ${ }^{16}$

Zur Debatte steht also insbesondere die Frage, welche Effekte die juristische Problematisierung der Gesellschaft für das Recht, aber auch für das Denken der Gesellschaft in der Soziologie zeitigte. Diese Sicht bereitet der Systemtheorie aber Probleme, gerade weil sie die Semantiken nicht als strukturbildend begreift. Die systembildenden Effekte, und das heißt zugleich: die Machteffekte solcher Semantiken, sind ihr nicht zugänglich. ${ }^{17}$

Somit bleibt die Frage: Wie kann man die Gesellschaft im Recht denken, ohne einerseits das Recht von der Gesellschaft zu entkoppeln (und damit dem soziologischen Blick zu entziehen), und ohne andererseits das Recht in der Gesellschaft aufzulösen (womit es nicht mehr als genuiner Ort der Herstellung von Gesellschaft für die soziologische Analyse adressierbar wäre)? Um dieses doppelte Konstitutionsverhältnis von Gesellschaft und Recht fassen zu können, wird Recht als ein dispositives Gefüge analysiert, das in seinen diskursiven Praktiken des rechtswissenschaftlichen epistemischen Dispositivs sowohl das Recht als auch das epistemische Ding

die mit der soziologischen vereinbar wäre, gilt jedoch: Die faktischen Entstehungsursachen eines Gesetzes sind aufgrund ihrer Komplexität nicht angebbar. Die Soziologie muss daher nach Luhmann ihre Perspektive verschieben und Gesetzgebung als variable Selektionsleistung beschreiben. Dieses letztlich logische Argument, das Luhmann mit der Differenz der Perspektiven der Rechtswissenschaft und der Soziologie begründet (vgl. Luhmann 2008: 207), führt jedoch aus der historischen Betrachtung heraus und verunmöglicht es, die Genese der Gesellschaft als wissenschaftliches Objekt in der Rechtsquellenlehre zu erkennen - und zwar gerade aufgrund der Vermischung der verschiedenen Ebenen.

16 Gegenwärtig findet die Frage nach dem Verhältnis sich wandelnder Gesellschaftskonzepte (Semantik) zum Recht in der systemtheoretischen Rechtssoziologie ihre Reformulierung in den Konzepten der „Sozialverfassung“ bzw. nun dem „sozialen Konstitutionalismus“ (Teubner 2012, 2013), die auf der Idee der „reflexiven Steuerung“ des Rechts (Teubner, Willke 1984) aufbauen. Das Paradigma der Autonomie des Rechts als autopoietisches System bleibt hierbei auch angesichts des Semantikwandels bzgl. der Gesellschaft unangetastet bzw. wird in einen Semantikwandel der eigenen Theorie transferiert.

17 Es geht also um die Frage einer evolutorischen Wirkung von Semantiken. Genau darin zeigen sich selbst aus systemtheoretischer Sicht die Probleme, Luhmanns Theorie wie bei Marie Theres Fögen (2002a, 2002b) für die Rechtsgeschichte fruchtbar zu machen (vgl. Amstutz 2002). 
,Gesellschaft systematisch als Gegenstände bildet, von denen es spricht (II.). ${ }^{18}$

\section{Die soziologiegeschichtliche Perspektive: Gesellschaft als „epistemisches Ding“}

Über den Gegenstand ,Gesellschaft' wurde im 19. Jahrhundert ein neuer Wirklichkeits- und Wissensbezug generiert, der zur Ausdifferenzierung der Soziologie als eigenständige Disziplin führte. Um diese Entwicklung in den Privatrechtswissenschaften nachzuverfolgen, wird Gesellschaft als ein „epistemisches Ding“ (Rheinberger) des Rechts analysiert.

\section{Das „epistemische Ding"Rheinbergers}

Anhand der Untersuchung der Laborexperimente zur Biosynthese von Proteinen entwickelte der Wissenschaftshistoriker Hans-Jörg Rheinberger das Konzept des „epistemischen Dings“ (Rheinberger 1992b, 2006). ${ }^{19}$ Die Wissensobjekte der Biochemiker sind nicht einfach da und warten darauf, entdeckt zu werden. Es handelt sich vielmehr um Objekte, deren Struktur und Funktionsweise gerade noch nicht geklärt sind. Sie sind durch eine „irreduzible[] Verschwommenheit und Vagheit“ gekennzeichnet. „Epistemische Dinge“ sind daher „die Dinge, denen die Anstrengung des Wissens gilt“. Rheinberger will den „Entdeckungszusammenhang“ gegenüber einer

18 Damit sucht die vorliegende Arbeit Anschlüsse an die neueren Rechtssoziologien, die das Recht als Ort der Herstellung und der Emergenz sozial relevanten und wirksamen Wissens adressiert (vgl. etwa Pottage, Mundy 2004, 2014; Valverde 2006, 2007; Baer 2010; Krasmann 2012). Insofern gilt: Gesellschaft wird im Recht hergestellt (vgl. Nelken 1986: 325; Cotterrell 1998: 175ff.). Allerdings geht die vorliegende Untersuchung in einem entscheidenden Punkt darüber hinaus: Es geht nicht um die performative (Re-)Produktion von bestimmten sozialen $\mathrm{Zu}$ sammenhängen, gesellschaftlichen Kategorien oder spezifischen begrenzten Kollektivitätsformen, sondern um den Entwurf einer gesellschaftlichen Totalitätsperspektive. Es wird nach der ,Gesellschaft im Recht" im wörtlichen Sinne gefragt.

19 Das „epistemische Ding“ Rheinbergers ist seither fester Bestandteil der naturwissenschaftlich orientierten Wissenschaftsforschung und -geschichte. Darüber hinaus hat es eine erstaunliche Karriere hinter sich: Es ist sukzessive aus den Laboren in die soziologische und kulturwissenschaftliche Theorie gewandert und wird zur Untersuchung immer umfassenderer Bereiche herangezogen. Mittlerweile erscheint jegliches soziale Phänomen als epistemisches Ding fassbar (vgl. Schweitzer 2015c: 1 m.w.N.). 
immer erst herzustellenden Verfestigung des Objekts rehabilitieren: „Es geht vielmehr darum, das Primat der im Werden begriffenen wissenschaftlichen Erfahrung, bei der begriffliche Unbestimmtheit nicht defizitär, sondern handlungsbestimmend ist, gegenüber ihrem begrifflich verfaßten und verfestigten Resultat zur Geltung zu bringen." (Rheinberger 2006: 27)

Genau diese Perspektive auf ein Wissen im Werden, auf den Entdeckungszusammenhang, soll sich hier zunutze gemacht werden. Denn die Gesellschaft wird erst im 19. Jahrhundert eine Konzeption und Problematisierung erfahren, die sie zum Bezugspunkt einer neuen Wissenschaft werden lassen konnte (vgl. Eßbach 2014: 28ff.). Die Konzentration auf die Privatrechtswissenschaften legt mithin den Fokus auf einen prägenden Moment des Entdeckungszusammenhangs des epistemischen Dings ,Gesellschaft" für die Soziologie. Und gerade hier gilt: Die Gesellschaft steht nicht im Zentrum. Sie ist, wie das epistemische Ding, nicht dasjenige, worauf der Wissenschaftler „frontal starrt“, sondern das, „was er dagegen eher im Augenwinkel behält" (Rheinberger 2001: 61). Denn ohne den Charakter einer ausdifferenzierten Wissenschaft zu verlieren, wendet sich die Privatrechtswissenschaft im 19. Jahrhundert zwar der Gesellschaft zu, hat dabei jedoch stets die eigene, d.h. juristische Methode im Sinn (s. $\$ 2$ ).

Mit dem epistemischen Ding geht es hierbei weniger um die Antworten, sondern um die Fragen und Problematisierungen, die es aufwirft. Insofern bezeichnet Rheinberger es als „Fragemaschine“ (Rheinberger 1992a: 72, 2006: 33). Im Folgenden soll mit Blick auf die Privatrechtswissenschaften gezeigt werden, wie das Objekt, Gesellschaft ${ }^{\prime}$ in seiner jeweiligen spezifischen Konzeption die Rechtstheorie, aber auch die Dogmatik und Methodik in Frage zu stellen vermag. Im Vordergrund stehen dabei die Problematisierungen, die die Hinwendung zur, Gesellschaft für das Privatrecht bedeutet, und nicht die Antworten, die hierdurch gegeben werden.

Das Wissensobjekt, hier die Gesellschaft, ist nicht vorbegrifflich und müsste einfach nur auf den Begriff gebracht werden. Vielmehr entsteht es während des Forschungsprozesses (vgl. Rheinberger 2012: 3). Neue Wissensobjekte werden nicht einfach entdeckt oder entschleiert und ans Licht gebracht. Sie werden nach und nach innerhalb bestimmter Anordnungen hergestellt und gestaltet. Damit gilt: Epistemische Dinge und epistemische Praktiken gehören untrennbar zusammen. Der Blick der Untersuchung richtet sich auf die Praktiken und Techniken, in und mittels derer, Gesellschaft' entdeckt, erzeugt und verobjektiviert wird.

Ein epistemisches Ding ist also ein Objekt, das sich im Verfahren konstituiert. Zugleich vermag es aber auch aufgrund seiner Eigenschaften und Qualitäten das Verfahren mitzubestimmen, kann es doch auch zu einem 
konstituierenden Moment der Forschung werden (vgl. Rheinberger 1992a: 70f., 2006: 29f.). Denn das Ding ist bei Rheinberger nicht - wie im Konstruktivismus - nur Folge der gedanklichen Konstruktion, sondern ebenso Akteur. Es entwickelt eine Art Eigenleben bzw. eine spezifische Eigendynamik (Martus 2015: 28). Man muss also erforschen, wie das Ding, Gesellschaft' bestimmte Arten des Fragens und Vorgehens stimuliert, bestimmten Forschungsbedarf generiert und bestimmte Problematisierungsweisen institutionalisiert.

Wenn die Analyse den Gegenstand mitkonstituiert, und dieser wiederum auf die Analyse zurückwirkt, so zeigt das gerade jene spezifische Verwobenheit der Gesellschaftsanalyse mit ihrem Gegenstand, die in der soziologischen Theorie insbesondere unter dem Stichwort der Reflexivität gefasst wird: Die Gesellschaftstheorie, aber auch ihre Methoden sind immer selbst Teil der Gesellschaft und wirken daher reflexiv auf ihren Gegenstand zurück. Dieselbe Verwobenheit ist zwischen den rechtlichen Gesellschaftskonstruktionen und der jeweiligen juristischen Dogmatik und Methode festzustellen. Denn, so wird zu zeigen sein: In den privatrechtswissenschaftlichen Dogmatiken und Methoden liegen Formen der Gesellschaftskonstruktion, so wie jedes spezifische Gesellschaftskonzept bestimmte dogmatische und methodische Ausrichtungen in der Jurisprudenz impliziert. Die Privatrechtswissenschaften und ihre Methoden werden dadurch als Produzent von Gesellschaft, und mithin von Gesellschaftstheorie, lesbar - und als solche auch in ihrer Form für die entstehende Soziologie adressierbar.

\section{Soziologiegeschichte als Geschichte des epistemischen Dings, Gesellschaft ${ }^{\star}$}

Gerade aus der soziologiegeschichtlichen Perspektive mag das Vorhaben, Gesellschaft als epistemisches Ding zu untersuchen, auf Widerstände stoßen. Zwei prominente Einwände aus der Phase der Gründung der Soziologie können hier ins Feld geführt werden, die beide um das Objekt, Gesellschaft ${ }^{`}$ kreisen: Der erste Einwand richtet sich gegen die Gesellschaft als legitimer Bezugspunkt einer soziologischen Untersuchung, der zweite dagegen, Gesellschaft als epistemisches Ding zu analysieren. In der Diskussion dieser Einwände lässt sich das heuristische Potenzial der Perspektive auf die Soziologiegeschichte als Geschichte des epistemischen Dings, Gesellschaft ${ }^{\natural}$ herausarbeiten. 


\subsection{Soziologiegeschichte als Objektgeschichte}

Von Anfang an wurde die Soziologie sowohl extern als auch intern scharf dafür kritisiert, dass sie den Begriff der Gesellschaft zur Grundlage einer neuen Disziplin im überkommenen Fächerkanon der Universitäten zu machen versuchte. Darauf zielte die vernichtende Kritik des Staatswissenschaftlers Heinrich von Treitschke (1859) an den Ansätzen seiner Kollegen Lorenz von Stein und Robert von Mohl, die Gesellschaftswissenschaft als Teil bzw. neben der Staatswissenschaften zu etablieren (vgl. Stein 1850; Mohl 1992 [1851]). ${ }^{20}$ Damit hatte Treitschke den Gesellschaftsbegriff in der deutschem Theorielandschaft nachhaltig diskreditiert (vgl. Lichtblau 2005). Und auch von Seiten der Geisteswissenschaften, namentlich durch Wilhelm Diltheys im Jahr 1883 veröffentlichte Einleitung in die Geisteswissenschaften, erfuhren nicht nur die Gesellschaftskonzeptionen der englischen und französischen Soziologien des 19. Jahrhunderts eine deutliche Absage (vgl. Dilthey 1883: 106ff.). Vielmehr richtete Dilthey sich gegen die Versuche der Verobjektivierung der Gesellschaft als ein eigenständiges Ganzes, das gegenüber Staat und Individuum autonom sei.

Beeinflusst von dieser Kritik wird auch aus der sich etablierenden genuin ,soziologischen' Perspektive bezweifelt, dass der Bezug auf Gesellschaft sinnvoll sei, ja dass ein solcher autonomer Gegenstand überhaupt existiere: „Es gibt niemals schlechthin Gesellschaft“, schreibt etwa Georg Simmel in seiner Begründung der Soziologie im Jahre 1908. Sie sei vielmehr ein Gegenwartsphänomen, ein Produkt der jeweiligen Wechselwirkungen zwischen den Individuen, „mit deren Auftreten eben Gesellschaft da ist und die weder die Ursache noch die Folge dieser, sondern schon unmittelbar sie selbst sind“ (Simmel 1908: 11). Jedwede Verselbstständigung der Gesellschaft gegenüber diesen Wechselwirkungen, dem Geflecht der Vergesellschaftungen, sei letztlich nur ein Schein, eine unzulässige Substantialisierung. ${ }^{21}$ Und auch Max Weber, der sich erst spät als Soziologe begriff, sprach von Vergesellschaftung, um den umstrittenen und kritisierten Gesellschaftsbegriff als terminus technicus zu vermeiden, ohne dabei jedoch

20 Nach Treitschke lassen sich so "heterogene Dinge“ wie religiöse, ökonomische oder künstlerische Genossenschaften nicht unter ein gemeinsames Kriterium zusammenfassen (Treitschke 1859: 66). Daher könne ,Gesellschaft' nicht als umfassender Oberbegriff all dieser gesellschaftlichen Erscheinungen dienen und damit zur Begründung einer eigenständigen Disziplin herangezogen werden.

21 Das Spezifische der soziologischen Disziplin liegt für Simmel also nicht in einem Gegenstand sui generis, sondern in einer besonderen Perspektive auf das „Gesellschaft-Sein der Menschheit“" (Simmel 1908: 12). 
das Vorhaben einer eigenständigen Soziologie aufzugeben (vgl. Tenbruck 1981: 337; Tyrell 1994; kritisch Peter 2001: 15).

Nicht nur Undeutlichkeit und Konturlosigkeit des Gesellschaftsbegriffs werden Ende des 19., Anfang des 20. Jahrhunderts - und auch heute noch - bemängelt (vgl. etwa Rümelin 1889; Spann 1907; Riedel 1975b; Nassehi 2015). Vor allem das Motiv der Abstandnahme vom Gesellschaftsbegriff und damit von einer wie immer gearteten Gesellschaftstheorie im strengen Sinne bildet seit der Etablierungsgeschichte der Soziologie eine wiederkehrende Konstante (vgl. Lichtblau 2001; Merz-Benz, Wagner 2001; kritisch hierzu Habermas 1992b). Bestritten wird nicht nur der systematische Stellenwert des Gesellschaftsbegriffs für die Soziologie, sondern ebenso auf ontologischer Ebene die Existenz eines solchen Objekts ${ }^{22}$ - eine Kritik, die seither immer wieder geäußert wird. ${ }^{23}$

Wenn also schon in der Gründungsphase der Soziologie bestritten wurde, dass es so etwas wie ein Objekt, Gesellschaft ${ }^{\star}$ gibt und es daher nicht als legitimer Bezugspunkt soziologischer Wissensformen gelten kann, so stellt sich natürlich die Frage, ob ,Gesellschaft' dann überhaupt als Bezugspunkt einer soziologiegeschichtlichen Untersuchung fungieren kann. Die Konzeption der Gesellschaft als ,epistemisches Ding in seinem vagen und verschwommenen Charakter ist jedoch gerade nicht primär darauf ausgerichtet, die Genese positiver Objekteigenschaften in den Privatrechtswissenschaften zu konstatieren, die als solche dann problemlos in die Soziologie eingegangen wären. Der Blick richtet sich vielmehr auf die Fragestellungen und Problematisierungsweisen, die sich am Gegenstand ,Gesellschaft ${ }^{\star}$

22 Für manche ist dies jedoch keine ontologische Frage, sondern eine Folge der gegenwärtigen Entwicklungen. Für sie gilt: So etwas wie Gesellschaft gab es einmal, gibt es aber heute nicht mehr. Baudrillard etwa sieht in der massenmedialen Entwicklung hin zur Simulationsgesellschaft das „Ende des Sozialen“ (Baudrillard 2010); für andere erscheint aufgrund der Zunahme der internationalen wie transnationalen Vergesellschaftung der nationalstaatlich-territorial konnotierte Begriff der Gesellschaft geradezu veraltet (so bereits Tenbruck 1981); oder aber habe „die Gesellschaft“ als Bezugspunkt der Regierungstechnologien mittlerweile ausgedient, so dass Niklas Rose gar den „Tod des Sozialen“ ausruft (Rose 1996). Auch theoriegeschichtlich wird ein Untergang des Gesellschaftsbegriffs erkannt, nachgezeichnet an „Verfallsstadien“ des Begriffs bis hin zu Luhmanns Systemtheorie, "die ihn als analytisches Konzept unbrauchbar macht" (Schwinn 2011: 29).

23 Prominent für diese Kritik steht heute v.a. Bruno Latour: „So etwas wie Gesellschaft gibt es nicht!" (Latour 2007: 16), proklamiert er und richtet sich damit primär gegen eine vorgeblich objektivistische Soziologie à la Durkheim (s.a. Latour 2001b). Die einzig verbleibende Möglichkeit scheint für Latour in der vollständigen Verabschiedung des Gesellschaftsbegriffs zu liegen (Latour 2007: 283; kritisch hierzu Marchart 2013: 129ff.). 
entspannen. Hierzu gehört gerade auch die Diskussion über den systematischen und epistemischen Status des Begriffs - sowohl für die Entwicklung der privatrechtlichen Methodik als auch für die sich ausdifferenzierende Soziologie. Oder anders formuliert: Selbst wenn es aus ontologischer Sicht Gesellschaft nicht geben sollte, ist damit noch nicht geklärt, wie und v.a. in welcher Form sie - gerade auch in negativer Hinsicht - zu einem machtvollen, fragengenerierenden Bezugspunkt des Wissens, zu einem epistemischen Ding, werden konnte. Genau darum geht es im Folgenden.

Das impliziert zugleich ein verändertes Verständnis der Soziologiegeschichte. Nicht die „Gedanken und Absichten der Handelnden“ stehen im Vordergrund, sondern die Objekte, „auf die sich ihr Handeln und ihr Begehren richtet" (Rheinberger 2006: 7). Soziologiegeschichte wird damit nicht geschrieben als Ideen-, Schulen- oder Klassikergeschichte, auch wenn Ideen und Klassiker untersucht werden. ${ }^{24}$ Sie wird auch nicht betrieben als Milieugeschichte, als Sozialgeschichte der der Disziplin zuzurechnenden Wissenschaftler und Wissenschaftlerinnen und ihrer Aktivitäten, oder als Sozial- und Institutionalisierungsgeschichte der Soziologie, ihrer Fachzeitschriften und ihrer Verbände. ${ }^{25}$ Ebenso wenig geht es, wie so häufig, um die Frage der Identität des Faches, die trotz der Heterogenität des Materials oft als Voraussetzung der Ausdifferenzierung zu einer eigenständigen Disziplin angesehen wird. ${ }^{26}$ Vielmehr geht es darum, eine Geschichte des soziologischen Denkens vom Objekt, d.h. vom epistemischen Ding ,Gesellschaft' her zu schreiben, das nicht primär oder ausschließlich in der Soziologie zu verorten ist.

Mit anderen Worten: Das Augenmerk liegt also auf dem Entdeckungszusammenhang der Gesellschaft als eigenständiges Fragen generiendes Objekt. ${ }^{27}$ Dieser Entdeckungszusammenhang ist ein heterogenes, plurales Gefüge, in dem eine Reihe unterschiedlicher politischer und

24 Vgl. zu solchen ,Idealtypen“ der Soziologiegeschichtsschreibung mit zahlreichen Literaturhinweisen immer noch Käsler 1984: 105ff.; zum Überblick über etablierte soziologiegeschichtliche Ansätze vgl. daneben insbesondere Lepenies 1981a; Peter 2001; Moebius 2004 jeweils mit m.w.N.

25 Vgl. etwa Käsler 1984; Wallgärtner 1991; Lepsius 1981; Glatzer 2014 m.w.N. zur Institutionengeschichte.

26 Vgl. hierzu die umfangreichen Studien zur kognitiven, sozialen und historischen Identität der Soziologie (Lepenies 1981b), jüngst auch den Versuch, diese über identitätsstiftende Kontroversen bzgl. der begrifflichen, theoretischen und methodischen Grundlagen einer Wissenschaft vom Sozialen zu rekonstruieren (Kneer, Moebius 2010).

27 Insofern geht es auch nicht um die Frage der Anfänge soziologischen Denkens, für die je nach Ausformung der Soziologie etwa als "Gruppwissenschaft“, als Kon- 
gesellschaftlicher Faktoren, Institutionen, Wissensarten und -bestände sowie Praktiken und Techniken zusammenspielen. Die soziologiegeschichtliche Forschung hat viele von ihnen herausgearbeitet. Einer der Hauptfaktoren für die Entdeckung der Gesellschaft wird in der Herauslösung des Marktsystems aus dem sozialen Gefüge gesehen, dessen gravierende Folgen mit der „sozialen Frage“ ins Bewusstsein gelangten: „Pauperismus, Nationalökonomie und die Entdeckung der Gesellschaft waren miteinander eng verflochten." (Polanyi 1977 [1944]: 114) Angesichts dieser grundlegenden Veränderungen wird die Gesellschaft für sich selbst zum Problem, und es stellt sich die Frage, wie soziale Ordnung überhaupt möglich ist bzw. sein kann (vgl. Luhmann 1981b). In dem Moment, in dem die Möglichkeit der Gesellschaft fraglich wurde, hat man sie als eigenständiges wissenschaftliches Objekt entdeckt.

Angesichts der Pauperismusproblematik wird aber auch auf die Rolle der spezifischen Techniken der Verobjektivierung der Gesellschaft hingewiesen, die sich in den wohlfahrtsstaatlichen Interventionen wie Versicherung, Sozialgesetzgebung und Fürsorgepraktiken entfalteten (s.u. II.4). Statistik und Wahrscheinlichkeitsrechnung, die diesen Interventionen zugrunde liegen, produzieren ein spezifisches Wissen über die Bevölkerung. In dieser Form kann sie der Regierung als Objekt der Normierung und Disziplinierung dienen (Foucault 2006, 2009a)..28 Die Gesellschaft wird als Bevölkerung zum Steuerungsobjekt.

Erklärungsmodelle für die Entstehung der verschiedenen Soziologien sind auch in unterschiedlichen nationalen geistigen Milieus zu suchen (vgl. etwa Tenbruck 1994), d.h. in der je spezifischen Ökonomie des Wissens (vgl. Lepenies 1981b). Insofern gehören zum Entdeckungszusammenhang auch die bereits etablierten Disziplinen. Denn Soziologie entstand nicht aus dem Nichts. Sie differenzierte sich vielmehr hinsichtlich des Untersuchungsgegenstandes, der Methoden und der Techniken als eine Art „irritierende Integrationswissenschaft“ (Schnädelbach 1983: 96, H.i.O.) aus dem bereits vorhandenen Fächerkanon aus, indem sie etwa philosophische, ökonomische historische, seinem Anspruch nach naturwissenschaftliche und eben auch juristische Gesichtspunkte zusammenführte (vgl. ebd.:

flikt- oder Evolutionstheorie oder als historische Wissenschaft etc. verschiedene Datierungsstrategien angewendet werden, vgl. hierzu Prahl 1986 m. zahlr. N.

28 Kritisch zu einem solchen immer wieder konstatierten Zusammenhang zwischen der Entwicklung des Instrumentariums der empirischen Sozialforschung und der Soziologie als Disziplin Oberschall 1997. 
96f.). ${ }^{29}$ Das Fach konnte seine Identität „nur in der Auseinandersetzung mit bereits existierenden und in den meisten Fällen längst hoch angesehenen Fächern innerhalb der Universität und anderer Institutionen finden“ (Lepenies 1981a: XX). Wissen über Gesellschaft war (und ist) nicht an die Wissenschaft von der Gesellschaft gebunden. Zahlreiche Wissenstransfers in das sich etablierende soziologische Denken fanden statt und führten zu spezifischen Konkurrenzlagen: Die Soziologiegeschichte wies hin auf die Nähe und Abgrenzungsproblematik zur Geschichtswissenschaft, zur Nationalökonomie, zur Biologie, zur Psychologie, Staatswissenschaft, zu den Naturwissenschaften sowie - insbesondere in Deutschland - zu den Geisteswissenschaften im Allgemeinen. ${ }^{30}$

Der objektzentrierte Blick auf die Formierungsphase der Soziologie vermag dieses Spektrum zu erweitern. Hier zeigt sich in der Retrospektive: Gerade die Frage, wie in ihrer Gründungsphase Gesellschaft als normative Ordnung gefasst wird, eröffnet den Weg in die Rechtswissenschaft - jene Disziplin, die zu jener Zeit von vielen als eigentliche Normwissenschaft angesehen wird, und in der ein deutliches Bewusstsein für eine Konkurrenzlage zwischen Soziologie und Rechtswissenschaft herrscht. So konstatiert Hans Kelsen im Jahr 1912 aus juristischer Perspektive: „[D]iese Auseinandersetzung der Soziologie mit ihren Grenzwissenschaften ist noch am ehesten geeignet, eine Rechtfertigung der um ihre Existenzberechtigung kämpfenden jungen Disziplin zu liefern“ (Kelsen 1912: 601). Insofern gilt für den Rekurs auf Max Weber, Ferdinand Tönnies und Émile Durkheim, dass sie nicht in ihrer Eigenschaft als Klassiker zu Wort kommen. $\mathrm{Zu}$ zeigen ist vielmehr, wie sich diese drei Autoren an den privatrechtlichen Problematisierungsweisen des epistemischen Dings ,Gesellschaft' durch das Recht orientieren. Ihre Arbeiten sollen von diesem

29 Insofern ist es auch nicht verwunderlich, dass soziologisches Denken in Deutschland vor seiner späten Institutionalisierung an den verschiedensten Lehrstühlen anzutreffen war. Die Herkunft der Soziologie aus anderen Wissenschaften kommt auch in den Professionen der Gründungsmitglieder der DGS zum Ausdruck: Mitglieder des ersten Vorstandes stammten aus der Ökonomie, Statistik, Philosophie, Psychologie, Geschichte, Rechtswissenschaft, Sozialpolitik und Theologie oder hatten mehrere Fächer studiert (vgl. Glatzer 2014).

30 Siehe für das Verhältnis der Soziologie zur Nationalökonomie etwa Kruse 1990; Albert 1998 [1967]: 13ff.; Takebayashi 2003 (bzgl. Werner Sombart und Max Weber); Stölting 1986 (aus institutionengeschichtlicher Perspektive); Lichtblau 2011: 317ff. m.w.N; zur Biologie etwa Hejl 1998; Lüdemann 2004: 107ff.; Meyer 1969; Gerhardt 2009: 25ff.; zur Psychologie siehe schon Simmel 1908: 3ff.; Weber 1988j: 432ff.; zu den Staatswissenschaften Wagner 1990; zu den Geisteswissenschaften im Allgemeinen Tenbruck 1994; Lepenies 2006; S̆uber 2007. 
Objektbezug her rekonstruiert werden, um im Rahmen der Geschichte der Gegenwart Anschlussmöglichkeiten für die Frage nach dem Verhältnis von Recht und Soziologie aufzuzeigen.

Es geht also nicht darum, über das Konzept der Gesellschaft als epistemisches Ding die Genese der Soziologie erklären zu wollen. Vielmehr dient dieses Konzept als ein heuristisches Instrument, um Gesellschaftskonstruktionen, -theorien sowie Praktiken und Techniken ihrer Verobjektivierung in bestimmten Bereichen lesbar zu machen - und hiervon ausgehend den Transfer in die Soziologie nachzuzeichnen. Soziologiegeschichte erweist sich in dieser Perspektive nicht als monokausal, auch nicht als Geschichte einer einheitlichen Theorie- und Objektbildung, sondern als multikausaler und multivariabler Entdeckungszusammenhang.

An diesem Punkt kommt eine weitere Eigenschaft des epistemischen Dings zur Geltung: Aufgrund seines performativen Charakters trägt die Art und Weise der Bestimmung des Entdeckungszusammenhangs zur Bestimmung des Wissensobjekts bei. Denn dieses existiert nur in seiner Veränderlichkeit, als „Liste“ von Aktivitäten und Eigenschaften, die mit jedem weiteren Listeneintrag umdefiniert und in ihrer Gestalt verändert wird (Rheinberger 2006: 28). Die Frage nach dem epistemischen Ding, Gesellschaft' wird dadurch eine eminent historische - nicht nur, weil es sich um ein geschichtlich wandelbares Objekt handelt, ${ }^{31}$ sondern weil die Art und Weise der historischen Bestimmung dieses Objekts, die Soziologiegeschichte selbst, damit historisch wandelbar wird. Denn je nach Definition des Entdeckungszusammenhangs, d.h. der Aufstellung einer (neuen) Liste an relevanten Faktoren oder das Hinzufügen weiterer Listeneinträge, ändert sich auch das Verhältnis der Soziologiegeschichte zur Gegenwart - ein Umstand, der sich v.a. im politischen Charakter der juridischen Soziologien zeigen wird (vgl. hierzu das Schlusskapitel).

\subsection{Objektgeschichte und Gesellschaftstheorie}

Diese Überlegungen leiten direkt über zum zweiten Einwand, den man der Geschichte der Soziologie entnehmen kann. Er richtet sich auf gesellschaftstheoretischer Ebene gegen die konkrete Ausformung, unter der hier die Gesellschaftskonstruktionen untersucht werden. Denn das Vorhaben, Gesellschaft wie ein ,epistemisches Ding ${ }^{\complement}$ zu analysieren, erinnert letztlich

31 Die Wandelbarkeit kann bis zum Verstummen eines Objekts führen. Mithin gilt: „Epistemische Dinge haben ihre Zeit.“ (Rheinberger 2006: 283). 
an eine der berühmtesten und berüchtigtsten Definitionen aus der Gründungsphase der Soziologie: Die „erste und grundlegendste Regel“ der soziologischen Methode laute, so Durkheim im Jahre 1894, „die soziologischen Tatbestände wie Dinge zu betrachten“ (Durkheim 2007 [1894]: 115). ${ }^{32}$

Durkheim geht von einem Mangel an Objektivität der Gesellschaft aus. Die Phänomene, die die Gesellschaft konstituieren, seien nur schwer fassbar. Angesichts dessen zieht Durkheim die Analogie zur naturwissenschaftlichen Erkenntnisweise, um den gleichen Grad an Wirklichkeit in Anspruch zu nehmen, der dort den Dingen zuerkannt wird: „Wir behaupten also keineswegs, daß die sozialen Phänomene materielle Dinge sind, sondern daß sie mit dem gleichen Rechtstitel Gegenstände sind wie die materiellen Dinge, wenn auch solche anderer Art.“ (Ebd.: 89) Die Eigenständigkeit der Sphäre des Sozialen gegenüber der Natur wird nicht in Frage gestellt, und das Soziale soll nur durch das Soziale erklärt werden. Mittels der Analogisierung fordert Durkheim jedoch, eine bestimmte geistige Haltung gegenüber den sozialen Tatsachen einzunehmen: Sie sollen wie die materiellen Dinge in den Naturwissenschaften als etwas Äußerliches, Gegebenes, der individuellen Willkür Entzogenes betrachtet werden, über das man zunächst nichts weiß (vgl. ebd.: 89ff.; Stedman Jones 1996). Als Dinge betrachtet gewinnen die sozialen Tatsachen ein unabhängiges Eigenleben, sie sind Objekte sui generis mit eigenständigen Gesetzen, die nach Durkheim den Individuen nun von außen (und zwar mittels Zwang) entgegentreten. Und die Gesellschaft als „Synthese sui generis“ (Durkheim 2007 [1894]: 94) der sozialen Phänomene wird damit selbst zu einem solchen eigenständigen, den Individuen enthobenen Objekt.

Von Anfang an wurde Durkheims Forderung, die faits sociaux wie Dinge zu behandeln, zum Ausgangspunkt fundamentaler Kritiken. ${ }^{33}$ Obwohl Theodor W. Adorno den Bezug auf die Gesellschaft wie Durkheim für unverzichtbar hält (Adorno 2012 [1968]: 65), formulierte er eine der scharf-

32 Es ist umstritten, ob es sich bei dem Ausdruck „soziologische Tatbestände“ um eine treffende Übersetzung der faits sociaux handelt (so etwa König 2007), oder ob man nicht besser von „sozialen Tatsachen“ sprechen sollte (vgl. Keim 2013). Ich verwende beide Ausrücke synonym.

33 Vgl. zur Rezeption der Regeln in Deutschland Keim 2013; in Frankreich Berthelot 1995: 143ff. und Borlandi, Mucchielli 1995; in England Platt 1995; sowie in Russland Gofman 1997. 
züngigsten Kritiken an dessen sogenanntem chosisme. ${ }^{34}$ Die spezifische Fehlleistung einer solchen, auf positiv feststellbare Tatsachen ausgerichteten Soziologie kennzeichnet er mit dem Schlagwort der Verdinglichung: Sie sei Durkheims „blinder Fleck, die Formel, auf die sein Werk verhext ist" (Adorno 1976: 13). ${ }^{35}$ Zwar beschreibe Durkheim eindringlich - und für Adorno auch richtigerweise - „die institutionelle Verselbständigung des vom Menschen gemachten gegen die Menschen“" (Adorno 2012 [1968]: 140). Indem er aber das institutionell Verselbstständigte verobjektiviere, zum eigenständigen und eigengesetzlichen Untersuchungsgegenstand der Soziologie mache, werde sein eigentliches Grundwesen verdeckt, nämlich eine Beziehung zwischen Menschen zu sein. Erst dadurch vermag die derart verdinglichte Gesellschaft für Durkheim den Individuen von außen entgegenzutreten: „[E]ine solche ,zweite Natur ${ }^{6}$ der von Menschen gemachten und gegen sie verselbständigten Institutionen“ (ebd.) wird Durkheim nun zur ersten Natur - eben zu einem Ding, wie es in der natürlichen Umgebung anzutreffen ist. Deshalb ist es Durkheim möglich, in naiver Nachahmung der positivistischen Haltung der Naturwissenschaften der Gesellschaft gegenüberzutreten (Adorno 1976: 12). Diese Haltung offenbart für Adorno jedoch den fundamentalen Mangel in Durkheims Denken: Es ist dualistisch, die Kategorien erstarren, werden verdinglicht.

Adornos Verdinglichungskritik baut auf einem dreifachen Vorwurf auf. Erstens liege ein Kategorienfehler vor: Etwas, was an sich keine dinglichen Eigenschaften besitzt, wird wie ein Ding im Sinne eines äußeren, materiellen Phänomens betrachtet. Die Gesellschaft als etwas Menschengemachtes wird als Gegenstand, als unveränderliches Objekt verstanden. Das führt zweitens zur Verdinglichung des Denkens: Es erstarrt, die sozialen Phäno-

34 Die Treffsicherheit von Adornos Kritik lässt sich mitunter bezweifeln, da die Bezugnahme auf Durkheim insbesondere der eigenen Positionierung im Rahmen des Positivismusstreits in der deutschen Soziologie diente (Peter 2013; s.a. Adorno 1976: 8f., 1979: 280, 2012 [1968]: 57ff.). Hier interessiert aber weniger die Frage, ob seine Kritik zutreffend ist oder nicht, sondern das Verhältnis von Ding und Gesellschaft, wie es bei Durkheim und Adorno zur Debatte steht.

35 Adorno griff für die Entfaltung seiner Verdinglichungskritik auf Georg Lukács' Geschichte und Klassenbewußtsein aus dem Jahre 1923 zurück, kritisierte dessen Konzept aber später als Ausdruck eines Idealismus, der sich insbesondere in dessen „Wunschbild ungebrochener subjektiver Unmittelbarkeit“ (Adorno 2003 [1972]: 367) zeige. ,Verdinglichung' bezeichnet bei Adorno eine bestimmte, nämlich instrumentelle Art und Weise des In-Beziehung-Tretens. Kennzeichnend ist eine Unfähigkeit, die Besonderheit des Daseins von Menschen, aber auch von Dingen zu erfassen (vgl. Seel 2004: 13). Konsequenterweise gibt es bei ihm also auch eine „Verdinglichung der Dinge“ (vgl. Caligiuri 2013: 73ff.). 
mene werden zu Dingen im wörtlichen Sinne, d.h. als Dinge wahrgenommen (vgl. Nassehi 2009: 70). Dadurch wird drittens jedwede Kritik unmöglich. Denn Durkheim legt sich in den Augen Adornos damit auf das positivistische Geschäft der unkritischen Beschreibung fest. Der dialektische Charakter der Gesellschaft, der Ausdruck des der bürgerlichen Warengesellschaft zugrunde liegenden Antagonismus zwischen IndividuellBesonderem und Kollektiv-Allgemeinem ist, muss Durkheim zwangsläufig entgehen. Und damit entgeht ihm zugleich, dass sein Denken selbst historisch bedingt ist: Es ist Ausdruck des verdinglichten Bewusstseins der bürgerlichen Gesellschaft und damit als ideologisch anzusehen. Durkheims „Bündnis mit falschem Bewußtsein“ enthalte „schiefe Projektionen der Wahrheit auf ein Bezugssystem, das selbst in den gesellschaftlichen Verblendungszusammenhang fällt" (Adorno 1976: 44).

Mit Verweis auf Adornos Verdinglichungskritik ließe sich dem Vorhaben, die Entdeckung des epistemischen Dings ,Gesellschaft ${ }^{\prime}$ in der Privatrechtswissenschaft zu untersuchen, entgegenhalten, dass hier Gesellschaft erneut nur in ihrer verdinglichten Form zum Ausdruck komme und kommen könne. ${ }^{36}$ Man verlege sich erneut auf das positivistische Geschäft einer Rekonstruktion der vermeintlich feststehenden gesellschaftlichen Tatsachen, ohne die dialektische Spannung und Dynamik zwischen Individuum und Gesellschaft fassen zu können. Dieser Vorwurf würde insbesondere auch für die vorgeblich neutrale Beobachtungsperspektive einer historischen Untersuchung gelten, da mit Blick auf den Untersuchungsgegenstand ,Gesellschaft ${ }^{\star}$ als allumfassende Totalität die Ebene der Beobachtung immer schon mit der Ebene der Gesellschaftstheorie in eins fällt (vgl. Demirovic 2001). Oder anders formuliert: Die Soziologie und ihre Gesellschaftstheorien sowie damit auch die Soziologiegeschichte befinden sich in der erwähnten widersprüchlichen Situation, Teil ihres Gegenstandes und mithin der Geschichte ihres Gegenstandes zu sein. Die Untersuchung der Gesellschaftskonzeptionen kommt dann ohne einen gesellschaftstheoretischen Begriff nicht aus - und sei es nur, um ihn als Vergleichsfolie für die Einordnung der verschiedenen Konzeptionen zu verwenden. ${ }^{37}$ Die Entdeckung der Gesellschaft als epistemisches Ding in der Privatrechtswissen-

36 Im Übrigen zählt auch das Privatrecht mit seiner Institutionalisierung des Privateigentums in der marxistischen Theorie als Prototyp der Rechtsform der „bürgerlichen Gesellschaft".

37 Es handelt sich hier m.E. nicht nur um ein Problem der Begriffswahl, sondern vor allem um eines der Theoriearchitektur: Sobald man ,Gesellschaft' zum Bezugspunkt macht, droht diese Gefahr der Essentialisierung, der Verobjektivierung im Sinne der Objekt- oder Dingwerdung und damit der Verselbstständigung - 
schaft zu untersuchen hat damit unweigerlich gesellschaftstheoretische Implikationen. Diese lassen sich gerade mit Blick auf die Verdinglichungskritik verdeutlichen - und zeigen hierin auch ihr spezifisches heuristisches Potential:

(1) Auf wissenschaftstheoretischer Ebene bedeutet das Konzept des epistemischen Dings eine Relativierung der Ontologie des empirischen Seins. Das ist für die Soziologie nicht nur von Interesse, weil sie sich als Seinswissenschaft gegenüber der Rechtswissenschaft als Sollenswissenschaft zu etablieren sucht (s.u. $\$ 5$ ), sondern weil sie wie jede andere Wissenschaft auf ontologischen Annahmen basiert - egal, wie weit man etwa in den gegenwärtigen, v.a. poststrukturalistisch geprägten Ansätzen den Begriff der Ontologie prozessualisiert, historisiert oder von der Negativität her zu bestimmen (oder zu umgehen) sucht. ${ }^{38}$

Rheinberger interveniert mit seinen Laborstudien in die Frage nach der Objektivität des materiellen Dings als naturwissenschaftlicher Untersuchungsgegenstand. Gegenüber der auch von Durkheim vertretenen An-

egal welchen Begriff man wählt. Insofern hilft der Versuch nicht weiter, den Dingbegriff zu umgehen und Ausdrücke wie ,Erkenntnisgegenstand' oder ,Wissenschaftsobjekt' zu verwenden (vgl. etwa Daston 2000; Knorr Cetina 2008: 57; für den Gegenstand ,Gesellschaft' siehe Wagner 2000, 2001: 128ff.). Der Gefahr der Verdinglichung entgeht man dadurch nicht. Bei Rheinberger zeigt sich dieses Begriffsproblem am Wandel und der Ausdifferenzierung seiner Begriffswahl: Er verwendete zunächst die Ausdrücke „epistemisches Ding“, „epistemisches Objekt“, „Forschungsgegenstand“ und „Wissenschaftsobjekt“" noch synonym (vgl. etwa Rheinberger 1992a: 70). Erst später stellt er klar, dass er den Ausdruck, Ding‘ gegenüber dem ,Objekt ${ }^{\star}$ bevorzugt, da letzteres der cartesianischen Epistemologie entspringe: Das Objekt sei das „Vorliegende, das Vor-Augen-Liegende“, das auf ein erkennendes Subjekt verweist, und damit die Objekt/Subjekt-Dichotomie reproduziere. Gerade hiervon grenzt er das epistemische Ding ab (vgl. Rheinberger 2001: 61).

38 Die generelle Kritik an holistischen, essentialistischen Gesellschaftsbegriffen, die Gesellschaft in Form eines Containermodells als einen Gegenstand sui generis mit bestimmten und genau bestimmbaren Eigenschaften begreifen, gehört mittlerweile zum guten Ton. Im Lichte eines anti-essentialistischen Ontologieverständnisses erscheint es gegenwärtig jedoch wieder möglich, die Soziologie explizit über den Gegenstand ,Gesellschaft' zu bestimmen: Die „Unmöglichkeit der Gesellschaft“ (Laclau 1990; Laclau, Mouffe 2000) setzt den Bezug auf den Gegenstand ,Gesellschaft ${ }^{\star}$ als notwendig, wenn auch immer schon als verfehlt voraus (vgl. Stäheli 1995; Bonacker 2008); und auch die Ansätze zur Gesellschaft als „imaginäre Institution“ (Castoriadis 1990), als kontingentes, performatives und postfundamentalistisches „unmögliches Objekt“ (Marchart 2013) oder „kritische Totalität“" (Gertenbach, Moebius 2008) gehen weder von einer vorgegebenen Analyseeinheit noch von einer stabilen äußeren Realität aus. 
nahme, dass in den Naturwissenschaften feststehende Tatsachen - nämlich vorgegebene äußere Objekte - untersucht würden, decken seine Arbeiten den historischen und spezifisch vagen, performativen und instabilen Charakter des Dings auf. Das Sein, selbst das materielle Sein, enthält also immer schon einen Mangel an Objektivität. ${ }^{39}$ Das bewirkt eine Relativierung des chosismes Durkheims: Der Mangel der Objektivität der Gesellschaft kann nicht mehr durch Analogisierung mit den Dingen der Naturwissenschaften behoben werden, wenn bei ihnen derselbe Mangel herrscht. Damit gilt: Es ist nicht mehr der Gegensatz zur Natur, die Annäherung oder die Abgrenzung von den Naturwissenschaften, die den Ort der Soziologie zu bestimmen vermögen. Sowohl für die Naturwissenschaften als auch für die Geisteswissenschaften vertreten die Laborstudien eine Ontologie jenseits eines Essentialismus. Für ,Gesellschaft' gilt im Lichte dieser Logik: Trotz der Orientierung am Ding erweist sich aufgrund der Relativierung der Objektivität der Objekte eine essentialistische Bestimmung der Gesellschaft als ein vorgängiges, statisches und unabänderliches Ding als unmöglich.

Damit verliert aber zugleich die Verdinglichungskritik ihre Angriffsfläche, steht doch im Zentrum der Vorwurf, dass Gesellschaft als etwas ÄuBerliches, Starres, Feststehendes behandelt würde. Fasst man die Gesellschaft als ,epistemisches Ding', so geht dieser vorgeblich sichere Boden verloren, der Begriff wird prozessualisiert, unscharf, schwankend und zutiefst historisch. Seine Bestimmung erfolgt jeweils historische spezifisch, er ist kontingent.

(2) Die Kategorie der Gesellschaft wird dynamisiert. Das zeigt sich, wenn man die Verdinglichungskritik als Warnung liest - davor, dass der Gesellschaftsbegriff im Prozess seiner Entwicklung auf Dauer gestellt werden kann, indem sich seine Eigenschaften verfestigen und die Gesellschaft damit als unwandelbares, verselbstständigtes Objekt hypostatiert wird. Dieser Gefahr eines möglichen Übergangs zu einem erstarrten Konzept kann man mit der Konzeption der Gesellschaft als epistemisches Ding be-

39 Allerdings muss man hier kritisch anfügen: Die Relativierung des Dingcharakters ist - historisch gesehen - ein Produkt der Episteme der Naturwissenschaften selbst (vgl. etwa. Bachelard 1994, 1987; Barad 2012). Rheinberger greift für sein Vorhaben jedoch nicht auf diese naturwissenschaftlichen Erkenntnisse zurück. Sein kritisches Verfahren besteht in einer Art „erklärenden Vertauschung“ (Serres 1991: 265): Sozialwissenschaftliche und philosophische Methoden und Theorien werden in das Labor transportiert, um gegen naive und konkretistische Vorstellungen über das Objekt anzuschreiben. Überspitzt formuliert: Rheinberger kulturalisiert die Natur. 
gegnen - allerdings nur, wenn man den Begriff des epistemischen Dings bei der Übersetzung in den Bereich der Gesellschaftstheorie transformiert.

Denn bei Rheinberger findet sich dieser mögliche Übergang in der spezifischen Dynamik, die das epistemische Ding im Verhältnis zu seinem Gegenüber, dem technischen Ding, entfaltet: „Während technische Dinge eine angebbare Funktion in der Herstellung anderer Dinge haben oder als Dinge selbst zum Gebrauch und Verbrauch bestimmt sind, sind epistemische Dinge Erkenntnisgegenstände, also Objekte, an denen oder über die wir Wissen gewinnen wollen." (Rheinberger 2001: 61) Technische Dinge sind von einer charakteristischen Bestimmtheit, die eine Identität in der Ausführung ermöglicht (Rheinberger 1992a: 70f.). Genau das vermag die Forschungspraxis zu stabilisieren. Sie sind nicht wie epistemische Dinge „Fragemaschinen“, sondern „Antwortmaschinen“, die in ihrer spezifischen Anordnung die Emergenz von Wissenschaftsobjekten erlauben (ebd.: 72).

In Rheinbergers Studien fungieren die beiden Dingarten als gegenseitiger, sich jedoch nicht ausschließender Abgrenzungshorizont. Sie stehen in einer Beziehung des wechselseitigen Austausches, der die Grenzen verschwimmen lässt. Es kann sich sogar ein Übergang vom epistemischen zum technischen Ding vollziehen - bzw. auch vice versa. Und wenn sich ein epistemischer Gegenstand zu einem technischen verfestigt hat, kann er seinen eigentlichen Ort, das Labor, sogar verlassen. In diesem Wechselspiel entfaltet sich für Rheinberger die spezielle Dynamik in einem Experimentalsystem, das dadurch Neues hervorzubringen vermag (vgl. Rheinberger 2006: 30f., 1992a: 70f.).

Wenn man das Konzept des epistemischen Dings nun in der Gesellschaftstheorie anwendet, verlässt man das Labor. Damit geht das topologische setting des Begriffs verloren: Der spezifische begrenzte Ort seiner Herstellung, das Experimentalsystem, und mit ihm sein Abgrenzungshorizont, das technische Ding, finden keine Entsprechung bei einem Gegenstand, der wie die Gesellschaft als eine die Beobachterin umfassende Totalität fungiert. Zwar werden auch im Bereich der Soziologie Techniken und Methoden samt ihrer materialen Vorrichtungen und Gegenstände angewendet, wenn man so will: technische Dinge, um das Objekt ,Gesellschaft' hervorzubringen und zu stabilisieren (vgl. etwa Kalthoff 2003). Doch stößt die Analogie darin an ihre Grenze, dass nicht ein spezifisches Teilphänomen in einem gehegten experimentellen setting untersucht wird, sondern ein umfassendes Totalitätsphänomen außerhalb eines (aktiv) verfestigten (Labor-)Raumes. Der Verlust der Grenzen des Labors kennzeichnet die Grenze einer solchen Übertragbarkeit aus dem Bereich der Laborstudien (vgl. 
Schweitzer 2015c). Die Gesellschaft ist kein Labor, ${ }^{40}$ in der das Ding, Gesellschaft' einen Laborraum innerhalb der Gesellschaft verlassen könnte. Wohin sollte es auch gehen?

Damit wird nicht bestritten, dass ,Gesellschaft ${ }^{\circ}$ in bestimmten Theorietraditionen wie ein technisches Ding behandelt wird. Ausgeschlossen ist aber die Annahme, dass auf ontologischer Ebene ein tatsächlicher Übergang der Gesellschaft zu einem solchen technischen Ding erfolgen kann, d.h. die Gesellschaft als äußeres, objektives, beobachtbares Ding tatsächlich fassbar ist. Folgt man dieser Prämisse, zeigen sich Verobjektivierungen, Verfestigungen und Fixierungen des Gesellschaftsbegriffs als kontingente Praktiken und Techniken, die in ihrer Spezifik analysiert werden müssen. Die im Folgenden untersuchten Gesellschaftskonstruktionen decken mithin also nicht, die Wahrheit' über das Objekt Gesellschaft auf, sondern sind als spezifische Hervorbringungs- oder Entdeckungszusammenhänge, aber auch als Objektivierungs- und Stabilisierungspraktiken der Gesellschaft lesbar - und das sowohl in den Privatrechtswissenschaften als auch in der Soziologie.

Wenn angesichts des Gegenstandes Gesellschaft das topologische setting, das in Rheinbergers Begriff eingelagert ist, verloren geht, so sind dies die „Kosten“ einer Übersetzung des epistemischen Dings in die Gesellschaftstheorie (vgl. Langenohl, Schweitzer 2015; Schweitzer 2015c). Allerdings handelt es sich um einen Preis, den man gerne zahlt. Denn daraus folgt eine auf Dauer gestellte Dynamisierung des Gesellschaftsbegriffs. Als ,epistemisches Ding' betrachtet ist Gesellschaft ein Wissen im Werden, das ständig performativ hervorgebracht wird. Betont wird damit die Unmöglichkeit der endgültigen Stabilisierung der Gesellschaft, einer abschließenden, auf Dauer gestellten Bestimmung. Soziologie kommt damit an kein Ende, sondern wird zur ständigen Aufgabe.

(3) Eine antiessentialistische Ontologie sowie eine Dynamisierung der Kategorien sind nicht nur den Laborstudien geläufig. Daher liegt das eigentliche heuristische Potential der Konzeption der Gesellschaft als epistemisches Ding in seinem spezifischen Dingcharakter. Der Kampf gegen vermeintliche Objektivitäten, dieses Credo des Konstruktivismus, bedeutet für Rheinbergers Dingbegriffe nämlich keineswegs die Aufgabe der Vorstellung von der ,Dinghaftigkeit des Dings', wie sie in ihrer Materialität zu sehen ist. Denn auch wenn es gelegentlich scheint, als spiele die Materialität für seine Konzeption des epistemischen Dings keine Rolle, besteht seine Strategie gerade nicht darin, die materielle Seite im Ding aufzulösen, 
sei es in Bewusstsein, in Sprache oder in sonstige Ansätze eines radikalen Konstruktivismus (kritisch hierzu Bloor 2005). Epistemische Dinge sind "Mischgebilde“ bzw. „Diskurs-Objekte“ (Rheinberger 2006: 28, 16): Sie sind aufgespannt zwischen Natur- und Geisteswissenschaften. Das Ding ist also nicht mehr als ,rein' anzusehen, d.h. einer reinen Sphäre der äußeren Natur zuzuordnen. Allerdings geht es Rheinberger auch weiterhin um die Körperlichkeit, die Materialität und damit die physisch-haptischen Qualitäten des Dings:

The general thrust of my whole argument is about the power of material objects - in contrast to ideas or concepts - as driving forces in the process of knowledge acquisition. [...] My goal was to provide an objectcentered, materially founded account of knowledge production. According to my position, scientific or epistemic objects are clearly material things. (Rheinberger 2005: 406)

Epistemische Dinge haben ein materielles Substrat, auch wenn die Besonderheit in ihrer Opazität liegt (vgl. ebd.). Ebenso wie die anderen neuen Dingbegriffe wie etwa ,Hybride`, ,Quasi-Objekt' oder ,Grenzobjekt ${ }^{\star}$ befindet das epistemische Ding sich in einer spezifischen konzeptionellen Zwischenlage, die Konstruktivismus und Realismus, Materialismus und Idealismus zu verbinden sucht. An die Stelle der Dialektik mit ihren antagonistischen Spannungsverhältnissen und Dynamiken tritt ein eigenständiger Zwischenbereich, der durch das epistemische Ding besetzt bzw. in ihm erkennbar wird.

Rekurriert man auf einen solchen Dingbegriff, tritt eine Verschiebung in der Diskursmatrix bzgl. des chosisme ein. Denn im Kern beruhen sowohl die Verdinglichungskritik als auch die Soziologie à la Durkheim auf derselben Struktur: Etwas Nicht-Dingliches wird wie bzw. als ein Ding betrachtet - einmal positiv, als Voraussetzung für die Wissenschaftlichkeit der Soziologie, das andere Mal negativ, als Ausgangspunkt der Kritik. Für beide gilt: Die Gesellschaft ist in der Sphäre des Nicht-Dinglichen zu verorten, und nicht in der der materiellen Phänomene (auch wenn der Materialität natürlich eine je spezifische Rolle zukommt). Durkheim hat dies explizit betont, als er die „Immaterialität sui generis“ (Durkheim 2007 [1894]: 221) der sozialen Phänomene herausstellte. Und für den historischen Materialismus nach Marx, aus dessen Tradition heraus sich die Verdinglichungskritik entwickelte, spielt die Materie letztlich nur eine vermittelnde Rolle: Zwar bestimmt die Produktions- und Tauschweise, und damit die materielle Seite des Lebens, die Gesellschaft. Der Fluchtpunkt des Klassenkampfoder Wertmodells liegt jedoch in den materiellen Interessen, d.h. den menschlichen Interessen an den materiellen Dingen. Letztlich geht es also 
nicht um die konkreten materiellen Dinge selbst, sondern um mit Interessen und Wertformen überformte Dinge. Selbst wenn es heißt, dass das gesellschaftliche Sein das Bewusstsein bestimme, so wird für Marx damit eben gerade das immaterielle Bewusstsein zum Fluchtpunkt der Theorie.

Das gilt auch für Adorno, der trotz seiner Kritik an der Geschichtsteleologie des historischen Materialismus und an Lùkacs' Idealismus an die marxistische Verdinglichungskritik anschließt. Ausgehend vom Widerspruch zwischen Gebrauchs- und Tauschwert entwickelt er den Vorwurf des Kategorienfehlers: Etwas werde fälschlicherweise für etwas anderes gehalten. D.h. konkret: Etwas Nicht-Dingliches wie die Gesellschaft werde für ein Ding gehalten. Vor allem in der Negativen Dialektik besitzt das Ding noch eine weitergehende Funktion: Es wird zum Grenzfall der Erkenntnis(-theorie). Wenn Adorno hier (wie in der Ästhetischen Theorie) vom „Vorrang des Objekts“ (Adorno 2003 [1972]: 367) spricht, so setzt er anhand dieser unbegreiflichen Dinghaftigkeit des Dings als das Negative der Vernunft die dialektische Bewegung des Denkens in Gang. Die Markierung einer nicht-sozialen Umwelt eröffnet somit erst die Möglichkeit der Verflüssigung des Denkens, die Grundvoraussetzung der Identifizierung des falschen Bewusstseins ist. Damit zielt auch diese Bezugnahme auf das Ding letztlich auf das Bewusstsein als nicht-materielles gesellschaftliches Phänomen. Und erst wenn man derart den Schwerpunkt auf das Bewusstsein setzt, wird auch ersichtlich, warum die Verdinglichung der Gesellschaft überhaupt für Adorno eine Kritik darstellen kann, nämlich als Entlarvung der herrschenden Ideologie.

Sowohl Durkheim als auch die Verdinglichungskritik trennen die Sphäre einer scheinbar unveränderlichen, unzugänglichen äußeren Natur als Ort des Materiellen von derjenigen des Sozialen. ${ }^{41}$ Hier ist also jene Episteme der Moderne am Werk, die für Michel Serres und in seinem Gefolge für Bruno Latour in der unüberbrückbaren Kluft von Natur und Kultur besteht (Serres 1994c, 1994b; Latour 1995). Nicht Verdinglichung, sondern Entdinglichung ist das zentrale Motiv eines solchen Gesellschaftsbegriffs, der einerseits die Untersuchungsgegenstände der Soziologie auf menschliche Akteure und Aktionen beschränkt und gleichzeitig die der Naturwissenschaften auf feststehende materielle Tatsachen festschreibt.

41 Damit treffen sie den Geist ihrer Zeit. Beobachtbar ist seit der Formierungsphase der Soziologie eine materialreiche ,Entmaterialisierung' der zentralen soziologischen Kategorien. Dabei etablierte sich ein anthropozentrischer Begriff der Gesellschaft, der dem Materiellen keinen Platz im Gefüge des Sozialen zuerkennt, sondern auf eine rein menschliche Sphäre des Zusammenlebens abstellt (Rehberg 2008: 27; Gross 2001). 
Wenn Rheinberger bei diesem zweiten Aspekt mit seiner Intervention mittels des epistemischen Dings einsetzt, so wird die Entdinglichung zum Interventionspunkt des Transports des Konzepts in die Gesellschaftstheorie. ${ }^{42}$ Gerade hierin liegt sein heuristisches Potential für den Gesellschaftsbegriff, bedeutet dies doch nun - auf den soziologischen Gegenstand gewendet - eine Aufwertung der Dinge. Nicht mehr passiv, sondern aktiv und widerständig erscheinen die Dinge nun in der Soziologie, mithin also konstitutiv für die Etablierung, die Institutionalisierung und den Wandel sozialer Phänomene (vgl. Passoth 2012; Nordmann, Schwarz 2012 jeweils m.w.N.). Der Relativierung der Dinghaftigkeit der Dinge im Kontext der Naturwissenschaften entspricht damit im Rahmen der Übersetzung des epistemischen Dings in die Gesellschaftstheorie eine Relativierung der Immaterialität der Gesellschaft. Der Heterogenität des epistemischen Dings, das eben nicht nur als ein rein materielles Objekt, sondern als ein Gefüge aus materiellen und immateriellen Komponenten anzusehen ist, entspricht in der Übersetzung die Heterogenität der Gesellschaft, die ein ebensolches Gefüge darstellt. Derart erfolgt eine Annäherung an einen Materialismus, der anerkennt, dass das Soziale nicht nur durch das Soziale, sondern ebenso durch das Materielle konstituiert und zu verstehen und erklären ist. Die Wandlung des Bedeutungsgehalts des Dingbegriffs bewirkt eine Verschiebung auf der Ebene der Bestimmung dessen, was die Gesellschaft ausmacht: Die materielle Seite der Gesellschaft wird zum gleichwertigen Konstitutionsmoment. ,Verdinglichung' im Rahmen des epistemischen Dings bedeutet dann die Aufwertung der Dinge im sozialen Gefüge.

Legt man der Untersuchung der Entdeckung des epistemischen Dings Gesellschaft einen solchen Gesellschaftsbegriff zugrunde, dann hat das konkrete Folgen. Erstens erscheinen gesellschaftliche Phänomene als Gefüge aus materiellen und immateriellen Komponenten, wie sie vorliegend mittels der Dispositivanalyse untersucht werden. ${ }^{43}$ Zweitens gilt: Wenn der Gesellschaftsbegriff wie geläufig und so auch in den hier untersuchten

42 Insofern kann der hier vorgeschlagene Import als kritischer Versuch einer Reformulierung des Gesellschaftsbegriffs auf der Beschreibungsebene verstanden werden. Gerade mit Blick auf die Verdinglichungskritik Adornos zeigen sich aber auch die Grenzen des heuristisch-kritischen Potentials des Konzepts des epistemischen Dings für die Gesellschaftstheorie, beinhaltet die Aufwertung der Dinge im gesellschaftlichen Gefüge doch noch keinerlei Aussage über die Kritikwürdigkeit der gesellschaftlichen Zustände. Auf diese Frage antwortet das epistemische Ding in der Gesellschaftstheorie nicht (vgl. hierzu Schweitzer 2015c).

43 Genau aus diesem Grund ist die Kritik am Entdinglichungsparadigma der Soziologie für die vorliegende Studie von zentraler Bedeutung: Im Folgenden schlage ich vor, Recht mittels der Dispositivanalyse im Sinne Foucaults zu analysieren. 
Diskursen auf eine rein menschliche Sphäre beschränkt wird, dann ist der Fokus auf die spezifischen Reinigungsarbeiten, Ausschließungsstrategien und -techniken zu legen, die eine solche Konzeption ermöglichen. Diese Strategien und Techniken werden mithin zu eigenständigen Analysekategorien, wenn es um die Frage der performativen Hervorbringung des epistemischen Dings ,Gesellschaft ${ }^{\star}$ geht. Die Entscheidung, Soziologiegeschichte als Objektgeschichte des epistemischen Dings ,Gesellschaft' zu betreiben, hat somit gesellschaftstheoretische Implikationen, die die Methode und die Analysekategorien bestimmen.

\section{Rechtssoziologische Orientierungen: Das epistemische Dispositiv der Rechtswissenschaft}

Verortet man nun die soziologiegeschichtliche Frage nach dem Entdeckungszusammenhang des epistemischen Dings ,Gesellschaft im Recht, dann bedarf es der Ausarbeitung einer rechtssoziologischen Analytik der juristischen Praktiken und Techniken, die diese als Produzentinnen von Gesellschaftskonstruktion adressiert. Diese Perspektive auf rechtliche Phänomene verpflichtet darauf, sich jegliche soziologische Bestimmung des Rechts zu untersagen, die aus gesellschaftstheoretischer Perspektive apriorisch das Wesen des Rechts zu bestimmen versucht. „[D]as Recht gibt es nicht“ (Ewald 1993: 37, H.i.O.), weil es keinen die Zeiten überdauernden essentialistischen Wesenskern aufweisen kann. Recht ist im höchsten MaBe historisch bestimmt. ${ }^{44}$ Und trotzdem kann es als Entdeckungszusam-

Dispositive umfassen sowohl diskursive wie nicht-diskursive, und das heißt auch materielle Komponenten. Somit erlaubt erst eine wie hier vorgenommene verdinglichte Perspektive auf Gesellschaft, in konsistenter Weise das gesellschaftliche Phänomen des Rechts mittels der Dispositivanalyse zu untersuchen.

44 Letztendlich versucht der Foucault-Schüler François Ewald, an dessen Rechtssoziologie ich hier anschließen möchte, einen dritten Weg zwischen zwei herkömmlichen Lösungen zu entwerfen: Entweder wird ,Recht' inhaltlich bestimmt - dann ist das andere etwa Unrecht; oder aber man betrachtet das Recht „als normative Ordnung" in seinen jeweiligen unterschiedlichen historischen Realisierungen, d.h. jede normative Ordnung, die Zwangscharakter hat, wäre eine Rechtsordnung. Beide Lösungen sind für Ewald jedoch essentialistisch: „Sie unterstellen, dass sowas wie das Recht existierte, das sich in einem Fall in einem Rechtssystem, im anderen in einer abstrakten normativen Ordnung verkörperte.“ (Ewald 1993: 37, H.i.O.). Und hierin sind beide letztendlich gegen die Geschichte gerichtet: Im ersten Fall zerstört die Geschichte das Recht; im zweiten Fall zeigt sich ,das Recht' gegenüber der Geschichte indifferent. Für Ewald gilt allerdings: 
menhang der Gesellschaft untersucht werden - wenn man es nämlich mit Foucault als ein dispositives Gefüge analysiert, das in seinen Praktiken und Techniken die Gegenstände ,Recht' und ,Gesellschaft' in ihrem doppelten Konstitutionsverhältnis systematisch hervorbringt. 45

\section{Dispositivanalyse, epistemisches Dispositiv und Recht}

\section{Das Recht wird damit betrachtet als}

ein entschieden heterogenes Ensemble, das Diskurse, Institutionen, architekturale Einrichtungen, reglementierende Entscheidungen, Gesetze, administrative Maßnahmen, wissenschaftliche Aussagen, philosophische, moralische oder philanthropische Lehrsätze, kurz: Gesagtes ebensowohl wie Ungesagtes umfaßt (Foucault 1978a: 119f.).

Es zeigt sich damit nicht allein in sprachlichen Phänomenen wie etwa im systemkonstituierenden Code „Recht/Unrecht“ (Luhmann) oder in einem "clef de lecture“ (Latour 2004: 37), die darüber entscheiden, was zum Recht zählt und was nicht. Auch ist Recht nicht allein durch seine Institutionalisierungsform charakterisierbar, das es von anderen sozialen Normen unterscheidet (so etwa Jhering, Durkheim und Weber, s.u.). Wie das epistemische Ding, Gesellschaft kann das Recht nur durch ein Set an unterschiedlichen Praktiken, Techniken, Verfahren, Medien, Diskursen, Institutionen und Dingen zu seiner Existenz und Wirkung gelangen.

Das Dispositiv selbst ist das Netz, das in diesem heterogenen Ensemble aus Redeweisen, Techniken, Strategien und Institutionen geknüpft werden kann (vgl. Foucault 1978a: 120). Es ist keine starre, statische Struktur, sondern eine dynamische Matrix aus verschiedenartigen Verbindungslinien: aus „Sichtbarkeitslinien, Linien des Aussagens, Kräftelinien, Subjektivierungslinien, Riß-, Spalt- und Bruchlinien“, die sich überkreuzen, vermi-

„Wir möchten eine dritte Einstellung vorschlagen, die es ermöglicht, das Recht mit seiner Geschichte in Einklang zu bringen." (Ebd., H.i.O.).

45 Das Recht wird hier also nicht als ein Dispositiv betrachtet, sondern es wird als ein dispositives Gefüge untersucht, als ein „Komplex“ (Rose, Valverde 1998: 542f.), innerhalb dessen sich Dispositive als „Funktionsknoten“ (Gehring 2004: 109) von Wissen und implizit institutionalisierten Zugriffsformen ausfindig machen lassen (vgl. etwa Vismann 2011). In den teils kontroversen Diskussionen über die Dispositivanalyse besteht zumindest dahingehend weitgehend Einigkeit, dass Foucaults Überlegungen nicht im Bereich der Methoden, sondern auf methodologischer Ebene anzusiedeln sind. 
schen und „wieder andere erzeugen“ können (Deleuze 1991: 157). Daher lässt sich kein Element, kein Punkt im Netz fixieren, da alle Linien „Variationslinien“ ohne „konstante Koordinaten“ sind (ebd.). Ordnungsmuster und Ordnungsprozess fallen aufgrund der Pluralisierung und Dynamisierung des Relationsbegriffs im Dispositiv in eins (vgl. Gehring 2004: 45). Dabei gilt: Die Struktur eines Dispositivs ist durch die jeweiligen funktionalen Beziehungen der Elemente untereinander zu bestimmen, seine Dynamik kann formal in ständig auftretenden Positionswechseln der Elemente im jeweiligen Netz beschrieben werden (Hubig 2000: 39f.).

Hieraus resultiert aus methodologischer Sicht zunächst eine prinzipielle Gleichbehandlung der verschiedenen heterogenen Elemente des rechtlichen Gefüges: Gesetzgebung, Rechtsdogmatik und konkrete Rechtsanwendung, Gerichtsgebäude, Videoüberwachung, Akten, Datenbanken und Kommentare, Gefängnisgebäude, Bewährungsstelle, Kläger, Delinquent, Gerichtsvollzieher und ,Kuckuck ${ }^{6}$ usw. usf. sind auf einer Ebene angesiedelt. Kein Element ist gegenüber einem anderem a priori privilegiert oder untergeordnet, jeder Punkt hat sein eigenes Wirkungsvermögen, das immer nur Folge von bestimmten Relationen, Nachbarschaften, Anordnungen und Problemzusammenhängen ist. Wenn also die Privatrechtswissenschaft, wie etwa zu Beginn des 19. Jahrhunderts, ihre Dominanz gegenüber Gesetzgebung, Justiz und Philosophie beansprucht, dann kann sie das nur, indem sie bestimmte Nachbarschafts(an)ordnungen und Problemzusammenhänge etabliert. Für diese (An-)Ordnungen ist ab diesem Zeitraum gerade das epistemische Ding, Gesellschaft‘ zentral. Denn die Rechtswissenschaft vermag sich über die Vergesellschaftung des Rechts, die Folge der Hinwendung zu diesem Objekt ist, zunächst von Politik und Philosophie (Ethik) zu lösen, um dann als vergesellschaftetes Recht ihre eigene, nämlich normativ begründete, Funktion gegenüber der Gesellschaft zu konstatieren.

Die Verknüpfungen des Dispositivs zeitigen zudem Effekte: Die durch die Relationen vorgenommenen Nachbarschafts(an)ordnungen und Problemzusammenhänge sind nicht nur Folge der Anordnung bereits existierender Elemente, sondern generieren ihrerseits Gegenstände, Probleme und Objekte. Die analytische Perspektive wird also verdoppelt: Relationen können nicht nur als Verbindung zwischen Elementen angesehen, sondern die Elemente auch als Kreuzungen mehrerer Relationen begriffen werden. Das trifft nicht nur auf die Gesellschaft zu, kann sie doch als umfassender Totalzusammenhang sowie als Gegenstand betrachtet werden, der systematisch in den Praktiken und Techniken der Verknüpfung hergestellt wird. Das Recht kann ebenso als ein solches Gefüge beschrieben werden, in dem bestimmte Elemente verbunden sind, aber auch als ein Gegen- 
stand, der in der Verknüpfung entsteht. Diese zweite Ebene steht hier im Vordergrund. Denn in der Analyse der Privatrechtswissenschaft macht sich das Recht selbst zum Gegenstand - und, wie zu zeigen sein wird, seit Beginn des 19. Jahrhunderts insbesondere in Form eines vergesellschafteten Rechts. ${ }^{46}$

Insbesondere mit Blick auf den Gegenstand ,Recht' gilt, dass aufgrund der Pluralisierung und Dynamisierung des Relationsbegriffs den Universalien eine Absage erteilt werden muss: Gerechtigkeit, Totalität oder Universalität des Rechts (oder von Rechtsprinzipien) sind immer nur „singuläre Prozesse der Vereinheitlichung, der Totalisierung, der Verifizierung [...] wie sie in jedem Dispositiv immanent sind“ (Deleuze 1991: 157). Es sind „im Werden befindliche Prozesse“ (ebd.), partikulare, lokale Schließungen zu Gebilden mit Universalitäts- oder Totalitätsanspruch. Gerade in dieser Partikularität - zwar ausgestattet mit universellen Geltungsansprüchen, aber jenseits des tatsächlichen Bestehens einer solchen Geltung - gilt es, die jeweiligen Prozesse der Schließung zu analysieren. Die Bestimmungen dessen, was Recht ist bzw. in den Rechtswissenschaften als Recht adressiert wird, sind selbst als solche historischen Prozesse der Schließung (und damit auch: Ausschließung) zu untersuchen.

\subsection{L'urgence}

Daher sind Dispositive auch nicht neutrale (An-)Ordnungen, sondern treten als „Dispositive der Macht" auf. Sie sind in das komplexe und unpersönliche Zusammenspiel in dem Geflecht von Machtbeziehungen eingelassen, welches von keinem Ort aus beherrschbar ist: „[D]ie Macht ist nicht eine Institution, ist nicht eine Struktur, ist nicht die Mächtigkeit einiger Mächtiger. Die Macht ist der Name, den man einer komplexen strategischen Situation in einer Gesellschaft gibt.“ (Foucault 2003: 94) Macht ist weder subjektiv noch durch einen Willen beherrschbar. Sie ist unpersönlich und gleicht „einer Art steuerungslos-gesteuerten Maschinerie“ (Gehring 2004: 122f.). Oder anders formuliert: Sie ist allgegenwärtig, ohne Au-

46 Daher rührt auch der zentrale Stellenwert der Rechtstheorie bei Luhmann, bewirkt sie doch als Selbstreflexion des Rechtsystems eine selbstreferentielle SchlieBung des Systems (vgl. Luhmann 1999a). Bezeichnenderweise beschränkt sich Luhmann in der Analyse der historischen Veränderungen der Rechtstheorie auf Naturrechtsdenken und Rechtspositivismus. Die historisch relevante Frage, in welchem Verhältnis Recht zur Gesellschaft steht, deutet er in die Problematik des Verhältnisses von Rechtssystem zu seiner gesellschaftlichen Umwelt um. 
ßen, eine immanente Vollzugskategorie. Damit ist sie nicht allein repressiv, sondern vor allem produktiv (vgl. Foucault 2003: 93ff.). ${ }^{47}$ In der Analytik der Rechtsmacht geht es um die Mobilisierungseffekte und Effizienzformen, die für die Organisation und Umorganisation von Wirklichkeit sorgen (vgl. Gehring 2004: 118). Die Frage nach dem Verhältnis von Recht und Macht muss also primär von der Seite der Produktivität und nicht von der Bestimmung des Rechts etwa als Herrschaftsinstrument oder als repressive juridische Machtform, die das Recht nur vom Verbot her definiert (vgl. Foucault 2003: 83ff.), angegangen werden (vgl. Spreen 2010). Das Recht zeigt sich auch immer als Rechtsmacht, die ihre Gegenstände und so auch das epistemische Ding ,Gesellschaft ${ }^{\star}$ - produktiv hervorbringt.

Innerhalb dieses Spiels der Macht bildet ein Dispositiv eine „Formation, deren Hauptfunktion zu einem gegebenen historischen Zeitpunkt darin bestanden hat, auf einen Notstand (urgence) zu antworten“ (Foucault 1978a: 120, H.i.O.). Das Dispositiv stellt eine spezifische Verknüpfungs(an)ordnung dar, die als sich institutionalisierende Antwort auf gesellschaftlich definierte Problemlagen zu verstehen ist. In der Genese eines Dispositivs gibt es also eine „Prävalenz einer strategischen Zielsetzung“ (ebd.: 121) angesichts eines Notstandes, einer Störung, die behoben werden muss. Insofern folgt das Dispositiv einem „strategischen Imperativ“ (ebd.: 120), der eine Formation erscheinen lässt, „weil er die Vorgabe dafür ausmacht, daß bestimmte Binnenrelationen im Dispositiv überhaupt als funktional erachtet werden können“ (Hubig 2015: 69). Kurz: „Das Dispositiv hat also eine vorwiegend strategische Funktion" (Foucault 1978a: 120) im Spiel der Macht. Damit rückt für die Analyse die Notlage ins Zentrum: Wenn etwa in der Historischen Rechtsschule die Privatrechtswissenschaft das epistemische Ding, Gesellschaft' Anfang des 19. Jahrhunderts zu einem zentralen Gegenstand macht, so reagiert sie damit auf ein spezifisches Problem (urgence) - hier etwa die drohende Kodifikation. Diese Notlage bildet die funktionale „Matrix“ (ebd.) für die Lösungen, die die Rechtswissenschaft mittels der Hinwendung zur Gesellschaft im „Repräsentationsdispositiv“ des Volksgeistes anzubieten sucht (s. $\$ 2$ ).

Gleichzeitig stellt das Dispositiv als (An-)Ordnung Bedingungen für die Verwirklichung der Macht bereit (vgl. Hubig 2015: 71). Damit produziert es Anschlussmöglichkeiten, die zu nicht intentionalisierten Effekten füh-

47 In seiner berühmten Kritik der Repressionsmodells macht Foucault geltend, dass darin all das ausgeblendet wurde, was „die produktive Effizienz, den strategischen Reichtum und die Positivität der Macht ausmacht“ (Foucault 2003: 87). 
ren können. Es eröffnet die Möglichkeit der „strategischen Wiederauffüllung“ (Foucault 1978a: 121), die neuartige Strategien hervorrufen kann (vgl. Hubig 2000: 45f.). Dieser Aspekt wird in der Analyse der Entwicklung der Privatrechtswissenschaft ab Mitte des 19. bis Anfang des 20. Jahrhunderts zentral. Denn sie reagiert zu dieser Zeit nicht nur auf neue Problemlagen (Entfremdung des Rechts von der Wirklichkeit, die soziale Aufgabe des Rechts, die Eigenständigkeit des Rechts), vielmehr zeigen sich strategische Anschlüsse an das Repräsentationsdispositiv der Historischen Rechtsschule, die zentral am epistemischen Objekt,Gesellschaft ${ }^{\star}$ ansetzen, aber zu gänzlich anderen Ergebnissen und Problemstellungen führen (s. $\mathbb{S} \mathbb{S} 4,5)$.

\subsection{Das epistemische Dispositiv der Rechtswissenschaften}

Ein Dispositiv ist nicht nur in ein Spiel der Macht eingebunden, sondern immer auch an Grenzen des Wissens gebunden, die aus diesem Spiel hervorgehen, es aber gleichwohl auch bedingen. Im Zentrum der Dispositivanalyse stehen daher die Verkettungen der Wissens- und Machtstrategien in den „Macht/Wissen-Komplexen“ (Foucault 2009b: 39; 2003: 100f.): „Eben das ist das Dispositiv: Strategien von Kräfteverhältnissen, die Typen von Wissen stützen und von diesen gestützt werden.“ (Foucault 1978a: 123)

Die vorliegende Untersuchung legt im Folgenden den Fokus auf den Wissensaspekt. Denn es wird nicht das dispositive Gefüge des Rechts in seiner gesamten heterogenen Spannbereite untersucht, sondern nur ein Teil davon: die Wissensordnung der deutschen Privatrechtswissenschaft des 19. Jahrhunderts und Anfang des 20. Jahrhunderts. Das, was Foucault mit Blick auf die Wissenschaften als „Episteme“ bezeichnet, wird zu einem Spezialfall des Dispositivs - sie ist ,im Unterschied zum Dispositiv im allgemeinen, das seinerseits diskursiv und nicht-diskursiv ist, und dessen Elemente sehr viel heterogener sind, ein spezifisch diskursives Dispositiv" (ebd., H.i.O.). Die Episteme bezieht sich in strategischer Weise auf die Wissenschaft, sie ist ein „strategisches“ (ebd.: 124) oder eben „epistemisches Dispositiv“ (Hubig 2015: 70), das es erlaubt, „das wissenschaftlich Qualifizierbare vom Nicht-Qualifizierbaren zu scheiden“ (Foucault 1978a: 124). Gerade hier gewinnt die Gesellschaft an Gewicht: Wenn Recht als gesellschaftliches Produkt gefasst wird, so bestimmt das nicht nur die Frage, was als Gegenstand einer rechtswissenschaftlichen Behandlung gelten kann. Vielmehr wirkt sich diese Auffassung auch direkt auf die rechtswissenschaftlichen Techniken und Praktiken aus. Der Wissenschaftscharakter der 
Rechtswissenschaft wird durch die Vergesellschaftung des Rechts problematisiert - sei es, um zwei kurze Beispiele zu nennen, in der Frage, ob dieses Recht überhaupt einer wissenschaftlichen Behandlung zugänglich ist (vgl. $\$$ 2.III.2.3), sei es, dass die probate Methode in einer „soziologischen Jurisprudenz" zu erblicken ist (vgl. $\$ 5 . I I I .1)$.

Nimmt man den Diskurs, das diskursive Dispositiv, der Privatrechtswissenschaft in den Blick, muss die Analyse des Wissens, der diskursiven Formationen und ihrer Aussagen in Abhängigkeit von den Machtstrategien durchgeführt werden (vgl. Ewald 1978: 10). ${ }^{48}$ Damit gilt nach wie vor, dass Diskurse als Formationen von Aussagen untersucht werden. ${ }^{49}$ Die Basiseinheit der Aussage wird jenseits von Wahrheitsanspruch und Bedeutung als historisches Objekt einer manifesten sprachlichen Performanz, als diskursive Praktik in seiner Äußerlichkeit, untersucht (vgl. Dreyfus, Rabinow 1987: 70ff.; Lemke 1997: 49ff.):

Die Aussageanalyse ist also eine historische Analyse, die sich aber auBerhalb jeder Interpretation hält: sie fragt die gesagten Dinge nicht nach dem, was sie verbergen, was in ihnen und trotz ihnen gesagt wurde [...]. Sondern umgekehrt, auf welche Weise sie existieren, was es für sie heißt, manifestiert geworden zu sein, Spuren hinterlassen zu haben und vielleicht für eine eventuelle Wiederverwendung zu verbleiben; was es für sie heißt, erschienen zu sein - und daß keine andere an ihrer Stelle erschienen ist. (Foucault 1981: 159)

Eine Aussage ist dabei nie aus sich selbst heraus erklärbar, sondern erst, „wenn sie in ein Aussagenfeld eingetaucht ist, wo sie dann als ein besonde-

48 Mit dieser Analyseperspektive wird die Dispositivanalyse weder als Erweiterung der Diskursanalyse angesehen (vgl. etwa Jäger 2001; Bührmann, Schneider 2008; Diaz-Bone 2010), noch dient das Dispositiv als Infrastruktur der Diskursproduktion (vgl. Keller 2011: 67); auch verdrängt die Dispositivanalyse nicht die Diskurstheorie, die als methodologisch gescheitert anzusehen sei (vgl. Dreyfus, Rabinow 1987: 105ff.; vgl. zur Frage des Verhältnisses der Dispositivanalyse zur Diskursanalyse auch die Beiträge in Caborn Wengler et al. 2013; Angermüller, van Dyk 2010), sondern zeitigt spezifische methodologische Folgen für die Analyse von Diskursen, die im Folgenden herauszuarbeiten sind. Oder methodentechnisch formuliert: Genealogie und Archäologie sind in der Dispositivanalyse aneinander gekoppelt.

49 Hierin liegt, trotz aller Vagheit der Verwendung des Diskursbegriffes bei Foucault, die Spezifik der Diskursanalyse begründet; vgl. zur Abgrenzung zu anderen sozialwissenschaftlichen Diskursbegriffen Keller 2011: 13ff. 
res Element erscheint" (ebd.: 144). ${ }^{50}$ Die Analyse des Diskurses arbeitet aus einem solchen Feld der Aussagen über Verteilungsregelmäßigkeiten die spezifische Einheit einer „diskursiven Formation“ (ebd.: 58) heraus.

Diskurse als Formationen zu verstehen erlaubt, durch Rückschlüsse auf innere Regelmäßigkeiten Wissensordnungen zu identifizieren. Über solche Formationsregeln und Diskursmechanismen lässt sich die Eigenlogik einer diskursiven Formation, die „Ökonomie des Diskurses“, entschlüsseln. ${ }^{51}$ Es wird eine Ordnung identifiziert, die nicht nur zeigt, was gesagt wurde, sondern ebenso, was überhaupt hätte gesagt werden können (vgl. Gehring 2004: 61f.; Dreyfus, Rabinow 1987: 110f.). Dadurch werden die historisch-spezifischen Bedingungen der Möglichkeit der Aussagen als Wissens- und Wirklichkeitsordnungen offengelegt - als positive Ordnungen mit beschreibbaren Regelmäßigkeiten, aber ebenso als dynamische Ordnungen, über die Regeln der Aussagenherstellung herausgearbeitet werden (vgl. Gehring 2004: 72f.).

Ein Diskurs, eine diskursive Verteilung, ist als eine solche beschränkende Ordnung keine verzerrte Sicht auf die Wirklichkeit, sondern generiert Wirklichkeit. Denn Diskurse sind „als Praktiken zu behandeln, die systematisch die Gegenstände bilden, von denen sie sprechen“" (Foucault 1981: 74). Beschreiben lässt sich diese Weise der Bildung von Gegenständen, und

50 Insofern stellt eine Aussage ein „paradoxes Objekt“ (Foucault 1981: 153) dar, das zwar ein Ereignis, also singulär ist, zugleich aber wiederholt werden kann, allerdings nur unter strengen Bedingungen (vgl. ebd.). Um den singulären Charakter zu kennzeichnen, führt Foucault eine begriffliche Unterscheidung ein: Eine Äußerung ist ein Ereignis, das sich nicht wiederholt (ebd.: 148). Sie kann einer spezifischen Situation, einem spezifischen Ort und einer bestimmten Person zugeschrieben werden. Verdichten sich solche singulären Akte, so können sie zur Generierung einer Struktur bzw. Formationsregel beitragen, die historisch-spezifische Aussagen ermöglicht. Eine Aussage ist sozusagen ein strukturelles Ereignis und daher keinem Subjekt zuzuschreiben (kritisch hierzu Kneer 1999: 62ff.).

51 Bezeichnet Foucault in der Archäologie des Wissens die Formationsregeln als „Existenzbedingungen“, denen die Elemente einer bestimmten Verteilung unterworfen sind (Foucault 1981: 58), so verschiebt er in Die Ordnung des Diskurses (2007) den Schwerpunkt auf die begrenzenden und beschränkenden Strategien, die die diskursive Ordnung als Ordnung bestimmen (Lemke 1997: 53). Damit verlagert sich der Fokus der Diskursanalyse auf die Machtfrage, bereits hier wird die Archäologie durch die Genealogie ergänzt. Allerdings wird die Macht noch primär negativ adressiert, als äußere Prozeduren der Ausschließung oder innere Prozeduren der Verknappung. Wenig später trennt sich Foucault von dieser Sichtweise, die „die Verhältnisse der Macht zum Diskurs als negative Verhältnisse der Verknappung dargestellt hat“ (Foucault 1978d: 105). Insofern gilt es, die produktiven Machtwirkungen der Diskursmechanismen in den Vordergrund zu stellen. 
im Bereich der Wissenschaften insbesondere von epistemischen Dingen, indem man die Beziehungen zwischen den Oberflächen des Auftauchens, den Instanzen der Abgrenzung, den Kategorisierungs- und Charakterisierungsebenen und Rastern sowie den Praktiken der Wissensproduktion herausarbeitet (vgl. ebd.: 62ff.).

Genau darum wird es im Folgenden gehen: Der rechtswissenschaftliche Diskurs wird dahingehend untersucht, an welchem (thematischen) Ort, wie und durch welche diskursiven Praktiken, Techniken und Mechanismen der Abgrenzung und der Eingrenzung er das epistemische Ding, Gesellschaft" bildet, von dem er im 19. Jahrhundert in systematischer Weise zu sprechen beginnt - und das v.a. auch mit Blick auf die Techniken des Rechts. Jenseits der Frage von Richtigkeit oder Bedeutung konkreter Aussagen (oder Äußerungen) geht es darum, die Mechanismen herauszufiltern, die solche Aussagen über die Gesellschaft ermöglichen. Es geht um die Struktur sowie die strukturierende Leistung des Feldes des Sagbaren, die Bedingungen der Möglichkeit, in den Rechtswissenschaften zu einer bestimmten Zeit bestimmte Aussagen über das Ding, Gesellschaft ${ }^{`}$ zu treffen. Man untersucht, was und wer ausgeschlossen werden musste, wie die Aussagen gruppiert wurden und welche Subjektpositionen generiert wurden, damit solche spezifischen Aussagen überhaupt getroffen werden und Sinn machen konnten. Es geht um die Formationsregeln und Regelmäßigkeiten der diskursiven Praktiken, die die ganze Bandbreite möglicher Aussagen umfassen. Sie ermöglichen auch widersprechende Aussagen und fundamentale Kritiken, d.h. also ebenso das ganze „Feld der Gegnerschaft“ (Foucault 2009a: 155). In der Analyse des juristischen Diskurses können die Formationsregeln deswegen nicht über einzelne Autoren (z.B. Savigny, Jhering oder Heck) herausgearbeitet werden, auch wenn ich von deren Äußerungen ausgehen werde. Sie zeigen sich nur über die Analyse des breiten, auch widersprüchlichen Feldes der Aussagen, das sich entlang dieser Äußerungen entspannt - hier exemplifiziert an der Kritik an der Historischen Rechtsschule, an den Debatten über die soziale Aufgabe des BGBs sowie anhand des juristischen Methodenstreits Anfang des 20. Jahrhunderts.

Werden die Diskurse der Privatrechtswissenschaft als epistemische Dispositive untersucht, erweisen sich ihre diskursiven Ordnungen selbst als strategische Elemente: Denn

[a]us der Perspektive der Macht ist das Gegebene nicht mehr als ein Netz von strategischen Optionen - und die Ordnungen sind Dispositionen in einem Einsatzfeld. Auf diese zweite Perspektive, nicht die von den Ordnungen ausgehende Frage nach der Macht, sondern die 
von der Macht ausgehende strategische Blickrichtung auf Ordnungen, zielt Foucaults Terminus ,Dispositiv'. (Gehring 2004: 119, H.i.O.)

Diskurse sind „taktische Elemente oder Blöcke im Feld der Kraftverhältnisse" (Foucault 2003: 101). Sie sind in das Spiel der Machtverhältnisse eingeschrieben, können selbst Positions- und Funktionswechseln unterliegen so kann ein

Diskurs bald als Programm einer Institution erscheinen, bald im Gegenteil als ein Element, das es erlaubt, eine Praktik zu rechtfertigen und zu maskieren, die ihrerseits stumm bleibt, oder er kann auch als sekundäre Reinterpretation dieser Praktik funktionieren, ihr Zugang zu einem neuen Feld der Rationalität verschaffen (Foucault 1978a: 120).

Diskurse werden aus der Perspektive der Macht interpretiert - auch wenn sie auf die Macht zurückwirken.

\subsection{Problematisierung}

Das epistemische Dispositiv, das immer schon als Teil eines umfassenderen Netzes betrachtet wird, wird von vornherein unter strategischen Gesichtspunkten untersucht. ${ }^{52}$ Das hat Auswirkungen auf die Qualifizierung seiner Relationen: Als Linien der Aussageformationen werden sie nun nicht

52 Damit einher geht eine Ausweitung des Ordnungsbegriffs, so dass dispositive Ordnungen nun sehr viel heterogenere Elemente als Diskurse umfassen. Mit dem Dispositivbegriff wird die Reduktion des Ordnungsverständnisses auf Wissensoder Redeordnungen überwunden. Damit aber gilt m.E. zugleich: Jene noch für die Diskursanalyse der Archäologie so zentrale und auch in den gegenwärtigen Debatten um die methodologischen Prämissen Foucaults stark umstrittene Unterscheidung zwischen diskursiven und nicht-diskursiven Praktiken (vgl. Bührmann, Schneider 2008: 47ff.; Reckwitz 2008: 138; Laclau, Mouffe 2000: 157; Bröckling, Krasmann 2010; Dreyfus, Rabinow 1987: 105ff.) verliert an Relevanz. Zentral ist diese Unterscheidung für das Diskurskonzept der Archäologie des Wissens, da der Diskurs erst in dieser Unterscheidung seinen Ort findet: Er ist an der Grenze zwischen Diskursivem und Nicht-Diskursivem angesiedelt (Wrana, Langer 2007). Dementsprechend bestimmt die Differenz zwischen diskursiven und nicht-diskursiven Praktiken den Ort eines Diskurses, der als eine Grenzpraxis des Übergangs vom Sprachlichen zum Nicht-Sprachlichen zu verstehen ist. In der Dispositivanalyse verliert die Abgrenzung an Bedeutung: Denn sie ist nicht mehr wie in der Diskursanalyse der Archäologie an der Ordnungsgrenze angesiedelt, die im Verhältnis von Innen und Außen die Ordnung zuallererst konstituiert - beide 
mehr als Linien der Sagbarkeit interpretiert, sondern als Funktionslinien (Gehring 2004: 119). Diese strategische Dimension des diskursiven Dispositivs zeigt sich insbesondere in seinen spezifischen „Problematisierungen“ (vgl. Lemke 1997: 334ff.). Im Speziellen geht es um die jeweiligen Problematisierungsweisen, d.h. sowohl um die Frage der Formierung eines Problems als solches (Problematisierung) als auch um die Formation oder Formierung der Probleme im Bereich des Denkens (Problematisierungsform). ${ }^{53}$

Zur Debatte steht also auf der einen Seite, ,[w]ie und warum bestimmte Dinge (Verhalten, Erscheinungen, Prozesse) zum Problem wurden" (Foucault 1996: 178, H.i.O.). Etwas als Problem, als urgence, zu formulieren ist selbst eine spezifische Art des Umgangs mit einer konkreten Situation. Ein in den Quellen beschriebenes Problem ist dementsprechend nicht einfach als Gegebenheit zu akzeptieren, sondern muss selbst als strategische Intervention in ein dynamisches Feld gesellschaftlicher Auseinandersetzungen verstanden werden (vgl. Klöppel 2010: 256). Das Denken wird auf einen historischen Kontext bezogen, auch wenn es sich nicht um ein einfaches Kausalitätsverhältnis handelt, in dem der historische Kontext das Denken determiniert: So ist „eine gegebene Problematisierung nicht die Wirkung oder Folge eines historischen Kontextes oder einer historischen Situation“ (Foucault 1996: 179f.). Sie beinhaltet immer etwas Schöpferisches. Denn

Formen sind nun Teil der Ordnung. Daher erscheint es nicht verwunderlich, wenn Foucault anmerkt, dass „für das, was ich mit dem Dispositiv will, [...] es kaum von Bedeutung [ist,] zu sagen: das hier ist diskursiv und das nicht" (Foucault 1978a: 125). Nicht im Diskurs zeigt sich nun die „Ökonomie einer Machtform“ (Gehring 2004: 119; vgl. auch Krasmann 1995; Wrana, Langer 2007: [8ff.]). Stattdessen richtet sich der Blick nun ausgehend von der Macht auf den Diskurs. Oder anders formuliert: Die Unterscheidung von diskursiven und nicht-diskursiven Praktiken ist nicht mehr Voraussetzung dafür, die Ökonomie der Macht fassen zu können.

53 Foucault erklärt in einem Interview aus dem Jahre 1984 die Problematisierung quasi zum "Grundbegriff“ seiner Untersuchungen seit seiner Histoire de la folie aus dem Jahre 1961 - allerdings mit dem Hinweis, dass er „diesen Begriff noch nicht hinreichend herausgehoben hatte“ (Foucault 2005a: 825). So benutzt er den Begriff der Problematisierung bzw. Problematisierungsweise auf äußerst unterschiedliche, manchmal auch diffuse Weise, jedoch generell als eine Art Überbegriff, der die verschiedenen Aspekte (Problematisierung und Problematisierungsform) zu bündeln vermag. Gerade im Begriff der Problematisierung zeigt sich die von Foucault vertretene Koppelung von Archäologie und Genealogie. Diese präsentieren sich als zwei Seiten des Problems: „Die archäologische Dimension der Analyse bezieht sich auf die Formen der Problematisierung selbst; ihre genealogische Dimension bezieht sich auf die Formierung ausgehend von den Praktiken und deren Veränderungen.“ (Foucault 1991: 19). 
sie ist "eine von bestimmten Individuen gegebene Antwort“ (ebd.: 180) so wie Savignys Reinterpretation der Kodifikationsfrage als wissenschaftliches Problem der Rechtsquellenlehre oder aber Jherings Umdeutung der Gesellschaft als mechanische Einheit, die es angesichts des drohenden Gerechtigkeitsverlusts zu steuern gilt.

Ausgehend von einer bestimmten Äußerung, die einem Subjekt zugeschrieben werden kann, entfaltet sich ein bestimmter Aussagemodus, eine Problematisierungsform, die sich jenseits der Subjekte befindet (vgl. ebd.). Damit arbeitet die Problematisierungsweise gegenüber den ganz allgemeinen Diskursstrukturen angesichts einer historisch-spezifischen Problemlage, der urgence, „die Bedingungen heraus, unter denen mögliche Antworten gegeben werden können; sie definiert die Elemente, die das konstituieren werden, worauf die verschiedenen Lösungen sich zu antworten bemühen" (Foucault 2005b: 733). Die Diskursmechanismen bzw. die diskursiven Formationen sind in der Analyse auf ein Problem hin ausgerichtet - es geht also nicht um die konkret angebotenen Lösungen, das Primat liegt vielmehr beim Problem, auf das diese antworten.

In der Untersuchung der diskursiven Praktiken der Privatrechtswissenschaft wird also weder eine Hierarchie der möglichen Lösungsvorschläge erstellt, noch unterscheidet man zwischen richtigen und falschen Lösungen oder deckt verborgene bzw. verschleierte Widersprüche auf. Man trägt nicht externe Kriterien an das Feld des Denkens heran, um es über Wahrheit und Falschheit oder Zulässigkeit oder Unzulässigkeit einer Aussage zu belehren und letztlich dadurch zu beschneiden, indem gewisse Lösungen ausgeschlossen werden. Vielmehr wird versucht, dieses Feld gerade in seiner Spannbreite möglicher Lösungen eines Problems zu erfassen und ausgehend von dem Punkt der Problemstellung seine Entfaltung zu rekapitulieren:

Diese Ausarbeitung einer Gegebenheit zu einer Frage und diese Umwandlung einer Gesamtheit an Hemmnissen und Schwierigkeiten in Probleme, worauf die verschiedenartigen Lösungen eine Antwort beizubringen versuchen, konstituieren den Punkt einer Problematisierung und die spezifische Arbeit des Denkens. (Foucault 2005b: 733)

Die Art und Weise, das Problem zu stellen, die „spezifische Problematisierungsform“, ist dieser verbindende Punkt, die „Wurzel“ einer Denkform (ebd.). Hiervon ausgehend eröffnet sich das Feld der vielfältigen möglichen, sich auch widersprechenden Antworten - es umfasst also gerade auch die Kritiken und Widersprüche zu den angebotenen Lösungen. Mittels des Konzepts der Problematisierung wird diejenige Strukturierung des 
Feldes herausgefiltert, die die Verschiedenartigkeit sowie die Widersprüchlichkeit der unterschiedlichen Aussagen möglich macht.

In dieser Verschränkung von Freiheit (der Problematisierung) und Einhegung des Denkens (in der Problematisierungsform) gilt es den Punkt zu finden, an dem eine Reproblematisierung möglich wird. Denn „wenn die Arbeit des Denkens einen Sinn hat - dann den, die Art und Weise, wie die Menschen ihr Verhalten [...] problematisieren, an ihrer Wurzel wieder aufzugreifen" (Foucault 2005c: 751). Das markiert den kritischen Einsatz der Analyse der Macht-Wissen-Komplexe als Problematisierungsformen im Rahmen jener kritischen „Geschichte der Gegenwart“ (vgl. Dean 1994: 4, 20f.; Castels 1994). Daran schließt der vorliegende Versuch an, das Verhältnis von Recht und Gesellschaft über die Genese des soziologischen Problems in den Rechtswissenschaften zu reproblematisieren.

Die Analyse der Privatrechtswissenschaft legt also den Fokus darauf, wie sich bestimmte Wissensformen mit spezifischen Problemdiagnosen verbinden. Die Strategien zu ihrer Bewältigung, an die bestimmte Techniken und Verfahren anknüpfen, verweisen allerdings nicht nur auf eine ,Denkform', sondern bringen ihrerseits neue Objekte und Subjekte hervor:

Problematisierung bedeutet nicht die Darstellung eines zuvor existierenden Objekts, genauso wenig aber auch die Erschaffung eines nicht existierenden Objekts durch den Diskurs. Die Gesamtheit der diskursiven oder nicht-diskursiven Praktiken lässt etwas in das Spiel des Wahren und Falschen eintreten und konstituiert es als Objekt für das Denken (sei es in der Form der moralischen Reflexion, der wissenschaftlichen Erkenntnis, der politischen Analyse, usw.). (Foucault 2005a: 826)

Die Gesellschaft wird als ein solches Objekt zu analysieren sein, das angesichts bestimmter Probleme (Kodifikation, Entfremdung, Gerechtigkeit) in das epistemische Dispositiv der Rechtswissenschaften eintritt, dabei selbst problematisiert wird, aber zugleich die Rechtswissenschaften und das Recht zu problematisieren vermag. Gerade deshalb handelt es sich bei der Gesellschaft auch um ein epistemisches Ding, das in der Lage ist, die Rechtswissenschaft in zentralen Punkten zu hinterfragen. Davon ausgehend zeigt sich das doppelte Konstitutionsverhältnis von Recht und Gesellschaft, in dem ,das Recht' ${ }^{\star}$ mit ,der Gesellschaft in je spezifische Formen der Beziehung tritt - und zwar sowohl in den Rechtswissenschaften als auch in der entstehenden Soziologie. 


\section{Recht und Autonomie}

Mit dieser Annahme kehrt man zum Problem der Frage nach der Autonomie des Rechts zurück, die in der Rede über seine Problematisierung enthalten ist. Wenn man davon ausgeht, dass es ,das Recht ${ }^{6}$ nicht gibt, muss das keineswegs heißen, dass man auch nicht über ,das Recht' sprechen kann. Allerdings lässt sich diese Einheit des Rechts nicht aus einer philosophischen, rechts- oder gesellschaftstheoretischen Bestimmung oder aus einer Theorie der gesellschaftlichen Differenzierung herleiten. Man kann nicht a priori bestimmen, was das Recht ist, welche Praktiken als ,Recht ${ }^{6}$ bezeichnet werden müssen. Dies hängt vielmehr davon ab, was jeweils historisch-spezifisch als Recht reflektiert wird, wie es problematisiert wird und welche Problematisierungsform es annimmt (vgl. Ewald 1993: 38). Das Erfordernis, Recht zu definieren, um Praktiken qualifizieren zu können, kann selbst nicht ahistorisch festgelegt werden. Identifikationsweisen des Rechts, die Problematisierungsweisen des Verhältnisses von Recht und Moral, von Recht und Macht oder Recht und Gerechtigkeit - all dies sind umkämpfte und variable juristische Praktiken der Adressierung des Rechts: „Die Idee des Rechts, die Kriterien der Rechtlichkeit, und selbst die, die sie äußerst dürftig als Zwangsordnung definieren, unterliegen der Geschichte; sie sind mit den positiven Praktiken des Rechts verknüpft.“ (Ebd.) Die Elemente der Anerkennung und Identifikation des Rechts sind selbst historisch, und sie machen das Recht zu einem historischen Gegenstand.

Gerade in den Rechtswissenschaften stehen derartige Problematisierungsweisen ,des Rechts' im Zentrum der Debatte. Denn hier macht sich ,das Recht' zu seinem eigenen Gegenstand: In selbstreflexiver Weise wird es in den vorliegend untersuchten epistemischen Dispositiven als einheitlicher Gegenstand adressiert. Es fungiert als eine

Denkkategorie, die keine Essenz bezeichnet, sondern dazu dient, bestimmte Praktiken zu charakterisieren: normative Praktiken, Praktiken des Zwangs und der sozialen Sanktion zweifellos, eine politische Praxis gewiß, und auch eine Praxis der Rationalität, die alle voneinander sehr verschieden sein können; das Recht ist als ganzes in jeder einzelnen dieser Praktiken vollständig enthalten, ohne daß dies die Permanenz einer Essenz voraussetzte (ebd.: 37f.).

Damit bringen die diskursiven Praktiken der Rechtswissenschaften ,das Recht $^{6}$ als einheitlichen Gegenstand performativ hervor, und zwar in dem Moment, in dem sie es problematisieren. Der Verzicht auf jegliche essentielle Bestimmung des Rechts legt zudem den Gedanken nahe, dass „es im 
Recht kein Erkenntnisziel gibt, das nicht strategisch wäre“ (ebd.: 41) - strategisch in dem Sinne, dass die rechtswissenschaftlichen Aussagen über das Recht sich nicht auf einer außerhalb des Rechts gelegenen Metaebene befinden, sondern selbst zur Konstitution ihres Gegenstandes beitragen.

In diesem Sinne lassen die Problematisierungsweisen strategische „Finalisierungen des Rechts“ (ebd.: 38) erkennen, d.h. Momente der selbstreflexiven Schließung, die zur Annahme der Autonomie - wie immer sie historisch-spezifisch bestimmt wird - des Rechts bzw. ebenso der Rechtswissenschaften führt. In diesen Problematisierungsweisen zeigt sich der Punkt des Denkens, an dem es möglich wird, über ,das Recht ${ }^{`}$ zu sprechen. Das Wesen des Rechts, seine Totalität oder Ontologie, ist damit keine die Untersuchung leitende Bestimmung, sondern das Produkt historisch divergierender Praktiken, die sich auf ein solches Wesen oder eine solche Einheit beziehen. Wenn hier folglich über ,das Recht' gesprochen wird, dann ist damit diese jeweils historisch-spezifische Art und Weise gemeint, in der das Recht zu einem einheitlichen Gegenstand der rechtswissenschaftlichen (Selbst-)Reflexion gemacht wird.

Analysiert man das juristische epistemische Dispositiv über seine Problematisierungsweisen, so ist man also auf einen Nominalismus verwiesen, der über keinen Rechtsbegriff verfügt, welcher vorab bestimmte Praktiken als rechtlich qualifiziert. Der Vorteil eines solchen Nominalismus besteht in der radikalen Historisierung des Gegenstandes (vgl. Ewald 1993: 37f.) denn das, was Recht jeweils ist, legen erst die jeweiligen historischen Praktiken und Techniken fest. Aus der Anerkennung der Historizität des Rechts ergibt sich eine Art Zirkelschluss, der in den rechtswissenschaftlichen Diskursen die Problematisierungsweise des Rechts als Recht zu identifizieren sucht.

Dies wird zum Ausgangspunkt für die Untersuchung der Hervorbringung des epistemischen Dings ,Gesellschaft' im Recht. Denn von diesen Prämissen ausgehend lässt sich das konstitutive Doppelverhältnis zwischen Recht und Gesellschaft bestimmen, wie es eingangs als Problem der vorliegenden Arbeit definiert wurde: Die Gesellschaft wird als das epistemische Ding eines Rechts untersucht, das einen Eigensinn proklamiert, jedoch selbst erst im Zuge der diskursiven Praktiken der Rechtswissenschaften hervorgebracht wird. Hierbei wird sich zeigen: Gerade im privatrechtswissenschaftlichen Diskurs Anfang des 19. Jahrhunderts kann man über die Entdeckung der Gesellschaft die erwähnten „Finalisierungen des Rechts“ erkennen. Und genau hier wird das epistemische Objekt, Gesellschaft', wie es die Rechtswissenschaften konzipieren, relevant. Denn gerade weil auf rechtstheoretischer Ebene das Recht aufgrund der Rechtsquellenlehre der Historischen Rechtsschule als Produkt weder der Vernunft (Naturrecht) 
noch des Staates (Rechtspositivismus) bestimmt, sondern als ein gesellschaftliches Produkt (des Volkgeistes) gefasst wird, vermag sich die Rechtswissenschaft paradoxerweise autonom zu setzen: Sie kann sich nun von Politik und Philosophie emanzipieren. Die Gesellschaft wird selbst zu einer Problematisierungsweise des Rechts. ${ }^{54}$ Denn durch sie gelangt die Problematisierung des Verhältnisses des Rechts zu den (vorausgesetzten) gesellschaftlichen Verhältnissen in die Rechtswissenschaft - ein Umstand, der über Umwege sowohl von juristischer wie von soziologischer Seite zum Problem der Abgrenzung zwischen Sein und Sollen führen wird.

Aber nicht nur auf der Ebene der Rechtstheorie lassen sich solche Effekte der Vergesellschaftung des Rechts erkennen: Indem mittels der Gesellschaft die juristische Selbstreflexion aus einer Totalitätsperspektive erfolgt, bettet sich zugleich das Recht in die gesellschaftliche Totalität ein, was wiederum - wie zu zeigen sein wird - gerade im Bereich der juristischen Methodenlehre auf das Recht in seinen Techniken und Praktiken zurückwirkt. Zur Debatte steht also, welche Folgen es hat, wenn die Rechtswissenschaft ihren Gegenstand ,Recht' als vergesellschaftetes Phänomen problematisiert - auf theoretischer wie methodischer Ebene. ${ }^{55} \mathrm{Zu}$ gleich machen gerade diese expliziten Konstruktionsleistungen das Recht anschlussfähig für die entstehende Soziologie. Denn indem man das Recht als vergesellschaftetes Phänomen auffasst, wird die Gesellschaft als epistemisches Ding der Analyse zugänglich - ein Umstand, der etwa bei Durkheim für die Genese der Disziplin der Soziologie ein entscheidenden Faktor ist (s. \$6).

54 Das Verhältnis von Gesellschaft und Recht wird dementsprechend nicht im Rahmen einer solch allgemeinen Aussage analysiert, dass jede Theorie des Rechts eine Gesellschaftstheorie impliziere. Zwar ist richtig, dass den rechtlichen Regulierungen, ihren Anwendungen (und Anwendungsregeln), der Durchsetzung von Recht und seinen Geltungsansprüchen immer auch bestimmte Annahmen über die Gesellschaft oder das Soziale zugrunde liegen, die als Bedingung der Möglichkeit des Funktionieren des Rechts fungieren (vgl. Wiethölter 1974) - mit Durkheim gesprochen etwa die außervertraglichen Voraussetzungen des Vertrages. Vorliegend geht es aber um das Verhältnis von Gesellschaft und Recht, wie es zu einer expliziten Problematisierungsweise sowohl für die Rechtswissenschaft als auch die Soziologie wird.

55 Hier folge ich insofern dem Ansatz von Jan Schröder, als er schreibt: „Die Entwicklung der juristischen Methodenlehre steht in engstem Zusammenhang mit der Entwicklung des Rechtsbegriffs und läßt sich ohne sie nicht verstehen. Rechtsquellen- und Methodenlehre gehören zusammen und beleuchten sich gegenseitig.“ (Schröder 2012: Vorwort zur 2. Auflage). 


\section{Recht, Wabrheit und Normativität}

Auf methodologischer Ebene stellt das Recht allerdings für eine Dispositivanalyse im Anschluss an Foucault einen problematischen Untersuchungsgegenstand dar (vgl. hierzu Schweitzer 2015a). Die Problematik rührt daher, dass Foucault nie direkt eine episteme oder einen discours der Jurisprudenz in den Blick genommen und auch keine genealogische Untersuchung des Rechts, der Formen oder der Ordnung des Juridischen geschrieben hat (Gehring 2000: 18). Es geht ihm in der Regel auch nicht um das Recht als spezifisches Untersuchungsobjekt: „[J]e croise sans cesse le droit sans le prendre comme objet particulier." (Foucault in Berten, Foucault 1988: 19) Mehr noch: Betrachtet man die drei dominierenden Erscheinungsweisen des Rechts bei Foucault - materielle Strafrechtsgeschichte, Epochensignatur der Souveränität (beides v.a. in Foucault 2009b) sowie juridische Konzeption der Macht (v.a. Foucault 2003), - so werden die Schwierigkeiten deutlich, eine Rechtstheorie stricto sensu zu extrahieren, die produktive Anschlussmöglichkeiten eröffnet (vgl. Gehring 2007: 157ff.; 2000: 18; Hunt, Wickham 1998: viii; Biebricher 2009: 135). ${ }^{56}$ Zwar enthält Foucaults „Kritik der Repressionsvorstellung der Macht“, so Petra Gehring, ,in ihrer Strafrechtslastigkeit und Souveränitätsorientierung eine Rechtstheorie - oder zumindest eine Art systematische Skizze, nämlich die Skizze einer Verbotstheorie, einer Verbotssatztheorie, des Rechts“ (Gehring 2007: 175, H.i.O.). Als solche erscheint sie angesichts der Komplexität des Rechts aber geradezu naiv. Und selbst wenn man zugesteht, dass Foucault gar nicht den Anspruch erhoben hat, eine Rechtstheorie zu entwerfen, so zeigt insbesondere der Rekurs auf die juridische Macht als repressive Machtform die Tendenz, das Recht als negativen Hintergrund

56 Vor allem im englischsprachigen Raum wird die These vertreten, dass Foucault in seinem Werk von einer „Expulsion of Law“ im 19. Jahrhundert ausgehe (Hunt 1992; Hunt, Wickham 1998; vgl. auch Baxter 1996; Golder, Fitzpatrick 2009: $11 \mathrm{ff}$. m.w.N.). Dagegen wendet sich vor allem Ewald, der argumentiert, dass nach Foucault nicht das Recht zurückweiche, sondern das Juridische als eine spezifische Funktionsweise des Rechts und der Macht anzusehen sei (Ewald 1990). Die These der Kolonisierung des Rechts in Form des juridischen Machttyps durch die Disziplinen verweist damit auf eine andersgelagerte Einbindung des Rechts in den Macht-Wissen-Komplex. Das überzeugt insofern, als Foucault die Disziplin ja gerade nicht als Nicht-Recht, sondern explizit als eine Form des "Gegenrechts“ bezeichnet (Foucault 2009b: 285). 
einzusetzen, auf dem er seine Theorie entfaltet. Das Recht fällt bei Foucault an vielen Stellen sozusagen selbst unter die Repressionshypothese. ${ }^{57}$

Beruft man sich also in der Analyse rechtlicher Phänomene auf Foucault, so muss eine Übertragungsleistung hinsichtlich seiner methodologischen Verfahrensweise auf den Untersuchungsgegenstand Recht erbracht werden (vgl. auch Valverde 2010). Und genau hier tritt ein Problem auf: Die Analyse von Diskursen entwickelte Foucault anhand der und für die Untersuchung von Wissensformen, die sich auf Wahrheit beziehen. Ihn interessierte, wie man bestimmte Gegenstände wie z.B. „die Frage nach dem Wahnsinn im Sinne der Wahrheitsdiskurse, das heißt im Sinne von Diskursen, die Status und Funktion eines wahren Diskurses haben - im Abendland ist das der wissenschaftliche Diskurs -, hat funktionieren lassen können“ (Foucault 1978a: 144, H.i.O.). Den Prototyp eines Diskurses bilden die Aussageordnungen derjenigen Wissenschaft, in denen ,Wahrheit ${ }^{\star}$ als Kriterium und Maß der Aussagen herrscht (Gehring 2004: 71). Aber selbst in den diskursiven Wissensordnungen jenseits der Wissenschaften geht es Foucault um Wahrheitsdiskurse (vgl. Schweitzer 2015a: 207ff.), denn der Diskurs erscheine in jeder Gesellschaft in eine „,allgemeine Politik' der Wahrheit" (Foucault 1978b: 51) eingebettet, von der aus die Formation in ihren Mechanismen zu erklären sei. ${ }^{58}$ Erst mit der Fokussierung auf Wahrheitsdiskurse lässt sich auch die kritische Intervention der Diskursanalyse im Feld der Philosophie erklären, die in entscheidender Weise die Ausarbeitung der methodologischen Prämissen prägt. ${ }^{59}$ Foucault wen-

57 Es würde allerdings zu weit führen, zu behaupten, dass Foucaults Blick auf das Recht nur negativ bestimmt sei; zu einem Überblick der Erscheinungsweisen des Rechts bei Foucault - mit divergierenden Einschätzungen - vgl. Schauer 2006; Gehring 2000, 2007; Biebricher 2009, 2014; zu den Entwürfen einer „Foucault'sche Rechtstheorie“ vgl. etwa Hunt, Wickham 1998; Tadros 1998; Golder, Fitzpatrick 2009, wobei immer noch die Arbeiten von Ewald hervorzuheben sind, auf die auch ich mich hier beziehe.

58 Es wäre müßig, all die Stellen aufzuzählen, an denen Foucault vom Zusammenhang von Diskurs und Wahrheit explizit oder implizit spricht, da „[d]as Problem der Wahrheit in allen Arbeiten Foucaults präsent" ist (Lemke 1997: 322).

59 Foucault beschreibt dies deutlich in Die Ordnung des Diskurses: Mit seinem Entwurf der Diskursanalyse wandte er sich explizit gegen die sich in ihrem Selbstverständnis „als Diskurs der Wahrheit par excellence begriffene Philosophie“ (Foucault 1978c: 75). Denn diese habe auf das „Einschränkungs- und Ausschließungsspiel“ reagiert, indem „sie eine ideale Wahrheit als Gesetz des Diskurses und eine immanente Rationalität als Prinzip ihrer Abfolge [vorschlägt] und indem sie eine Ethik der Erkenntnis begründet, welche die Wahrheit nur dem Begehren nach der Wahrheit selbst und allein der Fähigkeit, sie zu denken, verspricht“" (Foucault 2007: 30f.). 
det sich gegen den Universalitäts- und Objektivitätsanspruch einer einzig möglichen Wahrheit, die sich jenseits der Macht platziert, indem er die machtvollen, historisch-variablen Produktionsbedingungen von Wahrheit untersucht. Wahrheit erscheint nun als ein kontingentes Produkt. Dabei werden die verschiedenen methodischen Analyseraster mit Blick auf diese Relativierung der Wahrheit entworfen, da sie gerade jene Momente betonen, die gemeinhin nicht als konstitutiv für die Wahrheit angesehen werden: Macht, Begehren, Zufall, Ereignis, Bruch. ${ }^{60}$

Genau diese Fokussierung auf Wahrheitsdiskurse führt aber zu Problemen, wenn man die diskursiven Formationen des Rechts untersuchen will. ${ }^{61}$ Denn zu den Eigenarten des juridischen Diskurses gehört, dass er sich nicht immer oder vollständig als Wahrheits-, sondern ab einem gewissen Punkt (auch) als normativer Diskurs bestimmt - und entsprechend andere Diskursmechanismen ausbildet. Das gilt insbesondere für das sich wandelnde epistemische Dispositiv der deutschen Privatrechtswissenschaft. Hier zeigt sich, dass das Verhältnis von Sein und Sollen im Recht, d.h. Wahrheit und Normativität, auf unterschiedliche Weise problematisiert wird und zunehmend in ein Spannungsverhältnis zueinander tritt: Für die erste Hälfte des 19. Jahrhunderts lässt sich bei der Historischen Rechtsschule noch von einer Anbindung an die Wahrheit sprechen, da sich im positiven Recht, dem Sein des Rechts, der Wertezusammenhang, d.h. das Sollen, zeigt. Allerdings kann man schon hier feststellen, dass angesichts des „lebendigen Organismus Volksgeist“ über die Methodenlehre (insbesondere die Auslegungslehre) ein flexibles, anpassungsfähiges System entworfen wird. Die Diskursmechanismen passen sich dem Gegenstand an, und die eine wahre Rechtsauslegung, die alle anderen aufgrund ihrer Objektivität und Universalität ausschließt, erscheint damit nicht am Horizont - allenfalls eine richtige und vertretbare. Dieses Verhältnis von Wahrheit und Normativität wird sich in den Rechtswissenschaften Ende des 19. Jahrhunderts grundlegend wandeln: Auch wenn auch hier zunächst noch von einer Anbindung an die Wahrheit auszugehen ist, wenn

60 Es geht keinesfalls um den Nachweis, dass es keine Wahrheit gebe. Foucault relativiert lediglich den Monotheismus der einen Wahrheit mit ihrem Anspruch auf alleinige Gültigkeit. Er öffnet den Blick auf die spezifischen diskursiven Mechanismen der Wahrheitserzeugung - Praktiken der Universalisierung, der Verallgemeinerung, der Enthistorisierung, der Evidenzerzeugung etc.

$61 \mathrm{Zu}$ welchen Fehlschlüssen eine solche an Foucault angelehnte Analyse der Wahrheitsdiskurse des Rechts verleiten kann, habe ich anhand der Studie Der VorsorgeStaat von François Ewald an anderer Stelle ausführlich analysiert, vgl. Schweitzer 2015a. 
nach der gesellschaftlichen Funktion des Rechts gefragt wird, wird genau in dieser Frage nach der Funktion des Rechts für die Gesellschaft das Sollen des Rechts aufgewertet - bis hin zur grundlegenden Problematisierung des eigenen wissenschaftlichen Diskurses anhand der Scheidung von Sein und Sollen. Damit wird die Relationierung von Wahrheit und Normativität zu einer der entscheidenden Problematisierungsweisen des Rechts am Anfang des 20. Jahrhundert, die auch in den Debatten um die juristische Methodenlehre erkennbar ist.

Auf einer abstrakten Ebene geht es um die Frage, wie man die Normativität des Rechts, wie immer sie auch zur Wahrheit in Beziehung gesetzt wird, analytisch zugänglich macht. Hierfür müssen gewisse methodologische Prämissen in der Analyse der diskursiven Formationen umgestellt werden: Erstens geht es nicht darum, zu analysieren, was die Bedingungen der Möglichkeit des Wahrsprechens sind, sondern, was die Bedingungen der Möglichkeit des juridischen Sprechens sind. Das mag zwar wie eine kleinliche Unterscheidung klingen, hat aber konkrete Folgen, da der juridische Diskurs auch auf die Funktionslogik der normativen Wissensformen hin untersucht werden muss (Schweitzer 2015a: 215). Vorliegend betrifft das insbesondere die Ebene der Methodenlehre, da hier Techniken und Mechanismen herausgebildet werden, die anders als Wahrheitsdiskurse explizit mit der Relativität des Wissens umgehen, indem sie Lücken, Kontingenz und zukünftigen Wandel konzeptualisieren und von der Unbestimmtheit ausgehen (vgl. Schweitzer 2015d). Die Relativität des Wissens gehört zu den Grundproblematiken des Rechts. Und überträgt man das auf die Richtertätigkeit, so wird sich zeigen: Den Subsumtionsautomat, der wie eine Wahrheitsmaschine funktioniert, gibt es nicht - allenfalls als Abgrenzungshorizont, um das eigene Vorgehen zu legitimieren.

Mit der Öffnung der Analyse für die Logik und die Mechanismen normativer Phänomene verschieben sich zweitens auch die Prämissen für die Macht-Wissen-Komplexe: Es geht in der Untersuchung also nicht um die Macht der Wahrheit oder die Wahrheit als Macht, sondern um die Macht der Nicht-Fixierung als Wahrheit - um die strategische Funktion der Normativität selbst. Damit steht die Frage im Mittelpunkt, angesichts welcher Problematisierungen die Rechtswissenschaft als Wissenschaft an den Punkt kommt, ihren eigenen Gegenstand auf eine Art und Weise normativ zu fassen, dass sie darüber ihren spezifischen Wissenschaftscharakter als Sollenswissenschaft in Abgrenzung zur Wahrheitsorientierung der Seinswissenschaft deklariert.

Das führt drittens zu einer Verlagerung der zu untersuchenden Ebene im rechtlichen Gefüge. Die an Foucault angelehnten rechtssoziologischen Studien haben den Fokus auf den Wandel der Rechtsform gelegt, wie sie 
in der Rechtsnorm zu erkennen ist (vgl. Gehring 2005/2006). In den Genealogien des Sozial- bzw. Wohlfahrtsstaates im 19. Jahrhundert der Foucault-Schüler Giovanna Procacci (2002), Jacques Donzelot (1994a) und François Ewald (1987) wird Recht nicht mehr als Norm gefasst, die in der Form des Gebots, des Verbots und der Verpflichtung in Erscheinung tritt, sondern es nähert sich einer empirischen, technischen Norm - man könnte auch sagen: der Norm im Sinne der Normalverteilung, der Wahrscheinlichkeit und der Normalisierung (vgl. Ewald 1990, 1993). Das Recht der Sozialrechtsgesetzgebung ist nun auf Maßzahlen, auf den Durchschnitt (etwa das durchschnittliche Auftreten von Unfällen), also letztlich auf quantitative Zielgrößen gerichtet (vgl. Schweitzer 2015b: 42). Die rechtliche Norm nähert sich damit der Wahrheit an, sie wird zur Wahrheitsnorm, da sie auf wahrheitsfähige Größen ausgerichtet ist - selbst wenn in der Intervention eine präskriptive, d.h. normative Regelung der gesellschaftlichen Ordnung erfolgt. Das normativ orientierte liberale Recht (des Zivilrechts) wird - so die These dieser Studien - durch das normalisierende Sozialrecht verdrängt (vgl. Ewald 1993: 16). ${ }^{62}$

Fragt man jedoch nach der strategischen Funktion der Normativität selbst, so verschiebt sich der Fokus weg von den Rechtsregeln hin zur Rechtswissenschaft: Während auf der Ebene der Gesetzesinhalte seit dem Ende des 19. Jahrhunderts durch die wohlfahrtsstaatliche Gesetzgebung eine eklatante Zunahme der Anteile deskriptiver, normalisierender Normen (bzw. Norminhalte) zu verzeichnen ist, ist auf der Ebene der (privatrechtlichen) Rechtsdogmatik und -methodik eine auffällige Aufwertung des Normativen festzustellen. Und genau hier wird eine zentrale strategische Funktion des Normativen erkennbar sein: Sie immunisiert das Recht vor den Zumutungen der Tatsachenfeststellung, die in einer normalisierenden, deskriptiven Norm eingelagert ist.

Um das erkennen zu können, muss die Analyse des epistemischen Dispositivs des Rechts sich der rechtlichen Normativität mit ihren Formationsregeln, ihren Diskursmechanismen und strategischen Funktionen öffnen. Die Normativität wird dann nicht untersucht als Wesensbestimmung

62 Beim Recht handele es sich dann um ein dynamisches Instrument, das auf die jeweilige Datenlage rekurriert und mit dieser variiert. Es habe damit die Seite gewechselt - es begrenzt nicht mehr im Namen der Freiheit, sondern vergleicht, bewertet und reagiert auf die datenmäßig erfassten Bedürfnisse mit Steuerungsinteresse: „Das Recht wird sozial und korrektiv.“ (Ewald 1993: 21). 
oder Abgrenzungskriterium des Rechts, sondern als strategischer Einsatz in spezifischen Macht-Wissen-Komplexen. ${ }^{63}$

\section{Recht und Soziologie}

Diese Blickverlagerung hin zur strategischen Funktion der rechtlichen Normativität führt zudem zu einer anderweitigen Bestimmung des historischen Verhältnisses von Recht und Soziologie im 19., Anfang des 20. Jahrhunderts, als sie die an Foucault angelehnten rechtssoziologischen Studien von Procacci, Donzelot und Ewald statuieren.

Gemeinsamer Ausgangspunkt dieser Arbeiten ist die These, dass die historischen Entwicklungen zum Sozialstaat nicht von einer epistemologisch-politischen Verschiebung in der Objektivierung von Gesellschaft zu trennen ist (vgl. hierzu Lemke 1997: 192ff.; Krasmann 2003: 99ff.). In der liberalen Gouvernementalität bildet das Individuum die zentrale Referenz der Regierung. Denn die Gesellschaft wird lediglich in Form einer Anhäufung von Individuen gedacht, sie ist mit der Summe ihrer Teile identisch. Dieses Denken findet seinen Ausdruck im Recht in der (vernunftrechtlichen) Annahme der allgemeinen Rechtsgleichheit, der ein auf dem freien Willen beruhendes Verantwortlichkeitskalkül korrespondiert. Und der Staat ist darauf beschränkt, die durch die Individuen etablierte Ordnung zu gewährleisten, indem er die Freiheit der Individuen zu sichern hat (Lemke 1997: 193f.). Die „Erfindung des Sozialen“ (Donzelot 1994b), die Problematisierung der sozialen Frage (Procacci 1993) bzw. die Entdeckung des „sozialen Risikos“ (Ewald 1991) ab der zweiten Hälfte des 19. Jahrhunderts markiert einen Wandel in diesem Schema: ,Gesellschaft ${ }^{`}$ gewinnt eine eigene Dichte, die es unmöglich macht, sie auf die bloße Aggregation der Individualwillen zurückzuführen (Lemke 1997: 193). Sie erscheint nicht mehr als Vereinigung individueller Subjekte, sondern wird selbst zu einem Subjekt mit einem Eigenleben, einer Realität sui generis, mit eigenen Gesetzen und Regelmäßigkeiten.

Symptomatisch für diesen Wandel in der Art und Weise, Gesellschaft zu konzeptualisieren, ist das Aufkommen der neuen Wissenschaft der Soziologie. Sie hat die Gesellschaft und die ihr eigenen Gesetzmäßigkeiten zum

63 Indem sie eine solche machtkritische Perspektive ermöglicht, unterscheidet sich die Analyse der diskursiven Formationen gerade von den gängigen rechtssoziologischen Bestimmungen, die die Normativität des Rechts in den Blick nehmen (vgl. Weber in $₫ 8$; Habermas 1992a; Luhmann 1993). 
Gegenstand. Dadurch trägt sie zur Konstruktion und Objektivierung der Gesellschaft bei (Krasmann 2003: 100), jedoch in einer ganz spezifischen Form: als empirische Wissenschaft, die in ihren statistischen Verfahren die Konstanz der Wahrscheinlichkeit entdeckt (vgl. Hacking 1990). Armut und Verelendung erscheinen nicht mehr als Folge eines mangelhaften Willens des betroffenen Individuums, und der Arbeitsunfall in der Fabrik stellt sich nicht mehr als unvorhersehbares Ereignis dar. Man nimmt derlei nicht mehr als ein individuelles, selbstverschuldetes oder exzeptionelles Schicksal wahr, sondern sieht es in Form der statistischen Wahrscheinlichkeit als eine gemeinsame wie unvermeidliche Last an, die auf dem Sozialen liegt, das nun als Ganzes gedacht wird.

Damit trägt die Soziologie, und das heißt für die Foucault-Schüler: die wahrheitsorientierte empirische, statistisch gestützte Sozialforschung, zur Etablierung eines Denkens bei, das sich nachhaltig von der normativ orientierten liberalen Konzeption der Gesellschaft unterscheidet. Denn diese Rationalität läuft den klassischen normativen Rechtsprinzipien (des Vernunftrechts) zuwider (vgl. Link 2009: 129), da sie die Prinzipien der individuellen Verantwortung negiert. Von diesem Widerstreit ausgehend entwickeln sich neue Regierungstechniken, allen voran das Sozialrecht, das nicht primär eine quantitative Zunahme des Rechts bewirkt, sondern wie bereits erwähnt das Recht in seinem grundlegenden Charakter, d.h. seine Rechtsform, verändert (vgl. Procacci 1993, 1991; Donzelot 1980, 1994a; Ewald 1993: 29ff.). Anders als es der Liberalismus vorsah, beschränkt sich der Staat damit nicht mehr darauf, eine etablierte Ordnung zu gewährleisten. Er steht der Gesellschaft nicht als ein Fremdkörper gegenüber, sondern hat nun die Steuerung und Förderung des Sozialen zur Aufgabe. Da$\mathrm{zu}$ ist er in der Lage, weil die Gesellschaft als positivistische Tatsache sui generis zum Zugriffsobjekt werden kann. Gegen Ende des 19. Jahrhunderts übernimmt der Staat damit die „Führung“ und die Verantwortung für sozialen und ökonomischen Fortschritt (Krasmann 2003: 105). Er wird „zum Staat der Gesellschaft: zum Sozial-Staat“ (Lemke 1997: 192, H.i.O.).

Recht und Soziologie werden in diesen Studien als zwei verschiedene Wissensbereiche adressiert, die miteinander in Verbindung treten: Die Soziologie liefert über das Wahrscheinlichkeitskalkül eine Wissensform, die zur Transformation des epistemologischen Feldes des Regierens mittels des Rechts beiträgt. Soziologie, d.h. empirische Sozialforschung, wird damit zur Basis des neuen Rechtsdenkens: Es sind spezifisch rechtliche Techniken der Versicherung und des Sozialrechts, die die Gesellschaft in ihrer sozialwissenschaftlich, d.h. datenmäßig erfassten Eigenständigkeit gegenüber den Individuen erscheinen lassen und politische Wirkungsmacht erlangen. 
Das moderne Sozialrecht ist somit soziologisch fundiert, und vice versa wird die Soziologie politisch (vgl. Schweitzer 2015b: 43).

Dieser Befund erstaunt insofern, als die entstehende Soziologie um die Jahrhundertwende nicht nennenswert an der empirischen Sozialforschung interessiert war (vgl. Oberschall 1997: 233). Die großen Entwürfe der Soziologie sind nicht auf dem Gebiet der Empirie anzusiedeln, sondern auf dem der Sozialtheorie und -philosophie sowie der Gesellschaftstheorie. ${ }^{64}$ Daher muss sich das Verhältnis von Recht und Soziologie gegenüber den an Foucault orientierten Studien anders bestimmen lassen, insbesondere da das Recht eines der zentralen Themen für die entstehende Soziologie war. Dieses andere Verhältnis wird erkennbar, wenn man den Blick auf die Frage der Normativität des Rechts richtet: Seit Beginn des 19. Jahrhunderts wird in den deutschen Privatrechtswissenschaften die Gesellschaft zum zentralen Bezugspunkt eines Rechts, das sich selbst als gesellschaftliches Produkt versteht. Es handelt sich dabei aber nicht um die über Daten, Statistik und Wahrscheinlichkeit verobjektivierte Gesellschaft, sondern um ein epistemisches Ding, das einen genuin normorientierten Charakter hat: Gesellschaft wird als ein Normzusammenhang konzipiert. Auf diese norm-, und in der Folge normativ gestützte Gesellschaft bezieht sich die sich etablierende Soziologie, indem sie auf das Recht als Normenordnung rekurriert. Dabei wird die Soziologie nicht politisch, weil sie dem Recht eine Wissensform liefert, das diese für neue Regierungstechnologien nutzbar macht, sondern umgekehrt: Indem die Soziologie die juristischen Problematisierungsweisen adaptiert, akzeptiert sie die Regierungstechnologien des Rechts. Damit verhält sie sich keineswegs - wie bei Durkheim, Tönnies und Weber gezeigt werden kann - neutral gegenüber der Rechtswissenschaft. Gerade in der Frage der Relationierung von Normativität und Wahrheit, wie sie insbesondere in der Untersuchung der strategischen Funktion der Normativität im Recht zum Ausdruck kommt, lassen sich somit Verbindungslinien zwischen Recht und Soziologie ausfindig machen.

64 Anthony Oberschall schreibt mit Blick auf Deutschland: „Die Soziologen selbst waren in erster Linie damit befaßt, sich akademisch zu legitimieren und ihre Disziplin zu definieren und abzugrenzen, was im deutschen akademischen Milieu nur dadurch geschehen konnte, daß man sich in philosophische Auseinandersetzungen über Methoden, Werte und Objektivität in den Kulturwissenschaften einließ." (Oberschall 1997: 237) Empirische Forschung wurde zum einen außeruniversitär betrieben und interessierte sich zum anderen kaum für methodische Fragen. 


\section{Recht und Macht}

Mit der Frage nach der strategischen Funktion der Normativität im Recht steht das Verhältnis des Rechts zur Macht zur Debatte. Diese Fragestellung besitzt eine spezifische Dringlichkeit, bewirkt dies doch eine Verschiebung in der gängigen Problematisierungsweise des Rechts mit Blick auf die Macht. Denn ihrzufolge erscheint das Recht einerseits als Produkt des Staats, Instrument der Souveränität; andererseits jedoch als Mittel der Begrenzung der Macht des Staates. Recht wird herkömmlicherweise mit Blick auf die staatliche Macht problematisiert.

Macht ist für Foucault jedoch nicht an den Staat gebunden. Sie ist vielmehr ein „offenes, mehr oder weniger [...] koordiniertes Bündel von Beziehungen" (Foucault 1978a: 126), welches nicht allein repressiv, sondern vor allem produktiv ist. Legt man wie in der vorliegenden Untersuchung den Fokus auf die produktiven Effekte der juridischen Macht-Wissen-Komplexe, und d.h. konkret auf die performative Hervorbringung des epistemischen Dings ,Gesellschaft', so wird sich zeigen: Der Staat kommt nur am Rande vor. Das hat mit dem epistemischen Dispositiv der Privatrechtswissenschaft selbst zu tun: Das politische Argument der Historischen Rechtsschule liegt in der Entstaatlichung des Rechts, ohne dem Recht aber damit die Funktion einer Begrenzung der staatlichen Macht zuzuschreiben. Die Abgrenzung zwischen Privatrecht und Öffentlichem Recht, die dieser Konstruktion zugrunde liegt, platziert den Staat auf der anderen Seite des ,wahren', nämlich gesellschaftlich gewachsenen Rechts. Damit wird aber die staatliche Interventionsgewalt nicht angetastet, zeigt sich doch das Recht als genuin unpolitisches Instrument. Der Staat wird zum Diener des gesellschaftlich gewachsenen Rechts und damit weder als Produzent noch als Adressat einer Begrenzung der staatlichen Macht aufgefasst, sondern als Garant einer gesellschaftlichen Ordnung, die dem Staat vorgängig ist. Damit wird das Recht gegenüber der staatlichen Macht neutralisiert. Und als solches kann die Soziologie es nun als ein soziales Phänomen adressieren, das etwas über die Gesellschaft, und nicht über die Macht aussagen wird.

Auch wenn hier eine Nähe (und Anschlussfähigkeit) zum (früh-)liberalen Schema aufscheint, das ebenfalls das nicht-staatliche Recht gegenüber dem Staat in Anschlag bringt, ist doch ein entscheidender Unterschied zu markieren: Das Recht begrenzt den Staat Anfang des 19. Jahrhunderts nicht im Namen der subjektiven Freiheit, indem das subjektive Recht ein Abwehrrecht des Individuums gegenüber staatlichen Interventionen darstellen würde. Vielmehr begrenzt es den Staat im Namen einer Freiheit der Gesellschaft, die als normative soziale Ordnung jenseits der staatlichen Verfassung bestimmt wird (das unterscheidet dieses Konzept zugleich von 
der Reduktion der Gesellschaft auf ein statistisch gestütztes Steuerungsobjekt bei Ewald, Donzelot und Procacci).

Damit wandelt sich das zugrunde liegende Schema: Das Recht wird in Beziehung zur Gesellschaft gesetzt, es wird zu einem zentralen Mittel, sie zu erkennen, sie zu steuern oder sie zu ermöglichen. Hierin zeigen sich seine Machteffekte in Bezug auf das epistemische Ding ,Gesellschaft', hierin liegt seine Rechtsmacht für die Gesellschaft und die Soziologie. Vor allem wird das Recht angesichts dieses Dings, Gesellschaft', d.h. der vorausgesetzten gesellschaftlichen Wirklichkeit, selbst zu einem Problem. Die Versuche der Rechtswissenschaft, sich angesichts dieser Probleme zu behaupten, betreffen eine ganz andere Ebene als diejenige des Staates. Sie werden in die normativistische Trennung zwischen Sein und Sollen Anfang des 20. Jahrhunderts münden, die sowohl für die Soziologie nach Weber (und bis heute) als auch für die Rechtswissenschaft zum Differenzkriterium der eigenen Disziplin wird.

Damit gerät die Normativität ins Zentrum der Frage nach der Rechtsmacht. Man muss m.E. mit Petra Gehring fragen: „Was wäre, wenn hier gerade die Juridizität ihre Strategie ansiedelt?“ die Macht des Juridischen eben darauf, dass es sich als diese Trennung zur Geltung bringt und vermittels dieser Trennung wirkungsvoll inszeniert" (Gehring 2000: 30, H.i.O.). Daher darf man in der Analyse der Macht-Wissen-Komplexe das epistemische Dispositiv des Rechts nicht als Formation von Wahrheitsaussagen präfigurieren und dem folgend nach Mechanismen der Wahrheitsaussagen untersuchen. Denn dann entginge der Analyse genau dieser strategische Einsatz der Normativität - und damit ein zentraler Aspekt der Macht des Juridischen in der (westlichen) Moderne. Verkannt würde dann aber zugleich sein Einfluss auf die entstehenden Soziologien - und damit der politische Charakter dieser Soziologien, die in ihren genuinen Formen der Adressierung des Rechts zum Ausdruck kommt.

\section{Erschließungsebene}

Die bisherigen Überlegungen bezogen sich auf die methodologischen Prämissen der Analyse des epistemischen Dispositivs des Rechts. Darüber ließen sich die zentralen Themenfelder aufzeigen, die es bei der Untersuchung des doppelten Konstitutionsverhältnisses von Recht und Gesellschaft im Blick zu behalten gilt: Die Autonomie des Rechts, die Normativität des Rechts, das Verhältnis von Recht und Soziologie sowie die Problematisierung von Recht und Macht. Damit ist jedoch noch nicht ge- 
klärt, was man für die Frage, wie und in welcher Form die Entdeckung des epistemischen Dings ,Gesellschaft' im deutschen Recht des 19. Jahrhunderts die entstehende Soziologie beeinflusste, zu untersuchen hat. Oder anders formuliert: Die Ebene der Erschließung ist noch nicht geklärt.

Die hier gewählte Perspektive auf das doppelte Konstitutionsverhältnis von Recht und Gesellschaft bestimmt jedoch zugleich diese Erschließungsebene der Untersuchung. Denn wird als Ausgangsproblem der soziologiegeschichtlichen Untersuchung das heute problematische Verhältnis zwischen Recht und Gesellschaft in der Soziologie gewählt, so folgt die Auswahl des Materials dem strategischen Paradigma des Problems. Daher wird der Interferenzraum zwischen diesen beiden Bereichen zum Ausgangspunkt der Untersuchung genommen. Die Auswahl der soziologischen Autoren erfolgt über die augenscheinliche Wichtigkeit des Rechts der bis heute als zentrale Figuren fungierenden Soziologen Émile Durkheim, Ferdinand Tönnies und Max Weber. Ins Auge sticht dabei, dass sie für das Vorhaben vorwiegend das Privatrecht adressieren. Die Auswahl des rechtswissenschaftlichen Materials wiederum erfolgte über einen doppelten Filter: einerseits über die Bezüge, die Durkheim, Tönnies und Weber zum Recht herstellen; andererseits über die Frage, in welchen diskursiven Praktiken der Privatrechtswissenschaft die Gesellschaft als fragengenerierendes epistemisches Ding eine Rolle spielte. ${ }^{65}$

In diesem Interferenzraum zeigen sich gerade über das epistemischen Ding ,Gesellschaft ${ }^{\star}$ Anschlussmöglichkeiten an die juristischen Diskurse und Bestimmungen für die soziologischen Entwürfe sowie Konvergenzen in der Adressierung des Sozialen und in der soziologischen Adressierungen des Rechts. Zugleich werden Differenzen zwischen den proklamierten juristischen und soziologischen Perspektiven deutlich. Sowohl in den Konvergenzen als auch in den Differenzen sind die Gründe für die genannten Schwierigkeiten der Soziologie mit dem Recht zu suchen, auf die man heute trifft. Denn hier wurden - wie anhand von Durkheims, Tönnies und Webers Versionen der Soziologie zu zeigen sein wird - Abzweigungen gewählt, die in der Folge das Recht für die Soziologie aus dem Blick geraten ließen.

65 Die Frage nach der Erschließungsebene betrifft das Archiv als Beschreibung des allgemeinen Operationsraums der Untersuchung. Hier unterscheidet sich die vorliegende Untersuchung am deutlichsten von der Analyse diskursiver Dispositive nach Foucault (vgl. hierzu Gehring 2004: 63ff.), wird doch die Eingrenzung des Materials über die ,Vorgaben` der analysierten soziologischen Autoren gelöst. 


\section{Erster Teil. \\ Von der Gesellschaft im Recht zum Recht der Gesellschaft: Juridische Adressierungen des Sozialen}

In der ersten Hälfte des 19. Jahrhunderts dominiert die Historische Rechtsschule die deutsche Rechtswissenschaft (vgl. Schröder 2012: 194ff.; Wieacker 1996: 348ff.). Sie entfaltet sowohl in sachlicher wie in geographischer Hinsicht eine enorme Breitenwirkung, weit über die deutschen Privatrechtswissenschaften hinaus, in denen sie ihre Ursprünge hat. Seitdem gilt: An der Historischen Rechtsschule ist kein Vorbeikommen nicht nur, weil sie die juristischen Lehren grundlegend veränderte, sondern auch, weil sie über ihre Theorie des Rechts einen „Apparat allgemeiner Ideen" (Jhering 1861: 364) entwickelte, der das Recht in ein direktes Verhältnis zu einer vom Staat unabhängigen Sozialsphäre setzt und es dadurch mit Blick auf die gesellschaftliche Wirklichkeit nachhaltig zu problematisieren vermag.

Wenn nun diese Sozialsphäre Gegenstand der rechtswissenschaftlichen Überlegungen wird, tritt das epistemische Ding, Gesellschaft ${ }^{6}$ in den rechtswissenschaftlichen Diskurs ein. Die Problematisierung des Verhältnisses von Recht und Gesellschaft erfolgt dabei je nach Notlage (urgence), auf die reagiert wird, in unterschiedlicher Weise: als Repräsentationsdispositiv im Rahmen der Debatten um die Kodifikation und der Kritik an der Historischen Rechtsschule, als gesellschaftsfunktionales Zweckdispositiv im Streit über die soziale Aufgabe des Bürgerlichen Gesetzbuches (BGB) und als normatives Zweckdispositiv im juristischen Methodenstreit zu Beginn des 20. Jahrhunderts. Es lässt sich ein Wandel von der Suche nach der Gesellschaft im Recht hin zur Bestimmung des Rechts der Gesellschaft feststellen, in dem die Rechtswissenschaft die umfassende Sozialsphäre, d.h. die Gesellschaft und später dann die Soziologie, auf je unterschiedliche Weise adressiert. Mit diesen juridischen Adressierungen des Sozialen entfalten sich zugleich unterschiedliche strategische Effekte für die Frage der Autonomie des Rechts, des Verhältnisses von Recht und Macht, aber auch der wissenschaftstheoretischen Debatten um die Erkenntnisweisen des Rechts. 


\section{\$2. Die Entdeckung der Gesellschaft im Privatrecht: Das Repräsentationsdispositiv der Historischen Rechtsschule (1814-ca. 1860er Jahre)}

$\mathrm{Zu}$ den Gründungsdokumenten der Historischen Rechtsschule gehört die Schrift Vom Beruf unserer Zeit für Gesetzgebung und Rechtswissenschaft des Romanisten Friedrich Carl von Savigny aus dem Jahre 1814. ${ }^{66}$ Der Ort, an dem Savigny seine grundlegenden Ideen breitenwirksam kundtut, ist keine wissenschaftliche Debatte, sondern eine politische: der sogenannte Kodifikationsstreit Anfang des 19. Jahrhunderts.

\section{L'urgence: Die drohende Kodifikation (Anton Friedrich Justus Thibaut)}

Nach der Völkerschlacht bei Leipzig 1813 und der Auflösung des Rheinbundes werden Forderungen nach einer per Gesetzgebung herzustellenden deutschen Rechtseinheit (wieder) verstärkt erhoben. ${ }^{67}$ Ausgangspunkt ist ein radikaler Rechtspluralismus in den deutschen Gebieten: Das Neben-, Gegen- und Nacheinander von lokalen Statuten, Gewohnheitsrecht, Stadt- und Landrechten, Reichsgewohnheiten, Reichsgesetzen, kanonischem und römischem Recht sowie zunehmend auch Partikularrechten führt zu dem zentralen Problem, welches Recht vor Gericht überhaupt Anwendung finden müsse. Das römische Recht, auch das gemeine (da all-

66 Savigny selbst bekräftigt im Jahr 1850, wie wichtig diese Flugschrift für sein gesamtes Vorgehen sei (vgl. Savigny 1850b: 105) - und damit für dasjenige der Historischen Rechtsschule. Von der ausufernden Literatur über Savigny (1779-1861) vgl. zu Leben und Wirken insbesondere Rückert 1984, zur Bedeutung seines Werkes für die Rechtswissenschaft sei auf die umfassende Literaturliste in Kleinheyer, Schröder 2017: 386ff. verwiesen.

67 Bereits in der Spätphase des Heiligen Römischen Reiches wird eine lebhafte Diskussion über die Frage der Herstellung einer Rechtseinheit mittels Gesetzgebung in Deutschland geführt. In den Rheinbundstaaten setzt man diese Debatte angesichts der Rezeption des Code Napoleon unter veränderten Vorzeichen fort, und sie kommt auch im Folgenden trotz Kodifikationsstreit und Durchsetzung der kodifikationsfeindlichen Historischen Rechtsschule auf der Ebene der Rechtsdogmatik und -methodik keinesfalls zum Erliegen (vgl. hierzu die ausführliche Studie von Schöler 2004). 
gemein verbreitete) Recht genannt, kommt in der Regel subsidiär zur Anwendung (kritisch hierzu Oestmann 2002). ${ }^{68}$ Allerdings gerät es seit Ende des 18. Jahrhunderts aufgrund der Schaffung neuer, territorialstaatlicher Gesetzbücher zunehmend unter Druck, zielen doch nicht wenige solcher naturrechtlich inspirierter Partikularrechte - wie etwa das Preußische Allgemeine Landrecht (ALR) - auf dessen vollständige Ablösung. ${ }^{69}$

Eine gemeinsame Kodifikation des Zivilrechts wird als drängendes Problem erachtet - nicht nur aus sehr praktischen und wirtschaftlichen Gründen, sondern vor allem motiviert durch ein erstarktes Nationalgefühl. ${ }^{70}$ Zahlreiche Abhandlungen befassen sich in den Jahren 1813/14 mit dem Gedanken der Rechtseinheit (vgl. Wrobel 1975: 44ff.; Stern 1959: 8f., jeweils m.w.N.). Eine der prominentesten Stimmen ist diejenige von Anton Friedrich Justus Thibaut (1772-1840), seit 1805 Professor für römisches Recht an der Universität Heidelberg. 1814 veröffentlichte er seine Flugschrift Über die Nothwendigkeit eines allgemeinen bürgerlichen Gesetzbuchs für Deutschland (Thibaut 1959 [1814]), auf dessen erste Ausgabe Savigny mit dem Beruf noch im selben Jahr reagiert. ${ }^{71}$

Für Thibaut stellt sich die Frage eines nationalen Gesetzbuches nach den Befreiungskriegen mit absoluter Dringlichkeit: Die Zeichen der Zeit

68 Das gemeine Recht (ius commune) umfasst neben der Sammlung des antiken römischen Rechts im Corpus iuris civilis des Kaisers Justinian auch die Sammlung des kanonischen Rechts im Corpus iuris canonici, d.h. das Recht der römisch-katholischen Kirche (vgl. zum ius commune Repgen 2007).

69 Zudem verschwand 1806 mit der Reichskammergerichtsordnung das letzte Reichsgesetz, das die Anwendung des ius commune vor Gericht ausdrücklich vorgeschrieben hatte. Dies führte zu einer Legitimationskrise. Kritiker des ius commune gingen nun davon aus, es gelte nur noch territoriales Recht. Denn spreche sich ein Territorium - wie die meisten - nicht ausdrücklich für das gemeine Recht aus, so gelte es nicht mehr (vgl. Haferkamp 2010: 84 m.w.N.; 2004: 161ff.).

70 Hierbei lassen sich die Positionen nicht eindeutig politisch zuordnen: Die Forderung wird in den 1810er Jahren sowohl von Befürwortern einer ständisch gegliederten Gesellschaft als auch von Befürwortern einer ,bürgerlichen' Gesellschaft erhoben. Auch stehen in der rechtswissenschaftlichen Debatte nicht die wirtschaftspolitischen Überlegungen im Vordergrund, sondern die Stärkung des deutschen Nationalgefühls (vgl. Schöler 2004: 129; anders aus marxistischer Perspektive jedoch Wrobel 1975; Klenner 1991).

71 Veranlasst wurde Thibauts Schrift durch August Wilhelm Rehbergs Arbeit Ueber den Code Napoleon und dessen Einfübrung in Deutschland (1814), in der dieser sich unter polemischen Angriffen auf den Code Napoleon für eine Rückkehr zu den alten Verhältnissen ausspricht und dabei jede Kodifikation verwirft. Thibaut hatte diese Schrift zunächst in den Heidelbergischen Jahrbüchern für Litteratur rezensiert (Thibaut 1840b [1814]), bevor er seine Ansichten noch im gleichen Jahr in der eigenständigen Abhandlung Über die Nothwendigkeit ausarbeitet. 
„zwingen“ den Patrioten geradezu, seine Wünsche zu äußern, damit „man diesen herrlichen Augenblick benutze, um endlich alte Mißbräuche zu zerstören“ (ebd.: 40, 41 [11]). Ein „einfaches National-Gesetzbuch, mit Deutscher Kraft im Deutschen Geist gearbeitet", solle die Hindernisse für die „Möglichkeit einer glücklichen Zukunft“ beseitigen (ebd.: 48 [26], 38 [5]). Gerade im Bereich des bürgerlichen Rechts, bei den „heiligsten Verhältnissen des Bürgers" (ebd.: 40 [10]), herrsche ein eklatanter Missstand und damit ein akuter Handlungsbedarf für das Glück der Deutschen.

Der Grund des Übels ist nach Thibaut in den bestehenden privatrechtlichen Rechtsquellen zu suchen. Sein Urteil über den gegenwärtigen $\mathrm{Zu}$ stand des Privatrechts fällt vernichtend aus: Das ganze einheimische Recht, d.h. die altdeutschen Gesetzbücher, die Partikulargesetze und etwaige Reichsgesetze, ist in seinen Augen „ein endloser Wust einander widerstreitender, vernichtender, buntschäckiger Bestimmungen, ganz dazu geartet, die Deutschen von einander zu trennen, und den Richtern und Anwälden die gründliche Kenntniß des Rechts unmöglich zu machen" (ebd.: 42 [14]). Da es außerdem unvollständig sei, müsse man in der Mehrzahl der Fälle auf das römische Recht zurückgreifen. Das mache die Situation aber keinesfalls besser. Denn es handele sich beim römischen Recht um ein Gesetzbuch, dessen Text nicht vorhanden sei; es existiere lediglich „der ganze Wust jämmerlich zerstückelter Fragmente“, zudem noch von einer „innere[n] Schlechtigkeit seiner mehrsten Bestimmungen, besonders in Beziehung auf Deutschland“ (ebd.: 44 [17f.]). Das mache das römische Recht gänzlich unpraktikabel. Sein Hauptmangel liege aber in seiner Herkunft: „[E]s ist das Werk einer uns sehr ungleichen fremden Nation" (ebd.: 43 [15]). Da die Deutschen nicht die „Römischen Volks-Ideen“ (ebd.: 43 [16]) besäßen, ja einen gänzlich anderen „Volksgeist“" (Thibaut 1840c [1814]: 12) hätten, bleibe das römische Recht letztlich unverständlich: „[D]er wahre Schlüssel dazu wird uns ewig fehlen.“ (Thibaut 1959 [1814]: 43 [16]) Es passe nicht und könne aufgrund dieser Fremdheit auch nicht passend gemacht werden.

Was Thibaut mit Blick auf die Fremdheit des römischen Rechts, aber ebenso bzgl. der anderen Gesetzeswerke geltend macht, sind nicht nur formelle, d.h. technische Mängel, sondern insbesondere eklatante materielle Defizite: Römische Rechtsvorschriften gestalten die bürgerlichen Einrichtungen gerade nicht „weise und zweckmäßig“, da sie sich nicht „,nach den Bedürfnissen der Unterthanen“ richten (Thibaut 1959 [1814]: 41 [13]). Damit behandelt Thibaut das Recht als Mittel zum Zweck, und seine Güte bemisst sich anhand der Frage, ob der Zweck erreicht werde, d.h.: ob mit Blick auf die Gegenwart die Gestaltung der rechtlichen Verhältnisse den 
„Bedürfnisse[n] des Volkes“ entspreche, sowie ob mit Blick auf die Zukunft das „Bürgerglück“ gefördert werde (ebd.: 46 [23]).

In der zukunftsbezogenen Perspektive wird das Recht als eine Art pädagogisches Instrument der Regierung des Volkes angesehen: Es soll für eine glückliche Zukunft schulen. Denn Thibaut verfolgt mit seiner Befürwortung einer Gesamtkodifikation vor allem ein politisches Ziel: Ihm geht es darum, das Nationalgefühl der Deutschen zu stärken. Recht - v.a. das bürgerliche Recht - sieht er als Integrationsfaktor an. ${ }^{72}$ Durch ein einheitliches Gesetzbuch würde eine innere Einheit der Deutschen entstehen, trotz politischer Trennung durch die verschiedenen Länder und Staaten. ${ }^{73}$ Denn: „Gleiche Gesetze erzeugen aber gleiche Sitten und Gewohnheiten, und diese Gleichheit hat immer zauberischen Einfluß auf Völkerliebe und Völkertreue gehabt.“ (Ebd.: 51 [33]) Das Volk wird zur normativen politischen Zielgröße. Die Forderungen nach einer Gesetzgebung, das Ob der Kodifikation, ist für Thibaut ein rein politisches und kein wissenschaftliches Problem. ${ }^{74}$ Sie soll letztlich dem Ziel dienen, die nationale Einheit zu stärken und zu festigen. ${ }^{75}$

In der gegenwartsbezogenen Perspektive ist das Volk nicht Produzent des Rechts, sondern sein Adressat, nicht politischer Akteur, sondern Objekt der patrimonialen Fürsorge. Die Bestimmung der „Bedürfnisse des Volkes“ als „Bedürfnisse der Zeit" bereitet Thibaut dabei keinerlei Proble-

72 Das gilt auch für die Mehrzahl der Kommentatoren und Rezensenten des Streits zwischen Thibaut und Savigny (vgl. Schöler 2004: 129).

73 Thibaut geht es keineswegs um die Frage der künftigen verfassungsmäßigen Neugestaltung Deutschlands. Die Souveränität der einzelnen Staaten tastet er nicht an (vgl. Thibaut 1840c [1814]: 39 [7ff.]). Er zielt allein auf das bürgerliche Recht, das er jenseits der verfassungspolitischen Frage verortet. Konkret schlägt Thibaut vor, ein solches Nationalgesetzbuch kollegial mit Vertretern aus den einzelnen Ländern nach Vernunftmaßstäben auszuhandeln. Das Kollegium sollte dabei aus der geistigen und moralischen Elite seitens der Rechtskundigen bestehen (vgl. insbesondere Thibaut 1838: 397ff.) Das bedeutet, dass das Volk in Thibauts Augen kein politischer Akteur im Gesetzgebungsprozess ist (vgl. Rückert 1984: 163f.) - Mitentscheidungsrechte von Nicht-Juristen lehnt er explizit ab (vgl. Thibaut 1817: 405f.).

74 Die Vermischung der Frage der Kodifikation mit der wissenschaftlichen Behandlung des Rechts beschreibt er später in seiner Kritik der Historischen Rechtsschule als Unsinn (vgl. Thibaut 1838: 402).

75 Es ist umstritten, wie Thibaut mit seinen Vorschlägen politisch einzuordnen ist. Zumeist wird er - mit entsprechenden Spezifikationen - dem liberalen Lager zugeordnet (vgl. zu einer ausführlichen Diskussion der verschiedenen Positionen sowie der Einordnung diesbezüglich Rückert 1984: 168ff.; D. Kaufmann 2014; s.a. Wilhelm 1958: 25ff.; Wieacker 1996: 390f). 
me. Er weiß, wie der deutsche ,Volksgeist' zu charakterisieren ist: Die Deutschen sind ein „edles, kräftiges, hochherziges Volk“ (ebd.: 41 [11]), dabei traditionsbewusst, autoritätshörig und bieder (was als Kompliment gemeint ist, vgl. ebd.: 58 [45]). Für dieses Volk gilt:

Der deutsche Sinn ist immer auf das Feste, Mäßige, Einfache gegangen; auf billige, sittliche, häusliche Verhältnisse; Gleichheit der Geschlechter; wohlwollende, achtungsvolle Behandlung der Weiber, besonders der Mütter und Wittwen; weise und kräftige Einwirkung der Obrigkeit in allen Verhältnissen, wo man ihrer bedarf; Einfachheit der Verpflichtungsarten, aber auch dagegen Sicherheit des Eigenthums und der Hypotheken durch wohlgeordnete, offenkundige Staatsanstalten. (Thibaut 1840c [1814]: 12)

Es handelt sich durchwegs um normative Bestimmungen. Das Volk wird durch bestimmte Werte charakterisiert. Als geistige Gebilde haben diese Werte zwar eine lebensweltliche, da volksspezifische Verankerung und müssen sich - so die seit Montesquieu verbreitete Forderung - nach dem besonderen Geist des Volks, nach Zeit, Ort und Umständen richten. ${ }^{76}$ Sie lassen sich jedoch nicht auf empirischem Weg über materialistische oder quantifizierbare Faktoren ermitteln (vgl. Thibaut 1959 [1814]: 60 [51]). Nach Thibaut kann es nicht darum gehen, ob eine Sitte oder eine Gewohnheit weite Verbreitung hat und von vielen ausgeübt wird. Es komme vielmehr darauf an, ob diese "gerechtfertigt" seien (ebd.: 61 [52]). Das wiederum sei aber eine Frage der Vernunft, d.h. eines Kriteriums, das jenseits des Objekts ,Volk' anzusiedeln ist: „Das Mehrste dabey ist nichts, als reine Vermengung gewöhnlicher Folgen einer Erscheinung mit dem, was nach der Vernunft seyn kann, und seyn sollte.“ (Ebd.: 61 [51f.]) Aus dem Sein folgt bei Thibaut kein Sollen. Recht existiere zwar in Form von historischspezifischen Gesetzbüchern, die Ausdruck eines bestimmten Volksgeistes und daher in ihrer geschichtlichen Eigenart zu verstehen seien. ${ }^{77}$ Was aber legitimerweise als Recht gilt (oder gelten sollte), entziehe sich der empirischen Bestimmung. Die empirisch vorfindlichen Werte (das positive Recht) werden selbst einer empiriefernen vernunftgeleiteten Wertung (ver-

76 Dass der Geist der Gesetze in Sitten, Gewohnheiten, Denkungsart und Volksgeist wurzele, war im 18. Jahrhundert zu einem Gemeinplatz geworden (Würtenberger 1991: 60).

77 Aus diesem Grund verbittet er sich die Bezeichnung als „unhistorische Schule“ durch Savigny (vgl. Thibaut 1838). 
nünftiges Recht) unterzogen. ${ }^{78}$ Das Volk dient letztlich nur als Referenzfolie für die Verwirklichung dieses Rechts, hierin besteht die lebensweltliche Verankerung des vernünftigen Rechts.

Rechtswissenschaft wird in dieser Perspektive um des Rechts und der Wahrheit willen betrieben. Dementsprechend stellt sich die Frage, wie das Volk mit seinen gegenwärtigen Bedürfnissen zu bestimmen sei, auch nicht als wissenschaftliches Problem. Anders formuliert: Beim Volk bzw. beim Volksgeist handelt es sich gerade nicht um ein epistemisches Ding der Rechtswissenschaft, dem die Anstrengungen des Wissens gelten und das Fragen an die Wissenschaft stellt. Als Objekt der patrimonialen Fürsorge, auf das die Wirkung der Gesetzgebung abzielt, vermag es zwar einige Kriterien der Beurteilung zu liefern: So werden Thibaut Eigenheit versus Fremdheit, Gegenwart versus Vergangenheit bzw. gegenwärtige Bedürfnisse versus veraltete Bestimmungen zu Kriterien der Qualifikation der Gesetzbücher. Aber das juristische Wissensproblem liegt in der Vernunft. Das Volk ist nicht problematisch, wird nicht problematisiert und vermag das Recht auch nur ganz bedingt zu problematisieren - nämlich in der Kriterienwahl der Beurteilung des vorliegenden Rechts aus Vernunftgründen. Das bedeutet jedoch weder die Aufgabe des Universalitätsanspruchs der Vernunft, noch werden die Techniken und Methoden der Vernunftbeurteilung, und d.h. der Rechtswissenschaft, affiziert.

\section{Die Entdeckung des Volksgeistes im Recht (Friedrich Carl von Savigny)}

Noch im Jahr 1814 veröffentlicht Savigny mit dem Beruf eine Gegenschrift zu Thibauts „Schandschrift“ (Savigny 1927 [1814]: 117), in der er ganz grundlegend seiner Zeit die Fähigkeit zur Kodifikation abspricht. Was er im wissenschaftlichen Feld anhand seiner Arbeit am römischen Recht entwickelte, wird zu einem politischen Argument. ${ }^{79}$ Denn auch Savigny geht

78 Mit Jan Schröder gesprochen schließt Thibaut damit an den seit Mitte des 17. Jahrhunderts gebräuchlichen dualistischen Rechtsbegriff an, demzufolge das Recht auf zwei Quellen beruht: dem positiven und dem natürlich-vernünftigen Recht (vgl. Schröder 2012: 99ff.).

79 Ansätze zur Volksgeistlehre sind schon in Savignys frühen Vorträgen und Notizen zu erkennen (vgl. etwa Savigny 1993b [1802]: 88f.; 1993c [1809]: 139; 1993a [1812]: 182f.), die er in einer geplanten Einleitung für den ersten Band seiner Abhandlung über die Geschichte des Römischen Rechts im Mittelalter veröffentlichen wollte (vgl. Savigny [1814] in Henning 1936: 395f.; Wieacker 1996: 388). Durch Thibauts Intervention sieht er sich aber nach eigenem Bekunden dazu veranlasst, 
es im Beruf um die politische Frage der nationalen Einheit. Und auch er sieht das Übel im gegenwärtigen Zustand, dem es an Rechtssicherheit fehle (vgl. Savigny 1814: 161). ${ }^{80}$ Allerdings verschiebt er das Problem: Die Einheit ist keine Frage der vernünftigen Regierung und der passenden Gesetzgebung. Sie ist auch keine Frage der Gestaltung der politischen $\mathrm{Zu}$ kunft, sondern ein Problem der Erkenntnis der Vergangenheit. Alles hängt für Savigny davon ab, wie man die Entstehung des Rechts erklärt: Es geht um die Rechtsquellenlehre, die darüber bestimmt, wie Recht entsteht, was man im Recht erkennen kann und - darauf aufbauend - wie man es zu handhaben hat.

\section{Die Umdeutung der Kodifikation in ein epistemisches Problem}

\subsection{Die Rechtsentstehung im Volksgeist}

Savigny verwirft rigoros jegliche Ansätze, die meinen, dass das Recht in der Vernunft oder im Staat entsteht. Naturrechtslehre bzw. Vernunftrecht sowie Rechtspositivismus verkennen in seinen Augen den wahren Charakter des Rechts. Denn beiden Richtungen mangele es am (neu erwachten) geschichtlichen Bewusstsein, verloren seien „Sinn und Gefühl für die Größe und Eigenthümlichkeit anderer Zeiten" (Savigny 1814: 4). ${ }^{81}$ In Savignys Augen gibt es keine zeitlosen, ahistorischen Ideen, die über die Vernunft oder das Subjekt hergeleitet werden könnten, und dementsprechend gibt es auch kein vorgegebenes ahistorisches Recht, das es zu entdecken und darzustellen gelte. Trotz seines historisch-kontingenten Charakters entste-

diese Grundgedanken in einer gesonderten Abhandlung zu veröffentlichen (Savigny 1834: ix).

80 Thibaut und Savigny werden in den Rechtswissenschaften, v.a. in der Rechtsgeschichte, zumeist als Antipoden verstanden. Demgegenüber stellt insbesondere Joachim Rückert die Nähe der beiden Rechtswissenschaftler heraus, um hiervon ausgehend die Eigenart des Savigny'schen Denkens zu bestimmen (Rückert 1984: 160ff.).

81 Savigny schreibt sich die „Entdeckung“ des geschichtlichen Moments nicht auf die Fahne. Zum einen nimmt er - wenn auch mit einer gewissen Distanz - Bezug auf die Arbeiten Hugos (vgl. Savigny 1814: 14; 1817: 35f.; 1838); zum anderen stellt er fest: „Geschichtlicher Sinn ist überall erwacht, und neben diesem hat jener bodenlose Hochmuth“ des Rationalismus der Aufklärung „keinen Raum“, und der Rationalismus sei aufgrund der Entwicklung des romantischen Denkens auch „gar nicht mehr herrschender Geist“" (Savigny 1814: 5f.). 
he es aber weder willkürlich noch zufällig. Der historische Blick auf das Recht beweist für Savigny vielmehr,

daß alles Recht auf die Weise entsteht, welche der herrschende, nicht ganz passende Sprachgebrauch als Gewohnheitsrecht bezeichnet, d.h. daß es erst durch Sitte und Volksglaube, dann durch Jurisprudenz erzeugt wird, überall also durch innere, stillwirkende Kräfte, nicht durch die Willkühr eines Gesetzgebers (ebd.: 13f., H.i.O.). ${ }^{82}$

Recht ist ihm zufolge also wesentlich „Gewohnheitsrecht“. Es ist jedoch gerade nicht die Gewohnheit im empirischen Sinne, d.h. die beobachtbare beständige Übung bzw. das wiederholte Handeln, die für Savigny als Entstehungsgrund des Rechts gilt (daher hegt er auch Vorbehalte gegenüber diesem Namen). Eine empirisch festgestellte (und feststellbare) Gewohnheit habe lediglich die Funktion eines Indizes, sie sei Wirkung und nicht Ursache. Sie verweise auf etwas, das als eigentlicher Entstehungsgrund anzusehen sei: das „gemeinsame Bewußtseyn des Volkes“ (ebd.: 11; 1840a: 35) bzw. der „Volksgeist“ (Savigny 1840a: 14) - jener Begriff, den schon Thibaut verwendete, den Savigny aber später von seinem Schüler Puchta übernimmt und der zum Schlagwort für die Historische Rechtsschule wird. ${ }^{83}$ Gegenüber dem Naturrecht und Rechtspositivismus sucht Savigny den Ort der Rechtsentstehung im kollektiven Sein, d.h. in einer vom Staat unabhängigen Sozialsphäre des Volkes. ${ }^{84}$ Das Volk ist also kein Fürsorgeobjekt, auch wenn es Savigny um das Glück der Deutschen geht. Vielmehr wird der Volksgeist zum eigentlichen Ort der Rechtsproduktion, und das

82 Später stellt Savigny klar, dass Gesetz und Wissenschaft Organe dieses auch als „Volksrecht“ zu bezeichnenden Gewohnheitsrechtes seien (vgl. Savigny 1840a: 17); an dieser Anordnung entzündet sich Puchtas Kritik (s.u. IV.1.1).

83 Thibaut verwendet den Begriff des Volksgeistes in einem Zusatz in der zweiten, ebenfalls im Jahr 1814 erschienenen erweiterten Auflage seiner Flugschrift Über die Nothwenigkeit. Er spricht damit also schon vor Savigny und Puchta vom Volksgeist, und das bereits in einer Form, die Savignys Argumentationsgang nahekommt, ohne jedoch die Konsequenzen aus einer lebensweltlichen Verankerung des Rechts zu ziehen (vgl. Thibaut 1840a [1815]: 122). Savigny selbst spricht vom Volksgeist erst im Jahr 1840 im System des heutigen Römischen Rechts. Zur Begriffsund Wortgeschichte des einer Formulierung Montesquieus nachgebildeten und seit Herder und Hegel häufig gebrauchten Terminus ,Volksgeist', der durch die Arbeiten des Savigny-Schülers Puchta zum Schlagwort der Historischen Rechtsschule wurde, vgl. Kantorowicz 1912a; Mecke 2008: 147ff.

$84 \mathrm{Ab}$ dem 17. Jahrhundert wurde das einstmals der Sitte entspringende Gewohnheitsrecht dem Gesetzesrecht angenähert, da es auf einer stillschweigenden Anordnung des Gesetzgebers ruhe (vgl. Schröder 2012: 108ff.). Savigny befreit das Gewohnheitsrecht aus dieser Kopplung an den Souverän. 
Volk ist - wie er später schreibt - „das thätige, persönliche Subject“ der Rechtserzeugung (ebd.: 18).

Das Recht habe dementsprechend - ebenso wie die jeweilige Sprache, Sitte und Verfassung eines Volkes - „kein abgesondertes Daseyn“. Dies sind für Savigny alles nur „einzelne Kräfte und Thätigkeiten des einen Volkes“ (Savigny 1814: 8). Dabei engt er diesen Gegenstand auf eine geistige Tradition ein. Im Ganzen werden die für eine soziale Gesamtheit typischen Bewusstseinsstrukturen be- bzw. festgeschrieben: Das ,Kollektivgefühl', das ,gemeinsame Bewusstsein` bzw. der ,Volksgeist' bezeichnen den geistigen Zustand dieser Kollektiveinheit. Der alles bestimmende Totalitätszusammenhang wird als eine kulturelle Wertegemeinschaft gefasst, die Savigny als ein homogenes Gebilde darstellt, in dem es um die Präsenz typischer und damit typisierender Normen geht. Savigny hat also weder die politische, die wirtschaftliche oder die gesellschaftsstrukturelle Realität im Blick noch die Konflikthaftigkeit und Kontingenz sozialer Verhältnisse, sondern die durch gemeinsame Bildung verbundene geistige und kulturelle Gemeinschaft. Die Verbindung bzw. Verbundenheit stellt sich über die gemeinsamen Werte her. Insofern ist der Volksgeist ein genuin normgeprägtes Objekt, und das im normativen Sinne.

Wie so viele andere Denker seiner Zeit betrachtet Savigny das Recht folglich als Teil der Gesamtkultur (vgl. Kantorowicz 1912a). Und wie so viele Denker seiner Zeit gibt er dem Volkgeist dabei eine konkrete Form: Er sei ein Organismus, und zwar ein „Organismus höherer Art“ (Savigny 1850a [1815]: 131).

\subsection{Organologische Volksgeistlehre}

Durch die Bestimmung als Organismus wird der Volksgeist verobjektiviert und mit gewissen Eigenschaften versehen. Ein Organismus besteht aus vielen Teilen, den Zellen und Organen, die unterschiedliche Funktionen und Fähigkeiten haben. Zugleich ist jedoch auch gewährleistet, dass es sich um eine Einheit handelt. So gilt für Savigny: Ein Volk ist eine „natürliche Einheit" (Savigny 1840a: 20), deren Ganzes mehr ist als die Summe ihrer Teile. Das Volk ist eine selbstständige Einheit, ein eigenständiges Objekt, dessen Teile immer schon in einem organischen Zusammenhang miteinander stehen. Dies gilt in Bezug auf das Individuum, denn für Savigny „giebt es kein vollkommen einzelnes und abgesondertes menschliches Daseyn", wie er im Jahr 1815 schreibt: „vielmehr, was als einzeln angesehen werden kann, ist, von einer anderen Seite betrachtet, Glied eines höheren Ganzen“ (Savigny $1815 \mathrm{c}$ : 3 ). Es trifft aber ebenso auf die Wesensbestimmung des 
Rechts als Teil einer umfassenden Gesamtkultur zu: Savigny geht von einem „organische[n] Zusammenhang des Rechts mit dem Wesen und Charakter des Volkes“ aus (Savigny 1814: 11). Die einzelnen Teile - z.B. Individuum oder Recht - erhalten ihren Sinn erst dadurch, dass sie auf das übergeordnete Einheitsprinzip des selbständigen Organismus ,Volk` bezogen sind.

Der „organische Zusammenhang“ - das betont Savigny immer wieder ist vorgegeben und notwendig. Das Volk sei ein Naturgegenstand und unterliege als natürlicher Organismus in seiner Entstehung nicht menschlichen Konstruktionsprinzipien. Daher werde das Recht vom ,natürlichen Leben selbst hervorgebracht, und nicht durch Gesetzgeber oder Vernunftüberlegungen. ${ }^{85}$ Es entstehe „auf organische Weise, ohne eigentliche Willkühr und Absicht" (Savigny 1814: 12). Daher sei es seinem Wesen nach „ganz eigenthümlich und nothwendig“ gegeben, jede „zufällige und willkührliche Entstehung" schließt Savigny aus (ebd.: 48, 8). Und da es dieses positiv vorgegebene Dasein hat, nennt Savigny es später auch „positives Recht“ (Savigny 1840a: 14). ${ }^{86}$

Die Naturalisierung des Rechts im Organismusgedanken führt jedoch letztlich zu dessen Historisierung. ${ }^{87}$ Als lebendiger Naturgegenstand unterliege der Organismus ,Volk' zugleich einer Entwicklung - und mit ihm das Recht: „Das Recht wächst also mit dem Volke fort, bildet sich aus mit diesem, und stirbt endlich ab, so wie das Volk seine Eigenthümlichkeit verliert." (Savigny 1814: 11) Es befinde sich in keinem Augenblick im Zu-

85 Das gilt ebenso für die Vergangenheit: Auch dort verneint Savigny die Rechtserzeugung durch gesetzgeberische Interventionen (vgl. Savigny $1815 \mathrm{c}$ : 3f.). Insofern ist das Volk, frei ${ }^{6}$ von solchen Einflüssen, und diese Freiheit wird zum Rechtsentstehungsgrund. Das hat nichts mit der Frage der Willensfreiheit im Privatrecht als Grundlage der Privatautonomie des Einzelnen zu tun (vgl. hierzu Haferkamp 2008; Hofer 2001).

86 Damit setzt Savigny an die Stelle des dualistischen Rechtsbegriffs der Aufklärung, der den gesetzgeberischen Willen sowie die Natur als zwei eigenständige Rechtsquellen behandelte, einen einheitlichen. Jegliches Recht ist im Volksgeistmodell positiv vorgegebenes Recht, in seiner Diktion also „positives Recht“.

87 Schon Ernst Troeltsch wies darauf hin, dass der Organismusbegriff der Historischen Rechtsschule, der einen historischen Gegenstand bezeichnet, nicht mit der biologisch-empirischen Organologie bei Spencer und Comte zu verwechseln sei (vgl. Troeltsch 1922a: 280f.; zum Organismusbegriff aus rechtshistorischer Perspektive vgl. Böckenförde 1978; Coing 1973). Später wird gerade an der Historisierung des Rechts in der Historischen Rechtsschule der Vorwurf des Historismus ansetzen (vgl. Kantorowicz 1912b). 
stand eines absoluten Stillstandes. ${ }^{88}$ Daher sei es wie das Volk eine historische Kategorie, denn es folge der „naturgemäße[n]“ bzw. „organische[n] Entwicklung" des Volkes (ebd.: 4, 32). Und wie die Organismen in der Natur unterliege die Entwicklung bestimmten organischen Gesetzen, die vorgegeben seien und mit „innerer Nothwendigkeit“ (ebd.: 11) bestünden.

Mit der Historisierung durch Naturalisierung geht es um die Verhältnisbestimmung von Vergangenheit und Gegenwart, von Werden und Sein (Savigny 1815c: 2f.). Savigny fundiert dabei den organischen Entwicklungsgedanken in der Idee einer harmonisch verlaufenden Kontinuität: Die Vergangenheit sei in der Gegenwart präsent, die immanente Gesetzmäßigkeit der geschichtlichen Entwicklung eines Volkes erlaube nur ein Fortschreiten in „unauflöslicher Gemeinschaft mit der ganzen Vergangenheit" (Savigny 1815c: 3; vgl. auch 1840a: 20). Anders formuliert: Die Vergangenheit als Tradition ist hier eine Form, in der die Gegenwart sich versichert, was ihr gegeben und was ihr nicht verfügbar ist (vgl. Luhmann 2006: 960). Daher gilt für Savigny: Der historisch überlieferte Rechtsstoff ist mit einer inneren Notwendigkeit der Gegenwart gegeben - oder wie er im Jahr 1815 schreibt:

Die geschichtliche Schule nimmt an, der Stoff des Rechts sey durch die gesammte Vergangenheit der Nation gegeben, doch nicht durch Willkühr, so daß er zufällig dieser oder ein anderer seyn könnte, sondern aus dem innersten Wesen der Nation selbst und ihrer Geschichte hervorgegangen. (Savigny 1815c: 6)

Daher müsse man versuchen,

jeden gegebenen Stoff bis zu seiner Wurzel zu verfolgen, und so sein organisches Princip zu entdecken, wodurch sich von selbst das, was noch Leben hat, von demjenigen absondern muß, was schon abgestorben ist, und nur noch der Geschichte angehört (Savigny 1814: 117f.).

Das „organische Princip“ findet man also nur über die Hinwendung zur Vergangenheit, und mit diesem rückwärts gewendeten Blick lassen sich Traditionslinien als Beweis für die Lebendigkeit und Notwendigkeit bestimmter Elemente des Volksgeistes im Recht rekonstruieren. Die Gegenwart ist sozusagen nur das äußere Erscheinungsbild einer inneren Wahr-

88 Später schreibt Savigny: „Denn wie in dem Leben des einzelnen Menschen kein Augenblick eines vollkommnen Stillstandes wahrgenommen wird, sondern stete organische Entwicklung, so verhält es sich auch in dem Leben der Völker, und in jedem einzelnen Element, woraus dieses Gesammtleben besteht“ (Savigny 1840a: 16f.; s.a. 1817: 4). 
heit, die über die historische Untersuchung ermittelt werden muss. ${ }^{89}$ Denn nur in der Vergangenheit finde man die Wahrheit eines Zustandes begründet (vgl. ebd.: 114). Diese zeigt sich aber nicht über die schlichte historische Faktizität. Der organische Gedanke ermöglicht nach Savigny vielmehr, das noch heute Lebendige von bereits Abgestorbenem, das Notwendige von Unnötigem, das aus „wahrhaft praktische[m] Bedürfniß“ Entstandene von dumpfen und unkundigen Interventionen $\mathrm{zu}$ trennen (ebd.: 119). Es gilt: Rückkehr zu den Wurzeln, um daraus über und für die Gegenwart zu lernen und zu einem Subjekt des Fortschritts zu werden.

Der Raum der Geschichte verengt sich damit auf Kontinuität, Tradition und Verwurzelung, die Gegenwart verliert ihren Eigenwert. Savigny behauptet damit eine „Unabhängigkeit des Rechts von dem Leben der gegenwärtigen Volksglieder" (Savigny 1840a: 20). Die aktuellen gesellschaftlichen und sozialen Zustände bilden keine legitime Grundlage zur Beurteilung des Rechts. Nur das historisch gewachsene Recht kann Gültigkeit beanspruchen..$^{90}$ Geschichte wird so als Beweisprinzip eingeführt, die Erkenntnis von Historischem wird zur Erkenntnis des notwendig vorgegebenen und damit gegenwärtig ,wahren' Rechts, wie es dem organischen Volksgeist entspringt (vgl. Rückert 1993: 74). Das (Privat-)Recht erscheint derart als Ausfluss einer unpolitischen, vorgegebenen und durch geschichtlich bewiesene Notwendigkeiten bestimmten Sozialsphäre.

\subsection{Von der politischen zur epistemischen Frage}

Über diese geschichtlich eingebettete Rechtsentstehungslehre erfährt die Frage nach der Notwendigkeit einer nationalen Gesetzgebung eine folgenreiche Umdeutung. Denn Savigny entzieht das dem Volksgeist entsprungene Recht der politischen Verfügbarkeit (vgl. Savigny 1814: 131; 1817: 47ff., 1840a: 14). Recht entstehe im Volk, und nicht durch staatliche Gesetzgebung. Der Staat sei lediglich eine Objektivierung des Volksgeistes, die „leibliche Gestalt der geistigen Volksgemeinschaft“ (Savigny 1840a: 22), in

89 So schreibt Savigny im Jahr 1840: Die Historische Rechtsschule „legt nur darauf das höchste Gewicht, daß der lebendige Zusammenhang erkannt werde, welcher die Gegenwart an die Vergangenheit knüpft, und ohne dessen Kenntniß wir von dem Rechtszustand der Gegenwart nur die äußere Erscheinung wahrnehmen, nicht das innere Wesen begreifen" (Savigny 1840a: XV).

90 Nicht nur Kontingenz, sondern insbesondere das Ereignis, der Bruch und jegliche Idee des radikalen Wandels werden damit aus dem geschichtlichen Denken ausgeschlossen. 
der ihr eine äußere, durch Grenzen klar definierte Form gegeben werde. Er sei dementsprechend dem Volk nachgelagert, nur seine „organische[] Gestalt" oder „organische Erscheinung“ (ebd.: 28, 22) bzw. nur eines seiner Organe.

Nicht nur zwischen Volksorganismus und Staat als Organ besteht nach Savigny ein organischer Zusammenhang, sondern ebenso zwischen Recht und Staat. ${ }^{91}$ Denn obwohl Recht nicht durch Gesetzgebung hervorgebracht wird, bestreitet er keinesfalls den Einfluss des Staates auf das (Privat-)Recht. Dieses erhalte im Staat „durch Aufstellung des Richteramtes, Leben und Wirklichkeit“ (ebd.: 23), ja könne nur durch den Staat in seinem Bestand und seiner Befolgung gesichert werden. Allerdings komme der Gesetzgebung legitimerweise gerade nicht die Aufgabe zu, neues Recht $\mathrm{zu}$ erlassen, sondern nur über bestehende Kontroversen zu entscheiden bzw. die alten Gewohnheiten zu verzeichnen (Savigny 1814: 131; vgl. auch 1817: 47ff.).

Damit bewirkt Savignys Argumentation die Rechtfertigung der bestehenden Rechtsordnung und verordnet rechtspolitische Passivität. Sie nimmt dem kritischen Denken ebenso wie den revolutionären Bestrebungen, die auf die Veränderung der gesellschaftlichen Verhältnisse gerichtet sind, jeden Impuls (vgl. Wilhelm 1958: 36ff.).92 Savigny erteilt auf der Ebene der Rechtsquellenlehre, d.h. bei der Frage nach der Entstehung des Rechts, den Ideen einer direkten politischen Einflussnahme im Bereich des Privatrechts durch Gesetzgebung eine Absage. Politische Instrumentalisierung zum Zwecke der Steuerung der Gesellschaft erscheint dann als illegitim - oder in Savignys Worten: als willkürliche Anomalie.

Seine Antwort auf die Frage nach der Notwendigkeit einer nationalen Gesetzgebung lautet damit: Recht ist gesellschaftlich gewachsenes Recht. Indem er sich dem Volksgeist zuwendet, erscheint das politische Problem

91 Savigny parallelisiert Recht und Staat so weit, dass er im Staat „die höchste Stufe der Rechtserzeugung“ erkennt (Savigny 1840a: 22; vgl. auch 1840b: 311). Der organische Zusammenhang zeigt sich in der Notwendigkeit der Einrichtung des Staates: „Denn in ihm zuerst erhält das Volk wahre Persönlichkeit, also die Fähigkeit zu handeln." (Savigny 1840a: 23) Ein Volk erscheint notwendigerweise in der Form des Staates. Eine zeitliche Priorität besteht nicht. Nichtsdestotrotz geht das Volk in kausaler Hinsicht dem Staat voraus bzw. ist ihm übergeordnet. Zusammengefasst gilt, „daß der Staat ursprünglich und naturgemäß in einem Volk, durch das Volk, und für das Volk entsteht" (ebd.: 29, H.i.O.).

92 Das Paradox der Doppelrolle des Staates, sowohl das Subjekt als auch das Objekt der Gesetzgebung zu sein, wird im Bereich des Privatrechts durch die Verlagerung der Rechtsentstehung in ein jenseits des Staates liegendes Kollektiv entschärft. 
im Kodifikationsstreit durch das gemeine römische Recht als bereits gelöst. Mit Blick auf die nationale Einheit ist für ihn eine Gesamtkodifikation nicht notwendig. Das deutsche Volk sei keine mittels eines gemeinsamen Gesetzbuches hervorzubringende Einheit, da es als Organismus immer schon eine Einheit ist. Diese Einheit, die ihren Ausdruck im Recht findet, brauche nicht künstlich durch neue Kodifikationen hergestellt zu werden, da sie im römischen Recht schon verwirklicht sei (vgl. Baldus 1995: 59ff.). Denn im Zustand der Rechtszersplitterung in Deutschland, den ja auch Thibaut so deutlich angeklagt hatte, gilt das römische Recht im Gegensatz zu den räumliche begrenzten Rechten der Länder als das ,gemeine $e^{6}$ d.h. als das allgemeine respektive allgemeingültige Recht. In diesem Faktum sieht Savigny die nationale Einheit gewährleistet: „große Mannichfaltigkeit und Eigenthümlichkeit im einzelnen, aber als Grundlage überall das gemeine Recht, welches alle Deutschen Volksstämme stets an ihre unauflösliche Einheit erinnerte" (Savigny 1814: 43). ${ }^{93}$

Das eigentliche Problem liegt in der Frage der Erkennbarkeit dieser Einheit, also in einem politisch entlasteten Bereich. Daher handelt es sich für Savigny bei der Debatte über die Notwendigkeit der Kodifikation nicht um einen politischen, sondern um einen „wissenschaftlichen Streit“ (Savigny 1817: 1). Zur Disposition steht die Art und Weise der wissenschaftlichen Erkenntnis eines Rechts, das dem Volksgeist entspringt. Die Rechtsentstehungslehre problematisiert Recht unter dem Blickwinkel seiner Erkennbarkeit - eine Problematisierungsweise, die sich von der Diskussion um eine Gesamtkodifikation seiner genuin politischen Dringlichkeit (urgence) entledigt. Wenn es angesichts der Volksgeistlehre eine Dringlichkeit gibt, dann betrifft sie die Wissenschaft.

\section{Epistemische Folgen I: Die Rechtstheorie der Volksgeistlehre}

Indem Savigny das Recht vergesellschaftet, da er die Rechtsentstehung in der unabhängigen Sozialsphäre des Volksgeistes verortet, wird dieser Volksgeist zum Gegenstand für die Rechtswissenschaft. Er wird dabei

93 Insofern gilt Savigny das römische Recht auch nicht als ,fremd', wie es durch Thibaut bzw. generell in dieser Zeit oftmals angegriffen wurde, da in seiner Perspektive die Rezeption niemals „ohne innere Nothwendigkeit“ geschehen wäre und daher selbst dem Volksgeist entspringe (Savigny 1814: 37; s.a. 1840a: 4f.). Savigny konnte aber nicht verhindern, dass auch in der Historischen Rechtsschule, namentlich bei den Germanisten, das römische Recht später als „fremd“ bestimmt wurde (vgl. $\$ 2 . I I I .2 .1)$. 
nicht nur als lebendiger Organismus verobjektiviert, der damit spezifische Eigenschaften und Entwicklungsgesetze aufweist. Vielmehr wird er bei Savigny zu einem epistemischen Ding, das die Rechtswissenschaft hinsichtlich ihres Gegenstandes, ihres methodischen Vorgehens und ihrer Stellung in der Gesellschaft zu bestimmen vermag. Damit löst Savigny auf der Ebene der Rechtstheorie eine Reihe von Problemen, die sich um das Verhältnis von Recht, Macht und Wissenschaft drehen und zur Autonomisierung des Rechts und der Rechtswissenschaft beitragen. ${ }^{94}$

\subsection{Rechtswissenschaft als „Wissenschaft der Wirklichkeit“}

Das Volksgeistmodell bestimmt den grundlegenden Wissenschaftscharakter der Jurisprudenz: Der organisch-natürliche Entstehungszusammenhang beansprucht den Status von Objektivität, Wirklichkeit und Wahrheit für sich. Darüber wird die Rechtskunde der Wahrheit verpflichtet. Denn was aufgrund des Rechts sein soll, die normative Seite des Rechts, ist für Savigny primär eine Tatsachenfrage. Werte erscheinen als Wahres im Wirklichen (Rückert 1984: 381). Daher liegt das Hauptproblem nicht in der Frage der vernünftigen Wertung, sondern darin, das ,positive Recht' richtig zu erkennen..$^{95}$ Rechtswissenschaft ist Wissenschaft der Wirklichkeit, und Recht wird unter dem Blickwinkel seiner wissenschaftlichen Erkennbarkeit problematisiert.

\subsection{Die Reinigung des Rechtsbegriffs}

Mit seiner Rechtsentstehungslehre wendet sich Savigny gegen die im Kodifikationsgedanken enthaltene drohende Politisierung und Instrumentali-

94 Der Terminus Rechtstheorie wird in der Jurisprudenz zumeist erst für die Ausdifferenzierung einer eigenen Subdisziplin der Rechtswissenschaft v.a. durch den Jhering-Schüler Adolf Merkel Ende des 19. Jahrhunderts verwendet (vgl. hierzu Brockmöller 1997). Vorliegend wird der Terminus jedoch ganz untechnisch im Sinne von theoretischen Annahmen über das Recht (Definition, Entstehung, Funktion, Wirkung etc.) verwendet.

95 Eine solche Problematisierung des Rechts erscheint zu dieser Zeit nicht nur aufgrund des herrschenden Rechtspluralismus plausibel, der zu der Frage führt, welches Recht im konkreten Fall überhaupt anzuwenden sei, sondern ebenso aufgrund des Zustandes der Rechtsmassen selbst, da etwa - wie schon Thibaut bemerkt - das römische Recht nicht als Gesetzbuch existiert, sondern nur in Form von Kompilationen, Fragmenten, Fallsammlungen etc. 
sierung des Rechts. Denn wenn das Recht als gesetzgeberisch gestaltbar angesehen wird, lässt es sich als Mittel der gesellschaftlichen Steuerung und damit als Instrument der politischen Ideen verstehen. Savigny bestreitet eine solche Verfügbarkeit des Rechts - was bei ihm verbunden ist mit einem schneidenden Contra gegen Revolution, Aufklärung, Liberalismus, Republikanismus, Demokratie, Kommunismus sowie der Bauern- und Judenemanzipation (vgl. Klenner 1991: 3; Rückert 1984: 208ff.; Wilhelm 1958: 39 m.N.). Das Volksgeistmodell wirkt zudem auf einer ganz substantiellen Ebene einer Instrumentalisierung des Rechts entgegen. Denn die Rechtsentstehungslehre gilt Savigny zugleich als Wesenslehre des Rechts und ermöglicht es daher, die Substanz des Rechts von politischen und sonstigen Einflüssen zu reinigen (vgl. Haferkamp 2010).

Wie ein Organismus weise das Volk spezifische Charakteristika auf, die den einen Organismus bzw. das eine Volk von einem anderen unterscheiden. Zugleich unterliege der Organismus aber auch allgemeinen Bestimmungen, d.h. Naturgesetzen, die auf alle anwendbar seien. Damit gelte für das Recht: Es gibt nicht nur je individuelles, in seiner Eigentümlichkeit zu bestimmendes „Volksrecht“, sondern ebenso eine „allgemeine Aufgabe alles Rechts“ (Savigny 1840a: 53), das die generelle Funktion des Rechts für ein jedes Volk beschreibt.

Diese allgemeine Aufgabe des Rechts lässt sich nach Savigny auf die sittlichen Bestimmungen der menschlichen Natur zurückführen, die der christlichen Lebensführung entspringen (ebd.: 53f.). Am „reinsten und unmittelbarsten" erscheine die sittliche Natur als "die Anerkennung der überall gleichen sittlichen Würde und Freyheit des Menschen"96 sowie „die Umgebung dieser Freyheit durch Rechtsinstitute“ (ebd.: 55). Der Rechtsbegriff erhält damit eine spezifische normative Bestimmung, ,reines Recht ist auf ein material bestimmtes normatives Ziel ausgerichtet. In Savignys Augen handelt es sich dabei allerdings nicht um eine normative Frage, also danach, was sein soll, sondern um eine faktische Gegebenheit. Denn die „christliche[] Lebensansicht“ leitet sich für ihn aus einer in der organischen Entwicklung hervorgetretenen Notwendigkeit her, die in der prägenden Bedeutung des Christentums in der Weltgeschichte zum Aus-

96 Aufgrund dieser Bestimmung, die ihre rechtstechnische Ausformung im subjektiven Recht findet (s.u.), besteht eine ausufernde und sehr kontrovers geführte Debatte über die Frage, inwieweit Savigny mit seiner Rechtskonzeption an Kant anschließt (vgl. statt vieler Ikadatsu 2002; Nörr 1991: 21ff.; Dedek 2007: $106 \mathrm{f}$. m.w.N.). 
druck komme (ebd.: 53f.). ${ }^{97}$ Die Geschichte hat als organischer Entwicklungszusammenhang diese Tatsache für Savigny bewiesen.

Die normative Zielvorgabe des Rechts sieht Savigny als Faktum an. Damit sondert er das Recht von inhaltlichen Fragen des sittlichen Sollens. Recht und Sittlichkeit begreift er als zwei streng getrennte Sphären:

Durch diese Anerkennung eines allgemeinen Zieles wird keineswegs das Recht in ein weiteres Gebiet aufgelöst und seines selbstständigen Daseyns beraubt: es erscheint vielmehr als ein ganz eigenthümliches Element in der Reihe der Bedingungen jener allgemeinen Aufgabe, in seinem Gebiet herrscht es unumschränkt, und es erhält nur seine höhere Wahrheit durch jene Verknüpfung mit dem Ganzen. (Ebd.: 54)

Das Recht ist Voraussetzung für die Erfüllung der Sittlichkeit, ist aber nicht selbst sittlich. ${ }^{98}$

Anhand dieses ,Faktums' der allgemeinen Aufgabe jeglichen Rechts vermag Savigny eine Qualifikation der verschiedenen Rechtsnormen über die Frage ihrer zugrunde liegenden Wertentscheidungen vorzunehmen. Innen und Außen des Organismus werden voneinander geschieden in innerrechtliche und außerrechtliche Einflüsse. Liegen die Gründe für eine Regelung in der Beachtung der Staatsinteressen, in patrimonialen Fürsorgeüberlegungen oder generell in anderen sittlichen Zwecken als der Freiheit des Menschen (etwa gute Sitten oder sonstige Zweckmäßigkeitserwägungen), so handele es sich um „anomalische“ Rechtsregeln. Diese Wertentscheidungen zählen nicht zum „reinen Rechtsgebiet“, sondern greifen als "fremde Elemente“ in das Recht ein und gehen daher „contra rationem juris" (ebd.: 61).

Hier zeigt sich die Besonderheit des Privatrechts. Denn ausgehend von der Unterscheidung der zugrunde liegende Wertentscheidungen sondert Savigny das Öffentliche Recht vom Privatrecht. Es bleibt ihm zufolge

zwischen beiden Gebieten ein stets bestimmter Gegensatz darin, daß in dem öffentlichen Recht das Ganze als Zweck, der Einzelne als untergeordnet erscheint, anstatt daß in dem Privatrecht der einzelne

97 Zum Einfluss der Erweckungsbewegung auf die Historische Rechtsschule in der ersten Hälfte des 19. Jahrhunderts vgl. Haferkamp 2010.

98 Recht ermöglicht nach Savigny den freien Raum der sittlichen Entfaltung, indem es die Grenzen der Würde und Freiheit jedes Menschen anerkennt und sichert. Was sich innerhalb dieser Grenzen bewegt, ist rechtmäßig (vgl. Savigny 1840a: 332). Die Frage nach der sittlichen oder unsittlichen Ausübung eines Rechts ist demgegenüber keine Rechtsfrage im strengen Sinne (ebd.: 371). 
Mensch für sich Zweck ist, und jedes Rechtsverhältniß sich nur als Mittel auf sein Daseyn oder seine besonderen Zustände bezieht (Savigny 1840a: 23). ${ }^{99}$

Da das Öffentliche Recht auf allgemeine Sittengesetze, gesellschaftspolitische Zwecke bzw. Staatsinteressen und nicht auf die Freiheit des Einzelnen gerichtete sei, erscheine das allgemeine Ziel des Rechts nur „[m]ittelbar und in gemischterer Natur" (ebd.: 55). Es sei letztlich also „anomalisches Recht“ (ebd.: 57).

Das ,reine Recht' findet seinen Ort hingegen im Privatrecht. Privatrechtliche Regelungen entspringen dem ,reinen Rechtsgebiet', wo Savigny (zum größten Teil) die Herrschaft des Rechtsgesetzes vollständig verwirklicht sieht. Keine sittlichen Bestandteile belasten dieses „regelmäßige“ Recht (ebd.). ${ }^{100}$ Überlegungen bzgl. der Staats-, Wirtschafts- und Sozialordnung finden hier ebenso wenig statt wie moralische, sittliche und soziale Erwägungen - eine Reinigung des Rechtsbegriffs, die zudem zu einer Hierarchisierung der Rechtsgebiete führt: Das reine Privatrecht, das uns Aufschluss über das Recht gibt, steht in erkenntnistheoretischer Hinsicht für die Rechtswissenschaften höher als das gemischte, ,unreine` öffentliche Recht.

Allerdings wird damit nicht nur eine entpolitisierte Sphäre des reinen Rechts in Form des Privatrechts freigesetzt. Umgekehrt bleibt auch die staatliche Herrschaft unangetastet. Denn Forderungen nach Freiheit und Gleichheit haben ihren Ort nur im abgesonderten Privatrecht (vgl. Nörr 1991). Es handelt sich also mitnichten um Rechte, die gegen die Staatsmacht gerichtet, sondern nur gegenüber Sachen und anderen gleichgeord-

99 Es fehle zwar nicht an „Übergängen und Verwandtschaften“ (ebd.: 22), aber an der prinzipiellen Unterteilung hält Savigny fest. Er greift also die Unterscheidung des Rechts in ius privatum und ius publicum auf, wie sie sich im 16. und 17. Jahrhundert als Wissenschaftsgebiete aufgespalten hatten und im Vernunftrecht des 18. Jahrhunderts zu zwei allgemeinen Rechtssystemen ausgeformt wurden. Diese Differenz, die im Vernunftrecht jedoch nicht als zwei sich ausschließende Rechtsgebiete konzipiert wurde, wird von Savigny im Geiste seiner Zeit zu einem systematischen Wesensunterschied erhöht. Zu dieser Scheidung vgl. grundlegend Bullinger 1968: 13ff.; Ehrlich 1970; Gagnér 1960; Stolleis 1996.

100 Daher „kann der Reiche den Armen“ im Privatrecht nach Savigny auch legitimerweise „untergehen lassen durch versagte Unterstützung oder harte Ausübung des Schuldrechts“. Allerdings gilt: „[D|ie Hülfe, die dagegen Statt findet, entspringt nicht auf dem Boden des Privatrechts, sondern auf dem des öffentlichen Rechts; sie liegt in den Armenanstalten, wozu allerdings der Reiche beyzutragen gezwungen werden kann“ (Savigny 1840a: 371). 
neten Personen in Anschlag zu bringen sind. ${ }^{101}$ Die Frage nach dem Verhältnis des Individuums zum Staat verlagert sich aufgrund des Gegensatzes der Rechtsgebiete in das Öffentliche Recht. Dadurch löst Savigny sie über den herrschaftlichen Aspekt des öffentlich-rechtlichen Subordinationsverhältnisses (vgl. Savigny 1840a: 371). Der ,freie Mensch' Savignys ist gegenüber der Staatsmacht ein gehorchendes Subjekt, das gegenüber dem Staat keine Rechte in Anschlag bringen kann - nicht zuletzt aufgrund der institutionellen Lage der Zeit. ${ }^{102}$

Zugleich erscheint die Frage, wie selbstständig agierende, entscheidungsfähige Personen ein soziales System konstituieren können, ebenfalls als gelöst. Denn die „Freyheit des Menschen“ erweist sich im Lichte der Volksgeistlehre als sehr begrenzt: Das Individuum mag zwar in Savignys Rechtssystem mit „subjektiven Rechten“ ausgestattet sein (vgl. u. II.3.2). Allerdings ist es immer schon in die vorgegebene holistische Ordnung des Volksgeistes eingebettet: Der Gesamtwille des Volkes ist immer auch der Wille des Einzelnen, das Individuum ist immer schon ein vergesellschaftetes Individuum. Dementsprechend besteht das Unrecht bzw. die Rechtsverletzung für Savigny darin, dass der Einzelne sich vermöge seiner Freiheit, „durch Das was er für sich will, gegen Das auflehnen [kann], was er als Glied des Ganzen denkt und will“ (vgl. Savigny 1840a: 24) Jenseits der Verfolgung privatrechtlicher Einzelinteressen gibt es immer schon eine substantielle Einheit im Volk, die im einzelnen Individuum präsent ist. So-

101 Konsequenterweise scheidet Savigny dann auch das „Urrecht“, d.h. das auf die eigene Person gerichtete Recht, aus seiner Untersuchung aus (vgl. ebd.: $335 \mathrm{ff}$.$) .$ Denn ein solches Urrecht, das dem Menschen aufgrund seines Menschseins Rechte zugesteht, könnte auch gegenüber der Staatsmacht geltend gemacht werden.

102 Seit der zweiten Hälfte des 18. Jahrhunderts waren die Landesherren bestrebt, Gesetzgebung und Verwaltung von der gerichtlichen Kontrolle zu befreien und diese auf Privatverhältnisse von geringem öffentlichen Interesse zu beschränken. Wie Martin Bullinger ausführt, trafen sich dabei „Erwägungen verschiedenen Ursprungs, vom Staatsdenken des fürstlichen Absolutismus bis zum liberalen Reformstreben, [...] in rechtspolitischer Zufallsgemeinschaft mit dem Ziel einer Beschränkung der Gerichtskontrolle zugunsten größerer Bewegungsfreiheit der Gesetzgebung und Verwaltung" (Bullinger 1968: 52f., H.i.O.). Streitigkeiten öffentlich-rechtlicher Natur wurden im Zuge dieser Entwicklung der Gerichtskontrolle entzogen. Die Unterscheidung zwischen Öffentlichem Recht und Privatrecht erlangte damit eine Prozessfunktion, die Streitigkeit auf den Rechtsweg oder den ungesicherten Weg etwa der Verwaltungsbeschwerde zu verweisen ein Umstand, den Robert Mohl im Jahre 1829 als notwendige Voraussetzung zur Erhaltung jeglicher geordneten Verwaltung ansieht (Mohl 1829: 329). 
ziale Ordnung ist nicht nur möglich, sondern im Volksgeist immer schon gegeben.

\subsection{Die Autonomisierung des Rechts und der Rechtswissenschaft}

Das Volksgeistmodell ermöglicht aber nicht nur die Bestimmung der Substanz des Rechts, sondern bedingt zugleich die Art und Weise der rechtswissenschaftlichen Adressierung des Rechts - und das in mehrfacher Hinsicht:

\section{Autonomisierung in der geschichtlichen Entwicklung}

Als lebendiger Naturgegenstand unterliegt das Volk, und mit ihm sein Produkt, das Recht, einer Entwicklung. Die historische Betrachtung dieser Entwicklung zeigt für Savigny eine Ausdifferenzierung des Rechts als eigenständiges Organ:

Am Anfang habe das Recht - wie die Sprache - unmittelbar im Bewusstsein des jeweiligen Volkes gelebt. ${ }^{103}$ Die Regeln des Privatrechts seien selbst Gegenstände des Volksglaubens gewesen. Sitte und Volksglaube, d.h. tatsächliche Übung und Rechtsbewusstsein seien in der "Jugendzeit der Völker" (Savigny 1814: 9) unmittelbar gegeben. Kennzeichnend für die Entwicklung der Völker ist nun nach Savigny ihre zunehmende Ausdifferenzierung, mit Luhmann gesprochen: die funktionale Differenzierung: „Bey steigender Cultur nämlich sondern sich alle Thätigkeiten des Volkes immer mehr, und was sonst gemeinschaftlich betrieben wurde, fällt jetzt einzelnen Ständen anheim.“ (Ebd.: 12) Der Organismus bildet in seiner Entwicklung die verschiedenen Organe heraus, die unterschiedliche Funktionen mit Blick auf das Ganze haben.

Bezogen auf das Recht bedeute das zunächst Ausdifferenzierung eines eigenen Juristenstandes als besonderes „Organ“ des Volkes (Savigny 1840a: 50; s.a. 1817: 4). Dies führe zu einer Verwissenschaftlichung der Behandlung des Rechts, das nun eine technische Seite erhalte: „Das Recht bildet sich nunmehr in der Sprache aus, es nimmt eine wissenschaftliche Rich-

103 Die Frage, wie diese individualisierten Volkstotalitäten entstanden sind, erklärt Savigny für historisch nicht zu beantworten und letztlich auch für irrelevant. Insofern setzt er in seiner Untersuchung an den ersten urkundlichen Zuständen der bereits ausdifferenzierten Volkseinheiten an (vgl. Savigny 1814: 8ff.). 
tung, und wie es vorher im Bewußtseyn des gesammten Volkes lebte, so fällt es jetzt dem Bewußtseyn der Juristen anheim" (Savigny 1814: 12).104 Dies ist Folge des „natürlichen Entwicklungsgang[s] der Völker“ (Savigny 1840a: 45).

Savigny erkennt aber nicht nur eine zunehmende Professionalisierung des Rechts, sondern eine Ausdifferenzierung des Rechts selbst. Es werde zu einem eigenständigen Organ des Volkes, ein selbständiger „Rechtsorganismus" (ebd.: 57, 381), der sich von den anderen Organen absondere und für das Ganze eine spezifische Funktion erfülle. Die Eigenschaften, die dem Volk als Organismus zukommen, werden nun zu Eigenschaften des Rechts: Das Ganze geht den Teilen voraus; dies garantiert Einheit in der Vielfalt, da jedes Teil seinen Sinn erst im Bezug zum Ganzen erhält; schließlich wird das Innen vom Außen, Fremdes wird vom Eigenem unterschieden; und zugleich entfalte sich das Recht wie ein lebendiger Organismus, es entwickelt sich weiter (vgl. Coing 1973: 150). Das Recht als Organ ist also autonom, auch wenn es im organischen Zusammenhang mit dem Ganzen steht. Es organisiert sich fortan selbst. Das Volksgeistmodell liefert der Rechtswissenschaft also einen Gegenstand, der sich als sinnvolles Ganzes darstellt. Damit erfolgt eine Absicherung der Jurisprudenz als eigenständige Wissenschaft, kann sie sich doch über die Definition ihres Gegenstandes von Ansätzen der Kameral-, Policeywissenschaften und Staatslehre, aber auch von der Philosophie abgrenzen. ${ }^{105}$

\section{Die Bestimmung der rechtswissenschaftlichen Methode}

Das Volksgeistmodell als Rechtsentstehungslehre bedingt für Savigny zudem die konkrete Form der Rechtswissenschaft als historisch-systematische. Da das Recht lebendig sei (vgl. Savigny 1814: 33, 34, 146) und die

104 Das Recht hat fortan aufgrund seiner Ausdifferenzierung ein „doppeltes Lebensprincip“, es ist Teil des Volkslebens sowie Teil der Wissenschaft. Ersteres nennt er „das politische Element“, letzteres „das technische Element“ (ebd.: 12).

105 Letztlich werden in der Bestimmung des Rechts als einheitliches Ganzes (Organ) die verschiedenen philosophischen Naturrechtskonzeptionen in ihren diversen Funktionsbestimmungen für die Jurisprudenz Ende des 18., Anfang des 19. Jahrhunderts zurückgedrängt: Naturrecht gilt für Savigny weder subsidiär noch als Lückenfüller; noch sind über Naturrecht , unveräußerliche' Freiheitsrechte herleitbar, die zum Widerstand legitimieren würden; schließlich hat die naturrechtliche Philosophie keine Beratungsfunktion im Rahmen der Gesetzgebung (als "Gesetzgebungswissenschaft"), da ,richtiges Recht' keine Frage der Vernunft, sondern des Volksgeistes ist (vgl. Haferkamp 2008: 199ff. m.w.N.). 
Rechtswissenschaft das „lebende[] Recht“ (Savigny 1840a: 189) zum Gegenstand habe, müsse es in seiner organischen Entwicklung erfasst werden - und d.h. mittels der historischen Methode. Da die Struktureigenschaften des Volks als Organismus jedoch auch für das Recht als selbstständiges Organ gelten, müsse der Rechtsorganismus zugleich mittels der systematischen Methode untersucht werden. Denn der systematische Sinn schreibe vor, ,jeden Begriff und jeden Satz in lebendiger Verbindung und Wechselwirkung mit dem Ganzen anzusehen, d.h. in dem Verhältniß, welches das allein wahre und natürliche ist" (Savigny 1814: 48). Der Wahrheitswert des Entstehungszusammenhangs des Rechts im Volk als übergeordnete Ganzheit wird derart in den Wahrheitswert der Erkenntnis des Rechts selbst überführt. Denn die Erkenntnis des Systems des Rechts macht seinen „organischen Zusammenhang" im Inneren, d.h. das wahre und natürliche Wesen des Rechts, sichtbar. Historische und systematische Methode werden im Volksgeistmodell vereint, ,beweist' doch die historische Betrachtung die Ausdifferenzierung des Rechtsorganismus, der daher systematisch zu erforschen ist (vgl. ebd.). Dabei kann wiederum nur die historische Betrachtung in ihrer Scheidung von Lebendigem und Abgestorbenem zeigen, was wirklich zu diesem System - dem heutigen römischen Recht - gehört. ${ }^{106}$

Aber erst die organische, d.h. systematische Betrachtungsweise ermöglicht in Savignys Augen überhaupt eine wissenschaftliche Behandlung des Rechts im wissenschaftstheoretischen Sinne (vgl. Rückert 1993: 72). Im Trend seiner Zeit gilt: Wer nicht systematisch arbeitet, betreibt keine Wissenschaft. ${ }^{107}$ Für Savigny ist es daher von entscheidender Bedeutung, dass das Recht selbst systematisch ist, in seiner Wortwahl: ein organisches Ganzes bildet. Denn nur in diesem Fall enthalte es „leitende Grundsätze“, von denen ausgehend man den „innern Zusammenhang und die Art der Ver-

106 In Savignys Worten: „Entstehung der Rechtswissenschaft - ihr Charakter nothwendig bestimmt durch die eben beschriebene Entstehung des Rechts - Sie ist ein systematisches Ganze, weil nur dann die innere Einheit erkannt und ausgesprochen wird, welche dem Recht selbst inwohnt - Sie ist Geschichte, weil das Recht selbst in steter Bewegung und Entwicklung existirt, folglich auch nur so begriffen werden kann [...]." (Savigny Einl. Pandecten 1812, fol. 2r (neu 66r), zitiert nach Rückert 1993: 73; zur methodischen Doppelorientierung vgl. insbesondere ebd.: 68ff.).

107 Zum Verwissenschaftlichungsschub um 1800, im Zuge dessen die Jurisprudentia flächendeckend zur "Rechtswissenschaft" wurde, vgl. grundlegend Schröder 1979; zum Zusammenhang des Wissenschaftsbegriffs der Historischen Rechtsschule mit dem Wandel des Wissenschaftsideals um 1800 vgl. Wieacker 1996: 367ff.; Stichweh 1992. 
wandtschaft aller juristischen Begriffe und Sätze zu erkennen“ habe. Genau dieses Vorgehen „ist eigentlich dasjenige, was unsrer Arbeit den wissenschaftlichen Character giebt" (Savigny 1814: 22). Nur dann stelle sich Rechtserkenntnis als systematische Erkenntnis und damit Rechtswissenschaft als systematisch und damit überhaupt als Wissenschaft dar.

Die systematische Einheit ist also kein Formmodell für die Ordnung und Darstellung des Stoffes, sondern die Eigenschaft des Stoffes ,Recht ${ }^{\star}$ selbst (Savigny 1815b: 395; vgl. Baldus 1995: 56). ${ }^{108}$ Indem Recht als Rechtsorganismus, d.h. als autonome Einheit, adressierbar wird, wird die Rechtswissenschaft autonom gesetzt, da sie für ihre wissenschaftliche Arbeit keine außerjuristischen Elemente heranziehen muss. Mit dieser Prämisse behauptet Savigny aber keinesfalls, dass das vorfindliche Recht ohne Lücken, widerspruchsfrei oder nicht mit veralteten und mangelhaften Regelungen durchsetzt sei (vgl. Savigny 1840a: 222ff.). Die Wesensbestimmung des Rechts als Einheit ermöglicht ihm jedoch, in diesen Fällen entsprechende juristische Techniken im Umgang mit Lücken, Widersprüchen und mangelhaften Gesetzen zu entwickeln (ebd.: 263f., 223). Anders formuliert: Die Regeln zur Lückenfüllung produziert der Organismus aus sich selbst heraus (vgl. Baldus 1995: 57). ${ }^{109}$

Das System, und mit ihm das systematische Denken, sei jedoch nichts Starres, Fixierbares, Zeitloses und Unwandelbares. Angesichts des lebendigen "Rechtsorganismus“ müsse die Rechtswissenschaft selbst lebendig sein. Eine Vereinseitigung hinsichtlich der systematischen Seite würde ansonsten den Bezug zum Leben kappen. Daher könne und dürfe Rechtswissenschaft nicht rein deduktiv verfahren. Sie sei vielmehr eine „Kunst“, die die leitenden systematischen Grundsätze in historischer Untersuchung ,herausfühlt' und diese, lebendige Anschauung' in Anbetracht etwa der Entstehung neuer Rechtsverhältnisse fortentwickele (vgl. Savigny 1840a: 211, 16). Savigny wählt also einen bewusst intuitiven Zugang zu einem Recht, das er als Ausfluss des Lebens versteht (vgl. Haferkamp 2010: 94).110 Daher kann und darf die Tätigkeit des Rechtskundigen nicht auf die bloß

108 Hierin liegt der Unterschied zu den naturrechtlichen und philosophischen Ansätzen (vgl. Baldus 1995: 24ff.). Für Savigny gilt es, die dem Recht innewohnende Einheit zu erkennen, und nicht durch die Juristen herstellen zu lassen.

109 Das Volksgeistdenken hat also konkrete rechtsdogmatische und methodische Auswirkungen. Die Rechtswissenschaft wird nicht nur in ihrer Theorie über den Gegenstand sowie in ihrer Bestimmung als Wissenschaft, sondern ebenso in ihrer konkreten Techniken und Praktiken affiziert.

110 Daher bedarf es für Savigny neben der logischen Gesamtschau einer „organischen“, die diesen Lebensbezug verwirklichen soll (vgl. Savigny 1840a: 292; s.u.). 
buchstäbliche, mechanische Anwendung beschränkt werden. Das Rechtssystem muss als dynamisch, anpassungsfähig und damit flexibel bzw. wandelbar verstanden werden. Es ist nach Savigny ein „lebendig waltende[s] und fortschreitende[s] Recht“ (Savigny 1840a: 57), dem eine „wirklich lebendige Rechtswissenschaft“ (Savigny 1814: 147) zu entsprechen hat. Da sich der Volksgeist, und damit sein Produkt, das Recht, immer im Werden befinden, ist das Wissen der Rechtswissenschaften ebenfalls immer ein Wissen im Werden, das sich nicht auf eine logische Tätigkeit reduzieren lässt.

Das Vorbild für eine solche juristische Methode, die letztlich Wirklichkeits- und Wissenschaftsbezug miteinander zu vereinen sucht, sieht Savigny bei den römischen Juristen. Im römischen Recht stoße man auf das ,organische Prinzip', dort erkennt Savigny die weltgeschichtlich höchste juristische Leistung in einer allgemein verbreiteten „Meisterschaft in der juristischen Methode“ (ebd.: 35). Denn der Rechtsstoff sei für die römischen Juristen eine Einheit gewesen, in der sie ausgehend von leitenden Grundsätzen den inneren Zusammenhang und die Art der Verwandtschaft aller juristischen Begriffe und Sätze zu erkennen vermochten. Aus diesem Grund beherrschten die römischen Juristen ihren Stoff in vollendeter Form: „Darum eben hat ihr ganzes Verfahren eine Sicherheit, wie sie sich sonst außer der Mathematik nicht findet, und man kann ohne Uebertreibung sagen, daß sie mit ihren Begriffen rechnen." (Ebd.: 29) Dass sie nichtsdestotrotz die Begriffe und Sätze dabei durch die „lebendigste[] Anschauung" (ebd.: 30 ) und nicht durch logisch-rationalistische Abstraktion gewonnen hätten, habe die römischen Juristen vor der drohenden Gefahr des Realitätsverlusts eines rein deduktiven Verfahren bewahrt. Hierin liege das Geheimnis ihres lebendigen Fortschreitens, ihrer „organischen Entwicklung“, bestimme sich der Charakter der römischen Methode doch durch „das Festhalten am Herkömmlichen, ohne sich durch dasselbe zu binden, wenn es einer neuen, volksmäßig herrschenden Ansicht nicht mehr entsprach" (ebd.: 32).

Nach Savigny muss daher das römische Recht durchdrungen werden, um von ihm zu lernen - nicht um zum vergangenen Zustand zurückzukehren, sondern um „den eigenen Werth desselben in frischer Anschauung gegenwärtig [zu] erhalten“ (ebd.: 117). Damit schließt sich der Kreis: Das römische Recht zeigt als gemeines Recht nicht nur Einheit des deutschen Volkes, sondern liefert zugleich die richtige Methode im Umgang mit dem Recht. Der Rückblick auf die Vergangenheit führt hinsichtlich 
Rechtsmaterie wie Rechtsmethode zum römischen Recht, und von dort aus in die Gegenwart: zum ,heutigen römischen Recht'. ${ }^{611}$

\section{Die rechtserzeugende Kraft der Rechtswissenschaft}

Dieser Weg führt zugleich in die Zukunft. Denn die Tätigkeit der wissenschaftlichen Rechtsfindung wird selbst zu einer Art Rechtserzeugung. In seinem historischen Entwicklungsschema stellt Savigny nicht nur eine Professionalisierung und Ausdifferenzierung des Rechts fest, sondern schreibt den Juristen in dieser Situation eine bestimmte Funktion zu: Wenn das Recht „vorher im Bewußtseyn des gesammten Volkes lebte, so fällt es jetzt dem Bewußtseyn der Juristen anheim“ (Savigny 1814: 12). Damit wird der Rechtswissenschaftler zum „Repräsentanten des Ganzen“ (Savigny 1840a: 46). Die Wissenschaft sei zwar lediglich ein „Organ“ des Volksrechts, im Zuge der funktionalen Differenzierung gehe aber aufgrund des Repräsentationsgedankens die rechtsbildende Kraft des Volkes auf sie über. Diese liege nun in der Rechtswissenschaft selbst und erscheine auch nur dort unmittelbar (vgl. ebd.: 50ff.). Der Jurist wird also selbst rechtserzeugend tätig.

Diese Tätigkeit hat für Savigny zwei Seiten: „eine materielle, indem sich die rechtserzeugende Thätigkeit des Volks großentheils in ihn zurückzieht, und von ihm, als dem Repräsentanten des Ganzen, fortwährend geübt wird“, sowie "eine formelle, rein wissenschaftliche, indem von ihm das Recht überhaupt, wie es auch entstanden seyn möge, in wissenschaftlicher Weise zum Bewußtseyn gebracht und dargestellt wird“ (ebd.: 46). Diese beiden sehr verschiedenen Formen sind für Savigny gleichermaßen „wissenschaftliche[s] Recht" (ebd.: 49). Er setzt sie letztlich in eins, sieht er doch „die wesentliche Identität des Gewohnheitsrecht mit dem wissenschaftlichen Recht" (ebd.: 91). Kurz: Juristenrecht ist Volksrecht. Die Wissenschaft wird damit zur Quelle neuen Rechts, ja sie habe gegenwärtig sogar aufgrund des historischen Entwicklungsschemas einen Vorrang (vgl.

111 Allerdings muss man zur Klarstellung einfügen: Hinsichtlich der Rechtsmaterie interessiert Savigny der Umstand der Einheit, nicht die konkret-materielle Regelung im römischen Recht. Denn da es um das heutige römische Recht geht, kann es immer sein, dass die konkrete Rechtsregelung mittlerweile abgestorben ist - eine Frage, die die historische Forschung zu beantworten versucht. Es geht also nicht um die bedingungslose Rückkehr zum römischen Recht, sondern um die Rückkehr zur römisch-rechtlichen Methode. 
Stichweh 1992: 342). ${ }^{112}$ Damit kann sich die Rechtswissenschaft gegenüber der Gesetzgebung, aber auch gegenüber dem gegenwärtigen Volk absichern: Ihr Stoff ist nicht von ihnen abhängig. Und sie wird aufgewertet: Ihr kommt es zu, über neues Recht zu entscheiden.

Aus diesem Grund ist Savignys Schrift als Erneuerung der Rolle der (Gemein-)Rechtswissenschaft für den Fortgang der Nation zu lesen. Angesichts des von Thibaut so deutlich beklagten Zustands der Rechtszersplitterung in Deutschland kann das rechte Mittel nicht in der Gesetzgebung liegen. Fortschritt der Nation kann nicht über willkürliche Rechtssetzung geschehen, sondern nur über eine gesteigerte Bildung. ${ }^{113}$ Und das Mittel dafür liegt ,in einer organisch fortschreitenden Rechtswissenschaft, die der ganzen Nation gemein seyn kann“" (Savigny 1814: 161; vgl. auch 1817: 45).

\subsection{Recht und Repräsentation}

Savigny vermag über seine Verankerung im Volksgeist das Recht gegenüber Politik und Naturrecht zu reinigen und autonom zu setzen. Gleichzeitig eröffnet sich aber eine neue potentielle Konkurrenzsituation für die Rechtswissenschaft: Wer das Wissen über den Volksgeist hat, kann zu den Fundamenten des Rechts vordringen.

\section{Repräsentation I: Recht als Repräsentation des unsichtbaren Volksgeistes}

Savigny begegnet diesem Problem zum einen mittels einer Strategie der Verdunklung. Auch wenn er den Volksgeist als eine reale, objektiv vorgegebene Sphäre ansieht, die die spezifischen Objekteigenschaften eines Organismus aufweist, engt er diesen Gegenstand auf eine geistige Tradition

112 Savigny verwendet den Ausdruck, Quelle‘ im doppelten Sinne: Einmal als allgemeinen Entstehungsgrund des Rechts - das ist der Volksgeist, und dementsprechend handelt es sich um Volksrecht -, und das andere Mal als konkrete Quelle, in der man das Recht erkennen kann, weil es darin seinen Ausdruck findet. Davon gibt es drei: das Gewohnheitsrecht, das Gesetz sowie, wie eben ausgeführt, das wissenschaftliche Recht (vgl. Savigny 1840a: 34ff.).

113 Damit wird die Hinwendung zum römischen Recht für die Rechtswissenschaft zu einer Notwendigkeit: Die gegenwärtige Rechtswissenschaft erweist sich als grundlegend mangelhaft. Was in einem solchen Zustand geschaffen wird, kann nur schlecht und verderblich sein - für den Code Civil, das Preußische ARL oder das österreichische BGB, die diesem Geist entwachsen sind, hat Savigny nur vernichtende Worte übrig. 
ein. Als solche sei er jedoch mit einem Erkenntnismangel behaftet: Das Volk sei ein „unsichtbare[s] Naturganze[s]“ (Savigny 1840a: 21), in dem „innere, stillwirkende" bzw. „unsichtbare“ Kräfte walteten (Savigny 1814: 14; 1840a: 41). Das "gemeinsame[] Bewußtsein“ eines Kollektivs, sein ,Geist', habe ein unsichtbares Dasein (Savigny 1840a: 35). Kurz: Es handelt sich um einen „unsichtbar arbeitenden Volksgeist“ (ebd.: 56).

Über diese Bestimmung entzieht sich der Volksgeist der direkten wissenschaftlichen Untersuchung. ${ }^{114}$ Er verweist auf ein Wissen im Werden, nicht nur weil das Wissen über einen lebendigen und sich wandelnden Organismus immer im Werden begriffen ist, sondern insbesondere auch, weil man sich ihm aufgrund des Erkenntnismangels nur annähern kann. Die Erkenntnishindernisse bzgl. dieses Objekts bewirken, dass das Wissen nicht auf einer gesicherten Grundlage steht. Das ,Ding' Volksgeist ist unsichtbar, es bleibt notwendigerweise vage und verschwommen. ${ }^{115}$ Es kann letztlich nur durch seine Vergegenständlichungen und Verobjektivierungen sichtbar werden. Daher bedarf es bestimmter „Mittel“, um es zu erkennen (Savigny 1840a: 35). Diese findet Savigny in sich wiederholenden äußeren Handlungen (vgl. ebd.: 35ff.). Solche Institutionalisierungen sind Erscheinungsformen des Volksgeistes, und als solche zu untersuchen. Sie geben dem unsichtbaren Wesen eine Gestalt und Form, d.h. eine äußere Wirklichkeit. In und durch sie wird also das unsichtbare Wesen der Erkenntnis mittelbar zugänglich gemacht. ${ }^{116}$

114 Mit Verweis auf die göttliche Fundierung des Volksorganismus als „Organismus höherer Art, zu dessen Haupt Gott gesetzt hat, und mit welchem er innerlich eins werden soll“ (Savigny 1850a: 131) formuliert Ross: Der Volksgeist wird nicht als Kausalnexus gefasst, sondern als prima causa, als göttlich-anthropologisches Prinzip, das sich nicht erklären und vorhersagen, sondern nur erahnen lässt (vgl. Ross 1929: 158f.).

115 Diese Vagheit bedingt auch die divergierenden Lesarten der Rechtsentstehungslehre, wird doch von jeher darum gestritten, wie der Volksgeist bei Savigny richtigerweise zu verstehen sei: etwa als eigenständige überindividuelle Sphäre (Stammler 1925a: 354); als Glied einer allgemeinen ,kultursoziologischen` Lehre (Rothacker 1923: 420); als ein empirischer Sachverhalt (Jakobs 1983: 27); als metaphysisch und kulturphilosophisch (Böckenförde 1965: 15), oder, wie heutzutage vor allem angenommen wird, als objektiv-idealistisch (Rückert 1984, siehe folgende Fn.).

116 Diesen Denktypus, der in der äußeren Wirklichkeit einen geistigen Zusammenhang nachweist, um durch diesen die Wirklichkeit verständlich zu machen, wird in verschiedenen Spielarten für Savigny von Dilthey, Rothacker, sowie seitens der Rechtswissenschaft prominent von Rückert als „objektiv-idealistisch“ gekennzeichnet (vgl. Rückert 1984). 
An dieser Stelle kommt das Recht ins Spiel: Recht ist ,Gewohnheitsrecht', und es zeigt sich in der Gewohnheit. In demjenigen, was sich als Recht und im Recht tradiert, wird die „ordnende Sitte der Privatverhältnisse“ (Savigny 1817: 21) und damit die gesellschaftliche Ordnung erkennbar. Der Volksgeist erfährt also eine Form der Verobjektivierung in den überlieferten Rechtsverhältnissen, Rechtsfragmenten und Rechtsentscheidungen aus dem reinen Gebiet des Privatrechts, wie es im Corpus iuris civilis enthalten ist. Diese werden zu seinem Erkenntnismittel. ${ }^{117}$ Mehr noch: Weil das Recht ein selbsttätiger Organismus ist, weil es als solches wie der Volksgeist eine systematisch-organische Einheit bildet, wird das Rechtssystem selbst zum Erkenntnismittel des „Volksorganismus“. Das Recht als System ist die wissenschaftlich zugängliche Repräsentation des Volksgeistes.

Der Rechtswissenschaftler hat zwar den Volksgeist im Blick, aber er kann ihn nicht direkt anvisieren. ${ }^{118}$ Konsequenterweise behandelt Savigny den Volksgeist auch nicht als rechtstechnischen Begriff. Vielmehr dient er als prä-rechtliche Voraussetzung der Etablierung eines Binnenraums des ausdifferenzierten Privatrechts. Oder anders formuliert: Gerade weil Savigny das Recht vergesellschaftet, kann er es als einen ausdifferenzierten Bereich, ein eigenständiges ,Organ', konzeptionalisieren. Die Autonomie des Rechts ist zwar relativ zum Ganzen, in das es immer schon eingebettet ist. Auf wissenschaftlicher Ebene handelt es sich aber um eine absolute Autonomie, da man sich dem Produzenten ,Volksgeist' immer nur über das Recht nähern kann.

Diese Annäherung wiederum kann nicht über quantitative Erkenntnisse erfolgen. Denn die Gewohnheit ist Wirkung und nicht Ursache. Sie verweist auf das gemeinsame Bewusstsein als eigentlicher Entstehungsgrund. Bei diesem Geist oder Bewusstsein handelt es sich aber gerade nicht um eine quantifizierbare, der statistischen Messung zugängliche Kategorie; wenn überhaupt kann Statistik in diesem Modell nur Indizfunktion für

117 Das positive Recht weist an sich denselben Erkenntnismangel wie der Volksgeist auf: Als Bewusstseinsform (Rechtsbewusstsein) ist es ebenfalls unsichtbar (vgl. Savigny 1840a: 35), allerdings ist es unmittelbarer über Gewohnheit und die genannten Indizien erkennbar.

118 In Walter Wilhelms Interpretation gibt daher die Volksgeisttheorie des Rechts keine Antwort auf die Frage nach dem Verhältnis von Recht und gesellschaftlicher Wirklichkeit: „Ihre These vom Volksgeist“, der wesentlich mit einem Erkenntnismangel behaftet ist, „,bedeutet den Verzicht auf eine exakte Formulierung dieses Verhältnisses." (Wilhelm 1958: 35) Dem wird hier widersprochen: Das Verhältnis wird - auch im Diskurs der Privatrechtswissenschaften - als ein solches der Repräsentation bestimmt. 
ein qualitatives Moment haben. Daher sind Wissensformen der Kameralistik, der Policeywissenschaften und der Statistik, die Aufschluss über die Bevölkerung geben, für die Rechtswissenschaft nicht anwendbar. Qualitative Wissensformen wie Sprichwörter, Poesie oder Sagen sind dann relevant, wenn sie sich auf das Recht beziehen. Sie können als Indiz für das Bewusstsein des Volkes gelten.

Letztlich gilt: Den potentiellen disziplinären Spielraum (etwa für die Volks- und Völkerkunde, aber letztlich auch die Soziologie), den Savigny eröffnet, indem er den Volksgeist als ein epistemisches Ding fasst, begrenzt er, indem er ihn in den Bereich des Unsichtbaren, Dunklen, nicht Zugänglichen verlagert. Nicht nur dem Rechtswissenschaftler ist der Volksgeist unzugänglich. Eine eigenständige Wissenschaft zur Erforschung des Volksgeistes als kollektiver Totalitätszusammenhang erscheint nicht möglich.

\section{Repräsentation II: Der Privatrechtswissenschaftler als Gesellschaftswissenschaftler}

Zum anderen begegnet Savigny dem Problem eines konkurrierenden Wissens über den Volksgeist mit einer Strategie der Verlagerung. Weil das epistemische Ding, Gesellschaft' nicht zu erkennen ist, ist man auf Hilfsmittel angewiesen. In seinem geschichtlichen Entwicklungsschema des Rechts geht das Rechtsbewusstsein im Zuge der funktionalen Differenzierung auf den Juristenstand über. Dieser repräsentiert den Volksgeist. Und genau deshalb erweist sich das Recht und die Rechtswissenschaft als der bevorzugte Ort, an dem sich dennoch etwas über den an sich nicht zugänglichen Gegenstand äußern lässt. Da die Erkenntnismittel also im Recht liegen, ist die Rechtswissenschaft die eigentliche Gesellschaftswissenschaft. Selbstbeobachtung des Rechts führt zur Erkenntnis der zugrunde liegenden Sozialsphäre, während eine Fremdbeobachtung des Rechts aus einer solchen Perspektive nicht möglich ist.

Überspitzt formuliert gilt also: Der wahre Gesellschaftswissenschaftler ist der Privatrechtswissenschaftler. ${ }^{119}$ Denn letztlich geht es darum, die natürliche und wahre Ordnung des Rechts durch die Wissenschaft zutage zu fördern - und damit zugleich die grundlegende (normative) Ordnung des Volkes. Savigny formuliert also eine Asymmetrie zwischen den möglichen

119 Für die Bestimmung des Rechts als Kulturprodukt gilt: Der wahre Kulturwissenschaftler ist der Rechtswissenschaftler, wie dies etwa der in der Tradition der Historischen Rechtsschule stehende Wilhelm Arnold in seinen Untersuchungen zu Cultur und Rechtsleben statuiert (vgl. Arnold 1865; s.a. 1868). 
Reflexionstheorien, indem er die Möglichkeit einer (gesellschaftstheoretischen) Fremdbeschreibung zugunsten einer juristischen Selbstbeschreibung verneint, da letztere genau diese Funktion zu erfüllen vermag.

Das bedeutet für Savigny aber zugleich: Die Rechtswissenschaft wird zum Motor der Volksentwicklung. Im historischen und systematischen Studium des römischen Rechts soll das klare und lebendige Bewusstsein für das organische Ganze entstehen, die Wiederherstellung des Bezugs zum Volksgeist. ${ }^{120}$ Nicht der Gesetzgeber, sondern der Juristenstand wird damit zum legitimen Subjekt der Volksverbesserung, da er der eigentlich Volkskundige ist. Und der Rechtswissenschaftler, hier Savigny, wird, wenn er die Kenntnisse des Juristenstandes kundtut, als eigentlicher Repräsentant des gemeinsamen Bewusstseins des Volkes zum legitimen Subjekt, diese Annahmen über den Volksgeist in den Diskurs einzubringen. Indem der Volksgeist ins Zentrum des Rechts rückt - auch wenn dieses Zentrum unsichtbar ist -, wird nicht nur der Gegenstand ,Recht ${ }^{`}$ autonom gesetzt, was die Unabhängigkeit der Rechtswissenschaft garantiert, sondern zugleich wird auch das legitime Subjekt der Äußerung über den Volksgeist bestimmt: Es ist der Rechtswissenschaftler, der das Recht zu erkennen vermag und in seiner Tätigkeit weiterbildet und damit das gemeinsame Bewusstsein des Volkes fortschreibt.

Der Volksgeist wird in Savignys Äußerungen in der Auseinandersetzung mit der Kodifikationsfrage systematisch hervorgebracht: Es ist eine normative Sphäre, die die Eigenschaften eines lebenden Organismus aufweist. Gerade auf der Ebene der Rechtstheorie, d.h. der generellen Annahmen über das Recht, zeigt sich, dass der Volksgeist für Savigny eine spezifische Art und Weise darstellt, das Verhältnis von Recht, Macht und Wissenschaft zu konzeptionalisieren: Das Recht entzieht sich als Produkt des Volksgeistes der politischen Macht, und das Problem wird auf der vorgeblich machtneutralen Ebene der Wissenschaft reformuliert. Das Recht wird autonom. Zugleich entfaltet der Volksgeist epistemische Wirkungen, da er im Rahmen der Rechtsquellenlehre nicht nur zur Charakterisierung des Rechts beizutragen vermag, sondern zudem die Frage der Erkenntnis und der Erkennbarkeit des Rechts aufwirft.

120 Hierin liegt die Hoffnung Savignys, denn ist „die Rechtswissenschaft auf die hier beschriebene Weise Gemeingut der Juristen geworden, so haben wir in dem Stand der Juristen wiederum ein Subject für lebendiges Gewohnheitsrecht, also für wahren Fortschritt, gewonnen“ (Savigny 1814: 133). 


\section{Epistemische Folgen II: Dogmatisch-methodische Praktiken der Volksgeistlehre}

Diese Fragen der Erkenntnis und der Erkennbarkeit des Rechts versucht Savigny über seine dogmatischen und methodischen Arbeiten zu lösen. Der Volksgeist zeigt darin nicht nur in der abstrakten Bestimmung der richtigen Herangehensweise seine Wirkung, indem er durch seine Eigenschaften die Rechtswissenschaft zu der charakteristischen Doppelung in die historisch-systematische Methode verpflichtet. Vielmehr wirkt er ebenso auf die Ausformung der konkreten Praktiken auf der genuin rechtswissenschaftlichen Methodenebene ein.

\subsection{Historische Wissenschaftspraktiken}

Die Unsicherheit bei der Frage danach, was als Recht gilt und daher Recht ist, beruht bei Savigny auf der Tatsache, dass der Volksgeist und damit sein Produkt, das Recht, nur über seine Entwicklung von der Vergangenheit bis zur jüngeren Gegenwart zugänglich ist. Daher fordert Savigny, das Recht ausgehend von seinen, Wurzeln' zu studieren, um über die inneren Entwicklungslinien und organischen Entwicklungsgesetze die Genese und konkrete Ausformung des heutigen römischen Rechts im notwendigen Traditionszusammenhang erklärbar zu machen. Es bedarf der historischen Forschung, d.h. des Suchens nach den historischen Quellen. Diese literarische Indizien ermöglichen das Wissen über das ,wahre ${ }^{6}$ Recht. ${ }^{121}$

Für die Frage des Volksgeistes im Recht (sowie die der richtigen rechtswissenschaftlichen Methode) wird das römische Recht zentral gesetzt. Als relevante Wurzel gilt Savigny der Corpus iuris civilis ${ }^{122}$, v.a. seine zentralen Bestandteile: die Pandekten, eine Sammlung an Auszügen aus den Schriften klassischer römischer Juristen, sowie die Lehrbuchordnung der Institutionen. ${ }^{123}$ Er begrenzt den Stoff der historischen Untersuchung auf eine

121 Zur Doppelung der historischen Methode in „absolute“ Methode, die auf die Erkenntnis der Entstehung und damit der Wurzeln des Rechts zielt, und „Literargeschichte“ (Savigny 1815a: III), die die wissenschaftliche Bearbeitung dieses Stoffes untersucht, vgl. Kriechbaum 1999.

122 Die vom oströmischen Kaiser Justinian (528-534) mit Gesetzeskraft versehene Kompilation im corpus iuris umfasst neben den Pandekten und den Institutionen den Codex Justinianus (Sammlung römischer Kaisergesetze) sowie die Novellen Justinians (Gesetzesänderungen und Ergänzungen).

123 Da das römische Recht nur in den Zeiten des römischen Volkes wirklich lebendig ausgeübt wurde (und damit auf den Volksgeist verweist), muss die histo- 
konkrete Wurzel, die sich in der Geschichte bewiesen habe. ${ }^{124}$ Damit schließt er sowohl die Rechtsanwendung als auch breitere historische Arbeiten aus, die politische, gesellschaftliche oder allgemeinhistorische Aspekte einbeziehen. Das impliziert zugleich eine eingeschränkte Bedeutung der neueren rechtswissenschaftlichen Literatur, die Savigny letztlich nur als Interpretation der zugrunde liegenden Quellen begreift (vgl. Coing 1979: 16; Kriechbaum 1999).

Savigny erwarb große Bücherbestände und durchforstete unermüdlich die europäischen Bibliotheken nach antiquarischen Handschriften und seltenen Drucken (vgl. Wieacker 1959: 129f.). Im Grunde forderte er eine vollständige und erschöpfende Lektüre der gesamten Literatur von den Glossatoren bis zur Gegenwart (vgl. Savigny 1840a: XLVIf.). Genau deshalb erweist sich das Recht aber als unsicher: Man weiß nicht, ob man alle Quellen bereits gefunden hat und muss daher weitersuchen. Die historische Forschung als Quellensuche wird so bis zum Anfang der 1840er Jahre zu Savignys Hauptaufgabe, aber auch der Anhänger der Historischen Rechtsschule. ${ }^{125}$

\subsection{Die dogmatisch-methodische Arbeit: Der Volksgeist in den rechtswissenschaftlichen Praktiken und Techniken}

Zugleich verpflichtet der Volksgeistcharakter des Rechts die Rechtswissenschaft zur systematischen Methode, die im Zentrum v.a. seines mehrbändigen Systems des heutigen Römischen Rechts (ab 1840) steht. Mit dem Volksgeistmodell baut Savigny dabei seine Arbeit auf der holistischen Prämisse auf, dass das Recht eine organische Ganzheit darstelle, dessen Struktur sich über die leitenden Grundsätze erkennen lasse, die zugleich den Zusammenhang unter allen Einzelbestimmungen (egal ob Regel oder Ausnahme) vermitteln. Das Zurückführen auf die dem Recht „inwohnende Ein-

rische Arbeit bei der Jurisprudenz der römischen Zeit ansetzen (vgl. Kriechbaum 1999: 54).

124 Da nach Savigny nur der corpus iuris rezipiert worden war, und für ihn die Rezeption den Geltungsgrund des römischen Rechts darstellt, lässt er das römische Recht vor Justinian außer Acht. Nicht berücksichtigt wird aber für das heutige römische Recht auch all das, was aus dem gegenwärtigen deutschen Rechtszustand verschwunden ist (Savigny 1840a: 2) - wie immer man das auch bestimmen mag.

125 Vgl. insbesondere Savignys seit 1815 erschienene mehrbändige Geschichte des römischen Rechts im Mittelalter. 
heit“ (Savigny 1815b: 395) garantiert nicht nur die Erkenntnis des, wahren Rechts', sondern zugleich dessen Wirklichkeitsbezug, handelt es sich doch um die Erkenntnis des organischen Prinzips des Lebens. Damit ist jedoch noch nicht bestimmt, wie dieses Systemerkenntnis vonstattengehen soll, d.h. unter welchen Vorgaben und nach welcher Methode der Systemaufbau analysierbar wird.

\section{Volksgeist und Systemerkenntnis: Induktion - Deduktion - Rekonstruktion}

Savignys Rechtsanalyse basiert auf der Prämisse, dass das Recht ein System bildet. Insofern muss man von einem holistischen Blick auf das Recht sprechen. Für die Ermittlung des Systemaufbaus entscheidet er sich aber für eine andere Herangehensweise, nämlich für einen methodologischen Individualismus: ${ }^{126}$ Ausgangspunkt bildet das „Rechtsverhältniß“, d.h. eine „durch eine Rechtsregel bestimmt[e]" Beziehung zwischen zwei Personen (Savigny 1840a: 333). ${ }^{127}$ Ein Rechtsverhältnis (des Privatrechts) hat demzufolge zwei Seiten: zwischenmenschliche Relation (als materielles, tatsächliches Element) und Rechtsregel (als formelles, geistiges Element, vgl. ebd.). ${ }^{128}$ Die Rechtsregel ist damit bei Savigny immer schon unmittelbar mit den tatsächlichen Verhältnissen verknüpft, den „Lebensverhältnissen“ (ebd.: 48), an denen sie sich gebildet hat und deren Natur sie ausspricht (vgl. Wilhelm 1958: 47). Sie hat für Savigny eine wesentlich „organische Natur“, d.h. sie ist nicht starr, sondern dem Wandel der Lebensverhältnisse bzw. des Rechts in seiner organischen Entwicklung unterworfen.

126 Anders gesagt: Da die holistische Ebene, der Volksgeist in seiner dunklen Werkstätte, wissenschaftlich nicht zugänglich ist, setzt Savigny an den einzelnen intersubjektiven Beziehungen (Rechtsverhältnissen) an. Man muss insofern von einem „methodologischen“ Individualismus sprechen, als die Hinwendung zur Individualebene nur aus methodologischen Gründen erfolgt - und nicht aufgrund der Fundierung des Rechts im Individuum.

127 Zur Entstehungsgeschichte des $₫ 52$ „Wesen der Rechtsverhältnisse“ in Band 1 des Systems des heutigen Römischen Rechts, den Savigny mehrfach grundlegend überarbeitet hatte, vgl. Kiefner 1982.

128 Ein Rechtsverhältnis ist abstrakt gesehen „das auf bestimmte Weise geregelte Zusammenleben mehrerer Menschen“ (Savigny 1840a: 18). Nicht alle zwischenmenschlichen Beziehungen sind für Savigny Rechtsverhältnisse: Er unterscheidet „[m]enschliche Verhältnisse, die ganz“ (z.B. Eigentum), „andere die gar nicht“ (z.B. Freundschaft), "noch andere die nur theilweise dem Rechtsgebiet angehören, oder durch Rechtsregeln beherrscht werden“"(z.B. Ehe; ebd.: 334). 
Die „Bestimmung durch eine Rechtsregel“ besteht nun für Savigny seiner Definition der allgemeinen Aufgabe des Rechts folgend - „darin, daß dem individuellen Willen ein Gebiet angewiesen ist, in welchem er unabhängig von jedem fremden Willen zu herrschen hat" (Savigny 1840a: 333). Durch das Recht wird in der Einrichtung der Lebensverhältnisse die Sphäre einer Handlungsmacht zur Willensbetätigung bestimmt, und das in der rechtstechnischen Form des „subjektiven Rechts“ (vgl. schon Savigny, Hammen 1993 [1824/25]: 13).

Das subjektive Recht ist dem Rechtsverhältnis nachgängig, es stellt „nur eine besondere, durch Abstraction ausgeschiedene Seite“ (Savigny 1840a: 7) desselben dar. Auch wenn es jenseits der Pflicht als Recht oder Befugnis konzipiert wird (vgl. ebd.), ${ }^{129}$ besteht das subjektive Recht nicht aus sich selbst heraus, sondern nur in der rechtlich geregelten interpersonalen Beziehung. Es kommt den Individuen nicht kraft ihres Menschseins zu, sondern wird ihnen in der Regelung der intersubjektiven Beziehungen gewissermaßen verliehen: „Die Regel, wodurch jene Gränze und durch sie

129 Bei Savigny ist erkennbar, dass er das Recht in der Form des subjektiven Rechts von der Pflicht entkoppelt - jener Umstand, der später mit dem Verweis auf den sozialen Charakter des germanischen Rechts in die Kritik gerät (s.u. $\$ 2 . I I I .2 .4)$. Genau in diesem Sinne stellt die Rechtsfigur des subjektiven Rechts für Luhmann einen Bruch mit der Tradition dar (Luhmann 1999b: 364). Denn das römisch-rechtliche ius, wie es sich aufgrund der Rezeption in die westliche Rechtstradition tradierte, bezeichnet bis in die Neuzeit eine Einheit von Rechten und Pflichten und damit „sozial gesehen, konsolidierte Reziprozität“ (Luhmann 1981a: 50). Die dem ius immanente Reziprozität wird in der Entkopplung nun so Luhmann - „zur bloßen Komplementarität verdünnt“, denn: „[D]as soziale Gegenüber wird in den Rechtsanspruch nur noch mit komplementären Erwartungen in Bezug auf die Rechtsausübung eingebaut, aber nicht mehr mit korrespondierenden Rechten und Pflichten“ (ebd.: 72f.). Auch wenn Savigny sein System nicht auf dem subjektiven Recht aufbaut, muss er als einer der zentralen Protagonisten in der Entwicklung dieser Rechtsfigur angesehen werden - nicht nur, weil er das subjektive Recht vom Klagerecht unterschied, daher das materielle Recht vom Prozessrecht trennte und damit die Überwindung des römischrechtlichen actionen-System ermöglichte, sondern insbesondere, weil er ein politisch gereinigtes subjektives Recht entwarf, das erst aufgrund dieser vorgeblichen Neutralität in den Bereich des öffentlichen Rechts überwandern konnte (vgl. Wilhelm 1958). Insofern weist Luhmann zu Recht darauf hin, dass gerade die systematische Entfaltung und begriffliche Artikulation des subjektiven Rechts als „markanteste Figur spezifisch neuzeitlichen Rechtsdenkens“ der Pandektistik zu verdanken sei (Luhmann 1981a: 45; vgl. auch 1999b: 370f.). Allerdings müsste man hinzufügen, dass dies nur unter der Bedingung einer holistischen Fundierung des Rechts im Volksgeist vonstattenging. 
dieser freye Raum bestimmt wird, ist das Recht.“ (ebd.: 332)130 Daher ist das Privatrecht - um in Webers Terminologie zu sprechen - nicht gebietend oder verbietend, sondern wesentlich ein ermächtigendes Recht (Weber 1976 [posthum]: 397f.). Und das subjektive Recht ist nicht der Grundstein des Systemaufbaus. Anders gesagt: Da das Recht in seiner Emergenz nicht auf die Handlungen der Individuen rückführbar ist, sondern dem Volksgeist entspringt, kann es als eine von Gruppen getragene Anschauungsweise nicht von einer Ansammlung isolierter Individuen, rechtstechnisch gefasst als Personen mit subjektiven Rechten, her erklärt werden. ${ }^{131}$ Dementsprechend handelt es sich beim privatrechtlichen Vertrag als Kern des Privatrechts auch nicht um eine Rechtsquelle (vgl. Savigny 1840a: 12), würde damit doch das Recht unter den Willen Einzelner fallen. ${ }^{132}$

Aufgrund des organischen Gedankens ist das Einzelne nie aus sich selbst heraus erkennbar, sondern erst in seinem organischen Zusammenhang mit dem Ganzen. Das gilt auch für die Rechtsverhältnisse. Sie befinden sich nicht in beliebiger Vielfalt und im zufälligen Nebeneinander, sondern schließen sich über innere Verwandtschaft zu höheren systematischen Einheiten bzw. Typen zusammen: Um zum „Wesen der Sache“ vorzudringen und nicht bei der äußeren Erscheinung insbesondere im Gesetz stehen zu

130 Konsequenterweise verneint Savigny, wie bereits erwähnt, das Urrecht, das dem Mensch qua Menschsein zukommt, und nimmt nur die sogenannten „erworbenen Rechte" in den Blick, die den Individuen durch Recht zugesprochen werden (vgl. Savigny 1840a: 335ff.). Allerdings konzentriert sich die kritische Auseinandersetzung mit dem modernen Recht meist auf das subjektive Recht als Kernbestand der liberalen Rechtsidee, wobei Savigny eine zentrale Rolle zugesprochen wird (vgl. jüngst Menke 2015: 29ff.). Verkannt werden m.E. die zugrunde liegenden gesellschaftstheoretischen Annahmen, die mit einem solchen Liberalismusbegriff nicht kompatibel sind (schon gar nicht bei Savigny). Damit bleibt die Frage, wie der Übergang zu einer liberalen Gesellschaftsauffassung vonstattenging - wenn man nicht, wie Menke, bei der Diagnose einer sozusagen „gesellschaftslosen" Naturalisierung eines vorsozialen Individuums stehen bleiben will (siehe hierzu die nächste Fn.).

131 Insofern kann man auch sagen, dass Savigny nicht von fertig vorgegebenen Subjekten ausgeht, sondern von solchen, die in sozialen Konstellationen produziert werden, diese Konstellationen ihrerseits in den Einrichtungen ihrer Lebensverhältnisse, den Rechtsverhältnissen, produzieren und sich dabei reproduzieren bzw. wandeln, so wie sich die Rechtsverhältnisse und mit ihnen die subjektiven Rechte ändern.

132 Den Vertrag begreift Savigny als Unterfall der Willenserklärung (Savigny 1840b: 307). Wesen, Zustandekommen und Wirksamkeit des Vertrags konzipiert er also ausgehend von der Willenserklärung und stellt diese Konzeption als Rechtsgeschäftslehre in einem Allgemeinen Teil dem System voran. 
bleiben, müsse erkannt werden „daß in der That jedes Rechtsverhältniß unter einem entsprechenden Rechtsinstitut, als seinem Typus, steht, und von diesem auf gleiche Weise beherrscht wird, wie das einzelne Rechtsurtheil von der Rechtsregel“" (ebd.: 9f.). Das Rechtsinstitut ist der eigentliche Grundbegriff in Savignys System (vgl. ebd.: 10, 386; Wilhelm 1958: 47f.).

Da dem Einzelnen im Rechtsverhältnis „ein Gebiet unabhängiger Herrschaft des individuellen Willens" gewährt wird, nimmt Savigny die Typenbildung im Rechtsinstitut anhand der Frage vor, auf welchen „Gegenstand" dieser Wille einwirkt (Savigny 1840a: 334). Er unterscheidet dabei die äußere Natur (Sachen) sowie andere Personen als die zwei Hauptgegenstände der rechtlichen Willensherrschaft. ${ }^{133}$ Mittels der Annahmen von "Verwandtschaft", „notwendigem" oder „organischem Zusammenhang“ und „Ergänzungen“ (vgl. ebd.: 398, 339 u.ö.) werden über diese Unterscheidung der Willensrichtung aus den Rechtsverhältnissen die typisierenden Rechtsinstitute und Klassen gewonnen (Sachenrecht, Obligationenrecht und Familienrecht). ${ }^{134}$

Über die Rechtsinstitute gelangt Savigny dann zum System. Denn auch für diese gelte, „daß alle Rechtsinstitute zu einem System verbunden bestehen, und daß sie nur in dem großen Zusammenhang dieses Systems, in welchem wieder dieselbe organische Natur erscheint, vollständig begriffen werden können" (ebd.: 10). ${ }^{135}$ Erst das Vordringen zu den Rechtsinstituten in ihrem organischen Systemzusammenhang ermögliche dann die richtige Anwendung des Rechts: Nur wer das Wesen des in Frage stehenden Rechtsinstituts in seiner Stellung im System erkenne, könne das konkrete Rechtsverhältnis, das vom Institut beherrscht wird, in seiner Wahrheit erfassen und somit die rechtliche Regel im Urteil über den konkreten Le-

133 Savigny schließt die Einwirkung auf die eigene Person als Gegenstand eines möglichen Rechtsverhältnisses aus, stellt dies für ihn doch eine Auswirkung der kritisierten naturrechtlichen Urrechtslehre dar (vgl. Savigny 1840a: 334ff.).

134 Das Sachenrecht (Recht an einer Sache) und das Obligationenrecht (Herrschaft über einzelne Handlungen fremder Personen) bilden zusammen das Vermögensrecht. Das Familienrecht hat demgegenüber einen Sonderstatus, da es das notwendig gesellige Wesen des Menschen regelt. Denn erstens sei die Familie wesentlich nicht-rechtlicher Natur, und zweitens werde nicht wie im Vermögensrecht die Macht der berechtigten Person erweitert, sondern sich auf das „in der Familie erweiterte“ (ebd.: 344), da "unselbständige" Selbst bezogen.

135 Wie Wilhelm feststellt, bedeutet dieses systematische Verfahren „die freie Nachschöpfung der natürlichen Ordnung des Rechts durch die Wissenschaft" (Wilhelm 1958: 60). Savigny baut sein System auf dieser inneren Ordnung des Rechts auf, die er in seiner Analyse herausarbeitet, nämlich: Allgemeiner Teil, Sachenrecht, Obligationen, Familienrecht, Erbrecht (vgl. Savigny 1840a: 389ff.). 
benssachverhalt korrekt anwenden (vgl. ebd.: 9). Die Analyse der Rechtsverhältnisse dient Savigny also dazu, durch gedankliche "Construction" oder „Reconstruction“ (ebd.: 8, 226, 213) auf induktivem Weg die übergeordneten Rechtsinstitute und darüber das System zu ermitteln. Das sei die eigentliche wissenschaftliche Aufgabe, die dann eine richtige Deduktion für den einzelnen Fall erlaube. Für die Frage der Rechtsanwendung, also für das Geschäft der Justiz und der Richterschaft, nimmt daher bei Savigny die Wissenschaft eine führende Rolle ein. ${ }^{136}$

Gegenüber dem Rechtsverhältnis, das „durch die Lebensereignisse“ gegeben wird und daher „unmittelbar in seiner concreten Zusammensetzung und Verwicklung erscheint", verliert das Rechtsinstitut an konkretem Lebensbezug. Daher lassen sich die Rechtsinstitute „zuerst gesondert construiren, und hinterher willkührlich combiniren" (ebd. 10), bevor sie wieder „in das Leben übergehen“ (ebd.: 206). Diese Rückbindung an das Leben erfolgt nach Savigny jedoch nicht nachträglich, sondern ist den Rechtsinstituten wesentlich, da sie organisch verfasst sind: Werde ihre wahre Natur richtig erkannt, ihr lebendiger Charakter und organischer Zusammenhang, so zeige sich das Recht selbst als ein Teil des Lebens, als lebendiger Volksgeist, der in ständiger Entwicklung begriffen sei. Insofern endet Savigny nicht bei der Deduktion aus den durch die Typenbildung im System gewonnenen Rechtsinstituten als letztlich einzig verbleibende wissenschaftliche Methode. Vielmehr muss man sich aufgrund des lebenden Charakters des Rechts, das immer im Werden begriffen ist, immer wieder der Ebene der empirischen Rechtsverhältnisse, die der Rekonstruktion zugrunde liegt, zuwenden. Nur in diesem Übergang der Deduktion zur Ebene der (Re-)Konstruktion kann der „heutige“ Charakter des Rechts zutage treten.

\section{Der methodische Weg: Volksgeist, Auslegung und Sinnverstehen}

Wie aber erkennt man nun die Rechtsverhältnisse und -institute? Wie lässt sich ihre ,Reconstruction' auf methodischem Weg erreichen? Ganz grundlegend geht es Savigny um das richtige Vorgehen, „den Inhalt der Rechtsquellen aufzunehmen" (Savigny 1840a: 206). Und auch in dieser Frage haben die Bestimmungen des Dings ,Volksgeist' konkrete Auswirkungen.

136 Das bedeutet aber noch nicht, dass die richterliche Praxis für die Pandektistik gar keine Rolle spielt (vgl. hierzu die grundlegende Studie von Regina Ogorek 1986; zur richterlichen Praxis der Pandektisten selbst vgl. Haferkamp 2011f). 
Dies betrifft zunächst Erkenntnisziel und generelle Methodenwahl: Da das eigentliche Erkenntnisproblem in der Erfassung des „wirklichen“ bzw. „wahren Rechts“ als „Factum“, und nicht des gesetzgeberischen Willens oder der abstrakten Vernunft liegt, richtet sich das Ziel auf die Ermittlung des gelebten Rechts als „eigentliche[r] Willen des Volks“ (Savigny 1814: 17f.). Und so wie der Volksgeist ein geistiger Zusammenhang ist, kann es sich beim Recht ebenfalls nur um ein gedankliches Produkt handeln. Die Bestimmung des Rechts, d.h. die Bewusstwerdung des Entstandenen, erfolgt daher wesentlich über dessen Interpretation, d.h. über die Auslegung als „Reconstruction des dem Gesetze inwohnenden Gedankens“ (Savigny 1840a: 213).

Auch bestimmt der Volksgeistgedanke die Auslegung als eine verstehende Tätigkeit: Ein rein logisches Verfahren sei ausgeschlossen, würde das doch dem organischen Charakter des Rechts nicht gerecht werden. Daher handele es sich bei der Auslegung notwendig um eine „freye Geistesthätigkeit" (ebd.: 207) und keinesfalls um eine mechanische, die mittels abstrakter Gesetze über Grund und Folge zu einem adäquaten Verständnis ihres Gegenstandes gelangen könne (ebd.: 292). Der Gedanke im Gesetz könne nicht erklärt, sondern nur durch eine einfühlende Rekonstruktion des Sinnzusammenhangs verstanden werden. Auslegung ist für Savigny daher eine „Kunst““ (ebd.: 211), die sich im Grunde nicht durch Regeln mitteilen, erwerben oder erlernen lässt. Dementsprechend habe die Theorie der Auslegung nur einen begrenzten Wert, helfe jedoch dabei den intuitiven $\mathrm{Zu}$ gang zum Volksgeist zu finden (ebd.).

Bei der Annäherung an die methodischen Schritte der Auslegung spielt der Gedanke der organischen Ganzheit im Volksgeistdenken eine bestimmende Rolle. Für die Auslegung - prototypisch am Beispiel der Gesetzesauslegung dargelegt ${ }^{137}$ - gilt nach Savigny: Handelt es sich um ein „gesundes" Gesetz, dessen "Ausdruck“ die Natur des zugrunde liegenden Rechtsverhältnisse als „einen in sich vollendeten Gedanken“ darstellt

137 Auch wenn die Auslegung die allgemeine Methode für alle Rechtsquellen darstellt, geht Savigny bei der Ermittlung des methodischen Vorgehens von der Gesetzesauslegung als (vorgeblich) schwierigstem Fall aus. So schreibt er: „Jedoch bey dem Gewohnheitsrecht und bey dem wissenschaftlichen Recht ist das Geschäft einfacherer Natur. Zwar über das Wesen dieser Arten der Rechtserzeugung kommen sehr einflußreiche Irrthümer vor [...]. Sind aber diese erkannt und vermieden, so ist das Geschäft selbst einer ins Einzelne gehenden Anweisung nicht bedürftig. Anders verhält es sich mit den Gesetzen, bey welchen gerade dieses Geschäft oft eine sehr verwickelte Natur hat.“ (Savigny 1840a: 207). 
(ebd.: 222), ${ }^{138}$ dann kommen vier Elemente der Auslegung zum Tragen. Neben das grammatische, das historische und das logische Element (das vom logischen Verhältnis seiner Bestandteile ausgeht) tritt nun das systematische, das bei der Auslegung auf den inneren, organischen Zusammenhang des Rechts als Einheit abstellt (vgl. ebd.: 213f.). ${ }^{139}$ Mittels dieser vier Elemente wird das Gesetz aus verschiedenen Perspektiven beleuchtet, wobei jede davon Einsichten in den zugrunde liegenden Gedanken liefert. Daher kann die Auslegung nur gelingen, wenn die vier Perspektiven „vereinigt“" werden (ebd.: 215). Es existiert also keine Hierarchie, keine Stufenfolge der Anwendung der Elemente, sondern ein je nach Gesetz variierendes Zusammenspiel der Perspektiven, um den jeweiligen Gedanken zu „verlebendigen“.

Dem organischen Volksgeistgedanken kommt aber v.a. bei der Auslegung „mangelhafter“ Gesetze eine entscheidende Rolle zu. Bei der Interpretation von Gesetzen mit „unbestimmte[m]“ oder „unrichtige[m] Ausdruck“ des Gedankens (ebd.: 222) stelle die Auslegung anhand der systematischen Gesamtschau das wichtigste unter den drei zulässigen Hilfsmitteln dar. Denn sie reduziere die Gefahr einer unzulässigen Grenzüberschreitung zur Rechtsfortbildung gegenüber der Auslegung anhand des "Grund[es] des Gesetzes“ und derjenigen anhand der Frage des „inneren Werths des Resultats“" (vgl. ebd.: 224f.). ${ }^{140}$

Legt man nicht mangelhafte Einzelgesetze, sondern ganze Rechtsquellen aus, so folgt bei Savigny aus dem Systembegriff des Volksgeistdenkens sowohl die Definition des Mangels als auch das Vorgehen zu dessen Behebung. Das Ganze sei mangelhaft, wenn ein Widerspruch im Rechtsganzen vorliege (ebd.: 263). ${ }^{141} \mathrm{Um}$ diesen zu beseitigen, verwendet er ein synthetisierendes Verfahren, das den Widerspruch angesichts des „verborgenen

138 Savigny geht davon aus, dass jedes Gesetz dazu bestimmt sei, „die Natur eines Rechtsverhältnisses festzustellen, also irgend einen Gedanken (sey er einfach oder zusammengesetzt) auszusprechen, wodurch das Daseyn jenes Rechtsverhältnisses gegen Irrthum und Willkühr gesichert werde“ (ebd.: 212).

139 Zur Besonderheit eines solchen „exegetischen“ Ansatzes, der ausgehend von einer allgemeinen Neuorientierung der Hermeneutik auf die generelle Rekonstruktion des Gedankens, welchen das Gesetz aussprechen soll, abstellt, vgl. Schröder 2012: 212ff. Im System kombiniert Savigny diese „Exegese“ mit den traditionellen Themen der juristischen Auslegungslehre (ebd.: 223f.).

140 Daher legt Savigny hier nun doch eine explizite Stufenfolge der Hilfsmittel fest und unterscheidet je nach Auslegungsgegenstand mehr oder weniger bedenkliche Mittel (vgl. Savigny 1840a: 225, 228).

141 Savigny beschäftigt sich hier insbesondere mit den Problemen, die zum einen aus der Existenz konkurrierender Rechtsquellen im Zustand des Rechtspluralis- 
Grunds“ in der systematischen, organischen Einheit als „Schein“ aufzudecken vermag (vgl. ebd.: 273f.). ${ }^{142}$

Die Rechtsquelle als organisches Ganzes sei aber auch dann mangelhaft, wenn das Gesetz nicht vollständig, d.h. lückenhaft ist - wenn z.B. ein neues, unbekanntes Rechtsverhältnis vorliege, aber insbesondere auch dann, wenn in einem bekannten Rechtsinstitut neue Rechtsfragen entstehen. Hier hat der Gedanke des organischen Systems bei Savigny am meisten Gewicht. Denn dann gilt, dass das positive Recht „aus sich selbst ergänzt [wird], indem wir in demselben eine organisch bildende Kraft annehmen“ (ebd.: 290). Technisch wendet Savigny hier das Verfahren der Analogiebildung an, das für ihn aus „der vorausgesetzten inneren Consequenz des Rechts" folgt - und zwar sowohl der logischen als auch der organischen Konsequenz, „die aus der Gesammtanschauung der praktischen Natur der Rechtsverhältnisse und ihrer Urbilder hervorgeht" (ebd.: 292). Über die Analogie werden die Rechtsgrundsätze auf die neuen Fälle und Rechtsfragen übertragbar. Gerade weil dadurch das Recht aus sich selbst heraus weiterentwickelt wird, ist die Analogiebildung bei Savigny ein Abgrenzungskriterium zur ausdehnenden Gesetzesauslegung und zur Rechtsfortbildung. Sie ist eine „Art reiner Auslegung“ (ebd.), d.h. nicht die Juristen schaffen die Regeln, sondern der vorgegebene Gedanke wird in der wissenschaftlichen Behandlung bewusst gemacht und auf neue Fälle angewendet. Zugleich trägt der Jurist als Repräsentant des Volksbewusstseins zur Entwicklung des Rechts bei.

Savigny geht also davon aus, dass das, was wir als Belege des Rechts kennen, sehr wohl widersprüchlich und lückenhaft ist. Unbestimmtheit und Unrichtigkeit sind gängige Formen, in denen uns das Recht in seiner Materialisierung begegnet. Über den Systemgedanken im Volksgeist besitzt das Recht eine eigene Kraft, sich angesichts dieser Unzulänglichkeiten der vorfindlichen Gesetzesmaterie aus sich selbst heraus zu entwickeln. Die Autonomisierung, die die Rechtsentstehungslehre für das Recht bewirkt,

mus folgen, zum anderen aber auch aus dem Zustand des römischen Rechts selbst, da hier Widersprüche ganzer Quellenschichten mit ihren unterschiedlichen Textklassen auftreten. Für das erste Problem zieht er Kollisionsregeln heran (vgl. ebd.: 264ff.), das zweite Problem wird im Folgenden dargestellt.

142 Die Synthese erfolgt systematisch, wenn der Widerspruch über ein Regel-Ausnahme- oder ein Regel-Konkretisierung/Einschränkung-Schema aufgelöst wird; historisch, wenn er über ein Regel-historisches Material-Schema beseitigt wird (wobei die systematisch Auslegung vorgeht); und wenn beides nicht funktioniert, über die Bestimmung derjenigen Stelle, die im Vergleich mit anderen Stellen dem Grundsatz am ehesten entspricht (vgl. ebd.: 274ff.). 
findet hier auch angesichts von Wandel und Neuerungen seinen Ausdruck: Das Recht wird zu einem lebendigen System, das auf Recht rekurriert, um sich - untechnisch gesprochen - weiterzuentwickeln. Und die rechtswissenschaftliche Rechtsentwicklung erlangt den Status nicht einer (rechtspolitischen) Rechtsfortbildung, sondern der Verwirklichung des Rechts. Allerdings weiß Savigny, dass „im Einzelnen die Gränze zwischen reiner Auslegung und eigentlicher Fortbildung des Rechts oft sehr zweifelhaft seyn kann“ (ebd.: 329f.). Über den Begriff der „reinen Auslegung“ versucht er diese Gefahr zu bannen und das Geschäft der Jurisprudenz auf eine reine wissenschaftliche Tätigkeit der Erfassung des „Willen des Volkes“ - auch in seinem Wandel - zu beschränken. Damit wertet Savigny die Rechtswissenschaft auch in der Frage der Rechtsfortbildung gegenüber der Gesetzgebung auf, kommt ersterer doch die Aufgabe zu, sich einer gewandelten Situation anzupassen.

Der Volksgeist wird letztlich, gerade weil er mit einem Erkenntnismangel behaftet ist, mittels epistemischer Praktiken und Techniken der Systembildung und Auslegung geformt und hervorgebracht. Denn nun zeigt sich: Die Frage der Erkennbarkeit des organischen Ganzen ist wesentlich eine Sinnfrage (Hermeneutik). Hierbei wird eine strenge Bindung an eine Interpretation als kausales Erklären bzw. als logisches Verfahren aufgelockert. Die Ermittlung des Sinns tendiert zum ,Verstehen', und es wird ein flexibles, anpassungsfähiges System entworfen - und zwar sowohl auf der Ebene der Bestimmung des systematischen Charakters des Rechts als auch auf der Ebene der Methode, die keine strengen Regeln vorgibt, sondern Hilfsmittel zur Erreichung der systematischen Einheit bereitstellt. Damit erweist sich der Volksgeist selbst als ein normatives Gebilde, das nur über seinen Systemcharakter verstanden werden kann, der wiederum wandelbar und flexibel ist. So wie der Volksgeist die Eigenschaft des Rechts als System garantiert, so plausibilisiert bzw. garantiert vice versa das System des Rechts, dass es sich beim Volksgeist um ein solches lebendes System handelt.

Nicht nur auf der Ebene der Rechtstheorie, sondern insbesondere auf der der Rechtsdogmatik und -methodik spielt die Rechtsentstehungslehre damit eine entscheidende Rolle. Ihre Besonderheit besteht genau in diesem Konnex, den sie zwischen diesen Ebenen herzustellen vermag. Bei Savigny leistet die Vergesellschaftung des Rechts also eine Kongruenz der Ebenen - gerade weil das Recht und die Rechtswissenschaft über die Rechtsentstehungslehre autonom gesetzt werden. 


\section{Der Volksgeist im rechtstheoretischen „Feld der Gegnerschaft“: Die Problematisierung des Rechts angesichts der vorausgesetzten gesellschaftlichen Wirklichkeit}

Savignys Beruf und seine darauf aufbauenden Annahmen über Quelle des Rechts und Form der Rechtswissenschaft entfalten nicht nur in der römisch-rechtlichen Privatrechtswissenschaft, die zunehmend mit der Pandektistik gleichgesetzt wird, eine dominierende Wirkung, sondern gehen schon in den Anfängen darüber hinaus: Mit Gründung der Zeitschrift für geschichtliche Rechtswissenschaft im Jahr 1814 zusammen mit dem Germanisten Karl Friedrich Eichhorn wandert das epistemische Schema der Rechtsentstehungslehre bereits früh in die wissenschaftliche Arbeit am deutschen, einheimischen Recht ein. ${ }^{143}$ Im Verbund des romanistischen mit dem germanistischen Zweig deckt die Historische Rechtsschule damit den größten Teil der existierenden Privatrechtsmaterie ab und wird zur herrschenden Rechtslehre im Privatrecht.

Savignys Thesen finden aber auch jenseits der Rechtswissenschaften eine große Anhängerschaft. Dazu tragen nicht nur die offenkundigen Bezüge zum romantischen Denken bei, sondern ebenso die Anschlussmöglichkeiten und Übertragungen in andere Disziplinen: So sieht der Germanist Jakob Grimm, Schüler und Freund Savignys, wechselseitige Beziehungen und die Verbindungen der drei in der Germanistik vertretenen Wissenschaften Sprachwissenschaft (Philologie), Historie und Recht (Grimm 1966 [1846]). Damit weist er einerseits auf die insbesondere von ihm selbst verwirklichte Verbindung der Historischen Rechtsschule mit der Philologie und der germanistischen Sprachwissenschaft hin, andererseits aber auch auf die Verbindungswege zur Geschichtswissenschaft (hier mit Blick auf die römische Rechtsgeschichte v.a. Niebuhr, Ranke, Mommsen). ${ }^{144}$ Die Nationalökonomen Wilhelm Roscher und Bruno Hildebrand nehmen ebenfalls Bezug auf die Historische Rechtsschule und ihre Vertre-

143 Savigny gesteht dem gewachsenen einheimischen Recht im Vergleich zu den Partikulargesetzgebungen eine große Nähe zum Volksgeist zu: Es könne als Volksrecht gelten - was jedoch nichts an der Meisterschaft der Methode des römischen Rechts ändert. Daher kann nur die Beschäftigung mit dem römischen Recht für Savigny zum Fortschritt führen. Den Germanisten spricht er damit von Anfang an eine untergeordnete wissenschaftliche Position zu.

144 Zur Ausdifferenzierung der Rechtsgeschichte als eigenständige Disziplin ausgehend von der Entwicklung der Historischen Rechtsschule vgl. Wieacker 1996: 416ff. m. zahlr. N. 
ter, um die historische Schule der Nationalökonomie zu begründen (vgl. Roscher 1843: V [Savigny und Eichhorn]; Hildebrand 1848 [Grimm]). ${ }^{145}$

Die Volksgeistlehre veranlasst aber auch zu zahlreichen polemischen Kritiken. Heinrich Heine sieht in seinem ehemaligen Professor Savigny den „elegant geleckten, Süßlichen Troubadour der Pandekten“ (Heine 1913: 382); ${ }^{146}$ dem von Kant beeinflussten Straf- und Zivilrechtler Paul Johann Anselm von Feuerbach kommen die historischen Juristen „wie Leute vor, die die Knochen einer Mumie benagen und die Fasern am Mumienkasten zählen" (Feuerbach 1832, zitiert nach Radbruch 1969: 192); ${ }^{147}$ und für den ehemaligen Savigny-Schüler Karl Marx betreibt die Historische Rechtsschule „historischen Reliquiendienst": Sie „schände“ sämtliche rechtlichen, sittlichen und politischen Heiligtümer „vor den Augen der Vernunft, um sie hinterher zu Ehren zu bringen vor den Augen der Historie, zugleich aber auch, um die historischen Augen zu Ehren zu bringen“ (Marx 1976a [1842]: 79, H.i.O.).

Fast allen grundlegenden Thesen, aber auch den Lösungen der Problemfelder, in die Savigny über das Volksgeistmodell interveniert, wird (nicht nur) von juristischer Seite widersprochen. Doch zeigt sich in all diesen Debatten die Verfestigung einer bestimmten Problematisierungsweise, die im Volksgeistmodell eingelagert ist: Die Problematisierung des Ver-

145 Anfang des 20. Jahrhunderts wird angesichts dieser Entwicklung in den Geisteswissenschaften (wieder) verstärkt nach dem Zusammenhang der Historischen Rechtsschule mit der Historischen Schule des 19. Jahrhunderts gefragt, steht doch in Auseinandersetzung mit Dilthey (und Diltheys Bezügen zur Historischen Rechtsschule) die Frage der Herkunft und der Fundierung der historischen Ausrichtung der Geisteswissenschaft bzw. auch der Soziologie zur Debatte, vgl. Troeltsch 1922b, 1922a; Rothacker 1923. Über den Umweg der Rezeption der Historischen Rechtsschule in der Nationalökonomie - gerade auch durch die Kritik Carl Mengers an einer letztlich gänzlich verfehlten Bezugnahme auf die Historische Rechtsschule (vgl. Menger 1883: 83ff., 200ff.) - erfuhr Savignys Konzeption auch eine Kritik durch Max Weber (s. $\$$ 8.II.2).

146 Für einen Überblick über Heines scharfe Attacken gegen Savigny s. Stiegler 1988.

147 Feuerbach und Savigny werden - einem Diktum Gustavs Radbruchs zufolge zumeist als „Antipoden“ bezeichnet: hier der Vertreter der kantisch fortgebildeten Aufklärung, dort der Romantiker; hier vernunftgeleitete Kodifikation, dort Rückzug auf das geschichtliche Werden (Radbruch 1969: 51; vgl. auch Jakobs 1991: 351, m.w.N.) Eine inhaltliche Divergenz betrifft jedenfalls nicht die persönliche Ebene: Die Briefe von Feuerbach an Savigny vor dem Kodifikationsstreit zeugen nicht nur von seiner Hochachtung (vgl. Feuerbach et al. 1990), sondern weisen v.a. auch Parallelen zur Rechtsentstehungslehre Savignys auf (vgl. Jakobs 1991: 362f.). Manche sehen Feuerbach gar als Vorläufer der Volksgeistthese (etwa Wolf 1963: 575). 
hältnisses des Rechts zur vorausgesetzten gesellschaftlichen Wirklichkeit im „lebenden Recht“ (hierzu 1.). Dieses Problem wird über das Repräsentations-Modell gelöst - auch im Feld der Gegnerschaft, die ihre Kritik anhand der Fragen der Repräsentation, der Missrepräsentation und der Nichtrepräsentierbarkeit der Gesellschaft im Recht formiert (hierzu 2.). Der Gesellschaftsbezug des Rechts stellt sich im Diskurs der Privatrechtswissenschaften bis Mitte des 19. Jahrhunderts damit primär als Repräsentationsproblem dar (3.).

\section{Recht als "lebendes Recht"}

\subsection{Der lebendige Charakter des historisch gewachsenen Rechts}

Insbesondere das Vorgehen der sich selbst als „geschichtlich“ bezeichnenden Rechtswissenschaftsschule fordert Widerspruch heraus. Es wird kritisiert, dass die Protagonisten der Historischen Rechtsschule ihren eigenen Anforderungen an eine wahrhaft geschichtliche Betrachtung des Rechts nicht erfüllen:

Wahre Rechtsgeschichte steht in der Perspektive der Historischen Rechtsschule im Dienst der Gegenwart (vgl. Wilhelm 1958: 28ff.). Indem sie das Gegebene „aufwärts durch alle seine Verwandlungen hindurch bis zu seiner Entstehung aus des Volkes Natur, Schicksal und Bedürfniß“" (Savigny 1850a [1815]: 141) verfolgt, zeigt sie, wie das bestehende Recht zu seiner aktuellen Gestalt gekommen ist. Im Gegensatz zur antiquarischen Forschung, die - wie der herausragende Romanist Georg Friedrich Puchta (1798-1846) schreibt ${ }^{148}$ - einen vergangenen Rechtszustand als ruhend betrachtet, „ohne uns zu sagen, wie er entstanden und was aus ihm geworden ist" (Puchta 1841: 103), zielt die, innere Rechtsgeschichte' auf das Werden des Rechts, d.h. die Entwicklungs- bzw. „Bildungsgeschichte“ (Eichhorn 1815: 135) der einzelnen Rechtsinstitute und Lehren.

Savigny stellt in seinem seit dem Jahre 1815 veröffentlichten Bänden der Geschichte des Römischen Rechts im Mittelalter, bereits selbst fest, dass er entgegen seines ursprünglichen Vorhabens der Untersuchung der Ent-

148 Puchta ist neben Savigny einer der wichtigsten Theoretiker des romanistischen Zweiges der Historischen Rechtsschule in der ersten Hälfte des 19. Jahrhunderts (zu Puchta vgl. insbesondere Haferkamp 2004; Henkel 2004; Mecke 2008). Seine Arbeiten gehören zu dieser Zeit zu den meistgelesenen Werken (Haferkamp 2004: 48) und haben eine unmittelbare Einwirkung auf die richterliche Praxis (vgl. Scheuermann 1972: 55, 73). 
wicklungsgeschichte des gegenwärtigen Rechts „die neuere Zeit [...] davon auszuschließen“" (Savigny 1815a: VI) hätte. Er bietet gerade in seinem bedeutendsten rechtshistorischen Werk explizit keine, innere Rechtsgeschichte - wie auch die Mehrzahl der Juristen der Historischen Rechtsschule bis zu den 1850er Jahren (vgl. Wilhelm 1958). Dies beklagt Friedrich Julius Stahl im Jahre 1830 in seiner philosophisch-christlichen Fundierung der Historischen Rechtsschule, wenn er feststellt, dass bis dato durch die historische Richtung nur eine „treue Auffassung des Vergangenen oder äußerlich noch Bestehenden“ gegeben worden sei, „ohne daß das Band mit den gegenwärtigen Verhältnissen und ihrem Bedürfnisse erkannt wäre" (Stahl 1830: IX). ${ }^{149}$

Auch die zeitgenössischen Kritiker der Historischen Rechtsschule werfen ihr vor, dass die historischen Studien die Forderung des Gegenwartsbezugs nicht erfüllten. Der ehemalige Savigny-Schüler und nun überzeugte Hegelianer Eduard Gans, mit dem Savigny und Puchta im erbitterten Streit liegen (vgl. Haferkamp 2007a: 27ff.; Rückert 2002; Braun 1998), kritisiert im Jahr 1827 Savignys Geschichte des Römischen Rechts im Mittelalter als ,äußerlich“: Es handele sich nur um eine Geschichte der Rechtsquellen und der Literatur, die sich zudem in Details verliere (Gans 1827a). Thibaut stellt 1838 fest, dass zwar die rechtshistorische Forschung einen enormen Auftrieb bekommen habe, aber gerade die „Dogmengeschichte“, die als "Geschichte der Ausbildung des Justinianischen Rechtes seit der Glosse“ eigentlich im Zentrum der Pandektistik stehen müsse, liege fast ganz "danieder" (Thibaut 1838: 413) - ein Befund, zu dem wenige Jahre später auch der der Historischen Rechtsschule zuzurechnende Germanist Georg Beseler kommen wird (Beseler 1843: 316).

149 Auch Puchta kritisiert ab Mitte der 1820er Jahre in einer Reihe von Rezensionen zunehmend die antiquarische und unpraktische Ausrichtung der historischen Rechtsforschung seiner Zeitgenossen (vgl. Haferkamp 2004: 132ff.). Darüber hinaus kritisieren Stahl und Puchta, aber ebenso Savignys Lieblingsschüler Moritz August von Bethmann-Hollweg Savignys Weigerung, der Frage der Entstehung des Volksgeistes auf den Grund zu gehen. Dies führe letztlich zum Verlust jeglichen sittlichen Gehalts des Rechts, mangele es doch dadurch dem Recht eines philosophischen Fundaments. Sie wechseln insofern von der Frage der Rechtsentstehung zum Grund des Rechts, den diese drei Vertreter einer „historischchristlichen Schule“ in Gott suchen (vgl. hierzu Haferkamp 2009b). Auch wenn Savigny dieser christlichen Fundierung in der Diskussion um das Wesen des Rechtsverhältnisses folgen wird (vgl. Savigny in Kiefner 1982: 159f.), wird er für seine Rechtsdogmatik m.E. trotzdem die Frage der Rechtsentstehung nicht als Fundierungs- oder Gründungsfrage stellen, da es ihm wesentlich um den „lebendigen" Charakter geht. 
Nicht nur die tatsächlich vorgenommene historische Forschung wird anhand ihrer eigenen Ansprüche kritisiert, sondern auch grundsätzlich bestritten, dass über die Hinwendung zu den antiquarischen Wurzeln des römischen Rechts überhaupt ein Gegenwartsbezug hergestellt werden könne. So vertreten für Thibaut die „gelehrte[n] historischen Mückenfänger“ der Historischen Rechtsschule eine Geisteshaltung, die durch eine „steife, antiquarische, von der Gegenwart abführende Richtung " charakterisiert sei (Thibaut 1838: 415, 411; vgl. auch - aus junghegelianischer Richtung - Ruge 1841: 509). ${ }^{150}$

Das Problem wird von zahlreichen Kritikern - zwar aus unterschiedlichen Gründen, aber in einvernehmlicher Problemverortung - im Charakter des Untersuchungsgegenstandes der historischen Forschungen gesehen, der den geforderten Gegenwartsbezug geradezu verhinderte. Denn es handele sich um tote Materie: Bereits im Jahr 1816 schreibt Feuerbach im Rahmen seiner Kritik der Historischen Rechtsschule: „Was der Geschichte angehört ist schon dem Leben abgestorben." (Feuerbach 1833 [1816]: 143) Auch Georg Friedrich Hegel spricht dieses Problem in seinen Polemiken gegen die Historische Rechtsschule im Jahre 1820 an, wenn er anmerkt, dass man in dieser Rechtsschule "gerade da am meisten vom Leben und vom Übergehen ins Leben" spreche, „wo man in dem totesten Stoffe und in den todesten Gedanken versiert“ (Hegel 1996 [1820]: 362; H.i.O.; vgl. auch Gans 1824: XIII). Nach Johann Friedrich Martin Kierulff, einem Vertreter der von Hegel beeinflussten philosophisch-praktischen Jurisprudenz, liegt der Grund für den mangelnden Gegenwartsbezug der Historischen Rechtsschule in der Fokussierung auf das römische Recht als „seinem größten Theil nach todtes Material, welches außer lebendigem Zusammenhang steht mit dem Recht der Gegenwart" (Kierulff 1839: XIX). ${ }^{151}$ Wer sich nun einer solchen toten Materie wie dem römischen Recht in seinen Quellen zuwendet, vermag die Gegenwart nicht zu erkennen. Verkannt wird demzufolge das wirkliche Recht, das sowohl von Befürwortern wie Kritikern genannte „heutige“ Recht (Savigny 1840a; Puchta 1847) bzw.

150 Für den im Bereich des römischen Rechts historisch(-philosophisch) forschenden Zivilisten Karl Georg Bruns stellt sogar schon die Ansicht, dass die Methode der Römer zu reaktivieren sei, selbst eine gänzlich unhistorische These dar (Bruns 1843: 130).

151 Mit diesem Vorwurf steckt er sie pikanterweise in denselben Topf wie die Naturrechtslehre: „Diese historische Richtung verläßt nicht minder, als jene naturrechtliche Theorie, den practischen Boden der Gegenwart.“ (Kierulff 1839: XIX). 
„Recht der Gegenwart“ (Gans 1824: XII; Kierulff 1839: XIX; Beseler 1843: 130, 135; Wunderlich 1848). 152

Bei diesem heutigen Recht der Gegenwart handelt es sich - auch hierin stimmen Befürworter wie Kritiker überein - um ein „lebendes“ bzw. „lebendiges" Recht. In nur rein beiläufigen Erwähnungen zeigt sich schon, wie sehr sich bei Autoren der Historischen Rechtsschule die Vorstellung über den Gegenstand ,Recht' als etwas Lebendiges verselbstständigt hat und zur fundamentalen Zielbestimmung wurde: Die Anwendbarkeit eines Satzes als Recht wird verneint, da es sich nicht um „lebendes Recht" handele (vgl. etwa Koch 1840: 520); für eine Rezension einer historischen Untersuchung wird nur das herangezogen, was „für die Einsicht in unser lebendes Recht bedeutsam erscheint" (Bluntschli 1853: 388); und letztlich wird der Untersuchungsgegenstand selbst nicht als ein durch Abstraktion zu gewinnendes, „sondern als ein substantielles, selbstständiges, in eigener Kraft lebendes Recht" behandelt (Homeyer 1828: 234).

Auch die Gegner der Historischen Rechtsschule gehen vom „lebenden Recht" aus: So fundiert sich Feuerbachs Angriff gerade in dem Zweifel, ob „das Recht, welches die geschichtliche Rechtswissenschaft lehrt, wirklich das volksthümliche, lebende" ist (Feuerbach 1833 [1816]: 143f.); Kierulff wirft der antiquarischen Forschung vor, dass sie „vergißt, daß eben dieses Recht nur durch die Praxis in Deutschland Eingang gefunden, und nur so, wie es die Praxis gestaltet, und nur das, was durch sie lebendes Recht geworden ist" (Kierulff 1839: XX); und der liberale und kodifikationsoffene Germanist August Ludwig Reyscher beschwört in seinem Plädoyer für die Kodifikation und seiner Kritik der Einseitigkeiten der Historischen Rechtsschule das „Leben“ bzw. „Volksleben“ (Reyscher 1828: 7, 17, 25), den „lebendigen Stoffe" (Reyscher 1842: 144) und das „lebende Recht" an zahlreichen Stellen (vgl. etwa Reyscher 1842: 126; 1839: 12; s.a. Rückert 1974: 247ff.).

Gerade auch durch das Feld der Gegnerschaft formiert sich ein Aussagenfeld, das sich um den Gegenstand des „lebenden Rechts“ dreht. Darin erfolgt eine Rückbindung des Rechts an die soziale Wirklichkeit. Das ist

152 Der Fehler wird jedoch nicht nur in der historischen Methode, dem geforderten Rückgang zu den Wurzeln, sondern ebenso in der Theorie gesehen: Entgegen ihrer Prämissen und ihres eigenen Anspruchs trenne die Historische Rechtsschule die Theorie von der Praxis, dem gelebten Recht (vgl. etwa Köstlin 1846). Das Wissen, das sie lehrt, sei als bloß formale Theorie „dem Leben zu sehr entfrem-

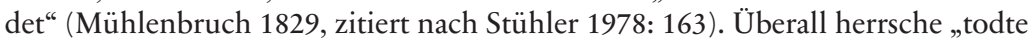
Gelehrsamkeit und dem Leben entfremdete Theorie“ (Beseler 1843: 351; ähnlich auch Feuerbach 1833; Stein 1841b; Reyscher 1839). 
gleichzusetzen mit der Anerkennung der Rechtsentstehungslehre der Historischen Rechtsschule. Und so ist es bezeichnend, dass manche Kritiker gerade diesen Punkt bestätigen: Für Feuerbach ist es "ganz unbestreitbar“, dass das Recht „überall [...] aus dem Geiste des Volks gebohren“ ist (Feuerbach 1833 [1816]: 139). Reyscher erkennt die „Volks-Gewohnheit“ als "Quelle des Rechts“ an, insbesondere als „Zeugniß für ein im Volke lebendes Recht" (Reyscher 1839: 12). Für den von Kant beeinflussten Naturrechtler und entschiedenen Kritiker der Historischen Rechtsschule Carl Christian Collmann ist es ganz „natürlich“, dass „stillwirkende Kräfte des Volks als erste Lebenselemente des Rechts anzunehmen“ seien, „die fern von allem Zufälligen und Willkührlichen ihren nothwendigen Grund in dem Sinne und Charakter des Volks, in seinem individuellen Leben und in dem Bildungsstande seiner noch dunklen Jugendzeit haben" (Collmann 1836: 141). Obwohl sich für die hegelianischen Rechtswissenschaftler der Staat dem Volksgeist nicht unterordnen lässt, so gilt doch auch für das vom Staat gesetzte Recht, dass es „Ausfluß der Volksüberzeugung“ ist und daher das positive Recht „als Ausdruck des Volkswillens“, d.h. des „Volksgeistes“ erscheint (Köstlin 2011 [1855]: 172) bzw. dass dort, „wo das Gewohnheitsrecht in anerkannter practischer Wirksamkeit bestehe, dies eben Wille der Gesetzgebung sey“ (Kierulff 1839: 13).

Auch wenn Rechtsphilosophie und Naturrecht verglichen mit der Historischen Rechtsschule ein grundsätzlich anderes Verhältnis zum positiven Recht haben (s.u. $\$ 2$.III.1), ${ }^{153}$ so gibt es aufgrund der Historisierung des jüngeren deutschen Naturrechts seit Ende des 18. Jahrhunderts diese unproblematischen Überschneidungen mit Blick auf die Rechtsentstehungslehre (vgl. Klippel 1997b: 110ff.). Geschichte und Erfahrung liegen nicht außerhalb des Naturrechtsdenkens, wobei ihre Funktionen begrenzt sind: Sie entfalten sich in der Sphäre des positiven Rechts, das den empirisch zu ermittelnden Stoff liefert, „worauf wir die Rechtsgedanken der Vernunft anwenden können" (Thomas 1803: 10). Insofern können sich auch verschiedene Entwicklungsstufen des positiven Rechts nachweisen

153 Das Verhältnis der einflussreichen Rechtsphilosophie Hegels zum Naturrecht erscheint umstritten (vgl. Klippel 1993: 28, m.w.N.). Da Hegel mit seiner Selbstverortung innerhalb des Naturrechts jedoch diesem Aussagenfeld zuzuordnen ist (so auch Tönnies 2006 [1912]) und zudem Rechtsphilosophie und Naturrechtslehre - nicht zuletzt aufgrund von Hugos Versuch der Umdeutung des Naturrechts in die „Philosophie des positiven Rechts“ (Hugo 1799) - im 19. Jahrhundert nebeneinander treten bzw. zunehmend ineinander aufgehen und synonym verstanden werden (vgl. Klippel 2012a; 1997b), verwende auch ich die beiden Ausdrücke synonym. 
lassen, die entweder auf die historischen Schwierigkeiten der Erkenntnis hinweisen oder Ausdruck der Vernunft auf den verschiedenen Stufen ihrer Entwicklung sind (vgl. Gans 1824: XIII). Letztlich wird der geschichtliche Charakter des positiven Rechts - und damit auch die Herkunft aus dem Volk - als selbstverständlich akzeptiert. ${ }^{154}$ Es wird verwiesen auf eine soziale Sphäre jenseits von Staat und abstrakter, ortloser Vernunft, die das positive Recht in der Zeit hervorbringt. Und genau deshalb handelt es sich um „lebendes Recht“.

Damit erkennen auch ihre Gegner die Prämisse der Historischen Rechtsschule an, dass im Rahmen der Frage nach dem positiven Recht Rechtsregel und Rechtsausübung untrennbar zusammengehören. Faktizität und Geltung sind aneinander gebunden: Nicht das, was faktisch als Recht (v.a. in Form von Gesetzen) bezeichnet wird, kann Auskunft über das bestehende Recht geben, sondern nur das, was als Recht Geltung beansprucht und daher "gelebt" wird, was in der Praxis als geltendes Recht angenommen und daher verwirklicht wird, wird als Recht verstanden. ${ }^{155} \mathrm{Oh}-$ ne diese Geltung - so die Kritik - handele es sich im Bereich des positiven Rechts um „totes Recht“, reines historisch-antiquarisches Faktum, ohne Bezug zum Leben. Dieses Leben entspringe - so ein gängiger Topos - der Natur des Volkes: Es handele sich um ein „natürliches und volksthümliches Recht" (etwa Oberdeutsche Zeitung 1881, Nr. 32, zitiert nach Reyscher 1842: 143). Die Historisierung tritt wie bei Savigny als Folge der Naturalisierung in Erscheinung - auch wenn der Historischen Rechtsschule die Verkennung dieses lebenden, natürlichen Rechts vorgehalten wird.

So unterschiedlich die Verwendungskontexte, so verschieden der Einsatz des Topos, so schillernd letztlich der Gegenstand des „lebenden Rechts", so allgemein verbreitet erscheint er und beansprucht Plausibilität und Evidenz für sich - selbst bei den entschiedensten Kritikern der Historischen Rechtsschule. (Positives) Recht wird problematisiert über seinen Bezug zum Leben, wie er in der Rechtsentstehungslehre seinen Ausdruck findet. Der Diskurs formiert sich - gerade auch im Feld der Gegnerschaft um dieses "lebende“ und „lebendige Recht“ (vgl. a. Haferkamp 2011d). Davon ausgehend wird der Historischen Rechtsforschung vorgeworfen, dass sie den Bezug des Rechts zur gesellschaftlichen Wirklichkeit verfehlt,

154 Es erscheint so selbstverständlich, dass es kein Leitthema innerhalb der Naturrechtsliteratur darstellt: Dort ging es um die Abgrenzung von Recht und Moral, Naturrecht und Politik sowie die Bestimmung des obersten Prinzips des Naturrechts (Klippel 1997b: 111f.).

155 Umstritten ist aber der Geltungsanspruch dieses Rechts (s. das anschließende Kapitel 1.2). 
sei es aufgrund ihrer theoretischen Prämissen oder sei es aufgrund ihrer Methode. Damit wird die grundsätzliche Möglichkeit einer solchen Anbindung nicht in Frage gestellt. Es handelt sich also um keine grundsätzliche Kritik am epistemischen Schema des Volksgeistes, sondern nur an der Erfüllung der eigenen Vorgaben.

\subsection{Das Scheitern des normativen Rechtsbegriffs: Der Rückzug der naturrechtlich-rechtsphilosophischen Kritik}

Viel schwerer wiegt der Vorwurf, dass die Historische Rechtsschule überhaupt keine Theorie des Rechts habe. Problematisiert wird damit nicht der falsche Lebens- bzw. Wirklichkeitsbezug des positiven Rechts als „lebendes Recht“. Zur Debatte steht nun vielmehr das Problem der Rechtfertigung des Rechts, d.h. sein Geltungsanspruch. Die Kritik zielt v.a. auf den spezifischen Geltungsanspruch des positiven Rechts, wie ihn die Historische Rechtsschule mit ihrer Rechtsquellenlehre proklamiert. Denn Savignys Ansatz läuft letztlich auf die Behauptung hinaus - so Thibaut 1838 -, dass das historische Entstandene genau aufgrund dieses Entstehungszusammenhangs „wahr" sei und „also dem Tadel nicht ausgesetzt" werden könne: „Damit wäre am Ende jede Sünde gerechtfertigt.“ (Thibaut 1838: 408) Karl Marx verschärft diese Kritik am geschichtlichen Rechtfertigungszusammenhang noch, wenn er schreibt, dass es sich um eine Schule handele, „welche die Niederträchtigkeit von heute durch die Niederträchtigkeit von gestern legitimiert, eine Schule, die jeden Schrei des Leibeigenen gegen die Knute für rebellisch erklärt, sobald die Knute eine bejahrte, eine angestammte, eine historische Knute ist" (Marx 1976c [1844]: 380). Die Geschichte ist ihr nur als Vergangenheit bekannt. Und insofern gilt: „Die historische Schule hat das Quellenstudium zu ihrem Schibboleth gemacht, sie hat ihre Quellenliebhaberei bis zu dem Extrem gesteigert, daß sie dem Schiffer anmutet, nicht auf dem Strome, sondern auf seiner Quelle zu fahren [...]." (Marx 1976a [1842]: 78) Kritisiert wird im scharfen Ton die Gleichsetzung von Entstehungsgrund und Geltungsanspruch.

Diese Angriffe beinhalten den Kern der naturrechtlichen und rechtsphilosophischen Kritik. Vorgeworfen wird ein Mangel der Theorie des Rechts, wie schon Hegel formulierte: Zwar hätten die geschichtlichen Bemühungen, „[d]as in der Zeit erscheinende Hervortreten und Entwickeln von Rechtsbestimmungen zu betrachten [...] in ihrer eigenen Sphäre ihr Verdienst und Würdigung" (Hegel 1996 [1820]: 35, H.i.O.), dies habe aber mit der philosophischen Betrachtung des Rechts nichts zu tun. Hegel wirft der Historischen Rechtsschule vor, dass sie die wahrhafte Rechtfertigung aus 
dem Begriff gegen eine „Rechtfertigung aus den Umständen“ (ebd.: 36) eingetauscht habe. Dabei verwechsele sie „das äußerliche Entstehen mit dem Entstehen aus dem Begriffe“, so dass sie letztlich - gänzlich unhistorisch - das Recht von heute durch das Recht von gestern begründe, selbst wenn eine Institution durch den Wandel der gesellschaftlichen Umstände „ihren Sinn und ihr Recht verloren hat" (ebd.: 37). ${ }^{156}$ Die fehlende Rechtsphilosophie zeigt sich im Mangel eines Rechtsbegriffs bzw. einer Theorie des Rechts, die bei der Historischen Rechtsschule, wenn überhaupt, nur in unzulässiger Vermischung mit der Geschichte des Rechts zu erkennen sei (vgl. Kierulff 1839: XXIV).

Savignys Emanzipationsversuchen der Rechtswissenschaft von der Philosophie wird damit vehement widersprochen. Neben der historischen Betrachtung des positiven Rechts bedarf es der philosophischen Bestimmung des sein-sollenden Rechts, um über die vernunftmäßige Ermittlung etwa des „Urrechts“ (Collmann 1836: 12ff.) oder des „,idealen Rechtes“ (Stöckhardt 1825: X) überhaupt ein wissenschaftliches Urteil über die Rechtmäßigkeit bestimmter Bestimmungen zu ermöglichen (vgl. a. Ahrens 1846: 9, 15ff.). Aus dem Sein - so das bekannte Diktum - kann kein Sollen folgen, die normative Seite des Rechts kann nicht über empirische Fakten im positiven Recht ermittelt werden. Dementsprechend bedarf auch die Historische Rechtsschule der „Fackel der Philosophie“, um dem Vorwurf zu entgehen, sie "stütze das Recht auf einen geschichtlichen Fatalismus“ (Warnkönig 1839: V). In diesem Punkt, an dem die Normativität des Rechts vehement eingeklagt wird, scheint die Kluft zwischen Historischer Rechtsschule und Naturrecht bzw. Rechtsphilosophie unüberbrückbar.

Von der Kritik zur Arbeitsteilung: de lege lata und de lege ferenda

Der Konflikt wird jedoch zum einen durch eine Art Arbeitsteilung zwischen Historischer Rechtsschule und Naturrecht entschärft. Denn angesichts der Dominanz der Historischen Rechtsschule in den Privatrechtswissenschaften ist eine Rücknahme des Geltungsanspruchs des Naturrechts

156 Vgl. zu der naturrechtlichen Kritik an der mangelnden philosophischen Grundlage durch C. Ch. Collmann, Karl David August Röder, Carl August Eschenmayer, Heinrich Ahrens, Heinrich Moritz Chalybäus die Nachweise bei Klippel 1997b: $118 \mathrm{ff}$. 
erkennbar (vgl. Klippel 1997b: 112ff.). ${ }^{157}$ In Abkehr zur absolutistischen Auffassung des älteren deutschen Naturrechts hält das jüngere Naturrecht als „Wissenschaft der Rechte des Menschen“ gegen Ende des 18. Jahrhunderts dem Staat einen umfangreichen Katalog von Rechten des Individuums entgegen. Einher damit geht die Annahme der Vorrangigkeit des Naturrechts gegenüber dem positiven Recht. ${ }^{158}$ Dieser Geltungsanspruch wird nun eingeschränkt: Das Naturrecht, dass zunehmend mit der Rechtsphilosophie gleichgesetzt wird, beansprucht nicht mehr, geltendes Recht zu sein: Beobachtbar ist - so Warnkönig - ein Rückzug auf das zukünftige Sollen (Warnkönig 1861: 246ff.). Das Naturrecht bzw. die Rechtsphilosophie beansprucht immer weniger eine unmittelbare Geltung für das positive Recht, sondern stellt die Mittel zur Verfügung, dasjenige wissenschaftlich zu bestimmen, was zukünftig gelten soll.

Einher damit geht eine Schwerpunktverlagerung hin zu einem Bereich, der der Historischen Rechtsschule aufgrund ihrer theoretischen Annahmen nicht zugänglich ist: Das Naturrecht versteht sich in der ersten Hälfte des 19. Jahrhunderts zunehmend als Gesetzgebungstheorie bzw. als „Gesetzgebungswissenschaft“" (vgl. Mertens 2004: 3f.; Klippel 1993: 46f.; jeweils m.w.N.). Gerade dadurch öffnet sich das Naturrecht für gesellschaftliche und wirtschaftliche Veränderungen, ${ }^{159}$ auf die die Gesetzgebung die im Übrigen trotz der Dominanz der Historischen Rechtsschule in der Rechtswissenschaft eine rege Tätigkeit entfaltet - zu reagieren hat. ${ }^{160}$ Es erfolgt letztlich eine arbeitsteilige Trennung von Sein und Sollen: positives

157 Das Naturrecht als Teildisziplin der Rechtswissenschaft wird mit der Verbreitung der Historischen Rechtsschule keineswegs verdrängt, was sich schon allein in zahlreichen Veröffentlichungen zu naturrechtlichen Problemstellungen in der ersten Hälfte im 19. Jahrhundert (vgl. Klippel 2012b) sowie in einer regen Vorlesungstätigkeit an den deutschen Universitäten zeigt (vgl. Schröder, Pielemeier 1995).

158 Allerdings zielt das Naturrecht nicht auf unmittelbare Geltung im Sinne eines Ersatzes des positiven Rechts. Allenfalls wird es - so stellt Diethelm Klippel fest - als subsidiär heranzuziehendes Recht angesehen. Nur selten wird formuliert, dass das Naturrecht widersprechenden Rechtssätzen des positiven Rechts derogieren könne, die Mehrzahl fordert vielmehr, dass der Gesetzgeber solches Recht abzuschaffen habe (Klippel 1997b: 113).

159 Gerade seitens vieler Naturrechtler wird im Vormärz auch weiterhin eine gesamtdeutsche Kodifikation gefordert. Neben der politischen Symbolkraft solcher Nationalgesetzbücher für den gesamten Deutschen Bund beziehen sie zunehmend wirtschaftspolitische Erwägungen in ihre Begründung mit ein (vgl. Schöler 2004: 132ff. m. zahlr. N.).

160 Klippel spricht insofern von einer Komplementärfunktion des Naturrechts für die Historische Rechtsschule (Klippel 1993: 46). Damit öffnet sich das Natur- 
Recht (de lege lata) als Frage des Seins, philosophisches Recht als Frage des vernünftigen, zukünftigen Sein-Sollens (de lege ferenda).

Damit erfährt die Selbstverortung der Historischen Rechtsschule auf der Seite des Seins gewissermaßen eine Bestätigung. Die historische (und damit empirische) Rechtswissenschaft wird in ihrem Charakter als Seinswissenschaft nicht angegriffen. Gleichzeitig lässt das Naturrecht mit dieser Schwerpunktsetzung die Vormachtstellung der Historischen Rechtsschule für Dogmatik und Methodik des positiven Rechts als Kernbereich der Rechtswissenschaft unangetastet - der Bereich, in dem sich ihre eigentliche Dominanz entfaltet und über den sie die Autonomie des Rechts gegenüber Politik, Ethik und Philosophie proklamiert. Damit besteht trotz naturrechtlicher Kritik die Tendenz, die systematische Methode der Historischen Rechtsschule, die (zumindest) auf der Begründungsebene aus den Bestimmungen der Rechtsentstehungslehre hervorgeht, nicht in die Sollensproblematik zu überführen. Anders formuliert: Die Normativität wird nicht zum vorherrschenden strategischen Problem der Rechtswissenschaft im Bereich der Dogmatik und Methodik, sondern nur hinsichtlich der Frage, welcher Teil der Rechtswissenschaft über zukünftige Sollensfragen zu entscheiden habe. Und darauf antwortet das Naturrecht: die Rechtsphilosophie.

\section{Kongruenzen zwischen Historischer Rechtsschule und Rechtsphilosophie}

Zum anderen wird die Kluft zwischen Historischer Rechtsschule und Rechtsphilosophie bzw. Naturrecht durch Kongruenzen überbrückt: Beide plädieren für ein Auseinandertreten von Staat und Gesellschaft. In Abkehr von der Gleichsetzung von Staat und bürgerlicher Gesellschaft unterscheidet Hegel 1821 in seinen Grundlinien der Philosophie des Rechts die ,politische' Sphäre des Staates vom ,bürgerlich' gewordenen Bereich der Gesellschaft (vgl. Riedel 1975a: 779ff.). ${ }^{161}$ Sie bezeichne eine „Sphäre der Besonderheit", in der jeder seine eigenen Interessen verfolgt (Hegel 1996 [1820]: 339f.). Das bürgerliche Leben als Spezifikum der modernen Ar-

recht aber zugleich für Politik und Ethik, was die Aussonderung der Rechtsphilosophie aus dem Bereich der Rechtswissenschaften begünstigen wird.

161 „Bürgerlich“ ist also nicht mehr gleichbedeutend mit „politisch“, sondern erhält einen „sozialen Sinn“: Der Begriff bezeichnet die gesellschaftliche Stellung des im absoluten Staat zum bourgeois privatisierten Bürgers (vgl. Hegel 1996: 348 $[\$ 190$, Zusatz]). Der Bürgerbegriff wird damit von seiner politisch-rechtlichen Bedeutung emanzipiert. 
beitsgesellschaft ist nicht Ausfluss des Staates, sondern bildet ein „System der Bedürfnisse“, das nicht mehr unmittelbar politisch verfasst ist. In dieser Sphäre stehen sich die bürgerlichen Privatleute als Personen und Eigentümer gegenüber, die durch ihre ökonomisch vermittelte Besonderheit (Bedürfnis, Tausch, Arbeit) miteinander verbunden sind. Plausibilisiert wird damit nicht nur eine nicht an die Existenz des Staates gebundene Form des gesellschaftlichen Lebens - selbst wenn diese für Hegel in der Sphäre der Sittlichkeit aufgeht, die in der Souveränität des neuzeitlichen Anstaltsstaates seinen krönenden Abschluss findet. ${ }^{162}$ Plausibilisiert wird vielmehr der herausragende Ort des Privatrechts gegenüber dem Öffentlichen Recht für die Frage der Gesellschaftsbildung (vgl. Auer 2014: 38ff.). ${ }^{163}$

Diese Aufwertung des Privatrechts für die Frage der Gesellschaft ist auch in der sich mit Kant auseinandersetzenden Tradition erkennbar (vgl. hierzu Klippel 1997a). Das ältere aufgeklärt-absolutistische Naturrechtsdenken geht davon aus, dass status naturalis und status civiles einander entgegengesetzt sind. Das Privatrecht wird dabei auf der Seite des status civiles verortet, d.h. es bezieht sich auf den Menschen im Staat. Damit hat es keine entscheidende Rolle für Systematik und Inhalt der Rechtsordnung. Kant hält an dieser Unterscheidung zwischen Naturzustand und status civiles fest, verschiebt jedoch den Ort des Privatrechts in den status naturalis (vgl. Kant 1975 [1897/98]: 350). Das Privatrecht wird zum „natürlichen Privatrecht" und erhält eine fundierende Funktion für die gesamte Rechtslehre. Selbst diese Aufwertung des Privatrechts greift die Vormachtstellung des Staates nicht an, es besteht weiterhin die Gefahr, dass im Übergang zum bürgerlichen Zustand das natürliche Privatrecht in den Zugriff des Staates gerät. Daher wenden sich zahlreiche naturrechtliche Autoren von Kant $a b$, indem sie entweder den Naturzustand umdefinieren oder die Zweiteilung in Naturzustand und staatlichen Zustand verwerfen. Damit erhalten sie einen naturrechtlichen Begriff des Privatrechts, der Geltung für alle gesellschaftlichen Verhältnisse des Menschen beanspruchen kann, also auch für das Leben der Menschen im Staat. Parallel zur Reinigung des Privatrechts in der Historischen Rechtsschule, die es zum „reinen Recht“ schlechthin erklärt, wird das „natürliche Privatrecht“ damit zum dominierenden Begriff in der Frage nach dem Recht, aber ebenso in der Frage

162 Denn nur dieser Staat kann verhindern, dass die bürgerliche Gesellschaft an ihren eigenen Widersprüchen zugrunde geht (vgl. Riedel 1970: 54ff.).

163 Insofern ist es auch nicht verwunderlich, dass Marx in seiner Kritik der Hegel'schen Rechtsphilosophie vom Problem des Privatrechts ausgeht (vgl. Marx 1976b [1843]: 203ff.). 
nach der vorstaatlichen Sphäre, d.h. der Gesellschaft (vgl. Klippel 1997a m.w.N.).

Diese Aufwertung des Privatrechts bewirkt zweierlei: Erstens stärkt auch die Rechtsphilosophie nicht nur die Existenz einer vom Staat unabhängigen Sozialsphäre, wie sie bei Savigny im Volksgeist ihren Ausdruck findet. Vielmehr ist auch für die Rechtsphilosophie das Privatrecht für die unabhängige Sozialsphäre der Gesellschaft zentral - juridische Gesellschaftslehre ist Privatrechtslehre. Zweitens zeigt sich darin eine Kongruenz in der Zentralität des subjektiven Rechts. Zwar gilt auch hier: Die Herleitungen sind nicht ineinander überführbar, das Urrecht hat nichts mit Savignys Annahme der faktischen Durchsetzung der christlichen Weltanschauung als Begründung der Aussonderung des subjektiven Rechts aus dem Rechtsverhältnis zu tun. Aber dadurch verkleinert sich die Angriffsfläche für die Rechtsphilosophie: Sie hat weder etwas gegen die Bestrebungen der Systematisierung noch gegen die zentrale Rolle des subjektiven Rechts für den Systemaufbau des Rechts einzuwenden. Hierin scheiden sich die Schulen nicht (vgl. Klippel 1997b: 223, m.w.N). ${ }^{164}$

Die Kluft, die sich in den polemischen Einlassungen zwischen historischer und ,philosophischer' Rechtslehre in der Frage nach dem geltensollenden Recht auftut, wird also nicht nur über die Arbeitsteilung, sondern auch anhand solcher Kongruenzen abgeschwächt. Mehr noch: Im Streit zwischen der historischen und der philosophischen Schule wird die Existenz einer vom Staat unabhängigen Sozialsphäre (Gesellschaft und Volksgeist) systematisch hervorgebracht, plausibilisiert und verobjektiviert - und das unter Aufwertung des Privatrechts. An genau diesem Punkt handelt es sich aber nicht um ein normatives Problem, sondern um ein Problem der adäquaten Erfassung der Wirklichkeit. Das zeigt sich auch in der Frage, was man im positiven Recht zu erkennen vermag: organischen Volksgeist, universalen Weltgeist oder etwa bürgerliche Produktionsverhältnisse. Da das Erkenntnisproblem des Rechts jedoch primär die Ebene der Dogmatik und Methodik betrifft, hier aber über Systemgedanke und Orientierung am subjektiven Recht eine Kongruenz und daher wenig Angriffsfläche besteht, wird die Normativität des Rechts nicht zum vorherrschenden strategischen Problem der Rechtswissenschaft.

164 Was zu der oben bereits erwähnten vieldiskutierten Frage führt, inwiefern Savigny naturrechtliches Gedankengut aufgegriffen habe. 


\section{2. „Lebendes Recht“ und Repräsentation der gesellschaftlichen Wirklichkeit}

Wenn mit dem „lebenden Recht“ die Problematisierung des Verhältnisses des Rechts zur vorausgesetzten gesellschaftlichen Wirklichkeit in den Diskurs eintritt, so steht damit die genaue Bestimmung dieses Verhältnisses noch aus. An den großen Debatten um die rechtstheoretischen Prämissen der Historischen Rechtsschule im Streit über Theorie, Gegenstand, Methode und Wissenschaftlichkeit der Rechtswissenschaften bis in die 1860er Jahre zeigt sich dabei die Formation eines Aussagenfeldes, die das Recht über seine Repräsentationsleistung problematisiert.

\subsection{Missrepräsentationen I: Eigenes versus fremdes Recht, gegenwärtiges Volksrecht versus Juristenrecht (Beseler)}

Der Vorwurf, dass sich die romanistische Historische Rechtsschule nicht dem wahren volkstümlichen Recht zuwende, zeigt sich nicht nur in der Kritik an der historischen Methode, sondern ebenso in den Angriffen auf die konkrete Rechtsmaterie, die Savigny und seine Schüler ins Zentrum der Untersuchung rücken. Denn man bezweifelt, dass das Ius Commune der Römer überhaupt das gelebte Recht in Deutschland darstellt. So gilt mit Kierulff für viele: Das in Deutschland wirklich lebendige Recht ist gerade nicht das römische Recht, sondern ein aus römischer und deutscher Wurzel erwachsenes selbständiges Recht, das aus sich heraus begriffen werden müsse (Kierulff 1839: IX).

Diesen Vorwurf spitzen die germanistischen Vertreter der Historischen Rechtsschule über den Gegensatz von Eigenem und Fremdem noch zu. Die Rezeption des römischen Rechts als „fremdes Recht“ stellt sich für Georg Beseler in seiner vieldiskutierten Schrift Volksrecht und Juristenrecht aus dem Jahr 1843 als „Nationalunglück“ dar, das im Zuge der Herausbildung der Dominanz der Romanisten - hier auch mit unmittelbarer Spitze gegen Puchtas Ausführungen zum Juristenrecht in der zweibändigen Abhandlung Das Gewohnheitsrecht ${ }^{165}$ - zur „Unterdrückung und Verkrüppelung

165 Mit seiner zweibändigen Abhandlung Das Gewohnheitsrecht (1828/1837) problematisiert Puchta Savignys Ausführungen auf wissenschaftlicher Ebene, indem er in der Diskussion um das Gewohnheitsrecht in der Rechtsquellenlehre insbesondere die Abgrenzung vom und Ausarbeitung des Juristenrechts hervorhebt (s. $\$ 2 . I V .1 .1$ ). Zum wissenschaftstheoretischen, justiziellen und politischen Kontext der Diskussion um das Gewohnheitsrecht zu dieser Zeit vgl. Haferkamp 2004: $141 \mathrm{ff}$. 
des eigenen Rechtslebens" geführt habe (Beseler 1843: 42). ${ }^{166}$ Er wiederholt damit den alten Vorwurf der Fremdheit des römischen Rechts, den Savigny gerade über das Faktum der Rezeption in Deutschland widersprochen hatte. Gegenüber dem deutschen Volksrecht zeigt sich im römischen Recht für Beseler das Volksfremde und damit potentiell Volksschädliche.

Dementsprechend gilt sein Angriff auch nicht der Rechtsentstehungslehre (vgl. ebd.: 58f.). Innerhalb dieser Lehre nimmt er jedoch zwei entscheidende Verschiebungen vor. Zum einen kritisiert er das historische Entwicklungsschema der Historischen Rechtsschule: Er bestreitet die These der nachlassenden rechtsschöpfenden Kraft des Volkes, die zur Aufwertung der Rolle des Juristen führt. ${ }^{167}$ Damit greift Beseler die Rechtfertigung eines vom Juristenstand neu hervorgebrachten Rechts, des Juristenrechts, an und protestiert dagegen, den Juristenstand mit seiner wissenschaftlichen Arbeit das Volksrecht produzieren zu lassen. Ein solches Juristenrecht ist für ihn kein Volksrecht. ${ }^{168}$ Es verliert folglich den Status der Rechtsquelle.

Zum anderen wendet sich Beseler gegen die Kontinuitätsannahme im Geschichtsmodell der Historischen Rechtsschule, die die Methode der wissenschaftlichen Erforschung des lebenden Rechts auf den Rückweg in die Vergangenheit zu den Wurzeln verpflichtet. Er macht den Eigenwert der Gegenwart gegenüber der Vergangenheit geltend: „Auch diese [die Gegen-

166 Seit den 1830er Jahren belebt sich der Streit um die Rezeptionsdeutung (vgl. die Nachweise bei Rückert 1974: 163f.). Beselers Schrift bündelt dabei insbesondere eine bereits seit Beginn der Historischen Rechtsschule schwelende Kritik seitens der Germanisten an der romanistischen Privilegierung des Römischen Rechts (vgl. Thieme 1963). Sie bewirkte einen zur Spaltung führenden Streit zwischen diesen beiden Zweigen (vgl. Wieacker 1996: 411ff.), der in den Germanistentagen von 1846 und 1847 in Frankfurt und Lübeck deutlich zum Ausdruck kommt. Beselers Terminus des „Nationalunglücks“ verbreitet sich wie ein Lauffeuer und bestimmt die Rezeptionsdeutung (vgl. Haferkamp 2007a: 42).

167 Damit greift Beseler Vorwürfe gegen die Absonderung des wissenschaftlichen Rechts und gegen das elitäre Schema der Historischen Schule auf, die in der lebhaften Diskussion um das Juristenrecht bereits von anderen, sehr unterschiedlichen Autoren geäußert worden waren (z.B. Reyscher, Thibaut, Eichhorn, Gans, Wächter, Siegen, Bornemann, von der Pforden; für dieses elitäre „Spezialistendogma" insbesondere Puchta, Savigny, Maurenbrecher und Weiske; vgl. hierzu die Nachweise bei Reyscher 1828: 340; Schröder 1976). Rechtstechnisch gesprochen wird der Rechtsquellencharakter der Wissenschaft bestritten (Kierulff 1839: 6).

168 Davon unterscheidet er die Deduktion aus dem „Geist des positiven Rechts“ durch Juristen, die damit kein neues Recht hervorbrächte und daher dem Volksrecht zuzurechnen sei (Beseler 1843: 87). 
wart, D.S.] hat wieder ihre selbständige Bedeutung, welche unmittelbar erfaßt und begriffen werden will; sie fügt den überlieferten Momenten neue Bildungen hinzu, und bekommt so für die Zukunft selbst den Charakter einer historischen Auctorität." (Ebd.: 128f.)

Dadurch vergegenwärtigt er das epistemische Ding ,Volksgeist'. Das, was im gegenwärtigen Volk lebt, könne man nicht durch Rückgriff auf die Vergangenheit ermitteln, sondern nur unter Berücksichtigung der aktuellen Volksüberzeugungen. ${ }^{169}$ Mit der Feststellung, dass das Volksrecht im Bewusstsein des Volkes lebe, werde dieses zur ersten „Erkenntnisquelle“ des Volksrechts: „[B]ei diesem ist zunächst die Kunde desselben zu suchen" (ebd.: 119).

Das Volksrecht werde dabei seiner Herkunft entsprechend am ehesten vom Volk selbst erkannt. ${ }^{170}$ Dementsprechend seien die Methoden der Rechtswissenschaften zu entwickeln. Denn das Problem bestehe für den Juristen darin, dass er aufgrund des Zustandes der Gerichtsverfassung und dem ausschließlich wissenschaftlichen Verlauf des Studiums dem aktuellen Volks- und damit Rechtsleben „entfremdet“ sei (ebd.: 120). Daher müsse er im Prinzip „ganz nach Art eines Naturforschers zu Werke gehen“, nämlich durch „Beobachtung und Erforschung“ (ebd.: 109, 119). ${ }^{171}$ Der Jurist betrachte das Volksbewusstsein als eine Tatsache, die es zu untersuchen gelte.

Mit Blick auf das Problem der Erkenntnis der aktuellen Volksüberzeugungen schlägt Beseler insbesondere drei methodische Vorgehensweisen vor: erstens die Untersuchung bestehender literarischer Zeugnisse, in denen sich unter Umständen die Volksüberzeugungen niedergeschlagen hätten. Zweitens empfiehlt er die Vornahme von Experteninterviews, da sich aufgrund der klassen- und arbeitsmäßigen Teilung der Gesellschaft verschiedene Rechtskreise mit je besonderer Rechtskunde herausgebildet haben (vgl. ebd.: 118f.; 121). Und drittens plädiert er für eine Form der teilnehmenden Beobachtung am Volksleben, damit der Jurist „sich durch die genaue Beobachtung der Rechtsverhältnisse und Geschäfte eine selbständi-

$169 \mathrm{Zu}$ den Vorläufern dieser Problematisierung des Volksgeistes über sein zeitliches Schema vgl. Landsberg, Stintzing 1978: 495ff.; Wieacker 1996: 407ff.; Rückert 1974.

170 Diesem Grundsatz entspricht die politische Forderung nach Laienrichtern, die in der breiten Diskussion über Volksgerichte und Schöffen einzuordnen ist.

171 Der Weg in die empirische Forschung jenseits der Literaturgeschichte erscheint für die Germanistik auch insofern schon näherliegend, als der einheimische Rechtskorpus zum großen Teil keine literarisch-wissenschaftliche Verfestigung aufweist. 
ge Ansicht verschaffen, sich selbst als einen Genossen des Volkes fühlen lernen, und die in den Thatsachen ruhende ratio ohne weitere Vermittlung verstehen könnte" (ebd.: 123). ${ }^{172}$ Historische Forschung erweise sich nur in dem (allerdings häufigen) Fall als notwendig, in dem die Unmittelbarkeit und Klarheit der Volksüberzeugung nicht mehr gegeben sei (vgl. ebd.: 126). ${ }^{173}$ Sie wird zum Hilfsmittel, das subsidiär zum Einsatz komme. ${ }^{174}$

Das Volksbewusstsein, die gegenwärtigen Volksüberzeugungen respektive ,das Volk' erscheinen als Gegenstände, denen man sich über solche methodischen Mittel der Beobachtung annähert. Ähnlich wie Savigny lehnt Beseler dabei ein quantitatives Verfahren ab, da die Gewohnheit als tatsächliche Übung, d.h. rein äußerliche Handlung, keinen Aufschluss über das Volksbewusstsein geben könne (vgl. ebd.: 112, 116). Auch er setzt auf das einfühlende Verstehen, wenn er postuliert, dass der "Jurist stets nach Kräften dahin streben müsse[], sich in die Denkweise des Volkes zu versetzen, und so viel möglich sich selbst als einen Träger des Volksrechts zu fühlen“ (ebd.: 123).

Was Beseler mit aller Macht einklagt, ist die Annahme, dass das Volksrecht im Volksleben der Gegenwart erkennbar wird. Der Bezug zwischen Recht und Volk wird vergegenwärtigt. Zu suchen ist dieses Recht in den

172 Insofern schließt Beseler an Puchtas Gewohnheitsrecht an, der ebenfalls die Gewohnheit als Mittel der Erkenntnis der Volksüberzeugung nicht nur über Übung, sondern ebenso durch Zeugenbefragung, Aufzeichnungen und Rechtssprichwörter zu ermitteln sucht (Puchta 1837: 120ff.). Allerdings trennt Puchta das Gewohnheitsrecht, das nur aufgrund der „äußeren Autorität“ gilt, scharf vom Juristenrecht in Form des „Rechts der Wissenschaft“, welches aus „inneren, systematischen Gründen“ deduziert wird und daher die innere Autorität „der wissenschaftlichen Wahrheit“ für sich beansprucht (ebd.: 14, 16; s. hierzu \$2.IV.1). Das hat nicht nur eine Aufwertung des Juristenrechts zur Rechtsquelle zur Folge, sondern ebenso eine Abwertung der gleichsam empirisch zu ermittelnden ,äußeren' Autorität. Insofern wird bei Puchta mit seiner Hinwendung zum „Recht der Wissenschaft“ dieser empirische Teil zunehmend überflüssig. Indem Beseler nun dieses Juristenrecht vehement bestreitet, kommt den hier vorgestellten empirischen Methoden eine zentrale Stellung für die gesamte Rechtslehre zu.

173 Ein solches unmittelbares und unverfälschtes Volksrecht ist in Beselers Augen mittlerweile nur schwer anzutreffen. Aufgrund der historischen Entwicklung, die auch Beseler als zunehmende Professionalisierung und Ausdifferenzierung beschreibt, wurde das Recht zunehmend vielschichtiger, komplexer, zu einer durch fremde und wissenschaftliche Einflüsse und Machtfaktoren durchsetzte unübersichtliche Rechtsmaterie.

174 Beseler widerspricht damit nicht der systematischen Aufgabe der Prinzipienbildung aus dem im Stoff vorfindlichen Prinzipien (vgl. Beseler 1843: 124). Seine Kritik richtet sich aber gegen die Art und Weise der Stoffermittlung. 
gegenwärtigen gesellschaftlichen Anschauungen, und daher auch mit veränderten methodischen Mitteln. Das, was bei Savigny (und Puchta, s.u.) im Dunkeln stattfindet und daher der Erkenntnis nicht zugänglich erscheint, fasst Beseler nun selbst als mögliches Objekt der wissenschaftlichen Untersuchung, dem die prinzipiellen Anstrengungen des Wissens gelten. ${ }^{175}$

Auch wenn Beseler damit in seinem vieldiskutierten Buch die Idee angreift, dass der Juristenstand der eigentlichen Repräsentant des Rechtsbewusstseins sei, so wird jedoch gerade durch diese Kritik der Repräsentationsgedanke im Kern bestärkt. Denn römisches Recht und Juristenrecht erscheinen letztlich in dieser Kritik als Missrepräsentationen - und zwar als Missrepräsentationen des deutschen gegenwärtigen Volksbewusstseins. Denn auch für Beseler entspringt das Recht dem Volksbewusstsein und repräsentiert es. Und nur aufgrund dieser Annahme kann er seine Kritik entfalten.

Allerdings wird bei Beseler das Volksbewusstsein selbst nun zum Ausgangspunkt der rechtswissenschaftlichen Arbeit. Die Wahrheit des Rechts ist über die empirische Erforschung des gelebten Rechts zu ermitteln. Damit rückt das Volksbewusstsein selbst, diese vom Staat unabhängige kontingente Sozialsphäre, trotz spezifischer Erkenntnisschwierigkeiten ins Zentrum der wissenschaftlichen Erforschung - und wird daher selbst zu einem Objekt der Rechtswissenschaft, das methodische Folgen zeitigt.

\subsection{Missrepräsentationen II: Die „Bedürfnisse der Zeit“ und das Recht der Gegenwart}

Auch wenn diese methodischen Forderungen geringen Widerhall finden, reiht sich Beseler damit in eine Kritik ein, die von verschiedenen Seiten auch aus den eigenen Reihen der Romanisten - der Historischen Schule zunehmend entgegengehalten wird: Recht stehe in einem Gegenwartsbezug, der nicht allein über die Vergangenheit vermittelt werde. Die Metho-

175 Doch auch Beseler verabschiedet nicht die These vom Erkenntnismangel in Gänze: „Die Art und Weise dieser Rechtsbildung läßt sich in ihrem stillen Wachsthume nur mit der schöpferischen Thätigkeit der Natur vergleichen; es ruht darüber ein gewisses Geheimniß, welches sich der unmittelbaren Anschauung nie vollständig erschließt, wie lange auch die sinnende Betrachtung bei der äußeren Erscheinung weilt" (Beseler 1843: 84). Auch für Beseler muss man sich über das positive Recht dem Geist des Rechts annähern, um es einfühlend verstehen zu können. 
de der Historischen Rechtsschule wird dahingehend kritisiert, dass die Vergangenheit wichtiger als die Gegenwart sei und daher der Eigenwert der Gegenwart gerade nicht zur Geltung komme.

Die Historische Rechtsschule zielt ihrem Anspruch nach aber auf die Gegenwart: Die Rekonstruktion der Normen des römischen Rechts korrespondiert über Rechtsentstehungslehre, Entwicklungs- und Kontinuitätsgedanken mit dem gegenwärtigen Volksgeist. Diese Koppelung von Recht und Leben erfolgt über das Bedürfnis (vgl. Haferkamp 2005; 2011e). Denn nach Savigny entsteht Recht aus dem Bedürfnis: „[E]in oft wiederkehrendes gleiches Bedürfniß“ ermögliche das „gemeinsame[] Bewußtseyn des Volkes“ (Savigny 1814: 13). Das Recht des Volkes entstehe aus „Natur, Schicksal und Bedürfniß“ (Savigny 1850a [1815]: 141), es resultiere aus „den Richtungen und Bedürfnissen des Lebens, die eine rechtliche Gestalt und Befriedigung erhalten sollen“ (Puchta 1838: 32). Daher liege „in der Mannigfaltigkeit dieser Lebensverhältnisse die Veranlassung zu einer Mannigfaltigkeit von Rechten“ (ebd.). Recht reagiere auf das Leben in seinem Wandel.

Diese Vorstellung durchzieht den Diskurs über alle Schulen hinweg (Haferkamp 2005: 86 m.w.N.): Nicht nur die hegelianischen Rechtswissenschaftler, die an Hegels „System der Bedürfnisse“ anschließen, betonen die Rolle des Bedürfnisses in der Rechtserzeugung (vgl. etwa Gans 1827b). Auch Thibaut sieht die „Bedürfnisse der Unterthanen“ (Thibaut 1959: 41 [13]) als handlungsleitend für die Kodifikation an (vgl. auch später Thibaut 1838: 395), ja es wird intensiv nach den „Bedürfnissen der Zeit“ für die Gesetzgebung gefragt (Reyscher 1828).

Diese „Bedürfnisse der Zeit" schwanken zwischen Bestimmtheit und Unbestimmtheit, Bestimmbarkeit und Unbestimmbarkeit. Für Savigny und Puchta sind sie Teil der „dunkeln Werkstätte“ (Puchta 1841: 30) des Volksgeistes, die einer direkten wissenschaftlichen Bestimmung nicht zugänglich ist. Sie sehen das Recht als Indiz an, in dem sich die Bedürfnisse zwar empirisch äußern, aber letztlich nur über die Teilnahme am Volksgeist intuitiv erfasst werden können (vgl. Haferkamp 2005: 88ff.).

Die hegelianische Rechtsschule wiederum sieht im historisch-spezifischen System der Bedürfnisse einen Ausdruck der Vernunft, weshalb es sie zu „begreifen“ gelte (Haferkamp 2011e) - und zwar nicht nur in geschichtlicher Hinsicht, sondern ebenso angesichts der Fragestellungen der Gegenwart (vgl. Stein 1841b: 366, 379). Darüber wird die Vernunft auf den ver- 
schiedenen Stufen ihrer Entwicklung im Recht sichtbar, und so auch in der Gegenwart. ${ }^{176}$

Für Thibaut wiederum sind die Bedürfnisse des Fürsorgeobjekts „deutsches Volk" unproblematisch bestimmt (s.o.). Sie werden ohne eigenen epistemischen Wert ins Feld geführt, sozusagen als gegebener Stoff, an dem sich die eigentlich wissenschaftliche Arbeit der vernünftigen Gesetzgebung beweisen muss. Angesichts dieses Fürsorgeobjekts öffnet sich das Recht für die instrumentalistischen Überlegungen der Steuerung der Gesellschaft über die Gesetzgebung. Auch hier können die Bedürfnisse der Zeit dem Recht der Romanisten entgegengehalten werden, denn sie verlangen nach neuer Kodifikation.

Aber auch in der Pandektistik regt sich zunehmend der Wunsch, die Bedürfnisse des Volks nicht in der spirituellen Sphäre einer kulturellen, nicht direkt wissenschaftlich zugänglichen Wertsphäre zu belassen, sondern selbst als expliziten Gegenstand der Untersuchung zu etablieren (Haferkamp 2011e: 113f.). Johannes Kuntze beschreibt diese Bestrebungen im Jahr 1856 in seinem Buch Der Wendepunkt der Rechtswissenschaft: Als Symptome der Krise der Historischen Rechtsschule werden die vermehrten Tendenzen hin zur Stärkung des Praxisbezugs, zur Emanzipation der Rechtsdogmatik von der Rechtsgeschichte, die Anstrengungen der Verfeinerung der Rechtsdogmatik, insbesondere mit Blick auf die Naturwissenschaften, sowie die Betonung der nationalen Perspektive interpretiert (Kuntze 1856). Dabei sollen die Bedürfnisse nicht gefühlt, sondern begriffen werden, und zwar in den unterschiedlichen historischen Zeiten (Haferkamp 2011e: 115 m.w.N.). ${ }^{177}$ Damit wird die Gegenwart ebenfalls von der Vergangenheit entkoppelt. Nun können - auch von Seiten einer an der Rechtsdogmatik orientierten Pandektistik - die Bedürfnisse der Zeit dem römischen Recht entgegengehalten werden (vgl. Windscheid 1853: 27, 42).

In all diesen Ansätzen formt sich über die Frage nach den Bedürfnissen der Gegenwart ein Aussagenfeld, das das Recht in ein direktes Verhältnis zur gegenwärtigen sozialen Wirklichkeit setzt. Dies wird zur dominierenden Problematisierungsweise. Im Zentrum steht das Problem der Bestimmung

176 Aufgrund der Eigenwertigkeit der Zeiten gibt es nicht nur einen Volksgeist, sondern viele Volksgeister: Denn „[i]n den einzelnen Volksgeistern offenbaret sich diese Vernunft in stufenmäßiger Entwickelung" (Gans 1824: XIII).

177 Haferkamp sieht hierdurch - ähnlich wie Alf Ross (vgl. Ross 1929: 169ff.) - den Boden für die zunehmende Positivierung der Rechtswissenschaften bereitet, die auf der Ebene der Rechtsdogmatik insbesondere in der naturhistorischen Methode Jherings seinen Ausdruck finden wird (vgl. Haferkamp 2011c; s.u. \$2.IV.2). 
dieser Bedürfnisse - ein Problem, das über historischen Kontinuitätsgedanken und Intuition gelöst wird, über die Setzung des Fürsorgeobjekts der Vernunft entproblematisiert wird, über den Vernunftgehalt begriffen werden soll oder über Methoden der Ermittlung der aktuellen Volksüberzeugung angegangen wird. Der Volksgeist erfährt dadurch im juristischen Diskurs als Gegenstand eine Vergegenwärtigung bis hin zur Entgegensetzung von aktuellen Bedürfnissen und bestehendem Recht.

Diese Vergegenwärtigung des Volksgeistes bricht jedoch nicht mit dem Repräsentationsgedanken. Denn im Kern geht es um die Frage der richtigen oder falschen Repräsentation der Sozialsphäre im Recht. Im Grunde basiert die Diskussion nämlich auf der Annahme, dass das Recht den gegenwärtigen Verhältnissen - oder eben: Bedürfnissen - zu entsprechen habe, die ihren adäquaten Ausdruck und damit ihre gelungene Repräsentation im positiven Recht finden sollen.

\subsection{Nichtrepräsentierbarkeit des lebenden Rechts: Die Unmöglichkeit der Rechtswissenschaft (Kirchmann)}

Die Vergegenwärtigung des Volkgeistes vermag aber auch den Wissenschaftscharakter der Jurisprudenz schlechthin in Frage zu stellen. Denn selbst wenn man der Rechtsentstehungslehre folgt, wenn man davon ausgeht, dass das Recht „natürliches Recht“ sei, wie es im Volk gelebt, gefühlt und verwirklicht werde (Kirchmann 1848: 7), so liegt gerade hierin der Grund für die Werthlosigkeit der Jurisprudenz als Wissenschaft, wie der Staatsanwalt Julius Kirchmann in einem viel und kontrovers diskutierten Vortrag aus dem Jahr 1847 ausführt.

Wie jede andere Wissenschaft - Kirchmann hat insbesondere die Naturwissenschaften vor Augen - habe die Jurisprudenz einen eigenen Gegenstand, der unabhängig von ihr existiere (ebd.: 7f.). Diesen Gegenstand versuche sie „zu verstehen, seine Gesetze zu finden, am Ende die Begriffe zu schaffen, die Verwandtschaft und den Zusammenhang der einzelnen Bildungen zu erkennen und endlich ihr Wissen in ein einfaches System zusammen zu fassen“ (ebd.: 9). Das „natürliche Recht" aber stelle einen besonderen Gegenstand dar: Es ruhe im Wissen und Gefühl des Volks, sei selbst nicht wissenschaftlich, da nicht auf die Regel, sondern auf den jeweils besonderen Fall bezogen. Es handele sich immer um gegenwärtiges Recht, das sich ständig verändere. Daher gelte: „Die Gegenwart ist allein berechtigt. Die Vergangenheit ist todt; sie hat nur Werth, wenn sie das Mittel ist, die Gegenwart zu verstehen und zu beherrschen." (Ebd.: 16, H.i.O.) 
Die Beweglichkeit eines derart präsentischen Gegenstandes bewirkt nach Kirchmann, dass keine adäquate Repräsentation des natürlichen, lebenden Rechts möglich sei, die einer wissenschaftlichen Untersuchung zugänglich wäre. Die Wissenschaft, in der sich die Wahrheit langsam den Weg bahnt, komme nicht nur immer zu spät, da die Gesetzmäßigkeiten, die heute aufgespürt würden, morgen schon wieder überholt sein könnten. Vielmehr stehe sie dem wesenhaften Fortschreiten des Rechts sogar feindlich gegenüber, indem die „Bildungen der Gegenwart in die wohlbekannten Kategorien erstorbener Gestalten" gezwungen würden (ebd.: 14).

Da das Recht zudem seinen Sitz im Gefühl - auch des Wissenschaftlers - habe, sei eine wertfreie Betrachtung fast gänzlich unmöglich. Dann handele es sich aber nicht um Wissenschaft, denn: „Das Gefühl ist nie und nirgends ein Criterium der Wahrheit“ (ebd.: 18). Wertfreie Betrachtung angesichts der wertenden Entscheidung, die im Recht gefällt werden, erscheint nicht denkbar.

Eine Lösung dieses Problems der Jurisprudenz könne aber auch nicht darin bestehen, dass sie das gesetzte und in diesem Sinne positive Recht zu ihrem Gegenstand mache. Denn anders als das natürliche Recht sei das positive Gesetz starr und abstrakt, könne nur zu einem kleinen Teil die Wahrheit des lebenden Rechts erfassen und sei daher ,in seiner letzten Bestimmtheit baare Willkühr" (ebd.: 21). ${ }^{178}$ Nicht nur das natürliche Recht leide unter dem positiven Gesetz, sondern auch die Wissenschaft: „Die Juristen sind durch das positive Gesetz zu Würmern geworden, die nur vom faulen Holz leben; vom gesunden sich abwendend. Es ist nur das kranke, in dem sie nisten und weben." (Ebd.: 23)

Das alles erkläre den schädlichen Charakter der sich als Wissenschaft verstehenden Jurisprudenz, den Kirchmann in wuchtigen Worten ausführt. Seine Provokationen führen zu heftigen Gegenreaktionen (vgl. Klenner 1993, m.w.N.). Die Radikalisierung des Volksrechts als gegenwärtiges natürliches Recht führt dabei zum Problem der Wissenschaftlichkeit der Rechtswissenschaft angesichts der Besonderheit ihres Gegenstandes, des lebenden Rechts, das seinem Wesen nach nicht repräsentierbar ist ${ }^{179}$ eine Problematisierungsweise des Repräsentationsgedanken, in deren Zen-

178 Wie Savigny bestreitet Kirchmann den „Beruf“ zur Gesetzgebung, allerdings nicht nur seiner Zeit, sondern aller Zeiten. Letztlich erweist sich das willkürlich gesetzte Recht noch unberechenbarer als das lebende Recht, da es jederzeit geändert werden kann: „[D]rei berichtigende Worte des Gesetzgebers und ganze Bibliotheken werden zu Makulatur" (Kirchmann 1848: 23).

179 Die seitdem so oft geäußerte Frage nach der Wissenschaftlichkeit der Rechtswissenschaft wird auch heute zumeist mit dem Verweis auf Kirchmann verbunden 
trum Kirchmann die Möglichkeit der wissenschaftlichen Untersuchung eines „lebenden Rechts“ prinzipiell in Frage stellt. Während Beseler eine Veränderung der Methode fordert, lehnt Kirchmann die Möglichkeit der wissenschaftlichen Untersuchung gänzlich ab.

Trotz aller Einwände aufgrund der spezifischen Eigenheiten des Gegenstands Rechts bleibt die Wissenschaft des Rechts wie bei Savigny auch für Kirchmann der Wahrheit verpflichtet - gerade deswegen scheitert sie ja an ihrem besonderen Gegenstand. Die Grundprämisse, dass die Rechtswissenschaft - bei Kirchmann analog zu den Naturwissenschaften - eine Seinswissenschaft ist, wird nicht bestritten. Genau aus diesem Grund bereitet nach Kirchmann auch der normative Charakter des Rechts, das „Gefühl“ bzw. das Gerechtigkeitsempfinden, der auf unveränderliche Wahrheit ausgerichteten Wissenschaft unlösbare Probleme. Die Rechtswissenschaft, der als Wissenschaft ein Bezug zum Sollen fremd sei, kann sich daher in ihrer Betrachtung des Rechts nur vom normativen Leben entfernen, wird selbst lebensfremd und steht dem Leben der Gegenwart feindlich gegenüber. Da Kirchmann das Faktum der Normativität des Rechts nicht aus der Vergangenheit herleitet und darüber zu klären sucht, weil er aber auch nicht die vernunftmäßige, da abstrakte und damit für ihn lebensfremde Entscheidung über Wertungsfragen befürwortet, wird die Normativität neben der Beweglichkeit des Gegenstandes für ihn zum Stolperstein der Rechtswissenschaft. Sie führt nicht zu einem Wandel im Wissenschaftsverständnis, sondern schließt die wissenschaftliche Behandlung eines Rechts aus, das sich mit den sozialen Gegebenheit jeweils wandelt. Anders gesagt: Die Rechtswissenschaft scheitert für Kirchmann an der Nicht-Repräsentierbarkeit ihres Gegenstandes, die aus dem lebendigen Charakter des Rechts und seiner Normativität folgt.

\subsection{Politische Repräsentationsprobleme: Römisch-liberales versus germanisch- soziales Recht}

Die Verortung des Rechts im Volksgeist führt trotz der Verwissenschaftlichung und Entpolitisierung des Rechts wieder zurück zur Politik. Denn wenn Recht den Volksgeist repräsentiert, dann zeigt sich im Volksgeist das Volk selbst. Es wird darin lesbar und bestimmbar. Dabei findet ausgehend

- allerdings nicht mit Blick auf das „lebende Recht“, sondern mit Blick auf das Problem der Abhängigkeit einer auf positiven Gesetzen fußenden Rechtswissenschaft von der Gesetzgebung. 
von der Konfrontation des römischen Rechts mit der gesellschaftlichen Wirklichkeit des deutschen Volkes ab Mitte des 19. Jahrhunderts eine bemerkenswerte Umdeutung in der politischen Zuordnung der Rechtslehre der Historischen Rechtsschule statt:

Das politische Argument liegt zunächst in der Reinigung des Rechts vor politischen Einflüssen, die dem Gesetzgeber jegliche Kompetenz zur Kodifikation abspricht, ein politischer Quietismus, der anschlussfähig ist für restaurative Gedanken nach 1815 in Deutschland. Denn das historisch Gewordene kann gegen jegliche Reformbewegung ausgespielt werden. Nicht nur prominente Vertreter der Historischen Rechtsschule wie etwa Friedrich Julius Stahl, Führer der Konservativen in Preußen, begünstigen die Einordnung des Gedankenguts der Historischen Rechtsschule in toto als Ausdruck eines „knöchersten Konservativismus“ (Goldschmidt 1865: 107; s.a. Bruns 1843: 130; Geib 1848: 23) bzw. „einer weit verbreiteten reaktionären Bewegung" (Seeger 1843: 153; s.a. Ruge 1841: 509; später auch Jhering 1861: 369). Demgegenüber erscheinen die Befürworter der Kodifikation ${ }^{180}$ namentlich das ,jüngere Naturrecht“ (Klippel), als liberal. ${ }^{181}$

Diese politische Zuordnung ändert sich Mitte des 19. Jahrhunderts nach der gescheiterten Revolution 1848/49 grundlegend. Nun erscheinen plötzlich die Verfechter des römischen Rechts als die eigentlichen Vertreter liberalen Gedankenguts. Anknüpfungspunkt ist dabei nicht die Rechtsentstehungslehre, sondern deren Produkt, d.h. der „Geist“, der im römischen Recht der Pandektistik zu erkennen sei.

180 Im Vormärz wird die Forderung nach einer gesamtdeutschen Kodifikation seitens vieler Naturrechtler, aber auch zahlreicher Vertreter des germanistischen Zweiges der Historischen Rechtsschule zunehmend mit der politischen Konzeption des Liberalismus verbunden. Sie wird damit zum Teil der liberalen Bewegung (vgl. Schöler 2004: 165ff. m. zahlr. N.) - und somit auch zum Widerpart der restaurativen Politik der deutschen Regierungen. Insofern verwundert es nicht, dass die Frage der Rechtsvereinheitlichung durch eine deutsche Nationalgesetzgebung auf der Tagesordnung der am 18. Mai 1848 zusammengetretenen Nationalversammlung steht. Zum Einfluss der Argumentationsweisen der Historischen Rechtsschule auf Debatten und Abstimmungen der (dominierenden) Juristen innerhalb der Nationalversammlung, die wiederum eine interne Dominanz der Historischen Rechtsschule aufweist, vgl. Siemann 1976.

181 Allerdings muss man sagen: Diese Zuschreibungen sind auf personaler Ebene nicht gleichzusetzen mit der Einteilung der Rechtsschulen in Historische Rechtsschule versus Naturrecht. Auf beiden Seiten ist eine politische Pluralität anzutreffen: Absolutismus, ständisches Recht, Kritik und Rechtfertigung eines Verfassungszustandes oder eben die liberale Konzeption von Individuum, Staat und Gesellschaft fanden gleichermaßen eine naturrechtliche Begründung wie Anhänger im Lager der Historischen Rechtsschule (vgl. Wieacker 1996: 280ff.). 
Im Jahr 1852 veröffentlicht Rudolf von Jhering den ersten Band vom Geist des römischen Rechts auf den verschiedenen Stufen seiner Entwicklung, in dem er Savignys methodologischen Individualismus, der aus seiner holistischen Perspektive folgt, hin zu einer individualistischen Herleitung von Staat und Recht radikalisiert (vgl. Jhering 1852: 101). Staat und Recht seien Produkte des individuellen Willens. ${ }^{182}$ Denn das Individuum trage immer schon, d.h. auch im vorstaatlichen Zustand, das Rechtsprinzip bzw. das Rechtsbewusstsein in sich. Um dieses individuelle Rechtsbewusstsein, das Voraussetzung der Erzeugung jeglichen Rechts sei, zu kennzeichnen, nennt Jhering es das „rein subjektive[] Recht[], beruhend auf der Idee, daß das Individuum den Grund seines Rechts in sich selber, in seinem Rechtsgefühl und seiner Thatkraft trägt und hinsichtlich der Verwirklichung desselben auf sich selbst und seine eigne Kraft angewiesen ist" (ebd.: 102). ${ }^{183}$ Das subjektive Recht, und nicht das Rechtsverhältnis, wird damit der „durch Rückschlüsse zu ermittelnde, äußerste Ausgangspunkt des römischen Rechts" (ebd.). Damit wird Egoismus und Selbstsucht, aber insbesondere der „subjektive Wille“ zu Leitkategorien der Untersuchung.

Der Oberappellationsrath zu Rostock Carl Adolf Schmidt schließt sich ein Jahr später in seiner Schrift Der principielle Unterschied zwischen dem römischen und germanischen Rechte Jherings Charakterisierung des Geistes des römischen Rechts an (vgl. Schmidt 1853: V). ${ }^{184}$ Er will in seiner Schrift allerdings nachweisen, „daß die Voraussetzungen und Principien des römischen Rechts etwas specifisch Römisches sind und mit den Grundprincipien unseres nationalen Staats- und Rechtslebens in directem Widerspruch stehen" (ebd.: VI). Das fremde Recht entspreche nicht dem germanischen Geist, wie er in der germanischen Rechtsordnung zum Ausdruck komme. Während nämlich Rom „lediglich den Begriff der subjectiven Freiheit in Staat und Recht zu realisiren" (ebd.: 17) suchte, gehe das germanische

182 So schreibt er: „Wenn Recht und Staat nicht im Individuum ihren innerlichen Grund hätten, wenn nicht schon jede dauernde Gemeinschaft von Individuen eine rechts- und staatsbildende Kraft in sich trüge: woher wäre denn Recht und Staat in die Welt gekommen?““ (Jhering 1852: 101).

183 Jhering begründet dieses subjektive Recht entsprechend dem Geschichtsdenken der Historischen Rechtsschule rein historisch: Auch wenn in der gegenwärtigen Zeit der Mensch gemeinhin als Rechtssubjekt angesehen werde, handele es sich dabei um eine historisch-spezifische Ansicht, und keinesfalls um eine ahistorische Vernunftwahrheit. Sie habe sich jedoch nur aus dem römischen Recht entwickeln können, weil der Keim in den Ursprüngen des Rechts angelegt sei (ebd.: 98ff.).

184 Vgl. zum Folgenden insbesondere Luig 1995: 114ff., v.a. mit Blick auf die Hegel'sche Unterscheidung zwischen römischen und germanischen Leben. 
Recht von einem „objective[n] Sittengesetz“ aus, das „über dem subjectiven Willen der Einzelnen" stehe (ebd.: 47). Es gehe damit von der Verpflichtung aus, „sich in allen rechten und sittlichen Dingen einander beizustehen“ (ebd.: 49). Kurz: Das römische Recht ist nach Schmidt Ausdruck eines individualistischen Geistes, das germanische Recht hingegen auf Gegenseitigkeit ausgerichtet und damit gemeinschaftsbezogen, d.h. sozial; und folglich rücken die Genossenschaften und gesellschaftliche Ordnungen in ihren Verbänden und Lebenskreisen als Rechtsmaterien in den Mittelpunkt. Genau hierin liegt für Schmidt der Vorzug des germanischen Rechts.

Auch wenn die Rezensionen der Schrift Schmidts kritisch ausfallen, stützen sie doch die Grundannahme hinsichtlich des charakteristischen Gegensatzes dieser beiden Rechtsordnungen als römisch-individualistisch versus germanisch-sozial (vgl. Bruns 1882 [1853]; Esmarch 1853: 1016; Dernburg 1853: 274f.). Verschärft wird die Debatte zudem durch das Buch Ueber die geschichtliche Entstehung des Rechts des Greifswalders Rechtsanwalts Gustav Lenz, demzufolge Schmidt die römischen Rechtsansichten scharf und treffend charakterisiert habe (Lenz 1854: 311 Anm. 214). Denn wie Schmidt bestimmt Lenz das römische Recht als eine Rechtsordnung, die die Person und deren Willen als Grundlage begreift. Darin sieht Lenz nun jedoch gerade seinen überlegenen Wert: Es sei ein „absolutes Recht“, das als Vorlage aller zukünttigen Gesetzgebung zu dienen habe (ebd.: 35). ${ }^{185}$

Während Schmidt das soziale Recht der Germanen und Lenz das individualistische Prinzip des römischen Rechts preisen, setzt sich der Naturrechtler Karl David August Röder für die Überwindung solcher Einseitigkeiten ein. Zwar erkennt auch er den individuellen Charakter des römischen Rechts, wohingegen die Germanen sich durch „die Gebundenheit durch die gesellschaftlichen Ordnungen“ auszeichneten (Röder 1855: 66). Doch handelt es sich Röder zufolge nicht um einen Gegensatz verschiedener Rechtsordnungen, sondern um zwei Seiten des einen Rechtsbe-

185 Lenz leitet dieses absolute Recht der Römer aus der Unabhängigkeit von der Sitte eines Volkes her. Wenn ein Recht im Volk als ein organisches Naturganzes begründet wird, so kann es nur lokale und partikulare Geltung beanspruchen. Demgegenüber handelte es sich bei den Römern um ein reines „Menschencollectiv“ bzw. einen „Verein von Menschen, der kein Volk war“ (Lenz 1854: 36, 35). Die Plebejer hätten in einer Gemeinschaft „ohne organischen Zusammenhang mit traditioneller Sitte und Sittlichkeit“ (ebd.: 152) gelebt und hätten daher ein Privatrecht von absolutem Charakter hervorbringen können (zu Lenz vgl. Hofer 2001: 58). 
griffs (so auch Bruns 1882 [1853]: 327). Damit verschiebt er die Frage hin zu einem allgemeinen Problem: Es geht um die Frage der „Vermittlung und Versöhnung der Einzelfreiheit mit der einheitlichen Gesellschaftsordnung“ (Röder 1855: 60). Im Recht und mit dem Recht geht es nun um das Verhältnis von Individuum und gesellschaftlicher Ordnung - ausgetragen anhand der verschiedenen Rechtsordnungen, wie sie sich im römischen und im germanischen Recht zeigen.

In all diesen Positionen verfestigt sich das Bild der entgegengesetzten Rechtsordnungen als römischen-individualistisch versus germanisch-sozial zu einer unhinterfragten Grundannahme - sei es, dass eine Seite bevorzugt wird, sei es, dass sie versöhnt werden sollen. ${ }^{186}$ Der Gegenstand ,Recht', der jeweils einen ganzen Rechtskorpus als Einheit umfasst, wird als Ausdruck bestimmter Geistes- und Volkshaltungen gesehen - aber nur, weil das Recht als Repräsentation der jeweils zur Debatte gestellten gesellschaftlichen Ordnungen angesehen wird.

Gleichzeitig wird darüber aber auch der politische Geist dieser Rechtsordnungen bestimmt, worin sich die erwähnte Umwertung zeigt: Richtet man den Blick auf den Systemaufbau der Romanisten, die sich in der Binnenperspektive einem methodologischen Individualismus verpflichten, dann erscheint das römische Recht nicht mehr konservativ oder reaktionär, sondern als Verwirklichung der liberalen Prinzipien. ${ }^{187}$ Die Orientierung im Binnenraum des Rechts an der Freiheit des Subjekts und die Privi-

186 So schreibt Klaus Luig: Mit Kuntzes Der Wendepunkt der Rechtswissenschaft aus dem Jahr 1856 „ist schließlich die These vom Individualismus des römischen Rechts und vom sozialen Geist des germanisch-deutschen Rechts bei Freund und Feind endgültig etabliert" (Luig 1995: 135); zur Herausbildung dieses ursprünglich nicht bestehenden Gegensatzes in der Historischen Rechtsschule vgl. Kroeschell 1977; mittlerweile hat sich aus rechtshistorischer Perspektive die Position etabliert, dass dieser Gegensatz nicht in der Rechtsmaterie begründet liegt, vgl. hierzu die Beiträge von Klippel, Landau, Kroeschell und Rückert in Rückert, Willoweit 1995.

187 An diese Perspektive schließt Marx in seiner Kritik des Rechts in der Politischen Ökonomie an, wobei für ihn kein anderes Recht aus der kapitalistischen Produktionsform erwachsen kann. Marx setzt an den privatrechtlichen Rechtsverhältnissen an, die für ihn aber weder ,aus sich selbst“ (gemeint ist Savigny) noch „aus der allgemeinen Entwicklung des menschlichen Geistes“ (gerichtet gegen Hegel) zu begreifen sind, sondern „in den materiellen Lebensverhältnissen“ wurzeln (Marx 1971 [1859]: 8). Die materiellen Grundlagen sind die Verhältnisse der sozialen Herrschaft in der bürgerlichen Gesellschaft, welche im Recht in die Ideologie der subjektiven Freiheit und rechtlichen Gleichheit verkehrt werden. Daher erweist sich das bürgerliche Recht des „heutigen römischen Rechts“ nach Savigny neben dem Naturrecht als Ort seiner Rechtskritik, wird hier doch 
legierung seines Willens werden als Ausdruck einer liberalen Gesinnung interpretiert. Mehr noch, die Freisetzung des Subjekts im Privatrecht wird mit der öffentlich-rechtlichen Forderung nach Volkssouveränität in Verbindung gebracht (Dernburg 1853: 270). Demgegenüber erscheint der germanische Geist mit seiner Koppelung an die sozialen Verpflichtungen nicht nur als Form eines modernen Konservativismus, sondern wird auch in die Nähe des „francösischen Socialismus“ gerückt (Bruns 1882 [1853]: 327.), wenn er nicht gar als sozialistische oder kommunistische Position verstanden wird (vgl. Röder 1855). Diese Debatten verdichten sich zur Koppelung römisch-liberal versus germanisch-sozial. ${ }^{188}$

Nicht in der Rechtsentstehungslehre, die das Recht durch die Verlagerung der Genese in den Volksgeist von der Politik zu reinigen sucht, sondern in dem, was durch ,das Volk' produziert wurde, d.h. im positiven Recht in seiner Einheit im jeweiligen Rechtskorpus, wird der politische Geist gesucht und gefunden. Im Recht, d.h. in seiner Ordnung, zeigt sich der "Geist" des Volkes, sein Spezifikum und Charakteristikum. Daher ist das Recht der herausragende Ort, um den Volksgeist bestimmbar zu machen. An diesem Geist lagern sich die politischen Probleme an - ein Geist, der jedoch der Repräsentationsleistung des Rechts entspringt und daher weder Rechtsentstehungslehre noch den Repräsentationsgedanken in Frage stellt.

\section{3. „Lebendes Recht“ als Repräsentationsproblem}

Wird das Recht im Diskurs der Privatrechtswissenschaft als „lebendes“ oder „lebendiges Recht“ gefasst, so wird darüber in den Debatten um die Prämissen der Historischen Rechtsschule der Bezug des Rechts zur gegenwärtigen sozialen Wirklichkeit problematisiert. Dieser Bezug nimmt gera-

das gleiche Recht der Person auf freie Verfügung über Sachen (Eigentum) und deren Tausch (Vertrag) etabliert. Dies ist für Marx die funktional notwendige Rechtsgestalt der Herrschaftsform der bürgerlichen Gesellschaft. Debatten um soziale Rechte (insbesondere seitens der französischen Sozialisten) erscheinen ihm als „Albernheit“ (vgl. Marx 1974 [1857/58]: 160), da sie an dieser Rechtsgestalt (respektive Rechtsform) nichts ändern (vgl. a. Marx, Engels 1972 [1848]). Letztlich hat Marx also nur das individualistische Privatrecht im Auge, das den sozialen Verhältnissen entsprungen und damit ebenso ein Produkt der Gesellschaft ist. Zur Kritik der marxistischen Rechtstheorie in ihrer Verengung auf das individuelle Privatrecht unter Ausschluss des sozialen Rechts vgl. Menke 2013.

188 Über Theodor Mommsen wandert das Bild des liberalistischen und individualistischen römischen Rechts in die Nationalökonomie ein, vgl. Luig 1995: 135. 
de auch im Feld der Gegnerschaft die Form eines Repräsentationsproblems an: Vorgeworfen werden der Historischen Rechtsschule Missrepräsentationen, insbesondere unter der Vergegenwärtigung der Sozialsphäre, das Scheitern der Wissenschaft an der Nicht-Repräsentierbarkeit des Gegenstandes bzw. die politischen Probleme des repräsentierten Geistes des Rechts. Auf der rechtstheoretischen Ebene geht es nicht um Bestimmungsversuche des Rechts etwa über seine gesellschaftlichen Funktionen (z.B. der Kontrolle, der Steuerung oder der Erwartungssicherung). Ebenso wenig stehen Abgrenzungsprobleme etwa von Recht und Moral oder Recht und Gewalt im Vordergrund. Die Aussagen formieren sich vielmehr um die Frage, ob das wissenschaftlich gefundene Recht dem Volksgeist als gegenwärtige, objektiv bestehende Wirklichkeit einen adäquaten Ausdruck gibt. Der Diskurs formiert sich um die Frage der Repräsentation der Sozialsphäre im Recht; das Repräsentationsproblem wird zur Problematisierungsform des Rechts und der Rechtswissenschaft.

Mit der Akzeptanz des Repräsentationsgedankens wird zugleich die Rechtsentstehungslehre in ihren Grundzügen anerkannt: Nur weil das Recht dem Volksgeist als eine unabhängige Sozialsphäre entspringt, ist es überhaupt in der Lage, diese Sphäre zu repräsentieren. Dabei zeigt sich: Das vage und verschwommene Ding „Volksgeist" vermag die Rechtswissenschaft in zentralen Punkten wie Theorie, Gegenstand, Methode und Wissenschaftlichkeit in Frage zu stellen. Es wird zu einer „Fragemaschine“ im Diskurs der Rechtswissenschaft, indem es bestimmte Arten des Fragens und Vorgehens stimuliert, bestimmten Forschungsbedarf generiert und das Repräsentationsproblem als eine bestimmte Problematisierungsform institutionalisiert.

Gerade dadurch wird die Sphäre des Sozialen im Aussagefeld des juristischen Diskurses über das Privatrecht systematisch hervorgebracht. Der „spiritualistische“ bzw. „mystische“ Charakter der Volksgeistlehre, den ihr von Anfang an auch Vertreter der Historischen Rechtsschule ankreiden, wird dabei nicht durch die Ablehnung der Rechtsentstehungslehre, sondern durch die Vergegenwärtigung der Sozialsphäre aufzulösen gesucht. Mit dem Repräsentationsgedanken werden damit Recht und gegenwärtiger Volksgeist (als Synonym für eine vom Staat und Vernunft unabhängige Sozialsphäre) systematisch als Gegenstände gebildet, von denen gesprochen wird. Der Volksgeist wird im Diskurs der Privatrechtswissenschaften zu einem epistemischen Ding, das über die Problematisierungsform der Repräsentation verhandelt wird. Die Macht des Rechts, die Rechtsmacht, besteht in der Generierung dieser Wirklichkeit, und das Repräsentationsproblem des Rechts wird als Wirklichkeitsproblem verhandelt. 


\section{Der Volksgeist in der Rechtsdogmatik: Die Problematisierung der Eigenart und des Werts der Rechtswissenschaft}

Jenseits dieser großen Debatten in den Rechtswissenschaften entfaltet die Rechtsquellenlehre der Historischen Rechtsschule gerade im Bereich der Rechtsdogmatik zusehends und nachhaltig ihre dominante Wirkung. Das Recht wird als System adressierbar, es erscheint nun als ein „inneres“ oder „organisches System“. ${ }^{189}$ Savignys Systemverständnis wird zur Grundlage für die systematische Betrachtungsweise der Romanistik (bzw. Pandektistik), aber auch der Germanistik, und greift davon ausgehend auch auf andere juristische Bereiche wie etwa das Staatsrecht-, das Kirchen- oder das Prozessrecht über, die in einer ganz anderen Tradition stehen (vgl. Wieacker 1996: 412; Wilhelm 1958).

Das Repräsentationsproblem, das im „lebenden Recht" eingelagert ist, wird in der Rechtsdogmatik als Erkenntnisproblem formuliert: Es geht um die spezifische Eigenart der rechtswissenschaftlichen Arbeit, die mittels ihrer Techniken die Erkenntnis des lebendigen Charakters des Recht gewährleisten soll. Dabei zeigt sich in der Entwicklung der rechtswissenschaftlichen Dogmatik, die v.a. im Bereich des römischen Rechts vorangetrieben wird, ${ }^{190}$ eine Aufwertung der juristischen Begriffs- für die Systembildung in ihrer spezifischen Technizität - nun auch im produktiven, systemerweiternden Sinne. In dieser Produktivität wiederum wird der besondere Wert der Rechtswissenschaft gesehen, vermag dies doch den geforderten Lebensbezug des Rechts zu garantieren und das Recht gewissermaßen am Leben zu erhalten. Und genau das lässt sich an den rechtsdogmatischen Entwürfen der beiden meist zitierten Vertreter der Romanistik zeigen: Georg Friedrich Puchta und Rudolph von Jhering.

189 Damit ist nicht unbedingt immer ein gleichartiger Systembegriff gemeint, allerdings wird auf der Rechtsentstehungslehre aufgebaut (vgl. die Nachweise bei Henkel 2004: 108ff.).

190 Dies liegt insofern nahe, als das römische Recht mit seiner Verankerung im corpus iuris eine ungleich sicherere gemeinsame Grundlage bietet als das schon allein aufgrund seiner Quellenbasis viel fragmentiertere einheimische, d.h. germanische Recht. 
1. Die Eigenart der Jurisprudenz angesichts des "lebenden Rechts": Produktive Jurisprudenz (Georg Friedrich Puchta)

Der Romanist Georg Friedrich Puchta schließt direkt an das epistemische Schema des von ihm bewunderten Savigny an: mit der axiomatischen Gründung des Rechts auf einer vorgängigen, objektiv existenten Sozialsphäre, die er - gegenüber dem hegelianischen Bedeutungsinhalt - erfolgreich mit dem Namen "Volksgeist“ belegt (vgl. Puchta 1828: 133ff.; 1841: 23ff.; 1838: 11; 1847: 20ff.); mit der Bestimmung dieser Sphäre als lebendigen Organismus (vgl. Puchta 1841: 45, 95; 1828: 158; 1847: 16); dadurch der Festlegung auf eine organische Einheit; ihrer Begrenzung auf das Bewusstsein (vgl. Puchta 1841: 23ff.); mit der Vorgängigkeit dieser Einheit vor den Individualinteressen, was die Unverfügbarkeit des Rechts durch Einzelne, aber auch durch den Staat impliziert (vgl. Puchta 1828: 157f.); schließlich auch mit der Aussonderung des Rechts als Glied des Ganzen, d.h. als eigenständiger lebendiger Organismus, der Gegenstand einer eigenen Wissenschaft sein kann (vgl. etwa Puchta 1841: 100, 45, 77). Daher problematisiert auch Puchta das Recht über die Frage, wie es eigentlich zu erkennen sei - und das ebenso im Hinblick auf das heutige gemeine, d.h. römische Recht. Wie Savigny behandelt er das positive Recht, d.h. die „geschichtliche Thatsache“ (ebd.: 96) des Rechts als ein Phänomen des Seins und nicht des Sollens.

Puchta trennt jedoch deutlicher als Savigny zwischen Recht und Volksgeist. Der Zugang zu der im Volksgeist liegenden geistigen Einheit ist dem Juristen im Grunde gänzlich verwehrt (vgl. Haferkamp 2012: 79). ${ }^{191}$ Daher erweist sich der proklamierte Zusammenhang zwischen Recht und Volksgeist selbst als problematisch.

\subsection{Das Recht der Wissenschaft}

Um diese nun offene Frage nach dem Verhältnis von Recht und Volksgeist zu klären, unterscheidet Puchta zwei Arten des Juristenrechts: Einerseits existiere das Juristengewohnheitsrecht, das die Juristen in ihrer Funktion als „natürliche Repräsentanten [...] des nationellen Rechtsbewußtseins“

191 Das liegt daran, dass der Erkenntnismangel bei Puchta auch für den Entstehungszusammenhang gilt: „Was uns sichtbar ist, das ist nur das Entstandene selbst, das Recht also, nachdem es aus der dunkeln Werkstätte, in der es bereitet wurde, hervorgetreten und wirklich geworden ist.“ (Puchta 1841: 30). 
(Puchta 1847: 39) aussprächen. ${ }^{192}$ Geltung beansprucht dieses Recht aufgrund der Tatsache, dass man es auf die dem Recht letztlich äußere Autorität der „unmittelbare[n] Volksüberzeugung zurück[...]führen“ könne, die im Zuge der Entwicklung des Rechts auf die Juristen übergegangen sei. Im Sinne des Repräsentationsgedankens können solche Rechtssätze der Juristen also Rechtsquelle sein.

Genau das aber kann nach Puchta „natürlich von der wissenschaftlichen Thätigkeit als solcher und ihrer Wirkung nicht gesagt werden" (Puchta [anonym] 1839: 730). ${ }^{193}$ Daher stehe dem Juristengewohnheitsrecht das "Recht der Wissenschaft" gegenüber, das sich aus der wissenschaftlichen Arbeit am Recht, d.h. aus inneren, systematischen Gründen herleite (vgl. Puchta 1837: 14f.). Es entstehe als „Product einer wissenschaftlichen Deduction“ (Puchta 1841: 37). Die Geltung beruhe dabei auf seiner „inneren“ Autorität, d.h. konkret auf „1) der Vernunftmäßigkeit des bestehenden Rechts, 2) auf der Wahrheit der daraus abgeleiteten Principien, und 3) auf der Richtigkeit der Folgerungen, die aus diesen Principien gemacht werden" (Puchta 1847: 39).

Puchta nennt also dezidiert „innere Gründe“ für die Geltung des Rechts. Er verweist auf einen Binnenraum des Rechts, der allein der wissenschaftlichen Handhabung zugänglich ist, nämlich über Vernunft, Wahrheit und korrekte Schlussfolgerung. Nur dieses Recht kann legitimerweise das „Recht der Wissenschaft“, also Gegenstand der Rechtswissenschaft sein.

Diese Konzeption entspricht einem veränderten Rechtsverständnis: Dass das Recht dem Volksgeist entspringe, zeige die freie Seite jeglichen Rechts. Es sei historisch-kontingent, Produkt der freien menschlichen Tätigkeit, immer ein Recht im Werden. Freiheit sei also der „Keim des Rechts" (Puchta 1841: 6), das daher in seiner Entwicklung keiner inneren Notwendigkeit folge. Gleichzeitig ist das Recht für Puchta aber „etwas Vernünftiges“ und daher ein „in seiner Entwicklung einer logischen Nothwendigkeit Unterliegendes“ (Puchta 1847: 22). ${ }^{194}$ Es entspringe der Tätigkeit des menschlichen Geistes, die den faktischen Ungleichheiten

192 Diese Ausdifferenzierung des Juristenrechts erfolgt im zweiten Teil der Abhandlung Das Gewohnheitsrecht (1837; vgl. hierzu Haferkamp 2004: 371ff.).

193 Die Autorenschaft Puchtas dieser anonym publizierten Rezension ergibt sich nach Haferkamp zweifelsfrei aus dem Text (Haferkamp 2004: 478).

194 Allerdings entstammt das Recht nicht der Vernunft, wie es das Vernunftrecht postuliert (vgl. Puchta 1841: 6). Puchta leitet die Vernunftseite vielmehr von anthropologischen Annahmen bzgl. des menschlichen Geistes ab (vgl. ebd.: 3ff.), die sich insbesondere in der Notwendigkeit zeigen, die „natürliche Ungleichheit 
und Mannigfaltigkeiten Herr zu werden suche. Das Recht ordne die natürlichen divergenten Verhältnisse unter Gleichheitsgesichtspunkten, d.h. über Vergleichung. Damit befinde sich das Recht immer in Spannung zwischen Freiheit und Gleichheit. Aber gerade die Seite der Vergleichung gewährleiste das „Band“ des menschlichen Zusammenhalts (Puchta 1841: 17). Dieses Band sei die ordnende Kraft des Rechts, die das menschliche Miteinander ermögliche und der zerstörenden Kraft des Individualismus entgegenwirke (ebd.). ${ }^{195}$ Nicht organische Harmonie wie bei Savigny, sondern Harmonisierung zum Zwecke der zwischenmenschlichen Bindung aneinander steht bei Puchta im Vordergrund. ${ }^{196}$

Volksgeist und logische, innere Notwendigkeit werden damit zum doppelten Bestimmungsgrund des Systems: Auf der einen Seite stellt sich das Rechtssystem als ein lebendiger, in freier Entwicklung begriffener organischer Zusammenhang dar; andererseits weist das Recht einen logisch-vernünftigen Zusammenhang auf, und „dieß ist die Seite von welcher es ein System ist, einen Organismus von Gattungen und Arten bildet“ (ebd.: 6). Damit wird die Erkenntnis der „inneren Gründe“, d.h. der logisch-vernünftigen Seite, zu einer Erkenntnisquelle des Rechts (ebd.: 45). ${ }^{197}$ Das hat Rückwirkungen auf die Anordnungsebene. Als vernünftiges Ganzes hat der Organismus, das System, nach Puchta - anders als bei Savigny - ein

der Menschen und Verhältnisse“ (ebd.: 18) unter Gleichheitsgesichtspunkten überhaupt handhabbar machen zu können. Daher bestehe der Sinn des Rechts darin, „die Gleichheit zu schützen“ (ebd.; vgl. hierzu Haferkamp 2004: 352ff.). Die Spannung von Ungleichheit und Ordnungssuche durch das vergleichende Recht wird zum Motor der Rechtsentwicklung (vgl. Puchta 1841: 36), handelt es sich doch bei der Gleichheit um ein Prinzip, das den Keim der Selbstergänzung des Rechts ausmacht (s.u.).

195 Eine weitere verbindende Kraft sei die Liebe, auf der die „natürlichen Verbindungen“ wie Ehe, Familie, Volk, Nächstenliebe bis hin zur Liebe zu Gott als „wahre Mutter derselben“ beruhten (Puchta 1841: 17f.).

196 Recht wird bei Puchta nicht nur zum Erkenntnismittel, sondern nun auch zum Garanten der gesellschaftlichen Ordnung. Da dieser Gedanke auf der dogmatischen Ebene keine Auswirkung hat, wird er hier nicht weiter berücksichtigt, auch wenn Übergänge zur Frage nach der gesellschaftlichen Funktion des Rechts erkennbar sind (vgl. $\$ 4$ ).

197 Dabei löst Puchta den Begriff des Rechts nicht in der Vernunft auf - es geht um den Blick in die "auch-vernünftige“ Natur des Rechts, die jedoch nicht dem Vorrang der freien Seite des Rechts zu widersprechen vermag (vgl. Puchta 1841: 36f.). 
„Fundament“: Die Freiheit des Einzelnen, d.h. die Gründung des Rechts auf der Möglichkeit eines Willens (ebd.: 9, 10). ${ }^{198}$

Systemdenken zeichnet sich bei Puchta durch Fundierung des Rechts im subjektiven Recht aus, der methodologische Individualismus wird als Grundlage der Erkenntnis des Systemaufbaus beibehalten bzw. noch gestärkt. ${ }^{199}$ Gegenüber Savigny leitet Puchta das subjektive Recht, die Willensmacht des Einzelnen als Recht entsprechend seines veränderten Rechtsbegriffs nicht von der intersubjektiven Beziehung im wirklichen Leben, d.h. aus den faktischen Verhältnissen in den Rechtsverhältnissen ab. ${ }^{200}$ Diese sind für ihn nur „schwankende[] Vorstellungen“ bzw. „wechselnde[] Wellen" (Puchta 1838: VII; 1841: 52). ${ }^{201}$ Vielmehr rekurriert er auf eine „philosophische“, bei genauerer Betrachtung jedoch anthropologischtheologische Bestimmung des Rechts (vgl. Puchta 1841: 3ff.). 202

198 Zur zeitgenössischen Kritik an der Überbetonung logischer Elemente in dieser Setzung vgl. Haferkamp 2004: 281ff.; zum Einfluss von Schellings Freiheitsphilosophie auf Puchta vgl. Haferkamp 2004; Landau 1992: 4ff. m.w.N.

199 Damit ist jedoch - entgegen späterer Interpretationen - noch nicht geklärt, ob es sich dabei um ein System in Form einer hierarchisierenden Stufenleiter oder um ein zirkulär verfahrendes System handelt (vgl. hierzu Henkel 2004: 52f.).

200 Er dreht vielmehr das Verhältnis um: „Rechte bilden den Kern der Rechtsverhältnisse, die Rechtsverhältnisse sind Complexe von Rechten“ (Puchta 1845: 42). Daher fügt er erst im Jahr 1841 das Rechtsverhältnis bzw. das System der Rechtsverhältnisse (hier aber verstanden als Einteilung der Personen nach ihrer Stellung, z.B. Einzelner, Familienmitglied, Volksglied oder Glied der Kirche), dem System der Rechte hinzu, wie er es schon in den 1820er Jahren entworfen hatte (vgl. Puchta 1841: 54ff.).

201 Die Abwendung vom Rechtsverhältnis ist verbunden mit einer Aufwertung des Rechtssatzes als sichere Grundlage - Puchta arbeite „[e]nger am Text“ (Haferkamp 2012: 78).

202 Auch wenn man hierin eine Annäherung von Puchtas Subjekt des subjektiven Rechts an das liberale Subjekt des Vernunftrechts zu erkennen vermag, wendet sich Puchta explizit gegen das Natur- und Vernunftrecht, indem er die philosophischen Bestimmungen im positiven Recht zu verankern sucht. Daher ist die „Person“ nicht Ausdruck einer Gleichheit des Subjekts als Mensch. Das Recht bildet keine natürliche Gleichheit ab, sondern ist Folge des vergleichend vorgehenden Rechts angesichts faktischer Ungleichheit: „So geht der Zug des Rechts nach einer Gleichheit, die der rechtlichen Anschauung der Dinge ein hartes und kaltes Ansehen giebt, und der weichen Phantasie, der spielenden Lust der Gefühle unheimlich erscheint. Die Vielseitigkeit des menschlichen Wesens wird im Recht zu dem farblosen Begriff der Person verflüchtigt, es läßt den Reichthum der äußeren Natur zu dem gleichmachenden Begriff der Sache einschwinden“" (Puchta 1841: 18f.). Daher lehnt Puchta auch die natur- und vernunftrechtliche Frage nach dem „Seynsollenden“ ab (ebd.: 97), derzufolge das Subjekt aus Gründen jenseits des positiven Rechts gleich ist und daher gleich sein soll. 
Trotz dieser Divergenz im Rechtsbegriff ermittelt Puchta den Systemaufbau ähnlich wie Savigny: Auf induktivem Weg werden die Rechtssätze anhand gleicher Merkmale über die Gegenstände der Unterwerfung unter den menschlichen Willen (subjektives Recht) in Gruppen zu Rechtsinstituten zusammengefasst (vgl. Puchta 1847: 94).203 Allerdings verlagert er den Schwerpunkt hin zur Begriffsarbeit und versucht die Rechtsinstitute unter Begriffe zusammenzufassen (vgl. Haferkamp 2003: Rn. 55). Ziel ist die typisierende und klassifizierende Arten- und Gattungsbildung in der Begriffsbildung (vgl. Puchta 1851: 247).

Mittels dieser systematisierenden Ordnung des Stoffs durch Begriffe habe man jedoch noch nicht den inneren Zusammenhang des Rechts erkannt - und damit letztlich auch nicht den wahren Begriff. Eine solche Kenntnis besitzt nach Puchta derjenige,

welcher des Zusammenhangs der Rechtssätze sich bemächtigt, ihre Verwandtschaft unter einander erforscht hat, so daß er die Abstammung eines jeden Begriffs durch alle Mittelglieder, die an seiner Bildung Antheil haben, auf und abwärts zu verfolgen vermag (Puchta 1841: 101). ${ }^{204}$

Denn nur aus der Stellung im System, vermittelt über die den verschiedenen Rechtsklassen zugehörigen Begriffe, und nicht aus sich selbst heraus könne die Natur und Bedeutung eines konkreten subjektiven Rechts er-

203 Darüber gewinnt Puchta grundverschiedene „Classen, durch die sich die Natur und Behandlung der ihnen zugehörigen Rechte bestimmen“ (vgl. Puchta 1847: 94). Trotz Einheit im Rechtsbegriff ergibt sich eine Ordnung, die aus streng zu unterscheidenden Rechten besteht. Eine Verschiedenheit der Gegenstände bedingt eine Verschiedenheit der Rechte (Puchta 1838: 32). Puchta identifiziert hierbei fünf Gegenstände der Unterwerfung unter den rechtlichen Willen, denen die Klassifikation der Rechte folgt: Rechte an der eigenen Person (hier ordnet er den Besitz ein), Rechte an Sachen, Rechte an Handlungen, Rechte an Personen außer dem Berechtigten, Rechte an Personen, die in den Berechtigten übergegangen sind (z.B. Erbrecht).

204 Hier siedelt Puchta die Frage nach der Methode der Rechtswissenschaft an (vgl. Puchta 1841: 100). Es geht um die Erkenntnis des systematischen Zusammenhangs. Anders als Savigny betont er an dieser Stelle nicht die Tätigkeit der Auslegung als zentrale Methode der Rechtswissenschaft, sondern vielmehr die dogmatische Herleitung von Rechtssätzen über die systematische Kenntnis. Entsprechend ändert er die Interpretationslehre: Gegenüber Savigny betont er die Wortlautgrenze der Auslegung (vgl. Haferkamp 2012: 77). Die Interpretation ist für ihn „in der That nur declaratorisch“ (Puchta 1847: 36). Die Rechtssätze werden zum festen Grund. Systematische Arbeit mit inneren Gründen weist jedoch darüber hinaus - sie ist Produktion (siehe dazu gleich). 
kannt werden. Die induktiv vorgehende Begriffsbildung dient zur Einordnung und Erkenntnis, das Begriffssystem macht den Rechtsstoff beherrschbar, indem es Erkenntnisse über den dogmatischen Gehalt, die Natur des Rechts und seine Stellung im Gesamtzusammenhang gibt (vgl. Henkel 2004: 84).

Über die Begriffe lassen sich zugleich die Prinzipien erkennen. Sie seien die Leitlinien, die Rechtsregeln bzw. die Grundsätze des Rechts, die die wertenden Aspekte des Rechts darstellen. Anders formuliert: Nach den Prinzipien, die im positiven Recht ihren Ausdruck finden, kann ein Fall beurteilt werden (vgl. etwa Puchta 1845: 21). ${ }^{205}$ Auf sie lassen sich die Wirkungszusammenhänge innerhalb der Rechtsinstitute sowie zwischen ihnen zurückführen (Haferkamp 2003: Rn. 55). Daher sei es

Aufgabe der Wissenschaft, die Rechtssätze in ihrem systematischen Zusammenhang, als einander bedingende und von einander abstammende, zu erkennen, um die Genealogie der einzelnen bis zu ihrem Princip hinauf verfolgen, und eben so von den Principien bis zu ihren äußersten Sprossen herabsteigen zu können (Puchta 1841: 36).

Dieser Wirkungszusammenhang zeige sich in den Konsequenzen und Analogien, die sich ausgehend von den Prinzipien aufzeigen ließen und zu den technischen Mitteln der Rechtswissenschaft würden: „Im allgemeinen gelangt man" zur Erkenntnis des wissenschaftlichen Rechts

durch eine doppelte Operation 1) Erschließung des Rechtssatzes aus den Principien, unter welche der Fall seiner Natur nach gehört (juristische Consequenz), 2) Nachweisung, daß dieselbe Folgerung auch sonst schon unter gleichen Umständen in dem bestehenden Recht vorkommt (Analogie) (Puchta 1844a: 26).

Während die Begriffe die Anordnungsebene des (vor-)gegebenen Materials betreffen, und damit die rezeptive Seite der Wissenschaft hervorheben, ${ }^{206}$ erlauben die Prinzipien die produktive Tätigkeit der Rechtswissenschaft.

205 Hier zeigt sich der normative Charakter des Volksgeistes, da die im Rechtssatz niedergeschlagen Prinzipien Ausdruck der Rechtsentstehungslehre sind.

206 Aufgrund dieser „Genealogie der Begriffe“ hat man Puchta als Protagonisten der Begriffsjurisprudenz angesehen (s. hierzu $\$$ 3.I.1.1, $\$$ 5.I.1.3), wobei manche einer solchen Einordnung vehement widersprechen (siehe etwa Haferkamp 2004; Henkel 2004; Mecke 2008: 763ff. m.w.N.). Ordnet man jedoch den Ausdruck "Genealogie der Begriffe“ in die Debatten zu Puchtas Zeit ein, so wird man auf die logische Ebene der Arten- und Gattungsbildung verwiesen. Puchtas Leipziger Kollege Wilhelm Traugott Krug beschreibt diesen Zusammenhang in sei- 
Denn bei der doppelten Operation der Rechtswissenschaft, der juristischen Konsequenz und Analogiebildung,

werden Rechtssätze zum Bewusstseyn gebracht und zu Tage gefördert werden, die in dem Geist des nationellen Rechts verborgen, weder in der unmittelbaren Ueberzeugung der Volksglieder und ihren Handlungen, noch in den Aussprüchen des Gesetzgebers zur Erscheinung gekommen sind, die also erst als Product einer wissenschaftlichen Deduction sichtbar entstehen (Puchta 1841: 36f.).

Die Rechtswissenschaft könne über systematische innere Folgerichtigkeit gemäß der in den Prinzipien vorzufindenden „ratio iuris" die im System verborgenen Rechtssätze erschließen (vgl. Puchta 1847: 51). Die Analogiebildung gewährleiste dabei, dass diese Rechtssätze in das bestehende Recht eingebettet sind, also nicht gänzlich neue Prinzipien eigenständig erschaffen werden. Arbeiten mit „inneren Gründen“ sei in dieser Hinsicht Produktion, oder eben, dem Duktus seiner Zeit entsprechend, Produktion einer Deduktion (Henkel 2004: 86). ${ }^{207}$

Das ist insofern von entscheidendem Interesse, als sich in dieser Tätigkeit Rückschlüsse auf den Umgang mit ungelösten oder unbekannten Fallkonstellationen ziehen lassen. Denn wie Savigny interessiert Puchta nicht ein Idealbetrieb des Rechts, sondern die Frage, wie man damit umzugehen habe, dass das vorfindliche (römische) Recht voller Ausnahmen, Fehlentwicklungen, Irrtümer, Widersprüche und Missverständnisse ist. Auch erweise sich das in Rechtssätzen festgehaltene Recht angesichts der „unendlichen Mannigfaltigkeit der Fälle“ zwangsläufig als „unzureichend“ (Puchta

nem Allgemeinen Handwörterbuch der philosophischen Wissenschaften: „Die Genealogie der Begriffe zeigt nämlich, wie die Begriffe von einander abzuleiten, dergestalt daß ihre Verwandtschaft sowohl in der Unterordnung als in der Beiordnung derselben erkannt werde. Dazu dient also die Generification und die Specification. S. diese Ausdrücke und Classensystem. Denn die Artbegriffe stehn neben einander unter den Gattungsbegriffen.“ (Krug 1827: 170).

207 „Neu“ sind die wissenschaftlich gefundenen Rechtssätze allerdings nur insofern, als sie „aus dem bestehenden Recht, in welchem sie als Keime allerdings schon liegen, hervorgetrieben werden“" (Puchta 1837: 15). Volksgeistcharakter und Vernunft, die beiden Seiten des Systems, ermöglichen in ihrem Zusammenspiel die Ergänzung des Rechts aus sich selbst heraus: „Jenes bestehende Recht enthält aber selbst den Keim seiner Ergänzung in sich, durch die Principien, auf denen es beruht, und durch seine vernünftige Natur, die von einem Satz einen Schluß auf einen anderen, daraus mit innerer Nothwendigkeit folgenden zuläßt" (Puchta 1847: 38). Insofern ist die Wissenschaft „ergänzende Rechtsquelle“ (Puchta 1845: 25$)$. 
1847: 38). Der Richter gerate notgedrungen in die Situation, neue, im positiven Recht nicht geregelte Rechtsfälle entscheiden zu müssen. Die rechtstechnischen Mittel beim Vorgehen in solchen Fällen entsprechen den Erkenntnismitteln des Rechts der Wissenschaft, nämlich „Feststellung der Prinzipien, Consequenz aus dieser, und Analogie gleicher Consequenzen, die in dem bestehenden Gewohnheitsrecht und gesetzlichen Recht aus denselben Principien für andere Fälle wirklich schon gemacht sind“ (ebd.: 39).

\subsection{Die Korrekturen der juristischen Logik durch den Volksgeist}

Puchta betont stärker als Savigny den Erkenntnismangel, der in das epistemische Ding ,Volksgeist' eingelagert ist. Es handelt sich zwar um eine objektiv gegebene Sphäre, zu der ein irgendwie wissenschaftlicher Zugang aber ausgeschlossen ist. Damit stärkt Puchta den Binnenraum des Rechts gegenüber dem unsichtbaren Volksgeist, da es nun dezidiert „innere“ Gründe der Geltung des Rechts gibt. Diese sind der wissenschaftlichen Tätigkeit zugänglich, die an der Vernunftseite des Rechts anschließt. Der Schwerpunkt der rechtswissenschaftlichen Arbeit liegt daher in der logisch-vernünftigen Systembildung über Begriffe und Prinzipien: Diese typisierende und damit systematisierende Begriffsbildung ermöglicht das Herausarbeiten von Prinzipien, die über Konsequenz und Analogie den Systemzusammenhang zeigen. Damit hebt Puchta stärker als Savigny eine im Systemverständnis angelegte Fähigkeit des Rechts zur Selbstergänzung hervor. Das Recht bildet sich selbst fort. Puchta verstärkt die Adressierung des Rechts unter dem Blickwinkel seiner Eigendynamik, die der Jurist in seiner systematischen Arbeit verwirklicht. Das Recht wird autonom auch für die Zukunft, da es den Keim ,neuen', oder besser: weiterführenden Rechts in sich trägt. Was bei Savigny noch wissenschaftliche Rekonstruktion ist, wird nun zur wissenschaftlichen, und d.h. dogmatischen Produktion.

Da jedoch das Recht nichtsdestotrotz Produkt des lebendigen Volksgeistes ist, muss sich die wissenschaftliche Methode dem Gegenstand anpassen: Nur die Rückbindung an den Entstehungszusammenhang ermögliche ein „billige[s] Recht“, d.h. die Anerkennung der Individualitäten und der gegenwärtigen besonderen Verhältnisse, „deren Befriedigung es zur Aufgabe hat" (Puchta 1841: 19, 23). Die „Form“ des Rechts, das Gleichheitsprinzip, müsse an den „Stoff“, d.h. das gegenwärtige Leben, zurückgebunden werden: „Die Rechtsinstitute sind so zu gestalten, wie sie den bestehenden 
individuellen Bedürfnissen entsprechen.“ Darin liege der eigentliche „Beruf der neuen Welt" (ebd.: 19, 22).

Diese Anbindung ans Leben ist der strategische Einsatzpunkt der Volksgeistlehre in der Rechtsdogmatik Puchtas. Denn auch wenn der Volksgeist als Erkenntnisziel (respektive -gegenstand und -möglichkeit) der Rechtswissenschaft ausgeschlossen wird, kommt ihm im dogmatischen Geschäft der Juristen eine entscheidende Funktion zu: Er korrigiert die logische Seite der Rechtswissenschaft, indem er als eigentlicher Grund des Rechts den Gegenstand geformt hat, und v.a. auch: immer weiter formt. Um den lebenden Organismus erfassen zu können, kann sich die Logik nicht auf formale Vorgaben zurückziehen.

Das gilt auch auf der systematisierenden Ebene der Begriffsbildung, d.h. der „Genealogie der Begriffe“: „[D]arin liegt, daß man diese Leiter nicht als ein bloßes Schema von Definitionen betrachten darf. Jeder dieser Begriffe ist ein lebendiges Wesen, nicht ein todtes Werkzeug, das bloß das Empfangene weiter befördert." (ebd.: 101f.) Zum einen müsse man die Begriffe immer am geschichtlich-freien Recht überprüfen und sie sodann an das Leben zurückbinden, um einer Verselbständigung des Rechts entgegenzuwirken. Zum anderen könne sich der juristische Syllogismus aufgrund des lebendigen Charakters der Begriffe nicht in einer logisch-formalen Handhabung von Begriffen erschöpfen, sondern stelle immer zugleich Änderungen und Modifikationen dar. Daher erhalten die gefundenen Grundbegriffe nicht den Status von ewigen Wahrheiten, sondern befinden sich immer im Werden. Gleiches gilt für die Prinzipien. Und selbst die rechtstechnischen Mittel der Konsequenz und Analogie werden affiziert: Auch hier sind Spielräume, Durchgriffe auf aktuelle Bedürfnisse und Modifikationen vorgesehen, die die einseitige Herrschaft einer formalen Logik ausschließen (vgl. Henkel 2004: 99ff. m.w.N.).

Vor allem aber relativiert der Volksgeistgedanke die wissenschaftliche Wahrheit: Nur in der Übereinstimmung mit dem Volksgeist kann ein Rechtssatz richtig sein. Die Wissenschaft ist jedoch gar nicht in der Lage, solche "nationellen“ Wahrheiten hervorzubringen (vgl. Haferkamp 2004: 452f.). Wissenschaftlich gewonnene Rechtssätze können dem Gewohnheits- und Gesetzesrecht nicht derogieren. Nicht absolut neues Rechts wird gebildet, sondern Lücken im bestehenden Recht werden produktiv aus dem systematischen Zusammenhang heraus gefüllt. Solche wissenschaftliche Wahrheiten haben aber per se einen prekären Status: Denn auch wenn die „wissenschaftliche Wahrheit" eines Rechtssatzes „die Bedingung seiner Gültigkeit" ist (Puchta 1845: 26), ist trotz allem ein Durchgriff auf den Rechtsentstehungsgrund, und damit auf Recht als "nationelle Wahrheit“ nicht möglich. Logische Gebundenheit hat nur einen relativen Wert. 
Über diese aus der Rechtsentstehungslehre resultierende Relativierung bzw. Qualifizierung der juristischen Logik zeigt sich für Puchta die Lebensanbindung der systematischen Tätigkeit des Juristen. Um dem Recht im Werden, dem geschichtlich-freien Recht des Volksgeistes zu entsprechen, muss es sich auch bei ihm um eine lebendige, d.h. flexible Tätigkeit handeln. ${ }^{208}$ Sie darf sich keinesfalls in mechanischer Deduktion erschöpfen, sondern ist - wie schon bei Savigny - in die Nähe der Kunst zu rücken (vgl. Puchta 1844b: Sp. 13f.). Das Recht wird unter der Frage nach der richtigen wissenschaftlichen Handhabung eines solchen gesellschaftlich produzierten Rechts problematisiert, und die Ebene, auf der dieses Problem angegangen wird, ist die Rechtsdogmatik, die zugleich die Eigenlogik des Rechts, seine produktive Seite, zur Geltung zu bringen vermag.

\section{Der „Wert" der Jurisprudenz für das Leben: Die Konstruktionsjurisprudenz (Rudolph von Jhering)}

Diese Problematisierung der Eigenart der rechtsdogmatisch verfahrenden Rechtswissenschaften findet seit den 1840ern eine enorme Aufwertung (unter Abwertung der historischen Forschung, s.o.). Die rechtsdogmatischen Debatten kreisen um die Frage der richtigen Methode angesichts eines Rechts, das als soziales Produkt anzusehen und daher kontingent und v.a. auch gegenwärtig ist. Es häufen sich die Versuche der Romanisten, auf dem Gebiet der Rechtsdogmatik eine neue oder verfeinerte Methode zu

208 Die Flexibilität dieses Systems zeigt sich auch in einem ausgefeilten Regel-Ausnahme-Schema hinsichtlich des Rechtsstoffes (vgl. Haferkamp 2003: Rn. 58): Puchta nimmt ganze Rechtssatzgruppen als Juristengewohnheitsrecht aus dem Systemzusammenhang heraus, so z.B. Form- oder Fristfragen, die kein wissenschaftlichen ,Recht' sind, da sie nicht aus ,aus inneren Gründen deducirt werden“ könnten (Puchta 1837: 17); er identifiziert Ausnahmerechte (ius singulare) als Zugeständnis an die „Unvollkommenheit menschlicher Dinge überhaupt, welche die vollständige Erreichung jener Idee des reinen Rechts, also die innere Vollendung des Rechts ausschließt" (Puchta 1841: 93f.); darüber hinaus erkennt er Grundverschiedenheiten im Recht, die aus der Natur von Rechtsinstituten folgen, aber nicht aus einem Rechtsbegriff als oberstes Prinzip des Rechts gefolgert werden können (vgl. Haferkamp 2004: 412f.); und er schließt auch die Möglichkeit der Berücksichtigung von Billigkeitsgesichtspunkten nicht aus (Puchta 1847: 235ff.; vgl. hierzu Henkel 2004). All dies zeitigt aber gleichwohl Konsequenzen, und es lassen sich Rechtssätze aus den Prinzipien ableiten, die erneut angesehen werden als „Mutter von logischen Nothwendigkeiten“ (Puchta 1845: $65)$. 
entwerfen, wobei sie insbesondere Anleihen an Naturwissenschaft und Naturphilosophie zu machen suchen (vgl. Schmid 1848; Beseler 1843; Leist 1854; Kuntze 1855, 1856). ${ }^{209}$ Der junge Puchta-Schüler Rudolf von Jhering radikalisiert diese Perspektive. Ihm geht es um die spezifische Technizität des Rechts, die ,Technik des Rechts', wie sie sich ausgehend von seiner Entstehung im Volksgeist entwickelt hat.

Jhering bestreitet also nicht Savignys Rechtsentstehungslehre (vgl. Jhering 1854: 25f.). Allerdings wendet er sich gegen den organischen Entwicklungsgedanken, der einen Traditionszusammenhang zwischen Vergangenheit und Gegenwart postuliert. Demgegenüber geht er von einer stufenweisen Entwicklung des Rechts aus. Die Anerkennung solcher verschiedener Stufen ist dabei nicht nur verbunden mit einer Kritik der Rechtsquellenlehre ${ }^{210}$, vielmehr folgt daraus die konsequente Historisierung des Gegenstandes: Die „psychische Organisation“ des Rechtsorganismus, d.h. die „allgemeinen Ideen und Grundanschauungen eines Volks“, sei „zu verschiedenen Zeiten eine verschiedene“. ${ }^{211}$ Unterschiedliche Zeiten führten zu unterschiedlichen Verfassungen des objektiven Rechts: „So ist denn der Geist des Volks und der Geist der Zeit auch der Geist des Rechts." (Jhering 1852: 34) Wenn es aber verschiedene „Geister“ des Rechts gibt, verliert die Geschichte ihr Beweisprinzip - historische Entwicklung ist zwar gegeben, nicht aber die Genese des heute notwendig Gegebenen durch die Vergangenheit. ${ }^{212}$

$209 \mathrm{Zu}$ Albert Hermann Posts Suche nach dem Naturgesetz des Rechts (1867), die repräsentativ für diesen Trend gelten kann, vgl. Kiesow 1997. Zu den Problemen der darin inhärenten rechtswissenschaftlichen Rezeption des Darwinismus vgl. Haferkamp 2011b.

210 Denn für Jhering stellt sich das Gewohnheitsrecht nicht als Überbegriff der verschiedenen Rechtsquellen dar, sondern entspringt der unmittelbaren Volksüberzeugung. Aufgrund der Positivierung des Rechts, d.h. der Gesetzgebung, die zur zunehmenden Ausdifferenzierung und Komplexitätssteigerung des Rechts und damit zur Professionalisierung geführt habe, erweise es sich aber mittlerweile als überholt (Jhering 1854: 26ff.).

211 An anderer Stelle schreibt Jhering, „daß jede Zeit Original und nicht Copie einer andern sein soll, daß jede Zeit einen und denselben historischen Gegenstand unter dem ihr eigenthümlichen Gesichtspunkt betrachten darf und muß, und daß auf diese Weise mit jedem neuen Geschlecht neue Seiten des Gegenstandes sich enthüllen“ (Jhering 1852: 39).

212 Damit ändert sich die Zielrichtung der historischen Forschung: Indem man versucht, das Wesen des römischen Rechts in seiner Zeit zu erfassen (spezialhistorische Untersuchung), wird der Boden dafür bereitet, dessen Einfluss auf die gesamte Entwicklung des Rechts zu eruieren (universalhistorische Betrachtung), um davon ausgehend die Frage nach der legislativen Brauchbarkeit angesichts 
Auch wenn die historische Untersuchung damit nicht ad acta gelegt wird, wird die dogmatische Betrachtungsweise in ihrer Eigenheit gestärkt (vgl. Jhering 1857: 4f.). Jhering dient die Volksgeistlehre insbesondere zur Begründung des Systemgedankens. Denn das Recht sei als „innerlich zusammenhängendes Produkt der Geschichte“ (Jhering 1852: 13) ein Organismus. Selbst als ein rein geistiges Gebilde (vgl. ebd.: 2) weise es als Organismus „die Eigenschaften eines Naturproduktes“ auf, „also Einheit in der Vielheit, Individualität, Wachsthum von innen heraus u.s.w.“ (ebd.: 13). Der innere Zusammenhang, der einheitliche "Geist" in der Mannigfaltigkeit des Rechtsstoffes, wird auch bei Jhering über die Rechtsentstehungslehre noch vor jeder wissenschaftlichen Behandlung dieses Stoffes gewährleistet. Das System ist damit wie bei Savigny und Puchta keine Ordnung, "die man in die Sache hinein bringt, sondern eine solche, die man berausholt". Denn es sei "gleichbedeutend mit innerer Ordnung der Sache selbst“ (ebd.: 26, H.i.O.). Das System ist daher immer ein ,inneres System (vgl. auch Schröder 2012: 247ff.).

\subsection{Innen und Außen des Rechtsorganismus: Logik und Leben}

Als Organismus ist das Recht als Einheit adressierbar. Und nur diese Adressierung als systematische Ganzheit ist sinnvoll. Weil das Recht einen Rechtsorganismus darstellt - und zwar nun, wie oben schon erwähnt, ganz unproblematisch einen „objektiven Organismus der menschlichen Freiheit" (Jhering 1852: 12) ${ }^{213}$-, weil es ein Naturprodukt ist, bedarf es einer „allgemeinen Naturlehre“ des Rechts (ebd.: 10) bzw. einer „naturhistorischen Methode“ (vgl. Jhering 1858: 385ff.). Die Naturwissenschaft dient als Vorbild, allerdings eine organische Naturwissenschaft, die sich nicht mit einer starren, äußeren Natur befasst, sondern mit dem Leben: eine „Natur-

der Bedürfnisse und Zwecke der Gegenwart zu stellen (legislativer Standpunkt, Jhering 1852: 3). Geschichtliche Forschung dient zur Vorbereitung der gegenwärtigen Aufgabe der Rechtswissenschaften. Aber auch Jhering geht es dabei um die Verteidigung des von Verdrängung bedrohten römischen Rechts (ebd.: 2). Allerdings zielt seine Arbeit auf die Erkenntnis des „Wesens des Rechts überhaupt" (Jhering 1858: 11), das er ausgehend von der "grandiosen Schöpfung“ (Jhering 1852: VIII) des römischen Rechts zu erkennen sucht.

213 Der Bezug des Privatrechts auf die individuelle Freiheit zeigt sich bei Jhering schon gänzlich entproblematisiert, letztlich sieht er darin aber auch den spezifischen Geist des römischen Rechts, nämlich „[d]as Prinzip des subjektiven Willens“ als den „Urquell des römischen Rechts“ (Jhering 1852: 103ff.). Zur Debatte um diesen individualisierenden Geist s.o. $\$ 2 . I I I .2 .4$. 
wissenschaft im Elemente des Geistes“ (ebd.: 389). Dieser Bezug der Rechtswissenschaft zur Naturwissenschaft zeigt deutlich: Es geht immer noch um die Wahrheit, d.h. um das „wahre Wesen“ des Rechts (Jhering 1852: 11), das sich nur in seiner Einheit zeigt.

Den Organismusgedanken mit seiner Herkunft aus der Biologie (respektive Medizin, vgl. Herberger 1981), den impliziten Naturalismus der Rechtsentstehungslehre, nimmt Jhering letztlich ernster als Savigny und Puchta. Er mache eine „anatomische“ und eine „physiologische Betrachtung" erforderlich: „[J]ene hat die Bestandtheile desselben und ihr Ineinandergreifen, also seine Structur, diese die Functionen desselben zum Gegenstand" (Jhering 1852: 14).214 Struktur und eine dem Organismusdenken innewohnende funktionalistische Perspektive ${ }^{215}$ auf das Recht werden zu den Leitgesichtspunkten der Ermittlung des objektiven Rechts - bzw. des schwer zu eruierenden Geistes darin (vgl. ebd.: 35).

Auch Jhering geht das Problem induktiv respektive „empirisch-comparativ[]" (ebd.: 11) an. ${ }^{216}$ Die Ermittlung der Struktur (Anatomie) kreist dabei ebenfalls um das Verhältnis von Rechtssatz, Lebensverhältnis und Rechtsinstitut. Ausgangspunkt ist der gegebene Stoff, d.h. für Jhering die Rechtssätze, wie sie im positiven Recht vorzufinden sind. Dabei gilt jedoch: Die Rechtssätze in ihrer regelmäßigen Erscheinungsform ,wenn - so stellen nur „die äußere sichtbare Oberfläche" des jeweils bestehenden objektiven Rechts dar, sie bleiben „hinter dem Rechte, wie es lebte und leibte, weit zurück" (ebd.: 25, 15). Wie bei Savigny und Puchta geht es darum, hinter dem Gesetz das Recht zu erkennen (vgl. ebd.: 22).

214 Diese Anlehnung an die biologische Betrachtungsweise handelt Jhering seitens des Savigny-Schülers Adolf Friedrich Rudorff den Vorwurf einer Verwendung der „unsichern, der niedern Naturwissenschaft entlehnten Terminologie“ für die höhere Sprache der Rechtswissenschaft ein (Rudorff 1857: VII). Allerdings schreibt Jhering generell sehr bildreich und bedient sich eines breitgefächerten Metaphernpools. So kommen zum Einsatz etwa: Architektur (Bau und Baustil); Chemie; Sprache und Sprachwissenschaft (Alphabet und Grammatik); Biologie/ Medizin (Organismus); Mechanik (Maschine) usw. Auch wenn er von einem zum anderen Metaphernfeld springt, lassen sich bereichsspezifische Leitmetaphoriken ausmachen: bzgl. des verselbständigten Rechts und seiner Funktion die Organismusmetaphorik, die hinsichtlich der internen Analyse der Rechtskörper zur Kombinatorik des Alphabets wechselt; und bzgl. der konstruktiven Seite der Jurisprudenz die Maschinenmetaphorik.

215 So schreibt Jhering: „Der Zweck der Organe liegt in ihren Functionen; die Organe sind vorhanden, damit sie bestimmte Verrichtungen ausüben" (Jhering 1852: 39).

216 Jhering zielt auf eine ,auf dem Wege der Analyse und Vergleichung des Einzelnen zu gewinnenden Naturlehre des Rechts“ (Jhering 1858: XIIf.). 
Bei Jhering zielt nun die rechtswissenschaftliche Arbeit auf die in den Rechtssätzen liegenden Lebensverhältnisse ab. Denn diese „sind abstrahirt aus einer Betrachtung der Lebensverhältnisse und bestimmt, die denselben innewohnende Natur auszusprechen und sie ihnen zu sichern" (Jhering 1852: 25). Die rechtlich geregelten Lebensverhältnisse, d.h. die Rechtsverhältnisse, sind wiederum voneinander abhängig. Sie können zu einigen weiten und streng unterscheidbaren ,Grundformen' zusammengefasst werden: zu den Rechtsinstituten, die in Rechtsbegriffe gefasst werden. Diese „bilden gewissermaßen das feste Knochengerippe des Rechts, um das die ganze Substanz desselben sich lagert“ (Jhering 1852: 25).

Auch bei Jhering sind die Rechtsinstitute und damit die Rechtsbegriffe für den systematischen Aufbau des Rechts maßgeblich. Die Erforschung der systematischen Gliederung des Rechts wird zur zentralen Aufgabe der Rechtswissenschaft, d.h. „für das Kleinste wie das Größte die richtige Stelle aufzusuchen" (ebd.: 26). In dieser Perspektive zeigt sich das Rechtssystem als eine Form der logischen Ordnung, als „logische Gliederung“ von Rechtsinstituten und -begriffen bzw. als „innere Natur des Rechts“ (ebd.: 31). Das „System“ als ,innere[] Ordnung der Sache selbst“ zeigt sich in seiner ,innere[n] logische[n] Substanz“ (ebd.: 27, 32).

Nur auf dem Weg der logischen Arbeit mit Begriffen könne man zum eigentlichen Verständnis des Rechts gelangen. Allerdings stellt Jhering diese Erkenntnis unter einen Vorbehalt, der aus der Natur des Rechts als Organismus entspringe. Selbst wenn das positive Recht nicht mehr explizit den Volksgeist repräsentiert, so ist - der Rechtsentstehungslehre entsprechend - unter oder innerhalb des oberflächlich und äußerlich gegebenen Rechts der Geist zu ergründen. Denn erst der Geist, d.h. die „psychische Organisation" des Rechts, stifte die substantielle Einheit in der Struktur eines jeweiligen Rechtsystems: Der Geist als Sitz der „das ganze Recht gleichmäßig gestaltenden und beherrschenden Kräfte" ist

das Herz des Rechtsorganismus, von dem aus belebend und erwärmend das Blut durch alle Theile strömt und dadurch auf dem allgemeinen logischen Knochensystem des Rechts Fleisch und Haut ansetzt, ihm den individuellen Charakter verleiht, an dem man eben erkennt, daß das Recht diesem Volke und dieser Zeit angehört (Jhering 1852: 34 ).

Wie bei Puchta erfährt die juristische Logik durch die Bestimmung des Rechts als Produkt des (Volks-)Geistes eine Umdeutung gegenüber rein formallogischen Gesichtspunkten. Dabei gilt immer noch: Der "Geist“ ist nicht direkt zu fassen. Auch er ist durch einen Erkenntnismangel gekennzeichnet: Die innere, treibende Kraft des Geistes 
läßt sich nicht unmittelbar erkennen, und es ist ein Nothbehelf, wenn wir zur Erklärung von Wirkungen, die wir sehen, treibende Kräfte, die wir nicht wahrnehmen, supponiren; sie sind Abstractionen, zu denen die Gebrechlichkeit unserer Erkenntniß uns zwingt. In diesem Sinne machen wir denn auch im Recht von den Wirkungen den Schluß auf treibende Kräfte; letztere sind eine Abstraction, mittelst deren wir uns im Grunde nur die Wirkungen ins Bewußtsein bringen, die Ursache selbst bleibt eine Hypothese. (Ebd.: 35, H.i.O.)

Recht ist also auch für Jhering das bevorzugte Erkenntnismittel eines Geistes, der zwar objektiv jenseits des Staates existiert, aber weder durch Vernunft noch Logik wissenschaftlich direkt zu fassen ist. ${ }^{217}$

Gegenüber Savigny und Puchta führt Jhering entlang der Organismusmetapher aber noch eine weitere Betrachtungsweise des Rechts ein. Neben der nach innen gerichteten anatomischen Struktur gibt es auch jene - bereits erwähnte - physiologische Seite des Rechts, die nach außen, auf die Umwelt des Rechtsorganismus gerichtet ist. Sie entspringe der Funktion des Rechts im wirklichen Leben, und nur die Kenntnis dieser Funktion führe „zum wahren Verständniß der Anatomie“. Denn „die ganze logische Gliederung des Rechts, und sei sie noch so vollendet", ist für Jhering letztlich „nur das Sekundäre, das Produkt der Zwecke, denen sie dienen soll“ (ebd.: 40). ${ }^{218}$

Diese „Function des Rechts im allgemeinen besteht nun darin, sich zu verwirklichen. Was sich nicht realisirt, ist kein Recht, und umgekehrt was diese Function ausübt, ist Recht, auch wenn es noch nicht als solches erkannt ist (Gewohnheits Recht)." (Ebd.: 41) Nur von dieser Seite aus betrachtet könne über den Wert des Rechts entschieden werden (Jhering 1858: 334). Recht muss daher immer in der Wirklichkeit realisierbar und anwendbar sein, es steht unter dem Primat seiner praktischen Brauchbarkeit. Nur diese könne zur Beurteilung dienen - nicht sein geistiger (logi-

217 So schreibt er: „Da nun jener Organismus nicht eine Theorie, ein logisches System, sondern die rechtliche Gestaltung der Wirklichkeit war, so gehört letztere insoweit in den Kreis unserer Darstellung, als eben jene psychische Organisation des Rechts sich an ihr bewährt oder sich aus ihr erklärt, und so dürfte, wenn uns ,der Geist' den Zugang zur materiellen Wirklichkeit zu verschließen scheint, doch die reale Natur ,des Rechts' uns denselben offen halten" (Jhering 1852: 50).

218 Insofern warnt Jhering eindrücklich vor einer Verselbständigung der Logik: „Nichts ist mithin verkehrter, als ein Recht gleich einem philosophischen System bloß von Seiten seines geistigen Gehaltes, seiner logischen Gliederung und Einheit zu beurtheilen“ (ebd.: 39). 
scher) Gehalt, bezeichnenderweise aber auch nicht die Gerechtigkeit und die Angemessenheit der materiellen Bestimmungen im Recht.

Daher interessiert Jhering für die rechtswissenschaftliche Arbeit nur die formelle Seite der Praktikabilität, d.h. die „formale Realisirbarkeit" des Rechts, worunter er die Leichtigkeit und Sicherheit der Anwendbarkeit des abstrakten Rechts auf die konkreten Fälle versteht (Jhering 1852: 42).219 Dieses, „der logischen Innerlichkeit der Rechtsbegriffe fremde[] Prinzip“, zwinge dazu, „die Innerlichkeit des Begriffes auf die Außenseite zu verlegen, für die inneren Unterschiede und Begriffe äußere möglichst zutreffende Kriterien aufzusuchen" (ebd.: 46). ${ }^{220}$ Logik und Leben, Binnenperspektive und der auf das Außen gerichtete Wirklichkeitsbezug, treten in ein dialektisches Spannungsverhältnis, und im Organismusbegriff des Rechts sind diese beiden Perspektiven - und ihre dialektische Dynamik - vereint. 221

\subsection{Die juristische Technik}

Jhering nimmt also gerade angesichts des unausweichlichen Lebens- und Wirklichkeitsbezugs des Rechts in der Frage der Wissenschaftlichkeit der Rechtswissenschaft ihre formale Seite ins Visier, d.h. ihre spezifische Technizität. Damit bezieht sich die ,juristische Technik“ (Jhering 1858: 334ff.) trotz der in der Formalisierung angelegten Distanz zum alltäglichen Leben in fundamentaler Weise auf die dem Leben zugewandte Seite des Rechts. Sie dient der Verwirklichung des Rechts und ist daher für Jhering eine „reine Frage der Zweckmäßigkeit“ (ebd.: 337). Die Theorie der Technik bereite daher das positive Recht in derjenigen Form auf, in der ihm auf-

219 Ganz im Gegensatz zu seinen späteren Einlassungen zum Zweck im Recht (s.u. \$3.I) betrachtet Jhering hier das Recht als ein Mittel der Selbstverwirklichung, die konkreten Zwecke aber erscheinen ihm für die wissenschaftliche Arbeit als Ansatzpunkt gänzlich ungeeignet, erweisen sie sich doch als „etwas höchst unbestimmtes, schwankendes“, das zudem im Institut nicht immer erkennbar ist. Daher gilt für die Wissenschaft: „Wir definiren den Körper [des Rechts, D.S.] also nicht nach dem, was er soll oder was er leistet, sondern nach seiner Structur, seinen anatomischen Momenten“ (Jhering 1858: 392).

220 Hierzu gehören etwa rechtliche Präsumptionen, Fiktionen oder Formen des Rechtsgeschäfts, die sich nicht logisch herleiten lassen, sondern nur durch ihre Praktikabilität erklärbar sind (vgl. Jhering 1852: 46f.).

221 Man kann auch sagen: In Jherings tautologischer Definition (Recht ist, was sich als Recht im wirklichen Leben verwirklicht), werden Selbstbezüglichkeit des Rechts und Lebensbezug vereint. 
grund seiner Beschaffenheit ein möglichst sicheres, leichtes und rasches "Verwirklichungsvermögen“ (ebd.: 335) zukomme. ${ }^{222}$ Kurz: Sie dient sowohl der Beherrschung des Rechtsstoffs als auch der Anwendbarkeit bzw. Praktikabilität des Rechts. Insofern beschäftige sich die juristische Technik auch nicht mit den materialen Inhalten des Rechts, sondern mit „Aufgaben, an deren Lösung jedes Recht sich zu versuchen hat" (ebd.: 323). Im Binnenraum des Rechts ziele sie daher auf allgemeine Wahrheitsaussagen über juristisches Arbeiten, auf eine in jeder Zeit gleichbleibende „mit innerer Nothwendigkeit durch das Recht selbst gesetzte einzige Art und Weise einer sicheren praktischen Beherrschung des Rechts" (ebd.: 324). ${ }^{223}$

Jhering identifiziert in seiner derart pragmatisch fundierten Theorie der juristischen Technik drei aufeinander aufbauende und miteinander verwobene „Fundamental-Operationen“: die juristische Analyse, die logische Konzentration und die juristische Konstruktion (ebd.: 359ff.). Sie bezeugen in je spezifischer Weise die produktive Seite der Jurisprudenz, worin für Jhering letztlich ihr spezifischer Sinn, nämlich der Lebensbezug, liegt:

Die juristische Analyse bereitet in einem ersten Schritt den Stoff auf, indem sie ihn in seine Einzelteile (Rechtsinstitute und Begriffe) zerlegt. Dadurch, dass man in den einzelnen Rechtsverhältnissen Besonderes (Lokales) und Allgemeines herausschält, lassen sich „einfache Körper“ isolieren (Jhering 1858: 361). Hier wird nicht mehr nur ausgelegt, sondern freigelegt (Seinecke 2013: 257). Im Idealfall kann man dabei die Bestandteile eines „Rechtsalphabets“ herausarbeiten. Die Rechtsverhältnisse stellen sich als Worte dar (Jhering 1858: 360), die in ihre nicht weiter aufzulösenden einfachen Elemente (die Buchstaben) zerlegt werden können. Bereits hier zeige sich der produktive Charakter der Jurisprudenz, eröffnet sich doch damit ein weites Feld der Kombinatorik, in dem die einzelnen Elemente (Buchstaben) sich zu neuen Einheiten (Wörtern) zusammensetzen lassen (Jhering 1858: 372). Das erlaube es, der unerschöpflichen „Combinationskunst des Lebens“ (Jhering 1852: 30) gerecht zu werden und auf neuartige Konstellationen rasch zu reagieren - und das insbesondere auf dem Weg der analogen Ausdehnung (vgl. Jhering 1858: 370ff.; Seinecke 2013: 255ff.).

222 Das Verwirklichungsvermögen stützt sich bei Jhering keinesfalls nur auf solche rechtsimmanenten Gründe. Auch wenn er eine Reihe von äußeren Gründen hierfür nennt, sieht er jedoch die spezifisch juristische Arbeit darauf beschränkt (Jhering 1858: 335f.).

223 Oder, wie Jhering klarstellt: „Das Historische dabei ist nicht sie selbst, sondern das Geschick und Talent, mit dem sie von diesem oder jenem Volk gehandhabt wird“ (ebd.: 324). 
Allerdings müsse man in der Analogisierung eine Grenze beachten: Da es sich bei den Rechtsverhältnissen und damit den Instituten und Begriffen um historisch wandelbare Einheiten handele, erweise sich das Alphabet selbst als historisch-kontingent (Jhering 1858: 374f.). Es sei ein „praktisches", nicht ein abstraktes Rechtsalphabet (ebd.: 375). Jhering spricht also nicht einer „Logik“, einem „absoluten Begriff“ oder einer zeitlos-analytischen „Form“ die Macht über das Recht zu. Es existiert kein letztgültiges Kriterium für die Überprüfung der Richtigkeit des juristischen Schlusses, allein Praxis und Positivität entscheiden letztlich über die Inhalte und Gestaltung des Rechts - allerdings unter Aufsicht der Wissenschaft (Seinecke 2013: 257).

Der zweite Schritt, die logische Konzentration, geht „entgegengesetzte Wege, statt durch Zersetzen durch Verbinden und Zusammendrängen“ (Jhering 1858: 380). Durch die logische Zusammenschau verschiedener Regelungen werde das abstrakte und höher liegende Prinzip gewonnen. Der Stoff wird konzentriert und dadurch leichter handhabbar gemacht. Gleichzeitig lassen sich aus den Prinzipien logische Schlussfolgerungen ziehen - und in diesem Sinne erweise sich auch die logische Konzentration als produktiv. Denn über die Konsequenz wird das Prinzip zu einer „Quelle neuer Rechtssätze“ (ebd.: 382). Aber auch hier gilt: Rechtliche Prinzipien sind nicht zeitlos, und die Wissenschaft kann sich nicht auf logische Gewissheiten gründen.

Zielen die beiden ersten Schritte auf die Aufarbeitung des Stoffs, so stellt der dritte Schritt das eigentliche Charakteristikum und Qualitätsmerkmal der Rechtswissenschaft dar: Die ,juristische Construction“ sei „höhere Jurisprudenz", hier schwinge sie sich auf zur „wahren Kunst und Wissenschaft“" (ebd.: 385, 389). ${ }^{224}$ Das liegt an ihrem eigentümlichen Charakter als Naturlehre des Rechts. Stoßen Analyse und Konzentration an die

224 Wie bei Puchta ist dabei eine Abwertung der juristischen Methodenlehre erkennbar: Jhering nennt die Erscheinungsform im Rechtssatz die „niedere Entwicklungsstufe“ des Rechts (Jhering 1852: 25; 1858: 386) und die interpretatorische Tätigkeit der Wissenschaft, die eine solche niedere Stufe zum Gegenstand hat, ist „niedere Jurisprudenz“ (Jhering 1858: 386). So klagt er in seinen Angriffen gegen die "Methode des orthodoxen Romanismus“ deren „Buchstaben-Fanatismus“ (Jhering 1857: 38) an, allenthalben sei ein falscher "Cultus des Wortes“ sowie die "Wortklauberei der Juristen“ (Jhering 1858: 468) vorzufinden. Letztlich stelle die Technik der Interpretation „keine specifisch juristische Operation“ dar. Darüber hinaus produziere sie „nichts specifisch Neues“, der Stoff selbst erhalte „durch diese Operation keinen eigenthümlich juristischen Charakter“, sondern lege die Quellen nur „auseinander“ (ebd.: 386). Dogmatik ist jedoch etwas anderes als Interpretation. Letztere ist zwar die notwendige Vorstufe (Jhering 
Grenze der historischen Kontingenz des Stoffes, so wird nun die vitalistische Eigenschaft des Stoffes selbst zum Gegenstand der Untersuchung. Denn die Rechtsinstitute und -begriffe sind in dieser Perspektive nicht mehr primär Typus, sondern , juristische Körper“ mit individuellem Sein und Leben (ebd.: 390ff.). Die Rechtssätze streifen nach Jhering ihre imperative Form ab und „und verflüchtigen sich zu Elementen und Qualitäten der Rechtsinstitute“ bzw. zu „Rechtsbegriffen“. Es trete ein Substanzwandel auf: Die Rechtssätze erreichen einen „höheren Aggregatzustand“ (Jhering 1852: 26, 27; 1858: 346). Und dies sei die spezifische Wirkung der systematischen Bearbeitung des Rechts durch die Rechtswissenschaft, die reflexiv auf ihren Gegenstand zurückwirke: Es werde „dadurch nicht bloß wie bei jeder andern Wissenschaft das einzelne an seine richtige Stelle gebracht“, sondern es zeige sich, „daß dieser formale Prozeß eine materielle Rückwirkung auf den Stoff ausübt, daß mit letzterem, nämlich den Rechtssätzen, eine innere Umwandlung vor sich geht“ (Jhering 1852: 26).

Die Rechtsinstitute sind für Jhering lebendige Wesen, d.h. lebendige Körper. Dies führe zur Notwendigkeit der begrifflichen Erfassung des Rechts. Denn als Begriff gefasst enthalte das Rechtsinstitut „die logische Quintessenz des Körpers, seinen innersten Kern oder Individualitätspunkt“. Im Begriff liege „die ganze Kraft des Körpers beschlossen“ (Jhering 1858: 390).225 Nicht in der Arbeit mit den Rechtssätzen, sondern in der Arbeit mit den Begriffen als Inbegriffe der Rechtskörper entwickele die Jurisprudenz also ihre spezifische Technizität. ${ }^{226}$

An diese Betrachtung als Körper schließt sich für Jhering an

mit Nothwendigkeit [...] die Frage nach seiner Natur, Beschaffenheit, Bestimmung, seinen Kräften, Eigenschaften, seiner Aehnlichkeit und Verschiedenheit von andern Körpern, den Verbindungen, die er mit ihnen eingehen, oder den Conflicten, in die er mit ihnen gerathen kann (ebd.: 389).

1857: 7f.; 1858: 387), aber - selbst als logisch-intuitive Interpretation (vgl. Seinecke 2013: 249ff.) - primär rezeptiv und daher nicht zu Höherem bestimmt.

225 Für Jhering gilt: „Die Angabe dessen, was der Körper ist, ist gleichbedeutend mit dem Begriff desselben, der Begriff, begreift" $d$. h. ergreift ihn in seiner Wesenheit, er ,definirt' ihn d. h. gränzt ihn von andern ab, gibt ihm ein logisches ,Für sich sein"“ (Jhering 1858: 390).

226 Das unterscheidet die Tätigkeit der Jurisprudenz auch fundamental vom Umgang der Laien mit dem Recht. Technizität bezeichnet für Jhering insofern einen spezifischen professionellen bzw. wissenschaftlichen Umgang mit dem Recht - und letztlich scheint auch nur diese Professionalisierung dem Recht gerecht werden zu können (vgl. etwa ebd.: 321f. u.ö.). 
Auf diese Weise wird das System als spezifische Form des Rechts freigelegt, und das heißt zugleich für Jhering: der organische und damit lebendige Charakter des Rechts. Die Wissenschaft „construiert und baut“ das System, d.h. den Rechtsorganismus bzw. -körper (ebd.: 400). Denn in der Analyse der lebendigen Kraft der Rechtskörper wird die lebendige Kraft im Recht diese innere, stillwirkende Kraft im Rechtsorganismus - in seinem Formprinzip selbst freigelegt.

Eine derart verfahrende Rechtswissenschaft zeigt (und verwirklicht) die Eigendynamik des Rechts, das sich im Bezug auf sich selbst angesichts eines sich immer wandelnden Lebens zur Geltung bringt. Nun gilt: „Durch Combination der verschiedenen Elemente kann die Wissenschaft neue Begriffe und Rechtssätze bilden; die Begriffe sind productiv, sie paaren sich und zeugen neue." (Jhering 1852: 29) Bei Jhering wird das Recht nun vollends autonom, mit eigenen Kräften ausgestattet und von sich selbst aus zur Verwirklichung drängend. Und die Wissenschaft des Rechts als juristische Konstruktion wird zu einer Kunst, diese Kraft freizulegen und damit freizusetzen. ${ }^{227}$ Die Bestimmung des Rechts als Produkt des Volksgeistes relativiert damit auch bei Jhering die formal-logische Seite der Rechtswissenschaft. Der Vitalismus im Organismusgedanken macht die rechtswissenschaftliche Tätigkeit zu einem, vitalen“ Geschäft: Sie wird „zu einer Kunst, die den Stoff künstlerisch bildet, gestaltet, ihm Leben einhaucht zu einer Wissenschaft, die trotz des Positiven in ihrem Gegenstande sich als Naturwissenschaft im Elemente des Geistes bezeichnen läßt" (Jhering 1858: 389).

In dieser Konstruktion des Systems liegt zugleich ihr praktischer Wert, d.h. die funktionale Seite des Rechts. Denn „das System ist die praktisch vortheilhafteste Form des positiv gegebenen Stoffs; und: es ist die Quelle neuen Stoffs“ (ebd.: 409). Es sei die praktikabelste Form, da das Recht in einer Gesamtschau erfasst werde, und zwar im Ganzen unter gleichzeitiger Beachtung seiner differenten Einzelteile (der Körper). Das Recht wird also weder atomistisch zersplittert, noch als undifferenzierte Einheit betrachtet. Damit sei die Betrachtung als System nicht nur „die bequemste, weil kürzeste, concentrierteste Form des Stoffs“, sondern ebenso „die ergiebigste,

227 Jhering nennt hierbei drei Gesetze der „kunstgerechten Gestaltung des juristischen Körpers": das Gesetz der Deckung des positiven Stoffs; das Gesetz des Nichtwiderspruchs oder der systematischen Einheit; sowie das Gesetz der juristischen Schönheit. Hierfür wird ein ganzer "Constructionsapparat" in Anschlag gebracht, womit Jhering die juristischen Techniken wie Scheingeschäfte, Fiktionen, künstliche Erweiterungen natürlicher Begriffe usw. fasst (Jhering 1858: 398ff.). 
durchsichtigste“. Auf diese Weise werde letztlich „die ganze Fülle seines Inhalts zu Tage gefördert" (ebd.: 410). Als System betrachtet gewinnt die Beschäftigung mit dem Recht an Geschwindigkeit, Sicherheit und Leichtigkeit.

Diese Form, das System, entfaltet bei Jhering ein Eigenleben, sie wird zur „unversiegbaren Quelle“ neuen Stoffs (ebd.: 412). Die Logik der Kombinatorik des Rechtsalphabets, die Konsequenz der Rechtsprinzipien und die ,juristische Speculation“ (ebd.) ermöglichen es, gänzlich Neues zu schaffen. Das erweist sich für Jhering aus zwei Gründen als einzig richtiger Weg der Jurisprudenz: Die produktive Seite des juristischen Denkens und Arbeitens ist ihm zufolge schlicht ein unausweichliches Faktum: "[J]ede Jurisprudenz produzirt, selbst wenn sie sich dessen nicht bewußt ist oder wohl gar in der Theorie sich das Recht dazu abspricht" (ebd.: 413). Darüber hinaus nötigt die Kombinatorik des praktischen Lebens das Recht dazu, sich beständig produktiv zu ergänzen (ebd.). Nur ein flexibles und produktives System könne dem beständigen Wandel des alltäglichen Lebens gerecht werden. Indem die Jurisprudenz in ihrer wissenschaftlichen Handhabung die Mittel hierfür bereitstelle, throne sie über der Gesetzgebung. Der Gesetzgeber liefere nur das Material. Konstruktion und Bau des Rechts fallen demgegenüber der Jurisprudenz zu (vgl. Seinecke 2013: 260).

Die Verwirklichung des Rechts im praktischen Leben gewährleiste zugleich, dass es zu keiner Verselbstständigung der gedanklichen Konstruktionen des Rechtswissenschaftlers komme: „Denn die praktische Natur der Welt, in die er sich versetzt findet, lenkt ihn immer wieder zu den realen Dingen zurück." Und nur diese praktische Gewalt vermag - entsprechend der Überlegungen zur physiologischen Betrachtung des Rechts - über den "wahren Werth" der Dogmatik zu entscheiden (Jhering 1858: 414). Die Technik des Rechts steht im Dienst des Lebens, wo sie geformt wird und sich beweisen muss. Die Eigenart der Rechtswissenschaft bestimmt zugleich ihren spezifischen Wert: Nicht mehr Rekonstruktion oder Produktion, sondern selbstbewusste Konstruktion wird zum Schlagwort einer solchen Rechtswissenschaft, die nun selbst eine lebendige Kraft im Dienste des Lebens darstellt.

\section{Rechtsdogmatik und Leben}

Die überwiegend rechtstheoretisch geführte Problematisierung des Rechts in seinem Verhältnis zum Leben wird auf rechtsdogmatischer Ebene in eine Problematisierung der Eigenart und des spezifischen Werts der rechtswissenschaftlichen Arbeit angesichts eines immer „lebenden Rechts“ über- 
führt. Im Vordergrund steht die Frage nach der spezifisch wissenschaftlichen Handhabung eines Gegenstandes, der sich aufgrund seiner Herkunft aus der unabhängigen Sozialsphäre zwar nicht als willkürlich, jedoch als historisch-kontingent erweist.

Das Recht wird in den rechtsdogmatisch-methodischen Debatten dabei zunehmend autonom gesetzt: Der Binnenraum des Rechtsorganismus wird vom Außen geschieden; die innere Autorität des Rechts von äußeren Einflüssen gesondert; und v.a. die Kraft der Weiterentwicklung des Rechts ins Recht selbst verlagert, das zu seiner Selbstverwirklichung drängt. Trotzdem erscheint das Recht an das Leben zurückgebunden. Denn die Verwirklichung des lebenden Charakters des Rechts erfolgt hier nicht über die Konfrontation des Rechts mit der gesellschaftlichen Wirklichkeit, sondern über den Konnex von Rechtstheorie und Rechtsdogmatik, wie ihn schon Savigny statuiert: Die Volksgeistlehre bestimmt entsprechend der Abbildund Repräsentationsidee das Rechtssystem nun selbst als organische, lebendige Einheit, die dem Recht schon vor jeglicher wissenschaftlichen Behandlung inhärent ist. Der lebendige Charakter des Rechts zeigt sich im System des Rechts selbst. Und nur wenn man dieses System richtig erkennt bzw. konstruiert, kann man folglich zur lebendigen Seite des Rechts vordringen.

Der Bezug des Rechts zum Leben wird hier unter Abwertung der historischen Perspektive durch die rechtsdogmatische Arbeit erkennbar. Die systematische Arbeit am Recht wird aufgewertet, und eine zunehmende Formalisierung findet statt, die die juristische Begriffsbildung für die Systembildung in ihrer spezifischen Technizität und Logizität in den Mittelpunkt rückt. Die Rechtswissenschaft ist hierin der Wahrheit verpflichtet allerdings unter dem Vorbehalt einer Relativierung und Korrektur der wissenschaftlichen Logik und Wahrheit durch den Volksgeistgedanken.

Dabei begrenzt sich die wissenschaftliche Arbeit nicht (mehr) auf eine rekonstruierende Tätigkeit. Denn über die Bestimmung des Systems wird der wahre Charakter des Rechts als lebendiger Organismus freigelegt. „Innere Kraft“, „organisches Prinzip“ oder „inneres System“ werden zu Schlagwörtern, um die Eigendynamik des Rechts als sich wandelnde, aber sehr wohl definierte organische Einheit fassen zu können. Wenn die Jurisprudenz diese Kraft in ihrer systematischen Arbeit freilegt, dann wird sie produktiv bzw. konstruktiv. Es geht um ein Erkennen im Sinne von Schöpfen, weil dieses Erkennen die schöpferische Kraft nicht nur freilegt, sondern zugleich verwirklicht, indem sie etwas Neues zutage fördert. Die Jurisprudenz wirkt auf den Stoff zurück, indem sie ihre Kompetenz in Bezug auf das Recht selbst erweitert. 
Darin liegt ihr spezifischer Wert für das Leben des Volkes. Nur eine Rechtswissenschaft, die sich dieser lebendigen Seite des Rechts zuwendet, die selbst ein flexibles, wandelbares System entwirft (konstruiert), vermag angesichts eines sich im ständigen Wandel befindlichen Lebens „billiges Recht“ (Puchta) bzw. „praktikables Recht“ (Jhering) zu finden. Die zentrale Figur eines solchen organischen Rechts ist daher der dogmatisch arbeitende Rechtswissenschaftler, der allein in der Lage ist, die organische Kraft des Rechts zutage zu fördern. Nur er vermag es, das Repräsentationsproblem im „lebenden Recht“ zu lösen, da nur er in seiner systematisch-wissenschaftlichen Arbeit den Lebensbezug erkennen und v.a. verwirklichen kann.

Die Verwirklichung des Lebensbezugs ist das eigentliche Problem, auf das man aus rechtsdogmatischer Sicht im „lebenden Recht" stößt und das die spezifische Technik ,Rechtswissenschaft' zu lösen hat - und die Lösung wird in der konstruktiv verfahrenden Jurisprudenz gesehen. Denn auch wenn Jhering mit seiner Naturlehre des Rechts eine Version einer autonomen und selbstbewussten Rechtswissenschaft liefert, die in ihrer Radikalität und Wortwahl auf viel Kritik stößt, so wird die juristische Konstruktion zu einem „methodischen Dogma innerhalb einer intensiv gepflegten allgemeinen Rechtlehre [...], zu welcher Beiträge nicht nur von der engeren $\mathrm{Zi}$ vilistik, sondern von der Prozeßrechtslehre, dem Staatsrecht und dem Strafrecht und auch der Rechtsgeschichte her geliefert" werden (Gagnér 1975: 295, m.w.N.). Mit dem Schlagwort der „Construction“ gelangt die Rechtswissenschaft zum Selbstbewusstsein ihres autonomen Daseins über die einzelnen Rechtsschulen hinweg. Hierin wird ihre spezifische Eigenart gesehen - und zugleich ihr besonderer Wert, wird darin doch der notwendige Lebensbezug des Rechts erblickt: Die Rechtswissenschaft allein vermag es, das Recht lebendig zu halten.

\section{Das epistemische Dispositiv der Repräsentation}

In der Rechtsentstehungslehre der Historischen Rechtsschule wird das Recht vergesellschaftet: Es erscheint nun als das Produkt eines Volkgeistes, der als Synonym für eine von Staat und Vernunft unabhängige Sozialsphäre den Bezug des Rechts zum gesellschaftlichen Leben in den Vordergrund stellt. Mit der erfolgreichen Ausbreitung und der weitverbreiteten Diskussion dieser Lehre erscheint Recht im Diskurs der Privatrechtswissenschaften nun als „lebendes Recht“, ein historisch-kontingentes Produkt, das sich der direkten Steuerung und Regulierung entzieht. Indem über die Anerkennung der Volksgeistlehre - auch im Feld der Gegnerschaft - der Bezug 
des Rechts zur vorausgesetzten gesellschaftlichen Wirklichkeit problematisiert wird, wird in den Privatrechtswissenschaften ein neuer Wirklichkeitsund Wissensbezug generiert. Denn vice versa tritt nun der Volksgeist respektive die Gesellschaft als epistemisches Ding der Rechtswissenschaften in Erscheinung - zwar vage und verschwommen, in seinem mystischen und spirituellen Charakter beständig kritisiert, aber nichtsdestotrotz als Gegenstand, um den die Debatten kreisen und der darin systematisch gefestigt und hervorgebracht wird.

\section{Recht und Repräsentation}

Der Diskurs der Privatrechtswissenschaften bis in die 1860er Jahre formiert sich im epistemischen Dispositiv der Repräsentation: Das Problem der richtigen, möglichen und erwünschten Repräsentation der Sozialsphäre im Recht steht im Zentrum und wird zur vorherrschenden Problematisierungsform der Rechtswissenschaft. Dabei zeigt sich, dass diese Problematisierungsform gerade in der Rechtsdogmatik zu überzeugen vermag: Wenn Recht als gesellschaftliches Produkt gefasst wird, so hat das direkte Auswirkungen auf die rechtswissenschaftlichen Techniken. Über den Repräsentationsgedanken wird das Recht in seinem organischen, systematischen Charakter bestimmt, dem die Jurisprudenz mit der Konstruktion eines dynamischen, flexiblen Rechtssystems zu entsprechen hat. Hierin liegt ihre spezifische Technik begründet, und daraus folgt ihre herausgehobene Position in der Gesellschaft. Denn nur sie vermag die lebendige Kraft der Gesellschaft im Recht freizulegen und zu verwirklichen. Die Rechtsdogmatik garantiert den Lebensbezug des Rechts - kann dies aber nur vor dem Hintergrund der Plausibilität des Repräsentationsgedankens.

Damit wird die Rechtswissenschaft der Wahrheit verpflichtet, darin besteht die strategische Kraft des epistemischen Dispositivs der Repräsentation. Wissenschaftliche Arbeit zeigt sich daran, das „wahre Recht“, die Wahrheit des Volksgeistes im Recht und die rechtliche Wahrheit zu erkennen. Die Normativität des Rechts, die im Grunde nicht bestritten, sondern als Tatsache anerkannt wird, wird dementsprechend nicht zu einem strategischen Problem der Rechtswissenschaft - insbesondere vor dem Hintergrund des Rückzugs der naturrechtlich-rechtsphilosophischen Kritik an der Historischen Rechtsschule. 


\section{Recht und Politik}

Die Rechtsentstehungslehre entzieht das Recht dem Zugriff von Philosophie und insbesondere Politik. Die drohende Kodifikation ist der Notstand, auf den Savigny mit der Volksgeistlehre reagiert. Sie wird abgewendet, wird doch damit das Recht dem autonomen Zugriff der Gesetzgebung entzogen. Savigny reinigt das Privatrecht von politischen Einflüssen, der politische Streit wird in einen wissenschaftlichen umgedeutet - und genau darin besteht sein strategisches Argument. Als Produkt des Volksgeistes erscheint das Recht politisch neutral.

Allerdings lässt sich dieses Argument selbst wieder politisch aufladen. Angesichts der Objektivität des Volksgeistes erscheint es möglich, das Volk im Volksgeist nun als politischen Akteur zu fassen. Bereits im Jahr 1815 hat der erbitterte Gegner Savignys im Kodifikationsstreit Nicolaus Thaddäus Gönner vor dieser Möglichkeit der strategischen Wiederaufladung gewarnt, als er die umstürzlerischen Tendenzen der Volksgeistlehre ankreidet, werde doch der Rechtsgewohnheit des Volkes die Rechtsetzungsbefugnis zugesprochen (vgl. Gönner 1815: 189f.). Und in der Tat wird dem Volk von verschiedenen Seiten der Status als tatsächlicher politischer Akteur zugeschrieben, sei es als Forderung, sei es als Vorwurf. 228

Savigny, aber mehr noch Puchta widersprechen schon früh vehement einer solchen politischen Aufladung (vgl. Mecke 2008: 159ff.), indem sie die „stete, oft unbewußte Verwechslung der ganz verschiedenen Begriffe, die mit dem gemeinsamen Namen Volk bezeichnet werden" (Savigny 1840a: 30), ankreiden. Das Volk, von dem sie sprechen, sei keine Bezeichnung für die Untertanen (vgl. Puchta 1828: 151; Savigny 1840b: 30), ge-

228 Dies zeigt sich z.B. in den Debatten über Öffentlichkeit und Mündlichkeit der Straf- und Zivilprozesse (vgl. die Nachweise all der namhaften Beteiligten bei Rückert 1974: 249ff.). Die Rechtsentstehungslehre öffnet sich über solche politischen Fassungen des Volksbegriffs damit den v.a. naturrechtlich inspirierten liberalen Forderungen nach Beteiligung des Volkes als politischer Akteur. Daneben ermöglicht die Volksgeistlehre aber ebenso die völkischen Bestimmung des Volkes - wie etwa über ein Germanentum im „germanischen Recht“, das das „fremde Recht“ der Römer abzuwehren sucht. Dieser Interpretation der Volksgeistlehre entspricht der heutige Streit darüber, inwiefern die Historische Rechtsschule die nationalsozialistische Rechtsentwicklung begünstigt habe oder eben nicht (vgl. hierzu exemplarisch etwa Rückert 1986). Zur nationalsozialistischen Rechtslehre und Rechtspraktik im Privatrecht ist nach wie vor die Untersuchung von Bernd Rüthers grundlegend (Rüthers 2005). 
schweige denn ein politischer Akteur. ${ }^{229}$ Es handele sich auch nicht um das „gemeine“ Volk (Puchta 1844b: Sp. 16f.) oder gar den „Pöbel“ (Puchta 1837: 233). V.a. sei es auch kein reiner Sammelbegriff für die Menge der Individuen, und lasse sich daher auch nicht über Mehrheitsmeinungen oder in alltäglichen Äußerungen entdecken (ebd.: 65; Savigny 1840a: 30). Entgegen dieser „Begriffsverwirrungen“ (Puchta 1844b: Sp. 28) bestehen Savigny und Puchta darauf, das „Volk im natürlichen Sinn“ (Puchta 1828: 137) zu verstehen bzw. als „Naturganze[s] [...], bey welchem von Wahl und Willkühr nicht die Rede seyn kann“ (Savigny 1840a: 30). Es wird als unpolitisches, natürliches und daher objektives Objekt betrachtet, dessen Eigenschaften und Entwicklungsgesetze nicht künstlich, d.h. willkürlich, hervorgebracht werden. Der Politisierung dieser Sphäre wird ihre Naturalisierung entgegengehalten, der staatlichen Sphäre wird eine unabhängige Sphäre entgegengesetzt.

Die Versuche der Verteidigung eines solchen natürlichen, und das heißt: unpolitischen, Volksbegriffs ändern jedoch nichts daran, dass die politischen Implikationen der Volksgeistlehre im Diskurs der Privatrechtswissenschaften immer wieder zur Debatte stehen. ${ }^{230}$ Seine eigentliche Wirkung entfaltet die Volksgeistlehre jedoch im Bereich der Rechtsdogmatik nämlich über den Konnex der Ebene der Rechtstheorie in Form der Rechtsentstehungslehre mit derjenigen der Rechtsdogmatik und -methodik. Hier zeigt die Volksgeistlehre ihre dominante Wirkung, und hier wird das Recht zu einem selbständigen Gegenstand erhoben, deren Handhabung der politischen Entscheidung entzogen ist. Die Privatrechtswissenschaft beansprucht im Repräsentations-Dispositiv gegenüber Gesetzgebung, Justiz und Philosophie ihre Autonomie, gerade weil sie es schafft, die Rechtsquellenlehre in direkter Beziehung und Nachbarschaft zur Rechtsdogmatik zu stellen. Hier erscheint der Rechtsdogmatiker als zentraler Akteur, der den Lebensbezug des Rechts in seiner systematischen Arbeit verwirklicht. Mittels der Hinwendung zum Volksgeist wird also primär ein wissenschaftliches, nicht ein politisches Problem gelöst. Und

229 So gilt für Puchta: „[D]as Volk in der natürlichen Bedeutung kann keinen Beschluss fassen, weder ausdrücklich noch stillschweigend" (Puchta 1828: 151).

230 Siehe hierzu auch die Debatten um das Volksrecht und den politischen Geist im Recht (s.o. \$2.III.2). Diese Versuche ändern im Übrigen nichts daran, dass die Lehre, die explizit nur für das Privatrecht, und gerade nicht für das Staatsrecht entwickelt wurde, in ihren allgemeinen Aussagen über die Natur des, reinen Rechts' anschlussfähig für das Öffentliche Recht wird; zur Rückübertragung dieses politisch gereinigten Denkens auf das Öffentliche Recht vgl. insbesondere Wilhelm 1958. 
selbst wenn - wie in der Debatte um römisch-liberales und germanisch-soziales Recht - über die politischen Implikationen gestritten wird, so geht es nicht darum, das Recht etwa durch neue Gesetzgebung zu ändern, sondern dasjenige Recht zu bestimmen, auf das man sich legitimer Weise berufen muss. Damit wird selbst in diesem Streit das Recht nicht dem ändernden politischen Zugriff ausgesetzt. ${ }^{231}$

\section{Die Entdeckung der Gesellschaft im Recht}

Der Volksgeist verliert in der ersten Hälfte des 19. Jahrhunderts in den Auseinandersetzungen der Privatrechtswissenschaften zusehends seine mystische, vergangenheitsorientierte Bestimmung. Das entspricht einem Wandel in der Begriffswahl: Um die Mitte des 19. Jahrhunderts wird in den Debatten anstelle von „Volk“, „Volksgeist“ oder „Volksüberzeugung“ (nicht nur seitens des Naturrechts) immer öfter von "Gesellschaft" bzw. „bürgerlicher Gesellschaft“ (vgl. etwa Kuntze 1855: 193), „Gesellschaftsordnung“ (Röder 1855: 60), „sociale[m] Lebenskreis“ oder „menschliche[r] Gesellschaft“" (vgl. etwa Beseler 1847: 20, 231) gesprochen. Die Objektivität des Volksgeistes wandelt sich immer mehr zur Objektivität der Gesellschaft. Das ermöglicht eine zweite strategische Wiederauffüllung der Volksgeistlehre: die Entwicklung einer eigenständigen Gesellschaftslehre. ${ }^{232}$

Dieser Weg ist deutlich bei dem Staatswissenschaftler (und Hegelianer) Lorenz von Stein zu erkennen, der mit seiner dreibändigen Geschichte der sozialen Bewegung in Frankreich aus dem Jahr 1850 zu den ersten im deutschsprachigen Raum gehört, die einen systematischen Entwurf einer „Wissenschaft der Gesellschaft" (Stein 1850: XII) vorlegen. ${ }^{233}$ Denn dieser Entwurf beruht unter anderem auf der Auseinandersetzung mit der Rechtsentstehungslehre der Historischen Rechtsschule (vgl. Takii 2014).

231 Diese Debatte ist ein Beispiel dafür, dass sehr wohl über die politischen Implikationen der Rechtswissenschaft gestritten wird, diese aber zugleich jenseits des politischen Zugriffs stattfindet.

232 Das gilt letztlich m.E. auch für den Weg in die Volkskunde, und so verwundert es nicht, dass Jakob Grimm, einer der Begründer der Volkskunde im 19. Jahrhundert, glühender Anhänger von Savigny war (vgl. zu Grimm und Savigny Schuler 1963).

233 Stein wird zumeist als Hegelianer betrachtet. Selten, aber doch immer wieder weist man auf den zentralen Einfluss der Historischen Rechtsschule bzw. Savignys hin (vgl. Nitzschke 1932: 116ff., hieran anschließend Takii 2014). Zu Lorenz von Stein vgl. Grünfeld 1908; Koslowski 2005; Blasius 2007. 
Insbesondere die Rechtsgeschichte, wie sie in der Historischen Rechtsschule betrieben wird, bildet anfangs einen Schwerpunkt von Steins Tätigkeit (vgl. etwa Stein 1839; 1841a; 1846) - und zwar mit einer Begründung, die einerseits deutlich an Savignys Schema erinnert, andererseits aber bereits den Weg zur Gesellschaftslehre ankündigt: „Das geltende Recht ist aber seinem Wesen nach nur die Erscheinung des Volksbewußtseins über das Recht“. Daher sei es „vergeblich, den Volkswillen durch Gesetze zwingen zu wollen“ (Stein 1842b: 278, 280). Insofern betont Stein den "Schatz“ der deutschen Jurisprudenz, nämlich „das einzige Volk der Welt" zu sein, "das die Geschichte seines Rechts sich zur Wissenschaft erhoben hat" (Stein 1846: VIIf.). Daran gelte es anzuschließen (vgl. auch Stein 1839). Denn auch Stein will vordringen zur ,innere[n] Lebenskraft“, die sowohl zu erklären vermag, wie das Rechts entstanden ist, als auch, wie es sich entwickelt. Denn ,jener ewig schöpferische Drang des Werdens, ein selbstständiges Lebendiges und Thätiges zu erzwingen, lebt auch in den Bewegungen des Rechts“ (ebd.: VIII).

Gegenüber Savigny ist Stein jedoch mehr auf das ,individuelle Ganze des Rechts gerade in seiner Verbindung zum je individuellen Volksleben aus (vgl. ebd.). Davon ausgehend wählt er nicht den Weg der Einfühlung, sondern denjenigen der Vergleichung: Über den Vergleich der differenten Erscheinungen des Rechts versucht er - den hegelianischen Prämissen folgend - der inneren Kraft im Recht, dem „ewig Lebendigen“, näher zu kommen. Sein Weg führt über die Rechtsvergleichung der empirisch ermittelbaren historisch differenten Formen des Volksbewusstseins verschiedener Länder (vgl. Stein 1841a; 1846).

Damit verbunden ist eine grundlegende, v.a. auch auf die logischen Mängel und historisch schlichtweg falschen Behauptungen eingehende Kritik an Savignys System (Stein 1841b). Stein wendet sich nicht nur gegen die Verankerung des heutigen Volksrechts im römischen Recht und die These seiner Repräsentation durch den Juristenstand, was ihn in die Nähe der germanistischen Kritik führt (vgl. auch Stein 1845b, 1845a). ${ }^{234}$ Besonders kritisiert er Savignys Hinwendung zum System des Rechts, d.h. zur

234 So schreibt er eine grundlegende Kritik an dem Begriff des „heutigen römischen Rechts“, der "weder an sich ein wissenschaftlicher, noch in seiner Ausführung ein praktisch brauchbarer ist" (Stein 1841b: 383). Dabei stellt er unter anderem auf die Reduktion des Rechtsbegriffs auf das Privatrecht ab, die dazu führt, dass sowohl germanische als auch öffentlich-rechtliche Institute außen vor bleiben. Von Hegel kommend, der das Recht an den Staat bindet, zeigt sich für den Staatswissenschaftler Stein das gesellschaftliche Problem des Rechts nicht allein auf das Privatrecht beschränkt. Mehr noch: Das eigentliche gesellschaftliche 
Rechtsdogmatik, um zu der inneren, organischen Kraft vorzudringen. Dies erscheint Stein als gänzlich „unbrauchbare Wissenschaft“, führe sie doch der bekannten, v.a. im Junghegelianismus prominenten Kritik folgend zur Entfremdung von Theorie und Praxis als "das wirkliche Leben des Rechts“ (Stein 1841b: 383, H.i.O.). Savigny habe es versäumt, „die Wirklichkeit und ihr wissenschaftliches wie praktisches Bedürfnis ins Auge“ (ebd.) zu fassen, und hierin - in der quasi wissenschaftlich implementierten Verkennung der Forderungen der Gegenwart - liege der grundlegende Mangel der Theorie der Historischen Rechtsschule.

Stein als ein Theoretiker des Vormärzes kreidet angesichts der „Bedürfnisse der Gegenwart" den quietistischen Zug der Historischen Rechtsschule an. In seinem Plädoyer für die Kodifikation - und zwar explizit als Vertreter der philosophischen Schule (Stein 1845b: 187) - versucht er eine Verbindung zwischen philosophischer und historischer Schule herzustellen: Er fordert ein Herauswachsen des neuen Rechts aus den Eigentümlichkeiten des deutschen Volkes und der gegenwärtigen historisch-gesellschaftlichen Situation (vgl. Nitzschke 1932: 124). ${ }^{235}$ Damit sei die Wissenschaft des Rechts dem Blick auf diese kulturellen und sozialen Bedingungen verpflichtet (vgl. a. Stein 1856: 226ff.).

Dieser Blick wird in Auseinandersetzung mit dem französischen frühsozialistisch-gesellschaftswissenschaftlichen Denken geschult. Gleichsam zeigt sich aber auch deutlich, wie sehr die 1842 schon angedeutete, dann Anfang der 1850er Jahre systematisch ausgearbeitete „Wissenschaft der Gesellschaft" die Bedürfnisse nach einer Theorie erfüllt, die die Mängel der Historischen Rechtsschule zu überwinden sucht. ${ }^{236}$ Die unabhängige Sozialsphäre, nun „Gesellschaft" genannt, zeigt sich als die gesuchte treibende Kraft „hinter der bisher bekannten Welt und ihrer Ordnung“" (Stein 1850: $\mathrm{XI})$. Sie gelte es mit den Mitteln der Wissenschaft direkt in den Blick zu nehmen, wolle man die Entwicklungen - auch des Rechts - verstehen. Es ist die Entdeckung dieses Gegenstandes, die sich Stein auf die Fahne

Recht, das der Ungleichheit in der Gesellschaft entspringt, ist Teil des öffentlichen Rechts, und nicht des auf Gleichheit basierenden Privatrechts (vgl. Grünfeld 1908: 44f.).

235 Mit diesem Versuch steht er nicht allein, vgl. die Verweise auf ähnlich gelagerte Ansätze von Seeger, Droysen, Kierulff und Warnkönig bei Nitzschke 1932: 124f.

2361842 veröffentlichte Stein seine Untersuchung über den Socialismus und Communismus des heutigen Frankreichs, in der er meines Wissens nach erstmals eine selbstständige Gesellschaftswissenschaft fordert (Stein 1842a: V). Die dreibändige Geschichte der socialen Bewegung (1850) sieht er als überarbeitete und erweiterte Neuauflage dieser Studie an. 
schreibt: „,[D]ie Erkenntniß des menschlichen Lebens hat in jenen Erscheinungen ein neues Gebiet gefunden, und dasselbe mit einem alten Namen bezeichnet. Es ist dies die Gesellschaft, ihr Begriff, ihre Elemente und ihre Bewegungen.“ (Ebd.: XIf., H.i.O.)

Die Gesellschaft ist nun auch bei Stein ein großartiger Organismus aus Kräften und Elementen (ebd.). Selbstständigkeit, innerer notwendiger Zusammenhang und Lebendigkeit sind wie bei Savigny seine Eigenschaften. Damit ist noch nichts Neues gesagt. Doch wird diese Sphäre aus der Dunkelheit herausgeholt. Denn Gesellschaft wird als eigentlicher Motor der Rechtsentwicklung direkt unter die Lupe genommen. Die Aufgabe der Wissenschaft von der Gesellschaft sieht Stein darin, die unendliche Mannigfaltigkeit von organischen Beziehungen und Kreuzungen auf die großen Grundbegriffe und Kategorien zurückzuführen, die in der Natur der einzelnen Elemente liegen sowie die Gesetze zu bestimmen, welche durch diese Natur für die Bewegungen der Gesellschaft gegeben sind (Grünfeld 1910: 39).237

Zur selbstständigen Analyse dieser Sphäre rücken für Stein, geprägt durch eine Auseinandersetzung mit dem Hegelianismus und dem französischen Sozialismus und Kommunismus, andere Kriterien in den Blick. Durch die Verbindung mit dem Staat und die Rückbindung an materielle Grundlagen (Arbeit und Eigentum) - und damit letztlich auch an die aufkommende „soziale Frage“ - ändern sich die Bestimmungen der Struktur des Organismus:

Die Gemeinschaft der Menschen, die in der Persönlichkeit des Staats die organische Einheit ihres Willens findet, hat in jener Ordnung eine eben so feste, eben so großartige, eben so mächtige organische Einheit ihres Lebens; und diese organische Einheit des menschlichen Lebens, durch die Vertheilung der Güter bedingt, durch den Organismus der Arbeit geregelt, durch das System der Bedürfnisse in Bewegung gesetzt und durch die Familie und ihr Recht an bestimmte Geschlechter dau-

237 Dafür spielt der organische Systembegriff mitsamt seinem Erkenntniswert eine zentrale Rolle: „Ich habe zuerst ein wirkliches System angestrebt; ich habe versucht, alsdann dieß System als einen Organismus von Begriffen und Gesetzen hinzustellen; ich habe endlich die letzte Einheit in einem einfachen Begriffe und Gegensätze zu finden gesucht. Mir schien es zuerst nothwendig für die ungemeine Masse staatswissenschaftlicher Thatsachen, die sich sammelt, die systematische Gestalt zu finden, in der jedes Einzelne seinen rechten Platz habe; denn dieser rechte Platz ist in Wahrheit nicht die richtige Anordnung, sondern die organische Bestimmung jedes Einzelnen“"(Stein 1852: IX). 
ernd gebunden, ist die menschliche Gesellschaft. (Stein 1850: XXVIII, H.i.O.)

Der Weg führt über die Suche nach der treibenden Kraft in der Rechtsentwicklung zur Gesellschaft bzw. von der Problematisierung des Verhältnisses des Rechts zur vorausgesetzten unabhängigen Sozialsphäre als seines Produktionsortes zur Entdeckung einer eigenständigen Wissenschaft der Gesellschaft. Denn wenn das Recht einer solchen vorausgesetzten Sozialsphäre entspringe, dann müsse man diese Sphäre selbst zum Gegenstand der Untersuchung machen.

Damit handelt es sich um die Kehrseite der Volksgeistlehre. Obwohl Stein Transformationen und Veränderungen im Blickwechsel vornimmt, bleibt es auch vor dem Hintergrund der Tatsache, dass auch er die Gesellschaft als Organismus fasst, die Kehrseite. Denn was bei Savigny und seinen Schülern dem wissenschaftlichen Blick entzogen ist und zu einer Verlagerung auf die Untersuchung des Rechtsorganismus führt, wird nun als Gesellschaftsorganismus direkt anvisiert und anvisierbar. In der Gesellschaftslehre wird die Gesellschaft nun als zentrales Objekt der Wissenschaft platziert. ${ }^{238}$

Lorenz von Stein zeigt einen Weg auf, die Rechtswissenschaft auf genuin rechtswissenschaftliche Weise in ihren Fundamenten anzugreifen, was nicht zuletzt die Debatten um die Platzierung der Gesellschaftslehre im System der Staatswissenschaften zeigen. Unabhängig von der Tatsache, dass es sich hier um einen Diskurs in den Staatswissenschaften handelt, und auch jenseits des Umstandes, dass Steins Gesellschaftslehre durch Treitschkes Kritik nachhaltig diskreditiert wird (Treitschke 1859), findet Steins Gesellschaftslehre keinen nennenswerten Widerhall in den Privatrechtswissenschaften - und das trotz der Vergegenwärtigung des Volksgeistes in der kritischen Auseinandersetzung mit der Historischen Rechtsschule. Eine Privatrechtswissenschaft unter der Ägide der

238 Der Naturrechtler Heinrich Ahrens und der Staatswissenschaftler Robert von Mohl entwickelten ihre Forderungen nach einer Gesellschaftslehre ebenfalls aus einer Kritik der Historischen Rechtsschule heraus (vgl. Ahrens 1852: XI; Mohl 1855: 258). Auch sie bleiben dabei dem Organismusbild verhaftet. Aber selbst wenn sie ihre Gesellschaftslehre deutlicher als von Stein zur Analyse des Rechtsorganismus bzw. der Rechtsordnung heranziehen, muss man letzterem m.E. die Eigenheit zusprechen, die Gesellschaftslehre als Konsequenz der Volksgeistlehre entwickelt zu haben. Anders formuliert: Mir geht es nicht um die Behauptung, dass alle Gesellschaftslehren im Schema der Historischen Rechtsschule gründen, sehr wohl aber darum zu zeigen, wie dieses Denken in eine Gesellschaftslehre münden kann und historisch gesehen zu solchen Ansätzen führte. 
Gesellschaftswissenschaft, eine Soziologisierung des Privatrechts, wird erst später gefordert - unter veränderten Problemlagen und kaum in Bezug auf Steins Überlegungen (vgl. \$5). Der Blick auf die Gesellschaft vermag Mitte des 19. Jahrhunderts das epistemische Dispositiv der Repräsentation, auf dem Rechtstheorie, Dogmatik und Methodik beruhen, aber noch nicht seine Wirkmacht anzugreifen. 


\section{\$3. Auf dem Weg zur Entdeckung des Rechts der Gesellschaft: Jherings Zweckdenken im Recht}

Das epistemische Dispositiv der Repräsentation wird erst durch das Zweckdenken des Rechts herausgefordert, zu dessen herausragenden Protagonisten Jhering mit seinem Spätwerk zählt. ${ }^{239}$ Seine Hinwendung zur Analyse des Zwecks im Recht stößt in den Privatrechtswissenschaften zwar zunächst auf große Ablehnung ( $\$ 3)$. Gleichsam lässt sich in den Debatten um die Kodifikation des BGBs eine Umstellung des Diskurses der Privatrechtswissenschaft auf das Zweckdenken nachzeichnen, indem die gesellschaftliche Funktion als Zweck des Rechts in den Vordergrund gerückt wird (hierzu gleich $₫ 4$ ). Dieses gesellschaftsfunktionale Zweckdispositiv wird in der Folge jedoch die Rechtswissenschaft vor Probleme stellen; es mündet letztlich in die Forderung einer Soziologisierung der Rechtswissenschaft. Dieser Angriff auf die Autonomie der Rechtswissenschaft wird in den Debatten über die juristische Methode mittels der Betonung des teleologischen Moments im Recht abgewehrt. Es bildet sich das normative Zweckdispositiv heraus, das die Rechtswissenschaft gegen die Soziologie erfolgreich zu immunisieren vermag (hierzu $\$ 5$ ).

\section{Rudolph von Jherings Entdeckung des „Rechts der Gesellschaft“}

Jhering bleibt in seiner Arbeit nicht bei einer rechtsdogmatischen Naturlehre des Rechts stehen. Vielmehr entwickelt er in seinen späteren Studien eine Kritik an der Historischen Rechtsschule, die bis zu einer radikalen Vergesellschaftung des Rechts führt - und das unter dem Schlagwort des "Zwecks im Recht“. Damit geht es nun nicht mehr um die Gesellschaft im Recht, sondern um das „Recht der Gesellschaft“.

239 Zur Problematik des Zweckdenkens in den Rechtswissenschaften vgl. die Studie von Wischmeyer 2015, die ebenfalls auf Jhering als zentrale Figur rekurriert. Im Unterschied zu Wischmeyer, der den ambivalenten Bedeutungsgehalt des jeweils verwendeten Zweckbegriffs untersucht, geht es mir im Folgenden um die jeweils historischen Problematisierungen der Rechtswissenschaft durch den Zweck (in seiner Ambivalenz). 


\section{L'urgence: Die Ungerechtigkeit der juristischen Konstruktion}

Im Winter 1858 liegt Jhering als Gutachter seiner Fakultät ein Fall in concreto vor, den er in seinen theoretischen Abhandlungen bereits 14 Jahre zuvor behandelt hatte: „Kann der Verkäufer, welcher Mehren hinter einander abgesondert dieselbe Sache verkauft hat, im Fall ihres casuellen Untergangs von jedem der Käufer den Kaufpreis fordern?"“ (Jhering 1859: 450)

Im Jahr 1844 hatte Jhering diesen Fall über die Anwendung der Gefahrtragungsregelung bei Paulus im römischen Recht gelöst. ${ }^{240}$ Danach trägt der Käufer ab Vertragsschluss die Gefahr des zufälligen Untergangs der Kaufsache. Geht die Sache noch vor Lieferung ohne Verschulden des Verkäufers unter, erhält dieser den Kaufpreis. Paulus wendet - so die damalige Interpretation - diesen Satz auch für den Fall an, dass die Sache vor ihrem Untergang zweimal verkauft wurde. Dem folgend vertrat Jhering in den 1840er Jahren noch die Ansicht, dass der Verkäufer zweimal den Kaufpreis erhalte - selbst wenn er in seinem „Bestreben, die Aeußerungen des Paulus [...] zu rechtfertigen, sowie den behandelten Stoff auf ein einfaches Princip zurückzuführen“, die „rigoristische Consequenz“ dieser Interpretation einräumte (Jhering 1844: 86). ${ }^{241}$

1858 kann Jhering mit diesem Ergebnis nicht mehr leben. Wortgewandt beschreibt er die "Gemüthsaufregung“, in die ihn die konkrete Entscheidungssituation versetze und die ihm seine „theoretische[n] Verirrungen"vor Augen führe (Jhering 1859: 451). Denn

[m]eine eigene, von der dabei interessirten Partei in Bezug genommene Ansicht zur Anwendung zu bringen, dagegen lehnte sich Alles, was von Rechtsgefühl und juristischem Takt in mir war, auf's Entschiedenste auf, und andererseits konnte ich doch Wochen lang keinen Ausweg finden, bei dem sich mein juristisches Gewissen hätte beruhigen mögen (ebd.).

Das Pferd wird damit sozusagen von hinten aufgezäumt: Das Ergebnis, dass der Verkäufer durch doppelte Kaufpreiszahlung nicht ungerechtfertigter Weise bereichert werde, bestimmt die Aufgabe, würde doch jede ande-

240 Vgl. Paulus quaestionum D 18, 4, 21 (s. hierzu Behrends 1987).

241 Dies führte Jhering letztlich dazu, „meinem Princip zu Liebe Consequenzen zugegeben zu haben“, zu denen sich die römischen Juristen ,in ihrem Billigkeitsgefühl nicht verstanden haben würden“ (Jhering 1844: 86). 
re Lösung nach Jhering dem Rechtsgefühl in eklatanter Weise widersprechen.

Den gesuchten Ausweg findet Jhering in der Bestimmung des Sinns der römischen Gefahrtragungsregelung: Der Zweck der Kaufpreiszahlung im Falle des Untergangs der Sache stelle eine gesetzlich zugesicherte „Versicherungssumme“ dar (ebd.: 473). Die Grenze der Haftung der Käufer ist hierbei für Jhering „das Interesse des Gegners“, d.h. des Verkäufers, „darüber hinaus, also wo die Haftung in eine reine Bereicherung des Gegners ausarten würde, erstreckt sie sich nicht" (ebd.: 484). Damit wendet er sich gegen die wörtlichen Auslegungen der Quellen, hätten diese es doch vielfach versäumt, „ihren eigentlichen Grund und Zweck näher anzugeben, und daß es unsere Aufgabe ist, ihn aufzusuchen und darnach den wirklichen Sinn des Rechtssatzes gegenüber einer vielleicht zu weiten oder engen Fassung festzustellen“ (ebd.: 480). Mittels einer „restrictiven Interpretation“ (ebd.: 481) aus Gründen des praktischen Resultats gilt ihm, „daß die Haftung des Käufers für die Gefahr nur die Schuldloshaltung des Verkäufers bezweckt" (ebd.: 484 f., H.i.O.). Da in dieser Perspektive nun bereits mit der Zahlung eines Kaufpreises der versicherte Schaden getilgt sei, entfalle jede weitere. $^{242}$

\subsection{Kritik am Wert der juristischen Konstruktion}

Jhering macht hier drei Leitmotive geltend, die ihn in der Folge zunehmend beschäftigen werden: Zum einen zieht er die proklamierte Leistungsfähigkeit der juristischen Konstruktion, die die dogmatisch arbeitende Rechtswissenschaft zum Leitstern in der Rechtsentwicklung macht, radikal in Zweifel. In seinen in den Jahren 1861 bis 1863 in der Preußischen (bzw. später Deutschen) Gerichtszeitung anonym veröffentlichten Vertraulichen Briefen eines Romanisten. Von einem Unbekannten überzieht er die „civilistische Konstruktion“, diese „neue civilistische Mode“, mit beißendem Spott: „[S]o wenig wie eine Dame heutzutage ohne Krinoline zu erscheinen wagt, so wenig ein moderner Civilist ohne Konstruktion“ (Jhering 2009a [1861]: 7).243 Er karikiert die lebensfremden, unverständlichen, bar

$242 \mathrm{Zu}$ der Entwicklung dieser Kritik bereits in Jherings früheren Schriften vgl. Mecke 2008a: 157ff.; 2010.

243 Jherings satirische Briefe stießen auf große Resonanz und wurden bald nachgeahmt (vgl. Jhering 2009f [1866]: 97). Auch wenn er versucht, seine Urheberschaft über Angriffe auf sich selbst sowie einem fiktivem Lebenslauf des Verfassers zu verbergen, gelingt ihm dies nur bedingt. 
jeglicher praktischer Anwendbarkeit vorgenommenen rein wissenschaftlich-theoretischen Konstruktionen und Spekulationen (vgl. Jhering 2009a [1861], 2009b [1861]). ${ }^{244}$ Schuld an dieser Misere sei neben institutionellen Entwicklungen die Historische Rechtsschule, die die Jurisprudenz „zwar dem Quellenstudium mehr zugeführt, der Praxis aber mehr entfremdet hat" (Jhering 2009c [1862]: 39). ${ }^{245}$ Dies zeige sich nicht zuletzt am Straucheln der Theorien angesichts der Praxis, wenn nämlich anhand von Lehrsätzen aus geläufigen Pandektenlehrbüchern und romanistischen Monographien einfache Fälle des täglichen Lebens entschieden werden sollen. Die derart erzielten Ergebnisse erwiesen sich durchwegs als praxisfern, -untauglich oder lachhaft, wenn sie nicht gar unsägliches Unheil anrichteten (s.a. Jhering 2009d [1863]). Genüsslich entfaltet Jhering eine „Galerie juristischer Mißgeburten, ein pathologisch-juristisches Kabinet“ zur „allgemeinen Abschreckung" (Jhering 2009f [1866]: 102). ${ }^{246}$ Es soll die Gefahren einer entfremdeten Theorie im „Himmel“ vor Augen führen, die es versäume, „auf die Erde hinab[zu]steigen“ (ebd.: 101).247 Letztlich gilt für Jhering, dass man „erst den Glauben an die Theorie vollständig verloren haben muss, um ohne Gefahr sich ihrer bedienen zu können“" (Jhering 2009c [1862]: 54).

Was Jhering ankreidet, ist nicht die theoretische Arbeit an sich, sondern eine vereinseitigte juristische Theorie, welche vergesse, dass es sich bei der Rechtswissenschaft um eine "praktische Wissenschaft“ (Jhering 2009e [1863]: 79) handele und welche daher die Praktikabilität der juristischen Konstruktion aus den Augen verliere (vgl. Klemann 1991: 132). Im dritten Teil seines Geistes radikalisiert er diese Kritik: Sie beruhe auf einem „Götzencultus des Logischen“, der in Puchta seinen „namhaftesten Repräsen-

244 Dabei bleibt fasst niemand verschont, egal ob Naturrechtler, Hegelianer oder der Historischen Rechtsschule verpflichtet: Jhering wirft sie alle in einen Topf und spottet in den beiden ersten Briefen über Helmolt, Fitting, Samhaber, Windscheid, Puchta, Böcking, Bekker, Rudorff, Röder, van Vangerow, Schnabel, Girtanner, Elvers, Kierulff, Bachofen, W. Sell, Gans, Hegel, Huschke und Lasalle - und eben auch über sich selbst.

245 Daher auch der verhalten wohlwollende bis teils sehr kritische Nachruf auf Savigny (vgl. Jhering 1861). Zu den institutionellen Rahmenbedingungen einer der Praxis entfremdenden universitären Lehre bzw. der wissenschaftlichen Lehrproduktion vgl. Jhering 2009e [1863], 2009f [1866].

246 Eine Fortsetzung der Kritik solcher den Standpunkt der Praktikabilität ignorierenden „civilistischen Mißschöpfungen“ (Jhering 1873: 319) folgt im Jahr 1873 in der Abhandlung Kritisches und Exegetisches Allerlei.

247 Die Praxis der gerichtlichen Entscheidung bleibt ebenso wenig verschont von seiner Kritik (vgl. Jhering 2009f [1866]: 101f.). 
tanten“ (Jhering 1865: 301) gefunden habe. ${ }^{248}$ Dieser „Irrwahn [...], der die Jurisprudenz zu einer Mathematik des Rechts hinaufzuschrauben gedenkt, ist eine Verirrung und beruht auf einer Verkennung des Wesens des Rechts“ (ebd.: 302). Dieses erkenne man nur, wenn man zu den Momenten vordringe, „denen ein Rechtssatz wirklich seinen Ursprung verdankt“ (ebd.: 303).

In dieser Kritik geht es also weiterhin zentral um die Rechtsentstehungslehre, d.h. um den Ursprung des Rechts. Jhering sucht diesen wie die Historische Rechtsschule ebenfalls im Geistigen - aber nicht im Geist des geschichtlich notwendigen Traditionszusammenhangs, der jedes Recht zwangsläufig an das römische Recht rückbindet und vice versa allem Neuen, was sich nicht in den römisch-rechtlichen Quellen verorten lässt, das „Stigma des Unjuristischen“ aufpräge (ebd.: 302). In diesem Zwang der Rückbindung an römisch-rechtliche Quellen erkennt er vielmehr eine Form des Positivismus, die „dem Positiven den Nimbus des Logischen“ (ebd.: 299f.) verleihe. Das ,Recht der Wissenschaft' ist in Jherings Augen jedoch gerade nicht produktiv. Vielmehr führe es in einer Art „logische[n] Selbsttäuschung von den wahren Quellen, in denen die letzten Gründe der Rechtssätze zu suchen, und damit vom wahren Verständniß des Rechts überhaupt“ (ebd.: 300) weg. Jhering macht demgegenüber geltend: „Das Leben ist nicht der Begriffe, sondern die Begriffe sind des Lebens wegen da. Nicht was die Logik, sondern was das Leben, der Verkehr, das Rechtsgefühl postulirt, hat zu geschehen, möge es logisch nothwendig oder unmöglich sein.“ (Ebd.: 302f.)

\subsection{Auf der Suche nach dem wahren Ursprung des Rechts}

Jhering sucht die wahren Quellen des Rechts also im Leben, im Verkehr und im Rechtsgefühl. Dabei rückt nun das zweite Leitmotiv seiner Abhandlung zum Doppelkauf in den Vordergrund: Die Hinwendung zu Zweck und Interesse. In scharfer Abkehr von jeglicher Theorie des Rechts, die es im Willen begründet, gilt für Jhering nun: „Die Rechte sind nicht dazu da, um die Idee des abstracten ,Rechtswillens' zu verwirklichen, sondern um den Interessen, Bedürfnissen, Zwecken des Verkehrs zu dienen.“

248 Zur Einbettung dieser scharfen Kritik in die romanistischen Diskussionen über Puchtas Vorgehen seit den 1860er Jahre vgl. Haferkamp 2004: 48ff. 
(Jhering 1865: 316) ${ }^{249}$ Die „bewegende Kraft“, jene Kraft der Rechtsentwicklung, die die Historische Rechtsschule über das organische Systemverständnis zu eruieren sucht, könne sich nur über das „praktische Verständnis“ (ebd.) des Rechts in einer funktionalen Betrachtungsweise offenbaren. Legte Jhering dabei in seiner naturhistorischen Methode im Rahmen der funktionalen, physiologischen Betrachtung den Fokus auf das formale, d.h. das technische Moment, weitet er nun den Funktionsbegriff auch auf die materielle bzw. substantielle Seite des Rechts aus. Denn das praktische Verständnis bringe nun zwei Seiten des Rechts ans Licht:

Zwei Momente sind es, die den Begriff des Rechts constituiren, ein substantielles, in dem der praktische Zweck desselben liegt, nämlich der Nutzen, Vortheil, Gewinn, der durch das Recht gewährleistet werden soll, und ein formales, welches sich zu jenem Zweck bloß als Mittel verhält, nämlich der Rechtsschutz, die Klage. (Ebd.: 316f.)

In Verbindung dieser beiden Elemente gelte dann: „Rechte sind rechtlich geschützte Interessen.“ (Ebd.: 317$)^{250}$

249 Die Kritik des Willensdogmas führt Jhering zu einer Kritik des subjektiven Rechts, das zur Durchsetzung der eigenen Willensmacht auf Kosten anderer berechtige: „Wohin dies im Verkehr führen muß, leuchtet ein. Ungehemmt und unbeschränkt kann die Saat der Unfreiheit ausgestreut werden, kann das Unkraut drückender, für den Verkehr wie für das berechtigte Individuum völlig werthloser Beschränkungen wuchern; unter der falschen Freiheit geht die wahre zu Grunde, und der Wille gräbt sich sein eigenes Grab.“ (Jhering 1865: 315) Dies kommt einer marxistischen Kritik des Privatrechts als Unterdrückungsverhältnis nahe. Zur positiven marxistischen Rezeption des "gewandelten“ Jhering" vgl. Losano 1984: 157ff.; Klenner 1992; zur Frage nach der geistigen Verwandtschaft von Marx und Jhering s. Viehweg 1970.

250 In einer späteren Auflage des Geistes schreibt Jhering: „Kein Recht ist seiner selbst wegen oder des Willens wegen da, jedes Recht findet seine Zweckbestimmung und seine Rechtfertigung darin, daß es das Dasein oder Wohlsein fördert, kurz in dem Nutzen [...]. Nicht der Wille oder die Macht bildet die Substanz des Rechts sondern der Nutzen [...].“ (Jhering 1888: 350) So enthält jedes Recht nach Jhering „den Ausdruck eines vom Gesetzgeber nach dem Standpunkt seiner Zeit für schutzfähig und für schutzbedürftig anerkannten Interesses“, die „sämmtlich einem ernsten Zweck des Verkehrs oder einem gerechtfertigten ethischen Interesse“ entsprechen (Jhering 1865: 320). Insofern ändert sich der „Interessenmaßstab mit der wirthschaftlichen, geistigen und socialen Entwicklung des Volks“ (ebd.: 321). Hier liegen die „realen Mächte des Lebens“ (ebd.: 300). 
Jhering verlässt die Volksgeistlehre nicht gänzlich; er vertritt weder einen Rechtspositivismus ${ }^{251}$, noch will er sich in den abstrakten Spekulationen der Vernunft verlieren. Auch gelte nach wie vor: „Es muss zugegeben werden, dass auch das Recht ganz wie die Sprache eine unabsichtliche und unbewußte, nennen wir sie mit dem hergebrachten Ausdruck: organische Entwicklung von Innen heraus kennt." (Jhering 2003 [1872]: 8) Daneben trete aber die Gesetzgebung, und in dieser politisch umkämpften Form der Hervorbringung des Rechts zeige sich sein wahrer Charakter: Recht sei das Ergebnis von Interessenkämpfen. Es sei immer umkämpft und könne sich v.a. nur durch den beständigen Kampf weiterentwickeln: „Das Recht ist Kampf“ bzw. „[a]lles Recht in der Welt ist erstritten worden“ (ebd.: 5). Das sei die „rauhe[] Wirklichkeit des Rechts“, seine „realistische[] Seite als Machtbegriff“ (ebd.: 7), wie Jhering in seinem berühmten, in 16 Sprachen übersetzten Vortrag Der Kampf um's Recht aus dem Jahr 1872 ausführt.

Was Jhering bestreitet, ist damit nicht die Herkunft des Rechts aus einer unabhängigen Sozialsphäre. Ebenso wenig steht ihr Charakter als geistige Wertsphäre zur Debatte. Was er bestreitet, ist die Idee des harmonischen Aufbaus und der Entwicklung dieser Sphäre, wie er sie in der "SavignyPuchtasche[n] Theorie von der Entstehung des Rechts“ erkennt, die das Recht dem politischen Kampf entzieht. Ihr zufolge

geht die Bildung des Rechts ebenso unvermerkt und schmerzlos vor sich wie die der Sprache, es bedarf keines Ringens, Kämpfens, ja nicht einmal des Suchens, sondern es ist die still wirkende Kraft der Wahrheit, welche ohne gewaltsame Anstrengung langsam, aber sicher sich Bahn bricht, die Macht der Überzeugung, der sich allmählich die Gemüter erschließen, und der sich durch ihr Handeln Ausdruck geben ein neuer Rechtssatz tritt eben so mühelos ins Dasein wie irgendeine Regel der Sprache (ebd.: 8).

Jhering betont demgegenüber den antagonistischen Charakter dieser Sphäre. Sie sei ein „chaotisches Getriebe menschlicher Zwecke, Bestrebungen,

251 Auch wenn man in Jherings Hinwendung zum positiv gesatzten Recht einen Positivismus erkennen mag (vgl. etwa Hippel 1951), hat er nur polemische Worte für den Rechtspositivismus übrig: Er sei der „Todfeind der Jurisprudenz“ als Wissenschaft, da er nur das „Zählen“, „Excerpiren[] und Compiliren[]“ (Jhering 1998 [1868]: 52) kenne. Mehr noch: Es werde die „Flucht aus dem eigenen Denken“ angetreten, eine „Selbstdahingabe an das Gesetz als willenloses Werkzeug“. Dies zu bekämpfen ist Jherings Ziel: „[D]arum stehe ich hier, das ist und soll meine Aufgabe sein, solange ich hier wirke.“ (Ebd.: 54f.). 
Interessen" (ebd.: 10f.). Das Recht befinde sich innerhalb dieses Chaos und hier kämen ihm nun spezifische Aufgaben zu: Es sichere die „feste Ordnung des Verkehrslebens“ und verteidige die „unerläßliche Ordnung des Gemeinwesens“ (ebd.: 27, 28). Denn Recht werde nicht nur über das gemeinschaftliche Handeln der Individuen hervorgebracht, sondern wirke als Teil der "politischen Pädagogik“ (ebd.: 34) auch auf die Individuen ein. ${ }^{252}$

Damit habe das Recht ein Ziel: den Frieden. Ein solches Recht wäre das ideale Recht als „Verwirklichung der Rechtsidee“. Das Mittel dazu sei jedoch der Kampf. Kurz: Das Recht diene dazu, Interessen zu verwirklichen, auf individueller Ebene, aber auch das „Interesse der Gesellschaft“ (ebd.: 28). Hierin liege seine Funktion innerhalb der Gesellschaft, es sichere die gesellschaftliche Ordnung. Und daher sei das Recht ein "Zweckbegriff“ (ebd.: 10).

Während Savigny und seine Mitstreiter aufgrund des Harmoniegedankens im Recht die Repräsentation des Volksgeistes erkennen, sieht Jhering im Recht ein Mittel, das innerhalb dieses Ganzen bestimmte Funktionen erfüllt. Und während erstere die Entstehung des Rechts in der Vergangenheit verorten und die Rechtsentwicklung den Juristen anheimstellen, erfolgt sie nach letzterem beständig und alltäglich im „Kampf um's Recht“ und das bedeutet: unter Berücksichtigung der Gesetzgebung und des individuellen Kampfes um das eigene Recht. Der Motor der Rechtsentwicklung sei nicht die Rechtswissenschaft (respektive der durch sie vermittelte Bildungsstand), sondern der alltägliche Kampf um die Behauptung des Rechts. Damit erfährt die Sozialsphäre eine Vergegenwärtigung und Aufwertung, die die Gegenwart gegenüber der Vergangenheit privilegiert.

\subsection{Das Ringen um Gerechtigkeit}

Hier schließt nun das dritte Motiv aus dem Problem des Doppelkaufs an: Die Frage nach der Gerechtigkeit. Aus dem Zweckgedanken lasse sich ableiten, dass das Recht nicht nur eine Vergangenheit, sondern auch eine Ge-

252 Nicht das Recht entstehe aus dem Rechtsgefühl (was nach Jhering in der Historischen Rechtsschule fälschlicherweise „Rechtsbewusstsein“ bzw. „rechtliche Überzeugung“ genannt werde, vgl. Jhering 2003 [1872]: 23), sondern das Recht erzeuge das Rechtsgefühl (Jhering 1877: XIII; vgl. auch später 1884b). Zur Debatte steht letztlich die vergesellschaftende Funktion des Rechts, und im Privatrecht sieht Jhering den Ort, wo die Vergesellschaftung der Individuen im alltäglichen Leben vonstattengeht (vgl. Jhering 2003 [1872]: 32f.). 
genwart habe. Diese bilde den Maßstab für eine gerechte oder „unrichtige“ Gerichtsentscheidung. Und in ihr seien die Gründe zu suchen, dem herrschenden Trend in der Romanistik die Bedürfnisse des Lebens und des Verkehrs entgegenzuhalten.

Das Recht habe aber auch eine Zukunft: die „Idee des Rechts“, in der Gerechtigkeit und Gewalt sich die Waage halten (vgl. Jhering 2003 [1872]: 5 ). Daher müsse man das Recht - wie Jhering in einem später eingefügten Schlussteil seines Kampfes ausführt - auch normativ verstehen: „[D]ie Ethik hat uns Aufschluss darüber zu geben, was dem Wesen des Rechts entspricht oder widerspricht" (Jhering 1992 [1874]: 151). ${ }^{253}$ In der Entwicklung des Rechts könne es aufgrund von Jherings Rechtsentstehungslehre jedoch keinen Endpunkt geben. Denn da es sich beim Recht um ein historisch-kontingentes, dem Traditionszusammenhang enthobenes Produkt handele, wie er schon im ersten Teil seines Geistes geltend macht, lasse sich das ideale Recht letztlich nicht in der Zeit fixieren. Vielmehr gelte: „[D]ie Idee des Rechts ist ewiges Werden“ (Jhering 2003 [1872]: 10).

Der Wandel des Rechts wird damit zu einer beständigen Aufgabe. ${ }^{254}$ Denn er erfolge nicht automatisch, sondern bedürfe des Einsatzes aller Zeitgenossen. Jhering verbindet die normative Betrachtung des Rechts mit einer Handlungsanweisung: Da das Recht „die moralische Lebensbedingung der Person" sei, diene die Verteidigung des Rechts ihrer eigenen „moralischen Selbsterhaltung“ (ebd.: 24). Der Kampf ums Recht erscheint als „eine Pflicht des Berechtigten gegen sich selbst" - aber zugleich als eine "Pflicht gegen das Gemeinwesen“ (ebd., H.i.O.). Denn nur in der konsequenten Verfolgung dieses Pflichtgedankens könne das sittliche Zusammenleben gedeihen (vgl. Mitteis 1905: 658). Jhering wiederholt mit diesen Bestimmungen das bekannte utilitaristische Schema (der Nationalökonomie): Der Mensch erfüllt die Zwecke der Gesellschaft und des Staates am besten, wenn er seine egoistischen Ziele verfolgt. Dementsprechend stellt sich für Jhering das Gemeinwesen der Nation zu dieser Zeit noch als

253 Genau das aber übersehe die Romanistik (vgl. Jhering 1992 [1874]: 88ff.).

254 So schreibt Schelsky über Jherings Modell: „Für ihn enthält alles geltende Recht immer einen Gehalt an ,Gerechtigkeit', der verallgemeinernd und prinzipialisierend weitergedacht werden kann und muß, so daß die Forderung der Veränderung und Aufhebung geltender Rechtsbestimmungen gerade mit einer Bestätigung und Anerkennung des positiven Rechts als solchem zusammenfällt.“ (Schelsky 1972: 66). 
„die Summe aller einzelnen Individuen“ (Jhering 2003 [1872]: 31f.) dar. ${ }^{255}$ Darin sind objektives und subjektives Recht miteinander versöhnt, ohne zugleich im Harmoniemodell der Historischen Rechtsschule zu enden.

\section{Die Entdeckung des Rechts der Gesellschaft: Der Zweck im Recht}

Ausgehend von der Kritik am Wert der juristischen Konstruktion, am Quietismus und Harmoniemodell der Rechtsentstehungslehre sowie am fehlenden Verständnis der Normativität des Rechts einer dem Kult des Logischen verpflichteten Rechtswissenschaft unterbricht Jhering seine Arbeit am Geist ${ }^{256}$ und wendet sich seit Mitte der 1870er Jahre dem Zweck im Recht zu (vgl. Jhering 1877: V). Darin sieht er die Möglichkeit, seine Kritik in ein positives Programm zu überführen. In beiden Bänden des Zwecks setzt Jhering dafür auf der Ebene der allgemeinen Theorie des Rechts an, auf der auch die Volksgeistlehre angesiedelt ist. ${ }^{257}$ Und er rückt ebenso die Frage nach dem Ursprung des Rechts ins Zentrum. Kurz und knapp fasst er sein Ergebnis zusammen: „Der Grundgedanke des gegenwärtigen Werkes besteht darin, daß der Zweck der Schöpfer des gesammten Rechts ist, daß es keinen Rechtssatz gibt, der nicht einem Zweck seinen Ursprung verdankt.“ (Ebd.: VI) $)^{258}$

255 Allerdings verwehrt sich Jhering dagegen, diese egoistischen Interessen auf materialistische Interessen festzuschreiben. Er zählt auch rein ideelle Interessen dazu (vgl. Jhering 2003 [1872]: 14ff.). Im Unrechtsgefühl, das aus der Verletzung dieser ideellen Interessen herrühre, sieht er den Antrieb zur Behauptung seines Rechts mittels eines Prozesses. Mehr noch: Die Tatsache, dass das heutige römische Recht den materiellen Ausgleich in den Vordergrund stelle, zeuge von dessen „platte[m], öde[m] Materialismus“ (Jhering 1992 [1874]: 140). Nicht zuletzt aus diesem Grund greift Jhering die Romanistik (nicht jedoch das römische Recht) an.

256 Er wird sie auch nicht mehr aufnehmen. Der Geist wird nicht vollendet, aber in zahlreichen Wiederauflagen der Bände überarbeitet und abgeändert.

257 Auch wenn Jhering sich „die Darlegung des Gesammtzusammenhanges des Rechts zur Aufgabe gemacht" hat, verfolgt er jedoch mit dem Zweck explizit „keinen praktisch dogmatischen Zweck“ (Jhering 1877: IX).

258 Da es vorliegend nicht um die Frage des „wirklichen“ Inhalts des Zwecks geht, sondern um den Wandel der Problematisierungsweise des Verhältnisses von Recht und Gesellschaft, die in den Äußerungen Jhering zu erkennen ist, werden jeweils die ersten Auflagen der beiden Bände des Zwecks $(1877,1883)$ untersucht, nicht die zahlreichen Änderungen, die er in späteren Auflagen vornahm. 


\subsection{Die treibende Kraft des Zwecks im Recht}

Was Jhering ebenso wie Savigny sucht, ist die bewegende Kraft im Recht. Dabei setzt auch er zunächst beim Individuum an. Allerdings stellt er nicht auf dessen Recht, sondern dessen Handlung ab: Jedes Geschehen habe einen Grund, auch der Wille. Es gebe jedoch keine absolute Freiheit des individuellen Willens, der als Ausgangspunkt einer Willensbetätigung genommen werden könne. Denn der Mensch handele, um etwas zu erreichen. Aufgrund dieser Bestimmung unterscheidet Jhering im Bereich der Ursache-Wirkungs-Relation das psychologische Zweckgesetz des Willens vom mechanischen Kausalitätsgesetz der Natur: „Das Causalitätsgesetz in diesem letztern Sinn lautet: [...] keine Wirkung ohne Ursache. Das Zweckgesetz lautet: kein Wollen, oder was dasselbe, keine Handlung ohne Zweck.“ (Jhering 1877: 4f., H.i.O.) Der Zweck verursache also eine Handlung, er binde den Willen, und jegliche Handlung lasse sich über den zugrunde liegenden Zweck erklären.

Die gesuchte treibende Kraft jeglichen menschlichen Geschehens sieht Jhering also im Zweck. Er sei das Naturgesetz im Bereich des Menschlichen, und der Zweck bestehe - so Jherings weiterhin biologisch-vitalistisches Credo - in der Selbstbestimmung und Selbsterhaltung (vgl. ebd.: 6f.). ${ }^{259}$ Die diesem Wollen folgende Handlung oder Tat - so bewusst oder unbewusst sie auch ausfallen mag - sei das Mittel zur Befriedigung dieses Zwecks. Der Mensch entwickele entsprechende Interessen als spezifische Zweck-Mittel-Relationen. Dadurch erlange das unbestimmte Wollen eine bestimmte Richtung (ebd.: 30), und das durch Interesse motivierte Handeln stehe unter dem Primat der Zweck-Mittel-Relation.

Jhering setzt bei der Rechtsbetrachtung damit nicht an der Freiheitssphäre der Einzelnen, rechtstechnisch gesprochen: nicht am subjektiven Recht an, sondern am individuellen Interesse. Nichtsdestotrotz verweise die treibende Kraft des Zwecks auf die kollektive Ebene: Die physische Selbstbehauptung (Überleben) rufe das Vermögen (das Habe) als Grundform der ökonomischen Selbstbehauptung hervor - „ohne Vermögen keine gesicherte Zukunft des Lebens“ (Jhering 1877: 70).260 Das wiederum

259 Insofern ist es weder verwunderlich, dass Jhering zu Darwin Stellung nimmt, noch, dass er seine Gesetzmäßigkeiten ausgehend von der untersten Stufe, d.h. dem Tier, entfaltet (vgl. Jhering 1877: XI, 26ff.); zur Debatte um den Einfluss Darwins auf Jhering vgl. die Nachweise bei Wischmeyer 2015: 75.

260 Dabei wandelt sich der Zweck von der Sicherung des Lebens zu der des Wohllebens. Denn Jhering erkennt im Vermögen eine ausnahmslos positiv zu beurteilende „allumfassende[] civilisatorische[] Mission und ethische[] Bedeutung“ 
führe zur Notwendigkeit des Rechts, denn für Jhering gilt: „ohne Recht keine Sicherung des Lebens und Vermögens" (ebd.). Er verdeutlicht das am Beispiel des Vertrags als Grundform des ökonomischen Verkehrs: Werde der Vertrag als koinzidierende Interessen betrachtet, dann erscheine das Problem der zukünftigen Interessenverschiebung, wenn sich also das Interesse einer Partei in der Zukunft wandele. Daher liege der Zweck der rechtlichen Anerkennung der bindenden Kraft der Verträge in der „Sicherung des ursprünglichen Zweckes gegen den nachtheiligen Einfluss einer späteren Interessen-Verschiebung oder veränderten Interessen-Beurtheilung in der in der Person des einen Theils oder: rechtliche Einflusslosigkeit der Interessenänderung" (ebd.: 78, H.i.O.). Recht sichert bei Jhering also Erwartungen. Dabei dränge das Recht wiederum zum Staat, da dieser seine Verwirklichung sichere. Für diese Stufenfolge von Individuum hin zu Recht und Staat gelte: „[D]ie (praktische) Triebkraft des Zwecks, nicht die (logische) des Begriffs erzeugt mit Nothwendigkeit das eine aus dem andern." (Ebd.: 79)

Diese Herleitung des Rechts zeigt eine deutliche Verschiebung hinsichtlich des epistemischen Schema der Volksgeistlehre: Wenn das Recht bei Savigny die Vergangenheit über den Traditionszusammenhang vor der Willkür der Gegenwart sichert, so sichert es bei Jhering die Gegenwart vor der Willkür und Gefahren der Zukunft. Damit wird das Recht nicht mehr zum Repräsentanten der Ordnung, sondern zielt auf ihre Sicherung. Das Recht erreicht dies, indem es - wie beim Vertrag - den gegenwärtigen $\mathrm{Zu}$ stand vor Veränderungen in der Zukunft sichert. Zwar erscheint auch hier noch das Recht (und der Staat) ganz im Dienste des Individuums, und das Recht lässt sich auf ein System der Rechte reduzieren. ${ }^{261}$ Allerdings stellt aus der Zweckperspektive Jherings das subjektive Recht nicht wie bei Savigny das Ziel oder die allgemeine Aufgabe des Rechts (bzw. wie im Naturrecht die Wesensbestimmung über das Urrecht) dar, sondern ist eine „Form“, in der das Recht im objektiven Sinn den Interessen seinen Schutz gewährt (ebd.: 70f.).

Zudem erscheint das Recht nicht als Abbild eines vorgegebenen, harmonischen Volksgeistes, sondern als Folge von Interessenkämpfen. Es ist, wie Jhering schon im $\operatorname{Kam} p f$ ausführte, ein überindividueller Kompromiss, zu dem das „Machtverhältnis der sich gegenüberstehenden Kräfte den Aus-

(Jhering 1877: 70) - und das trotz der drängenden Probleme des Pauperismus und der sozialen Frage.

261 Das ist sozusagen der Ausdruck einer klassisch liberalen Position, wie Jhering sie auch im Kampf propagiert. 
schlag gibt“" (Jhering 2003 [1872]: 9). Recht habe daher immer eine gewalttätige Seite. Denn die Gewalt „gebiert“ das Recht, „wenn sie sich mit Einsicht und Selbstüberwindung paart“. Recht sei letztlich die „Selbstbeschränkung der Gewalt im eignen Interesse“ (Jhering 1877: 250) - es „,ist nichts anders als der Niederschlag der Erfahrung in Bezug auf die richtige Verwendung der Gewalt" (ebd.: 254).

Die Rede von einem „Naturgesetz des Willens“ deutet schon an, dass es für Jhering nicht nur Zwecke des Individuums gibt, sondern ebenso den Zweck der Natur (Selbsterhaltung der Gattung) - oder eben im Bereich des Menschlichen: die "Zwecke[] der Gesammtheit" (ebd.: 45). Dementsprechend zerfallen für Jhering „[d]ie Zwecke des gesammten menschlichen Daseins [...] in zwei grosse Gruppen: die des Individuums und die der Gemeinschaft (Gesellschaft)“ (ebd.: 64, H.i.O.); anders formuliert: in „egoistische" und „sociale“ Zwecke.

Mit dieser Doppelung verlässt Jhering für die Untersuchung des Rechts die individualistische Ebene. Denn letztlich könne die Welt angesichts eines rein selbstbezüglichen Individualegoismus nicht bestehen. Mehr noch: Das isolierte Individuum des Naturzustandes ist für Jhering mit Blick auf reale Lebensverhältnisse nicht denkbar: „Niemand ist für sich allein da, so wenig wie durch sich allein, sondern Jeder ist, wie durch Andere, so zugleich für Andere da, einerlei, ob mit oder ohne Absicht." (Ebd.: 85, H.i.O.) Der Andere ist bei Jhering nun nicht alter Ego, sondern die übergeordnete Ganzheit: die Sphäre der Gesellschaft. Auf sie bezieht sich jegliches „sociale[s] Handeln“, das Jhering dementsprechend als die Tätigkeit des Individuums für die Zwecke der Gesellschaft definiert (ebd.: 65).262 Und hier seien die sozialen Zwecke zu suchen.

Damit wechselt Jhering zum Verständnis des Rechts auf die gesellschaftliche Ebene. Der methodologische Individualismus der Rechtsdogmatik der Historischen Rechtsschule weicht einer holistischen Perspektive auf das Recht: Es geht Jhering fortan um die Frage, wie das Recht in der Sphäre der Gesellschaft zu verorten ist, d.h. welche Zwecke die Gesellschaft durch das Recht verfolgt, bzw. welche sozialen Zwecke mittels des Rechts verwirklicht werden. Er sucht „die Aufgabe, die ihm [dem Recht, D.S.] für

262 Er wendet sich mit dieser Bestimmung explizit dagegen, „nach Art des Naturrechts das Individuum aus seinem geschichtlichen Zusammenhange mit der Gesellschaft künstlich $\mathrm{ab}[\mathrm{zu}] \mathrm{lösen}$, es [zu] isolieren und diesem bloss gedachten für-sich-sein des Individuums dann das wirkliche Leben in der Gemeinschaft, das Auch-für-andere-sein gegenüber[zu]stellen“. Stattdessen zielt sein Ansatz darauf, „das Individuum in der Stellung [zu betrachten], die es thatsächlich in der wirklichen Welt einnimmt“ (Jhering 1877: 64). 
die Zwecke der Gesellschaft zukommt, klar zu stellen und die Art zu bezeichnen, wie das Recht seine Aufgabe löst" (ebd.: 66). Recht wird nach seiner Funktion für die Gesellschaft befragt. ${ }^{263}$

\subsection{Die Gesellschaft und ibr Recht}

Da Jhering die Gesellschaft ins Zentrum seiner Untersuchung setzt (statt sie herzuleiten ${ }^{264}$ ), - wird es letztlich nötig, sich mit diesem - ihm zufolge - aus Frankreich stammenden und mittlerweile weitverbreiteten Begriff auseinanderzusetzen. Denn nach wie vor sei ,Gesellschaft' nicht definiert (Jhering 1977: 93f.). ${ }^{265} \mathrm{Um}$ dies zu leisten, überträgt Jhering die Definition der privatrechtlichen Gesellschaft, d.h. der societas, auf den Gesellschaftsbegriff im sozialtheoretischen Sinne: Eine Gesellschaft im juristischen Sinn

263 Gerade im Zweck zeigt sich das dynamische Voranschreiten von Jherings Denken, das nicht vor Um- und Abwegen sowie einem eklektizistisch Umgang mit verschiedenartigsten Quellen scheut. Seine Untersuchung wurde dementsprechend als in sich sehr widersprüchlich, eklektizistisch, unausgegoren, kurz: als ein „Durcheinander der Baustile“ bezeichnet (Wolf 1963: 651). Es sei ein „Musterstück eines gelehrten Dilettantismus“ (Helfer 1968: 558) - ein Dilettantismus, den Jhering jedoch bereits selbst eingeräumt hatte (Jhering 1877: VII). Aus diesem Grund lohne es sich laut Christian Helfer auch nicht, auf den grundlegenden Teil der Gesellschaftsanalyse im ersten Band vom Zweck einzugehen - insbesondere auch deshalb nicht, weil die Unzulänglichkeit Jhering in der Überarbeitung des ersten Bandes selbst bewusst geworden sei (vgl. Helfer 1970: 84; Jhering 1884a: 77f.). Helfers Annahme soll im Folgenden widersprochen werden.

264 So bemerkt schon im Jahr 1879 Felix Dahn in seiner monographischen Abhandlung zum ersten Band des Zwecks über Jherings Vorgehen: „Nicht philosophische Speculation, nicht juristische Methode, und (leider!) auch nicht anthropologische, völkerpsychologische, historische Methode soll ihn dabei leiten: sondern eine Construction, welche wir zwar nicht apriorisch nennen dürfen, weil sie nicht von einem philosophischen Princip a priori ausgeht, sondern von dem Gegebenen, den Thatsachen der ,menschlichen Gesellschaft““ (Dahn 1879: 2).

265 Auf wen genau sich Jhering mit dieser Begriffsgenealogie bezieht, ist schwer zu eruieren, gerade weil er bei den verschiedensten Autoren in teils sehr freier Anleihe wildert. Vermutlich hat er aber insbesondere die sozialistische Theorie aus Frankreich im Auge. Zu vermerken ist aber, dass er bei all den Autoren, auf die er sich zur Begründung seiner Theorie beruft (so prominent Spencer und Bentham, vgl. Jhering 1883: 168ff., jedoch mit deutlicher Kritik), die bereits existierenden Ansätze einer Gesellschaftslehre in Deutschland insbesondere auch von juristischer Seite wie diejenigen von Lorenz von Stein und von Robert von Mohl nicht aufgreift, obwohl er mit beiden Autoren in Kontakt stand. 
setze einen auf ihre Richtung und Regelung abzielenden Vertrag, den Gesellschaftsvertrag, voraus. Sie sei „ein Verein mehrerer Personen, welche sich zur Verfolgung eines gemeinsamen Zwecks verbunden haben, von denen daher jede, indem sie für den Gesellschaftszweck thätig wird, zugleich für sich handelt" (ebd.). Das Hauptmerkmal der Sozietät bestehe in der Kooperation zu gemeinsamen Zwecken. ${ }^{266}$ Dabei handele es sich aber nicht um einen spezifisch juristischen, sondern um einen alltäglichen Sachverhalt, der sich in allen Lebensbereichen wiederhole. ${ }^{267}$ Für Jhering gilt daher: „Auf dieser gegenseitigen Förderung der Zwecke beruht meines Erachtens der Begriff der Gesellschaft.“ (Ebd.: 94f.)

Mit dieser Übertragung werden bestimmte Eigenschaften der Gesellschaft hypostatiert: Die Gesellschaft als notwendige Koordination der Individuen sei „die thatsächliche Organisation des Lebens für und durch andere“ (ebd.: 95). Sie sei das eigentliche „Bindemittel“ der Teile untereinander (Jhering 1883: 175). Als „die Form der geregelten und dauerhaften Befriedigung“ (ebd.) des Bedürfnisses der Ergänzung des einen durch den Anderen besitzt sie bei Jhering - wie eine Gesellschaft im juristischen Sinne eine eigenständige Größe: So ist die Gesellschaft „nicht die blosse Vielheit der einzelnen, nicht der Plural vom Singular Mensch, sondern die Vielheit derselben in ihrer Verbindung" (ebd., H.i.O.). Anders als noch im Kampf ist die Gesellschaft für Jhering nicht mehr derivativ als bloße Summe der Individuen zu verstehen, sondern existiert eigenständig neben den einzelnen Individuen. ${ }^{268}$

266 Der Tauschvertrag - etwa ein Kaufvertrag - hat die Verschiedenheit des Zwecks der beiden Vertragsschließenden zur Voraussetzung, wohingegen die Assoziation, die Sozietät, auf der Gleichheit des Zwecks aufbaut. Die Interessen werden koordiniert, was aber keineswegs bedeutet, dass die Assoziation auf altruistischen Motiven beruht. Denn: „Der Verkehr kennt kein Wohlwollen; alle Verträge des Verkehrs sind auf den Egoismus gebaut und so auch die Societät." (Jhering 1877: 213).

267 So führt Jhering aus: „Aber das Factische der Gesellschaft: die Cooperation zu gemeinsamen Zwecken wiederholt sich im Leben auch ohne diese Form. Unser ganzes Leben, unser ganzer Verkehr ist in diesem factischen, thatsächlichen Sinn eine Gesellschaft: ein Zusammenwirken für gemeinsame Zwecke, bei dem Jeder, indem er für Andere handelt, auch für sich handelt, und die Anderen, indem sie dasselbe thun, es für ihn thun." (Ebd.: 94).

268 Menschlich-individuelles und gesellschaftliches Leben sind damit „gleichbedeutend" (Jhering 1877: 95). Für Jhering ist das Individuum letztlich nur als soziales, d.h. gesellschaftliches Individuum denkbar: Der Mensch lebe und erhalte sich selbst, indem er eine Gesellschaft bilde. In der Schaffung seiner kulturellen Welt sei er auf gesellschaftliche Kommunikation und Kooperation angewiesen. Damit kehrt Jhering das (altliberale) Schema des Kampfs um. Die Zwecke der 
Als ein solches eigenständiges Ganzes erscheint die Gesellschaft nicht nur als objektive Tatsache. In Jherings Analyse wird sie vielmehr selbst zu einem Subjekt: „Wir steigern unsere bisherige Vorstellung eines Ganzen, welches auch unbelebt sein kann, zu der eines belebten zur Einheit der Persönlichkeit zusammengefassten Wesens.“ (Ebd.: 191, H.i.O.) ${ }^{269}$ Als ein solches „belebtes Wesen“ unterliege sie dem „oberste[n] Gesetz der Natur: das der Selbsterhaltung“ (ebd.: 192, H.i.O.). Der Selbsterhaltungstrieb, der jedem Leben zu eigen ist, finde sich auch bei der Gesellschaft. Sie hat für Jhering eigenständige Interessen, einen Willen zur Selbstbehauptung, der sich auf das „das Wohl und Gedeihen der Gesellschaft“ bzw. ihr „Bestehen und Wohlergehen“ als genuin sozialer Zweck richtet (ebd.: 104, 277). Das sei der „Egoismus der Gesellschaft“ (ebd.: 195).

Als „Form“ der tatsächlichen Organisation des Lebens für und durch andere habe die Gesellschaft eine spezifische Ordnung, d.h. ihre Teile stehen in einer planvollen Beziehung der Teile zueinander. Diese Struktur weise den Individuen ihre Stelle im gesellschaftlichen Körper zu (vgl. Jhering 1877: 357) und beschreibe ihre Abhängigkeit voneinander. Es gilt: „[K]eine Gesellschaft ohne gesellschaftliche Ordnung.“ (Jhering 1883: 176) Für die Aufrechterhaltung der Ordnung müssen wiederum Normen geschaffen werden, „welche den einzelnen Gliedern, so weit dieselben nicht schon ihrer selbst wegen dasjenige thun, was die gesellschaftliche Ordnung mit sich bringt, ihr Verhalten vorzeichnet" (ebd.). Es handelt sich also um Normen im normativen Sinne, d.h. in Form von Imperativen, die ein bestimmtes Verhalten der Individuen vorgeben. Normen sind also nach Jhering unabdingbare Voraussetzung für das Bestehen jeder Gesellschaft und die Gesellschaft muss Normen schaffen, um sich selbst zu erhalten. Sie mache das in Form einer Normordnung. Normen bedürften aber zugleich der Befolgung, weil sie sonst reines Abstraktum blieben. Deswegen seien ihnen jeweils spezifische Mechanismen der Sicherung der Durchsetzung zu eigen. Die „Deduction“ lautet also: „Die Begriffe Gesellschaft, gesellschaftliche Ordnung, gesellschaftliche Norm, gesellschaftlicher Zwang

Gesellschaft und des Staates werden nicht am besten erfüllte, wenn der Mensch seinen egoistischen Zielen folgt, sondern vice versa: „[I]ndem der Mensch sich den gesellschaftlichen Zielen unterwirft, fördert er vernünftiger- und langfristigerweise seine Interessen als Individuum“ (Schelsky 1972: 55).

269 Allerdings handelt es sich nicht um eine Persönlichkeit im juristischen Sinne, d.h. eine juristische Person, denn: „Die Gesellschaft kann nicht vor Gericht auftreten“ (Jhering 1883: 192). Jhering erscheint diese Personifizierung aber gerade mit Verweis auf die Wirkmacht des Volksgeistes als legitim - jener „Persönlichkeit“, die seit Savigny durch die Rechtswissenschaften geistert (vgl. ebd.: 193). 
hängen demnach aufs engste zusammen, mit dem Begriff der Gesellschaft sind die drei letzteren implicite gesetzt.“ (Ebd.: 177)

\subsection{Das Recht der Gesellschaft: Norm und Zwang}

Die für das Bestehen jeder Gesellschaft notwendige Normordnung nennt Jhering das „objectiv Sittliche“. Sie umfasse nicht nur die Sittlichkeitsnormen im engeren Sinne (Moral, Ethik), sondern alle Formen der „socialen Imperative“, welche „die Gesellschaft ihren Mitgliedern vorzeichnet, und deren Beachtung sie von ihnen erzwingt“ (Jhering 1883: 227). Hierzu zählt Jhering auch die Sitte, die Mode und das Recht. ${ }^{270}$ All diese Normen seien auf den Zweck der Selbsterhaltung der Gesellschaft gerichtet.

Jhering postuliert damit eine radikal gesellschaftliche Theorie des Sittlichen. Alle sozialen Normen, auch die Moral, haben ihren Ursprung in der Gesellschaft. Erst diese Perspektive sichere, dass man des imperativen Charakters der Normen, ihrer normative Dimension des „Sollens“, gewahr werde. Gerade im Bereich der Ethik zeigt sich für Jhering dabei das Defizit der herkömmlichen Betrachtungsweise: Er wirft ihrer individualistischen Fundierung im Subjekt vor, dass „[a]n die Stelle des ,Solls ${ }^{\varsigma}$ der Norm [...] das ,Sein' des Begriffs (des sittlichen Gutes, der Tugend, der Pflicht, des sittlichen Menschen)" trete (ebd.: 100). Der Fehler liege darin, dass die Ethik vom Menschen als „sittliche[r] Idealtypus“ (ebd.: 145) ausgehe. Das Sittliche erscheine dann als „begrifflich nothwendige[r] Ausfluss seines Innern, als Emanation seines eigenen sittlichen Wesens" (ebd.: 101, H.i.O.). Das Soll werde im Sein dieses Begriffs des Menschen aufgelöst. Dadurch verschließe sich der Blick gegenüber dem Zweck als Moment des Sollens, und das heißt gegenüber dem „letzten Grunde der Sache“ (ebd.). 271

Um diese Gefahr der individualistischen Theorie der Ethik zu entgehen, entwirft Jhering eine "gesellschaftliche Theorie“ des Sittlichen (ebd.:

270 Jhering leitet diese Unterscheidung entwicklungsgeschichtlich her: Aus der Gewohnheit hätten die Griechen die Sitte als verbindlichen Teil ausgesondert, die Römer hätten davon wiederum das Recht ausgesondert, was zur Unterscheidung zwischen Recht und Moral/Sitte geführt habe; die Germanen schieden schließlich die Sitte von der Sittlichkeit. In jüngster Zeit sei noch die Mode - in Abgrenzung zur Tracht als Ausdruck der Zugehörigkeit zu einer Volksgemeinschaft - als (ständig umkämpftes) Merkmal der Standesdifferenzierung (heute würde man sagen: Habitus) hinzugekommen (vgl. Jhering 1883: 49ff.; 227ff.).

$271 \mathrm{Zu}$ seiner ausführlichen Kritik an der individualistischen Theorie des Sittlichen vgl. ebd.: $142 \mathrm{ff}$. 
154ff.). Er setzt an die Stelle des Individuums die Gesellschaft und entwickelt statt einer Individualethik eine „Socialethik“ (ebd.: 157). Alle sittlichen Normen sollen das Bestehen und Wohlergehen der Gesellschaft gewährleisten. Darin liege ihr Zweck. Dementsprechend befragt er sie im Rahmen seines „gesellschaftlichen Utilitarismus“ (ebd.: 211) nach ihren gesellschaftserhaltenden Nutzen. Dafür untersucht, klassifiziert und ordnet Jhering im zweiten Band des Zwecks ein breites phänomenologisches Spektrum an Normen der sittlich-praktischen Welt: In der Unterscheidung von Gewohnheit, Brauch und Sitte behandelt er Mode, Tracht, Trinkgeld, Leichenschmaus, Gastfreundschaft, Duell und vieles mehr, beginnt aber auch, die Umgangsformen (Anstand, Höflichkeit, Takt) zu differenzieren. ${ }^{272}$

Jhering rückt also diejenige Sphäre ins Zentrum der Untersuchung, die in der juristischen Volksgeistlehre aufgrund des Erkenntnismangels notwendigerweise im Dunkeln lag. Dies führt ihn ,in die niedersten Regionen des täglichen Lebens“, das „Material“ zur Lösung seiner Aufgabe sei, „ich möchte sagen: auf der Strasse und im Kehricht zu suchen“ (Jhering 1883: XIII). Seine These des praktischen Zwecks jeder Norm, d.h. die Frage nach ihrem praktischen Nutzen für die Gesellschaft, führt Jhering zur Untersuchung und Differenzierung der sozialen Normen anhand des empirisch vorfindlichen Materials. Dabei nimmt Jhering zwar das Sollen der Normen in seiner Normativität ernst, erforscht es aber als empirische Tatsache und verortet es daher letztlich im Sein. Die Gesellschaft und ihre Normordnung erscheinen damit nicht mehr nur als Tatsache gesetzt, sondern werden zugleich zum bevorzugten Objekt der Untersuchung.

Das Recht wiederum ist in diese gesellschaftliche Normordnung, d.h. in das umfassende System der verschiedenen Formen der „socialen Imperative“, eingebettet. ${ }^{273}$ Recht wird bei Jhering nicht als Organismus, d.h. als organisch eigenständiger Wertekosmos behandelt, der streng vom Gebiet des Sittlichen getrennt sei (Savigny), sondern als Norm unter anderen Nor-

272 Daneben unterscheidet er die Sitte und die Moral: Während die Verbote der Sitte sich prophylaktisch bloß auf das Gefährliche beziehen, verbiete die Moral für die Gesellschaft schädliches Verhalten. Man könne sie aber auch je nach Verbreitungsgrad innerhalb der Gesellschaft differenzieren: Während sich die Moral auf alle Klassen der Gesellschaft beziehe, gebe es die Sitte nur in den mittleren und höheren Regionen der Gesellschaft. Dies beruht bei Jhering auf der Verbindung von Sitte und guter Sitte, wobei er die guten Sitten nur in den höheren Schichten zu finden meint. Seine Sittenlehre ist insofern elitär (vgl. Jhering 1883: 260ff.).

273 Das Sittliche als Obergriff aller sozialen Normen umfasse daher auch das Recht, jeder Rechtssatz habe - wie schon im Geist dargelegt - eine imperative Form und daher ein Sollen zum Inhalt (vgl. Jhering 1877: 337). 
men. Das bewirkt zweierlei: Erstens geht Jhering vom Rechtsinstitut als Basiselement des selbstständigen Rechtsorganismus zum Rechtssatz über (vgl. Wiethölter 1974: 661f.). Zweitens wird es aufgrund dieser Relativierung der „normativen Autonomie“ des Rechts notwendig, rechtliche Normen von anderen sozialen Normen (Gewohnheit, Sitte, Moral) abzugrenzen. Die Differenz des Rechts liegt dabei nach Jhering weder in der Form (etwa das schriftlich fixierte Gesetz) noch in der Tatsache, dass zu seiner Durchsetzung Zwang angewandt wird (auch das Sittengesetz wende Zwang an, allerdings psychologischen). Sie sei vielmehr im Einsatz spezifischer Mittel zur Durchsetzung der Normen zu erkennen. Demzufolge bestimmt Jhering Recht als „Inbegriff der durch äusseren Zwang d.h. durch die Staatsgewalt gesicherten Lebensbedingungen der Gesellschaft im weiteren Sinn" (Jhering 1877: 499, H.i.O.). Gerade die staatliche Rechtsdurchsetzung mache eine soziale Norm zum Recht. ${ }^{274}$ Hierfür gebe es im Staat einen besonderen „Verwirklichungsapparat“ (ebd.: 50) wie zum Beispiel die Rechtspflege (Justiz), ohne die das Recht ,in die Irre geht“ (ebd.: 306). Das Recht „ist der Inbegriff der in einem Staat geltenden Zwangsnormen“" (ebd.: 318, H.i.O.).

Diese Sicht auf den Staat bewirkt zweierlei: Zum einen ist der Staat insofern Teil der Gesellschaft, als sich der Gesellschaftszweck nur durch äußeren Zwang realisieren lässt. ${ }^{275} \mathrm{Er}$ ist für Jhering also derjenige Teil der Gesellschaft, der zwingt, d.h. die Form der geregelten und gesicherten Ausübung der sozialen Zwangsgewalt, oder kurz: „die Organisation des sozialen Zwanges" (ebd.: 307, H.i.O.). Zum anderen sei die Scheidung zwischen Privatrecht und Öffentlichen Recht nicht mehr sinnvoll, wenn Recht sich immer mehr auf die Gesellschaft beziehe, egal, welche Rechtsmaterie geregelt werde. Denn

274 Recht ist für Jhering letztlich nur die vom Staat aufgestellte Zwangsnorm, das ist seine formale Qualität. Darin mag man eine Form des Rechtspositivismus erkennen. Allerdings handelt es sich nicht um eine klassische rechtspositivistische Position, da im Recht letztlich gesellschaftliche Zwecke sanktioniert werden, diese also dem Recht vorgelagert sind und die Grundlage für das Rechtsverständnis bilden.

275 Vice versa geht die Gesellschaft über den Staat hinaus, und zwar inhaltlich und geographisch. Der "Zug der gesellschaftlichen Bewegung“ gehe ins Globale, letztlich also zur Weltgesellschaft (ebd.: 97). Genau das hebt später der Statistiker Gustav Rümelin als Problem des Gesellschaftsbegriffs hervor: Um eine Gesellschaftslehre zu begründen, müsse man den Gesellschaftsbegriff eingrenzen, da eine Wissenschaft der ganzen „Menschheit“ keinen Sinn ergebe (vgl. Rümelin 1889: 39f.). 
dem Lehrer der Gesellschaftswissenschaft bleibt meines Erachtens keine Wahl, der Begriff der Gesellschaft, auf den er sein ganzes System bauen muss, macht jede principielle Scheidung zwischen den Formen, in denen die Gesellschaft ihre Daseinszwecke verwirklicht, unmöglich (Jhering 1877: 305).

Das eigentliche „Zwecksubject“ des Rechts sei letztlich weder Staat noch Individuum, sondern die Gesellschaft. Sie sei der Grund des Zwecks im Recht (ebd.: 453). Danach definiere sich die Funktion des Rechts als die "Sicherung der Lebensbedingungen der Gesellschaft" (ebd.: 434). ${ }^{276}$ Bei Jhering geht es also nicht mehr um die Gesellschaft im Recht, sondern um das Recht der Gesellschaft. Und dabei gilt: Recht ist der Teil der Gesellschaft, der mittels Staatsgewalt zwingt. Allerdings setze die Gesellschaft Recht zur Sicherung nur derjenigen materiellen wie ideellen Bedingungen ein, ohne die sie ihrer Erfahrung nach nicht bestehen könne (vgl. Jhering 1883: 112).

Das Recht hat also gegenüber den anderen sozialen Nomen einen Vorteil: die Sicherheit der institutionellen Verwirklichung durch - wie Jhering es nennt - „mechanischen Zwang“ (ebd.: 180). Die Gesellschaft drohe jedoch Strafe nur in den besonderen Fällen an, in denen diese der Abschreckung vor Handlungen diene, die die Lebensbedingungen der Gesellschaft gefährdeten. Das wiederum sei eine reine Frage der sozialen Politik, d.h. historisch kontingent und nicht absolut zu bestimmen. In den anderen Fällen, namentlich im Privatrecht, beschränke sich die Gesellschaft auf die Sicherung derjenigen Interessen, die für das Zusammenleben notwendig angesehen würden, indem entsprechende Ansprüche vor Gericht geltend gemacht werden können. Sie gewähre jedoch niemals absolute Rechte: Selbst beim Eigentum - jener gerade durch die sozialistischen und kommunistischen Theorien zentral angegriffenen rechtlichen Kategorie - behalte sie sich die Möglichkeit der Expropriation vor (vgl. Jhering 1877: 514ff.).

Norm und Zwang sind nach Jhering nur rein formale Momente des Rechts. Sein Inhalt werde demgegenüber durch den Zweck bestimmt. Dieser Zweck ist für Jhering - wie erwähnt - die Sicherung der Lebensbedingungen der Gesellschaft. An diese Funktion des Rechts schließt Jherings funktionale Betrachtung des Rechts an. Abgesehen von dieser Funktionsbestimmung weist Jhering aber die Möglichkeit einer genaueren Bestimmung konkreter Inhalte des Rechts zurück. Normen könnten immer nur

276 Daher sieht Schelsky Jherings hauptsächliches Verdienst in der „soziologischen Funktionsbestimmung des Rechts" (Schelsky 1972: 48, H.i.O.). 
relative Geltung beanspruchen. Die Zwecke der Gesellschaft sind für Jhering immer historisch kontingent und hängen von den historisch-spezifischen Lebensbedingungen der jeweiligen Gesellschaft ab. Damit sind sie für Jhering eine Frage der Kultur: eine jeweils zu bestimmende und damit auch wandelbare Normordnung, die dem Selbsterhalt der Gesellschaft dient.

Letztlich bindet er also das Sittliche radikal an den gesellschaftlichen Nutzen, wie Jhering in der zweiten Auflage des zweiten Bandes des Zwecks nochmals betont:

Das Nützliche in diesem Sinne deckt sich mit dem obigen Gesichtspunkte der Lebensbedingungen der Gesellschaft. Nur was der ganzen Gesellschaft und nur was ihr dauernd nützlich ist, kann sich rühmen, ihr wahrhaft förderlich, nützlich zu sein d.h. ihren Lebensbedingungen zu entsprechen und den Anspruch erheben, in die Form der rechtlichen oder gesellschaftlichen Norm gebracht zu werden. Nur was sich als solches ausweisen kann, verdient das Prädikat des Sittlichen d.i. des gesellschaftlich Nützlichen in diesem Sinne. Damit ist nicht bloss die letzte Quelle und der Zweck des Sittlichen namhaft gemacht, sondern zugleich ein Massstab gewonnen, um die vorübergehenden Acte der Staatsgewalt sowohl wie die von ihr als dauernd aufgestellten Normen (Gesetze) und die gesellschaftlichen Einrichtungen zu beurtheilen. Was dem wahren Wohle der Gesellschaft (auf dieser ihrer zeitlichen Entwicklungsstufe) nicht entspricht, ist unsittlich. (Jhering 1886: 212f.)

Der Maßstab der sittlichen Beurteilung, d.h. des Sollens, ist nicht abstrakt bestimmt oder bestimmbar, sondern nur konkret. Er ist dem Sein der Gesellschaft zu entnehmen. Damit werden nicht nur die Normen als empirische Fakten gesellschaftlich rückgebunden, sondern ebenso die normativen Maßstäbe jeglicher sittlichen Beurteilung. ${ }^{277}$

Diese Rückbindung gilt auch für die allgemeinen Prinzipien des Rechts: Wenn Jhering die Gleichheit als Grundsatz der Gerechtigkeit im Recht anerkennt, dann nur unter der Prämisse, dass sie zur Aufrechterhaltung der sozialen Ordnung nötig ist und den sozialen Kampf als Bedrohung und Erschütterung der gesellschaftlichen Ordnung abzuwenden sucht (vgl. Jhering 1877: 356ff.). Sie ist niemals ein Wert schlechthin, da es solche den praktischen Zwecken enthobene Werte in Jherings ,gesellschaftliche[m]

277 Damit relativiert Jhering die Maßstäbe des Rechts, wofür er heftig kritisiert wurde (Pleister 1982: 221ff. m.w.N.). 
Utilitarismus“ nicht gibt. Vielmehr gilt: Der Maßstab zur Bewertung der Normen ergibt sich aus dem jeweiligen Zustand der Gesellschaft. Der konkrete Zweck des Rechts ist immer kontingent und abhängig von den gesellschaftlichen Umständen. Damit widerspricht Jhering der inhaltlichen Aufladung des Zwecks des Rechts bei Savigny und Puchta, die ihn in der Sicherung der Freiheit des Einzelnen oder in der Herstellung der Gleichheit angesichts faktischer Ungleichheit sahen. Dem setzt er eine funktionale Perspektive auf die substantiellen Inhalte des Rechts entgegen, die sich am obersten Zweck des Rechts, nämlich seiner Funktion als Sicherung der Lebensbedingungen der Gesellschaft, orientiert. Es gilt: Kein Recht ohne den Zweck der gesellschaftlichen Selbsterhaltung.

Auch wenn es sich beim Recht in seiner konkreten Ausformung immer um ein kontingentes historisches Phänomen handelt, dessen Maßstab sich zudem ändert, so spricht ihm Jhering jedoch in seinem generellen Dasein den Status einer gesellschaftlichen Gesetzmäßigkeit zu: „[E]s gibt kein Volk, das ohne das Recht [...] ausgereicht hätte“ - aber auch keines, „das bloss mit dem Recht" bestehen könne (Jhering 1883: 180). Jede Gesellschaft bedarf neben anderen sozialen Normen auch einer Rechtsordnung und bilde eine solche im Laufe ihrer Entwicklung notwendigerweise heraus. Das folge aus der treibenden Kraft des Zwecks im Recht.

\subsection{Das Spannungsverhältnis zwischen Gesellschaft und Individuum: Die „sociale Mechanik“}

Wenn der Zweck der Gesellschaft in der Sicherung ihrer Lebensbedingungen liegt, dann tritt sie damit den Individuen entgegen: „Dem Anspruch auf Schutz, den der individuelle Egoismus erhebt, ist die Gesellschaft berechtigt, ihr eigenes Interesse gegenüberzustellen.“ (Jhering 1877: 148) In dieser Gegenüberstellung erkennt Jhering ein Spannungsverhältnis, das sich aus einem Ungleichgewicht der Macht ergebe. Denn die Gesellschaft trete an das Individuum „von aussen" heran und „fordert" von ihm die Einhaltung seiner Normen (Jhering 1883: 102, 103). Sie sei in einem gewissen Sinne mächtiger als der Einzelne, besitze sie doch „eine zwingende Kraft über den menschlichen Willen“ (Jhering 1877: 102). Das dürfe nicht als ein absolutes Determinationsverhältnis des menschlichen Willens missverstanden werden - der freie Wille des Individuums bestehe und müsse bestehen. Denn er sei die eigentlich schöpferische Kraft, ihm folge die Tat und damit die Bewegung im gesellschaftlichen Leben. Was die Gesellschaft jedoch gewissermaßen beeinflussen könne und müsse, sei die Ebene des Zwecks, d.h. der Grund jeglicher Willensbildung und -betätigung. 
Jhering schwebt keine Uniformität oder Verschmelzung der Individuen vor, sondern eine verbindliche Koordinierung ihres Wollens und d.h. Handelns. In dieser Frage nach der „Art, wie die Gesellschaft und der Staat das Individuum zur Mitwirkung in ihrer Verwirklichung heranziehen" (ebd.: 65) kann, verlässt Jhering nun die organische Volksgeistlehre: An die Stelle der stillwirkenden Kräfte des Organismus tritt ein mechanisches Modell der Gesellschaft. Sie sei eine „Maschine“, die den mechanischen Gesetzen der Bewegungslehre der Körper gehorche (ebd.: 101). ${ }^{278}$ Daher könne die Gesellschaft ihre Interessen über eine „sociale Mechanik“ verwirklichen, „durch welche die Gesellschaft den Willen für ihre Zwecke in Bewegung setzt, oder kurz gesagt: die Lehre von den Hebeln der sozialen Bewegung“" (ebd.: 102, H.i.O.). Dafür setzt die Gesellschaft an den „Triebfedern“ und Mächten an, die ein soziales Handeln der Individuen bewirken (ebd.: 103), nämlich Egoismus und „ethische Selbstbehauptung“ der Individuen. Jhering identifiziert vier solcher Hebel: Im Bereich des Egoismus der Lohn (positiver Reiz) und Zwang (negativer Reiz), im Bereich des Sittlichen das Pflichtgefühl und die freie Selbstverleugnung. ${ }^{279}$

Der Lohn ziele auf die Befriedigung der menschlichen Bedürfnisse (auch nicht-materieller Art). Die soziale Organisation des Lohnes wiederum sei der Verkehr, der dem Staat vorausgehe, gleichsam aber erst durch den Staat und das Recht, d.h. durch den Hebel des Zwangs, verwirklicht werden könne. Auch wenn Lohn und Zwang zu den „absoluten Postulate[n] der gesellschaftlichen Ordnung" gehören, ohne deren Existenz Gesellschaft „undenkbar" sei (Jhering 1883: 3), habe ihre „sociale[] Leistungsfähigkeit“ (ebd.: 4) Grenzen. Die gesellschaftliche Ordnung bedarf immer auch einer Verinnerlichung ihrer Normen. Mit Blick auf das Recht müsse man konstatieren: „, $[\mathrm{O}]$ hne Hinzukommen der sittlichen Gesinnung ist die ganze Rechtsordnung eine höchst unvollkommene, unsichere." (Ebd.: 8) Daher sei die ,Triebfeder' der Sittlichkeit ebenso ein „absolutes Postulat des gesellschaftlichen Daseins" (ebd.: 11, H.i.O.). Hier setzen gleichfalls die He-

278 Jhering drückt dies gewohnt bildstark aus: „Rastlos bewegen sich wie in einer gewaltigen Maschine tausende von Walzen, Rädern, Messern, die einen in dieser, die andern in jener Richtung, scheinbar völlig unabhängig von einander, gleich als wären sie nur für sich da, ja in feindseliger Stellung zu einander, als wollten sie sich gegenseitig vernichten und doch wirken alle schliesslich harmonisch zu einem Zweck zusammen, und ein einziger Plan regiert das Ganze." (Jhering 1977: 100f., H.i.O.).

279 Allerdings führt er nur die ersten beiden (Lohn und Zwang) in seinem Zweck aus, die Ausarbeitung der Hebel im Bereich der ethischen Selbstbehauptung bleibt im zweiten Band des Zwecks in der Analyse der sozialen Normordnung stecken, und dieses Werk bleibt - wie der Geist - unvollendet. 
bel der Mechanik an. Normen werden zu Mitteln, über Internalisierung in den Individuen bestimmte Mentalitäten zu erzeugen, die ein verbindendes Interesse für ihre Handlungen kreieren.

Im Zweck führt Jhering diese Überlegungen hinsichtlich des Rechts nicht mehr explizit aus, sie laufen aber auf die Frage des Rechtsgefühls hinaus, wobei gilt: Nicht das Rechtsgefühl erzeugt das Rechts, sondern vice versa (vgl. auch Jhering 1884b). Damit geht es nicht um die Funktion des Rechts als ein ausgesonderter eigenständiger Organismus, wie dies ja sowohl bei Savigny als auch bei Puchta und dann radikalisiert beim jüngeren Jhering immer auch zur Debatte stand und über die Binnenperspektive des Rechts angegangen wurde. Vielmehr liefert Jhering nun eine funktionale Beschreibung des Rechts als ein spezifisches Mittel der Gesellschaft, ihre Ordnung aufrechtzuerhalten.

Das ,Ding' Gesellschaft wird zum eigentlichen Ausgangspunkt der Analyse des Rechts. Jhering verlässt also zum einen die Binnenperspektive des Rechtsorganismus und wendet sich dem bisher im Dunkeln gelegenen gesellschaftlichen Kontext des Rechts zu, wie er eindrücklich im Bereich der Sitte unter Beweis stellt. Zum anderen tritt die Gesellschaft dem Individuum gegenüber, und das Recht wird zu einem Mittel, die individuellen Handlungen zu koordinieren. Recht ist nun nicht mehr Folge eines vorgegebenen Rechtsgefühls (Bewusstsein des Volkes), sondern ein Mittel, über Internalisierung ein solches verbindendes Gefühl zu erzeugen.

Wenn Jhering dabei den Zweck des Rechts als die Sicherung der Lebensbedingungen der Gesellschaft definiert, dann schließt sich für ihn der Kreis seiner Analyse, wie er sie ausgehend vom Problem der Handlungen der Individuen (rechtstechnisch gesprochen: vom subjektiven Recht) eröffnete:

Wenn alle Rechtssätze die Sicherung der Lebensbedingungen der Gesellschaft zum Zweck haben, so heißt das: die Gesellschaft ist das Zwecksubject derselben. Ein wunderliches Subjekt, wird man mir einwenden, eine blosse Abstraction; das wirkliche Zwecksubject ist der Mensch, der einzelne, ihm kommt schließlich jeder Rechtssatz zugute. Vollkommen richtig! [...] Aber das gesellschaftliche Leben, indem es den Menschen durch die Gemeinsamkeit dauernder Zwecke zu höheren Bildungen zusammenfügt, erweitert eben damit die Formen des menschlichen Daseins. Zu dem Menschen als für sich betrachtetem Einzelwesen, als Individuum gesellt es den gesellschaftlichen hinzu, der Mensch als Glied höherer Einheiten. (Jhering 1877: 453, H.i.O.)

Das Verhältnis von Freiheit des Individuums und gesellschaftlicher Determination bildet bei Jhering einen Kreislauf, oder wie er schreibt: „Jeder ist 
für sich - Jeder ist für die Welt - die Welt ist für Jeden da.“ (ebd.: 522)280 Wie dieses Verhältnis in concreto ausgeformt ist, ist allerdings selbst wiederum abhängig von der gesellschaftlichen Lage (vgl. ebd.: 523).

\subsection{Die funktionale Rechtsanalyse}

Jhering problematisiert das Verhältnis von Recht und Gesellschaft nicht mehr anhand der Eigenart und des besonderen Werts der Rechtswissenschaft, welche im epistemischen Dispositiv der Repräsentation den notwendigen Bezug des Rechts zur vorausgesetzten, aber letztlich nicht direkt erkennbaren gesellschaftlichen Wirklichkeit garantiert. Er stellt nun vielmehr den Zweck im Recht und des Rechts in den Mittelpunkt. Das Verhältnis von Recht und Gesellschaft problematisiert Jhering dabei unter dem Gesichtspunkt der gesellschaftlichen Funktion des Rechts. Es geht nun um das Recht der Gesellschaft. Denn Recht sei immer sozial, es habe einen „gesellschaftlichen Charakter", auch in Form des Privatrechts (Jhering 1877: 519).

Die Funktion des Rechts für die Gesellschaft buchstabiert Jhering für drei Bereiche aus: Erstens geht es um die Funktion des Rechts im Rahmen der Frage nach den Funktionsbedingungen von Gesellschaft. Mit der Bestimmung des Zwecks im Recht wird erneut nach der treibenden Kraft im Recht gesucht, d.h. nach jenem genetischen Prinzip, das nicht nur die Rechtsentstehung, sondern auch die „Entwicklungsgeschichte“ des Rechts zu erkennen geben soll. Zur Debatte steht dabei aber nicht mehr der Traditionszusammenhang, sondern die Evolution des Rechts in der Geschichte. Denn der Mensch entwickelt Rechtssätze, von denen er aus Erfahrung gelernt hat, dass das Leben ohne sie nicht funktioniert. Die im Recht gesicherten „Lebensbedingungen“ der Gesellschaft sind gleichsam deren Funktionsbedingungen. Wenn Recht aber in einem solchen Prozess erst entwickelt wird, dann ist es ein Produkt der Tat, und nicht ein Produkt der Natur. Damit ist es geschichtlich, d.h. historisch gemacht und nicht geschichtlich notwendig geworden. Die Rechtsquellenproblematik verweist nicht mehr auf das Problem einer Legitimation des Rechts durch seine Entstehung in der Vergangenheit, die daran anschließend die Vorgaben des römischen Rechts als sichere Ausgangsbasis der wissenschaftlichen Ar-

280 Diese vieldiskutierte Problematik markiert u.a. den Einsatzort der Kritiken an Jherings Position (vgl. hierzu Pleister 1982: 304 ff. m.w.N.) - eine Problematik allerdings, die Jhering keineswegs verhehlt. 
beit nehmen kann. Vielmehr entwirft Jhering eine Theorie der Rechtsentstehung und -entwicklung im Sinne einer ,realistischen oder teleologischen" (Jhering 1889: IX) Methode, die das Recht an die Funktionsbedingungen der Gesellschaft rückbindet. Dadurch öffnet es sich der Rechtskritik und der Rechtsfortbildung angesichts eines steten sozialen Wandels bzw. Fortschritts. ${ }^{281}$ Aufgrund der Kontingenz der eigentlichen Grundlage der Rechtsbeurteilung (gesellschaftliche Lage) verschiebt sich in der Auseinandersetzung mit dem Zweck im Recht zudem der Fokus weg vom System und Rechtsinstitut hin zum Rechtssatz, d.h. von den Rechtswissenschaften hin zur Gesetzgebung als willensgerichtete Tat bzw. zur Rechtspflege, die in der richterlichen Anwendung das Recht verwirklicht (vgl. Jhering 1877: 377ff.). ${ }^{282}$

Zweitens untersucht Jhering den Zweck des Rechts unter der technischfunktionalen Perspektive einer Zweck-Mittel-Relation: Er beschreibt das Recht als ein spezifisches „mechanisches“ Mittel der Gesellschaft, ihre Ordnung aufrechtzuerhalten. Dieses Mittel definiert Jhering in seiner Theorie des Rechts durch Norm und staatlichen Zwang. Der letzte Punkt kennzeichnet den Unterschied der rechtlichen Normen gegenüber allen anderen Arten von sozialen Normen, da Recht nun nicht mehr als selbstständiger Organismus adressiert wird, sondern in die gesellschaftliche

281 In dieser Öffnung wird der Entwurf einer „Evolutionsgeschichte“ bzw. ein „Modell des sozialen Wandels durch Recht“ gesehen (Luig 1993; Schelsky 1972; s.a. Dreier 1996). Denn durch Internalisierung entwickelt das Individuum ein Rechtsgefühl, das sich wiederum selbst als eine „rechtsschöpfende Kraft“ (Jhering 1894: 27) erweist, nämlich wenn das Rechts- bzw. Gerechtigkeitsgefühl als Grund einer Kritik am Recht herangezogen wird - z.B. wenn ein Bauer gegenüber dem Adel das volle Eigentumsrecht fordert (vgl. Luig 1993: 169ff.). Über das Rechtsgefühl zeigt sich die Möglichkeit der „Kritik des Rechts durch sich selbst“, woraus der Fortschritt des Rechts resultiert (vgl. Jhering 1894). Zur zentralen Rolle des Rechtsgefühls bei Jhering vgl. auch Duxbury 2007.

282 Da das Recht in seiner richterlichen Anwendung dem Gedanken der Zweckmäßigkeit folgt, könne und dürfe die richterliche Tätigkeit nicht als Subsumtionsautomat respektive als „bloße Schablonenarbeit“ (Jhering 1877: 378) verstanden werden. Die Kritik an der irrealen Idee der Urteilsmaschine in der Begriffsjurisprudenz (s.u. \$5.I) verdankt dem Zweck seine bildliche Darstellung: „[V]orn wird der Fall in die Urtheilsmaschine hineingeschoben, hinten kommt er ohne vorangegangene selbständige Thätigkeit des Richters als Urtheil wieder heraus ganz wie bei der Ente von Vaucanson, welcher das Problem der Verdauung durch einen Automaten gelöst hatte.“ (Ebd.: 386) Allerdings hat die Rechtspflege die Verwirklichung des Rechts zur Aufgabe - und nicht mehr (vgl. ebd.: 378ff.). Zu Jherings Ansatz der Vermittlung zwischen Richterfreiheit und Richterbindung vgl. Ogorek 1986: $221 \mathrm{ff}$. 
Normordnung eingebettet ist, die - egal in welcher Form die soziale Norm erscheint - auf die Sicherung der gesellschaftlichen Ordnung gerichtet ist. Die Bindung des Mittels an den Zweck im Rahmen der Zweck-Mittel-Relation erfolgt über die Analyse der Verwirklichung des gesellschaftlichen Nutzens des Rechts: Erwartungssicherung, Abschreckung und Internalisierung von Normen sind die Stichworte einer solchen Perspektive eines ,gesellschaftlichen Utilitarismus", die in der Dichotomie von Gesellschaft und Individuum die Wirkung im Individuum als Nutzen für den Selbsterhalt der Gesellschaft beschreibt. ${ }^{283}$

Drittens problematisiert Jhering die Funktion des Rechts hinsichtlich seines Telos bzw. seiner "Teleologie des objectiv Sittlichen" (Jhering 1883: 105, H.i.O.). Die Sicherung der Lebensbedingungen der Gesellschaft hat nicht nur eine technische Seite, sondern auch eine normative: Es geht um das Wohlsein, das Gedeihen der Gesellschaft. Die Rechtswissenschaft darf sich dieser normativen Seite des Rechts nicht verschließen. Damit sieht sich Jhering aber nicht in einen realitätsfernen Bereich des Sollens verwiesen, sondern bindet in seiner radikal gesellschaftlichen Nutzenanalyse das Sollen im Recht an die Funktionsbedingungen der Gesellschaft zurück. Das normative Ziel sieht er also in der Sicherung der Gegenwart vor einer bedrohlichen Zukunft. Den Nutzen in Bezug auf die Gegenwart (Selbsterhaltung) überführt er in das Sittliche. Aus der Analyse des Seins lassen sich bei Jhering damit letztlich die Kriterien der Sollensbeurteilung bestimmen. Das definiert insofern zugleich die kritische Aufgabe, als sich erst in dieser Perspektive die Frage beantworten lässt, ob etwas sein soll; oder wie Jhering schreibt: „die Beweisbarkeit" der sittlichen Normen „aus praktischen Gründen“ (ebd.: 129).

Jhering bündelt diese drei Perspektiven im Zweckbegriff. ${ }^{284}$ Trotz aller Widersprüchlichkeit der jeweiligen Ausrichtungen (gesellschaftliche Funktionsbedingungen, Mittel, Nutzen, Telos) vermittelt der Zweck als Leitka-

283 Über das Spannungsverhältnis von Gesellschaft und Individuum bindet Jhering das Recht an die Person. Insofern sieht Schelsky bei Jhering einen Denkansatz, der sowohl system- wie personfunktional sei (vgl. Schelsky 1972: 73).

284 Eine allgemeine Definition des Zwecks behielt sich Jhering für das 12. Kapitel vor, das allerdings nie veröffentlicht wurde. Insofern ist man auf eine Interpretation angewiesen, die vor der Schwierigkeit der Vielfalt der Verwendungsweisen steht (etwa Aufgabe, Funktion, Motiv, Ziel, Wert, Nutzen etc.). Wischmeyer sieht in dieser Vagheit zugleich das Geheimnis des Erfolges des Zwecks, da er dadurch für viele Richtungen anschlussfähig wurde (Wischmeyer 2015: 94f.). Hier wird demgegenüber die Ansicht vertreten wird, dass die jeweilige Anschlussfähigkeit sich in der Gleichartigkeit der Problematisierungsweise und nicht in der Bedeutungsvielfalt des Begriffs begründet. 
tegorie eine einheitliche Problematisierungsweise: Es geht um die Funktion des Rechts für die Gesellschaft.

\section{Die Neuverortung der Rechtswissenschaft}

\subsection{Rechtswissenschaft als Teil der Gesellschaftswissenschaft}

All diese Funktionsfragen sind jedoch nur zu beantworten, wenn man weiß, was die Gesellschaft ist. Damit wird genau jene Sphäre zum Ausgangspunkt der Untersuchung des Rechts, deren Erkenntnis in der Historischen Rechtsschule nicht möglich war: die gegenüber Staat und abstrakter Vernunft eigenständige Sozialsphäre, die dort noch „Volkgeist“ hieß, bei Jhering aber nun zur „Gesellschaft" wird. Hier ist die Frage des Rechts zu klären. 285

In der Bestimmung der Gesellschaft schwankt Jhering zwischen einer organischen und einer mechanischen Fundierung. Einerseits erfährt der Vitalismus im Organismusmodell eine Steigerung: Die Gesellschaft ist nicht nur eine objektive Tatsache, sondern sogar ein egoistisches Subjekt, das einen eigenen Willen hat und seine Interessen auf die Selbsterhaltung richtet. Das sei ihr Zweck. Und nur von diesem Zweck her lasse sich die Gesellschaft erkennen und in ihrer Entwicklung erklären. Ausgehend davon entwickelt Jhering aber ein mechanisches Gesellschaftsverständnis, das auf einer Dichotomie zwischen Gesellschaft und Individuen gründet. Die Gesellschaft zeigt sich unter dem Blickwinkel der zweckgerichteten Koordination der Interessen (societas) und der Mechanismen der Zweckverwirklichung der Selbsterhaltung (,sociale Mechanik“). Die Funktionsanalysen im Zweckdenken werden nicht mehr physiologisch, sondern physikalischmechanisch bestimmt. Und die Gesellschaft ist bei Jhering ein Objekt, das solchen allgemeinen Gesetzen wie denjenigen der Mechanik gehorcht.

Aufgrund dieser Perspektivverschiebung erkennt Jhering nun unabdingbare Strukturelemente und Entwicklungsgesetze der Gesellschaft: Die gesellschaftliche Ordnung könne nur durch Normen aufrechterhalten werden, deswegen seien Moral und Recht „unabweisbare[] Lebensbedingungen der Gesellschaft“" (Jhering 1883: XVII). Da jede soziale Norm erst mit der Möglichkeit ihrer Durchsetzung eine praktische Realität gewinnt, las-

285 Schon in den beiden ersten Teilen des Geists hatte Jhering dies eingeklagt (vgl. die Nachweise bei Mecke 2008a: 158f.), eine entsprechende Analyse m.E. allerdings erst mit einer Theorie der Gesellschaft im Zweck vorgenommen. 
sen sich die Normen über die verschiedenen Durchsetzungsmechanismen und -instanzen bestimmen. $\mathrm{Zu}$ den in jeder Gesellschaft vorhandenen ,Verwirklichungsapparten', mittels derer die Gesellschaft die Individuen zur Verwirklichung ihrer eigenen Zwecke anleite, gehören Lohn, Zwang und Sittlichkeit. Alle drei seien absolute Postulate der gesellschaftlichen Ordnung, ohne deren Existenz Gesellschaft schlichtweg undenkbar sei (ebd.: 11).

Da nun nicht der verselbstständigte Organismus des Rechts, sondern die Gesellschaft das eigentliche Objekt der Analyse ist, wird es notwendig, die Rechtswissenschaften neu zu bestimmen: Um das Recht bzw. die Rechtsnormen zu verstehen, bedarf es nach Jhering nicht der historischen Untersuchung im Sinne der Historischen Rechtsschule. Der Traditionszusammenhang vermag nichts über den - ohnehin jeweils historischkontingenten - Zweck auszusagen. Damit ist die historische Analyse nicht ausgeschlossen, erst die Einbettung der Norm in der Zeit erlaubt Aufschluss über den jeweiligen Zweck. Allerdings lässt die historische Analyse keine Aussagen über die Zweckmäßigkeit in der Gegenwart zu. Kurz, es gilt für Jhering: „Das reale Interesse der Gegenwart steht mir höher, als das der historischen Erforschung der Vergangenheit“" (Jhering 2009h [1884]: 340). Rechtssatz und Wirklichkeit stimmen nicht notwendigerweise überein. Und zur Überbrückung dieser Kluft ist man auf etwas anderes als die rechtsgeschichtliche Untersuchung angewiesen.

Mit der Hinwendung zu den Interessen, insbesondere auch den Interessen der Individuen, plädiert Jhering aber nicht für eine am Individuum anzusetzende psychologische Analyse. Es ist gerade der, soziale Zweck' jeden Rechts, der es notwendig mache, eine holistische Perspektive jenseits des Individuums einzunehmen. Daher scheidet im Übrigen auch ein methodologischer Individualismus aus.

Schließlich bedarf es nach Jhering trotz Betonung der normativen Seite des Rechts keiner philosophischen Analyse im Sinne des Vernunft- und Naturrechts - seine Ablehnung der Philosophie ist eindeutig. In seinem Buch sucht er jedoch die Auseinandersetzung mit den Philosophen, was er als philosophische Arbeit, wenn auch ,mit anderem Gesicht ${ }^{\star}$ begreift. Er nennt dieses andere Gesicht auch gelegentlich beim Namen: Es handele sich um die Gesellschaftswissenschaft. Denn die Ethik, jene wissenschaftliche Auseinandersetzung mit dem Normativen, sei ein "Zweig der Gesellschaftswissenschaft", in ihrem richtigen, d.h. praktischen Verständnis sogar die „Königin unter den Gesellschaftswissenschaften“ (Jhering 1883: 123, 132). Ihre „Zwillingsschwestern“, die ihren praktischen Zweck aus je eigener fachlicher Perspektive erfüllen, seien „alle diejenigen Disciplinen, die mit ihr auf demselben realen Boden der geschichtlich-gesellschaftli- 
chen Erfahrung stehen“ (ebd.: 123). Hierzu zählt Jhering neben der Statistik, der Nationalökonomie, der Politik und der Pädagogik auch die Jurisprudenz, die sich aufgrund ihres Gegenstandes ,Recht' der Ethik von der praktischen Seite des Zwecks her nähere (vgl. ebd.). ${ }^{286}$ Auch sie sei also eine praktische, d.h. faktisch-normative Gesellschaftswissenschaft. In den Gesellschaftswissenschaften findet die Rechtswissenschaft ihren angestammten Ort.

Die mühsam begründete Autonomie des Rechts als eigener Organismus, der die Autonomie der dogmatischen Rechtswissenschaft entspricht, wird damit angegriffen. Denn es wandelt sich das Verhältnis von Recht und Gesellschaft: Das Recht und die Rechtswissenschaft dienen nicht dazu, die Gesellschaft zu erkennen, sondern es bedarf einer Gesellschaftswissenschaft, um das Recht zu erkennen. Diese wird im Zweck zur Leitwissenschaft für die Jurisprudenz (vgl. Schelsky 1972: 59).

\subsection{Die Rechtswissenschaft in der Gesellschaftswissenschaft}

Jhering reklamiert für sich, das gesellschaftliche Gebiet des Sittlichen als erster der Wissenschaft zugänglich gemacht zu haben. Insofern kann er sich in seinem methodischen Vorgehen nicht auf bereits entwickelte Methoden zur Analyse von sozialen Normen stützen. Seine Lösung des Problems besteht in der Übertragung der juristischen Methode: „Ich habe meine Aufgabe ganz so zu lösen gesucht, als ob sie juristischer Art wäre, und ich glaube hierbei durch die That gezeigt zu haben, in welchem Masse und mit welchem Vortheil sich die juristische Methode selbst bei Dingen nicht juristischer Art verwerthen lässt" (Jhering 1883: XIV). Sein Ansatz zielt auch außerhalb des Rechts darauf, wissenschaftliche Begriffsarbeit zu leisten. Und nur der juristischen Methode

glaube ich es verdanken zu sollen, wenn es mir gelungen ist, den vielen Begriffen, die mir hier in den Wurf kamen, wie z.B. Höflichkeit, Achtung, Anstand, Aergernisse u. a. m. einen Grad der Klarheit und Sicherheit zu verleihen, die sie den juristischen Begriffen nahe bringt es steckt darin die specifische Arbeit des Juristen, vielfach auch eine Verwerthung der specifisch-juristischen Begriffe (ebd.).

286 Alle zusammen dienen sie der Entwicklung einer „Ethik der Zukunft“, sodass die einzelnen Disziplinen einen pädagogischen Auftrag im Namen des Sittlichen erhalten (vgl. Jhering 1883: 125). 
Neben der „genaue[n] Feststellung und Abgrenzung der Begriffe“ zielt Jhering - dem systematischen Verfahren der Rechtswissenschaft analog - auf „den Nachweis ihrer systematischen Gliederung zu einem höheren Ganzen" (ebd.). Auch im Bereich der Sitten gilt für ihn, dass die Begriffe erst in ihrem systematischen Zusammenhang eine klare Kontur erhalten.

In der Tat ist dieses juristisch-technische Vorgehen in Jherings Untersuchung genau zu erkennen: Erst nach einer grundlegenden Begriffsarbeit namentlich der Begründung der Gesellschaft „auf deductivem Wege“ (vgl. ebd.: 174ff.), die das Recht als eine spezifische Art der sozialen Normen im gesellschaftlichen Normensystem bestimmt - wendet sich Jhering der empirischen Untersuchung der sozialen Normen zu. Das empirische Material analysiert er anhand der theoretisch gewonnenen Prämisse - der sozialen Zweckgebundenheit jeglicher Normen. Die Begriffe dienen ihm als Folie, die einzelnen Phänomene einzuordnen und dadurch Mode, Brauch, Sitte und Recht etc. in ihrer Spezifik genau bestimmen zu können. Dabei gesteht Jhering dem empirischen Material zu, seine Theorie zu widerlegen, setzt es aber gerade nicht ein, um die Theorie der Gesellschaft und des gesellschaftlichen Rechts zu entwerfen. Die einzelnen Normen wiederum untersucht er dem Zweckgedanken entsprechend auf ihr qualitatives Moment hin. Wenngleich er gelegentlich das Argument der Zahl, die quantitative Untersuchung, anführt (im Sinne der Verbreitung einer Sitte), erkennt er doch selbst in der Statistik das qualitative Moment des Normativen, d.h. nicht „nackte Thatsachen, sondern praktische sittliche Anforderung an die Gesellschaft" (ebd: 126). Letztlich zielt Jhering immer auf eine qualitative Begriffsbildung von sozialen Normen.

Schließlich richtet sich seine Analyse auf ein Sinnverstehen, wie es schon im Doppelkauf beispielhaft in Anschlag gebracht wurde: Dort löste er den Fall ausgehend von der Bestimmung des Sinns der römischen Gefahrtragungsregelung. Diesen Sinn wiederum könne man nicht mittels einer Erklärung im Sinne des naturwissenschaftlichen Kausalitätsgesetzes ermitteln. Er sei vielmehr im Rahmen des Zweckgesetzes aller gesellschaftlichen Phänomene über die Beantwortung der Frage nach dem Warum der Rechtssätze offenzulegen. Der Sinn folgt bei Jhering also immer dem Zweckgesetz, d.h. jeder Handlung - auch jeder Gesetzgebung - liegt ein über die Zweck-Mittel-Relation zugänglicher Sinn zugrunde.

\subsection{Die Kritik an der „Begriffsjurisprudenz"}

Dieses Vorgehen zeigt: Jhering hat kein prinzipielles Problem mit der juristischen Methode, ja er wendet sie auch über das ihr angestammte Gebiet 
hinaus an. Nichtsdestotrotz greift er nach den ersten beiden Bänden des Zwecks im Jahr 1884 seine Polemik gegenüber der Methode der herrschenden romanistischen Wissenschaft wieder auf und spitzt sie auf ein Schlagwort hin zu: „Begriffsjurisprudenz“ (Jhering 2009h [1884]: 337).

Dieser Angriff richtet sich nicht wie bei Kirchmann gegen die Möglichkeit der Jurisprudenz als Wissenschaft. Er richtet sich auch nicht gegen die Arbeit mit Begriffen. Denn „[j]ede Jurisprudenz operirt mit Begriffen, juristisches und begriffliches Denken sind gleichbedeutend, in diesem Sinne ist also jede Jurisprudenz Begriffsjurisprudenz, die römische in erster Linie; eben darum braucht der Zusatz nicht erst hinzugefügt werden“ (ebd.: 347). Wenn er trotz dieser Tatsache seinen Angriff unter dem Ausdruck „Begriffsjurisprudenz“ bündelt,

so ist damit jene Verirrung unserer heutigen Jurisprudenz gemeint, welche, den praktischen Endzweck und die Bedingungen der Anwendbarkeit des Rechts außer Acht lassend, in demselben nur einen Gegenstand erblickt, an dem das sich selber überlassene, seinen Reiz und Zweck in sich selber tragende logische Denken sich erproben kann, eine Arena für logische Evolutionen, für die Gymnastik des Geistes, in der dem größten Denkvirtuosen die Palme zufällt (ebd.).287

Jhering richtet seinen Vorwurf also gegen die Art und Weise der Begriffsbildung. Er wirft der Romanistik - allen voran Puchta - vor, dass sie ihre Begriffe von jeglichem Lebensbezug gereinigt habe, da sie sich nicht für die praktische Brauchbarkeit ihrer Ergebnisse interessiere (ebd.: 345f.). Er meint damit durchaus auch sich selbst, wenn er schreibt:

Aus der niederen Welt des Positiven, die, heute so, morgen so, meinem wissenschaftlichen Bedürfnis, das etwas Dauerndes, Festes, an sich Wahres begehrte, keine Befriedigung gewährte, rettete ich mich in

287 Diese „Gymnastik des Geistes“ mit ihren spezifischen Techniken entfaltet Jhering in seiner Satire „Im Begriffshimmel“, die im Himmel der juristischen Theoretiker spielt: Dort findet er eine Haarspaltemaschine, eine Kletterstange der schwierigen juristischen Probleme, einen Konstruktionsapparat, eine dialektisch-hydraulische Interpretationspresse, eine dialektische Bohrmaschine und vieles mehr. Neben den reinen Begriffen findet sich auch ein anatomisch-pathologisches Begriffskabinett wieder (Jhering 2009g [1884]). Puchta als „Meister und Vorbild der juristischen Methode“ (Jhering 2009h [1884]: 338) sei der erste gewesen, der in den Begriffshimmel gekommen sei (ebd.: 253). Savigny hatte demgegenüber Probleme hineinzugelangen, wurde aber für seine Arbeit über den Besitz doch zugelassen, und seither seien viele gefolgt. 
die höhere Welt der in sich ruhenden Begriffe, an welcher die Macht des Gesetzgebers nicht hinanreichte. (Ebd.: 342)

Mehr noch: Der Gesetzgeber werde von dieser hohen Warte aus sogar korrigiert. So setzten ihm verschiedene Theoretiker „de[n] Einwand des begrifflich Unmöglichen, Widersinnigen, Verfehlten entgegen[]“ (ebd.: 343).

Das „Begriffsvermögen“ der herrschenden romanistischen Wissenschaft zeige sich jedoch letztlich „nicht im Stande [...], die reale Welt zu begreifen - eine einfache geistige Bankrotterklärung“. Das enthält für Jhering zugleich „den unwidersprechlichen Beweis“, dass der Romanist

sich über die wahre Natur der Begriffe, denen er diese Unantastbarkeit vindicirt, nicht klar geworden ist, denn sonst müßte er wissen, daß sie des Positiven und Historischen ebenso viel enthalten, wie das Neue, dem er den Zutritt verwehrt, und daß bloß die Gewohnheit ihm das überkommene Alte in einem andern Licht erscheinen läßt als das Neue (ebd.: 344).

Daher gilt für Jhering:

Es soll und muß anders werden mit unserer romanistischen Theorie, in der bisherigen Weise kann es nicht so weiter gehen, - sie muss ablassen von dem Wahn, als ob sie eine Mathematik des Rechts sei, die kein höheres Ziel kenne, als ein korrektes Rechnen mit Begriffen. (Ebd.: 341f.)

Denn dieses „formalistische“ (Jhering 1889: IX) Vorgehen, dass das Recht und die Rechtsfortbildung „ausschliesslich[]“ (Jhering 1883: 101) unter seinem begrifflichen Systemaufbau betrachte, könne nur zu einer Entfremdung von Theorie und Praxis führen, d.h. zu einer Theorie, die „mehr und mehr [...] das Leben aus den Auge" verliere (vgl. Jhering 2009h [1884]: 357). Mit Hilfe „rein formaler Operationen (Consequenz - Construction Speculation)" könne man jedoch niemals „die Wahrheit gewinnen“ (Jhering 1883: 102).

Letztlich geht es auch Jhering also um die Wahrheit. Diese Wahrheit lasse sich aber nur unter Anerkennung der normativen Natur der Rechtsnormen, d.h. des jeweilig historisch-kontingenten Zwecks, finden. Denn wahres Recht, das auf die Gesellschaft in ihrer jeweiligen Gegenwärtigkeit zurückzuführen ist, ist in dieser Sicht auch richtiges Recht. 


\subsection{Rechtswissenschaft und gesellschaftliche Entwicklung}

In Jherings rechtstheoretischen Bemühungen um ein funktional-normatives Rechtverständnis findet sich ein Widerhall gegenwärtiger rechtlicher, aber v.a. auch gesellschaftlicher Entwicklungen. Seine Aufwertung der Gesetzgebung entspricht einer ausgedehnten gesetzgeberischen Tätigkeit seit Ende der 1840er Jahre, und zwar nicht nur auf der Ebene der einzelnen Staaten, sondern ebenso gebietsübergreifend in Form von nationalen Gesetzen. Zwar trübte die gescheiterte Revolution von 1848/1849 die Hoffnung auf Einrichtung nationaler Gesetzbücher. Doch zahlreiche deutsche Staaten setzten die „Allgemeine Deutsche Wechselordnung“ von 1849 in Kraft, und 1861 wurde das „Allgemeine Deutsche Handelsgesetzbuch“ des Deutschen Bundes durch alle Staaten eingeführt. Beide Gesetze führt der Norddeutsche Bund im Jahr 1869 wiederum als nun originäre Bundesgesetze ein. Mit der Gründung des Deutschen Reiches im Jahre 1871 werden in der Reichsverfassung die Kompetenzen zur Reichsgesetzgebung festgesetzt. Art 4 Ziff. 13 der Verfassung des Reiches von 1871 legt die Gesetzgebungskompetenz für Strafrecht, Handels- und Wechselrecht, für das gerichtliche Verfahren sowie nur für das Obligationenrecht fest. Es folgen die Reichsjustizgesetze StPO, ZPO, GVG, KO, und nach Ausweitung der Kompetenz des Reiches auf eine zivilrechtliche Gesamtkodifikation wird im Jahr 1874 eine Vorkommission zum Entwurf eines Bürgerlichen Gesetzbuches eingerichtet (s. $\$$ 4.I.1.). Angesichts dieser voranschreitenden Kodifizierung, die nun auch den Kernbestand des Privatrechts betrifft, muss sich die Rechtswissenschaft also fragen, wie sie sich zur Gesetzgebung verhält. Das Festhalten an einer Position, die eine (Gesamt-)Kodifikation ablehnt bzw. diese Gesetzeswerke nicht umfassend beachtet, würde sie letztlich ins Abseits stellen.

Die Fokussierung auf den Zweck des Recht erscheint auch angesichts der zunehmenden Industrialisierung plausibel, deren gravierende Folgen mit der „sozialen Frage“ seit den 1860er Jahren mehr und mehr ins Bewusstsein gelangen (vgl. Pankoke 1970). Bevölkerungsexplosion, Verstädterung, Veränderung der Arbeitsstrukturen (Zunahme der Lohnarbeit) und damit einhergehend das Aufkommen des Vierten Standes und Pauperismus lassen die Gesellschaft sich selbst zum Problem werden. Die "Selbsterhaltung der Gesellschaft" wird problematisch, und erneut muss die Frage nach der Rolle des Rechts, seinem Zweck, für diesen Erhalt gestellt werden. Der Verweis auf die tradierten Rechtsvorschriften erscheint fragwürdig, will man das Recht nicht als gänzlich nebensächlichen Faktor in dieser Entwicklung betrachten. Das wiederum leuchtet kaum ein, wenn der wirtschaftliche Verkehr zentral im Privatrecht geregelt wird. Sieht man 
vice versa im Privatrecht die Hauptursache für diese Entwicklung, lässt sich aus diesem Grund seine Existenzberechtigung anzweifeln. Schließlich kann die Auslagerung der Problematik aus dem Bereich des Privatrechts, wie ihr ja die aufkommende öffentlich-rechtliche Sozialgesetzgebung begegnet, nur unter der Prämisse befriedigen, dass dem Privatrecht seine zentrale Stellung im Recht abgesprochen wird. Für die Privatrechtswissenschaft gilt es also, angesichts der sozialen Frage einer solchen Diskreditierung des Privatrechts entgegenzuwirken, will sie ihren Stellenwert beibehalten.

Sowohl Gesetzgebung als auch „soziale Frage“ kommen bei Jhering allerdings nur ganz am Rande vor. Nur gelegentlich bezieht er Stellung zu politischen, wirtschaftlichen und sozialen Problemen (vgl. Luig 1993 m.w.N.). Seine einzige explizit ausformulierte Forderung diesbezüglich richtet sich auf die Reform des Rechtsunterrichts, in den die Praxis verstärkt zu integrieren sei (vgl. Jhering 2009h [1884]; Hirsch 1984). Im Zweck entwickelt Jhering eine allgemeine Theorie eines gesellschaftlichen Rechts, das von der konkreten Situation unabhängig ist, ihr gegenüber jedoch offensteht. Und seine Polemik richtet sich gegen eine herrschende romanistische Wissenschaft, die die konkrete gesellschaftliche Lage aufgrund ihrer theoretischen Prämissen außer Acht lassen muss: Sie kann in seinen Augen weder neue Gesetze noch gesellschaftlichen Wandel erfassen. Die Rechtstheorie muss sich nicht aufgrund der sozialen Problematik oder der politischen Lage ändern, sondern sie muss mit solchen Problemlagen umgehen können. Das gelingt ihr nach Jhering durch die Hinwendung zum Zweckdenken, das im Rahmen einer Sozialethik das Recht der jeweiligen Gesellschaft unter funktional-normativen Gesichtspunkten im Blick hat. ${ }^{288}$

Jeglichen Versuchen der systematischen Arbeit der Rechtsdogmatik in der romanistischen Wissenschaft, die gegenwärtige Wirklichkeit zu berücksichtigen, erteilt Jhering mit seiner Kritik eine deutliche Absage. Er erwähnt sie nicht einmal. ${ }^{289}$ Sie sind für ihn hinsichtlich der Charakterisie-

288 Zur daraus resultierenden Schwierigkeit der politischen Einordnung von Jherings Denken, die vom „ehrlichen Konservativismus“ bis zum „reinen Socialismus" reicht, vgl. Luig 1993: $172 \mathrm{ff}$.

289 Genau diesen Punkt hat der Romanist Adolph Friedrich Rudorff im Blick, wenn er gegen Jhering in der Vorrede zu den von ihm fortgeführten Pandekten Puchtas schreibt: Jherings Einwürfe ließen „ganz außer Acht, daß Puchta die realen Faktoren der Rechtsbildung, die historischen, politischen, öconomischen, ethischen Elemente, mit einem Wort die ganze lebenskräftige rechtsbildende Vergangenheit des römischen Rechts noch in einem zweiten Hauptwerke so ausführlich wie befriedigend dargestellt hat“ (Rudorff 1877: VIII). 
rung der juristischen Technik nicht relevant. Den Vorwurf der Entfremdung vom Leben nimmt er angesichts der oben dargestellten systematischen Bemühungen um die Erforschung des Rechts als „lebendiges Recht" in der Volksgeistlehre kein Stück zurück. Was er bestreitet, ist also der proklamierte Eigenwert der Rechtswissenschaft, die nicht nur über das Modell des selbsttätigen Rechtsorganismus einen eigenständigen Gegenstand für ihre Rechtswissenschaft postuliert hatte, sondern zugleich versuchte, über die systematisch-dogmatische Arbeit zum Leben im „lebendigen Recht" vorzudringen. Systematisch-dogmatische - und das heißt nun in Jherings Diktion: rein logisch-formalistische - Arbeit innerhalb eines durch das römische Recht vorgegebenen Bestandes an Rechtsquellen kann keinen Bezug zu Leben und Wirklichkeit garantieren, kann nicht zu der treibenden Kraft im Recht vordringen und verschließt sich gegenüber jeglichem gesellschaftlichen Wandel. Dagegen führt Jhering den Zweck ein, eine Kategorie im Recht, der über die Anbindung an die Gesellschaft der Bezug zum gegenwärtigen Leben inhärent ist und die über ihre unterschiedlichen Funktionsperspektiven die gesuchte Lebensanbindung zu gewährleisten vermag.

Damit wendet er sich in seiner Kritik ganz grundlegend der das Recht fundierenden Ebene der überindividuellen Sozialsphäre zu. Hier liege der Denkfehler. Dem über die Tradition gewachsenen Volksgeist setzt er das Modell einer vergegenwärtigten Gesellschaft entgegen, die der wissenschaftlichen Erkenntnis seine normativen Funktionsmechanismen offenbare. Das ,Ding' Gesellschaft gelangt ins Zentrum der Rechtstheorie, und es ist bei Jhering insofern ,epistemisch', als es epistemische Folgen für die Beurteilung der herrschenden romanistischen Wissenschaft zeitigt. Allerdings bleibt der Zweck - wie auch der Geist - ein Torso. Jhering vollendet beide Werke nie. Ebenso wenig überführt er die veränderte Rechtsentstehungslehre auf die Ebene der Rechtsdogmatik und -methodik. Nichtsdestotrotz zeigt der Zweck im Diskurs der Privatrechtswissenschaften eine immense Wirkung - jedoch über Umwege.

\section{Die ambivalente Rezeption des Zwecks (ca. 1880-1900)}

Jhering wendet sich mit dem Zweck ebenfalls der Fundierung des Rechts in der überindividuellen Sphäre zu. Anders als Savignys Flugschrift Vom Beruf macht sein Werk jedoch zunächst eine widersprüchliche Karriere: Während es außerhalb der Rechtswissenschaften, namentlich in der Philosophie (und darüber in der Rechtsphilosophie) sowie in den Sozialwissenschaften eine breite Rezeption findet und innerhalb der Rechtswissen- 
schaften in den Staats- und in den Strafrechtswissenschaften eine tiefgreifende Wirkung entfaltet, stehen seine eigentlichen Kollegen, die Privatrechtswissenschaftler, dem Zweck äußerst kritisch gegenüber. ${ }^{290}$

\section{Der Erfolg des Zwecks außerhalb der Privatrechtswissenschaft}

\subsection{Der Zweck in der Philosophie und in den Sozialwissenschaften}

Aus der Philosophie werden in der direkten Auseinandersetzung mit dem Zweck grundsätzliche Einwände erhoben: Einerseits wird moniert, dass Jhering das Problem der Rechtfertigung des Rechts keineswegs gelöst habe. Denn auch wenn er die materialen Inhalte des Rechts nicht mehr historisch herleite, sondern an die gesellschaftliche Zweckmäßigkeit binde, leite er damit immer noch das Sollen vom Sein ab. Auf diesem Wege könne er nie zu einem verbindlichen, dauerhaften Sollen gelangen (Lasson 1879: 153; ähnlich auch Stammler 1922: 43). Recht könne nicht aus dem Nutzen hergeleitet werden (vgl. Lasson 1879: 149; Eucken 1883: 5339).291

Andererseits bleibt in den Augen von Kritikern wie dem Neuhegelianer Alfons Lasson oder den zwischen Idealismus und Phänomenologie zu verortenden Philosophen Rudolph Eucken nicht viel übrig von der angestrebten realistischen Methode. Das liege insbesondere an Jherings Gesellschaftsbegriff: Die Personifizierung der Gesellschaft als Zwecksubjekt des Rechts, jenes Kernelement seines Rechtsbegriffs, sei „phantastisch“ und „inconsequent“ (Lasson 1885: 135; s.a. Sommer 1885: 37f.). Mehr noch: Durch die Verselbstständigung und Personifizierung der Gesellschaft sei Jhering eher dem Idealismus als dem Empirismus zuzurechnen - Idealismus und Utilitarismus bestehen nebeneinander (vgl. Eucken 1883: 5339; Lasson 1885: 132; s.a. Merkel 1893: 30). ${ }^{292}$

290 Die Rezeption bzw. Auseinandersetzung mit dem Zweck begünstigt natürlich auch der Umstand, dass Jhering mit seinem Ansatz Impulse aus dem wissenschaftlichen Diskurs aufgriff (vgl. hierzu Wischmeyer 2015: 17ff.); zur ambivalenten Reaktion auf den späten Jhering vgl. Rückert 2005: $127 \mathrm{ff}$.

291 Jhering lasse - so Hugo Sommer - nicht nur die Rechtfertigung des Rechts auBer Acht, sondern verkenne auch den spezifischen Gehalt der sittlichen Normen, nämlich ihre „Hoheit und Würde“ (Sommer 1885: 43). Sommer kritisiert im Übrigen auch den Begriff des „Idealtypus“, was zwar Jherings Verwendungsweise gänzlich verfehlt, aber gleichsam den Idealtypus im Problemfeld des Sittlichen platziert (vgl. ebd.: 52).

$292 \mathrm{Zu}$ diesem Misslingen der Entwicklung eines klaren Gesellschaftsbegriffs s.a. Kühnast 1880b: 154; Sommer 1885: 37ff. Interessant ist Kühnasts Besprechung 
Der Germanist, Historiker und Schriftsteller Felix Dahn wendet in seiner monographischen Abhandlung zum ersten Band des Zwecks ein, Jhering habe letztlich nur den Mythos der organischen Rechtsentwicklung durch den Mythos der Entwicklung aus dem Zweck ersetzt, d.h. „nur ein[en] Mysticismus (,Mechanismus') an die Stelle des andern (,Organismus") gesetzt" (Dahn 1879: 219). Er operiere mit einer apriorischen Setzung der Gesellschaft, die er in seiner Begriffsarbeit gerade nicht empirisch herleite. Andererseits negiere er jedes spekulative Prinzip (wie etwa die Dialektik bei Hegel). Dies führe Jhering zu etwas zurück, das er in seiner ganzen Anlage eigentlich bekämpfen wolle: Er verteidigt nach Dahn „das alte - ,Naturrecht' mit dem ,Societätstrieb““ (ebd.: 8).

Jherings Bezug auf die Gesellschaft ist für den Entwurf eines neuen Rechtsbegriffs in den Augen seiner Kritiker missglückt. Der Befreiungsschlag, den Jhering damit anstrebt, führe letztlich zum Gegenteil seines Vorhabens: Er habe keine realistische Methode entworfen, ${ }^{293}$ sondern ende in Mystizismus, Idealismus, klassischem Naturrecht - alles Richtungen, gegen die er eigentlich angetreten ist. ${ }^{294}$

\section{Der Zweck in der Ethik}

Gleichzeitig erntet Jhering aber auch Anerkennung dafür, dass er etwas grundlegend Neues auf die Agenda setzt. Denn er habe als erster das Gebiet der Sitte wissenschaftlich erschlossen: „Damit erlangt ein von der Wissenschaft bisher bei aller gelegentlichen Anerkennung ungebührlich ver-

des Zwecks insofern, als er das Werk in den Zeitgeist einordnet und es als „antisozialistisch“, „national-ökonomisch“ und „darwinistisch“ kennzeichnet (1880b: $158,163,167 \mathrm{ff}$.$) .$

293 Genau die gegenteilige Diagnose fällt später Rudolf Stammler, markiere doch Jhering den „Übergang zur neueren Rechtsphilosophie“, d.h. den juristischen Empirismus (Stammler 1922: 42); aus dem Feld der dogmatisch-methodisch arbeitenden Juristen sehen etwa Alfred Merkel (Merkel 1893: 39) und Ludwig Goldschmidt Jhering als „Vorkämpfer“ der „realistische[n] Richtung in der Jurisprudenz" an (Goldschmidt 1890b: 187).

294 Aus juristisch-methodischer Sicht sei der Zweck kein Angriff auf die lebensfremde juristische Konstruktion, sondern ein Musterbeispiel dafür (vgl. Sommer 1884: 554). Allerdings ordnet der Jurist und Lotze-Schüler Hugo Sommer - wie viele Privatrechtswissenschaftler - Jhering nicht dem Idealismus, sondern dem Positivismus zu (Sommer 1885: 49). Für Ferdinand Tönnies wiederum ist der Zweck Ausdruck eines Rationalismus (s.u.; s.a. Hurwicz 1911: 83). 
nachlässigtes Gebiet endlich sein Recht." (Eucken 1883: 5339; vgl. a. Lasson 1885: 129; Eck 1893: 37)

Nicht nur Jherings gesellschaftliche Herleitung der Sitte, sondern auch die der Moral im Rahmen des gesellschaftlichen Utilitarismus wird als ein neuer Ansatz für die Ethik anerkannt. ${ }^{295}$ In der in den 1880er Jahren rapide anwachsenden philosophischen Literatur zu diesen Fragen wird der Zweck ein immer wichtigerer Bezugspunkt. So befassen sich etwa so unterschiedliche Autoren wie Paul Rée ${ }^{296}$, Heinrich Steinthal, Christoph Sigwart, Franz Brentano, Wilhelm Wundt, der langjährige Freund von Tönnies Friedrich Paulsen und Wilhelm Dilthey mehr oder weniger intensiv und mehr oder weniger wohlwollend mit Jherings Werk. ${ }^{297}$ Für alle gilt: Jherings Zweckdenken ist trotz kritischer Einwände für die Fragen der Moral und der Ethik eine Auseinandersetzung wert.

Die Rechtstheorie im Zweck erfährt so eine moralisch-ethische Problematisierung auf genuin philosophischem Terrain, das sich zunehmend von den Rechtswissenschaften entfernt. Auf diesem Feld markiert Jhering mit dem Zweck - in der Rückschau aus dem Jahr 1912 des Philosophen Friedrich Jodls aus dem Vorfeld des Wiener Kreises - einen Wandel:

Der erste Einbruch einer realistischen und dabei schärfer auf den Kern der Dinge blickenden Behandlungsweise in den Kreis ethischer Probleme geht nicht von einem Philosophen, sondern von einem allerdings mit philosophischem Geiste reichlich ausgestatteten Juristen aus. (Jodl 1912: 553f. $)^{298}$

295 Genau das bestreitet jedoch Friedrich Nietzsche: Er sieht im „Zweck im Recht“ ein geradezu klassisches Beispiel für die „bisherigen Moral-Genealogien“(Nietzsche 1887: 12), die auf Zwecke, und nicht auf den Willen zur Macht rekurrierten. Zu Nietzsches Jhering-Lektüre vgl. Kerger 1988: $45 \mathrm{ff}$.

296 Auch wenn Rée sich in Die Entstehung des Gewissens explizit nur auf den Geist bezieht, sieht Jhering darin seine Ansichten aus dem Zweck verteidigt (Jhering 1970: 87 Anm.); zu den Zusammenhängen zwischen Rée, Nietzsche und Jhering vgl. auch die Hinweise bei Treiber 1993.

297 Siehe Rée 1885; Steinthal 1885: 214ff.; Sigwart 1886: 17; Brentano 1889; Wundt 1892: 113, 115, 118, 120, 573f. u.ö.; Paulsen 1891: 21, 30, 116, 118, 156ff., 573f. u.ö.; Dilthey 1981: 94, 115, 120.

298 Damit wird Jhering im Bereich der Sitten, des Sittlichen und der Ethik jener Realismus zuerkannt, den ihm von anderer Seite für den Bereich des Rechts abgesprochen wurde (s.o.). 


\section{Der Zweck und die Kulturwissenschaften}

Auch für den gegen Ende des 19. Jahrhunderts erstarkenden Neukantianismus, und hier v.a. für den wissenschaftstheoretisch-erkenntnistheoretischen Streit um die Abgrenzung von Natur- und Kulturwissenschaften, wird der Zweck zu einem zentralen Bezugspunkt. ${ }^{299}$ Anschlussfähig erweist sich insbesondere Jherings Gegenüberstellung von menschlichem Zweck und naturwissenschaftlicher Kausalität. ${ }^{300}$

Dies zeigt sich insbesondere in Rickerts Dissertation Zur Lehre von den Definitionen aus dem Jahre 1888, in der er die Grundlagen seiner Unterscheidung zwischen natur- und kulturwissenschaftlicher Begriffsbildung als Kritik des Methodenmonismus entwickelt. ${ }^{301}$ Ausgangspunkt ist die Untersuchung der Differenz zwischen juristischen und naturwissenschaftlichen Definitionen, gilt ihm doch die juristische Begriffsbildung als wichtigstes Beispiel für die später sogenannte empirische Kulturwissenschaft (vgl. Haferkamp 2007b: 109). Rickert behandelt dabei die Frage, wie die Jurisprudenz es schaffe, für ihre Definitionen der Rechtsbegriffe „wesentliche Merkmale von unwesentlichen [zu] unterscheiden“. Dafür sei - hier greift er Jherings Gedanken auf - „ein Zweck nöthig“ (Rickert 1888: 34). ${ }^{302}$ Nur unter Berücksichtigung des Zwecks des Rechtssatzes, d.h. eines

299 Rickert verbindet die Bestimmung der Kulturwissenschaften mit einer Kritik am vieldeutigen Begriff der Geisteswissenschaft, wie ihn Dilthey (in Übrigen mit Rekurs auf die Historische Rechtsschule) in der Abgrenzung zu den Naturwissenschaften prominent ins Spiel gebracht hatte (vgl. Rickert 1896, 1899).

300 Vorliegend geht es primär um die Umdeutung des Zweckdenkens in eine Wertlehre, wie sie bei Rickert zu erkennen ist und analog zu Jhering ein verändertes Kausalitätsverständnis impliziert. Damit wird keinesfalls behauptet, dass die Beschäftigung mit dem Problem von Kausalität und Finalität im Diskurs der Philosophie im letzten Viertel des 19. Jahrhunderts auf Jhering zurückzuführen wäre.

301 Vgl. zu dieser Selbsteinschätzung das Vorwort zur dritten Auflage der Dissertation (Rickert 1929: X).

302 Jenseits der Problematisierungsweisen des positiven Rechts in den Rechtswissenschaften bindet Rickert das Recht an den Gesetzgeber. Er zeichnet dadurch ein Idealbild der vom Gesetzgeber erlassenen Rechtssätze (allein diese sind für ihn relevant), die über eindeutig auf die Wirklichkeit beziehbare Begriffe den für ihn ausschlaggebenden Willen des Gesetzgebers erkennen lassen (vgl. Rickert 1888: 30f.). Probleme entstehen dann durch den Wandel der Wirklichkeit, der einen Wandel der Begriffe bedingen kann. Dass genau diese Problematik bereits die älteren Historische Rechtsschule gesehen hatte, die ihr - anders als Jhering durch die Systematisierung beizukommen suchte, sieht Rickert nicht. Daher kommt er ganz unproblematisch zur teleologischen, zweckorientierten Bestimmung des Rechts. 
nicht rein logischen, sondern materialen Gesichtspunktes, sei der juristische Begriff definierbar, nur über ihn lasse sich der Sinn ermitteln und mit der Wirklichkeit vermitteln. ${ }^{303}$ Naturforscher weisen demgegenüber zu Recht den Zweckbegriff als Prinzip der Erklärung zurück:

Was für die Jurisprudenz der Zweck des Rechtes war, das ist für die Naturwissenschaft, wenn sie nicht die Sprache als Richtschnur für die Bildung von Begriffen benutzt, entweder eine bloße Klassification, die man jedoch nach Möglichkeit zu vermeiden suchen wird, oder die $H y$ pothese. (Ebd.: 35, H.i.O.) ${ }^{304}$

Diese Unterscheidung zwischen dem Zweck des Rechts in der Jurisprudenz als Vorbild der kulturwissenschaftlichen Begriffsbildung (vgl. ebd.: 34) und der naturwissenschaftlichen Begriffsbildung wird Rickert später wertphilosophisch deuten. Die Differenz erklärt er sachlich und methodisch: „Methodisch ist Natur die Wirklichkeit mit Rücksicht auf das Allgemeine im Gegensatz zum Besonderen, sachlich dagegen die Wirklichkeit abgesehen von allen Werthbeziehungen im Gegensatz zur Kultur.“ (Rickert 1896: 589)

303 Emil Lask, Schüler von Rickert, - betont diese Übernahme des Jhering'schen Gedankens bei seinen Lehrer: „Mit Benützung Iheringscher Gedanken hat Rickert den Zweck des Rechts als Prinzip der im juristischen Sinne ,wesentlichen“ Begriffsmerkmale bezeichnet, und G. Rümelin sowie Zitelmann haben darauf hingewiesen, daß hier wie stets der Wissenschaft die Aufgabe erwächst, die unbestimmte Allgemeinheit des vorwissenschaftlichen Denkens zu überwinden. Die Methodologie wird in Zukunft noch genauer zu ergründen haben, wie der Jurisprudenz, der doch begriffliche Exaktheit nachgerühmt wird, dieser Präzisierungsprozeß gerade in den Schranken der wert- und zweckbeziehenden Methode gelingt.“ (Lask 1905: 35f.).

304 Bezogen auf die Jurisprudenz als Teil der Kulturwissenschaft wendet sich Rickert damit scharf gegen den juristischen Naturalismus, der davon ausgehe, „dass ebenso wie die Naturwissenschaft mit den Gesetzesbegriffen zum unbedingt Allgemeinen vordringt und in ihm das wahre Wesen der Dinge findet, es auch möglich sei, in dem positiven gegebenen historischen Rechte das Wesentliche vom Unwesentlichen durch Bildung eines allgemeinen Begriffes zu scheiden und dadurch zur allgemeinen ,Natur' des Rechtes vorzudringen" (Rickert 1896: 729). Die - mit Jhering gesprochen - naturwissenschaftliche Idee des Kausalitätsgesetzes, derzufolge man über die Begriffsbildung zum wahren Kern des Rechts vordringe, habe im Bereich des historischen Rechts, das immer „Produkt der geschichtlichen Kulturentwicklung“ (ebd. 30) sei, keinen Erklärungswert. Der im juristischen Naturalismus des Naturrechts enthaltenen Frage nach der Normativität des Rechts begegnet Rickert mit dem Hinweis auf einen formalen normativen Rechtsbegriff (ebd.: 733), den sein Schüler Emil Lask in der Bestimmung der Rechtsphilosophie als Rechtswertbetrachtung ausbuchstabieren wird (s.u.). 
Das Zweckdenken im Recht, das nach Rickert die Jurisprudenz zum Vorbild für kulturwissenschaftlichen Begriffsbildung werden lässt, ${ }^{305}$ findet auf diesem Weg eine erkenntnis- und wissenschaftstheoretische Einbettung, die in eine Debatte um die Eigenart der Kulturwissenschaft mündet. Jherings Zweck deutet Rickert normativ als Telos, was den Weg zur Wertlehre ebnet, und die sein Schüler Lask im Rahmen seiner Rechtsphilosophie für das Recht ausbuchstabieren wird (s.u. \$3.II.1.3).

\section{Der Zweck in den Sozialwissenschaften}

In der philosophischen Rezeption des Zweckdenkens ist ein Spannungsverhältnis zwischen Empirie und Telos bzw. zwischen gesellschaftlicher Faktizität und Normativität zu erkennen, wie es sich auch in der sozialwissenschaftlichen Auseinandersetzung mit dem Zweck abzeichnet.

Jhering schreibt den Zweck in einer Zeit, in der sich die Jurisprudenz verstärkt für die Nationalökonomie interessierte (vgl. Hansel 2006: 10ff.; Hofer 2000; Hofer 2001: 107ff.; Wilhelm 1979: 27ff.). Immer öfter wurde ab der Mitte des 19. Jahrhunderts eingeklagt, dass die Bedürfnisse der Zeit nur mit Blick auf das Verkehrsleben - und damit mit Blick auf die Erkenntnisse der Nationalökonomie - bestimmt werden könnten. Wer die Bedürfnisse der Zeit geltend macht, wertet die Gegenwart auf. Daher erscheint es in den Rechtswissenschaften zunehmend plausibel, das Privatrecht mit Blick auf die gesellschaftlichen Strukturen, und d.h.: auf die Strukturen und Gesetze des Verkehrs, zu erklären. ${ }^{306}$ So gab etwa der Jurist Wilhelm Endemann in einer Rede aus dem Jahr 1864 zu bedenken: „Wer

305 Eine ähnliche Aufwertung der Rechtswissenschaft (unter Aufwertung des Zweckgedankens) ist bei Hermann Cohen, einem der Hauptvertreter des Marburger Neukantianismus, festzustellen: Er erkennt in der konstruktiven Begriffsbildung der Rechtswissenschaft eine Vorbildfunktion für die Logik der Geisteswissenschaften (vgl. Quensel 2007: 99 m.w.N.). Nach Quensel sind Anschlüsse Max Webers eher an Cohen als an Lask bzw. Rickert zu suchen (ebd.). Vorliegend geht es aber nicht um diese an einzelnen Personen nachzuzeichnenden Rezeptionslinien, sondern um die Einbettung Webers in die Problematisierungsweisen von Recht und Gesellschaft, wie sie sich in Anschluss an Jherings Zweck wandeln.

306 Vgl. die Nachweise etwa zu Heinrich Dankwardt, Burkhart Leist, Wilhelm Arnold, Karl Gareis und Otto Gierke bei Hofer 2000; 2001: 107ff. (daher sieht Johan Valkhoff in Dankwardt, Arnold und Leist Wegbereiter der Rechtssoziologie, Valkhoff 1972). Nach Sibylle Hofer hatte diese Perspektivverschiebung nur bedingt Auswirkungen auf die Prinzipiendiskussionen in den Privatrechtswissen- 
will [...] das Recht, welches den Verkehr mit materiellen Gütern in irgend einer Form zum Gegenstande hat, in seinen inneren Ursachen anders erfassen, als durch die Kenntnisse, welche den Inhalt der Nationalökonomie bilden." (Endemann 1864: 43) Damit holt er die soziale Sphäre aus der Verdunklung der Historischen Rechtsschule hervor - genau jenes Unterfangen, das Jhering später in seinem Zweck anstrebt. Allerdings bleibt umstritten, welcher der beiden Disziplinen hier eine Leitfunktion zukommt. ${ }^{307}$

Diese Aufwertung der Sozialsphäre als eigenständiges Objekt der wissenschaftlichen Untersuchung, die bei Jhering zu vereinzelten Verweisen auf Erkenntnisse der Nationalökonomie führt (vgl. Jhering 1877: 511), aber letztlich in die Forderung einer „gesellschaftswissenschaftlichen“ Ausrichtung der Rechtswissenschaft mündet, ${ }^{308}$ öffnet die Rechtswissenschaft für den Kreis der „Sozialwissenschaften“ (Menger 1883). Jhering verweist seitens der Rechtswissenschaft auf einen Interferenzraum zwischen Rechtswissenschaft und Nationalökonomie. Vice versa fragt zu dieser Zeit auch die Nationalökonomie verstärkt nach den Wechselwirkungen von Wirtschaft und Recht (z.B. Roscher, Schmoller, Wagner, Böhm-Bawerk; vgl. Hansel 2006: 10ff.; Hofer 2000, 2001: 107ff.; Wilhelm 1979: 27ff., jeweils

schaften (vgl. Hofer 2001: 107ff.), obwohl Juristen insbesondere die Frage der Sozialgebundenheit des Eigentums (als Kern des Privatrechts) seit der Mitte des 19. Jahrhunderts des Öfteren auch mit Blick auf die nationalökonomischen Erkenntnisse diskutierten (vgl. Wilhelm 1979).

307 Für die Leitfunktion der Nationalökonomie plädieren etwa die Nationalökonomen Wilhelm Roscher und Carl Dietzel, der Staatswissenschaftler Lorenz von Stein, aber auch die Juristen Heinrich Dankwardt und Wilhelm Endemann; für die führende Position der Jurisprudenz wiederum etwa der Jurist Wilhelm Arnold (vgl. Hansel 2006: 11ff.). Zum (mangelnden) Forschungsstand des Interferenzraumes zwischen Nationalökonomie und Jurisprudenz in der zweiten Hälfte des 19. Jahrhunderts vgl. ebd.: 41ff.; zur Interferenz zwischen Nationalökonomie und Jurisprudenz zwischen 1900 und 1933 vgl. die Beiträge in Nörr et al. 1994 sowie Schütze 1998.

308 Die positiven Verweise sind auch deshalb bei Jhering nur vereinzelt anzutreffen, da er der Nationalökonomie eine andere Aufgabe als der Jurisprudenz zuspricht. So schreibt er etwa mit Blick auf die gesellschaftlich notwendige Einrichtung des Verkehrs: „Die nationalökonomische Seite der Frage liegt meiner Untersuchung gänzlich fern, letztere ist ausschliesslich socialer Art, d.h. mir kommt es nur darauf an, auf welchen Einrichtungen für die Gesellschaft die Sicherung der Befriedigung des individuellen Bedürfnisses beruht, nicht aber darauf, nach welchen Gesetzen sich die Verkehrsbewegung regulirt." (Jhering 1877: 105; s.a. 140f. u.ö.). 
m.N.). ${ }^{309}$ Daher erstaunt auch nicht die ausdrückliche Zustimmung des Nationalökonomen Adolph Wagner zum Zweck:

Unter den Juristen hat kein Geringerer als der grosse Romanist von Ihering, in Anknüpfung an sein berühmtes Werk „Geist des römischen Rechts“, in seinem Buche „der Zweck im Recht“ [...] eine meiner „socialrechtlichen“ ähnliche Auffassung des Rechts und seines Verhältnisses zum Wirthschaftsleben vertreten. (Wagner 1892: 45) 310 $^{310}$

Dass explizit auf die Zwecklehre Jherings zurückgegriffen wird, um in den älteren Methodenstreit zwischen historischer Schule der Nationalökonomie und Grenznutzenlehre zu intervenieren (vgl. Dargun 1885), überrascht ebenso wenig. ${ }^{311}$ Denn das Zweckproblem liegt schon bei Jhering an einer dreifachen Kreuzung: individuelle Zwecke werden mit kollektiven Zwecken verbunden; Zwecke sind nicht nur historisch-kontingent, sondern verweisen auch auf objektive Lebensbedingungen der Gesellschaft; und drittens geht es um das Problem der Verbindung von Faktizität und normativen Telos - womit insbesondere in der späteren historischen Nationalökonomie gerungen wird (vgl. Nau 1996).

In diesem Diskurskontext wird Jherings Zweck auch für die sich als eigenständige Disziplin formierende Soziologie zu einer zentralen Referenz: Auch sie setzt sich mit Fragen von historischer Kontingenz und Strukturgesetzlichkeit der Gesellschaft, von Faktizität und Normativität sowie Individualismus und Holismus gerade mit Blick auf den Normtypus Recht auseinander - aber dazu im zweiten Teil dieses Buches.

\subsection{Der Zweck in den Staats- und Strafrechtswissenschaften}

Nicht nur außerhalb, sondern auch innerhalb der Rechtswissenschaften erfährt der Zweck eine positive Rezeption, die deutliche Spuren in den epis-

309 Seit den 1860er Jahren kritisiert die Historische Schule der Nationalökonomie das römischen Recht zunehmend als „unsozial“ (vgl. Hofer 2001: 77ff.).

310 In der dritten Auflage der Grundlegung verweist Wagner zudem auf Jherings Lehre der Hebel der sozialen Bewegung (Wagner 1892: 45) und analysiert nun die egoistischen und unegoistischen Motive des wirtschaftlichen Handelns (ebd.: 86ff.).

311 Der Jurist Lothar von Dargun legt eine „sociologische Studie“ vor, die im Gefolge von Jherings Zweck gegen die Vorherrschaft des Individual-Egoismus auf die Rolle des Altruismus hinweist (Dargun 1885; vgl. Wagner-Hasel 2000: 36f.). Dies wird Spuren bis in den Anarchismus hinterlassen (vgl. Kropotkin 2012 [1902]: 324). 
temischen Strukturen der rechtswissenschaftlichen Teilgebiete hinterlässt und ebenfalls das Spannungsverhältnis zwischen gesellschaftsfunktionalempirischer und teleologischer Zweckbestimmung erkennen lässt.

\section{Der Zweck in der Staatslehre}

Im Bereich des Staatsrechts würdigt insbesondere Georg Jellinek Jhering als den „führenden Meister vertiefter Erforschung der Rechtsidee“ (Jellinek 1892: Widmung), auch wenn er stets eine kritische Distanz wahrt (vgl. Wischmeyer 2015: 95; 117ff.).

Ausgangspunkt ist eine dem Zweck ähnlich gelagerte Aufwertung der gesellschaftswissenschaftlichen Betrachtungsweise für die Rechtswissenschaft: Kurz nach Erscheinen des ersten Bandes des Zwecks bestimmt der dem Neukantianismus nahestehende Jellinek unter scharfen Abgrenzung zur naturwissenschaftlichen Betrachtungsweise die Fundierung aller sozialen geistigen Phänomene - damit auch des Rechts - in der Gesellschaft. ${ }^{312}$ Damit rückt die Sozialwissenschaft an die Spitze der Disziplinen (vgl. Jellinek 1878: 11f.). Jellinek fragt dabei wie Jhering nach der „soziale[n] Funktion" des Rechts (Jellinek 1905: 49): Das Recht stelle als sozialer Normenkomplex objektiv "die Erhaltungsbedingungen der Gesellschaft“ (Jellinek 1878: 42) dar. Den Zusammenhang von imperativer Norm, Sicherung der Gesellschaft durch soziale Steuerung und Zweck formuliert er ebenfalls ganz ähnlich:

Dass dem Rechte der Zweck innewohnt, einen bestimmten Zustand der Gesellschaft zu erhalten, indem es ein zu dessen ungestörter Existenz notwendiges Gut durch befehlende oder verbietende Normen für das menschliche Handeln schützt, ist ein Satz, der eines stricten Beweises kaum bedarf. (Ebd.: 43) ${ }^{313}$

Aufgrund dieser gesellschaftsfunktionalen Perspektive setzt auch Jellinek den Zweck im Recht zentral. ${ }^{314}$ Aber anders als Jhering bilden die individuellen Zwecke, und nicht die Arbeit am Begriff der Gesellschaft, den

$312 \mathrm{Zu}$ Jellineks Verhältnis zur neukantianischen Erkenntnistheorie vgl. Lepsius 2000; zu Georg Jellinek vgl. insbesondere Kersten 2000.

313 Recht sei insofern das „ethische Minimum“, das zum Erhalt des Gesellschaftszustandes notwendig sei (Jellinek 1878: 42). Allerdings lehnt Jellinek das Kriterium des Zwangs zur Qualifikation einer Norm als Rechtsnorm ab (vgl. ebd.: 50 f.).

314 Dabei verortet Jellinek das eigentliche sozialwissenschaftliche Problem in der Erkenntnis des Zweckwandels, der zu einer Differenz von ursprünglichen Zwe- 
Ausgangspunkt seiner Untersuchung. ${ }^{315} \mathrm{Da}$ jeder individuelle Willensakt nach Jellinek einen Inhalt, und d.h.: einen Zweck hat, ${ }^{316}$ ließen sich die Erscheinungen anhand der individuellen Zwecke typisieren, ordnen und verstehen (vgl. Jellinek 1905: 171). Oder, wie er an anderer Stelle schreibt: "Ohne Anwendung der Zweckkategorie ist es überhaupt gar nicht möglich in die Willensäusserungen des Menschen Sinn und Ordnung zu bringen.“ (Jellinek 1892: 24) Wenn also soziale Phänomene - wie das Recht bei Jellinek zum „Reiche der Zwecke“ (Jellinek 1878: 12) gehören, dann rückt er die zweckorientierte individuelle Handlung in den Mittelpunkt. Daher weicht er von Jherings holistischer Perspektive $a b$ - und weist für die juristische Arbeit damit dem subjektiven Recht einen maßgeblichen Stellenwert zu (vgl. Wischmeyer 2015: 127f.). ${ }^{317}$

Auch auf erkenntnistheoretischer Ebene besteht eine grundlegende Differenz zu Jhering. Jellinek führt eine Unterscheidung in der Erkenntnisart des Rechts als soziales Phänomen ein: Zwar gehe es, wie er später ausführt, in den Sozialwissenschaften im Gegensatz zu den Naturwissenschaften immer um Typenbildung, die für die juristische Arbeitsweise geradezu charakteristisch sei. ${ }^{318}$ Man könne das Recht dann aber zum einen aus der Perspektive der theoretischen (erklärenden) Sozialwissenschaft betrachten, d.h. einer Wissenschaft, die jenseits jeglicher Wertungen nach dem Sein

cken des Rechts und gegenwärtigen Zwecken führen kann. Damit verbindet er eine harsche Kritik an der Historischen Rechtsschule, die aufgrund ihrer Verankerung in der Vergangenheit einen gegenwärtigen Zweckwandel gar nicht zu erkennen vermag (vgl. Jellinek 1905: 44ff.)

315 Da das Individuum, die „Grundlage aller sozialer Erscheinungen“ (ebd.: 28), sich niemals berechnen lasse, seien umfassende Erkenntnisse sozialer Gesetze unmöglich. Bedingungen für den Erhalt der Gesellschaft sind nach Jellinek nur soweit relevant, soweit sie vom menschlichen-individuellen Willen abhängig sind (Jellinek 1878: 42).

316 Auf der Kontingenz dieser (individuellen) Zwecke beruht die Differenz zwischen Natur und Sozialem, was eine notwendige Differenzierung der naturwissenschaftlichen und der sozialwissenschaftlichen Erkenntnis bewirkt (vgl. Jellinek 1905: 26ff.).

317 Die Hinwendung zum methodologischen Individualismus speist sich auch bei Jellinek aus der garantierten Einheit im Organismus, ist doch die „teleologische Einheit" in der "durch dauernde Zwecke miteinander verbundenen Vielheit" nicht nur in der sozialen Welt erkennbar, sondern auch in der Natur, wie dies im Organismusbegriff zum Ausdruck gebracht werde (ebd.: 171).

318 Jens Kersten verweist zu Recht darauf, dass die Staatslehre schon vor Jellinek mit dem Typus-Begriff gearbeitet habe. So bezog man sich auf "generelle Typen“ (etwa Gierke), „Prototypen“ (z.B. Hänel), „Grundtypen“ (z.B. Schmidt) sowie auf die Differenz von „Typen-,, und „Gattungsbegriff“ (Schmitt; vgl. Kersten 2000: 102 m.N.). 
dieser Zwecke und Werte frage (vgl. Jellinek 1878: 13f.). Man könne (und müsse) es aber ebenso von der Warte einer praktischen Sozialwissenschaft wie der Jurisprudenz aus untersuchen. Letztere sei die spezifische Perspektive der „Gesammtheit der juristischen Wissenschaften“, insofern „sie die Brauchbarkeit der Rechtssätze und die Art und Weise ihrer Anwendung auf concrete Rechtsverhältnisse prüfen" (ebd.: 14). ${ }^{319}$ Ihre wissenschaftliche Methode richte sich auf diese praktische, wertende Seite, ohne jedoch selbst eine Wertung zu sein (vgl. ebd.: 13). ${ }^{320}$ Es gebe also in Bezug auf das Recht einen Dualismus der Methode: eine auf das reale Sein und eine auf das Sollen des Rechts gerichtete Betrachtung, der die Unterscheidung zwischen empirischer Seinswissenschaft („Kausalwissenschaft“) und rechtswissenschaftlicher „Normwissenschaft“ entspricht (Jellinek 1905: 19ff.). Für letztere gelte:

Allein der dogmatische Gehalt der Rechtsnormen kann nur durch die ausschließlich vom Juristen geübte Kunst der Abstraktion aus den rechtlichen Erscheinungen und der Deduktion aus den also gefundenen Normen geübt werden. Diese Rechtsdogmatik ist durch andersgeartete Wissenschaft nicht zu ersetzen. (Ebd.: 49)

319 Im staatsrechtlichen Diskussionskontext zu dieser Zeit steht - anders als im Privatrecht - in der Debatte um Zwecke die Abgrenzung zur Politik im Vordergrund (vgl. Wischmeyer 2015: 99ff.). Zudem wendet sich eine Reihe von Autoren seit den 1880er Jahren einer explizit soziologischen Betrachtung des Staates $\mathrm{zu}$, und darüber auch der Rechtsordnung (z.B. Ludwig Gumplowizc, Gustav Ratzenhofer, Franz Oppenheimer), was jedoch zu Problemen der juristischen Anschlussfähigkeit führte (vgl. Stolleis 1992: 444ff. m.w.N.; zu den Anschlüssen der Soziologie an diese Richtung vgl. Käsler 1984). Aus dieser Entwicklung in den Staatswissenschaften resultiert die Spannungslage zwischen Faktizität und Normativität, der Jellinek mit seiner - von Kelsen kritisierten - Zwei-Seiten-Lehre (des Staates) und seiner Rechtsgeltungslehre begegnete (Stolleis 1992: 454). Das Ordnungsproblem, das sich entlang der individuellen Freiheit entspannt, wird jedoch im Privatrecht verortet (vgl. $\$ 4$ ).

320 Jellinek umschreibt diesen Unterschied zwischen erklärender-theoretischer und praktischer Wissenschaft später anhand der Zielsetzung: erstere wolle „Regeln ihres Zusammenhanges aufweisen“, letztere „ihre Verwendbarkeit für praktische Zwecke lehren“ (Jellinek 1905: 6). Allerdings unterscheide sich die Rechtswissenschaft von der Politik als Prototyp der praktischen Wissenschaft (vgl. ebd.: 13ff.) über den unterschiedlichen Charakter der zugrunde liegenden Normen. Während politische Normen nur kraft freier Anerkennung (empirische) Geltung erlangen könnten und daher immer bezweifelbar seien, seien die Rechtsnormen geltende, d.h. in Kraft stehende Normen, denen Garantien zur Erfüllung zur Seite stünden. Recht hat eine reale Macht, d.h. ein empirisches Substrat (ebd.: 20). 
Die Rechtslehre bleibt der juristischen Konstruktion verpflichtet, ist aber, um Einseitigkeiten zu vermeiden, mit der Analyse des Sozialen, insbesondere der faktischen Rechtsgeltung, zu vermitteln. ${ }^{321}$

Mit der Festlegung der Rechtswissenschaft auf die in der Deduktion liegende wertende Anwendung werde man jedoch nicht auf das spekulative Naturrecht verwiesen. Denn auch wenn man sich dem Bereich der Ethik zuwende, handele es sich doch nach wie vor um ein gesellschaftliches Phänomen, das es zu bestimmen gelte. Oder, wie man in Anlehnung an Jellineks spätere Aussagen formulieren kann: Es geht nicht um den „Idealtypus" als Sein-Sollendes (Jellinek 1900: 32), der wie im Naturrecht auf spekulativem Weg oder durch spekulative Verabsolutierung vorfindlicher Elemente gewonnen wird (und der einen letztlich in den Bereich der Politik verweist, vgl. ebd.: $32 f$.). ${ }^{322}$ Wissenschaftliche Arbeit kennzeichne sich vielmehr durch die Untersuchung des „Durchschnittstypus“ (ebd.: 33) aus, ${ }^{323}$ d.h. von Typen, die real existieren. Sie werden aus den in der Empirie mittels Abstraktion über Vergleichung und Analogiebildung induktiv gewonnenen gemeinsamen Merkmale gebildet (vgl. ebd.: 33f.). Aufgrund dieser Bindung an das soziale Sein, das sich beständig im Wandel befinde, handele es sich um dynamische Typen. Das gelte auch für ethische Normen: Nach Jellinek ist nur eine empirische Ethik relevant, die sinnvollerweise nur als gesellschaftliche, d.h. als Sozialethik, begriffen werden könne (Jellinek 1878: 15ff.).

Trotz der Aufwertung der Gesellschaft ${ }^{324}$ und damit der Sozialwissenschaften für die Rechtsbetrachtung, die wie bei Jhering in eine empirische Fundierung ethischer Normen mündet, markiert Jellineks Verdopplung

321 Auf der Basis der strikten Trennung von Sein und Sollen versucht Jellinek, zwischen Faktizität und Normativität zu vermitteln. Das bringt ihm unter anderem die Kritik von Kelsen, Radbruch und Weber ein (vgl. hierzu insbesondere Kersten 2000: 102ff.).

322 Jellinek verwendet den Begriff des Idealtypus also ähnlich wie Jhering (s.o. \$3.I.2.3). Zur Entwicklung der Typenlehre bei Jellinek vgl. die kritische Darstellung bei Kersten 2000: 102ff.

323 Zur Kritik an den Widersprüchen in Jellineks Typenlehre, wie sie ihm auch seine Zeitgenossen ankreideten, vgl. Kersten 2000: 118ff. Offensichtlich auf Webers Kritik am Begriff des Durchschnittstypus im Objektivitäts-Aufsatz reagierend ändert Jellinek in der zweiten Auflage der Allgemeinen Staatslehre die Bezeichnung und spricht fortan von „empirischen Typen“ (Jellinek 1905: 35). Zugleich stellt er klar, dass der empirische Typus nichts mit dem statistischen Durchschnitt zu tun habe (vgl. Kersten 2000: 135f.).

324 Diesbezüglich verweist Jellinek später auch auf Jherings Untersuchung des Gesellschaftsbegriffs (vgl. Jellinek 1905: 81 Anm. 2). 
der Betrachtungsweisen des Rechts eine eindeutige Differenz: Der Zweck im Recht kann (und muss) zwar sozialwissenschaftlich erforscht werden. Doch gilt im Gegensatz zu Jhering: „Der Zweck ist gewiss der ,Schöpfer des Rechts.' Aber es ist ein methodisch logischer Fehler, den Schöpfer mit dem Geschöpf zu confundiren." (Jellinek 1887: 192 Anm.4) Vom Sein könne man nicht auf das Sollen schließen, auch wenn die Genese des Sollens gesellschaftlich rückgebunden sei. Der Zweck als gesellschaftliche Funktion lasse sich nicht in den Zweck als normatives Telos überführen. Die Frage der Rechtsentstehung sei mithin von der Frage der rechtswissenschaftlichen Arbeit zu trennen. Anders formuliert: Der Zweck des Rechts ist vom Zweck im Recht zu unterscheiden. Für beide Zweckformen bedür$\mathrm{fe}$ es unterschiedlicher Methoden, die auf einem grundlegenden Unterschied in der Perspektive auf das Recht basieren. Die (erklärende bzw. theoretische) Sozial- bzw. Gesellschaftswissenschaft könne daher nicht als Leitdisziplin der Rechtswissenschaft fungieren, sondern stelle eine - wenn auch notwendige - Ergänzung der autonomen Rechtswissenschaft dar (vgl. Jellinek 1905: 49f.).

Über die einflussreichen Arbeiten Jellineks (vgl. Kelsen 1922: 115) gelangt das in der Theorie der Gesellschaft fundierte Zweckdenken Jherings in die Staatswissenschaften. In der Staatsrechtslehre bzw. im Öffentlichen Recht, das sich Ende des 19. Jahrhunderts und Anfang des 20. Jahrhunderts aus den Staatswissenschaften ausdifferenziert, wird der Zweck v.a. als normativer Telos problematisiert. ${ }^{325}$ Die Spannung zwischen Faktizität und Normativität im Zweck wandelt sich hier - wie in den Privatrechtswissenschaften - in ein wissenschaftstheoretisches Problem (s.u. \$5.IV.2). Und genau dies führt bei Jellinek zu einer Aufspaltung in theoretisch-erklärende und praktische Sozialwissenschaft.

325 Michael Stolleis erkennt in den 1880er Jahren im Bereich des Öffentlichen Rechts die Heraufkunft des Interventionsstaates, dessen wichtigstes Kennzeichen das Vordringen des Zweckmoments sei: „Intervention bedeutet gezielte, zweckgeleitete Einflußnahme durch Recht. Das Recht ist insoweit Mittel, nicht Selbstzweck.“ (Stolleis 1989: 140). Er betont dabei die Rolle des gesellschaftlichen Wandels, wenn er schreibt: „Reichsgründung, Verwaltungsreformen, Verwaltungsgerichtsbarkeit und Industrialisierung wirkten also in eine Richtung, die da lautete: rechtliche Ordnung der technischen Neuerungen, der neuen Energieträger und Transportmittel, rechtliche Bewältigung der Bevölkerungsvermehrung und der Wanderung in die industriellen und städtischen Zentren, Bewältigung der Sozialen Frage mit Hilfe einer neuen Großbürokratie, Bewältigung des über herkömmliche Wirtschafts- und Unternehmensformen hinauswachsenden Industriekapitalismus, und dies alles durch neues Öffentliches Recht.“ (Ebd.: 138). 


\section{Der Zweck im Strafrecht}

Seine unmittelbarste Wirkung entfaltet der Zweck jedoch im Strafrecht. Bereits im Jahr 1882 überträgt der Jhering-Schüler Franz von Liszt den Zweckgedanken ins Strafrecht: „Im Rechte steckt der Zweckgedanke; er ist das Wesen des Rechts.“ (Liszt 1905 [1882]: 144) Diesem „Grundgedanke[n] der Iheringschen Auffassung“ (ebd.) folgend könne man die Rechtsstrafe nicht (mehr) als Triebhandlung (etwa Rache oder Sühne), sondern müsse sie als Willenshandlung verstehen. ${ }^{326}$ Damit öffnet sich der Strafgedanke nicht nur der rationalen Begründung, sondern auch der empirischen Untersuchung unter der Perspektive des Strafzwecks:

Aber die Entwicklung der rechtlichen und sittlichen Norm, die Abschätzung der Handlung in ihrem rechtlichen und sittlichen Wert, die Reaktion in der Form der objektivierten Rechtsstrafe ist bedingt durch die Erfahrung und durch den in ihr gewonnenen Zweckgedanken. (Ebd.: 145)

Im expliziten Rekurs auf Jhering hatte Liszt bereits 1881 das Verbrechen bestimmt als „die von Seiten der Gesetzgebung konstatirte Gefährdung der Lebensbedingungen der Gesellschaft" (Liszt 1881: 12). Außerdem habe die Strafe den Zweck, die Existenz der Gesellschaft zu schützen. Sie sei als „Form des Rechtsgüterschutzes zweckbewußte Schöpfung und zielbewußte Funktion der staatlichen Gesellschaft" (Liszt 1905 [1882]: 126). ${ }^{327}$ Die Strafe habe sich in Art und Maß nach diesem Zweck zu richten (vgl. Liszt 1881: 4). Strafrechtliche Gerechtigkeit werde dadurch an die gesellschaftlich definierte Notwendigkeit der Strafe gebunden: „Die richtige, d.h. die gerechte Strafe ist die notwendige Strafe. Gerechtigkeit im Strafrecht ist die Einhaltung des durch den Zweckgedanken erforderten Strafmaßes.“ (Liszt 1905 [1882]: 161)

326 Zu weiteren Quellen des Zweckgedankens bei Liszt vgl. Kreher 2015.

327 Es klingt geradezu wie eine Zusammenfassung des Zwecks, wenn von Liszt schreibt: „Das Recht bezweckt den Schutz derjenigen Interessen, zu deren Schutz und Förderung die Einzelnen zur staatlichen Gemeinschaft zusammengetreten sind; wir können diese vom Recht, dem Gesammtwillen der Gemeinschaft, geschützten Interessen als Rechtsgüter bezeichnen. Das Recht erreicht seinen Zweck, Rechtsgüterschutz zu sein, durch den Zwang in der doppelten Form: des direkten physischen Zwanges, der unmittelbaren Gewalt einerseits; andererseits des indirekten psychischen Zwanges, der Motivation“ (Liszt 1881: $3)$. 
Damit wird die gesellschaftlich-funktionalistische Perspektive im Strafrecht implementiert: Die Strafe habe die Funktion der Verteidigung der Gesellschaft, aber immer vor dem Hintergrund, dass die Gesellschaft historisch bedingt sei. ${ }^{328}$ Das (Straf-)Recht schütze die Gegenwart der gesellschaftlichen Ordnung vor den Gefahren des Verbrechens bzw. genauer: vor den verbrecherischen Individuen. ${ }^{329}$ Vergeltung werde zu einem Mittel, diesen Zweck zu realisieren.

Die Aufwertung des gesellschaftsfunktionalen Zweckdenkens umfasst sowohl Rechtsdogmatik, Methodik, Kriminalpolitik als auch Kriminologie. Dieses von Liszt breit angelegte „Marburger Programm“ zeitigt eine immense Breitenwirkung. Hier entfaltet Jherings Perspektivverschiebung eine explizite (vgl. etwa Hurwicz 1911) und dauerhafte Wirkung. ${ }^{330}$ Auch in der rechtswissenschaftlichen Rezeption zeigt sich das Spannungsfeld des Jhering'schen Zweckdenkens zwischen Teleologie und empirischer, gesellschaftsfunktionaler Betrachtung - sei es, dass sie wie bei Jellinek voneinan-

328 Daher ist das Strafrecht bzw. das Recht auch in eine Entwicklungsgeschichte eingebunden, die von Liszt über weite Strecken in seiner Abhandlung darlegt (Liszt $1905[1882])$.

329 Im „Marburger Programm“ relativiert von Liszt den Strafgedanken: Der Fokus liege nicht auf der Vergeltung jenseits jeglicher Strafzwecküberlegungen (absolute Straftheorie), sondern auf der gesellschaftlich-funktionalistischen Bestimmung der Strafe. Damit rückt Liszt den Täter, und nicht die Tat, in den Vordergrund, d.h. insbesondere die Techniken der Besserung und der Abschreckung der Individuen (vgl. Liszt 1905 [1882]: 166), aber auch der Prävention (vgl. Liszt 1881: 4 u.ö.; zu den problematischen Konsequenzen dieser Sichtweise insbesondere auch mit Blick auf die Entwicklung des Strafrechts im Nationalsozialismus vgl. Muñoz Conde 2010). Es handelt sich um jene Aspekte, die nach Foucault in Überwachen und Strafen zur Entstehung der Disziplinargesellschaft beitragen (vgl. Foucault 2009b; Krasmann 2003).

330 Jhering habe - so Alessandro Baratta - „mit dem Begriff des Verbrechens als Verletzung der Lebensbedingungen der Gesellschaft die Gedankenentwicklung [gefördert], durch die die individualistisch-liberale Rechtsideologie überwunden wurde und die soziale Epoche im Strafrecht begann“ (Baratta 1970: 19; zur Wirkung von Liszts vgl. die Beiträge in Gedächtnisheft für Franz von Liszt der Zeitschrift für die gesamte Strafrechtswissenschaft 1969; Muñoz Conde 2010: 439f. m.w.N.; zu Wirkungen im Bereich der Psychologie vgl. die Beiträge in Schmoeckel 2009). Eine Generation später wird auch von neukantianischer Seite - vermittelt insbesondere über Jellinek und Lask - der Zweckgedanke in der Strafrechtstheorie aufgegriffen: $\mathrm{Zu}$ den heute noch prominentesten Vertreter dieser Richtung zählen sicherlich der Liszt-Schüler Gustav Radbruch sowie Hans Kelsen. Zur Diffusion des Zweckgedankens in die Wissenschaftstheorie und Wertphilosophie des Neukantianismus s. gleich; zum neukantianischen Strafrechtsdenken Anfang des 20. Jahrhunderts vgl. Ziemann 2009. 
der geschieden werden müssen, sei es, dass die gesellschaftsfunktionale Bestimmung des Strafrechts wie bei Liszt als Grundlage der Bestimmung des Telos herangezogen wird.

\subsection{Der Zweck in der Rechtsphilosophie}

Angesichts dieser Einbettung des Zweckdenkens in den philosophischen und sozialwissenschaftlichen Diskurs sowie seiner positiven Rezeption in den Staatswissenschaften und im Strafrecht verwundert es nicht, dass Jhering $\mathrm{zu}$ einem unerlässlichen Bezugspunkt für die wieder erstarkende Rechtsphilosophie wird. ${ }^{331}$

\section{Rechtspositivismus (Bergbohm)}

Karl Bergbohm, der mit seiner Schrift Jurisprudenz und Rechtsphilosophie aus dem Jahr 1892 einen Fundamentalangriff gegen das Naturrecht führt, ${ }^{332}$ arbeitet wie kein anderer seiner Zeit die Positivität des Rechts durch verbindliche Setzung (nicht unbedingt durch den Gesetzgeber) als dessen entscheidende Eigenschaft heraus (vgl. Bergbohm 1892: 546). ${ }^{333}$ Recht sei immer gemachtes Recht, es entspringe der Tat. Bergbohm zielt dabei auf eine ,Reinigung' des Rechts als Rechtsform von allen ethischen

331 Fritz Berolzheimer schreibt rückblickend im Jahr 1906: „Die herrschende Rechtsphilosophie hat zwar Jhering's Zwecklehre abgelehnt. Aber zahlreiche rechts- und staatswissenschaftliche Schriften, die rechtsphilosophische Fragen behandeln, sind völlig oder teilweise von der Zwecklehre angekränkelt." (Berolzheimer 1906: 112).

332 Ein ausdrückliches Bekenntnis zum Naturrecht in der Rechtsphilosophie findet sich um die Jahrhundertwende jedoch nur sehr selten (vgl. etwa Hertling 1897; Victor Cathrein 1901). Bergbohm geht es jedoch in seinem Angriff um den Nachweis strukturell naturrechtlicher Momente, die er jenseits solchen expliziten Bekenntnisses erkennt.

333 Seinen Zeitgenossen galt Bergbohm als „reinster Positivist“, womit jedoch umstritten bleibt, ob und welche Form des Rechtspositivismus er in seiner Rechtsphilosophie vertritt (kritisch zur Sinnhaftigkeit, von Positivismus zu sprechen, etwa Brockmöller 1997: 32ff.; zu Bergbohm vgl. Kremer 2001). Der Naturrechtsbegriff, gegen den er anschreibt, umfasst dabei „jede Vorstellung von einem Recht, das von menschlicher Satzung unabhängig ist" (Bergbohm 1892: 130f.). Hierzu zählt er auch die Historische Rechtsschule mit ihrer Fundierung des Rechts im Rechtsbewusstsein (ebd.: 480ff.), und ihr gelten seine Angriffe im eminenten Maße. 
Quellen und inhaltlichen Vorgaben. Dabei bezieht er sich in vielen Punkten explizit auf Jhering: für die Aufwertung des Verwirklichungsgedankens im Recht, für die Vorgängigkeit des Rechts vor dem Rechtsgefühl und die Kritik an den nativistischen Theorien ethischer Anlagen, für die Angriffe auf die Spekulation und für die Aufwertung der Tat im zweckgesetzten Recht (vgl. ebd.: 81, 450, 464, 194, 545f.). All das verwendet er zum Entwurf einer allgemeinen Rechtslehre, die von jeglichen, sei es noch so versteckten Werturteilen frei sei - wofür er jedoch Jherings gesellschaftliche Zwecksetzungen und damit die gesellschaftsfunktionale Rückbindung des Rechts außer Acht lässt. Was bleibt, ist die Strukturtheorie eines System der in sich geschlossenen (und daher logisch lückenlosen) Rechtsnormen (vgl. ebd.: $373 \mathrm{ff}.)^{3} 34$

\section{Neuhegelianismus (Berolzheimer)}

Demgegenüber steht für den Neuhegelianismus nach Fritz Berolzheimer Recht immer im unmittelbaren Zusammenhang mit der gegenwärtigen Kultur (vgl. Berolzheimer 1909). Jherings Zweck ist in dieser Perspektive Ausdruck der gegenwärtigen Dominanz einer Wohlfahrts-Sozialtheorie in der Rechts- und in der Wirtschaftsphilosophie (vgl. etwa Berolzheimer 1905: 212 u.ö.). 335 Bei der Suche nach einem gerechten Recht vermischen sich unter dem Zweckgedanken jedoch irrigerweise die Aufgaben der Rechtsphilosophie mit denjenigen der Rechtspolitik (ebd.: 22). Da Recht

334 Bergbohm zählt neben dem Jhering-Schüler Adolf Merkel zu den Protagonisten der Herausbildung der Rechtstheorie als eigenständige Disziplin (vgl. zu dieser Entwicklung Brockmöller 1997; Dreier 1992). Beobachtbar ist in diesem Feld, zu dem auch die Arbeiten von Karl Binding und Ernst Rudolf Bierling gerechnet werden, die Deutung des Rechtssatzes nicht mehr als Regel, sondern als Norm (vgl. etwa Binding 1872; Bierling 1894). Für den Neukantianer Gustav Radbruch zählen Binding, Bierling und Bergbohm im Jahr 1914 zu den Vertretern einer „rein empiristischen Allgemeinen Rechtslehre“, die in dieser Form eine „Euthanasie der Rechtsphilosophie“ darstelle (Radbruch 1993 [1914]: 34).

335 Daher behandelt Berolzheimer Jherings Zweck in seiner kulturhistorischen und völkerpsychologischen Untersuchung der Kulturstufen der Rechts- und Wirtschaftsphilosophie aus dem Jahre 1906 im Kapitel zum „Übergang zum modernen Klassenstaat“ unter der „Herrschaft der Sozialphilosophie“ (vgl. Berolzheimer 1906: 233ff.). Da Berolzheimer Anschluss an Marx sucht, wendet er sich gegen Stammler. Allerdings ist er gerade nicht auf die Überwindung, sondern auf die Erhaltung und Sicherung der Klassengesellschaft aus (vgl. Schulze, Schier 1987: 17ff.). 
nicht ein Produkt des Zwecks, sondern der Kultur sei, helfe der platte Sozialutilitarismus Jherings nicht weiter, denn: „Der Rechtsphilosoph muss die kulturelle Entwicklung des Rechts darstellen und deuten." (Berolzheimer 1909: 199)

Berolzheimer stellt also keineswegs die konkret-historische Bedingtheit des Rechts (wie des Staates) in Frage, werde es doch in seiner Entwicklung „von der jeweils herrschenden Kultur beeinflusst“ (ebd.: 196). Er bewegt sich also in den Bahnen des Repräsentationsgedankens. Auch wenn er damit den empirischen Bezug des Rechts nicht kappt, sei dieser jedoch nicht mit den Mitteln der Gesellschaftswissenschaft zu untersuchen. Denn das Recht zeige sich zugleich als „Voraussetzung für die Entstehung und das Weiterbestehen der Kultur" (ebd.). Insofern gehe es jeder gesellschaftstheoretischen Bestimmung, die es nur als ein Teilphänomen der Gesellschaft betrachte, voraus und bedürfe als solches der philosophischen Untersuchung. Der methodische Zugang zur empirischen Seite des Rechts ist bei Berolzheimer - dem Repräsentationsgedanken folgend - als ethnologische Rechtsvergleichung und (Universal-)Rechtsgeschichte $\mathrm{zu}$ verwirklichen (vgl. Berolzheimer 1907: 133f.).

\section{Neukantianismus (Stammler, Lask)}

Für die prominenten Vertreter des auch in der Rechtsphilosophie erstarkenden Neukantianismus, ${ }^{336}$ den der Marburger Schule zuzurechnenden Rudolf Stammler ${ }^{337}$ und den Rickert-Schüler Emil Lask, wird Jhering ebenfalls zum Prüfstein ihrer Rechtsphilosophien.

In Stammlers Wirtschaft und Recht nach materialistischer Geschichtsauffassung (1896) ist die Auseinandersetzung mit Jhering zentral. ${ }^{338}$ Das liegt daran, dass Stammler insbesondere zwei Prämissen der Jhering'schen Zweck-

336 Vgl. hierzu insbesondere Alexy et al. 2002.

337 Allerdings wehrt sich Stammler immer wieder gegen diese Zurechnung (vgl. Stammler 1931: 46), die jedoch schon seine Zeitgenossen ganz selbstverständlich vornahmen (vgl. Berolzheimer 1907: 130ff.; zur neukantianischen Rechtsphilosophie der Marburger Schule, und hier insbesondere zum Einfluss Stammlers, vgl. Müller 1994).

338 Zuvor hatte Stammler schon seine Ablehnung der Historischen Rechtsschule eindeutig zum Ausdruck gebracht: In der Festschriftgabe für Windscheid Über die Methode der geschichtlichen Rechtstheorie aus dem Jahr 1888 sieht er die Volksgeistlehre in der Romantik verankert. Sie sei der Ausdruck eines - wie er später schreibt - ,juristische[n] Spiritualismus“ bzw. einer "soziale[n] Mythologie“ (Stammler 1902: 152), die weder beantworten könne, was Recht sein solle, noch, 
bestimmung des Rechts folgt: Erstens bewegt sich auch Stammler in der Bahn der gesellschaftstheoretischen Bestimmung des Rechts. Dabei lässt sich auch für ihn der Gegenstand der Sozialwissenschaft (respektive der Sozialphilosophie), das soziale Leben, aus wissenschaftlicher Sicht sinnvollerweise nur als Einheit betrachten. Aus diesem Grund zielt Stammler - was Weber später vehement kritisiert (vgl. $\$ 8)$ - auf die Erkenntnis der „allgemeingültigen Gesetzmäßigkeit des sozialen Lebens“ (Stammler 1896: 4) als formales, einheitsstiftendes Prinzip. Das soziale Leben wiederum wird bei ihm ausgehend von der sozialen Norm bestimmt: Stammler definiert es als ein „durch äußerlich verbindende Normen geregeltes Zusammenleben von Menschen" (ebd.: 108), wobei diese normierenden Regeln auf Menschensatzung zurückzuführen seien (ebd.: 100). Das Recht stelle dabei eine besondere soziale Norm dar: Es sei die „repräsentative“, „regelnde Form“ des sozialen Lebens (ebd.: 135, 165), die sich seinem Inhalt nach auf einen empirisch wandelbaren Stoff beziehe. Recht - jene damit zentrale soziale Norm für die formale Erkenntnis des sozialen Lebens ${ }^{339}$ - sei also zunächst eine Form des sozialen Lebens, mithin eine unabdingbare Form, ohne deren Existenz das soziale Leben (oder die Gesellschaft) nicht denkbar sei.

Für diese auf die Gesellschaft bezogene Bestimmung des Rechts will Stammler aber gerade nicht an Jhering anschließen. Einerseits sei dessen Gesellschaftsbegriff zu unbestimmt (Stammler 1896: 647f. Anm. 40). Andererseits verwechsele Jhering mit der funktionalen Bestimmung des Rechts als Sicherung der Lebensbedingungen der Gesellschaft Ursache und Wirkung: Es gebe keine vorgängige Gesellschaft, die dann in ihrer Existenz durch das Recht gesichert werde. Vielmehr sei Gesellschaft erst dann vorhanden, wenn es Recht gebe. Letzteres sei das "logische Prius“ (vgl. ebd.: 112). Recht sichere nicht, sondern konstituiere die Gesellschaft (ebd.: 496). Und schließlich eigne sich der Zwang nicht als Definitionskriterium für rechtliche Normen, sei er doch auch bei den Konventionalregeln anzutreffen (ebd.). ${ }^{340}$

wie Rechtswandel erfolge (vgl. Stammler 1888: 12). Insbesondere ordnet er die Historische Rechtsschule dem zunehmend kritisierten Historismus zu - ein Vorwurf, an dem er festhalten wird (vgl. etwa Stammler 1922: 36ff.; kritisch zur Treffsicherheit der Historismus-Kritik Stammlers Wittkau-Horgby 1998: 81f.).

339 Daher betont auch Stammler die Notwendigkeit, die verschiedenen sozialen Normen zu differenzieren (Stammler 1896: 91), wobei er aber letztlich nur zwischen zwei Klassen unterscheidet: Recht und die alle anderen sozialen Normen umfassenden Konventionalregelungen (ebd.: 125).

340 Recht ist zwar auch bei Stammler eine Zwangsregelung menschlichen Zusammenlebens, sein Spezifikum bestimmt er jedoch im Anspruch der Unverletztlichkeit als dessen eigentümlichen Sinn des Geltungsanspruches. Dieser zeige 
Der zweiten Prämisse Jherings, der Stammler folgt, ist der Zweckgedanke: Auch für Stammler gehört das Recht dem „Reich der Zwecke“ an. Dabei gilt:

Das Recht erscheint danach nicht als ein beliebiger einzelner Zweckinhalt, der einmal auftaucht und wieder verschwindet, es beherrscht vielmehr in seinem Auftreten ganze Gruppen möglicher Ziele. Das Recht ist eine formale Eigenschaft vom menschlichem Wollen. Es stellt eine eigene Klasse von Willensinhalten dar, die es von sich aus bestimmt und zusammenhält; es ist eine bedingende Art und Weise des Setzens und Verfolgens von Zwecken. (Stammler 1911: 69, H.i.O.)

Zwar bestimmt Stammler entsprechend seines formalen Rechtsbegriffs die Rechtswissenschaft streng technisch-formalistisch, ${ }^{341}$ nichtsdestotrotz sei sie aber eine "Zweckwissenschaft" (vgl. Stammler 1906b: 378ff.; 1922: 28, 29). Mit der Bestimmung des Rechts über den Zweck verbindet Stammler dabei eine harsche Kritik an Jhering, namentlich an dessen Scheidung von Kausal- und Zweckgesetz: Es sei falsch, wie Jhering zwischen zwei Arten von Kausalität zu unterscheiden: „Begriff und Bedeutung der Ursache ist einheitlich.“ (Stammler 1896: 355, H.i.O.) Vielmehr sei der Zweck nicht eine besondere Art der Ursache, „sondern es ist die Vorstellung von einem Gegenstande, als einem zu bewirkenden Objekte, dessen Werden man als unvermeidlich sicher auf Grund der mittels Kausalitätsgesetze erworbenen Wissenschaften gerade nicht erkennt“ (ebd., H.i.O.). Zwecke entsprängen nicht dem bereits gesellschaftlich eingebetteten und daher kausal bedingten Interesse, sondern dem Gebiet des Wollens, d.h. dem Setzen von Zwecken. ${ }^{342}$ Wollen sei aber etwas anderes als Erkenntnis; die Differenz liege

sich in der Bindung auch der gesetzgebenden Instanz an die rechtlichen Regelungen (vgl. ebd.: 498). Später bestimmt Stammler das Recht als einen „Zwangsversuch zum Richtigen“ (Stammler 1902: 27ff.). Aber auch dort zeigt sich die beschriebene Notwendigkeit der expliziten kritischen Auseinandersetzung mit Jhering (vgl. ebd.: 603ff.)

341 Rechtswissenschaft richte sich auf die dogmatische Beherrschung des Rechtsstoffes, wofür ein Bezug zum sozialen Leben, das sich darunter abspiele, keinerlei Rolle spiele. Denn Genese, Anwendung und Wirkung des Rechts hat sie nach Stammler letztlich nicht zu interessieren (Stammler 1896: 166). Daher macht der Vorwurf der Begriffsjurisprudenz für Stammler auch keinen Sinn.

342 Das Recht ist eine besondere Art des Wollens bestimmter Zwecke (vgl. Stammler 1911: 42ff.). Für Kelsen ergibt diese Bestimmung aus wissenschaftstheoretischer Perspektive keinen Sinn, wie er im Jahr 1916 ausführt: „Es ist unzulässig, eine Einteilung der Wissenschaften auf den Gegensatz von Erkennen und Wollen zu gründen. Wissenschaft ist nie Wollenschaft.“ (Kelsen 1916: 97). 
in der jeweiligen Betrachtungsweise (ebd.: 356). Diesem Unterschied entspreche eine Differenz der Wissenschaftsformen: Naturwissenschaft und teleologische Wissenschaft, die jedoch als Wissenschaften beide ihre Vorstellungen auf eine Einheit zurückführen. Die Naturwissenschaft vollziehe dies durch das Kausalitätsgesetz. Im Bereich des Telos wird demgegenüber nach Mittel und Zweck bis hinauf zur obersten Einheit möglicher Zwecksetzung, dem Endzweck gefragt. Dieses „Endziel“ bestimme die Gesetzmäßigkeit des Telos, „die wir in unserer Sprache mit Sollen bezeichnen“ (ebd.: 368, H.i.O.). Das Sollen sei die „Einheit der Zwecksetzung“ (ebd.) und damit der formale Kern des Rechts.

Die Unterscheidung von Kausalität und Telos ist auch für Stammler konstitutiv für die Rechtsbetrachtung (s.a. Stammler 1902: 610ff.). Diese behandelt er allerdings nicht als ein Problem der Rechtsentstehung (wie Jhering), sondern als erkenntnis- und wissenschaftstheoretische Frage. Rechtsentstehung und wissenschaftliche Behandlung des Rechts seien zu trennen. Denn: „Der Zweck ist nicht der Schöpfer des Rechts, sondern das Recht ist eine besonders geartete Zwecksetzung [...]." (Stammler 1922: 43 Fn. 10, H.i.O.) Jhering stelle den Zweck über das Zweckgesetz in einen empirischen Kontext - und markiere deshalb den Übergang zur neueren Rechtsphilosophie des ,juristischen Empirismus“ (vgl. ebd.: 42ff.). Demgegenüber stellt Stammler Telos und Empirie in einen erkenntnistheoretischen Gegensatz: Ihr Verhältnis werde aus der Perspektive der allgemeinen Gesetzmäßigkeit des sozialen Lebens ausgeformt. Dies drückt sich bei Stammler im bereits früh entworfenen Konzept des „Naturrechts mit wechselndem Inhalt" aus:

Unter Naturrecht verstehe ich hiernach diejenigen Rechtssetzungen, welche unter empirisch bedingten Verhältnissen das theoretisch richtige Recht enthalten [...]. Der Beweis für die theoretische Richtigkeit eines Rechtssatzes ist dadurch zu liefern, daß kritisch geprüft und entschieden wird, welche Rechtssätze unter gegebenen empirischen Verhältnissen dem allgemeingültigen Endziele des sozialen Lebens entsprechen würden; wonach sich dann ergiebt, ob durch das geschichtlich überlieferte Recht in der betreffenden konkreten Lage der allgemeinen gesetzmäßigen Aufgabe der Rechtsordnung richtig entsprochen werde, oder aber ein Zwiespalt zwischen demjenigen entsteht, was als positives Recht überliefert gilt und dem, was in der genannten Richtung Rechtens sein sollte. (Stammler 1896: 185, H.i.O.)

Stammler bestimmt wie Jhering das Recht aus einer gesellschaftswissenschaftlichen respektive sozialphilosophischen Perspektive: Auch er rückt den Begriff der Gesellschaft, das soziale Leben, ins Zentrum und fragt ex- 
plizit danach, was „das feste Merkmal [ist], durch das der Begriff des sozialen Lebens der Menschen als eigener Gegenstand wissenschaftlicher Betrachtung konstituiert wird“ (ebd.: 83). ${ }^{343}$ Denn nur wenn die Gesellschaft ein fest umrissenes Objekt sei, könne sie als Fundament einer eigenständigen Soziallehre respektive Gesellschaftswissenschaft dienen (ebd.). Und nur dann ist nach Stammler die sozialphilosophische Bestimmung des Rechts möglich. Wie Jhering erkennt auch Stammler die Besonderheit des sozialen Phänomens ,Recht ${ }^{`}$ im Zweck. Allerdings bestimmt Stammler den Zweck als ein rein normatives Phänomen, das nicht empirisch herleitbar ist. Aufgrund dieser Umdeutung ist für ihn die kritische Auseinandersetzung mit der gesellschaftsfunktional fundierten Zwecklehre des Rechts bei Jhering notwendig. ${ }^{344}$

Auch für den Rickert-Schüler Emil Lask, der dem süddeutschen Neukantianismus zuzurechnen ist, ist eine Auseinandersetzung mit Jhering unabdingbar. Lask sucht in seiner v.a. in den Rechtswissenschaften vielbeachteten Abhandlung Rechtsphilosophie aus dem Jahr 1905 direkten Anschluss an die kritische Wertlehre seines Lehrers Rickert, um eine metaphysikfreie Rechtsphilosophie zu entwerfen (vgl. Lask 1905: 2). ${ }^{345}$ Dabei gilt sein Angriff sowohl dem Naturrecht als auch dem Historismus (namentlich der Historischen Rechtsschule); sie seien „die beiden Klippen, vor denen die Rechtsphilosophie sich hüten muss" (ebd.: 13). Was er Naturrecht und Historismus nämlich vorwirft, ist die Vermischung von Wert- und Wirklichkeitssphäre: „Das Naturrecht will aus der Absolutheit des Wertes das empirische Substrat, der Historismus aus dem empirischen Substrat die Absolutheit des Wertes hervorzaubern." (Ebd.) Weder lasse sich aus den durch metaphysische Spekulationen gewonnenen Rechtswerten eine Rechtswirklichkeit in Form einer empirischen Geltung ableiten, noch

343 Seine Antwort lautet: „Soziales Leben ist äußerlich geregeltes Zusammenleben von Menschen.“ (Stammler 1896: 90, H.i.O.) Daher ist das Recht zentral.

344 Stammler bleibt in der Folge nicht bei der sozialphilosophischen Bestimmung des Rechts stehen, sondern sieht die Aufgabe der Rechtsphilosophie zunehmend in der Bestimmung des „richtigen Rechts“ als logisch bedingende Form des positiv gesetzten Rechts (Stammler 1902). Auch in diesen Arbeiten setzt er sich immer wieder mit Jhering auseinander, wobei er an seiner grundlegenden Kritik festhält (vgl. etwa Stammler 1902; Stammler 1922). Diese schrittweise Erweiterung des sozialphilosophischen Grundgedankens über eine Theorie der rechtswissenschaftlichen Arbeit hin zu einer „reinen Rechtslehre“ (vgl. Stammler 1911) zeige sich auch - wie Claudius Müller darlegt - in den unterschiedlichen Ausgaben von Wirtschaft und Recht (Müller 1994: 142).

$345 \mathrm{Zu}$ Rezeption und Kritikpunkten an Lasks Rechtsphilosophie vgl. Friedrich 2002. 
könne man aus der Empirie, d.h. aus der geschichtlichen Wirklichkeit, Wertmaßstäbe gewinnen. Die Berücksichtigung der Kulturbedeutungen, d.h. der Empirie, dürfe nicht als „direkte Wertbeurteilung“ aufgefasst werden, „sondern lediglich als rein theoretische Wertbeziehung, also als Mittel der bloßen Wirklichkeitsumformung" (ebd.: 11).

Lask entwirft in Anlehnung an Rickert ein kulturwissenschaftliches Modell einer empirischen Wirklichkeit, die über Wertbeziehungen mit den Werten verbunden ist - respektive von Wert und empirischen Wertsubstrat. ${ }^{346}$ Daraus folgt eine grundlegende Zweidimensionalität der Perspektiven in den Kulturwissenschaften: Es sei streng zwischen der Betrachtungsweise dieser empirischen Wirklichkeit als empirisches Wertsubstrat, als Sein, und den überempirischen Werten als Sein-Sollendes zu scheiden (ebd.: 2f.). Dieser an Kant angelehnte methodische Dualismus gelte im Besonderen auch für das Recht. Man müsse ihn „mit Fug das ABC der juristischen Methodologie" nennen. Besonders mit Bezug auf Jellinek schreibt Lask:

Der rechtswissenschaftliche Methodendualismus beruht darauf, daß das Recht entweder als realer Kulturfaktor, als sozialer Lebensvorgang angesehen oder als Komplex von Bedeutungen, genauer von Normbedeutungen auf seinen "dogmatischen Gehalt" hin geprüft werden kann. (Ebd.: 31)

Lask rekurriert auf Jhering als Vorläufer der sozialtheoretischen bzw. empirisch-soziologischen Bestimmung des Rechts, der jedoch noch die sozialtheoretische mit der philosophischen Betrachtungsweise des Rechts vermischt habe.

Nur die letztere Betrachtungsweise ist für Lask von Bedeutung. Die Rechtsphilosophie ergibt für ihn nur als „Werttypuslehre“ einen Sinn, d.h. als systematische Wertwissenschaft, die die Rechtswerte als Wertgesamtheiten einer Mehrheit von Wirklichkeitsinhalten systematisch gliedert (ebd.: 4, 9). Daher sind die Bedeutungszusammenhänge, der „ideale Kosmos“, den sie untersucht, und die Wirklichkeit disparat (vgl. ebd.: 3, 9). ${ }^{347}$ In den Vordergrund rückt damit die Frage nach dem Verhältnis von Werttypus

346 Unter erkenntnistheoretischen Gesichtspunkten stellt sich die Wirklichkeit bei Lask als ein empirisches Substrat von Werten dar, da sie auch im Bereich der Kultur ein Erzeugnis kategorialer Synthesen ist (vgl. Lask 1905: 28f.)

347 Andererseits zeige auch der Werttypus eine der Wirklichkeit zugewandte Seite, wird letztere doch als sein Substrat angesehen, was sich insbesondere in der Rechtsanwendung, d.h. der Wertverwirklichung, zeige (vgl. ebd.: 10). Letztlich versucht Lask an einer transzendentalen Bestimmung des Rechtswerts trotz not- 
und Empirie, von Recht und gesellschaftlicher Wirklichkeit, die über Wertbeziehungen vermittelt, aber nicht vermengt werden.

Die Rechtswissenschaft im engeren Sinne wiederum bestimmt Lask als eine ,empirische Kulturwissenschaft (ebd.: 27). Dabei weise die Jurisprudenz gegenüber der Philosophie eine Besonderheit auf. Denn während das Sein-Sollende „in der Philosophie einer absoluten Werthaftigkeit entstammt, für die es keine empirische Autorität gibt“", habe es in der Jurisprudenz immer einen empirischen Bezug: Es habe „seinen formellen Grund in positiver Anordnung durch Gemeinschaftswillen" (Lask 1905: 34). Recht sei also immer eine empirische Gegebenheit, weshalb „die juristische Wissenschaft nur die ganz unvergleichbare Methode eines rein empirischen Operierens mit einer gedachten Welt von Bedeutungen darstellen" könne (ebd.).

Ihre spezifische Methodologie wiederum ließe sich nur begreifen, wenn man innerhalb der Kulturwissenschaften zwischen historischer und systematischer Tendenz unterscheide:

Die systematisierenden Disziplinen lösen aus der Komplexität des Gegebenen typische Kulturmomente heraus, um sie nicht, wie die Geschichte es tut, in den unvergleichbaren und unzerlegbaren Bedeutsamkeiten des Individuellen wieder verschwinden zu lassen, sondern um sie gerade in ihrer ausdrücklich isolierten formellen Struktur zu Leitbegriffen der einzelnen Kulturdisziplinen zu erheben. (Ebd.: 28) ${ }^{348}$

Rechtswissenschaft sei systematische Wissenschaft, die durch einen spezifischen Formalismus gekennzeichnet sei. Dabei dient Lask Jherings frühere Bestimmung der ,juristischen Technik“ der konstruktiven Jurisprudenz als beste Beschreibung dieser systematisierenden Tätigkeit (vgl. ebd.: $37 f$.). ${ }^{349}$

wendigem und historisch-kontingentem Bezug des jeweiligen Kulturzusammenhang festzuhalten (vgl. ebd.: 4f.). Dabei will er v.a. den „sozialen Werttypus“ als Ausdruck der unhintergehbaren Sozialität des Rechts integrieren (vgl. ebd.: 19, 25f.).

348 Dabei sei sie jedoch nicht mit der naturwissenschaftlichen Abstraktions- und Systematisierungsweise zu verwechseln, die ja gänzlich von Kulturbedeutungen absehe (vgl. Lask 1905: 28).

349 Wenn Lask trotz dieser Bestimmung der Rechtswissenschaften durch den Formalismus die „mit Recht verspottete[] ,Begriffsjurisprudenz““ kritisiert (ebd.: 45), dann kreidet er den vermeintlichen Bezug dieser Begriffsarbeit zum Leben an, jene Prämisse im Repräsentationsgedanken, dass man über die dogmatische Arbeit am Begriff zum Leben vordringen könne. Aufgrund der Trennung von Begriff und Wirklichkeit erweist sich das aber für Lask als Irrglaube. 
Lask rekurriert noch an weiteren entscheidenden Stellen auf Jhering, und hier nun auf den Zweck: Die Besonderheit der juristischen Methode liege in ihrer Form der ,vorwissenschaftlichen“ Begriffsbildung:

Es gibt - wenn man von der Wissenschaft selbst absieht - keine Kulturerscheinung, die sich als begriffsbildender Faktor auch nur annähernd mit dem Recht vergleichen ließe. Das Recht selbst nimmt bereits eine weitgehende Auseinandersetzung zwischen sich und der außerrechtlichen Wirklichkeit vor und bildet Begriffe von so hoher technischer Vollendung, daß sie sich oft nur dem Grade nach von denen der Wissenschaft unterscheiden und der wissenschaftlichen Bearbeitung zuweilen nichts anderes als die bloße Fortsetzung des vom Gesetz begonnenen Formungsprozesses übrig lassen. (Ebd.: 35)

Diese Begriffsbildung erfolge - wie bei Rickert - unter dem Gesichtspunkt der Teleologie: Der „Zweck des Rechts“ müsse „als Prinzip der im juristischen Sinne ,wesentlichen“ Begriffsmerkmale bezeichnet" werden (ebd.: 35f.). Lask geht also von einer ,teleologische[n] Färbung sämtlicher Rechtsbegriffe" (ebd.: 40) aus, und es ist gerade Jherings Zweckgedanke, auf den er in der Bestimmung des Rechts rekurriert. ${ }^{350}$ Das spezifisch juristische Verhalten zur Wirklichkeit zeige sich dann in zwei einander durchdringenden Aspekten: „Die von Zweckbeziehungen geleitete Umsetzung des realen Substrats in eine Gedankenwelt reiner Bedeutungen und die damit verbundene Herausfaserung bloßer Teilinhalte aus der Totalität des Erlebbaren.“ (Ebd.: 36f.) Gerade in der Entwicklung der wert- und zweckbeziehenden Methode angesichts dieses teleologischen Prinzips sieht Lask für die Jurisprudenz die methodologische Aufgabe der Zukunft. 351

350 So ist z.B. weder der juristische Begriff der Sache mit dem Körper, noch der der Person mit dem Menschen identisch. Es handelt sich um teleologische Begriffskonstruktionen (ebd.: 36ff.).

351 Denn für Lask gilt: „Häufig wird übersehen, daß die den juristisch geformten Stoff zu höheren systematischen Bildungen fortgestaltenden Operationen in ähnlicher, nur noch verwickelterer Weise von dem teleologischen Grundcharakter des Rechts durchherrscht werden wie die ursprünglichen, dem vorrechtlichen Substrat gegenüber betätigten juristischen Bearbeitungsfunktionen." (Ebd.: 46). 


\section{Der rechtsphilosophische Zweck}

In der rechtsphilosophischen Rezeption markiert Jherings Zweckdenken einen Bruch bzw. Übergang - sei es auf dem Weg zu einem rechtspositivistischen Verständnis, sei es als Ausdruck der gegenwärtigen Wohlfahrts-Sozialtheorie, sei es als Beginn der empirischen Jurisprudenz oder sei es als Beispiel einer neuen Logik der Erkenntnis- und Wissenschaftstheorie, die die Rechtswissenschaft nicht unberührt lassen kann. All diese Rezeptionen problematisieren in der Hinwendung zum Zweckmoment das Spannungsverhältnis von Empirie und Recht. Der Zweck zeichnet dabei zwar einerseits den Weg in die Empirie vor: So gilt Recht als eine empirische Setzung (Bergbohm), es offenbart sich über empirische Rechtsvergleichung (Berolzheimer), es ist als Form des sozialen Lebens an den "Stoff“ gebunden (Stammler), ja die Rechtswissenschaft ist eine „empirische Kulturwissenschaft" (Lask). Andererseits eint die verschiedenen Positionen trotz dieses Bezugs zur Empirie die Ablehnung einer explizit gesellschaftstheoretischen Auseinandersetzung mit dem Recht. ${ }^{352}$ Wenn Jherings Perspektivverschiebung im Zweck produktiv als Vorlage oder als Abgrenzungshorizont für den Entwurf eines eigenen Ansatzes verwendet wird, wird er seiner gesellschaftstheoretischen Implikationen entkleidet. Dies geschieht entweder durch die Idealisierung der Kultur, die im Recht ihren Ausdruck findet und daher das Recht nicht als bloßes soziales Teilphänomen ansehen kann (Berolzheimer), durch die Abtrennung und Reinigung der Rechtsform von den Fragen der Rechtsentstehung als soziales Phänomen (Bergbohm) oder durch die Abspaltung des rechtsphilosophisch relevanten teleologischen Moments von gesellschaftstheoretischen Bestimmungen (Lask). Und selbst Stammler, der seine Rechtsphilosophie als Sozialphilosophie ausformuliert und daher die Gesellschaft in den Mittelpunkt rückt, stellt zwar die teleologische Bestimmung unter den Vorbehalt der Abhängigkeit von der Gesetzmäßigkeit des sozialen Lebens, scheidet aber auf erkenntnistheoretischer Ebene die teleologische von der empirisch-kausalen Betrachtungsweise. Das Proprium des Rechts (Kulturerscheinung, Setzung oder Telos) wird gegenüber einer empirisch-kausal, historisch oder funktional orien-

352 Allerdings deutet Lask an, dass es gerade diese gesellschaftstheoretische Ebene ist, namentlich in Form der Soziologie, die Aufschluss über die Position der Rechtswissenschaft als Kulturwissenschaft zu erbringen vermag - wobei dieses Unterfangen jedoch in die Zukunft verlagert wird; dabei betont er die Zentralität des Sozialen, ohne sich jedoch näher damit zu beschäftigen (vgl. etwa Lask 1905: 30, 44f.). 
tierten Sozial- bzw. Gesellschaftswissenschaft bestimmt. Die Auseinandersetzung mit Jherings Zweck dient genau dieser Problementfaltung.

\section{Die Ablehnung des Zwecks im Fachdiskurs der Privatrechtswissenschaften}

Von seinen eigentlichen Fachkollegen, den Privatrechtswissenschaftlern, kommen wenige direkte Reaktionen auf den Zweck - und wenn ja, dann sind sie überwiegend äußerst ablehnend. Der Zweck sei ein „schwaches Werk" (Mitteis 1905: 658), urteilt etwa der Rechtshistoriker und Romanist Ludwig Mitteis: Bei der Philosophie sei Jhering „nur Gast“ (ebd.) gewesen, und wolle man das Buch als ein soziologisches gelten lassen, so falle der Vergleich „etwas beschämend“ aus: „Zweihundert Jahre früher würde sich Jhering's teleologisches System beträchtlich stärker herausgehoben haben als es zur Zeit von Herbert Spencer einer- und Karl Marx andererseits noch der Fall sein konnte" (ebd.). ${ }^{353}$ Angesichts der Erkenntnisse der Nationalökonomie gilt hinsichtlich des ersten Bandes des Zwecks für den Romanisten Johannes Emil Kuntze: ,Jhering war hier [...] auf einen Boden gerathen, wo er nicht heimisch war und nicht zu lehren, sondern zu lernen hatte." (Kuntze 1892: 614) Am deutlichsten wird nach der Jahrhundertwende jedoch der neuhegelianische Rechtswissenschaftler Joseph Kohler: Ein solcher gänzlich „unphilosophische[r] Kopf“ (Kohler 1909: 16) wie Jhering gebe nur "dilettantische Plattheiten“ (Kohler 1917: 46) von sich, die man allenfalls als die „Metaphysik eines friesischen Landpastors“ (Kohler 1904: 12) bezeichnen könne. ${ }^{354}$ Jhering tische "triviale Wahrheiten als Neues und Unerhörtes“ mit einer „Breite und Behaglichkeit“ auf, „wie es die Art des Dilettanten ist“ (Kuntze 1892: 614; s. a. Eck 1893: 37; Landsberg 1892: 3). 355 Während die Philosophen vom Fach Jhering Anerkennung zollen, kanzeln ihn seine eigentlichen Fachkollegen zumeist als philosophisch unzulänglich ab. 356

353 So auch später Schelsky, dem gegenüber dem „imponierenden und komlexen, in reflektierter Begrifflichkeit errichteten Theoriegebäude von Marx [...] Jherings Ansätze zu sozialwissenschaftlichen Theorien naiv und fast begriffslos" erscheinen (Schelsky 1972: 53).

354 Die genau gegenteilige Ansicht vertritt der Romanist Rudolf Leonhard: Der Zweck habe Jhering "die philosophische Doktorwürde verschafft" (Leonhard 1893: 607).

355 Allerdings gesteht Kuntze Jhering ein großes Verdienst an der Überwindung der philologischen Enge der Historischen Rechtsschule zu (Kuntze 1892: 617f.).

356 Diese Diskrepanz in der Rezeption bleibt nicht verborgen: „Bemerkt mag noch werden, daß es vornehmlich Juristen sind, welche sich zu Beschützern der Philo- 
Die Unzulänglichkeiten wirkten sich auf den Zweck direkt aus: Das Werk sei systemlos und kranke an Einseitigkeiten (Landsberg 1892: 3). Es basiere auf falschen, willkürlich postulierten Annahmen und sei in sich logisch widersprüchlich. Selbst in der einzelnen Begriffsbildung widerspreche Jhering sich ständig, und zudem führe die einseitige Konzentration auf den Zweck aus dem Gebiet des Rechts hinaus (vgl. etwa Thon 1878: VIII; Hölder 1892: 221; Eck 1893: 33ff.; Kühnast 1880a, 1880b; Sommer 1884, 1885; Kuntze 1890).357

Überhaupt scheint Jhering mit dem Zweck für prominente Vertreter des Faches nichts Neues entdeckt zu haben: Bernhard Windscheid, einer der führenden Pandektisten, ${ }^{358}$ betont wie sein österreichischer Kollege Ludwig Mitteis „die mangelnde Originalität des teleologischen Grundgedankens" (Mitteis 1905: 658):

Alles Recht verfolgt Zwecke; jeder Rechtssatz ist nur deswegen da, um menschliche Interessen und Bedürfnisse, wie er sie auffaßt, zu befriedigen. Das ist keine neue Entdeckung, ebensowenig wie es eine neue Entdeckung ist, daß bei der Ergründung des wahren Sinnes eines Rechtssatzes vorzugsweise auf dessen Zweck Rücksicht genommen werden muß. (Windscheid 1889, zitiert nach Dove 1893: 153) 359

Auch dass es sich bei der Rechtswissenschaft um eine „praktische Wissenschaft" handelt, steht für Windscheid außer Frage (Windscheid 1904: 108). Schließlich erkennt auch Windscheid - seit 1874 Mitglied der ersten Kommission zur Vorbereitung des BGBs (s.u.) - den zentralen Stellenwert der Gesetzgebung an: „Die Gesetzgebung steht auf hoher Warte; sie beruht in zahlreichen Fällen auf ethischen, politischen, volkswirtschaftlichen Erwägungen oder auf einer Kombination dieser Erwägungen“. Diese Selbstverständlichkeiten ändern für Windscheid aber nichts an der Arbeitsweise der Rechtswissenschaft, der verschmähten „Begriffsjurisprudenz“, die sich

sophie gegen Jherings angebliche Uebergriffe und des Jheringschen Ruhmes gegen seine angeblichen Mißgriffe berufen fühlten; die Philosophen vom Fach hatten dagegen in der Regel von seinem Schaffen eine bessere Meinung.“ (Leonhard 1893: 608).

357 Auch der Kampf erfuhr schon ähnlich fundamentale Kritiken, vgl. etwa Boas 1876; Kohler 1883.

$358 \mathrm{Zu}$ Windscheid siehe insbesondere Falk 1989.

359 Dabei gehört die Ermittlung des Zwecks - wie Windscheid in seinem Pandektenlehrbuch darlegt - zu den Hilfsmitteln der Auslegung (Windscheid 1870: 52).

Zu Eugen Ehrlichs Kritik an dieser Abwertung des Zweckgedankens s.u. 
schon gar nicht zu einer „Zweckjurisprudenz“ entwickeln müsse. ${ }^{360}$ Denn "deswegen ist es auch nicht weniger wahr, daß alle Wissenschaft des Rechts sich in Begriffen bewegt, ihre Aufgabe keine andere ist, als scharfe Begriffe zu fassen und den Inhalt derselben darzulegen" (Windscheid 1889, zitiert nach Dove 1893: 153). Die Erwägungen der Gesetzgebung seien zwar ehern, aber allesamt "nicht Sache des Juristen als solchen“ (Windscheid 1904: 112).

Selbst diejenigen Privatrechtswissenschaftler, die Jherings Zweck nicht grundlegend ablehnen, sind skeptisch (vgl. etwa Leonhard 1893; Merkel 1893). Positiv hervorgehoben wird v.a. der Gegenwartsbezug: die notwendige Anbindung an das Leben, an die gegenwärtigen Bedürfnisse des Verkehrs und die sozialen Verhältnisse, die Jherings Ansatz gewährleiste. Aber nur ganz am Rande findet Jherings Intervention auf der Ebene der Theorie der Gesellschaft eine Erwähnung - und wenn überhaupt, dann wird sie abgelehnt: Hugo Sommer wendet in seiner Kritik des Zwecks ein, dass das „Leben der Gesellschaft“ nur eine „Durchschnittsbildung“, ein Begriff der „Mittelmäßigkeit“ (Sommer 1885: 49) sei - die Gesellschaft könne kein eigenständiges Objekt sein, und schon gar kein „Zwecksubjekt“. Adolf Merkel wiederum glaubt im Zweck eine Gesellschaftstheorie zu erkennen, die die Gesellschaft als Summe der Teile beschreibt. Er moniert, dass - um den eigenständigen Charakter zu gewährleisten - hier nur der organische Gattungsbegriff richtig wäre, was Jhering aber wieder in die Nähe der organischen Theorien der bekämpften Romanisten brächte (vgl. Merkel 1893: 36). Mit seiner gesellschaftstheoretischen Fundierung vermag Jhering also nicht zu überzeugen.

Während der Zweck seit den 1880er und -90er Jahren außerhalb der Rechtswissenschaft eine breite Rezeption erfährt, zum unerlässlichen Bezugspunkt der rechtsphilosophischen Auseinandersetzung wird und mit großen Erfolg in die Staatswissenschaften und das Öffentliche Recht sowie ins Strafrecht diffundiert, ${ }^{361}$ lehnen ihn die Privatrechtswissenschaftler mit

360 So ist dem Pandektisten Immanuel Bekker auch gar nicht klar, was Jhering mit seinem Angriff gegen die Begriffsjurisprudenz genau im Visier habe, gelte doch sein „Feldzug durchaus nicht den Begriffen, deren sorgsamer Pflege und scharfer Begrenzung“ (Bekker 1892: 123). Denn genau dieses Anliegen verwirkliche Jhering in seinen Arbeiten ja beständig selbst (ebd.).

361 Die verschiedenen Gebiete, in denen Jherings Zweck einen Widerhall findet, überschneiden sich zum Teil wieder, was das Zweckdenken im Diskurs bestärkt. So wird beispielsweise Lasks Rechtsphilosophie, der wiederum stark auf Jellinek rekurriert, grundlegend für die neukantianische teleologische Richtung in den Strafrechtswissenschaften (Honig, Hegler, Grünhut, Schwinge, Zimmerl, Radbruch, Erik Wolf; vgl. Baratta 1970: 21). 
seinen Angriffen gegen die Historische Schule und die daraus hergeleitete „Begriffsjurisprudenz“ ganz überwiegend ab. Für sie erscheinen Jherings Äußerungen über den Zweck im Recht wenig anschlussfähig - und eine Rezeption erfolgt erst über die Problematisierung von Gesetzgebung und juristischer Methode. 


\section{\4. Zweck-Dispositiv I: Die soziale Aufgabe des Privatrechts und das gesellschaftsfunktionale Zweckdispositiv (ca. 1880er-1900)}

Die Ablehnung von Jherings Zweckdenken in den Privatrechtswissenschaften Ende des 19. Jahrhunderts erstaunt aus einem ganz bestimmten Grund. Denn Jhering schreibt sich mit seinen Perspektivverschiebungen in einen juristischen Diskurs ein, der sich schon aufgrund seiner real-politischen Entwicklungen für funktional-gesellschaftliche Fragen öffnet. Gemeint ist die Debatte um das Bürgerliche Gesetzbuch (BGB) und seine Entwürfe, die, obwohl sie ein genuin gesetzespolitisches Vorhaben betrifft, ihre Spuren auch in den Privatrechtswissenschaften hinterlässt. Hier sind Verschiebungen hin zu einer funktionalistischen Gesellschaftsorientierung im Recht zu erkennen, die auch Jhering im Zweck vollzogen hat. ${ }^{362}$

\section{L'urgence: Die zu bewältigende Kodifikation des Privatrechts}

Die Veröffentlichung des ersten Entwurfs des BGBs als Gesamtkodifikation für das Deutsche Reich im Frühjahr 1888 bildet eine Zäsur in den Privatrechtswissenschaften. Für alle sichtbar wird ein Wechsel der wichtigsten Textgrundlagen für das Privatrecht eingeleitet. Corpus iuris civilis und

362 Jhering selbst schaltet sich in die Debatte nur in geringem Maße ein. Lediglich in seinem Spätwerk Der Besitzwille aus dem Jahre 1889 nützt er das Nachwort, um seine abwertende Position zum Entwurf des BGBs darzustellen: Er wirft diesem „Künstelei“, „Nominalismus“ und „Transcendentaljurisprudenz“ (Jhering 1889: 475, 502, 515) vor; er sei das Ergebnis einer der Rechtslogik verhafteten, formalistischen „Begriffsjurisprudenz“ (ebd.: 501), die „der praktischen Realität entbehre" und daher Folgen zeitige, die "den praktischen Anforderungen Hohn" sprächen (ebd.: 474, 490). Allerdings relativiert er diese Kritik, indem er sie nicht mit Blick auf den generellen Charakter des Entwurfs entwickelt, sondern allein auf die vorgeschlagenen Besitzregelungen. Zum anderen betont er die politische Notwendigkeit der baldigen Kodifikation, die es rechtfertige, gewisse Kritikpunkte außen vor zu lassen (vgl. ebd.: 534). 
partikulare Gesetzbücher werden nur noch für eine kurze Zeit das geltende Recht direkt bestimmen (vgl. Repgen 2001: 32f.). ${ }^{363}$

\section{Eine kurze Geschichte der Kodifikation des BGBs}

Im Zuge der Gründung des Deutschen Reichs im Jahr 1871 treibt die Reichsgesetzgebung die Rechtsvereinheitlichung voran. Gerade im Bereich des Zivilrechts existieren zu dieser Zeit nach wie vor noch erhebliche territoriale Unterschiede. Nur in Teilbereichen des Privatrechts besteht eine einheitliche Gesetzgebung (z.B. Handelsrecht, ADWO). ${ }^{364}$ Allerdings stößt die Rechtsvereinheitlichung zunächst an Grenzen: Gem. Art. 4 Ziff. 13 der Verfassung des Reiches von 1871 ist die Gesetzgebungskompetenz seitens des Bundes nur für das Schuldrecht gegeben. ${ }^{365}$ Insbesondere die Nationalliberale Partei ist von Anfang an an der Gesamtkodifikation interessiert. Die Anträge der nationalliberalen Abgeordneten Eduard Lasker und Johannes Miquel auf eine entsprechende Verfassungsänderung scheitern jedoch zunächst mehrfach (zu den Gründen vgl. Schubert 1978: 28f.). ${ }^{366} \mathrm{Im}$ Jahre 1873 wird schließlich mit großer Mehrheit das Lex Lasker erlassen, das die Erweiterung der Bundeszuständigkeit für das gesamte bürgerliche Recht in die Verfassung aufnimmt.

Im Februar 1874 wird zunächst eine Vorkommission aus fünf Juristen gegründet. Sie wird beauftragt, „über Plan und Methode, nach welchen bei Aufstellung des Entwurfs eines deutschen bürgerlichen Gesetzbuches zu verfahren sei, gutachtliche Vorschläge zu machen“" (BR-DR Nr. 78 v. 9.6.1874, zitiert nach Benöhr 1977: 80). Bereits nach sechs Wochen über-

363 Zum zeitgenössischen Bewusstsein über diesen Wendepunkt durch das BGB vgl. Leonhard 1900a; Landsberg 1913; zur zeitgenössischen Debatte um die Problematik, welche Auswirkungen die Entziehung der herkömmlichen Textgrundlagen für die Rechtswissenschaft habe, vgl. die Literaturhinweise bei Maas 1899: 72f. Mit Blick auf die Entwicklung der Rechtsprechung wird heutzutage allerdings bezweifelt, dass es sich tatsächlich um einen Wendepunkt handelte (vgl. Zimmermann 2001: 6f.).

$364 \mathrm{Zu}$ den Debatten über eine Rechtsvereinheitlichung durch Gesamtkodifikation zwischen 1815 und 1866 vgl. Schöler 2004: $132 \mathrm{ff}$.

365 Zur Entstehungsgeschichte des BGBs vgl. insbesondere Vierhaus 1888; Sohm 1900; Schubert 1966, 1978, jeweils m.w.N.

366 Die Gegner der Gesamtkodifikation machen unter anderem auch das alte Motiv der Historischen Rechtsschule geltend, dass aufgrund des Zusammenhangs des Rechts mit dem Volksleben ein solches Gesetz nicht künstlich geschaffen werden könne (vgl. Vierhaus 1888: 38). 
reicht sie das angeforderte Gutachten, dessen Vorschlägen - mit einigen Ergänzungen des Justizausschusses - der Bundesrat zustimmt. ${ }^{367}$ Im Juli 1874 wird eine Kommission - die sogenannte erste Kommission - eingesetzt. Elf Juristen - neun Ministerialbeamte und Richter sowie zwei Professoren des Rechts (der Romanist Bernhard Windscheid sowie der Germanist Paul von Roth) - sollen nun unter dem Vorsitz des Präsidenten des Reichsoberhandelsgerichts Pape einen Entwurf für das BGB erstellen. ${ }^{368}$ Die Ausarbeitung der einzelnen Teile („Bücher“) des BGBs wird Redaktoren übertragen, deren Teilentwürfe ab 1881 als Grundlage der Diskussion der Kommission dienen. ${ }^{369}$ Die Arbeit am ersten Entwurf des BGBs dauert mehr als 13 Jahre. Am 12. Januar 1888 kommt er vor den Bundesrat, der ihn zugleich dem Justizausschuss überweist.

Auf Anraten des Justizausschusses beschließt der Bundesrat, den Entwurf des BGBs nebst den fünfbändigen - allerdings von der ersten Kommission niemals genehmigten - Motiven zu veröffentlichen (vgl. Motive zu dem Entwurfe 1888a). ${ }^{370}$ Schon bald nach der Veröffentlichung im Jahre 1888 setzt „mit der Plötzlichkeit und Heftigkeit eines Wolkenbruchs“

367 Allerdings liefern die Vorschläge des Gutachtens nach dem Willen des Bundesrates für die einzusetzende Kommission nur Anhaltspunkte und keine Bindung (vgl. Schubert 1966: 114). Das Gutachten verfasste übrigens der Handelsrechtler Levin Goldschmidt, bei dem später Max Weber promovierte.

368 Die Auswahl erfolgt aus politischen und sachlichen Gründen (vgl. Schubert 1978: 36ff.). Zu letzteren zählt der Anspruch, in den Personen der Kommissionsmitglieder die verschiedenen geltenden Rechtsgrundlagen zu repräsentieren. Da die Kommissionsmitglieder Windscheid und Planck, aber auch Gebhard und Karl von Mandry, Nachfolger des 1884 verstorbenen von Kübels, zu den Romanisten zu zählen sind, wird - neben des Einflusses Windscheids - von einer Übermacht der Romanisten in der Kommission ausgegangen. Dies zeigt sich auch in der Kritik am Entwurf (s.u. II.2).

369 Vgl. hierzu Schubert 1981-1986.

370 Bereits die Vorkommission hatte eine solche Empfehlung ausgesprochen (vgl. Rassow 1877: 188, 193). Bei den Motiven handelt es sich trotz ihres Untertitel „Amtliche Ausgabe“ um eine nicht-amtliche Zusammenfassung, da sie nicht von der Kommission geprüft und gebilligt wurden, sondern vielmehr eine Zusammenfassung der Motive der Kommission durch Hilfsarbeiter der Redaktoren darstellen. Daher wird ihr Aussagewert mithin sehr skeptisch beurteilt, auch schon zur damaligen Zeit (vgl. die Literaturhinweise bei Schubert 1966: 35; Repgen 2001: 10f.). Trotz dieser Kritik übten sie jedoch einen nicht unerheblichen Einfluss auf die Praxis und, wie Werner Schubert anmerkt, ,in geringerem Maße auch auf die Wissenschaft" aus (Schubert 1966: 35). Außerdem nimmt die kritische Literatur zum ersten Entwurf in großem Umfang auf die Motive Bezug, so dass sie insofern für die Auseinandersetzung um das BGB und seine Entwürfe von großer Bedeutung sind. 
(Laband 1906: Sp. 3) 371 eine unerwartet leidenschaftliche und breitgefächerte Debatte ein - mit Beiträgen nicht nur in den Fachjournalen, sondern weit darüber hinaus bis hin zur Tagespresse (Hattenhauer 2004); sie stammen nicht nur von Juristen, sondern auch von berufsständisch organisierten Interessensverbänden, den Parteien und zahlreichen weiteren Vereinigungen (vgl. Schubert 1966: S. 35f.). ${ }^{372}$ Allein die durch den damaligen Bibliothekar des Reichsgerichts erstellte Bibliographie für den Zeitraum von 1888 bis 1898 enthält über 5.000 Titel zum Entwurf und zum BGB (Maas 1899). ${ }^{373}$

Die heftige Kritik am ersten Entwurf, insbesondere an seiner „unsozialen Tendenz" (s. $\$ 4 . I I)$, führt im Jahre 1890 zur Einsetzung einer zweiten Kommission, die diesen überarbeiten soll (vgl. hierzu Schubert 1966: 50ff.; Schulte-Nölke 1995: 282ff.). Zu den 25 Mitgliedern in der zweiten Kommission zählen nicht nur Vertreter des in seinem Einfluss gestärkten Reichsjustizamts sowie der Bundesregierung und der Rechtswissenschaft, sondern auch solche der großen Parteien (mit Ausnahme der Sozialdemokraten), der Großagrarier, des Handels, der christlichen Konfessionen und des Judentums sowie der Nationalökonomie (vgl. Haferkamp 2009a: 230).374 Zum Generalreferenten wird Gottlieb Planck ernannt, Redaktor für das Familienrecht im ersten Entwurf. Am 22. Oktober 1895 erhält der Reichskanzler den zweiten, umgearbeiteten Entwurf. Dieser findet in der Öffentlichkeit - trotz begleitender öffentlicher Berichterstattung über die Arbeit der Kommission - weit weniger Beachtung als der erste. ${ }^{375}$ Nach einigen Änderungen durch den Justizausschuss passiert der Entwurf einstim-

371 Dagegen interessierten sich während der Vorbereitung des Entwurfs nur sehr wenige Rechtswissenschaftler für das Kodifikationsvorhaben (vgl. Landau 1999), auch wenn es an die Grundlagen des Fachs rührte.

$372 \mathrm{Zu}$ den Forderungen der bürgerlichen Frauenbewegung vgl. Riedel 2008; zu den Berufsständen vgl. Bähr 1972; zu den Parteien vgl. Brandt 1975 bzw. zur Sozialdemokratie Vormbaum 1997.

373 Diese Bibliographie wurde weitergeführt (vgl. hierzu Repgen 2001: 33 Fn. 42). Weitere Überblicke aus jener Zeit bieten etwa auch Reichsjustizamt 1967c [1890-1891]; O. Bähr 1888c, 1890; Neumann 1888, 1889a, 1889b; Sohm 1895; Petersen 1890; Ring 1888 - sie sind allesamt damit beschäftigt, die Literaturflut zu gliedern.

374 Gustav Schmoller lehnte die Teilnahme an der Kommissionsarbeit ab, die Berufung Gierkes an dessen Stelle war heftig umstritten und scheiterte insbesondere am Widerstand Bayerns. Stattdessen einigte man sich auf den Nationalökonom Johannes Conrad (Schubert 1978: 56).

375 Zur Einschätzung, dass das BGB - insbesondere nach der Abänderung im zweiten Entwurf (vgl. etwa Ennercerus 1896; Sohm 1895, 1900; kritisch Landsberg 1894/95) - seiner sozialen Aufgabe gerecht werde, vgl. die Literaturnachweise 
mig den Bundesrat und wird nach mehrfacher Lesung und Debatte per Mehrheitsentscheidung des Reichstags im Juli 1896 verabschiedet. ${ }^{376}$ Am 1. Januar 1900 - 27 Jahre nach der Begründung der Bundeskompetenz zur Gesamtkodifikation des Privatrechts - tritt das BGB in Kraft. 377

\section{Kodifikation als Bestandsaufnabme}

Die Aufgabe der Gesamtkodifikation sah man seinerzeit nicht als eine genuin politische Aufgabe an. Schon die Vorkommission bestimmt sie nämlich primär in der Bestandsaufnahme der bestehenden Rechtslage:

Der Entwurf soll unter Berücksichtigung der geltenden Gesetzbücher und der von den Einzelstaaten sowie im Auftrage des ehemaligen Deutschen Bundes über einzelne Rechtstheile ausgearbeiteten Gesetzesentwürfe, das den Gesammtzuständen des Deutschen Reichs entsprechende bürgerliche Recht in einer den Anforderungen der heutigen Wissenschaft gemäßen Form kodifizirend zusammenfassen. (Gutachten der Vorkommission 1978 [1874]: 182, H.i.O. ${ }^{378}$

Die Vorkommission empfiehlt aufgrund der zu bewältigenden Aufgaben, „daß an den bewährten gemeinschaftlichen Institutionen und Sätzen der innerhalb des Deutschen Reiches bestehenden Civilrechts-Systeme festgehalten“ werde (ebd.). Etwaige Neuerungen sollen nur bei „Divergenzen“ eingeführt werden, wobei die „Entscheidung in erster Linie nach Rücksicht des Bedürfnisses und der Zweckmäßigkeit, in zweiter Linie nach juristisch-logischer Folgerichtigkeit getroffen“ werden solle - jedoch immer

bei Repgen 2001: 511ff. Selbst so fundamentale Kritiker des BGBs und seiner Entwürfe wie Anton Menger und Otto von Gierke (s.u.) gestehen dem zweiten Entwurf zu, dass er sich stärker an der sozialen Realität und an den Problemen der Zeit orientiert habe, so dass man im Hinblick auf die Integration sozialpolitischer respektive sozialer Ideen manche Verbesserungen erkennen könne (Menger 1905: 30; Gierke 1896: 6; s.a. Pfizer 1891: 2).

376 Nur die Sozialdemokraten stimmten geschlossen gegen den Entwurf, vgl. hierzu Vormbaum 1997. Zu den problematischen Diskussionspunkten wie Vereinsrecht, Frauenrechte und Wildschadensregulierung vgl. Schlosser 1997: 16ff.

$377 \mathrm{Zu}$ den ambivalenten Reaktionen auf das Inkrafttreten des BGBs vgl. Schlosser 1997: 7ff. m.N.

378 Das Gutachten ist wiederholt abgedruckt worden, hier wird aus den Materialen zur Entstehungsgeschichte des BGB zitiert (Gutachten der Vorkommission 1978 [1874]). Vgl. zum Gutachten der Vorkommission insbesondere Benöhr 1977. 
„mit schonender Rücksicht auf das überlieferte Recht und eigenthümliche örtliche Verhältnisse“" (ebd.).

Der Ausschuss des Bundesrates für Justizwesen fasst die Meinung der Vorkommission nochmals dahingehend zusammen, „daß im Wesentlichen das Gegebene zu kodifiziren sei“ (zitiert nach Rassow 1877: 201). Die Vorkommission hatte also die Weiche nicht in Richtung einer Setzung neuen Rechts gestellt, und der Bundesrat folgte ihr in dieser Auffassung (Benöhr 1977: 80). Indem die Aufgabe in der Rechtsvereinheitlichung und nicht in der Rechtsschöpfung gesehen wird, erfolgt eine Beschränkung der politischen Aufgabe: Nach Ansicht des Ausschusses des Bundesrates für Justizwesen sei es nicht Sache der legislativen Politik, festzulegen, welche Prinzipien für die einzelnen Rechtsinstitute zur Anwendung zu bringen seien. Diese „größeren prinzipiellen Fragen“, d.h. die Festlegung der normativen Wertmaßstäbe, bleibe der Kommission vorbehalten (ebd.). ${ }^{379}$

Die Vereinheitlichung könne dabei letztlich nur unter dem Gesichtspunkt der Systematisierung erfolgen, d.h. der Herausarbeitung eines Zivilrechtssystems, das die „einheitliche[] systematische[] Beherrschung des Rechtsstoffes" gewährleiste (Gutachten der Vorkommission 1978 [1874]: 175). ${ }^{380}$ Es solle explizit keine Kasuistik darstellen (ebd.). „Man hat es“ wie der Ausschuss des Bundesrates für Justizwesen ergänzend feststellt -

nicht mit bloßen Zusammenstellungen, sondern mit der systematischen Verarbeitung eines ganzen, theils auf Gesetzen, theils auf Gewohnheitsrecht, Wissenschaft und Praxis beruhenden Rechtszustandes zu thun, der in Gesetzesform zu bringen ist (zitiert nach Rassow 1877: 207).

Damit verschiebt sich das gesetzgeberische Problem in Richtung eines wissenschaftlichen Problems. Entsprechend der Vorstellung der Rechtswissenschaft als Wissenschaft der Wirklichkeit wird die Gesetzgebung nicht an normative Vorgaben, sondern an die wissenschaftliche Wahrheit gekoppelt. So zeige sich - wie etwa bei dem zu schaffenden Allgemeinen Teil des

379 Entgegen der weitreichenden Kritik am ersten Entwurf des BGBs im Namen der verfehlten „sozialen Aufgabe“ des Privatrechts (s.u.) zieht die Veröffentlichung des Gutachtens keine Debatte über seine konservative Tendenz nach sich (Benöhr 1977: 81).

380 Damit ist auch die Entscheidung für die Einführung eines allgemeinen Teils getroffen, der die „wichtigsten allgemeinen Lehren“ und „allgemeine Rechtsprinzipien" enthalten soll (vgl. Gutachten der Vorkommission 1978 [1874]: 179). Zur Prinzipienorientierung des BGBs durch technische Behandlung des Stoffs vgl. Rückert 2003: 42 ff. [Rn. 16ff.]. 
BGBs - dass „die Abstraktion der allgemeineren Rechtsbegriffe und Rechtswahrheiten aus dem Besonderen [...] nicht Sache des Gesetzgebers, sondern der Theorie“ sei (ebd.: 205).

Die Aufgabe der Kodifikation eines einheitlichen BGBs wird also nicht primär als politisches Projekt angesehen. Es wird vielmehr als eine - entsprechend des Gedankens der Rechtsvereinheitlichung, nicht Rechtsschaffung - wissenschaftlich-systematisierende Aufgabe festgelegt. ${ }^{381}$ Trotz der damit verbundenen Orientierung am Gewordenen, am Recht, dass historisch gewachsen und das nun zu kodifizieren sei, erfolgt eine Verschiebung in der Rechtsquellenlehre.

\section{Die Verabschiedung des Gewohnheitsrechts}

Mit dem Entschluss zur Gesamtkodifikation wird die Gesetzgebung als legitime Rechtsquelle des Privatrechts nicht mehr in Frage gestellt. Mehr noch: Die Stellung des Gewohnheitsrechts wird explizit revidiert. ${ }^{382}$ Der erste Entwurf spricht sich in $\$ 2$ gegen das Gewohnheitsrecht aus: „Gewohnheitsrechtliche Rechtsnormen gelten nur insoweit, als das Gesetz auf Gewohnheitsrecht verweist." (Entwurf eines bürgerlichen Gesetzbuches 1888: 1) $)^{383}$ Laut den Motiven wird damit dem Gewohnheitsrecht „die Kraft, das Gesetzesrecht aufzuheben, zu ändern oder zu ergänzen“ (Motive zu dem Entwurfe 1888b: 6) versagt.

Die Idee des Gewohnheitsrechts der Historischen Rechtsschule, die die Kommissionsmitglieder als „herrschende Meinung ${ }^{“ 384}$ unter den Juristen

381 Respektive es wird die Rechtsvereinheitlichung selbst als die politische Aufgabe formuliert (vgl. etwa Kuntze 1889: 5f.).

382 Zur Revision der Stellung des Gewohnheitsrechts bei Windscheid vgl. Jakobs 1983: 74ff.

383 Explizit nicht tangiert ist durch $₫ 2$ die sogenannte „Gewohnheit im natürlichen Sinne - der thatsächlichen Uebung, dem Gebrauche, der Sitte - für die Ermittelung des rechtsgeschäftlichen Willens" (Motive zu dem Entwurfe 1888b: 9, H.i.O.). Die Ausdrücke „Verkehrssitte“ in $\$ \mathbb{S} 84,86$ IV, $\$ \$ 359$, 789 I Entwurf BGB sowie bei sachenrechtlichen Verhältnissen der Ausdruck „Ortsüblichkeit“ ( $\$ \$ 850,851$ III) stellen Verweise auf diese Gewohnheit im natürlichen Sinne dar.

384 Das Gewohnheitsrecht ist zu dieser Zeit auch von prominenter Seite immer wieder scharf kritisiert worden (vgl. Zitelmann 1883 m. zahlr. N.) - was aber selbst in den Augen der Kritiker nichts an seiner Stellung als „herrschende Ansicht“ in den 1880ern ändert (vgl. ebd.: 436). Der Delegitimierung des Gewohnheitsrechts entspricht nach Schröder ein Wandel des Rechtsbegriffs hin zu einem Willensbegriff: Recht erscheint etwa als „erklärter Gemeinwille“ (Binding), ,allgemei- 
identifizieren, wird auf mehrfache Weise angegriffen: Erstens wird das Gewohnheitsrecht selbst nun in ein Entwicklungsschema eingebettet, das es in der Gegenwart als überholt erscheinen lässt. So wird zwar in keiner Weise die „große Bedeutung des Gewohnheitsrechtes für das Rechtsleben eines in den Anfangsstadien der Entwicklung begriffenen Volkes“ (ebd.: 5) bestritten. Letztlich habe sich aber heute gegenüber „der Verherrlichung welche dem Gewohnheitsrechte unter dem Einflusse der historischen Schule mannigfach zu Theil geworden" ist, die Einsicht durchgesetzt, dass „das Recht durch seinen Uebergang von dem Gewohnheitsrechte zum Gesetzesrechte einen wesentlichen Fortschritt macht“. Mit „Erstarkung des staatlichen Gedankens und der wachsenden Verwicklung der Lebensverhältnisse“ erfahre das Gewohnheitsrecht im Bereich des Privatrechts „erfahrungsgemäß eine Einbuße; es verliert an rechtserzeugender Kraft und tritt mehr und mehr in den Hintergrund“ (ebd.).

Zweitens sprechen praktische Gründe für den Vorrang der Gesetzgebung. ${ }^{385}$ Zum einen bestehe - so die erste Kommission - kein „Zwingendes Bedürfnis“ für die Zulassung des Gewohnheitsrechts, auch nicht angesichts der anerkannten Unmöglichkeit einer vollständigen Kodifizierung (Motive zu dem Entwurfe 1888b: 6). ${ }^{386}$ Denn selbst wenn davon ausgegangen wird, dass die Kodifikation angesichts der Vielgestaltigkeit des Lebens immer unvollständig sei und die menschlichen Verhältnisse zudem stets wandelbar seien, würde diesen Faktoren durch die Gesetzgebung genügend Rechnung getragen: Sie reagiere mittlerweile hinreichend schnell auf ein verändertes Verkehrsleben und sich wandelnde Bedürfnisse. Und selbst wenn dies nicht der Fall sein sollte, dann gewährleiste die notwendige Anpassung "die in theoretischer und praktischer Arbeit sich bethätigende Wissenschaft“ (ebd.: 7), d.h. Rechtswissenschaft und Rechtsprechung. Denn die Rechtswissenschaft (und mit ihr der wissenschaftlich informierte

ner Wille“ oder als „erklärter Wille der Gemeinschaft“ (Heck; s. Schröder 2012: 281ff., 2007). Zum Wandel der Idee des Gewohnheitsrechts ab Mitte des 19. Jahrhunderts vgl. auch Ross 1929.

385 Das gelte selbst dann, wenn man wie das Mitglied der zweiten Kommission Rudolph Sohm das Gewohnheitsrecht ansieht als „den Lilien auf dem Felde vergleichbar, ohne Mühe und Arbeit zur Welt geboren, und doch herrlicher gekleidet als Salomo“, demgegenüber die Kodifikation aber „nothwendig unvollkommenes, gemachtes, in der Studirstube erzeugtes, von des Gedankens Blässe angekränkeltes, fabrikmäßig auf Vorrath gearbeitetes Recht" hervorbringt (Sohm 1895: 739). Denn für Sohm führt kein Weg an der Kodifikation vorbei, und zwar aus "praktischen Gründen“ der nationalen Einheit (ebd., H.i.O.).

386 Das gelte sowohl bzgl. eines ab- bzw. derogatorischen, d.h. zuwiderlaufenden, als auch bzgl. eines suppletorischen, d.h. ergänzenden Gewohnheitsrechts. 
Richter) zeige sich - so die Kommission - als „die lebendige Macht, welche mit stets verjüngter Kraft die Fülle des Rechtes erschließt, die den im Gesetz ausgesprochenen, in ihrer wahren Bedeutung und inneren Zusammengehörigkeit erkannten Rechtssätzen innewohnt“ (ebd.: 7f.).

Drittens verabschiedet die erste Kommission Savignys Idee der Repräsentation des holistischen Ganzen im Gewohnheitsrecht. Denn nun erscheint ein gemeines, d.h. das ganze Reich umfassendes Gewohnheitsrecht, auch gar nicht vorstellbar:

Bei der Ausdehnung des deutschen Rechtsgebietes, bei der Verschiedenheit der Stammeseigenthümlichkeiten, der Mannigfaltigkeit der Verkehrsgestaltungen und dem Widerstreite der Interessen bedürfte es eines besonderen Zusammentreffens von Umständen, wenn eine das gesammte Volk oder gewisse Berufskreise des Volkes umfassende Rechtsüberzeugung im Widerspruche mit dem Gesetzesrechte oder neben demselben sollte sich entwickeln und auf dem Wege der Uebung bethätigen können. (Ebd.: 8)

Savignys Prämisse, dass angesichts der Rechtszersplitterung das gemeinsame Band im Gewohnheitsrecht zu sehen sei, wird ad acta gelegt. ${ }^{387}$ In Bezug auf das ganze Reichsgebiet sei nur von der Existenz „partikularen“ Gewohnheitsrechtes auszugehen, wobei gerade diese Partikularität einer Rechtsvereinheitlichung zuwiderlaufe. ${ }^{388}$

Dieser auf breiter Linie gefahrene Angriff gegen das Gewohnheitsrecht mag zwar nicht verwundern, würde doch die Kommission mit der Verteidigung des Gewohnheitsrechtsgedankens der Historischen Rechtsschule ihre eigene Tätigkeit delegitimieren: die Vorbereitung der von Savigny so vehement abgelehnten Gesamtkodifikation. Bemerkenswert erscheint dieser Angriff aber gerade deshalb, weil er zwar heftig kritisiert wird. ${ }^{389}$ Doch auch in dieser Kritik wird gerade nicht die Legitimation der Kodifikation

387 Zudem macht die Kommission noch das Motiv der Rechtssicherheit geltend: Die Folgen der Unbestimmtheit des Gewohnheitsrecht rechtfertigen in ihren Augen seinen Ausschluss (Motive zu dem Entwurfe 1888b: 8f.).

388 Diese Feststellung ist insofern bemerkenswert, als es in den Verhandlungen des Gutachtens der Vorkommission - so der Bericht des Ausschusses des Bundesrates für Justizwesen an den Bundesrat vom 9. Juni 1874 - heißt, dass die „Kulturzustände, die Lebensverhältnisse [...] im Ganzen im Deutschen Reiche gleich“ seien und daher eine Gesamtkodifikation möglich sei (zitiert nach Rassow 1877: 200). Diese Gleichheit der Kulturzustände bezieht die erste Kommission jedoch gerade nicht auf das nun als partikulär verstandene Gewohnheitsrecht, sondern rückt das Bild der widerstreitenden Interessen in den Vordergrund.

389 Einen Überblick liefert Reichsjustizamt 1967a [1890]: 36ff.; 1967b [1891]: 25ff. 
des Privatrechts in Frage gestellt. ${ }^{390}$ Stattdessen geht es hauptsächlich um die Frage, in welchem Verhältnis die Rechtsquellen zueinander stehen: Es wird bestritten, dass es möglich sei, Gewohnheitsrecht durch Gesetzesrecht zu verbieten, da es als eigenständige Rechtsquelle in keinem Über- oder Unterordnungsverhältnis zum Gesetzesrecht stehe (vgl. Reichsjustizamt 1967a [1890]: 37 m.w.N.). Eine Beseitigung des Gewohnheitsrechts sei letztlich unmöglich (Schuppe 1890). Und selbst wenn der Gesetzgeber diesen widersinnigen Versuch unternehme, dann werde sich die Volksvernunft quasi contra legem durchsetzen (vgl. Pfizer 1889: 12), da die Kluft zwischen Volks- und Juristenrecht dadurch zementiert werde. ${ }^{391}$ Auch Gründe der Rechtssicherheit sowie die Gefährdung der Rechtseinheit sprechen nach Ansicht der Kritiker nicht gegen die Anerkennung des Gewohnheitsrechts als gleichwertige Rechtsquelle; und zudem überschätze der Ge-

390 Nur wenige lehnen unter Bezugnahme auf die Historische Rechtsschule das Vorhaben der Gesamtkodifikation ab bzw. halten es für ein grundlegendes Übel (vgl. Brinz 1879; Bähr 1888a: 398, 451, 454f. insbesondere mit dem Verweis auf den Lebensbezug des Rechts als organisches, geistiges Fluidum, wie es in Savignys System zum Ausdruck kommt; allerdings plädiert Otto Bähr für eine fortschreitende Einzelgesetzgebung, vgl. ebd.: 459; 1892: IV). Demgegenüber hatte Moritz Bethmann-Hollweg, Schüler von Savigny, bereits drei Jahre zuvor die Meinung vertreten, dass aufgrund der Entwicklung der Rechtswissenschaft eine Kodifikation nun möglich sei (vgl. Bethmann-Hollweg 1876; s.a. Landau 1999: $321 \mathrm{ff}$.). Ob es eine Gesamtkodifikation geben solle, wird von der Mehrheit nicht nur angesichts der gesetzgeberischen Entscheidungen als „spruchreif“ angesehen (Rassow 1877: 168; vgl. etwa auch Hölder 1889: 6, 14; Pfizer 1892b: 15-17), sondern ihre Unterlassung sei gar ein „nationales Unglück“ (Zitelmann 1889: 1; Goldschmidt 1889: III; s.a. Leonhard 1891: 2; Kloeppel 1889: 65).

391 Auch in der Frage des Gewohnheitsrechts wird eine Verbindung zu einem der Hauptvorwürfe gegen den ersten Entwurf gezogen, dass es sich bei dessen $₫ 2$ nämlich - in Anlehnung an Beseleres Unterscheidung - um Juristenrecht und nicht um Volksrecht handele (vgl. Sohm 1895: 741): Für Otto Gierke, den vehementen germanistischen Kritiker des Entwurfs, zeigt sich der $\$ 2$ als Ausdruck der Verdrängung bzw. Vernichtung von Volksrecht, der die innerste Seele des Entwurfs spiegele, nämlich das ganze Rechtsleben der „gereinigte[n] Pandektendoktrin" zu unterwerfen (Gierke 1889a: 129). Dieser Vorwurf konstatiert jedoch einen Mangel - namentlich den Mangel an Volkstümlichkeit (s.u.). Er stellt gerade nicht die Legitimation der Kodifikation des Privatrechts in Frage. Anton Menger lehnt demgegenüber das Gewohnheitsrecht generell ab, da es „sich im wesentlichen als das Resultat eines erfolgreichen Interessenkampfes der Mächtigen gegen die Schwachen darstellt" (Menger 1890: 6) und damit die Wurzel der bestehenden Ungerechtigkeiten sei. 
setzgeber die Gesetzgebungskunst (Hölder 1888: 14f.; Gierke 1889a: 127). 392

Indem man die Anerkennung des Gewohnheitsrechts fordert (bzw. deren Aberkennung kritisiert), zweifelt man nicht an der Legitimität der Gesetzgebung im Bereich des Zivilrechts. Anders formuliert: Das Gewohnheitsrecht ist nicht mehr die Problematisierungsweise der Legitimität der Kodifikation, sondern wird zum Prüfstein der Güte des Entwurfs. Was dabei das Gewohnheitsrecht in den Augen der Kritiker gewährleistet, ist die Anbindung des Rechts an das Volksleben, insbesondere im Hinblick auf dessen ständigen und schnellen Wandel. Das Gewohnheitsrecht antwortet nun nicht mehr auf eine (idealistische) Verankerung in der Vergangenheit, sondern verweist auf gegenwärtige gesellschaftliche Entwicklungen - sie sind das drängende Problem, wie es ja auch die Kommission mit ihren Ausführungen zu Schnelligkeit der Gesetzgebung und Flexibilität der Wissenschaft und Rechtsprechung sieht. Die Verschiebung hin zur Gegenwart, hin zur Frage, in welchem Verhältnis das Rechts zu den gegenwärtigen gesellschaftlichen Entwicklungen steht, zeigt sich aber am deutlichsten in der privatrechtswissenschaftlichen Debatte, die sich anhand der Kritik am ersten Entwurf des BGBs entspannt.

\section{Die Kritik des Entwurfs des BGBs im Namen der „sozialen Aufgabe“}

Das Schlagwort für die Kritik liefert 1889 der Germanist Otto von Gierke mit dem Titel seines Vortrags Zur sozialen Aufgabe des Privatrechts (Gierke 1889b). ${ }^{393}$ Damit bringt er die vernichtende Beurteilung in seiner Mono-

392 Die zweite Kommission trägt den Einwänden Rechnung und streicht den $₫ 2$ ganz. Die Regelung des Verhältnisses von Gesetzes- und Gewohnheitsrecht wird dem Einführungsgesetz (EGBGB) vorbehalten; allerdings regelt auch dieses letztlich das Gewohnheitsrecht nicht explizit, sondern übergeht es stillschweigend im Rahmen des Art. 2 EGBGB (vgl. Geyer 1998: 150ff.). Die zweite Kommission sieht aber auch keine Notwendigkeit, das Gewohnheitsrecht ausdrücklich anzuerkennen. Die Problematik wird - analog zur ersten Kommission - vielmehr in Wissenschaft und Rechtsprechung verlagert: „Rechtssätze, die sich in der Judikatur unter dem Namen der Analogie, der einschränkenden oder ausdehnenden Auslegung, der feststehenden Praxis und dergl. herausbildeten, seien in Wahrheit nichts als Gewohnheitsrecht, und dieses mit Fug und Recht ein Produkt der fortbildenden Thätigkeit des Richters.“ (Mugdan 1899: 570).

393 Gierke sehen sowohl Kritiker als auch Befürworter des BGBs als Wortführer in der Debatte an (vgl. etwa Sohm 1895: 740, 1900: 6; Oertmann 1896b: 7; Ring 1888: 193; Fuld 1891: 637; s.a. Repgen 2001: 16 m.w.N.). 
graphie Der Entwurf eines bürgerlichen Gesetzbuchs und das deutsche Recht auf einen einfachen Nenner. Betrachtet man den Entwurf als Ganzes, so mag er zwar auch für Gierke so manche lobenswerten Eigenschaften haben, jedoch gilt: „Nur ist er nicht deutsch, nur ist er nicht volkstümlich, nur ist er nicht schöpferisch - und der sittliche und sociale Beruf einer neuen Privatrechtsordnung scheint in seinen Horizont überhaupt nicht eingetreten zu sein!“ (Gierke 1889a: 2) Wenn man überhaupt von einer sozialen Tendenz des Entwurfs sprechen könne, so sei dies ihm zufolge „die individualistische und einseitig kapitalistische Tendenz des reinsten Manchestertums, [...] jene gemeinschaftsfeindliche, auf die Stärkung des Starken gegen den Schwachen zielende, in Wahrheit antisociale Richtung" (ebd.: 3). Die Frage, welche Aufgabe der Gesetzgebung zukomme, klärt sich in dieser Perspektive letztlich über die Beantwortung der Frage, welche soziale Aufgabe das Privatrecht hat.

\section{Die Diffusität des Sozialen: „Soziale Aufgabe“, „Sozialpolitik“, „Soziale Frage" etc.}

Insbesondere der Vorwurf der antisozialen Tendenz, das Verfehlen der sozialen Aufgabe des Privatrechts durch den Entwurf, wird zum zentralen Topos in der Debatte um das zu schaffende BGB (vgl. Fuld 1891: 636; Sohm 1895: 747). ${ }^{394}$ Es ist jedoch alles andere als eindeutig, was mit dem

394 Weite Teile begreifen entweder den Entwurf als geeignete Grundlage für die weitere Kodifikationsarbeit (Schubert 1978: 50; vgl. die Literaturnachweise in Reichsjustizamt 1967a [1890]: 1f.; 1967b [1891]: 1f.), oder aber treten trotz grundlegender Kritiken aus Gründen der nationalen Rechtseinheit für seine Verbesserung, nicht für seine Ablehnung ein (vgl. etwa Liszt 1889; Bekker 1888; Zitelmann 1889; Goldschmidt 1889). Dementsprechend befassen sie sich vorwiegend mit einzelnen Änderungsvorschlägen, auch wenn sie dabei grundsätzliche Fragen ansprechen. Die Grundsatzfrage nach der sozialen Aufgabe des Privatrechts diskutiert man daher auch zu überwiegenden Teilen nicht abstrakt, sondern bezogen auf einzelne Rechtsinstitute und Normen. Vorliegend wird nicht im Speziellen auf solche Einzelfragen eingegangen (vgl. etwa Schröder 1981; zu Teilen Repgen 2001) - nicht nur aus praktischen Gründen, da ein solches Vorhaben angesichts der Masse der Einlassungen den Rahmen sprengen würde, sondern weil vorliegend die Verschiebung der Problematisierungsweisen im Hinblick auf die Fassung des Gegenstandes ,Gesellschaft ${ }^{\star}$ im Recht in der Privatrechtswissenschaft untersucht wird. 
Begriff ,sozial' ${ }^{`}$ gemeint ist. ${ }^{395}$ Ganz unterschiedliche Aufgabenbeschreibungen und Motive werden damit auf den Plan gerufen - und zwar nicht nur von den Kritikern des BGBs und seiner Entwürfe, sondern ebenso von seinen Verteidigern. ${ }^{396}$ So wird nicht nur nach der „Sociale[n] Aufgabe des Privatrechts" (Gierke 1889b) gefragt, sondern ebenso nach derjenigen der „Rechtswissenschaft" (Menger 1895). ${ }^{397}$ Zudem wird die Aufgabe einer „socialen Gesetzgebungspolitik“ ins Feld geführt (Ehrlich 1890b). Mithin erscheint das Privatrecht selbst als „Sozialrecht“" (Gierke 1889b: 42); man spricht vom „socialem Recht“ (Pfizer 1893), der „Schaffung einer socialen Rechtsordnung“ (Pfizer 1891: 2) oder vom „sozialen Charakters des Privatrechtes" (Ofner 1894: 57).

Viele verstehen unter der „sozialen Aufgabe“ insbesondere den Schutz der Armen und Schwachen. ${ }^{398}$ Damit schneiden sie aber auch die Klassenfrage an; berühmt geworden ist etwa die Kritik des österreichischen Zivilrechtswissenschaftlers Anton Menger:

Mein Buch erscheint in der Form einer Streitschrift gegen den Entwurf eines bürgerlichen Gesetzbuchs für das Deutsche Reich. Schwerlich hätte ich in alter und neuer Zeit ein Gesetzeswerk finden können, welches die besitzenden Klassen so einseitig begünstigt und diese Be-

395 So bemerkt Gottlieb Planck in seiner Besprechung der Kritik am Entwurf: „Die Worte ,social', ,socialpolitisch', ,socialrechtlich' sind in neuerer Zeit Schlagworte geworden, welche in verschiedenem Sinne gebraucht werden. Dies gilt auch von ihrer Anwendung auf die Aufgabe des bürgerlichen Gesetzbuches." (Planck 1889: 405) Selbst Gierke beklagt die Beliebigkeit der Verwendung des Begriffs ,sozial' (Gierke 1902 in Repgen 2001: 5), was auch Stammler mit Blick auf die Debatte um das BGB kritisiert (Stammler 1896: 118).

396 Vgl. zum Folgenden insbesondere die Untersuchung von Tilmann Repgen, der darin eine Typologie der verwendeten sozialen Argumentationen in den Debatten über das BGB aufstellt (Repgen 2001: 50ff.).

397 Das ist als direkte Kritik an Windscheids Rektoratsrede von 1884 zu lesen, in der er "die Aufgaben der Rechtswissenschaft" hinsichtlich der Gesetzgebung auf die Bereitstellung genauer Begrifflichkeiten beschränkt (Windscheid 1904: 112).

398 Der Schutz der Schwächeren ist nach Repgen in der Diskussion über die Entwürfe des BGBs der am häufigsten geltend gemachte Topos, um die soziale Aufgabe zu bestimmen (vgl. Repgen 2001: 68ff. mit Nachweisen zu Planck, Anton Menger, Konrad Schneider, Paul Stolterfoth, Ernst Landsberg, Victor Mataja, Ludwig Ennecerus, Heinrich Dernburg, Gustav Pfizer, den Mitgliedern des Vereins für Socialpolitik sowie der Politik des Reichsjustizamtes). Auch Gierke und Fuld sehen den Schutz der Schwächeren als soziale Aufgabe des Privatrechts an (vgl. Gierke 1889b: 29, 31; Fuld 1889: 404, 1891: 656; weitere Nachweise in Reichsjustizamt 1967a [1890]: 6ff.; 1967b [1891]: 4ff.). 
günstigung so unumwunden zu erkennen gibt, wie der deutsche Entwurf. (Menger 1890: III) 399

Vor diesem Hintergrund wird auch explizit Bezug genommen auf die „soziale Frage" (Ehrlich 1892), die eine Brücke zu sozialpolitischen Problemstellungen und damit zur Sozialpolitik schlägt (vgl. Ehrlich 1890a, 1890b; Fuld 1891; Bar 1890; Mataja 1889: 114; Dernburg 1889: 177). Bezug genommen wird aber ebenso auf die „soziale Freiheit“ (Baron 1889: 231), die „soziale Gerechtigkeit“ (Dernburg 1894: 36; Sohm 1900: 8), die gesellschaftlichen bzw. sozialen Machtverhältnisse (Ofner 1894: 30, 34f.), auf den Rechtsfrieden bzw. den „socialen Frieden“ (Schulze-Gaevernitz 1890; s.a. Jacobi 1889). Die soziale Aufgabe wird aber auch ganz allgemein darin gesehen, die Bedürfnisse der Gegenwart zu berücksichtigen, was in seiner Vagheit aber ebenfalls zu keiner Begriffsklärung beiträgt (Repgen 2001: 109ff. m.N.).

Was Kritiker und Verteidiger des BGBs und seiner Entwürfe unter der sozialen Aufgabe des Privatrechts verstehen, ist alles andere als homogen. Nicht nur, dass sie verschiedene Topoi ins Feld führen. Zumeist werden diese auch miteinander kombiniert und nebeneinandergestellt (vgl. ebd.: 120ff.). Und doch steht mit der Frage nach der „sozialen Aufgabe des Privatrechts" in zentraler Weise das Selbstverständnis der Privatrechtswissenschaft auf dem Spiel. Das neue Gesetzbuch und seine Entwürfe sind - wie Josef Kohler bemerkt - „zur Probe“ für die Rechtswissenschaft geworden (Kohler 1896: 218).

\section{Der „kleine Windscheid“}

Denn unlösbar verknüpft mit der Diskussion über die soziale Aufgabe ist die Frage nach der spezifischen Art der rechtswissenschaftlichen Arbeit, auf die bei der Erstellung des BGBs und seiner Entwürfe rekurriert wurde.

399 Allerdings argumentiert Menger, dessen Rechtstheorie Engels und Kautsky ein paar Jahre zuvor als fehlgeleiteten "Juristen-Sozialismus“ kritisiert hatten (Engels, Kautsky 1887), in seiner Kritik des BGB-Entwurfs explizit nicht vom Standpunkt der sozialistischen Rechtsideen, sondern geht von den grundlegenden Prinzipien des heutigen Privatrechts aus, zu denen das Privateigentum gehört (Menger 1890: 3). Anton Menger, der jüngere Bruder von Carl Menger, war im Übrigen Lehrer von Carl Grünberg, der als „Vater des Austro-Marxismus“ gilt (Knoll et al. 1981: 76; zu Mengers Einordnung als Sozialist unter Kritik des marxistischen Rechtsverständnisses vgl. Vormbaum 1997: LXXff. m.w.N.; zum „Juristensozialismus in Deutschland“vgl. Ramm 1974/1975). 
Eine Vielzahl der Kritiker erkennt im ersten Entwurf ein Erzeugnis der Romanistik: Er sei, wie Gierke schreibt, „ein in Gesetzesparagraphen gegossenes Pandektenkompendium“ (Gierke 1889a: 2; ebenso Menger 1895: 19), und gerade das sei das Problem. Verantwortlich gemacht wird insbesondere der Einfluss des Kommissionsmitglied Bernhard Windscheid - und zwar trotz der Tatsache, dass er im Jahr 1883 aus der Kommission ausschied: Man habe sich nach dessen Pandektenlehrbuch gerichtet (vgl. Pfizer 1892a: 104; Bekker 1888: 75; Repgen 2001: 42 m.w.N.), ja letztlich sei der Entwurf selbst ein „kleiner Windscheid“ (Bähr 1888b: 327; differenzierter Planck 1909). ${ }^{400}$ Dies führe dazu, dass er „einen allzu doctrinären Charakter" habe (Bähr 1888c: 566), ${ }^{401}$ woraus ein „Mangel der Volksthümlichkeit“ folge (Bekker 1888: 50ff.; s.a. Dernburg 1888: VII; Bähr 1888a). ${ }^{402}$ Dies vertiefe die bereits bestehende Kluft zwischen Volksbewusstsein und Theorie (vgl. Bernhöft 1889: 3; Bähr 1890: 207).

\subsection{Römisch-individualistisches versus deutsch-soziales Recht}

Mit dem Vorwurf der einseitigen Orientierung am römischen Recht geht es nicht nur um die Frage, ob es sich um fremdes Recht handele (vgl. etwa Heusler 1890: 180; Bernhöft 1889: 3). Im Vordergrund steht vielmehr wie in den 1860er Jahren - die Deutung des politischen Geistes des jeweiligen Rechts, die in die Entgegensetzung von römisch-individualistischen und germanisch/deutsch-sozialen Rechtsdenken mündet. Besonders Gierke kann hier wieder als Stichwortgeber angesehen werden. Denn er greift dieses Schema explizit auf: Romanisches Recht sei naturrechtlich-individualistisch, zersetze die Gesellschaft und werde daher seiner sozialen Aufgabe in keiner Weise gerecht. Es gelte: „Weil der erste Entwurf römisch war, darum war er zugleich individualistisch und kapitalistisch." (Gierke 1896: 39) Demgegenüber führt Gierke ins Feld: „[S]oziales Recht ist deut-

400 Zur zentralen Rolle Windscheids in den Pandektenwissenschaften, der auch eine große praktische Wirkung in der Gerichtsbarkeit entsprach, vgl. Schröder 1988: $327 \mathrm{ff}$.

401 Der romanistische Kritiker des Entwurfs Ernst Immanuel Bekker hält dem Werk hingegen vor, dass es das wissenschaftliche Ideal der Romanisten gerade verfehlt habe und genau deshalb doktrinär sei (vgl. Bekker 1888: 67).

402 Zum Vorwurf des Doktrinarismus und der mangelnden Volkstümlichkeit, die sich insbesondere auch gegen Form und Sprache richtet, s.a. Reichsjustizamt 1967a [1890]: 13f.; 1967b [1891]: 8, jeweils m.N. Zur Kritik der Idee eines volkstümlichen Gesetzbuches angesichts der Komplexität des Rechts vgl. Zitelmann 1889: $2 \mathrm{ff}$. 
sches Recht.“ (Ebd.) ${ }^{403}$ Und genau deshalb sei „der Kampf um das Recht der Zukunft zugleich ein Kampf zwischen römischem und germanischem Rechtswesen" (Gierke 1889b: 15).

Manche fordern lediglich eine stärkere Berücksichtigung des deutschen Rechts (vgl. etwa Sohm 1888). Andere wiederum wenden ein, dass die Frage, ob römisch oder deutsch, unerheblich sei (vgl. etwa Schwartz 1889: 186f.; Meischeider 1889: 96f.; Bähr 1890: 190; Ehrlich 1890b). Letztlich gehe es um das, was gegenwärtig Geltung habe bzw. was den heutigen Verhältnissen angemessen und nützlich sei (Petersen 1890: 43; Bekker 1888: 63). Auch wird in der Debatte gelegentlich bezweifelt, dass das deutsche Recht tatsächlich so sozial sei, wie Gierke behauptet (vgl. Bar 1890). So erscheint etwa Max Weber Gierkes Gleichsetzung eines individualistischen römischen Rechts mit einem kapitalistischen Recht aus rechtshistorischer Perspektive schlichtweg falsch:

Aber längst habe ich mich überzeugt, daß gerade die ,agrarkapitalistischen' Institute (z.B. die moderne Hypothek, darüber habe ich mich Gierke gegenüber einmal geäussert in der, christlichen Welt $^{6}$ ), welche die romanistischen Völker in ihren entscheidenden Zügen gar nicht kennen gelernt haben, durchaus germanische Gewächse sind. Staatspapiere und Handelsgesellschaften erst recht, sodaß man geradezu das deutsche Recht als juristische Hebamme wichtigster kapitalistischer Institutionen ansehen muß. (Brief an Georg von Below vom 23. Aug. 1905, zitiert nach Mommsen 1993: 525, H.i.O.) ${ }^{404}$

Die große Zahl an Einlassungen zeigt jedoch, dass der Gegensatz der Rechte geradezu zu einem Allgemeinplatz wird, so dass ,römisch' und ,deutsch/ germanistisch' letztlich als Chiffren für die Frage nach der sozialen Aufgabe angesehen werden können (vgl. Schröder 1981: 48).405 Dabei gilt, wie Weber schreibt:

Das römische Recht ist der sozialpolitische Sündenbock: breite Kreise glauben allen Ernstes, die Rezeption des römischen Rechts in Deutschland trage den wesentlichen Teil der Schuld an der Entwicklung der

403 Und Gierke fährt fort: „Deutsches Recht ist Gemeinschaftsrecht. Es stellt auch im Privatrecht das Individuum nicht aus dem gesellschaftlichen Zusammenhange heraus, sondern mißt alle Rechte, die es dem Einzelnen zutheilt, an ihrer Funktion im Leben des Ganzen." (Gierke 1896: 39).

404 Allerdings zollt Weber der Kritik Gierkes insofern Hochachtung, als sie von der technischen Gestaltung des Rechtsformalismus des Entwurfs handelt (vgl. Weber 1993: 532).

405 Vgl. zu einem Überblick über die Positionen auch Schröder 1981: 37ff. m.w.N. 
sozialen Schäden der Gegenwart, die „Rückkehr zum deutschen Recht“ sei eins der Hauptschemata für eine moderne „Lösung der sozialen Frage“. (Weber 1993 [1895]: 526)

\subsection{Die soziale Aufgabe und die Rechtswissenschaft}

Für Gierke folgt aus dem Geist des römischen Rechts auch der unsoziale Geist der Pandektistik. Explizit mit Rekurs auf Jhering geht es ihm darum, „die besondere Gattung romanistischer ,Begriffsjurisprudenz' $[\mathrm{zu}]$ bekämpfen, die im Entwurfe ihr Spiel treibt“" (Gierke 1889a: 23).407 Er schreibt an gegen den „Geist“ des Romanismus,

[d]er sich vermißt, durch logische Ableitung aus abstrakten Begriffen eine lebendige und allumfassende Rechtsordnung zu gebären! Der die selbstgezimmerten „Prinzipien“ über die Sache, das folgerichtige „System" über die Zusammenhänge der Wirklichkeit, die juristische Gedankenwelt über die Welt der Realitäten stellt! (Ebd.)

Daher wende sich der Entwurf des BGBs ,an den gelehrten Juristen, aber zum deutschen Volke spricht es nicht“ (ebd.: 3). Kurz: Er sei Juristenrecht, nicht Volksrecht, wie einer der Hauptvorwürfe gegen den Entwurf lautet (vgl. Sohm 1895: 741). ${ }^{408}$

Basiert Gierkes Kritik an der rechtswissenschaftlichen Leistung auf dem Vorwurf, dass die falschen Rechtsquellen als Grundlage der Kodifikation herangezogen wurden, so wendet sich insbesondere Eugen Ehrlich gegen ein derartiges Verständnis der Rechtswissenschaft. Zwar liegt auch ihm zufolge das Problem in der rechtswissenschaftlichen Technik begründet: „[I]ch halte vielmehr an dem Standpunkt fest, die ganze Haltung des Entwurfes sei nichts als logische Folgerung aus den Lehren der historischen Schule." (Ehrlich 1892: 109)409 Allerdings gelte dies unabhängig von den

406 Exemplarisch für eine derartige Argumentation sind etwa die Abhandlungen von Carl Wilmanns und Franz Collet (Wilmanns 1890; Collet 1894).

407 Zur seit den 1870ern anschwellenden Debatte über das „bloß logische“ und formalistische Vorgehen der Rechtswissenschaft mit so namhaften Beteiligten wie Jhering, Rudorff, Gierke, Merkel, Baron, Brinz, Stein, Lotmar, Windscheid, Kohler, Laband u.a. vgl. die Nachweise bei Rückert 1988: 87ff. und Haferkamp 2004: 48ff.

408 Allerdings bestreitet Sohm die Berechtigung dieses Vorwurfs (vgl. Sohm 1895: 741).

$409 \mathrm{Zu}$ einer umfassenden Kritik an der „Pandektologie“ vgl. später Ehrlich 1966 [1925]. 
zugrunde liegenden Rechtsquellen, egal ob römisch oder deutsch, sondern beruhe vielmehr auf der Verkennung der Aufgabe der Rechtswissenschaft.

Denn der Entwurf habe sich Savignys Programm verpflichtet, indem er der Gesetzgebung keine andere Aufgabe zugesprochen habe, „als das geltende Recht in eine technisch vollendete Form zu bringen" (Ehrlich 1890a: 35). Nun sei aber das Problem, dass „selbst das beste System auch nicht einen gesetzgebungspolitischen Gedanken enthält“ (ebd.: 22, H.i.O.). Wenn die Rolle der Wissenschaft darin besteht, aus der bestehenden Rechtsmaterie die Rechtsinstitute zu definieren, dann kann ein Gesetz, das innerhalb dieser Wissenschaft entworfen wurde, nicht das Leben regeln, sondern nur angeben, wie das Leben sich selbst regelt: „Eine legislativ politische Richtung haben solche Bestimmungen naturgemäß nicht, es sei denn, daß man das laisser-aller als solche bezeichnet." (Ebd.: 23) Daher beruhten die einzelnen Bestimmungen des Entwurfes

in großer Mehrzahl der Fälle weder auf praktischen Erwägungen noch auf Billigkeitsrücksichten, und ebenso fremd ist ihnen in der Regel auch jeder sociale Hintergedanken, sondern sie sind logisch abgeleitet aus gewissen „allgemeinen Grundsätzen“, „Principien“, „Theorien“, „Lehren“ u.s.w. (ebd.: 24).

Dieses Verfahren sei nun keineswegs politisch neutral, sondern enthalte eine spezifische sozialpolitische Wertung. Denn wenn Abstraktionen aus den Bestimmungen des geltenden Rechts in Prinzipien umgewandelt würden, dann werde eine Unterteilung der Rechtssätze vorgenommen in solche, die als besonders "charakteristisch" gelten, und solche, die man für minder wichtig hält. Aus diesen charakteristischen Normen lasse sich induktiv der Begriff des Rechtsinstituts extrahieren, um dann zu zeigen, dass sich diese aus dem Begriff ableiten lassen, da sie darin schon enthalten seien: „[D]as geht natürlich sehr leicht, da er [der Jurist, D.S.] sie doch vor einem Augenblicke hineingelegt hatte“ (ebd.: 25). ${ }^{410}$ Die minder wichtigen Normen werden dann entweder ebenfalls dem Begriff untergeordnet, oder, wenn das misslinge, als „Anomalie“ behandelt, d.h. als singuläre Ausnahme zur Regel. Nach Ehrlich gestalten die Prinzipien die Grundsätze des Rechts daher nicht etwa bloß anders, sondern ,verfälschen [sie]; ist es doch etwas ganz anderes, ob man sagt: das Eigenthum ist frei, insofern es nicht durch gesetzliche Bestimmungen eingeschränkt wird, oder: das Eigenthum ist grundsätzlich frei, jede Einschränkung ist eine unberechtig-

410 Philipp Heck wird später dieses Verfahren der Konstruktionsjurisprudenz als „Inversionsmethode“ kritisieren, s.u. $\$$ 5.I.1.2. 
te Anomalie“ (ebd.). In diese letztgenannte Gestalt hat nun jedoch die Rechtswissenschaft das geltende Recht gebracht, genau so ging es in den Entwurf ein. ${ }^{411}$ Dieses Vorgehen mag zwar für die richterliche Entscheidung Hilfestellung bieten, für die Kodifikation sei das der falsche Weg, denn:

Der Gesetzgeber hat dagegen eine andere Aufgabe: er muß sich bei jedem einzelnen Falle fragen, welche Entscheidung das allgemeine Wohl, die Gerechtigkeit und die Billigkeit erheischt. Es bedarf wol keines weitern Beweises, daß das vom Entwurfe erwählte Verfahren [...] auf einer Verwechselung der Aufgaben des Richters und des Gesetzgebers beruht. (Ebd.: 26)

Ehrlich fordert eine Orientierung an sozialen Zwecken, die auf sozialpolitischen Beurteilungen statt auf einer Bestandsaufnahme des geltenden Rechts beruhen. Ein ähnliches Problem spricht auch Anton Menger an, wenn er vom Gesetzgeber „Anticipation“ der sozialen Entwicklungen verlangt, die angesichts der Veränderung der Machtverhältnisse in der Gesellschaft eine „Abänderung des geltenden Rechtszustandes“ verlange (Menger 1890: 11, 13).412 Auch Leon Petražycki sieht einen „Unterschied zwischen der richterlich-dogmatischen und der politischen Methode“ (Petražycki 1893: 330), und wirft wie Ehrlich den Verfassern des Entwurfs vor, sie hätten aufgrund der Orientierung an der überlieferten Methoden der Rechtswissenschaft ihre „politische Aufgabe schlichtweg nicht verstanden“ (ebd.: 333; s.a. Mataja 1889; Bar 1890: 403). ${ }^{413}$ Gesetzgebung sei etwas an-

411 Dementsprechend sei das Eigentumsrecht im Entwurf „ein protziges, feistes Ding, das für allen Jammer des Erdenwallens blind ist und taub, und den Verhungernden auf die Beiträge verweist, die es für den Verein gegen Verarmung und Bettelei bezahle. [...] Zwischen Eigenthum und den Besitzlosen gähnt ein Abgrund wie vielleicht in keinem Rechtssysteme der Welt." (Ehrlich 1890a: 28; zur Kritik am Eigentumsrecht vgl. auch Ehrlich anonym/1891: 539ff.).

412 Der Gesetzgeber "muss sich“ - so Menger -, „wenn er anders diesen Namen verdienen will, als Erzieher seiner Nation fühlen und sich über den Wust des seit Jahrtausenden angesammelten Rechtsstoffes zu erheben wissen“ (Menger 1890: 14). Allerdings lehnen viele Kritiker des Entwurfs Mengers Position vehement ab (vgl. etwa Bar 1890: 402; Fuld 1891: 644).

413 Man kann natürlich auch - wie etwa Friedrich Endemann - die politische Aufgabe des BGBs formal als Herstellung der Rechtseinheit definieren (vgl. Endemann 1899: 4; s. a. 1889). Inhaltlich bindet diese nationale Aufgabe nach Endemann das Recht an das Volksleben als Ausdruck der nationalen Kultur zurück. Damit steht für ihn aber auch fest, dass man im Zuge der Gesetzgebung nicht neues Recht schaffen kann, da ihm Recht als „äußere Ordnung der vorhandenen Lebensverhältnisse“ gilt (ebd., H.D.S.). 
deres als rechtswissenschaftliche Rechtsvereinheitlichung, und wenn man sich bei der Kodifikation an die überlieferte Form der Rechtswissenschaft halte, liege es in der Natur der Sache, die soziale Aufgabe des BGBs zu verfehlen (s.a Hölder 1889: 3f.). Kritisiert wird letztlich die Anmaßung der Rechtswissenschaft, über ihre systematisch-dogmatische Arbeit zum Leben vorzudringen und aus diesem Grund geeignet zu sein, jenseits einer politischen Entscheidung zentrale Belange des Lebens zu regeln.

\section{Der Zweck des Rechts: Die Sicherung der gesellschaftlichen Ordnung}

Die Diffusität des sozialen Gedankens und die damit verbundenen Vorwürfe führen nicht dazu, dass die Verteidiger des Entwurfs diese Kritik in Bausch und Bogen verwerfen. Vielmehr erkennen auch die Befürworter des BGBs und seiner Entwürfe die Frage nach der sozialen Aufgabe als Grundproblematik des Kodifikationsvorhabens des Privatrechts an. Es scheint außer Frage zu stehen, dass das Privatrecht immer auch einen sozialen Bezug hat. Selbstverständlich gelte, wie Gottlieb Planck feststellt: „Die Grundfragen jedes Privatrechtes, die Fragen, ob Eigenthum, ob Ehe, ob Erbrecht anzuerkennen, sind sociale Fragen in diesem Sinne." (Planck 1889: 406; ähnlich auch Baron 1889: 232)

Entsprechend der Vorgaben der Vorkommission und des Bundesrats sieht jedoch Planck - und mit ihm viele Privatrechtswissenschaftler - die Aufgabe der Kodifikation in der Bestandsaufnahme des Rechts: „Die Aufgabe einer solchen [Kodifikation, D.S.] besteht nicht darin, ein neues Recht für Deutschland zu machen.“ (Planck 1889: 331) Der sicherste Weg sei eingeschlagen, „wenn sie sich darauf beschränkt, die im Volke bereits lebenden Rechtsgedanken aufzufinden und ihnen durch die Gesetzesform nur die größere Bestimmtheit zu geben, sowie ihre Anwendung zu sichern" (ebd.). ${ }^{414}$ Man werde der sozialen Aufgabe nämlich nicht durch Schaffung neuen Rechts, sondern nur durch die Kodifikation des Gegebenen gerecht (vgl. etwa Opitz 1889: 6f.; Petersen 1889: 39ff.; Planck 1889: 331ff.; Loening 1890: 393; Reichsjustizamt 1967a [1890]: 8ff. m.w.N., 1967b [1891]: 5 m.w.N.).

Damit steht gerade nicht - wie noch bei Savigny - die Rückkehr zu den Wurzeln des Rechts auf dem Plan. Vielmehr verliert angesichts der sozia-

414 Letztlich sieht auch Gierke - wie Ehrlich richtigerweise bemerkt (Ehrlich 1892: 133) - den Zweck der Kodifikation in der Zusammenfassung des geltenden Rechts, wobei er allerdings das deutsche Recht berücksichtigt haben will. 
len Frage die über den Traditionszusammenhang bewerkstelligte Verankerung des ,heutigen Rechts' in der Vergangenheit seine Plausibilität. Wenn insbesondere von kritischer Seite eingeklagt wird, dass es um die „heutigen socialen Verhältnisse“ gehen müsse (Pfizer 1892a: 104), dass das „Bedürfniß der heutigen Zeit“" (Dernburg 1889: 177; Ehrlich 1892: 97) und die „Rücksichtnahme auf die Lebensverhältnisse und einer Würdigung der modernen Gesellschaftszustände“ (Kohler 1896: 222)415 im Vordergrund zu stehen hätten (vgl. Repgen 2001: 114ff. m.w.N.), so wird diese notwendige Orientierung an den Zuständen der Gegenwart von den Befürwortern des BGBs keinesfalls bestritten. Allerdings sehen sie diese Vorgabe als erfüllt an: Insbesondere der zweite Entwurf entspricht nach Sohm dem „innerhalb des deutschen Juristenstandes herausgearbeiteten und zur Klarheit geförderten Gesammtbewußtsein der Gegenwart" (Sohm 1895: 741, H.i.O. ${ }^{416}$; und für Planck liegt der soziale Charakter der Vorschriften des nun erlassenen BGBs gerade darin, dass sie „den gesellschaftlichen und wirtschaftlichen Verhältnissen der Gegenwart und den sich hieraus ergebenden Bedürfnissen entsprechen“ (Planck 1899: 181). Die Frage, ob dieser Gegenwartsbezug gelungen ist, wird letztlich zum Beurteilungskriterium der Güte des Entwurfs. ${ }^{417}$ Sowohl Kritiker als auch Befürworter beziehen sich in ihren Überlegungen nicht auf historische Wahrheiten, sondern auf die gegenwärtigen Zustände. ${ }^{418}$

\section{Die gefährdete Gesellschaft}

Wenn es also anerkanntermaßen darum geht - wie schon die Vorkommission feststellte - den „Verhältnissen der Gegenwart“ oder den „Bedürfnissen der Zeit" zu entsprechen, dann zeigt sich zwischen Kritikern und Befürwortern eine bemerkenswerte Einigkeit in der Charakterisierung dieser gegenwärtigen Verhältnisse: Sie sind selbst ein Problem. Dass die Gesell-

415 Zum Wandel in Kohlers Beurteilung des BGBs vgl. Repgen 2001: 516 Fn. 61.

416 Sohm trat schon im Jahr 1874 für die Kodifikation ein (Sohm 1874) - und zwar als rechtsgeschichtliches Erfordernis (vgl. Landau 1999: $327 \mathrm{ff}$.$) .$

417 Vgl. etwa Planck 1899: 181; Pfizer 1892a: 104; Dernburg 1889: 179; Ehrlich 1892: 97, 1890b; Menger 1890: 15; Bornhak 1891: 214; Kohler 1896: $219 f$.

418 Repgen geht in seiner Untersuchung der Debatten um das BGB und seine Entwürfe davon aus, dass die „Bedürfnisse der Zeit“ kein eigenständiger sozialer Topos seien, habe man damit doch einen nahezu beliebigen Inhalt verbunden (Repgen 2001: 119). Demgegenüber zeigt sich die Bedeutung der Bedürfnis-Formel m.E. aber nicht im Inhalt, sondern in der Vergegenwärtigung des Bezugsobjekts für die Debatte über die Güte des Entwurfs. 
schaft Ende des 19. Jahrhunderts durch raschen Wandel der Verhältnisse gekennzeichnet sei (Planck 1889: 331; s.a. Kohler 1896: 218f.; Ehrlich 1892: 97), hatte ja letztlich bereits die erste Kommission zu ihrer Kritik des Gewohnheitsrechts bewogen (s.o.). Darüber hinaus erscheint sie nun selbst angesichts der sozialen Probleme sowohl für Kritiker als Befürworter des Entwurfs in ihrem Bestand gefährdet: Es gelte, eine (sozialdemokratische) Revolution bzw. deren „Angriffe wider unsere Gesellschaftsordnung“ abzuwenden (Leonhard 1891: 71; s.a. Pfizer 1891: 4; Planck 1899: 181; zu Baron vgl. Schröder 1981: 129, 158), eine „Auflösung der heutigen Gesellschaft zu verhindern“ (Dickel 1889: 18), den gegenwärtigen "gesellschaftlichen Krisen [...] von ganz besonderer Wucht und Gewaltigkeit“" (Ehrlich 1892: 97) zu begegnen bzw. „den wirthschaftlichen Verfall, die sittliche Auflösung, die soziale Zersetzung“ aufzuhalten (Gierke 1889b: 6f.).

Die Gesellschaft wird als gefährdetes Objekt wahrgenommen. ${ }^{419}$ Angesichts dieses Krisenbewusstseins verliert die Annahme an Überzeugungskraft, dass das Recht einer harmonischen, sich in der Zeit kontinuierlich entwickelnden Sphäre entspringe. Die Gesellschaft zeichnet sich vielmehr u.a. durch den „Widerstreite der Interessen“ (Motive zu dem Entwurfe 1888b: 8) aus, wobei nicht nur die „Interessen der Einzelnen“ miteinander in Beziehung treten, sondern ebenso das „Interesse der Gesammtheit, welche zwar aus allen Einzelnen gebildet wird, deren Interesse aber nicht mit allen Einzelinteressen zusammenfällt", zu berücksichtigen sei (Planck 1889: 406). ${ }^{420}$ Dabei machen insbesondere manche Kritiker geltend, dass Recht das Ergebnis von Interessenkämpfen sei, und führen namentlich die Klasseninteressen an (Menger 1895: 22ff., s.a. Loening 1890: 393). Der Bezug des Rechts zu sozialen Machtverhältnissen und Machtverteilung gewinnt an Bedeutung (vgl. Ofner 1894: 34ff.; Menger 1895: 22f.; 1890).

419 Das führt wiederum zu Problemen beim Verfahren der Bestandsaufnahme. Denn wenn - wie die Vorkommission feststellt - die Gegenwart durch einen raschen Wandel der Verhältnisse gekennzeichnet sei, dann könne sich wiederum der Gesetzgeber - wie Planck betont - nicht damit begnügen, „bereits fertig gewordenes Recht gesetzlich festzustellen, sondern er wird auch das werdende Recht berücksichtigen und den nach rechtlicher Anerkennung drängenden Bedürfnissen des Lebens gerecht werden müssen“ (Planck 1889: 331). Wie dies zu erfolgen habe, steht aber zur Debatte.

420 Schon für Windscheid ist die Welt durch widerstreitende, mit einander konkurrierende Willen (nicht Interessen) gekennzeichnet, wobei das Recht „die Ordnung der in der Welt vorhandenen Willensmächte" sei (Windscheid 1904 [1884]: 101). Auch er erkennt dabei die Existenz eines eigenständigen, von den Individuen verschiedenen „Gesamtwillen[s]“ an (ebd.: 102). 


\section{Die Aufwertung des Zweckgedankens}

Angesichts einer im Bestand gefährdeten Gesellschaft erstarkt das Zweckmoment in den Debatten um die soziale Aufgabe des Privatrechts. Allenthalben wird vom "Zweck" des Privatrechts (Planck 1889: 405) bzw. über den „Zweck im Recht“ gesprochen (Fuld 1891: 637) und die „ZweckmäBigkeit" des Entwurfs diskutiert (z.B. Lobe 1896: 28; Hölder 1889: 18).

Der Rekurs auf den Zweck trägt jedoch nicht nur dem Umstand Rechnung, dass es sich hier um eine Debatte über die Aufgabe der Gesetzgebung handelt. Vielmehr beziehen sich viele Autoren auf den Zweck, um das Recht selbst zu bestimmen: Für Gierke steht - insbesondere mit Verweis auf Jhering - fest, dass eine Einsicht in das Wesen und den Entwicklungsgang des Rechts durch die Rechtswissenschaft nicht möglich sei, „ohne daß sie den Zweck erforscht, der als unbewußter oder bewußter Gestaltgeber des Rechtes waltet“ (Gierke 1889b: 3). Nach Ehrlich, für den der Entwurf der Logik der Historischen Rechtsschule folgt, hatte diese mit ihrem Spezialistendogma schlichtweg die Tatsache ignoriert, „daß nämlich das Recht um gewisser praktischer Zwecke willen da ist, daß es gewisse Bedürfnisse des Volkes, des Handels und Verkehrs zu befriedigen hat" (Ehrlich 1890b: 444). Der Zweck sei in der Pandektistik zur bloßen Billigkeitsüberlegung und Auslegungshilfe degradiert. Daher könne sie nicht erkennen, dass es sich beim Zweck im Recht um den „Hebel der Rechtsentwicklung" handele - und darin zugleich sein „rechtspolitisches Prinzip“ liege (ebd.). ${ }^{421}$ Denn die soziale Aufgabe im Recht beziehe sich immer darauf, „den Zwecken der Gesammtheit zu dienen“ (Ehrlich 1890a: 27).422 Auch für Heinrich Dernburg ist das Recht unzweifelhaft ein Zweckbegriff. Darin liegt die Differenz der Rechtswissenschaft zur Naturwissenschaft be-

421 Die Anbindung des Rechts an die praktischen Zwecke des Lebens erfolgt bei Ehrlich über das Lebensverhältnis, das - den Erkenntnissen der Historischen Rechtsschule folgend - einer Rechtsregel zugrunde liegt. Lebensverhältnisse hätten einen jeweils historisch-spezifischen Zweck - Ehrlich nennt das die „Natur der Sache“, die in den wissenschaftlichen Definitionen möglichst genau bestimmt wird (Ehrlich 1890a: 23).

422 Jhering konnte - so Ehrlich - im Übrigen auch nur vor dem Hintergrund der Dominanz der Historischen Rechtsschule als Entdecker des Zwecks auftreten (Ehrlich 1890b: 444). Oder wie Julius Ofner anmerkt: „Der Zweckgedanke ist alt; insbesondere haben ihn die englischen Philosophen Locke, Hume, Bentham vertreten. Nur die bisherige Lehre, dass der Jurist über das Gesetz nicht nachzudenken, sondern es anzunehmen und zu befolgen habe, macht es begreiflich, dass die Lehre Ihering's als ein Neues, Unbekanntes bewundert und angefeindet wurde.“ (Ofner 1894: 17). 
gründet ${ }^{423}$, denn: „Die Rechtswissenschaft dagegen hat ihre Sätze zu prüfen und zu entwickeln mit Rücksicht auf ibren Zweck." (Dernburg 1894: 36, H.i.O.).

Rechtsdenken sei - so wird geltend gemacht - „Zweckdenken“ (Ofner 1894: 13). Die „Auffassung des Rechtes als eines Zweckbegriffes“(Vierhaus 1888: 14) sei geradezu kennzeichnend für unsere heutige Anschauungsweise, wie Felix Vierhaus im Jahr 1888 proklamiert. Und es ist vermutlich genau dieses weit verbreitete Bewusstsein, auf das Windscheid im Jahre 1889 mit seiner Feststellung anspielt, dass sich in neuerer Zeit mit gewisser Aufdringlichkeit der Ruf der „Zweckjurisprudenz“ erhebe (Windscheid 1889, zitiert nach Dove 1893: 153). Der Zweck des Rechts bzw. der Zweck im Recht wird zu einem Schlagwort im Streit um die soziale Aufgabe des Privatrechts. ${ }^{424}$

\section{Recht als gesellschaftlicher Ordnungsfaktor}

Gerade aus dieser Zweckperspektive zeigt sich: Die Umdeutung der Sozialsphäre bewirkt gegenüber dem Repräsentationsschema der Historischen Rechtsschule eine veränderte Bestimmung des Rechts. Zwar wird dessen Grundlage, d.h. die Rechtsentstehungslehre, auch von den Kritikern gar nicht bestritten: Dass das Recht vom Leben erzeugt werde (Ehrlich 1890a: $22 \mathrm{f}$. ${ }^{425}$ bzw. aus der „Rechtsüberzeugung des Volkes“ erwachsen sei (Pfizer 1892a: 97), dass es daher ein „Niederschlag“ der Erfahrung sei (Petražycki 1895: 582) bzw. sich in der Rechtsordnung die jeweiligen gesellschaftlichen (Macht-)Verhältnisse „widerspiegeln“ (Menger 1895: 24), wird selbst von den schärfsten Kritikern anerkannt. ${ }^{426}$ Gerade vor diesem Hintergrund wird das Problem ja dahingehend formuliert, dass man ein der

423 Dernburg verweist hier auf die Rektoratsrede des österreichischen Juristen Adolf Exner (Dernburg 1894: 36), der die Möglichkeit einer naturwissenschaftlichen Betrachtung von Kulturphänomenen verneint, gleichsam aber die Wichtigkeit der kausalen Betrachtung betont (vgl. Exner 1892: 14f.).

424 Nach Jan Schröder liegt dieser Hinwendung zum Zweck der Wandel zum voluntaristischen Rechtsbegriff zugrunde: Wenn das Recht als Ausdruck eines allgemeinen Willens angesehen wird, kann jedem erklärten Willen ein Zweck zugrunde gelegt bzw. unterstellt werden (Schröder 2012: 283).

425 Ehrlich nennt das die „halbe[] Wahrheit" der Historischen Rechtsschule (Ehrlich 1890b: 443).

426 Gierke hatte sein Bekenntnis zur Rechtsentstehungslehre schon Anfang der 1880er Jahre kundgetan (Gierke 1883). Insofern verwundert es nicht, dass er seine Kritik gerade auf diesem Schema entfaltet (s.u.). 
Gesellschaft adäquates Recht zu finden habe, das die gegenwärtigen gesellschaftlichen Verhältnisse „widerspiegelt" (Sohm), das „unsern heutigen Verhältnissen“ (Kloeppel 1889: 67) ${ }^{427}$ bzw. dem „im Volke lebenden Rechtsbewußtsein entspreche[], mindestens nicht widerspreche[]“ (Bähr 1888b: 324$) .428$

Allerdings lässt sich angesichts des gefährdeten Objekts ,Gesellschaft ${ }^{\star}$ das Recht nun nicht mehr als Repräsentation einer harmonisch gewachsenen Sozialsphäre begreifen. Genau deshalb rückt seine gesellschaftliche Funktion, sein Zweck für den Erhalt der Gesellschaft, in den Blick: Es häufen sich die Bestimmungen des (Privat-)Rechts als „Organisation der Gesellschaft“ (Dernburg 1889: 176), als „Normirung der Verhältnisse der Gesellschaft und der vielseitigen Beziehungen, die in derselben existiren" (Fuld 1891: 637), als „Ordnung ihres [der Menschen, D.S.] Lebens und Verkehrs“ (Ofner 1894: 11) oder als „Fundament der Socialordnung“ (Petražycki 1893: 328). Hierin liegt der Zweck des Privatrechts, wie auch Planck betont: „Das Privatrecht hat den Zweck, und nur den Zweck, die Verhältnisse der einzelnen Menschen zu einander in einer, jenen Bedürfnissen entsprechenden Weise rechtlich zu ordnen." (Planck 1889: 405, H.i.O.)

Der Zweck des Rechts besteht also anerkanntermaßen in seiner gesellschaftlichen Ordnungsleistung. Angesichts einer bedrohten Gesellschaft sehen sowohl die Kritiker als Befürworter des Entwurfs die Aufgabe des zukünftigen BGBs in der Sicherung der Gesellschaftsordnung. Es geht wie für Planck - um die „Befestigung der Grundlagen der bestehenden Gesellschaftsordnung" (Planck 1899: 184), und Gierke will die Angriffe auf die „Lebensbedingungen der Gesellschaft“ abwehren (Gierke 1889b: 20). Insbesondere verlangen einige, dass die Kodifikation des Privatrechts zur „Lösung des sozialen Sphinxräthsels“ (Fuld 1891: 636), d.h. der sozialen Frage, beitragen solle (vgl. Menger 1890; Ehrlich 1892; Petražycki 1893). Gerade dadurch werde die Selbstauflösung bzw. das Auseinanderbrechen der Gesellschaft verhindert. An der Erfüllung dieser Aufgabe wird die Kodifikation gemessen.

$427 \mathrm{Zu}$ der Frage, ob die wirtschaftlichen Bedürfnisse dabei genügend Gehör fanden, vgl. die Literaturnachweise in Reichsjustizamt 1967a [1890]: 10ff.

428 Angesichts dieser Aufgabenstellung wird dem BGB und seinen Entwürfen im Gegenzug vorgeworfen, dass sie veraltet und daher „unzeitgemäß“ seien (vgl. die Literaturhinweise etwa zu den Juristen Hermann Jastrow und Franz Bernhöft, den Sozialdemokraten August Bebel und Frohme, später auch dem Zivilrechtler Justus Wilhelm Hedemann sowie dem Rechtsphilosophen Gustav Radbruch bei Repgen 2001: 511ff.). 
Das Recht wird in der Auseinandersetzung mit dem Entwurf nicht mehr als Selbstzweck, sondern als Mittel zum Zweck adressiert - und der Zweck wird in der Sicherung der gesellschaftlichen Ordnung gesehen. Recht wird als gesellschaftlicher Ordnungsfaktor problematisiert, und es etabliert sich eine gesellschaftsfunktionale Perspektive.

\section{Epistemische Folgen I: Theorie der Gesellschaft, Rechtstheorie und Gesetzgebungstechnik}

Die Frage, wie der soziale Zweck des Privatrechts zu verwirklichen bzw. ob dies dem ersten Entwurf bereits gelungen sei, wird auf einer grundsätzlichen rechtstheoretischen Ebene diskutiert. Es gilt: „Zweckmäßig ist aber eine einzelne Gesetzvorschrift, wenn sie dem Zweck entspricht, den das ganze Gesetz verfolgt. Es ist daher nötig, sich die Bedeutung und Aufgabe des Zivilrechts für ein Volk überhaupt einmal klar zu machen." (Lobe 1896: 29)

\section{Die Theorie der Gesellschaft und die soziale Aufgabe}

Sieht man den Zweck des Privatrechts in der Sicherung der gesellschaftlichen Ordnung, dann wird das Objekt,Gesellschaft' für Kritiker wie Befürworter zum Maßstab der sozialen Aufgabe: „Der Jurist, der Gesetze macht, soll nur das, was der Gesellschaft nützlich ist, in die bezüglichen Formen gießen.“ (Dernburg 1889: 177) Zur Debatte steht, wie „die soziale Ordnung unter den Menschen [...] am besten gedeiht" (Baron 1889: 231), wie man eine "friedliche und harmonische Entwicklung der sozialen Verhältnisse herbeizuführen und zu sichern" vermöge (Fuld 1891: 656). Genau hierüber entbrennt der Streit über die Güte des BGBs und seiner Entwürfe: Es geht um die „soziale Wirkung“ (Lobe 1896: 31) des Gesetzesvorhaben.

Viele Kritiker machen geltend, dass der Entwurf unheimlich „in seinem kalten, starren Individualismus“" (Ehrlich 1890a: 30, s.a. Schulze-Gaevernitz 1890: 167), ja Ausdruck eines reinen individualistischen Manchestertums sei (vgl. Gierke 1889a: 3; Bähr 1890: 199; Menger 1890: 29). Daher sei er gesellschaftsfeindlich, zersetze die Gemeinschaftsverhältnisse und verschärfe die Kluft zwischen den Menschen: Sollte der Entwurf Gesetz werden, werde er ,alles thun, was an ihm ist, um den Klassengegensatz zu vertiefen und die socialen Kämpfe zu verbittern“ (Ehrlich 1890a: 28). Da er in seiner 
Orientierung am römisch-individualistischen Privatrecht die soziale Zersetzung nicht aufhalten könne (Gierke 1889b: 6f.), sei der erste Entwurf letztlich "gesellschaftswidrig“ (Gierke 1896: 6).

Genau das bestreiten seine Verteidiger. Keinesfalls begünstige der Entwurf einseitige Interessen, namentlich die Interessen einer spezifischen Klasse (vgl. Planck 1889: 406; Sohm 1895: 741). Er habe weder individualistische, noch einseitig kapitalistische Tendenzen. Vielmehr gelte: „Der Entwurf beobachtet strengste Neutralität." (Krech 1889: 4 Anm.) Die Betonung der Freiheit des Einzelnen führe außerdem nicht zur Zersetzung der Gesellschaft. Vielmehr müsse man die gesellschaftliche Funktion der individuellen Freiheit in den Blick nehmen. Dann zeige sich, dass ihre Stärkung das Bestehen der Gesellschaft fördere:

Ich will vielmehr die Frage so formulieren, ob die soziale Ordnung unter den Menschen, ob die Gemeinschaft nicht dadurch am besten gedeiht, daß die Privatrechte dem Ermessen der Individuen überlassen, ihrer freien unbeschränkten Verfügung unterworfen werden, und ob nicht die Grenze des Privatrechts da gezogen werden muß, wo die Rechte nicht mehr dem beliebigen Ermessen, der freien Verfügung der Individuen aus Rücksicht auf die Gemeinschaft anheim gegeben werden können. (Baron 1889: 231) ${ }^{429}$

Zudem sprächen gerade die Bedürfnisse der Zeit dafür, namentlich die fortschreitende Individualisierung, der Freiheit des Einzelnen ein festes Fundament zu geben: Die heutigen sozialen Verhältnisse zeichnen sich durch eine „Atomisirung der Gesellschaft" aus (Bornhak 1891: 214), die Gegenwart werde durch das „Dogma der persönlichen Freiheit" beherrscht (Friesen 1900: 72f.). Daher könne eine Gesetzgebung, die ein „der heutigen wirthschaftlichen und sozialen Ordnung entsprechendes Rechts“ schaffen solle, nicht umhin, eine rein kapitalistisch-individualistische Rechtsordnung zu schaffen (Bornhak 1891: 214).

Es steht also zur Debatte, wie sich das BGB und seine Entwürfe auf die gesellschaftliche Ordnung auswirken. Um diese Wirkung abschätzen zu können, bedarf es - wie geltend gemacht wird - einer Theorie der Gesell-

$429 \mathrm{Zu}$ dieser Verknüpfung von (liberaler) Freiheitsvorstellung mit sozialen Anliegen im Topos der „sozialen Freiheit“ vgl. Repgen 2001: 83ff. m.w.N. zu Sohm, Leonhard Jacobi und Philipp Lotmar. Für Stammler handelt es sich immer um ein gesellschaftstheoretisches Problem: Man könne keinen Unterschied zwischen freiheitlichen und sozialen Regelungen menschlichen Zusammenlebens machen, sei doch jede Regelung - auch wenn sie die Freiheit des einzelnen betone - sozial (vgl. Stammler 1896: 123). 
schaft: Gierke etwa betont immer wieder, dass seiner Konzeption des Sozialrechts, auf der seine Kritik am BGB und dessen Entwürfen beruht, eine "moderne Gemeinschafts- und Gesellschaftstheorie“ zugrunde liege (Gierke 1887: 10, H.i.O.). Wenn er sich damit explizit gegen die ,individualistische[] Gesellschaftsauffassung" richtet (Gierke 1902: 5), so schreibt er letztlich gegen die Vorstellung an, dass die Gesellschaft nur als Summe ihrer Teile betrachtet werden könne.

Andererseits geht es um die Bestimmung der gegenwärtigen Gesellschaftsform: Gierkes Position hält man entgegen, dass gerade aufgrund der gesellschaftlichen Entwicklung der individualistischen Gesellschaftsauffassung der Vorzug zu geben sei, derzufolge so etwas wie ein Sozialrecht der gemeinschaftlichen Verhältnisse als überindividuelle selbständige Wesenheiten geschichtlich überholt erscheine. Die Gesellschaft könne man gegenwärtig sinnvollerweise nur als Summe ihrer Teile betrachten, als Menge von Individuen mit einzelnen Rechtsverhältnissen untereinander und gegenüber dem Staat (vgl. Repgen 2001: 117). Angesichts dieser Gesellschaftsdiagnose erweise sich die individualistische Tendenz des BGBs und seiner Entwürfe keinesfalls als gesellschaftszersetzend, da doch die Betonung der subjektiven Freiheit im Privatrecht eine Kongruenz zwischen Privatrecht und gegenwärtigem gesellschaftlichen Zustand herstelle.

Der Jurist, Nationalökonom und Politiker Gerhard von Schulze-Gaervenitz bringt im Jahr 1890 diese Streitlage auf den Punkt: Der germanistischen Rechtsschule - für ihn gleichzusetzen mit der Kritik am individualistischen Entwurf - „steht die individualistische Gesellschaftsauffassung [gegenüber, D.S.], welche nur einzelne menschliche Individuen und Beziehungen zwischen solchen, dagegen kein über beiden sich aufbauendes Gesamtdasein kennt" (Schulze-Gaevernitz 1890: 166). Damit wird die Gesellschaft zum Maßstab der Güte des Entwurfs. Denn letztlich gilt: Erst die richtige Theorie der Gesellschaft bzw. des gegenwärtigen Gesellschaftszustandes erlaubt die Bestimmung des zu schaffenden Rechts. Und in der Beantwortung dieser Frage stehen sich zwei verschiedene gesellschaftstheoretische Prämissen gegenüber, die sich jeweils um das Verhältnis von Individuum und Gesellschaft drehen.

\section{Privatrechtstheorie als Gesellschaftstheorie: BGB und Spezialgesetzgebung}

Diese gesellschaftstheoretische Frage wird in ein rechtstheoretisches Problem gewendet: in die Abgrenzung und Verhältnisbestimmung von Privatrecht und Öffentlichem Recht. Denn Savigny behandelt die Frage nach dem Ganzen und seinen Teilen über die Rechtsgebietszuweisung: Habe 
das Öffentliche Rechts „das Ganze als Zweck“, so sei im „Privatrecht der einzelne Mensch für sich Zweck“ (Savigny 1840a: 23). Gegenüber dem ,reinen' Privatrecht habe das Öffentliche Recht seine Wurzeln auch in außerrechtlichen Gründen und Zwecken, etwa in sittlichen, politischen, sozialstrukturellen und wirtschaftlichen Überlegungen (s.o.). Wenn nun aber genau diese Gründe und Zwecke als, sozial' gelten, so erklärt sich daraus die Einschätzung, dass das Privatrecht sozial indifferent sei: Die „herrschende Sicht“, so beschreibt Ofner kritisch, sei „blind für die Verhältnisse und Machtfaktoren in der Gesellschaft" (Ofner 1894: 30). Dementsprechend wendet sich die Kritik gegen diese Idee der Scheidung zwischen „anomalische[m]“ und „reine[m]“ Recht (ebd.: 30). ${ }^{430}$ Der Streit, ob und wie das BGB seine soziale Aufgabe verwirklichen könne, dreht sich also maßgeblich darum, wo der soziale Zweck im Recht verortet wird. Es geht damit um die rechtstheoretische Bestimmung des Zwecks - und damit des Wesens - des Privatrechts, und das mit Blick auf seine Abgrenzung zum Öffentlichen Recht.

Auch Gierke stellt die Verschiedenartigkeit des Öffentlichen Rechts und des Privatrechts nicht in Frage. Der grundsätzliche Gegensatz ist ihm zufolge vielmehr Ausdruck der doppelten Bestimmung der menschlichen Existenz als Individuum und als Teil eines höheren Ganzen: Das Öffentliche Recht sei „die Daseinsordnung höherer Gesammteinheiten mit selbständigem Lebenszweck“ und diene "der erhabenen Idee eines unsterblichen Gemeinwesens"; demgegenüber erkenne das Privatrecht das „Individuum als Selbstzweck“ an (Gierke 1889b: 11). Gierke wendet sich jedoch gegen die Aufspaltung der Rechtsordnung entlang dieser Unterscheidung. Er hält dieser Konstruktion den „großen germanischen Gedanken der Einheit alles Rechtes“ (ebd.: 12) entgegen ${ }^{431}$ - und dies gerade an-

430 Johannes Krech verteidigt die Idee des reinen Privatrechts vor diesen Angriffen. Denn wenn die Gesetzgebung von den jeweils beherrschenden Strömungen abhängig sei, so gelte mit Blick auf das Privatrecht: „Daß es daneben große Gebiete gibt, in denen ein über dem Wechsel der Zeiten und der Parteien stehendes Recht seine Hoheit und Stetigkeit bewahrt, ist ein Segen für Volk und Staat. Das geschmähte, reine Privatrecht', welches der Entwurf dem deutschen Volke bietet, ist dazu geeignet, diese segensreiche Wirkung für eine ferne Zukunft auszuüben, gerade weil aus demselben ausgeschieden ist, was einen tendenziösen Beigeschmack hat." (Krech 1889: 4).

431 Unter Berufung auf Jhering schreibt Gierke: „So kann auch die Rechtsordnung, wenn sie sich in Privatrecht und öffentliches Recht spaltet, wohl eine Weile davon absehen, daß der Einzelne für das Ganze und das Ganze für die Einzelnen da ist. Allein zuletzt darf sie die Einheit des Zieles nicht vergessen und muß 
gesichts einer im Bestand gefährdeten Gesellschaft. ${ }^{432}$ Der auf die Gesamtheit gerichtete Blick des Öffentlichen Rechts und derjenige auf das Individuum seien letztlich nur die beiden Seiten des einheitlichen Phänomens Recht. Daher müssten beide Seiten trotz Aufrechterhaltung ihrer grundsätzlich divergierenden Orientierung miteinander verwoben werden: „Schroff ausgedrückt: in unserem öffentlichen Recht muß ein Hauch des naturrechtlichen Freiheitstraumes wehen und unser Privatrecht muß ein Tropfen sozialistischen Oeles durchsickern!“ (Ebd.: 13)433

Diese Einheit des Rechts werde im Privatrecht durch das „Socialrecht“ der Verbände verwirklicht (Gierke 1887: 10), ${ }^{434}$ das Gemeinwohlinteressen sowie den Gedanken der Gemeinschaft berücksichtige. ${ }^{435}$ Den privatrechtlich geregelten menschlichen Verband wie Stiftung, Genossenschaft und Verein fasst Gierke als „reale Gesammtperson“ (ebd.: 5), d.h. als selbständi-

auch im Privatrecht, wo sie zuvörderst für Einzelinteressen sorgt, das Gemeinwohl erstreben, und im öffentlichen Recht, wo sie zunächst auf das Ganze blickt, den Einzelnen gerecht werden." (Gierke 1889b: 6).

432 Äußerst dramatisch erscheint für Gierke „die Frage nach dem Verhältniß zwischen öffentlichem Recht und Privatrecht als eine Lebensfrage der Gegenwart“" (ebd.: 10 f., H.i.O.), berge diese Trennung doch eine große Gefahr: „Das öffentliche Recht erstarrte zur Verwaltungsordnung einer absolutistischen Staatsmaschine. Das römische Privatrecht entwickelte sich zu jenem kunstvollen System, das wir Alle bewundern. Allein in aller seiner klassischen Schönheit vermochte es den wirthschaftlichen Verfall, die sittliche Auflösung, die soziale Zersetzung nicht aufzuhalten." (Ebd.: 6f.).

433 Gierke warnt im gleichen Atemzug aber vor einer Übertreibung dieses Gedankens: „Die Entstaatlichung des öffentlichen Rechts im Sinne des naturrechtlichen Individualismus bedeutet die Auflösung und den Tod, die Verstaatlichung des Privatrechts im Sinne des Sozialismus bedeutet die Unfreiheit und die Barbarei." (Ebd.: 12, H.i.O.).

434 Dabei handelt es sich um einen bereits im Privatrecht angelegten Gedanken des Gemeinschaftsbezugs: Sozialrecht ist das Recht der menschlichen Verbände (vgl. hierzu Pfeiffer-Munz 1979) und ist nicht mit heutigen Terminus des Sozialrechts zu verwechseln, der sich in dieser Zeit erst langsam herausbildete (vgl. Stolleis 2003). Gierkes Sozialrecht, wie er es insbesondere in seiner Genossenschaftstheorie herausgearbeitet hatte, nimmt eine Mittelstellung zwischen individuellem Privatrecht und gemeinschaftsbezogenem Öffentlichen Recht ein: „Tief in das Privatrecht führt es die Verbundenheit der Personen durch natürliche und gekorene Gemeinschaftsverhältnisse und durch vielgestaltige Genossenschaften ein, und durch eine Fülle lebensvoller Zwischengefüge vollzieht es den Aufstieg zum öffentlichen Recht.“ (Gierke 1896: 2; s.a. 1887: 10).

435 Aufgrund seiner Weiterentwicklung der germanistischen Genossenschaftstheorie gilt Gierke als einer der schärfsten Kritiker der romanistischen Lehre der juristischen Person als Fiktion. Zum politischen Hintergrund des Streits um die juristische Person vgl. Schröder 1982/1983. 
ge und real existierende ,soziale Körper', die überindividuelle Ganzheiten und damit reale Willensträger seien (ebd.: 10ff.). Es handele sich dabei um natürliche, dem Recht äußerliche „sociale Organismen“ (ebd.: 23), die die Gattungseigenschaften aller organischen Lebewesen aufwiesen. Gierke behauptet damit - wie er später betont - „das Dasein von Gesammtorganismen, deren Theile die Menschen sind, über den Einzelorganismen" (Gierke 1902: 13). Ihre privatrechtliche Regelung verwirkliche bereits den Gemeinschaftsgedanken:

Hier streift das Privatrecht überhaupt den Charakter des Individualrechts ab und geht in Sozialrecht über. Denn hier hat es nicht mehr blos mit verbundenen Individuen, sondern mit Wesen höherer Ordnung zu thun, die als beständige und dauernde Träger einer sozialen Willenseinheit sich der Erfüllung eines eignen Lebenszweckes widmen. (Gierke 1889b: 42f.)

Aus Gierkes Perspektive ist damit der Bezug auf das ,Ganze“ im rechtstechnischen Sinne im Privatrecht selbst angelegt. Aufgrund der Verknüpfung des sozialen Gedankens mit der germanistischen Rechtslehre im Deutschen Genossenschaftsrecht schreibt Gierke: „Deutsches Recht ist Gemeinschaftsrecht. Es stellt auch im Privatrecht das Individuum nicht aus dem gesellschaftlichen Zusammenhang heraus, sondern mißt alle Rechte, die es dem Einzelnen zutheilt, an ihrer Funktion im Leben des Ganzen." (Gierke 1896: 2) Auch im Privatrecht gelte: „kein Recht ohne Pflicht“ (Gierke 1889b: 20), d.h. keine schrankenlose rechtliche Herrschaft des Individualgedankens. Denn nur die Anerkennung des Sozialrechts - und mit ihm des sozialen Gedankens im Privatrecht - verhindere, dass die Einheit des „innere[n] Leben[s] des gesellschaftlichen Organismus" sowie die Einheit der Rechtsordnung von „Zerreißung und Zersetzung" bedroht seien (ebd.: 13f.).

Diesen Weg über das ,Sozialrecht' schlagen jedoch nicht alle Kritiker ein. Ehrlich sieht etwa die Einheit der Rechtsordnung durch den Entwurf ebenfalls bedroht, erkennt aber die Abhilfe nicht in der Integration des (germanistischen) Sozialrechts, sondern im Wandel des Rechtsbegriffs. Denn durch die öffentlich-rechtliche Sozialgesetzgebung seien neue Ideen in das geltende Recht eingeführt worden (Ehrlich 1892: 98). ${ }^{436}$ Angesichts dessen gilt für Ehrlich:

$436 \mathrm{Zu}$ diesen neuen Ideen gehöre vor allem „die Idee [...], daß das große Eigenthum der Gesammtheit gegenüber mit Rechtspflichten belastet sei, und daß der Staat berufen ist, zwangsweise Organisationen zu schaffen, welche dem Indivi- 
Was uns noththut, das ist eine einheitliche, von solchem Geiste getragene bürgerliche Gesetzgebung, eine Gesetzgebung, die von solchen Grundgedanken durchdrungen, durchwirkt und durchwebt wird; nur diese könnte auf die ganze Gesellschaft umgestaltend einwirken und eine friedliche Umwälzung anbahnen. (Ebd.: 99)

Menger beruft sich ebenfalls auf das Öffentliche Recht, wenn er die Berücksichtigung der Klasseninteressen und damit die Anerkennung von Ungleichgewichtslagen im BGB fordert. So zeige gerade der Blick auf die neuere Sozialgesetzgebung: „Man weiss eben heute, dass es keine grössere Ungleichheit gibt, als das Ungleiche gleich zu behandeln." (Menger 1890: 29; s.a. Fuld 1891: 638f.) Dieses Ungleiche sei aber eine gesellschaftliche Größe, die sich erst im Bezug auf das Ganze, d.h. die Gesellschaft bestimmen lasse. Damit führe es weg vom individualistischen Standpunkt der „romanistischen" Privatrechtskonzeption.

In der Debatte wird immer wieder auf die öffentlich-rechtliche Sozialgesetzgebung verwiesen, die - indem sie in klassische Kerngebiete des Privatrechts hineinreicht - auf die Idee des Privatrechts rückwirkt. ${ }^{437}$ Sieht man die Kodifikation als Verwirklichung der Rechtseinheit an, so verhindert

duum im Kampfe ums Dasein einen gewissen Rückhalt gewähren sollen.“ (Ehrlich 1892: 98).

437 Die idealtypische Scheidung zwischen Öffentlichem Recht und Privatrecht war bereits seit der zweiten Hälfte des 19. Jahrhunderts durch verschiedene, auch innerjuristische Entwicklungen in Frage gestellt worden: Das subjektive Recht, jenes Moment, das gerade das Privatrecht zum Ort der bürgerlichen Freiheit macht, ist in das öffentliche Recht gewandert (vgl. insbesondere Wilhelm 1958); durch die Einführung der Verwaltungsgerichtshöfe seit dem Jahr 1863 ist Rechtsschutz für den Bürger nicht mehr allein auf das Privatrecht begrenzt (vgl. Ogorek 1988); die Vorherrschaft des Privatrechts wird durch neue Gesetzgebungskompetenzen im Rahmen der Reichsgründung sowie die Herausbildung einer anerkannten, vorgeblich ,politisch neutralen' Staatsrechtswissenschaft angegriffen (vgl. Stolleis 1989); und schließlich gehört das Öffentliche Recht, namentlich das Verwaltungsrecht, zu den am schnellsten wachsenden Rechtsgebieten, das insbesondere über die Sozialgesetzgebung sowie einen Komplex an Normen, mit denen der Staat die Privatwirtschaft umgrenzt und reguliert (etwa Wuchergesetz oder Gesetze über Urheberrecht, Verlagsrecht, Patente, Gebrauchsmuster und Warenzeichen, Genossenschafts- und GmbH-Gesetz), die Grenze zwischen Privatrecht und Öffentlichem Recht zunehmend verwischte (vgl. ebd.: 139). In den Diskussionen über die Kodifikation des BGBs herrscht ein deutliches Bewusstsein für diese Grenzprobleme. Dies zeigt sich etwa schon in der Fassung des Regelungsgegenstandes des ersten Entwurfs des BGBs durch die Kommission: Gegenüber dem „nicht nachahmenswerthen Versuch“ (Motive zu dem Entwurfe 1888b: 1) des österreichischen (ebenso wie des sächsischen) 
die Absonderung vom Öffentlichen Recht in den Augen vieler Kritiker genau diese Rechtseinheit. Denn der Entwurf, der selbst die allernotwendigsten sozialpolitischen Reformen vermieden habe (vgl. etwa Ehrlich 1890a: 35; Fuld 1891: 646), habe „durchweg mit eiserner Konsequenz alles Privatrecht ausgeschieden [...], welches im sichtbarem Zusammenhange mit dem öffentlichen Rechte steht" (Gierke 1889a: 108; vgl. auch Bar 1890: 399). Dies führe letztlich zu einem „Widerspruch [...], der ebenso bedauernswerth wie schädlich wäre" (Fuld 1891: 655; s.a. Gierke 1889b: 16) und eine "Gefahr für das dem Deutschen Reich gemeinsame Recht“ (Bar 1890: 399) darstelle. Selbst wenn man anerkenne, „daß die Lösung der sozialen Frage dem bürgerlichen Rechte nur zum wesentlich kleineren Theile zufällt, als dem öffentlichen“, gelte: „[D]er Zweck im Recht, der doch für das bürgerliche Recht wahrlich nicht minder maßgebend ist wie für das öffentliche, verlangt die besondere Beachtung des sozialen Moments bei jeder Normengebung [...].“(Fuld 1891: 637)

Dieser radikalen Umdeutung der Wesensbestimmung des Privatrechts, d.h. seiner „sozialen Färbung“ (Baron 1889: 241) - sei es als Sozialrecht (Gierke), als zu korrigierendes Klassenrecht (Menger) oder als durch das öffentlich-rechtliche Sozialrecht beeinflusstes verändertes Rechtsverständnis (Ehrlich) - wird vehement widersprochen. Aber auch von der Gegenseite wird das Problem in Abgrenzung zum Öffentlichen Rechts bestimmt, gehe es doch um die richtige Aufgabenbestimmung und Begrenzung des Privatrechts (vgl. Krech 1889: 3). Das lässt sich exemplarisch an den Ausführungen von Planck zeigen: Das BGB habe die Funktion, die Freiheitssphäre des Einzelnen zu schützen, das sei seine soziale Aufgabe:

Die Interessen der Einzelnen werden überhaupt nur deshalb geschützt, Rechte im subjectiven Sinne nur deshalb anerkannt, weil das Interesse der Gesammtheit, welche zwar aus allen Einzelnen gebildet wird, deren Interesse aber nicht mit allen Einzelinteressen zusammenfällt, jene Anerkennung fordert. Dieselbe kann daher auch in jedem einzelnen

BGBs verzichte man bewusst darauf, eine positive Feststellung des Regelungsgegenstandes ,Privatrecht' und damit eine Abgrenzung zur Materie des Öffentlichen Rechts vorzunehmen. Denn eine solche funktioniere nicht: „Das Privatrecht und das öffentliche Recht haben zahlreiche, mannigfach geartete Berührungspunkte. Gewisse Verhältnisse sind gemischter Natur; andere weisen verschiedene Seiten auf, vermögen deren das Verhältniß theils dem einen, theils dem anderen Rechtstheile angehört." Dies wird als „Grenzgebiet" bezeichnet, das „nur durch eine genaue Prüfung der einzelnen in Betracht kommenden Materien zu ermitteln" sei (ebd.). 
Falle nur insoweit erfolgen, als das Interesse der Gesammtheit es gestattet. (Planck 1889: 405f.)

In diesem Sinne handele es sich eben auch bei den Grundfragen des Privatrechtes, nämlich ob Eigentum, Ehe, ob Erbrecht anzuerkennen sei, unzweifelhaft um „sociale Fragen“ (ebd.: 406). Es gehe dann letztlich darum, im BGB - dem Kernbereich des Privatrechts - „die subjektiven Rechte der einzelnen so zu bemessen und zu gestalten, daß sie, ohne ihre Bedeutung als Rechte zu verlieren, doch die Interessen anderer thunlichst wenig schädigen" (Planck 1899: 181).

Aber auch, wenn man wie Planck aufgrund der gegenwärtigen Lebensverhältnisse innerhalb des BGBs gewissen „Forderungen gerecht zu werden [sucht], die auf Beseitigung der sich aus dem gegenwärtigen Rechtszustand ergebenden Härten gerichtet sind“, so liege die

Hauptaufgabe in dieser Beziehung [...] außerhalb des Gebiets des bürgerlichen Rechtes. Unsere Gesetzgebung hat sich dieser Aufgabe in einer Reihe von Spezialgesetzen - ich erinnere nur an die Gesetze über Unfall-, Kranken-, Invaliden- und Altersversicherung - mit großem Erfolg gewidmet und sie wird auf diesem Wege auch ferner fortschreiten müssen. (Ebd.)

Ähnlich strikt trennen auch andere Autoren die soziale Aufgabe der Freiheitsgewährung durch das Privatrecht vom Öffentlichen Recht (vgl. etwa Bornhak 1891; Zeerleder 1896). So wendet Julius Baron gegen Gierkes Thesen ein:

Was aber das ewige Verdienst des römischen Rechts bleiben wird, das ist einerseits die formale Ausbildung der Rechtsbegriffe, andererseits die Durchdringung der Begriffe des Vermögensrechts mit dem Gedanken der Freiheit; denn das Privatrecht hat die Aufgabe, dem Einzelnen eine Freiheitssphäre anzuweisen, ad singulorum utilitatem spectat, es hat keine soziale Aufgabe zu verfolgen. (Baron 1889: 248) 438

Dem Freiheitsgedanken wird selbst eine soziale Funktion zugesprochen: Baron macht insbesondere gegenüber Gierke geltend, dass das von diesem so bekämpfte römische Vermögensrecht „eine Emanation des Gedankens der sozialen Freiheit" (ebd.: 232) sei - jener Freiheit, die die ungehinderte Berufsausübung und freie Berufswahl, die Fähigkeit der Teilnahme an ge-

438 Zum Romanisten und - nach eigenem Bekunden - Kathedersozialisten Julius Baron, der im Übrigen wie Gierke von Anfang an Mitglied im Verein für Socialpolitik war, vgl. Hofer 2001: 148ff., m.w.N. 
sellschaftlichen Gütern, die Niederlassungsfreiheit und die Koalitionsfreiheit umfasse und im 19. Jahrhundert verwirklicht worden sei. Das zu gewährleisten, sei die historisch und gesellschaftlich notwendige Aufgabe des BGBs, und die soziale Freiheit leiste alles, was Gierke als soziale Aufgabe des Privatrechts hinstelle. Dementsprechend gehe es im Privatrecht nicht wie bei Gierke um die Verbindung von Recht und Pflicht, sondern um Aufhebung und Einschränkung von Rechten (ebd.). Baron intendiert aber keineswegs, die soziale Frage im engeren Sinne nicht anzugehen. Er wendet sich etwa keineswegs gegen die Verstaatlichung des Eigentums aus Gründen der Sicherung der Verteilungsgerechtigkeit. Nur sei dies nicht Aufgabe des Privatrechts: „Sträuben wir uns nicht dagegen! denn darin liegt eine kerngesunde Weiterbildung des Privatrechts; in der Vermehrung des öffentlichen Eigentums liegt das Programm der Zukunft und nicht in der sozialen Färbung des Privateigentums.“ (Ebd.: 241)

In rechtstheoretischer Hinsicht geht es um die Frage, ob die soziale Aufgabe als Bezug zum Ganzen dem Privatrecht immanent, oder aber, ob sie im Öffentlichen Recht anzusiedeln sei; in gesetzgebungstechnischer Hinsicht geht es um die Frage, ob die soziale Aufgabe im Entwurf zum Ausdruck kommen müsse, 439 oder aber, ob man dafür auf die Spezialgesetzgebung verwiesen werde. Selbst wenn dabei für die Befürworter der Spezialgesetzgebung angesichts einer sich rasch wandelnden, im Bestand bedrohten Gesellschaft eine Korrektur innerhalb des BGBs über Generalklauseln oder allgemeine Billigkeitsgedanken zuzulassen sei, so handele es sich hierbei nur um Ausnahmen, d.h. um „Beschränkung der individuellen Rechte und Abschwächung der Konsequenzen derselben“ (Planck 1899: 184), die aber nichts an der prinzipiellen Orientierung an der indivi-

439 Gängiger Topos ist dabei die Forderung der Einschränkung der Vertragsfreiheit (vgl. hierzu die Literaturhinweise zu Konrad Schneider, Gierke, Bähr, Gustav Hartmann, Oscar Cleß und Ludwig von Bar bei Repgen 2001: 73f.). Repgen verweist zu Recht auf die bereits zuvor verstärkt aufgekommenen Überlegungen zur Notwendigkeit der Einschränkung der Vertragsfreiheit in der Nationalökonomie (etwa Jean-Charles-Léonard Simonde de Sismondi, Wilhelm Roscher, Adolph Wagner oder Karl Rodbertus; ebd.: 73). Deren Ideen wurden trotz der Tatsache, dass sie grundsätzliche rechtstheoretische Fragen berührten und dies auch von juristischer Seite wahrgenommen wurde (vgl. die Nachweise bei Hofer 2000, 2001: 107ff.; Wilhelm 1979), in der Debatte um die soziale Aufgabe des Privatrechts auf der Ebene der zivilrechtlichen Grundsätze und Prinzipien jedoch in der Regel außer Acht gelassen (anders jedoch bei Gierke, Menger und Baron, vgl. Hofer 2001: 153). Eine Bezugnahme auf nationalökonomische Erkenntnisse erfolgt meist auf der Ebene der Diskussion einzelner materialer Bestimmungen des BGB-Entwurfs. 
duellen Freiheit änderten - also genau jenes Regel-Ausnahme-Schema, das Ehrlich kritisiert (s.o.). Solche Vorschriften seien daher nur im beschränkten Maße zulässig. Denn die Hauptaufgabe mit Blick auf die sozialen Belange liege in der Spezialgesetzgebung, und hier v.a. im Öffentlichen Recht. ${ }^{440}$

Angesichts dieser ganz gegensätzlichen Positionen ist Ludwig Fuld zuzustimmen, wenn er im Jahr 1891 schreibt:

Bezüglich weniger Fragen, zu deren Erörterungen die Veröffentlichung des Entwurfes Anlaß gegeben hat, stehen sich die gegenseitigen Meinungen schroffer und unvermittelter einander gegenüber, als in Ansehung derjenigen, ob und in welchem Umfange das Gesetzbuch sozialpolitische Forderungen zu erfüllen habe. (Fuld 1891: 636)

Allerdings eint die Debatte die Problematisierung dieser Frage als Streit über die Wesensbestimmung des Privatrechts - und das im Hinblick auf die Verortung des sozialen Zwecks im Recht. Zur Disposition steht, ob dieser auch dem Privatrecht - und damit dem BGB - oder nur bzw. primär dem Öffentlichen Recht immanent sei. Dabei relativieren beide Positionen das Privatrecht: Erstens wird auch von den Verteidigern des Entwurfs anerkannt, dass das Privatrecht eine soziale Aufgabe habe - und zwar gerade durch die Verwirklichung der individuellen Freiheit, wohingegen die sozialen Belange, die sich auf die Gemeinschaft respektive die Gesellschaft beziehen, Sache des Öffentlichen Rechts seien. Gefragt wird damit nach der gesellschaftlichen Funktion der individuellen Freiheit: ob etwa ihre Überbetonung die Gesellschaft bedrohe, oder ob mithin die Freiheit des Individuums selbst eine gesellschaftliche Institution darstelle, deren Regelung im BGB dem Erhalt der Gesellschaft diene.

Zweitens stellen selbst die Befürworter einer Spezialgesetzgebung das Privatrecht nun nicht mehr über das Öffentliche Recht. Letzteres erscheint nicht mehr wie bei Savigny als „anomalisch“, sondern komplementär. Denn ihm komme aufgrund seiner gesellschafts- bzw. gemeinschaftsorien-

440 Diese Position trifft sich mit der Politik des Reichsjustizamtes, der treibenden Kraft im Verfahren der Erstellung des zweiten Entwurfs: Angesichts der vehementen Kritik implementiert es gewisse soziale und sozialpolitische Zugeständnisse, versucht aber zugleich politisch und wirtschaftlich brisante bzw. umstrittene Fragen aus der Kodifikation herauszuhalten: „Das BGB wurde bewußt entpolitisiert. Die Politik des Reichsjustizamts ging dahin, politisch aufgeladene Materien aus der Kodifikation herauszuhalten." (Schulte-Nölke 1995: 279) Diese seien der Spezialgesetzgebung zu überantworten. Damit setzt sich de facto diese Position im Gesetzgebungsverfahren durch. 
tierten Zwecksetzung die dringliche Aufgabe zu, soziale Härten zu korrigieren. Problematisiert wird die Spannung zwischen Individuum und Gesellschaft - die entsprechend der Positionen entweder über eine rechtsgebietsorientierte Arbeitsteilung oder aber in einem einheitlichen Rechtsbegriff aufzulösen sei.

Damit gewinnt die Gesellschaft als Bezugsobjekt an Bedeutung. Denn in der Verhältnisbestimmung zum Öffentlichen Recht wird die Spannungslage zwischen Individuum und Gesellschaft problematisiert. Und es ist im Spezifischen das Privatrecht mit seinem Bezug zum Individuum, über das dieses Spannungsverhältnis ausgehandelt wird. Der Ort der Freiheit ist nach wie vor das Privatrecht und nicht das Öffentliche Recht. Diese Verortungsprobleme werden angesichts der gefährdeten Gesellschaft zu einer dringlichen Frage. Dass dem Privatrecht dabei eine gesellschaftserhaltende Funktion zukommt, bestreiten daher weder Befürworter noch Kritiker des Entwurfs - man streitet lediglich darüber, ob sich der gesellschaftliche Zerfall im Privatrecht durch die Sicherung der individuellen Freiheiten oder die Stärkung sozialer Rechte mit Kollektivbezug abwenden lasse.

Problematisiert wird also letztlich die gesellschaftliche Ordnungsfunktion des Privatrechts. In einer solchen gesellschaftsfunktionalen Perspektive wird die Gesellschaft zum Gegenstand der Auseinandersetzung um das Privatrecht, hier entfaltet sie ihre epistemische Wirkung. Allerdings wird die gesellschaftstheoretische Frage, die der Debatte um die soziale Aufgabe immanent ist, über die rechtstheoretische Abgrenzung von Privatrecht und Öffentlichem Recht (die in die gesetzgebungstechnische Frage einer Notwendigkeit der Spezialgesetzgebung mündet) ausgehandelt. Über diese Umwandlung der Frage wird die Gesellschaft letztlich nur zu einem impliziten Gegenstand der Rechtswissenschaft. Aufgrund dessen aber erweist sich die Privatrechtstheorie dann selbst als Gesellschaftstheorie - oder wie Julius Ofner schreibt: „Ist Recht die Ordnung der Gesellschaft, so sind alle sozialen Fragen Rechtsfragen.“ (Ofner 1894: 21)

\section{Epistemische Folgen II: Wabrheit, Gesellschaftswissenschaft und Autonomie der Rechtswissenschaft}

Die Verfestigung der gesellschaftsfunktionalen Perspektive im privatrechtswissenschaftlichen Diskurs beantwortet allerdings noch nicht die Frage, welche Rolle in der Bestimmung des zu kodifizierenden, und d.h. des ,richtigen' Rechts, der Rechtswissenschaft zukommt. Mehr noch, es wird an der Autonomie der Rechtswissenschaft gekratzt, öffnet sie sich doch 
durch die Frage nach der gesellschaftlichen Funktion des Privatrechts für Politik sowie Sozial- und Gesellschaftswissenschaften.

1. Die Wahrheit in der Gesetzgebung: Die soziale Aufgabe des BGBs jenseits der Politik

Die Abgrenzung von der Politik erfolgt über die Orientierung an der wissenschaftlichen Wahrheit. Denn wie man der sozialen Aufgabe im BGB gerecht werden könne, wird als Wahrheitsfrage verhandelt. Dies lasse sich nämlich - so der übereinstimmende Tenor - über die wissenschaftliche Arbeit beantworten. Das bestreiten selbst diejenigen Autoren nicht, die geltend machen, dass der Entwurf seine politische Aufgabe völlig verkannt habe. Denn sowohl Ehrlich als auch Menger und Petražycki, die auf die Notwendigkeit der genuin politischen Entscheidungen in der Gesetzgebung hinweisen, berufen sich gerade nicht primär auf normativ-politische Zielsetzungen, sondern auf die Analysen der objektiven gesellschaftlichen Umstände und sozialen Mechanismen, um ihre Kritik zu formulieren.

Das Problem liegt für Ehrlich und Menger in der Kluft zwischen den gewachsenen Rechtssätzen und dem gegenwärtigen sozialen Entwicklungsstand, die es zu überwinden gelte: Ehrlich etwa geht von einem ganz offensichtlichen Widerspruch der Privatrechtsordnung zur gegenwärtigen kapitalistischen Produktionsweise aus (vgl. Ehrlich anonym/1891: 479f.). Das liege in der Natur der Sache (ebd.: 544). Denn gegenüber dem raschen gesellschaftlichen Wandel im Kapitalismus besitzen jene Institute, die bereits durch feste, in Worte gefasste Rechtssätze geregelt werden, eine „archaisirende Tendenz" (Ehrlich 1892: 97). Das betreffe namentlich das Privateigentum als Kernprinzip des Privatrechts - hier müsse man mit Blick auf den ersten Entwurf feststellen: „Zwischen Eigenthum und den Besitzlosen gähnt ein Abgrund wie vielleicht in keinem Rechtssysteme der Welt.“ (Ehrlich 1890a: 28) Für Ehrlich ist also offensichtlich, dass sich „das Recht von den thatsächlichen Verhältnissen gar weit entfernt hat" (ebd.: 30). Solle nun die soziale Krise, die aus der gesellschaftlichen Entwicklung resultiere, bewältigt werden, „so muß man selbstverständlich das Recht den veränderten Verhältnissen anzupassen trachten“ (Ehrlich 1892: 97). Ehrlich fordert dabei die Anpassung in zwei Richtungen:

[E]s muß durch Beschränkung des großen Eigenthums und der Vertragsfreiheit, die durch Entwickelung der Industrie ins Unermeßliche gesteigerte Macht des Einzelnen mit Pflichten gegenüber der Gesammtheit belastet und es müssen gesellschaftliche Organisationen ge- 
schaffen und die bereits vorhandenen Keime lebenskräftig ausgestaltet werden. (Ebd.: 98) 441

Das historisch gewachsene Recht muss nach Ehrlich seinem sich wandelnden Kontext angepasst werden, um die Kluft zwischen Recht und gesellschaftlicher Wirklichkeit zu überwinden. Der Kontext wiederum sei eine objektive Tatsache, die sich jedoch nicht durch genuin rechtswissenschaftliche Arbeit bestimmen lasse - vor allem nicht durch die spezifische juristische Technik der herrschenden Doktrin der Historischen Rechtsschule. ${ }^{442}$ Aufgrund des Spezialistendogmas und der damit einhergehenden Konzentration auf positive Rechtssätze sei sie nicht in der Lage, die gegenwärtigen Lebensverhältnisse - die Grundlage jeden Rechts und Rechtswandels - zu erkennen. Alles, was die Juristen zu den „Bedürfnissen der Zeit“ feststellten, sei rein subjektiv, eine rein „oberflächliche Beobachtung des täglichen Lebens“ bzw. ein „oberflächliches Herumreden“, ein „Abklatsch der täglichen Zeitungslektüre“ oder entspringe dem „berüchtigten ,gesunden Menschenverstande““ (Ehrlich 1890b: 450, 451). Ehrlich erkennt ein „Hinuntersinken ins Dilettantenhafte“, da die Feststellungen über die gegenwärtigen Lebensverhältnisse „nicht das Ergebnis des eingehenden Studiums eines sorgfältig gesammelten Materials“ sei. Daher sei erkennbar gerade „keine wissenschaftliche Grundlage für das Urtheil vorhanden“ (ebd.: 450, 451). Ehrlich klagt also in seiner Kritik des BGBs und der Entwürfe nicht das Verfehlen normativer Zielvorgaben, sondern den Mangel an Wissenschaftlichkeit an. Denn die Bestimmung der Lebensverhältnisse könne nicht durch herkömmliche rechtswissenschaftliche Arbeit erfolgen, und werde

441 Zur Lösung der sozialen Frage befürwortet Ehrlich bis in die 1890er Jahre vor dem Hintergrund einer dem Sozialismus und Materialismus nahestehenden Theorie der gesellschaftlichen Entwicklung richtungsweisende Eingriffe des Staates ins Privatrecht, die auf eine Änderung der wirtschaftlichen Grundlagen abzielen (vgl. Ehrlich anonym/1891). Dementsprechend erscheint er seinen Zeitgenossen als Vertreter eines Sozialismus, der „eine Brücke zwischen Menger und Marx“ zu bilden sucht (vgl. Redaktionelle Anmerkung Kautsky in Ehrlich anonym/1891: 430 Fn. *; Vogl 2003: 134). Später wird Ehrlich jedoch die Stärkung der Selbstregulierungskräfte in der Gesellschaft befürworten (vgl. etwa Ehrlich 1916 [1909]), und auch zunehmend liberale Argumente aufgreifen. Dieser Positionswandel führt bis heute zu Schwierigkeiten, Ehrlich politisch einzuordnen (vgl. hierzu Vogl 2003: 177ff.).

442 Angesichts dessen gilt für Ehrlich: „[B] evor unsere Gesellschaft auf diesem Wege zu einer gründlichen Socialreform gelangt, erlebt sie vielleicht eher die vollständige Erkaltung der Sonne, welche die Astronomen für die nächsten Jahrmillionen in Aussicht stellen." (Ehrlich 1890b: 445). 
dies versucht, so führe dies zu rein unwissenschaftlichen, subjektiven Urteilen.

Für Menger handelt es sich bei der Bestimmung der Lebensverhältnisse - anders als für Ehrlich - um eine explizit rechtswissenschaftliche Aufgabe. ${ }^{443}$ Er schlägt eine Erweiterung der Rechtswissenschaft vor, die die politischen Angelegenheiten als wissenschaftliche Fragen zu integrieren vermag. So habe die Rechtswissenschaft eine dreifache Aufgabe: Während die geschichtliche Rechtswissenschaft das gewachsene Recht untersuche und die dogmatische Rechtswissenschaft das gegenwärtige Recht in der „für seine Anwendung tauglichste[n] Form“ herausarbeite, bestehe die „Aufgabe der legislativ-politischen Jurisprudenz [...] darin, den überlieferten Rechtsstoff mit den Zuständen der Gegenwart zu vergleichen und daraus zu schließen, welche Änderungen desselben in der Zukunft notwendig sein werden" (Menger 1905: 4, H.i.O.). ${ }^{444}$ Da die geltende Rechtsordnung die „Machtverhältnisse der Vergangenheit widerspiegel[t] “, sei es „die Hauptaufgabe“ einer solchen legislativ-politischen respektive „sozialen Rechtswissenschaft, den Gegensatz zwischen dem geschichtlich gewordenen Rechtszustande und den Machtverhältnissen der Gegenwart festzustellen“ (ebd.: 24). Aus der Feststellung der "tatsächlichen Grundlagen“ (ebd.) und aus dem Vergleich bzw. der Frage der Vereinbarkeit der Rechtsnormen mit den ,gegenwärtigen Machtverhältnissen innerhalb der bürgerlichen Gesellschaft" (ebd.: 32) ergäben sich die notwendigen Änderungen der gegenwärtigen Rechtsordnung.

Sowohl Ehrlich als auch Menger fordern die Anpassung des Rechts an seinen Kontext, wobei sich der Kontext als Faktum darstellt, dem die Anstrengungen des Wissens gelten müssen. Damit steht die Orientierung an der Wahrheit weiterhin im Vordergrund. Nicht normative Zielvorgaben oder prinzipielle Werte, sondern das Erfordernis, dem Faktischen gerecht zu werden, bestimmen die Kritik am Entwurf.

443 Zum Wandel von Ehrlichs Kritik an Mengers Machttheorie des Rechts (vgl. Ehrlich anonym/1891) hin zur Ablehnung eines Verteilungssozialismus (Ehrlich 1986a [1906]), die mit einer Annäherung an Gierkes Position einhergeht, vgl. Vogl 2003: 217ff.

444 Paul Oertmann, der Mengers Erweiterung der Rechtswissenschaft im Grunde zustimmt, fordert demgegenüber noch eine vierte Betrachtungsweise: die rechtsphilosophische Rechtswissenschaft, da es nicht ausreiche, den sozialen Machtverhältnissen nachzugehen. Es sei ebenfalls notwendig, Korrekturen derselben anzubahnen (Oertmann 1896a: 200). Im Grunde klagt er an, dass Menger bei der Wahrheitsaufgabe stehen bleibt und sich kein Weg in die normative Betrachtung öffnet. 
Etwas anders gelagert argumentiert Petražycki. Der Entwurf lasse sich nur vom Standpunkt einer - noch zu entwickelnden - „Civilpolitik“ beurteilen. Diese verfolge zwar eine eminent normative Zielsetzung: „Das Ziel der Civilpolitik besteht in der fortwährenden Annäherung zur Liebe, in der Veredelung der Motivation im Socialleben." (Petražycki 1895: 541) 445 $^{445}$ Gleichsam handele es sich dabei aber - analog zur politischen Ökonomie um ein wissenschaftliches Projekt: Sie sei als eine „selbständige[], systematische[] und zielbewusste[] Wissenschaft" zu gründen (Petražycki 1893: 329). Im Fokus steht die Untersuchung der sozialpolitischen Seite des Zivilrechts, die sich jedoch weniger politisch als vielmehr sozialwissenschaftlich definiere:

Daraus ersieht man die hohe Bedeutung der Civilpolitik, welche den Mechanimus der Socialordnung in einzelnen Sätzen und in ihrem Zusammenhang analysirt, die sociale Bedeutung und Wirkung der civilrechtlichen Begriffe, Institute und Sätze feststellt, die Kritik der Civilgesetze liefert, diejenigen Sätze, deren Wirkung auf das Socialleben schädlich ist, rügt und Postulate, deren Verwirklichung durch die Gesetzgebung von Nutzen wäre, aufstellt. (Ebd.: 328)

Im Zentrum steht die wissenschaftliche Beurteilung der „socialen Wirkung der Sätze des Civilrechtes" (ebd.: 339). ${ }^{446}$ Sie habe anhand der Funktionsbestimmung des Zivilrechts (d.h. „in der Regelung der Vertheilung des Volkseinkommens“, Petražycki 1895: 458) sowie anhand der Analyse der psychologischen Effekte (auf die Volkspsychologie und auf den Einzelnen) $\mathrm{zu}$ erfolgen. ${ }^{447}$ Das bilde die Basis, um "für die Hygiene zu sorgen, den pathologischen Erscheinungen nach Möglichkeit vorzubeugen, die

445 Da Petražycki von der Liebe, und nicht von der Konkurrenz als gesellschaftliches Leitprinzip ausgeht, haben ihm zufolge die pädagogischen Effekte von Lohn und Strafe, die auf den Egoismus abzielen, eine gesellschaftszersetzende Wirkung (vgl. Petražycki 1895: 546). Jherings Zweck erscheint ihm dementsprechend nicht anschlussfähig (vgl. ebd.: 344 ).

446 Dies ist insofern zentral, als das Zivilrecht nach Petražycki „die wichtigsten Seiten des Menschenlebens" regelt und damit das Fundament der Sozialordnung bildet (Petražycki 1893: 327f.).

447 Auch wenn Petražyckis Arbeit als psychologische Rechtstheorie abgewertet wurde, steht - wie immer wieder betont wurde - das soziale respektive das soziologische Moment im Vordergrund (Lobe 1896: 31; Gella 1977; Podgórecki 1980). Das zeigt sich auch in seinem Einfluss auf die (rechts-)soziologischen Arbeiten seiner Schüler Georg Gurvitch, Pitrim Sorokin und Nicholas Timasheff (vgl. Baum 1967). Zu aktuellen rechtssoziologischen Anschlüssen an Petražycki vgl. Cotterrell 2015. 
Verwirklichung der gesunden Funktion des Rechtsgeschäftes nach Kräften herbeizuführen“ (ebd.: 461). ${ }^{448}$ Auch für Petražycki gilt letztlich: Trotz expliziter normativer Zielvorgaben ist das Sollen in den rechtlichen Normen des Entwurfs anhand objektiver gesellschaftlicher Kriterien zu beurteilen: den psychologischen und sozialen Effekten der gesetzlichen Regelungsvorgaben. ${ }^{449}$ Diese lassen sich aber nur wissenschaftlich - und d.h.: anhand des Wahrheitskriteriums - bestimmen. ${ }^{450}$ Damit zieht Petražycki v.a. aber auch nicht die Wahrheitsorientierung der Rechtswissenschaft im engeren Sinne, der "Civiljurisprudenz“, in Zweifel - er hält ihr nur eine ,bessere‘, objektivere Wahrheit entgegen. Die Civilpolitik nimmt daher nach Petražycki die Rolle des Naturrechts ein, da das positive Recht an ihr gemessen werde. ${ }^{451}$ Auch hier gilt: Das Sollen folgt aus dem Sein.

Auch wenn die Positionen von Ehrlich, Menger und Petražycki, für die die tatsächlichen gesellschaftlichen Umstände und die sozialen Dynamiken und Mechanismen für ihre Kritik ausschlaggebend sind, einen heftigen Widerspruch erfahren, wird die grundsätzliche Orientierung am epistemischen Ding ,Gesellschaft anerkannt. Dies zeigt sich selbst in den Einlassungen derjenigen Autoren, die einwenden, dass es gerade nicht Aufgabe der Kodifikation den BGBs sein könne, die soziale Frage zu lösen: Zwar handele es sich dabei sehr wohl um eine eminent wichtige Proble-

448 Aus dieser Perspektive erweist sich selbst der zweite Entwurf des BGBs, dem Petražycki Verbesserungen gegenüber dem ersten zugesteht, als „Chrestomathie civilpolitischer Fehler“ (Petražycki 1895: 437) - eine Einschätzung, die Sohm scharf attackiert, beruhe sie doch auf einer vollkommen falschen Vorstellung über die Aufgabe des Rechts (vgl. Sohm 1895: 765f.).

449 Nach Petražycki soll die Civilpolitik neben die "Civiljurisprudenz" treten und daher keineswegs die dogmatische und die geschichtliche Betrachtung des positiven Rechts verdrängen (vgl. Petražycki 1893: 343).

450 Zwar ebenso auf rechtswissenschaftstheoretischer Ebene, aber anders gelagert argumentiert Heinrich Dernburg, der auch von einer Kluft zwischen gewachsenem Recht und gegenwärtigen gesellschaftlichen Zuständen ausgeht (Dernburg 1889: 179; 1894: 19): Während Petražycki und Menger für die Etablierung einer politisch-wissenschaftlichen Perspektive auf das Recht (entweder als Teil der Rechtswissenschaft oder neben ihr) plädieren, setzt Dernburg auf die Integration der Phantasie: Da „[d]ie Frage des Zwecks [...] außerhalb der Erfahrung“ (Dernburg 1894: 36) liege, könne sie nicht nach dem Wissenschaftsideal der Naturwissenschaften behandelt werden. Die Rechtswissenschaft müsse sich vielmehr der Phantasie öffnen, dem eigentlichen „Grund“ des Rechts (ebd.: 38). Damit plädiert er - trotz vager Wortwahl - für die Integration des Gerechtigkeitskriteriums in die Rechtswissenschaft (vgl. ebd.) und damit für ihre Normativierung.

451 Aus diesem Grund nennt Petražycki die Civilpolitik auch die „Wiedergeburt des Naturrechtes“ (Petražycki 1895: 579). 
matik, in deren Sinne das Gesetz zu erlassen sei. Doch sei die Grundlage hierfür noch nicht spruchreif, da bei den wirtschaftlichen und sozialen Fragen das meiste „zur Zeit noch mehr oder minder umstritten“ sei (Bähr 1890: 190; s.a. Opitz 1889: 7; Loening 1890: 393). Es handele sich oft um "Verhältnisse, welche noch in der Entwicklung begriffen sind und stete Gestaltung noch nicht gewonnen haben, oder über deren gesetzliche Regelung die Ansichten noch nicht genügend geklärt sind“ (Planck 1889: 407). In dieser Hinsicht befände sich „noch Alles im Fluß“ (Heusler 1890: 186), weshalb diesbezügliche Annahmen nicht als „Unterlage für den massiven Aufbau der privatrechtlichen Gesetzgebung" verwendet werden könnten (Hartmann 1890: 1231). Bestritten wird also keinesfalls, dass der Gang der Entwicklung zu neuen Rechtssätzen gedrängt habe. Sie seien jedoch nur kodifizierbar, wenn „die Verhältnisse und Anschauungen schon soweit geklärt sind, daß auch über die Art und Form der Regelung kein erheblicher Zweifel mehr obwalten kann" (Planck 1889: 332).

Selbst wenn das Argument der „mangelnden Spruchreife“ - wie von der Kritik bemerkt - in vielen Fällen vorgeschoben wurde, um sich der Stellungnahme zu brisanten sozial-politischen Fragestellungen zu entziehen (vgl. Schröder 1981: 31ff. m.N.); und selbst wenn das Argument daher als ein Teil der erfolgreichen Strategie im Gesetzgebungsverfahren anzusehen ist, politisch und sozial aufgeladene Materien aus der Kodifikation herauszuhalten (vgl. ebd.: 506; Schulte-Nölke 1995: 279; Schlosser 1997: 10ff.), so bleibt festzuhalten, dass dabei im Kern mit dem Wahrheitskriterium und nicht mit normativen Vorgaben operiert wird. Menger, Ehrlich und Petražycki wird nicht entgegengehalten, dass das epistemische Objekt, Gesellschaft' wie in der Historischen Rechtsschule per se mit einem Erkenntnismangel behaftet sei, was jegliche Versuche der wissenschaftlichen Bestimmung dieses Objekts ad absurdum führen würde. Ihnen wird vielmehr entgegengehalten, dass objektive Aussagen über die sich rasch wandelnden gegenwärtigen Verhältnisse, namentlich über die Dynamik in den widerstreitenden Interessen, noch nicht möglich seien. Für eine objektive, und d.h. gesicherte Erkenntnis seien sie noch nicht genügend gefestigt. Da hierüber (noch) keine Wahrheitsaussagen möglich seien, sei auch ausgeschlossen, sich auf derartige Wahrheiten zu berufen. Deshalb müsse man die Kodifikation auf das beschränken, über das eine sichere Aussage gefällt werden könne - und den Rest der Spezialgesetzgebung überantworten (vgl. etwa Planck 1889: 406f.; Heusler 1890: 186f.; ähnlich auch Leonhard 1891: 72).

Dass sich hierfür das Verfahren der Bestandsaufname am besten eignet, folgt aus der noch präsenten Verankerung des epistemischen Schemas der Repräsentation, insbesondere der letztlich nicht bestrittenen Rechtsentste- 
hungslehre. Angesichts des Einwands der „mangelnden Spruchreife“ biete dieses Verfahren die einzige Möglichkeit, sich auf eine objektive Grundlage für die Kodifikation zu berufen. Der sicherste Weg für eine gelungene Gesetzgebung sei darin zu sehen - wie Planck betont -, „die im Volke bereits lebenden Rechtsgedanken aufzufinden“ (Planck 1889: 331). Diese seien im gegenwärtigen positiven Recht zu finden, nur sie könnten verlässliche Auskunft über das gegenwärtige Rechtsbewusstsein im Volke geben. Das genetische Argument wird dabei jedoch zugleich in ein funktionales Argument umgedeutet. Denn wenn man diese Rechtsgedanken durch die Kodifikation näher bestimme und damit ihre Anwendung sichere, dann befestige man die "Grundlagen der bestehenden Gesellschaftsordnung" (Planck 1899: 184). ${ }^{452}$

Auch die Annahme der Historischen Rechtsschule, dass das Recht die lebendige Kraft der gesellschaftlichen Sphäre repräsentiere und daher selbst ein solche lebende Kraft enthalte, findet Anhänger. Wenn man zum wahren Kern des Rechts vordringe, das eine "Verkörperung des im deutschen Volk lebendigen Rechts" darstelle (Pfizer 1889: 20), dann erkenne man das gerechte, wahre Recht für die Zukunft (etwa ebd.: 15f.; Sohm 1895: 742). Dadurch sichere man den Bestand der Gesellschaft. Denn nur eine gelungene Repräsentation des Rechtsbewusstseins des Volkes unterbreche nicht dessen natürlichen, organischen Entwicklungsprozess. Andernfalls würde man "seinen gesammten Rechtszustand in die heilloseste Verwirrung bringen“ (Opitz 1889: 7).453

Insbesondere Gierke entfaltet seine scharfe Kritik entlang dieses epistemischen Schemas der Repräsentation: Der wahre Kern des Rechts sei der „Rechtsgeist“ (Gierke 1889b: 15), d.h „ein inneres geistiges Element [...], durch welches es [das Recht, D.S.] mit allen den unwägbaren Stoffen und

452 Daneben werden im Namen der mangelnden Spruchreife v.a. pragmatische Gründe für die Beschränkung auf die Bestandsaufnahme geltend gemacht: Da letztlich alles umstritten sei, müsse man sich, wenn man eine zügige Rechtsvereinheitlichung zustande bringen wolle, auf die Bestandsaufnahme beschränken (vgl. etwa Loening 1890: 393f.).

453 Allerdings wendet der Romanist Otto Bähr den Repräsentationsgedanken - ähnlich der Kritik Kirchmanns - zur grundlegenden Kritik des Kodifikationsvorhabens: Nach Bähr ist das Recht als „geistiges Fluidum“ in seiner organischen Verwobenheit nicht in positiven Regeln repräsentierbar. Werde es in starre Regeln gedrängt, die mechanisch angewendet würden, verkümmere es, da es nicht mehr flexibel und anpassungsfähig sei. Das freie juristische Denken, wie es insbesondere in der Romanistik zu erkennen sei, werde unmöglich. Daher berge die Kodifikation eine große Gefahr für Rechtswissenschaft und Rechtsanwendung (vgl. Bähr 1888a). 
unmeßbaren Kräften zusammenhängt, die ein Volkstum bilden und fortpflanzen" (Gierke 1889a: 580). Lege man diese ,organische“ Kraft (Gierke 1889b: 14), die „innere Lebenskraft des Rechtes“ (Gierke 1889a: 4) frei, so schöpfe man ein volkstümliches lebendiges "nationales Zukunftrecht" (ebd.: 368). Denn „[n]ur aus Lebendigem geht Lebendiges hervor“ (ebd.: 3). Die Rechtswissenschaft könne auf genuin wissenschaftlichem Weg der Erforschung des gegebenen Rechts, d.h. jenseits der Frage, was sein soll, helfen, zu dieser "geheimnissevolle[n] Kraft“ (Gierke 1889b: 14) vorzudringen. ${ }^{454}$ Sie leiste dies, indem sie den Zweck des Rechts wissenschaftlich untersuche, d.h. „welche Aufgaben im Leben der menschlichen Gesellschaft die Rechtsordnung in der Vergangenheit erfüllt hat oder in der Gegenwart erfüllt und welche Gedanken über diese Aufgaben auf die Rechtsbildung bestimmend eingewirkt haben oder einwirken" (ebd.: 3). Dadurch werde das Verständnis für das Recht, die Einsicht in dessen Vergangenheit und gesellschaftlichen Zusammenhang gefördert, allesamt Voraussetzung, „um ein wahrhaft zukunftreiches Recht [zu] schaffen“ (ebd.: 15). 455

Auch Gierke wandelt das genetische Argument in ein gesellschaftsfunktionales um: Wenn man das wahre Volksrecht über die Bestandsaufnahme des Rechts erkannt habe - was für Gierke gleichbedeutend ist mit der Erkenntnis und Stärkung des sozialen „germanischen Rechtsgeist[es]“456 -, dann erfülle man seine gesetzgeberische Aufgabe: Die Schaffung eines guten „Recht[es] der Zukunft“ (ebd.). ${ }^{457}$ Nur dann könne man zur lebendigen Kraft im Recht vordringen - und v.a. auch einer Erstarrung des Rechts im Gesetz entgegenwirken, das letztlich jedem gesellschaftlichen Entwicklungsgedanken widerspreche (vgl. Bähr 1888a: 458). Dann erfülle man zu-

454 So schreibt Gierke: „Reiner Wissenschaft ist nur die Frage zugänglich, was ist, nicht die Frage, was sein soll. So hat auch die Rechtswissenschaft als solche sich nur mit der großen geschichtlichen Wirklichkeit zu beschäftigen, die wir Recht nennen." (Gierke 1889b: 3).

455 Ähnlich argumentiert Pfizer: Wenn gilt, dass das gerechte Recht ein solches sei, „das nach Form und Inhalt dem deutschen Volk und dem deutschen Geiste gerecht wird“ (Pfizer 1889: 15f.), so gebe sich aus der Erkenntnis der Vergangenheit und dem Verständnis der Gegenwart die Zukunft zu erkennen, d.h. des „in ewigem Werden begriffenen Rechts“ (ebd.: 28).

456 Gierke wendet sich also keinesfalls gegen die Rechtsentstehungslehre der Historischen Rechtsschule (vgl. Gierke 1973 [1903]: 6ff.), sondern gegen ihre pandektische Ausformung.

457 Auch Sohm sieht diesen Zusammenhang von Erkenntnis des „gerechten, wahren Volksrechts“ und der Gestaltung des guten Zukunftsrechts: „Die Vergangenheit wird ihm [dem Juristen; D.S.] zur Weissagerin der Zukunft, zur Lehrmeisterin für das Werk der Rechtsschöpfung, an dem er arbeitet.“ (Sohm 1895: 742; ähnlich auch Krech 1889: 4). 
gleich seine soziale Aufgabe und wehre die Angriffe auf die „Lebensbedingungen der Gesellschaft" ab (Gierke 1889b: 20).

Was sich hier also in aller Deutlichkeit zeigt, ist die strategische Wiederaufladung des Repräsentationsgedankens der Historischen Rechtsschule durch ein gesellschaftsfunktionales Zweckdenken. Wenn Gierke (und andere) erneut nach der Gesellschaft im Recht fragt, dann wird dies nun in die Frage nach der ordnungssichernden Funktion des Rechts umgedeutet. Kurz: Es geht um das Recht der Gesellschaft, denn es ist die gesellschaftliche Ordnungsleistung des Rechts, um die gestritten wird und die die Güte des Entwurfs bestimmt.

Die entgegengesetzten Positionen eint, dass über die soziale Aufgabe des Privatrechts nicht anhand normativer Kriterien gestritten wird. Im Zentrum stehen weder die Auseinandersetzungen über die normative Rechtfertigung des Entwurfs, d.h. ob die Gesetzesregelungen normative Zielvorgaben (etwa naturrechtlichen Idealen) gerecht werde, noch die Formulierung der Ordnungsleistung des Rechts als normatives Problem. Ebenso wenig geht es um den spezifisch normativen Charakter des Rechts als Sollensvorschriften. ${ }^{458}$ Rechtsgrundsätze erscheinen als „Rechtswahrheiten" (Ausschuss des Bundesrathes für Justizsachen, zitiert nach Rassow 1877: 205), die man entweder über die rechtswissenschaftliche Bestandsaufnahme zu ermitteln habe oder denen die Wahrheit der gesellschaftlichen Entwicklung entgegengehalten wird. Daher wird die soziale Aufgabe des Privatrechts, der Zweck des BGBs, auch nicht als normatives Problem, sondern im Hinblick auf die gesellschaftliche Funktion des Rechts diskutiert. Problematisiert wird, wie sich das Sollen des BGBs anhand einer gesicherten wissenschaftlichen Erkenntnis der gegenwärtigen gesellschaftlichen Situation herleiten lässt. Dafür verweist die eine Seite auf die Erkentnisse der Sozial- und Geisteswissenschaften, namentlich der Nationalökonomie. Die Gegenseite bestreitet, dass es sich dabei um gesicherte Erkentnisse handelt. Daher müsse man auf andere objektive Kriterien zurückgreifen, namentlich den Bestand des Rechts - und für die Bestandsaufnahme sei die

458 Wenn das Sollen - wie etwa bei Gustav Pfizer - zur Sprache kommt, dann erfährt es eine Problematisierung im Hinblick auf die Abgrenzung des Privatrechts: Sollens-Vorschriften, die Pflichten statuieren, seien nämlich so weit wie möglich aus dem Entwurf herauszuhalten, entspreche das doch gerade nicht dem Regelungsgegenstand des bürgerlichen Rechts als Ordnung der subjektiven Rechte (vgl. Pfizer 1889: 9, 44). 
Rechtswissenschaft zuständig. Bis auf wenige Ausnahmen ${ }^{459}$ wird die soziale Aufgabe des Privatrechts als eine wissenschaftliche Frage behandelt, und d.h. im Diskurs dieser Zeit: als eine Wahrheitsfrage, die anhand objektiver Kriterien zu entscheiden sei. Und wenn - wie gelegentlich - die Normativität des Rechts eingeklagt wird, dann dient dies oft als Abwehrargument: Gerade weil es sich im sozialpolitischen Bereich um politische Entscheidungen handele, sei es nicht Aufgabe der Privatrechtsgesetzgebung, sondern eben des Öffentlichen Rechts (vgl. etwa Stolterfoth 1890: 48).

Durch die Orientierung an der Wahrheit wird eine Politisierung des Privatrechts - und damit auch der Privatrechtswissenschaft - abgewendet. ${ }^{460}$ Die Normativität des Rechts bringen weder die Mehrzahl der Befürworter noch die der Kritiker des Entwurfs als strategisches Problem des Rechts in den Diskurs der Privatrechtswissenschaften ein. Was sein soll, folgt aus dem, was ist: entweder aus dem Bestand des positiven Rechts, oder aber aus dem gesellschaftlichen Entwicklungsstand. Gerade hieraus ergibt sich die Plausibilität der zentralen Stellung der Rechtswissenschaft für die Gesetzgebung bzw. die Notwendigkeit, die Rechtswissenschaft als Wissenschaft über die soziale Aufgabe zu problematisieren - jener Weg, den Ehrlich, Menger und Petrazycki für ihre Kritik einschlagen. Das Recht wird dabei als gesellschaftlicher Ordnungsfaktor angesehen, und die gegenwärtige Gesellschaft wird zum Maßstab für diese Frage. Daher wird der Zweck des Privatrechts gesellschaftsfunktional bestimmt. Zugleich zeigt sich die Rechtswissenschaft in diesem Diskurs weder als Sollens-, Normoder Zweckwissenschaft, sondern als eine Wissenschaft des Seins.

459 So etwa Pfizer, der geltend macht, dass nicht der Rechtswissenschaft (d.h. der Kommission), sondern dem Reichstag die Feststellung der „leitenden Grundsätze" obliege, "die in der heutigen Gesellschaft Anerkennung fordern, solche aber im positiven Recht der Gegenwart noch nicht gefunden haben" (Pfizer 1891: 3). Insbesondere sei es Sache des Reichstags, die Grundlagen für ein gerechtes Recht zu liefern (ebd.; s.a Pfizer 1889; s. zu diesem Problem auch Hölder 1889).

460 Daher lasse sich die entgegengesetzte Position auch nicht mit politischen Zuordnungen zu Konservativismus, Liberalismus oder Sozialismus gleichsetzen: Die Einordnungsschwierigkeiten bzgl. Jhering zwischen reaktionären Konservativismus und "Juristensozialismus" wiederholen sich bei Gierke (vgl. Dilcher 1974/1975), und Menger und Baron zählen trotz grundsätzlicher Divergenzen mit Blick auf das subjektive Recht beide zu den Kathedersozialisten. 


\section{Rechtswissenschaft und Gesellschaftswissenschaft}

Kann die Rechtswissenschaft über die Problematisierung der sozialen Aufgabe des BGBs anhand von Wahrheitskriterien die Politik ausschließen, so öffnet sie sich jedoch aufgrund der Aufwertung und der Vergegenwärtigung des epistemischen Dings ,Gesellschaft' den Sozial- respektive Gesellschaftswissenschaften. ${ }^{461}$

Diese Öffnung fordern insbesondere Menger und Petrazycki in ihrer Kritik des BGBs und seiner Entwürfe: ${ }^{462}$ Nach Menger etwa unterscheidet sich die soziale Rechtswissenschaft grundsätzlich von der strengen Technik der dogmatischen und der geschichtlichen Jurisprudenz. In der sozialen Rechtswissenschaft finde vielmehr die Sozialwissenschaft „ihren Mittelpunkt“ (Menger 1905: 29) - sie sei eine empirisch ausgestaltete „Erfahrungswissenschaft“ (ebd.: 28), die sich für die Festellung der Inkongruenz von Recht und Macht auf „tatsächliche Grundlagen“ berufe (ebd.: 24). Diese würden ermittelt durch „ein genaues Studium der Staats-, Rechtsund Kulturgeschichte jedes Landes“463, und zwar „, in Verbindung mit den statistischen Aufnahmen über soziale Zustände der Gegenwart" (ebd.: 24). V.a. aber verfahre die soziale Rechtswissenschaft kausalwissenschaftlich: Sie beobachte genau das „Auf- und Abwogen der Machtverhältnisse“ anhand ökonomischer, politischer und religiöser Entwicklungen, ${ }^{464}$ um daraus - und d.h. letztlich nur mittels kausaler Rückschlüsse von Ursachen

461 Gerade das im Gegenwartsbezug begründete Wissensproblem eröffnet den oben bereits erwähnten Interferenzraum zwischen Nationalökonomie und Rechtswissenschaft. Dies zeigt sich insbesondere in den Debatten über materiale Bestimmungen des BGB-Entwurfs, in denen nationalökonomische Argumente herangezogen bzw. abgewehrt wurden (vgl. etwa für die Frage des Wohnungsmietrechts Schneider 1893: 2ff.; für die Debatte über die erbrechtlichen Bestimmungen Schröder 1981: 306ff. m.N.; für die die Landwirtschaft betreffenden Regelungen Hansel 2006).

462 Ehrlich bleibt in seiner Kritik des BGBs und seiner Entwürfe diesbezüglich noch sehr vage. Nur vereinzelt gibt er Hinweise, welche Art von Wissen heranzuziehen sei (etwa die Untersuchungsergebnisse des Vereins für Sozialpolitik; vgl. Ehrlich 1890a: 28). Erst später wird er in der Soziologie des Rechts die Lösung dieser Frage erblicken (s.u. $\$ 5$ ). Zur Entwicklung des Ehrlich'schen Denkens vgl. die grundlegende Studie von Vogl 2003.

463 Der Untersuchung der geltenden Rechtsordnung, in der sich nach Menger die Machtverhältnisse der Vergangenheit widerspiegelten, komme dabei eine bedeutende, aber keine maßgebende Rolle zu (Menger 1905: 24).

464 Menger wendet sich damit dezidiert gegen das Basis-Überbau-Schema (vgl. Menger 1905: 24ff.). 
auf Wirkungen - „Schlüsse für die Rechtsgestaltungen der Zukunft“ zu ziehen (ebd.: 22).

Auch Petražycki betont die Notwendigkeit der Öffnung zu den Sozialwissenschaften, namentlich zur Nationalökonomie: Die „zukünftige Civilpolitik“ sei „keine juristische, sondern vielmehr eine volkswirthschaftliche Wissenschaft [...], nicht der Jurisprudenz, sondern vielmehr der politischen Oekonomie zu imputiren“ (Petražycki 1895: 565). ${ }^{465}$ Sie beruhe „wesentlich auf Deduktion“, die aus den „[a]llgemeinen Prämissen [...] der (auf Beobachtung, insbesondere Selbstbeobachtung, und Erfahrung beruhenden) Individual- und Massenpsychologie“ Schlussfolgerungen ziehe und d.h. für Petražycki insbesondere aus den „schon gewonnenen nationalökonomisch-theoretischen" Prämissen (ebd.: 581). ${ }^{466}$ Aus diesem Grund sei die Civilpolitik streng von der Civilrechtswissenschaft zu unterscheiden (ebd.: 579).

Menger und Petražycki versuchen, sozialwissenschaftliches Wissen neben Dogmatik (und Geschichte) zu integrieren - entweder über die Eingliederung des sozialwissenschaftlichen Wissens als eigenständiger Zweig einer weiter auszudifferenzierenden Rechtswissenschaft (Menger), oder aber, indem trotz grundlegender Differenz primär auf das notwendige Wechselverhältnis zwischen Civilpolitik und Civilrechtswissenschaft abgestellt wird (Petražycki). Dieses Wechselverhältnis könne nämlich der Gefahr der Entfremdung vom Leben entgegenwirken. Da es sich beim römischen Recht um einen „Niederschlag der langjährigen volkswirthschaftlichen Erfahrung" (Petražycki 1895: 582) bzw. um ein „Produkt der unbewussten Massenerfahrung“ handele, eigne es sich „als ein empirisches Kontrolmaterial für die deduktive Civilpolitik“ (ebd.: 584). Die anhand dieses Materials rechtswissenschaftlich herausgearbeiteten Prinzipien können mithin - bei Kongruenz - die Richtigkeit civilpolitischer Sätze beweisen (ebd.: 584f.).

Was insbesondere Menger und Petražycki bestreiten, ist nicht die Eigenständigkeit und Eigenart der genuin rechtswissenschaftlichen, und d.h. rechtsdogmatischen Arbeit. Sie fordern keinesfalls, dass die Gesellschafts-

465 Allerdings verbindet Petražycki dies mit einer Kritik der bestehenden nationalökonomischen Einlassungen zu Privatrechtsfragen, die sich auf allgemeine Grundsätze (wie etwa die Forderung der Einschränkung der Vertragsfreiheit) konzentrierten und daher weder das Civilrecht noch die Civilrechtsmechanismen verstünden. Letztlich verfehlten sie den Gegenstand der Kritik (vgl. Petražycki 1895: 566ff.).

466 Da die civilpolitische Aufgabe in der Deduktion psychologischer Wirkungen bestehe, könne man nach Petražycki jedoch nicht quantitativ vorgehen (ebd.: 582). 
und Sozialwissenschaft als Leitwissenschaft der Rechtswissenschaft anzusehen ist, was ja dogmatische und methodische Folgen zeitigen würde. Sie wenden sich vielmehr gegen die Anmaßung, dass sich durch dogmatischjuristische Arbeit gesellschaftstheoretische Aussagen über Zustand und Entwicklung der Gesellschaft treffen lassen. Damit bestreiten sie jene Idee, dass man über die dogmatische Arbeit zum Leben vordringen könne oder anders formuliert: dass das richtige Recht, das seiner sozialen Aufgabe gerecht wird, allein durch systematisierende Arbeit am Rechtsstoff erkannt werden könne. Hierfür sei der Rückgriff auf sozialwissenschaftliches Wissen als Korrektiv nötig.

Diese Forderung geht den Befürwortern, aber auch der Mehrzahl der Kritiker des Entwurfs des BGBs zu weit. Menger und Petražycki wird insbesondere entgegengehalten, dass die Gesellschaft aufgrund ihres raschen Wandels kein legitimes Bezugsobjekt für wissenschaftlich gesicherte Aussagen sein könne. Mittels des (letztlich erfolgreichen) Einwands der mangelnden Spruchreife (s.o.) wird bestritten, dass für die Frage der Gesetzgebung, aber letztlich auch die der Rechtserkenntnis dem sozial- und gesellschaftswissenschaftlichen Wissen eine Relevanz zukommen könne oder anders formuliert: das anderes als genuin juristisch-dogmatisches Wissen die Frage nach dem richtigen Recht beantworten könne. Auch wenn die Gesellschaft zum Bezugspunkt der Debatte über die soziale Aufgabe des Privatrechts wird, ist die Bezugnahme auf eine andere als eine juristische Form der Gesellschaftswissenschaft ausgeschlossen. Mehr noch: Aufgrund der mangelnden Spruchreife erweist sich die Rechtswissenschaft als eigentliche Gesellschaftswissenschaft. Denn „nur der gebildete Jurist“ sei letztlich in der Lage, das "gerechte, wahre Volksrecht" zu finden (Sohm 1895: 742); nur die Rechtswissenschaft könne das ,richtige‘ Recht erkennen, das den Bedürfnissen der Zeit entspreche und daher die soziale Aufgabe der Privatrechtskodifikation, nämlich die Befestigung und Sicherung der Gesellschaftsordnung, zu bewältigen vermöge; und nur die Rechtswissenschaft könne die Frage danach beantworten, wie die soziale Ordnung unter den Menschen am besten gedeihe; nur sie schaffe daher adäquates Zukunftsrecht. Selbst für Julius Ofner, der sich vehement für eine „soziale Jurisprudenz" ausspricht, ${ }^{467}$ die das Recht über das Zweckdenken in sei-

467 Ähnlich wie Menger und Petražycki argumentiert auch der Wiener Jurist und Politiker Julius Ofner in seinen Studien socialer Jurisprudenz aus dem Jahr 1894: Auch er beklagt die Aussonderung der Politik aus der Rechtswissenschaft und versucht, diese in Form einer "Jurisscienz" wieder zu integrieren, die das Recht als gesellschaftliches Produkt wissenschaftlich untersucht: „Nur als Ergebnisse 
nem Gesellschaftsbezug zu erkennen sucht, gilt, dass dies nur der Jurist zu leisten vermag:

Dem Beteiligten wie dem Gesetzgeber gegenüber ist der Jurist der Sachverständige für die Ordnung der sozialen Verhältnisse. Auch sein Denken ist Zweckdenken, das aber nach einem trefflichen Ausdruck von Brinz nicht Potestät, sondern Autorität hat, nicht zwingt, aber durch wissenschaftlich durchdachte Erfarung geleitet vorhersieht. Der Jurist soll die nach dieser Erfarung objektiv zweckmässige Einrichtung der sozialen Verhältnisse treffen. (Ofner 1894: 13, H.i.O.)

Allenfalls könne man das Wissen der Sozial- und Gesellschaftswissenschaften als Hilfsmittel betrachten - so etwa bei Gierke, wenn er die Rechtswissenschaften zu den Gesellschaftswissenschaften, d.h. zu „den Wissenschaften vom gesellschaftlichen Sein des Menschen“ rechnet (Gierke 1895: 106). Aufgrund dessen seien „für die tiefere Erkenntniß des Rechts alle anderen Gesellschaftswissenschaften nähere oder entferntere Hülfsmittel“ (ebd.). Sie tragen zum „Verständniß des deutschen Privatrechts und seiner Wandlungen" bei (ebd.). Als Hilfsmittel sind sie aber letztlich weder im Stande, die Autonomie noch die herausgehobene Stellung der Rechtswissenschaft in der Bestimmung der sozialen Aufgabe des Privatrechts zu relativieren.

Im privatrechtswissenschaftlichen Diskurs um die soziale Aufgabe des Privatrechts wird bereits das Verhältnis von Rechtswissenschaft und Sozialbzw. Gesellschaftswissenschaft problematisiert. Bedarf die Rechtswissenschaft - wie Menger und Petražycki angesichts der zur bewältigenden Kodifikation einklagen - eines sozial- und gesellschaftswissenschaftlichen Korrektivs, so macht die andere Seite geltend, dass die Rechtswissenschaft selbst solche Erkenntnisse liefere: Der Jurist erscheint nach wie vor als der

einer kausalen Entwicklung, als Folgen veränderter sozialer Verhältnisse und als Ursachen weiterer Veränderungen sind die geltenden Gesetze wissenschaftliches Material; ihre Eigenschaft, positives Recht zu sein, tritt in den Hintergrund." (Ofner 1894: 7) Ihr gegenüber stelle die Jurisprudenz nur eine „angewandte Wissenschaft" dar (ebd.: 28). Da Recht immer soziales, d.h. gesellschaftliches Recht sei, sei die Jurisscienz unzweifelhaft eine Sozialwissenschaft (auf psychologischer Grundlage), die versuche, „allgemeine Gesetze (Socialgesetze)“ (ebd.: 22) zu eruieren. Diese hätten dann den Status von „Naturgesetzen“ und nicht den von „praktischen Grundsätzen“ (ebd.). Anhand dieser Gesetze seien Vorteile und Schäden der Rechtsregeln zu prüfen. Da es sich dabei letztlich nicht um normative, sondern wissenschaftlich gewonnene Beurteilungen handelt, betrachtet Ofner die Rechtswissenschaft als „wissenschaftliche soziale Technik“ (ebd.: 26). Auch ihm geht es also um die Integration sozialwissenschaftlichen Wissens, das der Natur des Rechts als gesellschaftliches Produkt entspringt. 
Sachverständige für die soziale Ordnung, und die Rechtswissenschaft bestimmt die Funktion des Rechts für die Gesellschaft. Die Privatrechtstheorie fungiert dann selbst als eine Gesellschaftstheorie. Allenfalls könnten (bzw. müssten) Erkenntnisse der anderen Sozial- und Gesellschaftswissenschaften als Hilfsmittel für die Rechtswissenschaft dienen. ${ }^{468}$

Vor dem Hintergrund, dass es sich dabei jeweils um Wahrheitswissen handelt, konkurrieren also Wahrheitsaussagen über das Objekt ,Gesellschaft $^{\text {. }}$ Gestritten wird mithin über die gesellschaftstheoretische Aussagekraft der Rechtswissenschaft. Für beide Positionen gilt allerdings: An der Eigenart und der Autonomie der Rechtswissenschaft - und d.h.: der Dogmatik - wird nicht gerührt. Eine Soziologisierung der Rechtswissenschaft, die einen Wandel der Dogmatik und Methodik bedeuten würde, wird nicht gefordert. Stattdessen streitet man über die Frage, ob, und, wenn ja, auf welche Art und Weise sozial- und gesellschaftswissenschatfliches Wissen zu integrieren sei, um zu einer Bestimmung dessen zu kommen, was im Rahmen der BGB-Gesetzgebung als Recht gelten soll. Es geht sozusagen um die Frage, welches Sein als Grundlage dafür gelten kann, das Sollen des zukünftigen Rechts zu bestimmen.

\section{Zusammenfassung: Der gesellschaftsfunktionale Zweck im Privatrecht}

Das BGB und seine Entwürfe werden sowohl von Befürwortern als auch von Kritikern über die Frage nach der sozialen Aufgabe des Privatrechts problematisiert. Dass ihm eine solche Aufgabe zukomme, wird dabei nicht bezweifelt. Vielmehr diskutiert man darüber, was darunter zu verstehen sei und wie man ihr gerecht werde. Dies zielt insofern ins Herz der Rechtswissenschaft, als die zu bewältigende Gesamtkodifikation nicht als eine genuin politische Aufgabe, sondern primär als ein wissenschaftliches Projekt

468 Diese Hilfestellung für die Rechtswissenschaft sehen - insbesondere mit Blick auf die Erkenntnisse der Nationalökonomie - auch manche Befürworter als notwendig an: Denn eine gegenwartsbezogene „kritische“ Rechtswissenschaft, die sich nicht nur hinter den Prinzipien verstecke und außerrechtliche Entwicklungen völlig ignoriere (vgl. Baron 1877: 375f.), bzw. die nicht nur das Überlieferte entwickele, sondern ebenso auf die zwar historisch gewachsenen, aber tatsächlich vorhandenen Bedürfnisse der Zeit eingehe (Leonhard 1900b: 60), könne und dürfe sich den kritischen Impulsen aus der Nationalökonomie nicht widersetzen (vgl. hierzu Wilhelm 1979). 
verstanden wird. ${ }^{469}$ Die soziale Aufgabe, d.h. der Zweck des Rechts, wird im rechtswissenschaftlichen Diskurs daher nicht politisch-normativ, sondern gesellschaftsfunktional bestimmt.

Angesichts der sozialen Frage erweist sich die Gesellschaft in ihrem Bestand bedroht - sie erscheint als gefährdete Gesellschaft, deren Auflösung und Zersetzung es zu verhindern gelte. Damit verliert die Annahme, dass es sich bei der Gesellschaft um eine harmonische, sich in der Zeit kontinuierlich entwickelnde Sphäre handelt, seine Überzeugungskraft. In einer Gesellschaft, die durch antagonistische Verhältnisse gekennzeichnet und daher in der Gegenwart einem beschleunigten Wandel ausgesetzt ist, kann das Recht nicht mehr - wie im Repräsentationsdispositiv - als Selbstzweck verstanden werden, sondern wird als Mittel zum Zweck adressiert. Seine gesellschaftliche Funktion rückt in den Blick: Das Privatrecht ordnet die Gesellschaft - und dementsprechend hat die Aufgabe eines zukünftigen BGBs in der Sicherung der Gesellschaftsordnung zu liegen. Der Streit über die soziale oder unsoziale Tendenz des BGBs entfaltet sich entlang eines gesellschaftsfunktionalen Zweckdispositivs.

Dabei steht die Frage im Zentrum, wie sich das BGB und seine Entwürfe auf die gesellschaftliche Ordnung auswirken. Genau hierüber entbrennt die Diskussion über die Güte des BGBs und seiner Entwürfe: Wirft ihm die eine Seite individualisierende und daher gesellschaftszersetzende Tendenzen vor, so betont die andere Seite die soziale Funktion der Sicherung der individuellen Freiheit. Dieser Widerstreit, der letztlich auf zwei konkurrierenden Auffassungen über den Zusammenhang von Individuum und Gesellschaft beruht, mündet jedoch nicht in einen Streit über den richtigen Begriff oder eine Theorie der Gesellschaft. Die gesellschaftstheoretische Frage wird vielmehr über die rechtstheoretische Abgrenzung von Privatrecht und Öffentlichem Recht (die zur gesetzgebungstechnischen Frage einer Notwendigkeit der Spezialgesetzgebung führt) ausgehandelt. In dieser Form erweist sich die Privatrechtstheorie dann selbst als Gesellschaftstheorie, wird doch die Frage, wie eine Gesellschaft angesichts der Freiheit der Individuen möglich sein kann bzw. welche Entwicklungsdynamiken sie zeitigt, über die Klärung des, Wesens des Privatrechts' beantwortet.

Mit der Verfestigung der gesellschaftsfunktionalen Perspektive im privatrechtswissenschaftlichen Diskurs steht jedoch die Autonomie der

469 Vice versa lasten die Kritiker das Verfehlen der sozialen Aufgabe in der Kodifikation der anwendeten rechtswissenschaftlichen Arbeitsweise an, namentlich der romanistischen Dogmatik. 
Rechtswissenschaften auf dem Spiel. Denn einerseits rückt die politische Frage nach dem, was sein soll, in den Blick. Eine solche Politisierung des Privatrechts und der Privatrechtswissenschaft wird allerdings durch die Orientierung an der Wahrheit ausgeschlossen. Die Normativität des Rechts bzw. die normative Beurteilung der Kodifikation bringt weder die Mehrzahl der Befürworter noch die der Kritiker des Entwurfs als strategisches Problem in den Diskurs der Privatrechtswissenschaft ein. Was sein soll, folgt für die divergierenden Positionen vielmehr aus dem, was ist: entweder aus den Tatsachen und Mechanismen der gesellschaftlichen Entwicklung oder aber angesichts ihrer mangelnden Spruchreife aus dem Bestand des positiven Rechts. Aufgrund dieser Orientierung an den Tatsachen handelt es sich bei der Kodifikation auch um ein wissenschaftliches Problem einer Rechtswissenschaft, die sich nach wie vor als Wissenschaft des Seins versteht. Da der Zweck nicht normativ verstanden wird, da nicht das teleologische Moment des Rechts in den Vordergrund gestellt wird, handelt es sich nicht um ein wissenschafts- und erkenntnistheoretisches Problem, wie es den Annahmen über die Jurisprudenz als Norm-, Zweck- oder empirische Kulturwissenschaft zugrunde liegt (s.u. \$5.IV.2).

Das kodifikatorische Problem wird dahingehend formuliert, ein der Gesellschaft adäquates Recht zu finden, das den gegenwärtigen gesellschaftlichen Verhältnissen entspricht und daher den Bedürfnissen der Zeit gerecht wird. Daher ist man andererseits auf die Sozial- und Geisteswissenschaften verwiesen, muss man doch beantworten, was diese gegenwärtigen Verhältnisse und Bedürfnisse tatsächlich sind. Während die Rechtswissenschaft - wie Menger und Petražycki angesichts der zur bewältigenden Kodifikation einklagen - eines sozial- und gesellschaftswissenschaftlichen Korrektivs bedürfe, macht die andere Seite geltend, dass die Rechtswissenschaft selbst schon solche Erkenntnisse liefern könne: Der Jurist bleibt nach wie vor der Sachverständige für die soziale Ordnung und die Rechtswissenschaft bestimmt die Funktion des Rechts für die Gesellschaft. Auch wenn hier das Verhältnis der Rechtswissenschaft zu anderen Sozial- und Gesellschaftswissenschaften problematisiert wird, fordert keine Seite eine Soziologisierung der Rechtswissenschaft. An der Eigenart und Eigenständigkeit der Rechtsdogmatik und -methodik wird nicht gezweifelt, allenfalls an der Reichweite der Aussagekraft der Erkenntnisse der Rechtsdogmatik mit Blick auf die Verhältnisse der Gegenwart und die soziale Wirkung des Rechts.

Vor dem Hintergrund eines privatrechtswissenschaftlichen Diskurses, der sich entlang des gesellschaftsfunktionalen Zweckdispositivs entfaltet, erscheint es weder verwunderlich, wenn um zentrale Momente des Jhering'schen Zweckdenkens gerungen wird, noch, dass sein Zweckbegriff 
des Rechts immer wieder explizit als Bezugspunkt für die kritische Auseinandersetzung mit dem BGB und seinen Entwürfen fungiert (vgl. etwa Ehrlich 1890b: 444; Gierke 1889b: 6f.). Allerdings wird Jherings explizit gesellschaftswissenschaftlicher Fundierung der Rechtstheorie gerade nicht gefolgt. ${ }^{470}$ Die Setzung der Gesellschaft als Zwecksubjekt erscheint genauso wenig plausibel wie in den direkten Reaktionen auf den Zweck in den Privatrechtswissenschaften bzw. auch in der philosophischen Rezeption. Erkenntnisse der Sozial- und Gesellschaftswissenschaften werden allenfalls als notwendiges Korrektiv, wenn nicht gar nur als Hilfsmittel der Rechtswissenschaft angesehen. Oder aber man attestiert der Sozial- und Gesellschaftswissenschaft, dass sie angesichts ihres Gegenstandes (noch) nicht zu gefestigten Aussagen gelangt sei. Die Gesellschaft bietet aus dieser Sicht zwar den Rahmen der Argumentation, sie wird zum Maßstab der Güte des Entwurfs, kann aber nicht das Bezugsobjekt der wissenschaftlichen Untersuchung darstellen. ${ }^{471}$

Vor allem aber kommt man von Jherings mechanischem Gesellschaftsbild ab, obwohl nun die widerstreitenden Interessen in den Blick rücken: Wenn auf die Gesellschaft als überindividuelle Einheit Bezug genommen wird, dann dient nach wie vor der Organismusbegriff als Leitbegriff, um eine solche Einheit in ihren Eigenschaften zu fassen (vgl. etwa Ehrlich 1892: 99). Insbesondere dient der Organismusgedanke immer noch der Abwehr und der Abwertung des juristischen Denkens als eine mechanische Tätigkeit (vgl. etwa Bähr). Wider solcher mechanistischen ,Erstarrun-

470 Weitergehende Versuche, die das Recht vom Gesellschaftsbegriff abhängig machen, finden ebenso wenig Gehör: Wenn Alois Heilinger schreibt, „[d]er Begriff des Rechts steht und fällt mit dem Begriff der Gesellschaft“ (Heilinger 1890: 1) und davon ausgehend eine Theorie des Rechts als gesellschaftliche Macht begründet, so erscheint dies als „überaus eigenartige[] Grundgedanken“ (Goldschmidt 1890a: 187).

471 Daher erscheint die sich erst ausdifferenzierende Soziologie gar nicht am Horizont der Debatte. Die schon mehrfach zitierte Diagnose der "mangelnden Spruchreife“ liegt letztlich auch dem berühmten Vortrag „Ueber den Begriff der Gesellschaft und einer Gesellschaftslehre“ des Statistikers, Staatswissenschaftlers und Rechtsphilosophen Gustav Rümelin aus dem Jahr 1888 zugrunde. Darin macht er geltend, dass die „wissenschaftliche Bewältigung“ einer solchen allgemeinen Gesellschaftslehre "noch zu unfertig und lückenhaft zu sein scheint“ (Rümelin 1889: 37). Um diesem Problem beizukommen, wendet er sich dem Gesellschaftsbegriff zu, der als Grundlage einer Wissenschaft gegenüber seinem spezifisch modernen Gebrauch eine Begrenzung benötige - der sich aber fundamental von solchen mystischen Substantialisierungen wie Volksgeist oder Organismus unterscheide (vgl.ebd.: 42f.; zur Würdigung Rümelins als „großer Soziologe“ vgl. Wiese 1957). 
gen " wird nach wie vor versucht, mittels des Organismusbegriffs die Lebensanbindung des Rechts zu gewährleisten (vgl. Gierke, Opitz; anders jedoch Ofner). ${ }^{472}$ Daher erscheint es nicht notwendig, die Frage nach der sozialen Aufgabe des BGBs über die zugrunde liegende Theorie der Gesellschaft, d.h. die Arbeit am Begriff der Gesellschaft zu klären.

Man kann auch sagen: Jherings Zweckdenken schreibt sich trotz der expliziten Ablehnung seines Werks Ende des 19. Jahrhunderts in den Diskurs der Privatrechtswissenschaft ein, allerdings gewissermaßen verkürzt. Die teleologische Zweckseite, die auf die Normativität des Rechts verweist, wird zugunsten der gesellschaftsfunktionalen Seite des Zwecks außen vor gelassen. Man diskutiert über die soziale Funktion des Rechts, ${ }^{473}$ seine Ordnungsleistung und seine gesellschaftserhaltende Wirkung. Wenn damit das „Recht der Gesellschaft" in den Blick gerät, dann geschieht dies jedoch, ohne - wie bei Jhering - die Gesellschaft in den Mittelpunkt der privatrechtswissenschaftlichen Diskussion zu stellen. Die Gesellschaft ist hier ein epistemischen Objekt, das zwar implizite Wirkungen entfaltet, indem sie zum Bezugspunkt der Bestimmung des Wesens des Privatrechts und damit der Güte des BGBs und seiner Entwürfe wird. Sie wirkt sich aber weder auf die methodische noch auf die rechtsdogmatische Ebene aus. Auf Jherings Kritik der Begriffsjurisprudenz, in die sein Zweckdenken mündet (bzw. von der es auch ausgeht), wird zwar verwiesen, allerdings werden daraus keine die Arbeitsweise der Rechtswissenschaft im engeren Sinne betreffende Konsequenzen gezogen. Das wird erst in der Methodendiskussion um die Jahrhundertwende der Fall sein.

472 Exemplarisch ist hierfür auch die Argumentation des Soziologen und Rechtswissenschaftlers Elias Hurwicz aus dem Jahr 1911: Jherings Vorteil liege in der Abwendung vom Volksgeist und in der Hinwendung zur Gesellschaft. Allerdings müsse man richtigerweise die Gesellschaft als organisch und nicht als mechanisch fassen, wolle man vermeiden, wieder bei der Substantialisierung von leitenden Gesetzen zu landen. Denn lediglich das organische Denken sichere, dass die Definition des Rechts als „Sicherung der Lebensbedingungen der Gesellschaft" die innere Anhängigkeit und damit Wandelbarkeit des Rechts von der Gesellschaft in seiner ganzen Heterogenität aufnehmen könne (vgl. Hurwicz 1911: 35f.).

473 Dies macht in der Folge auch Karl Renner unter dem Pseudonym Josef Karner mit seiner Untersuchung der "sozialen Funktion der Rechtsinstitute“ (Karner 1904a). 


\section{\5. Zweck-Dispositiv II: Das Problem der Normativität des Rechts im Methodenstreit als normatives Zweckdispositiv (ca. 1900-1920er)}

In den Debatten über das BGB und seine Entwürfe deutet sich bezüglich der Bestimmung des Lebensbezugs des Rechts bereits eine Verschiebung hin zur Rechtsanwendung an, die gegen Ende des 19., aber insbesondere Anfang des 20. Jahrhunderts zum Gegenstand intensiver Auseinandersetzungen und Polemiken wird. ${ }^{474}$ So wendet etwa Kohler gegen Menger ein, dass Rechtspolitik und Dogmatik nicht so sehr getrennt seien, wie letzterer postuliere. Ihre Verbindung liege vielmehr in der Frage der Interpretation der Gesetze, wo gesetzespolitische Erwägungen eine entscheidende Rolle spielten, um den Bedürfnissen des Rechtslebens zu entsprechen: „Gesetzespolitik ist Interpretativmittel“ (Kohler 1896: 224). Der lebendige Charakter des Rechts zeige sich also nicht mehr primär in der rechtsdogmatischen Arbeit, sondern werde in der richterlichen Rechtsanwendung verwirklicht. ${ }^{475}$ Damit wird die ,soziale Aufgabe‘ des Rechts als Ausdruck einer adäquaten Lebensanbindung zu einem Problem der richterlichen Rechtsanwendung bzw. der rechtlichen Methode (vgl. etwa G. Hartmann 1888: 312; Sinzheimer 1976c [1909]: 23). ${ }^{476}$

474 Zum Aufstieg der Rechtsprechung sowie den Diskussionen um das Richterrecht seit dem späten 19. Jahrhundert vgl. Schröder 2006.

475 Das ist auch schon in den Motiven zum ersten Entwurf des BGBs angedeutet: Angesichts der anerkannten Unmöglichkeit einer vollständigen Kodifizierung werde die Anpassung an das Leben durch den Gesetzgeber mittels der Veränderung der Gesetze, aber auch durch die Rechtswissenschaft und Rechtsprechung gewährleistet (Motive zu dem Entwurfe 1888b: 6f.). Daher nimmt auch die Kommission im Entwurf bzgl. der Auslegung „von jeder einschlagenden Vorschrift Abstand“. Denn „,[d]er Gesetzgeber, welcher den Versuch macht, Regeln dieser Art in Gesetzesparagraphen einzukleiden, disponiert nicht, sondern unterweist“ (ebd.: 15). Der Kommission zufolge sei hierfür primär die Rechtswissenschaft zuständig (vgl. ebd.: 6f), der Richter in seinem Urteil nur sekundär.

476 Nach Sohm spielen hierfür v.a. die Generalklauseln, die Billigkeitshaftung sowie der soziale Eigentumsbegriff eine zentrale Rolle (vgl. Sohm 1895: 756ff.). Allerdings wirft der Zustand der Rechtswissenschaft auch in der Rechtsanwendung seine Schatten: Gerade aufgrund der technischen Entwicklung der Rechtswissenschaft, der das Bild des Richters als „Paragraphen- und Präjudizienautomaten“ entspreche, gilt nach Max Weber: „[D]er deutsche Richter wirft das ethische 
Diese Verlagerung der Frage des notwendigen Lebensbezugs des Rechts hin zur Rechtsanwendung vollzieht sich im sogenannten ,juristischen Methodenstreit' seit Mitte des ersten Jahrzehnts des 20. Jahrhunderts. ${ }^{477}$ Die Methodenkritiker werfen der dogmatisch-systematisch arbeitenden Rechtswissenschaft vor, dass ihre Methode unwissenschaftlich sei, den Bezug zum Leben kappe und daher zu ungerechten Urteilen führe - also jene drei Motive, die schon Jhering zur Untersuchung des Zwecks im Recht veranlassten. Das ist die Notlage, auf die sie mit der Entwicklung neuer juristischer Methoden zu antworten suchen; und dies wird in der Folge zur Problematisierung des normativen Zwecks im Recht führen.

\section{L'urgence: Die Anmaßungen der Begriffsjurisprudenz}

\section{Eine kurze Geschichte der Genese des Methodenstreits}

\subsection{Die schwelende Kritik an der dogmatischen Rechtswissenschaft}

Parallel zur Debatte um die Kodifikation des BGBs rückt im privatrechtlichen Diskurs seit den 1880er Jahren zunehmend das Problem der dogmatisch-methodischen Bestimmung der Rechtsanwendung in den Vordergrund. ${ }^{478}$ Symptomatisch hierfür ist Oskar Bülows Schrift Gesetz und

Richtschwert weit von sich und ruft nach formalen Merkmalen." (Weber 1993 [1895]: 534) Daher bringe die „breite Durchschnittsmasse der heutigen Juristen [...] die Voraussetzungen zur Ausfüllung einer größeren und würdigeren Rolle wohl nicht überall mit sich. Aber eben deshalb wird, so lange dies so bleibt, auch die ,soziale' Bedeutung der Zivilrechtspflege bei uns eine relativ bescheidene bleiben, der Inhalt des Rechts möge nun ,deutsch' oder ,römisch' sein.“ (Ebd.).

477 Die Festschreibung des Privatrechts im BGB beseitigt den bis dahin herrschenden Rechtspluralismus. Der Streit, wie man den Bedürfnissen der Zeit gerecht werde, kann nun nicht mehr über die Wahl der richtigen Rechtsgrundlage ausgetragen werden (etwa deutsches versus römisches Recht). Da angesichts der sozialen Frage die Krisensituation fortbesteht, stellt sich fortan die Frage, wie man das nun bestehende Gesetz (BGB) den sich rasch wandelnden Verhältnissen anpassen kann. Daher wendet man sich der Rechtsanwendung zu.

478 Die Debatte um die Rechtsauslegung ist zudem in die Diskussionen um Rechtsund Prozessreform, Aus- und Fortbildungsreformen der Richter, Klassenjustiz und Laienbeteiligung einzuordnen. Diese Fragen wurden miteinander in Verbindung gesetzt und sind - so Rainer Schröder - als Antworten auf die Überlastung des Justizsystems sowie als Reaktionen auf einen neuen, gesellschaftlich be- 
Richteramt aus dem Jahre 1885, ${ }^{479}$ die Anfang des 20. Jahrhunderts als Wendepunkt zu einem neuen Rechtsverständnis erschien. ${ }^{480}$ Gerade die zunehmende gesetzgeberische Tätigkeit, die zu einer Abwertung des Gewohnheitsrechts führt, veranlasst Bülow dazu, die Stellung des Richters gegenüber dem Gesetz zu problematisieren (vgl. Bülow 1972 [1885]: 1).481 Dabei zeige sich: Die - angenommene - herrschende Sicht auf die Rechtsanwendung als bloße logische Subsumtion sei grundlegend falsch. Geschichte und v.a. Gesetzestheorie beweisen, dass „sich im Richteramt eine

dingten Legitimationsbedarf zu lesen, der nicht mehr allein auf der Ebene des materiellen Rechts zu lösen war (Schröder 1988: 325).

479 Etwa zeitgleich entwickeln Karl Binding, Adolf Wach und Josef Kohler Auslegungsmethoden, die für eine ,objektive Theorie' der Gesetzesinterpretation (gegenüber der subjektiven Theorie, die auf den Willen des konkreten historischen Gesetzgebers abstellt) eintreten. Da das Objektive jedoch nicht im Wortlaut, sondern im Lebensbezug gesucht wird, wird damit für mehr Freiheiten der richterlichen Interpretation gegenüber dem Gesetz plädiert (vgl. Schröder 1985: 34ff. m.N.). Diese Auslegungstheorien finden mehr Gehör als Bülows Ansatz, zeigen jedoch zugleich, dass auch hier eine Problemverschiebung hin zur richterlichen Rechtsanwendung erfolgt.

480 Mit dieser Schrift wird in der Anfang des 20. Jahrhunderts entflammenden Methodendebatte Bülow zum „Säulenheiligen des Richterrechts" stilisiert (Henne, Kretschmann 1999: 211) und als Vorläufer der Methodenreformbewegung angesehen - eine Einordnung, gegen die er sich im Jahr 1906 in seinem Aufsatz „Über das Verhältnis der Rechtsprechung zum Gesetzesrecht“ zur Wehr setzt (Bülow 1992 [1906]; kritisch zum Bild der Bekehrung Bülows Henne, Kretschmann 1999: 223ff.). Demgegenüber sieht etwa der der Interessenjurisprudenz zuzurechnende Max von Rümelin in Bülow einen typischen Vertreter der bekämpften Begriffsjurisprudenz (Rümelin 1908: 29f.). Zur Problematik, wer als Vorläufer angesehen wird, vgl. Riebschläger 1968: 26ff.; Rückert 2008: 201ff., jeweils m.w.N.

481 Regina Ogorek betont insbesondere den etatistischen Charakter von Bülows Ansatz, sei das richterliche Urteil doch wie das Gesetz für Bülow „eine von der Staatsgewalt erlassene Rechtswillenserklärung“ (Bülow 1972 [1885]: 6). Allerdings bündele sein Aufsatz die verschiedenen Überlegungen mit einer veränderten politischen und gesellschaftlichen Lage: „Die rechtsproduktive Kraft des Richteramtes ist längst als Aktivposten der Staatsgewalt verbucht und von den Rechtsuchenden mit entsprechenden Ansprüchen konfrontiert worden. Diese neue ,Macht- und Bedürfnislage` erklärt es, weshalb Bülows Richterrechtstheorie in den achtziger Jahren auch eine neue ,Bewußtseinslage` begründen und zu einem Meilenstein der Rechtslehre werden konnte, obwohl in ihr nicht ein einziges (schon gar kein erkenntnistheoretisches) Argument Verwendung findet, das nicht auch schon früher - selbst zu Beginn des Jahrhunderts - bekannt gewesen wäre." (Ogorek 1986: 267f.). 
reiche rechtsordnende und rechtsschöpferische Kraft regt" (ebd.: 2). ${ }^{482}$ Denn gerade weil sich die Gesellschaft nicht als harmonisches Ganzes, sondern als ein "Gewirre und Kampfe der neben und gegen einander wirkenden Menschenkräfte" (ebd.: 3) darstelle, sei eine vorausschauende und umfassende Gesetzgebung, die sich an den "unabweisbaren gesellschaftlichen Bedürfnisse[n]“ orientiere (ebd.: 2), nicht möglich: „Das abstrakte stumme Gebot des Gesetzes vermag der vielgestaltigen stürmischen Bewegung des menschlichen Gemeinlebens nicht völlig Herr zu werden." (Ebd.: 46) Der „frei strebende menschliche Wille“, das „sich jeder menschlichen Voraussicht entziehende[] Walten des Zufalls" sowie technische Neuerungen wie etwa die „erstaunliche[] Vervollkommnung der Verkehrsmittel“ schaffen die „sonderbarsten und verwickelsten Rechtsprobleme [...], Probleme, an welche der Gesetzgeber gar nicht hat denken, für die er also auch keine Lösung hat wollen, noch weniger sie bereit stellen können" (ebd.: 30, 31). In diesen Fällen fehle die „logische[] Nothwendigkeit des Zusammenhangs zwischen Thatbestand und Rechtsfolge“ (ebd.: 32). Überhaupt scheitere der Versuch einer abschließenden Gesetzgebung an der Uneindeutigkeit jeder Begrifflichkeit, die immer eine Vielzahl sich widersprechender Interpretationen zulasse und die in den sich widersprechenden Urteilen verschiedener Instanzenzüge zum Ausdruck komme (ebd.: $35 \mathrm{ff}$. .). ${ }^{483}$

„Vollständigkeit, Bestimmtheit, Festigkeit, Untrüglichkeit des Gesetzesrechts“ seien also immer nur „vermeintlich[]“ (ebd.: 41). Daher könne es sich beim richterlichen Urteil nicht um eine „bloße logische Subsumtionsoperation“ (ebd.: 5), d.h. nicht um die „folgerichtige[] Ableitung einer Wahrheitserkenntniß aus anderen, schon feststehenden Wahrheiten“

482 Auf geschichtlicher Ebene gilt für Bülow: Bei den immer wieder auftretenden Wellen der Kodifizierung des Rechts durch Gesetz (zum Zwecke der Rechtssicherheit) handelt es sich um Phänomene, die v.a. im Bereich des Privatrechts der Rechtsproduktion durch Richterspruch regelmäßig nachgelagert sind. Insbesondere sei die Rezeption des römischen Rechts in Deutschland durch Gerichtsgebrauch erfolgt, nicht durch die Wissenschaft (vgl. Bülow 1972 [1885]: 24f., 27).

483 Bülow merkt an, dass zur Ermittlung des „wahre[n] Sinn[s]“ daher der Gesetzgeber oft auf die Wissenschaft verweise (ebd.: 38) - eine Gesetzgebungstechnik, die auch in den Motiven zum Entwurf des BGBs vorzufinden ist. Nicht das Gesetz ist die Quelle der Rechtserkenntnis, sondern diese „ist in dem Ganzen des Volksund Staatslebens verborgen“ (ebd.: 48). In der Konkretion der Rechtsfindung bleibt Bülow jedoch sehr vage: „Ernster Arbeit, reichen Wissens bedarf es um das Recht von dort hervorzuholen, scharfen und geschulten Geistes um es nach dem Maße des Gesetzes zu formen, feiner und zarter Rechtsempfindung um innerhalb der Gesetzesgrenzen die richtige Rechtsbestimmung zu treffen, eines fest und beständig auf das Rechte gerichteten Willens um dieses verantwortungsvollen hohen Berufes gerecht und unparteiisch zu walten!“ (Ebd.). 
(ebd.: 9) handeln. Richterliche Rechtsanwendung zeige sich dementsprechend ebenso vom „Willen“ geleitet wie die Gesetzgebung, sie sei rechtsschöpfend, gestalte ebenfalls die Rechtsordnung und sei daher dem Gesetz gleichzustellen. Mehr noch: Indem der Richter die im Gesetz abstrakt angedachte Rechtsordnung im unmittelbaren Lebensbezug des Einzelfalls verwirkliche, reiche erst der Richter an das „wirkliche Rechtsleben“ heran (ebd.: 46). Erst im richterlichen Urteil werde die Steuerungsfunktion des Gesetzes erfüllt (vgl. Henne, Kretschmann 1999: 214), die ja letztlich die Ordnungsleistung des Rechts garantiert.

Für Bülow steht damit nicht nur „die Bedeutung und Würde des Richteramts", sondern „in sogar noch höherem Grade auch die der Rechtswissenschaft auf dem Spiele“ (ebd.: 13): „Eine Rechtswissenschaft, die vom richterlichen Recht nichts wissen will, spricht sich selber die Existenzberechtigung ab!“ (Ebd.: 45) Betroffen sind auf rechtstheoretisch-dogmatischer Ebene v.a. die Rechtsquellenlehre (vgl. ebd.: VIII), wenn Bülow die rechtsschöpfende Kraft der Rechtsprechung betont, ${ }^{484}$ sowie auf dogmatisch-methodischer Ebene die Rolle des Systemdenkens für die Rechtsauslegung respektive der Rechtserkenntnis, wenn er gegen das Dogma der logischen Subsumtion anschreibt.

\subsection{Vom Streit um die Rechtsdogmatik zum Methodenstreit}

Bülow spricht in seiner Schrift zentrale Motive an, mit denen sich die Privatrechtswissenschaft zunehmend beschäftigt: Immer häufiger wird Ende des 19. Jahrhunderts die Lückenlosigkeit des Rechts in Frage gestellt, jene Maxime, die in der Historischen Rechtsschule die Ergänzung des Rechts aus sich selbst heraus mittels der juristischen Konstruktion ermöglicht hat-

484 Insbesondere lasse sich die Rechtsprechung nicht unter die Schablone des Gewohnheitsrechts drücken, auch nicht unter das "Juristenrecht“ oder das „Recht der Wissenschaft“ (vgl. ebd.: 19, 44). Denn die Gewohnheitsrechtsbildung wie das wissenschaftliche Recht erfolge bei Savigny seinem Systemdenken folgend „ähnlich wie die gesetzliche nur durch Schaffung abstrakter allgemeingiltiger Rechtsbestimmungen“ (ebd.: 42, H.i.O.). Der Gerichtsgebrauch entbehre aber einer solchen verallgemeinernden abstrakten Regelung und reiche nicht über das einzelne abzuurteilende Rechtsverhältnis hinaus (ebd.: 11, 42). Zum Angriff auf die Rechtsquellenlehre der Historischen Rechtsschule (Gewohnheitsrecht, Gesetz, Wissenschaft) unter Aufwertung des Gesetzesrechtes und der subjektiven Vernunft im richterlichen Urteil vgl. schon Adickes 1872. 
te (vgl. etwa Ehrlich 1967e [1888]). ${ }^{485}$ Verteidigungsversuchen der Annahme einer Geschlossenheit des Rechts auch von anderer Seite als den Vertretern der Historischen Rechtsschule, namentlich durch Karl Bergbohm, ${ }^{486}$ wird vehement widersprochen (vgl. Jung 1992 [1900])487, und spätestens mit Ernst Zitelmanns Rektoratsrede über Lücken im Recht aus dem Jahr 1903 wird die Frage, wann man überhaupt von einer echten Rechtslücke sprechen könne, zu einem drängenden rechtstheoretischen Problem im zeitgenössischen Diskurs der Privatrechtswissenschaft.

Mit der Kritik am Dogma der Lückenlosigkeit geht es nicht um die Erkenntnis, dass jedes Gesetz angesichts der gesellschaftlichen Entwicklungen unmöglich alle zukünftigen Fälle regeln könne - das war auch dem BGB-Gesetzgeber klar (vgl. Motive zu dem Entwurfe 1888b: 7) und hatte, wie Savignys Überlegungen zum Umgang mit fehlerhaften, unbestimmten etc. Gesetzen zeigen, auch die Historische Rechtsschule anerkannt. Viel-

485 Angesichts der immer unvermeidbaren Lücken im Recht (Ehrlich 1967e [1888]) gilt, dass das Recht - wie Ehrlich rückblickend sein Ergebnis im Jahr 1903 in der Freien Rechtsfindung zusammenfasst - „nicht ein abgeschlossenes, vollständiges System abstrakter Rechtsregeln ist, sondern aus Einzelentscheidungen besteht“ (Ehrlich 1967d [1903]: 170 [Vorrede]). Zur erst nach Veröffentlichung der Freien Rechtsfindung Anfang des 20. Jahrhunderts einsetzenden Rezeption der Lücken vgl. die Nachweise bei Vogl 2003: 109f.

486 So schreibt Bergbohm im Jahr 1892 trotz seiner Kritik an der Historischen Rechtsschule: „Die ganze Vorstellung von den Rechtslücken sollte endlich einmal aufgegeben werden. Ein Recht, und wenn es fast nichts an geregelten Stoffen umfasst, ist allemal etwas in lückenloser Gestalt Dastehendes. [...] Es bedarf niemals der Auffüllung von außen her, denn es ist jeden Augenblick voll, weil seine innere Fruchtbarkeit, seine logische Expansionskraft im eigenen Bereich jeden Augenblick den ganzen Bedarf an Rechtsurteilen deckt.“ (Bergbohm 1892: 384ff.) Auch wenn er in seinem Plädoyer für den Positivismus primär gegen den naturrechtlichen Rechtsdualismus argumentiert, demzufolge eine Lückenfüllung über das neben dem Gesetz bestehende Natur- bzw. Vernunftrecht zu erfolgen habe, richtet er seine Ausführungen auch explizit gegen die nicht naturrechtlichen Vertreter der These der Lückenhaftigkeit des Rechts (Bergbohm 1892: 384ff. Fn. 10, 11).

487 Ernst Jung widerspricht Bergbohm unter anderem mit Verweis auf den Entwicklungsgedanken des historischen Rechts vehement (vgl. Jung 1992 [1900]: 32). Aber anders als die Historische Rechtsschule betrachtet er das Recht nicht als organisches Ganzes, das daher in sich logisch geschlossen sei. Damit bekämpft er die Idee vom ,jederzeitigen Gedecktsein aller möglichen Komplikationen durch die logische Expansionskraft der positiven Sätze“ (ebd.: 33), d.h. der Möglichkeit der Lückenfüllung durch die logisch-systematisierende Arbeit der Rechtsdogmatik. Auch Stammler richtet sich gegen die Annahme der „logischen Geschlossenheit", dem er in Form des „richtigen Rechts“ jedoch den Gedanken einer Art teleologischer Geschlossenheit entgegensetzt (vgl. Stammler 1902: 272ff.). 
mehr steht die methodische Frage im Vordergrund, wie Lücken gefüllt werden. Denn in einem solchen Fall vermag der Rekurs auf ein organisches Ganzes des Rechts, d.h. die dogmatisch-systematische Arbeit am Rechtssystem, nicht mehr zu überzeugen. ${ }^{488}$ So hebt Gustav Rümelin (der jüngere) in seiner Prorektoratsrede von 1891 die Bedeutung persönlicher Werturteile und Willensentscheidungen hervor (Rümelin 1891). ${ }^{489}$ Natur der Sache, Analogie, Reduktion und Umkehrschluss erweisen sich in dieser Perspektive nicht als Techniken, die man mittels des Systemgedankens auf rein logische Operationen zurückführen könnte (vgl. Ehrlich 1967e [1888]; Rümelin 1891; Jung 1992 [1900]). Die juristische Konstruktion in ihrem Anspruch, im Rahmen der Rechtsfindung, neues` Recht zu erzeugen, gerät ins Visier der Kritik (vgl. Stampe 1905b), und zentrale Belange der dogmatisch arbeitenden Rechtswissenschaft werden zur Disposition gestellt.

Dabei findet eine Verlagerung des Kernproblems der Rechtsfindung statt: Es wird nun nicht mehr in der Rechtsdogmatik, sondern in der konkreten Rechtsinterpretation im richterlichen Urteil verortet. ${ }^{490} \mathrm{Im}$ „Mittelpunkt" steht nun die richterliche Rechtsauslegung (Rumpf 1906: 29; vgl. a. Wurzel 1904). An die Stelle des Rechtsdogmatikers rückt der Richter; er wird zur entscheidenden Figur (vgl. Ehrlich 1967d [1903]; Kantorowicz 1906; Rumpf 1906). ${ }^{491}$ Zur Debatte steht das Verhältnis des Richters zum Gesetz, wie es schon Bülow zum Ausgangspunkt seiner Überlegungen

488 Da auch in der Historischen Rechtsschule Gesetz und Gewohnheitsrecht Lücken aufweisen können, ist das Lückenproblem nicht neu (vgl. Heine 2004: 36ff.). Die Lücken lassen sich aber durch Rekurs auf das System, das organische Ganze des Rechts, schließen (s.o.) - und genau das wird nun bestritten. Zur Kritik am Verfahren der Pandektistik seit den 1880ern vgl. Haferkamp 2004: 62ff.

489 Es handelt sich um den gleichnamigen Sohn des oben erwähnten Statistikers sowie den älteren Bruder des ebenfalls sehr bekannten Rechtswissenschaftlers Max Rümelin, der zu den Vertretern der Interessenjurisprudenz zählt.

490 Diese Verlagerung des Kernproblems der Rechtswissenschaft folgt auch aus der Kodifikation des BGBs, stellt diese doch die herausragende Stellung der Rechtswissenschaft zusehends in Frage: Aufgrund der Abschaffung des Rechtspluralismus verliert die Rechtswissenschaft ihre Funktion als Rechtsquelle, da es nicht mehr der rechtswissenschaftlichen Bestimmung des überhaupt anzuwendenden Rechts bedarf. Damit bleibt letztlich allein die Interpretationsherrschaft zu retten (vgl. Schröder 1988: 325). Zudem birgt die Positivierung des Rechts im Gesetz die Gefahr der Degradierung der Rechtswissenschaft zu einer „bloßen Wortund Paragraphenjurisprudenz" (Zitelmann 1896: 14). Daher fürchtet man die Heraufkunft einer „neue[n] Epoche des Rationalismus“ oder eines „nackten Positivismus" (Oertmann 1899, zitiert nach Hofer 1999: 113).

491 Das Lückenproblem stellt sich im Rahmen der richterlichen Rechtsanwendung mit einer bestimmten Dringlichkeit: Aufgrund des Rechtsverweigerungsverbo- 
machte. Der Fokus liegt nun nicht mehr auf der Rechtsdogmatik, sondern auf der rechtsschöpfenden bzw. rechtsfortbildenden Kraft des richterlichen Urteils (etwa Ehrlich 1967d [1903]; Sternberg 1904; Rumpf 1905: 404f.). Wenn dabei eine "quasigesetzgeberische“ Stellung des Richters proklamiert wird (Jung 1992 [1900]: 21) ${ }^{492}$, streitet man über die Reichweite der „Richtermacht“ (vgl. Stampe 1992 [1905]) im Verhältnis zur Forderungen der "Gesetzestreue“ (Heck 1905) als ein verfassungstheoretisches Probleme der Gewaltenteilung (vgl. etwa Bülow 1992 [1906]: 91; Michaëlis 1906; Radbruch 1906: 363ff.).

Über die Rechtsauslegung und richterliche Rechtsanwendung werden wie ein Kritiker der neuen Methodenansätze bemerkt - „die letzten Fragen unserer Wissenschaft berührt“ (Mitteis 1909: Sp. 1038): Zur Debatte steht die Rechtsquellenlehre (vgl. etwa Ehrlich 1967d [1903]: 178ff.; später Kiß 1911), der Begriff des Rechts (etwa Jung 1912; Müller-Erzbach 1974 [1913]; Somló 1917: 52ff.), die Rolle der Rechtswissenschaft angesichts der Kodifikation des BGBs (z.B. Zitelmann 1903), ja letztlich die methodologischen und methodischen Prämissen der Rechtswissenschaft selbst (etwa Rumpf 1906: 1ff.). Es handelt sich um einen „Kampf um die Rechtswissenschaft“, den Hermann Kantorowicz in seiner vielbeachteten Schrift unter dem Pseudonym Gnaeus Flavius im Jahr 1906 ausruft. Dabei geht es ums Ganze: „Möge diese Schrift neue Streiter werben für den Befreiungskampf der Rechtswissenschaft, für den Sturm auf die letzte Bastion der Scholastik." (Kantorowicz 1906: 6)

Seit Beginn des Jahrhunderts finden die Vertreter der schöpferischen Rechtsanwendung immer mehr Befürworter, wie Landsberg in seiner Kritik der Methodenreformbewegung betont: „Keine schleichende Glut mehr, sondern die Flamme, die offen und zielbewußt emporschlägt!“ (Landsberg 1905: Sp. 925) Spätestens seit Kantorowicz' Aufwertung der Richterpersönlichkeit in seinem Kampf um die Rechtswissenschaft sei „[d]er Streit um die richterliche Rechtsschöpfung [...] jetzt endlich von den Geg-

tes darf sich der Richter selbst bei Vorliegen einer Lücke im Recht einer Entscheidung nicht entziehen (vgl. Radbruch 1906: 363; Somló 1917: 396). Zudem gelangte die Figur des Richters auch angesichts einer anhaltenden Justizkritik in den Fokus (zur Justizkritik Ende des Kaiserreiches sowie in der Weimarer Republik vgl. Schröder 1983; Kuhn 1983).

492 Da nach Jung der Richter im Falle der Lückenhaftigkeit auf das „natürliche Recht" zurückgreift, das jenseits des positiv gesatzten Rechts existiert, handelt er bei der Lückenschließung nicht willkürlich, sondern rechtsgebunden. Insofern agiere der Richter auch nur quasigesetzgeberisch, da er zwar eine Regel zum Recht erhebe, aber nicht wie die Gesetzgebung eine Willensentscheidung fälle (vgl. Jung 1912). 
nern angenommen worden“ - auf dem „Gebiete der juristischen Methodenlehre" herrsche "große Regsamkeit", wie Gustav Radbruch im Jahr 1907 feststellt (Radbruch 1907: 241). Der ,juristische Methodenstreit“ (Radbruch 1906) sei im Privatrecht im vollen Gange, ${ }^{493}$ und die „deutsche Rechtsprechung“ befinde sich - wie Hans Wüstendörfer im Jahr 1913 proklamiert - erneut an einem „Wendepunkt“ (Wüstendörfer 1913).

Das Stichwort für die neue Perspektive auf die juristische Methode liefert - in Anlehnung an François Génys Entwurf der "libre recherche scientifique" (Gény 1954 [1899]) - Eugen Ehrlich mit seinem Vortrag Freie Rechtsfindung und freie Rechtswissenschaft aus dem Jahr 1903. Drei Jahre später versucht Kantorowicz die disparaten kritischen Einlassungen zur herkömmlichen Methodenlehre unter dem Namen "freirechtliche Bewegung" zu bündeln (Kantorowicz 1906: 13, H.i.O.); den Namen ,Freirecht' übernehmen sowohl Befürworter als auch Kritiker der neuen Richtung (vgl. Rückert 2008: 203 m. zahlr. N.). ${ }^{494}$ Bereits 1905 führt Philipp Heck als Alternative den Terminus der Interessenjurisprudenz ein (Heck 1905), der

493 Zur anwachsenden Literatur vgl. die Auflistungen in Heck 1912: 48f. Anhang I; Heck 1914: 1f. Fn. 2; sowie die Nachweise in den in der Zeitschrift für die gesamte Strafrechtswissenschaft zwischen 1904 und 1908 erschienenen Literaturberichten Rechtsphilosophie von Gustav Radbruch (Radbruch, Kaufmann 1987: 445ff.) und in Justus Wilhelm Hedemanns Zivilistischen Rundschauen im Archiv für bürgerliches Recht (vgl. v.a. Hedemann 1908, 1910; zum Methodenstreit vgl. statt vieler Schröder 1988; Schröder 1976, sowie die Anthologien von Gängel, Mollnau 1992; Ellscheid, Hassemer 1974).

494 Die Freirechtsschule bezieht sich - wie schon Kantorowicz betont (Kantorowicz 1992 [1911]: 267f.) - auf eine Ansammlung relativ heterogener Positionen und Ideen. Erschwert wird ihre Bestimmung auch dadurch, dass manche Autoren ihr nur in Teilaspekten zustimmen (vgl. Rückert 2008: 205ff.). Darüber hinaus werden sehr unterschiedliche politische Positionen vertreten (vgl. ebd.: 212ff.), so dass man weder aus sachlichen noch aus politischen Gründen alle über einen Kamm scheren kann. Zu den am häufigsten genannten Vertretern der Freirechtsschule gehören Eugen Ehrlich, Hermann Kantorowicz und Ernst Fuchs. Daneben wird immer wieder auf Ernst Jung, Theodor Sternberg, Max Rumpf, Ernst Stampe sowie Gustav Radbruch verwiesen (vgl. zur Einordnung Radbruchs unten $\$$ 5.IV.2.1). Zur Freirechtslehre vgl. v.a. Kanigs 1932; Riebschläger 1968; Lombardi Vallauri 1971; Moench 1971; Schröder 1988; zu den einzelnen Protagonisten siehe v.a. Muscheler 1984 (Kantorowicz); Foukles 1965 (Fuchs); Bartels-Ishikawa 1998 (Sternberg); Vogl 2003 (Ehrlich). Arthur Nußbaums Rechtstatsachenforschung, die rechtssoziologischen Ansätze Hugo Sinzheimers oder Hans Wüstendörfers „soziologische Methode der Rechtsfindung“ sind nur bedingt dieser Schule zuordnen, auch wenn sie im Diskurskontext der Debatten um das Freirecht auftraten. 
ebenfalls auf breite Zustimmung stößt. ${ }^{495}$ Die Begriffe werden jedoch keineswegs einheitlich verwendet: Mal werden sie als Gegensätze verstanden, ${ }^{496}$ mal dient der eine, mal der andere als übergreifender Sammelbegriff (vgl. etwa Hedemann 1908: 296ff.; Kantorowicz 1992 [1911]: 268; vgl. auch die Nachweise bei Stoll 1974 [1931]: 155ff.).

Aber auch andere Bezeichnungen werden ins Feld geführt: Ernst Fuchs erkennt in der neuen Richtung die "wahre moderne Rechtswissenschaft“ bzw. einen „juristischen Modernismus“ (Fuchs 1909a: 204, 1), und dementsprechende werden die Vertreter v.a. des Freirechts als „Modernisten“ bezeichnet (vgl. etwa Kantorowicz 1992 [1911]: 268; Merkl 1993 [1920]: 266; Baumgarten 1929: 16). Ernst Stampe will sie mit Blick auf das Ergebnis als „Sozialjurisprudenz“ verstanden wissen (Stampe 1904, zitiert nach Rückert 2011: 915). Einzelne Autoren wiederum legen den Schwerpunkt auf das jeweils entscheidende Kriterium im Rechtsfindungsprozess und sprechen von „teleologischer" (Jung 1992 [1900]: 33) oder „wertender“ Jurisprudenz (Heck 1974 [1929]: 91 Fn. 5), von „Zweck“- (Baumgarten 1929: 16ff.; vgl. Kantorowicz 1992 [1911]: 268) und später von „Wertungsjurisprudenz“ (vgl. Stoll 1974 [1931]: 160 Fn. 13), von „realistischer“ (vgl. Heck 1974 [1929]: 91 Fn. 5) oder „soziologischer Jurisprudenz“ (etwa Wurzel 1904: 102) bzw. von „Gefühlsjurisprudenz““.997

Das Feld der Methodenreformbewegung spaltet sich in unterschiedliche Richtungen auf, wobei die Gegenüberstellung von Freirechtsbewegung und Interessenjurisprudenz dominiert. Einigkeit besteht trotz aller Differenzen in der grundsätzlichen Kritik an der dogmatischen Rechtswissenschaft.

$495 \mathrm{Zu}$ den Hauptvertretern der Interessenjurisprudenz werden neben Philipp Heck meist Max Rümelin, Heinrich Stoll, und im weiteren Sinne auch die Zivilrechtslehrer Paul Oertmann und Rudolf Müller-Erzbach (kritisch hierzu Knauthe 1968) gezählt; zur Interessenjurisprudenz vgl. Dombek 1969; Edelmann 1967; Kallfass 1972; Ellscheid, Hassemer 1974; zu einzelnen Vertretern insbesondere Schoppmeyer 2001 (Heck); Haßlinger 2014 (Rümelin); Brodhun 1999 (Oertmann).

496 Das liegt insbesondere an der Konfrontationslage, in der sich Interessenjurisprudenz und Freirechtslehre sehen.

497 Angesichts der Rechtsentstehungslehre der Historischen Rechtsschule, die das Recht im außerstaatlichen Rechtsbewusstsein verortet, wird das Rechtsgefühl als Quelle des Rechts (und damit der Rechtsfindung) und des Rechtswandels diskutiert (vgl. etwa Löning 1907; Jung 1912; Kübl 1913; Radbruch 1914/1915; Rümelin 1925). Dies führte zu der - oft abwertenden - Bezeichnung als „Gefühlsjurisprudenz". 


\subsection{Gemeinsame Polemik gegen die Begriffsjurisprudenz}

Die gemeinsamen Angriffe richten sich gegen das Dogma der Lückenlosigkeit des Rechts, das der herrschenden Rechtswissenschaft mit ihrem Schwerpunkt auf der dogmatisch-systematischen Arbeit am Recht zugrunde liegt. ${ }^{498}$ Zahlreiche Abhandlungen befassen sich seit der Jahrhundertwende mit dem Problem der Bestimmung des Lückenbegriffs, so dass Heck im Jahr 1914 schließlich feststellt: „Die Literatur des Lückenproblems ist schon sehr umfangreich, da sich jede ausführlichere methodische Untersuchung der neueren Zeit mit dem Lückenproblem auseinandersetzt." (Heck 1914: 157 Fn. 234) Der Lückenbegriff wird zum Teil ausdifferenziert: Echte werden von unechten Lücken abgegrenzt (Zitelmann 1903), unterschieden werden auch primäre und sekundäre Lücken, daneben aber auch Gebots-, Tatbestands- und Rechtsfolgelücken, Total-, relative oder Alternativlücken sowie Kollisionslücken (vgl. Heck 1914: 168ff.). Dabei erweist sich für manche schlichtweg jeder Rechtssatz als lückenhaft, müsse man doch generell von der Unbestimmtheit und der „Relativität der Begriffe“ (Müller-Erzbach 1912) ausgehen: „[G]etrost darf man behaupten, dass nicht weniger Lücken als Worte da sind. Kein einziger Begriff ist bis in seine Urmerkmale zerlegt, wenige nur sind definiert und diese wenigen wieder nur durch andere, selber undefinierte Begriffe." (Kantorowicz 1906: 15)

Nicht nur angesichts des gemeinhin anerkannten Problems der „notwendig unklaren, lückenhaften, widerspruchsvollen Werke des Gesetzesverfassers" (Radbruch 1906: 365), sondern ebenso mit Blick auf die Rechtsordnung und das Rechtssystem (etwa Stampe 1905b: Sp. 419f.) geht man von der Lückenhaftigkeit des positiven Rechts aus (vgl. Berolzheimer 1907: 145ff.) - auch wenn zum Teil erhebliche Differenzen im Verständnis der Lücke auszumachen sind. Aufgrund dieser Erkenntnis rückt aber nun die Frage, wie Lücken zu füllen sind, in den Vordergrund, da man hierfür nicht mehr auf ein wie auch immer geartetes organisch und/oder logisch

498 Lücken fordern auch den Systemgedanken des BGBs heraus, ging man doch bei seiner Verfassung davon aus, dass - selbst wenn keine Vorschrift unmittelbar anwendbar sei - das „BGB im Bedürfnisfall aus sich selbst, aus dem in ihm enthaltenen Rechtssystem ergänzt werden" könne (Mugdan 1899: 365; s.a. Riebschläger 1968: 82f.; Schröder 1988: 334). Dies geschehe nach der dogmatischsystematischen Methode mittels der Prinzipien des BGBs, die den Keim des weiteren Ausbaus in sich trügen und der sich auf dem Wege der Analogie vollziehe. 
geschlossenes Rechtssystem und damit auf das positive Recht zurückgreifen kann. ${ }^{499}$

Angesichts dieses Problems verbreitet sich eine Polemik gegen die kon-

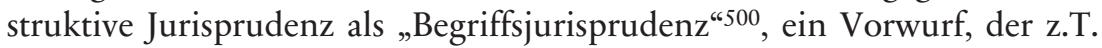
explizit an Jhering anschließt. ${ }^{501}$ Sie wird geschmäht als „Begriffsknetungs-“ und "Scheinwissenschaft" (Fuchs 1976 [1910]: 188), sei keine „wahre[] Wissenschaft“, sondern „Pandektologie“ (Fuchs 1965c [1908]: 119) bzw. „eine dem Querulantenwahnsinn verwandte psychopathische Erscheinung" (Fuchs 1909a: 59). Vorgeworfen wird ihr ein lebensfremder „Scholastizismus“ (Münch 1914/15: 391), Apriorismus (vgl. Fuchs 1976 [1910]: 185) und Formalismus (Müller-Erzbach 1908: 333f.; differenziert dazu Rümelin 1907: 36ff.) ${ }^{502}$, was in einem „Begriffsrealismus“ (Rumpf 1906: 35; Fuchs 1965a [1916]: 178) münde, indem irrigerweise die „wissenschaftlichen Begriffe als kausale Realitäten" aufgefasst würden (Heck 1912:

499 Da sich die Kritik gegen die Annahme jeglicher Form der Geschlossenheit des Rechts richtet, richtet sie sich sowohl gegen die Historische Rechtsschule als auch gegen den Positivismus (vgl. Kantorowicz 1906: 10; Reichel 1992 [1910]: 193). V.a. werden diese beiden an sich nicht vereinbaren Richtungen aufgrund der Positivierung des positiven Rechts im BGB nun auch oft in eins gesetzt (vgl. Ogorek 1986: 5, m.N.), indem den Vertretern der Historischen Rechtsschule unterstellt wird, dass sie sich fortan nur noch am positiv gesetzten Recht orientierten. Daher greift man nun die "gesetzespositivistische“ Begriffsjurisprudenz an (Rümelin 1930: 35; s.a. Heck 1912: 21; Baumgarten 1930: 329, 332).

500 Für die grundlegenden Zweifel an der juristischen Methode, die als Ausgeburt der juristischen Dogmatik erscheint, wird wie in der Debatte über die Kodifikation des Zivilrechts im BGB insbesondere Windscheid zu einer Schlüsselfigur (vgl. Rückert 1992; 2008: 202 m.w.N.; 1988: 87ff.), denn nach wie vor gilt: ,,Jurisprudenz, das heißt Pandekten - Pandekten, das heißt Windscheid.“ (Siber 1909: 964) Allerdings spielt nun angesichts der erfolgten Kodifikation die Frage, ob der Rekurs auf germanisches Recht diesen Auswüchsen vorbeugen würde, keinerlei Rolle mehr.

501 Die Referenz auf Jhering erfolgt in doppelter Hinsicht: Zum einen dient Jherings „Theorie der juristischen Technik“ als exakte Beschreibung der geschmähten juristischen Konstruktion (etwa Heck 1912: 14). Zum anderen schließt man sich seiner späteren Kritik (v.a. in Scherz und Ernst) der Konstruktionsjurisprudenz als Begriffsjurisprudenz an: Er habe als erster die Begriffsjurisprudenz entdeckt und bekämpft (Kantorowicz 1912b: 77). Das wird jedoch z.T. bestritten: Für manche geht auch der späte Jhering wie ein Begriffsjurist vor (etwa MüllerErzbach 1912: 205). Die Verteidiger der herkömmlichen Dogmatik und Methode verwenden nun selbst den Ausdruck ,Begriffsjurisprudenz' im positiven Sinne, um die unausweichliche Notwendigkeit der juristischen Arbeit mit Begriffen als „Form der Darstellung“ zu kennzeichnen (vgl. etwa Sohm 1909, 1910; Vierhaus 1909: Sp. 1171).

502 Zu Max Rümelins Kritik der Begriffsjurisprudenz vgl. Haßlinger 2014: 79ff. 
18). Die juristische Technik sei „Sünde gegen den heiligen Geist“ (Ehrlich 1967d [1903]: 188), und das Fundament der juristischen Konstruktion erweise sich als „ein Bau aus Münchhausenschen Luftsteinen“ (Stampe 1905b: 420; differenzierend Rümelin 1922b). ${ }^{503}$ Diese Kritik schlägt sich in einem bestimmten Richterbild nieder: Der Begriffsjurisprudenz degradiere den Richter zu einer „Denkmaschine“ mit „rein logische[n] Operationen“ als seine "Geheimtechnik" ohne jegliche andere Zutat (Kantorowicz 1906: 7). Er sei - so das bis heute wirkmächtige Bild - ein „Subsumtions-Automat" (etwa Fuchs 1907a: 184; s.a. Reichel 1992 [1910]: 193; Gmelin 1910c [1908]: 4; Heck 1914: 22), dem in überspitzter Form ein „Richterkönigtum" (Fuchs 1907b) entgegengehalten wird. ${ }^{504}$

Die Polemik gegen die Begriffsjurisprudenz beruht dabei auf der Feststellung einer mehrfachen Gefahr (l'urgence): Gegenüber den lebensfremden, rein spekulativen Begriffskonstruktionen gelte es, die Wissenschaftlichkeit der Jurisprudenz im Namen der Gerechtigkeit und der Rechtssicherheit zu verteidigen.

\section{Die Gefahren der Begriffsjurisprudenz}

\subsection{Der Streit um die Wissenschaftlichkeit}

Gemein ist den Ansätzen der Methodenreformbewegung, dass die zur Lückenfüllung erforderliche Rechtsfindung ein Problem der Wissenschaftlichkeit der Jurisprudenz darstellt. ${ }^{505}$ Genau das zweifeln die Gegner der Methodenkritik jedoch an: Man unterstellt, dass sie auf „die subjektive

503 Diesem Angriff auf die Dogmatik entspricht eine Umwertung in der Beurteilung Puchtas als herausragender Vertreter der konstruktiven Jurisprudenz: Habe zunächst „Puchtas machtvoll einseitige Persönlichkeit [...] alle dogmatisch interessierten Romanisten in den Bann seiner Methode" gezogen, gelte er nun im Gefolge von Jherings Scherz und Ernst ,als der typische Vertreter der einseitigsten, verstiegenen, weit- und lebensfremden, praktisch unanwendbaren, dialektisch haarspaltenden Begriffsjurisprudenz" (Landsberg 1910: 459, 460; vgl. zu dieser Umwertung v.a. Haferkamp 2004: 46ff.).

$504 \mathrm{Zu}$ dieser Spannungslage in den Überlegungen zur Richterfunktion, die bereits im 19. Jahrhundert vorlag, vgl. die grundlegende Studie von Regina Ogorek 1986.

505 So kann man mit Haferkamp feststellen: „Trotz aller bemängelten Schwächen hatte Jherings Schrift [Scherz und Ernst, D.S.] einen seit den achtziger Jahren sensibilisierten Punkt getroffen. Zunehmend machten sich Zweifel an der Wissenschaftlichkeit des bisher von der Rechtswissenschaft geübten Verfahrens breit.“ 
Willkür des Richters“ (Vierhaus 1909: Sp. 1174) rekurriere, eine „Suprematie des Individuums über das Gesetz" (Unger 1906: 783) und damit eine „antisozial[e]“ Überhöhung des Juristen (Klein 1906: 266) unterstütze, für eine Rechtsanwendung contra legem eintrete und daher eine „Kadi-Justiz“ befürworte (Vierhaus 1909: Sp. 1173). ${ }^{506}$ Denn der Richter werde gegenüber dem Recht freigesetzt, indem er bei Vorliegen einer Lücke in einen Bereich jenseits der wissenschaftlichen Erkenntnis des Rechts verwiesen werde. ${ }^{507}$ Letztlich führe der „Kampf um die Rechtswissenschaft“ zu ihrer Beseitigung, zur „Befreiung des Rechts von der Wissenschaft“ (Unger 1906: 787; vgl. auch Michaëlis 1906: 396).

Entgegen dieser Kritik wird vielmehr darum gerungen, das Urteil des Richters wissenschaftlich zu fundieren. Denn genau dafür sei die als "Kunst“" verstandene Begriffsjurisprudenz in ihrem "methodische[n] Quietismus" (Heck 1914: 3) vollkommen ungeeignet. Die angeblich wissenschaftliche Methode der Rechtsfindung durch die vorgeblich rein logischen Operationen der Subsumtion, Deduktion, Analogiebildung und Umkehrschluss in der Begriffsjurisprudenz erweise sich als trügerisch. Das Vorgehen der „technischen Begriffsjurisprudenz“ offenbare sich bei einem genaueren Hinsehen - so Philipp Heck - als ein unzulässiges „Inversionsverfahren“ (Heck 1909: Sp. 1461): ${ }^{508}$ Aus logischen Gründen sei nicht haltbar, aus den Rechtssätzen Rechtsprinzipien als systematisierende, abstrakte Ordnungsbegriffe zu extrahieren, aus denen dann für nicht geregelte Rechtsfälle neue (inhaltliche) Rechtssätze konstruiert werden. Denn das

(Haferkamp 2004: 63) Das bildete die Basis des Erfolgs des Schlagworts der Begriffsjurisprudenz.

506 Dass namentlich das Freirecht für eine Rechtsanwendung gegen das bestehende Gesetz (contra legem) eintrete, befinden nicht nur die Befürworter der juristischen Konstruktionsmethode, sondern wird auch von den Anhängern der Interessenjurisprudenz ins Feld geführt (etwa Heck und Rümelin). Gegen diesen Vorwurf setzt sich insbesondere Kantorowicz mit seinem Aufsatz Die contra-legemFabel zur Wehr (Kantorowicz 1911b; s.a. 1911a: 285 Fn. 10 m.w.N.; kritisch hierzu Muscheler 1984: 125ff.). Einer Reaktivierung der contra legem-Fabel wird heute vehement widersprochen (vgl. etwa Auer 2015: 785ff.).

507 Diese Vorwürfe, die unter anderem gegen seinen Vorschlag der Interessenabwägung gerichtet sind, fasst Stampe im Jahr 1905 treffend zusammen: Die neue Methode „leiste dem unreifen Dilettieren auf sozialem Gebiet Vorschub, bringe den Richter leicht in das Gefolge von Sonderströmungen und sei geeignet, die Rechtsordnung mit einem Chaos, von allen möglichen Zweckmäßigkeitsrücksichten entsprungenen und des Zusammenhaltes durch großzügige Prinzipien entbehrenden Einzelsätzen zu überschwemmen“ (Stampe 1905b: Sp. 418).

508 Zu Rümelins Kritik am Inversionsverfahren vgl. Haßlinger 2014: 92ff.; zur Kritik Stolls vgl. die Nachweise bei Kallfass 1972: 80 Fn. 297. 
formallogische System abstrakt-allgemeiner Begriffe eigne sich lediglich zur Darstellung des Rechts, nicht aber, um daraus neues Recht zu gewinnen. 509

Zudem bedeute dieses Verfahren eine Abwendung vom Leben: Die zugrunde liegenden Lebensbedürfnisse finden keinerlei Berücksichtigung, weder bei der Bildung der Gebotsbegriffe, noch bei der Deduktion von neuen Rechtssätzen (vgl. Heck 1912: 21f.). Darauf zielt auch der Vorwurf von Eugen Ehrlich ab, dass die Begriffsjurisprudenz „systematische Begriffe“ mit „Rechtsbegriffen“ verwechsele (Ehrlich 1976 [1918]: 214). $510 \mathrm{Da}$ erstere nur der Systematisierung und Darstellung des Rechtsstoffes dienten, könne man aus dem „System“ nicht mehr herauslesen, als man über konkrete Rechtsverhältnisse vorher hineingelegt habe. Deswegen scheitere eine systematisch-dogmatische Rechtsfindung, wenn sie angesichts konkreter neuartiger Lebensverhältnisse neue Rechtsbegriffe finden müsse (vgl. ebd.: 218).

Mehr noch: Dass Schlussverfahren wie Analogie, Deduktion, extensive und intensive Interpretation etc. als Grundlagen wissenschaftlich rationaler Rechtsfindung untauglich seien, zeige sich darin, dass sie nach „logischen“ Maßstäben geradezu zu „beliebigen“ Ergebnissen führten (etwa Kantorowicz 1906: 23ff.; s.a. Gmelin 1910e: 12f.). ${ }^{511}$ Letztlich lassen sich keine überzeugenden Metaregeln dafür angeben, weshalb auf der Grundlage einer bestimmten Methodenregel de facto einmal dieses, ein anderes Mal ein möglicherweise sogar gegenteiliges Ergebnis jeweils gleicherma-

509 So schreibt Heck: „Die Signatur des Inversionsverfahrens besteht darin, daß es ein Formulierungsprodukt, den Gebotsbegriff, als den Gegenstand der primären Erkenntnis hinstellt (Umkehr der Relation).“ (Heck 1909: 1461). Später richtet sich Heck auch speziell gegen die Deduktion, die mittels dieses Verfahrens eine „deduktive Begriffspyramide“ bilde, die als Grundlage der „Auslegung aus dem Systeme“ fungiere (Heck 1932a: 166).

510 Rechtsbegriffe beziehen sich auf konkrete Rechtsverhältnisse und Interessengegensätze, systematische Begriffe dienen der Systematisierung und Darstellung des Rechtsstoffes. Sie verhalten sich zueinander wie Arten und Gattung, d.h. Rechtsbegriffe wie z.B. Verein, Genossenschaft etc. können systematischen Begriffen wie der juristischen Person untergeordnet werden (Ehrlich 1976 [1918]: 214f.).

511 So schreibt Kantorowicz: „Wie es sein [des Juristen, D.S.] ,Wille zum Recht` verlangt, wird bald die restriktive, bald die extensive Interpretation angewendet, ohne daß $[\ldots]$ auch nur der Versuch gemacht wird, die Kriterien anzugeben, unter denen dieses oder jenes der zahlreichen Interpretationsverfahren geboten ist. [...] In allen diesen Fällen ist der wahre Acteur eben der Wille; leerer Schein die logische Deduktion. Sie steht im Dienste nicht der Wahrheit, sondern des Interesses" (Kantorowicz 1906: 36f.). 
Ben als lege artis begründbar erscheint (Auer 2015: 783; s.a. Müller-Erzbach 1906: Sp. 1236).

Angegriffen werden die "naive[] Methodenlosigkeit" der juristischen Konstruktion (Stampe 1905a: Sp. 716), die „Illusion eines ganz objektiven Verfahrens“ (Heck 1912: 17), der "versteckte[] und darum so gefährliche[] Subjektivismus der Begriffsjurisprudenz" (Kantorowicz 1992 [1911]: 264, H.i.O.), die „irrationalen Kräfte der zivilrechtlichen Urteilstätigkeit“ (Bendix 1927) usw. usf. Eine „grundlegende Reform unserer Wissenschaft“ erscheint nötig (Heck 1914: 2), da die „Rechtsfindung durch Konstruktion den Anspruch auf Wissenschaftlichkeit nicht erheben darf" (Stampe 1905b: 418).

Angesichts dessen erweist sich der „Kampf um die Rechtswissenschaft“ als Kampf um die Wissenschaftlichkeit der Jurisprudenz: Nach Kantorowicz müsse mit der „Wissenschaft als Rechtsquelle [...] endlich Ernst gemacht werden" (Kantorowicz 1906: 20, H.i.O.). Im Zentrum steht die Auseinandersetzung mit der „Aufgabe der Wissenschaft" (Ehrlich 1967d [1903]: $198)^{512}$, die Herausbildung „eine[r] methodisch klare[n] Wissenschaft, welche auch die Kritik und die Fortbildung des Rechts in den Kreis ihrer Aufgaben einbezieht“ (Heck 1912: 46) bzw. „die Schaffung einer festen Forschungsunterlage, die keine Wissenschaft entbehren kann" (MüllerErzbach 1906: Sp. 1238; s.a. Wolff 1914/15: 362). Oder wie Ernst Fuchs proklamiert: „Schaffen wir [...] eine echte Rechtswissenschaft! Nur Wissenschaft verbannt Willkür." (Fuchs 1965a [1916]: 179, H.i.O.)

Dieser Kampf um Wissenschaftlichkeit gilt selbst für diejenigen Autoren, die sich zur Lückenfüllung auf das Rechtsgefühl als Ursprung des Rechts, seinen Geltungsgrund sowie als Quelle weiterer Rechtsentwicklung beziehen: Man beruft sich auf das Gefühl, um die „Fehler der rein begrifflichen Spekulation“ zu vermeiden (Kuhlenbeck 1907: 16), dem „gefährlichsten Subjektivismus" im richterlichen Urteil vorzubeugen (Haff 1924: 142) bzw. das rein „subjektive Werturteil“ der Interessenabwägung zu vermeiden (Jung 1912: 34). Dabei erscheint das Gefühl als eine objektive, empirisch erforschbare Tatsache, die induktiv zu ermittelt sei (Pontes de Miranda 1922: 195 $)^{513}$ - und zwar mittels der Rechtspsychologie als die „an die Begriffe der Erfahrungswissenschaften und des Lebens anknüpfen-

512 Vgl. diesbzgl. die Nachweise zu Heck, Rümelin und Stoll bei Kallfass 1972: 18ff., $61 \mathrm{ff}$.

513 Dagegen wird eingewendet, dass es sich beim Gefühl nicht um eine objektive Kategorie handele, vielmehr weise es aus wissenschaftlicher Sicht einen ,indiskutablen Charakter“ auf (Dehnow 1914: 92). Daher beruhe die sogenannte Gefühlsjurisprudenz auf intuitiven, subjektiven und damit irrationalen Urteilen 
de Wissenschaft des Rechts in psychologischem Sinne“ (Haff 1924: 135f.) bzw. als „fundamentale Hilfswissenschaft“ (Kuhlenbeck 1907: 16). ${ }^{514}$

\subsection{Das Problem der Rechtssicherheit}

Die Verteidiger der juristischen Konstruktion weisen den „Vorwurf scholastischer Unfruchtbarkeit“" (Mitteis 1909: 1042) zurück und fragen angesichts der „Nebelwege[] freirechtlerischer Unklarheit“ (Vierhaus 1909: Sp. 1175): „,[W]o bleibt die Rechtssicherheit?"“ (Landsberg 1905: Sp. 925). Ihnen wird jedoch von den Methodenkritikern gerade der Mangel an Rechtssicherheit entgegengehalten, der aus der Begriffsjurisprudenz resultiere: „Die ,rechtsschöpferische“ Konstruktionsjurisprudenz hat die infolge der Unvollkommenheit der Gesetzgebung bestehende Rechtsunsicherheit nicht vermindert, sondern vermehrt." (Korsch 1914/15: 432; s.a. Fuchs 1965b [1927/28]) Da die Methodenkritik dazu berufen sei „einer heute nicht seltenen Willkür in der Gesetzesauslegung entgegenzutreten“ (Müller-Erzbach 1906: Sp. 1235), wende sie sich gegen die „formalistische[] Rechtsunsicherheit“" (Sternberg 1920: 151). Die freie Rechtsfindung biete „eine bessere Gewähr für die Rechtssicherheit [...] als die technische“ (Ehrlich 1967d [1903]: 187). Denn die Ansätze zur richterlichen Rechtsfortbildung richteten sich gegen die „Haupteinbruchspforte der Rechtsunsicherheit“" d.h. sie treten ein für eine

des Richters (vgl. aus neuhegelianischer Sicht Berolzheimer 1911: 609f.: kritisch auch Fuchs 1912). Demgegenüber müsse man - so Müller-Erzbach im Namen der Interessenjurisprudenz - „über ein Rechtschöpfen aus dunkeln Äußerungen des Empfindungslebens [hinauskommen, D.S.] und ein vernunftmäßiges Begreifen der Rechtserscheinungen anbahnen“ (Müller-Erzbach 1974 [1913]: 54). Auch für die Diskussion um das Rechtsgefühl gilt: Das subjektive, willkürliche Urteil soll ausgeschlossen werden - egal, welche Position man vertritt.

514 Vgl. a. Riezler 1921, Sturm 1910; Klein 1912. Da damit keinesfalls nur die Individualpsychologie gemeint ist, wird hier nicht nur auf die Massen- und Völkerpsychologie verwiesen, sondern auch auf die Soziologie (jedoch in Abgrenzung zu Durkheims kollektivistischem Ansatz, vgl. Klein 1912: 9ff.). Zum Problem des Verhältnisses von Psychologie und Rechtswissenschaft zu den Naturwissenschaften vgl. bereits aus dem Jahr 1905 die Schrift Die Rechtswissenschaft in ibren Beziebungen zu anderen Wissenschaften des sozialdarwinistischen und rassentheoretisch argumentierenden Jhering-Schülers Ludwig Kuhlenbeck (1905); zum Verhältnis von Psychologie und Jurisprudenz allgemein vgl. die Beiträge in Jakob, Rehbinder 1987, sowie in Schmoeckel 2009. 
nicht bloß subjektiven Empfindungen entquellende, sondern im bewiesenen Einklange mit der sozialen Entwicklung stehende Lösung dieses und vieler anderer Probleme, die Umprägung der verdeckt und unbewußt wirkenden Wertungen und sozialen Kräfte in klar erfaßte, ihrer Tragweite nach bestimmte logische Formeln (Wurzel 1904: 99).

\subsection{Die drohende Ungerechtigkeit der Begriffsjurisprudenz}

Der wie auch immer definierten Begriffsjurisprudenz werden nicht nur wissenschaftliche Unzulänglichkeiten angelastet. Das eigentliche Problem liege in ihrem mangelnden Lebensbezug, d.h. in der „Entfremdung von Recht und Volk“ (Radbruch 1906: 370): Sie „verdeckt den Zusammenhang mit den Lebensinteressen“ und „führt zur Herrschaft der Begriffe und Definitionen (Formelgefahr)“ (Heck 1909: Sp. 1460, 1461). Dabei wird der proklamierte Lebensbezug gerade der juristischen Konstruktion nun nicht wie in der Kodifikationsdebatte um das BGB primär im Namen der sozialen Aufgabe des Privatrechts, sondern im Namen der juristischen Auslegungsmethode in Frage gestellt. Begriffe könnten keinen Zugang zur Realität bieten, weshalb die Konzentration auf die dogmatisch-systematische Begriffsarbeit in der Rechtsanwendung den Zweck des richterlichen Urteils verfehle. Auf diesem Weg könne man kein Recht gewinnen, „wie es das Leben fordert“ (Heck 1912: 7).

Die Forderung nach der stärkeren Berücksichtigung der sozialen Wirklichkeit wird dabei als ein wissenschaftliches Problem definiert. Man müsse dafür die Rechtsfindung auf eine „reale Grundlage“ stellen (Müller-Erzbach 1906: 1235), eine „den Lebensinteressen am besten entsprechende Form der Gesetzesauslegung“ entwickeln (Heck 1914: 8) bzw. zum faktisch geltenden „Rechtsleben“ vordringen, das nicht mit dem gesetzten Recht identisch sei (vgl. Spiegel 1909: 7ff.; Ehrlich 1907). Die Lehre vom Recht sei - so Rudolf Müller-Erzbach - eine „Lebenswissenschaft“ (MüllerErzbach 1912: 345).

Im Zentrum dieser Kritik an der lebensfremden Begriffsjurisprudenz steht die Abwehr immenser Gefahren für die gesellschaftliche Entwicklung. ${ }^{515}$ Angesichts des raschen Wandels der Lebensverhältnisse erweise sich die juristische Konstruktion aufgrund ihres mangelnden Lebensbe-

515 Hierüber herrschte schon vor dem Ersten Weltkrieg ein deutliches Bewusstsein, dies wird aber insbesondere nach Kriegsende zu einem allgemeinen Problem (etwa Nußbaum 1916: 136; Haff 1924: 140). 
zugs nicht nur als rückständig und hemmend (vgl. Bozi 1916: 108), sondern berge ebenso „schwere soziale Gefahren in sich“ (Stampe 1905b: Sp. 418), ja es wird ihr gar „Gemeinschädlichkeit“ attestiert (Fuchs 1909a; s.a. Wüstendörfer 1913: 235). Vor allem aber bringe sie gerade aufgrund der raschen Veränderung der gesellschaftlichen Verhältnisse die Gerechtigkeit in Gefahr. Wenn man ohne Verständnis des Wandels der gegenwärtigen Verhältnisse ein seiner Natur nach veraltetes Gesetzesrecht streng nach den Regeln der Logik anwende, so führe das oft zu unbilligen Ergebnissen (kritisch hierzu Brie 1909): „Nur wo ein aus dem Buch ins Leben fortgewandter Blick des Handelns fernste Folgen und Bedingungen ermißt, nur wo Weisheit ist, - ist Gerechtigkeit.“ (Kantorowicz 1906: 47, H.i.O.) Die juristische Konstruktion, die „Pandektologie“ gelte es im Namen der Gerechtigkeit zu überwinden - und die Rechtswissenschaft sei, so Ernst Fuchs, eine „Gerechtigkeitswissenschaft“.

Die Kritik zielt damit nicht nur auf ein faktisches Moment ab, d.h. die Kongruenz des Rechts mit den tatsächlichen Lebensverhältnissen, sondern ebenso auf ein normatives Telos: die Gerechtigkeit. Diese Spannungslage zwischen Faktizität und Normativität wird zur vorherrschenden Problematisierungsweise, um die sich die Debatten innerhalb der Methodenkritik formieren werden.

\section{Die erneute Suche nach dem Lebensbezug des Rechts: Das Recht der Gesellschaft}

Um den Lebensbezug des Rechts und damit der Rechtswissenschaft zu gewährleisten, setzen insbesondere viele Vertreter des Freirechts erneut an der Rechtsentstehungslehre an: Da nicht alles Recht im Gesetz zu finden sei, müssten dem Gesetz noch andere Rechtsquellen zur Seite stehen, aus denen der Richter Recht schöpfen könne (vgl. Ross 1929: 185). Dafür wird nicht auf die Gewohnheitsrechtslehre der Historischen Rechtsschule zurückgegriffen, wird ihr doch Mystizismus, Spekulation und Idealismus vorgeworfen. Denn sie reduziere die Rechtsentstehung auf einen unergründlichen Faktor in Form des „einzig wissenschaftlich unbrauchbaren, weil unfaßlichen: den Volksgeist“" (Kantorowicz 1970 [1914]: 12). Dies führe zugleich zu einer Verzerrung der Perspektive, verpflichte die Gewohnheitsrechtslehre doch aufgrund der Prämisse des Traditionszusammenhangs den Blick auf die Vergangenheit zu richten. Daher sei sie - so Kantorowicz - dem bekämpften Historismus zuzuordnen (vgl. Kantorowicz 1912b). Und Ehrlich macht geltend: 
Wenn die Wissenschaft bisher zu einer befriedigenden Lehre vom Gewohnheitsrecht nicht zu gelangen vermochte, so liegt der Grund darin, daß sie es hartnäckig verschmähte, die Gesellschaft selbst in ihrer rechtsbildenden Arbeit zu beobachten und ihrer scholastischen Ueberlieferung folgend es vorzog, das Pergament für den heiligen Brunnen anzusehen, aus dem ein Trank den Durst auf ewig stillt. (Ehrlich 1907: $30)^{516}$

Neue Rechtsverhältnisse, die aufgrund des gesellschaftlichen Wandels stets entstehen, könnten dadurch nicht in den Blick geraten. ${ }^{517}$

Erkannt wird stattdessen nun ein "gesellschaftliches“ (Ehrlich 1970 [1902]: 240), „freies“ (Ehrlich 1967d [1903]) oder „lebendes Recht“ (Ehrlich 1967b [1911], 1967c [1911], 1967a [1912]; Bozi 1915), ein „natürliches Recht“ (Jung 1912) bzw. ein „Naturrecht[] in veränderter Gestalt“ (Kanto-

$516 \mathrm{Zu}$ Ehrlichs ambivalenter Stellung zu Savigny vgl. insbesondere Manigk 1974 [1914]. Auch bei Kantorowicz ist angesichts der Rechtsentstehungslehre eine solche Ambivalenz zu erkennen, die einerseits in der deutlichen Kritik an Savigny (vgl. Kantorowicz 1912b) und anderseits an der Selbstverortung in dieser Tradition zu sehen ist, wenn er schreibt: „Unsere Bewegung tritt hier die verlassene Erbschaft aus den besseren Anfängen der historischen Schule an." (Kantorowicz 1906: 32) Diese Nähe zur Rechtsentstehungslehre der Historischen Rechtsschule (insbesondere der wie auch immer gearteten soziologischen Ansätze in den Rechtswissenschaften) wurde im zeitgenössischen Diskurs auch öfters hervorgehoben (vgl. Somló 1911: 568f.; Oertmann 1914: 71f.). Hierin mag auch der Grund liegen, dass der Begriff der Rechtssoziologie - wie Rehbinder mit Verweis auf Fishman hervorhebt - bereits im Jahr 1882 zum ersten Mal von dem russischen Juristen Semen Pachman verwendet wurde, und zwar im Versuch, diese von der Rechtsdogmatik abzugrenzen. Er hatte vor, die Rechtsdogmatik der Historischen Schule unter Kritik an Jherings Zweckdenken weiterzuentwickeln (vgl. Pachman 1986 [1882]; Behlert 1990).

517 Die strategische Wiederaufladung des Gedankens der Rechtsentstehung in der vom Staat unabhängigen Sozialsphäre als eigentliches Problem der wissenschaftlichen Methode führt also zu einer erneuten expliziten Auseinandersetzung mit dem Gewohnheitsrecht (vgl. etwa Ehrlich 1907; Jung 1929; Rümelin 1924b; s. hierzu Mokre 1932: 88ff.; zum Wandel im Gewohnheitsrechtsbild vgl. Schröder 2007: 239ff). Dementsprechend sieht Jan Schröder in der Auseinandersetzung zwischen Freirecht und konservativer Jurisprudenz in mancher Hinsicht eine Fortsetzung des Rezeptionsstreits zwischen Romanisten und Germanisten (Schröder 1976: 38). Dabei deutet er die freirechtlichen Ansätze als konsequente wissenschaftstheoretische Ausbuchstabierung des Volksgeistgedankens in der Form des Volksrechts von Beseler (siehe etwa Ehrlich 1989 [1913]: 389f.). 
rowicz 1906: 10, H.i.O.; s.a. später Sternberg 1988 [1927]: 40).518 Die „Rechtswirklichkeit“ wird der aus der Masse der Rechtsvorschriften gebildeten „Rechtsordnung“ entgegengestellt (Sinzheimer 1976c [1909]: 5).519 Dabei zeige sich: „Die Rechtsordnung braucht sich mit der Rechtswirklichkeit nicht zu decken und deckt sich auch tatsächlich mit ibr in vielen Beziehungen nicht. Denn nicht alles geltende Recht ist wirksam und nicht alles wirksame Recht ist ausgesprochen." (Ebd., H.i.O.) Damit wird das Repräsentationsdispositiv radikal in Zweifel gezogen: Recht in Form des Gesetzes repräsentiert nicht mehr die Gesellschaft, sondern die Frage lautet, welches Recht die Gesellschaft jenseits des Gesetzes produziert. Das „lebende Recht“ zeichnet sich nach wie vor durch seine historische Kontingenz aus, es verweist aber nun nicht mehr auf die Vergangenheit, sondern auf seine aktuelle beständige Änderung. Daher wird durch das „lebende Recht“ nun nicht mehr die Repräsentation der vorausgesetzten gesellschaftlichen Wirklichkeit problematisiert, sondern es wird selbst als Teil dieser Wirklichkeit angesehen, das in seinem beständigen Wandel den geronnenen Rechtsformen gegenübertritt.

Dies mündet in einer Entgegensetzung von Gesetz und Recht als eine tatsächliche gegenwärtige gesellschaftliche Praxis: „Denn positiv ist doch nur das Recht, welches tatsächlich lebt, welches reale Geltung hat, mag es nun gesetzlich fixiert sein oder nicht." (Spiegel 1909: 21) Angesichts der erfolgten Kodifikation geht es hier immer um ein Recht, das jenseits der Gesetzgebung entsteht, wie Kantorowicz 1906 die Positionen zusammenfasst:

Denn ob wir nun blicken auf Stammlers „Richtiges Recht“, auf Ehrlichs „Freie Rechtsfindung“, auf Mayers „Kulturnormen“, auf Wurzels „Projektion“, auf Stampes „Interessenwägung“, auf Rümelins „Werturteile“, immer werden Sätze herangezogen, die bestimmt sind, staatliches Recht zu bewerten, zu ergänzen, fortzubilden oder umzustoßen. Sätze, die, eben dieser Funktionen wegen, nicht staatliches Recht sein

518 Das Naturrecht wird noch auf ganz andere Weise aktualisiert: So sieht Adolf Menzel einen Gleichlauf von moderner Soziologie und Naturrechtslehre (der Sozialkontraktslehren), verwendeten Vertreter der ersteren (z.B. Comte, Spencer, Coste, Gumplowicz und Ratzenhofer) doch das „Naturgesetz der Entwicklung“ als Wertmaßstab für und nicht als Erklärungsprinzip der Wirklichkeit. Bei beiden sei insofern eine Vermischung von normativer und tatsächlicher Betrachtung gegeben (vgl. Menzel 1912).

519 Und manch einer erklärt nun auch die „Bedürfnisse des Rechtslebens“ zu einer eigenständigen Rechtsquelle (Cosack 1903: 26). 
können, aber Recht und also freies Recht sein müssen. (Kantorowicz 1906: 11$)^{520}$

Freiheit wird in diesen Ansätzen weiterhin im Privatrecht verortet - hier entsteht in den intersubjektiven, privaten Beziehungen ein freies, gesellschaftliches Recht jenseits des Staates, das diesem gegenübersteht. ${ }^{521}$ Jedoch wird die Rechtsquellenlehre nun nicht mehr im Rahmen der dogmatischen Arbeit, sondern durch die Rechtsanwendungslehre bzw. die Rechtsfindung problematisiert. Denn - wie Spiegel schreibt - „[a]us der Beobachtung, daß sich das Recht vielfach anders gestaltet, als das Gesetz es haben will, ergibt sich nicht das Bedürfnis, das Recht zu ändern, sondern die Notwendigkeit, die Methode der Rechtswissenschaft zu revidieren" (Spiegel 1909: 14, H.i.O.). Das wissenschaftliche Problem besteht darin, Methoden zu entwickeln, dieses in der Gesellschaft entstehende freie, lebende, „dynamische“ 522 Recht zu ,finden', um auf dieser Grundlage das Recht richtig anzuwenden (vgl. kritisch Reichel 1915). Nicht die Rechtsfreiheit, sondern das Freirecht steht im Mittelpunkt.

Demgegenüber rücken v.a. (aber nicht nur) die Verfechter der Interessenjurisprudenz die gesellschaftliche Ordnungsfunktion des Rechts im Anschluss an das gesellschaftsfunktionale Zweckdispositiv in den Vordergrund. Zwar geht es ebenfalls um die Klärung der Frage der Rechtsentstehung (die später sogenannte "genetische Interessentheorie“, Heck 1932a: 73). In direkter Abgrenzung zur Historischen Rechtsschule

520 Stammler wehrt sich gegen die Vereinnahmung seiner Lehre des richtigen Rechts durch die Freirechtsbewegung bzw. gegen die Gleichsetzung mit der Methodenkritikbewegung (vgl. etwa Fuchs 1907a: 184; Hedemann 1908: 306f.; Radbruch 1906: 370). In seiner Theorie der Rechtswissenschaft aus dem Jahr 1911 setzt er sich daher kritisch mit dem Freirecht auseinander (Stammler 1911: 723ff.; s.a. 1906a; s.a. 1925b: 428). Zur Differenz zwischen Stammler und der Freirechtsbewegung vgl. Riebschläger 1968: 50ff.

521 Konsequenterweise wird auch die Methodenfrage aus der Perspektive des Privatrechts diskutiert. Genau diesen Umstand macht Ernst Neukamp zum Ausgangspunkt seiner Kritik: Er wendet ein, dass die Interessenabwägung bzw. die Annahme des Freirechts nur für das Privatrecht gelten könne und in den steuerungsrechtlichen Gebieten des Rechts, nämlich Strafrecht und Öffentliches Recht, zu Auswüchsen führen würde. Da es aber keinesfalls je nach Rechtsgebiet verschiedene Methoden geben dürfe, liege darin der Beweis, dass diese Ansätze zu verwerfen seien (vgl. Neukamp 1912: Sp. 47).

522 Ehrlich bezeichnet dies auch als eine „dynamische“ Rechtsauffassung, „für die es nicht bloß darauf ankommt, was ein Rechtssatz bedeutet, sondern wie er lebt" (Ehrlich 1967d [1903]: 197; s.a. Kantorowicz 1906: 12; Sinzheimer 1976a [1928]: 48). Zum Dynamikbegriff in der Rechtswissenschaft - insbesondere mit Blick auf seine Verwendung nach 1933 - vgl. Keppeler 2013. 
(und mit impliziter Ablehnung der Anerkennungstheorie) gilt jedoch - so Heck -,

daß die Rechtssätze nicht hervorgehen aus Vorstellungen, die sich in dem Gemeinbewußtsein hinsichtlich der juristischen Struktur von Rechtsgebilden entwickelt haben, sondern daß sie hervorgehen aus der Entscheidung angeschauter Interessenkonflikte, entschieden nach dem Werte, den die Rechtsgemeinschaft den beteiligten Interessen beilegt (Heck 1905: Sp. 1140f.).

Rechtssätze seien nicht gewachsen, sondern beruhten auf Entscheidungen. Sie seien Gebotsvorschriften, die angesichts sich widerstreitender Interessen Wertungen vollziehen: „Die Gesetze sind die Resultanten der in jeder Rechtsgemeinschaft einander gegenübertretenden und um Anerkennung ringenden Interessen materieller, nationaler, religiöser und ethischer Richtung. In dieser Erkenntnis besteht der Kern der Interessenjurisprudenz." (Heck 1914: 17; s.a. Kallfass 1972: 11ff. m.w.N.)

Angesichts einer solchen „Konfliktstheorie" (Heck 1933: 13), in der das „Leben“ keine homogene Sozialsphäre, sondern „nur eine zusammenfassende Bezeichnung für eine unendliche Mannigfaltigkeit“ (Heck 1932a: 38) darstelle und durch eine Vielzahl unterschiedlicher Interessenlagen gekennzeichnet sei, ${ }^{523}$ wird die gesellschaftliche Funktion des Rechts in der Regelung konfligierender Interessen gesehen (vgl. Stampe 1905a: Sp. 715; Müller-Erzbach 1906: Sp. 1235, 1974 [1913]: 55; aber auch Fuchs, Gmelin und Wüstendörfer, s.u. $\$ 5$.III.1). ${ }^{524}$ Dabei schütze das Recht nicht nur individuelle Privatinteressen, sondern ebenso die umfassende Sozialsphäre:

523 S. Rundstein verwendet dieses Argument gegen die Freirechtsschule, da das freie Recht nur dann einen Maßstab für die Rechtsanwendung bieten könne, wenn es ein einheitliches sei, was als Basis allerdings ein einheitliches Rechtsbewusstsein voraussetze. Diese Vorstellung sei aber angesichts der Tatsache der Ausdifferenzierung des Rechtsbewusstseins, das sich in den zahlreichen Interessenkämpfen zeige, nicht vertretbar (Rundstein 1910).

524 Autoren wie Fuchs und Gmelin werden oft dem Freirecht zugerechnet, bei Wüstendörfer scheiden sich die Geister, und alle drei gehen mehr oder minder auf Distanz zum Freirecht (vgl. etwa Wüstendörfer 1916b: 455; Gmelin 1910a: 38f.; Fuchs 1909a: 129, 1918: 21; wobei Fuchs sich dieser Richtung auch gelegentlich selbst zuordnet, vgl. Fuchs 1910c). Da ich hier die jeweilige Konzeption des Rechts der Gesellschaft und den daraus folgenden Rechtsbegriff als Ausgangspunkt der Einteilung der Autoren wähle, erscheinen alle drei im Bunde mit der Interessenjurisprudenz (s.u.). Aber auch Kritiker sowohl der Freirechtsbewegung als auch der Interessenjurisprudenz berufen sich auf die Ordnungsfunktion des Rechts (vgl. Neukamp 1912: Sp. 49). 
„Die Rechtsnormen schützen die Interessen der menschlichen Gemeinschaft und sichern dadurch ihre Lebensbedingungen." (Heck 1974 [1929]: 90) Dementsprechend stelle sich „die Rechtsordnung“ als „eine Ordnung sozialer Verhältnisse“ dar (Stampe 1905a: Sp. 717), und „[p]ositives Recht“ sei „die in einer menschlichen Gemeinschaft durch Zwangsgebote verwirklichte Ordnung des Zusammenlebens" (Rümelin 1924b: 149). ${ }^{525}$ Es sei also ein Friedens- und Ordnungsinteresse als Normierungsgrund bei allen Rechtsgeboten vorhanden (vgl. etwa Rümelin 1924a: 2ff., 1925: 30ff.; Heck 1932a: 39).

Egal, ob man auf den Ort der Rechtsentstehung oder auf die gesellschaftliche Funktion des Rechts verweist, das Ziel ist immer, in der Gesetzesanwendung das Problem des mangelnden Lebensbezugs des Rechts gerade auf wissenschaftliche Art und Weise zu überwinden. Dabei gerät die Gesellschaft entweder als Produktionsort des Rechts oder als Funktionszusammenhang bzw. als Telos des Rechts in den Blick. Gesucht wird nicht nach der Gesellschaft im Recht, sondern nach dem Recht der Gesellschaft: auf der einen Seite primär als gesellschaftliches Recht, das dem Gesetz gegenüber steht, und das es zu finden gelte; und auf der anderen Seite primär als ein Recht, das gesellschaftliche Funktionen erfüllt, denen es in der Rechtsanwendung gerecht zu werden habe. Das epistemische Objekt ,Gesellschaft' nimmt insofern eine entscheidende Rolle für die Rechtswissenschaft ein, als das Recht in beiden Versionen nun als gesellschaftliches Phänomen erscheint, das als solches erkannt werden muss.

\section{Epistemische Folgen I: Der Streit um die richtige juristische Methode}

Durch die Ablehnung des Dogmas der Lückenlosigkeit rückt die methodische Frage, wie die Lücken im Rahmen der Auslegung und der Anwendung von Gesetzen gefüllt werden müssen, in den Vordergrund. Die Diskussionsbeiträge erfolgen jedoch größtenteils als Kritik, die ihren Ausdruck v.a. in den Polemiken gegen die Begriffsjurisprudenz, aber auch gegen andere Fraktionen im Methodenstreit findet und oft nur sehr vage methodische Vorgaben enthält. So verweist etwa die Kluft zwischen kodifiziertem Rechtssätzen und „lebendem“, „gelebtem“ oder „freiem“ Recht

525 Ehrlich wendet sich gegen die auch von Rümelin vertretene Theorie, die wie Jhering Recht auf Zwang begründet (Zwangstheorie): „Ich bestreite nur, daß die vom Staate ausgehende Norm, der von den Gerichten oder andern Behörden gehandhabte Rechtszwang, ein wesentliches Merkmal des Rechts bilden" (Ehrlich 1907: 8). 
etc. auf die Lücken im Gesetzesrecht. Damit ist aber noch nicht beantwortet, wie diese zu füllen seien. Wenn etwa Ehrlich und Kantorowicz in ihren frühen Arbeiten dabei auf die „Persönlichkeit des Richters“ abstellen (vgl. Ehrlich 1967d [1903]: 188; Kantorowicz 1906: 41, 47), um deren herausragende Rolle in der Rechtsfindung zu explizieren, so benennen sie dadurch eher das Problem der Lücken nicht nur im Recht, sondern auch in den methodischen Vorgaben einer vorgeblich rein logischen Rechtsfindung, statt selbst eine Methode für die Lösung dieses Problems zu entwickeln (bzgl. Kantorowicz vgl. Auer 2015: 784ff.).

Positive juristische Methodenlehren im engeren Sinne entwerfen v.a. diejenigen Autoren, die auf die gesellschaftliche Ordnungsfunktion des Rechts abstellen und das Recht als Entscheidung einer Interessenkollision bestimmen. Dabei werden zwei gänzlich unterschiedliche Wege beschritten: Auf der einen Seite wird ein Rekurs auf die Soziologie gefordert, indem explizit juristisch zu definierende „soziologischen Methoden“ ins Feld geführt werden; auf der anderen Seite wird eine Teleologisierung des Rechts und der Rechtsanwendung vorgenommen, die auf das Wertungsmoment in der Interessenabwägung abstellt. Zwischen diesen beiden Polen divergieren die Positionen in der genuin um die juristische Methode geführten Debatte.

\section{1. „Soziologische Methoden“ der Rechtswissenschaft}

Prominenter Stichwortgeber für eine explizite Verbindung von Soziologie und Rechtswissenschaft auf der Ebene der genuin rechtlichen Methodenlehre ist der wortgewandte und in seinen Schriften stark polemisierende Rechtsanwalt Ernst Fuchs. Er ist der große Fürsprecher einer „soziologischen Rechtswissenschaft" (Fuchs 1976 [1910]), die im Rahmen der Rechtsfindungsproblematik für eine juristisch definierte „soziologische Methode" plädiert.

\subsection{Soziologische Kausalwissenschaft als Gerechtigkeitswissenschaft: Ernst Fuchs}

Der Befund der Lückenhaftigkeit des Gesetzes (etwa Fuchs 1907a: 181, 184; 1920: 9; 1923/24: 102) wirft nach Fuchs angesichts der „völligen Umwälzung des gesamten sozialen und Wirtschaftslebens“ im 19. Jahrhundert (Fuchs 1907a: 181f.) mit absoluter Dringlichkeit die methodische Frage auf, wie sich das Recht bei gesetzlich nicht geregelten Streitfällen finden 
lasse. Dass er die lebensfremde Begriffsjurisprudenz hierfür für nicht geeignet hält, ist seinen zahlreichen Polemiken gegen die Pandektologie zu entnehmen (vgl. v.a. Fuchs 1907b, 1909a, 1912). ${ }^{526}$ Dabei zielt sein Vorwurf auf die konstruktionsjuristische Verleugnung von Werturteilen als eigentliche Entscheidungsgründe, denen der falsche Schein der Objektivität gegeben werde (vgl. Fuchs 1920: 7). Diese nicht zu vermeidenden ,unlogischen' Bestandteile eines jeden Urteils möchte Fuchs auf eine realistische Grundlage stellen. Daher gelte es, an Stelle der „historisch-philologisch und konstruktiv-deduktiv“ arbeitenden Rechtswissenschaft „modern-naturwissenschaftlich und erfahrungsgemäß-induktiv" zu werden (Fuchs 1907a: 182). Fuchs entwirft dafür „die wahre psychologisch-soziologische Rechtswissenschaft, die man kurz die soziologische nennen kann, weil die juristische Psychologie im Sinne Comtes gleichfalls zur Soziologie gehört“ (Fuchs 1976 [1910]: 188).527

Diese Hinwendung zum Leben mittels der soziologischen Methode liegt bei Fuchs im Rechtsbegriff begründet: Das Recht sei „etwas Lebendiges, also sich von selbst Bewegendes und sich Umbildendes“ (Fuchs 1907a: 186). Diese Lebendigkeit des Rechts zeige sich in seinem beständigen Wandel, es müsse „sich fortgesetzt und vollständig den fortschreitenden Bedürfnissen des sozialen Lebens anpassen" (ebd.). ${ }^{528}$ Die treibende Kraft liege damit außerhalb des Rechts, nicht im Rechtssystem. Und die „Angleichung“ an dieses soziale Leben erfolge über die „schöpferische Rechtsauslegung“ (ebd.). Sie sei das spezifische „Instrument" der Rechtswissenschaft, mittels dessen das Recht seine „Mission“ erfüllen könne, „sich den allmählich durchringenden Fortschritten des sozialen und wirtschaftlichen Lebens zu öffnen und sie mitgestalten zu helfen" (ebd.). Das allein entspreche den "gesellschaftlichen Zwecken“, die jedem Gesetz immanent seien (Fuchs 1923/24: 101). Wenn also im Gesetz keine Regelung für den Streit-

526 Dass das Problem der Konstruktionsjurisprudenz, wie Fuchs annimmt, im „schauderhaften Abrakadabra“ des corpus juris gründe (Fuchs 1909a: 265), bestreiten sogar die Anhänger der soziologischen Rechtsanwendung (vgl. Gmelin 1910b: 2; Kiß 1913).

527 Darin sieht er das grundlegend Neue, denn: „Die soziologische Rechtswissenschaft besteht noch nicht, namentlich nicht auf unseren Hochschulen. Gerade diese Erkenntnis dieses scio nescire, ist der Ausgangspunkt der neuen Lehre.“ (Fuchs 1912: 63).

528 Dies erfolge im beständigen Kampf, so „daß das Recht seiner organischen, lebendigen Natur nach Kampf sei“ (Fuchs 1909b: 2). Auch an anderen Stellen wird deutlich, dass Fuchs einen organischen Begriff nicht nur des Rechts, sondern auch der Gesellschaft vertritt (Fuchs 1907a: 181), jedoch dabei die Interessenkonflikte und Kämpfe betont. 
fall erkennbar sei, dann müsse der Richter „selbst die sozialen Elemente [...] erforschen, aus denen er eine Regel bilden will“ (Fuchs 1907a: 185). Den „Hauptgegenstand“ der modernen Jurisprudenz bilde daher nicht das Rechtssystem, sondern „die Menschen und die Verkehrsbedürfnisse“ (Fuchs 1910b: Sp. 285). Für Fuchs gilt: Der Jurist muss in noch nicht geregelten Fällen „soziologisch“vorgehen.

Fuchs betont dabei immer wieder, dass das Wort „soziologisch“ für ihn den Gegensatz zur Begriffsjurisprudenz markiere (Fuchs 1910a: 54). Es sei ein Gegenbegriff, der im „weitesten Sinne gebraucht [wird], so daß er auch alle wirtschaftlichen, sozialen und ethischen Gesichtspunkte umfaßt" (ebd.). Das ist mit einer Abgrenzung zur Fachdisziplin der Soziologie verbunden: „Das Wort soziologisch ist deshalb nicht im Sinne der erst im Entstehen begriffenen Wissenschaft der Soziologie im engeren Sinne zu verstehen.“ (Ebd.; s.a. Fuchs 1976 [1910]: 188) Dementsprechend sind Fuchs' Anlehnungen an explizit soziologische Untersuchungen und Theorien marginal - außer August Comtes Klassifikation der Wissenschaften mit der Soziologie als Königsdisziplin bilden sie keinen nötigen Bezugspunkt für seine „soziologische Rechtskunde“ (vgl. Fuchs 1976 [1910]: 188; s.a. 1910c: Sp. 303).

Auch wenn damit der Charakter einer solchen Soziologie vage bleibt, dienen Fuchs als Vorbild die Fortschritte in den Naturwissenschaften und in der Heilkunde, in denen "längst die Induktion die Deduktion verdrängt, d.h. sie aus Begriffswissenschaften zu Beobachtungs- und Erfahrungswissenschaften gemacht hat" (Fuchs 1907a: 182; s.a. 1910b: Sp. 283) Die "wahre moderne Wissenschaft" und damit letztlich die einzig mögliche Wissenschaft sei „eine lebens- und sachkundige Beobachtungswissenschaft“" (Fuchs 1976 [1910]: 189), die zur Ermittlung der Tatsachen induktiv verfahre: „Bei der induktiven Methode versenke ich mich tief in Menschen und Dinge und schöpfe aus ihnen heraus ihr Recht." (Fuchs 1910b: Sp. 285) Fuchs zielt mit seiner Hinwendung zur Soziologie darauf ab, für die Rechtswissenschaft eine „lebenswahre reale Methode“ zu entwickeln (Fuchs 1907a: 186). Aufgrund dieser Verbindung der Soziologie mit den Naturwissenschaften aber gilt zugleich, dass die soziologische Rechtswissenschaft als Teil der Soziologie i.w.S. eine „juristische Naturwissenschaft" sei (Fuchs 1910c: Sp. 307).

Die soziologische Rechtswissenschaft suche letztlich „den Urgrund aller Gerechtigkeit und das Allgemeininteresse zu erreichen; ohne das gibt es kein Recht, das dieses Namens würdig wäre" (Fuchs 1907a: 186). Fuchs verbindet also die naturwissenschaftlich ermittelten Tatsachen mit den Gerechtigkeitsurteilen: Die „soziologischen“ bestimmten Tatsachen dienen im Urteil als Grundlage der Rechtsfindung. Fuchs nennt sie später in An- 
lehnung an Nußbaum auch „Rechtstatsachen“, welche „die allgemeinen, tatsächlichen, sittlichen, wirtschaftlichen, kurz gesellschaftskundlichen (,soziologischen') Verhältnisse [bezeichnen], deren Kenntnis für ein volles Verständnis der Rechtssätze selbst und für die richtige Eingliederung des Einzelfalls erforderlich ist“ (Fuchs 1920: 6). Insofern sei die "Soziologie im weitesten Sinne einschließlich der Nationalökonomie“ die "Grund-“ (Fuchs 1907a: 187) bzw. eigentlich die „Hauptwissenschaft“ (Fuchs 1910c: Sp. 352) der Jurisprudenz.

Zugleich bilden diese Tatsachen den Maßstab für das richterliche Urteil, das ja trotz allem ein Werturteil im Einzelfall darstellt. Denn man könne „Menschen und Dinge richtig nur aus ihrer eigenen Denkweise, aus ihrer eigenen Welt heraus beurteilen" (Fuchs 1910b: Sp. 286). Das richterliche Urteil in der „Interessenwägung“ (Fuchs 1907a: 186; 1910c: Sp. 304, 345ff.) beruhe insofern auf der Kenntnis der realen Verhältnisse und der an realen Wirkungen gemessenen Gerechtigkeitserwägung:

Nach der soziologischen Rechtslehre werden die Streitfragen über die Auslegung oder Ergänzung der Gesetze grundsätzlich und in erster Linie offen nach den Verkehrsbedürfnissen entschieden, also nach den praktischen Ergebnissen, indem die einander gegenüberstehenden realen Interessen mit Sachkunde und ethischem Rechtsempfinden gegeneinander abgewogen werden. (Fuchs 1910a: 54)

Tatsachenerkenntnis und Gerechtigkeitsurteil setzt Fuchs in der soziologischen Methode letztlich in eins, umfasse diese doch

die Erforschung und Gestaltung der Verkehrssitte, die Feststellung des Verkehrsbedürfnisses, also vor allem die Beantwortung der Frage, welche Seite bei der zwischen den Parteien streitigen rechtlichen Kontroverse Billigkeit und Gerechtigkeit für sich habe und warum (Fuchs 1910c: Sp. 345). ${ }^{529}$

Daher sei die soziologische Rechtslehre nach Fuchs eine „Gerechtigkeitswissenschaft“. Sie bezeichne „den Theil der Rechtswissenschaft i.w.S. (also einschließlich der Wahrheitsfindung) ${ }^{530}$, der nicht durch drei ändernde Worte des Gesetzgebers Makulatur werden kann, sondern Ewigkeitswert hat, also ihren Kern bilden muß" (Fuchs 1920: 8). Auch hier dient die Naturwissenschaft als Vorbild, bestehe doch Wissenschaft darin, „die Erschei-

529 Fuchs bezeichnet dieses Vorgehen daher auch als „soziologisch-ethisch“ (Fuchs 1909b: 2).

530 Damit meint Fuchs die Tatbestandsermittlung im Prozess. 
nungen - hier das Rechtsleben - planmäßig zu beobachten, sie zu ordnen und unter Gesetze (im wissenschaftlichen Sinn) zu bringen, wie in der $\mathrm{Na}$ turwissenschaft“ (ebd.). Daher ziele eine „wahre Privatrechtswissenschaft“ auf die „Erforschung der Entstehungsursachen, die Vorbeugung und die Heilung der echten Rechtsstreitigkeiten“ (ebd.). Hier gilt es, letztlich nach kausalwissenschaftlicher Manier, aus dem Faktischen zu allgemeingültigen normativen, und d.h. für Fuchs dann gerechten Aussagen vorzudringen..$^{531}$ In diesem Sinne sei die soziologische Rechtslehre letztlich beides: „Sachund Wertwissenschaft" (Fuchs 1912: 8).

Fuchs fordert eine genuin „soziologische Methode“, mit der eine an den Naturwissenschaften orientierte Soziologie aufgrund der Bestimmung der gesellschaftlichen Kontextfaktoren des Rechts (Ursache des Rechtssatzes sowie gesellschaftliche Wirkung des Urteils) sowohl die jeweils tatsächliche Bedeutung des Rechtssatzes als auch das je spezifisch tatsächlich Gerechte zu ermitteln vermag. Die Soziologie als ,Hauptwissenschaft' der Jurisprudenz wird zur Leitdisziplin, gerade weil sie nach Fuchs in der Lage ist, der Sach- und der Wertebene im Urteil eine wissenschaftliche Fundierung zu geben. Da dies die dogmatische Konstruktionsjurisprudenz nicht leisten könne, müsse die soziologische Rechtswissenschaft an ihre Stelle treten. In diesem Sinne tritt Fuchs für eine Soziologisierung der Rechtswissenschaft ein. Der Jurist muss in seinen Augen selbst soziologische Tatsachenforschung betreiben, um ein wissenschaftlich fundiertes Gerechtigkeitsurteil sprechen zu können.

\subsection{Wertungsgrundlage und Kulturwerte: Die soziologische Verankerung des juristischen Urteils (Gmelin, Wüstendörfer)}

Die Forderung einer explizit juristisch zu verortenden „soziologischen Methode" stößt auf heftige Kritik - im Übrigen auch seitens vieler Freirechtler. Sie bleibt aber nicht ohne Wirkung. Insbesondere der Oberlandesgerichtsrat Johann Georg Gmelin und der Privatrechtswissenschaftler Hans Wüstendörfer versuchen im Gegensatz zu den v.a. kritisch-polemisch Einlassungen von Fuchs, eine „positive Methode soziologischer Rechtsfin-

531 Allerdings warnt Fuchs davor, dadurch den Kontakt zur Lebenspraxis zu verlieren, denn dann würde die neue Methode zur „Soziologistik“, d.h. erneut zu einer Form des Dogmatismus (Fuchs 1910c: Sp. 389). 
dung“" (Wüstendörfer 1913) zu entwickeln. ${ }^{532}$ Auf diesem Weg solle eine "gerechtere, lebenswahrere, volkstümlichere Rechtsprechung" (Gmelin 1910a: 82, H.i.O.) verwirklicht bzw. die „unbilligen, ja lebensfeindlichen Ergebnisse" der Konstruktionsjurisprudenz vermieden werden (Wüstendörfer 1916a: 292).

Sowohl Wüstendörfer als auch Gmelin gehen davon aus, dass bei Lücken im Gesetz unausweichlich das nicht rein logisch operierende Rechtsgefühl zum Einsatz komme (Gmelin 1910a: 75; Wüstendörfer 1913: 248). Denn das Gesetz sei immer eine „Entscheidung von Interessenkonflikten, eine Interessenregulierung “ (Wüstendörfer 1913: 250; vgl. auch Gmelin 1910a: 34).533 Daher stelle die Rechtsanwendung ebenfalls eine Interessenabwägung dar. In zweifelhaften Auslegungsfragen bleibe als Maßstab dann letztlich immer nur ein Werturteil bzw. ein richterlicher Willensakt (vgl. Wüstendörfer 1916a: 311; 1916b: 427, 429).534 Um „kryptosoziologische“ Scheinlogik und Willkürlichkeit des Urteils zu vermeiden (vgl. Gmelin 1910a: 38; Wüstendörfer 1913: 242ff.), sei das Rechtsgefühl bzw. Werturteil (so weit wie möglich) wissenschaftlich zu fundieren - oder wie Gmelin schreibt: Es sei zu ergründen, ob für das „Rechtsgefühl in gewissen ,Realien' ein fester Boden gefunden werden kann" (Gmelin 1910a: 75). ${ }^{535} \mathrm{Zu}$

532 Denn Gmelin hebt deutlich hervor, dass hierfür „die volle Arbeit noch nicht getan" sei (Gmelin 1910a: 40). Anders als Wüstendörfer schließt Gmelin direkt an Fuchs an. Wüstendörfer wiederum setzt sich in seinen beiden Abhandlungen zur soziologischen Rechtsfindung (Wüstendörfer 1913, 1916a) deutlich systematischer als Gmelin mit den methodischen Fragen auseinander.

533 Oder wie Gmelin schreibt: Der „tatsächliche Rechtstoff“ habe „stets den Streit um rechtliche geschützte [...] Interessen, um ,Lebensgüter', zum Kern“ (Gmelin 1910a: 34).

534 Nach Wüstendörfer verkennt die Begriffsjurisprudenz aber nicht nur die wertenden Aspekte im Urteil, sondern ebenso die des Rechtssatzes: Als gesetzliches Gebot normiere er nicht nur einen Tatbestand, sondern verfolge immer auch einen „gesellschaftlichen“ respektive „sozialen Zweck“ (Wüstendörfer 1916a: 313; 1913: 250). Im normativen Charakter des Rechts, seinem Zweck, liege die Grenze der systematisch-logischen Arbeit begründet: Das „normativ Richtige [wird] als ein logisch Wahres behandelt, die Normsetzung, die ein Akt des Wertens und der Willensentscheidung ist, so aufgefasst, als wäre sie eine geschichtliche Wahrheitsermittlung, ein Akt des Erkennens und des Schließens. Durfte sich doch so auch die Rechtsdogmatik in der Illusion wiegen, Wissenschaft, reine Wissenschaft zu treiben“" (Wüstendörfer 1916a: 177).

535 Fuchs hatte die immer wieder anzutreffende Verschleierung soziologischer Überlegungen in der Rechtsfindung als logische Schlussfolgerung aus dem Gesetz (etwa über die Anwendung der Klausel „nach Treu und Glaube“) abwertend als „kryptosoziologische[n] Konstruktionismus“ bezeichnet (z.B. Fuchs 1909a: 255). 
diesem Zweck beziehen sich Gmelin und Wüstendörfer auf die Soziologie, die einer solchen wissenschaftlichen Klärung des Rechtsgefühls dienen soll (vgl. Wüstendörfer 1913: 232, 249; Gmelin 1910b: 6).

Was jedoch beide unter Soziologie verstehen, unterscheidet sich. Gmelin folgt Fuchs, wenn er davon ausgeht, dass die Soziologie die allgemeinen Gesetze des menschlichen Zusammenlebens erkunde: Sie sei eine „staatswissenschaftliche Lehre, die es versucht, die Gesetzmäßigkeit des Lebens und der gegenseitigen Beziehungen der sozialen Gruppen zu erforschen" (Gmelin 1910a: 35). Insofern kann sie auch objektive Kriterien für die Rechtsfindung und Rechtsanwendung liefern. Wenn dabei nach Gmelin im Rahmen der Rechtsfindung die soziologische Methode den „Primat der Begriffe durch denjenigen der realen Interessenabwägung“ (ebd.) ersetzt, so komme man zum einen mittels der soziologischen Forschung dem Verständnis des jeweiligen Interessenkampfes sachlich näher; zum anderen gelte es, „ihn zu schlichten durch Abwägung dieser Interessen vom Standpunkt des über dem Ganzen stehenden unparteiischen Beurteilers, der das Einzelwohl wie das Gesamtwohl im Auge hält" (ebd.: 34). Insofern berge die soziologische Methode "höchste ethische Werte in sich“ (ebd.: 82). Die soziologische Forschung stelle daher sowohl die Tatsachengrundlage als auch die Wertungsgrundlage auf ein sicheres wissenschaftliches Fundament:

Das vernünftige Endergebnis ist aber dasjenige, welches den Grundsätzen von Treu und Glauben im Rechtsverkehr und den Bedürfnissen des Lebens entspricht und bei Abwägung der widerstrebenden Interessen dem besser begründeten, schützwürdigeren Interesse zum Sieg verhilft („soziologische Methode“). (Gmelin 1910b: 4)

Dieses Fundament erweist sich für Gmelin als sicher, da auch die Wertungsgrundlagen sich aus den objektiven Gesetzmäßigkeiten des Lebens herleiten lassen.

Wüstendörfer geht demgegenüber ganz anders vor: Wesen, Gegenstand und Methode der Soziologie sind für ihn noch nicht eindeutig festgelegt. Daher möchte er sie als ein „heuristisches Prinzip“ verstanden wissen, das eine spezifische Perspektive und Methode für Einzelwissenschaften wie die Rechtswissenschaft bedinge (Wüstendörfer 1916b: 431f.; 1915: 401).536 Während gesellschaftliche Einzelwissenschaften wie Religions-, Wirt-

536 Um dies zu belegen, bezieht er sich jedoch im Jahr 1916 nicht auf die bereits existierenden soziologischen Versuche der Wesensbestimmung der Soziologie (allenfalls auf Otmar Spann), und das, obgleich ihm die Diskussionen um die 
schafts- oder eben Rechtswissenschaft verschiedene funktionelle Seiten des Ganzen gesondert in den Blick nähmen, richte die Soziologie den Blick auf die Wechselbeziehungen zwischen diesen verschiedenen Seiten. Dadurch bekomme sie das verbindende geistige Element in diesem „In- und Durcheinandergreifen dieser verwickelten Wechselbeziehungen" in den Blick (Wüstendörfer 1916b: 432). Dieses Verbindende bestehe in Kulturwerten, d.h. in Wertideen, denen historisch-spezifisch eine leitende Kulturbedeutung zukomme. Dementsprechend handele es sich bei der Soziologie um eine „nicht selber wertende, aber auf Kulturwerte sich beziehende ,soziologische“ Betrachtung“ - jedoch, wie er ausführt - „nicht als Sonderwissenschaft, sondern als Sondermethode im Rahmen der Einzelwissenschaften“ (ebd.). Die „soziologische Rechtsforschung“ nehme dementsprechend die Wechselbeziehungen zum Kontext des Rechts in den Blick: „Es sind die gesellschaftlichen Bedingtheiten als Ursachen und die gesellschaftlichen Leistungen als Wirkungen des Rechts die Tatsachen, die den Gegenstand soziologischer Rechtsbetrachtung ausmachen." (Ebd.)

Wüstendörfer plädiert zwar ebenfalls für eine empirische Herangehensweise, die die sozialen Tatsachen zu eruieren habe, fordert dies allerdings unter dem Vorbehalt des historisch-spezifischen Kulturwertebezugs der juristischen Wertung. Damit behauptet er nicht die Wissenschaftlichkeit des konkreten Wertens im richterlichen Urteil, das ist für ihn ein „Akt der richterlichen Kunst“ (ebd.: 429). Vielmehr will er herausarbeiten, auf welchen der Wissenschaft zugänglichen Fakten die Interessenwägung beruht. Da die drei Elemente des gesetzlichen Gebots an gesellschaftliche Tatsachen rückgebunden sind - der Tatbestand spiegele eine „typische gesellschaftliche Interessenlage“ wider, die Norm sei ihrem Wesen nach die "Schlichtung eines gesellschaftlichen Interessengegensatzes“ und der Zweck „eine gesellschaftliche Zweckvorstellung, die sich des Gebots als eines Mittels für die Erreichung ihres gesellschaftlichen Ziels bedient" (ebd.: 313) - bietet ihm die soziologische Forschung eine das Urteil „vorbereitende Tatsachenforschung" (ebd.: 433).

Aber auch das konkrete richterliche Urteil erweise sich letztlich als gesellschaftlich gebunden. Denn die Rechtsprechung könne ihr Ziel, das wie

Soziologie etwa durch seine Teilnahme und Besprechung der ersten beiden Soziologentage bekannt sind (vgl. Wüstendörfer 1915). Im Jahr 1913 schreibt er, dass er den Begriff, soziologisch' als einen terminus technicus verwenden möchte, der gegenüber dem an sich ebenfalls passenden Ausdruck ,teleologisch' den Vorteil habe, über die Richtung der Zielstrebigkeit und der dafür aufgebrachten Mittel Auskunft zu geben (Wüstendörfer 1913: 248 Fn. 46). Insofern kennzeichnet seinen Soziologiebegriff ein intrinsischer Bezug zur Wertung. 
bei Fuchs in der Anpassung an die gesellschaftlichen Veränderungen liegt (vgl. Wüstendörfer 1916a: 309), nur durch den Bezug auf die gegenwärtigen gesellschaftlichen Verhältnisse erreichen. Daher fordert Wüstendörfer: „Die Rechtsfindung des Richters aus dem Gesetz muss erstens gesellschaftlich orientiert sein und zweitens auf die Ordnung der Gegenwart abgestellt.“ (Ebd.: 310) Sie leiste dies, wenn sie die „heutigen Interessenlagen und die ihnen adäquaten Werturteile zur Grundlage der Rechtsfindung" mache (1916b: 442f.), d.h. wenn sie den "Gegenwartszweck" der Norm (ebd.: 428) richtig erkenne. Das bedeutet, dass der Richter nicht nach subjektivem Empfinden werten soll, sondern sich an dem „deutlich erkennbar gewordenes allgemeine[n] Werturteil der führenden Kulturschicht des Volkes" (Wüstendörfer 1913: 348), d.h. den letztlich gesamtgesellschaftlich verankerten „Kultururteilen“ zu orientieren habe (vgl. Wüstendörfer 1916b: 446ff.). Diese Wertbeziehung im richterlichen Urteil auf die gegenwärtigen tatsächlich vorherrschenden und soziologisch zu ermittelnden Werte garantiert für Wüstendörfer die Objektivität des richterlichen Urteils - auch im Falle der Lückenausfüllung oder der gesetzesändernden Auslegung. Und in dieser Wertbeziehung liegt die Rückbindung des richterlichen Urteils an die empirischen Tatsachen.

Die Methode zielt also darauf ab, Verfahrensvorgaben zu entwickeln, die es ohne inhaltliche Wertvorgaben ermöglichen, im konkreten Einzelfall das Recht zu finden, das in tatsächlicher wie normativer Hinsicht den gegenwärtigen gesellschaftlichen Verhältnissen gerecht wird - v.a. auch angesichts deren beständigen und gegenwärtig beschleunigten Wandels (vgl. 1916a: 307). Auch wenn sich dafür Wüstendörfer nicht an den Naturwissenschaften, sondern an der neukantianischen Wertbeziehungslehre orientiert, führt dies bei ihm zu einer Verbindung von Sein und Sollen:

Alle diese für die Interessenwägung vorbereitende Forschungstätigkeit - Interessenforschung, Zweckforschung, Wirkungsforschung und Rechtswirklichkeitsforschung - ist nun wissenschaftlich im Sinne empirischer, wertbeziehender Tatsachenerkenntnis, und zwar ist sie „soziologisch": Wertbeziehende Seins-Wissenschaft und wertende Normwissenschaft treffen hier zusammen. (Wüstendörfer 1916b: 431)

Die Trennung von Sein und Sollen, jenes neukantianische Paradigma, mündet bei Wüstendörfer letztlich in eine Synthese. Genau hierin sieht er das Wesen und v.a. den Mehrwert der soziologischen Methode in den Rechtswissenschaften, vermag er dadurch doch das rechtliche Urteil in der Gesetzesanwendung auf eine wissenschaftliche Grundlage zu stellen.

Fuchs, Gmelin und Wüstendörfer rücken in ihren Entwürfen soziologischer Methoden der Rechtswissenschaft den Kontext des Rechts in den 
Vordergrund. Wenn das Recht als eine Entscheidung von Interessenkonflikten anzusehen ist, so werden diese Interessen sowie ihre Gewichtung als gegenwärtiges soziales Phänomen verstanden. Als solche sind sie der wissenschaftlichen Untersuchung, und d.h. der soziologischen Analyse, zugänglich und wirken auf die juristische Methodenlehre zurück - auch wenn unter dem Begriff „soziologisch“ sehr differente Vorgehensweisen verstanden werden. Dadurch versuchen die Autoren, das unumgängliche Problem des Wertens im Urteil auf eine wissenschaftliche Grundlage zu stellen. Das dient dazu, den Lebensbezug des Rechts auf wissenschaftliche Art und Weise zu verwirklichen, indem ein solches Vorgehen zur Anpassung des Gesetzes in seiner Anwendung an die Tatsachen des sich ständig im Wandel begriffenen gesellschaftlichen Kontext des Rechts führen soll.

\section{Wertungen in den Interessenabwägungen}

Ein ganz ähnliches Vorhaben verfolgen die Vertreter der Interessenjurisprudenz: Die Wissenschaft sei auf „den Boden der Wirklichkeit“ als reale, feste Forschungsgrundlage zu stellen (Müller-Erzbach 1908: 372); dazu gehöre „die Richtung des wissenschaftlichen Blicks auf die Bedürfnisse des Lebens selbst, denen ja die Rechtswissenschaft allein dienen will“ (MüllerErzbach 1906: 1238). Wenn dabei die Interessenjurisprudenz - wie ihr Name schon zeigt - ebenfalls die Interessenabwägung und damit das Wertungs- und Willensmoment in jedem Rechtssatz in den Vordergrund rückt, dann entwirft sie jedoch keine soziologische, sondern eine teleologische Methode.

Ausgangspunkt ist ebenfalls der Rechtsbegriff: Rechtssätze seien Konfliktregelungen kollidierender Interessen, d.h. sie sind Gebotsvorschriften, die bzgl. sich widerstreitender Interessen Wertungen vollziehen (vgl. Kallfass 1972: 11ff. m.N.). Dabei werden die widerstreitenden Interessen als kausal für die Rechtsbildung (Wertung) angesehen. Der Begriff des Interesses, also das, was einem Konflikt in rechtlicher Hinsicht zugrunde liegen kann, wird sehr weit gefasst: Er bezeichnet sämtliche „Begehrensdispositionen", d.h. materielle ebenso wie ideell-normative Interessen, empirische „Lebensinteressen“ und Wertmaßstäbe (vgl. Auer 2008: 522 m.N. zu Heck; Stoll 1974 [1931]: 160 Fn. 13; Haßlinger 2014: 124ff. m.N. zu Rümelin), 537

537 Nach Heck gehören zu den für die Rechtsentstehung kausalen „Interessen“ ausdrücklich auch normative Belange wie Gerechtigkeit, Billigkeit und Rechtssicherheit (s.a. Rümelin 1924a; Stoll 1974 [1931]: 160) sowie „,rechtstechnische In- 
und er bezieht sich nicht nur auf private, sondern ebenso auf „Gemeinschaftsinteressen" (Heck 1914: 59).538 Letztere bilden schließlich nach Heck das eigentliche Telos des Rechtssatzes, der ja keinen Kompromiss darstelle, sondern ein auf Abwägung beruhendes Werturteil. Den Maßstab für diese Abwägung bilden auch auf dem Gebiet des Privatrechts die „Gesamtinteressen der Gemeinschaft" (ebd.: 232 Fn. 357). Sie folgen der als maßgebend erkannten Wertidee (vgl. Schoppmeyer 2001: 95 m.w.N.), d.h. sie beruhen auf der Vorstellung einer zu erstrebenden Ordnung als „konkretes“ soziales Ideal (Heck 1932a: 41; ähnlich zuvor schon Rümelin 1920: 15f. m.N.; 1925: 57).539 Insofern werde „die Rechtsnorm aufgefaßt [...] als eine Abwägung von Interessen mit Rücksicht auf die von der Gemeinschaft verfolgten Zwecke" (Heck in Simmel et al. 1911c: 317). ${ }^{540}$ Dabei rückt die normative Seite des Rechtssatzes in den Vordergrund: Recht ist für die Interessenjurisprudenz primär durch seinen Wertungsaspekt bestimmt.

Dieser Rechts- bzw. Gesetzesbegriff bestimmt die richterliche Rechtsanwendung, handele es sich doch um „Aktivgebote [...], die der Richter auszuführen hat" (Heck 1914: 59). Grundlage bilde die Erkenntnis der von der Norm entschiedenen Interessen, die Interessenlage. Sie sei die „reale Grundlage“ des Rechtsfindungsprozesses (vgl. Müller-Erzbach 1906). In einem ersten Schritt müsse man also die widerstreitenden Interessen her-

teressen“, d.h. „Praktikabilitäts-, und „Darstellbarkeitsinteressen“, „legislative Interessen“, „Erfolgs-“, „Vollzugs-“ oder „Treffinteressen“ (vgl. Heck 1932a: 37, 40ff.; 1914: 59).

538 Dies zeigt sich zum einen an Hecks Unterscheidung verschiedener Formen der Interessenkollisionen, die (auch in Mischformen) dem Rechtssatz zugrunde liegen: Neben Konflikten, in denen private Interessen einander gegenüber treten, erkennt er innere Konflikte des Gesetzgebers, der zwischen verschiedenen Idealen zu wählen habe. Zudem gebe es Zwangs- bzw. „Sozialkonflikte“, in denen öffentliche und private Interessen im Widerstreit stünden (vgl. Heck 1932a: 39, Anm. 2; 45f.). Letztlich gibt es für Heck sogar ein Interesse der Menschheit (vgl. ebd.).

539 Nach Haßlinger wird der Interessenbegriff bei Rümelin ab 1918 zunehmend auf teleologische Erwägungen zurückgeführt und die Interessenabwägung durch eine „Interessenwertung“ ersetzt (Haßlinger 2014: 126ff.).

540 Dies zeigt, dass Heck den Interessenbegriff auf zwei Ebenen verwendet: Einmal zur Kennzeichnung der konfligierenden Bestrebungen als Ursache der gesetzlichen Regelung, zum anderen auf der Ebene des Bewertungsmaßstabes angesichts dieser Konfliktsituation. Was oft als Vagheit und Undifferenziertheit des Interessenbegriffes angekreidet wird, dient Heck jedoch dazu, eine differenzierende Analyse der unterschiedlichsten Lebensverhältnisse zu gewährleisten (vgl. Schoppmeyer 2001: 82; Heck 1932a: 46, 48). 
ausarbeiten. Da sie sich auf empirische Tatsachen beziehen, seien sie ,objektiv': „Wir müssen für die Zwecke der Rechtsanwendung die Tatsachen des sozialen Lebens in Form von Interessenlagen, Interessenkonflikten auffassen." (Heck in Simmel et al. 1911c: 317)

Dieser erste Schritt bildet die Voraussetzung für das „Verstehen“ der Norm, was für Heck gleichbedeutend ist mit der Ermittlung des vom Gesetzgeber gemeinten „subjektiven Sinns“ (Heck 1914: 23ff.). ${ }^{541}$ Heck geht daher historisch vor, er plädiert (im Gegensatz zu und in Abgrenzung von Vertretern der Freirechtsbewegung) für die Notwendigkeit der historischen bzw. genetischen Interessenforschung (vgl. ebd.: 59ff.; Schoppmeyer 2001: 261ff.). ${ }^{542}$ Denn keineswegs lasse sich die Interessenkollision sowie die gefällte Wertung umstandslos dem Wortlaut eines Rechtssatzes entnehmen (vgl. Heck 1914: 120ff.). ${ }^{543}$

Um die Gesetzesnorm zu verstehen, müsse der Richter also zu den die konkreten Interessenkonflikte regelnden Werturteilen und Wertideen vordringen. Er habe zu klären, welche Interessen das Gesetz vor Augen hatte, wie und aus welchem Grund es mittels des Gebots geregelt habe und wie sich die Norm auf die Interessen auswirken solle (Manegold 2012: 161). Die Interessenforschung richte sich allerdings nicht auf den „Zweck“ des Gesetzes (vgl. Heck 1912: 33f.; s.a. Rümelin 1922a: 63ff.; Stoll 1974 [1931]: 160 Fn. 13). Das reiche nicht aus, weil der als singulär verstandene "Zweck" fälschlicherweise nur das im Interessenkampf obsiegende Interesse widerspiegele und dabei vergessen mache, dass die konkrete Gestalt der

541 Seine Auslegungstheorie deklariert Heck als eine Form des Verstehens, die sich auf die Unterscheidung von subjektivem und objektivem Sinn gründet. Dafür bezieht er sich u.a. auf Max Webers frühe methodologische Arbeiten zu Roscher und zur Kulturwissenschaftlichen Logik (vgl. Heck 1914: 25f.). Dorndorf sieht darin eine eigenständige Adaption der Weber'schen Methodologie für die Rechtswissenschaft durch Heck, der auch mit der Wissenschaftslehre Rickerts vertraut war (Dorndorf 1995; zum Vergleich zwischen Weber und Heck siehe auch Petersen 2014: 51ff.).

542 Das schlägt sich nieder in einem Streit zwischen Verfechtern einer subjektiven und einer objektive Theorie der Auslegung. Zielt erstere auf möglichst genaue Ermittlung und Umsetzung des historischen Gesetzgeberwillens, so versucht die objektive Theorie einen vom Gesetzgeber gelösten, zeitbedingten objektiv sinnvollen Gesetzessinns zu ermitteln. Für Heck besitzt allein die subjektive Theorie ein wissenschaftlich objektivierbares Erkenntnisziel: die Feststellung der im Gesetzgebungsverfahren maßgeblichen Intentionen als empirisch-historische Tatsachen (vgl. Auer 2008: 528).

543 Für Heck hat v.a. die Auslegung nach den Sprachregeln nur eine heuristische und keine normative Bedeutung (Heck 1914: 120f.). 
Norm stets auf einer Interessenabwägung beruhe (vgl. Auer 2008: 524f.). 544 So könne der Inhalt der Rechtsnorm nur „begriffen“ werden, wenn auch die unterlegenen Gegeninteressen erkannt seien (Heck 1932a: 46). Als Bezugspunkt diene daher immer die Konfliktlage selbst, in der auch die Gegeninteressen eine für das Verständnis der Norm gewichtige Rolle spielen. ${ }^{545}$ Nur ausgehend von der Interessenkollision könne der Richter die jeweils maßgeblichen Gründe für die erfolgte Bewertung aufdecken und herausarbeiten. Und nur so lasse sich das zugrunde liegende Werturteil erkennen und die Schutzwürdigkeit des einen Interesses gegenüber dem anderen erklären (vgl. Manegold 2012: 161).

Ausgehend von dieser "historisch-teleologischen Auslegung" (Heck 1914: 8, H.i.O.) stellt sich die konkrete richterliche Fallentscheidung dann für Heck immer als eine doppelte dar: als „eine Abgrenzung einander gegenüberstehender Interessen“ sowie als „eine Abwägung dieser Interessen nach Werturteilen und Wertideen“ (Heck 1912: 32). Das richterliche Urteil ist Erkenntnis und Wertung. Die Wertung wurzelt dabei im Vergleich zwischen dem Interessenkonflikt im konkreten Streitfall mit demjenigen des in Frage kommenden gesetzlichen Tatbestandes. Decken sich die Interessenkonflikte von Sachverhalt und Norm, so erfolgt eine „Uebertragung des Werturteils“ (ebd.) durch einen Subsumtionsschluss (vgl. ebd.: 33). Da Heck aufgrund der Vielgestaltigkeit und Wandelbarkeit der Lebensan-

544 So schreibt Heck: „Der Zweck des Gesetzes zeigt nur das siegende Interesse. Aber der Inhalt der Rechtsnorm, der Grad der Zweckbefriedigung, ist von dem Gewichte der unterliegenden Interessen abhängig." (Heck 1933: 13) Er betont, dass das reine Zweckdenken zu ereignisbezogen und damit zu subjektiv konnotiert sei: „Das Wort Interesse bietet vor allen anderen den Vorzug, dass es die Elemente, auf die es uns ankommt, mit umfasst und in dieser Beziehung schon Bürgerrecht hat. Andere besser geeignete Ausdrücke bieten sich nicht. Bedürfnis, Bestrebung, Wert und Zweck betonen viel zu sehr das aktuelle Element. Namentlich können wir das Wort Zweck, ohne den Sprachgebrauch zu vergewaltigen und Missverständnisse zu wecken, nur für das bei einer Handlung vorgestellte Begehrungsobjekt gebrauchen, nicht für die einzelnen bei der Ueberlegung einwirkenden Begehrungstendenzen.“ (Heck 1912: 30 f.).

545 Marietta Auer betont, dass ein „teleologisches Rechtsdenken dann, wenn es seine Grundlage im Konflikt der zugrundeliegenden Zwecke bzw. Interessen vergisst, letztlich auf halbem Wege stehen bleibt und sich von der Begriffsjurisprudenz eben nicht ganz verabschiedet, sondern vielmehr einem ähnlichen Fehler wie diese verfällt: nämlich die Rechtsfindung gerade nicht konsequent durch Rückbindung an die empirischen Bedürfnisse des konkreten Falles zu rationalisieren, sondern an deren Stelle wiederum ein halb-idealisiertes System, wenn auch nicht der Begriffe, so doch der Zwecke zu setzen“" (Auer 2008: 542). Genau dies habe Heck vermieden. 
schauungen und -verhältnisse aber ebenfalls von der Lückenhaftigkeit des Gesetzes ausgeht, betrifft das eigentliche Methodenproblem die Rechtsgewinnung beim Vorliegen einer Lücke. Sie erfolge durch eine „wertende[] Gebotsbildung" (Heck 1914: 161) - entweder im Rahmen einer Norm, die die Wertung an den Richter delegiert (z.B. die Leistung nach „Treu und Glaube"), oder aber, wenn die historische Interessenforschung ergibt, dass Lücken vorliegen. Auch in diesem Fall sei der Richter an die gesetzliche Wertung gebunden:

Der Richter soll dann, wenn kein gesetzlicher Tatbestand gegeben ist, sich zuerst denjenigen Interessenkonflikt veranschaulichen, der in dem Streitfalle vorliegt. Er hat dann zu prüfen, ob nicht derselbe Interessenkonflikt in der Form anderer Tatbestände durch das Gesetz entschieden ist. Im Falle der Bejahung hat er das gesetzliche Werturteil zu übertragen, die gleichen Interessenkonflikte gleich zu entscheiden. Das ist ein Verfahren, das als Gesetzesanalogie oder Rechtsanalogie von jeher geübt wurde, das aber durch die Interessenjurisprudenz die richtige Begründung und auch eine bestimmtere Abgrenzung, eine größere Sicherheit der Anwendung, erhält. (Heck 1933: 20)

Nur ganz subsidiär greife eine Eigenwertung des Richters ein (Heck 1912: 32; bzgl. Rümelin vgl. Haßlinger 2014: 160ff.). 546

Die richterliche Rechtsentscheidung ist insofern bei Heck - und den anderen Vertretern der Interessenjurisprudenz - nicht auf die bloße Subsumtion unter den Gesetzeswortlaut beschränkt. Heck fordert darüber hinaus die Interpretation, Ergänzung und Korrektur mehrdeutiger, lücken- und fehlerhafter Gebote, um die Erkenntnis und Anpassung an das Leben zu gewährleisten (vgl. Auer 2008: 527). Denn das Recht diene letztlich immer „der Erhaltung oder Herbeiführung bestimmter sozialer Zustände“ (Stoll 1974 [1931]: 157). Dabei ist das richterliche Urteil immer Wertung: entweder Übertragung des Werturteils, wertende Gebotsbildung und in Ausnahmefällen richterliche Eigenwertung. Die Tätigkeit des Richters wird hier normativiert.

In dieser Wertung ist das richterliche Vorgehen aber nicht frei, sondern steht in der Interessenjurisprudenz unter dem Vorbehalt des „Willens des

546 Insofern erkennt auch Heck trotz seiner Polemik gegen die freie Rechtsfindung die Möglichkeit einer abweichenden Auslegung an, die jedoch mit der Gebotsvereitelung an ihre Grenze stoße und letztlich in der Verletzung der Autonomie der Rechtsgemeinschaft (der der Gesetzgeber durch das Gesetz Ausdruck verleiht) bestehe (vgl. Heck 1914: 201, 13). 
Gesetzgebers“. ${ }^{547}$ Damit zielt sie auf eine möglichst weitgehende Verwirklichung des richterlichen Gehorsams gegenüber dem Gesetz (s. Auer 2008: 526; Schoppmeyer 2001: 102ff.; m.w.N.). ${ }^{548}$ Da das Gesetz jedoch immer lückenhaft und widersprüchlich sei, schulde der Richter nicht strikten, sondern vielmehr „denkende[n]“, „interessegemäße[n] Gehorsam“ (Heck 1932a: 106f., 1914: 22; bzgl. Rümelin vgl. Haßlinger 2014: 153ff.). Indem man diesen ,denkenden Gehorsam' (Stoll 1974 [1931]: 166) gerade im Nachvollzug der Wertung sieht, handele es sich nicht um irgendeine, freie oder willkürliche Form der Rechtsgewinnung (vgl. Auer 2008: 527).

In der Konsequenz führe die neue Richtung der Interessenjurisprudenz „dazu, dass der Richter Gesetzeslücken nach teleologischen Gesichtspunkten ergänzt" (Heck 1912: 5). Daher wendet sie sich gegen die Beschränkung der Methode auf die logische Subsumtion: „Auch die Interessenjurisprudenz kennt eine Subsumtion, aber keine begrifflich logische, sondern eine interessenvergleichende teleologische.“ (Stoll 1974 [1931]: 162f.) Unzweifelhaft sei dem Recht in dieser Perspektive „eine normative Aufgabe gestellt“ (ebd.: 158), und die „praktische Rechtswissenschaft“ habe „in weitem Umfang normative Aufgaben“ (Heck 1912: 36, H.i.O.). Die Interessenjurisprudenz stellt sich als eine „Form der teleologischen Jurisprudenz“ dar (ebd.: 28; s. bereits Rümelin 1907). Sie basiert auf einem teleologischen Verständnis des Rechts und entwickelt dementsprechend teleologische Methoden der Rechtsanwendung.

Daher richten sich die Methodenvorschläge nicht auf den Versuch einer umfassenden richterlichen Faktenbindung durch eine wie auch immer geartete „soziologische Methode“, sondern auf den Entwurf einer teleologischen Methode. Nach Heck liegt

[i]n der Betonung der Interessenforschung bei Rechtserkenntnis und Lebenserkenntnis [...] der berechtigte Kern des stark betonten Verlangens nach einer soziologischen Rechtswissenschaft, einer Rechtssozio-

547 Allerdings deutet Heck diesen Begriff eigenwillig und ebenfalls normativierend: „Die alte Formel ,Wille des Gesetzgebers' hat einen Realgehalt. Aber der Willensbegriff ist kein psychologischer, sondern ein normativer, ein Interessenbegriff. Der ,Gesetzgeber" ist kein Phantom, sondern die zusammenfassende Bezeichnung für die kausalen Interessen." (Ebd.: 8, H.i.O.).

548 Heck zieht dabei die Parallele zum „Gehorsam des Dieners“ bzw. zum „militärischen Gehorsam“ (ebd.: 16, 19f. u.ö.). Dieser Gesetzesgehorsam ist für Vertreter der Interessenjurisprudenz eines der Hauptargumente gegen das Freirecht. Zur Kritik der Interessenjurisprudenz an der Freirechtsschule s. Kallfass 1972: 87ff. m.N. 
logie oder einer die dogmatische Rechtswissenschaft ergänzenden soziologischen Rechtswissenschaft (Heck 1912: 37).

So basiere ja auch die genetische Interessenforschung auf empirischen Tatsachen, womit man sich einer soziologischen Forschung annähere (vgl. Heck 1917: 271). Ebenso sei bei der systematisierenden Darstellung der Rechtswissenschaft zu erwarten, „daß die Ergebnisse der Interessenforschung, die soziologischen Elemente fortdauernd in die Darstellung eingearbeitet werden" (ebd.: 41). Insofern erkennt Heck die soziologische Forschung als eine Form der Hilfswissenschaft für die Rechtswissenschaft an (Schoppmeyer 2001: 164).549 Und auch Rümelin betont, dass eine Interessenwertung ohne Kenntnisse der zugrunde liegenden Lebensverhältnisse unmöglich sei. Daher gelte: „als Vorarbeit“ sei die Soziologie stets „unentbehrlich" (Rümelin 1929: 67).

Allerdings widerspricht Heck vehement jeglichen Versuchen, die Rechtswissenschaft durch die Soziologie zu ersetzen (s.u.), aber auch „der unmittelbaren Verwendung des von einer allgemeinen Soziologie erbrachten Materials“ (Heck 1912: 37 Anm. 3). Denn: „Die Rechtswissenschaft verfolgt normative Endziele und nur der Jurist kann das für seine Endziele wesentliche aus der Fülle der Wirklichkeit aussondern." (Ebd.) Insofern sei letztlich „[g]egen die Ausarbeitung einer Soziologie des Rechts [...] nichts einzuwenden, aber der Vorschlag der Namensänderung abzulehnen. Die normativen Aufgaben sind so wichtig und so umfassend, daß ihre Theorie stets den Rang einer Wissenschaft behaupten wird.“ (ebd.: 38 Anm.)

\section{Die Problematisierung der Normativität des Rechts}

Trotz des Umstandes, dass sehr unterschiedliche Wege beschritten werden, um eine neue Methodenlehre zu entwickeln, eint beide beschriebenen Positionen ihr Ausgangspunkt: Das eigentliche Problem liegt in der Unausweichlichkeit der normativen Wertung im richterlichen Urteil. Angesichts dieser Tatsache kann sich der Richter in der Rechtsanwendung nicht auf wissenschaftlich angeleitete rein logische Operationen und damit auf einen rein ,juristischen“ Erkenntnisgewinn berufen, um sein Urteil zu fällen. Im Rahmen der genuinen Methodendebatte wird die Normativität des

549 Heck ist auch an den Entwicklungen in der Soziologie interessiert, wie nicht nur seine Bezugnahmen auf Georg Simmel, Max Weber und andere zeigen, sondern ebenso seine Teilnahme am ersten deutschen Soziologentag. 
Rechts problematisiert, und das insbesondere auch von den Vertretern einer genuin juristischen, soziologischen Methode'.

Dabei zeigen sich auf der methodischen Ebene zwei Möglichkeiten der strategischen Wiederaufladung der Bestimmung des Rechts als ein gesellschaftliches Phänomen. Dieses Verständnis ist letztlich schon in der Rechtsentstehungslehre der Historischen Rechtsschule angelegt. Dort wurde das Recht jedoch noch als ein Produkt einer harmonischen und einheitlichen, in der Vergangenheit verankerten organischen Sozialsphäre angesehen. Demgegenüber ist es nun in Folge des gesellschaftsfunktionalen Zweckdispositivs in einer antagonistischen, durch Interessenkämpfe gekennzeichneten Sphäre verortet, die sich im fortwährenden Wandel befindet. Die erforderliche Anpassung oder Anbindung des Rechts an die jeweils gegenwärtig gegebenen gesellschaftlichen Umstände wird nun nach der Beendigung des Rechtspluralismus durch die Kodifikation des BGBs - über die Rechtsanwendung problematisiert. Dafür müssen entsprechende Methoden entwickelt werden. Hierfür wird einerseits für eine Soziologisierung plädiert, die die Tatsachen der Gesellschaft in den Blick nimmt und daraus Versuche entwickelt, Maßstäbe für die unausweichliche Wertentscheidung im Urteil zu gewinnen; andererseits wird für eine Teleologisierung der rechtlichen Methode eingetreten, die die genuine Wertentscheidung im Urteil basierend auf der Wertentscheidung im Rechtssatz und die normative Seite der richterlichen Tätigkeit in den Vordergrund stellt. Gestritten wird letztlich darum, ob und wie Faktizität und Normativität in der konkreten Rechtsanwendung methodisch korrekt in Beziehung zueinander gesetzt werden können. ${ }^{550}$

\section{Epistemische Folgen II: Die Rolle der Soziologie angesichts des Wesens der Rechtswissenschaft}

Beide Ansätze werden heftig kritisiert: Den Vertretern der Interessenjurisprudenz wirft man vor, dass sie zwar die Interessenwägung bzw. -abwägung methodisch zu fassen suchen, damit aber nur der halbe Weg zurückgelegt werde. Denn sie stellten für die daraus resultierende notwendige Wertung weder ein objektives Kriterium, noch Maßstäbe oder Grundsätze

550 Das zeigt sich auch in den Redebeiträgen von Fuchs, Wüstendörfer und Heck, die am ersten Soziologentag an Kantorowicz' Vortrag „Rechtswissenschaft und Soziologie" anschließen und sich allesamt um das Verhältnis von Werturteil und Tatsachenerhebung drehen (vgl. dies. in Simmel et al. 1911c). 
der Abwägung bereit (vgl. etwa Neukamp 1912: Sp. 47). ${ }^{551} \mathrm{Um}$ diese fundamentale Lehrstelle zu schließen, werden ,objektive“ (eigentlich verobjektivierte) Kriterien wie etwa Billigkeit (Schmölder 1907), Kultur (Brütt 1907), 552 Stammlers „soziale[s] Ideal“ (Stammler 1902: 196ff.; s.a. Münch 1918) oder das gesellschaftliche Rechtsbewusstsein (als Gerechtigkeitsgefühl, vgl. Kantorowicz 1909: 23ff.) genannt. Zentral aber bleibt der Vorwurf des logischen Problems, dass die Idee der Interessenwägung als solche kein Abwägungskriterium enthalte (vgl. Pokrovskij 2015 [1917]: 79) und man daher wieder bei der Ausgangsfrage lande, wie die Lücken im Recht zu füllen seien.

Aber auch den Versuchen einer Soziologisierung der Rechtswissenschaft, die mit Verweis auf die gesellschaftlichen Tatsachen genau diese Lücke zu schließen sucht, schlägt heftiger Wind entgegen. Insbesondere Fuchs wird vorgeworfen, dass er etwas proklamiere, das einer wissenschaftlichen Überprüfung nicht standhalte: Die Soziologie diskutiere selbst noch darüber, was ihre genuine Methode sei, weshalb man bezweifeln müsse, dass sie als wissenschaftliches Fundament für die Rechtswissenschaft dienen könne (vgl. Düringer 1909: 71; 1992 [1910]: 134). Zudem besitze die „soziologische Methode“ v.a. bei Fuchs, da sie ja auch ethische Erwägungen beinhalte, einen "nebelhaft weiten Sinne“ (Oertmann 1992 [1911]: 201; s.a. Hedemann 1910: 119), ja man müsse letztlich von der „völligen Unbestimmtheit dieses Begriffs" sprechen (Düringer 1992 [1910]: 134). Daher vergrößere dieses als Methode titulierte Vorgehen, das „im Nebel der ,Soziologie“ verhüllt bleibt“" (Vierhaus 1909: Sp. 1170), nur die Unsicherheiten der Rechtsfindung (vgl. Hedemann 1910: 119). Auf solch unsicherem Boden könne man keinen Maßstab für das richterliche Urteil finden und ende letztlich bei subjektiv-willkürlichen "soziologischen“ Urteilen des Richters (vgl. Oertmann 1992 [1911]: 206; s.a. Düringer 1992 [1910]: 138). Schließlich werde der falsche Adressat für die soziologische Methode gewählt: Jedem Gesetz liege ein praktischer, und d.h. soziologischer Gedanke zugrunde. Der „größte Soziologe“ sei daher der Gesetzge-

551 Zum Aufkommen des Abwägungsgedanken Anfang des 19. Jahrhunderts und seiner Karriere in der Jurisprudenz bis heute, die jedoch mit einem fundamentalen Funktionswandel des Abwägens verbunden ist, vgl. Rückert 2011.

552 Die Hinwendung zur Kultur soll einerseits aus der Gefängniszelle des Gesetzes herausführen (vgl. Haferkamp 2007b; 118f.; Sprenger 1991, jeweils m.N.), andererseits den Richter aber wieder an übersubjektive Werte binden. Auch wenn hier ,Kultur' nicht auf wissenschaftstheoretischer Ebene eingesetzt wird, wird dadurch doch die Annahme plausibel, Rechtswissenschaft sei eine Kulturwissenschaft (s.u. $\$ 5 . I V .2 .1)$. 
ber (Düringer 1992 [1910]: 138), soziologische Überlegungen betreffen die Rechtspolitik (Oertmann 1992 [1911]: 208f.; 218f. u.ö.; daher auch die Parallele zu Petražycki), ${ }^{553}$ und der Richter sei nicht berechtigt, ,seine eigene persönliche Soziologie an die Stelle des Gesetzgebers zu setzen“ (Düringer 1992 [1910]: 138). Kurz: Die Soziologie stellt aus dieser Perspektive keinen plausiblen Bezugspunkt für die Ausarbeitung einer wissenschaftlichen Methode der Rechtswissenschaft dar. ${ }^{554}$

Trotz dieser harschen Kritik v.a. seitens der Gegner der Freirechtsschule erscheint der Rekurs auf die Soziologie angesichts der Prämisse der Rechtsentstehungslehre für eine Vielzahl von Autoren plausibel. Denn wird das lebende, gesellschaftliche Recht dem Gesetz gegenübergestellt, so erscheint es einleuchtend, mittels der Soziologie (was immer auch darunter verstanden wird) den Blick auf den Produktionsort des Rechts, d.h. auf die gesellschaftlichen Verhältnisse, zu richten. Dabei geht es aber nicht primär um den Entwurf einer wie auch immer gearteten „soziologischen“ Methodenlehre im engeren Sinne für die Rechtswissenschaften. Vielmehr wird angesichts der Entstehung des Rechts „im Leben“ das Verhältnis von Recht und Soziologie als wissenschaftliche Disziplinen problematisiert. Anders formuliert: Man streitet um die Bestimmung der Rolle der Soziologie für die Rechtswissenschaften (hierzu 1.).

Hierbei unterscheiden sich jedoch die Positionen sowohl hinsichtlich dessen, was das gesellschaftliche Phänomen ,Recht ${ }^{6}$ kennzeichnet, was dementsprechend als soziologische Untersuchung des Rechts verstanden wird, als auch hinsichtlich der Frage, welche Bedeutung die neue, sich gerade konsolidierende Wissenschaft der Soziologie für die Rechtswissenschaften habe (vgl. Kanigs 1932: 77). Es wird darum gestritten, in welcher Beziehung die Soziologie zur Rechtswissenschaft steht. Da sich dies aber nur vor dem Hintergrund der wissenschaftstheoretischen Bestimmung der Soziologie beantworten lässt, geht es zugleich um wissenschaftstheoretische Fragen. Und da dies gleichermaßen die Rechtswissenschaft betrifft,

553 Abgesehen davon wenden Oertmann und Düringer ein, dass Fuchs gegenüber den Ansätzen von etwa Jhering oder Petražycki - außer allenfalls der Verwendung des Terminus „soziologisch“ - sowieso nichts Neues entwerfe (vgl. Oertmann 1992 [1911]: 202ff.; Düringer 1908: Sp. 258f.; 1992 [1910]: 135).

554 Für Sohm, der dem Repräsentationsgedanken verhaftet bleibt, kann die „soziologische“ Rechtsfindung sowieso nur mit den Mitteln der Begriffsjurisprudenz operieren: „Das ,soziologisch' richtige Recht kann [...] nur aus der Herrschaft gewonnen werden, welche uns die Begriffsjurisprudenz über den Inhalt des gegebenen Rechts vermittelt: in dem alten Recht ist bei richtiger Erkenntnis auch das werdende neue Recht angebahnt.“ (Sohm 1909: Sp. 1024, H.i.O.). 
wird ebenso um deren Wesensbestimmung gerungen (s. 2.). Beide Streitpunkte, d.h. das Bestimmungsproblem der Rolle der Soziologie und das Bestimmungsproblem der Rechtswissenschaft, zeigen sich als je spezifische Problematisierungsweisen von Sein und Sollen - nun jedoch auf wissenschaftstheoretischer Basis.

\section{Die Rolle der Soziologie in der Rechtswissenschaft}

\subsection{Rechtswissenschaft als Soziologie}

Dass es um die Problematisierung von Sein und Sollen geht, ist schon in einer der radikalsten Varianten der Begründung der Rechtswissenschaft in der Soziologie zu erkennen, ${ }^{555}$ nämlich in Ignatz Kornfelds oft zitierter Untersuchung Soziale Machtverhältnisse. Grundzüge einer allgemeinen Lehre vom positiven Rechte auf soziologischer Grundlage aus dem Jahr 1911. Denn Kornfeld richtet seine allgemeine Rechtslehre explizit gegen das „Dogma von dem normativen Wesen des positiven Rechtes“ (Kornfeld 1911: III).

Im Kern geht es ihm damit um die wissenschaftliche Fundierung der Jurisprudenz. Wissenschaft könne sich für ihn nur auf einen ihr äußerlich gegebenen Gegenstand, d.h. auf Tatsachen, beziehen: Sie „ist nichts anderes, als ein in allgemeinen Sätzen geordnetes Wissen; Wissen aber setzt ein Objekt voraus, das die menschliche Vernunft - entweder in sich selbst oder in ihren Lebenserfahrungen - als etwas ihr Gegebenes, ihrer Willkür Entrücktes vorfindet“" (ebd.). Das schließe eine Bestimmung des Rechts für die Rechtswissenschaft als Norm (Imperativ oder Erlaubnis), als Normenkomplex, bzw. über Rechtsideen oder normative Geltungsansprüche aus, wird doch in all diesen Fällen der Fokus nicht auf das tatsächlich Gegebene, sondern auf das Sein-Sollende gerichtet (sogenannte „Normentheori-

$555 \mathrm{Zu}$ dieser Gruppe ist neben Ofner (vgl. Ofner 1894, 1931) und Karner/Renner (Karner 1904b) insbesondere Ludwig Spiegel zu rechnen. Dieser fordert im Jahr 1909 ausgehend von der Bestimmung des Rechts als eine tatsächliche „soziale Erscheinung“ (Spiegel 1909: 2), dass die Rechtswissenschaft sich der induktiv-deskriptiven Methoden der Sozialwissenschaft bedienen müsse, wenn sie für sich beanspruchen wolle, eine Wissenschaft im „wahren Sinne des Wortes“ zu sein (ebd.: 17). Grundlage jeder Rechtswissenschaft kann nach Spiegel dabei nur das tatsächlich geltende Recht sein. Allerdings beschränke sich das Recht nicht auf die Rechtsvorschriften im Gesetz, da „das wirkliche Rechtsleben mit dem Rechte nicht übereinstimmen muß und auch vielfach nicht übereinstimmt" (ebd.: 7). Aus diesem Grund müssten die Sozialwissenschaften diese Tatsachen ausfindig machen. 
en“). Wenn man sich jedoch nicht auf das Sein, das tatsächliche Gelten des Rechts, sondern auf den normativen Gehalt, das Gelten-Sollen im Rechtssatz, beziehe, werde man auf ein Gedankensystem jenseits der Realität verwiesen, das letztlich nur deduktiv, analytisch und nicht empirisch das autoritativ (Gesetzgebung) oder fiktiv (Vernunftrecht) Vorgegebene ordnen könne (vgl. ebd.: 2). Ein solches Vorgehen kann aber nach Kornfeld nicht den Anspruch der Wissenschaftlichkeit für sich erheben, v.a. nicht i.S.d. „Erfahrungswissenschaft“, was ihm als Leitbild jeglicher Wissenschaftlichkeit gilt (vgl. ebd.: 2, 3, 15). ${ }^{556}$

Damit wendet sich Kornfeld aber keineswegs gegen die Bestimmung des Rechts über den Zweck, der normative Zielsetzungen kennzeichne und immer auf einer Willensentscheidung gründe. Allerdings dürfe man den entsprechenden Willen nicht im autoritativen Willen eines historischen Gesetzgebers oder in den vernunftrechtlichen Spekulationen suchen, sondern müsse ihn empirisch fundieren. Die empirische Fundierung ist für Kornfeld gleichbedeutend mit der Fundierung des Rechts in der Gesellschaft: Recht sei die „erfahrungsmäßig bestimmte[] Art von Regeln gesellschaftlichen Zusammenlebens" (ebd.: V), es werde gebildet aus dem „Inbegriff tatsächlich geltender Regeln des gesellschaftlichen Zusammenlebens“ (ebd.: 1), und die Rechtsverhältnisse werden als „durch Wohlfahrtszwecke bestimmte soziale Machtverhältnisse“ (ebd.: 18) verstanden. 557

Das Wesen jeder Gesellschaft wiederum werde „durch die ihr innewohnenden Zwecke und durch die von diesen Zwecken bestimmte Art des regelmäßigen Verhaltens ihrer Mitglieder bestimmt“ (ebd.: 20). Dabei habe

556 Denselben Vorwurf trifft nach Kornfeld auch die technische Seite der Rechtswissenschaft, d.h. die Rechtsfindungs- und Rechtsanwendungslehre, da auch sie in seinen Augen danach fragt, was in einem konkreten Fall rechtens ist und daher den Fokus mittels der Hermeneutik auf das Sein-Sollende richtet (vgl. Kornfeld 1911: 1, 17f.). Auch in diesem Bereich müsse jedoch der Erkenntnis des realen Wesens der rechtlichen Erscheinungen „das wissenschaftliche Primat" eingeräumt werden (ebd.: 18).

557 Wenn dabei die Gesellschaft in den Mittelpunkt rückt, bestimmt Kornfeld diesen Begriff (unter Bezugnahme auf Sigwarts Logik und Simmels Soziologie) in einem sehr weiten Sinne: Gesellschaft sei „ein Zusammenwirken von Menschen zu gemeinschaftlichen Zwecken, oder was dasselbe sagt, für gemeinschaftliche Interessen [...]. Die durch solches Zusammenwirken hervorgerufene Vorstellungseinheit ist überall Zweckeinheit, und zwar nicht bloß eine durch die Betrachtung eines Außenstehenden bewerkstelligte (wie die Zweckeinheiten in der Natur), sondern eine durch die Willensbestrebungen der Mitglieder selbst begründete“ (Kornfeld 1911: 326 Anm. 6). 
gerade die „Rechtsgesellschaft“ die „sozialen, d.h. in dem regelmäßigen Verhalten ihrer Mitglieder liegenden Existenzbedingungen allen gesellschaftlichen Zusammenlebens zum Gegenstande“: Ihr begrifflicher Zweck sei „die Verwirklichung der Existenzbedingungen, die Selbstbehauptung des sozialen Zusammenlebens“ (ebd.: 21). Kennzeichnend für das Recht sei also die Tatsache, dass es sich um eine grundlegende gesellschaftliche Erscheinung handele, ja dass letztlich Gesellschaft ohne Recht nicht denkbar sei (vgl. ebd.: 18, 20). Recht bestehe dementsprechend nicht aus Normen, sondern aus gesellschaftlichen Regeln, die Kornfeld als „empirische Gesetze sozialen Verhaltens“ (ebd.: 25) begreift. Er will diejenigen Regeln herausarbeiten, die in allen Gesellschaften vorkommen (ebd.: 22). Daher erscheint auch für ihn das Recht als gesellschaftlich gewachsenes Recht: Es ist das „in historischer Erfahrung gegebene gesellschaftliche Leben der Menschen, und ist, abgesehen von diesem, ihm vorausgehend, überhaupt nicht vorhanden" (ebd.: 4). Man könne und müsse es durch die RegelmäBigkeiten des gesellschaftlichen Lebens erklären.

Indem das Recht als Tatsache gesetzt wird, das - wie letztlich auch in der Volksgeistlehre ${ }^{558}$ - die sachliche Autorität tatsächlich geltender Regeln für sich beansprucht und daher nicht auf ein Sein-Sollendes, sondern auf „die Geltungsart eines Seienden“ (ebd.: 15) verweist, will Kornfeld die Rechtswissenschaft auf dieselben logischen Methoden gründen, welche „auf allen anderen Gebieten theoretischen Wissens befolgt werden“ (ebd.: 3). Denn dieses Vorgehen „ermöglicht die Einreihung der Rechtslehre in das System der menschlichen Erfahrungswissenschaften und der rechtswissenschaftlichen Methode in das System der für alle anderen Wissenschaften geltenden Erkenntnisgesetze“ (ebd.: 15). Das bedeute nicht, dass es sich damit notwendigerweise um eine Naturwissenschaft handele. Da es um die tatsächliche Geltung des Rechts gehe, könne man nicht von kausalen Notwendigkeiten und exakten, ausnahmslosen Gesetzen ausgehen. Allerdings seien aus diesen Tatsachen auf induktivem Weg Erfahrungswerte zu gewinnen, die Regeln und Regelmäßigkeiten als Wahrscheinlichkeiten statuieren können (vgl. ebd.: 15f.). Darin liegt das Ziel einer soziologischen Fundierung der Rechtswissenschaft.

558 Der Volksgeistlehre der Historischen Rechtsschule gesteht Kornfeld zu, diese sachliche Autorität als Basis eines erfahrungswissenschaftlichen Zugangs entdeckt zu haben (ebd.: 51). Allerdings habe sie sich aus Bequemlichkeit nicht der realen Seite zugewandt, sondern sich auf die deduktive Arbeit am System der Normen beschränkt (ebd.: 52). Auch hier zeigt sich, dass die Soziologisierung der Rechtswissenschaft eine Möglichkeit der strategischen Wiederaufladung der Rechtsentstehungslehre der Historischen Rechtsschule ist. 
Kornfeld versteht seinen Ansatz als „Prolegomena“ einer allgemeinen Rechtslehre (ebd.: V). Er will aus dem „sozialen Wesen des positiven Rechtes realistische Erklärungen [...] für das Rechtsleben als System sozialer Machtverhältnisse" ableiten, aber auch Erkenntnisse für die genuin rechtsdogmatischen und -methodischen Probleme der „Rechtsquellen“, der „Daseinsbedingungen und [des] Wesen[s] der wichtigsten Rechtsverhältnisse" liefern (ebd.: IV). Wenn er dabei auch das „Unrecht und seine Folgen“ (ebd.) erklären will, dann fundiert er das Normative ebenfalls empirisch in der Gesellschaft. ${ }^{559}$ Unter Aussonderung jeglichen normativen Gedankens versucht er nämlich über den Entwurf einer allgemeinen Rechtslehre eine Grundlage für die Rechtswissenschaft zu schaffen, die das Normative immer erst supplementär ins Spiel bringt (vgl. ebd.: 49) und daher einer rein faktenorientierten Wissenschaftlichkeit entspricht. Die entsprechende Wissenschaft, die die Leitlinien für ein solches Vorgehen zu liefern vermag, sei die Soziologie: Sie sei jene Erfahrungswissenschaft, die sich mit den Regeln des gesellschaftlichen Verhaltens befasse und theoretische Erkenntnisse der Regelmäßigkeiten des Rechtslebens als ein Erfahrungsobjekt zu liefern vermag (vgl. ebd.: 34).

Damit zielt Kornfeld auf eine radikale Soziologisierung der Rechtswissenschaft. ${ }^{560}$ Die soziologische Untersuchung des Rechts sei nicht nur eine

559 So schreibt Kornfeld: „Wir hingegen sind der Ansicht, daß im Begriffe ,rechte Gewalt', sofern wir ihn als Ergebnis positiven Rechtes auffassen, das Attribut ,rechte' nicht in einem ethischen, sondern in einem soziologischen Sinne zu verstehen ist, nicht als eine Gewalt, die ihrem Inhaber zustehen soll, sondern als eine Gewalt, die ihm vermöge der Regeln des rechtlich-sozialen Verhaltens in der Rechtsgesellschaft tatsächlich zusteht, und daß ihr ein ethischer Charakter erst auf Grund und infolge der an jene Regeln des realen rechtlich-sozialen Lebens sich anknüpfenden ethischen Werturteile beigelegt wird." (Ebd.: 49) Damit will er seine gesellschaftliche Fundierung des Normativen in Abgrenzung zu Jherings Begründung einer Sozialethik im Zweck im Recht verstanden wissen.

560 Das ist für Kornfeld gleichbedeutend mit der Abgrenzung von der Freirechtsschule. Denn selbst wenn deren frühe Ansätze wie Ehrlichs Freie Rechtsfindung und freie Rechtswissenschaft und Gnaeus Flavius' (Kantorowicz) Kampf um die Rechtswissenschaft unter Verweis auf die Trennung von Rechtsnorm (Gesetz) und tatsächlich geltender Rechtsregel (lebendes Recht) auf die Notwendigkeit einer soziologischen Untersuchung des Rechts verweisen, bleiben sie in Kornfelds Augen bei der hergebrachten Behandlung der Jurisprudenz stehen, da „sie diese bloß als Normenlehre, somit als eine rein praktische Disziplin betrachten und die Untersuchung des positiven Rechts als Komplexes tatsächlich geltender Regeln der Soziologie zuweisen“ (Kornfeld 1911: 325, Anm. 1). Eine solche Doppelung der Perspektive auf das Recht widerspricht aber seinem Wissenschaftsverständnis. 
Ergänzung und liege neben, unterhalb oder zwischen Tatsachen- und normativer Forschung. Sie müsse vielmehr als einzig mögliche Form der wissenschaftlichen Behandlung des Rechts angesehen werden. Um den Charakter der Rechtwissenschaft als „Erfahrungswissenschaft" zu sichern und damit ihren Wissenschaftscharakter überhaupt zu garantieren, muss die Jurisprudenz zur Soziologie werden.

\subsection{Soziologie des Rechts als „wissenschaftliche Grundlage“ der Jurisprudenz}

Bereits in Freie Rechtsfindung und freie Rechtswissenschaft aus dem Jahr 1903 versucht Ehrlich das Problem der freien Rechtsfindung über die Klärung der Frage der Rechtsentstehung, d.h. der Rechtsquellen anzugehen (Ehrlich 1967d [1903]: 178). ${ }^{561}$ Rechtliche Normen zeichnen sich nicht durch ihre Normativität (Gebot) oder durch die Art ihrer Durchsetzung aus, ${ }^{562}$ sondern treten in zweifacher Form auf: Liegen ihre Quellen im staatlichen Gesetz, handele es sich um Entscheidungsnormen, die „ausschließlich oder fast ausschließlich dazu dienen, die Beamten anzuweisen, wie sie sich in den überwiesenen Angelegenheiten zu verhalten haben, insbesondere, wie sie Rechtsstreitigkeiten entscheiden sollen" (ebd., H.i.O.). ${ }^{563}$ Die Entschei-

561 Vgl. zum Folgenden insbesondere Vogl 2003: 161ff; zu Ehrlichs Rechtssoziologie siehe Papendorf et al. 2014; Rehbinder 1986; Hertogh 2009 und Rottleuthner 2013.

562 Dementsprechend lehnt Ehrlich die Zwangs- oder Imperativtheorien des Rechts ab, die das Proprium der rechtlichen Norm gegenüber anderen sozialen Normen im eigens dafür zuständigen Rechtsstab bzw. in der Art der Normdurchsetzung sehen. Aus dieser Perspektive könne man letztlich nur die gesetzlichen Entscheidungsnormen erkennen. Ausgeblendet würden automatisch mögliche Gegensätze oder Widersprüche von gesetzlicher Rechtsregel und den Regeln, die das tatsächliche Leben beherrschen (vgl. Ehrlich 1986d [1906]: 90, 94f.). Ehrlichs eigene Abgrenzung der Rechtsnorm von anderen sozialen Normen erfolgt über eine Art Rechtsbewusstsein, was ihn in die Nähe der Historischen Rechtsschule führt: „Es kommt darauf an, ob sie [die Norm, D.S.] in der Gesellschaft die Gefühlstöne auslöst, die der Rechtsnorm eigentümlich sind, die opinio necessitatis der gemeinrechtlichen Juristen." (Ehrlich 1913: 136).

563 Zwar erkennt Ehrlich an, dass nicht alle staatlichen Gesetze Entscheidungsnormen seien, sondern der Gesetzgeber auch unmittelbar organisierend in die Gesellschaft eingreifen könne (z.B. im Bereich der modernen sozialpolitischen Gesetzgebung). Allerdings handele es sich bei ersteren um die dominierende Form des Gesetzes. Ehrlich warnt aber bereits sehr früh auch davor, sich nur der Organisationsnorm zuzuwenden: „So wenig es geraten ist, über den Einfluß der Entscheidungsnormen die Lebensverhältnisse zu übersehen, ebensowenig darf der 
dungsnorm sei aber weder die einzige noch die wichtigste Form des Rechts:

Das Recht ist um noch ganz anderer Zwecke willen da, als wegen der Entscheidung von Rechtsstreitigkeiten, es ist in der Tat die Grundlage der gesellschaftlichen Organisation, es ist, um in der heute schon ein wenig veralteten Sprache Schäffles zu reden, das Knochengerüst des gesellschaftlichen Körpers. (Ebd.)

Aus der Organisation der gesellschaftlichen Einrichtungen ergeben sich ebenfalls Normen, gesellschaftliche Organisationsnormen, ${ }^{564}$ und nach diesen gesellschaftlich geformten bzw. gewachsenen Normen müsse man im Falle einer Lücke im Recht die Rechtstreitigkeiten entscheiden (ebd.: 178f.). Für Ehrlich gilt: Aus den Tatsachen der Anerkennung gewisser Regeln im gesellschaftlichen Zusammenleben erwachsen Rechtsnormen (vgl. Ehrlich 1907: 4), ein Recht, das zwar „noch nicht in Satzungen festgelegt[]“" sei, ,aber doch das Leben beherrscht" (Ehrlich 1967b [1911]: 19).565

Aus dieser Bestimmung folgt zweierlei: zum einen die Notwendigkeit für die Rechtswissenschaft, dieses gesellschaftlich gewachsene und tatsächlich anzutreffende Recht, das „lebende Recht“, in seinem Produktionszusammenhang zu erforschen (vgl. Ehrlich 1967b, 1967c, 1967a). ${ }^{566}$ Zum anderen beruht Recht nach Ehrlich immer auf den gesellschaftlichen Tatsachen der Ordnungsbildung der sozialen Verbände (vgl. Ehrlich 1913:

Einfluß der Entscheidungsnormen auf das Leben unterschätzt werden“ (Ehrlich 1986d [1906]: 95). Es geht also sowohl um die Genese aus den tatsächlichen Verhältnissen als auch um die tatsächliche Wirkung, die sich nicht mit dem Geltungsanspruch der Norm decken muss.

564 Für Ehrlich ist die gesellschaftliche Organisation eine Regel: „Die Organisation ist die Regel, die jedem Einzelnen im Verbände seine Stellung und seine Aufgaben anweist." (Ehrlich 1913: 68).

565 Das „lebende Recht“ sei etwa in Verträgen, in landwirtschaftlichen Pachtverhältnissen bzw. in der Agrarverfassung, in tatsächlich gelebten Familienordnungen, in neuen Einrichtungen des Handels, insbesondere an der Börse, in der Organisation der Gütererzeugung in Trusts und Kartellen, in neuen Verkehrserrungenschaften und in Erfindungen enthalten (vgl. etwa Ehrlich 1967b [1911]: 14ff.; 1913: 5).

566 Es geht dabei also - wie er in seinem Vortrag „Die Tatsachen des Gewohnheitsrechts“ darlegt - um die Frage, „wie tatsächliche Beziehungen zu Rechten und Rechtsverhältnissen werden" (Ehrlich 1907: 9). Mit seinen entsprechenden Untersuchungen zielt Ehrlich darauf, die treibenden gesellschaftlichen Kräfte in der Rechtsentstehung und darüber die Rechtsentwicklung herauszuarbeiten (vgl. Ehrlich 1913: 67ff.). 
20ff.), 567 die geistig überformt werden: „Recht ist vor allem eine gesellschaftliche Ordnung" (Ehrlich 1986c [1913/14]: 186), und in dieser sei die „Werkstätte des Rechts“ zu suchen (Ehrlich 1913: 68). Daher sei die

Jurisprudenz dieser Art [...] in der Tat eine Morphologie der menschlichen Gesellschaft. Es ist unmöglich, das Recht zu lehren, ohne zugleich ein Bild der Gesellschaft zu geben, für die es gelten soll. Jetzt ist auch klar, warum die Jurisprudenz nicht ins Gesetz gehört. Das Gesetz kann eben nicht Morphologie sein. Wenn sie ins Gesetz aufgenommen ist, wird sie sofort etwas anderes: aus einer Darstellung dessen, was ist, eine Vorschrift darüber, was sein soll. (Ehrlich 1986d [1906]: 94)

Die wissenschaftliche Grundlage der Jurisprudenz, die das „Recht als gesellschaftliche[] Erscheinung" (ebd.: 100) untersuche, könne weder die rein juristische noch die historisch-juristische Betrachtung liefern. Diese erwiesen sich als „einseitig“, da sie nur dem Gesetz zugewandt seien - „Einseitigkeit und Wissenschaftlichkeit sind aber Gegensätze.“ (Ebd.: 99; s.a. 1913: 16f.) Wolle man eine Wissenschaft des Rechts betreiben, so müsse man sie als Soziologie betreiben. Denn nur die Soziologie könne streng wissenschaftlich eine Morphologie der menschlichen Gesellschaft und der in ihr wirkenden Kräfte erarbeiten.

,Soziologie' versteht Ehrlich dabei im Sinne von August Comte als Gesamtheit der theoretischen (und nicht der praktischen) Gesellschaftswissenschaften (vgl. Ehrlich 1986d [1906]: 100; 1913: 19): Sie sei eine „Naturlehre von den Gruppenbildungen“" (Ehrlich 1986d [1906]: 100), die es analog zu den Naturwissenschaften mit der Erforschung und Klarstellung reiner positiv gegebener Tatsachen zu tun habe (Ehrlich 1986c [1913/14]: 179). Daher habe sie den Charakter einer "Beobachtungswissenschaft“ (Ehrlich 1913: 382), die rein induktiv verfahre und ursächliche Zusammenhänge darstelle (vgl. ebd.; 1986c [1911]: 179). Die soziologische Rechtswissenschaft bzw. die „Soziologie des Rechts“"568, die als Lehre vom Recht als gesellschaftliche Erscheinung einen Zweig der Soziologie i.S.v.

567 Nicht nur aus der Differenz zwischen staatlichem und gesellschaftlichem „lebenden Recht“, sondern auch aus dieser Rückbindung an die Ordnungsnormen der Verbände folgt, dass Ehrlich sich schon dem Problem des Rechtspluralismus zuwendet (vgl. Nelken 2008; Seinecke 2015: 94ff.; Teubner 1996).

568 Ehrlich spricht von der „Soziologie des Rechts“, was v.a. in der Rezeption zur „Rechtssoziologie“ umgewandelt wurde (s. v.a. Rehbinder 1986). Im Unterschied zu Kantorowicz' Konzeption der Rechtssoziologie versteht Ehrlich die Soziologie des Rechts als Teildisziplin der Soziologie; insofern ist die Verwendung 
Comte bilde (Ehrlich 1986d [1906]: 100; 1913: 19), beschäftige sich mit dem Recht, das ist - also weder mit der Lehre der praktischen Anwendung (vgl. Ehrlich 1986d [1906]: 100) noch mit dem Recht, wie es sein soll (Ehrlich 1986c [1911]: 179; vgl. Ziegert 1979).

Damit verliert die Jurisprudenz bei Ehrlich jedoch nicht ihren Anwendungsbezug. Auch er bestimmt sie als „praktische Disziplin“ (Ehrlich 1986d [1906]: 100). Allerdings trennt er - mithilfe der Idee des wissenschaftlichen Stufenbaus von Comte - streng zwischen den Wissenschaften, die reine Erkenntnis liefern, und den praktischen Disziplinen, die die Ergebnisse der Forschung für die praktischen Zwecke verwerten (ebd.). ${ }^{569}$ Letzteres gelte für die Jurisprudenz: Sie sei die „kunstgerechte Verwertung der Ergebnisse wissenschaftlicher Arbeit“ (ebd.: 102) der Soziologie des Rechts, und in dieser kunstgerechten Verwertung bestehe ihr Proprium gegenüber der Wissenschaft. Indem die Jurisprudenz als rein praktische Disziplin ihren gesellschaftswissenschaftlichen Inhalt an die Soziologie abgebe, „erobert sie sich neu ihr ureigenstes Gebiet“ (ebd.: 103) ${ }^{570}$ - allerdings um den Preis, nach Ehrlich keine Wissenschaft zu sein. ${ }^{571}$ Daher bildet die Soziologie des Rechts als Teilgebiet der Soziologie die „wissenschaftliche Grundlage“ der Jurisprudenz (Ehrlich 1986c [1913/14]: 194; 1913: 15), ja letztlich die einzige Möglichkeit der wissenschaftlichen

der Soziologie an erster Stelle in der Namensgebung konsequent. Ehrlich sieht insbesondere Montesquieu (vgl. Ehrlich 1986c [1913/14]: 180; Ehrlich 1986b), aber letztlich auch die Historische Rechtsschule mit ihrer Rechtsentstehungslehre als Vorläufer einer solchen Soziologie des Rechts an (vgl. Ehrlich 1986c [1913/14]: 193).

$569 \mathrm{Zu}$ einem ähnlichen Ergebnis kommt der Kieler Rechtsprofessor Theodor Niemeyer: Er sieht die wissenschaftliche Grundlage der Rechtswissenschaft in der Soziologie, weil die Soziologie die höchste aller Wissenschaften sei (vgl. Niemeyer in Kohler et al. 1910: 205).

570 Auf diesem „ureigensten Gebiet“ spielt dann auch die Interessenabwägung eine zentrale Rolle. Genau deshalb könne man sie nicht als logischen Subsumtionsschluss aus der gesetzlichen Rechtsordnung verstehen (vgl. Ehrlich 1966: 299 [1925]), sie sei vielmehr "freirechtliche Interessenabwägungsjurisprudenz“ (Vogl: 328, 260ff.), die im richterlichen Urteil die gesetzgeberische Interessenabwägung verwirkliche oder aber vom Gesetzgeber unabgewägte Interessen mit Blick auf die gesellschaftliche Interessenlage ersatzweise abwäge (vgl. Ehrlich 1966: 310 [1925]: 310, 184ff.).

571 Erst diese Abgrenzung ermögliche also die wissenschaftliche Handhabung des Rechts: „Mit dieser Scheidung ist aber die selbständige Wissenschaft vom Rechte begründet, die nicht praktischen Zwecken dienen will, sondern der reinen Erkenntnis, die nicht von Worten handelt, sondern von Tatsachen.“ (Ehrlich 1913: 1). 
Handhabung des Rechts. Demgegenüber seien Gesetzgebung, Jurisprudenz und Rechtspflege nicht selbst wissenschaftlich, sondern lediglich ,angewandte Gesellschaftswissenschaft" (Ehrlich 1917: 434), die die soziologisch ermittelte Kenntnis der in der Gesellschaft wirkenden Kräfte voraussetze. Die „Logik der praktischen Jurisprudenz, als einer Kunstlehre (im Gegensatz zur theoretischen Wissenschaft des Rechts)" sei daher - wie die Logik der Maschinenbaukunde - die „Logik des praktischen Handelns des Juristen“ (ebd.: 125f.). Letztlich sei sie reine Technik:

Mit der wirklichen Logik hat die juristische Logik nichts gemein als den Namen. Sie ist überhaupt keine Logik, sondern eine Technik, denn sie will gar nicht den Prüfstein für die Richtigkeit der Methoden der juristischen Rechtsfindung liefern, sondern ist selbst nur eine solche Methode, die erst auf ihre Richtigkeit geprüft werden muß. (Ebd.: 423)

Anders als Kornfeld möchte Ehrlich nicht die dogmatische Ebene, die der Jurisprudenz eigene Sphäre, durch die Soziologie ersetzen. ${ }^{572}$ Recht sei nicht nur Regelung des Zusammenlebens, sondern enthalte ebenso Entscheidungsnormen, die im Einzelfall über eine „Interessenabwägung“ normative Entscheidungen und daher eine ihnen eigene Behandlung verlangten (vgl. Vogl 2003: 260ff.). Eine solche Entscheidung sei aber nicht aus den dogmatischen Begriffen deduktiv herleitbar:

Die Prüfung [der Richtigkeit der Methode, D.S.] hat ergeben, daß das Ziel, das die gegenwärtig herrschende juristische Technik angeblich verfolgt, jede Entscheidung dem Gesetz zu entnehmen, ihr vollständig unfaßbar ist, das Ziel, das sie allenfalls erreichen kann, eine Entscheidung ohne richterliche Interessenabwägung, wichtige gesellschaftliche Interessen schädigt, und daß das ihr zuweilen vorschwebende Ziel, das wirklich anstrebenswert wäre, eine aus richtiger Interessenabwägung hervorgegangene Entscheidung zu finden, ihr nur auf einem weiten, unnützen, zwecklosen Umwege zugänglich ist. (Ehrlich 1917: 423)

Ehrlichs Ziel ist demgegenüber, die unumgängliche und notwendige Entscheidung im Rechtsurteil über die Soziologie des Rechts wissenschaftlich zu fundieren. Denn: „Eine gerechte richterliche Entscheidung nennen wir eine solche, die die im Streite befangenen Interessen richtig würdigt, die Interessen fördert, die gesellschaftlichen Schutz verdienen, und andre

572 Allerdings fallen der soziologischen Rechtswissenschaft implizite Aufgaben in der juristischen Begriffsbildung zu (Vogl 2003: 349). 
wichtige Interessen so wenig als möglich schädigt.“ (Ebd.: 433) Das aber setze die Kenntnis der Gesellschaft und der in ihr wirkenden Kräfte voraus.

\subsection{Ergänzung der Rechtswissenschaft durch die Soziologie}

Einem solchen wissenschaftsklassifikatorischen Stufenbau, der die Jurisprudenz außerhalb der Wissenschaften ansiedelt oder allenfalls als angewandte Gesellschaftswissenschaft bestimmt, widersprechen jedoch selbst Befürworter der Hinwendung der Rechtswissenschaft zur Soziologie - und zwar mit Verweis auf den eigenständigen Charakter der Rechtswissenschaft als wissenschaftliche Disziplin.

Die Rechtswissenschaft ist für Karl Georg Wurzel unzweifelhaft eine Sozialwissenschaft. In historischer Perspektive sei sie sogar „die erste Sozialwissenschaft“. Denn der „Richter und der Gesetzgeber waren die ersten, welche sich bewußte Rechenschaft über die Grundsätze geben mußten, die das Zusammenleben des Menschen beherrschen“ (Wurzel 1904: 1). Recht wird aus dieser Perspektive - wie bei Jhering - als gesellschaftlich notwendiges Regelset angesehen, als „Inbegriff der ins Bewußtsein tretenden notwendigen Normen des menschlichen Verhaltens" (ebd.). Recht sei daher kein „nacktes Gebot“, sondern ein „gesellschaftliches Phänomen“ (ebd.: 102).

Aus dieser Bestimmung folgt für Wurzel zwar die Notwendigkeit der rechtswissenschaftlichen Integration der Erkenntnisfortschritte der Sozialwissenschaften, gerade auch angesichts der sich ausdifferenzierenden Soziologie als allgemeinste Wissenschaft dieser Art (ebd.: 2, 100). Allerdings könne und dürfe eine solche soziologische Perspektive die eigentliche Jurisprudenz nicht verdrängen. Denn diese arbeite normativ und sie orientiere sich an normativen Postulaten (Idealen) wie Unparteilichkeit und Rechtssicherheit (ohne diese aber tatsächlich verwirklichen zu können, vgl. ebd.: 7ff.) bzw. arbeite im Rahmen der Auslegung mit dem teleologischen Grund des Gesetzes, um (scheinlogische) Analogieschlüsse herstellen zu können (ebd.: 23ff.). Die Soziologie arbeite demgegenüber jedoch explikativ (ebd.: 100).

Damit stellt sich die Frage, in welcher Beziehung die beiden Wissenschaften stehen. Die Ergebnisse der soziologischen Forschung können den Unsicherheiten in Bezug auf die Verwirklichung der Postulate und der Auslegung entgegenwirken. Aufgrund der Verschiedenheit der Perspektiven befruchteten sich Soziologie und Rechtswissenschaft allerdings nur indirekt, was Wurzel unter den Begriff der „Projektion“ fasst (vgl. ebd.: 100, 43, 60ff.). Seine „soziologische[] Jurisprudenz“ (ebd.: 102) geht von einem 
gleichberechtigten Nebeneinander von soziologischer und juristischer Forschung und Methoden aus, wobei erstere die Rechtswissenschaft notwendigerweise ergänze. Dies trage v.a. dazu bei, das richterliche Urteil an die Dynamik der gesellschaftlichen Tatsachen zurückzubinden (ebd.: 98ff.).

Auch Hugo Sinzheimer will keineswegs die juristisch-dogmatische durch eine soziologische Methode ersetzen. Denn das technische Moment der rechtsdogmatischen Arbeit habe einen unverzichtbaren Nutzen: Ihrem „klassische Ideal“ folgend wird die Rechtsordnung gedacht als Masse von Rechtsvorschriften, die über Begriffe in ein widerspruchsfreies, vollkommenes System vereinheitlicht werden. Dadurch werde der Stoff geistig beherrschbar gemacht. Als "praktische" Wissenschaft (Sinzheimer 1976c [1909]: 5) leiste rechtsdogmatische Arbeit notwendige Vorarbeit für Rechtsprechung und Gesetzgebung. Daher sei sie „ein notwendiges Ideal, und der dogmatischen Methode wird die Rechtswissenschaft nie entraten können“ (ebd.).

Das Problem bestehe jedoch darin, dass sich das Recht nicht mit der Rechtsordnung im Gesetz decke: Weder sei alles geltende Recht wirksam, noch alles wirksame Recht ausgesprochen (ebd.) Neben der Rechtsordnung komme der Rechtswirklichkeit eine selbständige Bedeutung zu - ein Umstand, der sich insbesondere im Privatrecht zeige, da hier durch Verträge beständig neue Rechtsverhältnisse geschaffen würden. ${ }^{573}$ An dieser Stelle kommt die soziologische Methode ins Spiel: „Daraus folgt die Notwendigkeit einer Methode, die sich die Erkenntnis der Rechtswirklichkeit zur besonderen Aufgabe macht. Diese Methode ist die soziologische." (Ebd.: 10, H.i.O.) Sie ist es, die Aufschluss über die Rechtswirklichkeit zu geben und dadurch die Anbindung der Rechtswissenschaft an ,das Leben' zu gewährleisten vermag (vgl. ebd.: 3 ).

Anders als Fuchs, Gmelin, Kornfeld, Wurzel oder Spiegel nimmt Sinzheimer aber eine Beschränkung der soziologischen Methode in der Privatrechtswissenschaft vor: Sie beziehe sich nicht auf die gesellschaftlichen Lebensbeziehungen an und für sich, die - wie Sinzheimer mit Verweis auf Stammler feststellt - in ihrer Eigenart immer von menschlich gesetzten Regeln bestimmt seien, sondern untersuche nur diejenigen, „deren Form

573 Sinzheimer verdeutlicht diesen allgemeinen Gedanken durch Beispiele aus dem Arbeitsvertragsrecht, v.a. am neuartigen Phänomen des Arbeitskollektivvertrags. Zur Bedeutung Sinzheimers für die Entwicklung des deutschen Arbeitsrechts vgl. Blanke 2005; Becker 2005: $217 \mathrm{ff}$; Weiss 2014. 
sich durch Rechtsregeln bestimmt“ (ebd.: 11). ${ }^{574}$ Hinsichtlich des Gegenstandes der soziologischen Methode sei also immer eine „Vorentscheidung“ nötig, „ob nämlich die betreffende gesellschaftliche Beziehung überhaupt rechtliche Bedeutung hat" (ebd.). Insofern unterscheide sich die ,soziologische Methode in der Privatrechtswissenschaft" von der Soziologie, da der spezifisch juristische Gesichtspunkt auf die Untersuchung der Lebensverhältnisse als ,wirkliches Rechtsleben“ angewendet werde. Die soziologische Methode ist also nicht wie bei Ehrlich Teil der Soziologe, sondern an die Rechtswissenschaft gebunden.

Soziologische und dogmatische Methode stehen bei Sinzheimer daher nicht in einem Konkurrenzverhältnis, sondern durchdringen sich gegenseitig: Die soziologische Methode hänge in erheblichem Maße von der Rechtsdogmatik ab, ließen sich doch rechtlich relevante Tatbestände und Rechtsdarlegung nicht ohne die Ergebnisse der dogmatischen Methode ermitteln (ebd.: 19). Man könne sie nur vor dem Hintergrund der Angabe des Inhalts der Rechtsordnung betreiben. Letztlich handele es sich auch nicht um eine soziologische, sondern um eine juristische Perspektive:

Es ergibt sich aber auch weiter aus jener Erkenntnis, daß alle gesellschaftlichen Lebensbeziehungen, die Rechtsregeln unterworfen sind, der ausschließlich rechtswissenschaftlichen Betrachtung zugänglich sind. Weil diese gesellschaftlichen Lebensbeziehungen in ihrem Wesen mitbestimmt sind durch rechtliche Regeln, können wir sie nicht nur vom volkswirtschaftlichen, soziologischen, politischen Gesichtspunkt aus betrachten, sondern auch von dem rechtswissenschaftlichen. In dieser Hervorhebung des rechtlichen Gesichtspunktes bei der Betrachtung der gesellschaftlichen Lebensbeziehungen, in dieser Behandlung der Gesellschaftsformen als Rechtsformen, liegt die Eigenart der Aufgabe, die der Soziologischen Methode in der Privatrechtswissenschaft gestellt ist. (Ebd. 11, H.i.O.) $)^{575}$

574 Der Rekurs auf Stammler ist für Sinzheimer zentral, gilt er ihm doch als Gewährsmann für die Sicht auf das Recht als menschlich gesetzte Regelungen zum Zweck der Ordnung des sozialen Lebens: Das Recht sei „soziale Technik“ (Sinzheimer 1914/15: 381). Dadurch rückt er die Ordnungsfunktion des Rechts in den Vordergrund, die eben eine solche Zweckordnung sei. Auch Sinzheimer setzt also den Zweck zentral (vgl. Blanke 2005: 28f. m.w.N.). V.a. schließt er sich der gesellschaftsfunktionalen Zweckbetrachtung an, was ihm den Rekurs auf Karners/Renners Untersuchung über die „soziale Funktion der Rechtsinstitute“ (1904) ermöglicht.

$575 \mathrm{Zu}$ Sinzheimers Entwicklung der Idee der „soziologischen Methode in der Privatrechtswissenschaft" hin zu einer eigenständigen Rechtssoziologie in Form ei- 
Auf der anderen Seite sei die soziologische Methode für die Dogmatik „eine wertvolle Ergänzung“ (ebd.: 19), werde letztere doch durch die Anbindung an die Tatsachen des Lebens gleichsam dynamisiert. Erst die soziologische Methode vermittele dem Juristen eine volle Anschauung des Rechtslebens, indem sie die Rechtswirklichkeit auch jenseits der Rechtsordnung in den Blick rücke: „Die soziologische Methode ergreift nur ein Forschungsgebiet, welches von der dogmatischen Methode nicht in Angriff genommen werden kann" (ebd.: 10). ${ }^{576}$ Vor allem aber garantiere sie die notwendige Anbindung an das Leben, da einen die soziologische Methode davor bewahre, „das Recht einer Zeit nur aus ihrer Rechtsordnung zu erschließen, der die Rechtswirklichkeit widersprechen kann“ (ebd.: 21; s.a. 1976d [1922]).577 Gerade hierin liege das Irritationspotential der Rechtswirklichkeit für die Rechtsdogmatik, die dazu gezwungen sei, auf solche u.U. fundamentalen Herausforderungen - etwa durch die Aussonderung des Arbeitsrechts aus dem Privatrecht - zu reagieren (vgl. Rottleuthner 1986: 234f.).

Darüber hinaus habe die soziologische Methode in der Privatrechtswissenschaft eine besondere Bedeutung für die praktische Seite der Rechtswissenschaft, d.h. für die Rechtsprechung (und letztlich auch für die Gesetzgebung). Da das richterlichen Urteil kein rein logischer Subsumtionsschluss sei, sondern „in der Regel ein soziales, wirtschaftliches, ethisches Werturteil mitspielt", komme der soziologischen Methode die Aufgabe zu, „diese Werturteile von Willkür und Zufälligkeit zu reinigen und sie, soweit dies möglich ist, auf objektive Grundlage zu stellen“ (Sinzheimer 1976c [1909]:

nes „idealen Realismus“ - u.a. in Auseinandersetzung mit Scheler und Marx vgl. Seifert 2015; Blanke 2005: 28f., jeweils m.N.

576 Also gilt: „Beide Methoden schließen sich deshalb nicht aus, sondern sie streben, jede auf ihre Art, dem gemeinschaftlichen Ziele zu: den Rechtszustand eines Volkes unter der Herrschaft einer gegebenen Rechtsordnung zu erkennen.“ (Sinzheimer 1976c [1909]: 10).

577 Die Rechtswirklichkeit lässt sich nach Sinzheimer in zwei Schritten ermitteln: zunächst über die Tatbestandsermittlung, d.h. die Rechtsbeziehungen in ihren tatsächlichen Lebenserscheinungen; dann über die Ermittlung der Rechtsregeln, die auf diese Tatbestände angewendet werden. Bestehen diese nicht in der Anwendung existierender Rechtssätze oder -begriffe, würde mittels der soziologischen Methode neues Gewohnheitsrecht bzw. die von den Parteien tatsächlich gewollten Rechtsfolgen ermittelt. Letzteres könne sich aus dem klar artikulierten Willen ergeben, ansonsten aber aus der Interessenlage, die sich über die Entwicklung der gesellschaftlichen Lage und über Wertvorstellungen ermitteln lassen (Sinzheimer 1976c [1909]: 18f.). Sinzheimer hat damit die Untersuchung der tatsächlichen Rechtsgefühle und Rechtsanschauungen im Blick, die noch kein überparteilich existentes Gewohnheitsrecht darstellen. 
21). Der Richter entscheide dann nicht mehr ausgehend von „seiner bloßen zufälligen Lebenserfahrung“, sondern gehe bei der Auslegung von objektiven Tatsachen der Rechtswirklichkeit aus (ebd.). ${ }^{578}$

Schließlich folge aus der Integration der soziologischen Methode in die Privatrechtswissenschaft ein Wandel der Privatrechtswissenschaft selbst, da sie dadurch einen Schritt hin zu Positivismus und Entwicklungsdenken mache, wie dies bereits in den übrigen Sozialwissenschaften stattgefunden habe. Denn als Gegenstand der Rechtswissenschaft verliere die Rechtswirklichkeit „den Charakter des Unabänderlichen und Feststehenden; er wird beweglich und veränderlich. Der Entwicklungsgedanke dringt in die Betrachtung ein." (Ebd.: 22) Zugleich sei der Blick nicht auf das nach dem Gesetz geltende, sondern das tatsächlich wirksame Recht gerichtet. Das bedeute einen Übergang zum Positivismus (ebd.). Sinzheimer will also - wie Wurzel - die Rechtswissenschaft an die Entwicklungen in den Wissenschaften rückbinden, für die die sich konsolidierende Soziologie ein Beispiel ist - und zugleich diejenige Wissenschaft, an der man sich trotz andersgelagerter Perspektive auf das Recht orientieren müsse. Sei dies der Fall, dann werde die Rechtswissenschaft zugleich ihrer sozialpolitischen Aufgabe gerecht, nämlich der „Formung des sozialen Lebens“ (ebd.: 23).579

Wurzel und Sinzheimer sehen in der Hinwendung zur Soziologie bzw. in der Anwendung soziologischer Methoden im Privatrecht eine notwendige Ergänzung der Rechtswissenschaft, die jedoch weder die Dogmatik

578 Während Wurzel, der diese normative Form der rechtlichen Entscheidung herausarbeitet, daraus Schlüsse für den generell normativen Charakter der Rechtswissenschaft zieht, begrenzt Sinzheimer im Jahr 1909 das Problem der Normativität im Recht noch auf die Rechtsanwendung und rückt auf der Ebene der Rechtsdogmatik, die eigentlich wissenschaftliche Arbeit mit dem Recht, das technische Moment in den Vordergrund. Allerdings betont auch er bereits im Jahr 1914, dass die Wertung in der Jurisprudenz unumgänglich und sie daher als "geborene Wertwissenschaft" zu bezeichnen sei (Sinzheimer 1914/15: 378). Auch für Sinzheimer steht also das Problem der Verhältnisbestimmung von soziologisch ermittelten Tatsachen und der Normativität des Rechts im Mittelpunkt der Überlegungen.

579 Dank der soziologischen Methode könne man nach Sinzheimer nicht nur die sozialpolitischen Aufgaben der Rechtswissenschaft erkennen, sondern diese zugleich im Rahmen der Gestaltung des sozialen Lebens auf eine wissenschaftliche Grundlage stellen. Aufgrund dieser Annahme liegt nach Rottleuthner bei Sinzheimer der Schwerpunkt nicht auf der Entwicklung einer methodischen Hilfestellung für die Rechtsanwendung, sondern auf der Rechtsgestaltung, und hier insbesondere auf der legislativen Schaffung neuen Rechts - also weniger „soziologische Methode“ als „soziale Jurisprudenz“ (Rottleuthner 1986: 235; s.a. Seifert 2015: 421f.). 
verdrängt noch ihr den Wissenschaftscharakter abspricht. Für beide bewirkt diese Hinwendung die Anbindung der Rechtswissenschaft an das tatsächliche Leben. Und für beide ermöglicht sie eine wissenschaftliche Fundierung der unumgehbaren Wertungen im richterlichen Urteil, ohne aber diese Wertungen obsolet zu machen. ${ }^{580}$ Das zentrale Problem besteht also in der Frage nach dem Verhältnis von Tatsachen und Normativität des Rechts und im Recht - ein Problem, das, wie Sinzheimer betont, in Analogie zur Werturteilsdebatte in der Nationalökonomie steht (Sinzheimer 1914/15: 379).

Man hat es dabei mit einer innerjuristischen Problemlage zu tun, die bei Sinzheimer in der Begrenzung des Gegenstandes der soziologischen Methode durch die Rechtswissenschaft seinen Ausdruck findet: Die „soziologische Methode in der Privatrechtswissenschaft" ist eine Methode der Juristen, die sich ohne juristische Kenntnisse nicht betreiben lässt. Es geht also um Tatsachen, die für das Recht relevant sind. Genau diesem Gedanken gibt Arthur Nußbaum ein Jahr nach Erscheinen der Grundlegung der Soziologie des Rechts von Ehrlich einen prominenten Namen: „Die in die Jurisprudenz gehörigen Tatsachen kennzeichnen sich vielmehr durch ihre spezifisch juristische Färbung; will man sie mit einem Schlagwort bezeichnen, so wird dafür vielleicht der Ausdruck Rechtstatsachen gewählt werden können." (Nußbaum 1914: 7f. $)^{581}$ Auch Nußbaum gewährt der Rechtsdogmatik Vorrang vor den Tatsachenerkenntnissen, erfolge doch die Auswahl solcher Tatsachen „lediglich nach den Bedürfnissen der Rechtslehre selbst, also nach spezifisch juristischen Gesichtspunkten“ (ebd.: 6).

Nußbaums Eintreten für eine juristisch bestimmte Rechtstatsachenforschung erfolgt vor dem Hintergrund der Definition der Rechtswissenschaft als eine Wissenschaft, die den „rein praktischen Zweck“ habe, der Rechtsanwendung zu dienen (Nußbaum 1906: 16). Aus diesem Grund habe sie es nur mit Normen im normativen Sinne zu tun: Sie betrachte - wie Nußbaum schon im Jahr 1906 feststellt - den Rechtssatz „nur als Norm, nicht als kausal bedingte Tatsache des geistig-sozialen Lebens“ (ebd.: 4). Da Normen niemals Naturgesetze seien, könnten „die Methoden der naturwissenschaftlichen Forschungen, überhaupt aller Ursachenforschung, [...]

580 Letztlich wird nicht ganz klar, inwieweit hier das Sollen aus dem Sein folgen soll - auch wenn die Sollensentscheidung auf der Ermittlung des Seins aufbaut. Geschieht dies bei Wurzel im Rahmen der Projektionen, so betont Sinzheimer eher die Rolle im Rahmen der Tatbestandsermittlung (vgl. Sinzheimer 1976c [1909]: 20f.).

581 Zum Problem der Begriffsbestimmung der Rechtstatsachen vgl. Rehbinder 1995: 43ff. 
nicht die Methoden der Jurisprudenz sein“ (Nußbaum 1914: 5f.). Aber auch die Kulturwissenschaft (nach Rickert) scheide als Vorlage aus, da sie versuche, „auf induktivem Wege die Erscheinungen miteinander [zu] verknüpfen" (Nußbaum 1906: 10). Ganz anders verfahre jedoch die Jurisprudenz in ihrer „methodologischen Sonderstellung“:

Ihr Gegenstand ist nicht die Wirklichkeit, nicht das Sein, sondern das Sollen; die Frage nach der kausalen Verknüpfung kann hier überhaupt nicht entstehen. Das Recht als ursächlich bedingte Tatsache des geistigen und sozialen Lebens zu betrachten fällt, wie wir gesehen haben, nicht der Jurisprudenz, sondern andern Disziplinen anheim. Die juristische Theorie kann nichts weiter wollen als den Inhalt des ihr gegebenen positiven Rechts näher bestimmen. Dies geschieht und kann nur geschehen, wie dargelegt, auf deduktivem Wege, nämlich durch Umformung eines an sich schon gegebenen, aber unvollkommen gefaßten Denkinhaltes. (Ebd.)

Obwohl Nußbaum ,juristische Denkformen“ damit durch das herkömmliche Methodenarsenal der Subsumtion, Auslegung und Konstruktion gekennzeichnet sieht und darin die "wichtigsten Hebel aller Rechtsfindung“ erkennt (Nußbaum 1914: 6), sieht jedoch auch er das Manko des mangelnden Lebensbezugs der Privatrechtswissenschaft. Um dieses zu überwinden, könne man jedoch nicht auf eine letztlich den methodologischen Grundsätzen des juristischen Denkens widersprechende „soziologische Jurisprudenz" (womit er Fuchs und Ehrlich meint; s. a. Nußbaum 1908) rekurrieren, sondern müsse die spezifische „Technik“ der juristischen Denkform (vgl. Nußbaum 1906: 16) durch Tatsachenkenntnis ergänzen:

Was man nicht genügend beherzigt hat, ist nur, daß daneben in die Jurisprudenz und Lehre auch ein bestimmter Komplex von induktiv zu erforschenden Tatsachen hineingehört. Es sind dies, wie wir zunächst ganz allgemein sagen können, diejenigen Tatsachen, deren Kenntnis für ein volles Verständnis und eine sachgemäße Anwendung der Normen erforderlich ist. (Nußbaum 1914: 6; H.i.O.)

Das spezifisch juristische Denken werde durch diese Tatsachenerkenntnisse nicht geändert, auch wenn der Lehrstoff durch Heranziehung der Rechtstatsachen belebt werde „sowie fruchtbare Problemstellungen für die wissenschaftliche Einzelarbeit zu gewinnen" seien (ebd.: 8). Insofern stelle die Forderung nach der Rechtstatsachenforschung auch „kaum noch etwas wesentlich Neues" dar (ebd.). Schon damals sei es offensichtlich ein Gemeinplatz gewesen, den „Zweck im Recht“ zu berücksichtigen (vgl. Nußbaum 1906: 9) und im Lehrvortrag die tatsächlichen Verhältnisse heranzu- 
ziehen. Am „Wesen“ der Jurisprudenz als „die den Inhalt des objektiven Rechts entwickelnde“, d.h. als „dogmatische Jurisprudenz“ (ebd.: 5) in ihrer spezifischen Technizität, ändere dies jedoch nichts. ${ }^{582}$

Nußbaum zielt darauf, die Autonomie des Rechts gegenüber der Soziologie (und anderen tatsachenorientierten Wissenschaften) zu sichern, ohne dabei eine induktiv ermittelte Erkenntnis des Rechtslebens (Zwecke des Rechts, Wirkung, Prozesstypen, Anwendungshäufigkeiten etc.) zu vernachlässigen. Disziplinen, die solche Erkenntnisse lieferten, käme aber allenfalls der Status einer „Hilfsdisziplin“ zu (ebd.: 5). Aufgrund der methodologischen Wesensdifferenz zur Jurisprudenz können sie nach Nußbaum weder direkte (wie bei Kornfeld, Ehrlich, aber auch Fuchs, Gmelin und Wüstendörfer) noch indirekte methodische Auswirkungen (wie letztlich bei Wurzel und Sinzheimer) zeitigen. Nußbaum will die Jurisprudenz durch die auf die Rechtstatsachen gerichteten Einzelforschungen ergänzen, wie er und weitere Autoren sie in der Folge betreiben werden. ${ }^{583}$ Diese Ergänzung sei aber letztlich Sache der Juristen, die die Bestimmungshoheit darüber hätten, welche Tatsachen relevant seien. ${ }^{584}$

\subsection{Rechtssoziologie als „Zwischenwissenschaft"}

Kantorowicz geht es wie Nußbaum in der Frage der Verhältnisbestimmung von Soziologie und Jurisprudenz nicht um die Soziologie an sich, sondern um den gegenstandsgebundenen Teil der Soziologie, der sich mit dem Rechts befasst, kurz: die Rechtssoziologie. Ausgangspunkt bildet nun nicht der Methodendualismus (Jellinek), sondern eine Dreiteilung der Wissenschaften. ${ }^{585}$

582 Insofern ist nicht verwunderlich, dass Nußbaum von der „Lückenlosigkeit“ des Rechts ausgeht, derzufolge über theoretisch-systematische Arbeit auch für neuartige Konstellationen Lösungen im positiven Recht gefunden werden können: „Das positive Recht ist nun erschöpfend in dem Sinn, daß aus ihm für jeden möglichen Rechtsfall eine Entscheidung abgeleitet werden kann, daß mithin jeder mögliche Fall eine Norm findet, unter welche er gehört." (Nußbaum 1906: 6) Allerdings umfasst sein Begriff des positiven Rechts auch außergesetzliches Recht wie etwa das Gewohnheitsrecht (vgl. ebd.).

583 Vgl. hierzu die Literaturangaben bei Röhl 1974: 6f.

584 Zur Diskussion darüber, ob die Rechtstatsachenforschung damit ausschließlich eine ,juristische Disziplin“ sei, vgl. Rehbinder 1995: 36ff. m.w.N.

585 Bei Kantorowicz ist eine Entwicklung hin zu dieser Dreiteilung erkennbar (vgl. Saliger 2007: 93ff.). So vertritt er in seiner Kritik des Methodendualismus (nach etwa Jellinek) im Jahr 1906 noch die Position einer Verbindung der beiden Kul- 
Im Anschluss an Rickerts Wissenschaftstheorie bestimmt Kantorowicz die Soziologie als eine empirische Kulturwissenschaft mit generalisierender Begriffsbildung (Kantorowicz 1911a: 296). Ihre Gegenstände wähle sie kulturwissenschaftlich aus, d.h. „nach dem Maße ihrer Bedeutung für die Kultur" (Kulturwerte, Kantorowicz 1923: 81). Die Soziologie sei jedoch wie er im Jahr 1923 schreibt - „die systematische und theoretische Wissenschaft von der Wirklichkeit der Gesellschaften“ (ebd.: 75): Als systematische „Wirklichkeitswissenschaft" (ebd.: 80) bilde sie generalisierende Begriffe, als theoretische mag sie zwar Erkenntnisse für praktische Entscheidungen liefern, erfülle aber keine praktischen Zwecke und wertet daher trotz ihres Bezugs auf Kulturwerte selbst nicht. ${ }^{586}$

Die „dogmatische Jurisprudenz“ dagegen, die „Lehre vom Inhalte und System der Rechtsnormen“, steht außerhalb des Rickert'schen Schemas der Unterscheidung von Natur- und Kulturwissenschaften, „da sie, wie wir nach Ueberwindung der alten rationalistischen Rechtswissenschaftstheorie leicht erkennen, nicht - theoretisch - auf Werte beziehend verfährt, sondern - als Normwissenschaft - selber wertet (und zwar stets unter generalisierendem Verfahren)“ (Kantorowicz 1911a: 297). ${ }^{587}$ Die Spezifik des juristischen Denkens bestehe darin, dass sie „nicht eine kausale, sondern eine teleologische, nicht eine empirisch-soziologische, sondern eben eine juristisch-normative Operation darstellt, nicht nach dem Warum, sondern nach dem Wozu fragt“ (ebd.: 304).

turwissenschaften Jurisprudenz und Soziologie: Da Sollen Wollen sei, gebe es noch keine „prinzipielle[] wissenschaftstheoretische[] Unterscheidung“ zwischen den Disziplinen. Vielmehr gelte: „[E]in Zusammenwirken der Jurisprudenz mit Psychologie einerseits, Sozialwissenschaft andererseits wird daher als zwischen verwandten Wissenschaften von den meisten Vertretern der freirechtlichen Bewegung mit gutem Grund erstrebt." (Kantorowicz 1906: 34) Demgegenüber vertritt er in seinem Vortrag am ersten Soziologentag eine dreigeteilte wissenschaftstheoretische Unterscheidung, die er ausgehend von seiner Kritik am Methodendualismus (vgl. Kantorowicz 1911a: 303) erst in seiner Erinnerungsgabe an Weber in aller Deutlichkeit ausformuliert (vgl. Kantorowicz 1923: 84).

586 Diese Problematik hat Weber insbesondere in seinen Stellungnahmen zur Objektivität der kulturwissenschaftlichen Erkenntnis bzw. zur Werturteilsfreiheit behandelt (s.u. $\mathbb{\$} 8$ ), auf die sich Kantorowicz in seinem Beitrag zu Webers Erinnerungsgabe bezieht.

587 Ihr methodisches Mittel ist dabei, wie er v.a. später ausführt, die Ermittlung des Sinns (vgl. Kantorowicz 1923: 93). Das führt ihn zur Verabschiedung des Kantischen Dualismus von Sein und Sollen zugunsten eines Trialismus, da jeder Gegenstand der Erkenntnis auf drei grundlegend verschiedene Weisen betrachtet werden könne: als Bestandteil der Wirklichkeit (Da-Sein), als objektives Sinngebilde (So-Sein) und als Wert (Sollen-Sein). 
Von Rechtssoziologie spricht Kantorowicz nun dann, „wenn das soziale Leben auf seine Beziehung zu den Rechtsnormen hin untersucht wird" (Kantorowicz 1911a: 276, H.i.O.). Sie ist einerseits Teil der Soziologie und gehört damit zu den empirischen Wissenschaften mit generalisierender Begriffsbildung. Andererseits muss sie sich aufgrund ihres Gegenstandes auf den Kulturwert der Rechtsordnung beziehen:

Der Kulturwert nun, an dem die ganze Jurisprudenz in allen ihren Teilen (Rechtsdogmatik und Rechtssoziologie, Rechtshistorie und Rechtspolitik) orientiert ist, ist [...] die Gesamtheit der von einer bestimmten Rechtsordnung verfolgten Zwecke. An diesem Kulturwert muß sich daher auch die Rechtssoziologie orientieren. (Ebd.: 295)

Dabei ist die Rechtswissenschaft nach Kantorowicz in eminenter Weise auf die Rechtssoziologie angewiesen. Denn die Frage, ob man auf einen nicht gesetzlich geregelten Fall einen Rechtssatz analog anzuwenden habe, könne man nur mit Blick auf den Zweck der Norm klären. Denn schon aus rein rechtstechnischer Sicht gelte: „Nur soweit der Zweck der gleiche bleibt, so weit ,eadem ratio iuris' reiche, so weit gelte die Analogie." (Ebd.: 280) Die „Erforschung eben dieser Zwecke und Bedürfnisse“ müsse und könne aber letztlich nur „auf soziologischem Wege geschehen“ (ebd.: 287). Denn sie sei aus der (durchschnittlichen) Wirkung des Gesetzes im sozialen Leben herzuleiten: „Zweckforschung im Rechtssinn setzt also voraus eine Tätigkeit auf dem Gebiet der Rechtssoziologie [...].“ (Ebd.: 281, H.i.O. ${ }^{588}$ Damit sei offensichtlich, „daß die Soziologie nicht nur gelegentlich herangezogen werden darf, wie dies stets geschah, sondern als die vornehmste Hilfswissenschaft der dogmatischen Jurisprudenz, deren Arbeit [sie, D.S.] Punkt für Punkt vorbereiten und ergänzen muß“ (ebd.: 287, H.i.O.).

Damit überantwortet Kantorowicz also keinesfalls die Rechtswissenschaft der Soziologie. Denn die unerlässliche Hinwendung zur soziologischen Tatsachenforschung ändert für ihn letztlich nichts am Wissenschaftscharakter der Rechtswissenschaft. Im Gegenteil: Gerade die Berücksichtigung des Zwecks bewirke, dass sich nun tatsächlich der normativen Seite des Rechts zugewendet werde. Denn aus der Zweckperspek-

588 Man muss nach Kantorowicz untersuchen „welche Wirkungen im sozialen Leben das zu interpretierende Gesetz, genauer: die Anwendung dieses Gesetzes, im Durchschnitt der Fälle hervorruft oder hervorzurufen geeignet ist. Aus denjenigen unter diesen regelmäßigen Wirkungen, wobei es sich stets um den Schutz irgendwelcher Interessen handeln wird, welche im Sinne des Gesetzes als wertvoll anzusehen sind, müssen die Zwecke des Gesetzes erschlossen werden.“ (Kantorowicz 1911a: 281). 
tive gelte, dass die Jurisprudenz keinesfalls ,wie bisher als Wortwissenschaft $z u$ betreiben ist, ibr Geschäft sich nicht in der Auslegung von feststehenden Wörtern erschöpft, sondern eine Wertwissenschaft ist, im Dienste von Zwecken des sozialen Lebens steht" (ebd.: 286f., H.i.O.). Auch wenn die Rechtssoziologie für Kantorowicz die Anbindung der Rechtswissenschaft an das Leben gewährleistet, widersetzt er sich jeglichen Versuchen der Soziologisierung der Rechtswissenschaft:

Der richtige Weg ist also auch hier der kritische: der sich gleich weit entfernt hält von der alten Buchjurisprudenz, die den Tatsachen des Lebens überhaupt keine Beachtung schenkt, alle Jurisprudenz als totes Rechnen mit starren Begriffen auffaßt, und von modernen Uebertreibungen, die den Charakter der Jurisprudenz als einer Normwissenschaft verkennen. Dogmatik ohne Soziologie ist leer, Soziologie ohne Dogmatik ist blind. (Ebd.: 303)

Oder wissenschaftstheoretisch formuliert: Selbst wenn man sich mittels der Rechtssoziologie auf Werte bezieht, ändert das nach Kantorowicz nichts daran, wie „völlig verfehlt es ist zu meinen, die Jurisprudenz könne je durch Soziologie ersetzt werden“ (ebd.: 297). Denn sie wertet nach wie vor selbst - auch wenn sie sich dafür die rechtssoziologischen Erkenntnisse der theoretischen Beziehung zu Werten zu eigen macht.

Daher liegt für Kantorowicz trotz der Aufwertung der Soziologie im Rahmen der juristischen Arbeit die Kompetenz zur wissenschaftlichen Problemdefinition weiterhin in der Hand der Rechtswissenschaftler: „Die Rechtssoziologie jedenfalls wird [...] fruchtbringend nur von Fachmännern der Jurisprudenz, gewissermaßen im Nebenamt, betrieben werden können." (Ebd.: 278) Nur aus dogmatischer Sicht könne bestimmt werden, welche soziologischen Erkenntnisse für die Rechtswissenschaft von Relevanz seien. Die Rechtssoziologie gehöre zwar zu den „Grenzgebiete[n]“, die „von mindestens zwei Seiten her betreten werden können“ (Kantorowicz 1923: 91). Aber obwohl sie damit bei Kantorowicz eine Art vermittelnde Zwischenwissenschaft zwischen zwei wesensfremden Wissenschaften darstellt, steht sie doch unter der Ägide der Rechtswissenschaft. Sie ist und bleibt juristische Hilfswissenschaft, deren Arbeit von den Juristen und nicht den "Soziologen vom Fach“ zu erledigen sei (Kantorowicz 1911a: 278; s.a. 1923: 93ff.). 


\subsection{Der ,juristische Werturteilstreit“": Soziologie, Norm und Werturteil}

Die Befürworter einer Hinwendung der Rechtswissenschaft zur Soziologie schwanken zwischen einer radikalen Soziologisierung der Rechtswissenschaft (Kornfeld), einer wissenschaftlichen Fundierung der Jurisprudenz als Technik bzw. Kunstlehre in der Soziologie (Ehrlich), einer notwendigen Ergänzung der Rechtswissenschaft durch die Erforschung des Seins mittels der soziologischen Methode (Sinzheimer, Nußbaum) sowie dem Entwurf der Rechtssoziologie als „Zwischenwissenschaft“ zwischen Soziologie als Seinswissenschaft und Rechtswissenschaft als Sollenswissenschaft (Kantorowicz).

Diese Bestimmungsversuche der Rolle der Soziologie für und in der Rechtswissenschaft hängen davon ab, was man unter, Soziologie' versteht. Darüber besteht jedoch keinerlei Einigkeit. Für manche hat es die Soziologie mit der Erforschung und Klarstellung rein positiv gegebener und daher äußerlicher Tatsachen zu tun (vgl. Kornfeld). Sie sei analog der Naturwissenschaften eine „Beobachtungswissenschaft“ bzw. eine „Erfahrungswissenschaft". Dabei verfahre sie rein induktiv-deskriptiv, stelle ursächliche Zusammenhänge dar (vgl. Ehrlich, Fuchs, Gmelin, Spiegel, aber auch Szirtes 1916; im Ergebnis letztlich auch Kelsen, s.u. IV.2) und arbeite explikativ (Wurzel). Und selbst wenn man wie Kornfeld, Spiegel und Wurzel die Definition der Soziologie als Naturwissenschaft mit dem Hinweis auf die Zweckhaftigkeit des Rechts bzw. die Eigenlogik des menschlichen Handelns bestreitet, so hat das nicht zur Folge, dass man einem kausalen Denken in toto abschwören muss. Allerdings zeigen sich die Regeln und Regelmäßigkeiten nicht mehr als kausale Notwendigkeiten und exakte Gesetze, sondern als Erfahrungswerte, die Wahrscheinlichkeiten statuieren (Kornfeld). Letztlich zeichne sich die Soziologie durch ihren entwicklungsgeschichtlichen Ansatz sowie ihrem Positivismus aus (Sinzheimer) - auch wenn daraus nicht unbedingt zu folgern ist, dass die Rechtswissenschaft im engeren Sinne davon betroffen sei (v.a. Nußbaum).

Dem treten diejenigen Rechtswissenschaftler entgegen, die die Soziologie nicht der kausalgesetzlich verfahrenden Naturwissenschaft, sondern ihrem wissenschaftstheoretischen Gegenstück, den Kulturwissenschaften, zuordnen (vgl. Wüstendörfer, Kantorowicz). ${ }^{589}$ Sie sei wertbeziehende

589 Sternberg gehört zu den wenigen Privatrechtswissenschaftlern, die die Soziologie (und darüber die Rechtswissenschaft) in der Dilthey'schen Tradition als Geisteswissenschaft bestimmen - und zwar unter Bezugnahme auf die Abgrenzung vom naturwissenschaftlichen Kausalgesetz, d.h. „ursächlicher Gesetzmäßigkeit“, und menschlichem Zweckgesetz als „teleologische Gesetzmäßigkeit“ (Sternberg 
Seins-Wissenschaft (Wüstendörfer) bzw. systematische und theoretische Wirklichkeitswissenschaft (Kantorowicz), die entweder, als heuristisches Prinzip verstanden, die Wechselbeziehungen zwischen den verschiedenen funktionellen Seiten der Gesellschaft behandle bzw. als Wissenschaft von der Kultur genuin kulturwissenschaftlich verfahre, indem sie Gegenstände nach dem Maß ihrer Bedeutung für die Kultur auswähle.

Den unterschiedlichen Auffassungen über das Wesen der Soziologie entsprechen dabei keine eindeutigen Positionen in den Bestimmungsversuchen der Rolle der Soziologie für die Rechtswissenschaft: So wie eine genuin juristische „soziologische Methode“ sowohl über ein naturwissenschaftliches bzw. kausalwissenschaftliches Verständnis der Soziologie (Fuchs, Gmelin) als auch über eine neukantianisch inspirierte Kulturwertlehre entwickelt wird (Wüstendörfer), so wird mit dem Verweis auf den normativen Charakter der Rechtswissenschaft aus beiden Perspektiven die Wesensfremdheit der Jurisprudenz zur Soziologie festgestellt, und doch (oder gerade deshalb) für eine Hinwendung zur Soziologie plädiert (Ehrlich, Sinzheimer, Nußbaum, Kantorowicz). Aus einer kausalwissenschaftlichen Bestimmung der Soziologie folgt allenfalls die Tendenz, der Rechtswissenschaft im herkömmlichen Sinne die Wissenschaftlichkeit abzusprechen (Kornfeld, Ehrlich), wobei es aber auch hier Vertreter gibt, die die Rechtswissenschaft als anders gelagerte Wissenschaft verstehen (Wurzel, Nußbaum).

Trotz dieser grundlegenden Divergenzen sowohl in Herleitung als auch in Funktionsbestimmung der Soziologie ist allen Positionen gemein, dass sie diese neue Wissenschaft über die Tatsachenorientierung - sei es als Beobachtungs- und Erfahrungswissenschaft, sei es als empirische Kulturwissenschaft - charakterisieren, die sich jenseits einer deduktiv verfahrenden dogmatischen Arbeit der Rechtswissenschaft im herkömmlichen Sinne bewegt. ${ }^{590}$ Das ist das Proprium einer wie auch immer gearteten „soziologischen Rechtswissenschaft", und das ist der Grund, weshalb man sich ihr in der Kritik der Lebensferne der Begriffsjurisprudenz zuwendet.

Dieses Proprium entfaltet sich angesichts einer bestimmten Problemlage: Angesichts der Herkunft der Debatte aus dem juristischen Methoden-

1904: 146). Zu den Verwendungsweisen und Definitionen von Geisteswissenschaft im staatswissenschaftlichen Diskurs siehe die Hinweise unten in \$5.IV.2.1.

$590 \mathrm{Zu}$ diesem Streit über Induktion und Deduktion in den Rechtswissenschaften s. etwa auch Ofner 1913; kritisch zu dieser Abwertung der Deduktion im Recht seitens der Freirechtler und Rechtssoziologen äußert sich der Völkerrechtler Heinrich Rogge 1917/1918. 
streit erweist es sich als notwendig, auf die Frage der juristischen Entscheidung im Urteil zu antworten. Daher wird gerade die Normativität des Rechts (respektive der Rechtsentscheidung) zur eigentlichen Problematisierungsweise, auf das die wie auch immer gefasste Tatsachenorientierung durch die Hinwendung zur Soziologie reagieren muss. Diese soll ermöglichen, eine Tatsachenerkenntnis auf wissenschaftlich gesicherten Weg zu gewinnen und daher das unausweichliche Werturteil im Urteil entweder ganz, teilweise, vorbereitend oder ergänzend auf eine objektive Grundlage zu stellen.

Dabei wird eine Kontinuität mit der überkommenen Rechtswissenschaft gesehen, indem das auf dem Repräsentationsdispositiv aufbauende funktionale Zweckdispositiv strategisch wiederaufgeladen wird: So ist etwa für Kantorowicz oder Ehrlich offensichtlich, dass die Rechtsentstehungslehre der Historischen Rechtsschule als eine soziologische Rechtsentstehungslehre zu behandeln sei. Sie sehen - trotz aller vernichtenden Kritik an der Volksgeistlehre und der Gewohnheitsrechtstheorie (vgl. etwa Kantorowicz 1912b [1911], 1912a; Ehrlich 1913: 11ff.) - in Savigny den Vorläufer der Rechtssoziologie bzw. der Soziologie des Rechts (vgl. Kantorowicz 1923: 95; Ehrlich 1986d [1906]: 101, 1986c [1913/14]: 193). Dass es sich um gesellschaftlich gewachsenes Recht handele, wird als Ausgangspunkt einer soziologischen Untersuchung gesehen. Zugleich wird aber im Diskurs die Zweckorientierung des Rechts zentral gesetzt: Das gilt nicht nur für die Anhänger einer Theorie des Rechts, die es angesichts der Interessenkämpfe in der Gesellschaft über seine gesellschaftliche Konfliktlösungs- und damit Ordnungsfunktion bestimmen (etwa Heck et. al.; aber auch Fuchs, Gmelin, Wüstendörfer, s.o.). Vielmehr gehört es nun für viele $\mathrm{zu}$ einer Selbstverständlichkeit, dass das Recht einen Zweck hat und Rechtserkenntnis nur über Zweckerkenntnis erfolgen kann (vgl. etwa Nußbaum 1906: 9; Kantorowicz 1992 [1911]: 268; Kornfeld 1911: 18; Baumgarten 1929: 16ff.; zu Ehrlich vgl. Vogl 2003: 328ff.).

Wenn trotz solcher Übereinstimmungen mit Blick auf den Zweck des Rechts bzw. im Recht gänzlich unterschiedliche Positionen vertreten werden, so hat dies mit dem zugrunde gelegten Normbegriff zu tun: Auf der einen Seite wird der Charakter der rechtlichen Norm als Regel, Regelmäßigkeit, als allgemeines Gesetz des menschlichen Zusammenlebens respektive als empirisches Gesetz des menschlichen Verhaltens oder als Ordnungsnorm hervorgehoben (etwa Gmelin, Wurzel, Kornfeld, Ehrlich). Davon ausgehend wird der Zweck im Recht als gesellschaftlicher bzw. sozialer Zweck angesehen (etwa Kornfeld, Wüstendörfer, Gmelin). Daher erscheint es möglich, über die Bestimmung des gesellschaftlichen bzw. sozialen Zwecks oder der sozialen Zwecke zu soziologisch fundierten gerechten 
Urteilen zu gelangen, die eine Kongruenz von normativem Urteil und gesellschaftlichen Interessenlagen herbeiführen sollen - sei es über eine kausalwissenschaftlich begründete Gerechtigkeitswissenschaft (etwa Fuchs), über die Synthetisierung von Sein und gesellschaftlichem Sollen im Urteil (Wüstendörfer), über die Fundierung der Sollensentscheidung in der soziologischen Erkenntnis der notwendigen Anpassung an die gesellschaftliche Lage (Ehrlich, aber auch Sternberg 1904) oder aber über die Orientierung der Rechtswissenschaft an den Fortschritten der Wissenschaft insgesamt, wie sie gerade in der sich etablierenden Soziologie ihren Ausdruck finden (Wurzel, Sinzheimer).

Dem wird ein Normbegriff entgegengehalten, der im Zweck eine reine Wertentscheidung sieht, die nicht über irgendeine Kausalität hergeleitet werden könne (etwa Nußbaum, Heck). Die Norm erscheint in diesem Falle als Gebot, Imperativ, Befehl. Zwecke im Recht werden dementsprechend als ein Telos bestimmt, als eine normative Entscheidung bzw. sind normativ zu verstehen. Über seins-tatsächliche Forschung könne man nicht zu Sollensentscheidungen gelangen. Folglich erscheint die Soziologie als etwas anderes als Rechtswissenschaft und könne allenfalls als Ergänzung (Nußbaum), als Hilfsdisziplin (Heck) oder aber in vermittelter Form als Zwischendisziplin (Kantorowicz) angesehen werden.

Vor diesem Hintergrund zeigt sich in den Bestimmungsversuchen der Rolle der Soziologie in der Rechtswissenschaft - wie schon Sinzheimer betont - eine ähnliche Problemlage wie im Werturteilsstreit in der Nationalökonomie, allerdings unter umgekehrten Vorzeichen: Es geht nicht darum, ob und, wenn ja, wie man aus Tatsachenerkenntnissen Werturteile gewinnen könne. Vielmehr ringt man angesichts des unausweichlichen Werturteils im richterlichen Urteil darum, wie man Tatsachenerkenntnisse in die Rechtswissenschaften integrieren kann, um den Lebensbezugs des Rechts zu gewährleisten. Die Umkehrung des Werturteilsstreits besteht darin, dass nicht Werturteile bekämpft bzw. aus der Wissenschaft ausgesondert werden, sondern der Kampf sich gegen den Ausschluss der wertenden Aspekte des Rechts, des Rechts als Normenordnung im normativen Sinne - und damit der normative Charakter der Rechtswissenschaft - richtet. Daher geht es, anders als im ökonomischen Werturteilsstreit, nicht darum, gegen die "Gefahren“, Fehler oder wissenschaftlich nicht haltbaren Positionen einer Nationalökonomie anzuschreiben, die sich als historisch-ethische Wissenschaft begreift. Als Abgrenzungshorizont erscheint vielmehr die radikale Forderung des Ausschlusses der Normativität des Rechts durch die Hinwendung zur Soziologie. Wenn nämlich Kornfeld mit dem Entwurf einer Rechtslehre auf soziologischer Grundlage gegen das „Dogma von dem normativen Wesen des positiven Rechtes" (Kornfeld 1911: 
III) anschreibt, indem er das Recht nicht als Norm, sondern als gesellschaftliche Regelmäßigkeit bestimmt, so entgegnet ihm selbst Ehrlich, dass die Theorie (Soziologie des Rechts) die normative Praxis (Jurisprudenz) nicht verdrängen könne, sondern dass man sie unterscheiden müsse. Wurzel, Sinzheimer, Nußbaum und Kantorowicz halten diesen Ansätzen entgegen, dass die Rechtswissenschaft sehr wohl eine eigenständige Form der Wissenschaft sei, ob als normativ arbeitende „praktische Disziplin“ (Wurzel), als systematisch-dogmatisch verfahrende "praktische Wissenschaft", deren Urteile immer auch auf Werturteilen beruhe und daher als Wertwissenschaft zu qualifizieren sei (Sinzheimer 1914/15: 378), oder ob als Wissenschaft, die rein praktischen Zwecken diene und angesichts ihres Gegenstandes, den Normen im normativen Sinne, eine methodologische Sonderstellung aufweise (Nußbaum) bzw. als Normwissenschaft selber wertet (Kantorowicz). Vor diesem Hintergrund eines unhintergehbaren Bezugs zu Normativität und Wertung in der Rechtswissenschaft lässt sich dann die Rolle der Soziologie bestimmen: Sein und Sollen werden über Projektionen vermittelt (Wurzel), die Jurisprudenz wird durch soziologische Forschung befruchtet (Wurzel, Sinzheimer) bzw. irritiert (Sinzheimer, letztlich auch Nußbaum), und das Werturteil werde in der Folge möglichst weitgehend entsubjektiviert (Sinzheimer, Wurzel). Oder aber es handele sich bei der Soziologie um eine Hilfsdisziplin, die die Jurisprudenz ergänze und Erkenntnisse für das bessere Verständnis der Normen liefere (Nußbaum, Heck), bzw. sei die Rechtssoziologie eine Zwischenwissenschaft, die die Wirklichkeit des sozialen Lebens mit Bezug auf den Kulturwert des Rechtszwecks generalisiere (Kantorowicz).

All diese Ansätze, die ja für eine Hinwendung der Rechtswissenschaft zur Soziologie plädieren, greifen den Versuch einer rein tatsächlichen Fundierung des Rechts an, der in die Verkündung der Möglichkeit einer rein wertfreien Rechtswissenschaft als Soziologie mündet. Widersprochen wird dem Reduktionismus von Normativität auf Faktizität und von Rechtswissenschaft auf bloße empirische Sozialwissenschaft. Im Mittelpunkt der Überlegungen steht daran anschließend die Verhältnisbestimmung von soziologisch ermittelten Tatsachen und der Normativität des Rechts. Daher wird die Normativität auch für die Vertreter soziologischer Forschung in der Rechtswissenschaft zur Problematisierungsweise dieses Verhältnisses. Oder anders formuliert: Nicht die Faktizität, sondern die Normativität des Rechts bzw. des richterlichen Urteils ist das eigentliche Problem, an dem sich mit der Frage nach der Rolle der Soziologie in der Rechtswissenschaft abgearbeitet wird. 


\section{Das Wesen der Rechtswissenschaft}

Kantorowicz' Überlegungen v.a. zum Verhältnis von Rechtswissenschaft und Soziologie im Jahr 1910 verdeutlichen die Eigenart des rechtswissenschaftlichen Diskurses angesichts der Frage der Anbindung an das gesellschaftliche Leben: Nicht die Herleitung der Soziologie über die Auseinandersetzung mit dem Gesellschaftsbegriff steht im Vordergrund, die - wie bei Jhering - an der Bestimmung des epistemischen Dings, Gesellschaft ${ }^{\star}$ ansetzen würde. Dass das Recht ein gesellschaftliches Phänomen sei bzw. gesellschaftliche Funktionen habe steht außer Frage. Dies erscheint nicht begründungsbedürftig und bildet daher nicht das Problem, um das gestritten wird. Vielmehr geht es um eine wissenschaftstheoretische Auseinandersetzung mit den Disziplinen und ihre daraus folgende Verhältnisbestimmung - ein Terrain, auf dem sich zunehmend auch die Philosophie bzw. die Rechtsphilosophie einschaltet. Denn das Bestimmungsproblem der Rolle der Soziologie resultiert nicht nur aus der Unsicherheit, was man unter der Soziologie oder der soziologischen Methode zu verstehen, sondern ebenso aus dem Streit darüber, wie man die Rechtswissenschaft zu fassen habe. Und auch hier besteht keinerlei Einigkeit über Wesen und Charakteristikum der Rechtswissenschaft als Wissenschaft.

\subsection{Rechtswissenschaft als Sozialwissenschaft, Kulturwissenschaft oder Normwissenschaft}

Auf der einen Seite stehen diejenigen Wissenschaftler, die die Rechtswissenschaft selbst als eine Form der Sozialwissenschaft respektive Soziologie bestimmen. Nur dadurch lasse sich die Wissenschaftlichkeit der Rechtswissenschaft garantieren, was etwa für Kornfeld (und letztlich auch Ehrlich) einen Rekurs auf die Wissenschaftlichkeit der Naturwissenschaften bedeutet. ${ }^{591}$ Diese Perspektive führt dann entweder zur Forderung eines Ausschlusses der herkömmlichen rechtsdogmatischen Methode aus den eigentlichen Rechtswissenschaften (etwa Spiegel, Kornfeld), zur Reduktion der Jurisprudenz auf eine Kunst bzw. Technik (Ehrlich), oder aber zur Markierung einer Differenz zwischen einer empirisch-induktiven und einer genuin juristischen, d.h. normativ-deduktiven Betrachtung des Rechts, die diese Formen der Sozialwissenschaft in der „soziologischen Jurisprudenz" in ein Wechselverhältnis setzt (Wurzel).

591 So auch Ofner (vgl. Eckstein 1931: XIIIff. m.w.N.). 
Diesen Ansätzen stehen diejenigen Autoren gegenüber, die die Rechtswissenschaft als eine Form der Kulturwissenschaft begreifen. ${ }^{592}$ Am Ende des 19., Anfang des 20. Jahrhunderts wird das Recht zunehmend als Kulturphänomen verstanden (vgl. Sprenger 1991, m. zahlr. N.; Senn, Puskás 2007): „Die Rechtswissenschaft ist eine Kulturwissenschaft, eine Wissenschaft, die sich mit dem Kulturfaktor ,Recht' beschäftigt.“ (Löwenstein 1915: 1, H.i.O.) Diese Position wird prominent in der wiedererstarkten Rechtsphilosophie vertreten, ${ }^{593}$ und zwar von Seiten der Neukantianer so insbesondere von Lask (s.o.) und im Anschluss daran von dem der Methodenreform- und Freirechtsbewegung wohlgesinnten Gustav Radbruch (Radbruch 1993 [1914]: 175; Radbruch, Dreier 2003; s.a. auch Mayer 1903; Müller-Eisert 1917; Münch 1918; zu Jellinek s.o. \$3.II.1.2). ${ }^{594}$

Aber auch die Anfang des 20. Jahrhunderts zunächst noch weniger prominenten, aber wortreich agierenden Neuhegelianer wenden sich der Kultur zu. Denn man müsse das Recht - wie bereits im Jahr 1885 einer ihrer Wortführer, Joseph Kohler, schrieb - als „Kulturerscheinung“ definieren (Kohler 1885). Wenn Recht aber immer - so Berolzheimer - „Kulturrecht“ sei (Berolzheimer 1911: 604), müsse man über die „Kulturgeschichte“ (Kohler 1911: 558) oder die (kultur-)ethnologische Rechtsvergleichung und (Universal-)Rechtsgeschichte (vgl. Berolzheimer 1907: 133f.) zu den

592 Die Hinwendung zu den Kulturwissenschaften kann wie im Fall der geforderten Hinwendung zur Soziologie ebenfalls als strategische Wiederaufladung der aus der Rechtsentstehungslehre resultierenden Problemstellungen gelesen werden: Auch hier gilt die Historische Rechtsschule als Vorläuferin, erscheint sie doch als eine Kulturwissenschaft avant la lettre (vgl. prospektiv Arnold 1865; retrospektiv Mannheim 2003 [1925]: 125). Der Zweck rückt nun ebenfalls in den Vordergrund, nun aber als Wert, und die Kulturwissenschaft versteht sich als Auflehnung gegen den Naturalismus.

593 Einen hilfreichen Überblick über die rechtsphilosophischen Ansätze seit der Jahrhundertwende liefert der ebenfalls dem Neukantianismus zuzuordnende Wilhelm Sauer 1923.

$594 \mathrm{Ob}$ Gustav Radbruch mit seinen frühen Schriften, in denen er die freirechtlichen Ansätze positiv bespricht, zur Freirechtsbewegung zu zählen ist, ist umstritten (vgl. Foukles 1968; Neumann 2016 m.N.). Gegenüber anderen neukantianischen Autoren führt Radbruch in den Grundzügen der Rechtsphilosophie eine Differenzierung ein: Die Rechtswissenschaft sei einerseits Kulturwissenschaft; andererseits sei sie hinsichtlich ihrer Methode nicht von einer Normwissenschaft zu unterscheiden, weil ihre Aufgabe in der normativen Interpretation des geltenden Rechts liege (vgl. Radbruch 1993 [1914]: 175ff.). Die Rechtswissenschaft habe deshalb „den Gegenstand einer empirischen, einer Kulturwissenschaft, aber die Methode einer Normwissenschaft" (ebd.: 176). Zur Heterogenität des Neukantianismus in der Rechtsphilosophie, zu dem letztlich auch Stammler und Kelsen gehören, vgl. Paulson 2007: 83. 
dahinter liegenden entwicklungsgesetzlichen Ideen vordringen, um das empirische Material metaphysisch deuten zu können. Hier wird die Philosophie für die Rechtswissenschaft zentral - und aus dieser Perspektive erfolgt die Intervention in den Methodenstreit. ${ }^{595}$

Für eine dritte Gruppe lässt sich die Rechtswissenschaft jedoch nicht eindeutig einer der beiden Lager zuordnen, sondern stellt eine Mischform dar: Max Rumpf etwa will „die (geschichtlich-)gesellschaftlich-kulturwissenschaftliche Wissenschaftsgruppe“ (Rumpf 1929: 17) durch den „polarischen Gegensatz von Subjekt und Objekt, von Ich und Welt, von lebendigem Leben und toter Kultur" (ebd.: 16) einteilen in Sozialwissenschaft und Kulturwissenschaft. Beide durchdringen und ergänzen sich. Die Rechtswissenschaft wiederum sei „teils eine Sozialwissenschaft, teils eine Kulturwissenschaft" (ebd.: 7) und erst in diesem umfassenden Sinne eine Vollrechtswissenschaft (vgl. Rumpf 1924). Francisco Cavalcanti Pontes de Miranda wiederum schaltet sich in den Bestimmungsstreit mit einem Modell des Stufenbaus der Rechtswissenschaft ein, auf dessen verschiedenen Stufen sowohl die historisch-empirischen Kulturerscheinungen als auch die naturwissenschaftlichen Gesetzlichkeiten ihren Platz finden (vgl. Pontes de Miranda 1922: 184, wobei die Rechtswissenschaft jedoch auf ihrer höchsten Stufe empirisch-induktiv verfahre). ${ }^{596}$

Andere wiederum begreifen die Rechtswissenschaft als eine besondere Wissenschaft, die sich jenseits der Differenzierung von Natur- und Kulturwissenschaften respektive von Sozial- und Kulturwissenschaften bewegt: Für Nußbaum ist sie etwa eine Wissenschaft, die den „rein praktischen Zweck" habe, der Rechtsanwendung zu dienen. Da sie sich dabei auf das Sollen und nicht das Sein beziehe, habe sie gegenüber einer an den Naturwissenschaften orientierten Sozialwissenschaft und einer empirischen Kulturwissenschaften eine „methodische Sonderstellung“. Sie sei also eine

595 Vgl. die Nachweise in Gängel, Schaumburg 1989: 307ff. zu Kohlers Ausführung zu dieser Problematik bereits seit den 1880er Jahren, die im Rahmen des Methodenstreits zunehmend virulent wurden.

596 Der Rechtsanwalt Robert Lazarsfeld sieht noch ein ganz anderes Mischverhältnis am Werk: Das „Problem der Jurisprudenz“ bestehe gerade darin, dass sie sie „ein mixtum compositum von Wissenschaft und Moral“ sei (Lazarsfeld 1908: 45). Deshalb sei gerade die stets notwendige Scheidung der normativen von der kausalwissenschaftlichen Ebene das Problem, wolle man nicht zu falschen und v.a. scheinlogischen Schlussverfahren gelangen (vgl. ebd.: 45, 49). Lazarsfeld stellt angesichts der nicht logisch herleitbaren Entscheidung auf die Erklärung über sozialen Machtverhältnisse ab - ein Vorgehen, das Kantorowicz wiederum scharf kritisiert (Kantorowicz 1911a: 294). 
Wissenschaft eigener Dignität - ein Ansatz, der Kantorowicz mit der Bezeichnung als „Normwissenschaft“ einen Ausdruck gibt.

Diese Position nimmt auch der erstarkende philosophische (kritische) Rechtspositivismus ein, dessen prominentester Fürsprecher Hans Kelsen mit seinen methodologischen Einlassungen zum Problem der Rechtswissenschaft ist. ${ }^{597}$ Er radikalisiert den Gegensatz von Sein und Sollen als nicht weiter analysierbare Kategorien, die aus ihren je spezifischen Betrachtungsweisen ihren jeweils eigenen Gegenstand erzeugen. ${ }^{598}$ Dies führt ihn zu einer strengen „Unterscheidung zwischen explikativen, d.h. auf die Welt des Seins und deren kausale Erklärung durch Naturgesetze gerichteten, und normativen, d.h. der Welt des Sollens und den Normen zugekehrten Disziplinen, zwischen Kausal- und Normwissenschaften" (Kelsen 1911: VI). Die Grenze läuft nicht entlang der Scheidung von Natur- und Kulturwissenschaften, sondern entlang der Differenz von Wirklichkeitsund Wert- bzw. Normwissenschaften. 599

Für die Einordnung der Rechtswissenschaft gilt dabei nach Kelsen: Sie muss sich auf das Sollen richten, da ihr Gegenstand, die Rechtssätze, das Sollen statuierende Regeln, d.h. Normen darstellten. Sie behandle gerade nicht Regelmäßigkeiten des menschlichen Verhaltens, also Seinsregeln bzw. Gesetzmäßigkeiten im Sinne des Kausalgesetzes. Da sie sich mit Normen befasse, könne man die Rechtswissenschaft sinnvollerweise nur als normative Disziplin bestimmen, deren Erkenntnis auf das rechtliche Sollen gerichtet sei. Sie bewerte nicht den Inhalt der Gesetze, sondern gebe in

597 Kelsen wird ungeachtet des Titels seiner Habilitationsschrift Die Hauptprobleme der Staatsrechtslehre (Kelsen 1911) zunächst weniger als Staatsrechtler im engeren Sinne denn als Rechtstheoretiker und Methodologe wahrgenommen. Erst nach dem Ersten Weltkrieg tritt er verstärkt als Staatsrechtslehrer auf und wird - wie etwa im Methodenstreit der Weimarer Staatsrechtslehre - als solcher wahrgenommen und angegriffen (vgl. Dreier 2001: 20; zu Kelsens zeitgenössischen philosophischen wie staatsrechtlichen Kritikern s.a. Korb 2010).

598 Zur Frage, in welchem Verhältnis der Kelsen'sche Positivismus zum Neukantianismus steht, siehe bereits Sander 1921, 1923; vgl. hierzu Paulson 1988.

599 Das entspricht bei Kelsen wiederum einer Differenzierung von Kausal- und Geisteswissenschaften. Rechtswissenschaft sei eine echte Geisteswissenschaft, was aber gleichbedeutend mit einer Normwissenschaft sei (vgl. Kelsen 1922: 77ff.; 1925: 24). Zu den unterschiedlichen Verwendungsweisen und Definitionen von Geisteswissenschaft im staatswissenschaftlichen Diskurs, die sich nicht unbedingt mit Diltheys Vorschlag decken, vgl. mit Blick auf Kelsen Otaka 1932: 45f.; Korb 2010: 124ff. 
Werturteilen den Inhalt der Gesetze wieder (vgl. Rottleuthner 1984: 525). 600

Die Differenz zwischen Sein und Sollen bezeichnet nach Kelsen eine nicht auf einander rückführbare Verschiedenheit der „Betrachtungsrichtung und Denkform“, aus der sich „eine vollständige Verschiedenheit des Objekts" ergebe (Kelsen 1992b [1915]: 841). Je nachdem, ob man also eine Gegebenheit in der Form des Seins oder des Sollens denke, sei sie als Wirklichkeit, Natur bzw. Tatsache, oder aber als Wert, Zweck bzw. Norm gegeben. ${ }^{601}$ Auf Grundlage dieser erkenntnistheoretischen Bestimmung wendet sich Kelsen gegen jegliche Forderungen nach einer Hinwendung der Rechtswissenschaften zur Soziologie - hier insbesondere gegen Kantorowicz (vgl. etwa Kelsen 2010b [1911]: 79ff.; 1992e [1912]: 601ff.; 1916), gegen Kornfeld (Kelsen 1992e [1912]: 607ff.), gegen Spiegel (Kelsen 2010a [1914]) und in der berühmten Kontroverse über die Grundlegung der Soziologie des Rechts gegen Ehrlich (vgl. Kelsen 1992b [1915]; 1992c [1916]; 1992d [1916/1917] $)^{602}$ - respektive gegen eine soziologische Untersuchung des Rechts wie bei Max Weber (Kelsen 1992a [1921]; 1922).603 Denn letzt-

600 Die Rechtswissenschaft werte also nicht selber, sondern sei insofern normativ, als sie auf die Erkenntnis des rechtlich Gesollten gerichtet ist: Der Begriff der Normativität „kann nicht eine besondere Art des Wollens, er muß eine bestimmte Form des Denkens, eine eigenartige Betrachtungsweise kennzeichnen, die sich von der anderer Wissenschaften durch ihre spezifische Richtung unterscheidet und die darum eine normative genannt werden darf, weil sie nicht, wie z.B. die Naturwissenschaft, der Welt des Seins, sondern der Welt des Sollens zugewendet ist, weil ihr Ziel nicht, wie das der explikativen Disziplinen, eine kausale Erklärung des tatsächlichen Geschehens, also die Erkenntnis von Naturgesetzen, sondern die Erfassung von Normen ist" (Kelsen 1911: VIf.). Daraus folgt für Kelsen zugleich, dass die Rechtswissenschaft eine formale Disziplin ist, da sie sich mit der wissenschaftlichen Handhabung der Norm als Form des Sollens auseinandersetze (vgl. ebd.: VIII).

601 So schreibt Kelsen: „Die prinzipielle Verschiedenheit beider Denkformen läßt Sein und Sollen als zwei getrennte Welten erscheinen.“ (Kelsen 2010b [1911]: 27).

602 Zur Ehrlich-Kelsen-Kontroverse vgl. etwa Neukamp 1917; Rottleuthner 1984; Rein 1988; Paulson 1992; Lüderssen 2005.

603 Zur zeitgenössischen Diskussion über die Entgegensetzung des Kelsen'schen Ansatzes mit anderen Formen der Soziologie des Rechts vgl. etwa Darmstaedter 1926 (mit Bezug auf Jerusalem 1925). Allerdings werden manche Autoren über die Auseinandersetzung mit Kelsen wieder an die Sozialwissenschaft respektive die Soziologie zurückgeführt: Felix Kaufmann etwa versucht, auf der Grundlage des Kelsen'schen Positivismus die Möglichkeit der Sozialwissenschaft zu erkunden (Kaufmann 1936); der ehemalige Schüler und Anhänger Kelsens Fritz San- 
lich erweist sich eine wie auch immer geartete Rechtssoziologie aus Kelsens Perspektive als unmöglich: Für die Soziologie sei

insbesondere das Recht nicht eine als gültig vorausgesetzte Norm, kein objektiver Wert, sondern ein tatsächlicher - an sich wertindifferenter Vorgang, ein bestimmtes geistiges und körperliches Verhalten von Menschen, das in seiner Regelmäßigkeit zu erfassen ist. Ihr Gegenstand ist genau genommen gar nicht das Recht, sondern das Denken, Fühlen oder Wollen des Rechts, das was die Menschen vom Rechte meinen und in dieser Meinung tun oder lassen (Kelsen 1992b [1915]: 855 f.; s.a. 875 f.).

Die Soziologie des Rechts, die Rechtssoziologie bzw. die soziologischen Methoden in den Rechtswissenschaften beruhen daher auf einem Synkretismus der Methoden. Kelsen wirft den Autoren eine Vermengung von juristischer und soziologischer Betrachtung vor, die schon auf rein logischmethodologischer Ebene nicht haltbar sei und aus der die Inkonsistenzen dieser Ansätze herrührten. Insbesondere wendet sich Kelsen dabei auch gegen die Verortung des Problems in der Rechtsentstehungslehre. Da eine Sollen nicht aus einem Sein herleitbar sei, könne das Recht auf logischer Ebene auch nicht aus den Tatsachen des menschlichen Zusammenlebens abgeleitet werden (vgl. ebd.: 856ff.). ${ }^{604}$

Auf dieser erkenntnistheoretischen Grundlage widerspricht Kelsen aber auch Rickert, Lask und Radbruch (sowie Kantorowicz' Forderung einer kulturwissenschaftlich zu verstehenden Rechtssoziologie): Die Rechtswissenschaft sei keine Kulturwissenschaft, sondern eine „Normwissenschaft“ (Kelsen 1916). Der Fehler des kulturwissenschaftlichen Ansatzes liege darin, dass er die Rechtswissenschaft (respektive Kantorowicz' Rechtssoziologie) auf einer logisch nicht haltbaren vermittelnden Ebene der Wertbeziehung ansiedele. Da die Kulturwissenschaften auf dieser Ebene aber ebenfalls kausalwissenschaftlich verfahren, liege letztlich trotz prinzipieller Trennung von Sein und Sollen ebenfalls ein kausalwissenschaftliches Vor-

der wiederum plädiert ausgehend von seiner Kritik an Kelsens Version des Neukantianismus ab Mitte der 1920er Jahre für einen rechtssoziologischen Ansatz, der ihn zur Auseinandersetzung mit zentralen soziologischen Begrifflichkeiten wie ,Gesellschaft‘ führt (vgl. Sander 1927, 1930).

604 Allerdings bestreitet Kelsen nicht die Wichtigkeit der soziologischer Untersuchungen - nur sei ihr Gegenstand nicht das Recht, das sich durch seinen spezifisch normativen Gehalt auszeichne, sondern Seinstatsachen, d.h. sie habe es mit einer Art Parallelphänomen (Vorstellungen und Empfindungen von Rechtsnormen) zu tun (vgl. dazu auch Kelsen 1967 [1931]: 72ff.). 
gehen vor - selbst wenn man einen anderen Kausalitätsbegriff zugrunde lege als die Naturwissenschaften. Aufgrund der erkenntnistheoretischen Trennung in Sein und Sollen wendet sich Kelsen gegen jede Form von Methodendualismus oder -trialismus aus, der sich auf den einheitlichen Gegenstand Recht beziehen würde. 605

Diese wissenschaftstheoretischen Bestimmungsversuche der Rechtswissenschaft strukturieren die gegenseitigen Frontstellungen im Diskurs der Rechtswissenschaft: Kelsen wendet sich gegen jegliche sozialwissenschaftliche, soziologische oder kulturwissenschaftliche Bestimmung der Rechtswissenschaft, ${ }^{606}$ aber auch gegen alle metajuristischen, naturrechtlichen oder metaphysischen Ideen im Recht (Neuhegelianismus). ${ }^{607}$ Ehrlich kritisiert eine solche „reine Rechtslehre“ (vgl. Ehrlich 1992a [1916]; 1992b [1916/17]) und grenzt sich mit seiner Ablehnung der Zwangstheorien des Rechts von der Interessenjurisprudenz sowie durch seine Bestimmung der Jurisprudenz als Technik von den kulturwissenschaftlichen Bestimmungsversuchen der Rechtswissenschaft ab. Der Neuhegelianer Berolzheimer kritisiert sowohl den Neukantianismus, die Hinwendung zu den Naturwissenschaften und die Forderung nach einer Soziologie des Rechts (vgl. Berolzheimer 1907) sowie die Freirechtsbewegung und Interessenjurisprudenz in toto (vgl. Berolzheimer 1911: 609f.), wobei vor allem Kelsen ins Visier der neuhegelianischen Kritik gerät (vgl. Korb 2010: 24ff. m.N.). Kantorowicz kritisiert die Interessenjurisprudenz, aber auch seine freirechtlichen Kollegen wie etwa Ehrlichs Forderung der Soziologisierung der Rechtswissenschaft, auch wenn er für die Wichtigkeit der Rechtssoziologie eintritt (vgl. Kantorowicz 1911a). Heck widerspricht vehement dem „Wunsch nach einem Ersatz der Rechtswissenschaft durch eine Soziologie oder nach der unmittelbaren Verwendung des von einer allgemeinen Soziologie erbrachten Materials“ (Heck 1912: 37; s.a. 1914: 277ff.; 1925: 381 mit Blick auf Ofner). Obwohl Heck Max Webers kulturwissenschaftliche Erkenntnisse bewundert, scheitere eine Übernahme der von Rickert herrührenden Methodenlehre an der Eigenart der Rechtswissenschaft, die immer einen normativen Endzweck verfolge (vgl. Heck 1914: 312f.). Andererseits erscheint Kelsens Reine Rechtslehre nicht als Alternative (vgl. Heck 1917: 270;

605 Zu dieser Kritik mit Blick auf Radbruch vgl. ausführlich Neumann 2005.

606 Bezeichnend für die Zentralität dieser Frontstellung sind auch die kritischen Rezensionen des Kelsen-Schülers Adolf Julius Merkl etwa zu Jung, Oertmann, Heck, Reichel, Bozi sowie seine Diskussionen etwa der Lücken im Recht, des Interpretationsproblems und der Rechtsanwendung, des Freirechts und des Richterrechts (siehe die entsprechenden Beiträge in Merkl, Mayer-Maly 1993)

607 Zur den Frontstellungen Kelsens vgl. Dreier 1990: $27 \mathrm{ff}$. 
1924; 1932b), da es für Heck um das Grundproblem der „Betonung des engen Zusammenhangs von Leben und Recht" (Heck 1929: 210) und damit um den „Grundsatz der Lebensnähe“ (Heck 1925: 381) geht. Usw. usf.

\subsection{Konkurrenzproblem „Soziologie“}

Jenseits einer abstrakten Wesensbestimmung der Rechtswissenschaft eint den Diskurs die Suche nach der Antwort auf die Frage, ob und - wenn ja wie die Rechtswissenschaft nicht auf methodischer Ebene, sondern nun aufgrund ihres genuinen Wissenschaftscharakters die Tatsachen des gesellschaftlichen Lebens zu integrieren habe. Daher wird die Auseinandersetzung mit der Soziologie, jener sich konsolidierenden Disziplin für die Tatsachen des gesellschaftlichen Lebens, zur zentralen wissenschaftstheoretischen Herausforderung - sie ist der Abgrenzungshorizont, vor dem sich die Bestimmung der Rechtswissenschaft vollzieht. Denn wie Wilhelm Sauer mit Blick auf die Soziologie die Diskurslage beschreibt: „Die Gefahr droht von dieser jungen und zukunftsreichen Wissenschaft, daß sie sich als Rechtswissenschaft aufspielt, die sie eben wegen ihres bloß beschreibenden Charakters niemals sein darf." (Sauer 1923: 311) Das gilt insbesondere vor dem Hintergrund, dass Autoren wie Ehrlich, Kornfeld, Fuchs und Spiegel die Soziologie im Rahmen der Methodenkritik als Konkurrenzdisziplin zur herkömmlichen Rechtswissenschaft ins Spiel bringen: sei es als eigentliche Rechtswissenschaft (Kornfeld) bzw. als Grund- oder Hauptwissenschaft (Fuchs), oder sei es als einzig mögliche wissenschaftliche Grundlage einer Jurisprudenz, die selbst nur Technik sei (Ehrlich). Wie schon Jhering verstehen auch diese Autoren die Gesellschaftswissenschaft als wissenschaftliche Leitdisziplin für die Rechtswissenschaft. Rechtswissenschaft im engeren Sinne, d.h. Rechtsdogmatik und -methodik, könne angesichts einer solchen Bestimmung nicht mehr allein mit den überlieferten Techniken und Methoden der „Begriffsjurisprudenz“ betrieben werden.

Dabei handelt es sich letztlich um einen Angriff auf die Autonomie der Rechtswissenschaft, den es - trotz aller Kritik an der Begriffsjurisprudenz abzuwehren gilt, verliert sie doch dadurch entweder ihre eigene wissenschaftliche Berechtigung ${ }^{608}$ oder wird zu einem Zweig der Sozialwissenschaften respektive der Soziologie degradiert. Diese Abwehr eint die diffe-

608 So aus ,soziologischer Perspektive“ schon der Jurist Ludwig Gumplowicz (vgl. Gumplowicz 1885: 45ff.), wogegen (und zugleich gegen den Materialismus nach Marx) etwa Theodor Sternberg explizit anschreibt (vgl. Sternberg 1904: 144f.). 
renten Ansätze, die damit alle gegen eine drohende Soziologisierung der Rechtswissenschaft anschreiben. ${ }^{609}$ Dabei werden zwar gänzlich unterschiedliche Strategien verfolgt. Jedoch problematisieren sie allesamt in ihrer Kritik das wissenschaftstheoretisch zu bestimmende Verhältnis von Sein und Sollen, d.h. von Normativität und Faktizität des Rechts: ${ }^{610}$ Von den verschiedensten Seiten aus wird die Vermengung von Sein und Sollen angekreidet, und zwar einerseits auf der Gegenstandsebene, indem vorgehalten wird, dass Recht nicht als Norm, sondern als Regel gefasst werde und daher eine Verwechslung von Normalität und Normativität im Rechtsnormbegriff vorliege; 611 andererseits aber auch auf der wissenschaftstheoretischen Ebene, indem methodologische Defizite, ein logisch nicht haltbarer Methodensynkretismus bzw. die Verkennung der Eigenart der Rechtswissenschaft angeklagt wird. ${ }^{612}$

Im Zuge dieser Abgrenzung zeigt sich die Rechtswissenschaft entweder als Wissenschaft der Normen (im normativen Sinne) oder als Normwissen-

609 Das gilt auch für die Rechtsphilosophie, die sich gegen eine drohende Verdrängung durch die Soziologie wendet, vgl. etwa Kohler 1911: 561f.; Berolzheimer 1907: 130.

610 Das begründet auch den zentralen Stellenwert der Einlassungen von Kornfeld und Ehrlich. Denn auch wenn sie wenig Anhänger und Verfechter finden, so fungieren sie doch als gemeinsamer Abgrenzungshorizont in den Debatten.

611 Vgl. Somló 1917: 57f. gegen Ehrlich, Kornfeld, Jung, Spiegel; vgl. aber auch Kantorowicz 1911a: 28; Hahn 1913/1914: 405; Nußbaum 1914: 5f.; Salomon 1915: 340; bzw. in abgeschwächter Form Feilbogen 1914.

612 Vgl. zum Vorwurf der methodologischen Defizite Ehrlichs etwa Neukamp 1917: 232; Manigk 1974 [1914]: 241ff., zum Methodensynkretismus Kelsen [s.o.]; sowie zur Verkennung des spezifischen Wissenschaftscharakters der Rechtswissenschaft neben den bereits angeführten Positionen auch Bierling 1917: 19; Huber 1921: 21; Wundt 1918: 181f. Dieser Vorwurf liegt auch dem Einwand Radbruchs gegen Fuchs zugrunde, wenn er ihm vorhält, dass er doch besser die Bezeichnung als „soziologische Methode“ vermieden hätte, denn: „Soziologie ist Tatsachenforschung, Werturteile lassen sich aber nicht aus Tatsachen ableiten [...].“ (Brief Radbruch an Fuchs vom 08.10.1910, zitiert nach Foukles 1965: 249) Bei Fuchs sei „Soziologie“ nicht eine theoretische Wissenschaft, sondern nur "die unvollkommene Formel für eine werterfüllte Intuition des sozialen Lebens“ (Radbruch 1988: 64). Die neuhegelianischen Ansätze wiederum formulieren ihre Kritik an einer wie auch immer gearteten soziologischen Rechtswissenschaft insbesondere vor dem Hintergrund, dass sie die Soziologie als Teil der kausalwissenschaftlich verfahrenden Naturwissenschaften, d.h. als "Gesetzeswissenschaft “, verstehen (vgl. Kohler 1911: 558; Berolzheimer 1911: 605). Darüber könne man aber niemals zu den hinter den Erscheinungen waltenden Ideen vordringen, was genau jener Aspekt sei, der das Recht als Kulturerscheinung auszeichne (vgl. Kohler 1911: 561f.). 
schaft, als Wertwissenschaft oder als wertbeziehende Wissenschaft bzw. als praktisch-normative Wissenschaft respektive als normative Wissenschaft mit Blick auf die Rechtsidee. Es geht also um die Grenzen der Rechtswissenschaft als eigenständige Disziplin. Kelsen formuliert dies am deutlichsten, wenn er in seiner Habilitationsschrift im Jahr 1911 an den „Grenzgebieten“ der Jurisprudenz die juristische Begriffsbildung von „soziologischen oder psychologischen" Elementen zu befreien sucht (Kelsen 1911: V), um die Eigenständigkeit der Rechtswissenschaft durch konsequente Reinhaltung von solchen seinswissenschaftlichen (und metaphysischen) Elementen zu bewahren und zu sichern. ${ }^{613}$

Von dieser Grenzziehung ausgehend versucht man das Verhältnis zur Soziologie zu bestimmen - und die Soziologie selbst. Aus diesem Grund wird die Debatte nicht als eine wie auch immer zu definierende soziologische Auseinandersetzung verstanden, die dazu nötigen würde, sich der gerade entstehenden Fachdisziplin zuzuwenden, sondern es handelt sich um einen innerjuristischen Diskurs (ansonsten würde man ja auch den Anspruch auf Autonomie der Rechtswissenschaft aufgeben). Die Auseinandersetzungen über Wesen und Rolle der Soziologie gehen etwa von eigenständigen, meist sehr weiten Soziologiebegriffen aus, die z.T. explizit Abstand von den dezidiert soziologischen Bestimmungen nehmen (s.o.). ${ }^{614}$ U.a. deswegen erscheint der Rekurs auf die Soziologie in den Augen der Kritiker nebelhaft, dilettantisch und so vage, als dass man daraus methodische oder wissenschaftstheoretische Klarheit gewinnen könne (s.o.). ${ }^{615}$

613 So schreibt Kelsen programmatisch in der Vorrede seiner Reinen Rechtslehre im Jahr 1934, dass es sein Hauptanliegen sei, „eine reine, das heißt: von aller politischen Ideologie und allen naturwissenschaftlichen Elementen gereinigte, ihrer Eigenart, weil der Eigengesetzlichkeit ihres Gegenstandes bewusste Rechtstheorie zu entwickeln”, damit die Jurisprudenz „auf die Höhe einer echten Wissenschaft, einer Geistes-Wissenschaft zu heben” und ihre „ausschließlich auf Erkenntnis des Rechts gerichtete Tendenz zu entfalten und deren Ergebnisse dem Ideal aller Wissenschaft, Objektivität und Exaktheit, soweit als möglich anzunähern" (Kelsen 2008 [1934]: 3).

614 Das bedeutet nicht, dass kein Interesse für die Fachdiskussionen der sich konsolidieren Soziologie bestünde. So hielt Kantorowicz, wie erwähnt, am ersten Soziologentag im Jahr 1910 einen Vortrag, Wüstendörfer, Fuchs und Heck nahmen als Diskutanten teil.

615 Das liegt in den Augen der Kritiker z.T. am mangelhaften Zustand der Soziologie selbst, die daher überhaupt kein wissenschaftliches Fundament abgeben könne (vgl. Delbrück in Kohler et al. 1910: 208; Düringer 1909: 71, 1992 [1910]: 134). 
Für diese Distanzierung ist aber auch bezeichnend, dass Interventionsversuche von soziologischer Seite bei den Bestimmungsversuchen wenig Gehör finden: So wehrt sich etwa Ferdinand Tönnies vehement gegen die immer wieder proklamierte Festschreibung der Soziologie als Naturwissenschaft respektive als Kausalwissenschaft. Während in den Versuchen der Verhältnisbestimmung von Soziologie und Rechtsphilosophie der Neuhegelianer Kohler die Soziologie als "Gesetzeswissenschaft" und der Rechtspositivist Felix Somló sie als „Kausalwissenschaft“ deklarieren, und beide sie dabei als eine Form der Naturwissenschaft kennzeichnen, hält Tönnies ihnen entgegen: „Die Soziologie ist nicht lediglich Kausalwissens haft (sic!)." (Tönnies 1911b: 569) Die theoretische Soziologie sei in Abgrenzung zur angewandten und empirischen Soziologie „vielmehr, wie alle allgemeinen und dann philosophischen Wissenschaften, in erster Linie eine Wissenschaft von Begriffen" (ebd.). Und während Kohler aus seiner Bestimmung ableitet, dass die dem Reich der Ideen zugewandte Rechtsphilosophie etwas wesentlich anderes sei als eine empirische, nach Naturgesetzen suchende Tatsachenwissenschaft bzw. Somló daraus folgert, dass die Soziologie die Rechtsphilosophie niemals verdrängen könne, gilt für Tönnies, dass die Rechtsphilosophie eine Art Zwischenstellung einnimmt:

Die Rechtsphilosophie ist daher ihrem Wesen nach ein Teil der reinen oder theoretischen Soziologie, insofern als die Rechtsphilosophie die Wirklichkeiten des Rechts begreifen will. Sie liegt aber ausserhalb der Soziologie, insofern als sie Normen des richtigen oder guten oder zweckmässigen oder gerechten Rechtes aufzustellen unternimmt. (Ebd.: 570, H.i.O.)

Tönnies' Einwände stoßen auf taube Ohren: In der Diskussion dieser Beiträge auf dem II. Kongress der Internationalen Vereinigung für Rechts- und Wirtschaftsphilosophie, in dem das Verhältnis von Soziologie und Rechtsphilosophie zur Debatte stand, bestritt man die Existenzberechtigung der Soziologie rundweg aus dem Grund, dass sie doch neben der Geschichtsphilosophie nichts Neues zu liefern vermöge (vgl. Dürr in Kohler et al. 1911: 674f.). Allenfalls wird ihr Verdienst im Hinweis auf die Relevanz der Gruppenbeziehungen sowie der realen Faktoren in der Vergangenheit verortet. Heute könne man nichts mehr von ihr lernen (Berolzheimer in Kohler et al. 1911: 675).

Auch Webers explizite Stellungnahmen zu Begriffsjurisprudenz, Freirechtsschule und Interessenjurisprudenz in seiner zwischen den Jahren 1911 bis 1913 verfassten sogenannten „Rechtssoziologie“, die allerdings erst im Jahr 1921/22 posthum als Teil von Wirtschaft und Gesellschaft erscheint (s.u. $\$ 8$ ), werden ebenfalls kaum registriert, obwohl Heck und 
Kantorowicz seine wissenschaftstheoretischen Abhandlungen positiv aufnehmen (wenn auch mit eigenständigen Adaptionen, vgl. etwa Heck 1914: 24ff.; Kantorowicz 1923).616 Vielmehr gerät Webers Staatstheorie im staatswissenschaftlichen Diskurs ins Visier der Kritik von Kelsen, Carl Schmitt und anderen (vgl. Anter 2016; das gilt im Übrigen auch bzgl. Durkheim und Tönnies). Dasselbe Schicksal erfahren andere, explizit soziologische Ansätze: Sie scheinen zwar gelegentlich erwähnenswert, zeitigen im rechtswissenschaftlichen Diskurs der Privatrechtswissenschaft jedoch keinerlei neue Diskurseffekte. ${ }^{617}$

All diese Beispiele verdeutlichen die Eigenart des epistemischen Dispositivs der Privatrechtswissenschaft: Trotz der Tatsache, dass die Rechtswissenschaft sich in den Debatten über ihr Selbstverständnis auf die Soziologie bezieht - und sich angesichts der Forderungen nach der Hinwendung zu den Tatsachen des gesellschaftlichen Lebens auch beziehen muss -, wird die Auseinandersetzung mit der Soziologie bzw. ihren fachlichen Vertretern gerade nicht gesucht. Es handelt sich um eine rechtswissenschaftsinterne Auseinandersetzung, in der das Konkurrenzproblem der Disziplinen aus juristischer Perspektive angegangen wird. ${ }^{618}$

Dies zeigt sich schließlich auch in denjenigen Ansätzen, die gegen die Ersetzung der Rechtswissenschaft durch die Soziologie, aber trotzdem für eine Hinwendung zu soziologischen Erkenntnissen plädieren: Sie stellen diesen Bezug unter die Vorherrschaft der Rechtswissenschaft. Sinzheimer, Nußbaum und Kantorowicz wollen nicht die sich konsolidierende Fachdisziplin Soziologie, sondern eine durch die Rechtswissenschaft vorgezeichnete Soziologie integrieren. Nicht der Soziologe bestimmt die soziologisch relevanten Tatsachen, sondern der Rechtswissenschaftler, und nur der Jurist könne eine für die Rechtswissenschaft relevante Soziologie, die Rechtssoziologie, betreiben. Die Soziologie besteht neben der Jurisprudenz, dient allenfalls als Ergänzung oder Hilfsdisziplin (Nußbaum, Heck) oder vermittelt unter der Ägide der Juristen als Rechtssoziologie zwischen den beiden Disziplinen (Kantorowicz).

616 Zu Hecks Beziehung zu Weber vgl. Schoppmeyer 2001: 147ff.; zum Verhältnis Kantorowicz/Weber siehe Muscheler 1984: $58 f$.

617 Vgl. zu Jerusalems Soziologie des Rechts (1925) etwa Kunz 1926, Wolf 1926.

618 Nach Luhmann würde man das als re-entry beschreiben. 


\subsection{Die Relativierung der, Gesellschaft ${ }^{\circ}$}

Die Konkurrenz zur Soziologie wird also als ein (privat)rechtswissenschaftsinternes Problem bestimmt: Es ist die Rechtswissenschaft, die die Beziehung zur Soziologie als andersgeartete Disziplin nach ihren Bedürfnissen und Vorgaben bestimmt. Das impliziert zugleich eine Anerkennung dieser Disziplin im Kanon der Wissenschaften. Der Jurist erscheint nun nicht mehr als der Sachverständige für die soziale Ordnung, und damit obliegt es auch nicht mehr der Rechtswissenschaft, die Funktion des Rechts für die Gesellschaft zu bestimmen. Dies wird nun ausgelagert in eine eigenständige Disziplin, deren Erkenntnisse man sich zu nutzen machen muss, kann, oder sollte, die aber keineswegs die juristische Erkenntnisweise zu verdrängen oder im Wesen zu beeinflussen vermag. Das epistemische Ding ,Gesellschaft ${ }^{\star}$ verliert seine bestimmende Kraft für Rechtsdogmatik und -methodik.

Dieser Effekt tritt gerade deshalb ein, weil die Frage der Lebensanbindung des Rechts in ein erkenntnis- und wissenschaftstheoretisches Problem umgedeutet wird: Das Privatrecht steht nun nicht mehr über dem Öffentlichen Recht, und es geht auch nicht mehr um ein Komplementärverhältnis, in dem die spezifischen, streng zu unterscheidenden Funktionen des Privatrechts und des Öffentlichen Rechts sich gegenseitig ergänzen. Auf wissenschaftstheoretischer Ebene gibt es vielmehr keinen prinzipiellen Unterschied zwischen den verschiedenen Teilgebieten des Rechts. Im Zentrum der Debatte stehen allgemeine Rechtswissenschaftstheorien und allgemeine Rechtslehren und nicht spezifische Privatrechtswissenschaftstheorien, die sich vom Öffentlichen Recht oder Strafrecht unterscheiden würden. ${ }^{619}$ Als Extreme gegenüber stehen sich etwa die allgemeine Rechtslehre, die der Anwalt und Privatrechtswissenschaftler Ignatz Kornfeld auf soziologischer Grundlage entwirft, und die Reine Rechtslehre des Staatsrechtslehrers Kelsen - und das auf der Basis der Debatte eines allgemeinen Rechtsbegriffs.

Diese Verschiebung führt dazu, dass das Privatrecht damit nur noch bedingt in seinem spezifischen Gehalt als eigentlicher Normkomplex der

619 Daher besteht auch eine Verbindungslinie vom Methodenstreit in der Privatrechtswissenschaft zu den großen Debatten in der Staatsrechtslehre der Weimarer Zeit (vgl. hierzu Stolleis 2002: 153ff.) - und zwar nicht nur über Vermittlungsfiguren wie Kelsen oder Carl Schmitt, der ebenfalls zum Methodenstreit Stellung nahm (vgl. etwa Schmitt 1912), sondern insbesondere über die Gegenstandsfrage, d.h. die Debatte um Wissenschaftscharakter und Proprium der Rechtswissenschaft. 
zwischenmenschlichen Beziehungen angesehen wird - jene Perspektive, die im Rahmen der Rechtsentstehungslehre die Genese eines staatsfreien, gesellschaftlichen Rechts ermöglichte, und die das Privatrecht damit zum herausgehobenen Ort des Gesellschaftsbezugs machte. Das Privatrecht wird aus wissenschaftstheoretischer Perspektive nicht mehr als der genuine Ort der individuellen Freiheit adressiert (so wie sich im Übrigen in der Dogmatik des Öffentlichen Rechts seit dem Ende des 19. Jahrhunderts das subjektive Recht etabliert), das darüber die Frage nach der gesellschaftlichen Ordnungsbildung aufwirft, sondern als Teilgebiet des Rechts. Privatrechtstheorie ist nun nicht mehr zwangsläufig Gesellschaftstheorie, sondern löst sich von ihr.

\subsection{Die Sicherung der Autonomie der Rechtswissenschaft}

Dass bei der Suche nach einer Methode der Lebensanbindung des Rechts auf die abstrakte Ebene der Wissenschaftstheorie gewechselt wird, bewirkt aber insbesondere auch eines: Es tritt eine Vereindeutigung und Vereinfachung der Problemlagen ein. Die letztlich sehr differenzierte Debatte über die Rolle der Soziologie für und in den Rechtswissenschaften wird auf den Gegensatz von Sein und Sollen enggeführt. Die Fragen der Rechtsgenese (was zur Entgegensetzung von "lebendem Recht“ und Gesetz führt), der Funktionen des Rechts (etwa Ordnungssicherung und Konfliktregelung) oder der Wirkungen des Rechts sowie diejenige nach den gesellschaftlichen Entwicklungen treten zugunsten einer Theoretisierung des Wesens der Rechtswissenschaft auf der Folie Sein/Sollen in den Hintergrund.

Paradoxerweise bewirken gerade die Soziologisierungsversuche der Rechtswissenschaft aufgrund dieser Engführung auf die Frage von Sein und Sollen dann eine Normativierung des Selbstverständnisses der Rechtswissenschaft. Denn die Forderung einer Hinwendung zur Soziologie kratzt an der Autonomie der Rechtswissenschaft als eigenständige Disziplin. In der Bestimmung der Rechtswissenschaft als Soziologie durch Kornfeld, aber auch in den Arbeiten von Fuchs, Wüstendörfer, Gmelin und Ehrlich wird eine drohende Soziologisierung der Rechtswissenschaft identifiziert, die entweder ihren Wissenschaftscharakter bestreitet oder sie zu einer Teildisziplin der Soziologie herabstuft. Dieser Konkurrenzsituation begegnet man auf wissenschaftstheoretischer Ebene mit einer Unterscheidung der Wissenschaftsformen. Indem Sein und Sollen geschieden werden, tritt nun die Soziologie als Seinswissenschaft der Rechtswissenschaft als Normwissenschaft, als wertende Wissenschaft, Normwissenschaft usw. gegenüber. Soziologie erscheint nun als etwas anderes als 
Rechtswissenschaft. Und die Rechtswissenschaft wird unweigerlich an den Pol des Normativen gekoppelt - egal welche Version man dabei vertritt.

Im Selbstverständnis der Rechtswissenschaften ist also eine Normativierung festzustellen, und zwar auf breiter Front und selbst bei Befürwortern einer Hinwendung zur Soziologie. Damit gilt aber zugleich: Erst vor dem Abgrenzungshorizont der Soziologie erhält die Rechtswissenschaft ihre Kontur als eigenständige Wissenschaft, da sie sich im Zuge dieser Abgrenzung nicht mehr allein auf Wahrheit und Seinsgegebenheiten beziehen kann. Erst im Vollzug dieser Normativierung wird die Rechtswissenschaft eine autonome Disziplin: Die Herausforderungen der Vergesellschaftung des Rechts, wie sie letztlich in der Rechtsentstehungslehre der Historischen Rechtsschule zu erkennen sind und von einer Suche nach der Gesellschaft im Recht zur Bestimmung des Rechts der Gesellschaft führten, werden entschärft. Die Rechtswissenschaft immunisiert sich gegen solche Erkenntnisse. Denn für eine, normative Wissenschaft' führt sowohl auf methodischer wie auf wissenschaftstheoretischer Ebene nun weder die notwendige Beobachtung des gesellschaftlichen Seins zu den Problemen einer juristisch-soziologischen Methode (siehe etwa Heck, Rümelin et al.), noch vermag der Rekurs auf das gesellschaftliche Sein das juristisch zu ermittelnde Sollen in Frage zu stellen (siehe Nußbaum, Kantorowicz et al.). Der gesellschaftstheoretische und soziologische Blick auf das Recht als ein gesellschaftliches Phänomen wird ausgelagert in eine andere Disziplin.

Der Wechsel auf die wissenschaftstheoretische Ebene garantiert zugleich, dass mit dieser Normativierung des Rechts bzw. des Selbstverständnisses der Rechtswissenschaft keine Politisierung des rechtswissenschaftlichen Diskurses eintritt. Wertentscheidungen im Recht werden nicht als politische Entscheidungen bestimmt, sondern in ein methodisches (z.B. Hecks Wertungsnachvollzug) bzw. wissenschaftstheoretisches Problem der Bestimmung ,normativer Wissenschaften' umgedeutet. Es geht letztlich um die Frage der wissenschaftlichen Handhabung des Sollens, d.h. um die Möglichkeit und Form einer Wissenschaft des Normativen, und nicht um das konkrete politische Sollen bzw. um die politische Entscheidung mit Blick auf das Recht (oder im Recht). ${ }^{620}$ Fasst man Recht und Politik als getrennte Bereiche auf, dann wird auch der rechtswissenschaftliche Diskurs entpolitisiert. Das zeigt sich dann zum einen darin, dass die politische $\mathrm{Zu}$ -

620 Carl Schmitt fasst dies dann in der Unterscheidung zwischen juristischem Normativismus (Hauptvertreter Kelsen) und Dezisionismus (idealtypisch Hobbes, vgl. Schmitt 1922), dem er sein „konkretes Ordnungsdenken“ entgegenstellen wird (vgl. Schmitt 1934). 
ordnung der einzelnen Autoren, die die Methode in den Debatten kritisieren oder verteidigen, so gut wie keinerlei Rolle spielt.621 Es wird ganz überwiegend vermieden, die eigene politische Positionierung ins Spiel zu bringen oder auf politische Positionierungen der jeweiligen Autoren Bezug zu nehmen. Stattdessen diskutiert man das Problem unter rein rechtstechnischen und -theoretischen Gesichtspunkten. ${ }^{622}$ Zum anderen fällt es schwer, aus den rechtswissenschaftlichen Einlassungen eine solche politische Zuordnung zu rekonstruieren, nicht zuletzt aufgrund der politischen Entwicklungen hin zur Weimarer Republik. So stellt der Sinzheimer-Schüler Franz Neumann über das Freirecht im Jahr 1929 fest:

Vor dem Kriege wirkte das freie Ermessen zweifellos in weiten Maße fortschrittlich. Mit seiner Hilfe konnte man Breschen in die starre, reaktionäre Rechtsordnung legen. Damals erfüllte das Freirecht eine soziale Aufgabe. Heute jedoch muß die freiheitliche Rechtsprechung [...] notwendig reaktionär wirken. (Neumann 1929: 521; s.a. Fraenkel 1927: 45)

Das wirkt im Übrigen bis heute nach: Nach wie vor wird heftig darüber gestritten, welcher Ansatz denn nun die Politisierung des Rechts im Nationalsozialismus vorbereitet habe, etwa das (im NS als „nicht-arisch“ verpönte) Freirecht (vgl. z.B. Bloch 1985: 151f.; Behrends 1989; Rückert 2008) oder aber der - ebenfalls durch die NS-Theoretiker bekämpfte - Positivismus, wie in Folge von Gustav Radbruch lange Zeit geltend gemacht wurde (kritisch hierzu Walther 1989; Pauer-Studer 2014: 20ff.), um hier nur zwei prominente Narrative zu nennen. ${ }^{623}$ Jedenfalls bedeutet im juristi-

621 Ob etwa Sinzheimer oder Radbruch Sozialisten sind, spielt letztlich keine Rolle (vgl. zum „Juristensozialismus“ Ramm 1974/1975).

622 Mitteis’ Einschätzung des Freirechts als eine politische und soziologische Bewegung, die eine Abänderung des bestehenden Rechtszustandes in politischer oder sozialer Hinsicht bewirken wolle (Mitteis 1909: Sp. 1038), stellt insofern eine Ausnahme dar.

623 Diese Frage wird meines Erachtens zumeist falsch gestellt, da die Vorbereitung der Möglichkeit der Pervertierung der Rechtsanwendung in der NS-Zeit auf der Reaktualisierung spezifischer Elemente einzelner Positionen bezogen (etwa: Freisetzung des Richters durch das Freirecht, freirechtliche Entnormativierung des Rechts oder moralische Entlastung des Richters durch den Positivismus) und nicht als Folge eines epistemischen Dispositivs gesehen wird, das sich entlang einer bestimmten Problemlage (urgence) entfaltet. Demgegenüber müsste man der hier vertretenen Betrachtungsweise folgend - die Problematisierungsweise des Verhältnisses von Recht und Gesellschaft im NS untersuchen, was angesichts 
schen Methodenstreit die Hinwendung zur Normativität auf der Ebene des rechtswissenschaftlichen Diskurses keine Hinwendung zur Politik.

Im Streit zwischen einem gesellschaftlich-funktionalen und einem normativ-teleologischen Verständnis des Rechts verfestigt sich die normative Betrachtung in der Rechtswissenschaft, gerade weil die Normativität die Problematisierungsweise des Methodenstreits ist. ${ }^{624}$ Und letztlich erfolgt erst über die Normativierung des Rechtsbegriffs und der Rechtswissenschaft die Autonomisierung und auch die Immunisierung der Rechtswissenschaft. Denn nun steht die Soziologie, jener notwendige Abgrenzungshorizont für die Rechtswissenschaft, "vor den Toren der Jurisprudenz“ (Lautmann 1971), da es der Rechtswissenschaft darüber zu befinden obliegt, in welchen Fall und für welche Tatsachen man ihr partiellen Zugang gewährt. Hierin liegt der strategische Einsatz der Normativität. Recht tritt aus dieser Perspektive in der (Privat-)Rechtswissenschaft nun nicht mehr primär in ein repäsentierendes oder ordnendes, sondern in ein wertendes Verhältnis zur Gesellschaft. ${ }^{625}$

\section{Zusammenfassung}

Angesichts der erfolgreichen Kodifikation des BGBs rückt für die Rechtswissenschaft das Problem der Interpretation und Anwendung des Rechts in den Vordergrund. Denn nun kann man auf den weiterhin bestehenden Modernisierungsdruck nur mit einem interpretatorischen Freiraum gegenüber der begrifflich hochpräzisen Kodifikation des BGBs reagieren (vgl. Haferkamp 2011a: Abs. 2). Von dieser Warte aus formiert sich die Kritik an

des normativen Zweckdispositivs dann die Entwicklung solcher Phänomene wie der Wertungsjurisprudenz oder der Moralisierung des Rechts (Pauer-Studer 2014: 20ff.) erklären könnte. Unter Umständen zeigen sich dann die extremen Möglichkeiten einer normativistischen Regierungstechnologie, die sich im Wandel des normativen Zweckdispositivs (so bereits im Weimarer Methodenstreit) entfaltet. Allerdings wäre eine solche These empirisch zu untersuchen.

624 Insofern wird auch verständlich, weshalb sich trotz harscher Kritik seitens zahlreicher Rechtswissenschaftler die Interessenjurisprudenz letztlich gegenüber den soziologischen Ansätzen im Freirecht durchsetzt - ein Umstand, der durch die Hinwendung der Rechtspraxis selbst zur teleologischen Methode in den Zwischenkriegsjahren gestützt wird (vgl. etwa Dombek 1969: 57ff.).

625 Das bedeutet zugleich: Erst dadurch tritt die Wert- und Wertungsorientierung ins Zentrum der Rechtswissenschaft. Aus diesem Grund handelt es sich auch bei der „reinen“ Begriffs- und Konstruktionsjurisprudenz nicht um eine Prinzipienjurisprudenz im normativen Sinne (vgl. Petersen 2008: 99 m.w.N.). 
der herkömmlichen Rechtswissenschaft, die verstärkt als Begriffsjurisprudenz in Verruf gerät (l'urgence). Dabei wird deutlich, dass sich das richterliche Urteil keineswegs in einer logischen Ableitung erschöpft, sondern andere als juristisch-dogmatische Faktoren unausweichlich zum Tragen kommen, nämlich Wertungen und Werturteile. Die wissenschaftliche Behandlung dieses Problems erweist sich angesichts der nun hervorgehobenen Lückenhaftigkeit jeglicher Rechtssetzung als besonders dringlich, stößt die Begriffsjurisprudenz in solchen - aufgrund des gegenwärtigen schnellen gesellschaftlichen Wandels zudem vermehrt auftretenden - Situationen doch an ihre Grenzen.

Wenn die Angriffe gegen die Begriffsjurisprudenz nun im Namen der Wissenschaftlichkeit, der Rechtssicherheit und der drohenden Ungerechtigkeit einer lebensfernen Dogmatik erfolgen, so geschieht dies vor dem Hintergrund der Unausweichlichkeit des normativen Werturteils im Recht. Dabei wird einerseits erneut an der Rechtsentstehungslehre der Historischen Rechtsschule angesetzt: Recht wird als gesellschaftlich produziertes Recht verstanden, das als "gelebtes Recht“ jedoch nicht mehr im Gesetz die Gesellschaft repräsentiert, sondern in eine Gegenüberstellung von Recht und Gesetz mündet. Dieses Recht, das man als gesellschaftliche Tatsache wissenschaftlich erforschen kann, soll die Grundlage einer wie auch immer gearteten lebensnahen und wissenschaftlichen Fundierung des rechtlichen Urteils liefern. Andererseits wird im Anschluss an das gesellschafts-funktionale Zweckdispositiv die gesellschaftliche Ordnungsfunktion des Rechts in den Vordergrund gerückt. Allerdings wird nun die normative Seite im Rahmen der Konfliktlösung betont, was zu einer Teleologisierung des Rechtsverständnisses führt. Für beide Wege gilt, dass sie das Recht der Gesellschaft in den Blick nehmen und nicht die Gesellschaft im Recht suchen - und das vor dem Hintergrund des Problems der wissenschaftlichen Handhabung der Normativität im Recht.

Bei der Diskussion dieser Problemlage auf der genuin juristischen Methodenebene zeigen sich dabei zwei Wege der strategischen Wiederaufladung des gesellschafts-funktionalen Zweckdispositivs: Auf der einen Seite wird ein Rekurs auf die Soziologie gefordert, indem man explizit juristisch zu verortende „soziologische Methoden“ entwickelt, die das richterliche Urteil wissenschaftlich zu begründen vermögen; auf der anderen Seite führt diese Frage zu einer Teleologisierung des Rechts und der Rechtsanwendung, die auf das Wertungsmoment in der Interessenabwägung abstellt. Der Zweck im Recht erscheint also einerseits in einem gesellschaftlichen Werturteil, das man soziologisch fundieren könnte, und andererseits in einem über rechtswissenschaftliche Methoden zu behandelnden Telos, dem über den Nachvollzug der empirisch zu ermittelnden Wertung zu be- 
gegnen sei. Das Verhältnis von Faktizität und Normativität des Werturteils im Recht steht letztlich im Mittelpunkt der jeweiligen Ansätze.

In der Diskussion und v.a. auch in der Kritik dieser Ansätze findet ein Wechsel auf die wissenschaftstheoretische Ebene statt. Die beiden zentralen Streitpunkte dieser Perspektive, d.h. die Frage nach der Rolle der Soziologie in der Rechtswissenschaft sowie das Bestimmungsproblem des Wesens der Rechtswissenschaft, werden nun überwiegend über die Problematisierung des Verhältnisses von Sein und Sollen angegangen. Indem sich diese Verlagerung auf die wissenschaftstheoretische Ebene verfestigt, erhält die normative Seite des Rechts ihre strategische Funktion im Diskurs. Denn daraus folgen gewichtige Verschiebungen im epistemischen Dispositiv der Privatrechtswissenschaft:

Im Zuge des Wechsels auf die wissenschaftstheoretische Ebene geht die Privatrechtstheorie in einer allgemeinen Rechtstheorie auf. Damit löst sie sich zugleich von der Gesellschaftstheorie (s.o.). Mehr noch: Die Soziologie tritt nun in Konkurrenz zur Rechtswissenschaft. Denn ausgehend von der Kritik an der Lebensferne und den drohenden Ungerechtigkeiten der Begriffsjurisprudenz (l'urgence) muss man sich einerseits der gesellschaftlichen Seite des Rechts zuwenden - und in diesem Sinne kommt die Soziologie ins Spiel. Da die Forderung einer Hinwendung zur Soziologie aber andererseits die Autonomie der Rechtswissenschaft als eigenständige Disziplin gefährdet, wird der daraus entstehenden Konkurrenzsituation nun auf der wissenschaftstheoretischen Ebene über die Unterscheidung der Wissens- (und Wirklichkeits-)Formen begegnet. Die Soziologie tritt als Seinswissenschaft der Rechtswissenschaft gegenüber, die in welcher Form auch immer an das Sollen gekoppelt wird.

Wenn dabei der Wissenschaftscharakter sowohl der Soziologie als auch der Rechtswissenschaften umstritten bleibt, so eint diese Ansätze, dass sie allesamt um die Verhältnisbestimmung der nun über Sein und Sollen voneinander getrennten Disziplinen ringen - sei es, dass über die Hinwendung zur Soziologie einer sollensbezogenen Jurisprudenz der Wissenschaftscharakter abgesprochen wird; sei es, dass von einem Wechselverhältnis ausgegangen wird und/oder dass der Hinwendung zu den Tatsachen des Rechts mittels der Soziologie als Vorbereitung und notwendige Ergänzung (mit dem Potential zur Irritation) verstanden wird; sei es, dass die gesonderte Disziplin der Rechtssoziologie eine Vermittlungsposition einnimmt; oder sei es, dass mit Blick auf den normativen Charakter der Normen der Soziologie die Fähigkeit zur rechtswissenschaftlichen Arbeit (bzw. wissenschaftlichen Arbeit am Recht) abgesprochen wird. Ausgetragen wird ein Werturteilsstreit in umgekehrter Perspektive: nicht die Frage, ob man von Tatsachen zu Sollensaussagen gelangen könne, sondern ob 
man angesichts der Unausweichlichkeit des Werturteils im Recht bzw. im richterlichen Urteil Tatsachenerkenntnisse integrieren könne, und damit eine Hinwendung zur Soziologie zu erfolgen habe. Darüber wird in den verschiedenen Positionen gestritten - und über die unterschiedlichen Beantwortungen dieser Frage, die am Rechtsbegriff und in der Rechtstheorie ansetzten, scheiden sie sich.

Die Soziologisierungsversuche der Rechtswissenschaft, die auf die Verfestigung des gesellschafts-funktionalen Zweckdispositivs in der Debatte um die Kodifikation des BGBs folgen, führen dabei letztlich zu einer Normativierung im Selbstverständnis der Rechtswissenschaften - und zwar auf breiter Front und selbst bei Befürwortern einer Hinwendung zur Soziologie. Diese Normativierung wiederum bewirkt eine Autonomisierung der Rechtswissenschaft gegenüber den Erkenntnissen der Soziologie, die nun als wissenschaftstheoretisch different eingeschätzt wird und deren Beziehung zur Rechtswissenschaft daher nun geklärt werden muss. ${ }^{626}$ Die Rechtswissenschaft bildet auf der Ebene ihrer Selbstbeschreibung und Methodenlehre damit normativistische Techniken aus, die es ihr (zunehmend) ermöglichen, sich von den Zumutungen der empirischen Wissenschaften zu befreien. Und genau damit bewirkt sie eine Immunisierung eines sich unpolitisch verstehenden Rechts gegenüber der Gesellschaft, der sie nun wertend gegenüber tritt.

Diese Verschiebungen gegenüber dem gesellschaftsfunktionalen Zweckdispositiv erklären zugleich die sehr ambivalenten Rekurse auf Jhering: Vor dem Hintergrund eines privatrechtlichen Diskurses, der sich entlang der Problematik der Normativität des Rechts, sein als Telos verstandener Zweck, entfaltet, erscheint es weder verwunderlich, wenn um zentrale Moment des Jhering'schen Zweckdenkens gerungen wird, noch, dass man ihn mit seinem Zweck als Urheber der neuen Bewegung ansieht (vgl. etwa Gmelin 1910b: 3; Kantorowicz 1925: 38f.; Heck 1912: 5; Nußbaum 1914:

626 Aus dieser Perspektive heraus, nämliche der Normativierung des Rechtsbegriffs und darüber der Rechtswissenschaft, werden dann auch die Anmaßungen der Soziologie kritisiert, selbst zu Aussagen über das Recht als genuin normativer Gegenstand bzw. generell zu normativen Aussagen gelangen zu können. So gerät etwa Durkheims Moralwissenschaft ins Visier der Kritik von Kelsen und auch - vermittelt über Leon Duguits Arbeiten zum Recht - von Carl Schmitt (vgl. hierzu insbesondere Terrier 2017). Bei Kelsen mündet diese Kritik in den 1910er und 20er Jahren in dem Nachweis, dass die Soziologie als eigenständige Wissenschaft unmöglich und vor allem sinnlos sei. Später relativiert er diese harsche Ablehnung (vgl. hierzu Balog 1983). 
8). Schon im Methodenstreit Anfang des 20. Jahrhunderts gilt, wie Radbruch rückblickend beschreibt:

Vor allem aber ist Jherings Lehre für die Jurisprudenz von unermeßlicher Wirkung geworden: Erscheinungen wie die Interessenjurisprudenz, die freirechtliche Bewegung, die teleologische Begriffsbildung sind von ihm ausgegangen und haben ihrerseits die Rechtspraxis für sich gewinnen gewußt. Im Zweckgedanken war eine bisher vernachlässigte Seite des Rechts wirksam zum Ausdruck gekommen. (Radbruch 1965: 10)

Auch wenn nun - angesichts des Rekurses auf die Soziologie als Ausdruck des geforderten Lebensbezugs - eine wie auch immer geartete gesellschaftswissenschaftliche Fundierung am Horizont aufscheint, so erfolgt trotz allem keine Auseinandersetzung mit Jherings Begründung der Rechtswissenschaft in der Gesellschaftslehre. Jherings Arbeit am Begriff der Gesellschaft, die letztlich als Basis seiner Zweckerläuterung anzusehen ist, vermag Anfang des 20. Jahrhunderts genauso wenig wie in der außerjuristischen Rezeption und im gesellschafts-funktionalen Zweckdispositiv zu überzeugen. Vielmehr gilt es nun, durch die Problematisierung des Verhältnisses von Sein und Sollen den Angriff auf die Autonomie der Rechtswissenschaft in Jherings gesellschaftstheoretisch fundierter Herangehensweise abzuwehren. Dies führt zu einer Normativierung des Rechtsbegriffs und der Rechtswissenschaft, die in Jherings ambivalentem Zweckbegriff das teleologische Moment hervorhebt. Daher erstaunt es auch nicht, dass Jhering mit seinem Zweck als Vorreiter einer solchen Hinwendung zur Normativität angesehen wird (vgl. Heck 1912: 5). Er gilt nun - so Kantorowicz - als Vorreiter einer finalistischen Epoche in den Rechtswissenschaften, wie sie insbesondere die Freirechtsbewegung verwirkliche: Der Finalismus gehe nicht vom Gesetzesbuch, sondern vom "Sinn“ der Wirklichkeit aus, von den als wertvoll erachteten Zwecken und Bedürfnissen des sozialen, geistigen, sittlichen Lebens" (Kantorowicz 1970 [1914]: 1). Damit wird eine realistische Perspektive propagiert, die jedoch zugleich das wertende Moment im Recht hervorhebt, ein Finalismus, der also nicht unter dem Kausalgesetz, sondern als Telos anzusehen ist.

Die Spannung, die in Jherings Zweck zwischen gesellschaftswissenschaftlicher und normativer bzw. zwischen funktionaler und teleologischer Perspektive im Rahmen seines Sozialutilitarismus besteht, wird auch im Rekurs auf Jhering nun zum Ausgangsproblem des Methodenstreits in den Rechtswissenschaften. Dies mündet in eine Normativierung des Rechtsverständnisses und der Rechtswissenschaft. Wenn also im normativen Zweckdispositiv eine Verkürzung der Rezeption des Jhering'schen 
Zweckdenkens zu erkennen ist, die dessen gesellschaftstheoretische Überlegungen außen vor lässt, so führt das zum wissenschaftstheoretischen Streit über das Verhältnis von Sein und Sollen.

Die verschiedenen Ansätze im Methodenstreit bleiben bis in die 1920er Jahre in dieser Problematisierung des Verhältnisses von Sein und Sollen verfangen, die zu der Frage der Verhältnisbestimmung von Soziologie und Rechtswissenschaft führt. ${ }^{627}$ Anders formuliert: Das normative Zweckdispositiv in der Privatrechtswissenschaft zeichnet sich im Methodenstreit angesichts des Zwecks im Recht, der immer auch auf eine gesellschaftliche Ebene verweist, durch den Versuch der Bestimmung der Rolle der Erkenntnis gesellschaftlicher Tatsachen für die Rechtswissenschaften aus und bleibt damit selbst über die Abgrenzung der rechtswissenschaftlichen Tätigkeit vom soziologischen Blick in weiten Teilen dem Versuch einer Anbindung an die gesellschaftliche Praxis verpflichtet. Allenfalls Kelsen bricht in seiner radikalen Reinigung der Rechtswissenschaften aus diesem Schema aus, wobei selbst er immer wieder die Notwendigkeit soziologischer Forschung betont (vgl. Balog 1983: 515), auch wenn es sich dabei aber nicht um Rechtswissenschaft handele. ${ }^{628}$ Wenn also die Rechtswissenschaft über ihren Gegenstand oder ihren Wissenschaftscharakter in ein wertendes Verhältnis zur Gesellschaft tritt, so wird dieser Spannungscharakter im normativen Zweckdispositiv aufrechterhalten. Und die Soziologie steht zu Beginn des 20. Jahrhunderts in direkter Konkurrenz zur Rechtswissenschaft.

627 In diese Diskurslage sind auch die im Rahmen der staatstheoretischen Debatten anzusiedelnden marxistischen Ansätze etwa von Franz Neumann und Otto Kirchheimer einzuordnen, die beide in den 1920er und -30er Jahren das Verhältnis von Klassenstruktur und Recht problematisieren (vgl. hierzu Buckel 2007: 80ff.).

628 Letztlich markiert er m.E. einen Übergang zu einer neuen Problematisierungsweise von Recht und Gesellschaft, die sich v.a. im Methodenstreit der Weimarer Staatsrechtslehre entfaltet und in Texten wie Carl Schmitts Über die drei Arten des rechtswissenschaftlichen Denkens (Schmitt 1934) zum Ausdruck kommt. So wird in Folge die rechtswissenschaftliche Methode etwa über die Fragen nach Staat, Verfassung, Souveränität, politischer Form und Erkenntnistheorie problematisiert. Diese Thesen bedürfen allerdings ebenfalls konkreter empirischer Forschung. 


\section{Zweiter Teil.}

\section{Juridische Soziologien: Soziologische Adressierungen des Rechts in der entstehenden Soziologie}

Die Historische Rechtsschule führt das epistemische Ding, Gesellschaft ${ }^{\star}$ in den privatrechtswissenschaftlichen Diskurs ein. Nun muss das Verhältnis zwischen Recht und Gesellschaft bestimmt werden - ein Problem, das seinen Ausdruck zunächst im Repräsentationsdispositiv, dann im gesellschaftsfunktionalen und schließlich im normativen Zweckdispositiv findet. Das Recht steht der Gesellschaft also zunächst repräsentierend, dann ordnend und schließlich wertend gegenüber. Vice versa ist damit das Recht für die Bestimmung der Gesellschaft maßgeblich, gerade weil es diese repräsentiert, ihre Ordnung sichert oder aber als ihre abgesonderte Wertsphäre erscheint. Und in der Tat erweisen sich die drei verschiedenen Arten der Verhältnisbestimmung von Recht und Gesellschaft als wirkungsvolle epistemische Schemata, die zur Genese der Soziologie als eigenständige Disziplin beitragen. Dies lässt sich deutlich an den Arbeiten von Émile Durkheim, Ferdinand Tönnies und Max Weber zeigen, die ihre Soziologien unter anderem jeweils aus der Auseinandersetzung mit den drei rechtlichen Dispositiven entwickeln. Man kann daher von ,juridischen Soziologien'sprechen, gerade weil diese Auseinandersetzung eine jeweils theoriekonstitutive Funktion erfüllt. Genau diese Funktion wird im Folgenden rekonstruiert.

Zugleich aber werden innerhalb der soziologischen Aktualisierungen der Verhältnisbestimmung von Recht und Gesellschaft von den drei Autoren Abzweigungen gewählt, die das Recht in den Hintergrund treten lassen. In dieser Bewegung, die einerseits das Recht für die zu begründende Disziplin der Soziologie zentral setzt, jedoch zugleich der weiteren soziologischen Auseinandersetzung mit dem Recht die Notwendigkeit nimmt, ist der Ursprung der Probleme der Soziologie mit dem Recht zu suchen, wie sie eingangs erwähnt wurden. 


\section{\6. Émile Durkheim und das Repräsentationsdispositiv}

Émile Durkheim will in seinen frühen Arbeiten die Soziologie als eine neue, eigenständige Disziplin im wissenschaftlichen Fächerkanon begründen (statt vieler Lukes 1973: 66ff.). Für dieses Vorhaben ist die Auseinandersetzung mit dem Recht zentral (vgl. Schluchter 2000b). ${ }^{629}$ Daher findet sie sich v.a. in seinen frühen Schriften. ${ }^{630}$ Dort beschäftigt er sich unter anderem mit den wissenschaftlichen Vorläufern der neuen Disziplin Soziologie, um ihr eine wissenschaftliche Fundierung zu geben - und findet jene zu einem guten Teil bei den Juristen. ${ }^{631}$ Daneben folgt das besondere Interesse Durkheims am Recht nicht nur aus seiner Bestimmung als Gegen-

629 Diese Erkenntnis ist nicht neu, wobei die explizite Untersuchung der theoriekonstitutiven Funktion der Auseinandersetzung mit dem Recht bei Durkheim (vgl. etwa Gephart 1993a: 321ff.; Jones 1994b) nach wie vor eine Ausnahme darstellt. Allerdings lassen sich auch in diesen Arbeiten - wie im Übrigen in Webers Fall - eine Engführung auf die Rechtssoziologie erkennen.

630 Auch wenn Durkheim seine Vorlesung „Physiologie“ respektive „Physik der Sitten und des Rechts" aus dem Jahr 1890/91 bis an sein Lebensende abhielt und er fortlaufend Rezensionen juristischer Arbeiten für die L'Année sociologique verfasst, tritt das Recht nach der Jahrhundertwende in seiner theoriekonstitutiven Funktion zugunsten der Religion in den Hintergrund. Das bedeutet aber nicht, dass Durkheim seine Überlegungen zum Recht nicht weitergeführt hätte (vgl. etwa die Beiträge in Lukes, Scull 1983). Auch sind hier konzeptionelle Änderungen insbesondere infolge seiner religionssoziologischen Arbeiten - auszumachen, die Ansätze für die Überwindung der Schwächen der Indexthese bieten (vgl. insbesondere Cotterrell 1999). All das wird hier vernachlässigt, um die theorie- und disziplinen-konstitutive Funktion der Auseinandersetzung mit dem Recht in seinen frühen Schriften deutlich herauszuarbeiten.

631 Durkheims Strategie, die Soziologie als neue Wissenschaft im Kanon der Disziplinen zu etablieren, lässt sich sicherlich nicht nur über seine theoretischen $\mathrm{Ab}$ handlungen erklären, ohne eine Verbindung zur akademischen, intellektuellen, politischen und sozialen Geschichte zu ziehen (vgl. etwa Lepenies 2006: 49ff.). Eine entscheidende Rolle spielen auch institutionelle Aspekte wie die generelle Aufteilung (und Entgegensetzungen) der Fachgebiete an den Universitäten (vgl. Clark 1973; kritisch hierzu Chamboredon 2013: Rn. 10ff.), sowie die Etablierung einer außeruniversitären interdisziplinären eigenen Schule der Durkheimianer v.a. im Rahmen der von Durkheim begründeten Zeitschrift L'Année sociologique (vgl. Clark 1981). Da es hier jedoch nicht um die tatsächlichen Strategien in ihrer Fülle, sondern um den strategischen Rekurs auf das Recht im Rahmen der Begründung der Soziologie geht, wird sich auf Durkheims textuelle Adressierungen des Rechts konzentriert. 
stand einer - von der allgemeinen Soziologie zu unterscheidenden - „besonderen Soziologie“, 632 der im Rahmen einer gesonderten Sektion in der L'Année sociologique („Sociologie morale et juridique“) zahlreiche, zum Teil von ihm verfasste Rezensionen gewidmet sind. ${ }^{633}$ Das Recht als eine unzweifelhaft moralische Tatsache wird für Durkheim vielmehr zum zentralen Gegenstand einer Soziologie, die im Hinblick auf die krisenhaften Entwicklungen und Tendenzen der arbeitsteiligen Gesellschaft als eine positive, empirische „Wissenschaft der Moral“ zu entwerfen ist (vgl. Müller 1983). Eine solche Adressierung des Rechts hat Auswirkungen auf die Frage, was man im Recht erkennen kann, zeitigt aber ebenso Folgen auf methodologischer Ebene, wenn es nämlich darum geht, die Regeln der Methode einer soziologischen Moralwissenschaft zu entwickeln.

Um das Recht im Rahmen der Begründung der neuen wissenschaftlichen Disziplin der Soziologie auf diese Art und Weise adressieren zu können, rekurriert Durkheim in spezifischer Art und Weise auf das Repräsentationsdispositiv. Denn auch wenn er dieses epistemische Schema im Rahmen seiner soziologischen Adressierung des Rechts auf charakteristische Weise umdeutet, sind es doch gerade die Rechtsentstehungslehre sowie der Repräsentationsgedanke, denen er letztlich eine disziplinen-konstitutive Funktion zuschreibt.

\section{Die juristischen Vorläufer der Soziologie und die Gewohnheitsrechtslehre}

Durkheims Suche nach den juristischen Vorläufern der Soziologie führt ihn insbesondere zu Jhering und Montesquieu. In ihren Rechtsphilosophien bzw. -theorien macht Durkheim in der Frühphase seines Schaffens spezifische Umstellungen in der Analyse des Rechts aus, die er zu den Bedingungen der Etablierung einer genuin soziologischen Perspektive als Voraussetzung einer eigenständigen Disziplin zählt. Dabei setzt er sich durchaus kritisch mit diesen Autoren auseinander, während er den spezifisch soziologischen Gehalt ihrer Ansätze herausarbeitet. Diese Kritik offenbart zugleich seine spezifische Problematisierungsweise des Rechts, indem er nämlich die Rechtsentstehungslehre der Historischen Rechtsschule aufgreift.

$632 \mathrm{Zu}$ den verschiedenen Formen der Klassifikation der Soziologie in allgemeine und besondere Soziologie(n) bei Durkheim vgl. die Anmerkungen bei Chamboredon 2013: Rn. 30ff.

633 Siehe die entsprechenden Beiträge in der dreibändigen Sammlung der Texte Durkheims von Victor Karady (Durkheim, Karady 1975a-c). 


\section{Jhering und die positiven Moralwissenschaften in Deutschland}

In seinen frühen Publikationen aus den 1880er Jahren bekundet Durkheim ein großes Interesse an den philosophischen und sozialwissenschaftlichen Arbeiten in Deutschland. ${ }^{634}$ Dieses zeigt sich insbesondere in seinen akademischen Reiseberichten, die er nach einem mehrmonatigen Studienaufenthalt an deutschen Universitäten im Jahr 1887 veröffentlicht (Durkheim 1995a, b [1887]). ${ }^{635}$ Darin drückt er seine Wertschätzung der spezifischen deutschen Art der Moralwissenschaften jenseits von Spiritualismus, Kantianismus und Utilitarismus aus. Sie entsprang nach Durkheim dem „Protest gegen die Verwendung der Deduktion in den moralischen Wissenschaften und [ist] ein Versuch, in ihr endlich eine wahrhaft induktive Methode heimisch zu machen" (Durkheim 1995b [1887]: 165). Denn „[a]lle Moralphilosophen, von denen wir hier sprechen, sehen in den sozialen Phänomenen Fakten sui generis, die man mit einer besonderen Methode gesondert untersuchen muss" (ebd.: 107 FN 19). So gesehen erkennt Durkheim in der deutschen Moralwissenschaft den Wegbereiter der Soziologie. ${ }^{636}$

Das Besondere liege in den rechtstheoretischen Umstellungen. Die Leistung der deutschen Moralwissenschaft bestehe nämlich insbesondere darin, die Prämisse eines auf das Subjekt begründeten unwandelbaren Naturrechts zu Fall gebracht zu haben: „Die neuen Moraltheoretiker, wie auch die neuen Volkswirtschaftler weisen darauf hin, daß jener sich stets und überall gleich bleibende Mensch an sich eine reine Abstraktion ist und niemals real existiert hat." (Durkheim 1995a [1887]: 58) Damit aber erscheine die Moral nicht mehr als etwas „Abstraktes, Inertes und Totes, das von einer überpersönlichen Vernunft betrachtet wird“ (ebd.). Sie zeige sich

634 Vgl. etwa Durkheim 1885c; 1885b; 1886; 1888; 1889; 1991a [1889]. Im Vergleich zu Frankreich seien in Deutschland größere intellektuelle Anstrengungen zu erkennen, die Soziologie zu etablieren: „C'est ainsi que la sociologie, française d'origine, devint de plus en plus une science allemande.“ (Durkheim 1885b: 627).

635 Vgl. hierzu Lukes 1973: 87ff.; Filloux 1977: 24ff.; Gephart 1993a: 326ff.; Gipper, Schultheis 1995; zum ,deutschen Einfluss' insbesondere Lepenies 2006: 80ff.; Jones 1994b; Feuerhahn 2014 sowie „Chapitre 3: Sources et modèles, l'influence allemande" in Durkheim, Karady 1975a.

636 Gerade diese Herleitung der Soziologie aus Ansätzen des ehemaligen Kriegsgegners und ideologischen Erzfeinds der französischen Dritten Republik kritisiert der Neo-Thomist Simon Deploige in seiner Polemik gegen diese neue Disziplin, woraufhin Durkheim den Einfluss deutscher Denker zu relativieren sucht (vgl. die Nachweise bei Feuerhahn 2014: 80; Lepenies 2006: 80ff.). 
vielmehr als ein positiver Faktor des kollektiven Lebens, als ein eigenständiger Gegenstandsbereich (vgl. Durkheim 1995b [1887]: 107), der jedoch stets im Wandel begriffen sei. Durkheim erkennt in dieser Veränderung eine „faktenorientiertere Wendung“ (ebd.: 108), die die Moral dem „Kraftfeld der Metaphysik und der allgemeinen Philosophie“ (ebd.: 107) entzieht und zum Gegenstand einer empirischen Disziplin - und damit der Sozialwissenschaft - werden lässt.

Auch wenn sie erst in den Kinderschuhen stecke, erweise sich die deutsche Moralwissenschaft in dieser spezifischen Prägung als anschlussfähig für die neue Disziplin der Soziologie. Denn die Moral sei damit nicht nur Gegenstand einer spezifischen Sozialwissenschaft, sondern stellt für Durkheim - wie er bereits ein Jahr später in der Eröffnung seiner Vorlesung „Einführung in die Sozialwissenschaft" an der Universität Bordeaux aus dem akademischen Jahr 1887/88 kundtut - denjenigen Bereich der Soziologie dar, „dem wir den Vorzug geben und mit dem wir uns zuerst befassen werden" (Durkheim 1991b [1888]: 48). ${ }^{637}$ Das primäre Anliegen seiner Soziologie ist es, moralische Phänomene entsprechend der Methode der positiven Wissenschaften zu untersuchen bzw. - wie er im Vorwort zur ersten Auflage der Arbeitsteilung im Jahr 1893 schreibt - eine „Wissenschaft der Moral“ zu betreiben (z.B. Durkheim 1996 [1893]: 76).638 Das wollen auch die neuen Moraltheorien, wie er sie insbesondere in der deutschen Nationalökonomie und der Rechtswissenschaft vorfindet.

Über die Feststellung dieser Konvergenz wird die neue Disziplin Soziologie in das wissenschaftliche Feld eingebettet. Denn dank der Übereinstimmung mit diesen beiden Wissenschaften

verliert die Soziologie [...] schlagartig den Charakter der Improvisation, der ihr bisher angehaftet hatte und der manchmal Zweifel an ihrer Zukunft aufkommen ließ. Sie erscheint nicht mehr als ein Wunder, das eines schönen Tages aus dem Nichts entstand, sondern sie hat jetzt ihre historischen Vorläufer [...]. (Durkheim 1991b [1888]: 43)

Ja, letztlich habe man sich sogar bei der Schaffung der Vorlesung „Einführung in die Sozialwissenschaft“ gefragt, „ob ihr Platz nicht eher an der Ju-

637 Demgegenüber definiert Durkheim im Jahr 1887 die Soziologie noch nicht als Moralwissenschaft, wenn er schreibt: „Die Moral ist keine Folge oder eine Art Fortführung der Soziologie, sondern eine Sozialwissenschaft für sich und neben anderen." (Durkheim 1995b [1887]: 166).

638 Vgl. statt vieler Turner 1993; Karsenti 2013; Isambert 2013 jeweils m.w.N. 
ristischen Fakultät sei“ (ebd.: 50).639 Die Entwicklung der Moralwissenschaften garantiert bei Durkheim also die Wissenschaftlichkeit der neuen Disziplin Soziologie, die sich über ihre Hinwendung zur Moral in die Entwicklung der Wissenschaften selbst einzuschreiben vermag (vgl. ebd.).

Der beschriebene Transformationsprozess in den Moralwissenschaften ging nach Durkheim einerseits von den Wirtschaftswissenschaftlern, namentlich von Kathedersozialisten wie Schmoller und Wagner, aus;640 andererseits von den juristischen Entwürfen einer neuen Rechtsphilosophie jenseits des Naturrechtsdenkens, wie sie insbesondere Jhering ${ }^{641}$ vorgelegt habe (vgl. Durkheim 1995b [1887]: 86; 1995a [1887]: 53f.; 1991b [1888]: 43). ${ }^{642}$ Jherings Zweck im Recht stehe dabei paradigmatisch für ein solches Denken des Rechts, das einerseits Recht und Moral in einer einheitlichen Normenordnung miteinander verbindet und andererseits dadurch das em-

639 Nicht ohne Stolz berichtet Durkheim in seiner Einführung in die Soziologie der Familie davon, dass dieser Kurs wiederholt von der Rechtsfakultät beansprucht wurde (vgl. Durkheim 1991c: 74).

640 Durkheim ging von der Kritik an der naturrechtlich inspirierten Idee der Trennung von Moral und Ökonomie in der theoretischen ,Manchesterschule ${ }^{6}$ aus. Eine Sonderstellung bei den Wirtschaftswissenschaftlern gebühre Albert Schäffle, dessen Bau und Leben des sozialen Körpers. Erster Band Durkheim bereits in seiner ersten Veröffentlichung bespricht (Durkheim 1885c). Im Gegensatz zu den Kathedersozialisten habe jener nämlich den „schweren Irrtum“ vermieden, die Gesellschaft als vom Gesetzgeber leitbar anzusehen. Gegen diese konventionelle Rechtsauffassung habe Schäffle zurecht gekämpft (Durkheim 1995b [1887]: 102f.) Mit dieser Interpretation verteidigt Durkheim Schäffle gegen die in Frankreich dominierende Gruppe der „orthodoxen“, d.h. der freihändlerischen Ökonomen, die dessen Soziologie als Sozialismus verwerfen (Durkheim 1995b [1887]: 87; 1885a: 447; s.a. 1888; Feuerhahn 2014: 80f.; zu Durkheims ambivalentem Verhältnis zum Sozialismus vgl. Durkheim 1993; Filloux 1977; zu seinem Verhältnis zum französischen Solidarismus s. Gülich 1991).

641 Durkheims Interesse gerade für Jherings Arbeiten mag sich auch daraus erklären, dass in den 1880er Jahren begonnen wurde, Jherings Schriften ins Französische zu übersetzen (etwa L'esprit du droit romain dans les diverses phases de son développement 1880; Etudes complementaires de l'esprit du droit romain, 1880-1903).

642 Der von Durkheim so hoch geschätzte Wilhelm Wundt wiederum brachte mit seiner Ethik diese Entwicklung auf den Punkt, habe er es doch vermocht, ,all diesen Versuchen, die bis dahin ein wenig unentschlossen und über sich selbst und ihr Ziel nicht recht im klaren waren, Gestalt zu verleihen" (Durkheim 1995b [1887]: 85). In Rechtswissenschaft, Ökonomie und Ethik findet sich Durkheim mit einer Art Paradigmenwechsel vom Individuum zur Gesellschaft konfrontiert, der von der Kritik des Naturrechtsdenkens ausgeht und auf die Entstehung seiner Idee einer unabhängigen Soziologie als neu zu schaffende Wissenschaft von der Gesellschaft maßgeblichen Einfluss hatte (vgl. Gipper, Schultheis 1995: 12). 
pirische Studium der Sitten als Ausgangspunkt nehmen kann (vgl. Durkheim 1995b [1887]: 120).643 Dabei stimmt Durkheim den Jhering'schen Thesen in vielen Punkten explizit zu: Auch er versteht das Recht als eine Art der sozialen Normen, deren Spezifik gegenüber anderen Normen über die beiden Elemente „äußerlicher Zwang“" und „Körperschaft“ (Gericht, bei Jhering Staat) zu bestimmen sei (vgl. Durkheim 1996 [1893/1902]: 144ff.). ${ }^{644}$ Insofern ist Recht nach Durkheim ebenfalls ein Machtbegriff, da es aus Interessenkonflikten hervorgehe und diese regele (Durkheim 1995b [1887]: 116). V.a. aber stimmt er Jherings These zu, dass das Recht - ebenso die Moral, insofern Rechtsvorschriften doch letztlich nur besondere Kristallisationsformen bestimmter moralischer Regeln seien (vgl. 1991b [1888]: 45f., 51) - einen bestimmten Zweck habe: die Sicherung der Lebensbedingungen der Gesellschaft. ${ }^{645}$ Das sei seine "Sozialfunktion" (1995b [1887]: 104). Recht lasse sich weder von einem apriorischen Subjekt noch von Spekulationen der Vernunft ableiten, sondern sei ein Mittel zum Zweck (ebd.: 117). Dieser Zweck bestehe darin, die soziale Ordnung zu garantieren (ebd.: 118). Wenn man daher das - unzweifelhaft soziologische - Phänomen des Rechts erfassen wolle, muss man Durkheim (wie Jhering) zufolge seinen Zweck, und d.h. seine gesellschaftliche Funktion, zu erfassen suchen (vgl. ebd.: 110). Daher bildet auch für Durkheim der Nutzen den stets relativen Maßstab des Rechts: „Eine Rechtsbestimmung zu beweisen, bedeutet nicht, nachzuweisen, daß sie wahr ist, sondern daß sie etwas nützt, daß sie dem Zweck, den sie erfüllen soll, angemessen ist.“ (Ebd.)

643 Während Durkheim in diesem Aufsatz die empirischen Arbeiten zur Rechtsvergleichung von Albert Hermann Post dahingehend kritisiert, dass er letztlich nur Details sammele, aber nichts erkläre (Durkheim 1995b [1887]: 161ff.), schreibt er ihm ein Jahr später eine gleichbedeutende Rolle wie Jhering in der Entwicklung der Rechtswissenschaft zu (Durkheim 1991b [1888]: 43).

644 Da der äußerliche Zwang allen moralischen Normen eigne, betont Durkheim die Organisiertheit als Differenzierungskriterium, um das Recht von anderen sozialen Normen unterscheiden zu können (vgl. Durkheim 1900).

645 Mit dieser Annahme nähert sich Durkheim später auch Jherings Ansatz der Subjektivierung der Gesellschaft an. Obwohl Durkheim zwar von der Gesellschaft nicht als „Zwecksubjekt“, sondern in Anlehnung an Wundt als „Zweckobjekt" der moralischen Regeln spricht (Durkheim 1976a [1906]: 102), fasst er sie wie Jhering als „kollektives Subjekt“ oder „moralische Person“, die als eigenständiges Subjekt jenseits der individuellen Subjekte zu verstehen ist. Schon zuvor zog er nämlich den „logische[n] Schluß: Wenn die Gesellschaft das Ziel der Moral ist, so ist sie auch ihre Schöpferin." (Durkheim 2011 [1925 posthum]: 134). 
Trotz dieser Zustimmung steht Durkheim Jhering nicht kritiklos gegenüber. Seine Einwände richten sich insbesondere gegen die Idee des Rechtswandels, die Jhering aus der Fundierung des Rechts im Zweck entwickelt. ${ }^{646}$ Indem Jhering den Motor der Rechtsentwicklung im alltäglichen Kampf um die Behauptung des Rechts sieht, bestimmt er den Zweck als Telos, d.h. als praktisches Motiv der Rechtssätze, als bewegende Kraft im Recht. Dies führt in der Folge nicht nur zur Aufwertung der Gesetzgebung, die den Rechtssätzen ein solches Telos zugrunde legt, sondern mündet konsequenterweise in die Trennung einer am mechanischen Kausalgesetz orientierten Naturwissenschaft und einer am Zweckgesetz orientierten Wissenschaft des Rechts. Soziale Phänomene wie das Recht (und überhaupt die sozialen Normen) gehorchen nicht den Naturgesetzen und sind daher auch der menschlichen, willentlichen Intervention, der Zwecksetzung, zugänglich (s.o. \$3.I).

Durkheim wendet sich gegen die Annahme einer solchen Verfügbarkeit des Rechts. ${ }^{647}$ Er setzt mit seiner Kritik dabei an Jherings Rechtsentstehungs- und -entwicklungslehre an (Durkheim 1995b [1887]: 154) - und genau dies rückt ihn in die Nähe der Historischen Rechtsschule. ${ }^{648}$ Denn auch Durkheim sieht die Quelle des Rechts in der Gewohnheit: Mit den „Sitten“ entstehe ,jener Urkern, aus dem dann später das Recht und die Moral hervorgehen. Recht und Moral nämlich sind nichts anderes als Kollektivgewohnheiten, das heißt konstante Handlungsmuster, die einer ganzen Gesellschaft gemeinsam sind." (Ebd.: 95) Wenn also alles Recht aus dem - später explizit benannten - „Gewohnheitsrecht" komme (Durkheim 1996 [1893/1902]: 124), so liege die zwingende Kraft nicht nur in der "Autorität des Brauches“, sondern ebenso in dem „mehr oder weniger deutliche[n] Gefühl, daß der öffentliche Nutzen sie erfordert“ (Durkheim

646 Anders jedoch Werner Gephart, demzufolge Durkheim an Jhering v.a. die handlungstheoretische Fundierung der Sozialwissenschaft kritisiere (vgl. Gephart 1993a: 326ff.).

647 Dafür hatte er schon die ansonsten von ihm geschätzten Kathedersozialisten kritisiert (vgl. Durkheim 1995b [1887]: 102ff.).

648 Durkheim rechnet im Übrigen auch Jhering (sowie Post) der Historischen Rechtsschule zu, wobei er das Spezifikum dieser Schule - wie die französischen Juristen in ihrer Rezeption der Historischen Rechtsschule (vgl. Bürge 1991: 150ff.) - in der Historisierung des Rechts sieht (vgl. Durkheim 1995b [1887]: 155). Aus der dadurch bedingten Relativierung wird ihm zufolge die Verfügbarkeit des Rechts hergeleitet. Er erkennt nicht, dass die Historische Rechtsschule mit ihrer Lehre im Rahmen des Kodifikationsstreits gerade gegen eine solche Verfügbarkeit anschrieb. Zu Durkheims Verhältnis zur Historischen Rechtsschule siehe auch Jones 1999: 194ff. 
1995b [1887]: 95). Dieses Gefühl wiederum entspringe der kollektiven Ebene (ebd.; s.a. 1996 [1893/1902]: 126), d.h. der Gesellschaft, so wie Moral und Recht „Funktionen des gesellschaftlichen Organismus“ seien (Durkheim 1995b [1887]: 104). ${ }^{649}$

Ein Rechtswandel erfolgt nach Durkheim angesichts dieser Rechtsentstehungslehre also weder über einen willentlichen Akt oder eine Zwecksetzung noch über generalisierte Nützlichkeitserwägungen, sondern über den Wandel der kollektiven Sphäre des Brauchs bzw. des kollektiven Gefühls, also aufgrund dessen, was Durkheim später „Kollektivbewusstsein“ nennen wird. Der Wandel des Rechts folgt dem Wandel der Gesellschaft. Wenn demnach Moral und Recht historische Produkte sind, können sie nicht individuell bzw. willkürlich verändert werden (vgl. ebd.: 174f.). Daher nimmt der Gesetzgeber bei Durkheim eine ähnlich untergeordnete Rolle ein wie sie Savigny in seiner Volksgeistlehre bestimmt hatte: „Der Gesetzgeber erfindet die Gesetze nicht, sondern kann sie lediglich feststellen und klar formulieren." (Ebd.: 104f.) Oder, wie Durkheim ein Jahr später schreibt: „Das Recht arbeitet sich aus dem Innern der Gesellschaft selbst hervor, und der Gesetzgeber bestätigt nur ein Werk, das sich ohne ihn vollzogen hat." (Durkheim 1991b [1888]: 50f.) Gesetze (Recht) seien das "gemeinsame Werk der Gesellschaft“" (Durkheim 1995b [1887]: 105), und daher nicht der sozialpolitischen oder sonstigen Intervention anhand von „sozialen Zwecke[n]“ zugänglich (ebd.: 106). Sie ließen sich insbesondere deshalb nicht willkürlich gestalten, als Moral (und damit Recht) selbst ein „natürlicher Tatbestand“ sei: „Die moralischen Gesetze und das Reich des Sozialen unterscheiden sich von den anderen Bereichen der Natur nur durch Nuancen und Gradunterschiede.“ (Ebd.: 101f.) Dann könnten aber trotz ihrer (historischen) Flexibilität Veränderungen „nur aus einem Zusammenwirken von Naturgesetzen hervorgehen“ (ebd.: 102).

Wenn aber moralische und rechtliche Phänomene dem Wandel des Zusammenwirkens der Naturgesetze unterliegen, dann ergebe erstens Jherings Aussonderung der ,gesellschaftswissenschaftlichen' Analyse des Rechts aus dem Bereich der kausalgesetzlich verfahrenden Naturwissenschaft über das Zweckgesetz keinen Sinn. Zweitens müsse der soziale Zweck induktiv aus der Beobachtung abgeleitet werden, weshalb er gerade nicht als vorgegebenes Telos einer sozialpolitischen Intervention fungieren

649 So schreibt Durkheim über die Moral: „Sie ist eine Sozialfunktion oder vielmehr ein System von Funktionen, das sich allmählich unter dem Druck der kollektiven Bedürfnisse herausgebildet und gefestigt hat." (Durkheim 1995b [1887]: 104). 
könne. ${ }^{650}$ Wenn also Durkheim Jherings Zweckdenken zustimmt, dann nur unter der Prämisse, dass man unter dem „sozialen Zweck“ die gesellschaftliche Funktion des Rechts und keinerlei inhaltlich bestimmtes Telos oder Nutzen wie Sittlichkeit oder Nützlichkeit versteht (s.a. Durkheim 1996 [1893/1902]: 95). ${ }^{651}$ Dann wird das Recht und - über Jherings Einbettung in das Kontinuum der sozialen Normen auch - die Moral einer streng empirisch-induktiv verfahrenden Wissenschaft zugänglich. Die Moral wird zum Gegenstand der Sozialwissenschaft, der mit einer eigenen Methode, nämlich „Beobachtung und das indirekte Experimentieren, mit anderen Worten die vergleichende Methode“ (Durkheim 1991b [1888]: 44), untersucht werden könne (vgl. Durkheim 1995b [1887]: 165f.). Das setzt aber in Durkheims Argumentation voraus, dass man der Rechtsentstehungslehre der Historischen Rechtsschule folgt, da nur sie die Unverfügbarkeit der Moral und des Rechts sichert.

\section{Montesquieus Beitrag zur Gründung der Soziologie}

Wie sehr Durkheim dem epistemischen Schema der Rechtsentstehungslehre der Historischen Rechtsschule verhaftet ist, zeigt nicht nur seine Auseinandersetzung mit Jhering, sondern auch seine durchaus kritische Würdigung von Montesquieus bedeutendem Beitrag zur Gründung der Soziologie (Durkheim 1991d [1892]).652 Dieser habe mit seinem Werk De l'Esprit des

650 Durkheim sieht diesen Irrtum auch bei den nationalökonomischen Kathedersozialisten (vgl. ebd.: 103ff.).

651 Mit Blick auf Jhering müsse man also den Nutzen als Funktion und nicht im Sinne einer utilitaristisch zu verstehenden Nützlichkeit verstehen. Zudem wendet Durkheim gegen Jhering ein, dass das Kriterium der Nützlichkeit nicht unbedingt eine bewusste, bestimmende Ursache sei (Durkheim 1995b [1887]: 111). Zeitlicher Bestand und Verbreitung der Phänomene seien jedoch Indizien für eine solche Nützlichkeit: „Zweifellos gibt es Phänomene, die zu gar nichts dienen und die an nichts angepaßt sind; aber wenn sie fortdauern und vor allem wenn sie sich allgemein verbreiten, kann man einigermaßen sicher sein, daß sie nützlich sind, bzw. nützlich geworden sind. Zumindest kommt dieser Hypothese die größte Wahrscheinlichkeit zu, und daher muß sie auch vorrangig erprobt werden." (ebd.: 112).

652 Denn selbst wenn man anerkennt, daß es ,immer ein Fehler [war], die Geburtsstunde einer Wissenschaft diesem oder jenem Denker zuzuschreiben [...], dennoch bleibt Montesquieu derjenige, der die fundamentalen Prinzipien der Sozialwissenschaft zuerst dargelegt hat" (Durkheim 1991d [1892]: 126). Zu Durkheims lateinischer These über Montesquieu vgl. die Beträge von Peyre und Davy in Durkheim 1960 sowie insbesondere Jones 1994a. 
Lois den "Grundstein“ für die neue Wissenschaft der Soziologie gelegt (ebd.: 87). Denn er „entdeckte die beiden fundamentalen Ideen, die zur Errichtung der Sozialwissenschaften notwendig waren: Die Idee des ,Typs und die Idee des ,Gesetzes“" (ebd.: 126).

Montesquieu könne die Gesellschaften typisieren, da er jene Tatsache erkannt habe, die zu den notwendigen Voraussetzungen zur Gründung der Soziologie zu zählen sei: dass es sich bei der Sphäre der Gesellschaft um einen abgegrenzten Forschungsbereich handele (vgl. ebd.: 88). ${ }^{653}$ Die Gesetze, die Montesquieu in den Blick nehme, d.h. Völkerrecht, Privatrecht, Öffentliches Recht sowie alle wichtigen sozialen Erscheinungen, leiteten sich nämlich keineswegs wie im Naturrecht aus der Natur des Menschen ab (vgl. ebd.: 97f.), sondern eben aus der Natur der Gesellschaft als eigenständiges Phänomen. Insofern erkläre Montesquieu richtigerweise, dass „der gesamte Kontext der Gesetze, wie sie bei den verschiedensten Völkern gelten und galten, ,natürlich' seien: dies aber leitet er nicht aus der Natur des menschlichen, sondern aus der Natur des sozialen Organismus her" (ebd.: 100). Die Gesetze (lois) unterliegen als soziale Erscheinungen einer festen Ordnung und eignen sich für eine rationale Interpretation (ebd.: 110). ${ }^{654}$ Dabei deduziere Montesquieu seine drei Typen von Staatsformen (Republik, Monarchie und Despotie) nicht aus a priori gegebenen Prinzipien, sondern gewinne sie anhand des Vergleichs der Gesellschaften, d.h. auf empirischer Grundlage (vgl. ebd.: 103).655 Die Induktion in den Sozialwissenschaften trete bei Montesquieu zum ersten Mal in Erscheinung ${ }^{656}$ - auch wenn er sie noch mit der deduktiven Methode vermische (vgl. ebd.: 121), und trotz der Tatsache, dass er das historische Moment ver-

653 Denn nur dann lässt sich nach Durkheim von einer eigenständigen wissenschaftlichen Disziplin sprechen, deren eigentliche Funktion ja in der Beschreibung und Interpretation einer solchen Realität liege, um „ein möglichst getreues Abbild" zu erstellen (Durkheim 1991d [1892]: 89).

654 Da es sich um einen „sozialen Organismus“ handele, sei damit die zweite Voraussetzung zur Gründung der Soziologie erfüllt: Der Gegenstand ist typisierbar (vgl. ebd.: 92f.), so wie der Organismus in den Naturwissenschaften typisierbar ist (vgl. ebd.: 128).

655 Auch wenn Montesquieu die Klassifizierung an der Herrschaftsform festmacht, handelt es sich nach Durkheim dabei nur um eine begriffliche Ungenauigkeit. Denn tatsächlich leite er sie über den Vergleich der strukturellen Grundlagen (Zahl, Gliederung und Zusammenhang der Teile) sowie sämtlichen sozialen Phänomenen des Lebens (z.B. Religionen, Sitten, Familien etc.) her (vgl. ebd.: 103ff.).

656 Montesquieu folge aber auch einer zweiten wichtigen methodischen Regel, indem er die Phänomene nicht isoliere, sondern - dem Organismusgedanken folgend - in einem Zusammenhang analysiere (vgl. ebd.: 123). 
nachlässige (die Entwicklungsstufen der Gesellschaft) und daher eine statische Typik entwerfe (vgl. ebd.: 125).

Dass die Gesetze einer festen Ordnung folgen, beruht nach Durkheim auf ihrer Genese: Sie haben „ihre Wurzeln in den Gewohnheiten, d.h. im Leben selbst“, und entwickelten „sich in einem langsamen, unmerklichen Prozeß, ohne Eingriff des Gesetzgebers“ (ebd.: 94). Genau das aber habe Montesquieu mit seiner Betonung der herausragenden Rolle des Gesetzgebers verkannt. Dabei liege das Grundproblem nicht nur für Montesquieu, sondern für viele soziologische Ansätze in der Trennung von Brauch und Gesetz. Nach Montesquieu gelte: „Bräuche entwickeln sich von selbst aus dem sozialen Geschehen: Gesetze aber können ohne den Willen eines Gesetzgebers nicht zustande kommen." (Ebd.: 113) Die Natur der Gesellschaft sei für Montesquieu zwar Ursache der Gesetze, aber nur „zielgerichtete" Ursache (ebd.: 114), d.h. Telos. Der Gesetzgeber verfolge soziale Zwecke und setze als Mittel hierfür die Gesetze ein.

Für Durkheim können soziale Phänomene jedoch nicht das Ergebnis einer planmäßigen Handlung sein. Folglich sind Gesetze auch keine Einfälle des Gesetzgebers, sondern folgen „mit der gleichen Notwendigkeit aus jenen wirkenden Ursachen“ wie Bräuche:657 „Leugnet man das, so muß man annehmen, daß die meisten sozialen Erscheinungen, besonders die bedeutungsvolleren, völlig ohne Ursache zustande kommen." (Ebd.: 114f.) Auch wenn Gesetze eine nützliche Funktion in der Gesellschaft haben, sind sie "nicht wegen dieser Nützlichkeit geschaffen worden, denn diese wird in der Regel weder erkannt, noch vorausgesehen“" (ebd.: 115).

Das ist erneut - nun etwas abgewandelt - als Kritik an Jhering zu verstehen: Weder schaffe der Zweck das Recht noch könne man über den Zweck zu den kausal wirkenden Ursachen der Gesetze vordringen. Denn „[w]enn wir also untersuchen, inwiefern ein Gesetz nützlich ist, erfahren wir nichts über seinen Ursprung" (ebd.). Das gilt aber nicht nur für das Recht, sondern generell für die Soziologie: Über die Untersuchung der „zielgerichteten Ursachen“, d.h. das Telos oder den Nutzen der sozialen Erscheinungen, bleiben die Ursprünge verborgen: „Dies würde bei der Soziologie passieren, wenn wir der Methode Montesquieus folgen würden.“ (Ebd.)

657 Gesetze sind also letztlich für Durkheim „nichts anderes als einfach schärfer bestimmte Bräuche“ (ebd.: 115). 
Der Rechtsentstehungslehre in Form der Gewohnheitsrechtslehre zu

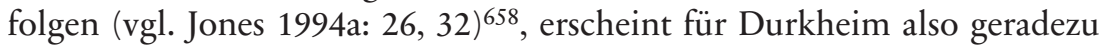
essentiell - und zwar nicht nur im Rahmen einer soziologischen Analyse des Rechts, sondern ebenso für die Begründung der Eigenständigkeit der Soziologie. Denn würde man die Gesetzgebung auf den Willen eines Souveräns zurückführen, der nach Belieben Gesetze schaffen, verändern oder aufheben könnte, dann müsste man die Ursachen für Gesetze, Institutionen und Sitten letztlich in zufälligen Ereignissen suchen, die den Gesetzgeber zu dieser oder jener Handlung veranlassen. Das ist für Durkheim nicht hinnehmbar. Denn „diese Ansicht akzeptieren heißt, die Existenz irgendeiner festen Ordnung in der menschlichen Gesellschaft leugnen" (Durkheim 1991d [1892]: 94). V.a. aber gelte: „Nichts hat die Entwicklung der Soziologie so behindert wie dieser Standpunkt [...]. Denn die anderen Hindernisse, von denen wir sprachen oder im folgenden sprechen werden, konnten nicht eher beseitigt werden, ehe diese Ansicht nicht ihre Bedeutung verloren hatte." (Ebd.: 94f.)

Für Durkheim wird die Anerkennung der Gewohnheitsrechtslehre also zur notwendigen Voraussetzung der Gründung der Soziologie. Andernfalls billige man zu, dass in Gesellschaften alles zufällig sei. Dann wäre aber eine Typenbildung nicht möglich. Wenn es wirklich Soziologie geben solle, müsse man der Gesellschaft eine gewisse „Eigennatur" zugestehen, d.h. sie müsse zu den Gegenständen gehören, „deren Natur in sich stabil ist und auch entgegen dem menschlichen Willen, konstant bleibt" (ebd.: 95). Das wirkt sich auf den Gesetzesbegriff aus. Denn dann müsse man anerkennen, dass „alle Regeln sowohl des Rechts als auch der Sitte und die das individuelle Dasein betreffenden, sich aus der gesellschaftlichen Existenz ergeben“" (ebd.: 102). Recht, Ethik und Moral sind für Durkheim gesellschaftliche Phänomene, die in der Gesellschaft ihren Ursprung haben und nicht vice versa, wie er in seiner Kritik der Idee des Rousseau'schen Gesellschaftsvertrags ausführt (vgl. Jones 1996: 331ff. m.N.).659 Das anzuer-

658 Dass bedeutet aber nicht, dass keine Differenzen zur Rechtsentstehungslehre der Historischen Rechtsschule auszumachen wären, s.u. \$6.IV.1.2.

659 Ohne die Existenz vorausgehender Normen, die die Einhaltung von Verträgen sichern, führe ein Vertrag nirgendwohin. Diese sozialen Normen - man kann sie auch die „außervertraglichen Voraussetzungen des Vertrages“ (Röhl 1978) nennen - können nur aus der überindividuellen Sphäre stammen. Die Kontrakttheorie setze daher das voraus, was sie begründen wolle (die Gesellschaft). Trotz dieser Polemik stellt Durkheim später in einem posthum veröffentlichten überarbeiteten Vorlesungsmanuskript aus dem Jahr 1901/1902 fest, dass Rousseau 
kennen, sei die Voraussetzung der Begründung der Soziologie als eigenständige Disziplin.

\section{Die Anerkennung der Gewohnheitsrechtslehre als Voraussetzung der Soziologie}

Obwohl Durkheim in den Bestimmungen der Wegbereiter der Soziologie schwankt (vgl. Lukes 1973: 277f.) und nur ein geringer Teil seiner Studien über den Ursprung der Soziologie erhalten sind, ${ }^{660}$ zeigt seine Auseinandersetzung mit den juristischen Vorläufern, dass er die Anerkennung der Gewohnheitsrechtslehre für notwendig hält, um die Soziologie als eine streng wissenschaftliche Disziplin begründen zu können. Einerseits garantiert der Rekurs auf die Rechtswissenschaft einen Anschluss der Soziologie ans wissenschaftliche Feld: Sie baut auf der Entwicklung der Moralwissenschaften auf, und zählt damit selbst als Wissenschaft. Andererseits gilt: Nur wenn gewährleistet ist, dass das Recht der Gesellschaft entspringt, dass es kondensierte respektive konsolidierte Gewohnheit ist, ist garantiert, dass es gegenüber dem menschlichen Willen und damit dem Zufall konstant bleibt. Erst dann zeigt sich die normative Struktur der Gesellschaft - der eigentliche Bereich der Soziologie als einer "Wissenschaft der Moral“ - als ein Gegenstand, der der wissenschaftlichen Analyse zugänglich ist. Denn auch wenn sich diese normative Struktur der Gesellschaft als historisch flexibel erweist, folgt sie doch den Gesetzen der Entwicklung der Gesellschaften - und damit den Gesetzen eines Gegenstandes, den man mit wissen-

den Eigenwert der Gesellschaft erkannt habe, d.h. dass die gesellschaftliche Ordnung „un ordre de faits hétérogènes par rapport aux faits purement individuels“ (Durkheim 1966 [1918 posthum]: 136) sei: „Pour lui, la société n'est rien si elle n'est pas un corps un et défini, distinct de ses parties.“ (Ebd.: 137) Weil er dabei das Problem des Zusammenhangs von Individuum und Gesellschaft insbesondere über die moralische Kraft der volonté générale zu lösen suche, sei er als Vorläufer der Soziologie anzusehen (zu Durkheims Wandel im Rekurs auf Rousseau vgl. Jones 1996).

660 Von seiner letzten Vorlesung an der Universität Bordeaux über die „Histoire des doctrines sociologiques“ (1901/02) ist nur der später überarbeitete Teil über Rousseau erhalten geblieben (Durkheim 1966 [posthum]). Zudem unterblieb die von Mauss angekündigte Veröffentlichung der Studien über den Ursprung der Soziologie bei Hobbes, Rousseau, Condorcet, Saint-Simon, Comte und Spencer (Mauss 1925: 15). Die entsprechenden Manuskripte existieren ebenfalls nicht mehr. Lediglich zu Saint-Simon wurde posthum eine Studie veröffentlicht (Durkheim 1925). 
schaftlichen Methoden der positiven Wissenschaften (Beobachtung und Experiment) untersuchen kann. Anders formuliert: Gerade weil Durkheim ein sehr enges Wissenschaftsverständnis vertritt, das letztlich nur den Verfahren einen wissenschaftlichen Charakter zuspricht, die sich an denjenigen der Naturwissenschaften orientieren, muss er der normativen Struktur der Gesellschaft Eigenschaften zusprechen, die es der Beobachtung und dem Experiment (respektive dem Vergleich) zugänglich machen. Genau dies gewährleistet in seinen Augen die Gewohnheitsrechtslehre.

\section{Recht als Repräsentation: Arbeitsteilung, Recht und soziale Solidarität}

Bereits im Reisebericht über die positiven Moralwissenschaften in Deutschland formuliert Durkheim das zentrale Problem, das ihn in der Arbeitsteilung beschäftigen wird: das „scheinbar[] widersprüchliche[] Phänomen" der Zunahme der individuellen Freiheit bei gleichzeitiger Zunahme der sozialen Verpflichtungen (Durkheim 1995b [1887]: 115). Denn obwohl das Individuum zusehends autonomer werde, hänge es immer mehr von der Gesellschaft ab (Durkheim 1996 [1893/1902]: 82). Im Grunde geht es um die Ordnungsfrage, d.h. wie gerade angesichts einer fortschreitenden Individualisierung soziale Ordnung möglich bzw. erklärbar ist. ${ }^{661} \mathrm{Die}$ "Auflösung dieser scheinbaren Antinomie“ liegt dabei für Durkheim in der Arbeitsteilung begründet, da diese selbst zu einer Veränderung der sozialen Solidarität führe (ebd.). Denn Arbeitsteilung erzeuge soziale Beziehungen durch Abhängigkeiten nach dem Muster, dass "Schuster ohne Schneider nicht leben können" (Luhmann 1996: 25).

Arbeitsteilung und soziale Solidarität werden dergestalt miteinander korreliert, dass die Moral der Gesellschaft ins Zentrum der Untersuchung rückt. Die Funktion der Arbeitsteilung besteht nach Durkheim in der Herstellung von sozialen Beziehungen. Sie erzeuge eine soziale Solidarität als das „soziale Band“ (Durkheim 1996 [1893/1902]: 111), das die Gesellschaft zusammenhält bzw. ihre Auflösung verhindert. Dieses Band ist bei Durkheim wiederum ein genuin moralisches Phänomen: „Moralisch ist, könnte man sagen, alles, was Quelle der Solidarität ist“ (ebd.: 468). Moral sei also

661 Nach Luhmann beruht Durkheims Fokussierung in der Ordnungsfrage auf die Moral - mit all ihren Inkongruenzen und Widersprüchlichkeiten - auf dem Umstand, dass er die beiden möglichen Bestandteile dieser Frage (Wie ist angesichts der Freiheit des Einzelnen soziale Ordnung möglich? Und wie ist das Verhältnis der Person zur immer schon konstituierten Sozialordnung?) nicht hinreichend voneinander trennt (vgl. Luhmann 1996: 28). 
letztlich immer auf die Gesellschaft gerichtet und habe keine individuellen Zwecke (vgl. ebd.: 469). ${ }^{662}$ Gesellschaft wiederum werde durch Moral zusammengehalten. Denn es seien moralische Tatbestände, definiert als „sanktionsbewehrte Verhaltensregeln“ (Durkheim 1999 [posthum]: 9), die den ,sozialen Körper' der Gesellschaft integrieren und seine Einheit sichern (vgl. Durkheim 1996 [1893/1902]: 109). ${ }^{663}$ Anders formuliert: Nur über gemeinsame Normen und Werte ist für Durkheim soziale Integration der Individuen und damit Gesellschaft möglich und erklärbar. Allerdings sei zu beachten: Die Gesellschaft folge nicht aus der Moral oder sei ihr aliud, sondern „[s]ie ist im Gegenteil deren notwendige Bedingung“ (ebd.: 469). Gesellschaft wird bei Durkheim zu einem genuin normativen Phänomen: „Jede Gesellschaft ist eine moralische Gesellschaft.“ (Ebd.: 285) Soziale Ordnung ist dann synonym mit normativer Ordnung zu verstehen. ${ }^{664}$

Will man nun beweisen, dass die gegenwärtige Gesellschaft über Arbeitsteilung integriert werde, dann muss man die Vorherrschaft der spezifischen arbeitsteiligen sozialen Solidarität nachweisen. Um dies bestimmen zu können, bedarf es eines Vergleichs. Daher unterscheidet Durkheim verschiedene Arten der sozialen Solidarität. Und genau hierfür kommt dem Recht eine entscheidende methodische Rolle zu: Es dient ihm als objektiver Indikator bzw. als sichtbares Symbol einer unsichtbaren sozialen Solidarität, die als „durch und durch moralisches Phänomen der unvermittelten, exakten Beobachtung nicht zugänglich [ist], vor allem nicht der Messung“ (ebd.: 111). Um die soziale Solidarität „also klassifizieren wie vergleichen zu können, muss man die innere Tatsache, die sich uns ent-

662 Das gilt auch für das Recht (vgl. Durkheim 1893).

663 Jenseits jeglicher individualistischer Moralkonzeption dient die Moral bei Durkheim also „keineswegs dazu, den Menschen zu emanzipieren, ihn aus dem ihn umgebenden Milieu zu loszulösen, sondern hat im Gegenteil die wesentliche Aufgabe, aus ihm einen integrierten Teil eines Ganzen zu machen und ihm folglich etwas von der Freiheit seiner Bewegung zu nehmen“ (Durkheim 1996 [1893/1902]: 468). Die Freiheit sei letztlich selbst Resultat des sozialen Handelns (ebd.: 456). Dem widerspreche nun nicht die zunehmende Individualisierung, da der „Kult des Individuums“ zum einen selbst Teil des Kollektivbewusstseins und daher nicht Bestandteil einer individuellen Moral sei (s.a. Durkheim 1986a [1898]: 66) - auch wenn es eine Ausnahme im Kollektivbewusstsein darstelle (s.u.); zum anderen führe dieser Kult ja gerade zum Postulat der Nächstenliebe, da man zunehmend von anderen abhängig werde (Durkheim 1996 [1893/1902]: 478; vgl. hierzu Müller 1986).

664 An anderer Stelle befindet Durkheim: „Recht und Moral sind die Gesamtheit der Bande, die uns untereinander und mit der Gesellschaft verbinden, die aus einer Masse von Individuen ein kohärentes Aggregat werden lassen.“ (Durkheim 1996 [1893/1902]: 468). 
zieht, durch eine äußere Tatsache ersetzen, die sie symbolisiert, und die erste vermittels der zweiten erforschen. Dieses sichtbare Symbol ist das Recht.“ (Ebd.: 111)

\section{Recht als Repräsentation der Solidaritätsform}

Recht repräsentiert nach Durkheim „alle wesentlichen Solidaritätsformen“ (Durkheim 1996 [1893/1902]: 113), ja man könne „sicher sein, im Recht alle wesentlichen Varianten der sozialen Solidarität widergespiegelt zu finden“ (ebd.: 112). Denn wenn das soziale Leben Bedeutung erlange und auf Dauer gestellt werde, nehme es notwendigerweise die „Rechtsform“ an (ebd.); eine Gesellschaft, die sich allein auf Sitten begründe, sei zu instabil und könne sich nicht erhalten (ebd.: 113). ${ }^{665}$ Daher sei die Anzahl der sozialen Beziehungen nach Durkheim mit der Zahl der Rechtsregeln „proportional“, so dass sich das Rechtsleben „zu gleicher Zeit und in demselben Verhältnis“ erweitere wie die Gesellschaft (ebd.: 112).

Durkheim denkt das Soziale in Begriffen der Repräsentation. Es geht um „kollektive Repräsentationen“ als eigenständige Form von Bewusstseinsinhalten (vgl. Durkheim 1976b [1898]). Das Recht wiederum sei das Symbol, das diese Repräsentationsleistung in sichtbarer Form erbringt. ${ }^{666}$ Eine Klassifikation der sozialen Solidarität erfolgt dementsprechend über die Klassifikation der verschiedenen Arten des Rechts (Durkheim 1996 [1893/1902]: 115). Für diese Arbeit könne man sich jedoch nicht der gebräuchlichen juristischen Unterscheidung zwischen Privatrecht und Öffentlichem Recht bedienen, da letztlich jedes Recht aufgrund seines Individualbezugs privat und aufgrund seiner sozialen Funktion öffentlich sei (ebd.: 116; s.a. Durkheim 1903b). Daher greift Durkheim auf die Bestim-

665 So schreibt Durkheim: „Die Verpflichtungen, die die Gesellschaft ihren Mitgliedern auferlegt, nehmen, wenn sie nur einige Bedeutung und Dauer haben, eine Rechtsform an; folglich erlaubt die relative Ausdehnung dieses Apparats das relative Ausmaß des sozialen Handelns genau auszumessen." (Ebd.: 260f.).

666 Zum Repräsentationsproblem bei Durkheim vgl. die Beiträge in Pickering 2000, zum Symbolismus bei Durkheim siehe Karsenti 2014. Denkt man das Soziale in der Begrifflichkeit von Repräsentationen, so sei man - wie Bruno Karsenti anmerkt - genötigt, es in der Form eines Kollektivbewusstseins zu hypostasieren (Karsenti 2013). Dieses Dilemma werde erst - so eine gängige Lesart - in Durkheims späterer Religionssoziologie gelöst. Davon ausgehend könne man dann Rückschlüsse auf die Lösung rechtlicher Problemstellungen ziehen (vgl. etwa Gephart 1993a: 407ff.). 
mung durch die Sanktionsart zurück, mit der auf die jeweiligen Rechtsregeln reagiert werde.

Er unterscheidet bekanntermaßen zwei Hauptformen der Sanktionen und entwickelt davon ausgehend das Konzept der aufeinanderfolgenden Typen der Solidarität (mechanische und organische), die in zwei verschiedenen Rechtsformen zum Ausdruck kommen: Einerseits handelt es sich um repressives Recht, das als Strafrecht darauf abziele, den Schuldigen zu bestrafen, indem er ihm Leid zufüge. Andererseits gebe es das restitutive Recht, zu dem Durkheim Zivil-, Handels-, Prozessrecht sowie Verwaltungs- und Verfassungsrecht zählt (vgl. Durkheim 1996 [1893/1902]: 117). Dessen Sanktionsart besteht darin, die Dinge gewissermaßen wieder zurechtzurücken respektive einen status quo ante wiederherzustellen.

Dem repressiven Recht entspricht der Typus der „mechanischen Solidarität“ bzw. der „Solidarität aus Ähnlichkeit“. Sanktioniert werde hier ein Verbrechen, das intensive und bestimmte Zustände der Kollektivgefühle verletze, die im Bewusstsein aller verankert seien (vgl. ebd.: 126f.). Das setzt die Existenz eines vorgängigen gemeinsamen Bewusstseins voraus, ${ }^{667}$ jener so umstrittene und vieldeutige Begriff des Kollektivbewusstseins als ein umgrenztes System der „Gesamtheit der gemeinsamen religiösen Überzeugungen und Gefühle im Durchschnitt der Mitglieder einer bestimmten Gesellschaft“, dem Durkheim eine eigenständige Wirklichkeit zuspricht (ebd.: 128). Die Regeln, die das gemeinsame Bewusstsein sanktioniert, drücken diese tief verwurzelten gemeinsamen Überzeugungen und damit „die wesentlichsten sozialen Ähnlichkeiten aus“ (ebd.: 155). Das Strafrecht symbolisiere also einen solidarischen Zusammenhalt, „dessen Ursache in einer bestimmten Übereinstimmung des Bewußtseins aller einzelnen Individuen mit einem gemeinsamen Typ liegt" (ebd.: 155). Und die Strafe habe als „rein mechanischen Reaktion“ (ebd.: 158) die Wirkung, diesen Zusammenhalt aufrechtzuhalten, indem sie das gemeinsame Bewusstsein am Leben erhalte (vgl. ebd.: 159).

Das restitutive Recht symbolisiere demgegenüber die „organische Solidarität", die sich der Arbeitsteilung verdanke. Denn auch wenn hier primär individuelle Interessen ausgeglichen werden und die entsprechenden Regeln nach Durkheim entweder ,gar nicht am Kollektivbewußtsein teil-

667 Insofern gilt: „Mit anderen Worten: man darf nicht sagen, daß eine Tat das gemeinsame Bewußtsein verletzt, weil sie kriminell ist, sondern sie ist kriminell, weil sie das gemeinsame Bewußtsein verletzt. Wir verurteilen sie nicht, weil sie ein Verbrechen ist, sondern sie ist ein Verbrechen, weil wir sie verurteilen." (Durkheim 1996 [1893/1902]: 130). 
haben oder nur schwach ausgebildet sind“ (ebd.: 163), ${ }^{668}$ kommen auch sie aus der gesellschaftlichen Sphäre und förderten daher den sozialen Zusammenhalt. ${ }^{669}$ Auch sie stellten soziale Beziehungen her, wie Durkheim am Beispiel des - hierfür prototypischen - Vertragsrechts erklärt: ${ }^{670}$ Verträge rufen korrelative und gegenseitige Verpflichtungen hervor oder bezögen sich auf bereits erbrachte Leistungen. Eine solche Gegenseitigkeit setze aber Zusammenarbeit voraus, „und diese ihrerseits entsteht nicht ohne Arbeitsteilung“ (ebd.: 175f.). Denn Arbeitsteilung führe zu einer Spezialisierung der Funktionen, was Bedingung eines jeden Tausches (im nicht rechtstechnischen Sinne) sei. Das restitutive Recht drücke damit eine soziale Solidarität aus, die den Zusammenhalt über kooperative Beziehungen herstelle und im Falle einer Verletzung durch Restitution ,sanktioniert' werde.

Damit rücken die privatrechtlichen Austauschverträge ins Zentrum der Bestimmung der Solidaritätsform der arbeitsteiligen Gesellschaft:

Die vertraglichen Beziehungen entwickeln sich notwendigerweise mit der Arbeitsteilung, da diese ohne den Tausch nicht möglich ist, dessen rechtliche Form der Vertrag ist. Anders ausgedrückt: Eine der bedeutendsten Spielarten der organischen Solidarität ist das, was man die Vertragssolidarität nennen könnte. (Ebd.: 450)

668 Die Kritik an Durkheims Begriff des Kollektivbewusstseins richtet sich insbesondere gegen den logischen Widerspruch, der aus seinen unterschiedlichen Verwendungsweisen resultiert: Zum einen handelt es sich beim Kollektivbewusstsein um ein allgemeines Strukturmerkmal jeder Gesellschaft, wenn Durkheim es als eine Art Set an gemeinsamen Glaubensvorstellungen und Gefühlen definiert, das die einzelnen Individuen in die Gesellschaft integriert. Zum anderen macht Durkheim das Kollektivbewusstsein zu einem entwicklungsgeschichtlichen Kriterium, wenn er den Wandel zur arbeitsteiligen Gesellschaft über die Abnahme des Kollektivbewusstseins beschreibt (vgl. Parsons 1966: 318; König 2007: 29f.).

669 Der Umstand, dass das Vorliegen eines sittenwidrigen Vertrages etwa sehr wohl große Empörung hervorrufen kann, nimmt Durkheim nur als Beweis, dass die verschiedenen Bereiche des moralischen Lebens nicht streng voneinander getrennt seien (Durkheim 1996 [1893/1902]: 163).

670 Durkheim unterscheidet innerhalb des restitutiven Rechts diejenigen Regeln, die das Nutzungsrecht anderer ausschließen oder Übergriffe in die eigene Sphäre sanktionierten und aufgrund dieser trennenden Wirkung Ausdruck einer „negativen Solidarität" seien (z.B. dingliche Rechte wie Eigentum, Schadensersatzund Deliktsrecht), von denjenigen Regeln, die auf Kooperation und Koordination abzielen und daher Ausdruck einer „positiven Solidarität“ seien. Nur letztere interessieren ihn, da sie ihren Grund in der Arbeitsteilung haben. Den Kern eines solchen Kooperationsrechts bildet das Vertragsrecht (vgl. Durkheim 1996 [1893/1902]: 166ff.). 
Das bedeutet nach Durkheim - in Abgrenzung zum individualistischen Utilitarismus à la Spencer - nun aber gerade nicht, dass die Gesellschaft das Produkt solcher individuellen Vertragsabschlüsse wäre (vgl. ebd.: 259). Vielmehr entwickelten sich die nicht-vertraglichen Beziehungen proportional zur Vervielfachung der Vertragsbeziehungen selbst (vgl. ebd.: 263, 434). Das zeige sich nicht nur in der tatsächlichen Zunahme rechtlicher Regeln, die sich auf nicht-vertragliche Verhältnisse wie beispielsweise die Familie richteten (vgl. ebd.: 266), sondern sei im Wesen des Vertrags selbst begründet. Denn letztlich gelte: „, $[\mathrm{N}]$ icht alles ist vertraglich beim Vertrag." (Ebd.: 267)

Durkheim geht davon aus, „daß der Vertrag sich nicht selber genügt; er ist nur möglich dank einer Reglementierung des Vertrags, die sozialen Ursprungs ist“" (ebd.: 272). Möglicher Regelungsgegenstand, Verbindlichkeit und Durchsetzbarkeit eines Vertrages beruhten nicht auf den Willen der Vertragsschließenden, sondern auf dem Vertragsrecht, das gesellschaftlichen Ursprungs sei: „Die Rolle der Gesellschaft kann also in keinem Fall darauf reduziert werden, die Verträge passiv auszuführen; sie besteht auch darin, zu bestimmen, unter welchen Bedingungen sie rechtskräftig sind, und ihnen, wenn nötig, ihre normale Form wiederzugeben.“ (Ebd.: 272) Das Vertragsrecht sei also die „Grundnorm“ respektive die „Basis“ der vertraglichen Beziehungen, und die Gesellschaft sei auch im privaten Vertrag immer regulierend präsent. Daher steige mit der Zunahme der vertraglichen Beziehungen in der arbeitsteiligen Gesellschaft auch der die Präsenz der Gesellschaft. ${ }^{671}$

Durkheim macht aus der Analyse der sozialen Solidarität „in Relation zum System juristischer Regeln“ (ebd.: 81) letztlich ein Argument der Zahl: Habe man das Recht und darüber die Arten der sozialen Solidarität klassifiziert, dann genüge es, deren jeweiligen Anteil zu messen, d.h. „die Anzahl der Rechtsregeln miteinander zu vergleichen, denen dieser Anteil im jeweiligen Gesamtvolumen des Rechts entspricht" (ebd.: 115). Über diese einfache proportionale Bestimmung sei dann ein fortschreitendes Übergewicht der organischen Solidarität zu erkennen. Denn das Strafrecht, das in "primitiven“ Gesellschaften das gesamte Recht ausmache (ebd.: 125), trete in quantitativer Hinsicht zunehmend in den Hintergrund: „Ein Blick auf unsere Gesetzbücher genügt, um den geringen Platz

671 So werde der Umfang des Rechtsapparats immer größer und komplizierter (vgl. ebd.: 261). Aber nicht nur die rechtlichen, sondern auch die moralischen Regeln nehmen zu, nämlich durch die Entwicklung bereichsspezifischer Berufsmoralsysteme (ebd.: 284). 
festzustellen, den das Strafrecht im Verhältnis zum kooperativen Recht einnimmt." (Ebd.: 200)

Wenn gegenwärtig also ein fortschreitendes Übergewicht der organischen Solidarität festzustellen sei, so entspreche diese Entwicklung dem "Gesetz der Geschichte“ (ebd.: 229) im Übergang von ,primitiven“ zu höheren sozialen Typen. Während die mechanische Solidarität eine gesellschaftliche Struktur voraussetze, die homogen sei und aus untereinander ähnlichen Segmenten bestehe, bildeten sich mit zunehmendem Entwicklungsstand verschiedene Organe heraus. Das gemeinsame Bewusstsein nehme in der arbeitsteiligen Gesellschaft ab zugunsten bereichsspezifischer Moralsysteme, so dass der „funktionalen Differenzierung“ der arbeitsteiligen industrialisierten Gesellschaft eine Art "moralischer Polymorphismus“ entspreche (Durkheim 1999 [posthum]: 18). ${ }^{672}$ Gesellschaft wird in diesem Fall durch funktionale Interdependanz integriert, und dies findet seinen Ausdruck im restitutiven respektive kooperativen Recht. Auch die Zusammenarbeit hat ihre „eigenständige Moralität" (Durkheim 1996 [1893/1902]: 285).

\section{Die Gewohnheitsrechtslehre in der Arbeitsteilung}

Wenn Durkheim in seiner Abhandlung über Montesquieu die Anerkennung der Gewohnheitsrechtslehre zur Voraussetzung der Soziologie macht, so zeigt sich ihr zentraler Stellenwert auch in der Arbeitsteilung, und zwar für zwei Bereiche: zum einen für die kausale Erklärung der sozialen Solidarität, zum anderen für den Rekurs auf das Recht als empirischer Indikator der Moral.

Mit Ausnahme der pathologischen Formen (anomische, erzwungene und auf innerorganisatorischem Koordinationsmangel beruhende Arbeitsteilung) erzeugt die in der Gesellschaft fortschreitende Arbeitsteilung nach

672 Wenn Durkheim in der arbeitsteiligen Gesellschaft als gemeinsame Glaubensvorstellung den Kult der ,Würde der Person“ ausmacht, in der „das Individuum der Gegenstand einer Art von Religion“ geworden sei (ebd.: 227), dann stelle das eine „völlige Ausnahmesituation im Kollektivbewußtsein“ dar (ebd.: 228). Denn die entsprechenden Ziele seien nicht sozial, sondern individuell. Daher bilde diese Gemeinsamkeit im Glauben kein soziales Band. Dieses entspringe vielmehr der Arbeitsteilung. Auch hier zeigt sich also wieder die widersprüchliche Bestimmung des Kollektivbewusstseins: Einerseits ist der Kult des Individuums der Inhalt des Kollektivbewusstseins, andererseits wird letzteres dadurch schwächer. 
Durkheim „normalerweise“, „von selbst“ und „spontan“ die soziale Solidarität (ebd.: 421, 434, 446). ${ }^{673}$ Die Lösung des Ordnungsproblem liegt somit in der ,normalen' Arbeitsteilung selbst. Denn der im Gefolge der Arbeitsteilung sich verstärkende Austausch „regelt sich von selbst, und mit der Zeit konsolidiert er sich vollends" (ebd.: 437). Dies geschehe einerseits durch die Entwicklung von berufsspezifischen Moralsystemen, denen sich der einzelne Akteur unterordne (vgl. Durkheim 1996 [Vorwort zur 2. Aufl. 1902]: 41ff.; Meier 1987: 35ff). Andererseits bewirke die Notwendigkeit, die ausdifferenzierten Tätigkeitsbereiche wieder zusammenzuführen, dass jedem Akteur die Abhängigkeit von anderen bewusst werde und er daher dazu bereit sei, die Bedürfnisse anderer Akteure zu erfüllen (vgl. Schmid 1989: 519) - allerdings nur unter der Voraussetzung, dass dieser wechselseitige Austausch als „gerecht" empfunden werde und sich eine entsprechende Vertragssolidarität herausbilde (vgl. Durkheim 1996 [1893/1902]: 451ff.). ${ }^{674}$

Um nun die normalerweise eintretende spontane Selbstregulierung in der Arbeitsteilung zu begründen, ${ }^{675}$ greift Durkheim auf die Gewohnheitsrechtslehre zurück: Erfolge der Austausch zunächst noch provisorisch, so wiederholten sich diese Handlungen und würden zu Gewohnheiten werden. „Diese Gewohnheiten“ wiederum „verwandeln sich, je stärker sie werden, sodann in Verhaltensregeln“ (ebd.: 435), die schließlich die Rechtsform annehmen und auf diese Weise verbindliche Verkehrsformen stiften

673 Quelle der organischen Solidarität sei also die Arbeitsteilung, wobei diese wiederum in einer bereits bestehenden Gesellschaft wurzele. So könne sich „die Arbeitsteilung nur unter den Mitgliedern einer bereits konstituierten Gesellschaft verwirklichen“ (Durkheim 1996 [1893/1902]: 335). Die Mitglieder müssen schon solidarisch sein, damit die Arbeitsteilung mit ihrer Spezialisierung und Konkurrenz selbst Solidarität erzeugen könne (vgl. ebd.). Die Ursachen für den Fortschritt der Arbeitsteilung sucht Durkheim dementsprechend in der Gesellschaft selbst, nämlich in den sozialökologischen Faktoren der Zunahme des Volumens und der materiellen wie moralischen Dichte von Gesellschaften (z.B. Bevölkerungswachstum und -konzentration, Ausbau der Verkehrs- und Kommunikationswege, Urbanisierung, vgl. ebd.: 314ff.). Daher kann nach Durkheim die Arbeitsteilung nicht als Quelle der Gesellschaft angesehen werden. Ein hohes Maß an Arbeitsteilung setze stets eine moralisch integrierte Gesellschaft voraus (vgl. Müller, Schmid 1996: 514).

674 Das Gerechtigkeitsempfinden sei v.a. insofern nötig, um die nicht erzwungene, „spontane“ Zustimmung und Bindung der Einzelnen an den Vertrag zu bewirken (vgl. Durkheim 1996 [1893/1902]: 452).

675 So schreibt Durkheim: „Was aber die Einheit der organisierten Gesellschaften wie eines jeden Organismus ausmacht, ist der spontane Konsensus der Parteien, ist die innere Solidarität" (ebd.: 429, H.i.O.). 
(vgl. Müller, Schmid 1996: 302). Auch in der Arbeitsteilung ist Recht immer gewachsenes Recht bzw. „Gewohnheitsrecht“, das sich „zum geschriebenen Recht wandelt und kodifiziert wird“ (Durkheim 1996 [1893/1902]: 124), das seinen Ursprung in der Sitte und im Brauch hat, und das letztlich vom Staat als Organ der moralischen Disziplin nur deklariert und nicht geschaffen wird (vgl. ebd.: 133).676 Im Gegensatz zur älteren Historischen Rechtsschule aber geht Durkheim angesichts der arbeitsteiligen Solidarität nicht davon aus, dass das Recht damit automatisch immer einer harmonischen Sphäre entspringe. Vielmehr resultiere die Entwicklung der Arbeitsteilung aus dem Konflikt selbst, und die Aufgabe der Moral sei gar nicht, den Konflikt zu beseitigen, sondern vielmehr ihn zu mäßigen.

Die Gewohnheitsrechtstheorie erfüllt in Durkheims Argumentation eine zentrale strategische Funktion. Denn nur auf ihrer Basis hat letztlich die von ihm proklamierte Kausalkette Bestand. Nur wenn er Recht nicht als eigenständigen Kausalfaktor in der gesellschaftlichen Entwicklung adressiert, indem es einer gesetzgeberischen Intervention zugänglich ist, kann er die eigentliche Ursache für die Entwicklung der Solidarität in der Arbeitsteilung sehen. Ein eigenständiger Kausalfaktor „ethische Überlegungen“ oder „individueller Wille“ des Gesetzgebers scheidet aus. Erneut geht es also darum, soziale Ordnung als normative Ordnung jeglicher willkürlichen Intervention zu entziehen. Zur „Basis der moralischen Ordnung" wird bei Durkheim vielmehr die Arbeitsteilung selbst (ebd.: 471). Die entsprechenden Kausalfaktoren sind dann in der Gesellschaftsstruktur zu suchen, und die Entwicklungsgesetze der Gesellschaft folgen aus der Veränderung dieser, objektiven' Faktoren.

Selbst wenn Durkheim am Ende seiner Untersuchung eine „schwere Krise" der arbeitsteiligen Gesellschaft konstatiert (ebd.: 479), weil sich die normalerweise durch Arbeitsteilung erzeugte organische Solidarität realiter durch die drei pathologischen Formen der Arbeitsteilung in einem „krankhaften Zustand“ befände, dann sucht er die Lösung nicht über sozialrechtliche Vorschläge, d.h. in einer Theorie der richtigen Gesetzgebung, zu geben. Angesichts der Krise sieht Durkheim zwar seine Pflicht darin, „eine neue Moral zu bilden“ und damit auf ein neues Recht hinzuwirken. Aufgabe der Wissenschaft sei es dabei aber, die Natur und die Ursache für dieses Missverhältnis zwischen der tiefgreifend veränderten Struktur der

676 Zur Gewohnheitsrechtslehre siehe auch Durkheim 1991c [1888]: 63f. Dort stellt Durkheim klar, dass es nicht um die schlichte Wiederholung einer Handlung geht, sondern um Verhaltensregeln in Form von sanktionierbaren Imperativen: „Die Existenz einer Sanktion ist das Kriterium, das eine Verwechslung des Brauchs mit einer einfachen Gewohnheit verhindert.“ (Ebd.: 63). 
Gesellschaft und dem gegenwärtigen Zustand der Moral zu verstehen. Für letzteres dient das Recht als empirischer Indikator, darüber wird die Moral objektiv erfassbar. Ihm kommt insofern eine entscheidende Bedeutung in der Feststellung der Pathologien zu. Und von der Analyse dieser Pathologien ausgehend könne man dann das Ziel der Bildung einer neuen Moral verdeutlichen (ebd.: 479f.).

\section{Rechtsentstehungslehre und soziologische Methode}

Auch in seiner grundlegenden Abhandlung zu den Regeln der soziologischen Methode erscheint Durkheim der Rekurs auf das Recht notwendig für die Soziologie - nun aber nicht nur mit Blick auf das Ordnungsproblem, sondern als ein allgemeines methodologisches Erfordernis. Dieser Rekurs erfolgt auf mehreren Ebenen.

\section{Der forschungspragmatische Rekurs auf das Recht in den Regeln}

Auf der Gegenstandsebene erscheint das Recht als der Prototyp des „soziologischen Tatbestands“677: Die Pflichten, die es begründet, liegen außerhalb des Einzelnen. Indem sie bereits für ein Leben jenseits des individuellen Gebrauchs vorhanden sind, wird der Mensch quasi in sie hineingeboren. ${ }^{678}$ Daher habe das Recht „etwas Objektives“, d.h. individuell Unverfügbares, an sich (Durkheim 2007 [1894]: 105). Sein zwingender Charakter sei in den Sanktionen, die im Falle des Normbruchs erfolgten, letztlich „unschwer zu konstatieren“ (ebd.: 112). Im Recht zeige sich auch deutlich die Spaltung zwischen kollektiven Zuständen und individuellen, psychologischen Tatsachen, selbst wenn letztere bei allen Mitgliedern einer Gesellschaft oder ihrer Mehrheit anzutreffen seien. Denn als „kollektive Gewohnheit" (ebd.: 109), d.h. als „kristallisierte[] Formen“ (ebd.: 107) des sozialen Handelns, existiere das Recht jenseits individueller Verwirkli-

677 Durkheims Definition lautet: „Ein soziologischer Tatbestand ist jede mehr oder minder festgelegte Art des Handelns, die die Fähigkeit besitzt, auf den Einzelnen einen äußeren Zwang auszuüben; oder auch, die im Bereiche einer gegebenen Gesellschaft allgemein auftritt, wobei sie ein von ihren individuellen Äußerungen unabhängiges Eigenleben besitzt.“ (Durkheim 2007 [1894]: 114).

678 So schreibt Durkheim über die rechtlichen Pflichten: „Denn nicht ich habe diese Pflichten geschaffen, ich habe sie vielmehr im Wege der Erziehung übernommen.“ (Ebd.: 105). 
chungen: „Keine dieser Normen geht vollkommen in den Anwendungen auf, die die Einzelnen von ihr machen, da sie ja vorhanden sein können, ohne wirklich angewendet zu werden." (Ebd.: 110) Recht gebe es also unabhängig von seinen einzelnen Verbreitungsformen. Dabei weise es gewissermaßen die gleiche Festigkeit auf wie die Erscheinungen der morphologischen Ordnung (z.B. Verkehrswege etc.): „[E]ine rechtliche Norm ist eine nicht minder dauerhafte Einrichtung wie ein architektonischer Typus, obwohl es sich um eine physiologische Tatsache handelt." (Ebd.: 114) Wenn also die soziologischen Tatbestände das genuine Gebiet der Soziologie bilden (ebd.: 107), dann kann man sich nach Durkheim beim Recht verstanden als Norm i.S.e. verfestigten Gewohnheit - sicher sein, einen solchen Tatbestand vor sich zu haben. Das gilt umso mehr, als die Gesellschaft in ihrer „Immaterialität sui generis“ (ebd.: 221) nur in ihren Erscheinungen analysierbar ist - und das Recht zählt unzweifelhaft zu diesen Erscheinungen.

Diese Form der Adressierung des Rechts wirkt sich auf die methodische Ebene aus: Wenn Durkheim als erste Regel der soziologischen Methode fordert, die soziologischen Tatbestände wie Dinge zu behandeln, dann kann man dies bzgl. der Analyse des Rechts in geradezu unproblematischer Weise verwirklichen. Dem geforderten Dingbezug der Betrachtungsweise der soziologischen Tatbestände entspricht eine Art der Dinghaftigkeit des Rechts (vgl. ebd.: 195). Für die kollektiven Gewohnheiten, die sich in den Rechtsformen kristallisiert haben und durch ihre Kodifizierung geradezu „ungezwungener" und „unmittelbarer dingliche Eigenschaften“ aufweisen (ebd.: 127), gelte:

Da diese Formen in Permanenz existieren und sich nicht mit ihren verschiedenen Anwendungen ändern, so stellen sie einen fixen Gegenstand dar, der dem Beobachter stets zur Verfügung steht und subjektiven Empfindungen sowie persönlichen Beobachtungsfehlern keinen Raum läßt. Eine Rechtsnorm ist, was sie ist; es gibt nicht zwei verschiedene Arten, sie aufzufassen. (Ebd.: 139)

Man besitze also mit dem Recht ein objektives, von den individuellen Manifestationen losgelöstes Kriterium, das man etwa wie in der Arbeitsteilung anhand seiner Sanktionsarten ordnen, klassifizieren und vergleichen könne, um daraus Rückschlüsse auf die vorherrschende Solidaritätsform zu ziehen (s.o.).

Oder aber man erkennt in den inhaltlichen Regelungen des Rechts die wesentlichen Einrichtungen der Gesellschaft (vgl. ebd.: 215). Diese finden in historisch gewachsenen Rechtsinstituten ihren Ausdruck: Familie (s.a. Durkheim 1991c [1888]: 62), Schutz des Lebens, Eigentumsrecht und Ver- 
trag (vgl. Durkheim 1999 [posthum]: 156ff.). Damit rücken dann gegenüber der formellen Betrachtung nach Sanktionsart nun die materiell-rechtlichen Regelungen in den Blick. Allerdings interessieren Durkheim weniger die einzelnen Rechtsregelungen, sondern eben die Bündelungen der Normen zu gesellschaftlichen „Institutionen“ (vgl. Durkheim 2007 [Vorwort zur 2. Aufl. 1901]: 100).

Wenn also Durkheim den soziologischen Tatbeständen durch die Gleichsetzung mit Dingen „den gleichen Grad an Wirklichkeit“ (ebd.: 89) zuspricht wie den Phänomenen der Außenwelt, ${ }^{679}$ und sie damit als Gegenstände konzipiert, die objektiv - und d.h.: im strengen Sinne wissenschaftlich - untersucht werden können (vgl. ebd.: 91), dann sei das im Falle des Rechts gewährleistet. Indem man sich dem Recht zuwende, werde man der Forderung gerecht, „die erste Niederlassung der Wissenschaft auf festen Grund und nicht auf Flugsand“ zu bauen (Durkheim 2007 [1894]: 140). Dass sei umso dringlicher, als die Wissenschaft der Soziologie noch im Entstehen begriffen sei und man auf keinerlei sonstigen Erkenntnisse zurückgreifen könne, die nicht die sozialen Phänomen verfälschten. Aufgrund der einfachen Möglichkeit der Klassifizierung von sozialen Handlungen anhand äußerer Merkmale eigne sich als Ausgangspunkt das Recht besonders, weil sich damit auch in der Folge umfassende Vergleiche anstellen ließen (vgl. ebd.: 131). ${ }^{60}$ Das Recht erweist sich forschungspragmatisch also als bevorzugter Untersuchungsgegenstand einer gerade entstehenden Soziologie. Denn sowohl die Strategie der Begründung einer autonomen Disziplin über einen spezifischen, ihr eigenen Gegenstand als auch die geforderte objektive Betrachtungsweise dieses Gegenstandes finden im Recht - verstanden als sanktionsbewährte Handlungsanweisungen, die man in Rechtsinstitutionen bündeln kann - ihr unproblematisches Anwendungsfeld.

Allerdings beschränkt sich die Rolle des Rechts auf der methodischen Ebene auf diesen pragmatischen Nutzen, ein besonders leicht zugängliches

679 Wenn Durkheim dabei keineswegs behauptet, dass die sozialen Phänomene materielle Dinge seien (s.o. $\$$ 1.I.2.2), ändert der immaterielle Charakter der Gesellschaft nichts daran, dass sie für Durkheim ein „natürlicher“ Gegenstand ist (Durkheim 2007 [1894]: 203).

680 In seiner Einführung in die Soziologie der Familie betont Durkheim als weiteren Vorteil, dass Brauch und Recht nicht nur objektive Tatsachen darstellten, sondern selbst als eine Zusammenfassung einer Vielzahl von Tatsachen anzusehen seien. Damit werde dem Forscher das Allgemeine unmittelbar und auf konkrete und greifbare Weise geliefert (Durkheim 1991c [1888]: 62), und dies am besten im gesatzten Recht (ebd.: 64). 
soziales Phänomen zu sein, das den methodischen Vorgaben zupass kommt. Für die weiteren Regeln der soziologischen Methode kann Durkheim aus dem Recht keine entscheidenden Impulse gewinnen. So sei das Normale als das, was sein soll, und das Pathologische als das, was nicht so sein soll, über den Allgemein- bzw. den Ausnahmecharakter einer Erscheinung in Bezug auf den Entwicklungsstand einer spezifischen Gattung zu bestimmen, d.h. aus Kriterien, die Durkheim in Analogie zur Biologie versteht. Diese seien rein objektiv und den Erscheinungen immanent (vgl. ebd.: 142) und hätten mit einem normativen Faktor wie etwa das rechtlich Gebotene nichts zu tun. Nur wenn man sein Vorgehen auf derartige objektive Kriterien stütze, verfahre man streng wissenschaftlich und vermeide, in eine ideologische Falle zu tappen (ebd.: 142). Selbst wenn also der Fluchtpunkt von Durkheims wissenschaftlicher Arbeit nach wie vor der moralische Zustand der Gesellschaft ist (vgl. ebd.: 219f.) und das Recht in seiner Sanktionsart Strafe nach wie vor auf das letztlich normativ bestimmte Kollektivbewusstsein verweist, kann Durkheim für die gattungsspezifische Unterscheidung von Normal und Pathologisch nicht auf das Recht zurückgreifen. Allenfalls lässt sich die Normalität einer Erscheinung mit Rechtsbezug darlegen, wie Durkheim auch mit Blick auf das Vorkommen des Verbrechens vorführt (vgl. ebd.: 155ff.).

Ähnliches gilt für die Regeln der Aufstellung der sozialen Typen: Die wesentlichen Eigenschaften sind morphologischer Art, d.h. sie liegen in Natur, Zahl und Verbindungsart der Komponenten, wobei diese Komponenten „einfachere Gesellschaften“ im Sinne von „sozialen Aggregaten“ seien (vgl. ebd.: 170). ${ }^{611}$ Die Rechtsformen korrespondieren mit den sozialen Typen und repräsentieren deren wesentlichen Eigenschaften, wobei sie selbst nicht zu diesen wesentlichen Eigenschaften zählen. So symbolisiert das Recht in seiner jeweiligen Sanktionsart die soziale Solidarität, deren Fundament aber in der sozialen Arbeitsteilung zu suchen ist.

Schließlich eignet sich ein Rekurs auf das Recht auch nicht für die Erklärung der soziologischen Tatbestände - insbesondere auch deshalb nicht, weil die erklärenden Ursachen nach Durkheim nicht aus dem Zweck oder der Funktion herleitbar sind. Solche teleologischen Erklärungsmuster, die über den Nutzen eines sozialen Phänomens auf dessen Entstehung oder Wesen schließen wollen, lehnt er strikt ab: Aus dem auch in der Soziologie geltenden biologischen Grundsatz, „daß das Organ von der Funktion unabhängig ist“, folge, „daß die Ursache, auf denen sein Da-

681 Daher stellt die monosegmentäre Horde das einfachste soziale Aggregat dar (Durkheim 2007 [1894]: 170). 
sein beruht, von den Zwecken, denen es dient, unabhängig ist“ (ebd.: 178). Nach Durkheim muss man also gegen Jhering einwenden, der Zweck sei nicht der Schöpfer des Rechts, und schon gar nicht liege jedem Rechtssatz ein praktisches Motiv zugrunde. Denn selbst wenn man die Zweckseite im Recht anerkenne, könne man daraus nicht auf Kausalitäten schließen. ${ }^{682}$ Daher verneint Durkheim auch in den Regeln die Möglichkeit, den Bereich des Sozialen über irgendein sogenanntes "Zweckgesetz" von der kausalgesetzlichen Betrachtungsweise zu scheiden (vgl. ebd.: 218). Die Konzentration auf den Zweck schließe sogar letztlich jede soziologische Erklärung aus, die ja auf Kausalbeziehungen gerichtet sei (vgl. ebd.: 205), denn wo das teleologische Prinzip und damit der subjektive Zweck herrsche, herrsche auch der Zufall (vgl. ebd.: 180).

Selbst wenn Durkheim darauf insistiert, die Erklärung des sozialen Lebens aus der Natur der Gesellschaft als Realität sui generis - seinem inneren sozialen Milieu - herzuleiten und das Recht dieser Sphäre unzweifelhaft zuzurechnen ist, führt er sozialen Wandel nicht auf das Recht zurück, nicht zuletzt weil er in dieser Hinsicht die Zweckperspektive ausschließt. Im Recht gibt es sozusagen nichts, was über das Recht hinausweist (vgl. ebd.: 198). Es hat eine Sozialfunktion (s.o.), aber kein Telos. Man kann allenfalls - wie in der Arbeitsteilung - die Ursachen für den Wandel des sozialen Phänomens ,Recht ${ }^{`}$ benennen, und zwar über die Formen der Assoziation (soziale Typen). Durkheim trennt also strickt zwischen Ursache und Funktion, und selbst wenn er anerkennt, dass beide in Wechselwirkung zueinander stehen und man für eine vollständige Erklärung auch auf die Feststellung der Funktion zurückgreifen muss, steht die Ursache für ihn an erster Stelle (vgl. ebd.: 181f.).

Wenn man also mit der vergleichenden Methode die Beweisführung für Kausalbeziehungen im Bereich der Soziologie antritt, dann bildet das Recht eine Tatsache in der zu variierenden Reihe - allerdings unter einer doppelten Bedingung: Erstens müsse man dann aufgrund der allgemeinen Verbreitung der Rechtsregeln im ganzen Land zum Vergleich mehrere Völker desselben Typus heranziehen (vgl. ebd.: 214); und zweitens müsse man aufgrund der Gewachsenheit der Rechtsinstitutionen (Ehe, Familie, Eigentum usw.) historisch ihre integrale Entwicklung durch alle soziale Typen nachverfolgen (vgl. ebd.: 215f.). Man mag auch hier dann aus for-

682 Selbst wenn die Strafe die nützliche Funktion habe, die intensiven Bereiche des Kollektivbewusstseins zu erhalten, so liege die Ursache für die Strafe nicht in diesem Nutzen, sondern in der Verletzung des Kollektivgefühls von entsprechender Intensität (ebd.: 181). 
schungspragmatischen Gründen eine Hinwendung zum Recht befürworten. Ein eigentlicher Beweiswert entspringt dem Recht aus eigener Kraft aber nicht.

\section{Die Rechtsentstehungslehre in den Regeln}

Wie für die Arbeitsteilung gilt für die Regeln: Die Art der Adressierung des Rechts im Rahmen des Entwurfs der Soziologie als eigenständige Disziplin erfolgt bei Durkheim vor dem Hintergrund der Gewohnheitsrechtslehre. Auch hier bestimmt er, dass sich Rechtsnormen (wie auch Moralgebote oder religiöse Dogmen usw.) auf „festgesetzte Glaubensvorstellungen und Gebräuche" stützten (ebd.: 107). Tatbestände, die dem Einzelnen mit äußerem Zwang gegenübertreten, leiten sich also vom Brauch her. Dementsprechend sieht Durkheim den Ursprung und die Natur rechtlicher (und sittlicher) Gebote in der Genese „kollektiver Gewohnheiten“:

In der Tat nehmen manche Arten des Handelns und des Denkens infolge ihrer ständigen Wiederholung eine gewisse Konsistenz an, welche sie gewissermaßen beschleunigt und sie von den einzelnen Ereignissen isoliert, in denen sie sich vollziehen. Sie nehmen körperhafte Gestalt, wahrnehmbare, ihnen eigene Formen an und bilden eine Realität sui generis, die sich von den individuellen Handlungen, in denen sie sich offenbart, vollständig unterscheidet. (Ebd.: 109)

Dass sich die rechtlichen Normen nicht mit den individuellen Willen oder Bedürfnissen decken, kennzeichnet bei Durkheim einen soziologischen Tatbestand. Und genau diese Kongruenz markiert die herausgehobene Stellung des Rechts sowohl für die Bestimmung der soziologischen Tatbestände als auch für deren adäquater Analyse.

\section{Die Kehrseite des Repräsentationsdispositivs}

Durkheim verbindet also die Rechtsentstehungslehre mit methodischen Fragen - eine Verbindung, die er über die Herleitung des Rechts aus der Gewohnheit begründet. Mit diesem Vorgehen bewegt er sich nicht nur in den Debatten über die Begründung der Soziologie als eigenständige Disziplin, sondern ebenso in einem privatrechtswissenschaftlichen Diskurs, der in seinen verschiedenen Formen das Verhältnis von Recht und Gesellschaft zu klären sucht. Dabei scheinen die juristischen Problemlagen für den Franzosen Durkheim ganz andere zu sein als im deutschen Diskurs: 
Mit den Napoleonischen Gesetzbüchern liegt bereits eine umfassende Kodifizierung vor, und angesichts dieser Positivierung des Rechts ist die école d'exégèse in den Rechtswissenschaften bis zum Ende des 19. Jahrhunderts vorherrschend. Und doch setzt Durkheim sich teils explizit, teils implizit mit den Problematisierungsweisen des deutschen Diskurses auseinander. Das folgt aus seiner Aufnahme des juristischen Repräsentationsdispositivs, wobei sich Durkheim in der Problematisierung des Verhältnisses von Recht und Gesellschaft dessen Kehrseite zuwendet.

\section{Durkheim und die Historische Rechtsschule}

\subsection{Konvergenzen mit dem juristischen Repräsentationsdispositiv}

Für die um ihre Eigenständigkeit ringende Soziologie erscheint es nach Durkheim - wie er in seinen frühen Schriften geltend macht - also notwendig, das Recht über die Gewohnheit herzuleiten. Darüber lassen sich Konvergenzen mit den Annahmen der Historischen Rechtsschule aufzeigen: Gerade weil das Recht aus der gesellschaftlichen Sphäre hervorgeht, gilt es für Durkheim genauso wenig als ein Mittel der gesellschaftlichen Steuerung, das als Instrument der politischen Ideen dienen könnte. Auch er entzieht es der willkürlichen Verfügbarkeit des Staates. Zudem geht Durkheim ebenfalls von einem dem Objekt,Gesellschaft' inhärenten Erkenntnismangel aus, der gerade die Notwendigkeit der Hinwendung zum Recht begründet: Da man letztlich die Moral bzw. das Kollektivbewusstsein genauso wenig erkennt wie bei Savigny oder Puchta den Volksgeist ist man auf Repräsentationen wie das Recht angewiesen.

Nicht nur aufgrund dessen wird der Einfluss der Historischen Rechtsschule im Savigny'schen Sinne auf Durkheims Denken von manchen als offensichtlich angesehen (vgl. Lascoumes 1991). ${ }^{633}$ Andere wiederum gehen von einem indirekten Einfluss aus, der über Jhering vermittelt werde: Dieser übernehme trotz seiner Kritik am Volksgeistkonzept die kritische Haltung der Historischen Rechtsschule gegenüber dem Naturrecht; auch Jhering orientiere sich diesbezüglich an Savigny - und in diesem Sinne dann auch Durkheim (Jones 1999: 196ff.).

683 Pierre Lascoumes hebt hervor, dass in der L'Année Sociologique zahlreiche Rezensionen über Arbeiten der Historischen Rechtsschule veröffentlicht wurden, Jherings Zweck im Recht erstaunlicherweise jedoch keine Beachtung fand (Lascoumes 1991: 41f.). 
Demgegenüber werden Isomorphien zwischen Durkheim und der Historischen Rechtsschule hervorgehoben, der Schwerpunkt jedoch auf die Differenz der Ansätze gelegt (vgl. Carbonnier 1974: 62). Denn die Gewohnheitsrechtslehre Durkheims ist bei genauerer Hinsicht ja nicht mit der der Historischen Rechtsschule in eins zu setzen: Selbst wenn Durkheim die Gesellschaft ebenfalls in Anlehnung an die biologische Organismuslehre konzipiert und sie der natürlichen Sphäre zurechnet, so ist diese Realität sui generis - wie ja gerade die arbeitsteilige Gesellschaft zeigt - bei ihm weder zwangsläufig homogen noch harmonisch. Zudem unterscheidet Durkheim das Recht von anderen moralischen Vorgaben nicht über die zugrunde liegende Wertentscheidung, die sich wie bei Savigny inhaltlich an einer allgemeinen Aufgabe allen Rechts orientiert und daher das reine Recht in Form des Privatrechts abzugrenzen vermag. Vielmehr bettet er das Recht in das Kontinuum der sozialen Nomen als sanktionsbewährte Verhaltensregeln ein, wobei die Trennlinie dann über die Organisiertheit der Sanktion läuft und nicht über die Abgrenzung (reines) Privatrecht/ (anormales) Öffentliches Recht.

Dass Durkheim die Grundzüge des epistemischen Schemas der Historischen Rechtsschule kannte, ist anzunehmen. So erwähnt er die "Juristen der historischen Schule“ in Deutschland schon in seinen frühen Arbeiten (vgl. Durkheim 1995b [1887]: 155). Auch nach der Jahrhundertwende wird er sich über seine Rezensionen mit der Historischen Rechtsschule im Gefolge Savignys auseinandersetzen (vgl. Durkheim 1903a) bzw. in seiner Treitschke-Kritik explizit auf sie zu sprechen kommen (vgl. Durkheim 1915: 29f.), wenn er ihre Opposition zum Naturrecht hervorhebt (vgl. Gephart, Hermes 2014: 237). Zudem lassen sich Verbindungen zwischen Durkheim und Vertretern einer französischen école historique nachzeichnen, die sich im Zuge der Rezeption der Historischen Rechtsschule, und hier insbesondere Savignys, herausgebildet hatte: ${ }^{684}$ So ist einerseits davon auszugehen, dass Durkheim aufgrund seiner These über Montesquieu die Arbeiten des Rechtshistorikers Édouard Laboulaye kannte, gehörte dieser damals doch zu den prominentesten Kommentatoren Montesquieus (vgl. Sembel 2013: 22f.). Zugleich hatte Laboulaye Savigny in Frankreich populär gemacht (vgl. Laboulaye 1842, 1855). Andererseits zählt Paul Huvelin zu den geschätzten Mitarbeitern der L'Année sociologique, der als Rechtshis-

684 Zum „Eindringen der historischen Rechtsschule in Frankreich“ seit Ende der 1810er Jahre insbesondere über die Arbeiten Savignys, was zur Wiederentdeckung der geschichtlichen Dimension des Rechts in Frankreich führte und damit zur Verfestigung einer französischen école historique beitrug, vgl. Bürge 1991: $150 \mathrm{ff}$. 
toriker ebenfalls mit den Arbeiten der Historischen Rechtsschule vertraut gewesen sein dürfte (vgl. hierzu Audren 2001; Cotterrell 2004a, 2005). ${ }^{685}$

Aufgrund dessen kann man davon ausgehen, dass Durkheim die allgemeine Rechtstheorie, d.h. die Gewohnheitsrechtslehre als Rechtsentstehungslehre der Historischen Rechtsschule, bekannt war (vgl. Durkheim 1915: 30). Ob er darüber hinaus die dogmatisch-methodischen Folgerungen kannte, die die Historische Rechtsschule aus der Gewohnheitsrechtslehre zog, ist jedoch anzuzweifeln. Die großen dogmatischen Konstruktionen etwa von Savigny, Puchta oder Windscheid finden keinerlei Erwähnung, nur Jherings zweiter Band des Geistes wird an so peripheren Stellen zitiert, dass dies keinerlei Rückschlüsse auf die Kenntnis der dogmatisch-methodischen Ausführungen in diesem Werk zulässt (vgl. Durkheim 1999 [posthum]: 86; 1899), so wie auch das überwiegende Gros von Durkheims Rezensionen sich auf rechtshistorische, -ethnologische und rechtsphilosophische Untersuchungen bezieht, nicht auf dogmatisch-methodische Werke (zu den Ausnahmen s. gleich).

Jenseits der Frage, ob und wieviel Kenntnis Durkheim von der Historischen Rechtsschule hatte, kann man eine deutliche Übereinstimmung erkennen: Beiden ist gemein, dass aus den jeweiligen Versionen der Gewohnheitsrechtslehre auf die gesellschaftliche Repräsentationsleistung eines staatlich unverfügbaren Rechts geschlossen wird. Auch Durkheim problematisiert das Verhältnis von Recht und Gesellschaft über die Repräsentation, und auch er sucht dementsprechend die Gesellschaft im Recht. Allerdings zieht Durkheim aus dieser Prämisse gänzlich andere Schlüsse für die Methode.

\subsection{Abweichungen vom juristischen Repräsentationsdispositiv}

\section{Recht und Rechtssystem}

Die Historische Rechtsschule geht davon aus, dass sich das Recht im Zuge der gesellschaftlichen Entwicklung ausdifferenziert und zu einem eigenständigen Organ wird. Die Repräsentation der Gesellschaft im Recht ver-

685 Zahlreiche Mitarbeiter der L'Année sociologique waren juristisch ausgebildet, sei es, dass sie in den Rechtswissenschaften promovierten oder juristische Abschlüsse besaßen (Hubert Bourgin, Maurice Halbwachs, Jean Ray, François Simiand, Georges Bourgin, Georges Davy, Louis Gernet und Marcel Mauss, vgl. Vogt 1983: 177f.), oder aber als Rechtsprofessoren arbeiteten (neben Paul Huvelin auch Emmanuel Lévy, vgl. hierzu Didry 2004; Cotterrell 2004b). 
doppelt sich: Zum einen repräsentiert das Recht den unsichtbaren Volksgeist, zum andern wird der Jurist zum Repräsentanten des Ganzen, indem im Zuge der Professionalisierung das Rechtsbewusstsein auf ihn übergeht. Um zur bewegenden Kraft in der unsichtbaren Kollektivsphäre vorzudringen, um die Gesellschaft im Recht zu finden, muss man diesen Organismus als solchen untersuchen, und d.h.: mittels der historisch-systematischen Methode. Zugleich erweist sich der Rechtswissenschaftlicher als der eigentliche Volkskundige, d.h. als dasjenige Subjekt, das in der Lage ist, solche Erkenntnisse zu gewinnen. Es ist dies die Idee des „lebendigen Rechts“, die in sich die Kraft der Entwicklung trägt und darüber die $\mathrm{Zu}$ ständigkeit des Rechtswissenschaftlers für diese Entwicklung begründet.

Demgegenüber interessiert sich Durkheim nicht für die Eigendynamik eines wie auch immer definierten Rechtssystems. Zwar bildet auch bei ihm das Recht ein „juristisches System“ (système juridique), d.h. eine individuierte Einheit, die auf fundamentale Elemente rückführbar ist (Durkheim, Fauconnet 1901). Diesen System-Charakter leitet er später ebenfalls aus dem Entstehungszusammenhang von Recht und Gesellschaft ab: „Un système juridique se définit par l'organisation sociale qu'il exprime [...].“ (Durkheim 1910: 286) Er sieht darin ein Ensemble von Praktiken, die sich auf Rechtsregeln beziehen (practiques juridiques), und die sich ihrerseits zu bestimmten Institutionen bündeln lassen, welche dann wiederum theoretisch ein System bilden (Durkheim, Fauconnet 1901). Abgesehen davon, dass dieser Systemzusammenhang in Durkheims Augen um die Jahrhundertwende noch ein Desiderat der Wissenschaft darstellt und er die Aufgabe der Soziologie gerade auch darin sieht, durch ihre Forschung diese systematisierende Leistung zuallererst zu ermöglichen, ${ }^{686}$ geht es bei ihm nicht um die Frage der Auswirkung eines solchen Systems auf die Bedeutung der Institutionen (oder Institute). Was ihn beschäftigt, sind Genese, Funktion und Funktionsmechanismus der „rechtlichen Institutionen“ (Durkheim 1991c [1888]: 73) wie Familie, Eigentum und Vertrag. Diese Fragen bilden für Durkheim den Ausgangspunkt einer jeden wissenschaft-

686 So schreibt er zusammen mit Fauconnet im Jahr 1901: „Quand la sociologie sera plus avancée, elle montrera comment les éléments d'un même système juridique tiennent les uns aux autres, comment ils sont tous placés sous l'influence de quelque élément dominateur. Mais actuellement cette étude synthétique n'est guère encore qu'un desideratum de la science." (Durkheim, Fauconnet 1901) Aufgrund der strikten Rückbindung des Rechts an die jeweiligen Gesellschaften (vgl. Durkheim 1910: 287f.) interessiert sich Durkheim zur Vorbereitung dieser Synthese für die Analyse insbesondere rechtsethnologischer Untersuchungen ganzer Völker bzw. „sozialer Typen“ (vgl. Durkheim 1903b). 
lichen Betrachtung des Rechts. Er formuliert sie auch explizit in seiner Vorlesung Physik der Sitten und des Rechts und führt bzgl. Eigentum und Vertrag aus:

Die Wissenschaft hat zu klären 1. wie diese Regeln im geschichtlichen Verlauf entstanden sind, das heißt, auf welche Ursachen sie zurückgehen und welchen Zwecken sie dienen; 2. wie sie innerhalb der Gesellschaft funktionieren, das heißt, auf welche Weise sie von den Individuen angewandt werden. (Durkheim 1999 [posthum]: 9) ${ }^{687}$

Durkheim nimmt also nicht den logisch-systematischen Zusammenhang der Rechtsregeln in den Blick, um sie über die Rekonstruktion des dem Gesetz innewohnenden Gedankens durch die Auslegung zu verstehen. Er analysiert stattdessen den Kausalzusammenhang sozialer Phänomene anhand der Untersuchung von Genese und Funktionieren des Rechts, was in seinen Augen die einzige Möglichkeit ist, Wissenschaft zu betreiben. Das Recht und die Sitten sind nach Durkheim „keine Systeme [...], die logisch mit abstrakten Maximen verbunden sind, sondern organische Phänomene, die im Leben von Gesellschaften selbst gelebt haben" (Durkheim 1991c [1888]: 69). Aus seiner Perspektive ergibt eine dogmatische Arbeit am Recht, wie sie die Historische Rechtsschule auf der Basis einer logisch-systematischen Arbeit entwickelte, für die Suche der Gesellschaft im Recht keinen Sinn. ${ }^{688}$ Man gelangt ihm zufolge nicht über Begriffskonstruktionen zum kausal definierten Leben, sondern nur durch Beobachtung und Erklärung. Wenn also auch für Durkheim Werte das Wahre im Wirklichen sind, dann gilt es, sie zu erklären, nicht sie zu verstehen.

687 Durkheim hielt die Vorlesungen zwischen 1896 und 1900 zweimal in Bordeaux sowie unter verschiedenen Bezeichnungen mehrfach zwischen 1902 und 1915 in Paris. Sie wurde 1950 in unvollständiger Form veröffentlicht (Müller 1999: 311). Es handelt sich um die wissenschaftlichen Vorarbeiten für eine „neue Moralökologie“ (ebd.: 316), in der Durkheim sich - so Hans-Peter Müller - mit den ungelösten Problemkomplexen aus der Arbeitsteilung beschäftigt, nämlich mit der Klärung der Rolle kollektiver Akteure sowie des Staates und der Entwicklung des modernen Kollektivbewusstseins (ebd.: 315). Wenn überhaupt, dann nimmt Durkheim in dieser Vorlesung eine Systematisierung des Rechts anhand der Geltungsreichweite der Rechtsnormen vor, nämlich ob es sich um Regeln mit universeller oder partikularer Geltung handele (Durkheim 1999 [posthum]: 11ff.; vgl. Gephart 1993a: 352ff.).

688 Diesen Vorwurf richtet Durkheim schon früh gegen die rechtsphilosophische logische Untersuchung von Gaston Richard, da man aus der gedanklich-logischen Konstruktionen des Rechts nicht auf die Empirie des Rechts schließen könne (vgl. Durkheim 1893: 295). 


\section{Recht und "lebendes Recht"}

Obwohl das Recht nach Durkheim in der Gesellschaft „gelebt“ hat (s.o.), lehnt er aus dem oben genannten Grund die Idee eines „lebendigen Rechts" ab - und zwar explizit: Das gesatzte Recht gehört für ihn zu den ,Dingen', die mit den Personen das innere soziale Milieu einer Gesellschaft bilden. Wenn er in den Regeln den Ursprung eines jeden bedeutungsvollen sozialen Vorgangs in diesem Milieu sucht, so kommen als aktive Faktoren jedoch nun gerade nicht die ,Dinge in Betracht: „Sie sind die Materie, an welcher die lebendigen Kräfte der Gesellschaft angreifen, doch entwickeln sie selbst keine lebendige" respektive keine „bewegende Kraft" (Durkheim 2007 [1894]: 195). Über die Analyse des Rechts lassen sich zwar Merkmale des jeweiligen sozialen Typs der Gesellschaft erkennen; eine Erklärung für die kollektive Entwicklung vermag das Recht allerdings nicht zu liefern und konsequenter Weise rekurriert Durkheim hierfür auf die Personen, d.h. das „menschliche Milieu“ (hier insbesondere auf Volumen und Dichte der Gesellschaft, ebd.: 195ff.).

Bemühungen wie die der Historischen Rechtsschule, über die Rechtsdogmatik eine Anbindung an das Leben zu gewährleisten, erkennt Durkheim folglich nicht an. Anders als in der Gewohnheitsrechtslehre der Historischen Rechtsschule führt der Repräsentationsgedanke Durkheim also nicht zur Annahme eines autonomen Rechts, das eine eigene Kraft der Entwicklung in sich trage. Daher bestreitet er letztlich die Existenz einer systemisch-organischen Eigendynamik des Rechts, über die man dann die gesellschaftliche Kraft der Entwicklung erkennen könne. Ein wissenschaftlich erzeugtes Recht, das „Recht der Wissenschaft“ oder - kritisch gewendet - das Juristenrecht, scheidet also bei Durkheim als Rechtsquelle aus. Recht ist bei ihm immer Volksrecht, dessen einzige Quelle in der Gesellschaft liegt. Der Franzose Durkheim, der über die napoleonischen Kodifizierungen mit einem rational ausgeformten, gesatzten Recht zu tun hat und daher die Probleme des Rechtspluralismus nicht (mehr) kennt, stellt sich weder Fragen der Rezeption oder der Oktroyierung von Recht (eigenes und fremdes Recht), noch sieht er sich mit sich widersprechenden Rechten konfrontiert, die zu einer Entscheidung zwingen (römisch-liberales versus germanisch-soziales Recht). Das Problem der richtigen Quelle des Rechts kennt Durkheim nicht. Das Recht erscheint bei ihm in Form des Gesetzes, und nicht wie in der Historischen Rechtsschule angesichts des Rechtspluralismus als freizulegendes Recht hinter den Rechtssätzen. Unabhängig von der Frage, ob Durkheim überhaupt die juristischen Debatten über Miss- oder Nicht-Repräsentation und -Repräsentierbarkeit der Gesellschaft im Recht kannte (s.o. $\$ 2$.III.2), hat es also konzeptionelle 
Gründe, dass diese Problematisierungen der rechtlichen Repräsentationsleistung im deutschen Diskurs der Privatrechtswissenschaften bei Durkheim keinen Widerhall finden.

\section{Die Bedürfnisse der Zeit}

Durkheim erwähnt allenfalls in verschiedenen Facetten das Problem, ob das gegebene Recht den Bedürfnissen seiner Zeit entspricht. So könne es sehr wohl der Fall sein, dass "eine juristische Institution die Ursachen für ihre Existenz um lange Zeit überleben [kann], sie bleibt mit sich selbst identisch, obgleich sich die sozialen Phänomene, die sie umfaßt, verändert haben" (Durkheim 1991c [1888]: 65). Auch für ihn ist es also denkbar, dass rechtliche Normen nicht mit dem tatsächlichen Zustand übereinstimmen und letztlich nur durch die Macht der Gewohnheit fortdauern (vgl. ebd.). Wenn also das Recht unter Umständen nicht den Bedürfnissen der Zeit entspricht, können „die Regeln selbst die Ursache des Übels“ sein (Durkheim 1996 [1893/1902]: 443).

Das sei aber letztlich kein Problem des Rechts respektive der Rechtswissenschaft. Denn sollte der - Durkheim zufolge - äußerst seltene Fall eintreten, dass sich die Sitten gegen das Recht stellen, dann würden sich die Sitten in neues Recht wandeln (vgl. ebd.: 113). ${ }^{689}$ Ein solcher pathologischer Zustand schaffe sich letztlich immer selbst ab: „Wenn sich dagegen eine Strafvorschrift eine Zeitlang hält, obwohl sie von jedem abgelehnt wird, dann dank eines Zusammenfallens außergewöhnlicher und folglich anormaler Umstände, und ein derartiger Zustand kann niemals andauern.“ (Ebd.: 123) Wenn Recht nicht mehr dem gegenwertigen Stand der Gesellschaft entspreche, gehe entweder die Sitte unter, da sie es nicht schaffe, sich zu verstetigen, oder aber das Recht wandele sich, indem die neuen Sitten in der Rechtsform auf Dauer gestellt würden.

Diese Selbstregulierung kann nach Durkheim weder über den Gesetzgeber (s.o.) noch unter der Ägide der Rechtswissenschaft erfolgen. Recht und Sitte initiieren nicht den sozialen Wandel, sondern folgen ihm. Folglich lehrt einen das Studium des Rechts auch nicht, was sich gerade im Wandel befindet: „Das Recht und die Sitten drücken nur den bereits fixierten und konsolidierten sozialen Wandel aus; sie lehren uns folglich nichts über die

689 So gilt für den Konflikt selber: „Das Recht drückt die Sitten aus, und wenn es sich gegen sie stellt, dann mit der Kraft, die es ihnen entnommen hat." (Durkheim 1996 [1893/1902]: 198). 
Phänomene, die noch nicht bis zum Grad der Kristallisation gelangt sind oder die etwa gar nicht dahin kommen werden [...]!" (Durkheim 1991c [1888]: 65) V.a. aber stellt die Rechtswissenschaft in Durkheims Rechtsentstehungslehre gerade keinen Kausalfaktor für rechtlichen Wandel dar. Anders als der Historischen Rechtsschule geht es Durkheim letztlich gar nicht um die Differenz zwischen Recht und Volksgeist als normativ-moralische Sphäre, sondern um diejenige zwischen Recht und gesellschaftlichem Entwicklungsstand. Die eigentliche Ursache für einen Rechtswandel liegt gar nicht in der Moral, denn auch ihr Wandel geht auf die Veränderung der Strukturmerkmale der Gesellschaft, d.h. ihres inneren Milieus zurück (s.o.). Die Arbeitsteilung erzeugt neues Recht - zwar vermittelt über neue Sitten und Gebräuche, aber die Ursache liegt trotzdem jenseits dieser Normen. Für die Erklärung müssen also die Strukturmerkmale der Gesellschaft in den Blick genommen und nicht auf Erkenntnisse der Rechtswissenschaften über die Normen des Rechts abgestellt werden.

Wenngleich Durkheim sich auch nach der Arbeitsteilung noch bemüht, eine neue Moral zu entwerfen, und obwohl er spätestens mit seiner SuizidStudie nicht mehr optimistisch auf die Selbstheilungskräfte der Arbeitsteilung verweist, erscheint ihm die neue Moral nicht als ein Rechtsproblem. Nicht nur aufgrund der vagen, und - wie die Kritik an Durkheim immer wieder anmerkt - widersprüchlichen Bestimmungen über den Zusammenhang von gesellschaftlichem Wandel und Recht, sondern aus konzeptionellen Gründen schließt Durkheim für die Suche nach einem Umgang mit der Krise der modernen Gesellschaft den Rekurs auf das Recht und die Rechtswissenschaft aus.

\section{Durkheims funktionale Perspektive jenseits des gesellschaftsfunktionalen Zweckdispositivs}

Da er die Rolle des Rechts respektive der Rechtswissenschaft für die Bewältigung der Krise der Moderne abwertet, ist Durkheim die Perspektive des gesellschaftsfunktionalen Zweckdispositivs, wie sie in der Debatte um die „soziale Aufgabe“ des BGBs anzutreffen ist, fremd. Er mag zwar umstandslos zentrale Prämissen mit diesem Diskurs teilen. Denn selbst wenn er durch die Gewohnheitsrechtslehre der Gesetzgebung die Legitimation zur eigenständigen Handlung abspricht - hierin ähnelt er der Historischen Rechtsschule -, geht es ihm ja nicht um eine (idealistische) Verankerung des Rechts in der Vergangenheit. Für ihn liegt - wie im gesellschaftsfunktionalen Zweckdispositiv - das Problem im krisenhaften Zustand der Gegenwart. Das epistemische Ding, Gesellschaft wird sich selbst zum Prob- 
lem, und damit rücken auch bei Durkheim das Ordnungsproblem, die Frage der gesellschaftlichen Bindungswirkung und der Erhalt der Gesellschaft in den Mittelpunkt. Wie Jhering sieht er den Zweck des Rechts in der Sicherung der sozialen Ordnung; das sei seine ,Sozialfunktion'. Dass angesichts dessen das Recht, und zwar gerade auch das Privatrecht, eine soziale Aufgabe hat, ist für Durkheim selbstverständlich. Das gelte für alle Bereiche des Rechts gleichermaßen, so dass eine Aufgabenteilung zwischen Öffentlichem Recht und Privatrecht - und damit auch eine Verlagerung der gesellschaftstheoretischen Frage in Rechtsgebietsstreitigkeiten nicht möglich ist.

Damit lassen auch Durkheims Überlegungen eine Aufwertung des Zweckgedankens für die Bestimmung des Rechts erkennen, wobei der Zweck gerade nicht normativ, sondern funktional zu verstehen und daher als ein Wahrheitsproblem anzusehen ist. Aber obwohl das Recht in Durkheims funktionaler Wendung des Repräsentationsgedankens kein Selbstzweck, sondern ein Mittel zum Zweck der gesellschaftlichen Ordnungssicherung ist, entzieht sich dieses Mittel sowohl der gesetzgeberischen als auch insbesondere der rechtswissenschaftlichen Verfügbarkeit. Während er eine gegenüber dem gewachsenen Recht selbstständig agierende Gesetzgebung aufgrund der Gewohnheitsrechtslehre ausschließt, gilt für die Rechtswissenschaft: Aus der Bestimmung der Funktion bzw. des Zwecks des Rechts lassen sich weder Vorgaben für die juristische Analyse des Rechts noch für die Bestimmung eines wie auch immer gearteten richtigen, angemessenen oder adäquaten Rechts durch die Rechtswissenschaft herleiten. Die erklärenden Ursachen können ihm zufolge ja gerade nicht über den Zweck oder die Funktion hergeleitet werden; vom Nutzen eines sozialen Phänomens könne man nicht auf dessen Entstehung oder Wesen schließen. Für Durkheim ist die „soziale Aufgabe“ also die gesellschaftliche Funktion des Rechts. Diesbezügliche Vorgaben sind hingegen nicht aus dem Recht herleitbar, geschweige denn dadurch zu erklären. Letztlich ist es vor diesem Hintergrund nicht möglich, über die Rechtswissenschaft zur „Lösung des sozialen Sphinxräthsels“ (Fuld) der sozialen Frage zu gelangen, weil das Recht keinen Kausalfaktor in der gesellschaftlichen Entwicklung darstellt. Daher ist der Sachverständige für die soziale Ordnung auch nicht der Rechtswissenschaftler, sondern der Soziologe, der sich damit einem eigenständigen Gegenstandsbereich zuwendet. Angesichts der Krise der gegenwärtigen Gesellschaft bedarf es in Durkheims Konzeption nicht eines soziologischen Korrektivs (etwa Menger, Petrazycki), sondern genuin und allein soziologischer Forschung.

Angesichts dieser Divergenzen verwundert es auch nicht, dass Durkheim sich trotz zahlreicher Rezensionen deutscher juristischer Arbeiten für 
die doch so prominente Debatte um die soziale Aufgabe des BGBs nicht interessiert. Das zeigt sich deutlich in der Rezension eines Beitrags aus dieser Diskussion, nämlich Ludwigs Fulds Aufsatz „Die Frauen und das bürgerliche Gesetzbuch“. Dort beleuchtet er die Problematik weder - wie Fuld - aus der Perspektive der Sozialpolitik, noch geht er auf die zugrunde liegende Frage der Angemessenheit der Ordnungsleistung des neuen Rechts mit Blick auf das Geschlechterverhältnis ein (vgl. Fuld 1900). Durkheim listet letztlich nur die von Fuld erwähnten positiven Regelungen des BGBs bzgl. der Stellung der Frauen auf (Durkheim 1901).

Dementsprechend kann man sagen: Auch wenn Durkheim letztlich den Repräsentationsgedanken im Recht funktional wendet, lassen sich daraus keine Rückschlüsse für die Rechtswissenschaft und das Recht ziehen. Er bleibt trotz allen in den Bahnen des Dispositivs der Repräsentation.

\section{Durkheims Ablehnung der Problemlagen des normativen Zweckdispositivs}

Die Irrelevanz der Rechtswissenschaft hat bei Durkheim auch einen wissenschaftstheoretischen Grund, womit er sich im normativen Zweckdispositiv verorten lässt. Denn aufgrund seines naturwissenschaftlich orientierten Wissenschaftsverständnisses hegt Durkheim starke Zweifel an der generellen Wissenschaftlichkeit der Jurisprudenz.

Dass die Spekulationen der Rechtsphilosophie für ihn keinerlei wissenschaftlichen Wert haben, ist selbstredend. Doch auch die eigentliche Anwendungsfrage des Rechts, die juristische Methodenlehre, die Anleitungen zur Auslegung des Gesetzes gibt, ist für Durkheim keine Wissenschaft: „Die Interpretation eines Textes stellt jedoch eine Kunst und keine Wissenschaft dar, weil sie nicht darauf hinausläuft Gesetze zu entdecken." (Durkheim 1991b [1888]: 43) Die Rechtswissenschaft habe praktische Ziele, und daher sei sie keine Wissenschaft im strengen Sinne des Wortes. So etwas wie eine ,normative Wissenschaft ${ }^{\text {' }}$ ist für Durkheim ein Widerspruch in sich (Durkheim 1904b: 380f). Er weist also die Möglichkeit einer Rechtswissenschaft im strengen Sinne insgesamt zurück, geht aber zugleich davon aus, dass sie ohne wissenschaftliche - und d.h. dann: soziologische Erkenntnis nicht agieren kann: „Die Praxis der Rechtsprechung ist im Wesentlichen eine Kunst, eine Angelegenheit der Erfahrung. Aber jede Kunst, die nicht Routine ist, stützt sich auf eine Wissenschaft, von der sie sich inspirieren läßt. Für das Recht kann diese Wissenschaft nur die Soziologie sein“ (Durkheim 1991c [1888]: 73) - auch wenn diese im Jahr 1888 noch in den Kinderschuhen stecke (ebd.). Da man für den Umgang mit den rechtlichen Institutionen deren Ursachen kennen müsse (ebd.), scheint es 
geradezu unmöglich, dass die Rechtswissenschaft nicht durch eine geänderte Vorstellung über die Gesellschaft und die sozialen Funktionen modifiziert werde. Für diese Erkenntnis bedürfe es aber der soziologischen Methode, denn „es gibt nur ein Mittel, diese Ursachen zu entdecken, und das ist die vergleichende Methode, die wir anwenden wollen" (ebd.).

Das gelte umso mehr, als die rechtswissenschaftliche Rechtsvergleichung, wie sie sich gegen Ende des 19. Jahrhunderts als Teildisziplin im juristischen Fächerkanon gegenüber der nun von der Rechtsdogmatik abgesonderten Rechtsgeschichte ausdifferenzierte (vgl. Vogenauer 2012), ebenfalls nur eine Kunst darstelle: „Le droit comparé, au contraire, est un art; son rôle est tout pratique." (Durkheim 1904a: 375) Als Wissenschaft anzusehen sei nur eine ,Rechtssoziologie (oder eben eine ,juridische Soziologie', „sociologie juridique“, ebd.), die in historischer Perspektive vergleichend verfahre, um die Ursachen der Rechtsinstitutionen zu ermitteln (ebd.). ${ }^{690}$ Allenfalls die Rechtsgeschichte verdient bei Durkheim also den Titel einer Wissenschaft (Durkheim 1902). Einer Rechtswissenschaft, die sich über Rechtsdogmatik und -methodik definiert, spricht er demgegenüber den Wissenschaftscharakter ab.

Das bedeutet allerdings nicht, dass Durkheim für die dogmatisch-methodischen Implikationen seiner Soziologie für die Rechtswissenschaft blind gewesen wäre, genauso wenig wie er die französischen Debatten seiner Zeit über die Reform der juristischen Methode ignoriert. ${ }^{691}$ Denn auch in Frankreich gerät um die Jahrhundertwende die vorherrschende Methode der école de l'exégèse (Gläser 1996: 43) zunehmend in die Kritik (etwa von Saleilles oder Gény) - unter anderem als Folge der Rezeption der Historischen Rechtsschule und Jherings Zweckdenken. ${ }^{692}$

Auch Durkheim wendet sich gegen diese vorherrschende Schule. Deren methodischer Kern ist in der Gleichsetzung des Rechts mit dem Gesetz sowie in der Auslegung des Gesetzes - gerade auch im Falle von Lücken -

690 So heißt es bei Durkheim: „Le droit civil comparé, tel que l'entend l'auteur, n'est pas l'histoire comparée du droit. Celle-ci est une pure science, qui, par voie de comparaison, cherche à déterminer la genèse des institutions juridiques. C'est un autre nom donné à ce que nous appelons ici sociologie juridique." (Durkheim 1904a: 375).

$691 \mathrm{Zu}$ Durkheims Verortung in den juristischen Debatten seiner Zeit in Frankreich vgl. Lascoumes 1991; Halpérin 2017.

$692 \mathrm{Zu}$ Génys eigenwilliger Adaption von Jhering vgl. Whitman 1997: 160ff.; zum Einfluss der Rezeption der Historischen Rechtsschule in Frankreich im 19. Jahrhundert auf die Methodenfrage vgl. insbesondere Bürge 1991: 199ff. 
nach dem Willen des Gesetzgebers zu sehen. ${ }^{693}$ Durkheim formuliert starke Vorbehalte gegen eine solche Rechtswissenschaft, die sich in einer reinen Exegese der Gesetze erschöpfe, indem sie lediglich Texte kommentiere. Dabei würden die juristischen Formulierungen als „Orakel“ angesehen, deren „mysteriösen Sinn“ es nach der verschleierten und oft unbewussten Intention eines Menschen oder einer Versammlung zu „erraten“ gelte (Durkheim 1991b [1888]: 51). Wenn es also vor allem darum gehe, die Intention des Gesetzgebers herauszufinden (ebd.: 50), dann werde die einzige Quelle des Rechts fälschlicherweise im Willen der Legislative verortet: „Dies hieße jedoch, den Buchstaben für den Geist, den äußeren Schein für die Wirklichkeit zu nehmen." (Ebd.) ${ }^{694}$

Trotz dieser Kritik an der école de l'exégèse erteilt Durkheim den juristischen Methodenreformbestrebungen in Frankreich eine harsche Absage: Zwar signalisiert er Zustimmung zu Raymond Saleilles, der als direkter Vorläufer der französischen Debatte um die Erneuerung der Rechtswissenschaft gilt (vgl. Durkheim 1903a: 302). Dieser hatte in Auseinandersetzung mit der Historischen Rechtsschule einen Rechtsbegriff entwickelt, der sich zwar nicht gegen die Kodifikation richtet, Recht jedoch als konkretes, in bestimmten sozialen Milieus erwachsendes historisches Phänomen begreift (vgl. Sabbioneti 2010). Das habe eine Auslegungsmethode zur Folge, die auf objektiven Faktoren jenseits des subjektiven Willens des Gesetzgebers, aber auch jenseits subjektiver Gerechtigkeitsempfindungen abstelle (vgl. Durkheim 1903a). Was Durkheim dabei vehement kritisiert, ist jedoch die Idee, dass es sich bei diesen objektiven Faktoren um „natürliches Recht" jenseits des Gesetzes handele (ebd.: 303). Dabei wendet er sich nicht nur gegen die missverständliche Bezeichnung, sondern gegen die Konzeption an sich: „Il n'est pas plus, ni moins naturel que celui d'hier qu'il remplace, ou celui de demain qu'il prépare. Il correspond à des changements qui se sont produits dans l'état des sociétés où il s'élabore, comme celui du passé répondait à un état qui n'est plus.“ (Ebd.) Da für Durkheim das Recht die im Gesetz kristallisierten Gewohnheiten sind, existiert kein gelebtes, ,natürliches‘ oder sonstiges Recht hinter oder neben dem Gesetz, auf das man im Falle von Anwendungsunsicherheiten rekurrieren könnte

693 Wobei jedoch der Wille des Gesetzgebers äußerst flexibel interpretiert wird (vgl. Gläser 1996: 44ff.).

694 Denn die Quelle liege im Kollektivbewusstsein, dem der Gesetzgeber nur einen Ausdruck verschaffe: „Das Recht arbeitet sich aus dem Innern der Gesellschaft hervor, und der Gesetzgeber bestätigt nur ein Werk, das sich ohne ihn vollzogen hat.“ (Durkheim 1991b [1888]: 50f.). 
und das - wie in der deutschen Debatte - dadurch methodische Implikationen für die Rechtswissenschaft entfalten würde. ${ }^{695}$

Auch der Ansatz des Saleilles-Schülers François Gény, der mit dem Entwurf der „libre recherche scientifique“ der französischen Methodenreformbewegung den entscheidenden Impuls gab, ist für Durkheim nicht haltbar. Nach Gény, den er vermittelt über Edouard Lambert bespricht, dürfe eine Rechtsfortbildung nur im Falle einer echten Lücke im Gesetz erfolgen. Die Kriterien für die richterliche Entscheidung seien dann wissenschaftlichen Untersuchungen etwa der Ökonomie, der Politik, der Moralökologie des Landes etc. zu entnehmen.696 Denn der Brauch, die Gewohnheit seien für Gény als Rechtsquelle aufgrund des zunehmenden Einflusses der Gesetzgebung mittlerweile absolut peripher. Recht entstehe nicht in unbewussten Gewohnheiten, sondern sei heute ein Produkt der rationalen gesetzgeberischen Entscheidung. Wenn Lambert nun dieser Abwertung der Gewohnheit als Rechtsquelle durch Gény widerspricht, so stimmt ihm Durkheim darin explizit zu (Durkheim 1904a: 376). Allerdings ist Durkheim nicht einverstanden mit dem, was Lambert unter, Gewohnheitsrecht ${ }^{`}$ verstanden wissen will, nämlich richterliches Gewohnheitsrecht, wie es sich in den rational gefällten Urteilen herausbilde. Der These, dass das Gewohnheitsrecht ein Produkt der Jurisprudenz sei (ebd.: 377), hält Durkheim entgegen, dass das Recht auch in diesem Fall dem Kollektivbewusstsein entspringe. Denn die Rechtsprechung gehöre zu den „centres secondaires“ (ebd.: 378) des Kollektivbewusstseins und repräsentiere in ihren Urteilen zwar nicht den ganzen Organismus, aber bestimmte Teile. ${ }^{697}$

Insofern hängt Durkheim auch in seinen Stellungnahmen zu den rechtswissenschaftlichen Methodenentwürfen seiner Zeit in Frankreich einer Gewohnheitsrechtslehre an, die die methodischen Überlegungen der

695 Durkheim richtet diesen Einwand ebenso gegen Stammler, aber auch gegen François Gény und seinen ehemaligen Kollegen Léon Duguit aus Bordeaux, die beide zu den Hauptakteuren in der französischen Methodendebatte um die Wende zum 20. Jahrhundert zählen (vgl. Chazal 2010).

696 Die freie wissenschaftliche Recherche hat nach Gény „pour préoccupation dominante, de découvrir elle-même, à défaut du secours des sources formelles, les éléments objectifs qui détermineront toute solution requise par le droit positif" (Gény 1954 [1899]: 77, H.i.O.) Zu diesen zählt er die „nature des choses“ bzw. die "réalités objectives“.

697 So heißt es über die rechtsprechenden Akteure: "Ils ne sont avertis que de certains besoins, ne sentent que certains courants et l'étendue de leur action législative doit se restreindre en raison de l'étendue restreinte de leurs informations." (Durkheim 1904a: 378). 
Juristen für obsolet erscheinen lassen. Denn selbst wenn Durkheim nicht bestreitet, dass es Lücken im Recht gibt bzw. das gesetzte Recht durch die gesellschaftlichen und ökonomischen Entwicklungen vor Probleme gestellt wird, so erscheint aus seiner Perspektive eine wissenschaftliche Reform der juristischen Methoden schlicht und ergreifend deshalb unnötig, weil man darüber keinerlei wissenschaftlichen Erkenntnisse über die Rechtsquellen gewinnen könne. Gerade weil er in einer strengen Gewohnheitsrechtslehre das Recht an die Gesellschaft rückbindet, bleibt diese Erkenntnis allein der Soziologie vorbehalten.

In dieser Aufwertung der Soziologie gegenüber einer nun als unwissenschaftlich qualifizierten Rechtswissenschaft lassen sich Ähnlichkeiten zu den Ansätzen einer Soziologisierung der Rechtswissenschaft erkennen, wie sie im normativen Zweckdispositiv im Diskurs der deutschen Privatrechtswissenschaft zur Debatte stand. Allerdings führt Durkheim die Normativität des Rechts nicht als strategisches Problem ein. Auch wenn er Recht als sanktionsbewährte Gebote definiert, reduziert er die normative Seite des Rechts auf ein Faktum. Daher erscheinen ihm die Probleme eines juristischen Werturteilsstreits nicht als wissenschaftliche Probleme, und Auslegungsfragen werden gar nicht erst adressiert. In der Rechtsform erscheine eine kollektive Gewohnheit jenseits seiner Anwendung in Permanenz. Daher gibt es für Durkheim - wie bereits erwähnt - keine „zwei verschiedene[n] Arten“, eine Rechtsnorm aufzufassen (Durkheim 2007 [1894]: 139). Aber auch auf inhaltlicher Ebene bewegt sich Durkheim jenseits von Interpretationsproblemen des Rechts, da er die Rechtsinstitutionen nur hinsichtlich ihrer Ursachen, Wirkungen und Funktionsmechanismen, aber nicht hinsichtlich ihrer jeweils konkreten Ausformungen in den jeweiligen Gesetzen bzw. in ihren Anwendungen untersuchen will. Damit steht für Durkheim folglich nicht zur Debatte, was ein konkreter Rechtssatz besagt, sondern welche Institutionen darin ihren Ausdruck finden.

Letztlich sieht Durkheim im Entwurf seiner Soziologie auch keine Konkurrenz zu den Rechtswissenschaften, nicht nur, weil sein Erkenntnisziel auf die außerrechtlichen Voraussetzungen des Rechts gerichtet ist, sondern weil er schlichtweg den Wissenschaftscharakter der Rechtswissenschaft bestreitet. Das Verhältnis zwischen Rechtswissenschaft und Soziologie erscheint bei Durkheim nicht diskussionswürdig. Insofern erstaunt es auch nicht, wenn Durkheim an Kantorowicz' Ausführungen zu dieser Frage am ersten deutschen Soziologentag aus dem Jahr 1910 einzig dessen Erkennt- 
nis nennenswert erscheint, dass das soziologische Wissen für die Juristen unverzichtbar sei (Durkheim 1913: 23f.). ${ }^{698}$

\section{Die Indexthese als Kehrseite des Repräsentationsdispositivs}

Durkheims explizite und implizite Ausführungen zur Rechtstheorie und zur Rechtswissenschaft basieren allesamt auf einem vollkommen entproblematisierten Verständnis des Rechts. In seinen Ausführungen zum Recht gibt es kein Bestimmungsproblem (Recht ist Gesetz und nicht lebendiges oder lebendes Recht), kein Verständnisproblem (Auslegung), keine Probleme der Angemessenheit des Rechts (Bedürfnisse der Zeit), und aus wissenschaftlicher Perspektive schon gar kein Wertungsproblem („soziale Aufgabe“). Durch den Ausschluss der Rechtswissenschaft aus dem Kanon der Wissenschaften besteht auch kein Konkurrenzverhältnis bezüglich der Erkenntnis des Rechts, insbesondere auch deshalb nicht, weil Durkheim die rechtliche Norm nur als kristallisierte kollektive Gewohnheit betrachtet. Recht ist der Prototyp eines soziologischen Tatbestandes, der in seiner Positivität und Objektivität der soziologischen Analyse als Grundlage dienen kann - oder wie König diese Position beschreibt: „Die Regeln des gesatzten Rechts sind nicht nur im juristischen Sinne eine ,Rechtsquelle', sondern auch im soziologischen Sinne eine Quelle für objektive Daten (wie die der Statistik), die weiterer analytischer Zerlegung zugeführt werden können." (König 1971: 49, H.i.O.) Dabei zieht die Soziologie ihre Erkenntnisse aus der Repräsentationsleistung des Rechts, das doch in seinem jeweiligen Bestand das kollektive Bewusstsein indiziert.

Diese sogenannte „Indexthese“ des Rechts, wie sie Durkheim insbesondere in der Arbeitsteilung aufstellt, wurde von Anfang an mit sehr überzeugenden Gründen einer harschen Kritik unterzogen. Schon der DurkheimSchüler Albert Bayet bezweifelt den soziologisch indikativen Wert der Rechtsnormen, wenn er darauf hinweist, dass bei einer gegebenen Norm weder klar sei, ob sie noch angewendet werde oder trotz gleichen Wortlauts durch Auslegung gänzlich modifiziert worden sei, ob sie von verschiedenen Kreisen und Klassen überhaupt in derselben Weise angewandt werde bzw. ob sie nicht auf Widerstand in der Gesellschaft stoße. In all diesen Fällen könne das methodische Vorgehen, aus dem kodifizierten Recht die gemeinsamen Vorstellungen einer Gesellschaft abzuleiten, in die

698 Für Weber erscheint die Auseinandersetzung mit Kantorowicz‘ Vortrag demgegenüber zentral, s.u. $\$ 8$.III. 
Irre führen (Bayet 1922, 1925, zitiert nach König 1971: 49). Darüber hinaus wies man immer wieder auf die Schwierigkeiten der Trennung zwischen repressivem und restitutivem Recht hin (Cotterrell 1999: 33). Die eigentümliche Art der Kategorisierung des Rechts wurde ebenfalls kritisch hervorgehoben, insbesondere Durkheims Einordnung des Verwaltungsund Verfassungsrechts als restitutives Recht (etwa Gephart 1993a: 384f.). Von rechtshistorischer Seite griff man wiederum Durkheims Konzept primitiver Gesellschaften im Rahmen seiner Entwicklungsthese des Rechts an (vgl. Müller, Schmid 1996: 512 m.N.). Kritisiert wurde ebenso das Vorgehen, das Recht zu einem Argument der Zahl zu machen, indem die verschiedenen Arten des Rechts in ein quantitatives Verhältnis gesetzt werden (vgl. Hart 1967: 6) Selbst ein Durkheim wohlgesonnener Autor wie Roger Cotterrell kommt zu dem Schluss: „In short, the index thesis, as he explains it, seems to show the worst aspects of the positivist orientations of his sociology.“ (Cotterrell 1999 : 33; s.a. Lukes, Prabhat 2013: 156)

Die Kritik an der „Indexthese“ wird aber mit einer generellen Kritik an der Arbeitsteilung verbunden, lautet doch die allgemeine Meinung in der Literatur, dass es Durkheim nicht gelungen sei, seine Untersuchung über den Zusammenhang zwischen Arbeitsteilung und gesellschaftlicher Solidarität zu einem befriedigenden Abschluss zu führen (Schmid 1989: 518ff. m.w.N.). V.a. die logischen Widersprüche der Bestimmung des Kollektivbewusstseins einerseits als Grundbegriff jeglicher Gesellschaftslehre und andererseits als Spezifikum der mechanischen Solidarität, welches mit der Zunahme der organischen Solidarität abnehme, werfen Durkheim nicht nur völlig aus der Bahn (vgl. Parsons 1966: 318), sondern wirkten sich auch auf die rechtlichen Fragestellungen aus. Denn welche Rolle in qualitativer Hinsicht dann das Strafrecht spielt, auf das Durkheim ja trotz seiner These der Abnahme des repressiven Rechts immer wieder zurückkommt, bleibt völlig unklar (vgl. Gephart 1993a: 384). Letztlich gründe auch das „,Durkheimsche Dilemma' in der Soziologie der Moral“ (Karsenti 2013) in der Arbeitsteilung: Über die Sanktionsanalyse des Rechts schreibt Durkheim darin die Moral auf eine objektive, empirische Tatsache fest, in der über den Normbruch nur Handeln als Abweichung oder Devianz in den Blick gerät. Die genuin normative Dimension der Moral samt ihrer verhaltensbestimmenden positiven Wirkungen, also Handlungen, die sich an Idealen orientieren, bleiben in ihrer strukturbildenden Funktion außen 
vor - bzw. sind nur über eine Revision der Prämissen zu integrieren (vgl. hierzu Isambert 2013; Karsenti 2013). ${ }^{699}$

Diese Einwände sind zwar triftig, übersehen aber alle die strategische Funktion bzw. das „Prinzip der Forschungstechnik“ (König 1971: 50), das der spezifischen Art der Adressierung des Rechts bei Durkheim zugrunde liegt - sowohl bezogen auf die Soziologie als auch auf die Rechtswissenschaft.

Wenn es nämlich um die Begründung der Soziologie als eine eigenständige Wissenschaft geht, die sich über einen spezifischen Gegenstandsbereich definiert, der zudem in seiner Konstitution den „Regeln der soziologischen Methode" zugänglich ist, und wenn man diesen Gegenstandsbereich außerdem als ein moralisches Phänomen definiert, dann bedarf es eines soziologischen Tatbestandes, der genau diese Anforderungen erfüllt. Würde er fehlen, gäbe es keinen Beweis dafür, dass man die Soziologie als Wissenschaft der Moral überhaupt auf eine empirische Basis stellen könne. Genau das gewährleistet für Durkheim das Recht. Denn welche anderen moralischen Normen kämen statt dem Recht in Betracht, die die gleichen Vorteile in sich vereinten, nämlich Sichtbarkeit, Permanenz, Objektivität und Repräsentation?

Sowohl für die Arbeitsteilung als auch für die Regeln gilt: Das Recht kann die von Durkheim proklamierte forschungspragmatische Funktionen nur in einer ganz bestimmten Form erfüllen. Die von Anfang an viel gescholtene Vorgehensweise, das Recht als Index der jeweiligen Solidaritätsform heranzuziehen, basiert auf der Annahme, dass das Recht die soziale Solidarität direkt repräsentiere. Durkheim muss vermeiden, das Recht gegenüber der Moral zu verselbständigen. Denn „wenn man Grund zur Annahme hätte, daß das Recht zu einem gegebenen Zeitpunkt nicht den wahren $\mathrm{Zu}$ stand der sozialen Beziehungen zum Ausdruck bringt“", dann wäre sein

699 Allerdings rückt auch Durkheim später die normative Dimension mehr und mehr in den Vordergrund, wenn er etwa im Jahr 1906 nun ein „gewisses Erstrebenswertsein" zu den Hauptmerkmalen der moralischen Tatsache zählt (Durkheim 1976a [1906]: 85) bzw. im Jahr 1911 versucht, Werturteile soziologisch zu fassen, ohne sie auf Wirklichkeitsurteile zurückzuführen „und damit den Begriff des Werts zum Verschwinden zu bringen“ (Durkheim 1976c [1911]: 153). In seiner letzten moraltheoretischen Schrift, der Einleitung zu dem Buch, das er über die Moral schreiben wollte, trennt er dann für seine Art der Wissenschaft der Moral zwischen Wert und Wirklichkeit. Wenn er nun zwischen der Sitte als angewandte Moral und der "Moral selbst, d[er] ideale[n] Moral, die über den menschlichen Handlungen schwebt" unterscheidet (Durkheim 1986b [1917]: 48f.), will er nun gerade diese „Moral selbst“ zum Ausgangspunkt seiner Wissenschaft machen (ebd.). 
Verfahren in der Arbeitsteilung - wie er selbst anmerkt - „unzulässig“ (Durkheim 2007 [1894]: 139 Anm.). Das bedeutet zugleich: Jegliche Intervention - sei es seitens des Gesetzgebers, seitens der Rechtswissenschaft oder des Individuums -, die eine Abweichung gegenüber dieser strengen und direkten Kopplung des Rechts an die soziale Sphäre bewirkt oder gar anderweitige Kausalfaktoren geltend macht, muss Durkheim ausschließen. Nur dann kann das Recht die geforderte Indexfunktion erfüllen, nur dann kann man es zu einem Argument der Zahl machen bzw. als Prototyp eines soziologischen Tatbestandes ansehen.

Genau das gewährleistet in Durkheims Konzeption die Rechtentstehungslehre, die er seinem Rechtsbegriff zugrunde legt. Nur in Form der Gewohnheitsrechtslehre, die das Verhältnis von Gesellschaft und Recht über die Repräsentationsleistung des Rechts konzeptionalisiert, sieht Durkheim sich also in der Lage, seiner Soziologie ein sicheres Fundament zu geben. Denn nur auf diese Weise wird das Recht unzweifelhaft zu einem soziologischen Tatbestand, der aufgrund seiner gänzlich entproblematisierten Bestimmung und seiner Dinghaftigkeit einer empirischen Analyse zugänglich ist - und zwar unabhängig von der Frage, ob man die Rechtssätze formal über die Sanktionsart oder inhaltlich über die darin geregelten Rechtsinstitutionen klassifiziert. Anders formuliert: Jede andere Herleitung des Rechts, jede Relativierung seines Gehalts über die Problematisierung der Ordnungsleistung oder gar der Normativität des Rechts, gefährdet das Projekt der Begründung einer Soziologie als „Wissenschaft der Moral" auf einer sicheren empirischen Basis. Es sind also theoriestrategische Gründe im Entwurf der Soziologie, die Durkheim in der Entstehungsphase der Soziologie das Recht aus der Gewohnheit herleiten lassen.

Durkheims soziologische Rechtsentstehungslehre steht dabei der juristischen Gewohnheitsrechtslehre sehr nahe. Daher ist sein Ansatz gegenüber den Rechtswissenschaften auch nicht neutral, und zwar nicht nur, wenn er explizit hierzu Stellung nimmt, sondern ebenfalls aufgrund der impliziten Konsequenzen. Durkheim gelangt jedoch zu gänzlich anderen methodischen Schlussfolgerungen als die Gewohnheitsrechtslehre der Historischen Rechtsschule, die letztlich zur Aberkennung des Wissenschaftscharakters für die Rechtswissenschaft führen. Dies folgt aus seiner soziologischen Verkehrung der Problematisierung des Verhältnisses von Recht und Gesellschaft über den Repräsentationsgedanken:

Wenn sowohl Durkheim als auch die Gewohnheitsrechtslehre aufgrund des dem Objekt ,Gesellschaft' inhärenten Erkenntnismangels auf das Recht rekurrieren, so entproblematisiert die Historische Rechtsschule in einem gewissen Sinne die Gesellschaft, um das Recht problematisieren zu können. Das Objekt ,Gesellschaft' bildet ja gerade aufgrund dieses Erkenntnis- 
mangels keinen legitimen Gegenstand für eine eigenständige Wissenschaft, und vice versa richtet sich dann das wissenschaftliche Interesse auf die Erkenntnismöglichkeiten des Rechts. Da eine - wie auch immer geartete - Wissenschaft der Gesellschaft nicht möglich erscheint, wird der eigentliche Gesellschaftswissenschaftler im dogmatisch arbeitenden Rechtswissenschaftler gesehen. Demgegenüber ist es für die Annahme der Indexfunktion des Rechts für Durkheim unerlässlich, dass er das Recht komplett entproblematisiert. Er weist die Möglichkeit einer Rechtswissenschaft zurück, die nicht selbst soziologisch bzw. soziologisch fundiert ist. Der Rechtswissenschaftler, will er als solcher und nicht als Praktiker auftreten, muss soziologisch verfahren. Durkheim reproduziert also die Asymmetrie der Historischen Rechtsschule in Bezug auf Fremd- und Selbstbeobachtung des Rechts, allerdings nun als soziologische Verkehrung des Repräsentationsgedankens, wie dies schon Lorenz von Stein - nur weit weniger erfolgreich - versucht hatte. Damit beschreibt Durkheims Entwurf der Soziologie die Kehrseite des juristischen Repräsentationsdispositivs.

\section{Der Verlust des Rechts im Repräsentationsgedanken}

Aus dieser theoriestrategischen Anlage eines notwendigen Bezugs zum Recht lässt sich zugleich erklären, weshalb der Stellenwert des Rechts in Durkheims weiteren Arbeiten immer geringer wird. Man könnte auch sagen: Indem Durkheim sich dem Recht zuwendet, wendet er sich von ihm ab. Wenn er nämlich zum einen auf die Rechtsphilosophie (und -theorie) rekurriert, um die im Entstehen begriffene Soziologie wissenschaftlich einzubetten, so ist dieser Bezug im Moment der Konsolidierung der Soziologie nicht mehr nötig. Wenn Durkheim zum anderen über die Gewohnheitsrechtslehre den moralischen Tatsachen einen eigenständigen und damit eigenständig erforschbaren Charakter zuspricht, dann bedarf es im Moment der Etablierung einer selbständigen soziologischen Theorie der "soziologischen Tatbestände“ dieser Legitimation über die Rechtsentstehungslehre nicht mehr.

Diese Abkehr vom Recht hat aber auch mit Durkheims besonderer Art zu tun, in der er das Recht adressiert. Zwar mag man anerkennen, dass er sich sowohl für die Bestimmung der Rechtsform über die Sanktionsart als auch in der Untersuchung der im positiven Recht geregelten Rechtsinstitute dem positiv gesatzten Recht zuwendet. Damit ist aber letztlich kein Interesse am konkreten Inhalt dieser Rechtssätze, d.h. ihrem materiell-rechtlichen Regelungsgehalt, verbunden. Für die Bestimmung der Sanktionsart ist er irrelevant - ob im Vertragsrecht Pacht, Kauf, Tausch oder Leasing 
etc. geregelt wird, macht dafür keinen Unterschied. Und weil er die Repräsentationsleistung auf inhaltlicher Ebene an den rechtlichen Institutionen festmacht und nicht an einzelnen positiven Regelungen, interessiert sich Durkheim auch nicht für aktuelle gesetzgeberische Vorhaben und Neuerungen. Das wird noch dadurch bestärkt, dass Durkheim mit seiner Betonung des Repräsentationsgedankens ja letztlich nicht auf die Steuerungsleistungen des Rechts zu sprechen kommt, d.h. auf die konkreten Auswirkungen der aktuellen Gesetze auf ökonomische, politische und soziale Prozesse.

Schließlich muss man sagen: Indem Durkheim jegliche Divergenz von Recht und Interpretation oder Wandel der Interpretation negiert, spielt für ihn der Wandel auch in der Rechtsanwendung keine Rolle. All das lässt nachvollziehen, weshalb Durkheim den Rechtswissenschaften im engeren Sinne, d.h. Rechtsdogmatik und Methodik, überhaupt keinen wissenschaftlichen Wert für die Soziologie zuspricht. Dass er sich mit seiner Konzeption des Rechts dabei gegenüber der Rechtswissenschaft keineswegs neutral verhält, ist für ihn daher auch nicht von Interesse, da es sich damit sowieso nicht um ein wissenschaftliches Problem handelt.

Recht erscheint als ein entproblematisierter Faktor, der in dieser Form in der Begründung der Soziologie eine notwendige Funktion erfüllt. Für eine konsolidierte Soziologie ist, wie erwähnt, ein Rekurs auf das Recht nicht mehr nötig. Ob man sich dann den rechtlichen Gegebenheiten zuwendet oder nicht, ändert nichts an der Selbstständigkeit der Soziologie und der Aussagekraft ihrer Ergebnisse. ${ }^{700}$ Recht wird damit zum Gegenstand einer Rechts-Soziologie, und nicht mehr der allgemeinen Soziologie. Dies folgt sozusagen aus der Kehrseite des Repräsentationsgedankens.

700 Dem widerspricht nicht, dass das Recht bzw. rechtliche Phänomene einen zentralen Topos im Werk seiner Schüler Georges Davy, Paul Fauconnets, aber auch von Marcel Mauss bilden. 


\section{\$7. Ferdinand Tönnies und das gesellschaftsfunktionale Zweckdispositiv}

Für Durkheim stellt in dem Versuch der Gründung der Soziologie die Auseinandersetzung mit dem Recht insbesondere eine forschungspragmatische Notwendigkeit dar. Dabei erfolgt die Bezugnahme auf anderweitige wissenschaftliche Ansätze zum Recht, namentlich auf die Rechtswissenschaft und die Rechtsphilosophie, vorwiegend implizit. Zwar enthalten Durkheims Annahmen über Genese, Eigenart und Wirkung des Rechts zwangsläufig Positionierungen in den rechtswissenschaftlichen Debatten, wie man dies insbesondere als Kehrseite des Repräsentationsdispositivs kennzeichnen kann. Doch die entsprechende Rechtstheorie beansprucht trotz dieser Implikationen, als soziologische Theorie des Rechts für sich selbst zu stehen.

Ganz anders stellt sich die Situation bei Ferdinand Tönnies dar: Für die Entfaltung einer genuin soziologischen Perspektive auf das menschliche Zusammenleben rekurriert er explizit auf die rechtlichen Diskussionen. ${ }^{701}$ So äußert er sich immer wieder zur Debatte um die Kodifikation des BGBs, schaltet sich aber auch in die Diskussionen um die juristische Methode ein (s.u. IV.2). ${ }^{702}$ Es ist aber namentlich die Kritik der Historischen

701 Nichtsdestotrotz erfahren Durkheim und Tönnies jedoch eine geradezu entgegengesetzte Rezeption: Gegenüber Durkheim, der heute immer noch als Klassiker der Rechtssoziologie gehandhabt wird, sind Tönnies' explizite Auseinandersetzungen mit dem Recht und der Rechtswissenschaft seiner Zeit in der Rechtssoziologie mehr oder minder in Vergessenheit geraten.

702 So schaltet sich Tönnies nicht nur mit seinen Beiträgen zur der von Kohler, Liszt und Berolzheimer initiierten Enquête „Ein deutsches Institut für Rechtsphilosophie und soziologische Fragen?"“ (Tönnies in Kohler et al. 1910: 220ff.) sowie zur Debatte um das Verhältnis von Soziologie und Rechtsphilosophie in die laufende Diskussion ein (Tönnies 1911b; s.o.). Vielmehr ist auch sein Aufsatz Gemeinschaft und Individuum (Tönnies 2012g [1914]) in diesem Kontext zu sehen, veröffentlicht er ihn doch im Jahr 1914 kurz vor Kriegsbeginn in einem Schwerpunktheft der Zeitschrift „Die Tat“, das ganz der juristischen Methodendiskussion gewidmet ist. Aufgrund der Kriegsereignisse erscheint diese Ausgabe nachträglich als eine Art Zwischenbilanz der Methodendiskussion, die mit Beiträgen u.a. von Radbruch, Sinzheimer, Fuchs, Rumpf, Korsch und Hedemann eine kleine Heerschau freirechtlicher und verwandter Richtungen enthielt (Gängel, Mollnau 1992: 291). 
Rechtsschule am Naturrechtsdenken, die - wie er immer wieder betont zum Ausgangspunkt der Entwicklung seiner Grundbegriffe, Gemeinschaft' und ,Gesellschaft' wird. Denn nach Tönnies gründet sich die Soziologie sowohl in geistesgeschichtlicher wie in sachlicher Hinsicht in dieser rechtstheoretischen respektive -philosophischen Konstellation. ${ }^{703}$

Angesichts dessen wird zwar immer wieder betont, dass die Auseinandersetzung mit dem Recht, einzelnen Rechtsinstituten und den theoretischen Überlegungen der Rechtswissenschaft (respektive der Rechtsphilosophie) bei Tönnies für den Entwurf der Soziologie als eigenständige Disziplin eine bedeutende Rolle spielt (vgl. etwa Jacoby 1971; Bickel 1991; Merz-Benz 2016). Allerdings werden daraus in der Regel keine Rückschlüsse für die Interpretation, aber v.a. auch für die Einordnung der Tönnies'schen Soziologie als neu zu begründende Disziplin gegenüber der Rechtswissenschaft gezogen (so ansatzweise bei Bond 2011a; 2011b).

Dabei wird erst vor dem rechtlichen Hintergrund Tönnies' theoretische Leistung und spezifischer geistesgeschichtlicher Einsatz in Gemeinschaft und Gesellschaft erkennbar, und hierin liegen in seinen Augen auch die Verständnisprobleme seines Werkes begründet: „Aber es gibt einigen Grund zu der Annahme, daß nur Wenige unter denen, die es des Lesens gewürdigt haben, wirklich mit dem Zustand und der Vergangenheit rechts- und sozialphilosophischer Lehren hinlänglich vertraut waren, um hier ein Kontrastierendes und Neues zu bemerken." (Tönnies 2012e [1899]: 104)

In dieser Perspektive, d.h. der Rückbindung auf die juristischen Diskurse, zeigt sich, dass Tönnies sich zwar auf die Konfrontationslage von Naturrecht und Historischer Rechtsschule bezieht, wie sie im Kodifikationsstreit Anfang des 19. Jahrhunderts gegeben war. Sein theoretischer Einsatz besteht jedoch in der Umdeutung der zugrunde liegenden Rechtsquellenproblematik. Das führt ihn dazu, Recht nicht über seine Repräsentationsleistung, sondern mit Blick auf seine Ordnungsfunktion zu problematisieren. Tönnies greift also in spezifischer Weise die Problematisierungsweisen des gesellschaftsfunktionalen Zweckdispositivs auf. Und erst daraus lässt sich die begriffliche Architektonik von Gemeinschaft und Gesellschaft erklären, nämlich die Tatsache, dass der Entwurf der Soziologie in den Entwurf

703 Gerade mit Blick auf den Entwurf der Grundbegriffe ist Cornelius Bickel zuzustimmen, wenn er schreibt: „In Gemeinschaft und Gesellschaft ist das Tönniesche Gesamtwerk in allen wichtigen Grundzügen bereits enthalten." (Bickel 2003: 120). 
einer neuen Naturrechtstheorie in Form des gemeinschaftlichen Rechts (später: gemeinschaftlichen Naturrechts) mündet.

\section{Die geistesgeschichtliche Fundierung von Gemeinschaft und Gesellschaft in der Rechtsphilosophie}

Tönnies gibt in seinen Schriften immer wieder Auskunft über jene wissenschaftlichen und intellektuellen Traditionen, die sein Denken und damit seine grundbegriffliche Unterscheidung zwischen ,Gemeinschaft' und ,Gesellschaft' maßgeblich geprägt haben. Gleich im ersten Satz seines Vorwortes zur ersten Auflage seines Hauptwerkes Gemeinschaft und Gesellschaft aus dem Jahr $1887^{704}$ benennt er den entscheidenden geistesgeschichtlichen Hintergrund: „Der Gegensatz der historischen gegen die rationalistische Auffassung ist im Laufe dieses Jahrhunderts in alle Gebiete der Social- oder Cultur-Wissenschaften eingedrungen.“ (Tönnies 1979 [1887]: XV)705 Zum Ausgangspunkt des Entwurfs seiner Soziologie wird also die Differenz zwischen Historismus, wie ihn Tönnies im Aufkommen der Romantik Anfang des 19. Jahrhunderts erblickt (vgl. Tönnies 1979 [1912]: XXVI), und

704 Vorliegend wird aus der Reproduktion der 8. Auflage von Gemeinschaft und Gesellschaft aus dem Jahr 1935 zitiert. Dabei wird das Zitat mit dem Verweis auf das Jahr 1887 versehen, wenn die Textstelle schon in der ersten Auflage vorhanden war. Abweichungen von der ersten Auflage werden mit Verweis auf das jeweilige Jahr gesondert gekennzeichnet; kleinere, nicht sinnverändernde Wortänderungen, genauso wie die terminologische Umstellung von Willkür zum Kürwillen, sind hiervon jedoch ausgenommen.

705 Bei Tönnies gibt es insofern ein Zusammenspiel von geistesgeschichtlicher Entwicklung, erkenntnis- und wissenschaftstheoretischen Prämissen und soziologischer Begrifflichkeit, wie Peter-Ulrich Merz-Benz darlegt: „Im Übergang von den historischen zu den rationalen Sozialformen sieht Tönnies nichts Geringeres ausgedrückt als die Genesis des menschlichen Zusammenlebens. Doch diese Genesis selbst und mit ihr die Konstitution der Sozialwelt wird nur erfassbar am Leitfaden des von Tönnies anhand seiner ,tieferen Erklärung‘ des Übergangs vom Empirismus zum Rationalismus erschlossenen Konstitutionsprinzips der Wirklichkeit selbst. Die Begriffspaare von ,Historismus und Rationalismus' sowie von ,Empirismus und Rationalismus' bezeichnen letztlich bloß die beiden Seiten derselben Sache. Was nunmehr gefordert ist, ist die auf diese Weise begründete Sozialwissenschaft in ihren Einzelbegriffen im Detail auszugestalten, und genau dies hat Tönnies mit seinem Werk Gemeinschaft und Gesellschaft getan.“(Merz-Benz 2016: 58f.). 
Rationalismus, wie er ihn in seiner typischen Form in den naturrechtlichen Entwürfen bei Hobbes erkennt (vgl. Tönnies 20121 [1932]: 263). ${ }^{706}$

\section{Naturrecht versus Historische Rechtsschule}

Um die Historismus-Rationalismus-Problematik entspannt sich bei Tönnies eine - aufgrund der Vielzahl von teils widersprüchlichen Bezügen nur schwer entwirrbare Reihe an Gedanken (vgl. Merz-Benz 2016: 49f.; Bickel 1991: 93ff.). Allerdings führt er von Beginn an diese Problematik auf den Gegensatz von rationalem Naturrecht und Historischer Rechtsschule zurück.

\subsection{Die Ursprünge der Grundbegriffe in Naturrecht und Historischer Rechtsschule}

Das rationale Naturrecht ist - wie Tönnies später schreibt - „die Lehre von der natürlichen Freiheit und Gleichheit der Menschen“, die als Tatsache (zuweilen auch als Postulat) der Vernunft aufgefasst wird (Tönnies 1998 [1932]: 247). Wenn dabei „völlig getrennte und geschiedene Willenssphären der Menschen als allgemein und notwendig" vorausgesetzt werden (Tönnies 1925 [1905-1911]: 192), ergeben sich daraus Folgerungen für die Gestaltung der Gesetzgebung und damit des Rechts, „die selbst als vernünftig, darum als allgemein und notwendig zu postulieren" seien (Tönnies 1998 [1932]: 247). Recht ist in dieser Konzeption Resultante rationaler Willensakte (so etwa auch im Gesellschaftsvertrag), und genau daher erweise es sich als streng rationales System (vgl. Tönnies 1911a: 397).

706 Vgl. zu Tönnies' Einsatz in der Historismus-Rationalismus-Problematik insbesondere Bickel 1991; Merz-Benz 2016: $37 \mathrm{ff}$. Tönnies entwickelt Gemeinschaft und Gesellschaft zunächst in seiner Habilitation als ein Theorem der „Kultur-Philosophie“" (Tönnies 2012a [1880/1881]), ordnet dann die Ausarbeitung der Habilitation der „Socialwissenschaft“ zu (vgl. Tönnies 1979 [1887]: XXII), um das Werk erst in der zweiten Auflage von 1912 als Beitrag zu den Grundbegriffen der „reinen Soziologie“ zu titulieren. Für all diese Phasen hält er an der Genese seiner Begrifflichkeit ,Gemeinschaft und Gesellschaft" aus dem Gegensatz der historischen zur rationalen Auffassung fest. Da diese Fundierung herausgearbeitet werden soll, geht es hier nicht um die Entwicklung des Tönnies'schen Denkens, sondern um die Grundstruktur. 
Die im Kern revolutionäre - sowie liberale (vgl. Tönnies 1998 [1932]: 248) - Konzeption des rationalen Naturrechts drückt für Tönnies in paradigmatischer Weise die moderne Weltsicht aus. Er sieht darin den ersten Entwurf der wissenschaftlichen Durchdringung der sozialen Wirklichkeit (vgl. Bickel 1991: 265), gehe doch mit der Freisetzung des Individuums ähnlich wie bei Durkheim - eine Zunahme der sozialen Verhältnisse und Verbindungen einher (vgl. Tönnies 1998 [1932]: 248):

Die Lehre [des Naturrechts, D.S.] ist daher Correlat eines gesellschaftlichen Zustandes, worin die persönliche Freiheit normale Erscheinung, und das Privateigentum ausgebildet ist; daher der entwickelten Arbeitsteilung und des regulären Verkehrs mit Tauschwerten, - der Geld und Kapitalwirtschaft. (Tönnies 1911a: 398)

Dieser individualistisch-rationalistische Begriff eines natürlichen, d.h. der Vernunft gemäß allgemeinen und notwendigen Rechts, wird Anfang des 19. Jahrhunderts durch das Aufkommen und den Erfolg der Romantik in Frage gestellt, wie sie in der Historischen Rechtsschule ihren Ausdruck findet. Hier erscheint das Recht nun nicht mehr als eine rationale Konstruktion, sondern historisch erwachsen aus Sitte, Brauch und Gewohnheit. Es ist die Gewohnheitsrechtslehre mit ihrer Idee der organischen Verbundenheit des Rechts mit dem Volksgeist, auf die Tönnies abhebt (vgl. Tönnies 2012d [1895]). Recht erscheint nicht - wie im Naturrecht - als rationaler Willensakt der Zukunft zugewandt, sondern als aus der Vergangenheit erwachsen. Es ist kein Produkt einer nach Vernunftmaßstäben agierenden Gesetzgebung, sondern der Kollektivsphäre in ihrer Einheit.

Tönnies steht jedoch der Historischen Rechtsschule äußerst kritisch gegenüber: Sie ist für ihn Ausdruck einer restauratorischen politischen Romantik, die aus dem „Zweifel an dem Werte der Aufklärung [...] seit den Entrüstungen über die Greuel der Revolution" erwachsen ist (Tönnies 1926d [1908]: 66) - d.h. Ausdruck der Reaktion, die der rationalen individualistischen Staatskonstruktion den Garaus machen wollte (vgl. Tönnies 1979 [1912]: XXVI). ${ }^{707}$ Die Annahmen der Historischen Rechtsschule auch wenn sie die rechtsgeschichtliche Forschung befruchteten - seien nicht nur „einseitig und unzulänglich“ (Tönnies 1926d [1908]: 69). Vielmehr drückten sie einen „Antirationalismus“ aus (ebd.), der sich in der „unbestimmte[n] Anschauung“ des Gewohnheitsrechts und in der „in Unklarheit verharrende[n] Analogie eines organischen Charakters alles positi-

707 In der Historischen Rechtsschule sieht Tönnies also weniger die Ambivalenz der Romantik, als deren konservativ-restaurative Seite. 
ven Rechtes“ (Tönnies 2012g [1914]: 204, H.i.O.) ganz auf das „Rechtsgefühl“ und die „still wirkenden Kräfte des Volksgeistes“ (Tönnies 1979 [1912]: XXXII) als ihrer pantheistischen Grundlage stützen (vgl. ebd.: XXVII; 1926d [1908]: 88). Damit verzichte die Historische Schule der Rechtswissenschaft (wie auch der Nationalökonomie) in Tönnies Augen „auf Begriffsbildung und Theorie mehr oder weniger ausdrücklich" (Tönnies 2012d [1895]: 82), so dass der wissenschaftliche Charakter dieses Unternehmens in Zweifel gezogen werden müsse.

Zudem schätze die Historische Rechtsschule ihre eigene Wirkung gänzlich falsch ein. Denn trotz der Tatsache, dass Savigny die Auffassung vertrat, dass das Recht durch einen „organischen Zusammenhang“ mit dem Wesen und Charakter des Volkes verbunden sei, wende er sich nicht dem einheimischen Recht zu, sondern bejahe inkonsequenterweise die Rezeption des römischen Rechts. Darüber entgehe ihm, dass das römische Recht, d.h. „ein fremdes Recht so wenig wie eine fremde Sprache mit dem Wesen und Charakter eines Volkes organisch zusammenhängen kann" (Tönnies 2012d [1895]: 79). Mehr noch: Das römische gemeine Recht greife wie das Naturrecht in die sozialen Verhältnisse ein. Denn als gemeines Recht, dass gegenüber den lokalen Besonderheiten die ratio scripta zu verwirklichen suche, sei es letztlich „in demselben Sinne revolutionär und gleichmachend tätig" wie der rationale Gesetzgeber (ebd.: 81). Insbesondere verhindere das römische Recht, wie es Savigny konzipiert (bzw. über das subjektive Recht systematisiert), in keiner Weise die typisch naturrechtlichen Folgen der Entwicklung des sozialen Lebens: die „Entfesselung des Privatrechtes, des willkürlichen Eigentums, der vollkommenen Freiheit aller Kontrakte“" (ebd.). ${ }^{708}$

Im Anschluss an Gierkes Kritik am BGB (vgl. ebd.: 79f.) greift Tönnies die Annahme auf, das römische Recht sei individualistisch und eben nicht ,organisch' erwachsen respektive, sozial'. Was dabei auf inhaltlich-systematischer Ebene als Kongruenz zwischen Naturrecht und Historischer

708 Angesichts dieser Entwicklung erklärt sich aber auch das Scheitern der Gewohnheitsrechtslehre, die das Recht moralisiert, indem sie es in der Sittlichkeit gründet und von ihr unablösbar denkt. Denn „vergebens mühen“ sich die „romantischen und restauratorischen Denker“, „das Recht einer kapitalistischen Gesellschaft als von sittlichem Inhalt erfüllt darzustellen. Erfüllt ist es von der Herrschaft des Privateigentums; und in diesem hat (nach einem neueren Meister der Jurisprudenz, Rudolf von Ihering), der nüchterne, platte Materialismus seine vollendete Ausprägung erhalten'. Natürlich können gleichwohl mit solchem Recht sittliche Gefühle und Gedanken zusammen bestehen; aber sie gehören nicht zu ihm, sie liegen außerhalb seines Wesens.“ (Tönnies 2012g [1914]: 205). 
Rechtsschule gesehen werden kann (so schon Tönnies 1880a: 3 [pag.]), d.h. subjektives Recht und Systembildung, wird bei Tönnies zu dem Vorwurf umgewandelt, dass Savigny unwissentlich genau das verwirklichte, was er zu verhindern suchte. Die Vertreter der Historischen Rechtsschule vermochten nämlich gerade nicht, „die in der wirklichen Rechtsauffassung und Rechtsbildung ausgeprägte Denkweise umzugestalten, d.h. deren individualistisch-gesellschaftliche Voraussetzungen zu tilgen, die vielmehr unter ihren ahnungslosen Händen um so üppiger wucherten" (Tönnies 2012g [1914]: 204).

Trotz dieser fundamentalen Kritik an der Historischen Rechtsschule erweist sich die Gewohnheitsrechtslehre nach Tönnies für die Soziologie ebenso anschlussfähig wie die "Sozialtheorie“ des Naturrechts (Tönnies 1979 [1912]: XXVI). Es handele sich bei den beiden um die Differenz zwischen einer „organischen“ und einer „mechanischen Auffassung“ des sozialen Lebens. Und genau in dieser Differenz fundiert Tönnies seine Grundbegriffe: Die Gemeinschaft wird als „reales und organisches Leben“, als „lebendiger Organismus“ begriffen, die Gesellschaft dagegen als „ideelle und mechanische Bildung“, d.h. als ein ,mechanisches Aggregat und Artefakt“ (Tönnies 1979 [1887]: 3f.). ${ }^{709}$ Letztlich gilt:

Der Ursprung meiner soziologischen Begriffe liegt in dem für Deutschland bedeutenden Gegensatz der historischen gegen die rationalistische Denkungsart und Schule, welcher Gegensatz der vorherrschenden Auffassung nach mit der Überwindung des rationalistischen durch das historische Denken gelöst worden ist. (Tönnies 2012k [posthum]: 257)

\subsection{Der Konflikt zwischen Naturrecht und Historischer Rechtsschule}

Der die Soziologie grundbegrifflich fundierende Gegensatz zwischen Historismus und Rationalismus tritt nach Tönnies aber nicht nur „am Auffallendsten in der Rechtsphilosophie zutage" (Tönnies 2012k [posthum]: 257). Vielmehr sei in der Rechtswissenschaft (in Verbund mit der Nationalökonomie) der Ursprung des soziologischen Denkens zu suchen: Die

709 Warum Tönnies damit das Durkheim'sche Schema verkehrt, lässt sich aus der Fundierung in der Rechtsphilosophie erklären, beruft er sich doch für die Kategorie der Gemeinschaft auf das organizistische Denken der Historischen Rechtsschule und für die der Gesellschaft auf das mechanistische Denken des Naturrechts, wie es ja auch bei Jhering zum Ausdruck kam. 
philosophische, die historische und die naturwissenschaftliche „Denkungsart" haben im 19. Jahrhundert in ihrem geistesgeschichtlichen Einfluss gerade auf die Jurisprudenz (und die Nationalökonomie) „teils einzeln, teils zusammen, teils nach-, teils gegeneinander das soziologische Denken erzeugt und soweit entwickelt, wie es bis zum Schlusse des Jahrhunderts gediehen ist" (Tönnies 1926d [1908]: 63, H.i.O.). Denn die Soziologie ist bei Tönnies „in erster Linie eine philosophische Disziplin“ (Tönnies 1926g [1910]: 125), die letztlich die Sozialphilosophie, wie sie in der Rechtsphilosophie (und Staatslehre) ihren Ausdruck fand, wissenschaftlich weiterentwickelte:

Die Spekulationen über das Wesen der menschlichen Gesellschaft, insbesondere der politischen Verbindungen, hingen immer mit den Ideen einer gesitteten und guten Lebensführung und Lebensgestaltung nahe zusammen. Die Philosophen sollten ja Wegweiser des Lebens sein, sie wollten die richtigen Wege finden und führen. So ist denn die Entwicklung der reinen theoretischen Soziologie, die man auch Sozialphilosophie nennen mag, unablösbar von der Geschichte der Rechtsphilosophie, mithin auch von der allgemeinen Staatslehre, von denen in neueren Zeiten die Theoreme vom richtigen wirtschaftlichen Leben, vom Wohlstande und, im Anschluß daran, von den natürlichen und gesetzmäßigen Zusammenhängen der Produktion, des Austausches und der Konsumtion, sich abgezweigt haben. (Ebd.)

Aus dieser Fundierung der Soziologie in der Rechtsphilosophie resultiert die spezifische Problemkonstellation, an die Tönnies in seiner Theoriebildung anknüpft. Es ist jener Punkt in der Entwicklung der Rechtswissenschaft, in der die Rechtsphilosophie Anfang des 19. Jahrhunderts ihre dominierende Position verliert. ${ }^{710}$ Denn das Erstarken der Historischen Rechtsschule

führte dazu, das Naturrecht, wie es in den letzten zwei Jahrhunderten ausgebildet war, gänzlich preiszugeben, hingegen das Gewohnheitsrecht als normales Gebilde des Volksgeistes höher zu schätzen als alles, was

710 Letztlich resultiert dieses Interesse aber aus der Wahl seines Ausgangspunktes, nämlich der Orientierung an den rechts- und staatsphilosophischen Schriften von Hobbes, die ihn zur Auseinandersetzung mit dem älteren Naturrecht führte (vgl. Tönnies 1926d [1908]: 97). Insofern verwundert es auch nicht, wenn er vor Abfassung von Gemeinschaft und Gesellschaft plante, ein Buch über „das Recht als philosophisches Problem“ zu verfassen, das „eine kurze Geschichte des Naturrechts" enthalten sollte und dadurch „mit etlichen der derbsten Irrtümer aufräumen könnte“ (Tönnies, Brief vom 30.10.1879, in Tönnies, Paulsen 1961: 63). 
im Gebiet des Rechtes aus der Vernunft abgeleitet werden kann oder sogar nachweislich aus der Vernunft eines Gesetzgebers hervorgegangen ist (Tönnies 2012k [posthum]: 257, H.i.O.).

Die Wissenschaft vom Naturrecht ,ist aber untergegangen, indem die ganze Philosophie der Aufklärung untergegangen ist. Sie wurde Anfang dieses Jahrhunderts bald mit mehr, bald mit weniger Geräusch in Acht und Bann getan" (Tönnies 1880c: 42 [eigene Pag.]). ${ }^{711}$ Tönnies bezieht sich also weder auf Ansätze, die auf eine Revision des Naturrechts abzielen, noch versucht er den Konflikt zwischen Naturrecht und Historischer Rechtsschule über Kongruenzen oder Arbeitsteilung zu lösen (s.o. \$2.III.1.2). Worauf er abstellt, ist die genuine Konfliktsituation zwischen den beiden Positionen, d.h. den Streit über Geltungsanspruch und Reichweite der jeweiligen Denkungsart, proklamieren doch beide Seiten, die jeweils einzig gültige Rechtstheorie zu sein.

Um diese Konfliktsituation zu fassen (und in der Synthese zu überwinden, s.u.), bezieht sich Tönnies explizit auf den Kodifikationsstreit in den Rechtswissenschaften Anfang des 19. Jahrhunderts (vgl. Tönnies 2012d [1895]: 79; 1926d [1908]: 68f.). Insbesondere schließt er sich Hegels Kritik an, dass die Historische Rechtsschule jeder Philosophie des Rechts ermangele (Tönnies 1926d [1910]: 97). ${ }^{712}$ Damit widerspricht Tönnies vehement den Emanzipationsversuchen der Rechtswissenschaft gegenüber der Philosophie, wie sie für die Historische Rechtsschule kennzeichnend war und die zum Gegenstand zahlreicher Kritiken in der ersten Hälfte des 19. Jahrhunderts wurde.

Diese Abspaltung von der Philosophie ist für Tönnies aus wissenschaftlichen Gründen nicht hinnehmbar. Mit dem Aufkommen der Historischen Rechtsschule zeigt sich das rechtsphilosophische Denken in ihrer Daseins-

711 Allerdings betont Tönnies immer wieder, dass es irrtümlich sei zu meinen, dass die Historische Rechtsschule derart zur Herrschaft gelangt sei, dass das Naturrecht gänzlich am Boden gelegen habe (vgl. etwa Tönnies 1926d [1908]: 69). Auch er sieht, dass das Naturrecht in das Öffentliche Recht abgewandert ist (Tönnies 1979 [1887]: 184). Daraus zieht er aber keine nennenswerten Konsequenzen, da es ihm ja um die Auflösung des genuinen Konfliktes geht.

712 Hegels Bedeutung liegt nach Tönnies darin, dass er die Gesellschaft (wie den Staat) als ein geistig-natürliches Gebilde in ihrer Notwendigkeit begriff, „anstatt sie lediglich als auf theoretischen Verirrungen beruhend zu verwerfen, wie es in der Romantik und der historischen Jurisprudenz, wie in allem restauratorischen und reaktionären Denken wesentlich angelegt war" (Tönnies 1979 [1912]: XXVII; zu Tönnies kritischen Auseinandersetzung mit Hegel vgl. Tönnies 1998 [1932]; Alwast 1991). 
berechtigung bedroht bzw. verlor de facto an Einfluss und Wirkungsmacht. Das wiegt für Tönnies aber schwer, geht es doch damit um die Wissenschaft selbst. Denn das Naturrecht ist nach Tönnies Ausdruck einer rationalistischen Tendenz, die selbst „Tatsache der Historie“ ist (Tönnies 2012d [1895]: 84). Die zunehmende Rationalisierung aller Bereiche des sozialen Lebens findet seine Entsprechung im Rationalismus der Wissenschaft, d.h. auf dem ihm „eigentümlichsten Gebiet“ (ebd.). Letztlich gilt nach Tönnies: „Alle Wissenschaft und mithin alle Philosophie als Wissenschaft ist rationalistisch." (Tönnies 1979 [1887]: XX, H.i.O.) ${ }^{713}$ Wenn also Tönnies den Rationalismus „als Prinzip des wissenschaftlichen Denkens überhaupt erkannte" (Tönnies 20121 [1932]: 263), dann ist für ihn das rationalistische Naturrecht der Prototyp des wissenschaftlichen Denkens. Der Angriff auf das Naturrecht durch die Historische Rechtsschule erweist sich somit als Angriff auf das wissenschaftliche Denken selbst.

Die im Kodifikationsstreit angelegte Konfliktsituation zwischen Rechtsphilosophie und Historischer Rechtsschule wird für Tönnies also zur eigentlichen Problemlage (l'urgence), aus der Gemeinschaft und Gesellschaft erwächst (vgl. Bond 2011b: Rn. 1). Darauf muss letztlich die (neue) wissenschaftliche Disziplin der Soziologie antworten. Angesichts dessen fasste Tönnies - so seine eigene Rekonstruktion der Entwicklung seines Denkens - „den Vorsatz, sowohl den wahren Sinn des Naturrechts als auch den der Kritik zu erfassen, die es vernichten wollte, und gelangte so dahin, mir ein Bild von der ganzen umfassenden Wirkung des Rationalismus zu gestalten, den ich bald als Prinzip des wissenschaftlichen Denkens überhaupt erkannte“ (Tönnies 20121 [1932]: 263).

713 Tönnies merkt jedoch im selben Atemzug an: „Aber alle Philosophie, mithin Wissenschaft als Philosophie ist empiristisch: in dem Verstande nach welchem alles Sein als Wirken, Dasein als Bewegung und die Möglichkeit, Wahrscheinlichkeit, Nothwendigkeit der Veränderung als eigentliche Wirklichkeit aufgefaßt werden muß, das Nicht-Seiende als das wahrhaft Seiende, also durch und durch auf dialektische Weise“ (Tönnies 1979 [1887]: XX, H.i.O.) Dieses dialektische Verhältnis zwischen einer rationalistischen und einer empiristischen Philosophie überträgt er auf den Gegensatz der reinen zur angewandten bzw. empirischen Soziologie (vgl. hierzu insbesondere Tönnies 1926g [1910]: 134). Sein Wissenschaftsverständnis aber zeigt sich am deutlichsten am Pol der reinen, rationalistischen Wissenschaft. Ob auch die Grundbegriffe bei Tönnies dialektisch angelegt sind (so etwa Schlüter 1991), oder aber dualistisch (vgl. etwa Parsons 1966: 686ff.; 1973), ist umstritten. 


\section{Die juristischen Vorläufer der Soziologie: Jhering als „Erneuerer des Naturrechts"}

Wenn Tönnies die Rechtsphilosophie zu den Vorläufern der Soziologie zählt, dann erstaunt es nicht, dass er zahlreichen juristischen Autoren einen starken Einfluss auf die Entwicklung seiner Art der Soziologie zuschreibt: Hierzu zählen nicht nur Hobbes als eigentlicher Begründer des Naturrechts (vgl. Tönnies 1931: 213; s.a. Bond 2011a) und Savigny als prägende Figur der Historischen Rechtsschule (vgl. Tönnies 2012k [posthum]: 257), vielmehr weist Tönnies auch immer wieder auf den großen Einfluss des „soziologisch denkende[n] Jurist[en]“ Henry Sumner Maine (Tönnies 2012f [1907]: 120) sowie Otto von Gierkes hin (z.B. Tönnies 1979 [1912]: XXX), um daneben auf eine Vielzahl naturrechtlicher und rechtsphilosophischer (etwa Samuel Pufendorf, Kant, Heinrich Ahrens oder Kohler, aber auch Stammler und Bergbohm, vgl. zu letzteren Tönnies 1925 [19051911]) sowie rechtshistorischer und -ethnographischer Autoren zu sprechen zu kommen (z.B. Burkard Wilhelm Leist, Johann Jakob Bachofen oder Albert Hermann Post, vgl. Tönnies 1926d [1908]). Im Reigen der juristischen Vorläufer sticht jedoch die Bezugnahme auf einen juristischen Autor hervor: Immer wieder setzt sich Tönnies mit Rudolf von Jhering auseinander. Seine eigene Theorie stehe - wie Tönnies in der Retrospektive bekundet - „in einem gewissen negativen Verhältnis zu Ihering“ (Tönnies 1922: 211 [13]). Oder, wie er an anderer Stelle über seine Grundbegriffe schreibt: „Die Hauptbegriffe waren auch in fortwährender kritischer Beziehung auf die Theoreme [...] Iherings“ gedacht (Tönnies 1926d [1908]: 98).

Jhering ist Tönnies schon als Autor des Geist des römischen Rechts bekannt, einem - so Tönnies - „geistreichen, aber selbstgefällig-weitschweifigen Buche“ (Tönnies, Brief vom 31.07.1879, in Tönnies, Paulsen 1961: 58). ${ }^{714}$ Es ist aber die kritische Auseinandersetzung mit dem Zweck, die für Tönnies zu einer der „Schlüsselsituationen“ (Bickel 1991: 70) in der Entstehung von Gemeinschaft und Gesellschaft wird. Dabei nimmt er von Anfang an Anstoß am Zweck: Zwar seien „nicht wenige einzelne geistreiche Bemerkungen darin, und auch der Grundgedanke ist ja richtig, d.h. doch auch nur derjenige der 2ten Hälfte, aber wie widerlich aufgeblasen ist die Ausführung!“ (Tönnies, Brief vom 31.10.1879, in Tönnies, Paulsen 1961: 63) Auch könne man - wie er später anmerkt - im „Torso [des Zwecks;

714 In Tönnies' Nachlass findet sich ein ca. 27-seitiges Exzerpt von vier Bänden des Geists (Tönnies unbekannt). 
D.S.] ein Werk hohen Ranges“ erkennen (Tönnies 1926d [1908]: 91) und Jhering unter den Juristen seiner Zeit als „eine[n] der hervorragendsten“ bezeichnen (Tönnies 1925 [1905-1911]: 188). Doch bekundet Tönnies bereits im Jahr 1879, er könne „fast nur Schlechtes“ über den Zweck sagen (Tönnies, Brief vom 31.10.1879, in Tönnies, Paulsen 1961: 63).

Diese Ambivalenz in den Stellungnahmen rührt aus einer intensiven Beschäftigung mit Jhering in der Zeit um die Wende zum Jahr 1880. Einerseits unterzieht Tönnies den ersten Band des Zwecks in einer - letztlich nicht veröffentlichten - Rezension einer vernichtenden Kritik. ${ }^{715}$ Auch wenn er Jhering insofern zustimmt, dass das Recht eine Willenstatsache sei und es kein Wollen ohne Zweckvorstellung gebe (Tönnies 1880a: 6 [pag.]), erscheint ihm auf logischer Ebene Jherings Ansatz nicht haltbar: Die Annahme eines Zweckgesetzes führe zu einem infiniten Regress (ebd.: 8f. [pag.]); in der Systematisierung der menschlichen Zwecke erliege Jhering der Täuschung, ,als gebe Einteilung von Begriffen Erkenntnis von Entstehung der Dinge“ (ebd: 12 [pag.]); und schließlich erweise sich die Lehre der Hebel der sozialen Bewegung als in sich widersprüchlich. Denn diese münde in einer reinen Zwangstheorie, die dem Willenstheorem widerspreche, richte sie sich doch auf die Brechung des Willens (ebd.: 17ff. [pag.]; Tönnies 1880b: 1ff. [pag.]). Daher kritisiert Tönnies auch Jherings Rückführung des Rechts auf Zwang bzw. auf Gewalt (Tönnies 1880b: 9 [pag.]). Dasselbe Problem zeigt sich nach Tönnies auch beim Begriff der Gesellschaft (vgl. ebd.: 16f. [pag.]), v.a. da Jhering diesen nicht konsequent auf einen Willen rückführe (was dann als Kollektivwille zu begreifen wäre; vgl. ebd.: 17 [pag.]). Letztlich erweise sich „die Hypostase des Zweckbegriffs“ als „große[r] Nachteil“ (Tönnies 1880a: 10 [pag.]), würden doch die Begriffsverwirrungen und „logischen Verkehrungen herrühren von der Mehrdeutigkeit eines, Wortes', [...] nämlich des Wortes, Zweck', welcher Mittelpunkt der ganzen Abhandlung ist“ (Tönnies 1880b: 5 [pag.]).

Andererseits aber lohnt sich nach Tönnies die Auseinandersetzung mit Jherings Zweck. Denn dieser habe, „ohne es zu wissen und zu wollen, die Gedanken der naturrechtlichen Doktrin erneuert“ (Tönnies 1925 [1905-

715 Tönnies hat die Rezension dem Herausgeber der Vierteljahresschrift für wissenschaftliche Philosophie angeboten (vgl. Tönnies, Brief vom 08.02.1880, in Tönnies, Paulsen 1961: 69), sie verbleibt jedoch als unvollendetes Manuskript im Nachlass (Tönnies 1880a; 1880b). Vermutlich darauf spielt er an, wenn er bzgl. Jhering schreibt: „Die Kritik ist, wie gar manches andere, im Gewahrsam meines Pultes geblieben.“ (Tönnies 1922: 211 [13]) Zum zweiten Band des Zwecks findet sich ebenfalls ein Exzerpt im Nachlass (Tönnies 1884; vgl. hierzu auch 1922: 210 [12]). 
1911]: 188). Trotz aller Kritik sei der Zweckgedanke „für die gegenwärtige Jurisprudenz ein Epochemachender“ (Tönnies 1880c: 46 [eigene Pag.]), 716 breche er doch völlig mit aller romantischen Auffassung des Rechts (ebd.: 44 [eigene Pag.]). Allerdings gehe es mit dem Zweck nicht - wie Jhering irrigerweise annimmt - um die formale Erkenntnis des Rechts. Vielmehr rücke dieser die ideelle Seite des Rechts in den Vordergrund, d.h. die Frage, wie das Recht beschaffen sein sollte. Indem Jhering den Zweck des Rechts wissenschaftlich, d.h. nach rationalen Kriterien, untersuchen will, werde damit auf die rationale Begründung der Entscheidungen des gesetzgeberischen Willens verwiesen (vgl. ebd.: 46f. [eigene Pag.]). Jhering greife damit klassisch naturrechtliche Theoreme auf: Willenstheorie, Nützlichkeitsdenken und rationale Moraltheorie (vgl. Tönnies 1880d: 22, 24 [eigene Pag.]). Trotz aller Ambivalenzen des Zweckbegriffs erscheint das Vorgehen Jherings daher für Tönnies als „Erneuerung des Naturrechts“ (ebd.: 56 [eigene Pag.]). Er kann sich mit dessen Anliegen der Kritik der Historischen Rechtsschule identifizieren, nämlich die Rechtstheorie „von dem Zauber, den die Romantik und die speculative Philosophie rings um sie her gewoben haben, [zu] erlösen" (ebd.: 24 [eigene Pag.]). Dabei wiederhole Jhering die Hobbes'sche Kritik am religiösen Denken. So wie das Recht früher religiös, d.h. supranaturalistisch, erklärt und behandelt wurde und Hobbes es demgegenüber naturalistisch erkläre, sei „seit Savigny die ganze deutsche Wissenschaft [...] supranaturalistisch; Jhering naturalistisch " (ebd: 30 [eigene Pag.]). Diese Kritik sei nun gerade angesichts der Lage des Proletariats vonnöten, gehe es doch letztlich darum, zur Befreiung dieser Klasse durch wissenschaftliche Erkenntnisse „den Boden eines positiven Rechtes zu schaffen“ (Tönnies 1880e: 44 [eigene Pag.]).

Trotz aller Kritik am Zweck bezieht sich Tönnies also auch positiv auf Jhering. ${ }^{717}$ Als ebenfalls im Jahr 1880 in ihm die Idee keimt, sich die soziale Wirklichkeit durch die Bildung der Begriffe ,Gemeinschaft' und ,Gesellschaft' begreiflich zu machen (Tönnies 2012a [1880/1881]), sieht er sich

716 Tönnies wiederholt hier nicht nur seine Kritik aus der Rezension, sondern macht insbesondere geltend, dass Jhering lediglich klassifiziere und daher Entwicklungstendenzen des Rechts nicht erkennen könne (vgl. Tönnies 1880e: 18ff. [eigene Pag.]).

717 Wie sehr Tönnies die Auseinandersetzung mit Jhering beschäftigt, zeigt auch die Tatsache, dass er im Jahr 1880 sein geplantes Buch über das Recht als philosophisches Problem mit einer eingehenden logischen Betrachtung beginnen wollte, woran ein Essay unter anderem über Jherings Erneuerung des Naturrechts anschließen sollte: „Das Ganze an Jhering anzuknüpfen, halte ich für einen guten Gedanken“ (Tönnies, Brief 01.04.1880, in Tönnies, Paulsen 1961: 78). 
„genötigt, zuvörderst eine Anzahl elementarer Begriffe zu entwickeln, wodurch sich das Thema vielfach mit Jherings Zweck im Recht, Band 1, berühren wird, auf den ich dann auch Bezug nehme“ (Tönnies, Brief vom 09.01.1881, in Tönnies, Paulsen 1961: 102). Anschlussfähig erweise sich nämlich dessen rationalistischer Entwurf einer „neue[n] Theorie der Gesellschaft" im Zweck (Tönnies 1979 [1912]: XXXIII), die am Willen ansetzt. Dabei verdeutlicht Jhering den Konnex zwischen Rechtsphilosophie und Sozialtheorie respektive soziologischer Theorie, führt ihn doch die Analyse des Zwecks im Recht zum Entwurf der Gesellschaftswissenschaft (s.o. $\$ 3 . I)$.

Weil Jhering dabei (zwar unwissentlich) zum Restaurator des Naturrechts wird (Tönnies 1925 [1905-1911]: 192), reaktualisiert für Tönnies der Rekurs auf ihn das Naturrechtsdenken angesichts dessen Bedrohung durch die Historische Rechtsschule. Dabei findet der Gedanke der „Erneuerung des Naturrechts" - wie unten gezeigt wird - auch eine Ausformung in Tönnies’ Hauptwerk Gemeinschaft und Gesellschaft. ${ }^{718}$ Denn wenn Tönnies die Rechtsphilosophie in eine Sozialtheorie transformiert, um daraus eine soziologische Erkenntnis abzuleiten, erweist sich konsequenter Weise seine reine Soziologie als eine Rechtsphilosophie und endet mit den „Prooemien“ (Tönnies 1887: 195) bzw. den „soziologischen Gründen des Naturrechts“ (Tönnies 1979 [1912]: 145).

Trotz aller Ambivalenz wird also Jhering für Tönnies zu einem notwenigen Bezugspunkt, und zwar sowohl in begrifflicher Hinsicht als auch in der Zielrichtung der eigenen Theoriebildung, die auf die Erneuerung des Naturrechts gerichtet ist.

\section{Die gegenstandsbezogene Fundierung der Soziologie im Recht}

Bezieht sich Tönnies mit seiner Fundierung der Soziologie in der Rechtsphilosophie auf eine geistesgeschichtliche Entwicklung, so erfolgt sein Rekurs auf das Recht aber auch aus sachlichen Erwägungen.

718 Vgl. hierzu auch Sibylle Tönnies 1987. 


\section{Die sachlich gebotenen Orientierung am Recht}

\subsection{Rechtsverhältnisse als soziale Verhältnisse}

In sachlicher Hinsicht erscheint das Rechtsverhältnis zentraler Gegenstand für eine Soziologie, die auf den intersubjektiven Beziehungen aufbaut: Der grundlegende Begriff der Tönnies'schen Soziologie ist der des ,sozialen Verhältnisses' (Tönnies 2012f [1907]: 114; s.a. 1911b: 569). Er erfasst damit von Beginn an nur die „Verhältnisse gegenseitiger Bejahung“ (Tönnies 1979 [1887]: 3) als „Komplexe positiver Beziehungen, die ein Band (vinculum) konstituieren“ (Tönnies 1926c [1925]: 433). ${ }^{719}$ Wenn nun die ,erste wissenschaftliche Aufgabe, die zum Wesen der Soziologie gehört", darin besteht, „[d]as soziale Verhältnis zu begreifen“, so müsse man dafür zwangsläufig auf die „rechtlichen Verhältnisse“ Bezug nehmen (Tönnies 2012f [1907]: 114, H.i.O.). Denn - so Tönnies - „[e]s bedarf nur geringer Überlegung, um zu gewahren, daß sich die sozialen Verhältnisse in weitem Umfang mit rechtlichen Verhältnissen decken“ (ebd.: 116).

Auch wenn Tönnies immer wieder betont, dass der Begriff des sozialen Verhältnisses weiter als der des Rechtsverhältnisses sei (etwa Tönnies $2012 \mathrm{f}$ [1907]: 114; 1911b: 570), ${ }^{720}$ konstruiert er das soziale Verhältnis nach dem Modell eines gegenseitig verpflichtenden Rechtsgeschäfts:

719 Damit schließt Tönnies für die soziologische Analyse jegliche antagonistischen und kämpferischen zwischenmenschlichen Beziehungen aus, diese seien vielmehr „das besondere und abgeschlossene Gebiet der Sozial-Psychologie“ (Tönnies 1926f [1915/1916]: 240). Später versucht Tönnies, die Einseitigkeit dieser Bestimmung zum Teil abzumildern, wenn er als Gegenstand der „allgemeinen Soziologie“ die „Lehre vom menschlichen Zusammenleben überhaupt" bestimmt, die als solche „alle Zusammenhänge der Menschen in Raum und Zeit, unabhängig davon, ob [...] sie einander bejahen oder verneinen“, umfasst (Tönnies 1926c [1925]: 430). Allerdings befasst sich auch hier die „besondere“ respektive die „spezielle Soziologie“, d.h. die Disziplin der Soziologie im eigentlichen Sinne, nur mit positiven Verhältnissen, die „als seiende[] und dauernde[] bejaht und gewollt" werden (ebd.: 435). Zur Kritik dieses das Feld der soziologisch relevanten zwischenmenschlichen Beziehungen einengenden Bestimmung vgl. etwa König 1955.

720 Tönnies scheidet von den rechtlichen die sittlichen Verhältnisse. Die jeweiligen Abgrenzungsschwierigkeiten stehen dann im Zentrum der reinen Soziologie: „Die Grenze zwischen bloss sozialen Verhältnissen einerseits, sittlichen und Rechts-Verhältnissen andererseits, ebenso wie die Grenze zwischen sittlichen und Rechts-Verhältnissen, ist fliessend. Es ist eine der Hauptaufgaben der reinen Soziologie, diese Grenzen zu ziehen und zugleich die Übergänge aus dem einen in das andere Gebiet zu beschreiben.“ (Tönnies 1911b: 570). 
Im Wesen jedes sozialen Verhältnisses liegt es, daß wenigstens von einer Seite, in einem vollkommenen, d.h. gegenseitigen Verhältnis aber von beiden - um von dem einfachen Fall eines Verhältnisses zweier Personen auszugehen,- der Anspruch auf ein gewisses Verhalten der anderen Person und die Erwartung eines solchen gehegt wird, und zwar eines Verhaltens, das aus dem freien Willen hervorgeht und dem Wunsch und Willen des Erwartenden gemäß ist: es wird also durch einen gemeinsamen, einen überindividuellen - sozialen - Willen gesetzt und geboten. (Tönnies 2012g [1914]: 203, H.i.O.)

Insofern werde auch „[j]edes soziale Verhältnis [...] als ein rechtliches begriffen, insofern als gedacht wird, daß die aus ihm hervorgehenden Pflichten durch Entscheidung eines Richters (eines Gerichtes) festgestellt werden können und (unter Umständen) sollen“ (ebd.). ${ }^{721}$

Innerhalb der möglichen Rechtsverhältnisse nimmt der Vertrag eine herausragende Stellung ein: Der Kontrakt ist für Tönnies „das typische Rechtsgeschäft“ und darin „zugleich charakteristisch für alle rationalen Rechtsverhältnisse“, die ihrerseits „die beglaubigten Ausdrücke aller rationalen Sozialverhältnisse“ sind (Tönnies 1979 [1912]: XXXIII). Die kontraktuellen, allein unter Vernunftgesichtspunkten getroffenen Übereinkünfte führen zu einer mechanischen, künstlichen und äußerlichen Verbindung der voneinander unabhängigen Individuen. Daher erscheint es letztlich für Tönnies „nur konsequent auch ,die‘ Gesellschaft und den Staat als auf Verträgen der Individuen, diese auf ihren freien und bewußten Willen beruhend zu denken" (ebd.). ${ }^{722}$

Tönnies versteht also den Vertrag als gegenseitiges Rechtsgeschäft, wie er durch zwei übereinstimmende, in Bezug aufeinander abgegebene, gewillkürte' Willenserklärungen zustande kommt. Dies bilde den ,ideellen Typus` des sozialen bzw. intersubjektiven gesellschaftlichen Verhältnisses.

721 Das begründet in empirischer Hinsicht die Abgrenzung von sittlichen und rechtlichen Verhältnissen: „Wenn hier sittliche Verhältnisse von rechtlichen unterschieden werden, so hat das Wort ,sittlich' einen soziologischen, nicht einen ethischen Sinn. Er soll nur diejenigen sozialen Verhältnisse zusammenfassen, die ihrem Wesen nach keiner richterlichen Erkenntnis unterliegen oder aber noch nicht zu einer solchen Anerkennung gelangt sind.“ (Tönnies 2012g [1914]: 206).

722 So definiert Tönnies bereits in Gemeinschaft und Gesellschaft: „Gesellschaft also, durch Konvention und Naturrecht einiges Aggregat, wird begriffen als eine Menge von natürlichen und künstlichen Individuen, deren Willen und Gebiete in zahlreichen Verbindungen zueinander, und in zahlreichen Verbindungen miteinander stehen, und doch voneinander unabhängig und ohne gegenseitige innere Einwirkungen bleiben.“ (Tönnies 1979 [1887]: 44, H.i.O.). 
Der Vertrag stelle die verbindliche und daher verbindende Koordination von unterschiedlichen subjektiven Willensäußerungen dar. Gesellschaftliche Sozialverhältnisse als gegenseitig bejahende Beziehungen, die insofern trotz der prinzipiellen Trennung der Individuen ein verbindliches Band herstellen, orientieren sich am Modell des privatrechtlichen Vertrages. Und das Privatrecht ist damit für die Soziologie zentral gesetzt.

Der Vertrag wiederum bildet den Kern des Obligationenrechts. Dementsprechend erkennt Tönnies im schuldrechtlichen Teil des Privatrechts die rationale Konstruktion der gesellschaftlichen Beziehungen. ${ }^{723}$ Das rationalistisch-individualistische Naturrecht erhält dadurch eine Umdeutung: Hobbes' Gesellschaftsvertrag als ein statusbegründender Herrschaftsvertrag wird über die Handlungsform der individuellen Vertragsabschlüsse privatrechtlich konzipiert (vgl. Tönnies 2012b [1887]: 59; 2012f [1907]: 114ff.; 2012g [1914]: 203f.; 2000 [1913]: 329; vgl. auch Bickel 1991; MerzBenz 1995). Dieser Konnex von privatrechtlich-gewillkürtem Vertragsdenken (Kürwille) und Gesellschaftsvertrag verweist aber zugleich auf die Rechtsentstehungslehre im Sinne eines gesellschaftlichen Rechts: Angesichts der Rationalisierung des sozialen Lebens kann es sich nach Tönnies nur um die an Übermacht gewinnende staatliche Gesetzgebung als rational-gewillkürte Setzung solcher Regelungen handeln.

Allerdings ist nach Tönnies zu beachten: „[K]eineswegs lassen sich alle rechtlichen Verhältnisse und Verbindungen nach dieser Formel [des Vertrags, D.S.] konstruieren; gerade die ursprünglichen, immer fortwirkenden, familienhaften nicht." (Tönnies 1979 [1912]: XXXIII) Nicht nur der Vertrag stellt also in Tönnies Augen ein sich gegenseitig bejahendes Rechtsverhältnis dar, das durch übereinstimmende Willenserklärungen zustande kommt. Das gleiche gelte vielmehr ebenso für die „natürlichen Verhältnisse“ (Tönnies 1911b: 570). Diese fänden ihre Ursache

in dem natürlichen Zustand, dem ,Status ' des Menschen, der heute nur noch in engsten Familienverhältnissen förmliche Bedeutung hat: nicht durch Vertrag, sondern durch Status sind wir Vater oder Sohn, Bruder oder Schwester, Monarch oder Staatsbürger und haben darauf sich gründende subjektive Rechte oder rechtliche Verpflichtungen, de-

723 Gerade weil Tönnies das soziale Verhältnis auf Beziehungen der Bejahung beschränkt, erscheint ihm eine deliktische Verbindung nicht maßgeblich: Der Vertrag „ist der Typus der Rechtsgeschäfte, und diese sind der regelmäßige Gegenstand rechtlich wirksamer Handlungen (Obligationen, die aus unrechtmäßigen Handlungen entstehen - ex delicto - würde ich nicht als unmittelbare rechtliche Verhältnisse verstehen)“ (Tönnies 2012f [1907]: 115). 
nen subjektive Rechte anderer entsprechen (Tönnies 2012f [1907]: 115, H.i.O.).

Auch bei diesen, nun als gemeinschaftlich qualifizierten, Sozialverhältnissen handelt es sich nach Tönnies um übereinstimmende Willensbeziehungen, richtet sich doch der Wille nun auf das Tradierte und Gewohnte, das den status zuweist. ${ }^{724}$ Allerdings werden nicht wie im Vertrag zwei Willenssphären gegeneinander abgeglichen. Vielmehr gehe die

Theorie der Gemeinschaft [...] von der vollkommenen Einheit menschlicher Willen als einem ursprünglichen oder natürlichen $\mathrm{Zu}$ stande aus, welcher trotz der empirischen Trennung und durch dieselbe hindurch, sich erhalte, je nach der nothwendigen und gegebenen Beschaffenheit der Verhältnisse zwischen verschieden bedingten Individuen mannigfach gestaltet (Tönnies 1979 [1887]: 7, H.i.O.).

Bejaht wird das Überlieferte, die Tradition, und damit das bereits bestehende Verhältnis zwischen den Menschen. ${ }^{725}$ Tönnies nennt diese Willensbeziehung, die sich auf das Wesen der gewollten Sozialverhältnisse als organische Einheit richtet, „Wesenwillen“. Dabei geschehe die „Bejahung der Gebilde lediglich um ihrer selbst willen“, wohingegen in den gesell-

724 Dies sind mithin die historischen Sozialformen, „zu denen“ - wie Peter-Ulrich Merz-Benz darlegt - „der einzelne eine auf Instinkten, Gefühlen, Glauben, Gewohnheiten und Gebräuchen beruhende Beziehung entwickelt, die ihm nur als ganze begegnen, die er auch nur von innen sieht und als deren Mitglied er sich vorkommen muss wie ein Teil eines Organismus“ (Merz-Benz 2016: 49).

725 Konsequenterweise bezeichnet für Tönnies die Gewohnheit daher, wie er in seiner Abhandlung über Die Sitte ausführt, „ein Wollendes oder einen Willen“ (Tönnies 1909: 8; s.a. 2012f [1907]: 117ff.). Tönnies wehrt sich dort gegen die undifferenzierte Gleichsetzung von Sitte mit „Gewohnheit und [...] Brauch, [...] Herkommen und Überlieferung; aber auch [mit] Mode, Manier, Gepflogenheit u. dgl.“ (Tönnies 1909: 7). Dabei grenzt er Recht und Sitte voneinander ab: „Recht wird gesprochen, Sitte wird befolgt; Sitte kann daher eher ein ungeschriebenes Gesetz als ein ungeschriebenes Recht genannt werden.“ (Ebd.: 35) Als ungeschriebenes Gesetz führt Tönnies die Sitte aber wieder an das Recht nun in Form des Gewohnheitsrechts - heran: So liege auch in der Sitte ein "gesetzgeberische[r] Willen“, der allerdings nicht auf einem bewussten Beschluss, sondern auf dem „Herkommen“ und der „Überlieferung“ beruhe (ebd.: 17). Daher könne man in der Sitte auch ein „natürliche[s] Recht, dem ursprünglichen Inhalt dieses Begriffes nach", erkennen (ebd.: 34). Es zeige sich dann, dass sich auch im modernen Rechtssystem letztlich in Gestalt des ,Gewohnheitsrechts und des ,ungeschriebenen Gesetztes` ältere Formen der Obligation erhalten haben, wie sie für die Geltung der ,Sitte charakteristisch seien (vgl. Lichtblau 2012: 22). 
schaftlichen Beziehungen die „Bejahung lediglich eines äußeren Zweckes halber gesetzt wird“ (Tönnies 2012i [1919]: 224). Insofern gelte: „Wesenwille richtet sich auf sittliche Werte unmittelbar (um ihrer selbst willen); Kürwille mißt sie an dem Nutzen ihrer Wirkungen." (Tönnies 1929 [1923]: 37)

Weil aber aus dieser Übereinstimmung der Willen im Wesenwillen Rechte und Pflichten der Individuen (mit Blick auf das Gemeinschaftsverhältnis) erwachsen, kann „[a]us diesem Verhältnis menschlicher Gemeinschaft" nach Tönnies ebenso „ein reines Rechtsverhältnis sich ergeben und hervorgehen“ (Tönnies 1925 [1905-1911]: 192f., H.i.O.). Die entsprechenden Sozialverhältnisse, jene von ursprünglichen, immer fortwirkenden und familienhaften Banden getragenen rechtlichen Verbindungen, finden ihren Ausdruck im Familienrecht. Diese Rechtsmaterie verweist also nicht auf das durch Beschluss staatlich gewillkürte Recht, sondern auf das Gewohnheitsrecht, wie es letztlich der Rechtsentstehungslehre der Historischen Rechtsschule zugrunde liegt. Und es gelte: „Wie ich den Beschluß als Typus des rationalen Wollens verstehe, so die Gewohnheit als Typus des irrationalen Wollens.“ (Tönnies 2012f [1907]: 117, H.i.O.)

Der Differenz der Rechtsverhältnisse entspricht also die Differenz der Grundbegriffe der Soziologie, die an jeweils unterschiedliche Rechtsmaterien und Rechtsentstehungsweisen gekoppelt sind: mechanische Gesellschaft - Vertragsrecht - gewillkürte Gesetzgebung versus organische Gemeinschaft - Familienrecht - tradiertes Gewohnheitsrecht. In den unterschiedlichen Rechtsverhältnissen erkennt Tönnies also sowohl die jeweiligen typischen Willensbeziehungen in ihrer spezifischen Form der gegenseitigen Bejahung, die den sozialen Verhältnissen zugrunde liegen, als auch ihre Entstehungs- und Wirkungsweisen. Die aus der Analyse der Rechtsverhältnisse gewonnene grundbegriffliche Unterscheidung dient zur Analyse, zur Klassifikation und zum Verständnis der sozialen Verhältnisse schlechthin.

Tönnies leitet dabei den grundbegrifflichen Unterschied von Gemeinschaft und Gesellschaft aus dem bzw. in Analogie zum „Unterschied und Gegensatz in der Sphäre des Rechts, also in einem notwendigen Gestalten des sich entwickelnden und entwickelten sozialen Lebens" ab. Daher werde der „Unterschied zwischen Gewohnheit und Satzung, also auch zwischen Gewohnheitsrecht oder Sitte auf der einen, Gesetzesrecht und Kodifikation als planmäßiger - der Schaffung von Gesetzesbüchern - auf der anderen Seite erklärt, welcher Gegensatz das eigentliche Thema bedeutet" (Tönnies 2012k [posthum]: 259, H.i.O.). 


\subsection{Recht als soziale Ordnung}

Auch wenn soziale Verhältnisse immer auf eine willentliche Leistung der Individuen verweisen, so ist diese Leistung nicht einseitig-individuell zugänglich (oder abänderbar). Denn ,[e]infach und abstrakt mag man das, was gilt, als Gegenstand einer Verabredung denken, und Verabredung ist immer ein gemeinsames und soziales Wollen “ (Tönnies 1931: 11).726 Dasjenige, was gilt (oder gegolten hat), erscheint als Inbegriff einer der Zeitlichkeit und Räumlichkeit enthobenen allgemein verbindlichen Verabredung (vgl. Merz-Benz 1991: 294).

Das zeige sich insbesondere am Rechtsverhältnis: Es entspringe der Annahme des ,sozialen Willens', der einem jedem rechtlichen Verhältnis vorausgesetzt ist (vgl. Tönnies 2012g [1914]: 203). Der ,soziale Wille‘ verweist bei Tönnies also auf die Existenz einer dem einzelnen Rechtsverhältnis vorgängigen Rechtsordnung, oder anders formuliert: auf die Vorgängigkeit des objektiven vor dem subjektiven Recht. Denn wenn, wie im Falle eines Vertrages, „durch eine solche Willenserklärung Bestandteile der Willenssphäre einer Person in die Willenssphäre einer anderen Person übergehen“, dann geschehe dies „,von Rechts wegen', d.h. einem sozialen Willen gemäß, der ebenso für die Beteiligten insgesamt Geltung hat" (Tönnies 2012g [1914]: 203). Letztlich gelte für alle Rechtsverhältnisse: „Zum Wesen des rechtlichen Verhältnisses gehört eben dies, daß ,das Recht ${ }^{\star}$ oder ,die Rechtsordnung' darin begründete Rechte gibt und daraus entspringende Pflichten auflegt.“ (Tönnies 2012f [1907]: 115) Daraus folgt auch Tönnies Definition des Rechts: „Die Ansicht, die ich bisher über den Begriff des Rechts gehegt und vertreten habe, ist etwa folgende. Recht ist ein Werk sozialen Wollens. Soziales Wollen schafft und erhält Recht als eines der Maße, an denen es individuelles Wollen und Handeln mißt.“ (Tönnies 1925 [1905-1911]: 180)

Wenn für Durkheim der privatrechtliche Vertrag auf dessen außerrechtlichen Voraussetzungen verweist, so verweist er für Tönnies auf die Vor-

726 Oder wie Tönnies an anderer Stelle erklärt: „Die soziale Verbundenheit will eine gegenseitige Abhängigkeit bedeuten, und dies heißt, daß der Wille des einen auf den Willen des anderen wirkt: fördernd oder hemmend oder beides. Wenn nun das Wollen des einen mit dem des anderen zusammentrifft und sich verbindet oder vermischt, so ergibt sich ein gemeinsames Wollen, das als einheitliches verstanden werden darf, weil es eben gegenseitig ist und sowohl das dem A gemäße Wollen des B als auch das dem B gemäße Wollen des A setzt oder fordert, also will. Dies ist der einfachste Fall des sozialen Willens zweier Individuen“ (Tönnies 2012j [1931]: 237, H.i.O.). 
gängigkeit der Rechtsordnung vor dem einzelnen Vertragsschluss. ${ }^{727}$ Dem entspricht auch eine Differenz im Rechtsbegriff: Für beide stellt sich das Recht als eine soziale Norm unter anderen dar (für Tönnies vgl. 1925 [1905-1911]: 180; 1909). Während Durkheim im Anschluss an Jhering das Recht gegenüber anderen Normen über die beiden Elemente, äußerlicher Zwang" und ,Körperschaft' abgrenzt (ähnlich i.Ü. auch Weber, s.u. $\$ 8$ ), bestimmt Tönnies das Spezifikum rechtlicher Normen inhaltlich, d.h.

durch die Dignität seiner Objekte, durch seine Beziehung auf diejenigen sozialen Interessen, die mehr und mehr als die vitalen Interessen anerkannt werden, daher vor allem - als Privatrecht - auf die materiellen Interessen, schlechthin aber auf solche, deren Ordnung für ein friedliches Zusammenleben als wesentlich und notwendig angesehen wird (Tönnies 1925 [1905-1911]: 181).

Recht sind also diejenigen Ordnungsnormen, die für das Zusammenleben als unabdingbar angesehen werden und denen daher auf empirischer Ebene der Status des Rechts zugesprochen wird (vgl. ebd.). ${ }^{728}$ Mit dieser Bestimmung verbindet Tönnies eine funktionalistische Perspektive auf das Recht mit der Anerkennungstheorie, wie sie der Rechtsentstehungslehre der Historischen Rechtsschule zugrunde liegt: Recht bestehe aus den für den Selbsterhalt der sozialen Ordnung als unabdingbar anerkannten Normen. Insofern erweise sich das Recht „seinem Wesen nach [...] auch als unabhängig vom Staate“ (Tönnies 1926d [1908]: 64). Denn wenn es „der Inhalt eines die Verhältnisse von Willenssphären zueinander regelnden gemeinsamen Willens" sei, dann sei es "daher soziale Tatsache im Unterschiede von politischen und vor diesen Tatsachen“ (ebd., H.i.O.).

727 Nach Nicola Marcucci teilen Durkheim und Tönnies die Kritik am älteren Naturrecht, auch wenn sie daraus gänzlich andere Schlussfolgerungen ziehen. Die Divergenz basiere darauf, dass Durkheim die rechtliche Verpflichtung als soziale Tatsache, Tönnies sie demgegenüber als Willensprodukt darstellt (Marcucci 2017). Man kann darin m.E. den Unterschied zwischen dem Rechtsentstehungsmodell der älteren Historischen Rechtsschule und Jherings Zweckdenken erkennen, was sowohl erklärt, weshalb Jhering für beide Autoren derart zentral ist (wenn auch aus entgegengesetzten Gründen), als auch, weshalb man Durkheim dem Repräsentationsdispositiv und Tönnies dem Zweckdispositiv (in seiner gesellschaftsfunktionalen Ausgestaltung) zuordnen kann.

728 So schreibt Tönnies: „Die empirische Abgrenzung des Rechts als eines Inbegriffs von Normen oder Satzungen gegen andere Normen und Satzungen ist daher, wie andere sprachliche Abgrenzungen, durch den Brauch, also durch Herkommen bestimmt und kann, wie alles derartige, als konventionell begriffen werden.“ (Tönnies 1925 [1905-1911]: 181). 
Diese Koppelung von Recht und sozialer Ordnung gehört bereits zu den Ergebnissen seiner Studie aus dem Jahr 1887, wenn er schreibt:

Es bietet sich dar der Gegensatz einer Ordnung des Zusammenlebens, welche, insofern als auf Übereinstimmung der Willen, wesentlich auf Eintracht beruht, und durch Sitte und Religion ausgebildet, veredelt wird: gegen eine Ordnung des Zusammenlebens, welche insofern als auf zusammentreffenden, vereinigten Kürwillen, auf Konvention gegründet ist, durch politische Gesetzgebung ihre Sicherung, und durch öffentliche Meinung ihre ideelle und bewusste Erklärung, Rechtfertigung empfängt. Ferner: der Gegensatz eines gemeinsamen und verbindlichen, positiven Rechtes, als eines Systemes von erzwingbaren Normen in bezug auf die Verhältnisse der Willen zu einander, welches, im Familienleben wurzelnd und aus den Tatsachen des Grundbesitzes seinen bedeutendsten Inhalt schöpfend, seine Formen durch Sitte wesentlich bestimmt erhält, welcher Religion ihre Weihe und Verklärung gibt $[\ldots]$; gegenüber einem gleichartigen positiven Rechte, das die Kürwillen durch alle ihre Verknüpfungen und Verschlingungen auseinanderzuhalten beflissen, in der konventionellen Ordnung des Handels und dergleichen Verkehres seine natürlichen Voraussetzungen hat; aber erst gültig und regelmäßig kräftig wird durch den souveränen Kürwillen und Macht des Staates, als das wichtigste Werkzeug seiner Politik, wodurch er die gesellschaftlichen Bewegungen teils erhält, teils hemmt oder fördert, und welches durch Doktrinen und Meinungen öffentlich verteidigt, angefochten, daher auch verändert, verschärft oder gemildert wird. (Tönnies 1979 [1887]: 207, H.i.O.)

Daher gilt nach Tönnies: „Ordnung ist natürliches Recht, Recht schlechthin = positives Recht.“ (Ebd.) Recht beinhalte (neben der Moral) die Regeln der sozialen Ordnung (vgl. Tönnies 1931: 206). Und objektives Recht erweise sich als „System von sozialen Normen“ (ebd.: 219), wobei soziale Normen allgemeinverbindliche Normen des Handelns oder sonstigen Verhaltens darstellen (vgl. ebd.: 189).

Damit negiert Tönnies nicht den normativen Charakter des Rechts. Denn sehr wohl erweisen sich soziale Normen, und damit auch das Recht, als normative Ge- und Verbote. ${ }^{729}$ Nehme man aber das Sollen in den Blick, dann werden solche Verhältnisse „Gegenstände normativer Diszipli-

729 Da die Scheidung von Recht und Moral nach Tönnies ein Produkt der Neuzeit ist und mitnichten für alle Rechtskonzeptionen Geltung beansprucht (und beanspruchen kann), erscheint ihm die Moral als „ideales Recht“ (Tönnies 1887: 
nen“ (Tönnies 2012f [1907]: 116, H.i.O.). Demgegenüber sei der genuin normative Charakter der Normen für die Soziologie nicht von Relevanz: "Wenn wir im soziologischen Sinne von einer Ordnung, einem Recht, einer Moralität reden, so muß darunter immer etwas, was ist, verstanden werden, also eine tatsächlich geltende Ordnung, ein tatsächlich in Kraft stehendes Recht, eine tatsächlich wirksame Moral [...].“ (Tönnies 1931: 240f.) Insofern erscheint Recht in Tönnies' Soziologie unter dem Blickwinkel seiner gesellschaftsfunktionalen Ordnungsleistung, die von den Mitgliedern anerkannt wird. ${ }^{730}$ Als solches vereint es prototypisch die soziale und die individuelle Ebene:

Der Zusammenhang der (sozialen) Lebens- und der (individualen) Willensformen führt hinüber zu ihrer Einheit in Formen des Rechtes. Recht entspringt nicht aus Gedanken und Meinungen über die Gerechtigkeit, sondern das Leben erzeugt beide Ausdrücke seiner Realität zugleich, welche dann zu einander in gegenseitiger Kausalität vielfach sich verhalten. (Tönnies 1979 [1887]: 143)

Aus dieser Rückbindung des Rechts an die Ordnungen des sozialen Lebens folgt für Tönnies auch die Entwicklungsgeschichte des Rechts, und mit ihr des sozialen Lebens:

Die hier zugrunde gelegte Denkungsart will und muß sich auf jeden historischen Zustand anwenden lassen und mithin auch auf die Entwicklung des sozialen Lebens im Ganzen, zumal insofern, als eine solche Entwicklung von gemeinschaftlichen in gesellschaftliche Formen und Inhalte stattfindet. Dies ist nun nicht allein am Recht erkennbar, sondern erstreckt sich auf die Gesamtheit des Zusammenlebens [...]. (Tönnies 2012k [posthum]: 259)

278). In seiner Einführung in die Soziologie setzt Tönnies Ordnung, Recht und Moral in ein Stufenverhältnis, wobei die Ordnung den basalen Begriff darstellt (vgl. Tönnies 1931: 203), über den Recht und Moral in ihren Eigenarten hinausgehen. Tönnies tendiert dazu, Moral mit sozialen Normen gleichzusetzen und diskutiert im Abschnitt „Moral“ auf vielen Seiten die an Jhering orientierte Differenzierung der verschiedenen Arten von sozialen Normen (vgl. ebd.: 247ff.).

730 In Gemeinschaft und Gesellschaft fasst Tönnies diesen Zusammenhang von Recht und sozialem Leben auch als Verhältnis von Form und Materie: „Recht ist, in jedem Sinne, nichts als gemeinsamer Wille; es ist in diesem Sinne, als natürliches Recht, die Form oder der Geist schlechthin, derjenigen Verhältnisse, deren Materie das Zusammenleben, oder, im allgemeinsten Ausdrucke, der Konnex von Willenssphären ist“" (Tönnies 1979 [1887]: 167, H.i.O.). 
Was Tönnies mit Henry Sumner Maine als Entwicklungsprozess der Ablösung statusbezogener durch rein vertraglich geregelte Sozialverhältnisse beschreibt, zeigt sich als generelle soziale Entwicklung, derzufolge sich die gemeinschaftlichen Verhältnisse zunehmend in gesellschaftliche gewandelt haben:

Mit Ort und Bedingungen ihres täglichen Lebens verändern die Menschen ihr Temperament; es wird hastig und wechselnd durch unruhiges Streben. Zugleich mit dieser Umwälzung der sozialen Ordnung und in parallelem Fortschritte, vollzieht sich eine allmähliche Verwandlung des Rechtes, nach seinem Inhalte und nach seinen Formen. Der reine Kontrakt wird die Basis des gesamten Systemes, und der Kürwille der Gesellschaft, durch ihr Interesse bestimmt, erscheint mehr und mehr, teils an und für sich, teils als vollstreckender Staatswille, als der alleinige Urheber, Erhalter und Beweger der Rechtsordnung, welche sie mithin von Grund aus verändern zu können und zu dürfen gedacht wird, nach ihrem Mögen und Belieben, das aber um ihrer selbst willen ein nützliches oder zweckmäßiges sein wird. [...] So verwandelt sich Recht, seiner Form nach, aus einem Gebilde der Sitte, oder aus Gewohnheitsrecht, zuletzt in ausschließliches Gesetzesrecht, ein Produkt der Politik. (Tönnies 1979 [1887]: 209f., H.i.O.)

In sachlicher Hinsicht liefert das Recht Tönnies also sowohl eine grundbegriffliche Differenzierung der sozialen Ordnungsformen also auch eine Beschreibung der Entwicklung des sozialen Lebens.

\section{Die wissenschaftstheoretisch gebotene Orientierung am Recht}

Daneben gibt es für Tönnies wissenschaftstheoretische Gründe für den Rekurs auf das Recht, die seinem Wissenschaftsverständnis entspringen und die die Relevanz speziell der juristischen Begrifflichkeit für seine Konzeption der Soziologie zeigen.

\subsection{Naturrecht als rationale Wissenschaft}

Tönnies orientiert sich in seinem Wissenschaftsverständnis prinzipiell an den Naturwissenschaften (vgl. Merz-Benz 2016: 31), insofern die moderne, rationalistische Philosophie "mit und an der Naturwissenschaft erwach- 
sen“ sei (Tönnies 1979 [1912]: XXV; s.a. 1896: 97ff.; 1926g [1910]: 136). ${ }^{731}$ Damit ist nun keineswegs die Idee verbunden, dass die Wissenschaft die äußere Realität schlicht abbilde oder repräsentiere. Denn rationalistisch ist die Wissenschaft nach Tönnies in dem Sinne, als ihre Gegenstände „Gedankendinge“ und „Constructionen“ sind (Tönnies 1979 [1887]: XX). 732

Wenn Soziologie für Tönnies - wie er immer wieder betont - eine „theoretische“ bzw. eine „philosophische“ Wissenschaft ist (etwa Tönnies 1926g [1910]: 125), ${ }^{733}$ dann hat sie es mit solchen gedanklichen Konstruktionen zu tun. Das bedeutet letztlich für Tönnies, dass sie wie „alle allgemeinen und dann philosophischen Wissenschaften, in erster Linie eine Wissenschaft von Begriffen" ist (Tönnies 1911b: 569, H.i.O.). Diese Begriffsorientierung sei das „Wesen der reinen oder abstrakten Soziologie, die von der angewandten und empirischen streng unterschieden werden muss" (ebd.: 569).

Begriffe liefern also nicht direkt die Erkenntnis der Tatsachen (Tönnies 1926g [1910]: 131), sondern sind selbst „rein als Konstruktionen“ zu verstehen, die vom Prinzip her indifferent gegen ihre Anwendbarkeit auf die Wirklichkeit sind (Tönnies, Brief vom 28.12.1889, in Tönnies, Paulsen 1961: 273). Sie sind für Tönnies ein Mittel oder "Gerät“ (Tönnies $1926 \mathrm{~g}$ [1910]: 131), um die Wirklichkeit zu erfassen, d.i. „Werkzeuge, um die fließenden Erscheinungen anzupacken, als Gefäße, um die flüssige Wirklichkeit darin zu fassen, und ganz besonders als Maßstäbe, um die Qualitäten der Dinge daran zu messen und dadurch untereinander vergleichbar zu machen" (Tönnies 1926e [1911]: 144). Die Wissenschaft ziele darauf ab, die zweckmäßigsten und tauglichsten Mittel oder Werkzeuge für die Erkenntnis herzustellen (vgl. Tönnies 1926g [1910]: 131). ${ }^{734}$ Genau darin sei dann

731 Insofern gibt es nach Tönnies eine Einheit des Wissens. Daher rührt auch seine Kritik an den verschiedenen Abgrenzungsversuchen von Natur- und Kultur- respektive Natur- und Geisteswissenschaften (s.u.). Das bedeutet aber wiederum nicht, dass Tönnies seine Soziologie damit automatisch auf einem organizistischen Biologismus bzw. auf einem Physikalismus fundiert (vgl. Merz-Benz 2016: 111ff.).

732 Zu Tönnies’ Erkenntnistheorie, die er aus seiner Arbeit über Hobbes gewonnen hat, vgl. insbesondere Jacoby 1971: 28ff.; Merz-Benz 2016.

733 Nach Königs Fundamentalkritik aus dem Jahr 1955 sei Tönnies daher „in Zukunft in die Geschichte der Philosophie und nicht mehr in die Geschichte der Soziologie einzuordnen" (König 1987: 189, H.i.O).

734 Tönnies verdeutlicht das an einem Beispiel: „[D]er Begriff selber, z. B. eines Kreises, ist ein pures Gedankending, nach dessen Ähnlichkeit aber Figuren in der 
das Denken in der ihm eigentlichen Leistung erkennbar, welche darin besteht, gegen die Vielfachheit und Wandelbarkeit der Erfahrung einfache und konstante Schemata auszubilden und festzuhalten, als worauf die mehreren Erscheinungen bezogen werden können, um desto besser eine in der anderen ausdrückbar zu sein (Tönnies 1979 [1887]: 93).

Wenn Tönnies die Soziologie als eine philosophische Disziplin versteht, dann meint er damit jedoch nicht nur ihren begrifflich-konstruktiven Charakter, sondern ebenso ihre systematischen Bestrebungen. Diese richten sich einerseits auf den begrifflich-systematischen Aufbau der Soziologie, ${ }^{735}$ andererseits auf die Einheit aller Erkenntnis: „Zweitens ist aber die Soziologie philosophisch, insofern sie die Grundtatsachen des sozialen Lebens in Beziehung setzt zu den Grundtatsachen des Lebens, insbesondere des psychischen Lebens, das sie in das System einer Gesamterkenntnis der ,Welt‘ hineinbildet.“ (Tönnies 1926e [1911]: 144f.) Dabei verfährt die Philosophie - und damit auch die Soziologie - „wesentlich deduktiv, nach dem Grundsatz, daß die allgemeinen und notwendigen Naturgesetze auch im Bereiche der menschlichen Tätigkeiten, der menschlichen Kultur gelten müssen“ (ebd.: 145, H.i.O.). Die Einheit ist auf möglichst einfache Prinzipien zurückzuführen, und aus diesen sollen die notwendigen Richtlinien des Seins und des Denkens abgeleitet werden (vgl. Tönnies 1926g [1910]: 131). ,Reine Soziologie' verfährt begrifflich und systematisch, indem sie aus möglichst zweckmäßigen Begriffen Konsequenzen deduziert, empirische Soziologie kann diese wiederum bestätigen oder berichtigen (vgl. ebd.: 134).

Ebene, die entweder gegeben oder konstruiert worden sind, als Kreise gelten und behandelt werden." (Tönnies 1979 [1887]: 93).

735 Tönnies differenziert diesen begrifflich-systematischen Aufbau der Soziologie seit der ersten Auflage von Gemeinschaft und Gesellschaft immer weiter aus: Die Bestimmung der genuin soziologischen Gegenstände erfolgt im Jahr 1887 angesichts seiner anfangs noch uneindeutigen Beziehung zur Soziologie noch implizit. Im Jahr 1907 bildet dann die Trias von „soziale Verhältnisse“, „sozialer Wille“ und „soziale Verbindungen“ den "natürliche[n] und notwendige[n] Gegenstand einer besonderen begrifflichen, d.h. philosophischen Wissenschaft, nämlich der Soziologie“ (Tönnies 2012f [1907]: 128). Ein Jahr später ersetzt Tönnies in diesem Schema den „sozialen Willen“ durch den Begriff der „Samtschaften“ und fügt ihm noch den Gegenstand „soziale Normen“ zu (Tönnies 1926d [1908]: 63), um später wiederum als Überbegriff für die Trias den Begriff der „soziale Wesenheiten“ einzuführen (vgl. etwa Tönnies 1926c [1925]: 434). Die Lehre von den "sozialen Normen“ wird zudem um die der „sozialen Werte“ und der „sozialen Bezugsgebilde“ ergänzt (vgl. ebd.; 1931: 133ff., 259ff.). 
Dieses Programm einer reinen Soziologie ist nach Tönnies wertfrei: Da "Zukunfts-Programme, alle sozialen und politischen Aufgaben" nach Tönnies nicht wissenschaftlich begründbar sind, will er sie „aus dem Spiele“ lassen und das Gebiet der Soziologie auf die „viel leichter lösbaren Aufgaben objektiver Erkenntnis der Tatsachen ein[]schränken“ (ebd.: 130, H.i.O.) auch wenn anerkanntermaßen vollkommene Objektivität ein unerreichbares Ideal ist. Nichtsdestotrotz gilt: „Wir wollen also als Soziologen uns nur beschäftigen mit dem, was ist; und nicht mit dem, was nach irgendwelcher Ansicht, aus irgendwelchen Gründen, sein soll.“ (Ebd., H.i.O.) ${ }^{736} \mathrm{Um}$ diese „Idee der reinen theoretischen Einsicht, der Betrachtung und Beobachtung“ zu verwirklichen, gelte es, „die Erkenntnis der Begriffe, ihrer Zusammenhänge und Konsequenzen, sowie Erkenntnis der Tatsachen, ihrer Ursachen und ihrer Wirkungen zum Selbstzweck“ des „reinen Denkens und Forschens“ zu erheben (ebd.: 126f.). Daher sollen soziale „Vorgänge unserer Umgebung “ mit größtmöglicher Distanz betrachtet werden, ,als ob sie Vorgänge auf dem Monde wären“, und „die Ansicht der menschlichen Leidenschaften“ zu einem Gegenstand gemacht werden, als „ob sie Winkel im Dreiecke oder berechenbare Kurven“ wären (ebd.: 127). In der Enthaltung von Werturteilen sieht Tönnies die Objektivität der Soziologie als reine Wissenschaft von dem, was ist, gewährleistet (vgl. ebd.: 139). ${ }^{737}$

Auf der einen Seite bestimmt Tönnies die reine, philosophische Soziologie über ihr spezifisch wissenschaftliches Vorgehen. Auf der anderen Seite grenzt sie sich über ihre Erkenntnisobjekte ab: „Die Soziologie hat als besondere Wissenschaft ihre besonderen Gegenstände: es sind die ,Dinge', die aus dem sozialen Leben und nur aus dem sozialen Leben hervorgehen." (Tönnies 2012j [1931]: 240) ${ }^{738}$ Aus soziologischer Perspektive wiede-

736 Die Wissenschaft könne allenfalls Prognosen in Form von Wahrscheinlichkeitsaussagen fällen (vgl. Tönnies 1926g [1910]: 130f.; 1926c: 430).

737 Mithin gilt nach Tönnies: „[A]ls Soziologen sind wir weder für noch wider Sozialismus, weder für noch wider Erweiterung der Frauenrechte, weder für noch wider Vermischung der Rassen; wir finden aber in allen diesen Fragen, in der Sozialpolitik wie in der Sozialpädagogik und Sozialhygiene Probleme auch für die auf das Tatsächliche gerichtete Erkenntnis; an dieser findet die Soziologie als solche ihre Grenzen, ohne sich anzumaßen, irgendwelche Ideen und Bestrebungen, die etwas anderes wollen, fördern oder hemmen zu wollen. Ob Förderung oder Hemmung aus der richtigeren Erkenntnis entspringe, das ist eine andere Frage. Im allgemeinen kann es allerdings erwartet werden." (Tönnies 1926g [1910]: 133, H.i.O.).

738 Darüber erfolgt letztlich die Abgrenzung zu den konkurrierenden Disziplinen Sozialbiologie und Sozialpsychologie (vgl. insbesondere Tönnies $1926 \mathrm{f}$ [1915/1916]; 1926c [1925]). 
rum stellt sich das menschlichen Zusammenleben nur unter dem Gesichtspunkt dar, dass der Mensch ein Vernunftwesen ist - man hat es nur „mit seinem Geistesleben zu tun“ (Tönnies 1908: 228, H.i.O.). Daher sind die sozialen ,Dinge“ reine Gedankenbilder: „Sie sind Erzeugnisse menschlichen Denkens und sind nur für ein solches Denken vorhanden [...].“ (Tönnies 2012j [1931]: 240)

In dieser Eigenschaft liegt letztlich die Angemessenheit des begrifflichkonstruktiven Vorgehens begründet: Da die genuin soziologischen Gegenstände „Gedankenbilder“ seien, unterscheide sich die Soziologie von den Naturwissenschaften „nur dadurch [...], daß ihre Objekte weder durch Teleskop, noch durch Mikroskop sichtbar werden und auch durch andere Sinne nicht wahrnehmbar sind" (Tönnies 2012f [1907]: 116). Um sie dennoch zu „begreifen“, gelte: „Nur der Gedanke vermag sie zu erkennen.“ (Ebd.) Es ist, wie Merz-Benz über Tönnies paraphrasierend schreibt - „die theoretische Wissenschaft ,Soziologie', welche die sozialen Verhältnisse ,eben dadurch ' , denkt', dass sie sie ,aus den Tatsachen, aus dem wirklichen Verhalten der Menschen zueinander, abzieht ${ }^{\star}$ und anschließend im Begriff erstehen lässt“" (Merz-Benz 2016: 10). Erkenntnis läuft dann über vernünftige Begriffsbildung, die gegenüber der sozialen Wirklichkeit dem Reich der Begriffe entspringt.

Die Soziologie hat es also nach Tönnies

wesentlich mit Begriffen zu tun, mit dem Begriffe des sozialen Lebens, mit den Begriffen sozialer Verhältnisse, sozialer Willensformen und sozialer Werte, sozialer Verbindungen, also unter anderen den Begriffen der Sitte und des Rechtes, der Religion und der öffentlichen Meinung, der Kirche und des Staates; sie muß diese Begriffe bilden, d.h. sie für den Gebrauch zurecht machen, sie schmieden und bebauen, um die Tatsachen der Erfahrung wie an Nägel daran zu hängen oder wie mit Klammem zu ergreifen; sie hat in diesem Bereiche nicht sowohl direkt die Erkenntnis der Tatsachen, sondern die zweckmäßigsten, tauglichsten Geräte für solche Erkenntnis herzustellen: eine überaus wichtige, von den bloßen Empiristen oft sehr zu ihrem Schaden gering geschätzte Aufgabe. (Tönnies 1926g [1910]: 131)

Die notwendige gedankliche Abstraktion bestehe in der Konstruktion von „Normalbegriffen [...], deren Gegenstände mit einer leichten Abänderung des Max Weberschen Terminus ich ideelle Typen nenne" (Tönnies 20121 [1932]: 271, H.i.O.). Hierzu zählen ,Gemeinschaft' und ,Gesellschaft', insofern wird das epistemische Ding ,Gesellschaft' nun als Sozialform gefasst, 
und die Gesellschaft im engeren Sinne ist eine der möglichen. ${ }^{739}$ Gemeinschaft und Gesellschaft sind dann die Begriffe, an denen die Sozialformen gemessen werden. Sie dürften aber nicht mit der Realität verwechselt werden, sie sind keine Dinge, die man in der Wirklichkeit antreffen könne. ${ }^{740}$ Und doch werden sie zu deren Erkenntnis herangezogen. Dabei müssen sie - wie alle Normalbegriffe - „geeignet sein, als Maßstäbe zu dienen, um die Beziehungen zwischen Inhalten, die in der Erfahrung gegeben sind und verglichen werden sollen, auszudrücken“ (Tönnies 1926b [1908]: 123).

\subsection{Rechtsbegriffe und soziologische Begriffe}

In dieser Bestimmung der Soziologie als reine bzw. als philosophische Wissenschaft liegt für Tönnies auch der Grund für die Hinwendung zum Naturrecht - respektive zur Naturrechtstheorie. Denn er erkennt im naturrechtlichen Denken den die Wissenschaft schlechthin begründenden Rationalismus (s.o.). Darüber hinaus liegt es aber auch an der Eigenart der naturrechtlichen Begriffsbildungen:

Die Hinwendung zum Naturrecht ermöglicht auf heuristischer Ebene das Heranziehen eines ent-theologisierten Begriffsarsenals. Das ältere Naturrecht sei seinem Charakter nach "notwendig antitheologisch“ (Tönnies 1979 [1912]: XXVI). Denn im rationalen Naturrecht werden scheinbar übersinnlichen Gestalten als Gebilde menschlichen Denkens und Wollens erklärt (ebd.: XXXII; 2012e [1899]: 108). Insofern gelte: „Die bleibende Bedeutung der naturrechtlichen Rechtsphilosophie liegt in der Ablösung der Begriffe des Rechts von der Theologie, in der behaupteten Autonomie des menschlichen Willens auch in bezug auf die moralisch und politisch gültigen sozialen Werte.“ (Tönnies 1911b: 570) Zwar weise das Naturrechtsdenken als Rechtsphilosophie immer auch eine normative Komponente auf,

739 König bezweifelt jedoch, dass Tönnies bereits in der ersten Auflage seines Hauptwerks ,Gemeinschaft' und ,Gesellschaft' als Normalbegriffe entwarf, dort habe dieser vielmehr noch entwicklungsgeschichtlich gedacht. Auch wenn Tönnies später etwas anderes behauptete, habe er das Konzept des Normalbegriffs erst um die Jahrhundertwende entwickelt (vgl. König 1955: 352f.).

740 Vielmehr muss eine soziale Verbundenheit als geistiges Gebilde, „durch das Medium des gemeinsamen Denkens derjenigen menschlichen Individuen gesehen und begriffen werden [...], die eine solche Wesenheit bilden und benennen. Nur durch diesen gemeinsamen Willen ist sie vorhanden, muß also immer in ihrer Abhängigkeit davon begriffen werden.“ (Tönnies 1926c [1925]: 433). 
gehe es doch um das „natürliche, normale oder richtige Recht, um den rationalen und den besten Staat, um ideale Gesetzgebungen als die von der Natur oder von der Vernunft gebotenen immer sich innig bemüht hat" (Tönnies 1926g [1910]: 126). Darüber hinaus habe das Naturrecht aber auch einen „objektiven begrifflichen Erkenntnisgehalt [...]: das ist eben ihr soziologischer oder sozialphilosophischer Gehalt, eine Lehre von den möglichen und wirklichen, (daher auch von den notwendigen) sittlichen und rechtlichen Beziehungen, Verhältnissen und Verbindungen der Menschen“ (ebd.: 126, H.i.O.). Diese Lehre lasse sich „aus dem ,Naturrecht ${ }^{\text {" }}$ herausschälen, um ein Stück höchst wichtiger theoretischer Soziologie aus ihr zu gewinnen“ (ebd.). ${ }^{741}$

Durch die Bereitstellung eines ent-theologisierten Begriffsarsenals ermöglicht das Naturrecht die rationale Konstruktion gesellschaftlicher sozialer Verhältnisse und Verbindungen. Diese sei namentlich in der „reinen Theorie des Privatrechts“ zu suchen (vgl. Tönnies 2012f [1907]: 114; s. schon 1880c: 30 [eigene Pag.]). Denn dort werde sich über den Vertrag mit dem Grundtyp der gesellschaftlichen Verhältnisse auseinandergesetzt, wie Tönnies explizit betont: „Für die rationale Konstruktion ist der normale Ursprung eines solchen Verhältnisses der Vertrag; und zwar insofern, als er durch gegenseitiges Versprechen geschlossen wird und gegenseitige ,Rechte', d.h. berechtigte Ansprüche und ,Pflichten' begründet.“ (Tönnies 2012g [1914]: 203, H.i.O.)

Die rechtlichen Konstruktionen sind nach Tönnies daher - wie er später hervorhebt - selbst als eine Art des soziologischen Denkens anzusehen: „Ich behaupte, daß es soziologisch außerordentlich wichtig ist, das juridische Denken und seine Figmente als eine Art des soziologischen Denkens zu verstehen, das sich freilich zu anderen als soziologischen Zwecken ausgebildet hat." (Tönnies 20121 [1932]: 275) So beschreibe die juristische Fiktion der ,juristischen Person' den fiktiven Charakter der ,sozialen Verbindungen' treffend (vgl. ebd.: 275; 1926h [1923]: 348). Zugleich bringe sie aber auch den notwendig personalen Charakter solcher Vielheiten zum Ausdruck, begreife sie diese doch als eine Person, die seinen Mitgliedern gegenübertrete, nach außen hin gegen andere auftrete und als solche schließlich - auch von den Theoretikern - adressiert werde (vgl. Tönnies 20121 [1932]: 275; 2012g [1914]: 207). ${ }^{742}$

741 Zu den Folgen dieser Konzeption der Abgrenzung von Normativität und Objektivität als rechtsphilosophie-interne Streitigkeit s. gleich IV.2.2.

742 In Anlehnung an Jhering schreibt Tönnies: „Der Verein ist der Typus der Gesellschaft, die aus freiem Kürwillen, sei es wirklich [sic], entsprungen ist oder doch ihrem Wesen nach hervorgeht." (Tönnies 2012f [1907]: 125, H.i.O.). Mit dieser 
Letztlich erfüllt die Orientierung am Naturrecht eine erkenntnisleitende Funktion. ${ }^{73}$ Für Tönnies stellt der Tausch die „einfachste[] Form der sozialen Verbundenheit“ dar (Tönnies 2012j [1931]: 238, H.i.O.). Die „mannigfachen Weisen der Verbundenheit“ lassen sich dann wiederum „am leichtesten verstehen, wenn wir sie alle auf den einfachsten Typus beziehen, der zugleich der rationale ist: nämlich auf den Fall des einfachen Tausches oder der gegenseitigen Bindung durch Versprechungen, die als verlängerter Tausch gedacht werden mögen" (ebd.). Dies ist der rationale Tauschvertrag, wie er sich aus den naturrechtlichen Konstruktionen ergibt (vgl. bereits Tönnies 2012a [1880/1881): 55f.). Seine spezifische Charakteristik sieht Tönnies in der Zweck-Mittel-Relation, „weil es sich in seinem einfachsten Fall um zwei getrennte Gegenstände handelt, die nichts miteinander zu tun haben, als daß jedes Mittel in Bezug auf den anderen (als Zweck) ist, jeder nützlich, also Wert habend, als Mittel, um den anderen zu erlangen“ (Tönnies 2012j [1931]: 238). Ausgehend hiervon lassen sich dann die Differenzen zu den gemeinschaftlichen Rechtsverhältnissen explizieren: etwa ihre Umkehrung der Zweck-Mittel-Relation (vgl. Tönnies 1929 [1923]) oder ihr organischer statt mechanischer Charakter.

V.a. aber zeigt sich vor der Folie der naturrechtlichen Konstruktion des Rechtsverhältnisses, dass man auch das Gemeinschaftsdenken über seine spezifische Art des Wollens bestimmen muss, die Tönnies mit dem „Kunstausdruck" Wesenwillen belegt (Tönnies 1909: 17). Aus der Orientierung am naturrechtlichen Rechtsverhältnis folgt also bei Tönnies die Notwendigkeit der Auseinandersetzung mit den Willensformen, und konsequenterweise bildet das den zweiten Teil von Gemeinschaft und Gesellschaft (Tönnies 1979 [1887]: 73ff.). ${ }^{74}$ Auch wenn die begrifflichen Konstruktionen des Naturrechts für Gemeinschaftsverhältnisse nicht passen, lassen

Bestimmung geht es Tönnies letztlich - der naturrechtlichen Theorie des Leviathans folgend - um die soziologische Theorie des Staates (vgl. ebd.: 123; 1926h [1923]).

743 Das folgt aus Tönnies' Prämisse, dass das Allgemeine dem Besonderen vorausgehe, dass sozusagen die konkrete Ausformung nur Ausdruck eines vorausgehenden allgemeinen Prinzips sei.

744 Der „soziale Wille“ zeigt sich als das vereinende Element: „Sitte und Gewohnheitsrecht, Religion und Gesetzgebung, Konvention und öffentliche Meinung, Stil und Mode sind lauter Ausdrücke für verschiedene Gestalten sozialen Willens.“ (Tönnies 2012f [1907]: 117) Nach Tönnies liegt in Verkennung der Rolle des Wollens eines der Probleme der Historischen Rechtsschule begründet: „In der Tat ist es die Schwäche der ganzen historischen Schule in der Rechtsphilosophie wie in der Nationalökonomie, daß sie sich niemals zu einer psychologischen Ableitung ihrer sozialen und ebensowenig zu einer soziologischen Vertie- 
sich nach Tönnies die Elemente der Qualifikation dieser Verhältnisse aus der Analyse der naturrechtlichen Konstruktion des sozialen Verhältnisses gewinnen. ${ }^{745}$

\section{Soziologie als Rechtsphilosophie: gemeinschaftliches Naturrecht}

Das Naturrechtsdenken bildet also für Tönnies die Grundlage einer wissenschaftlichen Behandlung von sozialen Verhältnissen, sozialen Willensformen und sozialen Verbindungen schlechthin. Allerdings erweist es sich - wie schon die Analyse der sozialen Verhältnisse zeigt - als „Irrtum [...], völlig getrennte und geschiedene Willenssphären der Menschen als allgemein und notwendig" vorauszusetzen (Tönnies 1925 [1905-1911]: 192; s.a. 2012e [1899]: 108):

Ich behaupte dagegen: es gibt eine ursprüngliche und wesentliche Einheit zwischen Mensch und Mensch, die in nächster Nähe der Instinkt, in unendlicher Entfernung nur die höchst entwickelte Vernunft zu erkennen vermag, die aber immer vorhanden ist, und durch die Vernunft auf allen Stufen ihrer Entwicklung sich kundbar macht. (Tönnies 1925 [1905-1911]: 192, H.i.O.)

Wenn also aus dem Verhältnis menschlicher Gemeinschaft gleichermaßen reine Rechtsverhältnisse hervorgehen, so zeigt dies die Beschränktheit des Naturrechts auf rationalistische und individualistische Begrifflichkeiten (vgl. Tönnies 1922: 211 [13]).

Diese Beschränktheit kann nun nicht dadurch überwunden werden, dass man sich auf die Seite der Historischen Rechtsschule schlägt, erweist diese sich doch weder als konsistent, noch als wissenschaftlich akzeptabel (s.o.). Naturrecht und Gewohnheitsrechtslehre stellen nach Tönnies vielmehr je spezifische „Ansicht[en] der sozialen, politischen usw. Weltdinge“ dar. Dabei könne „diesen Dingen und ihrer Beschaffenheit selber bald die eine, bald die andere [Ansicht; D.S.] adaequat sein" (Tönnies, Brief vom 21.06.1885, in Tönnies, Paulsen 1961: 216f.). Es sei letztlich falsch, von

fung ihrer psychologischen Begriffe aufgeschwungen hat. Wo sie dies versucht hat, ist sie regelmäßig in theologisches oder mythologisches Dunkel zurückgeglitten.“ (Tönnies 2012e [1899]: 106, Fn. 78).

745 Denn es gelte - so Tönnies -, „die Erscheinung des sozialen Verbältnisses in seine Elemente zu zerlegen und diese Elemente begrifflich darzustellen, unangesehen, ob ihre reine Gestalt in der Wirklichkeit vorkomme oder nicht“" (Tönnies $2012 \mathrm{f}$ [1907]: 114, H.i.O.). 
einem Gegensatz in dem Sinne auszugehen, dass eine Seite alleinige Gültigkeit für sich zu beanspruchen vermag (vgl. ebd.). Vielmehr seien Gewohnheitsrecht und Gesetzesrecht gleichermaßen als Quellen des Rechts anzuerkennen (vgl. Tönnies 1925 [1905-1911]: 180; 2012f [1907]: 115; 1931: 209).

Im Gegensatz zur Historischen Rechtsschule folgt für Tönnies aus der Gewohnheitsrechtslehre nicht der Ausschluss der gewillkürten Kodifikation, sondern diese stellt schlicht ein aliud zu ihr dar. Und vice versa verhält es sich mit Blick auf das Vernunft- bzw. das Naturrecht: Weder ist Gewohnheitsrecht ausgeschlossen, noch derogiert Naturrecht per se widersprechendem Recht. Beide Richtungen verkennen letztlich, dass sie ihre Einheit im „sozialen Wollen“ finden und nur die zwei Seiten der Medaille ,soziale Verhältnisse darstellen (vgl. Tönnies 1925 [1905-1911]: 180).746 Insofern stehen sie gleichberechtigt nebeneinander.

Angesichts dieses Nebeneinanders der beiden Rechtsquellenlehren ist das eigentliche Erkenntnisziel von Tönnies auf Synthese gerichtet. Bereits im Jahr 1879 formuliert er dieses Anliegen, wenn er an Friedrich Paulsen schreibt: „Und ich meine auch, wir müssen Romantik und Rationalismus zu einer höheren Synthese verbinden [...].“ (Tönnies, Brief vom 30.10.1879, in Tönnies, Paulsen 1961: 61) Beide Denkweisen seien in einer wissenschaftlichen Gesamtsicht des menschlichen Zusammenlebens aufzuheben. Damit wird einerseits ein genetisches Erklärungsinteresse verfolgt: Denn nur, wenn man die Wirklichkeitsauffassung um die romantische Denkweise erweitere (vgl. ebd.), könne man herausfinden, wie sich die historische Entwicklung und die darin hervortretende Genesis des modernen Zusammenlebens darstelle. Nur so könne man daher erklären, auf welchem Fundament das gegenwärtig primär rational gestaltete Zusammenleben aufruhe (vgl. Merz-Benz 2016: 48). Andererseits geht es aber um eine

746 In der Literatur wird immer wieder betont, dass Tönnies' Konzeption des Verhältnisses von Gemeinschaft und Gesellschaft sehr widersprüchliche Interpretationen zulässt. So macht René König in Tönnies' Hauptwerk allein sieben, durch Textstellen belegbare Deutungsmöglichkeiten aus (König 1987). Insbesondere die Lesart, bei Tönnies eine normative Bevorzugung der organizistischen Gemeinschaft zu erkennen, dergegenüber Gesellschaft ein Verfallsphänomen darstelle (vgl. etwa Freyer 1936), führt zu der immer wieder erörterten Frage, ob er als Vorläufer der Gemeinschaftsideologien der Weimarer- und der NS-Zeit zu sehen ist (statt vieler vgl. Käsler 1991; Breuer 2002). Im Lichte der Rechtsquellenlehren verkehrt sich diese normative Bewertung aber bei Tönnies, richtet er doch seine Kritik primär gegen die organizistische Gewohnheitsrechtslehre. Es geht dann vielmehr darum, Gemeinschaft überhaupt denkend erfassen zu können. 
Synthese im dialektischen Sinne. Insofern stellt für Tönnies „das ,historische' Denken, außer dem, was es sonst bedeutet, auch den Übergang zu einer neuen Gestalt des rationalistischen Denkens in Bezug auf die Tatsachen des sozialen Lebens dar" (Tönnies 2012d [1895]: 84, H.i.O.).

Da Tönnies seine Grundbegriffe an die Rechtsphilosophie respektive an die Theorie des Rechts zurückbindet, erscheint die Arbeit am Begriff des Rechts als der eigentliche Ort der Synthese. Hier stößt er jedoch auf ein Problem: Bietet das naturrechtliche Denken die Möglichkeit der genuin wissenschaftlichen Erfassung der gesellschaftlichen Verhältnisse, so ist das bei der Historischen Rechtsschule, also für die gemeinschaftlichen Verhältnisse, gerade nicht der Fall. Man muss also zunächst eine Rechtstheorie (und damit Sozialtheorie) der Gemeinschaft konstruieren, die gleichsam den spezifischen Eigenheiten der gemeinschaftlichen Verhältnisse als auch den wissenschaftlichen Anforderungen des rationalistischen (Naturrechts-)Denkens gerecht wird. ${ }^{77}$ Dementsprechend sucht Tönnies die „aus ihren Verhüllungen zu befreiende soziologische Rechtsphilosophie“ (Tönnies 2012g [1914]: 205) der Gewohnheitsrechtslehre herauszuarbeiten, die als Basis der Synthese fungieren kann. Ausgangspunkt hierfür wird im dritten Buch von Gemeinschaft und Gesellschaft das ,Natürliche im Recht', wie Tönnies es sowohl im Naturrechtsdenken als auch im Gewohnheitsrechtsdenken ausmacht.

\section{Das Natürliche im Recht}

Auch wenn das rationale Naturrecht auf Konstruktionen beruht, erkennt Tönnies darin etwas Natürliches im Recht: „Dies ist der individualistischgesellschaftliche Begriff eines natürlichen, d.h. der Vernunft gemäß allgemeinen und notwendigen Rechtes [...]." (Tönnies 2012g [1914]: 204, H.i.O.) Insofern folgt das gesellschaftliche Naturrecht aus der Natur des Menschen als vernunftbegabtes Wesen, hierin liegt seine Allgemeinheit und Notwendigkeit begründet.

Aber auch das gemeinschaftliche Recht stellt ein solches, natürliches Recht $^{\star}$ dar. Denn auch dieses ist allgemein und notwendig, jedoch nun nicht mehr bezogen auf die ratio, sondern auf die Natur der Sozialform:

747 Der Entwurfscharakter eines solchen Gemeinschaft und Naturrecht vereinenden Denkens wird in Tönnies Schriften daran deutlich, dass er an den entsprechenden Stellen in den Konjunktiv wechselt und vorsichtig davon spricht, dass eine solche Theorie „möglich“ sei (Tönnies 2012g [1914]: 204) bzw. dass man deren Idee darzustellen unternehmen „kann“ (Tönnies 1931: 217). 
Mithin ist eine verbundene Menschheit als natürliches und notwendiges Dasein vorausgesetzt, ja es ist ein Protoplasma des Rechtes vorausgesetzt, als ursprüngliches und notwendiges Produkt ihres Zusammenlebens und Zusammendenkens, dessen fernere Entwicklung wesentlich durch seine gleichsam eigene Tätigkeit, nämlich durch den vernünftigen Gebrauch seines Urhebers geschehen sei. (Tönnies 1979 [1887]: 176)

Recht ist daher nicht nur als gesatztes Recht, sondern in einem weiten Sinne zu verstehen: „[A]lles, was dem Sinne eines gemeinschaftlichen Verhältnisses gemäß, was in ihm und für es einen Sinn hat, das ist sein Recht; d. i. es wird als der eigentliche und wesentliche Wille der mehreren Verbundenen geachtet.“ (Ebd.: 17, H.i.O.) „Natürliches Recht“" in gemeinschaftlichen Sinne folge aus einem „stillschweigenden Einverständnis über das, was sein muß, einem Einverständnis, das aus den tatsächlich gegebenen Verhältnissen als eine Folgerung und Forderung sich ergibt: es ist ,selbstverständlich“ und also notwendig“" (Tönnies 1909: 19).

Letztlich handelt es sich beim Recht dann um Ordnungsnormen, und das natürliche Recht stelle „eine Ordnung des Zusammenlebens [dar], die jedem Willen sein Gebiet oder seine Funktion zuweist, einen Inbegriff von Pflichten und Gerechtsamen" (Tönnies 1979 [1887]: 17). Es erwachse aus einer ,natürliche[n] und a priori in ihrem Keime enthaltene[n] Ordnung und Harmonie, nach welcher jedes Mitglied das Seine tut, tun muss oder doch soll“ (ebd.: 189). In diesem Sinne müssen gemeinschaftliche Rechtsverhältnisse "ihrer Wurzel nach von Natur, gegeben` vorausgesetzt werden, d.h. als in der allgemeinen oder in einer besonderen Notwendigkeit menschlichen Zusammenlebens und Zusammenwirkens gegründet" (Tönnies 2012g [1914]: 204). ${ }^{748}$

Recht ist immer zu verstehen als ein Erzeugnis des menschlichen denkenden Geistes, egal ob in Form des Naturrechts oder in Form des gemeinschaftlichen Rechts. Als geistiges Produkt folgt es der Natur der Sache, es ist deren Ordnung bzw. stiftet diese. Wenn Ordnung notwendige Voraus-

748 In solchen Rechtsverhältnisses verändert sich die Funktion des Vertrages: „Hier erschiene dann der Vertrag nur als die Befestigung oder Bestätigung, besser vielleicht noch als die individuelle Erfüllung eines der Idee nach schon vorhandenen, weil in dem genannten Sinne notwendigen ,Bandes', das seinem Wesen nach ein Band der ,Treue' wäre, d.h. der zeitlich unbegrenzten Erhaltung eines dadurch hergestellten Zustandes [...].“ (Tönnies 2012g [1914]: 204). 
setzung jeglicher Form des sozialen Lebens ist, ${ }^{749}$ dann ist jedes Recht „natürlich", d.h. allgemein und notwendig - daher die bereits erwähnte Gleichung: „Ordnung ist natürliches Recht, Recht schlechthin = positives Recht.“ (Tönnies 1979 [1887]: 207) In der sozialen Ordnung liegen mithin die ,soziologische Gründe des Naturrechts'. Und im Begriff des ,natürlichen Rechts' in seinem zweifachen Sinne liegt die Behauptung, „daß Recht sowohl als gemeinsamer Wesenwille, wie als gemeinsamer Kürwille verstanden werden kann" (ebd.: 185). Das logische Nebeneinander des gemeinschaftlichen und des gesellschaftlichen Rechts erweist sich dann als ein logisches Nebeneinander der jeweiligen Rechtsquellenlehren.

\section{Der Entwurf eines gemeinschaftlichen Naturrechts}

Dieser Begriff des natürlichen Rechts markiert in seinem zweifachen Bedeutungsgehalt den Anfangs- und den Endpunkt der Entwicklung des Natürlichem im Recht: Von den ursprünglichen familiären Verhältnissen mit ihren tradierten Gewohnheitsrechten über die Entgegensetzung der Rechte zwischen den Häusern hin zu Formen der Freisetzung der Vernunft im ius gentium, das jedoch noch an das Gewohnheitsrecht zurückgebunden war, so dass das Rationale erst mit der Verwirklichung des allgemeinen und natürlichen Rechts im Sinne des rationalen Naturrechts zur Entfaltung kam (ebd.: 176ff.).

Auf philosophischer Ebene trat jedoch durch die Historische Rechtsschule eine Verkehrung ein, verdrängte sie doch Anfang des 19. Jahrhunderts erfolgreich das Naturrecht. Bereits im Jahr 1887 erkennt Tönnies nun angesichts der sozialen Frage ein Wiederaufleben des Naturrechts: „Nachdem es der Evolution der herrschenden Classe selber gedient hat, lebt es wieder auf als Programm der unterdrückten Classe, in der Forderung des Ertrages der eigenen Arbeit.“ (Tönnies 1887: 246) Dass Tönnies damit aber nicht das ältere rationale Naturrecht meint, zeigt sein Zusatz, den er im Jahr 1912 in der zweiten Auflage von Gemeinschaft und Gesellschaft anhängt:

In allgemeinster und unmittelbarster Weise richtet sich dieser Kampf gegen das freie und absolute Privateigentum am Grund und Boden,

749 So schreibt Tönnies: „Zufällig ist jede besondere Ordnung; notwendig ist nur eine Ordnung überhaupt, eine Weltordnung, auch diese aber nicht notwendig als Wirklichkeit, sondern als ein Mittel zum vernünftigen Leben, welches der Denkende setzen und bejahen muß.“ (Tönnies 1979 [1887]: 180f., H.i.O.). 
weil dessen Mißbrauch am deutlichsten - als „Bodenwucher“ - zutage tritt, und weil die Urerinnerung an ein gemeinschaftliches Recht, das „mit uns geboren ist“, schlummernd, wie das Weizenkorn in einer Mumie, jedoch der Entwicklung fähig, in der Volksseele sich erhalten hat. Denn als Idee der Gerechtigkeit verstanden ist das Naturrecht ein ewiger und unveräußerlicher Besitz des menschlichen Geistes. (Tönnies 1979 [Zusatz von 1912]: 184)

Der Entfesselung der Handlungsmöglichkeiten des Individuums auf dem kapitalistischen Markt hält Tönnies ein Naturrecht entgegen, dessen Ursprung in der Erinnerung an das genuin gemeinschaftliche Recht zu finden ist. Hier ist dann auch die Idee der Gerechtigkeit anzusiedeln, die angesichts der sozialen Frage zu einem dringlichen Problem geworden ist.

Diese Bestimmung markiert sehr deutlich den kritischen Einsatz dessen, was er später das „gemeinschaftliche Naturrecht“ (Tönnies 1931: 217) nennen wird: Wolle man eine solche Idee entwickeln, so stehe es dem Denkenden frei, den Menschen nicht als schlechthin egoistisch vorauszusetzen, sondern dem „System der sozialen Normen als natürliches Recht“ die „Hypothese des natürlichen Altruismus zugrunde [zu] legen“ (ebd.: 218, H.i.O.):

Es würde bedeuten, daß in jedem sozialen Verhältnis, das auf gegenseitiger Zuneigung und darin wurzelndem Pflichtgefühl beruhe, der Keim eines objektiven Rechtes gegeben sei und daß dieser Keim unter begünstigenden Umständen des Lebens wachse und sich zum Recht fortentwickele. (Ebd.)

Ein solches gemeinschaftliches Naturrecht würde - so Tönnies - (subjektive) Rechte und Pflichten entgegen deren naturrechtlicher Entkoppelung wieder zusammendenken: „, $[\mathrm{M}]$ it dem Recht wäre die Pflicht unmittelbar gegeben: mit dem herrschaftlichen Rechte die rechtliche Pflicht, es zum Wohle des Beherrschten zu gebrauchen; mit der Pflicht des Gehorsams der rechtliche Anspruch auf Schutz und Hilfe.“ (Ebd.: 219) Ein solches Recht, das auf dem obersten Grundsatz beruhe, dass die Menschen als vernünftige Wesen in engeren oder weiteren Kreisen zu Schutz und Trutz miteinander verbunden seien (vgl. ebd.), ist per se ein soziales Recht, das sich am Ganzen (als Gemeinschaft) orientiert:

Es stünde also seinem Wesen nach das gemeinschaftliche Naturrecht, wie das gesellschaftliche, unter den Begriffen einer als gültig anerkannten Vernünftigkeit oder Weisheit, die ihre Forderungen stellte, indem sie die wie auch immer zu motivierende Selbstbeherrschung und Selbstüberwindung zugunsten einer Idee verlangt, die auch in Ge- 
meinschaft als im letzten Grunde dem eigenen wahren Wohl und Heil dienend erkannt würde. (Ebd.: 221)

Ließe sich ein solches gemeinschaftliches Naturrecht am leichtesten im Familienrecht realisieren, so sieht Tönnies aber gleichermaßen die Möglichkeit, dies über gemeinsames Eigentum zu verwirklichen (ebd.: 219f.). Aber auch den Arbeitsertrag könne man nach dem Gesichtspunkt des allgemeinen Nutzens und nicht des individuellen Gewinns verteilen. Zur Debatte steht also ein Wandel der normativen Gesichtspunkte, die dem naturrechtlichen Denken in egal welcher Form zu Eigen ist:

Diese Idee [des gemeinschaftlichen Naturrechts, D.S.] erscheint in Anwendung auf das Handeln, insbesondere auf die friedliche Ordnung der Verhältnisse von Menschen zu Menschen und von Menschen zu Sachen, als die Idee der Gerechtigkeit, die von dem Gedanken des Naturrechts unlösbar ist. (Ebd.: 221)

Während es sich im gesellschaftlichen Naturrecht um eine kommutative Gerechtigkeit handelt, wandelt sie sich im gemeinschaftlichen Naturrecht in eine distributive. Einher damit geht eine Veränderung im Verhältnis von Recht und Moral: Während das gesellschaftliche Naturrecht von einer strikten Trennung ausgeht, verschmelzen beide im gemeinschaftlichen $\mathrm{Na}$ turrecht. ${ }^{750}$

Das gemeinschaftliche Naturrecht stellt letztlich die gesuchte Synthese zwischen historischer und rationaler Ansicht, zwischen Historischer Rechtsschule und Naturrecht dar. Auf der einen Seite versucht Tönnies damit die Einseitigkeit der individualistisch-rationalistischen Denkungsart zu überwinden, ohne das Wissenschaftsmodell, das dem Rationalismus zugrunde liegt, aufzugeben. Dadurch soll ein Abgleiten in Traditionalismus und Irrationalismus eines historistischen Gemeinschaftsdenkens verhindert werden. Auf der anderen Seite versucht Tönnies, dem Gemeinschaftsdenken einen wissenschaftlichen Ausdruck zu geben, der dessen anti-rationalen und organischen Charakter gerecht wird. Als gemeinschaftliches Recht ist es der Gewachsenheit des Rechts respektive der sozialen Ordnung verpflichtet, als Naturrecht behält es aber die Freiheit und Gleichheit

750 So schreibt Tönnies über die Idee des gemeinschaftlichen Naturrechts: „Sie verschmilzt die Moral mit dem Rechte, ordnet aber notwendigerweise das Recht der Moral unter. Es wird hier zum Organ eines Geistes der Selbstbeherrschung und Bescheidung des einzelnen Menschen, daher der Erziehung zur Fähigkeit solcher und der Uebung im Gebrauche der Tugenden, die ein gutes Zusammenleben erfordert.“ (Tönnies 1931: 222). 
der Individuen im Auge und hat eine der Zukunft zugewandte Dimension. Im gemeinschaftlichen Naturrecht werden bei Tönnies die beiden Rationalitätsformen, d.h. die analytische Zweckrationalität des Naturrechtsdenkens und die im theoretischen Sinne ganzheitliche-synthetische Vernunft und im praktischen Sinne ethische Vernunft des Gemeinschaftsdenkens, miteinander synthetisiert (vgl. Bickel 1991: 151; kritisch hierzu Kamenka, Erh-Soon Tay 1990). Dadurch versucht Tönnies die naturrechtliche Trennung von Recht und Moral in den ganzheitlich-kulturellen Vernunftformen der Gemeinschaft aufzuheben und das Gerechtigkeitsstreben des Naturrechts zu verwirklichen.

\section{Die Wertfreiheit der Soziologie als Rechtsphilosophie}

Wie in der Literatur immer wieder hervorgehoben wird, besteht der aufklärerische Impetus Tönnies' in der Integration der romantischen respektive historischen Denkweise in die wissenschaftliche Auffassung der Sozialwelt, d.h. in der Ausweitung der Zuständigkeit der Vernunft in ihrem umfassendsten Sinne auch auf diejenigen Bereiche, die an sich nicht rational strukturiert sind. Er richte sein Bemühen darauf - wie Merz-Benz darlegt -, „die Aufklärung auch in die Bereiche des Alogischen voranzutreiben, die Vernunft auf diese Weise nicht verabschiedend, sondern sie noch stärkend - mithin das sich Einlassen auf eine Paradoxie“ (Merz-Benz 2016: 51). In diesem Sinne fungiert der Entwurf des, gemeinschaftlichen Naturrechts" als „kritische Instanz" (Bickel 1991: 149), um eine - wie Bickel schreibt - „Korrektur der Pathologien des abendländischen Rationalisierungsprozesses durch die Freisetzung und wissenschaftlich geleitete Entwicklung der im Wesenwillen enthaltenen Vernunftkomponente" zu erreichen (ebd.: 150; vgl. auch Tönnies 2012d [1895]: 99f.).

Vorreiterin eines gemeinschaftlichen Naturrechts erkennt Tönnies in der modernen Konsum- und Genossenschaftsbewegung, von der er sich einen großen Beitrag zur gesellschaftlichen Reform erhofft (vgl. Lichtblau 2012: 15). ${ }^{751}$ In ihr gewinne - wie Tönnies in der zweiten Auflage von Ge-

751 Die Genossenschaftsidee stellt nach Tönnies insbesondere eine Alternative zu einer reinen staatlichen Interventionspolitik im Wohlfahrtsstaat dar, die letztlich zulasten des Rechtsstaates (verstanden als Verteidigung der Freiheitsrechte) geht (vgl. Tönnies 1914: 70; zur differenzierten Auseinandersetzung mit Tönnies' Verständnis des Staates - insbesondere auch des Sozialstaates - vgl. die Beiträge in Carstens 2014b; Opielka 1990). Daher widmet Tönnies dem Thema der Genossenschaft immer wieder seine Aufmerksamkeit. 
meinschaft und Gesellschaft hinzufügt - das Prinzip der Gemeinschaftsökonomie in einer "Gestalt, die den gesellschaftlichen Lebensbedingungen angepasst ist", ein neues Leben (Tönnies 1979 [Zusatz von 1912]: 174). ${ }^{752}$ Das erweise sich einerseits als sittliches Gebot der Stunde, sei aber andererseits auch für die reine Theorie des sozialen Lebens von Interesse, denn: „Eine Erneuerung des Familienlebens und anderer Gemeinschaftsformen wird, in Verbindung mit tieferer Erkenntnis ihres Wesens und ihrer Lebensgesetze, hier [in der Genossenschaftsbewegung, D.S.], wenn irgendwo ihre Wurzeln zu schlagen vermögen.“ (Ebd. ${ }^{753}$ Den „auflösenden Kräfte[n]“ des „kapitalistisch-gesellschaftlichen Weltsystems“ werde damit nämlich wie Tönnies in einem weiteren Zusatz aus dem Jahr 1922 spezifiziert nicht eine schlicht moralische Meinung entgegengehalten. Vielmehr handele es sich bei der „Idee der genossenschaftlichen Selbstversorgung" um ein „lebens-, also entwicklungsfähiges Prinzip[]“ (ebd. [Zusatz von 1922]: 175), das aus der Freiheit des Einzelnen erwachse und nicht aus einem Rückfall in den Traditionalismus. ${ }^{754}$

Auch wenn Tönnies auf diesem Weg auf die soziale Frage zu antworten sucht, ordnet er sein Vorhaben keineswegs den von ihm aus wissenschaftstheoretischen Gründen stark kritisierten Kathedersozialisten (der historischen Schule der Nationalökonomie) zu, ${ }^{755}$ sondern betont immer wieder, dass Soziologie in seinen Augen eine theoretische und damit wertfreie Wissenschaft sei. Dabei schreibt Tönnies der Wissenschaft ab einem gewissen Zeitpunkt in der Entwicklung des sozialen Lebens selbst einen Bezug

752 Diese eigentliche Bedeutung der Genossenschaft war ihm nach eigenen Bekunden im Jahr 1887 „noch nicht aufgegangen“ (Tönnies 2012h [1919]: 216, Fn. 105).

753 Insofern wird von Tönnies Gierkes monumentale historische Untersuchung über Das deutsche Genossenschaftsrecht (Gierke 1868-1913) als Darstellung der wichtigsten sozialen Erscheinungsform des Prinzips der Gemeinschaft aufgefasst (Bickel 2003: 119).

754 Dem widerspricht auch nicht, dass Tönnies in einem 1892 anonym veröffentlichten Aufsatz die Ansicht vertritt, dass die geschichtliche Bewegung vom Status zum Kontrakt noch gar nicht zu einem Abschluss gekommen sei und man daher „zunächst die Grundlage unserer heutigen Gesellschaftsordnung, den contractus, in der Weise anerkennen“ müsse, „daß wir alle Bedingungen schaffen, die nötig sind, um ihn zur Wahrheit zu machen“ (Tönnies 2012c [1892]: 77). Denn er richtet sein Plädoyer hier ja gerade auf die Verwirklichung der Gleichheit und damit auf eine Freiheit gegenüber den tradierten Verhältnissen (vgl. ebd.), die letztlich auch Voraussetzung eines ,freien“ sozialen Wollens in Form des gemeinschaftlichen Naturrechts ist.

755 Tönnies war jedoch auch Mitglied im Verein für Socialpolitik, der gemeinhin als Hort der Kathedersozialisten angesehen wird. 
zur Moral zu. Denn im Zuge des Rationalisierungsprozesses verliere die Religion ihren Führungsanspruch, an ihre Stelle trete die rationale Wissenschaft. Während die Religion jedoch „direkt und ihrem Wesen nach moralisch" sei, folge das bei der Wissenschaft aus ihrer neuen Funktion, die Denkungsart anzuleiten: „Wissenschaft erhält erst einen moralischen Inhalt durch Betrachtung der Gesetze des menschlichen Zusammenlebens, indem sie daraus die Regeln für eine willkürliche und vernünftige Ordnung desselben abzuleiten unternimmt.“ (Tönnies 1979 [1887]: 210) Selbst wenn Tönnies also einen streng rationalen Wissenschaftsbegriff vertritt, wonach die Wissenschaft nach objektiver Erkenntnis unter Ausschluss jeglicher Werturteile strebt, erkennt er diesem Wissen einen moralische Wert zu. Er besteht in der Funktion, unser Leben gemäß den wissenschaftlichen Erkenntnissen anzuleiten - und zwar gerade angesichts der Problemlagen der sozialen Frage. ${ }^{756}$

In diesem Sinne erfüllt die Wissenschaft selbst eine ,soziale Aufgabe allerdings nur dann, wenn sie streng wissenschaftlich verfährt. Letzteres wiederum ist im ,gemeinschaftlichen Naturrecht' erkennbar: Indem Tönnies es aus der Konfliktlage zwischen Naturrecht und Historischer Rechtsschule herleitet, wird es ihm nämlich möglich, diese neue Rechtsform rein rational zu begründen. Das gemeinschaftliche Naturrecht erscheint nicht als sozialpolitisches, Gebot der Stunde' oder als ordnungspolitisches Steuerungsinstrument im Sinne einer normativen Vorgabe, sondern als logische Konsequenz der Theorieanlage. ${ }^{757}$ Es ist letztlich dem inhärenten Erkenntnismangel des Naturrechts geschuldet, weil gilt:

Die Grenzen der naturrechtlichen Rechtsphilosophie bestehen darin, dass sie keinen Schlüssel zum Verständnisse der historisch gegebenen Rechtssysteme und ihrer Entwicklung darbietet. Ihre Begriffe sind ausschliesslich individualistisch und gesellschaftlich. Diese Begriffe bedürfen der Ergänzung durch gemeinschaftliche Begriffe, für die das individuelle (subjektive) Recht sekundär ist. (Tönnies 1911b: 571)

756 Seine Ansicht über die Aufgabe der Wissenschaft fällt im Geist der Neuzeit angesichts der Historisierung der Situation etwas differenzierter aus (vgl. Tönnies 1935: 208ff.).

757 Dies war zunächst auch Tönnies' Strategie im Umgang mit dem Sozialismus, versuchte Tönnies doch im Jahr 1887 noch, den Sozialismus als eine rationale Sozialform zu fassen, zu der im Zuge der Rationalisierung übergegangen werde (vgl. Tönnies 1887). Später erscheint ihm jedoch die Frage des Sozialismus als eine politische Wertungsangelegenheit, die somit außerhalb der Soziologie läge (vgl. Tönnies 1926g [1910]: 130,133). 
Mit den Mitteln der Willenstheorie wird im Rahmen der Ergänzung des rationalen Naturrechts eine Synthese mit dem Gemeinschaftsdenken herbeigeführt, die einerseits ,unter dem Begriff einer als gültig anerkannten Vernünftigkeit oder Weisheit' (s.o.) steht, aber andererseits dem Ganzen und nicht dem Individuum verpflichtet ist. Dies lässt sich mithin auch als logische Folge der Freisetzung der Individuen durch das Naturrecht bei gleichzeitiger Einbindung in soziale Ordnungsmuster beschreiben.

Ein derart konstruierter Begriff des gemeinschaftlichen Naturrechts vermag dann an der Synthese der verschiedenen Naturbegriffe im ,natürlichen Rechts' anzuschließen. Daraus lassen sich Folgen für das Verhältnis von Individuum und Gemeinschaft, aber auch von Recht und Moral (Gerechtigkeit) deduzieren. Es sind also nicht Gerechtigkeitserwägungen, die zum Entwurf des gemeinschaftlichen Naturrechts führen, sondern die rationale Arbeit am Begriff des natürlichen Rechts, wie sie bereits in Gemeinschaft und Gesellschaft begonnen wurde. Denn Ansatzpunkt ist jener ,objektive begriffliche Erkenntnisgehalt ${ }^{\star}$ des Naturrechts, nämlich seine Sozialtheorie, und nicht die Frage, was nach naturrechtlichen Kriterien sein soll. Das Gleiche gilt für das Gewohnheitsrecht: Auch hier setzt Tönnies an jener ,aus ihren Verhüllungen zu befreienden soziologischen Rechtsphilosophie‘ und nicht an deren normativen Überlegungen und Grundlegungen an.

Dass sich aus dem Begriff des gemeinschaftlichen Naturrechts dann Folgen für den Gerechtigkeitsbegriff ergeben, resultiert aus dem unauflösbaren Bezug der Rechtsphilosophie zur Gerechtigkeit (s.o.). Das ändert aber nichts daran, dass die Begriffskonstruktionen nach Tönnies auf rein wissenschaftlichem Weg erfolgen und in diesem Sinne wertfrei sind. Es geht ja nicht darum, was sein soll, sondern um die wissenschaftliche Erkenntnis der gesellschaftlichen Entwicklung und die gedankliche Deduktion der daraus resultierenden Möglichkeiten. In den soziologischen Gründen des Naturrechts, die in den Entwurf des gemeinschaftlichen Naturrechts münden, ist nicht nur eine Erneuerung des Naturrechtsdenkens in der Soziologie zu erkennen, ${ }^{758}$ sondern ebenso der Entwurf einer neuen Rechtsphilosophie. Letztlich zeigen sich im gemeinschaftlichen Naturrecht dann die ,soziale Aufgabe' der Wissenschaft Soziologie sowie die ,soziale Aufgabe‘ des Rechts als Ordnungsinstrument vereint.

758 Letztlich besteht die Funktion der Soziologie darin, das Naturrecht als Emanzipationsinstrument ehemals des Bürgertums, jetzt des Proletariats, zu erneuern (vgl. S. Tönnies 1987). 


\section{Tönnies' soziologische Problematisierung des Rechts im Lichte des gesellschaftsfunktionalen Zweckdispositivs}

\section{Die Ablehnung des Repräsentationsgedankens}

Diese eigenwillige Theoriearchitektur, die in Gemeinschaft und Gesellschaft in dem streng wissenschaftlichen Entwurf eines gemeinschaftlichen Rechts (später gemeinschaftlichen Naturrechts) als kritischer Instanz und Ausblick mündet, orientiert sich - wie erwähnt - an dem Konflikt zwischen Naturrecht und Historischer Rechtsschule, wie er im Rahmen des Kodifikationsstreits Anfang des 19. Jahrhunderts virulent wurde.

Auch wenn damit also ein Rekurs auf die Rechtswissenschaften in der ersten Hälfte des 19. Jahrhunderts verbunden ist, mündet Tönnies jedoch keinesfalls in der Problematisierungsweise des Repräsentationsdispositivs. Von Anfang an ist Tönnies' Bezugnahme auf das Gewohnheitsrecht mit einer starken Kritik der Historischen Rechtsschule verbunden (s.o.). Weder erkennt Tönnies den Anspruch der Historischen Rechtsschule an, die einzig gültige Rechtsquellenlehre darzustellen, noch, dass die konstruierten Begriffe die Realität widerspiegelten und man daher über die wissenschaftliche Begriffsanalyse zur treibenden Kraft im Leben vordringen könne (so schon Tönnies 1880a: 2 [pag.]). ${ }^{759}$ Deswegen kritisiert Tönnies auch vehement den Ansatz der Historischen Rechtsschule, die Gesellschaft als „Erfahrungs-Tatsache“ zu verstehen (Tönnies 2012e [1899]: 105). Man könne den naturrechtlichen Begriffen von Gesellschaft (und Staat) nicht den empirischen Standpunkt entgegenhalten. Das verkenne, dass es sich wie etwa beim Naturzustand um eine logische Konstruktion und nicht eine historische Tatsachenbehauptungen handele (vgl. schon Tönnies 1979 [1887]: 177f.). ${ }^{760}$

Die Annahme einer wie immer gearteten Repräsentation der Wirklichkeit im Begriff ist mit Tönnies' Erkenntnis- und Wissenschaftstheorie nicht

759 Wenn Tönnies gleichsam anerkennt, dass in einer organischen Ganzheit „der Begriff selber eine Realität, lebendig, sich verändernd und sich entwickelnd" ist (Tönnies 1979 [1887]: 6), dann steht das im Gegensatz zu der genuin wissenschaftlichen Arbeit mit Begriffen (vgl. ebd.). Selbst wenn nun für das Verständnis des Irrationalismus im organischen Denken der Bezug auf diese Begriffe notwendig ist, dann steht dafür die dogmatische Arbeit der Historischen Rechtsschule mit ihrer Annahme der die lebende Kraft des Rechts widerspiegelnden Begriffe gerade nicht Pate.

760 In historischer Hinsicht (die jedoch für die Begriffskonstruktion nachrangig ist) geht Tönnies von der Vorgängigkeit des gemeinschaftlichen Rechts aus (vgl. Tönnies 1979 [1887]: 176ff.). 
vereinbar. Die Debatten um Missrepräsentationen und Nichtrepräsentierbarkeit des Volkes im Recht liegen ihm fern: Wenn man von Volksrecht versus Juristenrecht sprechen möchte, so handelt es sich nach Tönnies allenfalls um den Gegensatz zwischen Gewohnheitsrecht sowie gesetztem und kodifiziertem Recht (Tönnies, Brief vom 28.12.1889, in Tönnies, Paulsen 1961: 272f.; vgl. a. Tönnies 1931: 209), und nicht um die Frage der Qualifikation des durch die Rechtswissenschaft produzierten Rechtwissens. Und wenn Tönnies dem romanistischen Zweig der Historischen Rechtsschule um Savigny zuschreibt, dass sie die individualisierenden Tendenzen der Gegenwart verstärken (s.o.), so liegt das nicht am ,Geist' des römischen Rechts, sondern daran, dass es als nicht organisch gewachsenes Recht von außen einwirke und dabei an der Persistenz des Naturrechtsdenkens nicht rüttele. Etwaige liberale Absichten erkennt er bei diesen für ihn typischen Vertretern der Restauration nicht.

Schließlich erscheint ihm der Vorwurf der Entzweiung von Recht und Leben widersinnig, erweise sich doch die Auflösung dieses Zusammenhangs als Voraussetzung dafür, dass das Recht seine systematische Vollkommenheit erhält (Tönnies 1979 [1887]: 182). Allerdings sieht Tönnies letzteres im Naturrecht und gerade nicht in der Historischen Rechtsschule verwirklicht, weshalb er keinerlei Notiz von den dogmatischen und methodischen Bemühungen der Historischen Rechtswissenschaft nimmt. Mehr noch, er spricht ihr jegliche wissenschaftliche und damit systematische Intention ab (s.o.).

Daher erkennt er auch keinerlei Rückwirkung der Theorie des Rechts, d.h. insbesondere der Art und Weise, wie die Historische Rechtsschule in der ersten Hälfte des 19. Jahrhunderts das epistemische Ding, Gesellschaft ${ }^{6}$ konzipierte, auf die dogmatische Arbeit. Dass gerade der organische Charakter des Volksgeistes über den Repräsentationsgedanken die systematisierende Arbeit der Dogmatik vorantrieb und hier zu spezifischen Arten der Begriffsbildung führten (konstruktive Jurisprudenz), übergeht er. Rechtssystem und juristische Begriffskonstruktionen erscheinen ihm eindeutig als Produkt des naturrechtlichen Denkens, und wenn man gerade mit Blick auf das subjektive Recht der Historischen Rechtsschule in diesem Bereich eine relevante Leistung zugestehen mag, dann liege dies in dem unbewussten Rekurs auf das Systemdenkens des Naturrechts begründet (s.o.). So etwas wie ein „lebendiges Recht“, zu dessen lebenden Kern man über die Arbeit am System vordringen könnte, gibt es bei Tönnies nicht. Die Problematisierungsweise des Repräsentationsdispositivs, die all diese Fragen eint, liegt Tönnies auf ganzer Linie fern. 


\section{Die Problemlosigkeit der Normativität des Rechts}

Tönnies nimmt aber auch nicht die Problematisierungsweise im normativen Zweckdispositiv auf, auch wenn er explizit Stellung zum Methodenstreit nimmt, und zwar insbesondere zum Freirecht sowie zur Frage der Verhältnisbestimmung von Soziologie und Rechtswissenschaft.

\subsection{Die Kritik am Freirecht}

Dass es Lücken im Gesetz gebe in dem Sinne, als der Richter einen Spielraum in der Interpretation habe, ist für Tönnies zweifellos der Fall. ${ }^{761}$ Aber selbst wenn er die Idee eines Rechts jenseits des Gesetzes vertritt (gemeinschaftliches Recht), so zieht er daraus keine methodischen Konsequenzen für die Rechtswissenschaft. Dieses Recht wird bei Tönnies nicht zur Lückenfüllung herangezogen. Denn letztlich handele es sich bei dem Lückenproblem nicht um ein solches der theoretischen Wissenschaften, sondern um ein normatives, gehe es doch um das Verhältnis von Recht und Moral: So dürfe man „den Zusammenhang der freieren Rechtsprechung und dessen, was die Engländer judge-made law nennen, mit der Idee der Billigkeit und den Zusammenhang dieser Idee mit dem Grundgedanken des Naturrechts nicht übersehen" (Tönnies 1931: 232). Hier mache sich „eine Erhebung der Moral über das Recht“ (ebd.) bemerkbar, der letztlich wissenschaftlich nicht beizukommen sei und die einen normativen Beurteilungsspielraum des Richters begründe. Es handele sich dabei nämlich um „freie Berichtigung des Rechts nach ethischen Beweggründen“ (ebd.: 233), die in der Anwendung des BGBs, das nach Tönnies nach den Grundregeln des rationalen Naturrechts konstruiert wurde, zum Zuge komme (vgl. ebd.).

761 Allerdings erstaunt der Einstieg, den Tönnies für seine Kritik des Freirechts wählt: Er nimmt Bezug auf eine Abhandlung Gierkes aus dem Jahr 1917, in der sich dieser mit Blick auf die Generalklauseln des BGBs allgemeine Gedanken über das Verhältnis von Recht und Sittlichkeit macht. Dabei rekurriert Gierke auf alle Motive des gesellschaftsfunktionalen Zweckdispositivs wie Recht als Ordnungsfaktor, das Verhältnis von Individual- und Sozialrecht, die Abgrenzung von Öffentlichen und Privatrecht etc. (vgl. Gierke 1963 [1917]). V.a. aber sieht Gierke in dieser Frage kein methodisches Problem, so dass der Link zum Methodenstreit zweifelhaft erscheint. Dementsprechend erfolgt - soweit ersichtlich auch keine nennenswerte Bezugnahme in der Debatte auf diese Schrift. 
Diesem richterlichen Spielraum kann man skeptisch gegenüberstehen, so sei etwa mit der Frage der schicht- oder religionsmäßigen Voreingenommenheit des Richters - wie Tönnies in Anspielung auf den Vorwurf der Klassenjustiz schreibt - auch sicherlich „ein schwieriges Problem“ angesprochen (ebd.). Allerdings besteht nach Tönnies das eigentliche Problem in der, sozialen Frage', also eigentlich genau jenem Themenkomplex, der im Methodenstreit zum Vorwurf der mangelnden Lebensanbindung der herrschenden Rechtswissenschaft führte. Unter Verkennung dieser Diskurslage merkt Tönnies daher an:

Die gegenwärtige Rechtslage weist auf einen neuen ganz anders gearteten Widerspruch zwischen dem geltenden Privatrecht und den Ansprüchen einer großen leidenden und nach Billigkeit verlangenden Menge - Ansprüchen, die nur durch eine neue große systematische Gesetzgebung im Sinne einer sozialistisch zu gestaltenden Gesellschaftsordnung befriedigt werden können. (Ebd.: 233)

Dass sich das Freirecht gegen die systematisch-begriffliche Arbeit der nun als Begriffsjurisprudenz in Verruf geratenen Dogmatik der Historischen Rechtsschule richtet, dass mit dem Verweis auf die Lücken im Recht gegen den Anspruch angeschrieben wird, aus dem System des Rechts über die Begriffsarbeit auch für neue Fälle - und zwar insbesondere auch mit Blick auf die soziale Frage - Lösungen konstruieren zu können, lässt Tönnies völlig unbeachtet. Wenn Anfang des 20. Jahrhunderts also im juristischen Diskurs die soziale Frage unter dem Gesichtspunkt der Rechtsfindung und -anwendung problematisiert wird, so hält Tönnies dem entgegen, dass es sich im Grunde um ein gesetzgeberisches Problem handele. Auf der wissenschaftlichen Ebene sei dem nicht beizukommen, gerade weil es Lücken im Recht gebe, die jedoch nach Tönnies durch subjektiv-normative und gerade nicht durch wissenschaftlich-methodisch angeleitete Urteile des Richters gefüllt werden. ${ }^{762}$ Insofern lässt er sich nicht auf die Problematisierungsweise des normativen Zweckdispositivs ein: Die Normativität des

762 Da Tönnies’ Überlegungen zum Recht für ihn keine methodisch-dogmatischen Rückwirkungen zeitigen, bestimmt er letztlich das rechtliche Problem, das aus der sozialen Frage erwächst, als ein gesetzgebungspolitisches. Daher hat auch die Frage der Sozialpolitik wie die des Sozialstaates einen zentralen Stellenwert in seinem Schreiben. 
Rechts oder im Recht wird in seiner Konzeption weder für die Soziologie noch für die Rechtswissenschaft zu einem strategischen Problem. ${ }^{763}$

\subsection{Wissenschaftstheoretische Bestimmungen von Soziologie und Rechtswissenschaft: Jenseits des Konkurrenzproblems}

Das gilt letztlich auch für seine eigentümlichen Stellungnahmen im Streit um die Verhältnisbestimmung von Rechtswissenschaft und Soziologie. Auch für Tönnies ergibt sich in der Begründung der Soziologie als neue, eigenständige Wissenschaft im Kanon der Disziplinen die Notwendigkeit, sie von anderen Disziplinen abzugrenzen. Wenn es um die Bestimmung der Soziologie im System der Wissenschaften (Tönnies 1926f [1915/1916]) geht, so bewegt sich Tönnies mit seiner Orientierung an den Naturwissenschaften jenseits der Debatten um den Unterschied von Kultur- respektive Geisteswissenschaft und Naturwissenschaft. ${ }^{764}$ Er sieht das eigentliche Problem in der Abgrenzung zur Sozialbiologie und zur Sozialpsychologie, die er in ein Stufenverhältnis zur „speziellen Soziologie“ als eigenständige Disziplin setzt (vgl. insbesondere Tönnies 1926f [1915/1916]; 1926c [1925]).

Damit kann Tönnies auch kein Konkurrenzverhältnis zwischen Soziologie und einer wie immer gearteten Wissenschaft des Rechts feststellen und zwar obwohl er im eminenten Maße auf die Rechtsphilosophie rekurriert und im Rechtsverhältnis ein gemeinsamer Gegenstand mit der Rechtswissenschaft zu sehen ist. Das liegt nicht nur daran, dass Tönnies aufgrund seiner Wissenschaftskonzeption der Soziologie keinerlei Überschneidungen mit normativ-dogmatischen Wissenschaften sieht. Der Grund ist vielmehr darin zu suchen, dass ihn die Rechtswissenschaft im engeren Sinne gar nicht interessiert. Dementsprechend nimmt er für seinen grundbegrifflichen Aufbau der Soziologie auch keinen Bezug auf dog-

763 Allenfalls zeigt das Problem der Normativität im richterlichen Urteil die Grenzen der streng rationalen Scheidung von Recht und Moral im Naturrecht (vgl. Tönnies 1931: 232).

764 Trotz seiner Kritik an Rickert (vgl. Tönnies 1901) sei - so Cornelius Bickel - sowohl eine Nähe zum Neukantianismus (vgl. Bickel 1991: 115ff.) als auch zu Diltheys Konzeption der Geisteswissenschaft erkennbar (vgl. ebd.: 259ff.). Allerdings distanziert Tönnies seine entwicklungsgeschichtlichen Thesen nachhaltig von der Geschichtswissenschaft - sie sei „keine Wissenschaft für sich. Die Geschichtsschreibung ist eine tiefsinnige Kunst, auch wenn sie auf der auf [sic!] Erforschung der Wahrheit beruht, die in wissenschaftlichem Geiste geschehen muß.“ (Tönnies 2012f [1907]: 128, H.i.O.). 
matische oder methodische Arbeiten. So stützt er etwa nach eigenen Bekunden seine Interpretation der Historischen Rechtsschule „vorzugsweise“ auf Savignys Beruf (Tönnies 2012k [posthum]: 257). Darin erscheint sie ihm wesentlich anti-rationalistisch (s.o.). Von den systematisch-logischen Bemühungen der Begriffsbildung in der Historischen Rechtsschule, die sich zudem etwa bei Puchta an der rationalen Handhabung eines lebendigen Gegenstandes und etwa bei Jhering an einer Naturlehre des Rechts abarbeiten, was letztlich große Überschneidungen mit Tönnies' Problemstellungen impliziert, nimmt er keinerlei Notiz.

Aber selbst wenn Tönnies die begrifflichen Bemühungen der juristischen Dogmatik anerkennen würde, dann wäre die Jurisprudenz in seinen Augen keine ,freie Wissenschaft“, d.h. Wissenschaft im eigentlichen Sinne, da sie „an Herkommen und Volksglauben, oft auch an Konvention und Gesetzgebung, bisher regelmäßig gebunden“ erscheint (Tönnies 1906 [1897]: 30, H.i.O.). Daher sei die selbständige begriffliche Arbeit nicht möglich. Wenn überhaupt schreibt Tönnies dem Naturrecht als „reine Rechtswissenschaft“ (Tönnies 1979 [1887]: XXII) eine solche konsequente Arbeit mit den Begriffen zu, die mit der Geometrie vergleichbar die Wirklichkeit an den ideellen Typen misst und dadurch die formale Konsequenzen der sozialen Verhältnisse durch Willensverbindungen entfaltet (vgl. ebd.; Tönnies 20121 [1932]: 276). Wissenschaftscharakter im strengen Sinne kommt im Rahmen der Rechtswissenschaften dementsprechend nur dem Naturrecht zu.

Diese Argumentation verdeutlicht einmal mehr: Worauf Tönnies sich beschränkt, ist die zugrundeliegende Rechtstheorie respektive -philosophie. Das ganze Problem der Rechtswissenschaft oder der juristischen Begriffsbildung wird bei ihm zugunsten der Rechtsquellenlehre vernachlässigt. Dogmatik und Methodik interessieren ihn nicht. „Die Rechtsphilosophie" ist aber in seinen Augen

ihrem Wesen nach ein Teil der reinen oder theoretischen Soziologie, insofern als die Rechtsphilosophie die Wirklichkeiten des Rechts begreifen will. Sie liegt aber ausserhalb der Soziologie, insofern als sie Normen des richtigen oder guten oder zweckmässigen oder gerechten Rechtes aufzustellen unternimmt. (Tönnies 1911b: 570, H.i.O.) ${ }^{765}$

765 Im Kontext dieser Debatte um die Verhältnisbestimmung von Soziologie und Rechtswissenschaft ist auch verständlich, warum sich Tönnies mit einem Vortrag über Das Wesen der Soziologie im Jahr 1906 namentlich an die Juristen wendet (so Jacoby 1971: 114). 
Nicht Rechtsphilosophie (als Basis der Rechtswissenschaft) und Soziologie werden abgegrenzt, sondern diejenigen Teile der Rechtsphilosophie, die der Soziologie zuzuschlagen sind, von denjenigen, die sich der normativen Seite des Rechts widmen. Und da ein Teil der Rechtsphilosophie Soziologie sei, macht Tönnies „geltend, daß alle juristischen Begriffe, sofern sie allgemeine und notwendige Gültigkeit in Anspruch nehmen, in soziologischen Begriffen beruhen müssen“" (Tönnies 1926h [1923]: 349). ${ }^{766}$ Damit verschiebt Tönnies das Problem der Verhältnisbestimmung von Seins- und Sollenswissenschaft in die Rechtsphilosophie selbst, diese wird letztlich als eine doppeldeutige Wissenschaft konzipiert. Die Abgrenzungsschwierigkeiten von Sein und Sollen werden zu einem rechtsphilosophie-internem Problem. Für diejenigen rechtsphilosophischen Teile wiederum, die der Seins-Betrachtung unterfallen, wird die Soziologie zur Leitdisziplin. ${ }^{767} \mathrm{Ja}$ letztlich „bedürfen“ sowohl die Rechtspflege als auch das ganze Gebiet der „sittlichen Volksleitung“ solcher Wissenschaft (Tönnies in Kohler et al. 1910: 221).

Wenn sich Tönnies also explizit in die Debatten um das Verhältnis von Soziologie und Rechtswissenschaft einschaltet (vgl. Tönnies in Kohler et al. 1910: 220ff.; Tönnies 1911b), dann nimmt er eine Position ein, die gegenüber der juristischen Diskurslage gleichsam verschoben ist: Man kann bei ihm ein Plädoyer für eine (teilweise) Soziologisierung der Rechtswissenschaft erkennen, insofern die Theorie des Rechts theoretische Soziologie darstellt. Damit gilt die Soziologie als Leitdisziplin für die seinswissenschaftlichen Anteile der Rechtsphilosophie (und damit der -wissenschaft). Die Normativität des Rechts und die Abgrenzung zu normativer Wissenschaft des Rechts ist bei ihm aber kein Problem der Soziologie, auch kein Problem der Abgrenzung der Disziplinen, sondern ein rechtswissenschaftsinternes. Wie genau man das dann im Binnenraum der Rechtswissenschaft abgrenzen müsste, interessiert Tönnies ebenso wenig wie letztlich die wis-

766 Das gilt insbesondere für den Staatsbegriff, wie er von Hobbes entwickelt wurde. Nach Tönnies stellt das Hobbes'sche Theorem ein soziologisches Theorem dar, da „diese Konstruktion des Leviathan, als des in die Luft des Gedankens gebauten Willensungetüms, allgemeine und notwendige, also abstrakt wissenschaftliche Geltung in Anspruch nimmt. Wenn die Jurisprudenz als Lehre des Allgemeinen Staatsrechts dieselbe Geltung in Anspruch nimmt, so ist sie eben eine soziologische Lehre.“ (Tönnies 1926h [1923]: 349f.).

767 Wenn die Rechtswissenschaft sich dabei auf das empirische Material bezieht, arbeitet sie als vergleichende Rechtswissenschaft, auf die Tönnies immer wieder Bezug nimmt (vgl. Tönnies in Kohler et al. 1910: 222 u.ö.). Daher rührt auch sein immer wieder bekundetes Interesse an den rechtsethnologischen und rechtsvergleichenden Arbeiten. 
senschaftstheoretische Bestimmung der Rechtswissenschaft. Der Einsatz der Normativität erfolgt in dieser Perspektive nicht zur Sicherung der Autonomie der Rechtswissenschaft (und ebenso wenig der Rechtsphilosophie), und auch nicht als Abgrenzungshorizont zur erkenntnis- und wissenschaftstheoretischen Bestimmung der Soziologie. Er markiert vielmehr denjenigen Teil der Rechtswissenschaft, der nicht der Soziologie unterfällt, da er auf einen normativen Überschuss des Gegenstands Recht verweist, der keinerlei wissenschaftstheoretische oder methodische Probleme bereitet.

\section{Tönnies und die Problematisierungsweise des gesellschaftsfunktionalen Zweckdispositivs}

Wenn Tönnies in der Bestimmung des Verhältnisses von Recht und Gesellschaft (respektive Soziologie) weder die Problematisierungsweise des Repräsentations- noch die des normativen Zweckdispositivs aufgreift, so lassen sich doch deutliche Kongruenzen zum epistemischen Schema des gesellschaftsfunktionalen Zweckdispositivs aufzeigen.

Auch bei Tönnies wird Recht über seine Ordnungsfunktion problematisiert, auch bei ihm geht es um die Frage des Verhältnisses von Individuum und Gemeinschaft bzw. Gesellschaft. Angesichts der zeitgenössischen gesellschaftlichen Verhältnisse, namentlich der sozialen Frage, erweist sich für Tönnies der Bezug auf eine harmonische bzw. einheitliche Sozialsphäre, wie sie die Gemeinschaft kennzeichnet, als geschichtlich überholt. Dementsprechend ist auch für ihn das Recht nicht mehr Selbstzweck, sondern Mittel zur Aufrechterhaltung der gesellschaftlichen Ordnung. Wenn also damit die soziale Ordnung in den Vordergrund rückt, wird sie gerade nicht unter dem Blickwinkel der Normativität, sondern streng wissenschaftlich unter dem der Objektivität und der Wahrheit untersucht. Rechtsprobleme sind sowohl im gesellschaftsfunktionalen Zweckdispositiv als auch für Tönnies nicht normativ, sondern objektiv zu beantworten. ${ }^{768}$

Da das Recht auf die soziale Ordnung bezogen wird, besteht auch bei Tönnies ein Konnex zwischen Rechtstheorie und Gesellschaftstheorie

768 Gerade weil das epistemische Dispositiv der Rechtswissenschaften im 19. Jahrhundert noch als Wahrheitsdiskurs funktioniert, wird der These Neill Bonds widersprochen, dass bei Tönnies „the displacement of normative discourse from legal theory to empirical sociology“ zu erkennen sei (Bond 2011b). 
(bzw. mit Blick auf die differenten Sozialformen neutral formuliert: soziologischer Theorie). Aus genau diesem Grund können Naturrecht und Historische Rechtsschule zur Herleitung der soziologischen Grundbegriffe dienen. In den Rechtswissenschaften wurde die Debatte über die der Gegenwart angemessenen Gesellschaftstheorie jedoch in eine rechtswissenschaftsinterne Rechtsgebietsfrage umgedeutet (Privatrecht versus Öffentliches Recht). Damit erscheint der Privatrechtswissenschaftler als eigentlicher Sachverständiger für die gesellschaftliche Ordnung. Demgegenüber muss man nach Tönnies den ,objektiven begrifflichen Erkenntnisgehalt ${ }^{\text {‘ }}$ der Rechtsphilosophien respektive Rechtsquellenlehren extrahieren, um durch genuin soziologische Begriffsarbeit die Ordnungsmuster in ihrer Entwicklung ermitteln und verstehen zu können. Nicht der Jurist, sondern der Soziologe wird zur leitenden Figur einer solchen Sozial- und Rechtsphilosophie - so wie die Soziologie zur Leitdisziplin der seinswissenschaftlichen Anteile der Rechtswissenschaft wird. ${ }^{769}$

Gerade weil die Ordnungsleistung und damit die soziale Steuerungsfunktion des Rechts in den Blick genommen wird, steht zur Debatte, welches Recht den gegenwärtigen gesellschaftlichen Problemlagen angemessen ist. Dabei bewegt sich Tönnies mit dem Entwurf des gemeinschaftlichen Naturrechts in ähnlichen Bahnen wie manche Kritiker des BGBs: Auch er will die Konzeption eines individualistischen Rechts, das durch die Trennung von Recht und Pflicht (im subjektiven Recht) das Individuum freisetzt, zugunsten einer Orientierung an der Gemeinschaft überwinden. Damit komme jedem Recht eine soziale Aufgabe zu. Insbesondere will Tönnies wie Gierke mit seinem Sozialrecht Recht und Pflicht zusammendenken, wobei die Pflicht sich auf die Gemeinschaft beziehe. Individuelle Freiheit stehe dann unter dem Vorbehalt der Gemeinwohlorientierung.

Tönnies selbst verweist an verschiedenen Stellen auf diesen Zusammenhang seines soziologischen Denkens mit dem gesellschaftsfunktionalen Zweckdispositiv, wenn er immer wieder auf die Kodifikation des BGBs und hier insbesondere Gierkes Kritik - zu sprechen kommt (vgl. etwa Tönnies 2012d [1895]: 79f.; 1926a: 7ff.; 1931: 227ff.). ${ }^{770}$ Dabei scheint nach

769 Dass damit bei Tönnies kein Angriff auf die Rechtsdogmatik und -methodik verbunden ist, liegt aber nicht daran, dass er - wie das gesellschaftsfunktionale Zweckdispositiv - deren Eigenart und Eigenständigkeit anerkennt, sondern vielmehr daran, dass er den Wissenschaftscharakter der Jurisprudenz letztlich bestreitet und dementsprechend die spezifisch rechtswissenschaftlichen Techniken gar nicht in den Blick nimmt.

770 Zu Tönnies' Rekurs auf Gierke vgl. insbesondere Bond 2011b: Rn. $21 \mathrm{ff}$. 
Tönnies im Rückblick die Kodifikation des Zivilrechts de facto eine Bestandsaufnahme gewesen zu sein, habe sich doch im BGB „eben der bestehende und sich immer mehr verfestigende Zustand der heutigen Gesellschaft durch ihren Staat gleichsam ihre Natürlichkeit und Notwendigkeit als gesetzliche Rechtsordnung bestätigen und beglaubigen lassen" (Tönnies 1931: 226). Wenn nun Gierke seine Kritik gegen den individualistischen und formalistisch-naturrechtlichen Charakter des BGBs richtet, so stimmt Tönnies mit diesem darin überein, dass dies Folge der Rezeption des römischen Rechts sei (Tönnies 2012d [1895]: 79f.). Denn das römische Recht erweist sich auch in Tönnies Augen nicht als ,organisch', sondern letztlich als individualistisch (s.o.). Ihm zufolge ruhe das gesamte zeitgenössische Recht, wie auch das spätere römische Recht, auf den Fundamenten des individualistisch-rationalistischen Naturrechts: „Es ist, wie dieses, durchaus individualistisch gedacht. Freiheit und Gleichheit aller Rechtssubjekte sind dort wie hier die Voraussetzungen.“ (Tönnies 1925 [19051911]: 184 $)^{771}$

Allerdings stimmt Tönnies nicht der These zu, dass man den Problemen einer zunehmenden Freisetzung des Individuums, d.h. der sozialen Frage, über die Wahl des richtigen Rechtskorpus beikommen könne. Zwar habe das individualistische römische Recht zur Entwicklung des Kapitalismus und den damit einhergehenden Herrschaftsstrukturen ${ }^{772}$ sowie zur Auflösung der gemeinschaftlichen Verhältnisse beigetragen. ${ }^{773}$ Das liege aber nicht im Rechtskorpus selbst begründet: „Es ist allerdings falsch, das römische Recht als eine Ursache oder Potenz zu betrachten, welche diese ganze Entwicklung bewirkt habe.“ (Tönnies 1979 [1887]: 183) Es sei dazu nur ein brauchbares Werkzeug gewesen, dass zudem oft nur unbewusst ergriffen

771 Selbst wenn das BGB keine unveräußerlichen Menschenrechte statuiere, seien sie nach Tönnies doch darin enthalten (vgl. Tönnies 1925 [1905-1911]: 184).

772 Dies liegt zum großen Teil am rationalen Charakter, den Tönnies dem römischen Recht zuschreibt. So stellt er bereits im Jahr 1887 fest: „Als wissenschaftlich erforschtes System, von großer Klarheit, Einfachheit und logischer Konsequenz, schien es die ,geschriebene Vernunft' selber zu sein. Diese Vernunft war allen Vermögenden und Mächtigen günstig, um ihr Vermögen und ihre Macht absolut zu machen [...].“ (Tönnies 1979 [1887]: 182f.).

773 So gilt für Tönnies: „Hingegen hat mit entschiedener Tendenz das römische Recht zur Auflösung aller Gemeinschaften, welche der Konstruktion des Privatrechts aus handlungsfähigen Individuen entgegen sind, mitgewirkt. Gemeinschaftliches und gebundenes Eigentum ist für die rationale Theorie ein Unding, eine Anomalie. Der Satz, dass Niemand wider seinen Willen in Gemeinschaft festgehalten werden kann (Nemo in communione potest invitus detineri), schneidet dem Rechte der Gemeinschaft die Wurzel ab.“ (Tönnies 1979 [1887]: 183). 
wurde, war aber an sich für den kapitalistischen Fortschritt - wie die Entwicklung in England zeige - auch nicht vonnöten. Daher sei es auch falsch, dem Problem durch den Rückgriff auf das germanische Recht zu begegnen. Das bedeute einen unzulässigen Rückfall in ein Gemeinschaftsdenken, dass dem Traditionalismus und Irrationalismus verhaftet sei. So zeige sich etwa bei Gierkes germanistischer Kritik des BGBs, dass auf normativer Ebene die naturrechtlichen Errungenschaften der Freiheit und Gleichheit zugunsten einer Refeudalisierung der sozialen Verhältnisse in Gefahr geraten (vgl. Tönnies 1931: 229). Angesichts der sozialen Frage müsse man vielmehr versuchen, die Probleme der Gesellschaft durch eine Synthese ihrer immanenten Widersprüche zu überwinden. Und genau diese Funktion erfüllt das gemeinschaftliche Naturrecht.

Wenn nun in der Privatrechtswissenschaft im gesellschaftsfunktionalen Zweckdispositiv das epistemische Ding ,Gesellschaft' zwar den Rahmen der Argumentation bildet, indem es zum Maßstab der Güte des Entwurfs wird, aber gerade nicht das Bezugsobjekt der wissenschaftlichen Untersuchung darstellt, rückt es demgegenüber bei Tönnies in den Mittelpunkt. Das letztlich in Gesellschaft und Gemeinschaft verdoppelte epistemische Ding wird zwar über den Willen in der geistigen Sphäre der Individuen fundiert, was zu einem methodologischen Individualismus führt. Gleichsam wird es nun in Form von theoretischen Grundbegriffen zum Ausgangspunkt der soziologischen Erkenntnis. Da aber eine solche soziologische Erkenntnis immer auch eine Rechtsphilosophie impliziert, dient die genuin soziologische Arbeit an den Fragen der sozialen Verhältnisse und Verbindungen dem Entwurf einer Rechtsphilosophie, die auf die Probleme der gegenwärtigen gesellschaftlichen Lage eine wissenschaftliche Antwort zu geben vermag. In diesem Sinne kann man Tönnies Entwurf der Soziologie, wie er schon in Gemeinschaft und Gesellschaft angelegt ist, als Kehrseite des gesellschaftsfunktionalen Zweckdispositivs der Privatrechtswissenschaft ansehen, wird doch beim ihm nicht das Recht über die Gesellschaft problematisiert (,soziale Aufgabe' des BGBs), sondern nun die Sozialform Gesellschaft durch das Recht (gemeinschaftliches Naturrecht).

Tönnies' Entwurf der Soziologie in seinem Hauptwerk Gemeinschaft und Gesellschaft beruht in grundlegender Weise auf der Auseinandersetzung mit dem Recht, namentlich auf der Herleitung der Soziologie aus der Rechtsphilosophie. Das betrifft nicht nur die Entwicklung seiner theorieleitenden Grundbegriffe aus der Denkungsart der Historischen Rechtsschule und des rationalen Naturrechts, sondern ebenso die argumentative Architektonik in Gemeinschaft und Gesellschaft. Erfolgt im „Ersten Buch“ die allgemeine Bestimmung der Hauptbegriffe entlang der beiden Denkungsarten, werden im „Zweiten Buch“ entsprechend der sachlichen Fun- 
dierung der sozialen Verhältnisse in den Rechtsverhältnissen die beiden jeweils konstitutiven Willensformen expliziert. Da Tönnies das Verhältnis der beiden Sozialformen über die Konkurrenz zwischen Historischer Rechtsschule und Naturrechtsdenken im Kodifikationsstreit Anfang des 19. Jahrhunderts problematisiert, nimmt er den Streit um Daseinsberechtigung und Reichweite dieser beiden Rechtsquellenlehren zum Ausgangspunkt. Angesichts dessen versucht er im „Dritten Buch“ eine Synthese, indem er nämlich die soziologischen Gründe des Naturrechts bestimmt, die die Soziologie in die begriffliche Konstruktion eines gemeinschaftlichen Naturrechts münden lässt.

Diese begriffliche und theoriearchitektonische Fundierung der Soziologie in den Rechtswissenschaften basiert auf Tönnies' Annahme, dass eine Rechtsphilosophie respektive eine Rechtstheorie immer eine Sozialphilosophie enthält. Vice versa mündet der Entwurf einer soziologischen Theorie in dem Entwurf einer Rechtstheorie - so wie sich aus der Bestimmung des Natürlichen im Recht das gemeinschaftliche Naturrecht begrifflich konstruieren lässt. Auch wenn es sich dabei um eine logischen Konsequenz der Theorieanlage handelt, liegt hierin die soziale Aufgabe der Soziologie begründet, besteht doch im Naturrecht in egal welcher Form immer ein Bezug zu den Fragen der Gerechtigkeit.

Wenn aber der Entwurf einer soziologischen Theorie immer auch eine Rechtstheorie hervorbringt, dann erscheint es offensichtlich, dass man diesen Entwurf immer auch in Bezug zum rechtlichen Diskurs verstehen muss. Dabei zeigt sich, dass Tönnies zwar auf den Kodifikationsstreit Anfang des 19. Jahrhunderts rekurriert, jedoch die Problematisierungsweise des Repräsentationsdispositivs über sein Wissenschaftsverständnis ablehnt. Naturrecht und Historische Rechtsschule widersprechen sich in seinen Augen nicht, sondern bringen jeweils verschiedene Sozialformen zum Ausdruck. Sie stehen gleichberechtig nebeneinander, und in dieser Annahme besteht auch nach Tönnies' Bekunden sein eigentlicher theoretischer Einsatz: „Meine Darstellung ist neu, in welcher ich sie nebeneinander stelle, ohne die eine als falsch zu bezeichnen und für die andere ein ausschließliches Recht in Anspruch zu nehmen.“ (Tönnies 2012e [1899]: 106) Selbst wenn Tönnies also auf das Problem der Bestimmung der Rechtsquelle Bezug nimmt, bewegt er sich jenseits der Fragen des Repräsentationsdispositivs. Denn er problematisiert demgegenüber die verschiedenen Rechtsquellen mit Blick auf ihre Ordnungsleistung. Daher lassen sich seine Überlegungen in das gesellschaftsfunktionale Zweckdispositiv einbetten. V.a. zeigt sich dann - in Umkehrung der juristischen Perspektive - Soziologie als Rechtstheorie, und der Soziologe wird zum eigentlichen Rechtstheoretiker. 


\section{Die Anschlussschwierigkeiten an Tönnies' soziologischer Adressierung des Rechts}

Im Ergebnis erweist sich aber Tönnies' spezifische Verankerung der Soziologie in den Rechtswissenschaften über die Problematik der Rechtsquellenlehre jedoch wenig anschlussfähig. Das gilt zum einen für die Rechtswissenschaft im engeren Sinne, da Tönnies den Bereich der Dogmatik und Methodik ausklammert und lediglich Interesse für die sozialtheoretischen Implikationen der zugrundeliegenden Theorie des Rechts zeigt. Zum anderen wurde Anfang des 20. Jahrhunderts im Methodenstreit in der Rechtswissenschaft mit der Hinwendung zur erkenntnis- und wissenschaftstheoretischen Ebene das Rechtsquellenproblem letztlich ad acta gelegt. Wenn Tönnies also darauf beharrt, das Problem des Rechts in der Verhältnisbestimmung der Rechtsquellen Gewohnheitsrecht und Naturrecht zu verorten, dann bewegt er sich damit in Problemfeldern jenseits des normativen Zweckdispositivs.

Das gilt v.a. auch vor dem Hintergrund, dass die Privatrechtswissenschaft im 19. Jahrhundert noch als Wahrheitsdiskurse funktioniert. Die Normativität des Rechts stellt noch kein strategisches Problem für die wissenschaftliche Behandlung des Rechts dar, sie wird als Faktum angesehen, das nur als solches methodische wie wissenschaftstheoretische Folgen zeitigt. Genau das wird aber im normativen Zweckdispositiv in Frage gestellt und führt letztlich sowohl zur Normativierung des juristischen Selbstverständnisses als auch der juristischen Methoden. Demgegenüber bleibt Tönnies in seiner Art und Weise der Problematisierung des Rechts der Wahrheitsorientierung des juristischen Diskurses im 19. Jahrhundert verpflichtet. Das hat zur Folge, dass Tönnies aus seinen rechtstheoretischen Überlegungen keine Rückschlüsse für die dann Anfang des 20. Jahrhunderts einsetzende juristische Methodendebatte zieht, bzw. vice versa er diese neuen juristischen Problemlagen überhaupt als solche der Wissenschaft anerkennt.

Aufgrund dieser Distanz zu den zeitgenössischen Problematisierungsweisen im Recht ist es auch nicht verwunderlich, dass Tönnies' Begründung eines neuen gemeinschaftlichen Naturrechts keine Überzeugungskraft entfaltet. Das sticht insofern ins Auge, wird doch auch im juristischen Methodenstreit das ,Naturrecht in veränderter Gestalt ${ }^{`}$ bzw. das ,natürliche Recht' in Anschlag gebracht, um dem Problem der Lückenhaftigkeit des Gesetzes zu begegnen (s.o. \5). Bei Tönnies jedoch fungiert das Natürliche im Recht aber gerade nicht zur Bestimmung eines wie immer auch gearteten tatsächlich gelebten Rechts, dass dem Gesetz gegenüberstehe und daher als Grundlage der Lückenfüllung im Gesetz dienen 
könnte. Für ihn lässt sich anhand des ,Natürlichen im Recht' vielmehr die Frage klären, auf welche ,Natur der Sache' sich sowohl im Falle des dem Gemeinschaftsleben entspringenden Gewohnheitsrechtes als auch des naturrechtlich gewillkürten Gesetzesrechtes bezogen wird: nämlich natürliches Zusammenleben oder menschliche Vernunft. Wozu es aber gerade nicht dient, ist eine Anbindung des Gesetzes ans Leben über das tatsächlich gelebte Recht zu verwirklichen. Das gemeinschaftliche Naturrecht wiederum stellt demgegenüber eine rationale synthetische Konstruktion dar, die keinerlei juristisch-methodische Wirkung entfaltet, sondern einen Wandel im normativen Maßstab bewirkt. Letzteres ist aber nach Tönnies gerade keine juristisch-technische Frage.

Zudem stellt Tönnies - wie seine Ausführungen zum Verhältnis von Soziologie und Rechtsphilosophie zeigen - die Rechtswissenschaft (zumindest zum Teil) unter die Ägide der theoretischen Soziologie (s.o.). Dabei ist vielen Juristen mit ihren diffusen Soziologiebegriffen das Konzept der theoretischen „reinen Soziologie“ fremd geblieben, wurde doch in den innerjuristischen Debatten der Auseinandersetzung mit der sich etablierenden Fachdisziplin Soziologie ausgewichen (s.o. $\$ 5 . I V .2) .774$ Darüber hinaus aber ist in Tönnies Konzeption des, gemeinschaftlichen Naturrechts ${ }^{6}$ letztlich ein Angriff auf die Autonomie der Rechtswissenschaft gerade im Namen der Konkurrenzdisziplin Soziologie zu sehen. Daher erstaunt es nicht, wenn von Seiten der Privatrechtswissenschaftler selten Bezug auf Tönnies genommen wird, ${ }^{775}$ obwohl er sich sowohl in die Diskussionen

774 Deutlich wird dies etwa in der Besprechung von Tönnies' Beitrag in der Schwerpunktausgabe zur Methodenreformbewegung der Zeitschrift Die Tat aus dem Jahr 1914/15, wenn der Rezensent Pagel schreibt: „Freilich ist eine ,reine‘ Soziologie, wie sie von Tönnies u.a. vertreten wird, für den, der eine Theorie des Rechts schaffen will, nur auf rechtsphilosophischer Basis möglich; nicht darf umgekehrt das Recht aus soziologischen Bestimmungen abgeleitet werden, sofern man die Begriffe Recht und Gemeinschaft in ihrer logischen und eben darum ethischen Grundfunktion zu durchschauen unternimmt." (Pagel 1919: 547).

$775 \mathrm{Zu}$ den Ausnahmen, die positiven Bezug auf Tönnies nehmen, gehört etwa Radbruch (vgl. Bond 2011b: RN 3 m.N.). Auch kann man Tönnies in den staatsrechtlichen Debatten durchaus eine Wirkung zuschreiben. So bezieht sich etwa Jellinek an verschiedenen Stellen in seiner Allgemeinen Staatslehre positiv auf Tönnies, und auch Carl Schmitt zitiert ihn immer mit Respekt (s. Breuer 2012: 85 ff. m.N.). Kelsen wiederum äußert sich bereits sehr früh negativ über Tönnies (s.o.). Auch für die Frage des Sozialstaates erweist sich der Ansatz Tönnies' durchaus als anschlussfähig, wie etwa Hellers Ausführungen zum sozialen Rechtsstaat zeigen (vgl. hierzu Brödel 1990). Mit dieser Rezeption wird aber die 
über das BGB als auch in die laufenden Debatten des Methodenstreits einschaltete.

Auch in der Soziologie fand die Idee des gemeinschaftlichen Naturrechts keine Weiterführung. Dass ist insofern erwähnenswert, als die Auseinandersetzung mit dem Naturrecht in der Konsolidierungsphase der Soziologie als eigenständige Disziplin durchaus für nötig befunden wurde (vgl. Chernilo 2013). ${ }^{776}$ Dabei wird das soziologische Denken häufig aus einer Naturrechtskritik hergeleitet (etwa Achelis 1908: 37; vgl. Marcucci 2017), habe es sich doch als „Naturlehre der menschlichen Gesellschaft“ explizit von der Naturrechtslehre abgesetzt (vgl. Sombart 1923: 6f.). Soziologie sei als „Oppositionswissenschaft“ zum Naturrechtsdenken anzusehen (Brinkmann 1919: 16). Aus dieser Perspektive erweist sich Tönnies’ Ansatz gerade nicht anschlussfähig, macht er doch geltend, dass die Soziologie als Wissenschaft dem Naturrecht entspringe.

Aber es gibt auch Vertreter der Annahme, dass man das Naturrecht als Suche nach allgemeinen Gesetzen des menschlichen Zusammenlebens verstehen müsse und man dort die Vorläufer der modernen Soziologie zu suchen habe. Dies wird sowohl von juristischer (vgl. Menzel 1912; s. etwa a. Ofner 1894: 4; Ehrlich 1989: 25f., 1966: $314 f$ f. $)^{777}$ wie von soziologischer Seite (etwa Barth 1897: 116ff. bzgl. Spencer) vertreten. Allerdings sticht Tönnies' Ansatz insofern heraus, als die Soziologie bei ihm selbst eine (neue) Form des Naturrechtsdenkens entwirft. Ihm geht es nicht um die Genealogie des soziologischen Denkens, das sich im Fortgang von seinen Ursprüngen löst, sondern um die Fortschreibung dieser Grundlage Natur-

Problematisierungsweise des Rechts gewechselt (zu Tönnies Position in den staatswissenschaftlichen und philosophischen Debatten um Verfassung, Demokratie und Liberalismus, vgl. Carstens 2014a; Schlüter-Knauer 2014 v.a. mit Blick auf Schmitt und Kelsen; zur Rezeption des Gemeinschaftsgedankens in den staatsrechtlichen Debatten vgl. Lepsius 1994: 51ff.).

776 So wurde etwa Ernst Troelsch zu einem Vortrag auf den ersten Soziologentag im Jahr 1910 über „Das stoisch-christliche Naturrecht und das moderne profane Naturrecht" eingeladen (Troeltsch 1911). Die Frage, inwiefern Soziologie und Naturrecht zusammenhängen, wurde auch anlässlich des Vortrags "Naturrecht" von Rudolf Goldscheid am fünften Deutschen Soziologentag ausführlich diskutiert (vgl. Menzel et al. 1927).

777 Auch Kelsen stimmt der Herleitung der Soziologie aus dem Naturrecht zu, er nimmt dies jedoch als Ausgangspunkt der Kritik der Soziologie, führe diese damit doch die Probleme des Naturrechts fort (vgl. Kelsen 1981: 46ff.). 
recht durch das gemeinschaftliche Naturrecht. Damit konnte er aber nicht überzeugen. ${ }^{778}$

Gerade weil es eine Kluft zwischen Tönnies' Konzeption des Rechts und dem juristischen Diskurs seiner Zeit gibt, kappt er durch die Fundierung der Soziologie in den rechtstheoretischen Kontroversen des 19. Jahrhunderts schließlich auch den Weg der Soziologie in die Rechtswissenschaft. Letztere erweist sich für die soziologischen Analysen nicht mehr anschlussfähig. Denn wenn man Tönnies in seinem Vorgehen folgt, wird man von jeglichen Entwicklungen in der Rechtswissenschaft abgeschnitten. Demgegenüber wird man in der Verhältnisbestimmung von Recht und Soziologie auf die Konfliktlage zwischen Gewohnheitsrecht und Naturrecht Anfang des 19. Jahrhunderts festgeschrieben. Daraus mag man - in Ablehnung des Repräsentationsgedankens - zwar zu den Problemlagen des gesellschaftsfunktionalen Zweckdispositivs gelangen. Aber dabei bleibt man dann zwangsläufig stehen. Andere grundbegriffliche Impulse werden aus der Rechtstheorie nicht mehr kommen, schon gar nicht mit Blick auf die Frage der Normativität des Rechts.

Darüber hinaus rührt diese Erstarrung des Verhältnisses von Rechtswissenschaft und Soziologie auch daher, dass Tönnies die dogmatisch-methodische Ebene gänzlich außen vor lässt und ihm damit die Effekte der unterschiedlichen Konzeptionen für das Recht verborgen bleiben. So spricht er etwa trotz Anerkennung der Spielräume des richterlichen Entscheidungsverhaltens dem Freirecht keinerlei Relevanz zu, obwohl es mit ihr um tiefgreifende methodische und wissenschaftstheoretische Fragen geht, die die Stellung der Soziologie im Kanon der Wissenschaften nicht unberührt lassen.

Diese mangelnde Anschlussfähigkeit an die rechtlichen und rechtwissenschaftlichen Entwicklungen zeigt sich ja auch bei Tönnies selbst: Zwar beschäftigt er sich mit den juristischen Debatten seiner Zeit, d.h. mit der Diskussion um das BGB sowie dem juristischen Methodenstreit. Das führt aber zu keinerlei Neuorientierung seiner theoretischen oder grundbegrifflichen Anlage der Soziologie. Letztlich subsumiert er all dies unter den grundbegrifflichen Gegensatz gemeinschaftliches Gewohnheitsrecht/ gesellschaftliches Gesetzesrecht. Irgendeinen Wandel im Rechtsdenken in der Hinwendung zum Zweckdenken des Rechts kann er damit nicht erkennen. Weder eine Änderung in den zugrundeliegenden Konfliktlagen

778 Dieses Fortschreiben der Aufklärungsphilosophie markiert zugleich die Distanz zu den lebensphilosophischen, phänomenologischen und kulturwissenschaftlichen Ansätzen seiner Zeit. 
(l'urgence), noch die differenten Streitpunkte (Problematisierungen), vermögen seiner Theorie neue Impulse zu geben. Und ganz grundlegende rechtstheoretische Veränderungen finden in seiner Theorieanlage letztlich keinen Platz. So nimmt er weder wahr, dass sich das naturwissenschaftliche Denken sehr wohl auch auf die Theorie des Rechts auswirkte, was nicht zuletzt Jherings früheren Entwurf einer, Naturlehre des Rechts führte. ${ }^{779}$ Allenfalls sieht er in Jhering einen Erneuerer des Naturrechts, aber auch hier richtet sich die Idee eines neuen, später als gemeinschaftlich bestimmten Naturrechts an der Konfrontation von Gewohnheitsrecht und rationaler Gesetzgebung aus. Die bei Jhering angelegten Umdeutungen der zentralen Probleme der Rechtswissenschaft, die in verschiedenen Arten und Weisen der Verhältnisbestimmung von Recht und Gesellschaft münden werden, verschließt sich der Tönnies'schen Perspektive. Insofern zieht er aus den rechtstheoretischen Umstellungen, Problemverlagerungen und methodischen Konsequenzen der Debatten um die soziale Aufgabe des BGBs bzw. um die juristische Methode keinerlei direkte Schlussfolgerungen für die Soziologie. Und schließlich vermag auch das Aufkommen und Erstarken des Rechtspositivismus irgendetwas an seinem grundbegrifflichen Aufbau zu ändern.

Insofern löst sich der Ansatz von Tönnies bereits von der Rechtswissenschaft seiner Zeit. Damit wird genau jene Distanz geschaffen, die in der Folge die Entwicklungen im Recht und in den Rechtswissenschaft für die Soziologie irrelevant macht. Selbst wenn also Tönnies in grundlegender Weise auf das Recht rekurriert, um einen grundbegrifflichen Entwurf der Soziologie vorlegen zu können, führt ihn sein konkretes Vorgehen letztlich vom Recht weg.

779 Offenbar nahm Tönnies keinerlei Kenntnis von Jherings früheren Naturlehre des Rechts, so dass er feststellen kann: „In ganz anderem Stile als Schäffle, in der Tat ohne erhebliche Fühlung mit den naturwissenschaftlichen Tendenzen des Zeitalters, unternahm um dieselbe Zeit (1877ff.) Rudolf von Ihering, die ,Gesellschaftswissenschaft‘ analytisch zu begründen.“ (Tönnies 1926d [1908]: 90). 


\section{\8. Max Weber und das normative Zweckdispositiv}

\section{Webers Auseinandersetzung mit dem Recht in der „Wissenschaftslehre“}

Dass das Recht für den promovierten und habilitierten Juristen Max Weber ${ }^{780}$, dem die Debatten um die Historische Rechtsschule, die Kodifikation des BGBs und den juristischen Methodenstreit wohl bekannt waren, einen zentralen Gegenstand im Rahmen der kulturwissenschaftlichen respektive soziologischen Theoriebildung darstellt, ist heute unbestritten. Dieser hohe Stellenwert beschränkt sich nicht nur darauf, dass Weber dem Recht mit seiner posthum im Rahmen von Wirtschaft und Gesellschaft veröffentlichten Rechtssoziologie ${ }^{781}$ eine eigenständige und ausfühliche Untersuchung widmet. Vielmehr schreibt Weber dem Recht eine entscheidende Rolle in der Entwicklung des Kapitalismus zu, wie insbesondere im Kapitel „Die Wirtschaft und die gesellschaftlichen Ordnungen“ aus Wirtschaft und Gesellschaft deutlich wird (Weber 1976 [posthum]: $181 \mathrm{ff}$.). ${ }^{782}$ Das Gleiche gilt v.a. auch bzgl. der Entwicklung des modernen okzidentalen Rationalismus, wofür die Rechtssoziologie als Analyse der „Entwicklungsbedingungen des Rechts" (Gephart et al. 2010) als ein besonders elaboriertes Beispiel erscheint (vgl. Schluchter 1998: 190ff.). Daher bilden das Recht und seine historischen Variationen bei Weber, wie Wolfgang Schluchter

780 Siehe zum juristischen Werdegang Webers Deininger 1988: 2ff.; Gephart 1993a: $421 \mathrm{ff}$.

781 Zur Überlieferungsgeschichte des Manuskripts der „Rechtssoziologie“, das Marianne Weber Karl Loewenstein wahrscheinlich zum Dank schenkte und welcher es Anfang der 1960er Jahre dem Münchner Max-Weber-Archiv überließ, vgl. Hermes 2010; zur collagenartigen Struktur des Textgewebes der Rechtssoziologie sowie den Datierungsversuchen der vielen Überarbeitungsschichten vgl. insbesondere Gephart 2003; Schluchter 2005b. Einigkeit besteht dahingehend, dass das rechtssoziologische Manuskript aus dem Nachlass zu den Vorkriegsmanuskripten von Wirtschaft und Gesellschaft gehört.

782 Obwohl mittlerweile die einzelnen, z.T. aus verschiedenen Schaffensphasen stammenden Teile von Wirtschaft und Gesellschaft in der Max-Weber-Gesamtausgabe vorliegen, zitiere ich dennoch aus der von Johannes Winckelmann besorgten Gesamtausgabe in der Reproduktion der fünften Auflage (wobei die Grundbegriffe aus der Wissenschaftslehre zitiert werden), um die Kongruenz mit der vorliegenden verwendeten Sekundärliteratur zu gewährleisten. Zur Entstehungsgeschichte von Wirtschaft und Gesellschaft vgl. insbesondere Schluchter 2009. 
betont, nicht ein Teilphänomen der (modernen) Gesellschaft, dem man sich im Rahmen einer Bindestrich-Soziologie dann zuwenden mag oder auch nicht, sondern eine konstitutive Komponente des sozialen Lebens und die soziologische Analyse des Rechts wird zum integralen Bestandteil der Sozialtheorie (vgl. Schluchter 2002: 257).

Diese Linie der Interpretation, die über die materialen Untersuchungen des Rechts bei Weber hinausgeht, wird insbesondere seit den 1990er Jahren verfolgt. Zwar immer noch selten, aber doch immer öfter wird bei der Interpretation der methodologischen und begrifflichen Ansätze Webers die Frage nach der Bedeutung seiner juristischen Bildung gestellt (vgl. Marra 1992; Gephart 1993a: 419ff.; Turner, Factor 1997). ${ }^{783}$ Der Schwerpunkt des Interesses liegt dabei auf der Klärung der Frage, „welche Anteile im soziologischen Denken Max Webers sich der juristischen Herkunft verdanken" (Gephart 1993a: 419). Hervorgehoben werden die Anleihen Webers an die juristischen Begrifflichkeiten: Für den Handlungsbegriff und die damit verbundene Problematik von Kausalität und Zurechnung lassen sich unzweifelhaft solche Zuammenhänge herstellen (vgl. Gephart 1993a: 421 ff.; vgl. auch 1990); ebenso für den Anschluss des Weber'schen Staatsbegriffs an die in der Staatsrechtslehre umstrittene juristische Konzeption der Anstalt (v.a. Hermes 2006). ${ }^{784}$ Methodische Anleihen sind ebenfalls auszumachen: Wurde in den 1980er Jahren bereits die Rolle der (auch) juristischen Theorie der adäquaten Verursachung im Rahmen der methodo-

783 Demgegenüber dominieren die Bestimmungsversuche der philosophischen Grundlagen von Webers methodologischen Überlegungen (vgl. Gephart 1993b m.N.): Neben strittigen Fragen insbesondere nach der (u.U. problematischen) Reichweite des Einflusses des Neu-Kantianers Rickert (vgl. etwa Schelting 1934; Nusser 1986; Burger 1987; Oakes 1988b, 1990; Wagner 1987; Bruun 2000; MerzBenz 2007; Schluchter 2005a) stehen Webers Verhältnis zu Marx (vgl. etwa Löwith 1932; Mommsen 1974a, 1974b; Antonio, Glassman 1985; Böckler, Weiß 1987; Wiley 1987; Löwy 1996; zur marxistischen Kritik an Weber vgl. Weiß 1981) und Nietzsche (etwa Hennis 1987; Oexle 1996; Petersen 2014: 12 m.w.N.) noch im Vordergrund, wobei heute zunehmend auf weitere philosophische Einflüsse hingewiesen wird. Daneben rückt nun auch die Frage nach naturwissenschaftlichen Einflüssen in den Vordergrund (vgl. Wagner, Härpfer 2015; Treiber 2016a, jeweils m.w.N.).

784 Weber spricht insbesondere im Kategorienaufsatz vom „unvermeidliche[n] Schicksal aller Soziologie“, sich der juristischen Ausdrücke bedienen zu müssen, um ihnen dann einen ,ihren eigenen, von dem juristischen der Wurzel nach verschiedenen Sinn unterzuschieben“ (Weber 1988g [1913]: 440; s.u. $\mathbb{8}$ 8.III.4.2). Dies müsse man Werner Gephart zufolge als eine "Generalklausel“ verstehen, „mit deren Hilfe sich alle von Weber verwendeten Begriffe auf ibre, juristische Wurzel' überprüfen lassen" (Gephart 1993a: 487; H.i.O.; vgl. auch 2001: 73). 
logisch bedeutsamen Kausalitätsfrage bei Weber untersucht (vgl. etwa Turner, Factor 1981; Wagner, Zipprian 1985), so wurden in der Folge insbesondere die juristischen Quellen und Vorbildungen der IdealtypusLehre im Rahmen einer Theorie der Deutung „sozialen Handelns“ herausgearbeitet (insbesondere Treiber, Quensel 2002; Quensel 2007: 99ff.; s.a. Gephart 1993a: 478ff.)..$^{785}$

Juristische Einflüsse werden dabei bei einzelnen Autoren gesucht, so insbesondere bei Jellinek (vgl. etwa Breuer 1999; Anter 2000, 2014, 2016: 24ff.; Quensel 2007: 178ff.; kritisch Kersten 2000: 123ff.; Treiber 2016b), aber auch bei Jhering (Turner 1991; Treiber, Quensel 2002). ${ }^{786}$ Weniger häufig wird nach der Rolle von Webers Auseinandersetzung mit Stammler gefragt: Bis heute ist offen, worin der Grund für die außergewöhnlich scharfe Polemik Webers gegen dessen Rechtsphilosophie zu suchen ist v.a. angesichts der Tatsache, dass Weber in seinen methodologischen Arbeiten dieser Kritik immer wieder einen zentralen Stellenwert zuschreibt (vgl. Weber 1988g [1913]: 427 Fn. 1; 1988j [1921]: 541; Weber in Simmel et al. 1911a: 268). ${ }^{787}$ Aber ebenso fragt man nach Webers zeitgenössischem Kontext der Rechtswissenschaft, sticht doch die immer wieder hervorgehobene erstaunliche Affinität seiner soziologischen Rechtsdefinition zur „Be-

785 Vgl. auch die Hinweise von Deininger 1988 und Dilcher 2008 bzgl. idealtypischer Ansätze in Webers frühen juristischen Arbeiten.

786 Noch Ende der 1980er Jahre werden in der Rezeption zu den für Weber relevanten „Zeitgenossen“ keinerlei Juristen gezählt (vgl. Mommsen, Schwentker 1988).

787 Während für Michel Coutu die Relevanz der Stammler-Kritik in der Rechtssoziologie liegt (Coutu 2013, ähnlich Gephart 2010: 9ff.), betonen schon in den 1970er Jahren Martin Albrow, Guy Oakes und Wolfgang Mommsen ihren Stellenwert im Rahmen der methodologischen Arbeiten (vgl. Albrow in Weber, Albrow 1975: 129ff.; Oakes 1977; Mommsen 1979; a.A. jedoch noch Freund 1965: 79). Den Grund für die immer wiederkehrende Polemik Webers gegen Stammler sieht etwa Christopher Adair-Toteff darin, dass Weber vor den methodologischen Fehlern in Stammlers einflussreichen Buch Wirtschaft und Recht nach materialistischer Geschichtsauffassung in seiner verführischen, aber trügerischen Einfachheit warnen wollte (Adair-Toteff 2014). Zudem führte Stammlers Werk - wie Martin Albrow herausstellt - in seinem Überwindungsversuch der materialistischen Geschichtsphilosophie zu einer von Weber nicht gewünschten Rezeption des Marxismus an den Universitäten (vgl. Albrow in Weber, Albrow 1975: 129ff.). Gegenüber solchen Interpretationen wird hier die Stammler-Kritik nicht als Warnung verstanden, sondern als ein notwendiger Abgrenzungshorizont der Kulturwissenschaft respektive der Soziologie zur Rechtswissenschaft und -dogmatik, da man erst dadurch den wissenschaftslogischen Ort der Soziologie zu markieren vermag (s.u. $\$ 8 . \mathrm{V})$. 
griffsjurisprudenz" ins Auge (vgl. statt vieler Treiber, Quensel 2002: 91; Dilcher 2007). ${ }^{788}$

Der Großteil dieser Arbeiten steht für die vorliegende Untersuchung jedoch unter einem doppelten Vorbehalt: Zum einen richten sie ihr Augenmerk auf genetische Aspekte, d.h. es geht um die juristischen Quellen, Anleihen und Vorprägungen von Webers Begrifflichkeit und seiner Methode (etwa Gephart 1993a; Turner, Factor 1997; Quensel 2007), und nicht um die Frage nach der strategischen Funktion von Webers Auseinandersetzung mit dem Recht für seine Art der Soziologie. Zum anderen wird diese Auseinandersetzung oft auf seine Rechtssoziologie enggeführt, d.h. die Ergebnisse werden primär mit Blick auf die Begründung und Konsistenz der Soziologie des Rechts, und weniger der Soziologie als eigenständige Disziplin diskutiert (statt vieler Quensel 1997; Treiber, Quensel 2002; Hermes 2007; Coutu 2018). ${ }^{789}$

Das alles beantwortet aber nicht die Frage, auf welche Problemlagen Weber mit seiner Hinwendung zum Recht und in seiner Auseinandersetzung mit der Rechtswissenschaft reagiert. ${ }^{790}$ Denn eines fällt auf: Neben seinen materialen Bestimmungen und historischen Untersuchungen des Rechts ${ }^{791}$ bezieht sich Weber in all seinen Abhandlungen, die zur soge-

788 Dies handelte Weber den Vorwurf ein, dass er Recht und Rechtswissenschaften seiner Zeit völlig verkannt habe (v.a. Rehbinder 1987; 1989).

789 Eine ähnliche Engführung betreibt die juristische Seite, wenn sie nach Anwendung und Nutzen der Weber'schen Auseinandersetzung mit dem Recht für Rechtsdogmatik und -methodik fragt (vgl. exemplarisch Loos 1982; Petersen 2014 mit Blick v.a. auf die Interessenjurisprudenz).

790 Schon Friedrich Tenbruck betonte, dass ein Verständnis für Webers Wissenschaftslehre nur aus den zeitgenössischen Problemstellungen zu entwickeln sei (Tenbruck 1999a: 4; ähnlich auch Hennis 1987: 4ff.; Eliæson 2002; kritisch hierzu Oakes 1988a). In der Weber-Forschung liegt der Fokus auf der Diskussion um Webers Stellung zur zeitgenössischen Nationalökonomie (v.a. im nationalökonomischen Methodenstreit), aber auch zur sich konstituierenden politischen Wissenschaft sowie zur Geschichtswissenschaft.

791 Neben der Rechtssoziologie gehören hierzu seine frühen wissenschaftlichen Arbeiten als Jurist, d.h. seine Dissertation, seine Habilitationsschrift sowie eine Reihe von Rezensionen. Diesen Schriften schenkt die Weberforschung wenig Beachtung, obwohl etwa Gerhard Dilcher, der Herausgeber der Geschichte der Handelsgesellschaften im Mittelalter (1889), immer wieder auf die Genese zentraler rechtssoziologischer wie methodischer Prämissen Webers in seiner Dissertation hingewiesen hat (vgl. Dilcher 2008). 
nannten Wissenschaftslehre gehören, ${ }^{792}$ sowie in seinen Einlassungen zum Werturteilsstreit an zentralen Stellen auf das Recht respektive die Rechtswissenschaft. Diese Auseinandersetzung spielt auf methodologischer Ebene in der Grundlegung der Kulturwissenschaft und später der Soziologie als „eine Wissenschaft, welche soziales Handeln deutend verstehen und dadurch in seinem Ablauf und in seinen Wirkungen ursächlich erklären will“ (Weber 1988j [1921]: 542), ${ }^{793}$ offensichtlich eine entscheidende, theoriekonstitutive Rolle - und zwar, indem sie, so die These, die Problematisierungsweise des normativen Zweckdispositivs aufgreift und daraus Schlussfolgerungen für die Soziologie als eigenständige Disziplin zieht. ${ }^{794}$ Dass Weber selbst dabei den Stellenwert der rein erkenntnistheoretischen

792 Die Aufsätze und Beiträge in Webers Wissenschaftslehre wurden unter Erweiterung und Abänderung einer ursprünglichen Zusammenstellung seitens Weber im Jahr 1922 posthum von Marianne Weber unter diesem Titel veröffentlicht (vgl. Wagner, Zipprian 1994b: 10ff.). Angesichts dieser Entstehungsgeschichte wird die Frage nach der inneren Einheit und dem Stellenwert der in der Wissenschaftslehre versammelten Beiträge kontrovers diskutiert: Die Aufsätze werden entweder als in sich widersprüchliche Einzelbeiträge (so früher Tenbruck 1999a [1959]) bzw. als polemische Gelegenheitsarbeiten angesehen (z.B. Parsons 1936: 675), oder sie bilden als Wissenschaftslehre eine „Einheit“ (etwa Schelting 1934; Henrich 1952; Weiß 1992; Bruun 2007) respektive eine „werdende Einheit“ (Tenbruck 1994: 373; zur Diskussion um Webers Wissenschaftslehre s.a. Oakes 1988a; Tenbruck 1989; Wagner, Zipprian 1994a). Zu unterscheiden ist dies von der Frage, ob man das gesamte Werk Webers unter einer einheitlichen Fragestellung lesen müsse (s. etwa Hennis 1987; Swedberg 1998). Entsprechend dieser unterschiedlichen Positionen erscheint eine Auseinandersetzung mit Webers Wissenschaftslehre entweder als irrelevant bzw. unmöglich (vgl. etwa Hennis 1982: 246 Fn. 15) oder aber sie wird als grundlegend für ein Verständnis der Weber'schen Soziologie angesehen. Vorliegend geht es nicht um die Beantwortung der Frage der Einheitlichkeit der Wissenschaftslehre, sondern um die methodologischen, methodischen und fachkonstitutiven Effekte der spezifischen Art und Weise, wie Weber das Recht ins seinen methodologischen Schriften zum Gegenstand macht.

793 Weber steht der Soziologie zunächst sehr skeptisch gegenüber und versteht sich selbst erst spät als Soziologe (vgl. Schluchter 2016). Da es vorliegend gerade nicht um diesen - die Weberforschung nach wie vor zentral beschäftigenden Wandel geht, sondern die Entwicklung der Auseinandersetzung Webers mit dem Recht und der Rechtswissenschaft ins Visier genommen wird, wird im Folgenden der Begriff, Soziologie‘ und seine Abwandlungen als Oberbegriff für seinen Ansatz in allen Werkphasen verwendet - auch wenn es sich dabei um eine begriffliche Ungenauigkeit handelt.

794 Will man die Spezifik des Rechts in seinem Entwurf der Soziologie erkennen, so nützen m.E. Webers explizite kulturwissenschaftliche respektive soziologische Untersuchungen des Recht als Ausgangspunkt wenig, geht es darin doch um die 
oder methodologischen Erwägungen zugunsten von forschungspraktischen Zweckmäßigkeitserwägungen konsequent relativiert, verdeutlicht nur eine solche pragmatische Funktion der Auseinandersetzung mit dem Recht respektive v.a. mit der Rechtsdogmatik.

\section{Wider die Prämissen des Repräsentationsdispositivs: Roscher und Knies und die Kritik an der Historischen Rechtsschule}

Bereits sehr früh erteilt Weber dem Repräsentationsdispositiv, wie es in der Zeit der Entstehung und Blüte der Historischen Rechtsschule eingelagert war, eine Absage. Schon in der Aufsatzfolge „Roscher und Knies und die logischen Probleme der historischen Nationalökonomie“ aus den Jahren 1903 bis 1906 bestreitet er vehement die Vorstellung der Emanation der Kulturerscheinungen aus einer vorgängigen Einheit.

\section{Von der Kritik an der Historischen Schule der Nationalökonomie...}

Weber, der sich selbst zu den „Kindern“ der Historischen Schule der Nationalökonomie zählt (Weber 1988b [1904]: 208), wirft deren „Altmeister[n]" Roscher und Knies „elementare logisch-methodische Probleme“ vor (Weber 1988a [1903-1906]: 1). Zwar verfahren die Autoren dem Anspruch nach historisch, d.h. sie bilden Begriffe, die die qualitativ-charakteristischen Besonderheiten der individuellen Realität der Wirklichkeit (des historischen Individuums) in ihrer ,universelle[n] (wir pflegen zu sagen: ,historische[n] $]^{\text {) }}$ Bedeutung" (ebd.: 6) zu erfassen suchen. Und doch ziehen sie naturwissenschaftliche Begriffe heran, die die qualitativen Differenzierungen der Wirklichkeit auf exakt messbare Quantitäten reduzieren und daraus allgemeingültige Abstraktionen bilden. Solche Gattungsbegriffe statuieren dann Gesetze in Form von Kausalgleichungen (ebd.: 4f.). ${ }^{795}$ Roscher und Knies vermischten die logisch nicht zu vereinbarenden Methoden der Begriffsbildung der Gesetzes- und der Wirklichkeitswissenschaften

soziologischen Bestimmungen des Rechts, nicht aber um die Herausforderungen des Rechts für die Soziologie. Allerdings ist der Verweis auf die Rechtssoziologie insofern aufschlussreich und wird hier an den entsprechenden Stellen herangezogen, als sie am deutlichsten Auskunft über Webers materialen Rechtsbegriff gibt.

795 Die Differenz liegt nicht auf ontologischer Ebene, d.h. im Objekt begründet, und beide Arten der Begriffsbildung sind prinzipiell gleichwertig. 
respektive der Natur- und der Kulturwissenschaften. ${ }^{796}$ Daher stelle die „historische Methode“ der Nationalökonomie „ein, rein logisch betrachtet, durchaus widersprüchliches Gebilde“ dar (ebd.: 41).

Mit dieser Kritik an den Begründern der Historischen Schule der Nationalökonomie interveniert Weber in den sich seit den 1880er Jahren verstärkenden nationalökonomischen Methodenstreit zwischen theoretischer und historischer Schule (vgl. insbesondere Nau 1996). Er richtet sich damit aber zugleich auch gegen die Prämissen der Historischen Rechtsschule. Denn mit verantwortlich für die logischen Probleme erscheint ihm Savignys Volksgeistlehre, wie sie bei Roscher und seinen Anhängern Anklang fand (vgl. Weber 1988a [1903-1906]: 9f.). ${ }^{797} \mathrm{Ihr}$ wirft Weber die unzulässige Hypostatierung einer kollektiven Einheit zu einem „einheitliche[n] reale[n] Wesen metaphysischen Charakters" (ebd.: 10) vor. Das führe zu einer Verwechslung: Dieses Wesen werde „nicht als Resultante unzähliger Kultureinwirkungen, sondern umgekehrt als der Realgrund aller einzelnen Kulturäußerungen des Volks angesehen, welche aus ihm emanieren" (ebd., H.i.O.). Die Folgen seien bei Roscher deutlich sichtbar: Er glaube an die „metaphysische Einheitlichkeit des ,Volkscharakters““, als selbständiges „Individuum“, das einen „nach Analogie der Lebensentwicklung des Menschen gedachten Lebensprozess" durchlaufe (ebd.: 10, H.i.O.). Obwohl er dabei das Volk nicht als Gattungsbegriff, sondern als ein „als Kulturträger bedeutungsvolle [s] Gesamtwesen“ (ebd.: 11, H.i.O.) verstanden wissen will, verlässt er - wie auch Knies (vgl. ebd.: 11 Fn. 4) - die Bahnen der historischen Begriffsbildung aufgrund seiner Hinwendung zu einer „organi-

796 Weber beruft hierfür sich explizit auf Rickert (Weber 1988a [1903-1906]: 4 Fn., 7 Fn. 1). Inwieweit er dabei jedoch inhaltlich auf ihn Bezug nimmt, ist umstritten.

797 Doch auch Weber hegt - im Anschluss an Carl Mengers Kritik der Historischen Schule der Nationalökonomie - Zweifel an der Berechtigung dieser Bezugnahme: „Roschers methodisches Vorbild war die Arbeitsweise der deutschen historischen Juristenschule, auf deren Methode er sich, als der seinigen analog, ausdrücklich beruft. In Wahrheit handelt es sich jedoch - wie im wesentlichen schon Menger erkannt hat - um eine charakteristische Umdeutung dieser Methode.“ (ebd.: 9) Weber lässt dabei unter den Tisch fallen, dass Menger nicht von einer Umdeutung, sondern eher von einer vollkommen verfehlten Bezugnahme ausgeht (vgl. Menger 1883: 83ff., 222), ebenso, wie er nicht erwähnt, dass Schmoller seinem Gegner Menger eine „lebhafte Sympathie für den Mystizismus des Savigny'schen Volksgeistes“ vorwirft, die „offenbar der manchesterlichen Abneigung gegen jede bewußte Thätigkeit kollektiver Gesellschaftsorgane“ entspringe (Schmoller 1883: 250 [986]). Auch im nationalökonomischen Methodenstreit ist insofern der Bezug zur Historischen Rechtsschule alles andere als eindeutig. 
sche[n]' Gesellschaftstheorie“" (ebd.). Denn damit werde das individuelle Volk, der jeweilige Volksgeist bzw. -organismus, auf ein „Exemplare ihrer Gattung“ (ebd.) reduziert. In der Tat wirft Weber Roscher - trotz dessen prinzipieller Anerkennung des Wesens der geschichtlichen Irrationalität und der daraus resultierenden Notwendigkeit einer kausal-geschichtlichen Parallelbildung - die Behandlung der ,Völker' als „biologische Gattungswesen" vor (ebd.: 23). ${ }^{798}$

Mehr noch: Als Gattung durchläuft bei Roscher jedes Volk einen typischen, geschlossenen Kreislauf der Kulturentwicklung, der sich im Aufsteigen, Altern und Untergang der Kulturnationen zeige. Hier offenbare sich am deutlichsten die spezifisch naturwissenschaftliche Betrachtungsweise, handele es sich doch um allgemeine Entwicklungsgesetze, das „biologische[] Entwicklungsschema" (ebd.: 26) im Lebensgang der Völker. Roschers Annahme setze dabei ein organisches Leben des gesamten Kosmos voraus, dessen Äußerungen die Einzelvorgänge seien - allerdings unter dem Vorbehalt, dass die „organische“ Einheitlichkeit der geschichtlich-sozialen Zusammenhänge“ ein Objekt darstelle, „welches prinzipiell unerklärt bleiben $m u \beta^{\prime \prime}$ (ebd.: 35f., H.i.O.). ${ }^{799}$ Der Volksgeist bzw. das Gattungswesen ,Volk ${ }^{6}$ garantiere trotz der Tatsache, dass es letztlich - wie in der Historischen Rechtsschule - nicht erkannt werden könne, für Roscher die Möglichkeit eines objektiven Prinzips der Gliederung des gewaltigen historischen Stoffes, um nicht in subjektiv-willkürliche Auffassungen zu versinken (ebd.: 22).

Dies führe Roscher nun in die Nähe des von Weber vehement bekämpften gesetzeswissenschaftlich verfahrenden Naturalismus, für den - wie

798 Roscher vermischt nach Weber also den naturwissenschaftlichen Begriff „gattungsmäßig allgemein (generell)“ und den historischen Begriff ,inhaltlich umfassend“ (vgl. Weber 1988a [1903-1906]: 18). Daher erscheine ihm das Gesetzmäßige als das Wesentliche der Erscheinung (ebd.). In der Folge könne Roscher im Ansatz die Wirklichkeit aus dem generellen Begriff deduzieren.

799 Um einigermaßen konsistente Aussagen fällen zu können, bleibe Roscher als Kritiker Hegels letztlich nichts anderes übrig, als seine obersten Begriffe metaphysisch zu fundieren, indem er eine unüberschreitbare Grenze der irdischen Erkenntnis festlege, d.h. den Volksgeist letztlich in die dunkle Werkstätte - bei Roscher: Gott - verlege. Das sei jedoch gegenüber Hegel ein Rückschritt, da es eine „ziemlich primitive Form schlichter religiöser Gläubigkeit“ darstelle (ebd.: 41). Erst indem Roscher jedoch diese Grenze markiere, derzufolge man nie zum obersten Begriff bzw. zu den letzten Gesetzen gelangen könne, ergebe sich die Notwendigkeit der konkreten historischen Forschung, da die Wirklichkeit nicht wie bei Hegel denkend erfasst werden könne. Das ändere aber nichts an der Annahme, dass aus diesem „unerklärbaren Hintergrund“ die Wirklichkeit emaniere (ebd.: 19). 
Weber später schreibt - der Versuch typisch sei, „Werturteile aus naturwissenschaftlichen Tatbeständen abzuleiten“ (Weber 1988g [1913]: 425, H.i.O.). ${ }^{800}$ Genau solche naturalistischen Fehlschlüsse seien bei Roscher an zahlreichen Stellen erkennbar: Zwar könne die Wissenschaft aufgrund des historischen Wandels der ökonomischen Erscheinungen nur relative Normen aufstellen; dieser Relativismus beziehe sich bei Roscher aber nur auf die jeweilige Entwicklungsstufe eines Volkes. Hinsichtlich des jeweiligen Entwicklungsgrades könne man nach Roscher jedoch wenigstens theoretisch objektive Grundlagen für die Aufstellung von Normen angeben (vgl. Weber 1988a [1903-1906]: 38). Auch wenn man sie aufgrund des im Volksgeist eingelagerten Erkenntnismangels nicht direkt fassen könne (vgl. ebd.: 41), nehme Roscher damit solchen Maximen ihren Charakter, ein Werturteil zu sein: Er spreche diesen keine subjektive Komponente zu und gehe daher von der Möglichkeit der wissenschaftlich eindeutigen Auffindung von Normen (Werturteilen) aus (ebd.: 38). Kurz: Bei Roscher ist (zumindest theoretisch und wissenschaftslogisch) der Schluss von Sein auf Sollen möglich.

In diesem Vorgehen sieht Weber nicht nur ein methodisches, sondern auch ein erkenntnistheoretisches Problem: Bei Roscher zeige sich eine an Hegel erinnernde emanatistische Logik, derzufolge „die Begriffsinhalte als metaphysische Realitäten hinter der Wirklichkeit stehen und diese in ähnlicher Art notwendig aus ihnen hervorgeht“ (ebd.: 16). Dies führe letztlich zu einer Verwechslung von Begriff und Wirklichkeit, der Deduktion der Gesetze der Wirklichkeit aus den theoretischen Begriffen, bis hin zur Deduktion der Normen aus diesem Schema. Das ist für Weber, der sich auf dem Boden „der auf Kant zurückgehenden modernen Erkenntnislehre“ (Weber 1988b [1904]: 208) verortet, nicht hinnehmbar. Vielmehr geht er mit dem südwestdeutschen Neukantianismus (und hier insbesondere mit Lask, vgl. Jacobsen 2001: 36f.) von einem „, hiatus irrationalis‘ zwischen Begriff und Wirklichkeit" aus (Weber 1988a [1903-1906]: 15): Begriffe seien weder „Abbilder der ,objektiven“ Wirklichkeit“ (Weber 1988b [1904]: 208, H.i.O.), noch repräsentierten sie diese oder enthielten „die wahre Realität der Dinge [...] in sich“ (ebd.: 188) - weder im Bereich der Naturwissenschaften noch in dem der Kulturwissenschaften. Aus der Einsicht in die „sinnlose[] Unendlichkeit des Weltgeschehens“, in das „Leben in seiner irrationalen Wirklichkeit“ (ebd.: 180, 213) bzw. in die „Unendlichkeit und absolute Irrationalität jedes konkreten mannigfaltigen“ folge vielmehr „die

$800 \mathrm{Zu}$ den Hintergründen von Webers Kritik am Naturalismus vgl. Tenbruck 1999a: $17 \mathrm{ff}$. 
absolute Sinnlosigkeit des Gedankens einer ,Abbildung' der Wirklichkeit durch irgendeine Art von Wissenschaft" (Weber 1988a [1903-1906]: 92 Fn. 1). Dieses Wirklichkeitsverständnis dient Weber ,als eine ,negative Instanz"“, denn es schließt aus, dass eine wie auch immer geartete Bestimmung der Wirklichkeit - etwa als Volksgeist oder als Volksbewusstsein „als historische Ursache oder überhaupt als Realgrund für die logische Konstitution unseres empirisch gegebenen Wissenschaftsbetriebes gelten kann“ (ebd., H.i.O.).

Roschers Vorgehen sei erkenntnistheoretisch nicht haltbar und führe auf methodisch-wissenschaftstheoretischer Ebene zu logisch nicht tragbaren Widersprüchen; dasselbe gilt letztlich auch für Knies. ${ }^{801}$ Der „letzte[] Grund all' dieser Widersprüche“ liege dabei - so Weber - „in den erkenntnistheoretischen Konsequenzen seiner ,organischen" Auffassung" (ebd.: 33). Und genau in dieser Vorstellung wirke „das bestechende Vorbild der historischen Juristenschule“ (ebd.: 22).

\section{2. ... zur Kritik des Repräsentationsgedankens der Historischen Rechtsschule}

Webers Angriffe auf die Altväter der Historischen Schule der Nationalökonomie richten sich also auch gegen die Historische Rechtsschule. Und in der Tat formuliert Weber seine Kritik an ihr in der Folge auch explizit: ${ }^{802}$ Schon die Historische Rechtsschule habe den Volksgeist als „überindividuelle organische Einheit hypostasiert“" (Weber 1976 [posthum]: 442), auch

801 Bei Knies erkennt Weber dieselben logischen Mängel wie bei Roscher: Verwendung von Gattungs- und Gesetzesbegriffen in seiner vorgeblich historischen Methode, Analogien zur Biologie, Hypostatierung einer naturalistisch-organischen Einheitlichkeit des Individuums als Einheitlichkeit des Volkes, Hypostatierung dieses Volksorganismus als nicht hinterfragter, metaphysischer Realgrund der Kulturerscheinungen (emanatistische Logik; ebd.: 138ff.) - wobei Weber Knies in dieser Abhandlung zugunsten weitschweifender Überlegungen zum Irrationalitätsproblem nur am Rande behandelt. Vor dem Erscheinen des auf Knies bezogenen zweiten und dritten Teils des Roscher und Knies-Aufsatzes veröffentlichte Weber im Jahr 1904 seinen Objektivitäts-Aufsatz - nach Tenbruck letztlich die einzige positive methodologische Abhandlung Webers (vgl. Tenbruck 1999a; s.a. Sukale 2002: 207). Angesichts dieser über die Kritik der Altmeister hinausragenden methodologischen Überlegungen besserte Weber den Teil zu Knies nach und veröffentlichte diese Auftragsarbeit letztlich in unabgeschlossener Fassung (vgl. Tenbruck 1999a: 39f.).

802 Explizit nennt er hier nur Otto von Gierkes organizistisches Denken, das diesen Prämissen entspringe (Weber 1988a [1903-1906]: 35f. Fn. 1; zu Webers Verhältnis zu Gierke vgl. Dilcher 2017). 
hier mündete die angestrebte Historisierung des Rechts in einem organizistisch-naturalistischen Emanatismus: ${ }^{803}$ Die

halb historischen, halb naturalistischen Theorien vom „Volksgeist“ als der einzig natürlichen und daher legitimen Quelle -, aus welchem Recht und Kultur emaniere, und speziell von dem "organischen“ Wachstum alles echten, auf unmittelbarem „Rechtsgefühl“ beruhenden und nicht „künstlichen“, d.h. zweckrational gesatzten Rechtes, oder wie sonst sich diese der Romantik eigentümlichen Gedankenreihen geben mochten,

offenbaren den „Irrationalismus dieser Axiome“ (ebd.: 497). Folge sei eine logisch nicht haltbare Vermischung methodisch differenter Prämissen: Aus dem Emanationsgedanken würden „,organische“ Entwicklungstheoreme des Historismus" hergeleitet (ebd.: 501), wie dies insbesondere auch in dem „,vom Historismus geschaffenen, halb mystischen Begriff des ,Gewohnheitsrechts“" (ebd.: 508) zum Ausdruck komme; zugleich werde aus naturalistischer Perspektive ein „Naturrecht des historisch Gewordenen“ (ebd.: 497) eingefordert, das letztlich das Sollen über das Gewohnheitsrecht aus dem historisch zu ermittelnden Sein herleite.

Denn auch der Begriff des Gewohnheitsrechts der Historischen Rechtsschule erweise sich als „wenig brauchbar[]“ (ebd.: 187). Zwar könnten faktische Regelmäßigkeiten des Verhaltens auch Quelle der Entstehung von Rechtsregeln sein (vgl. ebd.: 195) und in diesem Sinne die Rechtsentstehung in der Gewohnheit gesucht werden. ${ }^{804}$ Diesen Umstand dürfe man aber nicht mit dem Begriff des „Gewohnheitsrechts“ verwechseln: Denn erstens handele es sich bei der, Gewohnheit' als tatsächliche und regelmä-

803 So schreibt Weber, „daß trotz des gewaltigen Dammes, welchen die deutsche idealistische Philosophie seit Fichte, die Leistungen der deutschen historischen Rechtsschule und die Arbeit der historischen Schule der deutschen Nationalökonomie dem Eindringen naturalistischer Dogmen entgegenbauten, dennoch und zum Teil infolge dieser Arbeit an entscheidenden Stellen die Gesichtspunkte des Naturalismus noch immer unüberwunden sind“ (Weber 1988b [1904]: 187, H.i.O.).

804 Nach Weber betrifft dies insbesondere die Ebene der empirischen Rechtsgeltung: „Und während es allerdings nichts Seltenes ist, daß Rechtsnormen rational gesatzt werden, um bestehende ,Sitten' und Konventionen zu ändern, ist dennoch der normale Sachverhalt der: daß die Rechtsordnung nicht etwa infolge des Bestehens der Zwangsgarantie in der Realität empirisch ,gilt', sondern deshalb, weil ihre Geltung als ,Sitte' eingelebt und ,eingeübt' ist und die Konvention die flagrante Abweichung von dem ihr entsprechenden Verhalten meist mißbilligt." (Weber 1976 [posthum]: 195). 
ßige Übung nur um eine unter verschiedenen Quellen, die zur Genese von Rechtssätzen führen könnten. ${ }^{805}$ Wenn Recht aber - wie Weber in seiner universalhistorischen Rechtssoziologie in kausaler Hinsicht zeigt - ebenso durch Vertrag, Kautelarjuristen, Gerichtsurteile, charismatische Offenbarung oder (zunehmend) durch gezielte Satzung entstehen könne, dann könne man nicht die Entstehungsweise ,Gewohnheit' zum alleinigen Erkenntnisgrund und letztlich auch alleinigen Geltungsgrund des Rechts erklären. Genau das aber geschehe in der Gewohnheitsrechtslehre, die den Volksgeist als natürliche und daher einzige legitime Quelle des Rechts postuliere (ebd.: 497), um damit etwa die Fortgeltung des römischen Rechts aus dem Gewohnten zu legitimieren.

Darüber hinaus müsse man richtigerweise das "Gewohnheitsrecht" als einen rechtstechnischen Begriff verstehen, der das "nichtgesatzte Recht“ bezeichne (ebd.: 441). Als solcher sei er ein „relativ sehr moderner Begriff, der im römischen Recht erst spät auftaucht und bei uns Produkt der gemeinrechtlichen Jurisprudenz" sei. ${ }^{806}$ Denn „[v]ollends sind die Voraussetzungen: - 1. faktische gemeinsame Übung, 2. gemeinsame Überzeugung von der Rechtmäßigkeit, 3. Rationabilität, - an welche die gemeinrechtliche Wissenschaft seine Geltung zu knüpfen pflegte, Produkt des theoreti-

805 Gegenüber der Historischen Rechtsschule verkehrt Weber zudem das Verhältnis von tatsächlicher Übung und Rechtsbewusstsein, d.h. jene Annahme, dass die Gewohnheit als tatsächliche Übung nur ein Indiz für bzw. der Ausdruck eines vorgängigen Rechtsbewusstseins oder Rechtsgefühls sei. So schreibt Weber in der Diskussion des Übergangs von Sitte in Konvention am Beispiel des „Urmenschen“: „Wir kennen aber die ,subjektiven“ Vorgänge im ,Urmenschen“ nicht und mit der stets wiederkehrenden Redensart von der angeblichen absoluten Urtümlichkeit oder gar ,Apriorität' des ,Rechts' oder der Konvention kann keine empirische Soziologie etwas anfangen. Nicht weil eine ,Regel` oder ,Ordnung‘ als ,verbindlich' gilt, zeigt das Sichverhalten des ,Urmenschen' nach außen, insbesondere zu seinesgleichen, faktische ,Regelmäßigkeiten', sondern umgekehrt: an die von uns in ihrer psychophysischen Realität hinzunehmenden, organisch bedingten Regelmäßigkeiten knüpft sich die Konzeption ,verbindlicher Regeln“ an." (Ebd.: 188).

806 Daher eigne sich der Begriff des Gewohnheitsrechts im Übrigen auch nicht für historische Forschung: „Als Aussagen über die tatsächliche Entwicklung von Recht in der Vergangenheit, gerade in den Zeiten ganz oder fast ganz fehlender ,Gesetzgebung' wären diese juristischen Begriffe [die Geltungsbedingungen des ,Gewohnheitsrechts', D.S.] unbrauchbar und historisch unwirklich." (Weber 1976 [posthum]: 441). 
schen Denkens“ (ebd). ${ }^{807}$ Es handelt sich für Weber um einen rein dogmatischen Begriff, um eine ,juristische Konstruktion der Geltungsbedingungen" eines nicht-statuarischen Rechts (ebd.). So verstanden habe er auch seine Berechtigung. ${ }^{808}$ Damit könne man aber nur sehr bedingt bzw. nur in sehr geringem Maße „etwas Richtiges über die faktische Entstehung der empirischen ,Geltung' nicht durch Satzung geschaffenen Rechts aussagen“ (ebd., H.i.O.).

Da sich Begriff und Wirklichkeit für Weber niemals decken, erweist sich die proklamierte Emanation des Rechts aus dem organischen Volksgeist in Form des Gewohnheitsrechts als wissenschaftlich nicht haltbare Aussage, und zwar im soziologischen wie auch im rechtswissenschaftlichen Sinne. Mit einer solchen organischen Theorie, die auf Basis einer Naturalisierung in den Historismus münde - jene beiden von Weber bekämpften Richtungen (Weber 1988a [1903-1906]: 63) - sei letztlich "wissenschaftlich nichts anzufangen“ (Weber 1976 [posthum]: 442). Weber wendet sich ganz allgemein gegen den Repräsentationsgedanken, der aus der emanatistischen Logik entspringt (vgl. Weber 1988a [19031906]: 15). Dies erfolgt mit Blick auf die Prämissen der Historischen Rechtsschule zum Teil implizit, aber oft auch explizit:

Erstens bestreitet Weber die Notwendigkeit der historischen Untersuchung des Rechts für die Rechtsdogmatik, d.h. jene Vereinigung der historischen und der systematischen Methode in Savignys Volksgeistmodell, die kennzeichnend für die ältere Historische Rechtsschule war. Beide Methoden, die der dogmatischen Konstruktion und die der Rechtsgeschichte, sind für Weber unvereinbar, richte sich doch erstere auf die Ermittlung des idealen Sinns einer Rechtsnorm und letztere auf ihre Faktizität, wie er in seiner Stammler-Kritik deutlich betont:

807 Das Kriterium der Rationabilität macht die Vereinbarkeit mit der ratio zur Voraussetzung des Gewohnheitsrechts. Nach Puchta, der dieses Erfordernis erstmals präzisierte (vgl. Scheuermann 1972: 80), werden darüber aber auch schlechte Gewohnheiten ausgeschlossen (vgl. Puchta 1837: 49ff.).

808 Diese Feststellung verbindet Weber zugleich mit einer Kritik der Ansätze einer Soziologie des Rechts im genuin juristischen Feld: Der Gewohnheitsrechtsbegriff sei ,in der sublimierten Form, die etwa Zitelmann oder auch Gierke ihm gegeben haben, nicht entbehrlich, es sei denn durch die Beschränkung alles nicht statutarischen Rechts auf bindende Präjudizien. Auf juristischem Gebiet ist der heftige Kampf der Rechtssoziologen (Lambert, Ehrlich) gegen ihn m.E. durchaus unbegründet und bedeutet eine Vermischung juristischer und soziologischer Betrachtungsweise.“ (Weber 1976 [posthum]: 441). 
Man kann nun eine „dogmatische“ Betrachtung „formal“ nennen, weil sie in der Welt der „Begriffe“ bleibt, - dann ist als Gegensatz dazu aber gemeint: „empirisch“ im Sinn der kausalen Betrachtung überhaupt. Nichts steht andrerseits im Wege, die empirisch-kausale „Auffassung“" der „Rechtsregeln“ eine „naturalistische“ zu nennen im Gegensatz zu ihrer Behandlung in der juristischen Dogmatik. Nur muß man sich darüber klar sein, daß dann als „Natur“ die Gesamtheit alles empirischen Seins überhaupt bezeichnet ist, daß also z.B. alsdann auch die „Rechtsgeschichte“, logisch betrachtet, eine „naturalistische“ Disziplin ist, weil auch sie die Faktizität der Rechtsnormen, nicht ihren idealen Sinn, zum Objekt hat. (Weber 1988d [1907]: 356f., H.i.O.)

Die „rationale rechtsdogmatische Begriffsbildung“ ist nach Weber von der „empirische[n] Disziplin der Rechtsgeschichte“ zu unterscheiden (Weber 1988i [1918]: 536). Daher müsse man beide auch streng voneinander trennen. ${ }^{809}$ Denn Weber sieht - mit Jellinek - eine „prinzipielle logische Geschiedenheit der juristischen Gedankengebilde von denjenigen der rein empirisch-kausalen Disziplinen“, so dass die juristische Begriffsbildung "mit kausaler Interpretation der Wirklichkeit gar nichts zu schaffen hat" (Weber 1988a [1903-1906]: 87).

Weber greift zweitens zugleich die Vorstellung an, dass man über die rechtsdogmatische Arbeit am Rechtsorganismus zum Leben gelangen könne, dass mit anderen Worten die dogmatisch-systematische Arbeit den Lebensbezug des Rechts gewährleiste. Man könne demgegenüber gerade nicht davon ausgehen, den ,Bedürfnissen der Zeit', insbesondere den Bedürfnissen der Zeitgenossen, durch ein derartiges formales Rechtsdenken gerecht zu werden. ${ }^{810}$ Eine gewisse Entfremdung vom Leben sei vielmehr eine „unvermeidliche Folge der Disparatheit logischer Eigengesetzlichkeiten jedes formalen Rechtsdenkens überhaupt" (Weber 1976 [posthum]: 506, H.i.O.):

Nun aber haben wir gesehen, dass die rein fachjuristische Logik, die juristische „Konstruktion“ der Tatbestände des Lebens an der Hand abstrakter „Rechtssätze“ und unter der beherrschenden Maxime: daß das-

809 Allerdings betont Weber immer wieder, das die rechtsdogmatischen Konstruktionen als Idealtypen für die Rechtsgeschichte dienen können und müssen (vgl. Weber 1988d [1907]: 357f.; 1988i [1918]: 536; Weber in Simmel et al. 1911c: 328).

810 Im Übrigen ergibt der Begriff der „Anpassung“ als Reaktion auf die Entwicklungen der Gesellschaft, also die Forderung nach der Anpassung an die Bedürfnisse der Zeit, wissenschaftlich für Weber keinen Sinn (vgl. Weber 1988i [1918]: 516). 
jenige was der Jurist nach Maßgabe der durch wissenschaftliche Arbeit ermittelten „Prinzipien“ nicht „denken“ könne, auch rechtlich nicht existiere, unvermeidlich immer wieder zu Konsequenzen führen muß, welche die „Erwartungen“ der privaten Rechtsinteressenten auf das gründlichste enttäuschen. (Ebd.) $)^{811}$

Für die Romanistik sieht er diese Entfremdung vom Leben geradezu charakteristisch an: In ihrer Haltung gegen den Kodifikationsgedanken - namentlich angesichts des ALR - versuchte sie, mit Mitteln der historischen Methodik den „ursprünglichen, ,reinen' Gehalt“ des römischen Rechts herauszupräparieren (ebd.: 494). Dies hatte zur Folge, dass das römische Recht „unter den Händen der fachmäßig historisch gebildeten Juristen diejenigen Umwandlungen wieder abstreifte, durch welche es bei seiner Rezeption den Bedürfnissen der Rechtsinteressenten angepaßt worden war: der ,Usus modernus Pandectarum ““ (ebd.: 494f.). Auf diese Weise trat „der Verlust der Angepaßtheit des römischen Rechts an moderne Verkehrsinteressen" ein - allerdings wurde gerade durch diese Ausschaltung des historisch Zufälligen „die Bahn für die abstrakte Rechtslogik ganz frei“ (ebd.: 495; vgl. Gephart 2010: 116ff.), eine „spezifische[] Art von Logisierung des Rechts“, an der die „Bedürfnisse des Lebens“ gerade nicht „entscheidend beteiligt" waren (Weber 1976 [posthum]: 493).812

811 An anderer Stelle schreibt er: „Die Konsequenzen der rein logischen juristischen Konstruktion verhalten sich vielmehr zu den Erwartungen der Verkehrsinteressenten ungemein häufig gänzlich irrational und geradezu disparat: die vielberedete ,Lebensfremdheit ${ }^{6}$ des rein logischen Rechts hat hier ihren Sitz." (Weber 1976 [posthum]: 493) Mit Blick auf den juristischen Methodenstreit merkt Weber an: „Immer erneut entsteht daraus heute der Protest der Interessenten gegen das juristische Fachdenken als solches. Und er findet heute Unterstützung auch bei dem Denken der Juristen selbst über ihren eigenen Betrieb. Allein ohne gänzlichen Verzicht auf jenen ihm selbst immanenten formalen Charakter ist ein Juristenrecht mit diesen Erwartungen niemals völlig zur Deckung zu bringen, noch auch je gebracht worden [...]." (Ebd.: 506).

812 Weber erkennt darin eine Verschiebung des wissenschaftlichen Rationalismus, auch wenn er feststellt: „Eine rein logische Neusystematisierung des alten Rechts freilich gelang den historischen Juristen begreiflicherweise nicht in überzeugender Weise. Bekanntlich und nicht zufällig sind bis auf das Windscheidsche Kompendium hinab fast alle Lehrbücher der Pandekten unvollendet geblieben.“ Auch den Germanisten sei dies nicht gelungen, hätten sie doch gerade versucht, die irrationalen, der ständischen Rechtsordnung entstammenden, also anti-formalen Elemente zu formalisieren. Weber, der im Handelsrecht promoviert, kennt nur eine Ausnahme: „Nur die von den bürgerlichen Verkehrsinteressenten autonom an ihre Bedürfnisse angepaßten und durch die Praxis der Spezialgerichte empirisch rationalisierten Rechtspartikularitäten, vor allem also: das 
Daher repräsentiere drittens der Juristenstand auch nicht den Volksgeist, und man gelange über die juristische Arbeit niemals zu einem Volksrecht. Demgegenüber folgert Weber

[a]us der historischen Tatsache: daß das Recht lange Epochen hindurch ein Produkt der Tätigkeit der zunehmend juristisch beratenen Rechtsinteressenten und der zunehmend juristisch gebildeten Richter gewesen ist und teilweise noch ist, daß, m.a.W., alles "Gewohnheitsrecht" in Wahrheit Juristenrecht war und ist (ebd.: 508).

Genauso wenig, wie das Recht aus dem Volksgeist hervorgehe, emaniere die Wirklichkeit aus der juristischen Arbeit mit Rechtsbegriffen. Damit bestreitet Weber letztlich den proklamierten Wert der Jurisprudenz, nämlich diejenige Instanz zu sein, die die eigentliche lebendige Kraft des organischen Volkslebens freilegt. Für ihn gilt, dass das juristische Begriffssystem „ein rein ideales Gedankengebilde ist, etwas, was als solches keine empirische Realität im Leben hat, sondern eben etwas [...] ,Geltendes ${ }^{6}$ ist" (Weber in Simmel et al. 1911c: 326).

Indem Weber den Emanationsgedanken ablehnt, ergeben für ihn die Debatten über die Repräsentationsleistungen der Wirklichkeit im Recht, d.h. ihren etwaigen Miss- oder Nicht-Repräsentationen, keinen Sinn: So erweise sich etwa der Streit zwischen Germanisten und Romanisten über Volksrecht und Juristenrecht als obsolet, handele es sich doch beim Gewohnheitsrecht immer um Juristenrecht. Ebenso sinnlos sei es, vom römischen Recht als „fremdem Recht“ zu sprechen, da die Rezeptionsleistung nicht in der Aufnahme materialer Rechtssätze oder Prinzipien zu sehen sei, sondern: „Entscheidend wurde die Rezeption des römischen Rechtes nur insoweit, als es das formal-juristische Denken schuf.“ (Weber et al. 2011 [1919/1920]: 372, H.i.O.) Gerade weil aber Weber die Rezeption nicht auf dem Gebiet der materialen Rechtsinhalte verortet, erscheint eine Diskussion über die ,richtige Rechtsquelle' des deutschen Volksgeistes, wie sie zwischen Germanisten und Romanisten geführt wurde, fruchtlos. Im Übrigen gebe es auch keinen direkten Zusammenhang zwischen der Rezeption des römischen Rechts und der Entwicklung des Kapitalismus (vgl. etwa ebd.: 371ff.): Weder sei das zum „Sündenbock“ gestempelte römische Recht verantwortlich für das Aufkommen der sozialen Frage noch sei das germani-

Wechsel- und Handelsrecht, gelang es wissenschaftlich und schließlich kodifikatorisch ohne Verlust an praktischer Angepaßtheit zu systematisieren, weil hier zwingende und eindeutige ökonomische Bedürfnisse im Spiel waren." (Ebd.: 495) Dilcher erkennt darin eine „verdeckte Abrechnung mit der Historischen Rechtsschule“ (Dilcher 2007: 109). 
sche Recht unschuldig an dieser Entwicklung (vgl. Weber 1993 [1895]; s.a. Weber in Simmel et al. 1911b: 198). Die Gegenüberstellung von individualistisch-kapitalistisch und germanistisch-gemeinschaftlich/sozial erweist sich für Weber letztlich als hinfällig. Auch die daran anschließende politische Bewertung des Rechts - ob es nun liberal oder ,sozial' sei bzw. ob es eine demokratische Volkssouveränität begünstige oder nicht - kann Weber nicht nachvollziehen, denn: „Gewisse gemeinsame Züge in der logischen Struktur des Rechts können aber Produkt untereinander sehr verschiedener Herrschaftsformen sein.“ (Weber 1976 [posthum]: 469) Das impliziere sogar die Möglichkeit eines radikalen Wandels: „Meine Herren, es wäre sogar nicht ausgeschlossen, daß bei vollem Bestehenbleiben des Bürgerlichen Gesetzbuches eine sozialistische Gesellschaftsordnung entstehen könnte." (Weber in Simmel et al. 1911a: 269) Ebenso wenig lässt sich mit Weber dem Recht respektive der Rechtswissenschaft die Vernachlässigung der Bedürfnisse der Zeit als Missrepräsentation der Gegenwart vorwerfen, da dies vielmehr in der Natur der Sache eines jeden formalen Rechts liege. Und schließlich widerspricht Weber Kirchmanns These, dass das ,natürliche', d.h. das ,lebende Recht' aufgrund seiner Nicht-Repräsentierbarkeit wissenschaftlich nicht zugänglich sei. Denn Weber sieht die Eigenart des modernen Rechts gerade in ihrer besonderen Form der Wissenschaftlichkeit - und das ist auch der Punkt, an dem er trotz seiner vehementen Kritik an die Prämissen der Historischen Rechtsschule Anschluss sucht.

\section{Das Ringen um die Verhältnisbestimmung von Soziologie und Rechtswissenschaft}

\section{Objektivitäts-Aufsatz: Idealtypus und rechtsdogmatische Begriffsbildung}

Angesichts des Methodenstreits zwischen theoretischer und historischer (respektive historisch-ethischer) Schule in der Nationalökonomie geht es Weber im Objektivitäts-Aufsatz darum, den „empirischen sozialen Kulturwissenschaften“ (Weber 1988b [1904]: 213) als "Wirklichkeitswissenschaft" einen methodischen und begrifflich-theoretischen Zugang zur Kulturwirklichkeit zu eröffnen: ${ }^{813}$

813 Vgl. zum Problem der Konzeption einer Wirklichkeitswissenschaft Kruse 1999; kritisch zu Rickerts und - daran anschließend - zu Webers Verständnis von Wirklichkeitswissenschaft Weiß 1992: 21ff. 
Wir wollen die uns umgebende Wirklichkeit des Lebens, in welches wir hineingestellt sind, in ibrer Eigenart verstehen - den Zusammenhang und die Kulturbedeutung ihrer einzelnen Erscheinungen in ihrer heutigen Gestaltung einerseits, die Gründe ihres geschichtlichen Sound-nicht-anders-Gewordenseins andererseits. (Ebd.: 170f.; H.i.O.) ${ }^{814}$

Keine der beiden Richtungen im nationalökonomischen Methodenstreit bietet für Weber aus methodischer Sicht eine befriedigende Lösung: Auf der einen Seite scheitere der ,theoretische', gesetzeswissenschaftliche $\mathrm{Zu}$ gang zur Wirklichkeit an der Tatsache, dass die historische Wirklichkeit an jeder Stelle „stets individuell geartet[]“ (ebd.: 180) sei. Sie könne somit nicht durch Gesetze erkannt und noch weniger daraus deduziert werden. Die spezifische Eigenart der historischen Wirklichkeit bestehe in ihrer jeweiligen „Kultur“, die Weber definiert als „ein vom Standpunkt des Menschen aus mit Sinn und Bedeutung bedachter endlicher Ausschnitt aus der sinnlosen Unendlichkeit des Weltgeschehens" (ebd., H.i.O.). Sinn und Bedeutung sind dabei einerseits auf menschliche Handlungen, d.h. Stellungnahmen zurückzuführen. Andererseits setzen sie eine Beziehung zu Wertideen voraus, die sogenannten Wertbeziehungen ${ }^{815}$ - denn nur diese erlauben eine Stellungnahme zur Welt, die man ,verstehen' könne und müsse. „Kultur“ sei also letztlich ein „Wertbegriff“ (ebd.: 175, H.i.O.), deren „konkrete Gestaltung der Wertbeziehung“ aber immer „fließend, dem Wandel unterworfen" bleibe (ebd.: 213, H.i.O.). Werte und Wertewandel (und das heißt dann: Kulturwandel) aber lassen sich nicht aus Gesetzen deduzieren, genauso wenig wie man eine „Bedeutung der Gestaltung einer Kulturerscheinung“, d.h. das „Verstehen“, dem „noch so vollkommenen

814 So schreibt Weber: „Will man solche Disziplinen, welche die Vorgänge des menschlichen Lebens unter dem Gesichtspunkt ihrer Kulturbedeutung betrachten, ,Kulturwissenschaften' nennen, so gehört die Sozialwissenschaft in unserem Sinne in diese Kategorie hinein. Wir werden bald sehen, welche prinzipiellen Konsequenzen das hat." (Weber 1988b [1904]: 165, H.i.O.) Durch diese Festlegung der Sozialwissenschaft versucht Weber den Orientierungs- und Handlungsbedürfnissen des „Kulturmenschen“ zu entsprechen (vgl. Weiß 2010: 57).

815 Zum Problem der „theoretischen Wertbeziehung“ bei Weber, die von Wertung und Werturteil zu unterscheiden ist und im Gegensatz zu letzterem als Grundlage für die kulturwissenschaftliche Forschung dient, vgl. v.a. Weiß 1992: $33 \mathrm{ff}$. Letztlich geht es um das Deutungspotential, das sich aus der theoretischen Beziehungen der Handlungen auf Werte ergibt. Dabei stellt nicht der Inhalt der Werte, sondern die Relation den Ansatzpunkt für die Analyse dar. Johannes Weiß merkt zurecht an, dass bei Weber die Wertbeziehung auch noch auf der Ebene der Auswahl des Untersuchungsobjekts zum Tragen kommt, und dabei dann der kausalen Analyse (zumindest) einen Weg weist (vgl. ebd.: 39ff.). 
System von Gesetzesbegriffen“ (ebd.: 175, H.i.O.) entnehmen könne. ${ }^{816}$ Kulturelle Wirklichkeit ist Weber zufolge durch Bewertung konstituierte Wirklichkeit (Weiß 1992: 36). Das sei letztlich die „, [t]ranszendentale Voraussetzung jeder Kulturwissenschaft", nämlich „daß wir Kulturmenschen sind, begabt mit der Fähigkeit und dem Willen, bewußt zur Welt Stellung zu nehmen und ihr einen Sinn zu verleihen“"(Weber 1988b [1904]: 180, H.i.O.).

Auf der anderen Seite erteilt Weber der „historisch-ethischen“ Richtung der Nationalökonomie, namentlich der Schule von Gustav Schmoller, trotz ihrer Hinwendung zur individuellen historischen Wirklichkeit eine Absage - und zwar aus mehreren Gründen: Erstens bestreitet er die Möglichkeit der Nationalökonomie, als „Tatsachenwissenschaft“ (Weber in Simmel et al. 1911c: 329) zu Wertungen gelangen zu können: „Eine empirische Wissenschaft vermag niemanden zu lehren, was er soll, sondern nur, was er kann und - unter Umständen was er will." (Weber 1988b [1904]: 151, H.i.O. $)^{817}$ Werturteile und Wertungen sind nach Weber immer rein „subjektiven“ Ursprungs“ (ebd.: 149). Und eine Abwägung zwischen widerstreitenden Werten könne niemals auf wissenschaftlichen Weg erfolgen, sondern sei rein individuell durch den wollenden Menschen bestimmt: „[E]r wägt und wählt nach seinem eigenen Gewissen und seiner persönlichen Weltanschauung zwischen den Werten, um die es sich handelt." (Ebd.: 150)

Zweitens setzt Weber - wie die theoretische Schule - wissenschaftliche Erkenntnis mit Erkenntnis aus Gesichtspunkten, also mit einseitiger Erkenntnis, gleich (vgl. ebd.: 170), müsse man doch aufgrund der Unendlich-

816 Der Grund liegt in der qualitativen Färbung der zu untersuchenden kulturellen Lebenserscheinungen, d.h. ihrer Kulturbedeutung - oder wie Weber ausführlich beschreibt: „Die Bedeutung der Gestaltung einer Kulturerscheinung und der Grund dieser Bedeutung kann aber aus keinem noch so vollkommenen System von Gesetzesbegriffen entnommen, begründet und verständlich gemacht werden, denn sie setzt die Beziehung der Kulturerscheinungen auf Wertideen voraus. Der Begriff der Kultur ist ein Wertbegriff. Die empirische Wirklichkeit ist für uns ,Kultur', weil und sofern wir sie mit Wertideen in Beziehung setzen, sie umfaßt diejenigen Bestandteile der Wirklichkeit, welche durch jene Beziehung für uns bedeutsam werden, und nur diese. Ein winziger Teil der jeweils betrachteten individuellen Wirklichkeit wird von unserm durch jene Wertideen bedingten Interesse gefärbt, er allein hat Bedeutung für uns; er hat sie, weil er Beziehungen aufweist, die für uns infolge ihrer Verknüpfung mit Wertideen wichtig sind.“ (Weber 1988b [1904]: 175, H.i.O.).

817 Wissenschaftlich zu analysieren ist lediglich die Zweck-Mittel-Relation, vgl. Weber 1988b [1904]: 149ff.; 1988i [1918]. 
keit der Wirklichkeit gezwungenermaßen immer eine Auswahl treffen. In diesem Zusammenhang spielen dann Wertungsgesichtspunkte eine entscheidende Rolle, da die Auswahl des Untersuchungsgegenstandes immer auf einem spezifischen Erkenntnisinteresse beruhe: „[W]as Gegenstand der Untersuchung wird, und wie weit diese Untersuchung sich in die Unendlichkeit der Kausalzusammenhänge erstreckt, das bestimmen die den Forscher und seine Zeit beherrschenden Wertideen“"(ebd.: 184, H.i.O.). ${ }^{818}$ Daher gebe es auch „keine schlechthin ,objektive' wissenschaftliche Analyse des Kulturlebens" (ebd.: 170). Die Untersuchung selbst müsse wiederum nach den strengen Kriterien einer reinen Tatsachenwissenschaft erfolgen: werturteilsfrei. Dieses Kriterium der Wissenschaftlichkeit gilt für Weber unabhängig von Zeit und Ort: Man sucht nach einer Wahrheit, die „auch für den Chinesen die Geltung einer denkenden Ordnung der empirischen Wirklichkeit beansprucht" (ebd.: 156). ${ }^{819}$

Drittens zeigt Weber, dass auch die historische Schule der Nationalökonomie auf theoretische Begriffe und Gesetze angewiesen ist. Denn wenn das Ziel in der Erkenntnis der Wirklichkeit liege, Wirklichkeitserkenntnis aber immer die Erkenntnis eines kausalen Zusammenhangs sei, dann werde die Zurechnung einer Erscheinung als Ursache für eine andere Erscheinung als Erfolg nur durch die Kenntnis der regelmäßigen oder gesetzlichen Verbindung zwischen diesen Erscheinungen möglich (vgl. Tenbruck 1999a: 14). Insofern „wäre das Vorhandensein klarer Begriffe und die Kenntnis jener (hypothetischen), Gesetze' offenbar als Erkenntnismittel aber auch nur als solches - von großem Werte, ja sie wäre zu diesem Zwecke schlechthin unentbehrlich" (Weber 1988b [1904]: 175, H.i.O.). Daher geht es Weber zentral um das Problem, welche „Bedeutung der Theorie

818 Allerdings versucht Weber das subjektive Erkenntnisinteresse - wie Johannes Weiß anmerkt - über das Kriterium der Rückbindung an die leitenden Wertideen respektive an die Kulturbedeutung auf möglichst allgemeine Interessen zurückzuführen (Weiß 1992: 38). Daher schreibt Weber, dass der Kulturwissenschaftler „verstehen müsse, die Vorgänge der Wirklichkeit - bewußt oder unbewußt - auf universelle ,Kulturwerte“ zu beziehen und danach die Zusammenhänge herauszuheben, welche für uns bedeutsam sind“ (Weber 1988b [1904]: 181, H.i.O.).

819 Allerdings stellt Weber die Geltung der Wahrheit selbst unter einen historischspezifischen Kulturvorbehalt, ist doch der „Glaube[] an den Wert wissenschaftlicher Wahrheit" nichts Selbstverständliches oder "Naturgegebenes“, sondern selbst „Produkt bestimmter Kulturen“ (ebd.: 213), d.h. ein „Kulturideal'. Das markiert den Unterschied zu Foucaults Ansatz, der die Art und Weise, wie Wahrheit generiert wird, d.h. die Geltungsbedingungen der Wahrheit als solche, historisiert. 
und der theoretischen Begriffsbildung für die Erkenntnis der Kulturwirklichkeit“ zukommt. Er fragt also nach der „logische[n] Funktion und Struktur der Begriffe, mit der unsere, wie jede, Wissenschaft arbeitet" (ebd.: 185, H.i.O.). Letztlich geht es also um die Bestimmung der Rolle des theoretischen Wissens für die Erkenntnis der historisch-individuellen Wirklichkeit.

Webers Lösung dieses methodischen Problems besteht bekanntlich in der Einführung des Idealtypus als „Spezialfall einer Form der Begriffsbildung, welche den Wissenschaften von der menschlichen Kultur eigentümlich“ ist (ebd.: 189f.). ${ }^{820}$ Auch diese Form des Begriffs dient der „denkende[n] Ordnung der empirischen Wirklichkeit“ (ebd.: 150), die letztlich zwischen den beiden Positionen in der Nationalökonomie vermittelt. V.a. aber ist die idealtypische Begriffsbildung für Weber ein Mittel der empirischen Untersuchung der historischen Gegebenheit, und nicht deren Ziel (ebd.: 193).

Um diese Funktion erfüllen zu können, zielt Weber auf die Bildung möglichst klarer, eindeutiger Begriffe. Idealtypen sind dabei rein „theoretische Konstruktion[en]“ (ebd.: 195). Als Typen wenden sie sich den charakteristischen und nicht den gattungsmäßigen Merkmalen zu, um „die Eigenart von Kulturerscheinungen scharf zum Bewußtsein zu bringen“" (ebd.: 202, H.i.O.). Sie werden gewonnen nicht aus Durchschnittsmerkmalen, sondern

durch einseitige Steigerung eines oder einiger Gesichtspunkte und durch Zusammenschluß einer Fülle von diffus und diskret, hier mehr, dort weniger, stellenweise gar nicht, vorhandenen Einzelerscheinungen, die sich jenen einseitig herausgehobenen Gesichtspunkten fügen, zu einem in sich einheitlichen Gedankenbilde (ebd.: 191, H.i.O.).

Bei diesem Aufstieg von Einzelerscheinungen zum idealtypischen Begriff Weber nennt dies die Bildung eines "genetischen“ Begriffs (ebd.) - werden „bestimmte Beziehungen und Vorgänge des historischen Lebens zu einem in sich widerspruchslosen Kosmos gedachter Zusammenhänge" vereinigt (ebd.: 190, H.i.O.). Auf diese Weise entstehe ein „Idealbilde“ (ebd.: 191), das aber nichts mit einem Seinsollenden, d.h. normativen Ideal zu tun habe (ebd.: 192). Die Eigenart eines solchen Zusammenhangs werde viel-

820 Schon sehr früh wurde Weber die Mehrdeutigkeit des Idealtypus-Konzepts vorgehalten, wie er es im Objektivitäts-Aufsatz als Problemaufriss konzipiert (vgl. etwa Moeller 1920/21; Schelting 1922, 1934). 
mehr an einem Idealtypus pragmatisch veranschaulicht und insbesondere verständlich gemacht (ebd.: 190). ${ }^{821}$

Auch wenn der Idealtypus aus der Wirklichkeit abgeleitet wird, ist er nicht ihr Abbild. In seiner begrifflichen Reinheit ist er nach Weber nirgends in der Wirklichkeit empirisch vorfindbar, er ist eine „Utopie“ (ebd.: 191). Derart diene er zur Auffindung des wirklich Historischen durch Beziehung auf einen selbst unwirklichen Maßstab (vgl. ebd.: 233). Idealtypen lassen also weder den eigentlichen Sinn der Geschichte noch ihr Wesen erkennen. Ebenso wenig dürfe man sie als treibende Kräfte der Geschichte hypostatieren (vgl. ebd.: 195). Vielmehr fungieren sie im Erkenntnisprozess als Maßstab, an dem die Wirklichkeit gemessen werde, um ,in jedem einzelnen Falle festzustellen, wie nahe oder wie fern die Wirklichkeit jenem Idealbilde steht" (ebd.: 191, H.i.O.). Nur durch den Vergleich lasse sich letztlich das Spezifische der historischen Gegebenheit erkennen. Dabei werde die Wirklichkeit am Idealtypus nach Weber nicht im wertenden Sinne, sondern im Sinne von Sinn- und Kausaladäquanz gemessen (vgl. Weber 1988j [1921]: 551): „Solche Begriffe sind Gebilde, in welchen wir Zusammenhänge unter Verwendung der Kategorie der objektiven Möglichkeit konstruieren, die unsere, an der Wirklichkeit orientierte und geschulte Phantasie als adäquat beurteilt." (Weber 1988b [1904]: 194, H.i.O.)

Auch wenn „die Konstruktion einer rationalen ,richtigen' solchen Utopie dabei nur eine der verschiedenen möglichen Gestaltungen eines ,Idealtypus “" (Weber 1988i [1918]: 535, H.i.O.) sei, räumt Weber der Begriffsbildung nach dem Primat der Logik, also logischen Konsistenz und inneren Widerspruchslosigkeit, einen Vorzug ein (vgl. Weber 1988b [1904]: 200). Denn zum einen gilt: „Je schärfer und eindeutiger konstruiert die Idealtypen sind: je weltfremder sie also, in diesem Sinne, sind, desto besser leisten sie ihren Dienst, terminologisch und klassifikatorisch sowohl wie heuristisch“ (Weber 1988j [1921]: 561, H.i.O.). Zum anderen führe dieses Primat zu einer gesteigerten Eindeutigkeit der Begriffe aufgrund eines „möglichste[n] Optimum[s] von Sinnadäquanz“, weil diese Eindeutigkeit „bei rationalen (wert- oder zweckrationalen) Begriffen und Regeln besonders vollständig erreicht werden" könne (ebd.: 560, H.i.O.). Erst vor diesem rationalen Hintergrund werde nicht nur die - Weber besonders interessierende - Spezifik des okzidentalen Rationalismus deutlich (vgl. Weber

821 Daher ist der Idealtypus keine Hypothese, sondern weist der Hypothesenbildung eine Richtung (vgl. Weber 1988b [1904]: 190). 
1920: 11f.; Lepsius 2009: 45). Auch die Eigenart der irrationalen und affektuellen Abweichungen trete derart zutage. ${ }^{822}$

Weber führt die Auseinandersetzung mit dem Idealtypus im Objektivitäts-Aufsatz primär als Problemaufriss ein, in dem er notwendige Abgrenzungsarbeiten vollzieht. Dementsprechend erscheinen seine expliziten Bezugnahmen auf das Recht respektive die Rechtswissenschaft (noch) primär negativ: So bilde etwa die Rechtswissenschaft gattungsmäßige Begriffe, derer man sich zwar als Hilfsmittel zur Bildung von Idealtypen bedienen könne, die aber selbst noch keinen Aufschluss über die jeweilige Kulturbedeutung geben. ${ }^{823}$ Es sei aber doch gerade die "praktische Bedeutung" der rechtlichen Normen, „mit der die Arbeit der Sozialwissenschaft in unserem Sinn zu tun hat" (Weber 1988b [1904]: 195, H.i.O.). Insofern seien klare Begriffe nicht nach Art der dogmatischen Wissenschaft wie etwa der Rechtswissenschaft zu bilden: Eine Definition nach dem Schema: genus proximum, differentia specifica sei „natürlich ein Unding“, und eine „solche Form der Feststellung der Wortbedeutung gibt es nur auf dem Boden dogmatischer Disziplinen, welche mit Syllogismen arbeiten" (ebd.: 194). Dabei bestehe die „Eigenart des Erkenntnisziels einer jeden sozialwissenschaftlichen Arbeit“ ja gerade darin, dass sie anders als die Rechtsdogmatik „über eine rein formale Betrachtung der Normen [...] des sozialen Beieinanderseins hinausgehen will“ (ebd.: 170, H.i.O.). Dies geschehe, indem sie aufgrund der Vergänglichkeit aller idealtypischen Konstruktionen angesichts neuer Problemstellungen immer neue solcher Idealtypen bilde (vgl. ebd.: 206).

Weber wendet sich also schon zu diesem frühen Zeitpunkt gegen „mancherlei Verirrungen, welche das Hinübergreifen formal-juristischen Denkens in die Sphäre der Kulturwissenschaften gezeitigt hat" (ebd.: 182), was er auch in der zeitgleich verfassten Aufsatzfolge zu Roscher und Knies zum Ausdruck brachte. V.a. aber wendet er sich bereits gegen Stammlers Versuch, die Sozialwissenschaft als teleologische Wissenschaft zu bestimmen,

822 So gelte: „Die Konstruktion eines streng zweckrationalen Handelns also dient in diesen Fällen der Soziologie, seiner evidenten Verständlichkeit und seiner - an der Rationalität haftenden - Eindeutigkeit wegen, als Typus (,Idealtypus'), um das reale, durch Irrationalitäten aller Art (Affekte, Irrtümer) beeinflusste Handeln als ,Abweichung' von dem bei rationalem Verhalten zu gegenwärtigenden Verlaufe zu verstehen.“ (Weber 1988j [1921]: 544f., H.i.O.).

823 So schreibt Weber: „Die gattungsmäßigen Merkmale des Tausches, Kaufs usw. interessieren den Juristen, - was uns angeht, ist die Aufgabe, eben jene Kulturbedeutung der historischen Tatsache, daß der Tausch heute Massenerscheinung ist, zu analysieren.“ (Weber 1988b [1904]: 176, H.i.O.). 
die das Recht als Form des sozialen Lebens dem Reich der Zwecke zurechnet (vgl. ebd.). Die Fokussierung auf Rechtsnormen und die Analyse von Zwecken in Stammlers Teleologie führe zu keinerlei Verständnis der Kulturbedeutung respektive der kausalen Zusammenhänge. Denn „,[b]ei völliger formaler Identität der geltenden Rechtsnormen kann die Kulturbedeutung der normierten Rechtsverhältnisse und damit auch der Normen selbst sich grundstürzend ändern" (ebd.: 183, H.i.O.); theoretisch sogar so sehr, dass - wie Weber später betont - bei Bestehen des BGBs eine sozialistische Ordnung denkbar wäre. Zwecke sind bei Weber letztlich wie Wertungen rein subjektiv, nämlich Vorstellungen über einen zu erzielenden Erfolg, die Ursache eines Handelns werden. Als solche müssen sie ,verstanden werden, eignen sich aber nicht als Bezugspunkt einer Wissenschaft (vgl. ebd.). Insofern ergibt die Idee einer Zweckwissenschaft für Weber keinen Sinn - auch nicht, wenn man sie wie Stammler auf die Rechtswissenschaft bezieht.

Weber steht in seinen expliziten Ausführungen zur juristischen Begriffsbildung und Logik im Objektivitäts-Aufsatz der Rechtswissenschaft sehr kritisch gegenüber. Und doch nimmt er implizit positiv Bezug auf rechtsdogmatisches Denken und Vorgehen. Denn zum einen betont er - in Vorwegnahme seiner Kritischen Studien auf dem Gebiet der kulturwissenschaftlichen Logik aus dem Jahr 1906 -, dass man für die Bildung der Idealtypen auf die juristische Kategorie der objektiven Möglichkeit zurückgreifen müsse (vgl. ebd.: 194). Zum anderen ähnelt das Verfahren der Bildung der Idealtypen im hohen Maße der rechtsdogmatischen Bildung typisierender Begriffe in der Historischen Rechtsschule, wie sie später als Begriffsjurisprudenz in Verruf gerät. ${ }^{824}$ Schon Savigny bestimmte seinen Grundbegriff des Systems, das Rechtsinstitut, als Typus, und es finden sich entsprechende Verfahrensmerkmale der Begriffsbildung bei Weber wieder: Aufsteigende Bildung typologisierender Begriffe aus Analyse und Synthetisierung des vorgefundenen Materials über die Bestimmung ihrer wesentlichen Aspekte; Bildung solcher Begriffe (Prinzipien) als genetische Begriffe, wie sie etwa auch in Puchtas Genealogie der Begriffe erkennbar ist (s.o. $\$ 2 . I V .1 ;$ vgl. Dilcher 2008: 76; Heuß 1968: 68f.); Konstruktion eines systematischen Zusammenhangs, der den Vorgaben der Logik zu entsprechen hat; Deduktion der Konsequenzen daraus, wobei die Anwendung der Rechtsprinzipien

824 Insbesondere Hubert Treiber und Bernhard Quensel haben diesen Aspekt wiederholt deutlich herausgearbeitet (vgl. Treiber 1997; Treiber, Quensel 2002; Quensel 1997, 2007: 106ff.; s.a. Petersen 2008: 133ff.), wobei sie dies auf einzelne Autoren wie etwa Goldschmidt, Jhering, Cohen oder Sohm rückzuführen suchen. Instruktiv zum juristischen Typenbegriff ist Leenen 1971. 
zu einem ständigen Wandel führt (jene konstruktive bzw. produktive Seite des Systems, vgl. $\$ 2 . I V) .825$

Gerade weil Weber dabei den Repräsentationsgedanken ablehnt, erscheinen ihm die derart gebildeten Begriffe später als ideal: Ein ,juristische $[\mathrm{s}]$ Begriffssystem“ sei eben „ein rein ideales Gedankengebilde“ (Weber in Simmel et al. 1911c: 326, H.i.O.), das im Rahmen des Sinnverstehens jenseits jeglicher Repräsentationsabsicht abstrakte, wirklichkeitsfremde Begriffe in einem logisch, richtigen' Sinne konstruiert. Mittels dieser Begriffe werde jedoch versucht, sowohl über ihre Herleitung aus den Rechtsverhältnissen als auch über ihre Anwendung auf neue Rechtsverhältnisse einen Wirklichkeitsbezug im Sinne einer Sinn- und Kausaladäquanz herzustellen. ${ }^{826}$ Solche anhand einer formal-logischen Systematik gewonnenen juristischen Abstraktionen lassen Weber später von der „ungeheure[n] Ueberlegenheit des im Prinzip logisch klaren Gehaltes“ juristischer Begriffe sprechen (ebd., H.i.O.), weshalb sich ihm zufolge die soziologischen Begriffe regelmäßig an Rechtsbegriffen orientierten (vgl. ebd.; s.u. III.4.2). Im Objektivitäts-Aufsatz aber erscheint dieses Problem nur implizit; auf der expliziten Ebene versucht sich Weber gerade vom Verfahren der Rechtswissenschaft abzusetzen. ${ }^{827}$

825 Insofern ist es auch nicht verwunderlich, wenn das Konzept des Idealtypus schon in seiner handelsrechtlichen Habilitationsschrift in groben Zügen vorgezeichnet war (vgl. Dilcher 2008: 76).

826 Die prominente These, dass Weber den Begriff des Idealtypus unter Vertauschung seines Bedeutungsinhaltes von Jellinek übernommen habe, wird mittlerweile mit guten Gründen angefochten (vgl. Kersten 2000: 123ff.; Treiber 2016b). Der Begriff des Idealtypus taucht in der Jurisprudenz bereits vor Jellinek auf, etwa bei Jhering, der ihn zwar ähnlich wie Jellinek verwendet, damit aber - da er nicht zwischen soziologischer und juristischer Betrachtungsweise unterscheidet - eine Kritik am Emanationsgedanken verbindet (Jhering 1886: 145, s.o. \$3.I. 2). Verortet man stattdessen die Begriffsgenese in der Technik der Typenbildung der sogenannten Begriffsjurisprudenz, dann verweist der Begriff ,Ideal' im Idealtypus auf die Probleme des Idealismus im Recht. Das würde dann erklären, weshalb sich die begriffsjuristischen Konstruktionen als Idealtypen eignen.

827 Insofern spricht mehr dafür, dass Weber im Jahr 1904 die Anleihen an das juristische Begriffsbildungsverfahren - seiner juristischen Ausbildung und Prägung geschuldet - unbewusst gemacht hat. Für die entgegengesetzte Annahme müsste man die Frage beantworten, weshalb die juristischen Begriffe hier noch als gattungsmäßig bestimmt werden, was dem Verfahren der typisierenden Begriffsbildung widersprechen würde. 


\section{Objektive Möglichkeit und adäquate Verursachung: Juristisch-soziologische Zurechnungslebren}

Wissenschaftslogische Relevanz gewinnt die explizite Auseinandersetzung mit der Rechtswissenschaft für Weber im Zuge der für die historisch-empirische Kulturwissenschaft zentralen Kausalitätsfrage. Denn die Kritik an der defizitären und unklaren Begriffsbildung des Historikers Eduard Meyer, der als einer der führenden Vertreter seines Faches in die zentralen Auseinandersetzungen der Historiographie involviert war (vgl. hierzu Tenbruck 1999b), führt Weber zu der Frage:

$[W]$ ie ist eine Zurechnung eines konkreten „Erfolges“ zu einer einzelnen „Ursache“ überhaupt prinzipiell möglich und vollziehbar angesichts dessen, daß in Wahrheit stets eine Unendlichkeit von ursächlichen Momenten das Zustandekommen des einzelnen "Vorgangs“ bedingt hat, und daß für das Zustandekommen des Erfolges in seiner konkreten Gestalt ja schlechthin alle jene einzelnen ursächlichen Momente unentbehrlich waren? (Weber 1988c [1906]: 271, H.i.O.)

Ihm geht es um die Betrachtung des logischen Wesens solcher Urteile. Da die Methodologie der Geschichtswissenschaft jedoch diesbezüglich „im argen liegt" (ebd.: 268), greift Weber auf die Rechtswissenschaft zurück nämlich auf die juristische Verwendung der Theorie der „objektiven Möglichkeit" des Physiologen Johannes von Kries. ${ }^{828}$

Weber vollzieht diesen Rückgriff auf die Rechtswissenschaft, weil das juristische Problem der Zurechnung eines Handlungserfolges „von der gleichen logischen Struktur wie die historische Kausalitätsfrage" sei (ebd.: 270). Denn zum einen gehe es im Recht um die „anthropozentrisch“, da rein handlungstheoretisch orientierte Frage, unter welchen Umständen man behaupten könne, dass ein menschliches Individuum durch sein Handeln einen bestimmten äußeren Erfolg, verursacht ${ }^{\star}$ habe und daher strafrechtlich oder entschädigungsrechtlich dafür zu belangen sei (ebd.). Insofern handele es sich immer um eine handlungsbezogene Präzision. Zum anderen richte sich das Kausalitätsproblem in der Rechtsanwendung ebenso wie in der historischen Wissenschaft nicht auf die Ermittlung irgend-

$828 \mathrm{Zu}$ Webers Bezug auf Kries vgl. insbesondere Massimilla 2012; Treiber 2014a. Zur Theorie der objektiven Möglichkeit und adäquaten Verursachung in Anschluss an Kries siehe insbesondere Lübbe 1993. 
welcher abstrakter Gesetzlichkeiten, sondern „auf die Zurechnung konkreter Erfolge zu konkreten Ursachen" (ebd.). 829

Weber bezieht sich dabei auf die logischen Operationen, die eine solche konkrete Zurechnung der für wesentlich gehaltenen Kausalfaktoren ,objektiv' feststellen lassen. ${ }^{830}$ Die kausale Zurechnung vollziehe sich dabei über einen Gedankenprozess, der eine Serie von Abstraktionen enthalte:

Die erste und entscheidende ist nun eben die, daß wir von den tatsächlichen kausalen Komponenten des Verlaufs eine oder einige in bestimmter Richtung abgeändert denken und uns fragen, ob unter den dergestalt abgeänderten Bedingungen des Hergangs der (in den „wesentlichen“ Punkten) gleiche Erfolg oder welcher andere „zu erwarten gewesen“ wäre. (Ebd.: 273, H.i.O.)

Dieser Gedankenprozess beinhaltet nach Weber ein Möglichkeitsurteil: Dem geschichtlichen Verlauf werde durch die Abänderung des Geschehens eine andere mögliche Entwicklung als hypothetischer Kausalverlauf gegenüber gestellt. Diese Änderung müsse einen historisch relevanten Unterschied hervorrufen. Denn nur in diesem Fall erweise sich das in Frage stehende Ereignis als Kausalfaktor von historischem Interesse (vgl. ebd.: 274).

Bei solchen Möglichkeitsurteilen handele es sich um kontrafaktische Annahmen, nämlich um „Phantasiebilder[] durch Absehen von einem oder mehreren der in der Realität faktisch vorhanden gewesenen Bestandteile der, Wirklichkeit' und durch die denkende Konstruktion eines in Bezug auf eine oder einige ,Bedingungen“ abgeänderten Herganges“ (ebd.: 275, H.i.O.). Um nun ein solches Urteil über einen alternativen (positiven) Handlungsverlauf aber überhaupt fällen zu können, müsse man auf Erfah-

829 Die juristische Kausalitätsfrage unterscheidet sich nach Weber erst dann, wenn sie - wie etwa im Strafrecht - über die Klärung der Kausalitätsfrage auch die subjektive Schuld feststellen sucht, wohingegen die empirische Wissenschaft nach ,objektiven' Gründen konkreter Vorgänge und nach der Folge konkreter Handlungen frage (vgl. Weber 1988c [1906]: 271). Letzteres sei in zivilrechtlichen Haftungsfragen häufig der Fall, weshalb Weber gerade in den zivilrechtlichen $\mathrm{Zu}$ rechnungsfragen die "gleiche[] logische[] Lage“ mit der Geschichte erkennt (ebd.: 271 Fn. 1, H.i.O.; s.a. Turner, Factor 1981: 7f.).

830 Nach Weber werde nicht nur das Ereignis, das es kausal zu erklären gelte, nach Maßgabe des historischen Interesses ausgewählt, sondern ebenso die möglichen, d.h. als wesentlich bestimmten Kausalfaktoren. Wie beim Richter, der das Geschehen stets im Hinblick auf die anzuwendende Norm beurteile, bewirke dies „die Ausscheidung einer Unendlichkeit von Bestandteilen des wirklichen Hergangs als ,kausal irrelevant““” (Weber 1988c [1906]: 273). 
rungsregeln Bezug nehmen, d.h. auf „ein positives Wissen von ,Regeln des Geschehens', auf unser ,nomologisches ' Wissen, wie man zu sagen pflegt" (ebd.: 276, H.i.O.). Der gedachte mögliche Erfolg bei alternativem Handlungsverlauf muss also „objektiv möglich“ sein, „d.h. aber nur: daß, wenn wir ihn uns als faktisch eingetreten ,denken', wir die in jener Art abgeändert gedachten Tatsachen als ,zureichende Ursachen" anerkennen würden" (ebd.: 277, H.i.O.). 831

Das historische Kausalurteil stützt sich nach Weber - wie das juristische - also notwendigerweise auf ein Wissen darüber, dass eine Handlung generell und erfahrungsgemäß dazu geeignet ist, den in Frage stehenden Erfolg herbeizuführen (adäquate Verursachung). ${ }^{832}$ Der Historiker verfahre dabei wie der Jurist letztlich kontrafaktisch: „Um die wirklichen Kausalzusammenhänge zu durchschauen, konstruieren wir unwirkliche." (Ebd.: 287, H.i.O.) Denn nur im Vergleich zu diesen unwirklichen Kausalverläufen lasse sich die geschichtsrelevante Kausalität eines isolierten Ereignisses bestimmen.

Weber dient in der Kausalfrage das Recht respektive die rechtswissenschaftliche Methode nicht mehr als Negativfolie, sondern als Vorlage für die Bestimmung der Kausallogik der empirischen Wissenschaften. Und der Grund liegt in der gleichartigen logischen Struktur der kausalen Fragestellung in beiden Disziplinen.

\section{Die Stammler-Kritik: Die Abwehr der rechtswissenschaftlichen Bestimmung des Sozialen}

Wenn aber die Art und Weise, wie idealtypische Begriffe für die empirischhistorische Kulturwissenschaft gebildet werden können, im hohen Maße einer Form von juristischer Begriffsbildung entspricht, und die historische und die juristische Kausalitätsfrage für Weber dieselbe logische Struktur aufweisen, dann stellt sich auf wissenschaftslogischer Ebene die Frage, ob es sich bei den Sozialwissenschaften und der Rechtswissenschaft überhaupt um verschiedene Wissenschaftsformen handelt. Oder anders formuliert: Wenn Weber die empirische Wirklichkeit (auch) mit den Mitteln und dem logischen Verfahren der Rechtswissenschaft betrachtet, ist er genötigt dazulegen, warum eine derartig verfahrende Sozialwissenschaft auf

831 Dabei lasse das objektive Möglichkeitsurteil seinem Wesen nach graduelle Abstufungen zu (vgl. ebd.: 285).

$832 \mathrm{Zu}$ Abweichungen von der juristischen Kausaltheorie vgl. Gephart 1993a: $453 \mathrm{ff}$. 
erkenntnis- und wissenschaftstheoretischer Ebene gerade nicht den Rechtswissenschaften zuzuordnen ist. Erst dann kann die historisch-kausale Kulturwissenschaft, respektive in der Folge auch die Soziologie, ihre Autonomie als eigenständige Disziplin behaupten - und genau darum geht es in der Stammler-Kritik.

In Wirtschaft und Recht will Stammler den Geschichtsmaterialismus auf der erkenntnistheoretischen Ebene überwinden. Gerade als Erkenntnistheoretiker kann Weber Stammler jedoch nicht ernstnehmen. ${ }^{833}$ In einer an Schärfe kaum zu überbietenden Polemik wendet Weber sich gegen das „wahre[] Dickicht von Scheinwahrheiten, Halbwahrheiten, falsch formulierten Wahrheiten und hinter unklaren Formulierungen versteckten Nicht-Wahrheiten, von scholastischen Fehlschlüssen und Sophismen" (Weber 1988d [1907]: 292) in Stammlers Werk. ${ }^{834}$ Es sei ein „Weichselzopf [...] elementarer logischer Fehler" (ebd.: 310), die von der Verwendung uneindeutiger Begrifflichkeiten zu einer „schülerhaften Vermengung der allereinfachsten Kategorien“ (ebd.: 307), von einem beständigen salto mortale zwischen der Ebene der Tatsachen-Erkenntnis und der Tatsachen-Bewertung bzw. zwischen Erklärung und Werturteil bis zu gänzlich unhaltbaren Konstruktionen von Kategorien als Grundvoraussetzungen für alle Erfahrung reichten (vgl. ebd.: 304ff.). Aus dieser Gemengelage folgere Stammler, dass unter Beachtung des Satzes vom zureichenden Grund nur ein einziges allgemeines Gesetz existieren könne, das für das gesamte soziale Leben gelten müsse, und das als „,höchste' Allgemeinheit ,Form ' des Seins und zugleich des Erkennens der sozialen Wirklichkeit, als der entsprechenden ,Materiec, sei“ (ebd.: 318, H.i.O.). ${ }^{835}$ Diese Argumentation ist

833 Er unterstellt ihm sogar, dass die „Arbeiten der Fachlogiker“ - und hier muss man insbesondere an die Arbeiten über die Logik der Wissenschaften der Neukantianer denken, zu denen Stammler sich nach Weber zählt - „spurlos [an ihm] vorübergegangen“ seien (Weber 1988d [1907]: 293) bzw. er diese „nicht oder doch nur ganz oberflächlich kennt“ (ebd.: 321).

834 Weber rechtfertigt die Schärfe seiner Angriffe unter anderem mit der Tatsache, dass es sich um die zweite Auflage handele und Stammler genügend Zeit gehabt hätte, die logischen Fehler seines „ersten Wurf[s]" nachzubessern (ebd.: 293) das mag zwar versöhnlich gegenüber Stammlers erster Auflage klingen, mindert die inhaltliche Kritik aber ebenso wenig wie die Verweise auf ein etwaiges „hohes Maß nicht nur an Belesenheit, Scharfsinn und idealistischen Erkenntnisstreben" und „einzelne dauernd wertvolle Bestandteile" des Buches (ebd.: 291, H.i.O.).

835 Diese Allgemeinheit werde allerdings, so fährt Weber fort, zugleich wieder über die Fundierung der Form im Materiellen relativiert (vgl. ebd.: 318f.). Aufgrund 
für Weber logisch weder notwendig noch haltbar. ${ }^{836}$ Daher spricht er Stammlers Werk letztlich „die wissenschaftliche Existenzberechtigung überhaupt" ab (ebd.: 291) - und sucht trotzdem die sachliche Auseinandersetzung.

Der Grund liegt in der eigentlichen Problemstellung bzw. dem eigentlichen Zweck, den Weber in Wirtschaft und Recht erkennt, nämlich

die „Wissenschaft vom sozialen Leben“ als eine von den „Naturwissenschaften“ schlechthin verschiedene dadurch zu erweisen, daß „soziales Leben“ als ein von der "Natur" gänzlich verschiedenes Objekt der Betrachtung aufgezeigt und damit ein von der „naturwissenschaftlichen Methode" verschiedenes Prinzip der Sozialwissenschaft als logisch unvermeidlich dargetan wird (ebd.: 320, H.i.O.).

Der - nach Weber zwar gänzlich unklare - Rekurs Stammlers auf die Abgrenzung von Natur- und (nun) teleologischer Sozialwissenschaft berührt die erkenntnis- und wissenschaftstheoretische Ebene. Deswegen erscheint die Auseinandersetzung für Webers Vorhaben der Entwicklung der methodischen und begrifflich-theoretischen Vorgaben einer „empirischen sozialen Kulturwissenschaft" (Weber 1988b [1904]: 213) so wichtig.

Die Frontstellung ist nun aber eine andere als im nationalökonomischen Methodenstreit: Ging es für Weber im Roscher und Knies- bzw. im Objektivitäts-Aufsatz um die Frage des Verhältnisses von theoretischer Begriffsbildung und historisch-empirischer Forschung auf Basis der neukantianischen Abgrenzung von gesetzes- und historischen Wissenschaften, steht nun die Verhältnisbestimmung zu einem weiteren Wissenschaftstyp zur Debatte: den normativ-dogmatischen Wissenschaften. Diese Erweiterung der Wissenschaftsqualifikationen wird insbesondere in Webers Diskussion der Gruppierungsmöglichkeiten ersichtlich, die man angesichts Stammlers Abgrenzungsversuchen zu den Naturwissenschaften erstellen könne: Wenn man nicht „Natur' als ein Komplex bestimmter Objekte ge-

der logischen Mängel, die dieser Hypostatierung zugrunde liegen, bestreitet Weber, dass Stammler den Geschichtsmaterialismus in irgendeiner Weise überwunden habe.

836 So schreibt Weber: „Denn wieso aus der Geltung des Satzes vom zureichenden Grunde [nach Stammler, D.S.] für alles historische Geschehen und jede Erscheinung des Gesellschaftslebens folgen soll, daß alles historische Geschehen und jede Erscheinung des gesellschaftlichen Lebens in letzter Instanz aus einem seiner Elemente allein müsse erklärt werden können, widrigenfalls ein Verstoß gegen die Kategorie der Kausalität vorliege, das ist denn doch wahrlich nicht einzusehen." (Ebd.: 315, H.i.O.). 
gen andere heterogene“ (Weber 1988d [1907]: 321, H.i.O.) abgrenzt, sondern im Sinne der neukantianischen Erkenntnislehre nach Art der Betrachtungsweise die Naturwissenschaften von der Geschichte unterscheide, dann blieben „die dogmatischen Disziplinen ganz jenseits des Gegensatzes“ (ebd.: 322). ${ }^{837}$ Wenn man demgegenüber unter ,Natur' „die Gesamtheit der eine empirisch-kausale „Erklärung" erstrebenden Disziplinen“ fasse, also auch die historische Betrachtung mit ihren spezifisch individualisierenden Kausalitätszurechnungen, dann seien ihnen diejenigen Disziplinen „entgegengestellt, welche normative oder dogmatisch-begriffsanalytische Ziele verfolgen: Logik, theoretische Ethik und Aesthetik, Mathematik, Rechtsdogmatik, metaphysische (z.B. theologische) Dogmatiken“ (ebd.). Die Differenz beziehe sich auf den „Gegensatz der Urteilskategorien (,Sein` und ,Sollen')“ (ebd.), wobei allein erstere mit der Kategorie der Kausalität arbeite. Schließlich könne man Natur als das Sinnlose fassen, aber selbst dann müsse man im Bereich des Sinns zwischen faktischem und dogmatischem Sinn unterscheiden: Streng zu trennen sei die „empirischen Tatsache [...], daß Vorgänge bestimmter Art mit einem gewissen, nicht im einzelnen klar durchdachten, sondern unklar vorschwebenden ,Sinn' vorstellungsmäßig verbunden faktisch vorkommen " von der Frage: „wie läßt sich der ,Sinn' des Handelns der Beteiligten derart gedanklich konstruieren, daß ein in sich widerspruchsloses Gedankengebilde entsteht?" (Ebd.: 333f., H.i.O.) Dann verlasse man aber das Gebiet des Empirischen und betreibe „Dogmatik' des ,Sinns““ (ebd.: 334). In allen Varianten der Abgrenzung von Natur und Naturwissenschaften macht Weber eine Dreiteilung in nomothetische, individualisierend-historische und dogmatische Wissenschaft geltend. ${ }^{838}$

Weber reagiert mit dieser Dreiteilung auf ein spezifisches Problem. Anders als in seiner Kritik der historisch-ethischen Richtung der Nationalökonomie, die irrigerweise von Seinstatsachen auf Sollensaussagen schließe, geht es Weber in seiner Stammler-Kritik nun um die Kritik der Vorstel-

837 Klassifiziert man die Wissenschaften ausgehend von ihrer spezifischen Erkenntnisweise durch den logischen Gegensatz von ,naturwissenschaftlicher' Erkenntnis als die generelle (nomothetische) und individueller (historischer), dann gehören Wissenschaften wie „die ,Psychologie', die ,Sozialpsychologie', ,Soziologie', theoretische Sozialökonomik, ,vergleichende Religions'- und ,vergleichende Rechtswissenschaft““, die auf generelle Aussagen gerichtet seien, „zu den ,Naturwissenschaften“" (ebd.: 322).

838 Strenggenommen ist diese Dreiteilung für die erste Variante, die Abgrenzung über Objekte, irrelevant. Da Weber aber eine solche Einteilung der Wissenschaften ablehnt (vgl. Borchardt et al. 2013: 169 Fn. 44), ist dies für den Aufschluss über sein eigenes Denken hier nicht von Belang. 
lung, dass man vom Reich des Sollens, dem Recht, in das des Seins gelangen könne. Es handelt sich um die Problematisierung von Sein und Sollen in jenem umgekehrten, da juristischen Werturteilsstreit, in dem man ausgehend von der unumgehbaren Wertung im Recht um Beziehung der juristischen Begriffsbildung zu den Tatsachen des Lebens streitet. Und in der Tat lässt sich diese Engführung auf die spezifische juristische Problemstellung in Webers Stammler-Kritik zeigen, wenn er sein Anliegen dahingehend bestimmt, die „rechtsdogmatischen Verfälschungen des empirischen Denkens zu kritisieren“ (ebd.: 345 Fn. 1, H.i.O.). ${ }^{839}$ Was nottut, sei also Klärung der Beziehungen zwischen empirischem und juristischem Denken, d.h. die Verhältnisbestimmung der Jurisprudenz respektive der Rechtsdogmatik zur soziologischen Begriffsbildung - jene Engführung, mit der sich das Ende des veröffentlichten Teils seiner Stammler-Kritik ,Juristische und empirische Begriffe" befasst (vgl. ebd.: 345ff.). Was man dabei von Stammler lernen könne, sei, ,wie man mit diesen Problemen nicht umspringen darf“ (ebd.: 345, H.i.O.).

Vor diesem Hintergrund lassen sich auch Webers Ausführungen zum Regelbegriff verstehen. Sie setzen an Stammlers These an, dass die formale Eigenart des sozialen Lebens in ihrer Geregeltheit zu sehen sei, d.h. dass es unter äußeren Regeln stehe und Recht dann die Form der Gesellschaft darstelle (s.o. $\$ 3$ 3.II.1.3). Es geht also zentral um das Ordnungsproblem, zu dessen Lösung Stammler auf das Recht zurückgreift. Genau diese Verhältnisbestimmung von Recht und sozialem Leben greift Weber an, indem er eine Begriffsdifferenzierung vornimmt. Bekanntlich unterscheidet er dabei zwei mögliche Bedeutungsinhalte des Regelbegriffs: einerseits die „empirische Regelmäßigkeit“, die das „Sein“ unter dem Gesichtspunkt der generellen Gesetze oder Erfahrungssätze betrachtet; und andererseits und im strengen Gegensatz dazu die „Norm“ als eine „generelle Aussage also eines (logischen, ethischen, ästhetischen) Sollens“, die als Imperativ gilt und an

839 Insofern verwundert es auch nicht, wenn Weber dem „Juristen“ Stammler (vgl. Weber 1988g [1913]: 427) allenfalls dann eine logische Stringenz bzw. Berechtigung zuerkennen mag, wenn a) dessen ,Sozialwissenschaft' Jurisprudenz hätte sein sollen bzw. dessen Anliegen darin gelegen hätte, „auch die ,konventionellen' Regeln nach Art der dogmatischen Jurisprudenz [zu] erörter[n]" (Weber 1988e [aus dem Nachlass]: 383) oder er b) "von Anfang an klipp und klar gesagt“ hätte, „daß es ihm allein auf das Seinsollende ankomme, daß er ein ,formales“ Prinzip aufzeigen wolle, welches dem Gesetzgeber auf die Frage de lege ferenda, dem Richter in den Fällen, wo an sein billiges ,Ermessen' appelliert ist, einen Wegweiser an die Hand geben solle“ (Weber 1988d [1907]: 359, H.i.O.). 
dem „Vorgänge im Sinn eines Werturteils ,gemessen“ werden“ (ebd.: 323, H.i.O.).

Als dritten, quer dazu liegenden Begriff führt Weber die „,Maximen“ des Handelns“ (ebd.) in ihrer „das empirische Verhalten des Individuums kausal beeinflussenden Wirksamkeit“ (ebd.: 327) ein. Er fasst darunter kausal wirkende Handlungsorientierungen im Bereich des empirisch Seienden, d.h. subjektive Vorstellungen, an denen der Akteur sein Handeln orientiert und die damit auf den subjektiv gemeinten „Sinn“ der Akteure verweisen (ebd.: 336f.). Es handele sich um die Orientierung des Individuums an den „Regeln“ im mehrfachen Wortsinn: Als „Norm-Maxime“ (ebd.: 334) sind dies „Vorstellung[en] von der ,Norm', als reales Agens des Handelns wirkend“ (ebd.: 329), als „Zweck-Maxime“ (ebd.: 336), etwa im Bereich der Ökonomie, erfolge die Orientierung an einer Erfolgsvorstellung, wofür in der Zweck-Mittel-Abwägung dann ebenso Erfahrungssätze zum Tragen kommen. ${ }^{840}$ Als Maxime werden die Regeln in ihrem doppelten Wortsinn kausal wirksam: „Auf dem Gebiet des ,Seins““, d.h. auf dem „Gebiet der rein empirisch-kausalen Betrachtung“ (ebd.: 336, 338), gibt es die Regel „nur im Sinne einer kausal erklärbaren und kausal wirksamen empirischen ,Maxime“" (ebd.: 336).

$\mathrm{Zu}$ welchen Differenzierungen diese begriffliche Dreiteilung für die empirisch-kausale Betrachtung der Sozialwissenschaft führt, zeigt Weber am Beispiel der Skatregel: ${ }^{841}$ Wenn man unterstelle, dass die Skatregel „Voraussetzung" eines konkreten Spiels sei, so könne dies im Bereich der empirischen Betrachtung nur bedeuten, dass die Spielregeln zu einem der „Mitbestimmungsgründe“ bzw. „kausale[n] Determinante“ (ebd: 339, 342) des faktischen Handelns der Spielenden zu zählen sei. Denn diese setzten faktisch doch „- normalerweise - voneinander ,voraus', daß jeder die Spielregel zur ,Maxime“ seines Handelns machen werde" (ebd.: 339). Logisch anders gelagert sei demgegenüber die Aussage, dass die Skatregel „Voraussetzung“ der Skaterkenntnis sei. In diesem Fall liege zum einen der „Dienst des Normbegriffs bei der Klassifikation und Objekt-Abgrenzung“ (ebd.: 340): „Wir ,klassifizieren“ einen Komplex von Vorgängen dann als ,Skat', wenn solche für die Anwendung der Norm als relevant geltende

840 Weber geht empirisch von einem Wechselspiel zwischen Zweck- und Normmaxime aus (vgl. ebd.: 334f.), was in der Diskussion der erkenntnis- und wissenschaftstheoretischen Implikationen jedoch von untergeordnetem Interesse ist.

841 Will man den Hergang eines konkreten Skatspiels genau ergründen, so zeige sich zunächst, dass unterschiedliche, verschiedene "Orientierungspunkte“ liefernde Maximen (Weber nennt Sittlichkeits-, Rechtlichkeits- und Zweck-Maximen) kausal wirksam würden (ebd.: 338). 
Vorgänge sich darin finden. [...] Die Relevanz vom Standpunkt der ,Norm' grenzt das Untersuchungs-Objekt ab“ (ebd., H.i.O.). Diese Bildung eines „empirischen Kollektivum[s] eines ,Skatspiels““ (ebd.) sei dann aber nur den Ausgangspunkt für eine daran anschließende empirisch-kausale Betrachtung, die weitere Kausalfaktoren in Rechnung zu stellen habe. Schließlich habe die Kenntnis des „Skatrechts“ eine heuristische Funktion im Rahmen der kausalen Erkenntnis. Denn sie diene dazu, die „Art dieser Beeinflussung und also die empirische Kausalität des Handelns der Spieler erkennen zu können" (ebd.: 342). Das Wissen von der ideellen Norm diene so der Idealtypenbildung, da man neben der Annahme des streng rationalen Spielens eben davon ausgehe, dass „die ideale Spielregel (das ,Skatrecht") faktisch innegehalten "werde (ebd.).

Man müsse nun - so Weber - diese unterschiedlichen Funktionen der „Norm“ (Skatregel) im Rahmen der empirischen Erörterung eines konkreten Geschehens streng logisch unterscheiden, um der „stet[en] Gefahr der hoffnungslosen Konfusion des Empirischen mit dem Normativen" (ebd.: 343) zu begegnen. Das gelte vor allen dann, wenn man - wie Stammler auf das Gebiet der „Rechtsregel“ wechsele, auf dem „die an unserem Skatbeispiel demonstrierten Arten von logisch möglichen Betrachtungsweisen [...] wiederkehren“ (ebd.: 345). Die rechtspolitische Perspektive, d.h. die Frage nach dem Wert oder Unwert rechtlicher Regelungen, ist nach Weber für das logische Problem der „Beziehung der Rechtsregel zum ,sozialen Leben“" (ebd.: 349) irrelevant. Diese Einschätzung muss man als Absage an das gesellschaftsfunktionale Zweckdispositiv in der Debatte um die soziale Aufgabe des BGBs lesen. Denn bei der Diskussion darum, ob die Regelungen des BGBs das Ideal der gesellschaftlichen Ordnungssicherung verwirklichten und daher, richtiges Rechts' seien, handelt es sich in Webers Augen letztlich um eine „direkt wertende[] Erörterung“ (ebd.: 345) anhand von normativen Zielvorgaben. Zwar könne man die Wirkung von Rechtsnormen sozialwissenschaftlich erörtern; ob diese Wirkung aber erwünscht sei, könne jedoch auf wissenschaftslogischer Ebene für die kausal verfahrenden Sozialwissenschaften nicht von Belang sein (vgl. auch Weber in Simmel et al. 1911c: 312).

Demgegenüber müsse man bei der Erörterung eines Paragraphen (etwa des BGBs) aus wissenschaftstheoretischer Perspektive zwei Fragerichtungen streng voneinander trennen, die jeweils nicht auf Werte bezogen seien. Wenn man im ersten Fall danach frage: „[W]as ,bedeutet' er begrifflich?“ (Weber 1988d [1907]: 345, H.i.O.), so betrachte man die Rechtsregel als eine in Worte gefasste Gedankenverbindung, d.h. als „eine ideale gedanklich erschließbare Norm" (ebd.: 348, H.i.O.). Die Rechtswissenschaft strebe dabei nach der, ,juristischen Wahrheit“, indem sie frage, was in con- 
creto „gedanklich nach ,wissenschaftlichen' Grundsätzen als solche, gelten“ solle oder hätte ,gelten' sollen“ (ebd., H.i.O.). Eine Rechtsordnung gliedere sich in dieser Perspektive

in ein System von Gedanken und Begriffen, welches der wissenschaftliche Rechtsdogmatiker als Wertmaßstab benützt, um das faktische Verhalten gewisser Menschen: der „Richter“, „Advokaten“, „Delinquenten“, „Staatsbürger" usw. daran, juristisch wertend, zu messen und als der idealen Norm entsprechend oder nicht entsprechend anzuerkennen oder zu verwerfen (ebd.).

Dabei treten Sinn und Wertung in ein Stufenverhältnis, der Sinn der Norm wird zum Wertmaßstab: Die dogmatische Betrachtung etwa einer Satzung ermittele deren ,ideellen ,Sinn““, der wiederum die Basis bilde der "wertende[n] Messung des empirischen Handelns an ihr" (Weber 1988e [aus dem Nachlass]: 381, H.i.O.). ${ }^{842}$

Ganz anders verfahre man angesichts der zweiten Frage: ,[W]as , wirkt ${ }^{\star}$ er [der Paragraph des BGBs, D.S.] empirisch?"“ (Weber 1988d [1907]: 346, H.i.O.) Der Paragraph werde als empirische Tatsache betrachtet - als ein bestimmtes mit Schriftzeichen bedecktes Papier, v.a. aber als „empirisches Gelten" im Rahmen einer Serie komplizierter Kausalverknüpfungen (ebd.: 346). Die Rechtsregel sei dann „eine empirische, als mehr oder minder konsequent und häufig befolgt, feststellbare Maxime des Verhaltens konkreter Menschen“ (ebd.: 348, H.i.O.). Eine „empirische Rechtsordnung“ könne man dann nur „als eine das Handeln von Menschen kausal mitbestimmende Vorstellung von etwas, das sein soll, als ,Maxime' also", begreifen (ebd.: 347, H.i.O.): das empirische Sein des Rechts als Maxime-bildendes Wissen konkreter Menschen. Als solches sei sie nicht anders zu behandeln wie das Wissen von irgendeinem anderen Erfahrungssatz - etwa aus dem Bereich der Technik oder der Naturwissenschaften. Die empirische Rechtsordnung sei daher „nur ein Posten in der Wahrscheinlichkeitsrechnung betreffend den zu gewärtigenden empirischen Verlauf" (ebd.: 350, H.i.O.), und ihre kausale Bedeutung ändere sich je nach historisch-spezifischer Si-

842 Dabei handelt es sich nicht um die rein subjektiven, praktischen Wertungen, die Weber aus dem Bereich der Wissenschaft ausschließt (s.u.). Denn die Interpretation von Normen, seien es logische, ästhetische oder rechtliche, ermögliche wissenschaftliche Richtigkeitsurteile: „Eine bestimmte Wertung als die allein ,wissenschaftlich`zulässige uns zu oktroyieren, vermag sie [die Interpretation, D.S.] nur, wo, wie etwa bei dem Gedankengehalt von Marx’ Kapital, Normen (in diesem Fall solche des Denkens) in Betracht kommen." (Weber 1988c [1906]: 246, H.i.O.). 
tuation (vgl. ebd.: 352). Daher müsse man auch eine Grenze in der Analogie mit der Skatregel markieren: Der juristische Begriff etwa des Tausches könne nicht wie die Skatregel zur Klassifikation und ObjektAbgrenzung dienen - im empirischen Leben seien auch andere Kriterien, etwa ökonomische, von entscheidender Bedeutung (vgl. ebd.: 345).843

Was Weber mit seiner Begriffsdifferenzierung mit aller Macht geltend macht, um die unzulässige Konfusion zwischen Normativität und Empirie zu vermeiden, ist die wissenschaftstheoretische Trennung von juristischer und sozialwissenschaftlicher respektive soziologischer Betrachtungsweise des Rechts, auf die er immer wieder zu sprechen kommt. Diese Trennung ist für Weber streng logisch, ein Übergang dieser beiden Erkenntnisweisen ist ausgeschlossen (vgl. Weber 1988e [aus dem Nachlass]: 381). Die kausale Relevanz des Rechts für das soziale Leben, d.h. im Empirischen, vollziehe sich nur über Maximen, und eine Ordnungsleistung des Rechts entspringe nicht der juristischen Rechtsordnung, sondern nur der Geltung der „empirischen Rechtsordnung“.

Dabei erkennt Weber eine grundsätzlich hohe Relevanz einer solchen Handlungsorientierung der Menschen am Recht an: So bediene man sich aufgrund der hohen Entwicklung des juristischen Denkens oft der juristischen Begriffe als Vorformung des Materials (vgl. Weber 1988d [1907]: 353), ja dienten Rechtsbegriffe (wie etwa der des Tausches) „sehr häufig als ,Archetypos' des betreffenden ökonomischen Begriffs" (ebd.: 344) - um ihm dann aber einen anderen Sinn zu geben. Auch sei die faktische Tragweite der empirischen Rechtsordnung kaum zu überschätzen, nicht zuletzt auch deshalb, weil man sich dem Geltungsbereich des Rechts gar nicht entziehen könne. Schließlich wirke das Recht in der Form generalisierter Sätze, an denen man sich orientiere, "teils direkt, teils indirekt zur Erzeugung empirischer Regelmäßigkeiten" mit (ebd.: 355, H.i.O.). ${ }^{844} \mathrm{Nach}$ Weber vermag aber auch diese Anerkennung eines großen kausalen Einflusses des Rechts bzw. der Rechtsordnung auf die soziale Ordnung nicht

843 Es gelte mithin: „In ihrer Stellung als ,Voraussetzung“ der Bildung des Kollektivbegriffs scheidet die Rechtsnorm alsdann im Prinzip aus“ (Weber 1988d [1907]: 344). Allerdings kann der Rechtsbegriff als Idealtypus dienen (s.u. \$8.III.4.2).

844 Dabei handele es sich aber nicht um „Projektionen“ (ebd.: 355), wie Weber gegen Wurzel einwendet. Da die ausschließliche Orientierung an den Erwartungen anderer nach Weber letztlich durch „absolute Labilität“ gekennzeichnet ist (Weber 1988g [1913]: 446), wird die Orientierung an Satzungen (Recht) zur Voraussetzung einer stabilen Ordnung (Gephart 1993a: 479ff.). 
die logische Trennung juristischer und sozialwissenschaftlicher respektive soziologischer Betrachtungsweise des Rechts zu relativieren. ${ }^{845}$

Gerade aufgrund dieser Trennung sei es aber - trotz der hohen Relevanz des Rechts als Kausalfaktor im sozialen Leben - schlichtweg logisch nicht haltbar, wie Stammler das Recht als „Form“ des sozialen Lebens zu fassen:

Die Rechtsregel, als „Idee“ gefaßt, ist ja keine empirische Regelmäßigkeit oder "Geregeltheit", sondern eine Norm, die als "gelten sollend“ gedacht werden kann, also ganz gewiß keine Form des Seienden, sondern ein Wertstandard, an dem das faktische Sein wertend gemessen wird, wenn wir ,juristische Wahrheit" wollen. Die Rechtsregel, empirisch betrachtet, ist aber erst recht keine „Form“ des sozialen Seins, wie immer das letztere begrifflich bestimmt werden möge, sondern eine sachliche Komponente der empirischen Wirklichkeit, eine Maxime, die, in mehr oder minder großer „Reinheit“, das empirisch zu beobachtende Verhalten eines, in jedem einzelnen Fall unbestimmt großen, Teils der Menschen kausal bestimmt und im Einzelfall mehr oder minder bewußt und mehr oder minder konsequent befolgt wird. (Ebd.: 349, H.i.O.)

Weber wirft Stammler das Hinübergleiten vom Seinsollenden ins Sein vor, ohne die Vermittlung dieser Ebenen über faktisch kausal wirksame Maxime erkannt zu haben. Stammler habe den Sinn der wissenschaftlichen Begriffsbildungen missverstanden, weil er die logische Differenz zwischen einem ,ideellen' Geltensollen einer Norm und einem rein faktischen Tatbestand missachte (vgl. Weber 1988e [aus dem Nachlass]: 381). ${ }^{846}$ Dadurch richte er eine regelrechte Konfusion zwischen Telos und Kausalität an (vgl. ebd.: 362). Namentlich werde

die ideelle „Geltung“ einer Norm als eines Maßstabes der Bewertung, den wir, die Betrachtenden anwenden, wieder in einen empirischen Bestimmungsgrund menschlichen Handelns umgedeutet und dieser

845 Daher können nach Weber zwar auch neue Rechtsätze aus Gewohnheiten erwachsen (Gewohnheitsrecht). Das lasse aber keinerlei Rückschlüsse auf die rechtsdogmatische Ebene zu (vgl. Weber 1988d [1907]: 356).

846 Dabei handele es sich jedoch um gänzlich „verschiedene Fragestellungen und Richtungen unsres Erkennens [...]: im einen Fall dogmatische Betrachtung einer ,Satzung' auf ihren ideellen ,Sinn' hin und ,wertende“ Messung des empirischen Handelns an ihr, - im andern Fall Feststellung des empirischen Handelns als ,Tatsache' und kausale ,Erklärung' desselben“ (Weber 1988e [aus dem Nachlass]: 381, H.i.O.). 
empirische Tatbestand [...] als das spezifische Merkmal „äußerlich geregelten Zusammenlebens" hingestellt (ebd.: 372, H.i.O.).

Was Stammler im Zuge seiner Abgrenzungsbemühungen der Sozialwissenschaft von der Naturwissenschaft allenfalls "hätte meinen können“ (ebd.: 368, H.i.O.) bzw. „wollen könnte“, sei die

\begin{abstract}
Abgrenzung des Objekts vom Standpunkt der „äußeren Regel“, und zwar der Regel nicht als empirischer Faktizität, sondern als „Idee“, [...] indem das Ineinanderfließen von ideeller „Geltung“ und empirischem "Sein“ der „Regel“ beseitigt und zugleich die unglückselige Vorstellung abgeschnitten wäre, als ob in dem so abgegrenzten Gebiet eine eigene „Welt der Zwecke“ oder überhaupt irgend etwas nicht der kausalen Betrachtung Unterliegendes, dennoch aber empirisch Existentes gegeben sei (ebd.: 383, H.i.O.).
\end{abstract}

Die Auseinandersetzung mit Stammler wird für Weber in einem doppelten Sinne relevant: Zum einen zeigt sich darin, wie man das Ordnungsproblem in der Soziologie gerade nicht lösen kann. Zum anderen müsse man juristische und soziologische Wissenschaft auseinanderhalten, um das Werturteilsproblem zu klären und nicht unzulässigerweise vom Seinsollenden ins Sein zu gleiten.

\title{
4. Der Kategorien-Aufsatz: Die Konkurrenz zur Rechtsdogmatik
}

Wie man das Ordnungsproblem - gerade angesichts der hohen kausalen Relevanz des Rechts für das soziale und insbesondere das wirtschaftliche Leben - lösen könnte, was also Stammler „hätte meinen sollen“ (Weber 1988g [1913]: 427 Fn. 1), damit beschäftigt sich Weber im Kategorien-Aufsatz. ${ }^{847}$ Weber entwickelt darin die methodischen und begrifflichen

847 In der Vorbemerkung zum Kategorien-Aufsatz betont Weber die Nähe zur Stammler-Kritik, wenn er über seine eigene Begriffsbildungen schreibt: „Die Art der Bildung soziologischer Begriffe ist überaus weitgehend Zweckmäßigkeitsfrage. Keineswegs alle nachstehend [...] aufgestellten Kategorien sind wir genötigt zu bilden. Sie sind zum Teil entwickelt, um zu zeigen, was Stammler , hätte meinen sollen'." (Weber 1988g [1913]: 427 Fn. 1, H.i.O.) Daher liest Siegfried Hermes den Kategorien-Aufsatz als „positive Begriffskritik Stammlers“ (Hermes 2007: 426), womit man dieselbe intellektuelle Bewegung wie vom Roscher und Knies- zum Objektivitäts-Aufsatz erkennen könne: von der Kritik zur Problemlösung. 
Grundlagen seiner „verstehenden Soziologie“. ${ }^{848}$ Im Zentrum steht also das Ordnungsproblem, das er aus einer streng handlungstheoretischen Perspektive zu lösen sucht. Im Kontrast zum vergegenständlichten Gebrauch von Kollektivbegriffen (vgl. Tenbruck 1981: 337; 1984: 133 f., 203) und daher jenseits einer ambitionierten Theorie des Dings, Gesellschaft' vermeidet er den Gesellschaftsbegriff (vgl. Weiß 1988; Tyrell 1994; Lichtblau 2000, 2005). Stattdessen versucht Weber, die mit abstrakten Allgemeinbegriffen verbundenen Ordnungsvorstellungen über die empirische Geltung auf das sinnhaft deutbare Handeln der an den jeweiligen Beziehungen und Prozessen beteiligten Individuen zurückzuführen. Von dieser Warte aus unterliegt das faktische Zustandekommen der einzelnen Formen sozialer Ordnung einer probabilistischen Logik (vgl. Lichtblau 2000: 428f.) - es geht um die „Chancen“ der empirischen Geltung.

Damit begreift Weber „das Einzelindividuum und sein Handeln als unterste Einheit“ der verstehenden Soziologie, d.h. „als ihr ,Atom““ (Weber 1988g [1913]: 439). Diesem ,methodologischen Individualismus' folgend gelte es, das Handeln zu „verstehen“ und kausal zu erklären (vgl. ebd.: 436) - jener "Sinn“ der verstehenden Soziologie, den Weber später in den Soziologischen Grundbegriffen definiert: „Soziologie (im hier verstandenen Sinn dieses sehr vieldeutig gebrauchten Wortes) soll heißen: eine Wissenschaft, welche soziales Handeln deutend verstehen und dadurch in seinem Ablauf und seinen Wirkungen ursächlich erklären will.“ (Weber 1988j [1921]: 542)

Angesichts dieses handlungstheoretischen Fundaments nimmt Weber zwei wissenschaftslogische Abgrenzungen vor, um die Eigenart seiner, verstehenden Soziologie ' herauszuarbeiten: Zum einen sei diese nicht mit der psychologischen Betrachtungsweise zu verwechseln (Weber 1988g [1913]: 432ff.). Zum anderen - und das steht hier zur Debatte - müsse man das Verhältnis zur Rechtsdogmatik klären (ebd.: 439f.), das sich durch eine besondere Konkurrenz hinsichtlich der Begrifflichkeiten auszeichne:

Wenn sie [die soziologische Betrachtungsweise, D.S.] nun genötigt ist, hier wie oft das gleiche Wort wie die juristische Wissenschaft zu ge-

848 Die grundbegriffliche Terminologie aus dem Kategorien-Aufsatz liegt dem älteren und umfangreicheren Teil von Wirtschaft und Gesellschaft zugrunde, auch wenn umstritten ist, inwiefern der Aufsatz damit als Verbindungsglied der verschiedenen Werkphasen dieser Vorkriegsmanuskripte anzusehen ist (vgl. Orihara 1999; Schluchter 1999). Zum Datierungsproblem der einzelnen Teile des Aufsatzes, aus dem Rückschlüsse für die Werkgenese der Vorkriegsmanuskripte auch der Rechtssoziologie - zu ziehen sind, vgl. die divergierenden Einschätzungen von Schluchter 2000c, 2000a, 2005b; Hermes 2007; s.a. Weiß 2018: 60ff. 
brauchen, so ist doch dessen juristisch, richtiger' Sinn dabei nicht der von ihr gemeinte. Es ist aber allerdings das unvermeidliche Schicksal aller Soziologie: daß sie für die Betrachtung des überall stetige Uebergänge zwischen den ,typischen' Fällen zeigenden realen Handelns sehr oft die scharfen, weil auf syllogistischer Interpretation von Normen ruhenden, juristischen Ausdrücke verwenden muß, um ihnen dann ihren eigenen, von dem juristischen der Wurzel nach verschiedenen, Sinn unterzuschieben. (Ebd.: 440)

Es geht also darum, die Bedeutung der juristischen Begriffsbildung für die Soziologie Webers zu klären. Der Grund für diese Bedeutung liegt in den sachlichen Implikationen von Webers nach Zweckmäßigkeitsgesichtspunkten gebildeten Kategorien. ${ }^{849}$ Ihnen liegt die Engführung der handlungsleitenden Orientierungen auf normative Ordnungen zugrunde - und genau daraus folgt eine gewisse „Idealtypik“ der juristischen für die soziologische Begriffsbildung.

\subsection{Die kategoriale Orientierung an normativen Ordnungen}

Auf der streng handlungstheoretischen Basis entwirft Weber kategoriale bzw. grundbegriffliche Handlungstypen, ${ }^{850}$ mittels derer er soziale Ordnungsphänomene konzeptionalisiert: Unter Gemeinschaftshandeln versteht Weber ein menschliches Handeln, das subjektiv sinnhaft auf das Verhalten anderer Menschen bezogen ist. Den „rationale[n] Grenzfall“ (Weber 1988g [1913]: 442) des Gemeinschaftshandelns bilde die „sinnhafte Orientierung an den Erwartungen eines bestimmten Verhaltens anderer und den darnach für den Erfolg des eigenen Handelns (subjektiv) geschätz-

849 Wie der Titel des Aufsatzes zeigt, erhebt Weber mit seiner Begriffsbildung einen kategorialen Anspruch, aber keinen Anspruch auf kategoriale Vollständigkeit (vgl. Weber 1988g [1913]: 427 Fn. 1). An Hermann Kantorowicz schreibt Weber am 29. Dezember 1913 über seinen Kategorien-Aufsatz: „Es ist der Versuch, alles ,Organizistische', Stammlerische, Überempirische, ,Geltende` (= Normhaft Geltende) zu beseitigen und die ,soziologische Staatslehre' als Lehre vom rein empirischen typischen menschlichen Handeln aufzufassen, m.E. der einzige Weg - während die einzelnen Kategorien Zweckmäßigkeitsfragen sind.“ (Weber in Lepsius, Mommsen 2003: 442f., H.i.O.)

850 Weber verwendet die Ausdrücke ,Kategorien' und ,Grundbegriffe' synonym (vgl. Lichtblau 2006: 245; Schluchter 2016: 270). Vgl. zum Folgenden insbesondere Lichtblau 2000, 2017. 
ten Chancen“ (ebd.: 441, H.i.O.), also ein erwartungsorientiertes Verhalten.

Im Fall, dass dieses Gemeinschaftshandeln

1. sinnhaft orientiert ist an Erwartungen, die gehegt werden auf Grund von Ordnungen, wenn 2. deren „Satzung“ rein zweckrational erfolgte im Hinblick auf das als Folge erwartete Handeln der Vergesellschafteten, und wenn 3. die sinnhafte Orientierung subjektiv zweckrational geschieht (ebd.: 442),

nennt Weber dies Gesellschaftshandeln (vergesellschaftetes Handeln). 851 „[D]as die Vergesellschaftung herbeiführende Handeln“ (ebd.: 451, H.i.O.) wiederum, also dasjenige, durch das eine gesatzte Ordnung entweder durch Vereinbarung (z.B. Vertrag) oder durch oktroyierte Satzung (z.B. Gesetze) überhaupt erst zustande kommt, bezeichnet er als „Vergesellschaftungshandeln" (ebd.). Dabei unterscheidet Weber zwischen gelegentlichen („Gelegenheitsvergesellschaftung“) und dauernden Formen der Vergesellschaftung. Bildet für den ersten Fall der von der Existenz einer Rechtsordnung abstrahierte einzelne rationale Tausch den "Grenzfall“ (organlose Vergesellschaftung, ebd.: 451), stellt der "Zweckverein“ den „rationalen Idealtypus“ einer dauernden Vergesellschaftung dar. Für letzteren sind die Vereinbarung genereller Regeln (Satzung), die Existenz eigener Vereinsorgane, das für Vereinszwecke gebundene Vermögen sowie die Einrichtung eines Zwangsapparats konstitutiv. In seiner vollen Entwicklung bildet der Verein ein „perennierendes,soziales Gebilde““, da er in seinem Bestand vom Wechsel der am Gesellschaftshandeln Beteiligten unabhängig ist (ebd.: 448). 852

Daneben erkennt Weber noch einen weiteren Fall des Gemeinschaftshandeln: das Einverständnishandeln. Ihm liegt keine orientierungsleitende zweckrational vereinbarte Ordnung zugrunde. Dennoch verläuft dieser „Komplex von Gemeinschaftshandeln“ so ab, ,als ob eine solche stattgefunden hätte“ (ebd.: 452, H.D.S.). Man hat es also mit rein fiktiven Ordnun-

851 Zur divergierenden Einschätzung des Einflusses von Tönnies' Unterscheidung von Gemeinschaft und Gesellschaft auf Webers Verwendung der Begriffe, Vergemeinschaftung' und ,Vergesellschaftung' vgl. Bond 2012; Lichtblau 2000, 2017 jeweils m.w.N.

852 Vergesellschaftung liegt nicht nur im Falle der Existenz eines solchen Zweckvereins vor, da es nach Weber eine „Stufenleiter der Entwicklung von Gelegenheitsvergesellschaftung ausgehend und fortschreitend zum perennierenden ,Gebilde““ gibt (Weber 1988g [1913]: 451). Der Zweckverein ist jedoch der zweckrationale Idealtypus. 
gen zu tun, denen jedoch kein geringerer Geltungsanspruch zukommt als realen Ordnungen (vgl. Lichtblau 2017: 282, 293). Das Handeln der Beteiligten ist auf diese gemeinsam geteilte Unterstellung einer Ordnung, also als ob sie gesatzt worden wäre, sinnhaft bezogen, und zwar mit der Erwartung, dass dies auch seitens der anderen Interaktionsteilnehmern geschieht (vgl. Lichtblau 2000: 431). Weber will mit dem „Einverständnis“ also den Tatbestand fassen,

daß ein an Erwartungen des Verhaltens Anderer orientiertes Handeln um deswillen eine empirisch „geltende" Chance hat, diese Erwartungen erfüllt zu sehen, weil die Wahrscheinlichkeit objektiv besteht: daß diese anderen jene Erwartungen trotz des Fehlens einer Vereinbarung als sinnhaft „gültig" für ihr Verhalten praktisch behandeln werden (Weber 1988g [1913]: 456).

Dabei dürfe man das Einverständnis nicht mit einer freiwilligen Zustimmung, Eintracht oder Solidarität verwechseln. Auch verschiedene Arten der Kampfbeziehung zählt Weber zur „Einverständnis-Vergemeinschaftung" (vgl. ebd.: 463f.). Dass es sich also keinesfalls um eine harmonische, solidarische Einverständnisgemeinschaft handeln muss, zeigt sich auch am Beispiel der Marktgemeinschaft, die Weber neben der Sprachgemeinschaft als konkretes Beispiel für das Einverständnishandeln einführt.

Der Markt und die mit ihm verbundenen monetären Transaktionen sind also Teil einer einverständlichen Ordnung: ${ }^{853}$ So sei der Geldgebrauch an der Erwartung orientiert, dass auch die zukünftigen Marktteilnehmer Geld annehmen werden. Es erfolge also eine sinnhafte Orientierung an unbestimmt vielen Dritten. Dies sei allerdings „keine Orientierung an einer gesatzten Ordnung über die Art der Güterbedarfsdeckung der vorgestellten Beteiligten“ (ebd.: 453). Dennoch sei das Gesamtresultat vielfach so geartet, als ob es mittels einer solchen Orientierung erreicht worden sei und zwar aufgrund der Annahme, dass die anderen Marktteilnehmer sich genauso rational verhalten mögen wie man selbst (vgl. (Lichtblau 2000: 432). Webers ,Einverständnis` zielt also darauf, die Vielfalt nicht explizit satzungskoordinierter, aufgrund sinnhaft generalisierter Erwartungen gleichwohl „geordneten“ Wirklichkeitsbereiche soziologisch zu erfassen (vgl. Hermes 2007: 425).

853 In der Zuordnung des Marktes zu einer einverständlichen Ordnung liegt die Differenz zu Tönnies, der den Tausch eindeutig dem Bereich der Gesellschaft zuordnet (vgl. hierzu Lichtblau 2017). 
Diese Differenzierung des Gemeinschaftshandelns in Gesellschafts- und Einverständnishandeln spiegelt sich in zwei verschiedenen Ordnungsformen (Gemeinschaften) wider: Anstalt und Verband. Eine Anstalt - eine der typischen „rationalen Ordnungen einer Vergesellschaftung“ (Weber 1988g [1913]: 472) - beruhe auf einer gesatzten Ordnung, unterscheide sich aber vom Zweckverein dadurch, dass die Mitgliedschaft nicht freiwillig sei. Weber nennt den Staat (also Anstaltsstaat) und die Kirche als Beispiele (ebd.: 466). Auch im Verband sei die Teilnahme des Einzelnen gewissermaßen unfreiwillig, wobei sie hier nicht auf einer Satzung, sondern auf einem am Einverständnis orientierten Handeln beruhe. ${ }^{854}$

Der Übergang vom Verband zur Anstalt gestaltet sich nach Weber - wie auch in den anderen Fällen seiner Begriffsbildung - fließend (ebd.: 467). Allerdings erscheint das Einverständnishandeln als der vorgängige bzw. basale Modus. In historischer Hinsicht kann man im Zuge der zunehmenden gesellschaftlichen Differenzierung und Rationalisierung (vgl. ebd.: 473) eine Ablösung der Gemeinschaftsform Verband durch die Anstalt feststellen. So ist nach Weber

im Verlauf der für uns übersehbaren geschichtlichen Entwicklung, zwar nicht eindeutig ein „Ersatz“ von Einverständnishandeln durch Vergesellschaftung, wohl aber eine immer weitergreifende zweckrationale Ordnung des Einverständnishandelns durch Satzung und insbesondere eine immer weitere Umwandlung von Verbänden in zweckrational geordnete Anstalten zu konstatieren (ebd.: 470f.).

Das zeichne mithin die Moderne aus, sei doch ,in der modernen Zivilisation [...] fast alles Verbandshandeln mindestens partiell durch rationale Ordnungen - die ,Hausgemeinschaft ${ }^{\star}$ z. B. heteronom durch das von der Staatsanstalt gesatzte ,Familienrecht ${ }^{\star}$ - irgendwie geordnet" (ebd.: 467). ${ }^{855}$

854 Auch hier werden Zwangsapparate für einverständniswidriges Verhalten bereitgestellt - etwa in „urwüchsigen Hausgemeinschaften“ oder in Gemeinschaften eines „Propheten“" mit „Jüngern“, in denen Hausherr und Prophet die Gewalt innehaben (vgl. Weber 1988g [1913]: 467f.).

855 Die Rationalisierung der Ordnungen fördert nach Weber nicht unbedingt ihr rationales Verständnis - im Gegenteil tritt gerade aufgrund der zunehmenden Differenzierung und Rationalisierung eine zunehmende Distanzierung von der rationalen Basis der Ordnungen ein (vgl. ebd.: 473). Die „rationale Note“ bestehe vielmehr darin, dass ein spezifischer Glaube an das prinzipiell rationale Wesen der Ordnungen sowie die Zuversicht darauf vorhanden seien, dass die Bedingungen des Alltagslebens „rational, d.h. nach bekannten Regeln [...] funktionieren, daß man im Prinzip wenigstens, mit ihnen ,rechnen', ihr Verhalten ,kalkulieren', 
In sachlicher Hinsicht ist festzuhalten, dass zum einen der größte Teil des Gemeinschaftshandelns mittels des Einverständnishandelns ablaufe. So seien z.B. in politischen Anstalten (z.B. Staat) durch ihre Satzungen (Gesetze) nicht deren Gesamtheit, sondern „in aller Regel wenigstens, zunächst nur fragmentarische Tatbestände“ zweckrational geregelt (ebd.: 467). Damit gelte:

Das tatsächlich den Bestand des Gebildes konstituierende Einverständnishandeln übergreift also nicht nur normalerweise ihr an zweckrationalen Satzungen orientierbares Gesellschaftshandeln, wie dies ja auch bei den meisten Zweckvereinen der Fall ist, sondern es ist auch normalerweise dem letzteren gegenüber das ältere. (Ebd.)

In diesem Sinne sei die Anstalt ein Spezialfall des Verbandes: ein „partiell rational geordneter Verband“ (ebd.).

Zum anderen müsse man neue Anstaltssatzungen, die nun fast ausschließlich nicht vereinbart, sondern oktroyiert würden (ebd.: 468), ebenfalls auf das Einverständnishandeln zurückführen. Einerseits ist die oktroyierte Verfassung einer Anstalt auf das Einverständnis derjenigen angewiesen, denen sie oktroyiert wird (vgl. Sukale 2002: 467), und „die gesatzte Ordnung tritt bei den Anstalten in empirische Geltung in Gestalt von ,Einverständnis““ (Weber 1988g [1913]: 468). Andererseits komme im Falle der durch Herrschaft oktroyierten Verfassung dem Legitimitätseinverständnis eine zentrale Rolle zu - eine Thematik, die sich Weber für eine gesonderte Abhandlung vorbehält. ${ }^{856}$ Denn die Chance der empirischen Geltung steige mit steigendem „Legitimitäts-Einverständnis“ (ebd.: 470). Die empirische Geltung einer Ordnung aber ist dasjenige, was in Webers handlungstheoretischer Perspektive allein kausal relevant ist, und das Einverständnishandeln wird zur empirischen Geltungsvoraussetzung einer jeglichen Satzung. ${ }^{857}$

sein eigenes Handeln an eindeutigen, durch sie geschaffenen Erwartungen orientieren könne“ (ebd.: 473f., H.i.O.).

856 Das bestärkt Winkelmanns These, dass Webers aus dem Nachlass herausgegebenes Manuskript Die drei reinen Typen der legitimen Herrschaft an den KategorienAufsatz anschließe. Zur Datierungsproblematik des Manuskripts sowie zur Debatte um den Stellenwert der Herrschaftssoziologie in Webers Werk vgl. Breuer 1988 m.w.N.

857 Dasselbe Verhältnis von oktroyierter Satzung und Legitimitätseinverständnis gilt auch für den Verband (vgl. Weber 1988g [1913]: 469) - denn auch hier sieht Weber die Herrschaft als „wichtigste Grundlage fast allen Verbandshandelns an“ (ebd.: 470). Dem Legitimitätseinverständnis kommt also auch im Verband eine zentrale Rolle zu. 
In seinen grundbegrifflichen Bemühungen zur Begründung einer ,allgemeinen Soziologie sind im Kategorien-Aufsatz die subjektiven Motive der Beteiligten für Weber irrelevant (Weber 1988g [1913]: 456; vgl. Lichtblau 2017: 286f.). ${ }^{858}$ Es geht ihm vielmehr um den „durchschnittlich eindeutig verstandenen Sinngehalt" und die „wandelbare Durchschnittschancen der empirischen Geltung“" (Weber 1988g [1913]: 467, H.i.O.). Unter anderem deshalb müsse man eine solche ,allgemeine Soziologie" trotz ihrer handlungstheoretischen Sinnorientierung von der Psychologie unterschieden jene bereits erwähnte Abgrenzung, die Weber im ersten Teil seines Aufsatzes vornimmt (vgl. ebd.: 432).859

Aufgrund der Wahl seiner Kategorien ist nun aber auch eine Konkurrenz zur Rechtswissenschaft zu erkennen. Denn ausgehend vom Anliegen, die Grundlagen für eine allgemeine, verstehende Soziologie zu entwerfen, entwickelt Weber einen Begriffsaufbau, der letztlich dazu führt, dass die Orientierung an ,normativen Ordnungen' zum Grundtatbestand der Soziologie wird: Der Begriff des Gemeinschaftshandelns, der inhaltlich nicht spezifiziert wird (und später in den Grundbegriffen durch den Begriff des sozialen Handelns ersetzt wird), fungiert bei Weber als Oberbegriff für zwei verschiedene Handlungstypen: Einverständnishandeln und Gesellschaftshandeln, deren Sinn sich nur durch ihre jeweils ordnungsspezifische, d.h. geltungsmäßige Bezogenheit erschließt (vgl. Lichtblau 2017:

858 Diese verweist Weber in den Bereich der „inhaltlichen Soziologien“: „Gänzlich verschiedene subjektive Motive, Zwecke und innere Lagen', zweckrational oder ,nur psychologisch“ verständliche, können als Resultante ein seiner subjektiven Sinnbezogenheit nach gleiches Gemeinschaftshandeln, und ebenso ein seiner empirischen Geltung nach gleiches ,Einverständnis‘ erzeugen. Reale Grundlage des Einverständnishandelns ist lediglich eine auf die je nachdem verschieden eindeutige Geltung des ,Einverständnisses‘ und nichts anderes hinwirkende Konstellation ,äußerlicher ${ }^{\star}$ oder ,innerlicher ${ }^{\star}$ Interessen, deren Bestand durch untereinander im übrigen sehr heterogene innere Lagen und Zwecke der Einzelnen bedingt sein kann. Damit ist natürlich nicht etwa geleugnet, daß für die einzelnen, nach der vorwaltenden subjektiven ,Sinnrichtung' zu scheidenden Arten von Gemeinschaftshandeln sowohl wie speziell von Einverständnishandeln sich recht wohl Motive, Interessen und ,innere Lagen' inhaltlich angeben lassen, welche durchschnittlich am häufigsten deren Entstehung und Fortbestand begründen. Eben diese Feststellung ist ja eine der Aufgaben jeder inhaltlichen Soziologie. Solche ganz allgemeinen Begriffe aber, wie sie hier zu definieren waren, sind notwendig inhaltsarm." (Ebd.: 460).

859 Weber führt dazu die Unterscheidung ein zwischen dem subjektiv gemeinten Sinn eines Handelnden, der an der Zweckrationalität gemessen wird, und der ,Richtigkeitsrationalität‘ bzw. der kausalen Adäquanz einer Handlungsdeutung, die den Maßstab der kausalen Erklärung abgibt (vgl. ebd.: 432ff.). 
292). Beide betreffen die faktische Wirksamkeit und Verbindlichkeit von Erwartungen. Dabei wird das Gesellschaftshandeln über die Orientierung an Satzungen, also genuin normative Ordnungen, definiert. Aber auch das Einverständnishandeln bestimmt sich ebenfalls über die Orientierung an solchen Satzungen. Allerdings handelt es sich in diesem Fall nicht um explizite, sondern um implizite Satzungen, handele man doch, „als ob“ eine zweckrationale vereinbarte Ordnung - und d.h. letztlich: normative Ordnung - vorliege (Weber 1988g [1913]: 452). Diese Bestimmung gilt für Weber auch dann, wenn die Ordnung durch faktischen Interessenausgleich zustande gekommen ist (z.B. Markt). Damit betrachtet Weber auch solche Ordnungen, die durch solchen faktischen Interessenausgleich (Markt) oder durch Verständnisorientierung (Sprache) zustande kommen, als normative Ordnungen. Auch sie haben einen normativen Geltungsanspruch, dieser ist nicht nur auf wertrationales Handeln beschränkt. Da zudem das Einverständnis zur empirischen Geltungsvoraussetzung jeglicher Satzung wird (Legitimitätseinverständnis), wird es zum Oberbegriff für die unterschiedlichen Arten der empirischen ,Geltung' einer Ordnung. Letztlich handelt es sich beim Gesellschaftshandeln um „den durch Satzung geordneten Spezialfall“ des Einverständnishandelns (ebd.: 461). Damit definiert Weber das gesamte ,soziale Handeln' bzw. Gemeinschaftshandeln als ein an Normen orientiertes Handeln (Lichtblau 2017: 299), auf denen die Erwartungen aufbauen. Die Regelmäßigkeiten des sozialen Handelns resultiert aus den Orientierungen an Regeln mit normativen Geltungsansprüchen.

\subsection{Die „Idealtypik“ der juristischen Begriffsbildung}

Aus dieser Engführung auf normative Geltungsansprüche erklärt sich, warum die verstehende Soziologie notwendigerweise von der Rechtsdogmatik abzugrenzen ist (Weber 1988g [1913]: 439f.). Denn anders als im Roscher und Knies- sowie im Objektivitäts-Aufsatz stellt sich nun nicht das wissenschaftslogische Problem, wie man mit Begriffen der theoretischen Wissenschaften (der theoretischen Nationalökonomie) umzugehen habe. Da die normativen Ordnungen zentral sind, stellt sich nun vielmehr die Frage, wie die soziologische Begriffsbildung die Begriffe der Rechtswissenschaft $\mathrm{zu}$ behandeln habe, deren Begriffsbildung wiederum aus dem wissen- 
schaftlichen Umgang mit der normativen Ordnung des Rechts resultiert. ${ }^{860}$

Weber löst dieses Problem dabei in analoger Weise: Ebenso wie man rein wissenschaftslogisch die theoretische (nomothetische) von der historisch-kulturwissenschaftlichen respektive sozialwissenschaftlichen Begriffsbildung trennen müsse, habe man auch die - nun - soziologische von der juristischen Begriffsbildung zu unterscheiden. Aber ebenso wenig, wie man in den Kulturwissenschaften auf die theoretische Begriffsbildung verzichten könne, die für die Zwecke der historischen Wissenschaft ja gerade idealtypisch seien, könne die Soziologie auf die juristische Begriffsbildung verzichten. Denn Weber stellt für die konkrete Kategorienbildung der Soziologie auf Zweckmäßigkeitserwägungen ab. Dabei besitze die zweckrationale Deutung ein „Höchstmaß an ,Evidenz““ (ebd.: 428), so dass letztlich das "Zweckrationale als Idealtypus" fungiere (ebd.: 430). Gerade im Bereich der normativen Ordnungen weist nun die an den zweckrationalen Gesetzen entwickelte rechtswissenschaftliche Begriffsbildung diese spezifische Evidenz auf. Die Rechtsordnung ist daher der Idealtypus einer zweckrationalen normativen Ordnung - und zwar nicht nur beim Zweckverein, sondern v.a. im modernen Anstaltsstaat. Das erklärt die Verschiebung: Nicht mehr der Rückgriff auf Begriffe der theoretischen Wissenschaften erscheint nun als unvermeidliches Schicksal der Kulturwissenschaft. Aufgrund der Engführung des sozialen Handelns auf die Orientierung an normative Ordnungen besteht vielmehr das bereits erwähnte „unvermeidliche Schicksal aller Soziologie“ darin, „daß sie für die Betrachtung des überall stetige Uebergänge zwischen den, typischen' Fällen zeigenden realen Handelns sehr oft die scharfen, weil auf syllogistischer Interpretation von Normen ruhenden, juristischen Ausdrücke verwenden muß“ (ebd.: 440).

860 Allerdings wandelt sich auch der Anspruch, den Weber an die Begriffsbildung stellt: Während im Objektivitäts-Aufsatz die Idealtypen-Bildung primär auf das Problem der historischen Kausalerklärung bezogen ist (vgl. Lichtblau 2006: 242), und Weber unter Geringschätzung systematischer Formen der Erkenntnis in den Kulturwissenschaften bzw. Sozialwissenschaften (vgl. Weber 1988b [1904]: 184) den Fokus auf das Vergängliche legt, bemüht er sich im KategorienAufsatz (und später in den Grundbegriffen), seinem Beitrag zum Grundriß der Sozialökonomik eine solidere, kategoriale begriffliche Grundlage zu geben. Das resultiert dann in einer Abtrennung der Soziologie von der Geschichte: „Die Soziologie bildet - wie schon mehrfach als selbstverständlich vorausgesetzt - Typen-Begriffe und sucht generelle Regeln des Geschehens. Im Gegensatz zur Geschichte, welche die kausale Analyse und Zurechnung individueller, kulturwichtiger, Handlungen, Gebilde, Persönlichkeiten erstrebt.“ (Weber 1988j [1921]: 559, H.i.O.). 
Idealtypisch erweist sich die juristische Begriffsbildung, weil sie erstens ,scharfe' Begriffe bildet, zielt die Rechtswissenschaft nach Weber doch auf begriffslogische Klarheit und unbedingte Steigerung ihres Systemcharakters hin zu „logischer Geschlossenheit“ (vgl. Treiber, Quensel 2002: 96). Darin besteht der spezifische Wissenschaftscharakter der Rechtsdogmatik, die Wertung tritt erst subsidiär dazu (s.o.). Auch die Rechtswissenschaft strebt trotz ihrer wertenden Betrachtung des konkreten Sachverhalts nach Wahrheit - allerdings nach ,juristischer Wahrheit“ (Weber 1988d [1907]: 348). Dabei macht Weber schon im Roscher und Knies-Aufsatz geltend, dass die „eigenartige ,subjektive Welt' der juristischen Dogmatik“ (Weber 1988a [1903-1906]: 87) den ,objektiven Sinn' des zu definierenden Begriff so fasse, dass „alle diejenigen positiven Normen, welche jenen Begriff verwenden oder voraussetzen, widerspruchslos und sinnvoll neben- und miteinander bestehen können" (ebd.: $86 \mathrm{f}$.). Scharfe Begriffe werden nach Weber also aus dem systematischen Zusammenhang der Rechtsnormen der Rechtsordnung heraus - gebildet. Es sind Begriffskonstruktionen, Abstraktionen, die daher weltfremd sind und nicht die Wirklichkeit abbilden. Für Weber aber gilt, wie er ja in den Grundbegriffen schreibt: Je weltfremder solche eindeutigen Begriffe - zu Idealtypen gewendet - sind, desto besser leisten sie ihren Dienst.

Weber führt diese Schärfe der juristischen Begriffsbildung im Kategorien-Aufsatz zweitens auch auf eine spezifische Verfahrensweise angesichts eines bestimmten sachlichen Problems zurück. Dieses sachliche Problem besteht in der Tatsache, dass sich die Betrachtung auf die Übergänge zwischen den typischen Fällen des Handelns richtet. Wenn das Recht also typisierend verfährt und aufgrund seines anthropozentrischen Charakters dabei Handlungen typisiert, dann erweisen sich die Typen empirisch weder als „rein“, noch ist ihr Verhältnis abstrakt für alle Zeiten bestimmbar. Die entsprechenden Begriffe haben daher nicht den Status von ewigen Wahrheiten. Gerade das mache die Rechtswissenschaft anschlussfähig, weil die Präzision ihrer Begriffe letztlich auf ihrer syllogistischen Interpretation der Normen beruhe (vgl. Weber 1988g [1913]: 440). ${ }^{861}$ Gesetzt den Fall, Weber meint damit den juristischen Syllogismus in Form der Rechtsanwendung - und davon wird hier ausgegangen (vgl. Weber 1976 [posthum]: 457) -, so beruht die Schärfe der juristischen Ausdrücke einerseits darauf, dass die Begriffe in der Rechtsanwendung immer wieder mit den verschiedensten empirischen Fallkonstellationen konfrontiert werden, in

861 Zur Rolle des Syllogismus bei Weber vgl. Wagner 2014, der jedoch den juristischen Syllogismus gerade nicht in den Blick nimmt. 
denen die Typen in den allerwenigsten Fällen „rein“ vorkommen. Gerade durch die Konfrontation mit den unterschiedlichsten empirischen Sachlagen gewinnen die rechtsdogmatischen Begriffe in der Rechtsanwendung an Präzision. ${ }^{862}$ Zweitens befinden sich die Typen selbst im Wandel, können doch neue Fallkonstellationen des empirischen Handelns zu neuer regelleitender Typenbildung führen, die in ihrer Anwendung dann wiederum präzisiert wird - so sind privatrechtliche Rechtsgeschäfte etwa nicht an die Vertragstypen des BGBs gebunden, durch Vereinbarungen zwischen zwei (oder mehreren) Personen können neue Typen gebildet werden. Recht ist also auch in der rechtsdogmatischen Betrachtungsweise in gewisser Weise immer , lebendes Recht ${ }^{*}$ - auch für Weber, der aber aufgrund der Ablehnung des Repräsentationsgedankens daraus allerdings gerade nicht den privilegierten Lebenszugang über die rechtsdogmatische Forschung wie die Historische Rechtsschule erkennt. Es gilt also: Trotz prinzipieller Trennung zwischen juristischer und soziologischer Betrachtungsweise erweist sich die juristische Begriffsbildung gerade angesichts der Tatsache, dass man in der Empirie nicht mit reinen Typen zu tun hat, als anschlussfähig.

Drittens ist die rechtsdogmatische Begriffsbildung idealtypisch für die verstehende Soziologie, weil sie ebenfalls auf Sinnverstehen gerichtet ist. Sie ermittelt den „logisch richtigen ,objektiven“ Sinngehalt[] von ,Rechtssätzen““ (Weber 1988g [1913]: 440, H.i.O.). ${ }^{863}$ Für die empirische Wissenschaft, erweisen sich diese rechtsdogmatischen Begriffe, ihr ,objektiver

862 Man kann dieses Zitat allerdings auch dahingehend verstehen, dass Weber damit den logischen Charakter der Systembildung des Rechts anspricht, d.h. die Gewinnung von rechtlichen Grundbegriffen über die Extrahierung allgemeiner Regeln, die in den einzelnen Rechtssätzen ihren Ausdruck finden. Da die Argumentation aber in auffälliger Weise Puchtas Ansicht entspricht, dass aufgrund des juristischen Syllogismus die gefundenen Grundbegriffe nicht den Status von ewigen Wahrheiten besitzen, sondern sich immer im Werden befinden (vgl. \$2.IV.1), d.h. der Lebensbezug des Rechts über die Rechtsanwendung gewährleistet ist, wird hier die obige Interpretation vertreten.

863 In Die Wirtschaft und die Ordnungen schreibt Weber: Die juristische Betrachtungsweise „fragt: was als Recht ideell gilt. Das will sagen: welche Bedeutung, und dies wiederum heißt: welcher normative Sinn einem als Rechtsnorm auftretenden sprachlichen Gebilde logisch richtigerweise zukommen sollte. [...] Die juristische, genauer: die rechtsdogmatische, Betrachtung stellt sich die Aufgabe: Sätze, deren Inhalt sich als eine Ordnung darstellt, welche für das Verhalten eines irgendwie bezeichneten Kreises von Menschen maßgebend sein soll, auf ihren richtigen Sinn, und das heißt: auf die Tatbestände, welche ihr, und die Art, wie sie ihr unterliegen, zu untersuchen. Dabei verfährt sie in der Weise, daß sie die verschiedenen einzelnen Sätze jener Art, ausgehend von ihrer unbezweifel- 
Sinn', dann zur Hypothesenbildung geeignet, wie Weber in der StammlerKritik am Beispiel des Tausches feststellt: Denn ob und wie den juristischen Tauschvorschriften eine empirische Kausalität zukomme, sind für Weber „offenbar Fragen, bei denen uns [...] zum Zweck der Hypothesenbildung, als ,heuristisches Prinzip', unser ,dogmatisches' Gedankenbild vom ,Sinn' des, Tausches` sehr zu statten kommen muß" (Weber 1988d [1907]: 335, H.i.O.). Wenn nicht das konkrete Motiv oder eine solche Absicht des Handelnden zur Debatte steht, sondern der „subjektiv gemeinte Sinn" als eine Art Durchschnittssinn, so erweisen sich die juristischen Sinnkonstruktionen als ein Maßstab, an dem sich der subjektive Sinn messen lässt - allerdings unter der Voraussetzung, dass für die empirische Wissenschaft dieser Sinn nur als „Vorstellungen von Menschen über den ,Sinn“ und das ,Gelten“ bestimmter Rechtssätze“ betrachtet wird (Weber 1988g [1913]: 440, H.i.O.). Nichtsdestotrotz lässt sich die faktische Geltung einer Norm in Bezug auf vergangene oder gegenwärtige Geltung letztlich nur im Hinblick auf einen normativen Geltungssinn überhaupt beurteilen (Gephart 2010: 41). Daher gilt etwa im Falle des Tausches:

Der dogmatische „Sinn“ des „Tauschs“ ist für die empirische Betrachtung ein „Idealtypus“, der, weil in der empirischen Wirklichkeit sich massenhaft Vorgänge finden, welche ihm in einer mehr oder minder großen „Reinheit“ entsprechen, „heuristisch“ einerseits, „klassifizierend" andrerseits, von uns verwendet wird. (Weber 1988d [1907]: 335)

Der juristische ,objektive Sinn' mit seiner scharfen, systematischen Begriffsbildung, kann zur Hypothesenbildung bzgl. der Deutung des, subjektiven Sinns' dienen bzw. dient dazu (vgl. Weber 1988i [1918]: 533f.) - insbesondere vor dem Hintergrund einer hohen kausalen Relevanz der Rechtsordnung als Maxime-bildendes Wissen. ${ }^{864}$

ten empirischen Geltung, ihren logisch richtigen Sinn (nach) dergestalt zu bestimmen trachtet, daß sie dadurch in ein logisch in sich widerspruchsloses System gebracht werden. Dies System ist die ,Rechtsordnung' im juristischen Sinn des Wortes." (Weber 1976 [posthum]: 181, H.i.O.).

864 An anderer Stelle tut Weber kund: „Der Rechtsbegriff Vereinigte Staaten aber hat nun vor diesem soziologischen Begriff Vereinigte Staaten die ungeheure Ueberlegenheit des im Prinzip logisch klaren Gehaltes voraus, und deshalb orientieren sich die soziologischen Begriffe und die Kollektivbegriffe anderer Disziplinen regelmäßig an eben jenem Rechtsbegriffe, obwohl das juristische Begriffssystem ,Vereinigte Staaten' ein rein ideales Gedankengebilde ist, etwas, was als solches keine empirische Realität im Leben hat, sondern eben etwas - wie man zu sagen pflegt -, Geltendes“ ist“" (Weber in Simmel et al. 1911c: 326). 
Im Rahmen einer Deutungshypothese muss der kausale Einfluss einer Rechtsnorm oder der Rechtsordnung aber noch gesondert festgestellt werden, v.a. weil die Orientierung an der Rechtsordnung bei den „breiten Schichten der Beteiligten“ gerade nicht aufgrund „einer als Rechtspflicht gefühlten Obödienz" erfolgt (Weber 1976 [posthum]: 182). Die Rechtsordnung im empirischen Sinne ist dann ein „Komplex von faktischen Bestimmungsgründen realen menschlichen Handelns“ (ebd.: 181). Es ist dies der „andere“, da kausal wirksame Sinn in Form von erst festzustellenden faktisch kausal wirksamen Maximen, den Weber gegenüber der Rechtsdogmatik geltend macht und der dem juristischen Sinn „unterzuschieben“ sei (Weber 1988g [1913]: 440). Über das Konstatieren des tatsächlichen Vorhandenseins einer Geltungsvorstellung bestimmter Rechtssätze geht die Soziologie nämlich zudem

in der Weise hinaus, daß sie 1. auch die Wabrscheinlichkeit des Verbreitetseins solcher Vorstellungen in Betracht zieht, und 2. durch folgende Überlegung: daß empirisch jeweilig bestimmte Vorstellungen über den "Sinn“ eines als geltend vorgestellten „Rechtssatzes“ in den Köpfen bestimmter Menschen herrschen, hat unter bestimmten angebbaren Umständen die Konsequenz, daß das Handeln rational an bestimmten „Erwartungen“ orientiert werden kann, gibt also konkreten Individuen bestimmte „Chancen“ (ebd.: H.i.O.).

Sinnverstehen im soziologischen Sinne misst sich nicht an Vorstellungen über eine ideale bzw. ,richtige' Geltung (s.a. Weber 1988j [1921]: 542), sondern an dem faktischen Vorhandensein von Geltensvorstellungen, der Wahrscheinlichkeit der Verbreitung und der dadurch kausal bewirkten "Chance“ des Erfolgs des Handelns.

Den juristischen Begriffen ist aber noch in anderer Hinsicht ein „von dem juristischen der Wurzel nach verschiedene[r] Sinn unterzuschieben“ (Weber 1988g [1913]: 440). Nimmt man das Beispiel der Vertragstypenbildung bei Austauschverträgen zwischen zwei Personen (etwa Kauf, Miete, Pacht, Leihe etc.), so erscheint eine handlungstheoretische Rückbindung der juristischen - v.a. der privatrechtlichen - Begriffe über Maximen direkt nachvollziehbar, und es erscheint auch wenig verwunderlich, dass Weber den Handlungsbegriff selbst der Rechtswissenschaft entnimmt. Wenn er nämlich später im Grundbegriffe-Beitrag das Handeln nun, anders als im Kategorien-Aufsatz, explizit definiert als ein „menschliches Verhalten (einerlei ob äußeres oder innerliches Tun, Unterlassen oder Dulden)" (Weber 1988j [1921]: 542), mit dem der Handelnde einen subjektiven Sinn verbin- 
det, so zeigt gerade die Einbeziehung des Unterlassens und Duldens die juristische Herkunft dieses Begriffes (vgl. Gephart 1993a: 487f.). 865

Weber interessiert sich aber im Kategorien-Aufsatz insbesondere für Ordnungsgefüge, die in Kollektivbegriffen ihren Ausdruck finden. Und hier markiert er trotz der von ihm ins Spiel gebrachten idealtypischen Verwendung des Sinngehalts juristischer Begriffe wie ,Verein', ,Verband‘ und ,Anstalt ${ }^{\star}$ eine entscheidende Differenz zum juristischen Gebrauch: In den Rechtswissenschaften können und werden solchen „Kategorien für bestimmte Arten des menschliches Zusammenlebens" selbst, wie dem Einzelmenschen, „Rechtspersönlichkeiten“ zugesprochen (Weber 1988g [1913]: 439). Im Bereich der Rechtsdogmatik erweisen sich diese fingierten Rechtspersönlichkeiten für die objektive Sinndeutung als „begriffliche Hilfsmittel nützlich, vielleicht unentbehrlich“ (ebd.). ${ }^{866}$ Mit dem Postulat des „Verstehens“ menschlicher Handlungen als „Atom“ seiner Soziologie muss Weber sich aber von Kollektivbegriffen lösen, die letztlich nicht verstehbare Subjekte konstruieren: Auch ein substanzhaft vorgestellter Staat ist für Weber nur vermittels seiner Akteure verstehbar (vgl. Gephart 2010: 39). Der Sinn in der Soziologie muss also auf menschliche Handlungen zurückgeführt werden: „Für die soziologische Betrachtung steht daher auch hinter dem Worte ,Staat ${ }^{\star}$ - wenn sie es überhaupt verwendet - nur ein Ablauf von menschlichem Handeln besonderer Art.“ (Weber 1988g [1913]: 440, H.i.O.) Daher wird für die Kategorien der Soziologie das Einverständnis inklusive seiner verschiedenen Komposita (etwa Legalitäts- und Legtimitätseinverständnis) zentral, was auf die individuelle, und d.h. handlungstheoretische Sinnebene überführt. ${ }^{867}$ Mit dem Einverständnis zielt

$865 \mathrm{Zu}$ Recht betont Gephart aber auch die Einflüsse nationalökonomischer, geschichtswissenschaftlicher und philosophischer Auseinandersetzungen auf die Ausarbeitung der Weber'schen Handlungstheorie (vgl. Gephart 1993a: 421ff.).

866 Auch diese Annahme zeigt, wie sehr Weber dem romanistischen Zweig der Historischen Rechtsschule verhaftet ist, entscheidet er sich doch damit gegen die der germanistischen Genossenschaftstheorie entstammende „Theorie der realen Verbandspersönlichkeit" (Gierke) und für die im 19. Jahrhundert herrschende romanistische Doktrin der „Fiktionstheorie“ (Savigny).

867 Lichtblau sieht in Webers Konzeption des Einverständnisses eine Anleihe an das tatbestandsausschließende Einverständnis im Strafrecht: Für dessen Wirksamkeit ist der tatsächliche - innere - Wille unabhängig von seiner Kundgabe nach außen maßgeblich, was Lichtblau mit Webers Konzeption der impliziten Geltungsansprüche und deren stillschweigender Akzeptanz analogisiert (vgl. Lichtblau 2017: 282). Dem ist zu widersprechen, handelt es sich doch bei Webers Einverständnis primär um die Orientierung an fiktiven Ordnungen, und nicht um die Akzeptanz von (eigene Rechtsgüter verletzenden) Handlungen anderer. 
Weber letztlich wie Durkheim auf die außerrechtlichen Voraussetzungen des Rechts, die er jedoch nicht auf einer kollektiven, sondern der individuellen Ebene aufsucht. Gerade im Bereich der Kollektivbegriffe, bei denen Weber mit, Verein', ,Verband' und ,Anstalt' sozusagen extensiv auf juristische Begrifflichkeiten zurückgreift, wird man durch das Einverständnis zugleich auf einen anderen, da außerrechtlichen Sinn verwiesen.

Diese Wandlung der soziologischen Sinninhalte der aus der Rechtsdogmatik entlehnten Begrifflichkeiten ändert aber nichts an der idealtypischen Sinnbildung der Rechtsdogmatik für die verstehende Soziologie und der daraus entstehenden Notwendigkeit, das Verhältnis der rechtsdogmatischen zu den soziologischen Begriffen zu klären. Dabei liefert die Rechtsdogmatik nicht nur Idealtypen, sondern stellt sich aus sachlichen wie methodischen Erwägungen zugleich als idealtypisches Verfahren der Begriffsbildung dar. Daher ist es eben das, unvermeidliche Schicksal aller Soziologie', die juristischen Ausrücke verwenden zu müssen.

\subsection{Die Notwendigkeit der Abgrenzung zur Rechtsdogmatik}

Aus diesem Grund besteht die Notwendigkeit, die juristische von der soziologischen Begriffsbildung zu trennen. Denn ohne diese Trennung gerät die Soziologie in Verdacht, von der Jurisprudenz abhängig zu sein und damit nicht als autonome Disziplin mit eigenständiger Betrachtungsweise fungieren zu können - ein Einwand, den schon Kelsen gegen Weber vorgebracht hatte (vgl. Kelsen 1922). ${ }^{868}$ Solange Weber wie im Kategorien-Aufsatz das soziale Handeln an normative Geltungsansprüche bindet, ist er zur Grundlegung seiner typenbildenden, verstehenden Soziologie' auf eine Abgrenzung zur Rechtsdogmatik angewiesen, die keinerlei Verdacht einer solchen Abhängigkeit oder eben der „rechtsdogmatischen Verfälschungen des empirischen Denkens“ aufkommen lässt (Weber 1988d [1907]: 345,

868 Kelsen wirft Weber vor, dass dieser für das deutende Verstehen rechtlich geordneter sozialer Tatbestände, also für sein auf die empirische Wirkung von Rechtsbegriffen oder Rechtssätzen etc. gerichtetes Forschungsinteresse, des Rechtssystems und seiner normativen Sinngehalte als heteronomes "Deutungsprinzip“ bedürfe (vgl. hierzu Hermes 2006: 191ff.) Insofern stellt Kelsen fest: „Die ,verstehende' Soziologie muß, da der von ihr zu ermittelnde Sinn des sozialen Handelns sehr häufig eben das Recht ist, auch Jurisprudenz sein oder doch mit den Augen des Juristen sehen, um überhaupt etwas zu sehen." (Kelsen 1981 [1928]: 163, H.i.O.) Damit unterlaufe Weber aber die Trennung der soziologischen von der juristischen Betrachtungsweise (zum Vergleich Kelsens und Webers sei verwiesen auf die Beiträge in Bryan et al. 2016). 
H.i.O.). Anders formuliert: Die Eigenart seiner Soziologie lässt sich erst in strikter Abgrenzung zur Konkurrenzdisziplin der Rechtswissenschaft bestimmen. Das liegt daran, dass beide denselben Gegenstand haben - stellt doch das Recht in der Moderne einen relevanten kausalen Ordnungsfaktor dar und ist die Rechtsordnung zugleich der rationale Idealtypus der normativen Ordnungen. Wenn nun die Wirklichkeit an diesem Idealtypus gemessen wird, dann bedarf es einer Konstruktion dieses Idealtypus, wofür man sich letztlich nach Weber auf die Rechtswissenschaft berufen kann und muss. Um dann aber die Soziologie nicht von der Rechtswissenschaft abhängig zu machen, bedarf es einer strengen wissenschaftslogischen Unterscheidung von juristischer und soziologischer Betrachtungsweise. Daher gilt: „Wenn von ,Recht', ,Rechtsordnung', ,Rechtssatz' die Rede ist, so muß besonders streng auf die Unterscheidung juristischer und soziologischer Betrachtungsweise geachtet werden.“ (Weber 1976 [posthum]: 181) Gerade weil aus logischen Gründen keinerlei Übergänge zwischen diesen beiden Betrachtungsweisen des Rechts möglich sind, kann - und muss man, wie Weber im Kategorien-Aufsatz schreibt - für die verstehende Soziologie juristische Begriffe heranziehen, ohne dass damit die Soziologie ihren Status als autonome Disziplin verlieren würde, ja bei Beachtung der wissenschaftslogischen Scheidung auch gar nicht verlieren kann.

\section{Die Lösung des Problems der Werturteilsfreiheit: Der Sinn der Werte in den normativen Wissenschaften}

Schon Webers Kritik an der Historischen Schule der Nationalökonomie basiert auf der Ausscheidung von Werturteilen und Wertungen aus dem Bereich der Wissenschaft: Diese seien - wie auch die Zwecke ${ }^{869}$ - stets subjektiven Ursprungs, und eine Abwägung zwischen widerstreitenden Werten oder Zwecken könne niemals auf wissenschaftlichen Weg erfolgen. Andererseits müsse man der Wertbedingtheit jeglicher sozialwissenschaftlichen Forschung Rechnung tragen. Damit bezieht Weber Position im Kernkonflikt des nationalökonomischen Methodenstreits, der seinen Höhepunkt im sogenannten Werturteilsstreit im Verein für Sozialpolitik er-

869 Weber verortet, wie bereits erwähnt, den Zweck einer Handlung als „praktische Absicht" (Weber 1988i [1918]: 500) wie die Wertung ebenfalls auf der subjektiven Ebene, so dass die „Wahl der Zwecke“ für ihn eine „Wertung, die der Einzelne zugrunde legt“, darstellt (ebd.: 501). 
reichte, ${ }^{870}$ und welcher seine Spuren in $\ 1$ der Statuten der 1909 gegründeten Deutschen Gesellschaft für Soziologie hinterließ. ${ }^{871}$

Obwohl der Streit um die Werturteilsfreiheit in den genuin nationalökonomischen Debatten zu verorten ist, lässt die Kritik an den Positionen der nationalökonomischen Methodenlehren entscheidende Aspekte außer Acht. Denn dass man einerseits vom Sein nicht auf das Sollen schließen könne, dass man andererseits aber auch nicht das soziale Leben auf naturwissenschaftlich analysierbare Tatsachen reduzieren dürfe, sind letztlich Einwände, die sich gegen die jeweiligen erkenntnis- und wissenschaftstheoretischen Axiome der nationalökonomischen Positionen richten. Mittels dieser Kritik an den Axiomen wird einerseits der Untersuchungsgegenstand bestimmt (Kulturbegriff). Andererseits markiert sie logische Fehlschlüsse - insbesondere der historisch-ethischen Richtung der Nationalökonomie (kein Rückschluss vom Sein auf das Sollen). Daraus folgt, wie man nicht verfahren darf. Die Kritik lässt aber keine Rückschlüsse auf den richtigen wissenschaftlichen Umgang mit einem Gegenstand zu, der wie im Falle der Kultur selbst ein "Wertbegriff" ist, so dass man also unumgänglich mit Werturteilen konfrontiert ist. Anders formuliert: Aus der Kritik an den methodologischen Axiomen folgt weder eine Antwort auf die Frage, welche Rolle Werte nun genau in den historisch-empirischen Wissenschaften spielen, noch, wie man wissenschaftlich mit Werten umzugehen habe. Gerade aber aufgrund der gegenstandskonstitutiven Rolle der Werte erschöpft sich das Problem der Werturteilsfreiheit der Wissenschaft nicht in der bloßen Behandlung vorfindlicher empirischer Wertungen als Fakten. Denn will man diese wie Weber, erklärend verstehen' und damit reflexiv in einen tatsächlichen Wertezusammenhang einbetten (Wertbeziehung), muss man mit diesen Wertungen, Werten und Wertezusammenhängen sinndeutend umgehen. ${ }^{872} \mathrm{Im}$ Rahmen der verstehenden Soziologie muss also der Zusammenhang der normativen mit den empirischen Phä-

870 Zum wissenschaftshistorischen Hintergrund in der Ökonomie vgl. Nau 1996 m.w.N.; Feix 1978: 16ff.; zum Werturteilsstreit vgl. insbesondere Albert 2010.

871 Kritisch gegenüber der gängigen These, dass der Werturteilstreit im Verein für Socialpolitik zur Abspaltung der Deutschen Gesellschaft für Soziologie (DGS) führte, Rammstedt 1991; zur Geschichte der DGS vgl. Glatzer 2014 m.w.N.; zu Max Webers Rolle in der DGS s. Lepsius 2011.

872 Weber merkt hierzu an: „Und dies, Verstehen“ ist selbstredend nicht möglich, wenn wir nicht selbst einer inneren wertenden Stellungnahme zu der Frage, auf welche sich jene ,Werturteile' beziehen, fähig sind." (Weber in Simmel et al. 1911c: 324). 
nomenen für die wissenschaftliche Analyse etwas anderes darstellen, als die simple Reduktion von Werturteilen auf empirische Fakten.

Genau darum geht es auch im juristischen Werturteilsstreit, in dem angesichts der unausweichlichen Wertung um das Verhältnis zu den Tatsachen gestritten wird. Und so verweist das Problem der Wertbeziehung für Weber im Rahmen der Frage nach der Werturteilsfreiheit auf die Rechtsdogmatik - ebenso wie sich die Debatte in Anschluss an Kantorowicz' Vortrag über das Verhältnis von Rechtswissenschaft und Soziologie auf dem ersten Soziologentag in eminenter Weise um die Werturteilsfreiheit drehte (vgl. Simmel et al. 1911c). ${ }^{873}$ Wenn nämlich „die rechtsdogmatische Konstruktion und Analyse [...] das Prinzip der Auslese des für die Rechtsgeschichte wissenschaftlich Relevanten" enthalte, so gilt dies nach Weber „nun auch - da wir einmal in dieser Diskussion über ,Werturteile‘ begriffen sind $-[\ldots]$ für die Beziehung der Werte zu den Problemstellungen, womit wir uns hier in der soziologischen Gesellschaft wissenschaftlich zu befassen haben" (Weber in Simmel et al. 1911c: 328, H.i.O.). Es sind ja letztlich „Kultur- und das das heißt: Wertinteressen [...], welche auch der rein empirisch-wissenschaftlichen Arbeit die Richtung weisen" (Weber 1988i [1918]: 512, H.i.O.), indem sie „die Auslese und Formung des Objektes einer empirischen Untersuchung" beherrschen (ebd.: 511).

Gerade für diese der tatsächlichen Forschung vorausgehende - ja gerade wertende - Auswahl des Untersuchungsgegenstandes bedarf es eines Umgangs mit (Kultur-)Werten, der nicht rein subjektiv-willkürlich erfolgt, sondern letztlich diese Auswahl als bewusste Entscheidung ermöglicht. Es ist auch hier ein ,Prinzip der Auslese' des Relevanten nötig. Dieses liegt in der Erkenntnis des Sinns der Wertungen und Werte, genau dies ist der „Sinn“ bzw. der „Nutzen“ der Wertdiskussionen für die empirischen Wissenschaften (ebd.: 510f.): „Diese können dem wissenschaftlich, insbesondere dem historisch arbeitenden, Forscher vor allem die Aufgabe der, Wertinterpretation': für ihn eine höchst wichtige Vorarbeit seiner eigentlich empirischen Arbeit, weitgehend abnehmen oder doch erleichtern." (Ebd. 512; H.i.O) Diese Wertinterpretation hat - so Weber bereits in der Abhandlung zu Eduard Meyer - zum Ziel, „uns den ,geistigen“ Gehalt“ eines Phänomens „,verstehen' lehren, also das, was wir dunkel und unbestimmt ,fühlen', entfalten und in das Licht des artikulierten ,Wertens' erheben“"

873 Die Debatte endet schließlich bekanntermaßen in einem Eklat (vgl. etwa Weber, Brief vom 26.10.1910, in Weber 1994: 654; Lepsius 2011). Weber begründete seinen daran anschließenden Austritt aus der DGS unter anderem damit, dass es nötig sei, Platz für einen Juristen zu schaffen (Weber, Brief vom 27.10.1910, in Weber 1994: 656). 
(Weber 1988c [1906]: 245f.). Dabei wertet diese Interpretation nicht selbst, sondern eröffnet Sinnhorizonte: „Sie ist zu diesem Zweck keineswegs genötigt, selbst ein Werturteil abzugeben oder zu ,suggerieren'. Was sie tatsächlich analysierend ,suggeriert', sind vielmehr Möglichkeiten von Wertbeziehungen des Objektes." (Ebd.: 246, H.i.O.) Sie ist also primär keine Wertung, sondern logische Erschließung als objektive Sinndeutung mit Blick auf den Wertekosmos.

Einen solchen Umgang mit Werten sieht Weber nun in der Rechtsdogmatik verwirklicht, die als "normative Wissenschaft" genau solche Sinnhorizonte eröffne (vgl. Weber 1988i [1918]: 499). ${ }^{874}$ Denn sie frage nach dem objektiven Sinn der Rechtssätze, der sich aus der Errichtung eines systematischen Zusammenhangs unter Wahrung des Prinzips der Folgerichtigkeit und Widerspruchslosigkeit, also aus der der systematisch-konstruktiven Arbeit, ergebe. Dies gilt insbesondere auch angesichts eines Polytheismus der Werte, eines grundsätzlichen antagonistischen Verhältnisses der Werte untereinander: „Es handelt sich nämlich zwischen den Werten letztlich überall und immer wieder nicht nur um Alternativen, sondern um unüberbrückbar tödlichen Kampf, so wie zwischen ,Gott' und ,Teufel'. Zwischen diesen gibt es keine Relativierungen und Kompromisse.“ (Ebd.: 507) Denn aufgrund solcher kollidierenden und unvereinbaren letzten Werte bestehe kein objektiver Sinnzusammenhang, sondern müsse immer konstruktiv mittels spezifischer Denkmittel hergestellt werden. Dadurch könne man „den ,Sinn' der Wertungen, also ihre letzte sinnhafte Struktur und ihre sinnhaften Konsequenzen ermitteln, ihnen also den ,Ort innerhalb der Gesamtheit der überhaupt möglichen, letzten' Werte anweisen und ihre sinnhaften Geltungssphären abgrenzen“ (ebd.: 508, H.i.O.). Diese Denkmittel stammen wiederum aus der produktiven bzw. Konstruktionsjurisprudenz und wurden bereits als Vorbild für die idealtypische Begriffsbildung herangezogen: das induktiv ansetzende Herausarbeiten der letzten, innerlich konsequenten Wertaxiome, eine „von der Einzelwertung und ihrer sinnhaften Analyse ausgehende, immer höher zu immer prinzipielleren wertenden Stellungnahmen aufsteigende Operation“ (ebd.: 510), wie sie etwa Puchtas oder des frühen Jherings Prinzipienermittlung vergleichbar ist; daran anschließend die Deduktion der Konsequenzen für die wertende Stel-

874 So schreibt Weber: „Die Wissenschaften, normative und empirische, können den politisch Handelnden und den streitenden Parteien nur einen unschätzbaren Dienst leisten, nämlich ihnen zu sagen: 1 . es sind die und die verschiedenen ,letzten'Stellungnahmen zu diesem praktischen Problem denkbar; - 2. so und so liegen die Tatsachen, mit denen ihr bei eurer Wahl zwischen diesen Stellungnahmen zu rechnen habt.“ (Weber 1988i [1918]: 499; H.i.O.). 
lungnahme, die zwar sinnhaft in Bezug auf die Argumentation ist, aber an empirische Feststellungen gebunden ist und davon ausgehend - im produktiven und konstruktiven Sinne - zu neuen Wertaxiomen führen kann (vgl. ebd.: 511). Das alles steht bei Weber unter dem Primat der Logik, wie auch die logisch-dogmatischen Konstruktionen der Rechtswissenschaft unter dem Primat der Logik stehen. Daher ist „das Gelten im juristischen Sinn [...] ein logisches Soll“ (Weber in Simmel et al. 1911c: 325) - also logische Sinnermittlung und nicht subjektive Wertung. ${ }^{875}$ Als solche vermag sie aber auch für die empirische Wissenschaft an Relevanz zu gewinnen, nicht nur, da das „normativ ,richtig“ Geltende“ für Weber „als ein besonders leicht verständlicher konventioneller Typus in Betracht kommt" (Weber 1988i [1918]: 533, H.i.O.), sondern da damit ein logisches Verfahren entworfen wird, das in seiner Wertinterpretation der empirischen Forschung einen intersubjektiv vorgegebenen Rahmen für die Wertbeziehungen aufzuzeigen vermag.

Diese Orientierung am Verfahren der Rechtsdogmatik erweist sich aber auch hinsichtlich der Folgeprobleme von Webers methodologischer Wahl als relevant. So sehr sich Weber in erkenntnis- und wissenschaftstheoretischer Hinsicht auf die neukantianische Wertphilosophie beruft, so sehr versucht er die daraus folgenden Problemlagen des Neukantianismus zu umgehen, d.h. von den weitreichenden Konsequenzen der Wertbeziehungslehre und normativen Wahrheitstheorie Rickerts und dem daraus folgenden Entwurf eines Systems der Werte eingeholt zu werden (vgl. etwa Wagner 1987: 158; Wagner, Zipprian 1989: 10ff.; Treiber 1997: 412, 431). ${ }^{876}$ Weber kann dies vermeiden, indem er den „Umweg“ über die Rechtswissenschaft wählt (vgl. Treiber 1997: 431, 412; Treiber, Quensel 2002: 97ff.). Denn damit liegt ihm eine „normative Wissenschaft“ vor, die sich nicht mit wertphilosophischen Problemen der Wertbeziehung und Werthierarchisierung, mit letzten Werten und Wertesystemen auseinandersetzt, sondern die Werte rein logisch auf ihren Sinngehalt hin zu syste-

875 Da „auch die logische Analyse eines Ideals auf seinen Gehalt und auf seine letzten Axiome hin und die Aufzeigung der aus seiner Verfolgung sich logischer und praktischer Weise ergebenden Konsequenzen [... ] auch für ihn [einen Chinesen, D.S.] gültig sein muß“ (Weber 1988b [1904]: 155, H.i.O.), bewegt sich die Ermittlung des objektiven Sinns jenseits der subjektiven Wertungen.

876 Selbst Rickert hebt dies bei Weber hervor, wenn er in seiner Vorrede zur 3. und 4. Auflage von Die Grenzen der naturwissenschaftlichen Begriffsbildung schreibt: Weber „glaubte eigentlich nur an die ,Logik'. Daher stand er auch meinem Plan einer universalen wissenschaftlichen Weltanschauungslehre aufgrund eines umfassenden Systems der Werte [...] ,skeptisch“ gegenüber" (Rickert, zitiert nach Tenbruck 1999a: 57, Anm. 25). 
matisieren sucht. ${ }^{877}$ Daher wechselt Weber mit der Rechtswissenschaft sozusagen vom Wert zum Sinn, sie ist nicht - wie bei Lask - eine empirische Kulturwissenschaft, die als solche unter dem Diktum der Wertbeziehungslehre stünde (vgl. hierzu Treiber, Quensel 2002: 98ff.). Aufgrund der Subjektivität der Zwecke (s.o.) ist sie auch keine Zweckwissenschaft, sondern eine "Normwissenschaft“, die primär der Sinnermittlung der Normen dient.

Damit liefert die Rechtsdogmatik ein genuin wissenschaftliches Verfahren des Umgangs mit Werten, hierin besteht ihr spezifischer Wissenschaftscharakter, und daher eignet sie sich als Bezugspunkt eines wissenschaftlichen Umgangs mit Werten jenseits der Wertphilosophie. Zudem kann sich Weber mit der Orientierung an der Rechtsdogmatik ganz der Logik verpflichten, was angesichts einer zunehmenden Rationalisierung des Okizdents zugleich eine spezifische Evidenz besitzt. ${ }^{878}$

\section{Zusammenfassung: Webers wissenschaftslogische Bestimmung der Rechtsdogmatik}

Für Webers verstehende Soziologie, die über die idealtypische Begriffsbildung streng wissenschaftlich, d.h. spezifisch ,objektiv' und werturteilsfrei verfährt, ist die Orientierung an der Rechtsdogmatik wesentlich - allerdings unter der Prämisse, dass soziologische und juristische Betrachtungsweise streng voneinander getrennt sind, um die Autonomie der Soziologie nicht zu gefährden. Wenn Weber derart das Verhältnis der Jurisprudenz zur soziologischen Begriffsbildung bestimmt, dann setzt das eine bestimmte wissenschaftslogische Beschaffenheit der Rechtsdogmatik voraus (vgl.

877 Man kann auch sagen: Die Rechtsdogmatik tritt an die Stelle der Wertphilosophie. Diese Interpretation von Webers Rekurs auf die Rechtsdogmatik wird durch den eigentümlichen, von Rickert abweichenden Gebrauch des Wertphilosophie-Begriffs im Wertfreiheits-Aufsatz unterstützt: Wertphilosophie ziele auf der Basis des Polytheismus der Werte, der letztlich keine ,objektive' Systematisierung der Werte zulasse, auf die Ermittlung des jeweiligen ,idealen' Sinnzusammenhangs der Werte (vgl. Weber 1988i [1918]: 507f.).

878 Im Zuge der Rationalisierung haben sich nach Weber verschiedene Wertsphären ausdifferenziert, die jeweils nach eigenen Sinnregeln und mit eigener Dynamik funktionieren. $\mathrm{Ob}$ dazu auch das Recht zählt, ist angesichts der Tatsache, dass Weber es nicht als solche explizit bezeichnet, umstritten (vgl. Oakes 2007 m.w.N.). Da Weber bei der Frage der Rolle der Rechtswissenschaft für die empirische Wissenschaft auf der wissenschaftslogischen Ebene argumentiert, ist diese Frage m.E. hier jedoch nicht von Relevanz. 
Treiber, Quensel 2002: 96): Recht muss auch als Wissenschaft konstituierbar sein, so dass positives Recht der Rechtswissenschaft übereignet und insofern nach deren eigenen rationalen Prinzipien behandelt werden kann. Der Wissenschaftscharakter der Jurisprudenz steht für Weber nicht in Frage. Die Rechtsdogmatik hat dabei die Anforderungen der begriffslogischen Klarheit und unbedingte Steigerung ihres Systemcharakters hin zu „logischer Geschlossenheit" zu erfüllen, um die primäre Aufgabe der objektiven Sinndeutung (als Vorbereitung der Wertung) bewältigen zu können. Sie erweist sich darin aus wissenschaftslogischen Gründen als abstrakt und wirklichkeitsfremd. Ihre konzeptionelle Leistung besteht Weber zufolge dann gerade in der Schärfe und Eindeutigkeit ihrer Konstruktion gegenüber der Mannigfaltigkeit und Fülle der zu beschreibenden Wirklichkeit. Da das Recht über seine Anwendung (Geltung und Syllogismus) zugleich wirklichkeitsbezogen ist, stellen sich die juristischen Begriffskonstruktionen zumindest idealiter als realitätsbezogene Darstellungsmittel zur Erschließung des immanenten Sinnes im sozialen Zusammenhang dar (vgl. ebd.: 102f.).

Gerade der spezifische Wissenschaftscharakter der Rechtsdogmatik, d.h. die wissenschaftslogische Spezifizierung der rechtsdogmatischen Begriffsbildung, begründet also für Weber die Möglichkeit und die Vorteile der Orientierung der Soziologie an der Rechtswissenschaft. Dies gilt nicht nur im Bereich der Idealtypenbildung, sondern auch, um angesichts eines Gegenstandes, der sich über Werte und Wertungen konstituiert (Kultur), das Problem der Werturteilsfreiheit zu lösen.

\section{Webers Bestimmungen der Rechtsdogmatik und das epistemische Dispositiv der Privatrechtswissenschaft}

Mit diesen Bestimmungen der Rechtswissenschaft bewegt sich Weber aber nicht nur in den soziologischen Debatten über die Eigenart der eigenen Disziplin, sondern ebenso im (privat-)rechtswissenschaftlichen Diskurs. Denn nicht nur indem er den Repräsentationsgedanken ablehnt, bezieht er deutliche Positionen mit Blick auf das epistemische Dispositiv der Historischen Rechtsschule in der ersten Hälfte des 19. Jahrhunderts. Vielmehr lassen sich solche Positionierungen auch im Rahmen des gesellschaftsfunktionalen und des normativen Zweckdispositivs zeigen - und zwar letzteres nicht nur, weil Weber ebenfalls auf die wissenschaftstheoretische Ebene wechselt, sondern weil er zu den konkreten Fragestellungen innerhalb der Debatte explizit Stellung nimmt. 


\section{Recht und Ordnung: Webers Abkehr vom gesellschaftsfunktionalen Zweckdispositiv}

Weber adressiert im Kategorien-Aufsatz das Recht für die Soziologie primär unter der Frage seiner Ordnungsleistung: „[A]ls ,Recht' gilt uns soziologisch eine in ihrer empirischen Geltung durch einen ,Zwangsapparat (im bald zu erörternden Sinn), als Konvention eine nur durch ,soziale Mißbilligung' der zur ,Rechts'- bzw. ,Konventions'-Gemeinschaft vergesellschafteten Gruppe garantierte Ordnung." (Weber 1988g [1913]: 445 Anm. 1) Damit greift er letztlich die gesellschaftsfunktionale Betrachtungsweise des Rechts auf, nicht nur indem er die große kausale Relevanz des Rechts für das soziale Leben feststellt, sondern insbesondere auch, indem er das Recht zum rationalen Idealtypus der orientierungsleitenden Satzung erklärt. Im Mittelpunkt steht die ordnungsstiftende empirische Wirkung von Rechtssätzen und der Rechtsordnung. Dies ist auch die Perspektive, die Weber in seinem Beitrag Die Wirtschaft und die Ordnungen aus der ersten Werkphase von Wirtschaft und Gesellschaft einnimmt und die bis in die Grundbegriffe nachverfolgt werden kann. ${ }^{879}$

In der Tat sind in Webers soziologischer Betrachtung der Rechtsordnung deutliche Parallelen zu den gesellschaftsfunktionalen Bestimmungen des Rechts zu erkennen, wie sie sich in dem an Jhering anschließenden Diskurs der Privatrechtswissenschaft als gesellschaftsfunktionales Zweckdispositiv verfestigten: Auch für Weber ist die Gesellschaft keine harmonische Sphäre, das soziale Leben ist durch grundsätzliche Antagonismen gekennzeichnet. ${ }^{880}$ Daher bestimmt er die Funktion des Rechts ebenfalls in der Erwartungssicherung und darüber primär über seine ordnungsstabilisierende Leistung. Zudem wertet auch Weber die Gesetzgebung insofern auf, als Satzungen doch heute überwiegend oktroyiert seien.

Weber bestimmt Rechtssätze als „Normen“, als Sollens-Sätze, und trennt sie darüber wie Jhering vom Kausalitätsgesetz der naturwissen-

879 Ihm geht es um die Klärung der höchst intimen Beziehungen „Zwischen „Wirtschafts- und Rechtsordnung“, allerdings unter der Prämisse, dass „diese letztere dabei nicht in juristischem, sondern in soziologischem Sinne verstanden“ werde, d.h. „als empirische Geltung“ (Weber 1976 [posthum]: 181, H.i.O.).

880 V.a. Regis Factor und Steven Turner haben in ihrem Buch Max Weber. The Lawyer as Social Thinker die Relevanz von Jherings Zweck für Webers methodischen Ansatz herausgearbeitet (Turner, Factor 1997). Der Fokus liegt vorliegend aber nicht auf einem solchen Vergleich Webers mit einem juristischen Autor, sondern auf seiner Verortung in den jeweiligen juristischen epistemischen Dispositiven, für die auch Jhering zwar ein zentraler Bezugspunkt war (s.o.), die jedoch davon ausgehend auch andere Probleme (z.B. Methodenlehre) behandelten. 
schaftlichen Phänomene - ohne dann allerdings wie letzterer nach den „Naturgesetzen“ der Zwecksphäre zu suchen. Und auch für Weber zeichnet sich das Recht im Verbund der Normen durch die Existenz eines spezifischen Zwangs mittels eines dafür bereitgestellten Erzwingungsapparats aus (vgl. Weber 1988g [1913]: 454 Anm. 1; 1988j [1921]: 576f.; 1976 [posthum]: 182). Darüber lassen rechtliche Normen sich von Normen der Konvention - und später auch gegenüber Brauch, Mode und Sitte - abgrenzen (vgl. Weber 1988g [1913]: 445 Anm. 1; 1988j [1921]: 570ff.; 1976 [posthum]: 187ff.).

Schließlich rekurriert Weber wie Jhering auf den (Zweck-)Verein, um die überindividuelle Sphäre zu fassen. Er ist für ihn der rationale Idealtypus einer dauernden Vergesellschaftung, wobei Weber anders als Jhering die Gesellschaft über diesen Begriff dann nicht zu einem verselbständigten Zwecksubjekt hypostatiert. Damit lässt Weber die überindividuellen, d.h. sozialen oder gesellschaftlichen Zwecke und damit die holistische Perspektive für das Recht außer Acht. Wenn es also beiden um die Zweck-MittelRelationen geht, so führt Weber sie über den „gemeinten Sinn“ auf individuelle Handlungen zurück. ${ }^{881}$ Zwecke sind dementsprechend immer subjektiv gemeint. Ein "gesellschaftlicher Utilitarismus“, eine reine gesellschaftliche Zwecklehre oder die Suche nach Zweckgesetzen erweist sich weder von Interesse für die sinndeutende „verstehende Soziologie“, noch ist dies logisch haltbar, da die kausale Betrachtungsweise mit einer normativen vermischt wird. ${ }^{882}$

Letztlich schreibt Weber wie Jhering der rechtsdogmatischen Begriffsbildung eine zentrale Funktion in der Analyse gesellschaftlicher Normen zu - allerdings setzt er dafür gerade nicht am Begriff der Gesellschaft an, von dem aus dann Schlussfolgerungen deduziert würden. Das Ding, Gesellschaft ${ }^{\natural}$ bietet keinen legitimen Bezugspunkt seiner Soziologie. Vielmehr dienen ihm bereits entwickelte juristische Begriffe als Idealtypen, an

881 Allerdings haben Turner und Factor zu Recht darauf hingewiesen, dass auch bei Jhering eine handlungstheoretische Fundierung zu erkennen sei, leitet er doch den Zweck aus den menschlichen Handlungen her (das ist ja auch letztlich der Punkt, an dem Tönnies anschließt). Sie markieren die Differenz dahingehend, dass Jhering von einer abstrakten Theorie der Handlung ausgehe, während Weber damit eine Rückführung auf konkrete menschliche Handlungen jenseits einer abstrakten Definition beabsichtige (vgl. Turner, Factor 1997: 29). Daher unterscheidet sich auch die Definition des sozialen Handelns: Bei Jhering ist es Handeln für die Zwecke der Gesellschaft, bei Weber als seinem gemeinten Sinn nach auf das Verhalten anderer bezogen.

882 Daher lehnt Weber letztlich Jherings - und anderweitige - Bestimmung der Gesellschaftswissenschaft als Leitwissenschaft der Jurisprudenz ab. 
denen der subjektiv gemeinte Sinn konkreter Handlungen "gemessen“ werden kann, um sich dessen Spezifik jeweils gewahr zu werden.

Auch wenn Weber damit sehr ähnliche gesellschaftsfunktionale Bestimmungen des Rechts hervorhebt, lässt dies nach Weber keinerlei Rückschlüsse auf die genuin rechtswissenschaftliche Betrachtungsweise zu:

Zwischen dem juristisch-dogmatischen, normativen Gelten der Ordnung und einem empirischen Vorgang gibt es ja in der Tat kein Kausalverhältnis, sondern nur die Frage: wird der empirische Vorgang von der (richtig interpretierten) Ordnung juristisch „betroffen“?, soll sie also (normativ) für ihn gelten?, und, wenn ja, was sagt sie als für ihn normativ geltensollend aus? (Weber 1988j [1921]: 576, H.i.O.)

Vice versa sagt die rechtswissenschaftliche Betrachtung nichts über die faktische Funktion, das Funktionieren der empirischen Ordnungen des sozialen Lebens aus (siehe die Stammler-Kritik).

Um diese wechselseitige Nichtrückführbarkeit zu begründen, wechselt Weber zur wissenschaftslogischen Trennung der „dogmatischen“ von den „empirischen“ Wissenschaften (vgl. Weber 1988j [1921]: 542). Denn es gelte:

Es liegt auf der Hand, daß beide Betrachtungsweisen sich gänzlich heterogene Probleme stellen und ihre „Objekte“ unmittelbar gar nicht in Berührung miteinander geraten können, daß die ideelle „Rechtsordnung" der Rechtstheorie direkt mit dem Kosmos des faktischen wirtschaftlichen Handelns nichts zu schaffen hat, da beide in verschiedenen Ebenen liegen: die eine in der des ideellen Geltensollens, die andere in der des realen Geschehens. (Weber 1976 [posthum]: 181)

Gesellschaftsfunktionale, d.h. faktisch ordnungsstiftende Leistungen des Rechts, lassen sich weder aus einer juristischen Rechtstheorie oder Rechtsentstehungslehre, noch aus der Arbeit an der juristischen Rechtsordnung herleiten. Die juristische Ermittlung des gelten-sollenden Inhalts der Rechtsordnung kann keinerlei direkte, v.a. direkte kausale Erkenntnisse über das gegenwärtige soziale Leben geben. Aus dem Sollen folgt kein Sein. Vice versa lässt die kausale Bestimmung des Rechts als Resultante oder Determinante des menschlichen Handelns keinerlei Rückschlüsse auf den an der Rechtsordnung zu ermittelnden ,objektiven', ideellen Sinn zu. Aus dem Sein folgt kein Sollen.

Insofern erweisen sich die Problematisierungsweisen des genuin juristischen gesellschaftsfunktionalen Zweckdispositivs in den Debatten über das BGB und seine Entwürfe als nicht anschlussfähig, da sie nach Weber letztlich auch logisch nicht haltbar sind: Denn ob das BGB der sozialen 
Aufgabe gerecht werde, sei keine juristische, sondern eine kausale Frage, wenn man darunter - wie in den Debatten geltend gemacht wurde - den kausalen Einfluss, die „Wirkung“ des Rechts versteht. Der Streit über die soziale oder unsoziale Tendenz als Frage nach der gesellschaftszersetzenden oder -stabilisierenden Wirkung des BGBs und seiner Entwürfe lässt sich nicht mit rechtswissenschaftlichen Mitteln entscheiden: Denn einerseits ist aus wissenschaftslogischen Gründen die Integration der soziologischen Erkenntnisweise in die Rechtswissenschaften (wie etwa bei Menger, Petražycki und Ehrlich) auszuschließen, andererseits ist eine funktionale Wendung des Repräsentationsgedankens nicht möglich, wie Webers Kritik des Repräsentationsgedankens zeigt. Daher seien auch die Debatten über deutsches oder römisches Recht letztlich irreführend. Der Jurist ist für Weber weder der Sachverständige für die soziale Ordnung, noch kann er die jeweils kausale Funktion des Rechts für das soziale Leben bestimmen.

Darüber hinaus lassen sich gesellschaftstheoretische Fragen nicht in Rechtsgebietszuweisungen übersetzen. Die Abgrenzung von Privatrecht und Öffentlichem Recht ist für Weber aus soziologischer Sicht nicht möglich (vgl. Weber 1976 [posthum]: 387ff.). ${ }^{883}$ Daher ist die Privatrechtstheorie auch keine Gesellschaftstheorie. Will man das Recht als Mittel zum Zweck der gesellschaftlichen Ordnungssicherung einsetzen, so verlässt man sowohl die rechtswissenschaftliche als auch die soziologische Ebene, beruht doch die Beurteilung von solchen Zweck-Mittel-Relationen auf pragmatischen (Be-) Wertungen - nicht auf Sinnermittlung.

Eine solche Vermischung der pragmatischen mit der Sinnebene sei aber logisch nicht haltbar, und führe letztlich auch zu falschen Frontstellungen und Unterstellungen in der Debatte um die soziale Aufgabe des BGBs, wie Weber bereits im Jahr 1902 in seiner Lotmar-Rezension (insbesondere gegen Menger) anmerkte: „Wer [...] in dem [...] Formalismus der juristischen Begriffsbildung den Grund des vielbeklagten ,unsozialen' Charakters des geltenden Privatrechts oder der bestehenden Rechtspflege sucht, greift weit fehl.“(Weber 1902: 725, H.i.O.) ${ }^{884}$

883 Trotz allem liest sich Webers Rechtssoziologie über weite Strecken als Privatrechtsgeschichte des Okzidents. Das liegt nicht nur daran, dass für die Wirtschaft das Privatrecht zentral ist, sondern ebenso an der eigentlichen Frage, die Weber interessiert: die Rationalisierung des Rechts und des Rechtsdenkens in der Moderne (vgl. Weber 1976 [posthum]: 395). Dass sie gerade im Privatrecht zu verorten ist, zeigt letztlich Webers Rekurs auf die Begriffsjurisprudenz als „Höchstgrad methodisch-logischer Rationalität“ (ebd.: 397, s.u.).

884 Zur Rolle der Lotmar-Rezension in Webers Werk vgl. Coutu 2009 
Aus diesen wissenschaftslogischen Befund zieht Weber praktische Folgerungen für das diskutierte Problem: „Nicht unformale ,positive“ Begriffe, sondern passend spezialisierte Rechtsnormen und unbefangene, sich streng an die Norm und damit auch an die Form - ,die Zwillingsschwester der Freiheit" - bindende Rechtsprechung thun not." (Ebd.:, H.i.O.) Sozialpolitische Wertungen erweisen sich letztlich für Weber immer als willkürlich (ebd.), und um die Gefahr dieser Form der Willkür zu bannen, müsse die Rechtswissenschaft sich - wie Weber immer wieder mit dem Zitat aus Jherings früher Arbeitsphase von der "Zwillingsschwester" ${ }^{\text {“885 }}$ betont (s.a. Weber 1988f [1909]: 419; Weber in Simmel et al. 1911c: 327) - der formalen Betrachtungsweise verpflichten.

\section{Rechtsdogmatik und Begriffsjurisprudenz: Webers Positionierung im normativen Zweckdispositiv}

Wenn Weber die Fahne des rationalen Rechtsformalismus hochhält (vgl. Quensel 1997: 153), so interveniert er in den juristischen Methodenstreit Anfang des 20. Jahrhunderts und reagiert auf die Problematisierungsweisen im normativen Zweckdispositiv:

Auch Weber normativiert das Rechtsverständnis, indem er Recht als „Norm“ im normativen Sinne, d.h. als Gebot bestimmt. Für ihn sind Rechtssätze ja gerade keine Statuierung von Regelmäßigkeiten oder allgemeinen Gesetzen des Zusammenlebens, und der Zweck im Recht bzw. eines Rechtssatzes lässt sich nicht auf einen ,objektiven' sozialen Zweck zurückführen. Darauf basierende Ansätze der Soziologisierung der Rechtswissenschaft (etwa Kornfeld, Ehrlich, Spiegel, Wüstendörfer) sind daher in der Perspektive Webers abzulehnen.

Dass im richterlichen Urteil der Sachverhalt an den juristischen Begriffen „wertend" gemessen wird, dass die Wertung hier unumgehbar ist, steht für Weber außer Frage (vgl. Weber 1988d [1907]: 323, H.i.O.). Genau das begründet ja - neben der Ermittlung des ,objektiven Sinns` durch die Dogmatik - die Differenz zwischen empirisch-kausalen Wissenschaften und ",normative[n] 'Disziplinen, z. B. namentlich solche der Jurisprudenz" (Weber 1988a [1903-1906]: 86). ${ }^{886}$

885 Jhering schreibt im Geist des römischen Rechts: „Die Form ist die geschworene Feindin der Willkühr, die Zwillingsschwester der Freiheit.“ (Jhering 1858: 497).

886 Insofern unterscheidet sich auch die Nationalökonomie von der Rechtsdogmatik, welche nach Weber als Kunstlehre eminent normativ-praktische Zwecke ver- 
Auch für Weber sind Recht bzw. Rechtsordnung und soziales Leben nicht deckungsgleich - allerdings aus wissenschaftslogischen Gründen, und nicht als Ergebnis einer Fehlentwicklung der Rechtswissenschaft. Die Entfremdung der rechtsdogmatischen Begriffskonstruktionen vom Leben ist vielmehr natürliche Folge der ,Logisierung des Rechts'. Daher basiere der Vorwurf der Lebensferne der Begriffsjurisprudenz auf einem grundlegenden Missverständnis hinsichtlich des wissenschaftstheoretischen Spezifikums der dogmatischen Rechtswissenschaft und rechtfertige letztlich keine wie auch immer geartete „,soziologische[]“ Fundierung der Jurisprudenz" (Weber 1976 [posthum]: 508).

Diese Logisierung des Rechts garantiere die Wissenschaftlichkeit der Rechtsfindung, d.h. jene Abwehr der Willkür, in der Weber die Gewähr der Freiheit erblickt. Nur ein solcher rationaler Rechtsformalismus gewähre in der okzidentalen Moderne letztlich Rechtssicherheit. Denn „wenn einmal der rein formale Standpunkt des Rechts verlassen wird“, sei aus „allgemeinen Empfindungen heraus je nach der persönlichen Weltanschauung auch das gerade Gegenteil deduzierbar" (Weber 1902: 729f.). ${ }^{887}$ Dass es im Formalismus auch zu ,ungerecht' empfundenen Urteilen kommen könne, schließt Weber keinesfalls aus (s.o.). Allerdings seien objektiv gerechte Urteile als Werturteile wissenschaftlich nicht herleitbar.

Weber greift aber auch genuin rechtsdogmatische Problemlagen auf: Die Frage, ob de facto Lücken im Recht existieren, bejaht er in Die Wirtschaft und die Ordnungen umstandslos:

Die rechtliche Geordnetheit eines Sachverhalts, d.h. immer: das Vorhandensein einer menschlichen Instanz, wie immer geartet sie sei, welche im Fall des Eintritts der betreffenden Tatsache als (prinzipiell) in der Lage befindlich gilt, nach irgendwelchen Normvorstellungen anzugeben: was nun „von Rechts wegen“ zu geschehen habe, ist aber überhaupt nirgends bis in die letzten Konsequenzen durchgeführt. (Weber 1976 [posthum]: 193; s.a. Weber in Simmel et al. 1911c: 326)

folgt. Letztlich sei sie „offensichtlich eine Dogmatik in einem logisch sehr anderen Sinn" (Weber 1988i [1918]: 536).

887 Das gilt letztlich auch mit Blick auf eine allgemeine Verhaltenserwartung. So schreibt Weber: „Und hier liegt das spezifische Interesse des rationalen kapitalistischen ,Betriebes' an ,rationalen' Ordnungen, deren praktisches Funktionieren er in seinen Chancen ebenso berechnen kann wie das einer Maschine." (Weber 1988g [1913]: 474; s.a. 1920: 11) Insofern stellt das vielgeschmähte juristische Ideal des „Rechnens mit Begriffen“ für Weber eine Entwicklungsbedingung des okzidentalen Kapitalismus dar. 
Unzweifelhaft erscheint ihm, dass rechtliche (und konventionelle) Ordnungen „prinzipell [...] nur Fragmente“ des Einverständnis- und Gemeinschaftshandeln erfassen. Dies könne ganz bewusst geschehen, pflegten doch zumeist „gerade, grundlegende“ Fragen einer sonst sehr stark durchrationalisierten Rechtsordnung rechtlich überhaupt gar nicht geregelt zu sein“ (Weber 1976 [posthum]: 193f.). ${ }^{888}$ Ebenso erscheint Weber die „unzweifelhafte[] Tatsache: daß noch jetzt die Gerichtspraxis, z.B. auch des deutschen Reichsgerichts, gerade nach dem Inkrafttreten des Bürgerlichen Gesetzbuchs, gelegentlich teils praeter, teils sogar contra legem ganz neue Rechtsprinzipien aufstellt“ (Weber 1976 [posthum]: 508; s.a. Weber in Simmel et al. 1911c: 327).

Wie die Mehrzahl der Teilnehmer am juristischen Methodenstreit wechselt Weber angesichts dieser Problemlagen auf die Ebene der Erkenntnis- und Wissenschaftstheorie. Hier geht es für ihn ebenfalls um die Bestimmung des Verhältnisses zwischen Rechtswissenschaft und Soziologie, wofür Weber (wie viele Juristen) auf die wissenschaftslogische Trennung von Sein und Sollen rekurriert. Darüber siedelt er die Rechtswissenschaft als normativ-dogmatische „Normwissenschaft“ jenseits von Naturund Kulturwissenschaft an. Anders als im juristischen Werturteilsstreit, in dem es darum geht, ob und wie die Rechtswissenschaft die Erkenntnisse der empirischen Wissenschaft zu integrieren habe, stellt sich Weber aber die spiegelbildliche Frage, wie die empirische Wissenschaft der Soziologie die Erkenntnisse einer derart normativ-dogmatischen Rechtswissenschaft zu integrieren habe. Dies betrifft die Ebene der Sinnermittlung, genau hier zeigt sich für Weber der wissenschaftslogische Charakter der Rechtsdogmatik

Diese Sinnfrage, und d.h. ja letztlich die Interpretation von Normen, ist nach Weber nicht auf der Ebene der juristischen Methodenlehre, sondern nur auf der Ebene der Wissenschaftstheorie zu beantworten. Denn im Rahmen der juristischen Methodenlehre lassen sich die Probleme der de facto lückenhaften Rechtsordnung sowie der Aufstellung von Rechtsprinzipien contra legem nicht wissenschaftlich lösen. Bei der konkreten Rechtsan-

888 Solche Lücken im Recht öffnen die Rechtsordnung für den Einfluss der soziologisch relevanten jeweiligen Machtlagen, auf die sie Rückschlüsse zulassen: „Man kann geradezu die These aufstellen: daß es für jede ,Verfassung' im soziologischen Sinn, d.h. für die Art der faktischen, die Möglichkeit, das Gemeinschaftshandeln durch Anordnungen zu beeinflussen, bestimmenden Machtverteilung in einem Gemeinwesen charakteristisch ist, wo und welcher Art derartige, gerade die Grundfragen betreffende, ,Lücken' seine ,Verfassung` im juristischen Sinne des Worts aufweist.“ (Weber 1976 [posthum]: 194). 
wendung komme letztlich das wertende Element zum Tragen, also genau jenes Moment, das gerade nicht wissenschaftlich einzufangen ist. Daher wendet Weber sich auch gegen die Versuche, das konkrete richterliche Urteil wissenschaftlich zu begründen - sei es über eine soziologisch-juristische Methode, sei es über die Teleologisierung. So sind die Ansätze der objektiven Fundierung des Rechtsgefühls in den soziologisch-juristischen Methoden von Gmelin oder Wüstendörfer zum Scheitern verurteilt, da dieses „außerordentlich labil“ und „jäher Umschläge fähig“ sei (Weber 1976 [posthum]: 445): „Stark emotional, ist gerade das ,Gefühl‘ sehr wenig geeignet, stabil sich behauptende Normen zu stützen, sondern vielmehr eine der verschiedenen Quellen irrationaler Rechtsfindung." (Ebd.) Auch könne man das richterliche Werturteil nicht in den Seinstatsachen begründen (etwa Fuchs), ohne gegen die elementaren Regeln der Wissenschaftslogik zu verstoßen. Eine so ganz heterogene Betrachtungsweise wie die soziologische sei schlichtweg nicht geeignet, die juristische Methode zu ersetzen (vgl. Weber in Simmel et al. 1911c: 326). Aber auch gegenüber dem Verfahren der Abwägung der Interessenjurisprudenz hegt Weber Vorbehalte: Da die Abwägung zwischen widerstreitenden Interessen niemals auf wissenschaftlichen Weg erfolgen könne (vgl. Weber 1988b [1904]: 150; 1988i [1918]: 499), wird der Ort der Abwägung bei Weber - wie Joachim Rückert feststellt - „ganz treffend als ein staatsmännisch-politischer, nicht empirischer, ganz und gar nicht objektiv-wissenschaftlicher und normativ besonders wenig eindeutiger bezeichnet“ (Rückert 2011: 917, H.i.O.).

Genuin wissenschaftlich lässt sich nach Weber mit der normativen Seite im Recht nur auf der Ebene des Sinns umgehen: Die Ermittlung des juristisch ,objektiven Sinns' mit seiner scharfen, den Verfahrensweisen der Konstruktionsjurisprudenz folgenden Begriffsbildung erfolge aus dem Gesamtzusammenhang der Rechtsnormen, „deren Zusammenarbeitung zu einem in sich widerspruchslosen gedanklichen System die eine (elementarste) Arbeit der Jurisprudenz" sei (Weber 1988f [1909]: 420, H.i.O.). Dieser ,objektive Sinn' dient dann als Grundlage der Wertung, gliedere sich doch die Rechtsordnung ,in ein System von Gedanken und Begriffen, welches der wissenschaftliche Rechtsdogmatiker als Wertmaßstab benützt" (Weber 1988d [1907]: 348).

Mit diesen Bestimmungen bezieht Weber im juristischen Methodenstreit eine konkrete Position. Denn das, was er als wissenschaftslogisches Ideal der Rechtswissenschaft definiert, ist letztlich - wie schon von vielen angemerkt - die Rechtsdogmatik der Historischen Rechtsschule, d.h. der Begriffsjurisprudenz. Diese Konvergenz beruht nicht nur auf impliziten Verfahrensanleihen, sondern folgt für Weber aus der historischen Entwicklung des Rechts, insbesondere der Rationalisierung des Rechts und des 
Rechtsdenkens zur heutigen okzidentalen Denkform (vgl. Weber 1976 [posthum]: 503ff.): 889

$\mathrm{Zu}$ den möglichen rationalen „Denkmanipulationen“ zähle neben der Analyse des Tatbestandes bzgl. seiner rechtlich relevanten Bestandteile zunächst die „Generalisierung“, d.h. die Reduktion der für die Entscheidung des Einzelfalls maßgebenden Gründe auf eine oder mehrere ,Prinzipien` in Form von Rechtssätzen (ebd.: 395). Parallel zu der „analytischen Gewinnung von ,Rechtssätzen“ aus den Einzelfällen“ erfolge die „synthetische Arbeit der ,juristischen Konstruktion“ von ,Rechtsverhältnissen` und ,Rechtsinstituten“" (ebd.: 395f.). Als historisches „Spätprodukt“, das mit der Konstruktionsarbeit auch in Spannung treten kann, sieht Weber die „Systematisierung“ an: „Nach unserer heutigen Denkgewohnheit bedeutet sie: die Inbeziehungsetzung aller durch Analyse gewonnenen Rechtssätze derart, daß sie untereinander ein logisch klares, in sich logisch widerspruchsloses und, vor allem, prinzipiell lückenloses System von Regeln bilden [...].“ (Ebd.: 396) Dabei gilt nach Weber:

Erst die sinndeutende Abstraktion läßt die spezifisch systematische Aufgabe entstehen: die einzelnen anerkanntermaßen geltenden Rechtsregeln durch die Mittel der Logik zu einem in sich widerspruchslosen Zusammenhang von abstrakten Rechtssätzen zusammenzufügen und zu rationalisieren. (Ebd.: 397, H.i.O.)

Diese Möglichkeiten der rationalen Bearbeitung des Rechts im Rahmen der Rechtsfindung sieht Weber nun in der gemeinrechtlichen Jurisprudenz, also der Pandektistik, verwirklicht. Sie ziele mit ihrer Systematisierung auf „logische Sinndeutung“ (ebd.: 396) und habe dabei den „Höchstgrad methodisch-logischer Rationalität erreicht“ (ebd.: 397). Unabhängig von der faktischen Beschaffenheit des Rechts ermöglichten die gemeinrechtlichen Postulate die logische Lösung der Rechtsprobleme aus dem Recht selbst heraus, da sie auf den Annahmen beruhten:

1. daß jede konkrete Rechtsentscheidung ,Anwendung' eines abstrakten Rechtssatzes auf einen konkreten „Tatbestand“ sei, - 2. daß für jeden konkreten Tatbestand mit den Mitteln der Rechtslogik eine Entscheidung aus den geltenden abstrakten Rechtssätzen zu gewinnen sein müsse, - 3. daß also das geltende objektive Recht ein „lückenlo-

889 Hubert Treiber untersuchte jüngst Webers Annahmen über die Entwicklung des Rechts und der okzidentalen Rechtsrationalisierung kritisch mit Blick auf neuere rechtshistorische Erkenntnisse über die tatsächlichen Gegebenheiten (Treiber 2017). 
ses" System von Rechtssätzen darstellen oder latent in sich enthalten oder doch als ein solches für die Zwecke der Rechtsanwendung behandelt werden müsse, -4 . daß das, was sich juristisch nicht rational „konstruieren" lasse, auch rechtlich nicht relevant sei, - 5. daß das Gemeinschaftshandeln der Menschen durchweg als "Anwendung" oder „Ausführung“ von Rechtssätzen oder umgekehrt [als] „Verstoß“ gegen Rechtssätze gedeutet werden müsse [...], da, entsprechend der „Lückenlosigkeit“ des Rechtssystems, ja auch die „rechtliche Geordnetheit" eine Grundkategorie alles sozialen Geschehens sei (ebd.).

Dieser gemeinrechtlichen Logisierung entspricht die Formalisierung des Rechtsdenkens, jener spezifisch okzidentale Rechtsformalismus, der von idealen Gedankenbilder ausgeht und daher notwendigerweise eine gewisse Entfremdung vom Leben impliziert (s.o.).

Von dieser Warte aus formuliert Weber auch eine deutliche Kritik an den „antiformalen Tendenzen in der modernen Rechtsentwicklung“ (ebd.: 503), wie er sie in den Positionen im juristischen Methodenstreit erkennt. ${ }^{890}$ Denn auch wenn er der Doktrin der Lückenhaftigkeit des Gesetzes auf der empirischen Ebene durchaus zustimmt, könne man die Existenz einer solchen Regelungslücke mit Blick auf einen konkreten Fall, also die Frage, ob ein Tatbestand tatsächlich "neu“ sei, nur aus dem systematischen Zusammenhang, dem Rechtssystem, feststellen (vgl. Weber $1988 \mathrm{f}$ [1909]: 419f.). Die „Fiktion seiner systematischen Geschlossenheit" des Rechts (Weber 1976 [posthum]: 507) ist für Weber kein Argument gegen die Rechtsdogmatik, sondern vielmehr ihr wissenschaftslogisches Wesensmerkmal, ohne die eine wissenschaftliche Behandlung des Rechts - auch mit Blick auf neue Sachverhalte - schlicht nicht möglich sei.

Auch dass - wie im Methodenstreit vertreten - im richterlichen Urteil nicht nur logische Normen zur Anwendung kämen, bestreitet Weber letztlich nicht (vgl. ebd.: 511f.). Allerdings lehnt er die daraus gezogenen methodischen und dogmatischen Schlussfolgerungen explizit ab: Die freirechtlichen Ansätze gehörten zu den irrationalistischen Spielarten der Abkehr von der gemeinrechtlichen Wissenschaft; sie seien eine „Form der Flucht in das Irrationale“ (ebd.: 509), die gerade nicht den Status der Wissenschaftlichkeit für sich beanspruchen könne. „Wirklich bewußt ,schöpferisch', d.h. neues Recht schaffend“, wie dies im Methodenstreit für den

890 Dabei sind diese antiformalen Tendenzen nach Weber durchaus selbst „Konsequenzen der sich selbst überschlagenden wissenschaftlichen Rationalisierung und voraussetzungslosen Selbstbesinnung des Rechtsdenkens“ (Weber 1976 [posthum]: 509). 
Richter beansprucht wird, haben sich nach Weber „nur Propheten zum geltenden Recht verhalten“ (ebd.: 512, H.i.O.). Das sind aber Formen des "Wertirrationalismus" (ebd.: 508), und eben nicht der wissenschaftlichen Begründung der Rechtswissenschaft.

Darüber hinaus führe die Befreiung des Richters von der logischen Operation der gemeinrechtlichen Jurisprudenz, für Weber gleichzustellen mit der Legitimierung richterlicher Eigenwertungen, nicht unbedingt zu gerechteren Urteilen: „Übrigens ist nicht sicher, ob die heute negativ privilegierten Klassen, speziell die Arbeiterschaft, von einer unformalen Rechtspflege für ihre Interessen das zu erwarten haben, was die Juristen-Ideologie annimmt." (Ebd.: 512)

Weder die soziologische Fundierung der Rechtswissenschaft, die auf Normen außerhalb des Gesetzes zurückgreife, um aus den empirischen Rechtserwartungen objektive Maßstäbe zu ermitteln (wie etwa Jung oder Ehrlich, vgl. ebd.: 507f.), noch die Teleologisierung der Rechtswissenschaft - sei es auf methodischer Ebene durch den Versuch, die Abwägung methodisch anzuleiten, oder sei es durch die Proklamation eines „richtigen Rechts“ (z.B. Stammler, ebd.: 508) - seien wissenschaftlich haltbar: "Jedenfalls aber wird die juristische Präzision der Arbeit, wie sie sich in den Urteilsgründen ausspricht, ziemlich stark herabgesetzt werden, wenn soziologische und ökonomische oder ethische Räsonnements an die Stelle juristischer Begriffe treten." (Ebd.: 512)

Webers Polemik richtet sich nicht nur gegen die wissenschaftslogischen Fehlschlüsse der verschiedenen Ansätze in der Methodenreformbewegung, sondern ebenso gegen deren intellektuelle Redlichkeit: Letztlich sei die freirechtliche Bewegung, d.h. bei Weber die Methodenreformbewegung, ein „Produkt intellektualistischer Desillusionierung“ (ebd.) sowie des juristischen Standesdünkels, d.h. der ,ideologisch begründete[n] Machtansprüche des Juristenstandes" (ebd.: 513), der sich gerade gegen die Entmachtung durch die Kodifikation (BGB) wendet (ebd.: 509).891

891 Weber schreibt: „Durch die stetige Zunahme des formulierten Gesetzesrechts und namentlich der systematischen Kodifikationen fühlen sich die akademischen Juristen in ihrer Bedeutung und auch in den Chancen der Bewegungsfreiheit des wissenschaftlichen Denkens empfindlich bedroht, und die rapide $\mathrm{Zu}$ nahme der sowohl antilogischen wie antihistorischen Bewegungen in Deutschland, wo man das Los der französischen Rechtswissenschaft nach dem Code, des preußischen nach dem Allgemeinen Landrecht fürchtet, ist dadurch leicht erklärlich und insofern Produkt einer historischen, intern intellektualistischen Interessenkonstellation.“ (Ebd.: 509). 
Weber plädiert also für die Beibehaltung der logischen Postulate der Begriffsjurisprudenz, da nur sie aus wissenschaftslogischer Sicht haltbar seien. Um diese Position vertreten zu können, muss er auf die erkenntnisund wissenschaftstheoretische Ebene wechseln. Nur dann besteht die Möglichkeit, werturteilsfrei über diese Frage zu entscheiden - eine Möglichkeit, über die Weber mit seiner Warnung vor den freiheitsgefährdenden Wirkungen des Rechtsirrationalismus aber hinausgeht. ${ }^{892}$

Weber befürwortet also eindeutig die Begriffsjurisprudenz. Nicht nur seine expliziten Stellungnahmen zum Rechtsdenken, sondern auch seine wissenschaftslogischen Bestimmungen der Rechtsdogmatik erweisen sich also keineswegs als juristisch neutral innerhalb der heftig geführten Debatte im juristischen Methodenstreit. Das liegt daran, dass er im Wechsel auf die Ebene der Wissenschaftstheorie die Problematisierungsweise des normativen Zweckdispositivs aufgreift, wie sie im Zuge dieser Auseinandersetzung entwickelt wurde. Denn auch Weber geht es darum, das Verhältnis zwischen Rechtswissenschaft und Soziologie zu bestimmen, auch wenn er damit ein gänzlich anderes Anliegen verbindet: die wissenschaftslogische Bestimmung der Soziologie in ihrer methodischen Eigenart. Das ändert aber nichts daran, dass es in der Diskussion dieser Frage keine Position gibt, die jenseits des juristischen Diskurses anzusiedeln wäre. Wie auch immer man die Soziologie bestimmt, man muss im normativen Zweckdispositiv mit Rückwirkungen auf die Bestimmung der Rechtswissenschaft rechnen, da man - wie ja auch Weber - das Verhältnis dieser beiden Disziplinen zu bestimmen sucht. Und egal wie man die Rechtswissenschaft bestimmt, hat dies Auswirkungen auf die Möglichkeit der Soziologie als eigenständige Disziplin.

Genau diese Wechselwirkung verdeutlicht Webers Ansatz: Nur wenn er die Rechtswissenschaft als eine normativ-dogmatische Wissenschaft bestimmt - und zwar weder als Zweckwissenschaft noch als Kulturwissenschaft, sondern als rein an der Logik orientierte Normwissenschaft -, die in Form der Begriffsjurisprudenz auf dogmatisch-systematische Sinndeu-

892 So ist Weber nicht unbedingt stringent in seiner Argumentation: Gegen Ernst Fuchs etwa wendet er ein, dass man nur auf Basis der ,anzuerkennenden logischen Grundlagen der Rechtsinterpretation“ beurteilen könne, ob „das Gesetz unter irgend welchen Verhältnissen begriffliche Lücken haben kann oder nicht“ (Weber in Simmel et al. 1911c: 312), nicht aber, ob die Annahme der Doktrin der Lückenlosigkeit zu ungerechten, schädlichen oder sittlich verwerflichen $\mathrm{Zu}$ ständen führen würde (ebd.). Gleichzeitig aber verwirft er die freirechtlichen Ansätze aufgrund ihrer Wirkung, nämlich gerade weil sie freiheitsgefährdend seien (s.o.). 
tung gerichtet ist, kann sich seine verstehende Soziologie an ihr orientieren und dabei werturteilsfrei verfahren. Und nur wenn die Soziologie sich auf die deutende Erklärung des empirischen Handelns konzentriert, und daher zwischen Normen, Regelmäßigkeiten und Maximen unterscheidet, kann sie die Normordnung in ihrer idealen Geltung der Rechtswissenschaft überantworten und damit aus der Soziologie auslagern. Würde Weber eine der beiden Disziplinenbestimmungen ändern, könnte er seine Verortung der Soziologie mit seinen Bezügen und Abgrenzungen zur Rechtswissenschaft nicht aufrechterhalten. Daher ist die Bestimmung der Rechtsdogmatik in Form der Begriffsjurisprudenz für die Konstitution der Disziplin in höchstem Maße konstitutiv.

\section{Die Immunisierung der Soziologie gegen das Recht}

Weber greift im Rahmen der Verhältnisbestimmung von Rechtswissenschaft und Soziologie auf die erkenntnis- und wissenschaftstheoretische Trennung von Sein und Sollen zurück. Darüber werden die beiden Disziplinen streng logisch geschieden, und die Rechtswissenschaft wird der Seite der normativen Wissenschaften zugeordnet. Weber verfestigt also von der soziologischen Seite aus die Abgrenzung der Disziplinen entlang der Trennlinie, Wirklichkeitswissenschaft versus normativ-dogmatische Wissenschaft‘. Damit trägt er nicht nur zur Normativierung im Selbstverständnis der Rechtswissenschaften bei, sondern auch zur Immunisierung der Rechtswissenschaft gegen die Soziologie: Soziologische Erkenntnis ist auch bei Weber nicht in rechtswissenschaftliche überführbar, und die Rechtswissenschaft bestimmt selbst, inwiefern sie auf solche Begrifflichkeiten zurückgreifen will. Damit gilt aber zugleich: Indem die Soziologie die juristischen Problematisierungsweisen adaptiert, akzeptiert sie die normativistischen Regierungstechnologien eines Rechts, das sich zunehmend von den Zumutungen der empirischen Wissenschaften befreit. Damit trägt sie zur Immunisierung eines sich unpolitisch verstehenden Rechts gegen die Gesellschaft bei.

Dieses Vorgehen wirkt sich aber auch direkt auf den Entwurf der Soziologie aus. Es ermöglicht Weber, auf die Begriffe und Sinnermittlungen der Rechtsdogmatik zurückzugreifen, ohne den von ihm kritisierten ,rechtsdogmatischen Verfälschungen des empirischen Denkens ${ }^{6}$ anheimzufallen. Die Trennung der soziologischen von der juristischen Betrachtungsweise sichert also letztlich die Autonomie der Soziologie. Man muss eine Differenz im logischen Status setzen, um einen Unterschied der Disziplinen markieren zu können. Diese Differenz zieht Weber nicht anhand des Ob- 
jekts ,Recht', erweist sich doch das Recht als wichtiger empirischer Kausalfaktor in der gesellschaftlichen Entwicklung. Er unterscheidet die Disziplinen vielmehr im Sinne der neukantianischen Erkenntnislehre nach Art ihrer Betrachtungsweise, d.h. welcher Geltungsanspruch des Rechts in den Blick genommen wird (Seinsollen versus empirische Geltung) und daher die Begriffsbildung anleitet. Ist diese Unterscheidung garantiert, erweist sich die soziologische Orientierung an der Rechtsdogmatik als unproblematisch. Und es obliegt der Soziologie zu bestimmen, inwiefern und inwieweit sie auf die Begrifflichkeiten der Rechtsdogmatik zugreifen will.

Zudem hat Webers Soziologie das Problem der Normativität erfolgreich in die Rechtswissenschaft ausgelagert. Letztere ist es, die sich in ihrer praktischen Seite wertend auf Werte bezieht. Alles andere - auch ihre objektive Sinnermittlung - erweist sich dann als werturteilsfrei - und so auch die Soziologie. Damit hat die Soziologie gerade durch diese Abgrenzung ihren angestammten Platz gefunden. Die Konkurrenz zur Rechtsdogmatik in der Frage im Umgang mit Werten lässt sich über die wissenschaftslogische Trennung von Sein und Sollen von Seiten der Soziologie auflösen. Nun wird die Soziologie gegen die Rechtswissenschaft immun.

Sobald nun diese Trennungslinie gezogen ist, sobald der Platz der Soziologie im Kanon der Disziplinen gefunden ist, bedarf es einer Auseinandersetzung mit den Rechtswissenschaften nicht mehr. Anders formuliert: Sobald die Immunisierung der Soziologie erfolgreich vollzogen wurde, können zwar Zweckmäßigkeitsgründe für die Aufnahme dieser oder jener juristischen Begrifflichkeit sprechen, eine Hinwendung zu den aktuellen Debatten in der Rechtswissenschaft über Rechtsdogmatik oder -methodik ist aber nicht mehr notwendig, da von dieser Seite keine Konkurrenz mehr droht.

In der Tat lässt sich bei Weber eine Abnahme der Auseinandersetzung mit dem Recht nachzeichnen. Denn die proklamierte Notwendigkeit der soziologischen Orientierung an den juristischen Begrifflichkeiten wandelt sich später mit der Änderung der Architektur seiner Kategorien in den Soziologischen Grundbegriffen. ${ }^{893}$ Hier ersetzt er das "Gemeinschaftshandeln“ durch die genaue Definition des „sozialen Handelns“ als Handeln, „welches seinem von dem oder den Handelnden gemeinten Sinn nach auf das

893 Es ist stark umstritten, wie sehr Weber in den Grundbegriffen seine Terminologie gegenüber dem Kategorien-Aufsatz abgeändert hat bzw. was ihn in der der Zeit zwischen 1913 und 1920 zu der Umarbeitung bewogen hatte (vgl. hierzu die Literaturnachweise bei Treiber 2014b: 1; Weiß 2018: 60ff.). Fragt man nach der Rolle der Abgrenzung zur Rechtsdogmatik, lässt sich ein deutlicher theoriearchitektonischer Wandel konstatieren. 
Verhalten anderer bezogen wird und daran in seinem Ablauf orientiert ist“ (Weber 1988j [1921]: 542, H.i.O.) und unterscheidet vier mögliche sinnhafte Orientierungen des sozialen Handelns (zweck-, wertrational sowie traditional und affektiv/emotional). Davon aufsteigend gelangt er von den „sozialen Beziehungen“ (vgl. hierzu Schluchter 2016: 271f.), zu deren Formen nun Vergemeinschaftung und Vergesellschaftung zählen $(\mathbb{1 0})$, zu den sozialen Geordnetheiten: solchen, die innerhalb des tatsächlichen Lebens als beobachtbare Regelmäßigkeiten auftreten (Brauch, Sitte, Mode), und solchen, die aus der Orientierung an der Vorstellung über das Bestehen einer legitimen Ordnung (Konvention, Recht) resultieren. Das markiert zugleich den Übergang zur Herrschaftssoziologie. ${ }^{894}$ Soziale Beziehungen, bei denen zur Einhaltung ihrer Geordnetheit bestimmte Menschen (Leiter, Verwaltungsstab) vorhanden sind, nennt er nun Verband, zu deren Unterfällen dann auch Verein und Anstalt mit ihrer Satzungsorientierung gehören.

In dieser Neuanordnung der Grundbegriffe hebt Weber nun ausdrücklich die Existenz von Regelmäßigkeiten im sozialen Handeln hervor, die wie der Brauch, die Sitte oder die Mode, aber auch das ,nackte‘ Marktgeschehen mit keinem normativen Geltungsanspruch verbunden sind. Dieser geht nur noch mit der Konvention, dem Recht und den drei Formen der legitimen Herrschaft einher. Daher wird der ursprünglich mit dem Einverständnishandeln verbundene umfassende Geltungsanspruch auf diese Bereiche beschränkt, und die Kategorie des Einverständnisses verschwindet (vgl. Lichtblau 2017: 300). Es besteht zwar nach wie vor die Notwendigkeit, auf der Sinnebene zwischen normativen und empirischen Disziplinen über die Differenz von objektiv und subjektiv gemeintem Sinn zu unterscheiden $(\mathbb{1} 1$ ), ebenso wie es aus faktischen Gründen nach wie vor zweckmäßig erscheint, auf juristische Kollektivbegriffe zurückzugreifen (Weber 1988j [1921]: 553). Doch sieht Weber in den Grundbegriffen nun nicht mehr das ,unvermeidliche Schicksal' aller Soziologie in dem Rückgriff auf juristische Begrifflichkeiten, und zwar gerade weil die normativen Ordnungen nun nicht mehr die einzig soziologisch relevanten handlungsorientierenden Geordnetheiten darstellen. Aus diesem sachlichen Grund wendet Weber nun gegen Stammler ein: „Bei Stammler ist nicht nur das empirische und das normative Gelten nicht geschieden, sondern überdies verkannt, daß das soziale Handeln sich nicht nur an ,Ordnungen' orientiert [...].“ (Ebd.: 575, H.i.O.)

894 Insofern spielt das Recht als Strukturmerkmal der Legitimation der Herrschaftstypen eine zentrale Rolle in Webers Herrschaftssoziologie (vgl. Weber 1988h). 
Die Auseinandersetzung mit der Rechtswissenschaft erfolgt in den Grundbegriffen nun bei einzelnen sachlichen Punkten - aber nicht wie im Kategorien-Aufsatz als eigenständiger Topos im methodischen Teil zur Grundlegung der Soziologie als eigenständige Disziplin. Zu diesem Ergebnis konnte Weber aber erst über seine vorherige genaue Verhältnisbestimmung von Rechtswissenschaft und Soziologie gelangen. Daher erscheint es neben begrifflichen Anleihen plausibel, wenn er in der Vorbemerkung zu den Grundbegriffen erneut betont, dass seine Auseinandersetzung mit Stammler „die Grundlagen des Nachfolgenden vielfach schon enthielt“ (ebd.: 541).

$\mathrm{Zu}$ Recht wird davor gewarnt, die begriffsjuristische Fundierung von Webers soziologischer Betrachtungsweise zu verabsolutieren (vgl. Treiber, Quensel 2002: 105; Gephart 1993a: 497; Quensel 2007: 106). Jenseits einer solchen Konzentration auf die jeweiligen Begriffskonstruktionen zeigt jedoch die Analyse von Webers Auseinandersetzung mit dem Recht in seinen methodologischen Ausführungen, dass der Entwurf seiner Soziologie als Intervention nicht nur in den nationalökonomischen, sondern ebenso in den juristischen Methodenstreit zu lesen ist. Denn jene rechtswissenschaftliche Debatte drohte nicht nur den Umgang mit normativen Phänomenen in eine falsche Richtung zu lenken, sondern auch die Eigenständigkeit der Soziologie zu gefährden. Das erweist sich aber für Webers verstehende Soziologie als gefährlich - sowohl was die Bestimmung der disziplinären Eigenart der Soziologie, als auch was die Wissenschaftlichkeit dieser Disziplin im Sinne von Objektivität und Werturteilsfreiheit betrifft. Sobald die Kluft zwischen Rechtswissenschaft und Soziologie aber zementiert ist - ein Umstand, an dem nicht nur Weber von soziologischer Seite, sondern auch die rechtswissenschaftliche Seite im normativen Zweckdispositiv mitarbeitet - erscheint eine soziologische Auseinandersetzung mit den Rechtswissenschaften nicht mehr notwendig. Insofern ist auch bei Weber jene Bewegung erkennbar, dass die ursprüngliche Notwendigkeit der Beschäftigung mit dem Recht - und d.h. bei ihm v.a. mit den Rechtswissenschaften auf erkenntnis- und wissenschaftstheoretischer Ebene - in eine Abkehr vom Recht mündet. 


\section{Schluss}

Durkheim, Tönnies und Weber stehen paradigmatisch für die verschiedenen Formen der Auseinandersetzung der entstehenden Soziologie mit dem Recht und der Rechtswissenschaft. Das betrifft zum einen die Frage, welche rechtlichen Phänomene für den Entwurf der soziologischen Theorie fruchtbar gemacht werden: Während Durkheim primär die positiven rechtlichen Regelungen und Rechtsinstitutionen adressiert, legt Tönnies den Schwerpunkt auf die rechtsphilosophischen respektive -theoretischen Grundlagen der juristischen Arbeit. Weber wiederum setzt sich über die Rechtswissenschaft vornehmlich mit erkenntnistheoretisch-methodischen Fragen auseinander.

Zum anderen zeigen die drei Autoren, dass der Fokus auf dem Privatrecht liegt. Gerade im freiheits- wie subjektorientierten Privatrecht werden zentrale Problemlagen der entstehenden Soziologie verhandelt. Dabei ist von großer Bedeutung, dass das Recht im privatrechtlichen Diskurs als unpolitisch erscheint. Genau deshalb ist es für die Soziologien von Durkheim, Weber und Tönnies anschlussfähig. Es ist für sie zentral, dass das Recht (zumindest zu Teilen) der gesellschaftlichen Sphäre entspringt und nicht (allein) aus einer rein willkürlichen staatlichen Gesetzgebungspolitik hervorgeht. Daher muss es auch in die gesellschaftliche Normordnung eingebettet werden (womit sich die Frage der Abgrenzung gegenüber Brauch, Konvention und Sitte stellt). Das Recht als Produkt, Teil und Garant der gesellschaftlichen Ordnung wird letztlich gegenüber der staatlichen Macht und der Politik neutralisiert. Der Staat erscheint für die Frage der Rolle des Rechts in der Soziologie am Rande, auch wenn die drei Autoren vieldiskutierte Staatsbegriffe entwerfen.

Es ist also gerade das Privatrecht, das zum Entdeckungszusammenhang der Gesellschaft im 19. Jahrhundert zu zählen ist. An ihm entspannen sich die unterschiedlichen Problematisierungsweisen des Verhältnisses von Recht und Gesellschaft - je nachdem ob der repräsentierende, der ordnende oder der wertende Aspekt des Rechts in den Vordergrund gerückt wird. Zentral ist diese Verhältnisbestimmung, da hierüber die für die Soziologie so wichtige Relation zwischen Faktizität und Normativität verhandelt wird.

Gemein ist daher diesen frühen soziologischen Perspektiven auf das Recht, dass sie weit über den Bereich der sich ausdifferenzierenden Rechtssoziologie hinaus Effekte für das Disziplinenverständnis und die genuin 
soziologische Theoriebildung zeitigen (Schweitzer 2018b: 220). Das Recht und seine historischen Variationen werden nicht als ein Teilphänomen der Gesellschaft betrachtet, dem man sich im Rahmen einer Bindestrich-Soziologie zuwenden mag oder auch nicht, sondern als konstitutive Komponenten des sozialen Lebens. Recht spielt auf der Ebene der allgemeinen Soziologie, d.h. der Gesellschafts- und Sozialtheorie eine gewichtige Rolle. Es gibt einen Konnex zwischen der Bestimmung und der Analyse der rechtlichen Phänomene und der Entwicklung einer genuin soziologischen Theorie.

Diese Art und Weise der Adressierung des Rechts bei Durkheim, Tönnies und Weber bewirkt gegenüber der mittlerweile etablierten Rechtssoziologie eine Perspektivverschiebung: Denn weder geht es primär um die Rolle der Soziologie in der Rechtswissenschaft, noch um die soziologische Bestimmung des Rechts, vielmehr steht die Rolle des Rechts (inklusive der der Rechtswissenschaft) in der Soziologie zur Debatte. Über die Klärung dieser Frage wird die Soziologie bei den Autoren als eigenständige Disziplin entworfen. Es wird also nicht ,das Recht ${ }^{\natural}$ mittels ,der Gesellschaft', sondern vice versa, die Gesellschaft' letztlich (auch) mittels, des Rechts' problematisiert (vgl. ebd.). Dies bewirkt, dass ,Gesellschaft' in den Theorieentwürfen von Durkheim, Tönnies und Weber jenseits einer probabilistischen oder quantifizierenden Logik in Bezug auf die Normfrage als Wertfrage konzipiert wird. Das Recht trägt also wesentlich zur genuin soziologische Gegenstandskonstitution, d.h. zur Idee einer normintegrierten Gesellschaft, bei. Darüber hinaus spielt es für die Frage der Erkennbarkeit der gesellschaftlichen Phänomene, für die Probleme der sozialen Ordnung und Steuerung, aber auch auf methodischer Ebene eine herausragende Rolle. ${ }^{895}$ Insofern kann mit Blick auf die soziologischen Entwürfe von Durkheim, Tönnies und Weber in historischer Perspektive von ,juridischen Soziologien' gesprochen werden.

In diesen Entwürfen zeigt sich nicht nur das thematische, sondern ebenso das ideengeschichtliche Spektrum, aus dem die Soziologie entspringt. Viel diskutiert wird etwa das Verhältnis zum Naturrecht bzw. zur Historischen Rechtsschule (s.o.). Darüber hinaus wird speziell Jhering eine zentrale Rolle in der Entwicklung des soziologischen Denkens zugesprochen: Man zählt ihn zur relevanten sozialwissenschaftlichen respektive soziologi-

$895 \mathrm{Ob}$ man dann eine holistische Perspektive einnimmt, von einem methodologischen Individualismus ausgeht oder aber eine Synthese versucht, liegt nicht im Gegenstand Recht begründet. Für jede dieser Positionen lassen sich letztlich Anhaltspunkt in der rechtlichen sowie der rechtswissenschaftlichen Entwicklung finden. 
schen Literatur (z.B. Eisler 1903: 153, 171), auf den man daher immer wieder zu sprechen kommt (so schon Gumplowicz 1885: 116, 139; Ratzenhofer 1893) bzw. mit dem eine intensive Auseinandersetzung gesucht wird (z.B. Schmidt-Warneck 1889: 255ff.) - so etwa, wenn es um den Gesellschaftsbegriff geht (etwa Spann 1905: 68ff.; Sombart 1956: 35). Die Überlegungen Jherings zum Zweck im Recht stellen mithin einen gemeinsamen Scheidepunkt für die Rechtswissenschaft und die Soziologie dar, da sich daran anschließend die Problematisierungen des Verhältnisses von Recht und Gesellschaft neu formieren.

Gerade weil der Auseinandersetzung mit dem Recht eine derart zentrale Rolle zukommt, besteht die Notwendigkeit für die Soziologie, sich in ihrer Gründungs- und Konsolidierungsphase von der Rechtswissenschaft abzugrenzen. Das zeigt sich nicht nur bei Tönnies, Durkheim und Weber. Vielmehr versuchen zahlreiche Autoren, das Verhältnis zur Rechtswissenschaft (in egal welcher Form) bzw. zur rechtlichen Denkungsart zu klären (vgl. etwa Schmidt-Warneck 1889: 225ff.; Kistiakowski 1899; Eisler 1903: 11; Achelis 1908: 36ff.; Eleutheropulos 1908; Kracauer 1922: 33f., 101ff.; Freyer 1930: 9, 43, 115; zu Rudolf Goldscheid vgl. Mikl-Horke 2007: 175). Die Rechtswissenschaft zählt in dieser Zeit - wie Kelsen feststellt - zu den "Grenzwissenschaften“ der Soziologie, und es handelt sich für die „um ihre Existenzberechtigung kämpfende[] junge[] Disziplin“ (Kelsen 1912: 601) um eine notwendige Abgrenzungsstreitigkeit. Dabei wird das Verhältnis zur Rechtswissenschaft in unterschiedlicher Weise bestimmt, insbesondere in Abhängigkeit davon, ob man die repräsentierenden, die gesellschaftsordnenden oder die wertenden Aspekte des Rechts in den Vordergrund rückt.

Was bei Durkheim, Tönnies und Weber letztlich deutlich wird, ist der produktive Effekt, den der Gang ins Recht für die Soziologie haben kann. Daran kann einen ,Soziologie mit mehr Recht' anschließen. Paradoxerweise mündet dieser Gang bei ihnen jedoch im Verlust des Rechts für die Soziologie. Denn letztlich werden Adressierungsweisen des Rechts gewählt, die - einmal etabliert - die Notwendigkeit der weiteren Beschäftigung mit dem Recht ausschließen. Das Problem liegt nicht nur in der Tatsache begründet, dass die drei Autoren sehr spezifische Rechtsbegriffe verwenden, die einen Wandel im Recht nicht oder nur bedingt zu Kenntnis nehmen können. Es ist vielmehr auch in der spezifischen Kopplung von Recht und Sozial- respektive Gesellschaftstheorie zu suchen: Bei den drei Autoren geht es nämlich damit um das Ganze, d.h. um ,die Soziologie', ,die Gesellschaft' oder die Fundamente oder fundamentalen Mechanismen ,des Sozialen“ (vgl. Schweitzer 2018b: 221). So konstituiert sich bei Durkheim der Gegenstand ,Gesellschaft' mithin (auch) über das Recht, so dass seine Be- 
schäftigung mit den gesetzlich geregelten Rechtsinstituten der allgemeinen Sozialtheorie dient; Tönnies erkennt in den konkurrierenden Rechtsphilosophien bzw. theorien von Naturrecht und Historischer Rechtsschule die soziologischen Grundbegriffe Gemeinschaft und Gesellschaft; und bei Weber dient die erkenntnis- und wissenschaftstheoretische Auseinandersetzung mit der Rechtswissenschaft der Verortung der Soziologie als eigenständige Disziplin. Sobald man nun die Grundlagen und -begriffe geklärt hat, sobald die sozialen Tatsachen feststehen und die Soziologie ihren Ort innerhalb der wissenschaftlichen Disziplinen gefunden hat, bedarf es der Auseinandersetzung mit dem Recht nicht mehr.

Wenn man also das Recht für die Soziologie wieder adressierbar machen will, kann - und muss - man den Anspruch der Perspektive auf rechtliche Phänomene reduzieren, und zwar nicht nur, um sich nicht einer berechtigten Kritik an der Überbewertung des Rechtlichen für die Gesellschaft auszusetzen, sondern ebenso, um sich den Zugang zum Recht nicht zu verbauen. Es geht also nicht ums Ganze, sondern darum, im Recht nach gesellschafts- und sozialtheoretischen Impulsen zu suchen, die sich aus der Konvergenz der Problemlagen ergeben.

Hierfür muss man sich dem Recht zuwenden. In der Dispositivanalyse des rechtlichen Gefüges findet man dabei ein Handwerkszeug, das angesichts der geschilderten Problemlagen des Verhältnisses von Recht und Gesellschaft vier Vorteile bietet: Erstens wird sich an den historisch-spezifischen Bestimmungen dessen, was Recht ist, orientiert. Die Dispositivanalyse des Rechts verfügt über keinen festgefügten Rechtsbegriff, der wie bei Durkheim, Tönnies und Weber Gefahr läuft, sich auf eine bestimmte Situation in der Geschichte des Rechts festzulegen und damit den Blick zu vereinseitigen. Sie definiert nicht von soziologischer Seite vorab, was das (moderne) Recht ist. Damit öffnet sie sich für divergierende Bestimmungen.

Zweitens kann die Dispositivanalyse des Rechts Zugang zu den verschiedenen rechtliche Ebenen in ihrer jeweiligen Relevanz für die Problemstellung finden. So wurde vorliegend die konkurrierenden juristischen Rechtstheorien, die Wissenstransfers und die - seit Anfang des 20. Jahrhunderts mit Vehemenz vertretene - Eigennormativität des Rechts in den Blick genommen. Das führte letztlich zu einer soziologischen Analyse der Rechtsdogmatik und -methodik. Damit wird jene Kluft überwunden, die mit der Scheidung von soziologischer und juristischer Perspektive Anfang des 20. Jahrhunderts geschaffen wurde und die bis heute den soziolo- 
gischen Zugang zur Rechtsdogmatik behindert (vgl. Schulz-Schaeffer 2004). 896

Die Dispositivanalyse erweist sich drittens aufgrund ihrer historischen Ausrichtung offen für den Wandel im dispositiven Gefüge des Rechts. Das zeigt sich insbesondere in der Frage nach der Autonomie des Rechts. Jenseits pauschalisierender Annahmen einer zunehmenden Autonomie infolge der funktionalen Differenzierung der modernen Gesellschaft zeigt die Analyse der epistemischen Dispositive der Rechtswissenschaft, dass die Autonomie des Rechts nichts gegebenes ist, sondern ein stark umkämpftes Terrain. Sie muss immer wieder von neuem hergestellt werden. Daher bedarf es einer soziologischen Betrachtung des Rechts, die die entsprechenden Diskurse und Praktiken in aktu in den Blick nimmt und die etwaigen Umstellungen zu verstehen und zu erklären vermag. Das gilt, wie die Analyse des dispositiven Gefüges des Recht gezeigt hat, insbesondere für den Wandel auf der Selbstreflexionsebene der Rechtswissenschaft, d.h. der Rechtstheorie, aber auch für die daran anschließenden Änderungen der Rechtsdogmatik und -methodik. Am Beispiel der Historischen Rechtsschule zeigt sich dann, dass man zur Begründung der Autonomie des Rechts keineswegs dazu genötigt ist, auf die Normativität des Rechts zu rekurrieren. Vice versa wird erst vor dieser Folie dann auch der strategische Einsatz der Normativität zur Begründung der Autonomie des Rechts im Methodenstreit Anfang des 20. Jahrhunderts deutlich. Jegliche apriorische Fixierung des Rechts auf das Normative würde genau diesen Umstand übersehen (genauso wie jede Fixierung des Rechts auf Wahrheitsaussagen die daraus resultierenden normativen Praktiken im Recht verfehlt).

Schließlich vermag die Dispositivanalyse viertens den kritischen Charakter der soziologischen Adressierung des Rechts zu zeigen. Gerade bei Durkheim, Tönnies und Weber wird deutlich: Man muss für die Soziologie nicht nur das Verhältnis zur Rechtswissenschaft klären, sondern ihre Ansätze sind vielmehr selbst in den epistemischen Dispositiven der (Privat)Rechtswissenschaft zu verorten. Diese Verortungen wiederum zeigen, dass es nicht nur im Bereich des Rechts „kein Erkenntnisziel gibt, das nicht strategisch wäre" (Ewald 1993: 41), sondern ebenso in dem der Soziologie. Denn auch die soziologischen Aussagen über das Recht befinden sich nicht auf einer außerhalb des Rechts gelegenen Metaebene, "gehört

896 Franz Benda Beckmann nennt dies den „gap-approach“ der Rechtssoziologie, demzufolge sie „die Beschreibung des Rechts als einer Sollensordnung [...] weitgehend der darauf spezialisierten dogmatischen Rechtswissenschaft" überlasse (Benda-Beckmann 1991: 105). 
doch jeder Diskurs über das Recht einer juristischen Erfahrung an und muß sich in Beziehung zu ihr situieren" (ebd.). Gerade weil mit der Historischen Rechtsschule das Recht als gesellschaftliches Produkt verstanden wird, tragen gesellschaftstheoretische Aussagen zum Recht immer auch zur Konstitution des Gegenstandes Recht bei. Dies zeigt sich deutlich bei Durkheim und Tönnies.

Wenn aber die Soziologie in ihrer Adressierung des Rechts keineswegs neutral ist, dann wird sie politisch. Genau das zeigt sich besonders prägnant bei Webers Scheidung der soziologischen von der juristischen Perspektive. Indem er den normativen Charakter des Rechts in den Vordergrund stellt, adaptiert er die juristische Problematisierungsweise des normativen Zweckdispositivs. Er akzeptiert die Regierungstechnologien eines Rechts, in der die Selbstwahrnehmung als normative Wissenschaft als Stabilitäts- und Effektivitätsgarant dient, indem das Recht nun erfolgreich gegenüber den Herausforderungen der Gesellschaft geschützt wird. Denn wenn im strategischen Einsatz der Normativität ein zentraler Aspekt der Macht des Juridischen liegt, dann sichert Weber diese Macht nun von soziologischer Seite. Durch seine erkenntnistheoretische Bestimmung der Rechtswissenschaft wirkt er umstandslos an der Immunisierung der Rechtswissenschaft als Sollenswissenschaft mit.

Dieses Problem der mangelnden Neutralität gegenüber dem Recht betrifft m.E. aber nicht nur die frühen soziologischen Entwürfe. Zwar handelt es sich in der Gründungs- und Konsolidierungsphase der Soziologie um eine notwendige Abgrenzungsstreitigkeit, um das ihr angestammte Terrain markieren zu können. Aber bereits mit der Historischen Rechtsschule trat das epistemische Ding, Gesellschaft' in die Rechtswissenschaft ein, was die Rechtswissenschaft in einen spezifischen Bezug zur Soziologie setzt. Denn daran anschließend wird im juristischen Diskurs die adäquate Repräsentation der Gesellschaft im Recht, die soziale Ordnungsleistung des Rechts oder aber die Trennung der rechtlichen von der gesellschaftstheoretischen Erkenntnisweise problematisiert. Das Recht wird nun in Beziehung zur Gesellschaft gesetzt, es wird zu einem zentralen Mittel, sie zu erkennen, sie zu steuern oder sie zu ermöglichen. Hierin zeigen sich seine Machteffekte in Bezug auf das epistemische Ding, Gesellschaft', hierin liegt die Rechtsmacht für die Gesellschaft. Mit dieser Rechtsmacht muss sich die Soziologie durch eine genaue Analyse der dispositiven Gefüge des 
Rechts auseinandersetzen, will sie nicht Gefahr laufen, dieser Rechtsmacht - wie etwa Weber - das Wort zu reden. ${ }^{897}$

Die Soziologie ist also in Ihrer jeweiligen Art und Weise der Adressierung des Rechts keineswegs ,neutral'. Sie kann keine Außenperspektive einnehmen, auch wenn sie innerhalb der Rechtswissenschaft wenig Beachtung finden mag. Egal was man über das Recht sagt, die jeweiligen soziologischen Bestimmungen des Rechts korrespondieren mit juristischen Herangehensweisen bzw. lassen sich mit diesen in Beziehung setzen. Insofern ist die Soziologie immer schon responsiv gegenüber dem Recht - im Übrigen auch in ihrer Ignoranz.

Wenn man nun eine kritische Position zum Recht einnehmen will, dann wird der Gang ins Recht nötig. Der kritische Blick richtet sich dabei auf die gesellschaftstheoretischen Implikationen rechtlicher Phänomene. Letztlich lässt sich eine Kritik des Rechts, die das Recht als ein soziales Phänomen (und nicht als reines Vernunftprodukt) fasst, nur vor dem Hintergrund der Gesellschaft respektive einer Theorie der Gesellschaft formulieren. Nur dann kann man seine Wirkung bestimmen, erst dann zeigen sich Effekte und Implikationen mit Blick auf das Subjekt (z.B. Schweitzer 2017, 2018a), den sozialen Zusammenhalt und die Regierungskünste (etwa Procacci, Donzelot, Ewald), sowie das kapitalistische Gefüge. Und erst dann lässt sich das rechtlich produzierte Wissen aus einer gesellschaftsund sozialtheoretischen Perspektive kritisch hinterfragen.

897 Dies beruht letztlich auf der Abwandlung einer genuin juristischen Fragestellung. Denn wenn in der Rechtswissenschaft (und auch bei Luhmann) diskutiert wird, ob die juristische Methodenlehre zwangsläufig auf einer bestimmten Rechtstheorie basiert (vgl. Petersen 2008: 157 m.w.N.), so wurde hier stattdessen gefragt: Beruht die juristische Methodenlehre und Rechtsdogmatik zwangsläufig auf einer bestimmten Gesellschaftstheorie, wird doch in der Rechtstheorie das Verhältnis von Recht und Gesellschaft problematisiert? 


\section{Literaturverzeichnis}

Achelis, Thomas (1908): Soziologie. 2. Aufl. Leipzig: Göschen.

Adair-Toteff, Christopher (2014): „'Methodological Pestilence': Max Weber's Devastating Critique of Stammler", in: Max Weber Studies 14 (2), S. 245-268.

Adickes, Franz (1872): Zur Lebre von den Rechtsquellen insbesondere über die Vernunft und die Natur der Sache als Rechtsquellen und über das Gewohnheitsrecht. Cassel, Göttingen: Wigand.

Adorno, Theodor W. (1976): „Einleitung“, in: Durkheim, Émile (Hg.): Soziologie und Philosophie. Mit einer Einleitung von Theodor W. Adorno. Frankfurt am Main: Suhrkamp, S. 7-44.

- (1979): „Einleitung zum ,Positivismusstreit in der deutschen Soziologie“ [1969]“, in: ders. (Hg.): Soziologische Schriften 1. Herausgegeben von Rolf Tiedemann. Frankfurt am Main: Suhrkamp, S. 280-353.

- (2003 [1972]): Negative Dialektik. Jargon der Eigentlichkeit. Frankfurt am Main: Suhrkamp.

- (2012 [1968]): Einleitung in die Soziologie. Herausgegeben von Christoph Gödde. 3. Aufl. Frankfurt am Main: Suhrkamp.

Ahrens, Heinrich (1846): Das Naturrecht oder die Rechtsphilosophie nach dem gegenwärtigen Zustande dieser Wissenschaft in Deutschland. 2. Aufl. Braunschweig: Georg Westermann.

- (1852): Die Philosophie des Rechts und des Staates. Erster Theil: Die Rechtsphilosophie, oder das Naturrecht, auf philosophisch-anthropologischer Grundlage. 4. Aufl. Wien: Carl Gerold \& Sohn.

Albert, Gert (2010): „Der Werturteilsstreit“, in: Kneer, Georg; Moebius, Stephan (Hg.): Soziologische Kontroversen. Beiträge zu einer anderen Geschichte der Wissenschaft vom Sozialen. Berlin: Suhrkamp, S. 14-45.

Albert, Hans (1998): Marktsoziologie und Entscheidungslogik. Zur Kritik der reinen Ökonomik. Tübingen: Mohr Siebeck.

Alexy, Robert et al. (Hg./ 2002): Neukantianismus und Rechtsphilosophie. Baden-Baden: Nomos.

Alwast, Jendris (1991): „Die begriffene Wirklichkeit und die Wirklichkeit des Begriffs. Zur Kritik und Aneignung Hegels bei Ferdinand Tönnies“, in: Clausen, Lars; Schlüter, Carsten (Hg.): Hundert Jahre "Gemeinschaft und Gesellschaft". Ferdinand Tönnies in der internationalen Diskussion. Opladen: Leske + Budrich, S. 251-265.

Amstutz, Marc (2002): „Rechtsgeschichte als Evolutionstheorie. Anmerkungen zum Theorierahmen von Marie Theres Fögens Forschungsprogramm“, in: Zeitschrift für Rechtsgeschichte 1, S. 26-31. 
Angermüller, Johannes; van Dyk, Silke (Hg./ 2010): Diskursanalyse meets Gouvernementalitätsforschung. Perspektiven auf das Verhältnis von Subjekt, Sprache, Macht und Wissen. Frankfurt am Main, New York, NY: Campus.

Anter, Andreas (2000): „Max Weber und Georg Jellinek. Wissenschaftliche Beziehung, Affinitäten und Divergenzen“, in: Paulson, Stanley L.; Schulte, Martin (Hg.): Georg Jellinek. Beiträge zu Leben und Werk. Tübingen: Mohr Siebeck, S. 67-86.

- (2014): Max Webers Theorie des modernen Staates. Herkunft, Struktur und Bedeutung. 3. Aufl. Berlin: Duncker \& Humblot.

- (2016): Max Weber und die Staatsrechtslehre. Tübingen: Mohr Siebeck.

Antonio, Robert J.; Glassman, Ronald M. (Hg./ 1985): A Weber-Marx Dialogue. Lawrence, Kan.: University Press of Kansas.

Arnold, Wilhelm (1865): Cultur und Rechtsleben. Berlin: Dümmler.

- (1868): Cultur und Recht der Römer. Berlin: Dümmler.

Audren, Frédéric (2001): „Paul Huvelin (1873-1924). Juriste et durkheimien“, in: Revue d'histoire des sciences humaines (4), S. 117-130.

Auer, Marietta (2008): „Methodenkritik und lnteressenjurisprudenz. Philipp Heck zum 150. Geburtstag“, in: Zeitschrift für europäisches Privatrecht, S. 517-533.

- (2014): Der privatrechtliche Diskurs der Moderne. Tübingen: Mohr Siebeck.

- (2015): „Kampf um die Wissenschaftlichkeit des Rechts. Zum 75. Todestag von Hermann Kantorowicz“, in: Zeitschrift für europäisches Privatrecht, S. 773-805.

Bachelard, Gaston (1987): Die Bildung des wissenschaftlichen Geistes. Beitrag zu einer Psychoanalyse der objektiven Erkenntnis. Frankfurt am Main: Suhrkamp.

- (1994): Der neue wissenschaftliche Geist. Frankfurt am Main: Suhrkamp.

Baer, Susanne (2010): „Juristische Biopolitik: Das Wissensproblem im Recht am Beispiel 'des' demografischen Wandels“, in: Cottier, Michelle; Estermann, Josef; Wrase, Michael (Hg.): Wie wirkt Recht? Ausgewählte Beiträge zum ersten gemeinsamen Kongress der deutschsprachigen Rechtssoziologie-Vereinigungen, Luzern, 4. 6. September 2008. Baden-Baden: Nomos, S. 181-201.

Bähr, Otto (1888a): „Das Bürgerliche Gesetzbuch und die Zukunft der deutschen Rechtsprechung “, in: Die Grenzboten. Zeitschrift für Politik, Literatur und Kunst 47 (3), S. 391-399, 450-460.

- (1888b): „Entwurf eines bürgerlichen Gesetzbuchs für das Deutsche Reich. Erste Lesung. Ausgearbeitet durch die von dem Bundesrathe berufene Commission. Amtliche Ausgabe. Berlin und Leipzig, J. Guttentag. 1888“, in: Kritische Vierteljahresschrift für Gesetzgebung und Rechtswissenschaft 30, S. 321-414.

- (1888c): „Entwurf eines bürgerlichen Gesetzbuchs für das Deutsche Reich. Erste Lesung. Ausgearbeitet durch die von dem Bundesrathe berufene Commission. Amtliche Ausgabe. Berlin und Leipzig, J. Guttentag. 1888. (Schluss.)“, in: Kritische Vierteljahresschrift für Gesetzgebung und Rechtswissenschaft 30, S. 481-570.

- (1890): „Weitere Schriften über den Entwurf eines bürgerlichen Gesetzbuchs für das Deutsche Reich“, in: Kritische Vierteljahresschrift für Gesetzgebung und Rechtswissenschaft 32, S. 188-207. 
- (1892): Gegenentwurf zu dem Entwurfe eines bürgerlichen Gesetzbuches für das Deutsche Reich. Kassel: Brunnemann.

Bähr, Ursula (1972): Die berufsständischen Sonderinteressen und das BGB. Ein Beitrag zur Entstehungsgeschichte der Kodifikation. Heidelberg: Univ., Diss.

Baldus, Manfred (1995): Die Einheit der Rechtsordnung. Bedeutungen einer juristischen Formel in Rechtstheorie, Zivil- und Staatsrechtswissenschaft des 19. und 20. Jahrhunderts. Berlin: Duncker \& Humblot.

Balog, Andreas (1983): „Kelsens Kritik an der Soziologie“, in: ARSP: Archiv für Rechts- und Sozialphilosophie 69 (4), S. 515-528.

Banakar, Reza (2000): „Reflections on the Methodological Issues of the Sociology of Law“, in: Journal of Law and Society 27 (2), S. 273-295.

Bar, Ludwig von (1890): „Der Entwurf eines bürgerlichen Gesetzbuchs, besonders in sozialpolitischer Beziehung“, in: Die Nation. Wochenschrift für Politik, Volkswirtschaft und Literatur 7 (27), S. 399-403.

Barad, Karen (2012): Agentieller Realismus. Berlin: Suhrkamp.

Baratta, Alessandro (1970): „Über Jherings Bedeutung für die Strafrechtswissenschaft", in: Wieacker, Franz; Wollschläger, Christian (Hg.): Jherings Erbe. Göttinger Symposion zur 150. Wiederkehr des Geburtstags von Rudolf von Jhering. Göttingen: Vandenhoeck \& Ruprecht, S. 17-26.

Baron, Julius (1877): „Jurisprudenz und Nationalökonomie: Literatur: Lehrbuch der politischen Oekonomie. Erster Band, 1876“, in: Kritische Vierteljabresschrift für Gesetzgebung und Rechtswissenschaft 19, S. 372-401.

— (1889): „Das römische Vermögensrecht und die soziale Aufgabe“, in: Jabrbücher für Nationalökonomie und Statistik N.F. 19, S. 225-248.

Bartels-Ishikawa, Anna (1998): Theodor Sternberg - einer der Begründer des Freirechts in Deutschland und Japan. Berlin: Duncker \& Humblot.

Barth, Paul (1897): Die Philosophie der Geschichte als Sociologie. Erster Teil: Einleitung und kritische Übersicht. Leipzig: Reisland.

Baudrillard, Jean (2010): Im Schatten der schweigenden Mebrheiten oder das Ende des Sozialen. Berlin: Matthes \& Seitz.

Baum, Karl Berthold (1967): Leon Petražycki und seine Schüler. Der Weg von der psychologischen zur soziologischen Rechtstheorie in der Petražyckigruppe. Berlin: Duncker \& Humblot.

Baumgarten, A. (1930): „Literatur: Rumpf, Max: Rechtswissenschaft als Sozialwissenschaft?", in: Kritische Vierteljahresschrift für Gesetzgebung und Rechtswissenschaft 23 (59), S. 329-332.

Baumgarten, Arthur (1929): Rechtsphilosophie. München, Berlin: Oldenbourg.

Baxter, Hugh (1996): „Review Essay: Bringing Foucault into Law and Law into Foucault", in: Stanford Law Review 48 (2), S. 449-479.

Bayet, Albert (1922): Le suicide et la morale. Paris: Alcan.

- (1925): La science des faits moraux. Paris: Alcan. 
Beck, Susanne (2013): „Über Sinn und Unsinn von Statusfragen - zu Vor- und Nachteilen der Einführung einer elektronischen Person“, in: Hilgendorf, Eric (Hg.): Robotik und Gesetzgebung. Beiträge der Tagung vom 7. bis 9. Mai 2012 in Bielefeld. Baden-Baden: Nomos, S. 239-262.

Becker, Martin (2005): Arbeitsvertrag und Arbeitsverhältnis während der Weimarer Republik und in der Zeit des Nationalsozialismus. Frankfurt am Main: Klostermann.

Behlert, Wolfgang (1990): „An den Gründen der Rechtssoziologie: Zu Semen V. Pachman und Eugen Ehrlich“, in: ARSP: Archiv für Rechts- und Sozialphilosophie 76 (3), S. 400-406.

Behrends, Okko (1987): „Rudolf von Jhering (1818-1892). Der Durchbruch zum Zweck des Rechts“, in: Loos, Fritz (Hg.): Rechtswissenschaft in Göttingen. Göttinger Juristen aus 250 Jahren. Göttingen: Vandenhoeck \& Ruprecht, S. 229-269.

- (1989): „Von der Freirechtsschule zum konkreten Ordnungsdenken“, in: Dreier, Ralf; Sellert, Wolfgang (Hg.): Recht und Justiz im "Dritten Reich". Frankfurt am Main: Suhrkamp, S. 34-79.

Bekker, Ernst Immanuel (1888): System und Sprache des Entwurfes eines Bürgerlichen Gesetzbuches für das Deutsche Reich. Berlin, Leipzig: Guttentag.

- (1892): Ernst und Scherz über unsere Wissenschaft. Festgabe an Rudolf von Jhering zum Doctorjubiläum. Leipzig: Breitkopf und Härtel.

Below, Georg v. (1926): „Zum Streit um das Wesen der Soziologie“, in: Jahrbücher für Nationalökonomie und Statistik 69 (124) (3/4), S. 218-242.

Benda-Beckmann, Franz von (1991): „Unterwerfung oder Distanz. Rechtssoziologie, Rechtsanthropologie und Rechtspluralismus aus rechtsanthropologischer Sicht", in: Zeitschrift für Rechtssoziologie 12 (1), S. 97-119.

Bendix, Ludwig (1927): Die irrationalen Kräfte der zivilrichterlichen Urteilstätigkeit auf Grund des 110. Bandes der Entscheidungen des Reichsgerichts in Zivilsachen. Breslau: Schletter.

Bennett, Jane (2010): Vibrant matter. A political ecology of things. Durham [u.a.]: Duke Univ. Press.

Benöhr, Hans-Peter (1977): „Die Grundlage des BGB - Das Gutachten der Vorkommission von 1874“, in: $J u S(2)$, S. 79-82.

Bergbohm, Karl (1892): Jurisprudenz und Rechtsphilosophie. Bd. 1: Einleitung - Erste Abhandlung. Das Naturrecht der Gegenwart. Leipzig: Duncker \& Humblot.

Berndt, Thorsten (2010): Richterbilder. Dimensionen richterlicher Selbsttypisierungen. Wiesbaden: VS Verlag für Sozialwissenschaften.

Bernhöft, Franz (1889): Kauf, Miethe und verwandte Verträge in dem Entwurfe eines Bürgerlichen Gesetzbuches für das Deutsche Reich. Berlin: Guttentag.

Berolzheimer, Fritz (1905): System der Rechts- und Wirtschaftsphilosophie. Band 2: Die Kulturstufen der Rechts- und Wirtschaftsphilosophie. München: Beck.

- (1906): System der Rechts- und Wirtschaftsphilosophie. Band 3: Philosophie des Staates samt den Grundzügen der Politik. München: Beck.

- (1907): „Die Deutsche Rechtsphilosophie im zwanzigsten Jahrhundert (1900-1906)“, in: Archiv für Rechts- und Wirtschaftsphilosophie 1 (1), S. 130-148. 
- (1909): „Für den Neuhegelianismus“, in: Archiv für Rechts- und Wirtschaftsphilosophie 3 (2), S. 193-199.

- (1911): „Die Gefahren einer Gefühlsjurisprudenz in der Gegenwart. Rechtsgrundsätze für freie Rechtsfindung“, in: Archiv für Rechts- und Wirtschaftsphilosophie 4 (4), S. 595-610.

Berten, André; Foucault, Michel (1988): „Entretien avec Michel Foucault“, in: Les Cahiers du GRIF 37/38, S. 8-20.

Berthelot, Jean-Michel (1995): 1895 Durkheim. L'avènement de la sociologie scientifique. Toulouse: Presses universitaires du Mirail.

Beseler, Georg (1843): Volksrecht und Juristenrecht. Leipzig: Weidmann.

- (1847): System des gemeinen deutschen Privatrechts. Erster Band. Leipzig: Weidmann.

Bethmann-Hollweg, Moritz August von (1876): Ueber Gesetzgebung und Rechtswissenschaft als Aufgabe unserer Zeit. Bonn: Marcus.

Bickel, Cornelius (1990): „'Gemeinschaft' als kritischer Begriff bei Tönnies“, in: Schlüter, Carsten; Clausen, Lars (Hg.): Renaissance der Gemeinschaft? Stabile Theorie und neue Theoreme. Berlin: Duncker \& Humblot, 17-46.

- (1991): Ferdinand Tönnies. Soziologie als skeptische Aufklärung zwischen Historismus und Rationalismus. Opladen: Westdeutscher Verlag.

— (2003): „Ferdinand Tönnies (1855-1936)“, in: Kaesler, Dirk (Hg.): Klassiker der Soziologie. Band 1: Von Auguste Comte bis Alfred Schütz. 4. Aufl. München: Beck, S. 114-127.

Biebricher, Thomas (2009): „Macht und Recht: Foucault“, in: Buckel, Sonja et al. (Hg.): Neue Theorien des Rechts. 2. Aufl. Stuttgart: Lucius \& Lucius, S. 135-155.

— (2014): „Souveränität und Recht in der Staatsanalytik Foucaults“, in: Vasilache, Andreas (Hg.): Gouvernementalität, Staat und Weltgesellschaft. Studien zum Regieren im Anschluss an Foucault. Wiesbaden: VS Verlag für Sozialwissenschaften, S. 21-41.

Bierling, Ernst Rudolf (1894): Juristische Prinzipienlehre. Erster Band. Freiburg (Breisgau), Leipzig: Mohr (Paul Siebeck).

- (1917): Juristische Prinzipienlehre. Fünfter Band. Freiburg (Breisgau), Leipzig: Mohr (Paul Siebeck).

Binding, Karl (1872): Die Normen und ibre Übertretung: Eine Untersuchung über das rechtmässige Handlung und die Arten des Delikts. Erster Band, erste Abtheilung: Normen und Strafgesetze. Leipzig: Engelmann.

Blanke, Sandro (2005): Soziales Recht oder kollektive Privatautonomie? Hugo Sinzheimer im Kontext nach 1900. Tübingen: Mohr Siebeck.

Blasius, Dirk (2007): Lorenz von Stein. Deutsche Gelehrtenpolitik in der Habsburger Monarchie. Kiel: Lorenz-von-Stein-Institut für Verwaltungswissenschaften.

Bloch, Ernst (1985): Naturrecht und menschliche Würde. Frankfurt am Main: Suhrkamp.

Bloor, David (2005): „Toward a Sociology of Epistemic Things“, in: Perspectives on Science 13 (3), S. 285-312. 
Bluntschli, Johann Casper (1853): „Die Lehre von dem deutschen Erbrecht: Heinr. Siegel. Das deutsche Erbrecht nach den Rechtsquellen des Mittelalters in seinem innern Zusammenhang dargestellt. Heidelberg 1853. Dr. Heinr. Siegel. Die germanische Verwandschaftsberechnung mit besonderer Beziehung auf die Erbfolge. Habilitationsschrift. Gießen 1853. Prof. Dr. E. Th. Gaupp. Ueber einige Grundzüge des deutschen Erbrechts in den Germanistischen Abhandlungen. Mannheim 1853“, in: Kritische Überschau der deutschen Gesetzgebung und Rechtswissenschaft 1, S. 387-404.

Boas, Felix (1876): Der Kampf um's Recht ein Pflichtgebot? Antwort und Entgegnung an Herrn Professor Dr. Rudolf von Jhering. Berlin: Heymann.

Böckenförde, Ernst-Wolfgang (1965): „Die Historische Rechtsschule und das Problem der Geschichtlichkeit des Rechts“, in: ders. (Hg.): Collegium philosophicum: Studien. Joachim Ritter zum 60. Geburtstag. Basel, Stuttgart: Schwabe, S. 9-36.

- (1978): „Organ, Organismus, Organisation, politischer Körper“, in: Brunner, Otto; Conze, Werner; Koselleck, Reinhardt (Hg.): Geschichtliche Grundbegriffe. Historisches Lexikon zur politisch-sozialen Sprache in Deutschland. Band 4: Mi-Pre. Stuttgart: Klett-Cotta, S. 519-622.

Böckler, Stefan; Weiß, Johannes (Hg./ 1987): Marx oder Weber? Zur Aktualisierung einer Kontroverse. Opladen: Westdeutscher Verlag.

Bonacker, Thorsten (2008): „Gesellschaft: Warum die Einheit der Gesellschaft aufgeschoben wird“, in: Moebius, Stephan; Reckwitz, Andreas (Hg.): Poststrukturalistische Sozialwissenschaften. Frankfurt am Main: Suhrkamp, S. 27-42.

Bond, N. (2012): „Ferdinand Tönnies and Max Weber“, in: Max Weber Studies 12 (1), S. 25.

- (2011a): „Rational Natural Law and German Sociology: Hobbes, Locke and Tönnies“, in: British Journal for the History of Philosophy 19 (6), S. 1175-1200.

- (2011b): The displacement of normative discourse from legal theory to empirical sociology: Ferdinand Tönnies, natural law, the Historical School, Rudolf von Jhering and Otto von Gierke. Article dated 23. September 2011. forum historiae iuris. https://forhistiur.de/2011-09-bond/ (zuletzt geprüft am 16.01.2019).

Bora, Alfons (2016): „Responsive Rechtssoziologie“, in: Zeitschrift für Rechtssoziologie 36 (2), S. 261-272.

Borchardt, Knut; Hanke, Edith; Schluchter, Wolfgang (2013): Max Weber-Gesamtausgabe. Band I/23: Wirtschaft und Gesellschaft. Soziologie. Unvollendet. 1919-1920. Tübingen: Mohr Siebeck.

Borlandi, Massimo; Mucchielli, Laurent (Hg./ 1995): La sociologie et sa méthode. Les Règles de Durkheim un siècle après. Paris: L'Harmattan.

Bornhak, Conrad (1891): „Der Entwurf des bürgerlichen Gesetzbuchs und das öffentliche Recht“, in: Annalen des Deutschen Reiches für Gesetzgebung, Verwaltung und Volkswirtschaft 24, S. 212-224.

Bozi, Alfred (1915): Lebendes Recht. Ein Ausblick in die Probleme der Justizreform. Hannover: Helwing.

- (1916): „Am Wendepunkt des Rechts“, in: Beiträge zur Erläuterung des deutschen Rechts 60, S. 95-113. 
Brandt, Dietmar (1975): Die politischen Parteien und die Vorlage des Bürgerlichen Gesetzbuches im Reichstag. Heidelberg: Heidelberg, Univ., Jur. Fak.

Braun, Johann (1998): „Gans und Puchta — Dokumente einer Feindschaft“, in: $J u$ ristenZeitung 53 (15/16), S. 763-770.

Brentano, Franz (1889): Vom Ursprung sittlicher Erkenntnis. Leipzig: Duncker \& Humblot.

Breuer, Stefan (1988): „Max Webers Herrschaftssoziologie“, in: Zeitschrift für Soziologie 18 (5), S. 315-327.

- (1999): Georg Jellinek und Max Weber. Von der sozialen zur soziologischen Staatslehre [Vortrag gehalten am 4. Februar 1999]. Baden-Baden: Nomos.

- (2002): „'Gemeinschaft' in der 'deutschen Soziologie' / 'Community' in German Sociology (1933-1945)“, in: Zeitschrift für Soziologie 31 (5), S. 354-372.

- (2012): Carl Schmitt im Kontext. Intellektuellenpolitik in der Weimarer Republik. Berlin: Akademie Verlag.

Brie, S. (1909): „Billigkeit und Recht: mit besonderer Berücksichtigung der Freirechtsbewegung", in: Archiv für Rechts- und Wirtschaftsphilosophie 3 (4), S. 526534 .

Brinkmann, Carl (1919): Versuch einer Gesellschaftswissenschaft. München, Leipzig: Duncker \& Humblot.

Brinz, Alois von (1879): Festrede zu Friedrich Karl von Savigny's hundertjährigem Geburtstag gehalten am 21. Februar 1879 in der Aula der Kgl. Ludwig-MaximiliansUniversität München. München: Wolf.

Bröckling, Ulrich; Krasmann, Susanne (2010): „Ni méthode, ni approche. Zur Forschungsperspektive der Gouvemementalitätsstudien - mit einem Seitenblick auf Konvergenen und Divergenzen zur Diskursforschung“, in: Angermüller, Johannes; van Dyk, Silke (Hg.): Diskursanalyse meets Gouvernementalitätsforschung. Perspektiven auf das Verhältnis von Subjekt, Sprache, Macht und Wissen. Frankfurt am Main, New York, NY: Campus, S. 23-42.

Brockmöller, Annette (1997): Die Entstehung der Rechtstheorie im 19. Jahrhundert in Deutschland. Baden-Baden: Nomos.

Brödel, Rainer (1990): „Tönnies als Anreger für die Volks- und Erwachsenenbildung am Beispiel der Rezeption durch Hermann Heller“, in: Schlüter, Carsten; Clausen, Lars (Hg.): Renaissance der Gemeinschaft? Stabile Theorie und neue Theoreme. Berlin: Duncker \& Humblot, S. 191-215.

Brodhun, Rüdiger (1999): Paul Ernst Wilhelm Oertmann (1865-1938). Leben, Werk, Rechtsverständnis sowie Gesetzeszwang und Richterfreiheit. Baden-Baden: Nomos.

Bruns, Carl Georg (1843): „Ueber Gegenwart und Zukunft des Privatrechts“, in: Jahrbücher der Gegenwart, S. 129-135, 137-139, $141 \mathrm{f}$.

- (1882): „Rezensionen: Schmidt, Dr. Carl Adolf, der principielle Unterschied zwischen dem römischen und germanischen Rechte. Liter. Centralblatt. 1853. Nr. 6.“, in: ders. (Hg.): Kleinere Schriften. Band 2. Weimar: Boehlau, S. 326-328.

Brütt, Lorenz (1907): Die Kunst der Rechtsanwendung. Zugleich ein Beitrag zur Methodenlehre der Geisteswissenschaften. Berlin: Guttentag. 
Bruun, Hans Henrik (2000): „Weber on Rickert: From Value Relation to Ideal Type“, in: Max Weber Studies 1 (2), S. 138-160.

- (2007): Science, values and politics in Max Weber's methodology. 2. Aufl. London, New York: Routledge.

Bryan, Ian; Langford, Peter; McGarry, John (Hg./ 2016): The foundation of the juridico-political. Concept formation in Hans Kelsen and Max Weber. Abingdon, Oxon, New York: Routledge.

Buckel, Sonja (2007): Subjektivierung und Kohäsion. Zur Rekonstruktion einer materialistischen Theorie des Rechts. Weilerswist: Velbrück Wissenschaft.

Bührmann, Andrea D.; Schneider, Werner (2008): Vom Diskurs zum Dispositiv. Eine Einfübrung in die Dispositivanalyse. Bielefeld: Transcript.

Bullinger, Martin (1968): Öffentliches Recht und Privatrecht. Studien über Sinn und Funktionen der Unterscheidung. Stuttgart [u.a.]: Kohlhammer.

Bülow, Oskar (1992): „Über das Verhältnis der Rechtsprechung zum Gesetzesrecht (1906)“, in: Gängel, Andreas; Mollnau, Karl A. (Hg.): Gesetzesbindung und Richterfreiheit. Texte zur Methodendebatte 1900 - 1914. Freiburg (Breisgau), Berlin: Haufe, S. 82-100.

- (1972): Gesetz und Richteramt. Neudr. d. Ausg. Leipzig 1885. Aalen: Scientia.

Bürge, Alfons (1991): Das französische Privatrecht im 19. Jahrhundert. Zwischen Tradition und Pandektenwissenschaft, Liberalismus und Etatismus. Frankfurt am Main: Klostermann.

Burger, Thomas (1987): Max Weber's theory of concept formation. History, laws, and ideal types. Durham, N.C.: Duke University Press.

Caborn Wengler, Joannah; Hoffarth, Britta; Kumięga, Łukasz (Hg./ 2013): Verortung des Dispositiv-Begriffs. Analytische Einsätze zu Raum, Bildung, Politik. Wiesbaden: VS Verlag für Sozialwissenschaften.

Caligiuri, Francesca (2013): „'das Unwürdige der Welteinrichtung erfahren'“, in: Goll, Tobias; Keil, Daniel; Telios, Thomas (Hg.): Critical Matter. Diskussionen eines neuen Materialismus. Münster: Edition Assemblage, S. 65-81.

Carbonnier, Jean (1974): Rechtssoziologie. Berlin: Duncker \& Humblot.

Carstens, Uwe (2014a): „Ferdinand Tönnies und die Staatswissenschaft“, in: ders. (Hg.): Ferdinand Tönnies: Der Sozialstaat zwischen Gemeinschaft und Gesellschaft. Baden-Baden: Nomos, S. 13-28.

— (Hg./ 2014b): Ferdinand Tönnies: Der Sozialstaat zwischen Gemeinschaft und Gesellschaft. Baden-Baden: Nomos.

Castels, Robert (1994): „'Problematization' as a Mode of Reading History“, in: Goldstein, Jan Ellen (Hg.): Foucault and the writing of history. Oxford, UK, Cambridge, Mass., USA: Blackwell, S. 237-252.

Castoriadis, Cornelius (1990): Gesellschaft als imaginäre Institution. Entwurf einer politischen Philosophie. Frankfurt am Main: Suhrkamp.

Cathrein, Victor (1901): Recht, Naturrecht und positives Recht. Eine kritische Untersuchung der Grundbegriffe der Rechtsordnung. Freiburg (Breisgau) [u.a.]: Herder. 
Chamboredon, Jean-Claude (2013): Emile Durkheim. Das Soziale als Gegenstand der Wissenschaft. Vom Moralischen zum Politischen? Trivium: revue franco-allemande de sciences humaines et sociales. http://trivium.revues.org/4452 (zuletzt geprüft am 16.01.2019).

Chazal, Jean-Pascal (2010): „Léon Duguit et François Gény. Controverse sur la rénovation de la science juridique", in: Revue Interdisciplinaire d'Etudes Juridiques 65 (2), S. 85-133.

Chernilo, Daniel (2013): The Natural Law Foundations of Modern Social Theory. A Quest for Universalism. Cambridge: Cambridge Univ. Press.

Clark, Terry Nichols (1973): Prophets and Patrons. The French University and the Emergence of the Social Sciences. Cambridge, Mass.: Harvard University Press.

- (1981): „Die Durkheim-Schule und die Universität“, in: Lepenies, Wolf (Hg.): Geschichte der Soziologie - Studien zur kognitiven, sozialen und historischen Identität einer Disziplin. Band 2. Frankfurt am Main: Suhrkamp, S. 157-205.

Coing, Helmut (1973): „Bemerkungen zur Verwendung des Organismusbegriffs in der Rechtswissenschaft des 19. Jahrhunderts in Deutschland“, in: Mann, Gunter (Hg.): Biologismus im 19. Jahrhundert. Vorträge eines Symposiums vom 30. Oktober 1970 in Frankfurt am Main. Stuttgart: Enke, S. 147-157.

- (1979): „Savigny und die deutsche Privatrechtswissenschaft“, in: Ius Commune VIII, S. 9-23.

Collet, Franz (1894): Deutsches und römisches Recht in ibrem Einfluss auf die Volkswirtschaft. Ein Beitrag zum Verständnis der sozialen Frage. Leipzig: Werther.

Collmann, Carl Christian (1836): Grundlinien der Wissenschaft des bestehenden Rechts nebst einer Kritik der philosophischen und historischen Schule. Berlin: Reimer.

Cosack, Konrad (1903): Lehrbuch des bürgerlichen Rechts auf der Grundlage des Bürgerlichen Gesetzbuchs. Band 1: Die allgemeinen Lehren und das Recht der Forderungen. 4. Aufl. Jena: Fischer.

Cotterrell, Roger (1998): „Why Must Legal Ideas Be Interpreted Sociologically?“, in: Journal of Law and Society 25 (2), S. 171-192.

- (1999): Emile Durkheim. Law in a moral domain. Stanford, Calif: Stanford University Press.

- (2004a): „Constructing the Juristic Durkheim? Paul Huvelin's adaptation of Durkheimian sociology“, in: Durkheimian Studies / Études Durkheimiennes 10 (1), S. 56-69.

- (2004b): „Emmanuel Lévy and Legal Studies. A View from Abroad“, in: Droit et société 56-57 (1), S. 131-141.

- (2005): „Durkheim's Loyal Jurist? The Sociolegal Theory of Paul Huvelin“, in: Ratio Juris 18 (4), S. 504-518.

- (2009): „Ehrlich at the Edge of Empire: Centres and Peripheries in Legal Studies“, in: Hertogh, Marc L. M. (Hg.): Living law. Reconsidering Eugen Ehrlich. Oxford: Hart, S. 75-94.

- (2015): „Leon Petražycki and contemporary socio-legal studies“, in: International Journal of Law in Context 11 (1), S. 1. 
Coutu, Michel (2009): „Max Weber on the Labour Contract. Between Realism and Formal Legal Thought“, in: Journal of Law and Society 36 (4), S. 558-578.

- (2013): „Weber Reading Stammler: What Horizons for the Sociology of Law?“, in: Journal of Law and Society 40 (3), S. 356-374.

- (2018): Max Weber's Interpretive Sociology of Law. London: Taylor \& Francis.

Dahn, Felix (1879): Die Vernunft im Recht. Grundlagen der Rechtsphilosophie. Berlin: Janke.

Dargun, Lothar (1885): Egoismus und Altruismus in der Nationalökonomie. Sociologische Studien I. Leipzig: Duncker \& Humblot.

Darmstaedter, Friedrich (1926): „Rechtslogismus und Rechtssoziologie in ihrer Stellung zum Problem der Rechtsgeltung“, in: Archiv für Rechts- und Wirtschaftsphilosophie 20 (1), S. 103-135.

Daston, Lorraine (Hg./ 2000): Biographies of scientific objects. Chicago: University of Chicago Press.

Dean, Mitchell (1994): Critical and effective histories. Foucault's methods and historical sociology. London, New York: Routledge.

Dedek, Helge (2007): Negative Haftung aus Vertrag. Tübingen: Mohr Siebeck.

Dehnow, Fritz (1914): „Wesen und Wert des Rechtsgefühls“, in: Archiv für systematische Philosophie 20, S. 90-92.

Deininger, Jürgen (1988): „Einleitung“, in: Weber, Max; Deininger, Jürgen (Hg.): Die römische Agrargeschichte in ihrer Bedeutung für das Staats- und Privatrecht. 1891. Studienausg. Tübingen: Mohr, S. 1-54.

Deleuze, Gilles (1991): „Was ist ein Dispositiv?“, in: Ewald, François; Waldenfels, Bernhard (Hg.): Spiele der Wahrheit. Michel Foucaults Denken. Frankfurt am Main: Suhrkamp, S. 153-162.

Demirovic, Alex (2001): „Die Herausforderung der Soziologiegeschichte für die Gesellschaftstheorie“, in: Klingemann, Carsten et al. (Hg.): Jabrbuch für Soziologiegeschichte 1997/98. Wiesbaden: VS Verlag für Sozialwissenschaften, S. 91-103.

Dernburg, Heinrich (1853): „Rezension: Carl. A. Schmidt, Der prinzipielle Unterschied“, in: Kritische Zeitschrift für die gesammte Rechtswissenschaft 1, S. 270-275.

- (1888): Pandekten. Erster Band: Allgemeiner Theil und dingliche Rechte. 2. Aufl. Berlin: Müller.

- (1889): „Diskussionsbeitrag zur Frage der Beibehaltung des Vermieterpfandrechts“, in: Staendige Deputation des Deutschen Juristentages (Hg.): Verhandlungen des 20. Deutschen Juristentages. Band 4. Berlin: Guttentag, S. 176-180.

- (1894): Die Phantasie im Rechte. Vortrag. Berlin: Müller.

Diaz-Bone, Rainer (2010): Kulturwelt, Diskurs und Lebensstil. Eine diskurstheoretische Erweiterung der Bourdieuschen Distinktionstheorie. 2. Aufl. Wiesbaden: VS Verlag für Sozialwissenschaften.

Dickel, Karl (1889): Über das neue bürgerliche Gesetzbuch für Montenegro und die Bedeutung seiner Grundsätze für die Kodifikation im allgemeinen mit Bemerkungen über den neuen Entwurf eines deutschen bürgerlichen Gesetzbuches. Marburg: O. Ehrhardt. 
Didry, Claude (2004): „Emmanuel Lévy et le contrat, la sociologie dans le droit des obligations“, in: Droit et société 56-57 (1), S. 151-164.

Dilcher, Gerhard (1974/1975): „Genossenschaftstheorie und Sozialrecht: ein 'Juristensozialismus' Otto v. Gierkes?"“, in: Quaderni Fiorentini per la storia del pensiero giuridico moderno 3/4, S. 319-365.

- (2007): „Von der Rechtsgeschichte zur Soziologie: Max Webers Auseinandersetzung mit der Historischen Rechtsschule“, in: Juristenzeitung 62 (3), S. 105112.

- (2008): „Einleitung“, in: ders.; Lepsius, Susanne (Hg.): Max-Weber Gesamtausgabe. Band I/1: Zur Geschichte der Handelsgesellschaften im Mittelalter. Schriften 1889 - 1894. Tübingen: Mohr Siebeck, S. 1-97.

- (2017): „Historische Sozialwissenschaft als Mittel zur Bewältigung der Moderne - Max Weber und Otto von Gierke im Vergleich“, in: Gephart, Werner; Witte, Daniel (Hg.): Recht als Kultur? Beiträge zu Max Webers Soziologie des Rechts. Frankfurt am Main: Klostermann, S. 199-228.

Dilthey, Wilhelm (1883): Einleitung in die Geisteswissenschaften. Versuch einer Grundlegung für das Studium der Gesellschaft und der Geschichte. Erster Band. Leipzig: Duncker \& Humblot.

— (1981): System der Ethik. 4. Aufl. Leipzig [u.a.]: Teubner.

Dombek, Bernhard (1969): Das Verhältnis der Tübinger Schule zur deutschen Rechtssoziologie. Berlin: Duncker \& Humblot.

Donzelot, Jacques (1980): Die Ordnung der Familie. Mit einem Nachwort von Gilles Deleuze. Frankfurt am Main: Suhrkamp.

— (1994a): „Die Förderung des Sozialen“, in: ders.; Schwarz, Richard (Hg.): Zur Genealogie der Regulation. Anschlüsse an Michel Foucault. Mainz: Decaton, S. 109160.

- (1994b): L'invention du social. Essai sur le déclin des passions politiques. Paris: Éditions du Seuil.

Dorndorf, Eberhard (1995): „Zu den theoretischen Grundlagen der Interessenjurisprudenz: Die Beziehungen von Philipp Hecks allgemeiner Auslegungstheorie zu Max Weber und Heinrich Rickert", in: ARSP: Archiv für Rechts- und Sozialphilosophie 81 (4), S. 542-562.

Dove (1893): „Rudolf von Jhering und Bernhard Windscheid“, in: Akademischer Gesamt-Ausschuß (Hg.): Berichte des Freien Deutschen Hochstiftes zu Frankfurt a.M. Band 9. Frankfurt am Main: Gebrüder Knauer, S. 138-154.

Dreier, Horst (1990): Rechtslehre, Staatssoziologie und Demokratietheorie bei Hans Kelsen. 2. Aufl. Baden-Baden: Nomos.

- (2001): Rezeption und Rolle der Reinen Rechtslehre. Festakt aus Anlass des 70. Geburtstags von Robert Walter. Wien: Manz.

Dreier, Ralf (1992): „Zum Verhältnis von Rechtsphilosophie und Rechtstheorie“, in: Schöneburg, Volkmar; Klenner, Hermann (Hg.): Philosophie des Rechts und das Recht der Philosophie. Festschrift für Hermann Klenner. Frankfurt am Main, New York: P. Lang, S. 15-28. 
- (1996): "Jherings Rechtstheorie - eine Theorie evolutionärer Rechtsvernunft", in: Behrends, Okko (Hg.): Jherings Rechtsdenken. Theorie und Pragmatik im Dienste evolutionärer Rechtsethik. Göttingen: Vandenhoeck \& Ruprecht, S. 111-129.

Dreyfus, Hubert L.; Rabinow, Paul (1987): Michel Foucault. Jenseits von Strukturalismus und Hermeneutik. Frankfurt am Main: Athenäum.

Düringer, Adelbert (1908): „Eine neue Methode der Rechtsprechung und der Kritik“, in: Das Recht. Rundschau für den deutschen Juristenstand 12 (7), S. 257-265.

- (1909): Richter und Rechtsprechung. Leipzig: Veit.

— (1992): „Zur Kritik der Rechtsprechung [1910]“, in: Gängel, Andreas; Mollnau, Karl A. (Hg.): Gesetzesbindung und Richterfreiheit. Texte zur Methodendebatte 1900 - 1914. Freiburg (Breisgau), Berlin: Haufe, S. 132-141.

Durkheim, Émile (1885a): „Alfred Fouillée: La Propriété sociale et la démocratie“, in: Revue philosophique XIX, S. 446-453.

— (1885b): „Gumplowicz, Ludwig, Grundriss der Soziologie“, in: Revue philosophique XX, S. 627-634.

- (1885c): „Schaeffle, A., Bau und Leben des sozialen Körpers: Erster Band“, in: Revue philosophique XIX, S. 84-101.

- (1886): „Les études de science sociale. Herbert Spencer, Ecclesiastical institutions: being part VI of the Principles of Sociology, London, 1885. - A. Regnard, L'État, ses origines, sa nature et son but. Paris, Derveaux. - . A. Coste, Aug. Burdeau et Lucien Arréat, Les questions sociales contemporaines. Paris, Alcan et Guillaumin, 1886. - Dr A. Schaeffle, Die Quintessenz des Sozialismus. Achte Auflage, Gotha, 1885“, in: Revue philosophique XXII, S. 61-80.

— (1888): „Le Programme économique de M. Schaeffle“, in: Revue d'économie politique 11, S. 3-7.

— (1889): „Lutoslawski, W., Erhaltung und Untergang der Staatsverfassungen nach Plato, Aristoteles, und Machiavelli“, in: Revue philosophique XXVII, S. 317-319.

- (1893): „Gaston Richard. Essai sur l'origine de l'idée de droit. Paris, 1892, xxiii-263 p. “, in: Revue Philosophique de la France et de l'Étranger 35, S. 290-296.

— (1899): „Cornil George. Contribution à l'étude de la 'patria potestas'”, in: L'Annee sociologique 2, S. 327-328.

- (1900): „Ernst Neukamp. Das Zwangsmoment im Recht in entwicklungsgeschichtlicher Bedeutung “, in: L'Année sociologique 3, S. 324-325.

— (1901): „Ludwig Fuld: Die Frauen und das bürgerliche Gesetzbuch, 1900”, in: L'Annee sociologique 4, S. 365.

- (1902): „Ch. Seignobos. La Methode historique appliquee aux sciences sociales. Paris: F. Alcan, 1901, p. 11-322”, in: L'Annee sociologique 5, S. 123-127.

- (1903a): „L. von Savigny. - Das Naturrechtsproblem und die Methode seiner Lösung. 1901; R. Saleilles. - Ecole historique et droit naturel. 1902“, in: L'Année sociologique 6, S. 302-303.

- (1903b): „P. Bonfaute. - La progressiva diversificazione del diritto publico e privato. Rivista italiana di Sociologia, Anno VI, fase. 1, p. 1-16.“, in: L'Année sociologique 6, S. 304-305. 
- (1904a): „Édouard Lambert. La Fonction du droit civil compare. Vol. I, Les Conceptions etroites et unilaterales. Paris: Giard et Briere, 1903", in: L'Annee sociologique 7, S. 374-379.

- (1904b): „Lucien Lévy-Bruhl. La Morale et la science des moeurs. Paris: F. Alcan, 1903", in: L'Annee sociologique 7, S. 380-384.

- (1910): „Note sur 'Les systèmes juridiques et moraux”, in: L'Année sociologique 11, S. 286-288.

- (1913): „Le premier Congrès allemand de Sociologie. - Communications et discussions (Publications de la Deutsche Gesellschaft für Soziologie), t. I, Tübingen: Mohr, 1911, 335 pp.”, in: L'Annee sociologique 12, S. 23-26.

- (1915): Deutschland über alles. Die deutsche Gesinnung und der Krieg. Lausanne: Payot.

- (1925): „Saint-Simon, fondateur du positivisme et de la sociologie. Extrait d'un cours d'Historie du socialisme“, in: Revue Philosophique de la France et de l'Étranger 99, S. 321-341.

- (Hg./ 1960): Montesquieu and Rousseau: Forerunners of Sociology. Translated by R. Manheim with a foreword by Henri Peyre. Ann Arbor: University of Michigan Press.

- (1966): „Le 'contrat social' de Rousseau“, in: ders. (Hg.): Montesquieu et Rousseau. Précurseurs de la sociologie. Paris: Librairie Marcel Rivière et Cie, S. 115198.

— (1976a): „Bestimmung der moralischen Tatsache [1906]“, in: ders. (Hg.): Soziologie und Philosophie. Mit einer Einleitung von Theodor W. Adorno. Frankfurt am Main: Suhrkamp, S. 84-117.

— (1976b): „Individuelle und kollektive Vorstellungen [1898]“, in: ders. (Hg.): Soziologie und Philosophie. Frankfurt am Main: Suhrkamp, S. 45-83.

- (1976c): „Werturteile und Wirklichkeitsurteile“, in: ders. (Hg.): Soziologie und Philosophie. Frankfurt am Main: Suhrkamp, S. 137-157.

- (1986a): „Der Individualismus und die Intellektuellen [1898]“, in: Bertram, Hans (Hg.): Gesellschaftlicher Zwang und moralische Autonomie. Frankfurt am Main: Suhrkamp, S. 54-70.

— (1986b): „Einführung in die Moral [1917]“, in: Bertram, Hans (Hg.): Gesellschaftlicher Zwang und moralische Autonomie. Frankfurt am Main: Suhrkamp, S. 33-53.

- (1991a): „Besprechung von Ferdinand Tönnies: Gemeinschaft und Gesellschaft. Abhandlung des Communismus und des Socialismus als empirische Culturformen. Leipzig, 1887. Erste Veröffentlichung: Revue Philosophique de la France et de l'etranger XXVII, (1889), p. 416-422“, in: ders.; Heisterberg, Lore (Hg.): Frühe Schriften zur Begründung der Sozialwissenschaft. [Nachdr. der Ausg.] Darmstadt [u.a.] 1981. Niedernberg: Pfeffer, S. 71-84.

- (1991b): „Einführung in die Sozialwissenschaft. Eröffnungsvorlesung. Erste Veröffentlichung: Revue Internationale de l'Enseignement XV (1888), p. 23-48“, in: ders.; Heisterberg (Hg.): Frühe Schriften zur Begründung der Sozialwissenschaft. S. $25-52$. 
— (1991c): „Einführung in die Soziologie der Familie [1888]“, in: ders.; Heisterberg (Hg.): Frühe Schriften zur Begründung der Sozialwissenschaft. S. 53-76.

— (1991d): „Montesquieus Beitrag zur Begründung der Soziologie [1892]“, in: ders.; Heisterberg (Hg.): Frühe Schriften zur Begründung der Sozialwissenschaft. S. 85-139.

- (1993): „Note sur la définition du socialisme“, in: Revue philosophique XXXVI, S. 506-512.

- (1995a): „Die Philosophie an den deutschen Universitäten [1887]“, in: ders.; Schultheis, Franz; Gipper, Andreas (Hg.): Über Deutschland. Texte aus den Jahren 1887 bis 1915. Konstanz: UVK, S. 27-83.

- (1995b): „Über positive Moralwissenschaft in Deutschland [1887]“, in: ders.; Schultheis, Franz; Gipper, Andreas (Hg.): Über Deutschland. Texte aus den Jahren 1887 bis 1915. Konstanz: UVK, S. 85-175.

- (1996): Über soziale Arbeitsteilung. Studie über die Organisation höherer Gesellschaften [1893/1902]. Mit einer Einleitung von Niklas Lubmann: Arbeitsteilung und Moral. Durkheims Theorie. 2. Aufl. Frankfurt am Main: Suhrkamp.

- (1999): Physik der Sitten und des Rechts. Vorlesungen zur Soziologie der Moral. Frankfurt am Main: Suhrkamp.

— (2007 [1894]): Die Regeln der soziologischen Methode. Herausgegeben und eingeleitet von René König. Frankfurt am Main: Suhrkamp.

- (2011): Erziehung, Moral und Gesellschaft. Vorlesung an der Sorbonne 1902/1903. Frankfurt am Main: Suhrkamp.

Durkheim, Émile; Fauconnet, Paul (1901): „Systèmes juridiques“, in: L'Année sociologique 6, S. 305.

Durkheim, Émile; Karady, Victor (Hg./ 1975a): Textes. Éléments d'une théorie sociale. Bd. 1. Paris: Éditions de Minuit.

— (Hg./ 1975b): Textes. Religion, morale, anomie. Bd. 2. Paris: Les editions de Minuit.

- (Hg./ 1975c): Textes. Fonctions sociales et institutions. Bd. 3. Paris: Minuit.

Duxbury, Neil (2007): „Jhering's Philosophy of Authority“, in: Oxford Journal of Legal Studies 27 (1), S. 23-47.

Eck, Ernst (1893): Zur Feier des Gedächtnisses von B. Windscheid und R. v. Ihering. Vortrag gehalten in der Juristischen Gesellschaft zu Berlin am 17. December 1892. Berlin: Heymann.

Eckstein, Walther (1931): „Einleitung des Herausgebers“, in: Ofner, Julius (Hg.): Recht und Gesellschaft. Gesammelte Vorträge und Aufsätze. Herausgegeben und eingeleitet von Walther Eckstein. Wien, Leipzig: Gerold, S. VII-XXII.

Edelmann, Johann (1967): Die Entwicklung der Interessenjurisprudenz. Eine historischkritische Studie über die deutsche Rechtsmethodologie vom 18. Jahrhundert bis zur Gegenwart. Bad Homburg v. d. H. [u.a.]: Gehlen.

Ehrlich, Eugen (1890a): „Der Entwurf eines bürgerlichen Gesetzbuchs und die socialpolitischen Bestrebungen der Gegenwart. Band 2“, in: Unsere Zeit (7), S. 21-35. 
- (1890b): „Sociale Gesetzgebungspolitik auf dem Gebiete des deutschen Privatrechts", in: Unsere Zeit (1), S. 433-451.

- (1892): „Die sociale Frage im Privatrechte“, in: Juristische Blätter XXI (9, 10-12), S. 97-99, 109-111, 121-123, 133-135.

- (1907): Die Tatsachen des Gewohnheitsrechts. Inaugurationsrede, gehalten am 2.12.1906. Leipzig, Wien: Deuticke.

- (1913): Grundlegung der Soziologie des Rechts. München, Leipzig: Duncker \& Humblot.

— (1916 [1909]): Die Aufgaben der Sozialpolitik im österreichischen Osten (Juden- und Bauernfrage). 4. Aufl. München, Leipzig: Duncker \& Humblot.

- (1917): „Die juristische Logik“, in: Archiv für die civilistische Praxis 115 (2/3), S. $125-439$.

- (1966): Die juristische Logik. Neudruck der 2. Auflage Tübingen 1925. Aalen: Scientia.

— (1967a): „Das lebende Recht der Völker der Bukowina [1912]“, in: ders. (Hg.): Recht und Leben. Gesammelte Schriften zur Rechtstatsachenforschung und zur Freirechtslehre. Ausgewählt u. eingel. von Manfred Rehbinder. Berlin: Duncker \& Humblot, S. 43-60.

- (1967b): „Die Erforschung des lebenden Rechts. (Aus: Schmollers Jahrbuch für Gesetzgebung, Verwaltung und Volkswirtschaft im Deutschen Reich 35 [1911], S. 129-147)“, in: ders. (Hg.): Recht und Leben. Gesammelte Schriften zur Rechtstatsachenforschung und zur Freirechtslehre. Berlin: Duncker \& Humblot, S. 11-27.

— (1967c): „Ein Institut für lebendes Recht [1911]“, in: ders. (Hg.): Recht und Leben. Gesammelte Schriften zur Rechtstatsachenforschung und zur Freirechtslehre. Berlin: Duncker \& Humblot, S. 28-42.

- (1967d): „Freie Rechtsfindung und freie Rechtswissenschaft. (Leipzig: Verlag C. L. Hirschfeld 1903)“, in: ders. (Hg.): Recht und Leben. Gesammelte Schriften zur Rechtstatsachenforschung und zur Freirechtslehre. Berlin: Duncker \& Humblot, S. 170-202.

- (1967e): „Über Lücken im Rechte. (Aus: Juristische Blätter 1888, S. 447-630 [in Forts.])“, in: ders. (Hg.): Recht und Leben. Gesammelte Schriften zur Rechtstatsachenforschung und zur Freirechtslehre. Berlin: Duncker \& Humblot, S. 80-169.

- (1970): Beiträge zur Theorie der Rechtsquellen [1902]. 1. (einziger) Teil. Das ius civile, ius publicum, ius privatum. Aalen: Scientia.

- (1976): „Die Juristische Konstruktion. Aus: Die juristische Logik, 1918, S. 252-287", in: Krawietz, Werner (Hg.): Theorie und Technik der Begriffsjurisprudenz. Darmstadt: Wissenschaftliche Buchgesellschaft, S. 208-237.

— (1986a): „Anton Menger. (Süddeutsche Monatshefte III 2 [1906], S. 285-318)“, in: ders.; Rehbinder, Manfred (Hg.): Gesetz und lebendes Recht. Vermischte kleinere Schriften. Berlin: Duncker \& Humblot, S. 48-87.

- (1986b): „Montesquieu and Sociological Jurisprudence. (aus: Harvard Law Review 29 [1915/16], S. 582-600)“, in: ders.; Rehbinder, Manfred (Hg.): Gesetz und lebendes Recht. Vermischte kleinere Schriften. Berlin: Duncker \& Humblot, S. 195210. 
- (1986c): „Soziologie des Rechts. (aus: Die Geisteswissenschaften 1913/14, S. 202-205 und 230-234)“, in: ders.; Rehbinder, Manfred (Hg.): Gesetz und lebendes Recht. Vermischte kleinere Schriften. Berlin: Duncker \& Humblot, S. 179-194.

- (1986d): „Soziologie und Jurisprudenz. (aus: Österreichische Richter-Zeitung III 1 [1906], Sp. 57-72)“, in: ders.; Rehbinder, Manfred (Hg.): Gesetz und lebendes Recht. Vermischte kleinere Schriften. Berlin: Duncker \& Humblot, S. 88-103.

- (1989): Grundlegung der Soziologie des Rechts [1913]. Durchgesehen und herausgegeben von Manfred Rehbinder. 4. Aufl. Berlin: Duncker \& Humblot.

- (1992a): „Entgegnung. (Archiv für Sozialwissenschaft und Sozialpolitik. Band 41 (1916), S. 844-849“, in: Paulson, Stanley L. (Hg.): Hans Kelsen und die Rechtssoziologie. Auseinandersetzungen mit Hermann U. Kantorowicz, Eugen Ehrlich und Max Weber. Aalen: Scientia, ohne fortlaufende Pagnierung, abgedruckt: 844-849.

- (1992b): „Replik. (Archiv für Sozialwissenschaft und Sozialpolitik. Band 42 (1916/17), S. 609-610)“, in: Paulson, Stanley L. (Hg.): Hans Kelsen und die Rechtssoziologie. Auseinandersetzungen mit Hermann U. Kantorowicz, Eugen Ehrlich und Max Weber. Aalen: Scientia, ohne fortlaufende Paginierung, abgedruckt: 609-610.

- (anonym/ 1891): „Die soziale Frage und die Rechtsordnung“, in: Die neue Zeit: Revue des geistigen und öffentlichen Lebens, S. 430-438, 476-480, 539-544.

Eichhorn, Carl Friedrich (1815): „Ueber das geschichtliche Studium des Deutschen Rechts“, in: Zeitschrift für geschichtliche Rechtswissenschaft I, S. 124-146.

- (1823): Einleitung in das deutsche Privatrecht mit Einschluß des Lehensrechts. Göttingen: Vandenhoeck \& Ruprecht.

Eisler, Rudolf (1903): Soziologie. Die Lehre von der Entstehung und Entwickelung der menschlichen Gesellschaft. Leipzig: Weber.

Eleutheropulos, Abrotelēs (1908): Rechtsphilosophie, Soziologie und Politik. Zwei Abhandlungen. Innsbruck: Wagner.

Eliæson, Sven (2002): Max Weber's methodologies. Interpretation and critique. Cambridge, UK, Malden, MA: Polity Press.

Ellscheid, Günter; Hassemer, Winfried (Hg./ 1974): Interessenjurisprudenz. Darmstadt: Wissenschaftliche Buchgesellschaft.

Endemann, Friedrich (1889): „Die politische Frage bei dem Entwurfe des Bürgerlichen Gesetzbuches“, in: Deutsches Wochenblatt 2, S. 159-161.

- (1899): Lehrbuch des bürgerlichen Rechts. Band 1: Einleitung; Allgemeiner Theil; Recht der Schuldverhältnisse. 6. Aufl. Berlin: Heymann.

Endemann, Wilhelm (1864): „Nationalökonomie und Jurisprudenz. Rede zum Antritt des Prorektorats gehalten am 6. Februar 1864 zu Jena“, in: Deutsche Gerichtszeitung 6 (11, 12), 41-43, 45-46.

Engels, Friedrich; Kautsky, Karl (1887): „Juristen-Sozialismus“, in: Die Neue Zeit 5 (2), S. 49-62.

Ennercerus, Ludwig (1896): „Die parlamentarischen Aussichten des Bürgerlichen Gesetzbuches“, in: Deutsche Juristen-Zeitung 1, S. 6-8. 
Entwurf eines bürgerlichen Gesetzbuches für das Deutsche Reich. Erste Lesung. Ausgearbeitet durch die von dem Bundesrathe berufene Kommission. Amtliche Ausgabe (1888). Berlin, Leipzig: Guttentag.

Esmarch (1853): „Römisches und germanisches Recht. Mit Beziehung auf: der principielle Unterschied zwischen dem römischen und germanischen Rechte von Dr. C. A. Schmidt, Grossherzogl. Mecklenb. Oberappelrath zu Rostock“, in: Allgemeine Monatsschrift für Wissenschaft und Literatur, S. 1012-1054.

Eßbach, Wolfgang (2014): „Die historischen Quellen soziologischen Denkens: Aus welchen Traditionen entwickelt sich die Soziologie?", in: Lamla, Jörn et al. (Hg.): Handbuch der Soziologie. München, Konstanz: UVK, S. 25-44.

Eucken, Rudolf (1883): „Eine Ethik der Gegenwart (Schluss)“, in: Beilage zur Allgemeinen Zeitung (München) (363), S. 5338-5340.

Europäisches Parlament, Rechtsausschuss (2017): Bericht vom 27.01.2017 mit Empfehlungen an die Kommission zu zivilrechtlichen Regelungen im Bereich Robotik (2015/2103(INL)). Rechtsausschuss. http://www.europarl.europa.eu/sides/getDoc. do?pubRef=-//EP//TEXT+REPORT+A8-2017-0005+0+DOC+XML+V0//DE (zuletzt geprüft am 08.12.2018).

Ewald, François (1978): „Foucault - ein vagabundierendes Denken“, in: Foucault, Michel (Hg.): Dispositive der Macht. Über Sexualität, Wissen und Wahrheit. Berlin: Merve, S. 7-20.

- (1987): „Risk, Insurance, Society“, in: History of the Present (3), S. 1.

- (1990): „Norm, Disciplin, and the Law. Special Issue: Law and the Order of Culture“, in: Representations 30, S. 138-161.

- (1991): „Insurance and risk“, in: Burchell, Graham et al. (Hg.): The Foucault effect. Studies in governmentality: with two lectures by and an interview with Michael Foucault. London: Harvester Wheatsheaf, S. 197-210.

- (1993): Der Vorsorgestaat. Mit einem Essay von Ulrich Beck. Frankfurt am Main: Suhrkamp.

Exner, Adolf (1892): Über politische Bildung. Rede gehalten bei Übernahme der Rektorswürde an der Wiener Universität. 3. Aufl. Leipzig: Duncker \& Humblot.

Falk, Ulrich (1989): Ein Gelehrter wie Windscheid. Erkundungen auf den Feldern der sogenannten Begriffsjurisprudenz. 2. Aufl. Frankfurt am Main: Klostermann.

Feilbogen (1914): „Rezension Ehrlich: Grundlegung“, in: Zeitschrift für das Privatund öfentliche Recht der Gegenwart 40, S. 727-735.

Feix, Nereu (1978): Werturteil, Politik und Wirtschaft. Werturteilsstreit und Wissenschaftstransfer bei Max Weber. Göttingen: Vandenhoeck \& Ruprecht.

Feuerbach, Paul Johann Anselm von (1833): „Einige Worte über historische Rechtsgelehrsamkeit und einheimische teutsche Gesetzgebung [1816]“, in: ders. (Hg.): Kleine Schriften vermischten Inhalts. Nürnberg: Theodor Otto, S. 133-151.

Feuerbach, Paul Johann Anselm von; Savigny, Friedrich Carl von; Kadel, Herbert (1990): Zwölf Stücke aus dem Briefwechsel. Omnia quae exstant. Hrsg., eingeleitet und kommentiert von Herbert Kadel. Lauterbach: Officina Librorum. 
Feuerhahn, Wolf (2014): „Zwischen Individualismus und Sozialismus: Durkheims Soziologie und ihr deutsches Pantheon“, in: Hübinger, Gangolf (Hg.): Europäische Wissenschaftskulturen und politische Ordnungen in der Moderne (1890-1970). Berlin, Boston: de Gruyter, S. 79-98.

Filloux, Jean-Claude (1977): Durkheim et le socialisme. Genève: Droz.

Fögen, Marie Theres (2002a): „Rechtsgeschichte - Geschichte der Evolution eines sozialen Systems. Ein Vorschlag“, in: Zeitschrift für Rechtsgeschichte 1, S. 14-20.

- (2002b): Römische Rechtsgeschichten. Über Ursprung und Evolution eines sozialen Systems. Göttingen: Vandenhoeck \& Ruprecht.

Foucault, Michel (1978a): „Ein Spiel um die Psychoanalyse. Gespräch mit Angehörigen des Departement de Psychoanalyse der Universität Paris/Vincennes“, in: ders. (Hg.): Dispositive der Macht. Über Sexualität, Wissen und Wabrheit. Berlin: Merve, S. 118-175.

— (1978b): „Wahrheit und Macht“, in: ders. (Hg.): Dispositive der Macht. Über Sexualität, Wissen und Wabrheit. Berlin: Merve, S. 21-54.

— (1978c): „Recht der Souveränität/ Mechanismen der Disziplin. Vorlesung vom 14. Januar 1976“, in: ders. (Hg.): Dispositive der Macht. Über Sexualität, Wissen und Wahrheit. Berlin: Merve, S. 75-95.

— (1978d): „Die Machtverhältnisse durchziehen das Körperinnere. Ein Gespräch mit Lucette Finas“, in: ders. (Hg.): Dispositive der Macht. Über Sexualität, Wissen und Wabrheit. Berlin: Merve, S. 104-117.

- (1981): Archäologie des Wissens. Frankfurt am Main: Suhrkamp.

- (1988): Die Ordnung der Dinge. Eine Archäologie der Humanwissenschaften. 7. Aufl. Frankfurt am Main: Suhrkamp.

- (1991): Der Gebrauch der Lüste. Sexualität und Wabrheit 2. 2. Aufl. Frankfurt am Main: Suhrkamp.

- (1996): Diskurs und Wabrheit. Die Problematisierung der Parrhesia: 6 Vorlesungen, gehalten im Herbst 1983 an der Universität von Berkeley/Kalifornien. Berlin: Merve.

- (2003): Der Wille zum Wissen. Sexualität und Wabrheit, Band 1. 14. Aufl. Frankfurt am Main: Suhrkamp.

— (2005a): „Die Sorge um die Wahrheit. 'Le souci de la vérité' (Gespräch mit F. Ewald), in Magazine littéraire, Nr. 207, Mai 1984, S. 18-23“, in: ders. (Hg.): Schriften: In vier Bänden. Bd. 4: 1980-1988. Herausgegeben von Daniel Defert und François Ewald unter Mitarbeit von Jacques Lagrange. Frankfurt am Main: Suhrkamp, S. 823-836.

— (2005b): „Polemik, Politik und Problematisierung., Polémique, politique et problématisations'; Gespräch mit P. Rabinow, Mai 1984“, in: ders. (Hg.): Schriften: In vier Bänden. Bd. 4: 1980-1988, S. 724-734.

- (2005c): „Zur Genealogie der Ethik: Ein Überblick über die laufende Arbeit. [1984]“, in: ders. (Hg.): Schriften: In vier Bänden. Bd. 4: 1980-1988, S. 747-776.

- (2006): Sicherheit, Territorium, Bevölkerung. Geschichte der Gouvernementalität I. Vorlesung am Collège de France 1977-1978. Frankfurt am Main: Suhrkamp. 
- (2007): Die Ordnung des Diskurses. Inauguralvorlesung am Collège de France, 2. Dezember 1970. Mit einem Essay von Ralf Konersmann. 10. Aufl. Frankfurt am Main: Fischer.

- (2009a): Die Geburt der Biopolitik. Geschichte der Gouvernementalität II. Vorlesung am Collège de France 1978-1979. 2. Aufl. Frankfurt am Main: Suhrkamp.

— (2009b): Überwachen und Strafen. Die Geburt des Gefängnisses. 17. Aufl. Frankfurt am Main: Suhrkamp.

Foukles, Albert (1965): „Ernst Fuchs und die Freirechtslehre. Ein Lebensbild“, in: Fuchs, Ernst; Foukles, Albert; Kaufmann, Arthur (Hg.): Gerechtigkeitswissenschaft. Ausgewählte Schriften zur Freirechtslehre. Karlsruhe: Müller, S. 225-257.

- (1968): „Gustav Radbruch in den ersten Jahrzehnten der Freirechtsbewegung“, in: Kaufmann, Arthur (Hg.): Gedächtnisschrift für Gustav Radbruch. 21.11.1878 23.11.1949. Göttingen: Vandenhoeck \& Ruprecht, S. 231-241.

Fraenkel, Ernst (1927): Zur Soziologie der Klassenjustiz. Berlin: E. Laubsche Verlagsbuchhandlung.

Frank, Jerome (1973): Courts on trial. Myth and reality in American justice. 3. Aufl. Princeton, N. J.: Princeton University Press.

Freund, Julius (1965): „Introduction“, in: Weber, Max (Hg.): Essais sur la théorie de la science. Recueil d'articles publiés entre 1904 et 1917 traduits de l'Allemand et introduits par Julien Freund. Paris: Plon, S. 9-116.

Freyer, Hans (1930): Soziologie als Wirklichkeitswissenschaft. Logische Grundlegung des Systems der Soziologie. Leipzig, Berlin: B. G. Teubner.

- (1936): „Ferdinand Tönnies und seine Stellung in der deutschen Soziologie“, in: Weltwirtschaftliches Archiv 44, S. 1-9.

Friedrich, Rainer (2002): „Emil Lasks 'Rechtsphilosophie'“, in: Lask, Emil; Friedrich, R. (Hg.): Fichtes Idealismus und die Geschichte. Kleine Schriften. Jena: Scheglmann, S. 347-353.

Friesen, Heinrich Freiherr von (1900): Die Familien-Anwartschaften in ibrer geschichtlichen Entwicklung und volkswirtschaftlichen Bedeutung. Dresden: Zahn \& Jaensch.

Fuchs, Ernst (1907a): „Philologische und soziologische Rechtsprechung“, in: Monatsschrift für Handelsrecht und Bankwesen, Steuer und Stempelfragen 16 (8), S. 181-211.

- (1907b): Schreibjustiz und Richterkönigtum. Ein Mahnruf zur Schul- und Justizreform. Leipzig: Teutonia.

- (1909a): Die Gemeinschädlichkeit der konstruktiven Jurisprudenz. Karlsruhe: Braun.

— (1909b): „Konstruktionsjustiz oder Interessenjustiz?“”, in: Württembergische Zeitschrift fuer Rechtspflege und Verwaltung 2 (1), S. 1-10.

- (1910a): „Das Difformitätsprinzip und die soziologische Rechtslehre“, in: Juristische Wochenschrift: Organ des Deutschen Anwaltvereins 39, S. 53-55.

- (1910b): „Die soziologische Rechtslehre. Eine Erwiderung“, in: Deutsche JuristenZeitung 15 (5), Sp. 283-288.

- (1910c): „Freirechtlerei und soziologische Rechtslehre“, in: Deutsche Richterzeitung 2 (8), Sp. 303-310; Sp. 345-353; Sp. 389-391. 
- (1912): Juristischer Kulturkampf. Karlsruhe: Braun.

- (1918): „Jhering und die Freirechtsbewegung (Glossen zu Jherings 100. Geburtstag)“, in: Archiv für Rechts- und Wirtschaftsphilosophie 12 (1), S. 10-23.

- (1920): „Gerechtigkeitswissenschaft“, in: Juristische Wochenschrift: Organ des Deutschen Anwaltvereins 49, S. 6-10.

- (1923/24): „Von scholastischer Jurisprudenz zu erfahrungswissenschaftlicher Rechtskunst“, in: Die Tat 15 (1), S. 98-114.

- (1965a): „Bovigus, Bovigismus und echte Rechtswissenschaft [1916]“, in: ders.; Foukles, Albert S.; Kaufmann, Arthur (Hg.): Gerechtigkeitswissenschaft. Ausgewählte Schriften zur Freirechtslehre. Karlsruhe: Müller, S. 169-179.

— (1965b): „Jurisprudenz und Rechtssicherheit [1927/28]“, in: ders. et. al. (Hg.): Gerechtigkeitswissenschaft. Ausgewählte Schriften zur Freirechtslehre. Karlsruhe: Müller, S. 193-206.

— (1965c): „Recht und Wahrheit in unserer heutigen Justiz [1908]“, in: ders. et. al. (Hg.): Gerechtigkeitswissenschaft. Ausgewählte Schriften zur Freirechtslehre. Karlsruhe: Müller, S. 65-165.

— (1976): „Begriffsjurisprudenz und soziologische Rechtsfindung [1910]“, in: Krawietz, Werner (Hg.): Theorie und Technik der Begriffsjurisprudenz. Darmstadt: Wissenschaftliche Buchgesellschaft, S. 185-190.

Fuld, Ludwig (1889): „Der Entwurf eines bürgerlichen Gesetzbuches“, in: Die Gegenwart: Zeitschrift für Literatur, Wirtschaftsleben und Kunst 35, S. 402-404.

- (1891): „Das bürgerliche Gesetzbuch und die Sozialpolitik“, in: Beiträge zur Erläuterung des deutschen Rechts 35, S. 635-657.

- (1900): „Die Frauen und das Bürgerliche Gesetzbuch“, in: Zeitschrift für Sozialwissenschaft 3, S. 256-262.

Gagnér, Sten (1960): Studien zur Ideengeschichte der Gesetzgebung. Stockholm [u.a.]: Almqvist \& Wiksell.

- (1975): „Zielsetzung und Werkgestaltung in Paul Roths Wissenschaft“, in: ders.; Schlosser, Hans; Wiegand, Wolfgang (Hg.): Festschrift für Hermann Krause. Köln [u.a.]: Böhlau, S. 276-450.

Gängel, Andreas; Mollnau, Karl A. (Hg./ 1992): Gesetzesbindung und Richterfreiheit. Texte zur Methodendebatte 1900 - 1914. Freiburg (Breisgau), Berlin: Haufe.

Gängel, Andreas; Schaumburg, Michael (1989): „Josef Kohler Rechtsgelehrter und Rechtslehrer an der Berliner Alma mater um die Jahrhundertwende“, in: ARSP: Archiv für Rechts- und Sozialphilosophie 75 (3), S. 289-312.

Gans, Eduard (1824): Das Erbrecht in weltgeschichtlicher Entwickelung. Eine Abhandlung der Universalrechtsgeschichte. Erster Band: Das Römische Erbrecht in seiner Stellung zu vor- und nachrömischem. Berlin: Maurer.

- (1827a): „Rezension: Geschichte des römischen Rechts im Mittelalter; von Friedrich Carl von Savigny“, in: Jabrbücher für wissenschaftliche Kritik (41-42), S. 323-344.

- (1827b): System des Römischen Civilrechts im Grundrisse nebst einer Abhandlung über Studiums und System des römischen Rechts. Berlin: Ferdinand Dümmler. 
Gedächtnisheft für Franz von Liszt. Zur 50. Wiederkehr seines Todestages am 21. Juni 1919 (1969). Zeitschrift für die gesamte Strafrechtswissenschaft 81 (3).

Gehring, Petra (2000): „Epistemologie? Archäologie? Genealogie? - Foucault und das Recht", in: Internationale Zeitschrift für Philosophie (1), S. 18-33.

- (2004): Foucault - Die Philosophie im Archiv. Frankfurt am Main, New York, NY: Campus.

- (2005/2006): Recht und Macht 2: Ewald und Derrida. Rechtsphilosophie, Vorlesung im Wintersemester 2005/2006. https://openlearnware.de/resource/433 (zuletzt geprüft am 16.01.2019).

- (2007): „Foucaults 'juridischer' Machttyp, die Geschichte der Gouvernementalität und die Frage nach Foucaults Rechtstheorie“, in: Krasmann, Susanne; Volkmer, Michael (Hg.): Michel Foucaults "Geschichte der Gouvernementalität" in den Sozialwissenschaften. Internationale Beiträge. Bielefeld: Transcript, S. 157-179.

Geib, Gustav (1848): Die Reform des deutschen Rechtslebens. Leipzig: Weidmann'sche Buchhandlung.

Geißler, Rainer; Marißen, Norbert (1988): „Junge Frauen und Männer vor Gericht. Geschlechtsspezifische Kriminalität und Kriminalisierung“, in: Kölner Zeitschrift für Soziologie und Sozialpsychology 40, S. 505-526.

Gella, Aleksaner (1977): „An Unrecognized Social Theorist: Petražycki“, in: The Polish Review 22 (2), S. 76-79.

Gény, François (1954): Méthode d'interprétation et sources en droit privé positif [1899]. Tome 2: Essai critique. 2. Aufl. Paris: Libr. Générale de Droit et de Jurisprudence.

Gephart, Werner (1990): „Juristische Ursprünge in der Begriffswelt Max Webers oder wie man den juristischen Ausdrücken einen soziologischen Sinn unterschiebt“, in: Rechtshistorisches Journal 9, S. 343-362.

- (1993a): Gesellschaftstheorie und Recht. Das Recht im soziologischen Diskurs der Moderne. Frankfurt am Main: Suhrkamp.

— (1993b): „Max Weber als Philosoph? Philosophische Grundlagen und Bezüge Max Webers im Spiegel neuer Studien und Materialien. Rezensionsessay“, in: Philosophische Rundschau 40 (1/2), S. 34-56.

- (2001): „Juridische Grundlagen der Herrschaftslehre Max Webers“, in: Hanke, Edith; Mommsen, Wolfgang J. (Hg.): Max Webers Herrschaftssoziologie. Studien zu Entstehung und Wirkung. Tübingen: Mohr Siebeck, S. 73-98.

- (2003): „Das Collagenwerk. Zur so genannten 'Rechtssoziologie' Max Webers“, in: Rechtsgeschichte - Legal History 2003 (3), S. 111-127.

- (2010): „Einleitung“, in: ders.; Hermes, Siegfried; (Hg.): Max Weber Gesamtausgabe: Wirtschaft und Gesellschaft. Die Wirtschaft und die gesellschaftlichen Ordnungen und Mächte. Nachlaß. Teilband 3: Recht. Tübingen: Mohr Siebeck, S. 1-133.

Gephart, Werner; Hermes, Siegfried (2014): „Nachwort“, in: dies. (Hg.): Studienausgabe der Max Weber-Gesamtausgabe Band I/22,3: Wirtschaft und Gesellschaft. Die Wirtschaft und die gesellschaftlichen Ordnungen und Mächte: Teilband 3: Recht. Tübingen: Mohr Siebeck, S. 167-244. 
- (Hg./ 2010): Max Weber Gesamtausgabe: Wirtschaft und Gesellschaft. Die Wirtschaft und die gesellschaftlichen Ordnungen und Mächte. Nachlaß. Teilband 3: Recht. Tübingen: Mohr.

Gerhardt, Uta (2009): Soziologie im zwanzigsten Jahrhundert. Studien zu ihrer Geschichte in Deutschland. Stuttgart: Steiner.

Gertenbach, Lars; Moebius, Stephan (2008): „Kritische Totalität oder das Ende der Gesellschaft? Zum Gesellschaftsbegriff des Poststrukturalismus“, in: Rehberg, Karl-Siegbert (Hg.): Die Natur der Gesellschaft. Verhandlungen des 33. Kongresses der Deutschen Gesellschaft für Soziologie in Kassel 2006. Frankfurt am Main, New York, NY: Campus, S. 4130.

Geyer, Peter (1998): Das Verbältnis von Gesetzes- und Gewohnheitsrecht in den privatrechtlichen Kodifikationen. Göttingen: Univ., Diss.

Gierke, Otto (1883): Naturrecht und deutsches Recht. Rede zum Antritt des Rektorats der Universität Breslau am 15. Oktober 1882 gehalten. Frankfurt am Main: Rütten \& Loening.

- (1868-1913): Das deutsche Genossenschaftsrecht. Berlin: Weidmann.

- (1887): Die Genossenschaftstheorie und die deutsche Rechtsprechung. Berlin: Weidmann.

- (1889a): Der Entwurf eines bürgerlichen Gesetzbuchs und das deutsche Recht. Leipzig: Duncker \& Humblot.

- (1889b): Die Soziale Aufgabe des Privatrechts. Vortrag gehalten am 5. April 1889 in der juristischen Gesellschaft zu Wien. Berlin: Julius Springer.

- (1895): Deutsches Privatrecht. Band 1. Leipzig: Duncker \& Humblot.

- (1896): Das Bürgerliche Gesetzbuch und der Deutsche Reichstag. Berlin: Heymann.

- (1902): Das Wesen der menschlichen Verbände. Rede, bei Antritt des Rektorats am 15. Oktober 1902. Leipzig: Duncker \& Humblot.

- (1963): Recht und Sittlichkeit [1917]. Sonderausg. Darmstadt: Wissenschaftliche Buchgesellschaft.

- (1973): Die historische Rechtsschule und die Germanisten. Rede zur Gedächtnisfeier d. Stifters d. Berliner Univ. König Friedrich Wilhelm III in d. Aula derselben am 3. Aug. 1903 gehalten. Nachdr. der Ausg. Berlin 1903. Aalen: Scientia.

Gipper, Andreas; Schultheis, Franz (1995): „Einleitung. Emile Durkheim und Deutschland: Eine ambivalente Wahlverwandtschaft“, in: Durkheim, Émile; Schultheis, Franz; Gipper, Andreas (Hg.): Über Deutschland. Texte aus den Jahren 1887 bis 1915. Konstanz: UVK, S. 7-25.

Gläser, Mathias (1996): Lehre und Rechtsprechung im französischen Zivilrecht des 19. Jahrbunderts. Frankfurt am Main: Klostermann.

Glatzer, Wolfgang (2014): Deutsche Gesellschaft für Soziologie (DGS): Die akademische soziologische Vereinigung seit 1909. DGS. http://www.soziologie.de/de/ die-dgs/geschichte.html (zuletzt geprüft am 16.01.2019).

Gmelin, Johann Georg (1910a): „Die soziologische Methode in der Rechtsprechung“, in: ders. (Hg.): Quousque? Beiträge zur soziologischen Rechtsfindung. Hannover: Helwing, S. 33-83. 
- (1910b): „Die soziologische Methode in der Rechtsprechung“, in: Württembergische Zeitschrift für Rechtspflege und Verwaltung 3 (1), S. 1-6.

- (1910c): „Kritik der Schrift: Recht und Wahrheit in unserer heutigen Justiz von Ernst Fuchs [1908]“, in: ders. (Hg.): Quousque? Beiträge zur soziologischen Rechtsfindung. Hannover: Helwing, S. 1-6.

— (Hg./ 1910d): Quousque? Beiträge zur soziologischen Rechtsfindung. Hannover: Helwing.

— (1910e): „Über die Kunst der Rechtsprechung [1909]“, in: ders. (Hg.): Quousque? Beiträge zur soziologischen Rechtsfindung. Hannover: Helwing, S. 7-22.

— (1992): „Zur Kritik der Rechtsprechung [1910]“, in: Gängel, Andreas; Mollnau, Karl A. (Hg.): Gesetzesbindung und Richterfreiheit. Texte zur Methodendebatte 1900 - 1914. Freiburg (Breisgau), Berlin: Haufe, S. 142-145.

Gofman, Alexandre (1997): „La réception russe des Règles“, in: Cuin, Charles-Henry (Hg.): Durkheim d'un siècle à l'autre. Lectures actuelles des Règles de la méthode sociologique. Paris: Presses universitaires de France, S. 81-101.

Golder, Ben; Fitzpatrick, Peter (2009): Foucault's Law. London: Routledge-Cavendish.

Goldschmidt (1865): „Savigny“, in: Bluntschli, J. C.; Brater, K. (Hg.): Deutsches Staats-Wörterbuch. Neunter Band. Stuttgart u. Leipzig, S. 98-109.

Goldschmidt, Ludwig (1889): Kritische Erörterungen zum Entwurf eines Bürgerlichen Gesetzbuchs für das Deutsche Reich. Erstes Heft: Die formalen Mängel des Entwurfs. Leipzig: Duncker \& Humblot.

- (1890a): „Civilistische Rundschau: Alois Heilinger, Recht und Macht. 1890. Wien, Manzsche k. und. k. Hof-, Verlags- und Universitäts-Buchhandlung“, in: Archiv für bürgerliches Recht 4, S. 185-187.

- (1890b): „Civilistische Rundschau: Ernst Immanuel Bekker, System des heutigen Pandektenrechts. Erster Band 1886. Zweiter Band 1889. Weimar, Hermann Böhlau“, in: Archiv für bürgerliches Recht 4, S. 187-188.

Gönner, Nicolaus Thaddäus (1815): Über Gesetzgebung und Rechtswissenschaft in unserer Zeit. Erlangen: Johann Jacob Palm.

Graf, Dieter (1988): Im Namen der Republik. Rechtsalltag in der DDR. München: Herbig.

Grimm, Jacob (1966): „Über die wechselseitigen Beziehungen und die Verbindung der drei in der Versammlung vertretenen Wissenschaften [1846]“, in: ders. (Hg.): Kleinere Schriften: Band 7. Recensionen und vermischte Aufsätze: 4. Teil. Hildesheim: Olms, S. 556-563.

Gross, Matthias (2001): Die Natur der Gesellschaft. Eine Geschichte der Umweltsoziologie. Weinheim, München: Juventa.

Gruber, Malte-Christian (2014): Legal subjects and partial legal subjects in electronic commerce. Frankfurt am Main: Univ.-Bibliothek Frankfurt am Main.

Grünfeld, Ernst (1908): Die Gesellschaftslehre von Lorenz von Stein. Halle: Kaemmerer \& Co.

- (1910): Lorenz von Stein und die Gesellschaftslehre. Jena: Gustav Fischer. 
Gülich, Christian (1991): Die Durkheim-Schule und der französische Solidarismus. Wiesbaden: Deutscher Universitätsverlag.

Gumplowicz, Ludwig (1885): Grundriß der Sociologie. Wien: Manz.

Gutachten der Vorkommission vom 15.4.1874 (1978), in: Schubert, Werner (Hg.): Materialien zur Entstehungsgeschichte des BGB. Einführung, Biographien, Materialien. Berlin, New York: de Gruyter, S. 170-185.

Habermas, Jürgen (1992a): Faktizität und Geltung. Beiträge zur Diskurstheorie des Rechts und des demokratischen Rechtsstaats. Frankfurt am Main: Suhrkamp.

— (1992b): „Soziologie in der Weimarer Republik“, in: Coing, Helmut et al. (Hg.): Wissenschaftsgeschichte seit 1900. 75 Jahre Universität Frankfurt. Frankfurt am Main: Suhrkamp, S. 29-53.

Hacking, Ian (1990): The Taming of Chance. Cambridge [U.K.], New York: Cambridge University Press.

Haferkamp, Hans-Peter (2003): Recht als System bei Georg Friedrich Puchta. forum historiae iuris. http://www.forhistiur.de/2003-11-haferkamp/ (zuletzt geprüft am 16.01.2019).

- (2004): Georg Friedrich Puchta und die "Begriffsjurisprudenz". Frankfurt am Main: Klostermann.

- (2005): „Der Jurist, das Recht und das Leben“, in: Verein zur Förderung der Rechtswissenschaft (Hg.): Fakultätsspiegel Sommersemester 2005. Köln, S. 83-98.

— (2007a): „Die Bedeutung von Rezeptionsdeutungen für die Rechtsquellenlehre zwischen 1800 und 1850“, in: ders.; Repgen, Tilman (Hg.): Usus modernus pandectarum. Römisches Recht, Deutsches Recht und Naturrecht in der Frühen Neuzeit. Klaus Luig zum 70. Geburtstag. Köln [u.a.]: Böhlau, S. 25-44.

— (2007b): „Neukantianismus und Rechtsnaturalismus“, in: Senn, Marcel; Puskás, Dániel (Hg.): Rechtswissenschaft als Kulturwissenschaft? Kongress der Schweizerischen Vereinigung für Rechts- und Sozialphilosophie, 15. und 16. Juni 2007, Universität Zürich. Stuttgart: Steiner, S. 105-120.

- (2008): „Die Bedeutung der Willensfreiheit für die Historische Rechtsschule“, in: Lampe, Ernst-Joachim; Pauen, Michael; Roth, Gerhard (Hg.): Willensfreiheit und rechtliche Ordnung. Frankfurt am Main: Suhrkamp, S. 196-225.

— (2009a): „Bürgerliches Gesetzbuch“, in: Basedow, Jürgen; Hopt, Klaus J.; Zimmermann, Reinhard (Hg.): Handwörterbuch des Europäischen Privatrechts. Band I: Abschlussprüfer - Kartellverfahren. Tübingen: Mohr Siebeck, S. 229-233.

- (2009b): „Einflüsse der Erweckungsbewegung auf die 'historisch-christliche' Rechtsschule zwischen 1815 und 1848“, in: Cancik, Pascale et al. (Hg.): Konfession im Recht. Auf der Suche nach konfessionell geprägten Denkmustern und Argumentationsstartegien in Recht und Rechtswissenschaft des 19. und 20. Jahrhunderts. Frankfurt am Main: Klostermann, S. 71-93.

- (2010): „Die sogenannte Begriffsjurisprudenz im 19. Jahrhunderts - 'reines' Recht?", in: Depenheuer, Otto (Hg.): Die Reinheit des Rechts. Kategorisches Prinzip oder regulative Idee? Wiesbaden: VS Verlag für Sozialwissenschaften, S. 79-99. 
- (2011a): Begriffsjurisprudenz. Enzyklopädie zur Rechtsphilosophie. IVR (Deutsche Sektion) und Deutsche Gesellschaft für Philosophie. http://www.enzyklopaedie-recht sphilosophie.net/inhaltsverzeichnis/19-beitraege/96-begriffsjurisprudenz (zuletzt geprüft am 23.03.2017).

— (2011b): „Rechtsgeschichte und Evolutionstheorie“, in: Siep, Ludwig (Hg.): Evolution und Kultur. Symposium der Nordrhein-Westfälischen Akademie der Wissenschaften und der Künste 2009. Paderborn [u.a.]: Schöningh, S. 35-60.

— (2011c): „Dogmatisierungsprozesse im 'heutigen Römischen Recht' des 19. Jahrhunderts“, in: Essen, Georg; Jansen, Nils (Hg.): Dogmatisierungsprozesse in Recht und Religion. Tübingen: Mohr Siebeck, S. 259-276.

- (2011d): „Lebensbezüge in der Zivilrechtsdogmatik des 19. und 20. Jahrhunderts“, in: Breneselović, Luka (Hg.): Gedächtnisschrift für Valtazar Bogišić. Zur 100. Wiederkehr seines Todestages. Band 1. Belgrad: Sluzbeni \& Institute of Comparative Law, S. 301-313.

- (2011e): „'Needs' - Pandectists between Norm and Reality“, in: Morigiwa, Yasutomo; Stolleis, Michael; Halperin, Jean-Louis (Hg.): Interpretation of Law in the Age of Enlightenment. Dordrecht [u.a.]: Springer, S. 107-121.

- (2011f): „Pandektistik und Gerichtspraxis“, in: Quaderni Fiorentini per la storia del pensiero giuridico moderno 40, S. 177-211.

- (2012): „Methode und Rechtslehre bei Georg Friedrich Puchta (1798-1846)“, in: Rückert, Joachim; Seinecke, Ralf (Hg.): Methodik des Zivilrechts - von Savigny bis Teubner. 2. Aufl. Baden-Baden: Nomos, S. 73-96.

Haff, Karl (1924): „Die Bedeutung der Rechtspsychologie für die moderne Rechtsfindung“, in: Archiv für Rechts- und Wirtschaftsphilosophie 18 (2), S. 133-142.

Hahn, Friedrich (1913/1914): „Eine Soziologie des Rechts“, in: Der Kampf. Sozialdemokratische Monatsschrift 7, S. 401-407; 527-529.

Halpérin, Jean-Louis (2017): „Durkheim et la culture juridique de son temps“, in: Gephart, Werner; Witte, Daniel (Hg.): The Sacred and the Law. The Durkheimian Legacy. Frankfurt am Main: Klostermann, S. 73-92.

Hannover, Heinrich; Hannover-Drück, Elisabeth (1987): Politische Justiz. 1918-1933. Bornheim-Merton: Lamuv.

Hansel, Rüdiger (2006): Jurisprudenz und Nationalökonomie. Die Beratungen des BGB im Königlich Preussischen-Landes-Ökonomie-Kollegium 1889. Köln [u.a.]: Böhlau.

Hart, H. L. A. (1967): „Social Solidarity and the Enforcement of Morality“, in: The University of Chicago Law Review 35 (1), S. 1-13.

Hartmann, Bernhard (1890): „Der Entwurf des Einführungsgesetzes“, in: Adams et al. (Hg.): Gutachten aus dem Anwaltsstande über die Lesung des Entwurfes eines bürgerlichen Gesetzbuchs. Herausgegeben im Auftrag des Deutschen Anwaltsvereins von den Rechtanwälten Adams, Wilke, Mecke, Hartmann und Erythropel. Berlin: Moeser, S. 1227-1272.

Hartmann, Gustav (1888): „Der Civilgesetzentwurf, das Aequitätsprincip und die Richterstellung“, in: Archiv für die civilistische Praxis 73 (3), S. 309-407.

Haßlinger, Nikolas (2014): Max von Rümelin (1861-1931) und die juristische Methode. Tübingen: Mohr Siebeck. 
Hattenhauer, Hans (2004): „Das BGB in der Zeitung“, in: Häuser, Franz; Hammen, Horst; u.a (Hg.): Festschrift für Walther Hadding zum 70. Geburtstag am 8. Mai 2004. Berlin: de Gruyter, S. 57-79.

Heck, Philipp (1905): „Interessenjurisprudenz und Gesetzestreue“, in: Deutsche Juristen-Zeitung 10 (24), Sp. 1140-1142.

— (1909): „Was ist diejenige Begriffsjurisprudenz, die wie bekämpfen?“, in: Deutsche Juristen-Zeitung 14, Sp. 1457-1461.

- (1912): Das Problem der Rechtsgewinnung. Tübingen: Mohr.

- (1914): „Gesetzesauslegung und Interessenjurisprudenz“, in: Archiv für die civilistische Praxis 112 (1), S. 1-318.

- (1917): „Rezension: Ernst Fuchs, Juristischer Kulturkampf“, in: Juristische Wochenschrift: Organ des Deutschen Anwaltvereins 46, S. 270-273.

- (1924): „Die reine Rechtslehre und die jungösterreichische Schule der Rechtswissenschaft“, in: Archiv für die civilistische Praxis 122 (2), S. 173-194.

— (1925): „Rezension: Julius Ofner, Das soziale Rechtsdenken“, in: Archiv für die civilistische Praxis 123 (3), S. 380-381.

- (1929): „Rezension: Ernst Schwind, Grundlagen und Grundfragen des Rechts“, in: Archiv für die civilistische Praxis 131 (1/2), S. 207-210.

- (1932a): Begriffsbildung und Interessenjurisprudenz. Tübingen: Mohr.

- (1932b): „Rezension: Arnold Gysin, Recht und Kultur auf dem Grunde der Ethik“, in: Archiv für die civilistische Praxis 136 (2), S. 236.

- (1933): Interessenjurisprudenz. Gastvorlesung an der Universität Frankfurt a.M., gebalten am 15. Dezember 1932. Tübingen: Mohr.

— (1974): „Begriffsjurisprudenz und Interessenjurisprudenz [1929]“, in: Ellscheid, Günter; Hassemer, Winfried (Hg.): Interessenjurisprudenz. Darmstadt: Wissenschaftliche Buchgesellschaft, S. 88-108.

Hedemann, Justus Wilhelm (1908): „Zivilistische Rundschau 1906-1907“, in: Archiv für bürgerliches Recht 31, S. 287-438.

- (1910): „Zivilistische Rundschau 1908-1909“, in: Archiv für bürgerliches Recht 34, S. 115-208.

Hegel, Georg Wilhelm Friedrich (1996): Grundlinien der Philosophie des Rechts oder Naturrecht und Staatswissenschaft im Grundrisse. Mit Hegels eigenhändigen Notizen und mündlichen Zusätzen. 5. Aufl. Frankfurt am Main: Suhrkamp.

Heilinger, Alois (1890): Recht und Macht. Das Prinzip der vier Elemente der Gesellschaft. Wien: Manz.

Heine, Heinrich (1913): "Zeitgedichte XVIII: Die Menge tut es“, in: ders. et al. (Hg.): Heinrich Heines sämtliche Werke. Dritter Band. Leipzig: Insel, S. 381-384.

Heine, Steffi (2004): Die Methodendiskussion nach Inkrafttreten des Bürgerlichen Gesetzbuches und die Gründung des Vereins Recht und Wirtschaft. Frankfurt am Main [u.a.]: Peter Lang.

Hejl, Peter M. (1998): Protosoziologie. Wissenschaftliches Selbstverständnis und Beziehungen zur Biologie der deutschsprachigen Soziologie bis 1914. Siegen: Lumis. 
Helfer, Christian (1968): „Rudolf von Jhering als Rechtssoziologe. Eine Erinnerung zum 150. Geburtstag“, in: Kölner Zeitschrift für Soziologie und Sozialpsychologie; KfZSS 20 (3), S. 553-571.

- (1970): "Jherings Gesellschaftsanalyse im Urteil der heutigen Sozialwissenschaft", in: Wieacker, Franz; Wollschläger, Christian (Hg.): Jherings Erbe. Göttinger Symposion zur 150. Wiederkehr des Geburtstags von Rudolf von Jhering. Göttingen: Vandenhoeck \& Ruprecht, S. 79-88.

Henkel, Thomas (2004): Begriffsjurisprudenz und Billigkeit. Zum Rechtsformalismus der Pandektistik nach G.F. Puchta. Köln [u.a.]: Böhlau.

Henne, Thomas; Kretschmann, Carsten (1999): „Ein Mythos der Richterrechtsdiskussion: Oskar Bülow 'Gesetz und Richteramt' (1885)“, in: Ius Commune - Zeitschrift für Europäische Rechtsgeschichte 26, S. 211-237.

Henning, Johann (1936): „'Vom Beruf unserer Zeit' und 'Geschichte des römischen Rechts im Mittelalter', ihre Entstehung und ihr Verhältnis zueinander; mit einem unbekannten Brief Savignys an Zimmer", in: Zeitschrift für Rechtsgeschichte, Germanistische Abteilung 56, S. 394-398.

Hennis, Wilhelm (1982): „Max Webers Fragestellung“, in: Zeitschrift für Politik 29 (3), S. 241-281.

- (Hg./ 1987): Max Webers Fragestellung. Studien zur Biographie des Werks. Tübingen: Mohr.

Henrich, Dieter (1952): Die Einheit der Wissenschaftslehre Max Webers. Tübingen: Mohr.

Hermes, Siegfried (2006): „Der Staat als 'Anstalt'. Max Webers soziologische Begriffsbildung im Kontext der Rechts- und Staatswissenschaften“, in: Lichtblau, Klaus (Hg.): Max Webers "Grundbegriffe". Kategorien der kultur- und sozialwissenschaftlichen Forschung. Wiesbaden: VS Verlag für Sozialwissenschaften, S. 184216.

— (2007): „Vom Aufbau der sozialen Welt. Zur Genese, Genealogie und Kategorienlehre von Max Webers Soziologie des Rechts“, in: Rechtstheorie 38 (4), S. 419449.

- (2010): „Editorischer Gesamtbericht“, in: Gephart, Werner; Hermes, Siegfried (Hg.): Max Weber Gesamtausgabe: Wirtschaft und Gesellschaft. Die Wirtschaft und die gesellschaftlichen Ordnungen und Mächte. Nachlaß. Teilband 3: Recht. Tübingen: Mohr Siebeck, 135-173.

Hertling, Georg von (Hg./ 1897): Kleine Schriften zur Zeitgeschichte und Politik. Freiburg (Breisgau): Herder.

Hertogh, Marc L. M. (Hg./ 2009): Living law. Reconsidering Eugen Ehrlich. Oxford: Hart.

Heusler, A. (1890): „Zum Entwurfe eines bürgerlichen Gesetzbuchs für das Deutsche Reich. Otto Gierke, der Entwurf eines bürgerlichen Gesetzbuchs und das deutsche Recht. Veränderte und vermehrte Ausgabe der in Schmoller's Jahrbuch für Gesetzgebung, Verwaltung und Volkswirthschaft erschienenen Abhandlung. Leipzig, Duncker \& Humblot. 1889. XX und 592 S.“, in: Kritische Vierteljahresschrift für Gesetzgebung und Rechtswissenschaft 32, S. 177-187. 
Heuß, Alfred (1968): Zur Theorie der Weltgeschichte. Berlin: de Gruyter.

Hildebrand, Bruno (1848): Die Nationalökonomie der Gegenwart und Zukunft. Erster Band. Frankfurt am Main: Literarische Anstalt (J. Rütten).

Hippel, Ernst von (1951): „Rudolf von Jhering als Begründer des Rechtspositivismus“, in: Neues Abendland 6, S. 322-326.

Hirsch, Ernst Eduard (1984): „Jhering als Reformator des Rechtsunterrichts (Die Jurisprudenz des täglichen Lebens)“, in: ders. (Hg.): Rechtssoziologie für Juristen. Eine Aufsatzsammlung. Berlin: Duncker \& Humblot, S. 54-67.

Hofer, Sibylle (1999): „Haarspalten, Wortklauben, Silbenstechen? 100 Jahre Lehrbücher zum BGB - eine Lebensbilanz", in: JuS 39 (2), S. 112-117.

- (2000): „Jurisprudence, History, National Economics after 1850“, in: Koslowski, Peter (Hg.): The theory of Capitalism in the German Economic Tradition. Historism, Ordo-Liberalism, Critical Theory, Solidarism. Berlin: Springer, S. 467-505.

- (2001): Freiheit ohne Grenzen? Privatrechtstheoretische Diskussionen im 19. Jahrhundert. Tübingen: Mohr Siebeck.

Hölder, Eduard (1888): „Zum allgemeinen Theile des Entwurfes eines deutschen bürgerlichen Gesetzbuches für das Deutsche Reich“, in: Archiv für die civilistische Praxis 73, S. 1-160.

- (1889): Ueber den Entwurf eines deutschen bürgerlichen Gesetzbuches. Vortrag geh. am 20 März 1889 i. d. jurist. Ges. zu Wien. Erlangen [u.a.]: Deichert.

- (1892): „Zur Besitzlehre“, in: Kritische Vierteljahresschrift für Gesetzgebung und Rechtswissenschaft 34, S. 219-256.

Homeyer, Carl Gustav (1828): „Nachweisung der Recensionen und Anzeigen in anderen Zeitschriften: In den Jahrbüchern für wissenschaftliche Kritik. Nr. 164-167. Sp. 1305-1335. Grundsätze des deutschen Privatrechts nach dem Sachsenspiegel, mit Berücksichtigung und Vergleichung des Schwabenspiegels, vermehrten Sachsenspiegels und sächs. Wichbildes, von Jul. Weiske, Leipzig 1826. 8.; Der Sachsenspiegel oder das sächs. Landrecht, nach der berl. Handschrift v. J. 1369, mit Varianten aus 17. anderen Texten. herausgeg. von Dr. C. G. Homeyer. Berlin 1827. 8.“, in: Jahrbücher der gesammten deutschen juristischen Literatur 7 (2), S. 233-238.

Huber, Eugen (1921): Recht und Rechtsverwirklichung: Probleme der Gesetzgebung und der Rechtsphilosophie. Basel: Helbing \& Lichtenhahn.

Hubig, Christoph (2000): „'Dispositiv' als Kategorie“, in: Internationale Zeitschrift für Philosophie (1), S. 34-47.

- (2015): Die Kunst des Möglichen III. Grundlinien einer dialektischen Philosophie der Technik. Band 3: Macht der Technik. Bielefeld: Transcript.

Hugo, Gustav (1799): Lehrbuch eines civilistischen Cursus. Zweyter Band, welcher das Naturrecht, als eine Philosophie des positiven Rechts enthält. Zweyter, ganz von neuem ausgearbeiteter Versuch. Berlin: August Mylius.

Hunt, Alan (1992): „Foucault's Expulsion of Law: Toward a Retrieval“, in: Law \& Social Inquiry 17 (1), S. 1-38.

Hunt, Alan; Wickham, Gary (1998): Foucault and Law. Towards a Sociology of Law as Governance. 2. Aufl. London: Pluto Press. 
Hurwicz, Elias (1911): Rudolf von Ihering und die deutsche Rechtswissenschaft. Mit besonderer Berücksichtigung des Strafrechts. Berlin: Guttentag.

Ikadatsu, Yasuhiro (2002): Der Paradigmenwechsel der Privatrechtstheorie und die Neukonstruktion der Vertragstheorie in seinem Rahmen. Pufendorf, Wolff, Kant und Savigny. Ebelsbach: Aktiv Druck \& Verlag.

Isambert, François-A. (2013): „Durkheim: Eine Moralwissenschaft für eine laizistische Moral“, in: Trivium [En ligne] 13, http://journals.openedition.org/trivium/4 474 (zuletzt geprüft am 19.01.2019).

Jacobi, Leonard (1889): Miethe und Pacht. Ihre Stellung in der Kulturgeschichte, im Privatrecht und im Systeme des Entwurfes eines bürgerlichen Gesetzbuches für das Deutsche Reich. Berlin: Heymann.

Jacobsen, Björne (2001): „Hiatus irrationalis. Der Bruch zwischen Sein und Sollen“, in: Riesebrodt, Martin; Kippenberg, Hans G. (Hg.): Max Webers Religionssystematik. Tübingen: Mohr Siebeck, S. 31-50.

Jacoby, E. G. (1971): Die moderne Gesellschaft im sozialwissenschaftlichen Denken von Ferdinand Tönnies. Eine biographische Einführung. Stuttgart: F. Enke.

Jäger, Siegfried (2001): „Diskurs und Wissen. Theoretische und methodische Aspekte einer Kritischen Diskurs- und Dispositivanalyse“, in: Keller, Reiner et al. (Hg.): Handbuch sozialwissenschaftliche Diskursanalyse. Band 1: Theorien und Methoden. Wiesbaden: VS Verlag für Sozialwissenschaften, S. 81-112.

Jakob, Raimund; Rehbinder, Manfred (Hg. /1987): Beiträge zur Rechtspsychologie. Berlin: Duncker \& Humblot.

Jakobs, Horst Heinrich (1983): Wissenschaft und Gesetzgebung im bürgerlichen Recht nach der Rechtsquellenlehre des 19. Jahrhunderts. Paderborn [u.a.]: Schöningh.

- (1991): „P. J. A. Feuerbachs Ansichten über Gesetzgebung und Deutschland überhaupt in sieben Briefen Feuerbachs an Savigny“, in: Zeitschrift für Rechtsgeschichte (Romanistische Abteilung) 108, S. 351-366.

Jellinek, Georg (1878): Die socialethische Bedeutung von Recht, Unrecht und Strafe. Wien: Hölder.

- (1887): Gesetz und Verordnung. Staatsrechtliche Untersuchungen auf rechtsgeschichtlicher und rechtsvergleichender Grundlage. Freiburg: Mohr.

— (1892): System der subjektiven öffentlichen Rechte. Freiburg: Mohr.

— (1900): Allgemeine Staatslehre. Berlin: Haering.

- (1905): Allgemeine Staatslehre. 2. Aufl. Berlin: Haering.

Jerusalem, Franz (1925): Soziologie des Rechts. Jena: Gustav Fischer.

- (1930): Grundzüge der Soziologie. Berlin, Wien: Spaeth \& Linde.

Jhering, Rudolf (1844): „Erste Abhandlung: In wie weit muß der, welcher eine Sache zu leisten hat, den mit ihr gemachten Gewinn herausgeben?“, in: Jhering, Rudolf (Hg.): Abhandlungen aus dem römischen Recht. Leipzig: Breitkopf und Härtel, S. 3-86.

- (1852): Geist des römischen Rechts auf den verschiedenen Stufen seiner Entwicklung. Erster Theil. Leipzig: Breitkopf und Härtel. 
- (1854): Geist des römischen Rechts auf den verschiedenen Stufen seiner Entwicklung. Zweiter Theil. Erste Abtheilung: Breitkopf und Härtel.

- (1857): „Unsere Aufgabe“, in: Jahrbücher für die Dogmatik des heutigen römischen und deutschen Privatrechts 1, S. 1-52.

- (1858): Geist des römischen Rechts auf den verschiedenen Stufen seiner Entwicklung. Zweiter Theil. Zweite Abtheilung. Leipzig: Breitkopf und Härtel.

- (1859): „Beiträge zur Lehre von der Gefahr beim Kaufcontract. I. Ueber den Sinn des Satzes: Der Käufer trägt die Gefahr, mit besonderer Beziehung auf den Fall des mehrfachen Verkaufs", in: Jahrbücher für die Dogmatik des heutigen römischen und deutschen Privatrechts 3, S. 449-488.

- (1861): „Friedrich Karl von Savigny“, in: Jahrbücher für die Dogmatik des heutigen römischen und deutschen Privatrechts 5, S. 354-377.

- (1865): Geist des römischen Rechts auf den verschiedenen Stufen seiner Entwicklung. Dritter Theil. Erste Abtheilung. Leipzig: Breitkopf und Härtel.

- (1873): „Kritisches und Exegetisches Allerlei“, in: Jahrbücher für die Dogmatik des heutigen römischen und deutschen Privatrechts 12, S. 313-398.

- (1877): Der Zweck im Recht. Erster Band. Leipzig: Breitkopf und Härtel.

- (1883): Der Zweck im Recht. Zweiter Band. Leipzig: Breitkopf und Härtel.

— (1884a): Der Zweck im Recht. Erster Band. 2. Aufl. Leipzig: Breitkopf und Härtel.

— (1884b): „Ueber die Entstehung des Rechtsgefühls“, in: (Wiener) Allgemeine Juristische Zeitung 7 (11), $121 \mathrm{ff}$.

- (1886): Der Zweck im Recht. Zweiter Band. 2. Aufl. Leipzig: Breitkopf und Härtel.

- (1888): Geist des römischen Rechts auf den verschiedenen Stufen seiner Entwicklung. Dritter Theil. Erste Abtheilung. 4. Aufl. Leipzig: Breitkopf und Härtel.

- (1889): Der Besitzwille. Zugleich eine Kritik der herrschenden juristischen Methode. Jena: Gustav Fischer.

- (1894): Entwicklungsgeschichte des römischen Rechts. Einleitung - Verfassung des römischen Hauses. Aus dem Nachlaß herausgegeben. Leipzig: Breitkopf und Härtel; Duncker \& Humblot.

- (1970): Der Zweck im Recht. Zweiter Band. Herausgegeben mit einem Vorwort und mit zwei bisher unveröffentlichten Ergänzungen aus dem Nachlaß Jherings versehen von Christian Helfer. Reprografischer Nachdruck der 4. Auflage Leipzig 1905. Hildesheim, New York: Olms.

— (1992): „Der Kampf ums Recht“, in: ders.; Ermacora, Felix (Hg.): Der Kampf um's Recht. Zum hundertsten Todesjahr des Autors. Neudr. nach der 18. Aufl., Wien 1913. Frankfurt am Main: Propyläen, S. 59-151.

— (1998): „Ist die Jurisprudenz eine Wissenschaft? [1868]“, in: ders.; Behrends, Okko (Hg.): Ist die Jurisprudenz eine Wissenschaft? Jherings Wiener Antrittsvorlesung vom 16. Oktober 1868. Göttingen: Wallstein, S. 47-92.

- (2003): Der Kampf ums Recht. Bearbeitet von Alexander Hollerbach. 8. Aufl. Frankfurt am Main: Klostermann. 
— (2009a): „Erster Brief: Einleitung. - Die civilistische Konstruktion [1861]“, in: ders.; Leitner, Max (Hg.): Scherz und Ernst in der Jurisprudenz. Eine Weihnachtsgabe für das juristische Publikum. Wien: Linde International, S. 3-17.

- (2009b): „Zweiter Brief: Die spekulative Methode der Jurisprudenz - Huschke, Lasalle [1861]“, in: ders.; Leitner, Max (Hg.): Scherz und Ernst in der Jurisprudenz, S. 17-34.

- (2009c): „Dritter Brief: Der Eintritt in die Praxis - das Examen - Entscheidungen nach Lehrbüchern [1862]“, in: ders.; Leitner, Max (Hg.): Scherz und Ernst in der Jurisprudenz, S. 35-54.

— (2009d): „Vierter Brief: Fortsetzungen dieser Entscheidungen [1863]“, in: ders.; Leitner, Max (Hg.): Scherz und Ernst in der Jurisprudenz, S. 54-70.

- (2009e): „Fünfter Brief: Die Volkmar'schen Anträge über die Reform des juristischen Studiums und Examens [1863]“, in: ders.; Leitner, Max (Hg.): Scherz und Ernst in der Jurisprudenz, S. 70-96.

— (2009f): „Sechster Brief: Die Literatur - Die äußere Nöthigung zum Schreiben [1866]", in: ders.; Leitner, Max (Hg.): Scherz und Ernst in der Jurisprudenz, S. 97117.

— (2009g): „Im juristischen Begriffshimmel. Ein Phantasiebild [1884]“, in: ders.; Leitner, Max (Hg.): Scherz und Ernst in der Jurisprudenz, S. 247-333.

— (2009h): „Wieder auf Erden. Wie soll es besser werden? [1884]“, in: ders.; Leitner, Max (Hg.): Scherz und Ernst in der Jurisprudenz, S. 337-383.

Jodl, Friedrich (1912): Geschichte der Ethik als philosophischer Wissenschaft. Band II: Kant und die Ethik im 19. Jahrhundert. 2. Aufl. Stuttgart, Berlin: Cotta'sche Buchhandlung Nachfolger.

Jones, Robert Alun (1994a): „Ambivalent Cartesians: Durkheim, Montesquieu, and Method“, in: American Journal of Sociology 100 (1), S. 1-39.

- (1994b): „The Positive Science of Ethics in France: German Influences on 'De la division du travail social' “, in: Sociological Forum 9 (1), S. 37-57.

- (1996): „Durkheim, realism, and Rousseau“, in: Journal of the history of the behavioral sciences 32 (4), S. 330-353.

- (1999): The Development of Durkheim's Social Realism. Cambridge, U.K., New York: Cambridge University Press.

Jung, Erich (1912): Das Problem des natürlichen Rechts. Leipzig: Duncker \& Humblot.

- (1929): „Das sogenannte Gewohnheitsrecht als Grundfrage der Rechtsquellenlehre", in: Archiv für Rechts- und Wirtschaftsphilosophie 22 (2), S. 227-259.

— (1992): „Von der 'logischen Geschlossenheit' des Rechts [1900]“, in: Gängel, Andreas; Mollnau, Karl A. (Hg.): Gesetzesbindung und Richterfreiheit. Texte zur Methodendebatte 1900 - 1914. Freiburg (Breisgau), Berlin: Haufe, S. 7-36.

Kahn, Paul W. (1999): The cultural study of law. Reconstructing legal scholarship. Chicago: University of Chicago Press.

Kallfass, Wilfried (1972): Die Tübinger Schule der Interessenjurisprudenz. Darstellung und Würdigung. Frankfurt am Main: Klostermann. 
Kalthoff, Herbert (2003): „Beobachtende Differenz. Instrumente der ethnografischsoziologischen Forschung“, in: Zeitschrift für Soziologie 32 (1), S. 70-90.

Kamenka, Eugene; Erh-Soon Tay, Alice (1990): „'Gemeinschaft', 'Gesellschaft' and the Nature of Law“, in: Schlüter, Carsten; Clausen, Lars (Hg.): Renaissance der Gemeinschaft? Stabile Theorie und neue Theoreme. Berlin: Duncker \& Humblot, S. 131-152.

Kanigs, Hanskarl (1932): 25 Jahre Freirechtsbewegung. Zur Entwicklung eines Methodenstreits über die Rechtsanwendung. Erlangen: Univ., Diss.

Kant, Immanuel (1975): „Die Metaphysik der Sitten. Metaphysische Anfangsgründe der Rechtslehre (1797/1798)“, in: ders. (Hg.): Werke. Band 4: Kritik der reinen Vernunft. Teil 2. Herausgegeben von Wilhelm Weischedel. Darmstadt: Wissenschaftliche Buchgesellschaft.

Kantorowicz, Hermann U. (1906): Der Kampf um die Rechtswissenschaft. Von Gnaeus Flavius. Heidelberg: Carl Winter's Universitätsbuchhandlung.

- (1909): Zur Lehre vom richtigen Recht. Berlin, Leipzig: Rothschild.

— (1911a): „Rechtswissenschaft und Soziologie“, in: Simmel, Georg (Hg.): Deutscher Soziologentag: Verhandlungen des Deutschen Soziologentages. 19. - 22. Okt. 1910 in Frankfurt a.M.; Reden und Vorträge von Georg Simmel [u.a.] und Debatten. Tübingen: Mohr, S. 275-309.

— (1911b): „Die Contra-legem-Fabel“, in: Deutsche Richterzeitung (8), S. 258-263.

- (1912a): „Volksgeist und historische Rechtsschule“, in: Historische Zeitschrift 108 (2), S. 295-325.

- (1912b): Was ist uns Savigny? Berlin: Heymann.

— (1923): „Der Aufbau der Soziologie“, in: Palyi, Melchior (Hg.): Hauptprobleme der Soziologie. Erinnerungsgabe für Max Weber. I. Band. München, Leipzig: Duncker \& Humblot, S. 73-96.

- (1925): Aus der Vorgeschichte der Freirechtslehre. Mannheim, Berlin, Leipzig: Bensheimer.

- (1970): „Die Epochen der Rechtswissenschaft. aus: Die Tat 6 (1914), 345-361 (Eugen Diedrichs Verlag, Düsseldorf)“, in: Coing, Helmut; Immel, Gerhard (Hg.): Rechtshistorische Schriften. Von Hermann Kantorowicz. Karlsruhe: C. F. Müller, S. 1-14.

— (1992): „Methodenreform und Justizreform [1911]“, in: Gängel, Andreas; Mollnau, Karl A. (Hg.): Gesetzesbindung und Richterfreiheit. Texte zur Methodendebatte 1900 - 1914. Freiburg (Breisgau), Berlin: Haufe, S. 263-274.

Karner, Josef (1904a): „Die soziale Funktion der Rechtsinstitute. [Karl Renner]“, in: Hilferding, Rudolf; Renner, Karl; Adler, Max (Hg.): Marx-Studien 1: Böhm-Bawerks Marx-Kritik / von Rudolf Hilferding. Die soziale Funktion der Rechtsinstitute / von Josef Karner. Kausalität und Teleologie im Streite um die Wissenschaft / von Max Adler. Wien: Brand, S. 63-194.

- (Karl Renner) (1904b): Die soziale Funktion der Rechtsinstitute, besonders des Eigentums. Wien: Brand. 
Karsenti, Bruno (2013): „Das ,Durkheimsche Dilemma' in der Soziologie der Moral“, in: Trivium [En ligne] 13, http://journals.openedition.org/trivium/4447 (zuletzt geprüft am 19.01.2019).

— (2014): „Der Symbolismus bei Durkheim und Mauss“, in: Trivium [En ligne] 17, http://journals.openedition.org/trivium/4933 (zuletzt geprüft am 19.01.2019).

Käsler, Dirk (1984): Die frühe deutsche Soziologie 1909 bis 1934 und ihre EntstehungsMilieus. Eine wissenschaftssoziologische Untersuchung. Opladen: Westdeutscher Verlag.

— (1991): „Erfolg eines Mißverständnisses? Zur Wirkungsgeschichte von 'Gemeinschaft und Gesellschaft' in der frühen deutschen Soziologie“, in: Clausen, Lars; Schlüter, Carsten (Hg.): Hundert Jahre "Gemeinschaft und Gesellschaft". Ferdinand Tönnies in der internationalen Diskussion. Opladen: Leske + Budrich, S. 517-526.

Kaufmann, Dörte (2014): Anton Friedrich Justus Thibaut (1772-1840). Ein Heidelberger Professor zwischen Wissenschaft und Politik. Stuttgart: Kohlhammer.

Kaufmann, Felix (1936): Methodenlehre der Sozialwissenschaften. Wien: Julius Springer.

Keim, Wiebke (2013): „Émile Durkheims Programm einer wissenschaftlichen Soziologie in Deutschland“, in: Bogusz, Tanja; Delitz, Heike (Hg.): Émile Durkheim. Soziologie - Ethnologie - Philosophie. Frankfurt am Main, New York, NY: Campus, S. 48-72.

Keller, Reiner (2011): Diskursforschung. Eine Einführung für SozialwissenschaftlerInnen. 4. Aufl. Wiesbaden: VS Verlag für Sozialwissenschaften.

Kelsen, Hans (1911): Hauptprobleme der Staatsrechtslehre entwickelt aus der Lehre vom Rechtssatze. Tübingen: Mohr.

— (1912): „Zur Soziologie des Rechts. Kritische Betrachtungen“, in: Archiv für Sozialwissenschaft und Sozialpolitik 34, S. 601-614.

- (1916): „Die Rechtswissenschaft als Norm- oder als Kulturwissenschaft: Eine methodische Untersuchung“, in: Schmollers Jahrbuch fuer Gesetzgebung, Verwaltung und Volkswirtschaft im Deutschen Reich 40 (3), S. 95-151.

- (1922): Der soziologische und der juristische Staatsbegriff. Kritische Untersuchung des Verhältnisses von Staat und Recht. Tübingen: Mohr.

- (1925): Allgemeine Staatslehre. Berlin: Springer.

- (1941): Vergeltung und Kausalität. Eine soziologische Untersuchung. The Hague: van Stockum.

- (1967): „Allgemeine Rechtslehre im Lichte materialistischer Geschichtsauffassung [1931]“, in: ders.; Leser, Norbert (Hg.): Demokratie und Sozialismus. Ausgewählte Aufsätze. Darmstadt: Wissenschaftliche Buchgesellschaft, S. 69-136.

- (1981): Der soziologische und der juristische Staatsbegriff. Kritische Untersuchung des Verhältnisses von Staat und Recht. Neudr. d. 2. Aufl. Tübingen 1928. Aalen: Scientia. 
— (1992a): „Der Staatsbegriff der 'verstehenden Soziologie'. (Zeitschrift für Volkswirtschaft und Sozialpolitik. N.F. Band 1 (1921), S. 104-119)“, in: Paulson, Stanley L. (Hg.): Hans Kelsen und die Rechtssoziologie. Auseinandersetzungen mit Hermann U. Kantorowicz, Eugen Ehrlich und Max Weber. Aalen: Scientia, ohne fortlaufende Paginierung, abgedruckt: 104-119.

- (1992b): „Eine Grundlegung der Rechtssoziologie. (Archiv für Sozialwissenschaft und Sozialpolitik. Band 39 (1915), S. 839-876)“, in: Paulson, Stanley L. (Hg.): Hans Kelsen und die Rechtssoziologie. Aalen: Scientia, ohne fortlaufende Paginierung, abgedruckt: 839-876.

- (1992c): „Replik. (Archiv für Sozialwissenschaft und Sozialpolitik. Band 41 (1916), S. 850-853)“, in: Paulson, Stanley L. (Hg.): Hans Kelsen und die Rechtssoziologie. Aalen: Scientia, ohne fortlaufende Paginierung, abgedruckt: 850-853.

— (1992d): „Schlußwort. (Archiv für Sozialwissenschaft und Sozialpolitik. Nad 42 (1916/17), S. 611“, in: Paulson, Stanley L. (Hg.): Hans Kelsen und die Rechtssoziologie. Aalen: Scientia, ohne fortlaufende Paginierung, abgedruckt: 611.

- (1992e): „Zur Soziologie des Rechts. Kritische Betrachtungen. (Archiv für Sozialwissenschaften und Sozialpolitik. Band 34 (1912), S.601-614)“, in: Paulson, Stanley L. (Hg.): Hans Kelsen und die Rechtssoziologie. Aalen: Scientia, ohne fortlaufende Paginierung, abgedruckt: 601-614.

- (2008): Reine Rechtslehre. Einleitung in die rechtswissenschaftliche Problematik. Hrsg. und eingeleitet von Matthias Jestaedt. Studienausgabe der 1. Aufl. 1934. Tübingen: Mohr Siebeck.

- (2010a): „Buchbesprechung: Ludwig Spiegel, Gesetz und Recht. Vorträge und Aufsätze zur Rechtsquellentheorie, München und Leipzig 1913 [1914]“, in: ders.; Jestaedt, M. (Hg.): Veröffentlichte Schriften 1911-1917. Tübingen: Mohr Siebeck, S. 427-438.

- (2010b): „Über die Grenzen zwischen juristischer und soziologischer Methode. Vortrag gehalten in der Soziologischen Gesellschaft zu Wien (1911)“, in: ders., Jestaedt, Matthias (Hg.): Veröffentlichte Schriften 1911-1917. Tübingen: Mohr Siebeck, S. 22-56.

Keppeler, Lutz Martin (2013): Oswald Spengler und die Jurisprudenz. Die Spenglerrezeption in der Rechtswissenschaft zwischen 1918 und 1945. Tübingen: Mohr Siebeck.

Kerger, Henry (1988): Autorität und Recht im Denken Nietzsches. Berlin: Duncker \& Humblot.

Kersten, Jens (2000): Georg Jellinek und die klassische Staatslehre. Tübingen: Mohr Siebeck.

- (2017): „Relative Rechtssubjektivität. Über autonome Automaten und emergente Schwärme“, in: Zeitschrift für Rechtssoziologie 37 (1), S. 8-25.

Kiefner, Hans (1982): „Das Rechtsverhältnis. Zu Savignys System des heutigen Römischen Rechts: Die Entstehungsgeschichte des $\$ 52$ über das 'Wesen der Rechtsverhältnisse'“, in: Horn, Norbert et al. (Hg.): Europäisches Rechtsdenken in Geschichte und Gegenwart. Festschrift für Helmut Coing zum 70. Geburtstag. Band 1. München: Beck, S. 149-176. 
Kierulff, Johann Friedrich Martin (1839): Theorie des gemeinen Civilrechts. Band 1. Altona: Hammerich.

Kiesow, Rainer Maria (1997): Das Naturgesetz des Rechts. Frankfurt am Main: Suhrkamp.

Kirchmann, Julius von (1848): Die Werthlosigkeit der Jurisprudenz als Wissenschaft. Ein Vortrag, gehalten in der Juristischen Gesellschaft zu Berlin. Berlin: Springer.

Kiß, Géza (1911): „Gesetzesauslegung und 'ungeschriebenes' Recht: Kritische Beiträge zur Theorie der Rechtsquellen“, in: Jherings Jabrbücher für die Dogmatik des bürgerlichen Rechts 58, S. 413-486.

- (1913): „Soziologische Rechtsanwendung im römischen Rechte“, in: Archiv für bürgerliches Recht 38, S. 214-235.

Kistiakowski, Theodor (1899): Gesellschaft und Einzelwesen: Eine methodologische Untersuchung. Berlin: Otto Liebmann.

Klein, Franz (1906): „Der Kampf um die Rechtswissenschaft“, in: Allgemeine österreichische Gerichtszeitung 57, S. 265-267.

- (1912): Die psychischen Quellen des Rechtsgehorsams und der Rechtsgeltung. Berlin: Vahlen.

Kleinheyer, Gerd; Schröder, Jan (Hg./ 2017): Deutsche und Europäische Juristen aus neun Jahrhunderten. Eine biographische Einführung in die Geschichte der Rechtswissenschaft. 6. Aufl. Tübingen: utb.

Klemann, Bernd (1991): "Jherings Wandlung“, in: Mohnhaupt, Heinz (Hg.): Rechtsgeschichte in den beiden deutschen Staaten (1988-1990). Frankfurt am Main: Klostermann, S. 130-150.

Klenner, Hermann (1991): „Savignys Forschungsprogramm der Historischen Rechtsschule und die geistesgeschichtliche Lage Berlins im 19. Jahrhundert“, in: Mohnhaupt, Heinz (Hg.): Rechtsgeschichte in den beiden deutschen Staaten (1988-1990). Frankfurt am Main: Klostermann, S. 2-33.

- (1992): „Jherings Kampf ums Recht“, in: Jhering, Rudolf von; Klenner, Hermann (Hg.): Der Kampf ums Recht (1872). Herausgegeben und mit einem Anhang versehen von Hermann Klenner. Freiburg (Breisgau), Berlin: Haufe, S. 133-148.

— (1993): „Kirchmann als Rechtstheoretiker“, in: Bast, Rainer A. (Hg.): Julius Hermann von Kirchmann, 1802-1884. Jurist, Politiker, Philosoph. Hamburg: Meiner, S. $1-14$.

Klippel, Diethelm (1993): „Naturrecht und Politik in Deutschland des 19. Jahrhunderts“, in: Ballestrem, Karl Graf (Hg.): Naturrecht und Politik. Berlin: Duncker \& Humblot, S. 27-48.

— (1997a): „Das 'natürliche Privatrecht' im 19. Jahrhundert“, in: ders. (Hg.): Naturrecht im 19. Jahrhundert. Kontinuität, Inhalt, Funktion, Wirkung. Goldbach: Keip, S. 221-250.

- (1997b): „Die Historisierung des Naturrechts. Rechtsphilosophie und Geschichte im 19. Jahrhundert“, in: Kervégan, J.-F; Mohnhaupt, Heinz (Hg.): Recht zwischen Natur und Geschichte. Le droit entre nature et histoire. Deutsch-französisches Symposion vom 24. bis 26. November 1994 an der Universität Cergy-Pontoise. Frankfurt am Main: Klostermann, S. 103-124. 
- (2012a): „Einführung“, in: ders. (Hg.): Naturrecht und Rechtsphilosophie. Einen Bibliographie. 1780 bis 1850. Tübingen: Mohr Siebeck, S. IX-XVI.

- (Hg./ 2012b): Naturrecht und Rechtsphilosophie. Einen Bibliographie. 1780 bis 1850 . Tübingen: Mohr Siebeck.

Kloeppel (1889): „Das Familien- und Erbrecht des Entwurfs zum bürgerlichen Gesetzbuche“, in: Beiträge zur Erläuterung des deutschen Rechts 33, S. 64-92.

Klöppel, Ulrike (2010): „Foucaults Konzept der Problematisierungsweise und die Analyse diskursiver Transformationen“, in: Landwehr, Achim (Hg.): Diskursiver Wandel. Wiesbaden: VS Verlag für Sozialwissenschaften, S. 255-263.

Knauthe, Karlheinz (1968): Kausales Rechtsdenken und Rechtssoziologie. Eine Würdigung der Lehre von Müller-Erzbach. Berlin: Duncker \& Humblot.

Kneer, Georg (1999): „Struktur und Ereignis bei Jürgen Habermas und Michel Foucault. Ein Theorienvergleich“, in: Greshoff, Rainer; Kneer, Georg (Hg.): Struktur und Ereignis in theorievergleichender Perspektive. Ein diskursives Buchprojekt. Opladen [u.a.]: Westdeutscher Verlag, S. 51-69.

Kneer, Georg; Moebius, Stephan (Hg./ 2010): Soziologische Kontroversen. Beiträge zu einer anderen Geschichte der Wissenschaft vom Sozialen. Berlin: Suhrkamp.

Knoll, Reinhold et al. (1981): „Der österreichische Beitrag zur Soziologie von der Jahrhundertwende bis 1938“, in: Lepsius, M. Rainer (Hg.): Soziologie in Deutschland und Österreich 1918 - 1945. Materialien, Emigration und Wirkungsgeschichte. Opladen: Westdeutscher Verlag, S. 59-101.

Knorr Cetina, Karin (2008): „Theoretischer Konstruktivismus: Über die Einnistung von Wissensstrukturen in soziale Strukturen“, in: Kalthoff, Herbert; Hirschauer, Stefan; Lindemann, Gesa (Hg.): Theoretische Empirie. Zur Relevanz qualitativer Forschung. Frankfurt am Main: Suhrkamp, S. 35-78.

Koch, Christian Friedrich (1840): Das Recht der Forderungen nach Gemeinem und nach Preußischem Rechte, mit Rücksicht auf neuere Gesetzgebungen, historisch-dogmatisch dargestellt. Band 2. Breslau: Georg Philipp Aderholz.

Kohler, Josef (1883): Shakespeare vor dem Forum der Jurisprudenz. Würzburg: Stahel.

- (1885): Das Recht als Kulturerscheinung. Einleitung in die vergleichende Rechtswissenschaft. Würzburg: Stahel.

- (1896): „Die deutsche Rechtswissenschaft und das deutsche bürgerliche Recht. Mit Bezug auf Anton Menger's Rectoratsrede über die socialen Aufgaben der Rechtswissenschaft", in: Zeitschrift für das Privat- und öffentliche Recht der Gegenwart XXIII, S. 217-228.

- (1904): „Rechtsphilosophie und Universalrechtsgeschichte“, in: ders.; Holtzendorff, Franz von (Hg.): Enzyklopädie der Rechtswissenschaft in systematischer Bearbeitung. Band 1. 6. Aufl. Leipzig, Berlin: Duncker \& Humblot, Guttentag, S. 162.

- (1909): Lehrbuch der Rechtsphilosophie. Berlin: Rothschild.

- (1911): "Soziologie und Rechtsphilosophie“, in: Archiv für Rechts- und Wirtschaftsphilosophie 4 (4), S. 558-563.

- (1917): Lehrbuch der Rechtsphilosophie. 2. Aufl. Berlin, Leipzig: Rothschild. 
Kohler, Josef et al. (1911): „Diskussionsbeiträge“, in: Archiv für Rechts- und Wirtschaftsphilosophie 4 (4), S. 674-687.

Kohler, Josef; Liszt, Franz von; Berolzheimer, Fritz (1910): „Ein deutsches Institut für Rechtsphilosophie und soziologische Fragen? Eine Enquète“, in: Archiv fuer Rechts- und Wirtschaftsphilosophie 4, S. 190-224.

König, René (1955): „Die Begriffe Gemeinschaft und Gesellschaft bei Ferdinand Tönnies“, in: Kölner Zeitschrift für Soziologie und Sozialpsychologie 7, S. 348-420.

- (1971): „Das Recht im Zusammenhang der sozialen Normensysteme“, in: Hirsch, Ernst Eduard; Rehbinder, Manfred (Hg.): Studien und Materialien zur Rechtssoziologie. 2. Aufl. Opladen: Westdeutscher Verlag, S. 36-53.

- (1987): „Ferdinand Tönnies“, in: König, René (Hg.): Soziologie in Deutschland. Begründer, Verfechter, Verächter. München [u.a.]: Hanser, S. 122-197.

- (2007): „Einleitung“, in: Durkheim, Émile (Hg.): Die Regeln der soziologischen Methode. Herausgegeben und eingeleitet von René König. Frankfurt am Main: Suhrkamp, S. 21-82.

Korb, Axel-Johannes (2010): Kelsens Kritiker. Ein Beitrag zur Geschichte der Rechtsund Staatstheorie (1911-1934). Tübingen: Mohr Siebeck.

Kornfeld, Ignatz (1911): Soziale Machtverhältnisse. Grundzüge einer allgemeinen Lehre vom positiven Rechte auf soziologischer Grundlage. Wien: Manz.

Korsch, Karl (1914/15): „Freirechtsbewegung und Kodifikationsidee“, in: Die Tat. Sozial-religiöse Monatsschrift für deutsche Kultur 6 (4), S. 429-433.

Koslowski, Stefan (2005): Zur Philosophie von Wirtschaft und Recht. Lorenz von Stein im Spannungsfeld zwischen Idealismus, Historismus und Positivismus. Berlin: Duncker \& Humblot.

Köstlin, Reinhold (1846): „Ueber den Widerspruch zwischen Theorie und Praxis in der deutschen Jurisprudenz", in: Monatsblätter zur Ergänzung der Allgemeinen Zeitung, S. 239-253.

- (2011): „System des deutschen Strafrechts (1855). (Ausschnitte)“, in: Vormbaum, Thomas (Hg.): Moderne deutsche Strafrechtsdenker. Berlin, Heidelberg: Springer, S. 165-178.

Kracauer, Siegfried (1922): Soziologie als Wissenschaft. Eine erkenntnistheoretische Untersuchung. Dresden: Sibyllen-Verlag.

Kranenpohl, Uwe (2010): Hinter dem Schleier des Beratungsgeheimnisses. Der Willensbildungs- und Entscheidungsprozess des Bundesverfassungsgerichts. Wiesbaden: VS Verlag für Sozialwissenschaften.

Krasmann, Susanne (1995): „Simultaneität von Körper und Sprache bei Michel Foucault", in: Leviathan 23 (2), S. 240-262.

- (2003): Die Kriminalität der Gesellschaft. Zur Gouvernementalität der Gegenwart. Konstanz: UVK.

- (2012): „Law's knowledge: On the susceptibility and resistance of legal practices to security matters", in: Theoretical Criminology 16 (4), S. 379-394.

- (2015): „Über die Kraft im Recht“, in: Zeitschrift für Rechtssoziologie 35 (2), S. $185-200$. 
Krech, Johannes (1889): Die Rechte an Grundstücken nach dem Entwurfe eines Bürgerlichen Gesetzbuches für das Deutsche Reich. Berlin: Guttentag.

Kreher, Christian O. (2015): Herkunft und Entwicklung des Zweckgedankens bei Franz von Liszt. Eine rechtshistorische Analyse des Marburger Programms. Zürich: Schulthess.

Kremer, Thomas F. (2001): Die "wissenschaftliche Rechtsphilosophie" Carl Magnus Bergbohms. Versuch einer analytisch-kritischen Rekonstruktion. Frankfurt am Main [u.a.]: Lang.

Kriechbaum, Maximilian (1999): „Römisches Recht und neuere Privatrechtsgeschichte in Savignys Auffassung von Rechtsgeschichte und Rechtswissenschaft“, in: Zimmermann, Reinhard; Knütel, Rolf; Meincke, Jens Peter (Hg.): Rechtsgeschichte und Privatrechtsdogmatik. Heidelberg: Müller, S. 41-63.

Kroeschell, Karl (1977): „Zur Lehre vom 'germanischen' Eigentumsbegriff“, in: Thieme, Hans (Hg.): Rechtshistorische Studien. Hans Thieme zum 70. Geburtstag zugeeignet von seinen Schülern. Köln, Wien: Bohlau, S. 34-71.

Kropotkin, Peter (2012 [1902]): Mutual Aid: A Factor of Evolution. Mineola, New York: Dover Publications.

Krug, Wilhelm Traugott (1827): Allgemeines Handwörterbuch der philosophischen Wissenschaften, nebst ibrer Literatur und Geschichte. Nach dem heutigen Standpuncte der Wissenschaft. Zweiter Band: F bis M. 2. Aufl. Leipzig: Brockhaus.

Kruse, Volker (1990): „Von der historischen Nationalökonomie zur historischen Soziologie: Ein Paradigmenwechsel in den deutschen Sozialwissenschaften um 1900“, in: Zeitschrift für Soziologie 19 (3), S. 149-165.

- (1999): "Geschichts- und Sozialphilosophie" oder "Wirklichkeitswissenschaft"? Die deutsche historische Soziologie im Kontext der logischen Kategorien Rene Königs und Max Webers. Frankfurt am Main: Suhrkamp.

Kübl, Friedrich (1913): Das Rechtsgefühl. Berlin: Puttkammer \& Mühlbrecht.

Kuhlenbeck, Ludwig (1905): Die Rechtswissenschaft in ibren Beziehungen zu anderen Wissenschaften. Jena: Costenoble.

- (1907): „Zur Psychologie des Rechtsgefühls“, in: Archiv für Rechts- und Wirtschaftsphilosophie 1 (1), S. 16-25.

Kuhn, Robert (1983): Die Vertrauenskrise der Justiz (1926-1928). Der Kampf um die „Republikanisierung" der Rechtspflege in der Weimarer Republik. Köln: Bundesanzeiger.

Kühnast, Ludwig (1880a): „Jhering's Definition des Rechts“, in: Beiträge zur Erläuterung des deutschen Rechts 24 (1), S. 1-20.

- (1880b): "Jhering's Definition des Rechts. (Schluß von Nr. 1 dieses Jahrgangs.)“, in: Beiträge zur Erläuterung des deutschen Rechts 24 (2), S. 153-170. 
Kuntze, Johannes Emil (1855): „Das römische und das germanische Recht in der Gegenwart und die Aufgabe der modernen Rechtswissenschaft in der Zukunft. Rezension: Rud. Ihering. Geist des römischen Rechts auf den verschiedenen Stufen seiner Entwickelung. 1. Theil ; C. A. Schmidt. Der principielle Unterschied zwischen dem römischen und germanischen Rechte, 1. Band: Die Verschiedenheit der Grundbegriffe und des Privatrechts; Gust. Lenz. Ueber die geschichtliche Entstehung des Rechts. Eine Kritik der historischen Schule; Esmarch: Römisches und germanisches Recht. Mit Beziehung auf Schmidt u.s.w.", in: Kritische Ueberschau der deutschen Gesetzgebung und Rechtswissenschaft (2), S. 173-228.

- (1856): Der Wendepunkt der Rechtswissenschaft; ein Beitrag zur Orientierung über den gegenwärtigen Stand- und Zielpunkt derselben. Leipzig: Hinrichs.

- (1889): Betrachtungen über den Entwurf eines Bürgerlichen Gesetzbuchs für das Deutsche Reich. Leipzig: Edelmann.

- (1890): Zur Besitzlehre, für und wider Jhering. Leipzig: Hinrichs.

— (1892): „Rudolph von Jhering [gestorben]“, in: Sächsisches Archiv für bürgerliches Recht und Prozeß 2, S. 609-618.

Kunz, Josef L. (1926): „Jerusalems 'Soziologie des Rechts'“, in: Archiv für Rechtsund Wirtschaftsphilosophie 19 (3), S. 484-493.

Laband, Paul (1906): „Die Fortschritte des Rechts 1896-1905“, in: Deutsche JuristenZeitung 11, Sp. 1-9.

Laboulaye, Édouard (1842): Essai sur la vie et les doctrines de Frédéric Charles de Savigny. Paris: Durand.

- (1855): „De la méthode historique en jurisprudence et de son avenir“, in: Revue historique de droit français et étranger (1855-1869) 1, S. 1-23.

Laclau, Ernesto (1990): „The Impossibility of Society“, in: ders. (Hg.): New reflections on the revolution of our time. London, New York: Verso, S. 89-92.

Laclau, Ernesto; Mouffe, Chantal (2000): Hegemonie und radikale Demokratie. Zur Dekonstruktion des Marxismus. 2. Aufl. Wien: Passagen.

Landau, Peter (1992): „Puchta und Aristoteles. Überlegungen zu den philosophischen Grundlagen der historischen Schule und zur Methode Puchtas als Zivilrechtsdogmatiker“, in: Zeitschrift der Savigny-Stiftung für Rechtsgeschichte / Romanistische Abteilung 109, S. 1-30.

- (1999): „Zwei Programmschriften aus den Anfangsjahren der Redaktion des BGB: Moritz August v. Bethmann-Hollweg und Rudolph Sohm“, in: Hadding, Walther (Hg.): Festgabe, Zivilrechtslehrer 1934/1935. Berlin, New York: de Gruyter, S. 319-332.

Landsberg, Ernst (1892): „Ihering und Windscheid“, in: Beilage zur Allgemeinen Zeitung (München) (278), S. 1-4.

— (1894/95): „Soziale Bestimmungen im bürgerlichen Gesetzbuch“, in: Die Nation. Wochenschrift für Politik, Volkswirtschaft und Literatur 12, S. 131-133.

- (1905): „Das entgegengesetzte Extrem?“, in: Deutsche Juristen-Zeitung 10, Sp. 921-925. 
- (1910): Geschichte der deutschen Rechtswissenschaft. Abt. 3, Halbbd. 2. München, Berlin: Oldenbourg.

- (1913): Der Geist der Gesetzgebung in Deutschland und Preußen 1888 - 1913. Festrede gehalten im Auftrag der Rheinischen Friedrich-Wilhelm-Universität bei der Jubiläumsfeier Sr. M. des Kaisers und Königs Wilhelm II. am 16. Juni 1913. Bonn: Cohen.

Landsberg, Ernst; Stintzing, Johann August Roderich von (1978): Geschichte der deutschen Rechtswissenschaft. Abt. 3, Halbbd. 2: 19. Jahrhundert bis etwa 1870. 2. Neudr. der Ausg. München 1910. Aalen: Scientia.

Langenohl, Andreas; Schweitzer, Doris (2015): Die Gesellschaft als Labor? Wissenschaftsforschung meets soziologische Theorie. DGS. http://publikationen.soziologie.d e/index.php/kongressband_2014/article/view/164 (zuletzt geprüft am 16.01.2019).

Lascoumes, Pierre (1991): „Le droit comme science sociale. La place d'E. Durkheim dans les débats entre juristes et sociologues à la charnière des deux derniers siècles (1870-1914)“, in: Commaille, Jacques; Chazel, François (Hg.): Normes juridiques et régulation sociale. Paris: L.G.D.J., S. 39-50.

Lask, Emil (1905): Rechtsphilosophie. Seperatdruck aus: Die Philosophie im Beginn des 20. Jahrbunderts. Festschrift für Kuno Fischer, 2. Band. Heidelberg: Carl Winter's Universitätsbuchhandlung.

Lasson, Adolf (1879): „Rezension: Der Zweck im Recht. Von R. v. Ihering. 1. Bd. Leipzig, Breitkopf und Härtel. 1877“, in: Philosophischen Monatshefte XV, S. 146155.

— (1885): „Rezension: Der Zweck im Recht. Von R. v. Ihering. 2. Bd. Leipzig, Breitkopf und Härtel. 1883“, in: Philosophischen Monatshefte XXI, S. 128-144.

Latour, Bruno (1995): Wir sind nie modern gewesen. Versuch einer symmetrischen Anthropologie. Berlin: Akademie Verlag.

- (2001a): Das Parlament der Dinge. Für eine politische Ökologie. Frankfurt am Main: Suhrkamp.

— (2001b): „Gabriel Tarde und das Ende des Sozialen“, in: Soziale Welt (3), S. 361376.

- (2004): „Note brève sur l'écologie du droit saisie comme énonciation“, in: Cosmopolitiques: Pratiques cosmopolitiques du droit 8, S. 34-40.

- (2007): Eine neue Soziologie für eine neue Gesellschaft. Einführung in die AkteurNetzwerk-Theorie. Frankfurt am Main: Suhrkamp.

- (2010): The making of law. An ethnography of the Conseil d'Etat. Cambridge, UK, Malden, MA: Polity.

- (2013): On sociology of law, an alternative approach. Keynote lecture by Bruno Latour at the International congress of Sociology of Law, Toulouse, September 2013. http:/www.modesofexistence.org/bruno-latour-on-sociology-of-law-an-alternativ e-approach-bruno-latour-on-sociology-of-law-an-alternative-approach/ (zuletzt geprüft am 16.01.2019).

- (2014): Existenzweisen. Eine Anthropologie der Modernen. Berlin: Suhrkamp.

Lautmann, Rüdiger (1971): Soziologie vor den Toren der Jurisprudenz. Zur Kooperation der beiden Disziplinen. Stuttgart [u.a.]: Kohlhammer. 
- (2011): Justiz - die stille Gewalt. Teilnehmende Beobachtung und entscheidungssoziologische Analyse. Wiesbaden: VS Verlag für Sozialwissenschaften.

Lazarsfeld, Robert (1908): Das Problem der Jurisprudenz. Wien: Manz.

Leenen, Detlef (1971): Typus und Rechtsfindung. Die Bedeutung der typologischen Methode für die Rechtsfindung dargestellt am Vertragsrecht des BGB. Berlin: Duncker \& Humblot.

Legnaro, Aldo; Aengenheister, Astrid (1999): Schuld und Strafe. Das soziale Geschlecht von Angeklagten und die Aburteilung von Tötungsdelikten. Pfaffenweiler: Centaurus.

Leist, Burkhard Wilhelm (1854): Civilistische Studien auf dem Gebiete dogmatischer Analyse. Erstes Heft: Über die dogmatischen Analysen römischer Rechtsinstitute. Jena: Friedrich Fromann.

Lemke, Thomas (1997): Eine Kritik der politischen Vernunft. Foucaults Analyse der modernen Gouvernementalität. Berlin: Argument Verlag.

— (2017): „Einführung zu 'Neue Materialismen'“, in: Bauer, Susanne; Heinemann, Torsten; Lemke, Thomas (Hg.): Science and Technology Studies. Klassische Positionen und aktuelle Perspektiven. Berlin: Suhrkamp, S. 551-573.

Lenz, Gustav (1854): Ueber die geschichtliche Entstehung des Rechts. Eine Kritik der historischen Schule. Greifswald, Leipzig: Koch.

Leonhard, Rudolf (1891): Der Entwurf eines bürgerlichen Gesetzbuchs für das deutsche Reich und seine Beurteilung in einer kurzgefassten Uebersicht dargestellt. Marburg: Elwert'sche Verlagsbuchhandlung.

— (1893): „Rudolf von Jhering [gestorben]“, in: Die Zukunft 3 (27-39), S. 600-608.

- (1900a): Das neue Gesetzbuch als Wendepunkt der Privatrechtswissenschaft. Breslau: Marcus.

- (1900b): Der Allgemeine Theil des Bürgerlichen Gesetzbuchs in seinem Einflusse auf die Fortentwicklung der Rechtswissenschaft. Berlin: Guttentag.

Lepenies, Wolf (1981a): „Einleitung. Studien zur kognitiven, sozialen und historischen Identität der Soziologie“, in: ders. (Hg.): Geschichte der Soziologie - Studien zur kognitiven, sozialen und historischen Identität einer Disziplin. Band 1. Frankfurt am Main: Suhrkamp, S. I-XXXV.

- (Hg./ 1981b): Geschichte der Soziologie - Studien zur kognitiven, sozialen und historischen Identität einer Disziplin. Frankfurt am Main: Suhrkamp.

- (2006): Die drei Kulturen. Soziologie zwischen Literatur und Wissenschaft. 3. Aufl. Frankfurt am Main: Fischer.

Lepsius, M. Rainer (Hg./ 1981): Soziologie in Deutschland und Österreich 1918 - 1945. Materialien, Emigration und Wirkungsgeschichte. Opladen: Westdeutscher Verlag.

- (2011): „Max Weber und die Gründung der Deutschen Gesellschaft für Soziologie“, in: Soziologie 40 (1), S. 7-19.

— (2009): Interessen, Ideen und Institutionen. 2. Aufl. Wiesbaden: VS Verlag für Sozialwissenschaften.

Lepsius, M. Rainer; Mommsen, Wolfgang J. (Hg/ 2003): Max Weber-Gesamtausgabe. Band II/8: Briefe 1913-1914. Tübingen: Mohr Siebeck. 
Lepsius, Oliver (1994): Die gegensatzaufhebende Begriffsbildung. Methodenentwicklungen in der Weimarer Republik und ibr Verhältnis zur Ideologisierung der Rechtswissenschaft im Nationalsozialismus. München: C.H. Beck.

- (2000): „Georg Jellineks Methodenlehre im Spiegel der zeitgenössischen Erkenntnistheorie“, in: Paulson, Stanley L.; Schulte, Martin (Hg.): Georg Jellinek. Beiträge zu Leben und Werk. Tübingen: Mohr Siebeck, S. 309-343.

Lichtblau, Klaus (2000): „'Vergemeinschaftung' und 'Vergesellschaftung' bei Max Weber: Eine Rekonstruktion seines Sprachgebrauchs“, in: Zeitschrift für Soziologie 29 (6), S. 423-443.

- (2001): „Soziologie und Anti-Soziologie um 1900. Wilhelm Dilthey, Georg Simmel und Max Weber“, in: Merz-Benz, Peter-Ulrich; Wagner, Gerhard (Hg.): Soziologie und Anti-Soziologie. Ein Diskurs und seine Rekonstruktion. Konstanz: UVK, S. $17-35$.

- (2005): „Von der 'Gesellschaft' zur 'Vergesellschaftung'. Von der deutschen Tradition des Gesellschaftsbegriffs", in: Zeitschrift für Soziologie, Sonderheft "Weltgesellschaft", S. 68-88.

- (2006): „Zum Status von 'Grundbegriffen' in Max Webers Werk“, in: ders. (Hg.): Max Webers "Grundbegriffe". Kategorien der kultur- und sozialwissenschaftlichen Forschung. Wiesbaden: VS Verlag für Sozialwissenschaften, S. 242-256.

- (2011): „Krise als Dauerzustand? Weltanschauliche Implikationen der Weimarer Soziologie“, in: ders. (Hg.): Die Eigenart der kultur- und sozialwissenschaftlichen Begriffsbildung. Wiesbaden: VS Verlag für Sozialwissenschaften, S. 315-326.

— (2012): „Einleitung“, in: ders.; Tönnies, Ferdinand (Hg.): Soziologische Schriften. Studien zu Gemeinschaft und Gesellschaft. Wiesbaden: VS Verlag für Sozialwissenschaften, S. 7-26.

- (2017): „Die Bedeutung der Kategorie des 'Einverständnisses' in Max Webers Wissenschaftslehre“, in: ders. (Hg.): Zwischen Klassik und Moderne. Die Modernität der klassischen deutschen Soziologie. Wiesbaden: Springer VS, S. 279-302.

Link, Jürgen (2009): Versuch über den Normalismus. Wie Normalität produziert wird. 4. Aufl. Göttingen: Vandenhoeck \& Ruprecht.

Liszt, Franz von (1881): Das deutsche Reichsstrafrecht auf Grund des Reichsstrafgesetzbuchs und der übrigen strafrechtlichen Reichsgesetze unter Berücksichtigung der Rechtsprechung des Reichsgerichts systematisch dargestellt. Berlin [u.a.]: Guttentag.

- (1889): Die Grenzgebiete zwischen Privatrecht und Strafrecht. Berlin [u.a.]: Guttentag.

— (1905): „Der Zweckgedanke im Strafrecht (1882). Marburger Universitätsprogramm 1882. Abgedruckt Z. III 1.“, in: ders. (Hg.): Strafrechtliche Aufsätze und Vorträge. Erster Band: 1875 bis 1891. Berlin: Guttentag, S. 126-179.

Lobe, Adolf (1896): Was verlangen wir von einem bürgerlichen Gesetzbuch? Ein Wort an den Reichstag. Leipzig: Grunow.

Loening, E. (1890): „Litteratur: 'Das bürgerliche Recht und die besitzlosen Volksklassen' v. A. Menger“, in: Jahrbücher für Nationalökonomie und Statistik N.F. 21, S. 392-401. 
Lombardi Vallauri, Luigi (1971): Die Geschichte des Freirechts. Frankfurt am Main: Klostermann.

Löning, Richard (1907): Ueber Wurzel und Wesen des Rechts. Rede, gehalten bei der akad. Preisverteilung am 15. Juni 1907 in der Kollegienkirche zu Jena. Jena: Fischer.

Loos, Fritz (1982): „Max Webers Wissenschaftslehre und die Rechtswissenschaft“, in: $J u S(2)$, S. 87-93.

Losano, Mario G. (1984): Studien zu Jhering und Gerber. Ebelsbach: Gremer.

Löwenstein, Alfred (1915): Der Rechtsbegriff als Relationsbegriff: Studien zur Methodologie der Rechtswissenschaft. München: Beck.

Löwith, Karl (1932): Max Weber und Karl Marx. Tübingen: Mohr.

Löwy, Michael (1996): „Figures of Weberian Marxism“, in: Theory and Society 25 (3), S. 431-446.

Lübbe, Weyma (1993): „Die Theorie der adäquaten Verursachung: Zum Verhältnis von philosophischem und juristischem Kausalitätsbegriff“, in: Journal for General Philosophy of Science 24 (1), S. 87-102.

Lüdemann, Susanne (2004): Metaphern der Gesellschaft. Studien zum soziologischen und politischen Imaginären. München: Fink.

Lüderssen, Klaus (2005): „Hans Kelsen und Eugen Ehrlich“, in: Paulson, Stanley L.; Schulte, Martin (Hg.): Hans Kelsen. Staatsrechtslehrer und Rechtstheoretiker des 20. Jahrhunderts. Tübingen: Mohr Siebeck, S. 264-275.

Luhmann, Niklas (1970): „Positivität des Rechts als Voraussetzung einer modernen Gesellschaft“, in: Lautmann, Rüdiger (Hg.): Die Funktion des Rechts in der modernen Gesellschaft. Bielefeld: Bertelsmann, S. 175-202.

- (1973): „Die juristische Rechtsquellenlehre aus soziologischer Sicht“, in: Albrecht, Günter et al. (Hg.): Soziologie. Sprache, Bezug zur Praxis, Verbältnis zu anderen Wissenschaften. René König zum 65. Geburtstag. Opladen: Westdeutscher Verlag, S. 387-399.

- (1981a): „Subjektive Rechte. Zum Umbau des Rechtsbewußtseins für die moderne Gesellschaft“, in: ders. (Hg.): Gesellschaftsstruktur und Semantik. Studien zur Wissenssoziologie der modernen Gesellschaft. Band 2. Frankfurt am Main: Suhrkamp, S. 45-104.

— (1981b): „Wie ist soziale Ordnung möglich?“, in: ders. (Hg.): Gesellschaftsstruktur und Semantik. Studien zur Wissenssoziologie der modernen Gesellschaft. Band 2. Frankfurt am Main: Suhrkamp, S. 195-285.

- (1993): Das Recht der Gesellschaft. Frankfurt am Main: Suhrkamp.

- (1996): „Arbeitsteilung und Moral. Durkheims Theorie“, in: Durkheim, Émile (Hg.): Über soziale Arbeitsteilung. Studie über die Organisation höherer Gesellschaften. Mit einer Einleitung von Niklas Lubmann: Arbeitsteilung und Moral. Durkbeims Theorie. 2. Aufl. Frankfurt am Main: Suhrkamp, S. 19-38.

- (1999a): „Selbstreflexion des Rechtssystems. Rechtstheorie in gesellschaftstheoretischer Perspektive“, in: ders. (Hg.): Ausdifferenzierung des Rechts. Beiträge zur Rechtssoziologie und Rechtstheorie. Frankfurt am Main: Suhrkamp, S. 419-450. 
- (1999b): „Zur Funktion des 'subjektiven Rechts'. Erschienen in: Jahrbuch für Rechtssoziologie und Rechtstheorie I (1970), 321-330“, in: ders. (Hg.): Ausdifferenzierung des Rechts. Beiträge zur Rechtssoziologie und Rechtstheorie. Frankfurt am Main: Suhrkamp, S. 360-373.

- (2006): Die Gesellschaft der Gesellschaft. Frankfurt am Main: Suhrkamp.

- (2008): Rechtssoziologie. 4. Aufl. Wiesbaden: VS Verlag für Sozialwissenschaften.

Luig, Klaus (1993): „Jherings Evolutionstheorie des Werdens des Rechts durch Tun und der gesellschaftliche Charakter des Privatrechts“, in: Behrends, Okko (Hg.): Privatrecht heute und Jherings evolutionäres Rechtsdenken. Köln: Schmidt, S. 161183.

- (1995): „Römische und germanische Rechtsanschauung, individualistische und soziale Ordnung“, in: Rückert, Joachim; Willoweit, Dietmar (Hg.): Die Deutsche Rechtsgeschichte in der NS-Zeit. Ihre Vorgeschichte und ibre Nachwirkungen. Tübingen: Mohr Siebeck, S. 95-137.

Lukes, Steven (1973): Émile Durkheim: His life and work. A historical and critical stu$d y$. London: Allen Lane.

Lukes, Steven; Prabhat, Devyani (2013): „Durkheim über Recht und Moral: Die Desintegrationsthese“, in: Bogusz, Tanja; Delitz, Heike (Hg.): Émile Durkheim. Soziologie - Ethnologie - Philosophie. Frankfurt am Main, New York, NY: Campus.

Lukes, Steven; Scull, Andrew T. (Hg./ 1983): Durkheim and the Law. New York: St. Martin's Press.

Maas, Georg (1899): „Bibliographie des Bürgerlichen Rechts: Verzeichniß von Einzelschriften und Aufsätzen über das im Bürgerlichen Gesetzbuche für das Deutsche Reich vereinigte Recht, fachlich geordent von Dr. jur. Georg Maas, Bibliothekar bei dem Reichsgericht. 1888-1898“, in: Archiv für bürgerliches Recht 16.

Machura, Stefan (2001): „Die Aufgabe(n) der Rechtssoziologie. Eine Antwort an Theo Rasehorn“, in: Zeitschrift für Rechtssoziologie 22 (2), S. 293-298.

Manegold, Jutta (2012): „Methode und Zivilrecht bei Philipp Heck (1858-1943)“, in: Rückert, Joachim; Seinecke, Ralf (Hg.): Methodik des Zivilrechts - von Savigny bis Teubner. 2. Aufl. Baden-Baden: Nomos, S. 151-174.

Manigk, Alfred (1974): Savigny und der Modernismus im Recht. Neudr. d. Ausg. Berlin 1914. Aalen: Scientia.

Mannheim, Karl (2003): Konservatismus. Ein Beitrag zur Soziologie des Wissens. Frankfurt am Main: Suhrkamp.

Marchart, Oliver (2013): Das unmögliche Objekt. Eine postfundamentalistische Theorie der Gesellschaft. Berlin: Suhrkamp.

Marcucci, Nicola (2017): „Between facts and wills. Tönnies, Durkheim, and the sociological critique of modern obligation", in: Journal of Classical Sociology 17 (4), S. 276-292.

Marra, Realino (1992): Dalla comunità al diritto moderno. La formazione giuridica di Max Weber, 1882-1889. Torino: G. Giappichelli.

Martus, Steffen (2015): „Epistemische Dinge der Literaturwissenschaft?“, in: Albrecht, Andrea et al. (Hg.): Theorien, Methoden und Praktiken des Interpretierens. Berlin: de Gruyter, S. 23-52. 
Marx, Karl (1971): „Zur Kritik der politischen Ökonomie [1859]“, in: Marx, Karl; Engels, Friedrich (Hg.): Gesamtausgabe. Band 13. 7. Aufl. Berlin: Dietz, S. 3-160.

- (1974): Grundrisse der Kritik der politischen Oekonomie (Rohentwurf). 1857 - 1858; Anh. 1850 - 1859. 2. Aufl. Berlin: Dietz.

- (1976a): „Das philosophische Manifest der historischen Rechtsschule. 'Rheinische Zeitung' Nr. 221 vom 9. August 1842“, in: Marx, Karl; Engels, Friedrich (Hg.): Gesamtausgabe. Band 1. Berlin: Dietz, S. 78-85.

- (1976b): „Zur Kritik der Hegelschen Rechtsphilosophie. Kritik des Hegelschen Staatsrechts (\$S 261-313) [1843]“, in: Marx, Karl; Engels, Friedrich (Hg.): Gesamtausgabe. Band 1. Berlin: Dietz, S. 203-333.

- (1976c): „Zur Kritik der Hegelschen Rechtsphilosophie. Einleitung. 'DeutschFranzösische Jahrbücher', Paris 1844“, in: Marx, Karl; Engels, Friedrich (Hg.): Gesamtausgabe. Band 1. Berlin: Dietz, S. 378-391.

Marx, Karl; Engels, Friedrich (1972): „Manifest der Kommunistischen Partei [1848]", in: dies. (Hg.): Gesamtausgabe. Band 4. 6. Aufl. Berlin: Dietz, S. 459-493.

Massimilla, Edoardo (2012): „Die von Weber 'geplünderte' Idee: objektive Möglichkeit und adäquate Verursachung bei Johannes von Kries“, in: ders. (Hg.): Max Weber zwischen Heinrich Rickert und Johannes von Kries. Drei Studien. Köln [u.a.]: Böhlau, S. 140-224.

Mataja, Viktor (1889): „Das Schadensersatzrecht im Entwurf eines bürgerlichen Gesetzbuchs für das Deutsche Reich“, in: Archiv für bürgerliches Recht 1, S. 267282.

Mauss, Marcel (1925): „In memoriam. L'oeuvre inédite de Durkheim et de ses collaborateurs“, in: L'Année sociologique, S. 8-29.

Mayer, Max Ernst (1903): Rechtsnormen und Kulturnormen. Breslau: Schletter.

Mecke, Christoph-Eric (2008): Begriff und System des Rechts bei Georg Friedrich Puchta. Göttingen: V\&R unipress.

- (2008a): „Objektivität in Recht und Rechtswissenschaft bei G. F. Puchta und R. v. Jhering“, in: Archiv fuer Rechts- und Sozialphilosphie 94 (2), S. 147-168.

- (Hg./ 2010): Rudolf von Jhering. Anonym publizierte Frühschriften und unveröffentlichte Handschriften aus seinem Nachlass; mit Textsynopsen, Erläuterungen und werkgeschichtlicher Einordnung. Göttingen: V\&R unipress.

Meier, Kurt (1987): Emile Durkheims Konzeption der Berufsgruppen. Eine Rekonstruktion und Diskussion ihrer Bedeutung für die Neokorporatismus-Debatte. Berlin: Duncker \& Humblot.

Meischeider, Emil (1889): Die alten Streitfragen gegenüber dem Entwurfe eines Bürgerlichen Gesetzbuches für das Deutsche Reich. Berlin [u.a.]: Guttentag.

Menger, Anton (1890): Das Bürgerliche Recht und die besitzlosen Volksklassen. Eine Kritik des Entwurfs eines Bürgerlichen Gesetzbuches für das Deutsche Reich. Tübingen: Laupp.

- (1895): Über die socialen Aufgaben der Rechtswissenschaft. Inaugurationsrede, gehalten am 24. October 1895. Feierliche Installation des Rektors der Wiener Universität für 1895/96. Wien [u.a.]: Braumüller. 
- (1905): Über die socialen Aufgaben der Rechtswissenschaft. Inaugurationsrede, gehalten am 24. October 1895. Feierliche Installation des Rektors der Wiener Universität für 1895/96. 2. Aufl. Wien [u.a.]: Braumüller.

Menger, Carl (1883): Untersuchungen über die Methode der Socialwissenschaften, und der Politischen Oekonomie insbesondere. Leipzig: Duncker \& Humblot.

Menke, Christoph (2013): „Die 'andre Form' der Herrschaft. Marx' Kritik des Rechts“, in: Jaeggi, Rahel; Loick, Daniel (Hg.): Nach Marx. Philosophie, Kritik, Praxis. Berlin: Suhrkamp, S. 273-295.

- (2015): Kritik der Rechte. Berlin: Suhrkamp.

Menzel, Adolf (1912): Naturrecht und Soziologie. Wien: C. Fromme.

Menzel, Adolf et al. (1927): „Diskussion über 'Naturrecht'“, in: Deutsche Gesellschaft für Soziologie (DGS) (Hg.): Verhandlungen des 5. Deutschen Soziologentages vom 26. bis 29. September 1926 in Wien: Vorträge und Diskussionen in der Hauptversammlung und in den Sitzungen der Untergruppen. Tübingen: Mohr Siebeck, S. 168-191.

Merkel, Adolph (1893): "Jhering. [Nachruf auf Rudolph von Jhering, 1818-1892]“, in: Jherings Jahrbücher für die Dogmatik des bürgerlichen Rechts 32, S. 6-40.

Merkl, Adolf (1993): „Freirecht und Richterfreiheit (1920)“, in: ders.; Mayer-Maly, Dorothea (Hg.): Merkl, Adolf Julius: Gesammelte Schriften. Band 1: Grundlagen des Rechts. Teilbd. 1. Berlin: Duncker \& Humblot, S. 259-266.

Merkl, Adolf; Mayer-Maly, Dorothea (Hg./ 1993): Merkl, Adolf Julius: Gesammelte Schriften. Band 1: Grundlagen des Rechts. Teilbd. 1. Berlin: Duncker \& Humblot.

Mertens, Bernd (2004): Gesetzgebungskunst im Zeitalter der Kodifikationen. Theorie und Praxis der Gesetzgebungstechnik aus historisch-vergleichender Sicht. Tübingen: Mohr Siebeck.

Merz-Benz, Peter-Ulrich (1991): „Rationalität und soziale Wirklichkeit: Die Genese von Rationalitätsstrukturen als Gegenstand der Gesellschaftstheorie“, in: Clausen, Lars; Schlüter, Carsten (Hg.): Hundert Jahre "Gemeinschaft und Gesellschaft". Ferdinand Tönnies in der internationalen Diskussion. Opladen: Leske + Budrich, S. 287-298.

Merz-Benz, Peter-Ulrich (1995): Tiefsinn und Scharfsinn. Ferdinand Tönnies' begriffliche Konstitution der Sozialwelt. Frankfurt am Main: Suhrkamp.

- (2007): Max Weber und Heinrich Rickert. Die erkenntniskritischen Grundlagen der verstehenden Soziologie. 2. Aufl. Wiesbaden: VS Verlag für Sozialwissenschaften.

- (2016): Erkenntnis und Emanation. Ferdinand Tönnies' Theorie soziologischer Erkenntnis. Wiesbaden: VS Verlag für Sozialwissenschaften.

Merz-Benz, Peter-Ulrich; Wagner, Gerhard (Hg./ 2001): Soziologie und Anti-Soziologie. Ein Diskurs und seine Rekonstruktion. Konstanz: UVK.

Meyer, Ahlrich (1969): „Mechanische und organische Metaphorik politischer Philosophie“, in: Archiv für Begriffsgeschichte 13, S. 128-199.

Michaëlis (1906): „Die Emanzipation des Richters vom Gesetzgeber“, in: Deutsche Juristen-Zeitung 11 (7), Sp. 394-399. 
Mikinovic, Stephan; Stangl, Wolfgang (1978): Strafprozeß und Herrschaft. Eine empirische Untersuchung zur Korrektur richterlicher Entscheidungen. Neuwied [u.a.]: Luchterhand.

Mikl-Horke, Gertraude (2007): „Vergessene Hoffnungen - Rudolf Goldscheids Soziologie“, in: Fritz, Wolfgang; Mikl-Horke, Gertraude (Hg.): Rudolf Goldscheid Finanzsoziologie und ethische Sozialwissenschaft. Münster, Wien, Berlin: LIT, S. 87-224.

Mitteis, Ludwig (1905): „Jhering, Rudolph“, in: Historische Kommission bei der Bayerischen Akademie der Wissenschaften (Hg.): Allgemeine Deutsche Biographie. Band 50: Nachträge bis 1899: Harkort - v. Kalchberg. Leipzig: Duncker \& Humblot, S. 652-664.

- (1909): „Freirechtslehren und Juristenzunft“, in: Deutsche Juristen-Zeitung 14 (15/16), Sp. 1038-1042.

Moebius, Stephan (2004): Praxis der Soziologiegeschichte. Methodologien, Konzeptionalisierung und Beispiele soziologiegeschichtlicher Forschung. Hamburg: Kovač.

Moeller, Hero (1920/21): „Zur Frage der Objektivität des wirtschaftlichen Prinzips“, in: Archiv für Sozialwissenschaft und Sozialpolitik 47, S. 154-199; 418ff.

Moench, Dietmar (1971): Die methodologischen Bestrebungen der Freirechtsbewegung auf dem Wege zur Methodenlehre der Gegenwart. Frankfurt am Main: Athenaeum.

Mohl, Robert von (1829): Das Staatsrecht des Königreiches Württemberg. Erster Theil: Das Verfassungsrecht. Tübingen: Laupp.

- (1855): Die Geschichte und Literatur der Staatswissenschaften. Erster Band. Erlangen: Enke.

- (1992 [1851]): Gesellschaftswissenschaften und Staatswissenschaften. Hrsg. und eingel. von Klaus H. Fischer. Schutterwald/Baden: Wiss. Verl.

Mokre, Hans (1932): Theorie des Gewohnheitsrechts. Problementwicklung und System. Wien: Springer.

Mommsen, Wolfgang J. (1974a): „Kapitalismus und Sozialismus. Die Auseinandersetzung mit Karl Marx“, in: ders. (Hg.): Max Weber. Gesellschaft, Politik und Geschichte. Frankfurt am Main: Suhrkamp, S. 144-181.

- (1974b): „Max Weber als Kritiker des Marxismus“, in: Zeitschrift für Soziologie 3 (3), S. 256-278.

- (1979): „Review: Critique of Stammler. By Max Weber. Translated by Guy Oakes. New York: Free Press, 1977. Pp. viii+184. \$12.95. “, in: American Journal of Sociology 85 (3), S. 670-672.

- (1993): „'Römisches' und 'deutsches' Recht: Editorischer Bericht“, in: ders. (Hg.): Landarbeiterfrage, Nationalstaat und Volkswirtschaftspolitik: Schriften und Reden 1892 - 1899. Max Weber Gesamtausgabe: Abt. 1, Bd. 4. Tübingen: Mohr, S. 524-525.

Mommsen, Wolfgang J.; Schwentker, Wolfgang (Hg./ 1988): Max Weber und seine Zeitgenossen. Göttingen, Zürich: Vandenhoeck \& Ruprecht.

Morlok, Martin; Kölbel, Ralf; Launhardt, Agnes (2000): „Recht als soziale Praxis. Eine soziologische Perspektive in der Methodenlehre", in: Rechtstheorie 31 (1), S. 15-46. 
Motive zu dem Entwurfe eines Bürgerlichen Gesetzbuches für das Deutsche Reich. Amtliche Ausgabe, Band 1-5 (1888a). Berlin, Leipzig: Guttentag.

— Band 1: Allgemeiner Theil (1888b). Berlin, Leipzig: Guttentag.

Mugdan, Benno (Hg./ 1899): Die gesammten Materialien zum Bürgerlichen Gesetzbuch für das Deutsche Reich. Band 1: Einführungsgesetz und allgemeiner Theil. Berlin: Decker.

Müller, Claudius (1994): Die Rechtsphilosophie des Marburger Neukantianismus. Naturrecht und Rechtspositivismus in der Auseinandersetzung zwischen Hermann Cohen, Rudolf Stammler und Paul Natorp. Tübingen: Mohr.

Müller, Hans-Peter (1983): Wertkrise und Gesellschaftsreform. Emile Durkheims Schriften zur Politik. Stuttgart: Ferdinand Enke.

- (1986): „Gesellschaft, Moral, Individualismus. Émile Durkheims Moraltheorie“, in: Bertram, Hans (Hg.): Gesellschaftlicher Zwang und moralische Autonomie. Frankfurt am Main: Suhrkamp, S. 71-105.

- (1999): „Die Moralökologie modernen Gesellschaften. Durkheims 'Physik der Sitten und des Rechts'“, in: Durkheim, Émile; Müller, Hans-Peter (Hg.): Physik der Sitten und des Rechts. Vorlesungen zur Soziologie der Moral. Frankfurt am Main: Suhrkamp, S. 307-341.

Müller, Hans-Peter; Schmid, Michael (1996): „Arbeitsteilung, Solidarität und Moral. Eine werksgeschichtliche und systematische Einführung in die 'Arbeitsteilung' von Emile Durkheim“, in: Durkheim, Émile (Hg.): Über soziale Arbeitsteilung. Studie über die Organisation höherer Gesellschaften. 2. Aufl. Frankfurt am Main: Suhrkamp, S. 481-532.

Müller-Eisert, Franz Arthur (1917): Rechtswissenschaft und Kulturwissenschaft. Tübingen: Mohr.

Müller-Erzbach, Rudolf (1906): „Rechtsfindung auf realer Grundlage“, in: Deutsche Juristen-Zeitung 11, Sp. 1235-1238.

- (1908): „Der Durchbruch des Interessenrechts durch allgemeine Rechtsprinzipien“, in: Jherings Jahrbücher für die Dogmatik des bürgerlichen Rechts 53, S. 331372.

- (1912): „Die Relativität der Begriffe und ihre Begrenzung durch den Zweck des Gesetzes: Zur Beleuchtung der Begriffsjurisprudenz. Vortrag, gehalten in der Wiener Juristischen Gesellschaft", in: Jherings Jahrbücher für die Dogmatik des bürgerlichen Rechts 61, S. 343-384.

— (1974): „Gefühl oder Vernunft als Rechtsquelle? Zur Aufklärung über die Interessenjurisprudenz [1913]“, in: Ellscheid, Günter; Hassemer, Winfried (Hg.): Interessenjurisprudenz. Darmstadt: Wissenschaftliche Buchgesellschaft, S. 47-71.

Münch, Fritz (1914/15): „Rechtsreformbewegung und Kulturphilosophie“, in: Die Tat. Sozial-religiöse Monatsschrift für deutsche Kultur 6 (4), S. 391-400.

- (1918): Kultur und Recht. Nebst einem Anhang: Rechtsreformbewegung und Kulturphilosophie. Leipzig: Felix Meiner. 
Muñoz Conde, Francisco (2010): „Franz von Liszt (1851-1919). Franz von Liszt als Strafrechtsdogmatiker und Kriminalpolitiker", in: Grundmann, Stefan et al. (Hg.): Festschrift 200 Jahre Juristische Fakultät der Humboldt-Universität zu Berlin. Geschichte, Gegenwart und Zukunft. Berlin: de Gruyter, S. 439-453.

Muscheler, Karlheinz (1984): Relativismus und Freirecht. Ein Versuch über Hermann Kantorowicz. Heidelberg: Müller.

Nassehi, Armin (2009): Der soziologische Diskurs der Moderne. Frankfurt am Main: Suhrkamp.

— (2015): „Gesellschaft“, in: Farzin, Sina; Jordan, Stefan (Hg.): Lexikon Soziologie und Sozialtheorie. Hundert Grundbegriffe. Ditzingen: Reclam, S. 85-90.

Nau, Heino Heinrich (1996): „'Zwei Ökonomien'. Die Vorgeschichte des Werturteilsstreit in der deutschsprachigen Ökonomie“, in: ders. (Hg.): Der Werturteilsstreit. Die Äußerungen zur Werturteilsdiskussion im Ausschuss des Vereins für Sozialpolitik (1913). Marburg: Metropolis, S. 9-64.

Nelken, David (1986): „Beyond the Study of 'Law and Society'? Henry's 'Private Justice' and O'Hagan's 'The End of Law?' ', in: American Bar Foundation Research Journal 11 (2), S. 323-338.

- (2008): „Eugen Ehrlich, Living Law, and Plural Legalities“, in: Theoretical Inquiries in Law 9 (2), S. 443-471.

Neukamp, Ernst (1912): „Der gegenwärtige Stand der Freirechtsbewegung“, in: Deutsche Juristen-Zeitung 17 (1), Sp. 44-50.

Neukamp (1917): „Literatur: Kelsen, Dr. Hans: Hauptprobleme der Staatsrechtslehre; Ehrlich, Eugen: Grundlegung der Soziologie des Rechts“, in: Zeitschrift für die gesamte Staatswissenschaft 73 (1/2), S. 226-232.

Neumann (1888): „Literatur zum Entwurfe eines bürgerlichen Gesetzbuchs für das Deutsche Reich“, in: Beiträge zur Erläuterung des deutschen Rechts 32, S. 679-683.

- (1889a): „Literatur zum Entwurfe eines bürgerlichen Gesetzbuches für das deutsche Reich“, in: Beiträge zur Erläuterung des deutschen Rechts 33, S. 93-106.

- (1889b): „Literatur zum Entwurfe eines bürgerlichen Gesetzbuches für das deutsche Reich (Fortsetzung)“, in: Beiträge zur Erläuterung des deutschen Rechts 33, S. 383-405.

Neumann, Franz (1929): „Gegen ein Gesetz über Nachprüfung der VerfassungsmäBigkeit von Reichsgesetzen“, in: Die Gesellschaft. Internationale Revue für Sozialismus und Politik VI, S. 517-536.

Neumann, Ulfrid (2005): „Wissenschaftstheorie der Rechtswissenschaft bei Hans Kelsen und Gustav Radbruch. Zwei 'neukantianische' Perspektiven“, in: Paulson, Stanley L.; Schulte, Martin (Hg.): Hans Kelsen. Staatsrechtslehrer und Rechtstheoretiker des 20. Jahrhunderts. Tübingen: Mohr Siebeck, S. 35-55.

- (2016): „Gustav Radbruch und die Freirechtsbewegung“, in: Scritti per Luigi Lombardi Vallauri. Vol. 2. Assago Milanofiori, Padova: Wolters, S. 1001-1018.

Nietzsche, Friedrich (1887): Zur Genealogie der Moral. Eine Streitschrift. Leipzig: Neumann. 
Nitzschke, Heinz (1932): „Die Geschichtsphilosophie Lorenz von Steins. Ein Beitrag zur Geistesgeschichte des neunzehnten Jahrhunderts“, in: Historische Zeitschrift. Beihefte 26, S. 1-26.

Nordmann, Alfred; Schwarz, Astrid (2012): „Alte Objekte, neue Dinge: Von Wissenschaft zu Technoscience“, in: Maasen, Sabine et al. (Hg.): Handbuch Wissenschaftssoziologie. Wiesbaden: VS Verlag für Sozialwissenschaften, S. 291-302.

Nörr, Knut Wolfgang (1991): Eher Hegel als Kant. Zum Privatrechtsverständnis im 19. Jabrhundert. Paderborn [u.a.]: Schöningh.

Nörr, Knut Wolfgang; Schefold, Bertram; Tenbruck, Friedrich H. (Hg./ 1994): Geisteswissenschaften zwischen Kaiserreich und Republik. Zur Entwicklung von Nationalökonomie, Rechtswissenschaft und Sozialwissenschaft im 20. Jahrhundert. Stuttgart: Steiner.

Nußbaum, Arthur (1906): „Über Aufgabe und Wesen der Jurisprudenz“, in: Zeitschrift für Socialwissenschaft IX, S. 1-17.

— (1908): „Rezension: Stampe, Ernst: Unsere Rechts- und Begriffsbildung“, in: Archiv für Rechts- und Wirtschaftsphilosophie 2 (1), S. 157-158.

- (1914): Die Rechtstatsachenforschung. Ihre Bedeutung für Wissenschaft und Unterricht. Tübingen: Mohr.

- (1916): „Theoreme und Wirklichkeit in den Allgemeinen Lehren des Bürgerlichen Rechts“, in: Archiv für bürgerliches Recht 42, S. 136-193.

Nusser, Karl-Heinz (1986): Kausale Prozesse und sinnerfassende Vernunft. Max Webers philosophische Fundierung der Soziologie und der Kulturwissenschaften. Freiburg (Breisgau), München: Alber.

Oakes, Guy (1977): „Introductory Essay“, in: Weber, Max; Oakes, Guy (Hg.): Critique of Stammler. Translated, with an introductory essay, by Guy Oakes. New York: Free Press, S. 1-56.

- (1988a): „Reading Weber's 'Wissenschaftslehre': Remarks on the Recent German Literature“, in: Sociological Forum 3 (2), S. 301-307.

- (1988b): Weber and Rickert. Concept formation in the cultural sciences. Cambridge, Mass.: MIT Press.

- (1990): Die Grenzen kulturwissenschaftlicher Begriffsbildung. Heidelberger Max Weber-Vorlesungen 1982. Frankfurt am Main: Suhrkamp.

— (2007): „Wertrationalität und Wertsphären. Kritische Bemerkungen“, in: Gostmann, Peter; Merz-Benz, Peter-Ulrich (Hg.): Macht und Herrschaft. Zur Revision zweier soziologischer Grundbegriffe. Wiesbaden: VS Verlag für Sozialwissenschaften, S. 27-47.

Oberschall, Anthony (1997): Empirische Sozialforschung in Deutschland 1848 - 1914. Freiburg (Breisgau), München: Alber.

Oertmann, Paul (1896a): „Civilistische Rundschau“, in: Archiv für bürgerliches Recht 11, S. 180-214.

- (1896b): „Das bürgerliche Gesetzbuch im Deutschen Reichstag“, in: Archiv für bürgerliches Recht 11, S. 4-25. 
- (1914): „Staatliche und gesellschaftliche Rechtsbildung“, in: Archiv für bürgerliches Recht 40, S. 70-91.

— (1992): „Soziologische Rechtsfindung [1911]“, in: Gängel, Andreas; Mollnau, Karl A. (Hg.): Gesetzesbindung und Richterfreiheit. Texte zur Methodendebatte 1900 - 1914. Freiburg (Breisgau), Berlin: Haufe, S. 200-227.

Oestmann, Peter (2002): Rechtsvielfalt vor Gericht. Rechtsanwendung und Partikularrecht im Alten Reich. Frankfurt am Main: Klostermann.

Oexle, Otto Gerhard (1996): „Von Nietzsche zu Max Weber: Wertproblem und Objektivitätsforderung der Wissenschaft im Zeichen des Historismus“, in: ders. (Hg.): Geschichtswissenschaft im Zeichen des Historismus. Studien zu Problemgeschichten der Moderne. Göttingen: Vandenhoeck \& Ruprecht, S. 73-94.

Ofner, Julius (1894): Studien sozialer Jurisprudenz. Wien: Hölder.

- (1913): „Induktion im Recht“, in: Recht und Wirtschaft. Monatsschrift des Vereins zur Förderung zeitgemässer Rechtspflege und Verwaltung, S. $328 \mathrm{ff}$.

Ofner, Julius (Hg./ 1931): Recht und Gesellschaft. Gesammelte Vorträge und Aufsätze. Herausgegeben und eingeleitet von Walther Eckstein. Wien, Leipzig: Gerold.

Ogorek, Regina (1986): Richterkönig oder Subsumtionsautomat? Zur Justiztheorie im 19. Jahrbundert. Frankfurt am Main: Klostermann.

- (1988): „Individueller Rechtsschutz gegenüber der Staatsgewalt. Zur Entwicklung der Verwaltungsgerichtsbarkeit“, in: Kocka, Jürgen (Hg.): Bürgertum im 19. Jahrhundert. München: DTV, S. 372-405.

Opielka, Michael (1990): „'Gemeinschaft' und Sozialpolitik“, in: Schlüter, Carsten; Clausen, Lars (Hg.): Renaissance der Gemeinschaft? Stabile Theorie und neue Theoreme. Berlin: Duncker \& Humblot, S. 163-190.

Opitz, Hugo Gottfried (1889): Gutachten über den Entwurf eines Bürgerlichen Gesetzbuchs für das Deutsche Reich. Erstattet für den Landeskulturrath des Königreichs Sachsen von H. G. Opitz. Leipzig: Roßberg.

Opitz, Sven (2012): An der Grenze des Rechts. Inklusion/Exklusion im Zeichen der Sicherheit. Weilerswist: Velbrück.

Oppenheimer, Franz (2015): „Die beiden Wurzeln des Rechts [1929]“, in: Lichtblau, Klaus; Oppenheimer, Franz (Hg.): Schriften zur Soziologie. Herausgegeben von Klaus Lichtblau. Wiesbaden: Springer VS, S. 303-318.

Orihara, Hiroshi (1999): „Max Webers Beitrag zum 'Grundriss der Sozialökonomik'. Das Vorkriegsmanuskript als ein integriertes Ganzes“, in: Kölner Zeitschrift für Soziologie und Sozialpsychologie 51 (4), S. 724-734.

Otaka, Tomoo (1932): Grundlegung der Lehre vom sozialen Verband. Wien: Springer.

Pachman, Semen V. (1986): Über die gegenwärtige Bewegung in der Rechtswissenschaft. Neubearbeitet und herausgegeben von Manfred Rehbinder. Berlin: Duncker \& Humblot.

Pagel (1919): „Rezension: 'Die Tat'. Sozial-religiöse Monatsschrift für deutsche Kultur. VI. Jahrgang 1914/1915, Heft 4 (Juliheft). Jena, Eugen Dietrichs“, in: Kritische Vierteljahresschrift für Gesetzgebung und Rechtswissenschaft 18 (54), S. 547-549. 
Pankoke, Eckart (1970): Sociale Bewegung - Sociale Frage - Sociale Politik: Grundfragen der deutschen „Socialwissenschaft" im 19. Jahrhundert. Stuttgart: Klett.

Papendorf, Knut; Machura, Stefan; Hellum, Anne (2014): Eugen Ehrlich's Sociology of Law. Wien, Zürich, Berlin: Lit Verlag.

Parsons, Talcott (1936): „Book reviews: Max Webers Wissenschaftslehre. By Alexander von Schelting. Tübingen, J. C. B. Mohr, 1934. Pp. vii-42o RM 16.“, in: American Sociological Review 1 (4), S. 675-681.

- (1966): The Structure of social action. A study in social theory with special reference to a group of recent European writers. 4. Aufl. New York: Free Press.

- (1973): „Some Afterthoughts on Gemeinschaft und Gesellschaft", in: Cahnman, Werner Jacob (Hg.): Ferdinand Tönnies. A new evaluation. Leiden: Brill, S. 151159.

— (1977): „Law as an Intellectual Stepchild“, in: Sociological Inquiry 47 (3-4), S. 1158.

Passoth, Jan-Hendrik (2012): „Dinge der Wissenschaft“, in: Maasen, Sabine et al. (Hg.): Handbuch Wissenschaftssoziologie. Wiesbaden: VS Verlag für Sozialwissenschaften, S. 203-212.

Pauer-Studer, Herlinde (2014): „Einleitung: Rechtfertigung des Unrechts. Das Rechtsdenken im Nationalsozialismus“, in: dies.; Fink, Julian (Hg.): Rechtfertigungen des Unrechts. Das Rechtsdenken im Nationalsozialismus in Originaltexten. Berlin: Suhrkamp, S. 15-135.

Paulsen, Friedrich (1891): System der Ethik mit einem Umriß der Staats- und Gesellschaftslehre. 2. Aufl. Berlin: Herz.

Paulson, Stanley L. (1988): Die Rolle des Neukantianismus in der reinen Rechtslehre. Eine Debatte zwischen Sander und Kelsen. Aalen: Scientia.

- (Hg./ 1992): Hans Kelsen und die Rechtssoziologie. Auseinandersetzungen mit Hermann U. Kantorowicz, Eugen Ehrlich und Max Weber. Aalen: Scientia.

- (2007): „Ein 'starker Intellektualismus': Badener Neukantianismus und Rechtsphilosophie“, in: Senn, Marcel; Puskás, Dániel (Hg.): Rechtswissenschaft als Kulturwissenschaft? Kongress der Schweizerischen Vereinigung für Rechts- und Sozialphilosophie, 15. und 16. Juni 2007, Universität Zürich. Stuttgart: Steiner, S. 83-103.

Peter, Lothar (2001): „Warum und wie betreibt man Soziologiegeschichte?“, in: Klingemann, Carsten et al. (Hg.): Jahrbuch für Soziologiegeschichte 1997/98. Wiesbaden: VS Verlag für Sozialwissenschaften, S. 9-64.

- (2013): „Dialektik der Gesellschaft versus 'Conscience Collective'. Zur Kritik Theodor W. Adornos an Émile Durkheim“, in: Bogusz, Tanja; Delitz, Heike (Hg.): Émile Durkheim. Soziologie - Ethnologie - Philosophie. Frankfurt am Main, New York, NY: Campus, S. 73-94.

Peters, Dorothee (1973): Richter im Dienst der Macht. Zur gesellschaftlichen Verteilung der Kriminalität. Stuttgart: Enke.

Petersen, Jens (2008): Max Webers Rechtssoziologie und die juristische Methodenlehre. Berlin: de Gruyter.

- (2014): Max Webers Rechtssoziologie und die juristische Methodenlehre. 2. Aufl. Tübingen: Mohr Siebeck. 
Petersen, Julius (1889): Die Berufung zur Erbschaft und die letztwilligen Verfügungen überhaupt nach dem Entwurfe eines Bürgerlichen Gesetzbuches für das Deutsche Reich. Berlin: Guttentag.

- (1890): „Der Entwurf eines bürgerlichen Gesetzbuchs für das deutsche Reich und die Kritik“, in: Beiträge zur Erläuterung des deutschen Rechts 34, S. 32-78.

Petražycki, Leo (1893): Die Lehre vom Einkommen. Vom Standpunkt des gemeinen Civilrechts unter Berücksichtigung des Entwurfs eines bürgerlichen Gesetzbuches für das Deutsche Reich. Band I: Grundbegriffe. Berlin: Müller.

- (1895): Die Lehre vom Einkommen. Vom Standpunkt des gemeinen Civilrechts unter Berücksichtigung des Entwurfs eines bürgerlichen Gesetzbuches für das Deutsche Reich. Band II: Einkommensersatz. Berlin: Müller.

Pfeiffer-Munz, Susanne (1979): Soziales Recht ist deutsches Recht. Otto von Gierkes Theorie des sozialen Rechts untersucht anhand seiner Stellungnabmen zur deutschen und zur schweizerischen Privatrechtskodifikation. Zürich: Schulthess.

Pfizer, Gustav (1889): Was erwartet Deutschland von dem bürgerlichen Gesetzbuch? Hamburg: Verlagsanstalt.

- (1891): „Geflickte Schienen“, in: Beilage zur Allgemeinen Zeitung (München), 10.10.1891 (237), S. 1-4.

- (1892a): „Der Reichstag und das Bürgerliche Gesetzbuch (Morgenblatt der Allgemeinen Zeitung vom 4. Januar 1991). Abgedruckt als Anhang 1", in: ders. (Hg.): Wort und That. Ein Nothruf für ein Deutsches Recht. Leipzig: Otto Wigand, S. 93-109.

- (Hg./ 1892b): Wort und That. Ein Nothruf für ein Deutsches Recht. Leipzig: Otto Wigand.

- (1893): Sociales Recht. Vortrag gehalten in der Versammlung der deutschen Partei am 25. November 1892 zu Ulm. Ulm: Nübling.

Pickering, William S. F. (Hg./ 2000): Durkheim and representations. London: Routledge.

Planck, Gottlieb (1889): „Zur Kritik des Entwurfes eines bürgerlichen Gesetzbuches für das deutsche Reich“, in: Archiv für die civilistische Praxis 25, S. 327-429.

- (1899): „Die soziale Tendenz des BGB“, in: Deutsche Juristen-Zeitung 4, S. 181184.

- (1909): „Windscheid als Mitarbeiter am Bürgerlichen Gesetzbuche“, in: Deutsche Juristen-Zeitung 14, Sp. 951-954.

Platt, Jennifer (1995): „La réception des Règles de la méthode sociologique en Angleterre et aux Etats-Unis (1930-1970)“, in: Borlandi, Massimo; Mucchielli, Laurent (Hg.): La sociologie et sa méthode. Les Règles de Durkheim un siècle après. Paris: L'Harmattan, S. 321-351.

Pleister, Wolfgang (1982): Persönlichkeit, Wille und Freiheit im Werke Jherings. Ebelsbach: Gremer.

Podgörecki, Adam (1980): „Unrecognized Father of Sociology of Law: Leon Petražycki: Reflections based on Jan Gorecki's Sociology and Jurisprudence of Leon Petražycki“, in: Law \& Society Review 15 (1), S. 183-202. 
Pokrovskij, Iosif A. (2015): Grundprobleme des Bürgerlichen Rechts (1917). Übers., hrsg. u. eingel. v. Martin Avenarius u. Anastasia Berger. Tübingen: Mohr Siebeck.

Polanyi, Karl (1977 [1944]): The Great Transformation. Politische und ökonomische Ursprünge von Gesellschaften und Wirtschaftssytemen. Wien: Europaverlag.

Pontes de Miranda, Francisco Cavalcanti (1922): „Rechtsgefühl und Begriff des Rechts“, in: Archiv für Rechts- und Wirtschaftsphilosophie 16 (2), S. 157-196.

Posner, Richard A. (1993): „What do Judges and Justices maximize? (The same thing everybody else does)“, in: Supreme Court Economic Review 3, S. 1-41.

Post, Albert Hermann (1867): Das Naturgesetz des Rechts. Einleitung in eine Philosophie des Rechts auf Grundlage der modernen empirischen Wissenschaft. Bremen: Gesenius.

Pottage, Alain (2014): „Law after Anthropology: Object and Technique in Roman Law“, in: Theory, Culture \& Society 31 (2-3), S. 147-166.

Pottage, Alain; Mundy, Martha (2004): Law, anthropology, and the constitution of the social. Making persons and things. Cambridge, New York: Cambridge University Press.

Prahl, Hans-Werner (1986): „Der Streit um die Vaterschaft. Die Anfänge der Soziologie in der Sicht deutscher Soziologie vor 1933“, in: Papcke, Sven (Hg.): Ordnung und Theorie. Beiträge zur Geschichte der Soziologie in Deutschland. Darmstadt: Wissenschaftliche Buchgesellschaft, S. 48-68.

Procacci, Giovanna (1993): Gouverner la misère. La question sociale en France: 1789-1848. Paris: Editions du Seuil.

— (1991): „Social economy and the government of poverty“, in: Burchell, Graham et al. (Hg.): The Foucault effect. London: Harvester Wheatsheaf, S. 151-168.

— (2002): „Pour une généalogie de l'Etat social“, in: Gilomen, Hans-Jörg; Guex, Sébastien; Studer, Brigitte (Hg.): Von der Barmherzigkeit zur Sozialversicherung. Umbrüche und Kontinuitäten vom Spätmittelalter bis zum 20. Jahrhundert. Zürich: Chronos, S. 213-220.

Puchta, Georg Friedrich (1828): Das Gewohnheitsrecht: Erster Theil. Erlangen: Palm'sche Verlagsbuchhandlung.

- (1837): Das Gewohnheitsrecht: Zweiter Theil. Erlangen: Palm'sche Verlagsbuchhandlung.

- (1838): Lehrbuch der Pandekten. Leipzig: Johann Ambrosius Barth.

- (anonym/ 1839): „Romeo Maurenbrecher. De auctoritate prudentum prolusio academica“, in: Kritische Jahrbücher für deutsche Rechtswissenschaft 3 (6), S. 728737.

- (1841): Cursus der Institutionen: Erster Band. Einleitung in die Rechtswissenschaft und Geschichte des Rechts bey dem römischen Volk. Leipzig: Breitkopf und Härtel.

- (1844a): Pandekten. 2. Aufl. Leipzig: Johann Ambrosius Barth.

- (1844b): „Rezension: Georg Beseler: Volksrecht und Juristenrecht, Leipzig 1843“, in: Jahrbücher für wissenschaftliche Kritik (1), Sp. 1-30.

— (1845): Pandekten. 3. Aufl. Leipzig: Johann Ambrosius Barth. 
- (1847): Vorlesungen über das heutige römische Recht. Erster Band. Aus dessen Nachlaß herausgegeben von Dr. Adolf August Friedrich Rudorff. Leipzig: Tauchnitz.

— (1851): „Zu welcher Classe von Rechten gehört der Besitz? Beantwortet durch eine Classification der Rechte überhaupt (1829)“, in: Rudorff, Adolph August Friedrich (Hg.): Georg Friedrich Puchta's kleine civilistische Schriften. Gesammelt und herausgegeben von Dr. Adolph August Friedrich Rudorff. Leipzig: Breitkopf und Härtel, S. 239-258.

Quensel, Bernhard K. (1997): „Logik und Methode in der 'Rechtssoziologie' Max Webers. Ein Beitrag zur Klärung der grundlegenden Begriffe und Perspektiven“, in: Zeitschrift für Rechtssoziologie 18 (2), S. 133-159.

- (2007): Max Webers Konstruktionslogik. Sozialökonomik zwischen Geschichte und Theorie. Baden-Baden: Nomos.

Radbruch, Gustav (1906): „Rechtswissenschaft als Rechtsschöpfung. Ein Beitrag zum juristischen Methodenstreit“, in: Archiv für Sozialwissenschaft und Sozialpolitik 22, S. 355-370.

- (1907): „Literaturbericht. 11. Rechtsphilosophie“, in: Zeitschrift für die gesamte Strafrechtswissenschaft 27 (1), S. 241-255.

- (1914/1915): „Über das Rechtsgefühl“, in: Die Tat. Sozial-religiöse Monatsschrift für deutsche Kultur 6 (4), S. 337-345.

— (1965): „Einleitung“, in: Jhering, Rudolf von; Rusche, Christian (Hg.): Der Kampf ums Recht. Ausgewählte Schriften mit einer Einleitung von Gustav Radbruch. herausgegeben von Christian Rusche. Nürnberg: Glock \& Lutz, S. 7-14.

- (1969): Paul Johann Anselm Feuerbach. Ein Juristenleben. Dritte Auflage, herausgegeben von Erik Wolf. Göttingen: Vandenhoeck \& Ruprecht.

- (1988): „Nachruf Ernst Fuchs“, in: ders.; Kaufmann, Arthur (Hg.): Gustav Radbruch Gesamtausgabe. Band 16: Biographische Schriften. Heidelberg: Müller, S. 6465.

— (1993): „Grundzüge der Rechtsphilosophie [1914]“, in: ders.; Kaufmann, Arthur (Hg.): Rechtsphilosophie II. Heidelberg: Müller, S. 9-205.

Radbruch, Gustav; Dreier, Ralf (Hg./ 2003): Rechtsphilosophie. Studienausgabe. Heidelberg: Müller.

Radbruch, Gustav; Kaufmann, Arthur (Hg./ 1987): Gustav Radbruch Gesamtausgabe. Band I: Rechtsphilosophie I. Heidelberg: Müller.

Ramm, Thilo (1974/1975): "Juristensozialismus in Deutschland“, in: Quaderni Fiorentini per la storia del pensiero giuridico moderno 3/4, S. 7-23.

Rammstedt, Otthein (1991): „Die Frage der Wertfreiheit und die Gründung der Deutschen Gesellschaft für Soziologie“, in: Clausen, Lars; Schlüter, Carsten (Hg.): Hundert Jahre "Gemeinschaft und Gesellschaft". Ferdinand Tönnies in der internationalen Diskussion. Opladen: Leske + Budrich, S. 549-560.

Rassow (1877): „Die Verhandlungen der Kommission zur Ausarbeitung eines bürgerlichen Gesetzbuchs für Deutschland“, in: Beiträge zur Erläuterung des deutschen Rechts 21, S. 167-245.

Ratzenhofer, Gustav (1893): Wesen und Zweck der Politik: Als Theil der Sociologie und Grundlage der Staatswissenschaften. 3. Bde. Leipzig: Brockhaus. 
Reckwitz, Andreas (2008): Subjekt. Bielefeld: Transcript.

Rée, Paul (1885): Die Entstehung des Gewissens. Berlin: Carl Duncker's Verlag.

Rehberg, August Wilhelm (1814): Ueber den Code Napoleon und dessen Einführung in Deutschland. Hannover: Hahn.

Rehberg, Karl-Siegbert (2008): „Soziologie als 'Wirklichkeitswissenschaft' jenseits von Naturalismus und Virtualitätseuphorie: Eröffnungsvortrag des 33. Kongresses der Deutschen Gesellschaft für Soziologie“, in: ders. (Hg.): Die Natur der Gesellschaft. Verhandlungen des 33. Kongresses der Deutschen Gesellschaft für Soziologie in Kassel 2006. Frankfurt am Main, New York: Campus, S. 23-41.

Rehbinder, Manfred (1986): Die Begründung der Rechtssoziologie durch Eugen Ehrlich. 2. Aufl. Berlin: Duncker \& Humblot.

- (1987): „Max Weber und die Rechtswissenschaft“, in: ders.; Tieck, Klaus-Peter (Hg.): Max Weber als Rechtssoziologe. Berlin: Duncker \& Humblot, S. 127-149.

— (1989): „Recht und Rechtswissenschaft im Werk von Max Weber“, in: Weiss, Johannes (Hg.): Max Weber heute. Erträge und Probleme der Forschung. Frankfurt am Main: Suhrkamp, S. 497-514.

- (1995): „Die Rechtstatsachenforschung im Schnittpunkt von Rechtssoziologie und soziologischer Jurisprudenz (1970)“, in: ders.; Würtenberger, Thomas (Hg.): Abhandlungen zur Rechtssoziologie. Berlin: Duncker \& Humblot, S. 31-66.

— (2003): Rechtssoziologie. 5. Aufl. München: Beck.

Reichel, Hans (1915): Gesetz und Richterspruch: Zur Orientierung über Rechtsquellenund Rechtsanwendungslehre der Gegenwart. Zürich: Orell Füssli.

— (1992): „Zur Freirechtsbewegung [1910]“, in: Gängel, Andreas; Mollnau, Karl A. (Hg.): Gesetzesbindung und Richterfreiheit. Texte zur Methodendebatte 1900 - 1914. Freiburg (Breisgau), Berlin: Haufe, S. 193-199.

Reichsjustizamt (1967a): Zusammenstellung der gutachtlichen Äusserungen zu dem Entwurf eines Bürgerlichen Gesetzbuchs gefertigt im Reichsjustizamt. Band I.: Aeußerungen zum allgemeinen Teil. Neudruck der Ausgabe 1890. Osnabrück: Otto Zeller.

- (1967b): Zusammenstellung der gutachtlichen Äusserungen zu dem Entwurf eines Bürgerlichen Gesetzbuchs gefertigt im Reichsjustizamt. Band VI.: Nachträge. Neudruck der Ausgabe 1891. Osnabrück: Otto Zeller.

- (1967c): Zusammenstellung der gutachtlichen Äusserungen zu dem Entwurf eines Bürgerlichen Gesetzbuchs gefertigt im Reichsjustizamt. Band I-VI [1890-1991]. Osnabrück: Otto Zeller

Rein, Ulrike (1988): „Rechtssoziologie und Rechtspositivismus. Die Kontroverse zwischen Eugen Ehrlich und Hans Kelsen 1915/16“, in: Paulson, Stanley L.; Hammer, Stefan (Hg.): Untersuchungen zur reinen Rechtslehre. Ergebnisse eines Wiener Rechtstheoretischen Seminars 1985/86. Wien: Manz, S. 91-108.

Repgen, Tilman (2001): Die soziale Aufgabe des Privatrechts. Eine Grundfrage in Wissenschaft und Kodifikation am Ende des 19. Jahrhunderts. Tübingen: Mohr Siebeck.

- (2007): „Ius Commune“, in: Haferkamp, Hans-Peter; Repgen, Tilman (Hg.): Usus modernus pandectarum. Römisches Recht, Deutsches Recht und Naturrecht in der Frühen Neuzeit. Klaus Luig zum 70. Geburtstag. Köln [u.a.]: Böhlau, S. 157173. 
Reyscher, August Ludwig (1828): Ueber die Bedürfnisse unserer Zeit in der Gesetzgebung mit besonderer Rücksicht auf den Zustand der letzteren in Württemberg. Stuttgart [u.a.]: Cotta'sche Buchhandlung.

- (1839): „Ueber das Daseyn und die Natur des Deutschen Rechts“, in: Zeitschrift für deutsches Recht und deutsche Rechtswissenschaft 1, S. 11-53.

— (1842): „Für und wider das deutsche Recht“, in: Zeitschrift für deutsches Recht und deutsche Rechtswissenschaft 7, S. 121-156.

Rheinberger, Hans-Jörg (1992a): „Das 'epistemische Ding' und seine technischen Bedingungen“, in: ders. (Hg.): Experiment, Differenz, Schrift. Zur Geschichte epistemischer Dinge. Marburg an der Lahn: Basilisken-Press, S. 67-86.

- (Hg./ 1992b): Experiment, Differenz, Schrift. Zur Geschichte epistemischer Dinge. Marburg an der Lahn: Basilisken-Press.

- (2001): „Objekt und Repräsentation“, in: Heintz, Bettina; Benz, Arnold (Hg.): Mit dem Auge denken. Strategien der Sichtbarmachung in wissenschaftlichen und virtuellen Welten. Zürich, Wien: Voldemeer [u.a.], S. 55-61.

— (2005): „A Reply to David Bloor: 'Toward a Sociology of Epistemic Things'“, in: Perspectives on Science 13 (3), S. 406-410.

- (2006): Experimentalsysteme und epistemische Dinge. Eine Geschichte der Proteinsynthese im Reagenzglas. Frankfurt am Main: Suhrkamp.

— (2012): „Epistemische Dinge und Verkörperung“, in: Blume, André; Krois, John M.; Rheinberger, Hans-Jörg (Hg.): Verkörperungen. Berlin: Akademie Verlag, S. 3-9.

Rickert, Heinrich (1888): Zur Lehre von der Definition. Freiburg (Breisgau): Mohr.

- (1896): Die Grenzen der naturwissenschaftlichen Begriffsbildung. Eine logische Einleitung in die historischen Wissenschaften. Freiburg (Breisgau) [u.a.]: Mohr.

- (1899): Kulturwissenschaft und Naturwissenschaft: Ein Vortrag. Freiburg (Breisgau) [u.a.]: Mohr.

- (1929): Zur Lehre von der Definition. 3. Aufl. Tübingen: Mohr.

Riebschläger, Klaus (1968): Die Freirechtsbewegung. Zur Entwicklung einer soziologischen Rechtsschule. Berlin: Duncker \& Humblot.

Riedel, Manfred (1970): Bürgerliche Gesellschaft und Staat. Grundproblem und Struktur der Hegelschen Rechtsphilosophie. Neuwied, Berlin: Luchterhand.

- (1975a): „Gesellschaft, bürgerliche“, in: Brunner, Otto; Conze, Werner; Koselleck, Reinhart (Hg.): Geschichtliche Grundbegriffe. Historisches Lexikon zur politisch-sozialen Sprache in Deutschland. Bd. 2: E-G. Stuttgart: Klett-Cotta, S. 719800.

— (1975b): „Gesellschaft, Gemeinschaft“, in: Brunner, Otto; Conze, Werner; Koselleck, Reinhart (Hg.): Geschichtliche Grundbegriffe. Historisches Lexikon zur politisch-sozialen Sprache in Deutschland. Bd. 2: E-G. Stuttgart: Klett-Cotta, S. 801862.

Riedel, Tanja-Carina (2008): Gleiches Recht für Frau und Mann. Die bürgerliche Frauenbewegung und die Entstehung des BGB. Köln [u.a.]: Böhlau. 
Riezler, Erwin (1921): Das Rechtsgefühl. Rechtspsychologische Betrachtungen. München, Berlin, Leipzig: Schweitzer.

Riles, Annelise (2005): „A New Agenda for the Cultural Study of Law: Taking on the Technicalities“, in: Buffalo Law Review 53, S. 973-1033.

Ring, V. (1888): „Der Entwurf eines bürgerlichen Gesetzbuchs und seine Beurtheiler", in: Archiv für bürgerliches Recht 1, S. 190-232.

Röder, Karl David August (1855): Grundgedanken und Bedeutung des römischen und germanischen Rechts. Leipzig: Breitkopf und Härtel.

Rogge, Heinrich (1917/1918): „Deduktivismus im Recht“, in: Archiv für Rechts- und Wirtschaftsphilosophie 11 (3), S. 339-346.

Röhl, Klaus F. (1974): Das Dilemma der Rechtstatsachenforschung. Mit einem Vorwort von Rolf Bender. Tübingen: Mohr.

— (1978): „Über außervertragliche Voraussetzungen des Vertrages“, in: Kaulbach, Friedrich; Krawietz, Werner (Hg.): Recht und Gesellschaft. Festschrift für Helmut Schelsky zum 65. Geburtstag. Berlin: Duncker \& Humblot, S. 435-480.

- (1987): Rechtssoziologie. Ein Lehrbuch. Köln: Heymann.

Roscher, Wilhelm (1843): Grundriss zu Vorlesungen über die Staatswirthschaft. Nach geschichtlicher Methode. Göttingen: Dieterichsche Buchhandlung.

Rose, Nikolas (1996): „The death of the social? Re-figuring the territory of government", in: Economy \& Society 25 (3), S. 327-356.

Rose, Nikolas; Valverde, Mariana (1998): „Governed By Law?“, in: Social \& Legal Studies 7 (4), S. 541-551.

Ross, Alf (1929): Theorie der Rechtsquellen. Ein Beitrag zur Theorie des positiven Rechts auf Grundlage dogmengeschichtlicher Untersuchungen. Leipzig, Wien: Deuticke.

Rothacker, E. (1923): „Savigny, Grimm, Ranke. Ein Beitrag zur Frage nach dem Zusammenhang der Historischen Schule“, in: Historische Zeitschrift 128 (3), S. $415-445$.

Rottleuthner, Hubert (1973a): Richterliches Handeln. Zur Kritik der juristischen Dogmatik. Frankfurt am Main: Athenäum.

- (1973b): Rechtswissenschaft als Sozialwissenschaft. Frankfurt am Main: Fischer.

— (1984): „Rechtstheoretische Probleme der Soziologie des Rechts. Die Kontroverse zwischen Hans Kelsen und Eugen Ehrlich (1915/1917)“, in: Krawietz, Werner; Schelsky, Helmut (Hg.): Rechtssystem und gesellschaftliche Basis bei Hans Kelsen. Berlin: Duncker \& Humblot, S. 523-551.

- (1986): „Drei Rechtssoziologien: Eugen Ehrlich, Hugo Sinzheimer, Max Weber“, in: Heyen, Erk Volkmar (Hg.): Historische Soziologie der Rechtswissenschaft. Frankfurt am Main: Klostermann, S. 227-252.

- (2013): „Das lebende Recht bei Eugen Ehrlich und Ernst Hirsch“, in: Zeitschrift für Rechtssoziologie 33 (2), S. 191.

Rückert, Joachim (1974): August Ludwig Reyschers Leben und Rechtstheorie. 1802-1880. Berlin: J. Schweitzer.

- (1984): Idealismus, Jurisprudenz und Politik bei Friedrich Carl von Savigny. Ebelsbach: Gremer. 
- (1986): „Das 'gesunde Volksempfinden' - eine Erbschaft Savignys?“, in: Zeitschrift für Rechtsgeschichte/ Germanistische Abteilung 103, S. 199-247.

- (1988): Autonomie des Rechts in rechtshistorischer Perspektive. Hannover: Juristische Studiengesellschaft Hannover.

- (1992): „Bernhard Windscheid und seine Jurisprudenz 'als solche' im liberalen Rechtsstaat (1817-1892)“, in: JuS 32 (11), S. 902-908.

- (1993): „Savignys Konzeption von Jurisprudenz und Recht, ihre Folgen und ihre Bedeutung bis heute", in: Tijdschrift voor Rechtsgeschiedenis (The Legal History Review) 61 (1), S. 65-95.

- (2002): „Thibaut, Savigny, Gans: Der Streit zwischen 'historischer' und 'philosophischer' Rechtsschule“, in: Blänkner, Reinhard et al. (Hg.): Eduard Gans (1797 1839). Politischer Professor zwischen Restauration und Vormärz. Leipzig: Leipziger Univ.-Verl., S. 247-311.

- (2003): „Das BGB und seine Prinzipien: Aufgabe, Lösung, Erfolg“, in: Schmoeckel, Mathias; Rückert, Joachim; Zimmermann, Reinhard (Hg.): Historisch-kritischer Kommentar zum BGB. Band I: Allgemeiner Teil, SS 1 - 240. Tübingen: Mohr Siebeck, S. 34-122.

- (2005): „Der Geist des Rechts in Jherings 'Geist' und Jherings 'Zweck'. Teil 2“, in: Zeitschrift für Rechtsgeschichte 6, S. 122-142.

- (2008): „Vom 'Freirecht' zur freien 'Wertungsjurisprudenz' - eine Geschichte voller Legenden“, in: Zeitschrift der Savigny-Stiftung für Rechtsgeschichte / Germanistische Abteilung 125, S. 199-255.

— (2011): „Abwägung - die juristische Karriere eines unjuristischen Begriffs oder: Normenstrenge und Abwägung im Funktionswandel“, in: Juristenzeitung 66 (19), S. 913-923.

Rückert, Joachim; Willoweit, Dietmar (Hg./ 1995): Die Deutsche Rechtsgeschichte in der NS-Zeit. Ihre Vorgeschichte und ihre Nachwirkungen. Tübingen: Mohr.

Rudorff, Adolf August Friedrich (1877): „Vorrede des Herausgebers zur elften Auflage“, in: Puchta, Georg Friedrich (Hg.): Pandekten. 12 Aufl. Leipzig: Ambrosius Barth, S. V-XI.

- (1857): Römische Rechtsgeschichte. Erster Band: Rechtsbildung. Leipzig: Tauchnitz.

Ruge, Arnold (1841): „Die berliner Juristenfacultät“, in: Hallische Jabrbücher für deutsche Wissenschaft und Kunst (126-130), S. 501-518.

Rümelin, Gustav (der Ältere/ 1889): „Ueber den Begriff der Gesellschaft und einer Gesellschaftslehre“, in: Deutsche Rundschau 61, S. 36-49.

Rümelin, Gustav (1891): Werturteile und Willensentscheidungen im Civilrecht. Prorektoratsrede. Freiburg (Breisgau): Lehmann.

Rümelin, Max (1907): Bernhard Windscheid und sein Einfluss auf Privatrecht und Privatrechtswissenschaft. Rede gehalten am Geburtsfest seiner Majestät des Königs Wilhelm II von Württemberg am 25. Febr. 1907 im Festsaal der Aula der Universität Tübingen. Tübingen: Schnürlen.

— (1908): „Oskar Bülow“, in: Archiv für die civilistische Praxis 103 (1), S. 1-33. 
- (1920): Die Gerechtigkeit. Rede gehalten bei der akademischen Preisverteilung am 6. November 1920. Tübingen: Mohr.

- (1922a): Rudolph von Ihering. Rede, gehalten bei der akademischen Preisverteilung am 6. November 1922. Tübingen: Mohr.

- (1922b): „Zur Lehre von der juristischen Konstruktion“, in: Archiv für Rechtsund Wirtschaftsphilosophie 16 (4), S. 343-355.

- (1924a): Die Rechtssicherheit. Rede gehalten bei der akademischen Preisverteilung am 6. November 1924. Tübingen: Mohr.

— (1924b): „Gesetz, Rechtsprechung und Volksbetätigung auf dem Gebiet des Privatrechts", in: Archiv für die civilistische Praxis 122 (2), S. 145-172.

- (1925): Rechtsgefühl und Rechtsbewusstsein. Rede gehalten bei der akademischen Preisverteilung am 6. November 1925. Tübingen: Mohr.

- (1929): Die bindende Kraft des Gewohnheitsrechts und ibre Begründung. Rede gehalten bei der akademischen Preisverteilung am 6. November 1929. Tübingen: Mohr.

- (1930): Erlebte Wandlungen in Wissenschaft und Lehre. Rede gehalten bei der akademischen Preisverteilung am 6. November 1930. Tübingen: Mohr.

Rumpf, Max (1905): „Zum jetzigen Stand der Lehre von der adäquaten Verursachung im Zivilrecht", in: Jherings Jahrbücher für die Dogmatik des bürgerlichen Rechts 49, S. 333-406.

- (1906): Gesetz und Richter. Versuch einer Methodik der Rechtsanwendung. Berlin: Liebmann.

— (1914/15): „Vom Berufe unserer Zeit zur Gesetzgebung“, in: Die Tat. Sozial-religiöse Monatsschrift für deutsche Kultur 6 (4), S. 409-423.

- (1924): „Was ist Rechtssoziologie?“, in: Archiv für die civilistische Praxis 122 (1), S. 36-51.

- (1929): Rechtswissenschaft als Sozialwissenschaft? Nürnberg: Krische u. Co.

Rundstein, S. (1910): „Freie Rechtsfindung und Differenzierung des Rechtsbewusstseins", in: Archiv für bürgerliches Recht 34, S. 1-40.

Rüthers, Bernd (2005): Die unbegrenzte Auslegung. Zum Wandel der Privatrechtsordnung im Nationalsozialismus. 6. Aufl. Tübingen: Mohr Siebeck.

Sabbioneti, Marco (2010): Democrazia sociale e diritto privato. La Terza Repubblica di Raymond Saleilles (1855-1912). Milano: Giuffrè.

Saliger, Frank (2007): „Radbruch und Kantorowicz“, in: ARSP. Archiv für Rechtsund Sozialphilosphie 93 (2), S. 236-251.

Salomon, Max (1915): „Rezension: Eugen Ehrlich. Grundlegung“, in: Zeitschrift für Socialwissenschaft 6, S. 339-341.

Sander, Fritz (1921): „Rechtsdogmatik oder Theorie der Rechtserfahrung? Kritische Studie zur Rechtslehre Hans Kelsens“, in: Zeitschrift für öffentliches Recht 2, S. 511-610.

- (1923): Kelsens Rechtslehre. Kampfschrift wider die normative Jurisprudenz. Tuebingen: Mohr. 
- (1927): „Literaturbericht: Seiß, Dr. H. H.: Das Wesen der Gesellschaft und des Staates. Grundri $\beta$ einer neuen Gesellschafts-, Rechts- und Staatsphilosophie, Verlag Dr. Walter Rothschild, Berlin-Grunewald, 1926“, in: Zeitschrift für die gesamte Staatswissenschaft 83 (2), S. 384-386.

- (1930): Allgemeine Gesellschaftslehre. Jena: G. Fischer.

Sauer, Wilhelm (1923): „Übersicht über die gegenwärtigen Richtungen in der deutschen Rechtsphilosophie. Zum 200. Geburtstage Kants“, in: Archiv für Rechtsund Wirtschaftsphilosophie 17 (3), S. 284-313.

Savigny, Friedrich Carl von (1814): Vom Beruf unsrer Zeit für Gesetzgebung und Rechtswissenschaft. Heidelberg: Mohr und Zimmer.

- (1815a): Geschichte des römischen Rechts im Mittelalter. Erster Band. Heidelberg: Mohr und Zimmer.

- (1815b): „Recension. N. Th. von Gönner, Über Gesetzgebung und Rechtswissenschaft in unserer Zeit. Erlangen, bei Palm. 1815“, in: Zeitschrift für geschichtliche Rechtswissenschaft 1 (3), S. 373-423.

- (1815c): „Ueber den Zweck dieser Zeitschrift“, in: Zeitschrift für geschichtliche Rechtswissenschaft 1, S. 1-17.

- (1817): „Stimmen für und wider neue Gesetzbücher“, in: Zeitschrift für geschichtliche Rechtswissenschaft 3, S. 1-52.

- (1834): Geschichte des römischen Rechts im Mittelalter. Erster Band. 2. Aufl. Heidelberg: Mohr und Zimmer.

- (1838): „Der zehente Mai 1788: Beytrag zur Geschichte der Rechtswissenschaft“, in: Zeitschrift für geschichtliche Rechtswissenschaft 9, S. 421-432.

- (1840a): System des heutigen römischen Rechts. Erster Band. Berlin: Veit und Comp.

- (1840b): System des heutigen römischen Rechts. Dritter Band. Berlin: Veit und Comp.

- (1850a): „Recension. N. Th. von Gönner, Über Gesetzgebung und Rechtswissenschaft in unserer Zeit. Erlangen, bei Palm. 1815 [1815]. Erste Ausgabe in der Zeitschrift für geschichtliche Rechtswissenschaft Bd. 1. Heft 3. 1815. Num. XVII. S. 373-423“, in: Savigny, Friedrich Carl von (Hg.): Vermischte Schriften. Fünfter Band. Berlin: Veit und Comp., S. 115-172.

- (1850b): „Ueber den Zweck der Zeitschrift für geschichliche Rechtswissenschaft", in: Savigny, Friedrich Carl von (Hg.): Vermischte Schriften. Erster Band. Berlin: Veit und Comp., S. 105-126.

— (1927): „Nr. 273: Brief an Arnim v. 20. 9. 1814“, in: Stoll, Adolf (Hg.): Friedrich Karl v. Savigny. Ein Bild seines Lebens mit einer Sammlung seiner Briefe. Band II: Professorenjahre in Berlin 1810-1842: mit 317 Briefen aus den Jahren 1810-1841. Berlin: Heymann, S. 116-117.

- (1993a): „Einleitung zu den Pandekten. Berlin Sommer 1812“, in: ders. (Hg.): Vorlesungen über juristische Methodologie 1802-1842. Herausgegeben und eingeleitet von Aldo Mazzacane. Frankfurt am Main: Klostermann, S. 182-188.

- (1993b): „Methodologie. Winter 1802“, in: ders. (Hg.): Vorlesungen über juristische Methodologie 1802-1842. Frankfurt am Main: Klostermann, S. 86-131. 
— (1993c): „Methodologie. Zweyter Versuch. Sommer 1809“, in: ders. (Hg.): Vorlesungen über juristische Methodologie 1802-1842. Frankfurt am Main: Klostermann, S. $138-171$.

Schauer, Christian (2006): Aufforderung zum Spiel. Foucault und das Recht. Köln [u.a.]: Böhlau.

Scheffer, Thomas (2014): „Rechtssoziologie“, in: Endruweit, Günter; Trommsdorff, Gisela; Burzan, Nicole (Hg.): Wörterbuch der Soziologie. 3. Aufl. Konstanz: UVK, S. 396-400.

Schelsky, Helmut (1970): „Systemfunktionaler, anthropologischer und personfunktionaler Ansatz in der Rechtssoziologie“, in: Jahrbuch für Rechtssoziologie und Rechtstheorie 1, S. 37-89.

- (1972): „Das Jhering-Modell des sozialen Wandels durch Recht. Ein wissenschaftsgeschichtlicher Beitrag“, in: Rehbinder, Manfred; Schelsky, Helmut (Hg.): Zur Effektivität des Rechts. Düsseldorf: Bertelsmann, S. 47-86.

- (1980a): „Die Soziologen und das Recht“, in: ders. (Hg.): Die Soziologen und das Recht. Abhandlungen und Vorträge zur Soziologie von Recht, Institution und Planung. Opladen: Westdeutscher Verlag, S. 77-94.

- (1980b): „Soziologiekritsche Bemerkungen zu gewissen Tendenzen von Rechtssoziologen“, in: ders. (Hg.): Die Soziologen und das Recht. Opladen: Westdeutscher Verlag, S. 187-195.

Schelting, Alexander von (1922): „Die logische Theorie der historischen Kulturwissenschaft von Max Weber und im besonderen sein Begriff des Idealtypus“, in: Archiv für Sozialwissenschaft und Sozialpolitik (49), S. 623-752.

- (1934): Max Webers Wissenschaftslehre. Tübingen: Mohr.

Scheuermann, Reimund (1972): Einflüsse der historischen Rechtsschule auf die oberstrichterliche gemeinrechtliche Zivilrechtspraxis bis zum Jahre 1861. Berlin, New York: de Gruyter.

Schlosser, Hans (1997): „Zivilrecht für 100 Jahre? - Das janusköpfige bürgerliche Gesetzbuch“, in: ders.; Behr, Volker; ders. (Hg.): Bürgerliches Gesetzbuch 1896-1996. Ringvorlesung aus Anlass des hundertjährigen Jubiläums der Verkündung des Gesetzes sowie des fünfundzwanzigjährigen Bestehens der Juristischen Fakultät der Universität Augsburg. Heidelberg: Müller, S. 5-34.

Schluchter, Wolfgang (1998): Die Entstehung des modernen Rationalismus. Eine Analyse von Max Webers Entwicklungsgeschichte des Okzidents. Frankfurt am Main: Suhrkamp.

- (1999): „'Kopf' oder 'Doppelkopf' - das ist hier die Frage. Replik auf Hiroshi Orihara“, in: Kölner Zeitschrift für Soziologie und Sozialpsychologie 51 (4), S. 735743.

- (2000a): „Max Webers Beitrag zum Grundriß der Sozialökonomik. Editionsprobleme und Editionsstrategien“, in: ders. (Hg.): Individualismus, Verantwortungsethik und Vielfalt. Weilerswist: Velbrück, S. 190-210.

- (2000b): „Rechtssoziologie als empirische Geltungstheorie“, in: Dreier, Horst; Wenz, Edgar M. (Hg.): Rechtssoziologie am Ende des 20. Jahrbunderts. Gedächtnissymposion für Edgar Michael Wenz. Tübingen: Mohr Siebeck, 8ff. 
— (2000c): „Vorbemerkung: Der Kategorienaufsatz als Schlüssel“, in: ders. (Hg.): Individualismus, Verantwortungsethik und Vielfalt. Weilerswist: Velbrück, S. 179189.

- (2002): „The Sociology of Law as an Empirical Theory of Validity“, in: Journal of Classical Sociology 2 (3), S. 257-280.

- (2005a): „Werturteilsfreiheit und Wertdiskussion. Max Weber zwischen Immanuel Kant und Heinrich Rickert“, in: ders. (Hg.): Handlung, Ordnung und Kultur. Studien zu einem Forschungsprogramm im Anschluss an Max Weber. Tübingen: Mohr Siebeck, S. 86-107.

- (2005b): „Zur Entstehung von Max Webers Hauptbeitrag zum Handbuch der politischen Oekonomie, später: Grundriss der Sozialökonomik“, in: ders. (Hg.): Handlung, Ordnung und Kultur. Studien zu einem Forschungsprogramm im Anschluss an Max Weber. Tübingen: Mohr Siebeck, S. 229-238.

- (2009): „Entstehungsgeschichte“, in: ders. (Hg.): Max Weber Gesamtausgabe. Abt. 1, Bd. 24: Wirtschaft und Gesellschaft. Entstehungsgeschichte und Dokumente. Tübingen: Mohr Siebeck, S. 1-128.

- (2016): Max Webers späte Soziologie. Tübingen: Mohr Siebeck.

Schlüter, Carsten (1991): „Intuition und Dialektik. Eine These zur Idee des Normalbegriffs“, in: Clausen, Lars; Schlüter, Carsten (Hg.): Hundert Jahre "Gemeinschaft und Gesellschaft". Ferdinand Tönnies in der internationalen Diskussion. Opladen: Leske + Budrich, S. 131-170.

Schlüter-Knauer, Carsten (2014): „Die kontroverse Demokratie: Carl Schmitt und Hans Kelsen mit und gegen Ferdinand Tönnies“, in: Carstens, Uwe (Hg.): Ferdinand Tönnies: Der Sozialstaat zwischen Gemeinschaft und Gesellschaft. Baden-Baden: Nomos, S. 123-168.

Schmid, Michael (1989): „Solidarität und Arbeitsteilung: Bemerkungen zu Durkheims Theorie“, in: Haller, Max; Hoffmann-Nowotny, Hans-Joachim; Zapf, Wolfgang (Hg.): Kultur und Gesellschaft. Verhandlungen des 24. Deutschen Soziologentags, des 11. Österreichischen Soziologentags und des 8. Kongresses der Schweizerischen Gesellschaft für Soziologie in Zürich [04.-07. Oktober], 1988. Frankfurt am Main: Campus, S. 518-531.

Schmid, Reinhold (1848): Theorie und Methodik des bürgerlichen Rechts. Jena: Friedrich Fromann.

Schmidt, Carl Adolf (1853): Der principielle Unterschied zwischen dem römischen und germanischen Rechte. Erster Band: Die Verschiedenheit der Grundbegriffe und des Privatrechts. Rostock, Schwerin: Stiller.

Schmidt-Warneck, Fedor (1889): Die Sociologie im Umrisse ihrer Grundprincipe. Braunschweig: Selbstverlag.

Schmitt, Carl (1912): Gesetz und Urteil. Eine Untersuchung zum Problem der Rechtspraxis. Berlin: Liebmann.

- (1922): Politische Theologie. Band 1: Vier Kapitel zur Lehre von der Souveränität. München, Leipzig: Duncker \& Humblot.

- (1934): Über die drei Arten des rechtswissenschaftlichen Denkens. Hamburg: Hanseatische Verlagsanstalt. 
Schmoeckel, Mathias (Hg./ 2009): Psychologie als Argument in der juristischen Literatur des Kaiserreichs. Baden-Baden: Nomos.

Schmölder, Karl (1907): Die Billigkeit als Grundlage des bürgerlichen Rechts: Ein Beitrag zur Berichtigung der amtlichen Rechtsauffassung. Hamm: Griebsch.

Schmoller, Gustav (1883): „Zur Methodologie der Staats- und Sozialwissenschaften", in: Jahrbuch fuer Gesetzgebung, Verwaltung und Volkswirtschaft im Deutschen Reich, S. 239-258 [975-994].

Schnädelbach, Herbert (1983): Philosophie in Deutschland. 1831-1933. Frankfurt am Main: Suhrkamp.

Schneider, Konrad (1893): Das Wohnungsmietrecht und seine sociale Reform. Leipzig: Duncker \& Humblot.

Schöler, Claudia (2004): Deutsche Rechtseinheit. Partikulare und nationale Gesetzgebung (1780-1866). Köln [u.a.]: Böhlau.

Schoppmeyer, Heinrich (2001): Juristische Methode als Lebensaufgabe. Leben, Werk und Wirkungsgeschichte Philipp Hecks. Tübingen: Mohr Siebeck.

Schröder, Jan (1976): „Savignys Spezialistendogma und die 'soziologische' Jurisprudenz", in: Rechtstheorie 7 (1), S. 23-52.

- (1979): Wissenschaftstheorie und Lehre der "praktischen Jurisprudenz" auf deutschen Universitäten an der Wende zum 19. Jabrhundert. Frankfurt am Main: Klostermann.

— (1982/1983): „Zur älteren Genossenschaftstheorie. Die Begründung des modernen Körperschaftsbegriffs durch Georg Beseler", in: Quaderni Fiorentini per la storia del pensiero giuridico moderno 11/12, S. 399-459.

- (1985): Gesetzesauslegung und Gesetzesumgehung. Das Umgehungsgeschäft in der rechtswissenschaftlichen Doktrin von der Spätaufklärung bis zum Nationalsozialismus. Paderborn [u.a.]: Schöningh.

— (2006): „'Richterrecht' und Rechtsbegriff im frühen 20. Jahrhundert“, in: Berger, Klaus Peter et al. (Hg.): Zivil- und Wirtschaftsrecht im europäischen und globalen Kontext. Festschrift für Norbert Horn zum 70. Geburtstag. Berlin: de Gruyter Recht, S. 1255-1270.

- (2007): „Zur Theorie des Gewohnheitsrechts zwischen 1850 und 1930“, in: Haferkamp, Hans-Peter; Repgen, Tilman (Hg.): Usus modernus pandectarum. Römisches Recht, Deutsches Recht und Naturrecht in der Frühen Neuzeit. Klaus Luig zum 70. Geburtstag. Köln [u.a.]: Böhlau, S. 219-244.

- (2012): Recht als Wissenschaft. Geschichte der juristischen Methodenlehre in der Neuzeit (1500-1933). 2. Aufl. München: Beck.

Schröder, Jan; Pielemeier, Ines (1995): „Naturrecht als Lehrfach an den deutschen Universitäten des 18. und 19. Jahrhunderts“, in: Dann, Otto; Klippel, Diethelm (Hg.): Naturrecht - Spätaufklärung - Revolution. Hamburg: Felix Meiner, S. 255269.

Schröder, Rainer (1981): Abschaffung oder Reform des Erbrechts. Die Begründung einer Entscheidung des BGB-Gesetzgebers im Kontext, sozialer, ökonomischer und philosophischer Zeitströmungen. Ebelsbach: Gremer. 
- (1983): „Die Richterschaft am Ende des zweiten Kaiserreiches unter dem Druck polarer sozialer und politischer Anforderungen“, in: Buschmann, Arno et al. (Hg.): Festschrift für Rudolf Gmür zum 70. Geburtstag, 28. Juli 1983. Bielefeld: Gieseking, S. 201-253.

- (1988): „Die deutsche Methodendiskussion um die Jahrhundertwende: Wissenschaftstheoretische Präzisierungsversuche oder Antworten auf den Funktionswandel von Recht und Justiz", in: Rechtstheorie, S. 323-367.

Schubert, Werner (1966): Die Entstehung der Vorschriften des BGB über Besitz und Eigentumsübertragung. Ein Beitrag zur Entstehungsgeschichte des BGB. Berlin: de Gruyter.

- (1978): „Entstehungsgeschichte des bürgerlichen Gesetzbuchs“, in: ders. (Hg.): Materialien zur Entstehungsgeschichte des BGB. Einführung, Biographien, Materialien. Berlin, New York: de Gruyter, S. 27-68.

- (Hg./ 1981-1986): Die Vorlagen der Redaktoren für die erste Kommission zur Ausarbeitung des Entwurfs eines Bürgerlichen Gesetzbuches. Mebrbändiges Werk. Berlin: de Gruyter.

Schuler, Theo (1963): "Jacob Grimm und Savigny“, in: Zeitschrift der Savigny-Stiftung für Rechtsgeschichte/ Germanistische Abteilung 80 (1), S. 197-305.

Schulte-Nölke, Hans (1995): Das Reichsjustizamt und die Entstehung des Bürgerlichen Gesetzbuchs. Frankfurt am Main: Klostermann.

Schulze, Lothar; Schier, Walter (1987): „Fritz Berolzheimer und das ARSP“, in: ARSP: Archiv für Rechts- und Sozialphilosophie 73 (1), S. 15-29.

Schulze-Gaevernitz, Gerhart (1890): Zum socialen Frieden. Eine Darstellung der socialpolitischen Erziehung des englischen Volkes im neunzehnten Jahrhundert. Erster Band. Leipzig: Duncker \& Humblot.

Schulz-Schaeffer, Ingo (2004): „Rechtsdogmatik als Gegenstand der Rechtssoziologie. Für eine Rechtssoziologie 'mit noch mehr Recht'“, in: Zeitschrift für Rechtssoziologie 25 (2), S. 141-174.

Schuppe, Wilhelm (1890): Das Gewohnheitsrecht - zugleich eine Kritik der beiden ersten Paragraphen des Entwurfs eines bürgerlichen Gesetzbuches für das deutsche Reich. Breslau: Koebner.

Schütze, Daniel (1998): Kooperation zwischen Volkswirtschaftslehre und Jurisprudenz. Eine Analyse am Beispiel der deutschen Kartelldebatte vor 1914. Marburg: Metropolis.

Schwartz, Ernst (1889): „Die Geschichte der privatrechtlichen Kodifikationsbestrebungen in Deutschland und die Entstehungsgeschichte des Entwurfs eines bürgerlichen Gesetzbuchs für das Deutsche Reich“, in: Archiv für bürgerliches Recht 1, S. 1-189.

Schweitzer, Doris (2015a): „Diskursanalyse, Wahrheit und Recht: Methodologische Probleme einer Diskursanalyse des Rechts“, in: Zeitschrift für Rechtssoziologie 35 (2), S. 201-221.

- (2015b): „Soziologische Rationalitäten im Recht. Rudolf von Jhering gelesen mit François Ewald“, in: Gephart, Werner; Suntrup, Christoph (Hg.): Rechtsanalyse als Kulturforschung II. Frankfurt am Main: Klostermann, S. 35-58. 
- (2015c): Zum Kritikpotential der Untersuchung sozialer Phänomene als sepistemische Dinger. DGS. http://publikationen.soziologie.de/index.php/kongressband_2014/ article/view/127 (zuletzt geprüft am 16.01.2019).

- (2015d): „Macht der Unbestimmtheit? Unbestimmte Rechtsbegriffe als Provokation für die poststrukturalistische Theorie“, in: Zeitschrift für Rechtssoziologie 35 (1), S. 91-116.

- (2016): „Wie das Recht dem Ethnographen im Gerichtssaal abhandenkam“, in: Twellmann, Marcus (Hg.): Wissen, wie Recht ist. Bruno Latours empirische Philosophie einer Existenzweise. Paderborn: Konstanz University Press, S. 145-166.

— (2017): „Die digitale Person. Die Anrufung des Subjekts im 'Recht auf Vergessenwerden'“, in: Österreichische Zeitschrift für Soziologie 42 (3), S. 237-257.

- (2018a): „Die Subjektwerdungen der juristischen Person. Subjektivierungstheoretische Überlegungen zur rechtlichen Personalisierung von Kollektiven“, in: Alkemeyer, Thomas; Bröckling, Ulrich; Peter, Tobias (Hg.): Jenseits der Person. Zur Subjektivierung von Kollektiven. Bielefeld: Transcript, S. 175-194.

- (2018b): „Rechtssoziologie versus 'Recht in der Soziologie'. Anmerkungen zum Verhältnis von Rechtswissenschaft und Soziologie aus soziologiegeschichtlicher Perspektive“, in: juridikum. zeitschrift für kritik / recht / gesellschaft (2), S. 210-221.

Schwinn, Thomas (2011): „Von starken und schwachen Gesellschaftsbegriffen. Verfallsstufen eines traditionsreichen Konzepts“, in: ders.; Kroneberg, Clemens; Greve, Jens (Hg.): Soziale Differenzierung. Handlungstheoretische Zugänge in der Diskussion. Wiesbaden: VS Verlag für Sozialwissenschaften, S. 27-44.

Seeger, Adolf (1843): „Die deutsche Rechts-Wissenschaft in ihrem Verhältnis zu unserer Zeit“, in: Herwegh, Georg (Hg.): Einundzwanzig Bogen aus der Schweiz. Erster Theil. Zürich, Winterthur: Verlag des Literarischen Comproirs, S. 130156.

Seel, Martin (2004): Adornos Philosophie der Kontemplation. Frankfurt am Main: Suhrkamp.

Segal, Jeffrey Allan; Spaeth, Harold J. (2002): The Supreme Court and the attitudinal model revisited. Cambridge, UK, New York: Cambridge University Press.

Seifert, Achim (2015): „Die Rechtssoziologie von Hugo Sinzheimer: Eine Annäherung“, in: Kohte, Wolfhard; Absenger, Nadine (Hg.): Menschenrechte und Solidarität im internationalen Diskurs. Festschrift für Professor Dr. Armin Höland. BadenBaden: Nomos, S. 411-430.

Seinecke, Ralf (2013): „Rudolf von Jhering anno 1858. Interpretation, Konstruktion und Recht der sog. 'Begriffsjurisprudenz'“, in: Zeitschrift der Savigny-Stiftung für Rechtsgeschichte / Germanistische Abteilung 130, S. 238-280.

- (2015): Das Recht des Rechtspluralismus. Tübingen: Mohr Siebeck.

Sembel, Nicolas (2013): „La liste des emprunts de Durkheim à la bibliothèque universitaire de Bordeaux. Une ,imagination méthodologiqu' en acte“, in: Durkheimian Studies 19 (1), S. 5-48.

Senn, Marcel; Puskás, Dániel (Hg./ 2007): Rechtswissenschaft als Kulturwissenschaft? Kongress der Schweizerischen Vereinigung für Rechts- und Sozialphilosophie, 15. und 16. Juni 2007, Universität Zürich. Stuttgart: Steiner. 
Serres, Michel (1991): Hermes I. Kommunikation. Berlin: Merve.

- (1994a): Der Naturvertrag. Frankfurt am Main: Suhrkamp.

- (1994b): Hermes V. Die Nordwest-Passage. Berlin: Merve.

- (1994c): „Vorwort, dessen Lektüre sich empfiehlt, damit der Leser die Absicht der Autoren kennenlernt und den Aufbau dieses Buches versteht", in: Serres, Michel (Hg.): Elemente einer Geschichte der Wissenschaften. Frankfurt am Main: Suhrkamp, S. 11-37.

Siber (1909): „Erinnerungen an Windscheid“, in: Deutsche Juristen-Zeitung 14 (15/16), Sp. 964-965.

Siemann, Wolfram (1976): Die Frankfurter Nationalversammlung 1848/49 zwischen demokratischem Liberalismus und konservativer Reform. Die Bedeutung der Juristendominanz in den Verfassungsverhandlungen des Paulskirchenparlaments. Frankfurt am Main [u.a.]: Lang.

Sigwart, Christoph (1886): Vorfragen der Ethik. Herrn Dr. Eduard Zeller als Festschrift zur Feier seines fünfzigjäbrigen Doctorjubiläums am 25. August 1886. Freiburg (Breisgau): Mohr.

Simmel, Georg (1908): Soziologie. Untersuchungen über die Formen der Vergesellschaftung. Berlin: Duncker \& Humblot.

Simmel et al. (1911a): „Debatte: Erste Samstagssitzung“, in: ders. (Hg.): Deutscher Soziologentag: Verhandlungen des Deutschen Soziologentages. 19. - 22. Okt. 1910 in Frankfurt a.M.; Reden und Vorträge von Georg Simmel [u.a.] und Debatten. Tübingen: Mohr, S. 265-274.

— (1911b): „Debatte: Zweite Freitagssitzung“, in: ders. (Hg.): Deutscher Soziologentag: Verhandlungen des Deutschen Soziologentages. 19. - 22. Okt. 1910 in Frankfurt a.M.; Reden und Vorträge von Georg Simmel [u.a.] und Debatten. Tübingen: Mohr, S. 192-214.

— (1911c): „Debatte: Zweite Samstagssitzung“, in: ders. (Hg.): Deutscher Soziologentag: Verhandlungen des Deutschen Soziologentages. 19. - 22. Okt. 1910 in Frankfurt a.M.; Reden und Vorträge von Georg Simmel [u.a.] und Debatten. Tübingen: Mohr, S. 309-335.

Sinzheimer, Hugo (1914/15): „Der Wille zur Rechtsgestaltung“, in: Die Tat. Sozialreligiöse Monatsschrift für deutsche Kultur 6 (4), S. 375-385.

— (1976a): „Der Wandel im Weltbild der Juristen (1928)“, in: Kahn-Freund, Otto et al. (Hg.): Hugo Sinzheimer: Arbeitsrecht und Rechtssoziologie. Gesammelte Aufsätze und Reden. Bd. 1. Frankfurt am Main [u.a.]: Europäische Verlagsanstalt, S. 4249.

— (1976b): „Der Wille zur Rechtsgestaltung [1914]“, in: Kahn-Freund, Otto et al. (Hg.): Hugo Sinzheimer: Arbeitsrecht und Rechtssoziologie. Gesammelte Aufsätze und Reden. Bd. 2. Frankfurt am Main [u.a.]: Europäische Verlagsanstalt, S. 24-32.

- (1976c): „Die soziologische Methode in der Privatrechtswissenschaft“, in: KahnFreund, Otto et al. (Hg.): Hugo Sinzheimer: Arbeitsrecht und Rechtssoziologie. Gesammelte Aufsätze und Reden. Bd. 2. Frankfurt am Main [u.a.]: Europäische Verlagsanstalt, S. 3-23. 
- (1976d): „Über soziologische und dogmatische Methode in der Arbeitsrechtswissenschaft [1922]", in: Kahn-Freund, Otto et al. (Hg.): Hugo Sinzheimer: Arbeitsrecht und Rechtssoziologie. Gesammelte Aufsätze und Reden. Bd. 1. Frankfurt am Main [u.a.]: Europäische Verlagsanstalt, S. 33-41.

Sisk, Gregory C.; Heise, Michael; Morriss, Andrew P. (1998): „Charting the Influences on the Judicial Mind: An Empirical Study of Judicial Reasoning“, in: New York University Law Review 73 (5), S. 1377-1500.

Sohm, Rudolph (1874): „Die deutsche Rechtsentwicklung und die Codifikationsfrage", in: Zeitschrift für das Privat- und öffentliche Recht der Gegenwart 1, S. 245280.

- (1888): „Die deutsche Genossenschaft“, in: Festgabe der Leipziger Juristenfakultät für Dr. Bernhard Windscheid zum 22. Dezember 1888. Leipzig: Duncker \& Humblot, S. 3-43 [139-181].

- (1895): „Ueber den Entwurf eines bürgerlichen Gesetzbuches für das Deutsche Reich in zweiter Lesung“, in: Beiträge zur Erläuterung des deutschen Rechts 39, S. 737-765.

— (1900): „Die Entstehung des deutschen Bürgerlichen Gesetzbuches“, in: Deutsche Juristen-Zeitung 5, S. 6-9.

— (1909): „Über Begriffsjurisprudenz“, in: Deutsche Juristen-Zeitung 14, Sp. 10191024.

— (1910): „Begriffsjurisprudenz“, in: Deutsche Juristen-Zeitung 15, Sp. 114-118.

Sombart, Werner (1923): „Die Anfänge der Soziologie“, in: Palyi, Melchior (Hg.): Hauptprobleme der Soziologie. Erinnerungsgabe für Max Weber. I. Band. München, Leipzig: Duncker \& Humblot, S. 3-19.

- (1956): Noo-Soziologie. Berlin: Duncker \& Humblot.

Somló, Felix (1911): „Das Verhältnis von Soziologie und Rechtsphilosophie, insbesondere die Förderung der Rechtsphilosophie durch die Soziologie“, in: Archiv für Rechts- und Wirtschaftsphilosophie 4 (4), S. 563-569.

- (1917): Juristische Grundlehre. Leipzig: Felix Meiner.

Sommer, Hugo (1884): „Rudolf von Jherings Theorie des gesellschaftlichen Utilitarismus“, in: Preußische Jabrbücher 54, S. 533-554.

- (1885): „Rudolf von Jherings Theorie des gesellschaftlichen Utilitarismus“, in: Preußische Jahrbücher 55, S. 28-57.

Spann, Othmar (1905): Untersuchungen über den Gesellschaftsbegriff zur Einleitung in die Soziologie. Tübingen: Laupp.

- (1907): Wirtschaft und Gesellschaft. Eine dogmenkritische Untersuchung. Dresden: Böhmert.

Spiegel, Ludwig (1909): „Jurisprudenz und Sozialwissenschaft“, in: Zeitschrift für das Privat- und öffentliche Recht der Gegenwart 36, S. 1-30.

Spreen, Dierk (2010): „Was bedeutet die Rede von Machtdispositiven? Zum Verhältnis von Macht und Recht nach Michel Foucault“, in: Ästhetik \& Kommunikation 41 (151), S. 97-103. 
Sprenger, Gerhard (1991): „Recht als Kulturerscheinung“, in: Cramer, Konrad et al. (Hg.): Deutsche Rechts- und Sozialphilosophie um 1900. Zugleich ein Beitrag zur Gründungsgeschichte der Internationalen Vereinigung für Rechts- und Sozialphilosophie (IVR). Stuttgart: Steiner, S. 134-153.

Stäheli, Urs (1995): „Gesellschaftstheorie und die Unmöglichkeit ihres Gegenstandes: diskurstheoretische Perspektiven“, in: Schweizerische Zeitschrift für Soziologie 21 (2), S. 361-390.

— (1998): „Die Nachträglichkeit der Semantik. Zum Verhältnis von Sozialstruktur und Semantik“, in: Soziale Systeme. Zeitschrift für soziologische Theorie (4), S. 315339.

- (2000): Sinnzusammenbrüche. Eine dekonstruktive Lektüre von Niklas Luhmanns Systemtheorie. Weilerswist: Velbrück Wissenschaft.

Stahl, Friedrich Julius (1830): Die Philosophie des Rechts nach geschichtlicher Ansicht. Erster Band: Die Genesis der gegenwärtigen Rechtsphilosophie. Heidelberg: Mohr.

Stammler, Rudolf (1888): „Über die Methode der geschichtlichen Rechtstheorie“, in: Festgabe zu Bernhard Windscheids fünfzigjährigem Doktorjubiläum. Zwei Abhandlungen von Dr. Rudolf Stammler und Dr. Theodor Kipp. Halle: Niemeyer, S. 1-63.

- (1896): Wirtschaft und Recht nach materialistischer Geschichtsauffassung. Eine sozialphilosophische Untersuchung. Leipzig: Veit und Comp.

- (1902): Die Lehre vom richtigen Rechte. Berlin: Guttentag.

- (1906a): „Die grundsätzlichen Aufgaben des Juristen in Rechtsprechung und Verwaltung“, in: Archiv für Verwaltungsrecht 15, S. 1-59.

- (1906b): Wirtschaft und Recht nach materialistischer Geschichtsauffassung. Eine sozialphilosophische Untersuchung. 2. Aufl. Leipzig: Veit und Comp.

- (1911): Theorie der Rechtswissenschaft. Halle: Buchh. d. Waisenhauses.

- (1922): Lehrbuch der Rechtsphilosophie. Berlin, Leipzig: de Gruyter \& Co.

— (1925a): „Die grundsätzlichen Richtungen der neueren Jurisprudenz [1923]“, in: ders. (Hg.): Rechtsphilosophische Abhandlungen und Vorträge. Band 2: 1914-1924. Charlottenburg: Heise, S. 333-392.

- (1925b): „Wesen des Rechts und der Rechtswissenschaft [1913]“, in: ders. (Hg.): Rechtsphilosophische Abhandlungen und Vorträge. Band 1: 1888-1913. Charlottenburg: Heise, S. 387-443.

- (1931): „Rechtsphilosophie“, in: ders. (Hg.): Das gesamte deutsche Recht. Band 1: Rechtsphilosophie, Römisches Recht, Deutsches Recht, Bürgerliches Recht, Handels-, Wechsel- und Seerecht, Urheber- und Erfinderrecht, Arbeitsrecht, Internationales Privatrecht. Berlin: Stilke, S. 1-88.

Stampe, Ernst (1905a): „Rechtsfindung durch Interessenwägung“, in: Deutsche Juristen-Zeitung 10, Sp. 713-719.

- (1905b): „Rechtsfindung durch Konstruktion“ ,in: Deutsche Juristen-Zeitung 10, Sp. 417-422. 
— (1992): „Gesetz und Richtermacht [1905]“, in: Gängel, Andreas; Mollnau, Karl A. (Hg.): Gesetzesbindung und Richterfreiheit. Texte zur Methodendebatte 1900 1914. Freiburg (Breisgau), Berlin: Haufe, S. 69-76.

Stedman Jones, Susan (1996): „What does Durkheim mean by 'thing'?““, in: Durheimian Studies (2), S. 43-59.

Stegmaier, Peter (2009): Wissen, was Recht ist. Richterliche Rechtspraxis aus wissenssoziologisch-ethnografischer Sicht. Wiesbaden: VS Verlag für Sozialwissenschaften.

Stein, Lorenz von (1839): „Die Wissenschaft der römischen Rechtsgeschichte im Grundrisse, von Dr. Christiansen, erster Band, Altona 1838“, in: Hallische Jahrbücher für deutsche Wissenschaft und Kunst 2, S. 1601-1648.

- (1841a): Die Geschichte des dänischen Civilprocesses und das heutige Verfahren. Als Beitrag zu einer vergleichenden Rechtswissenschaft. Kiel: Schwers.

— (1841b): „Zur Charakteristik der heutigen Rechtswissenschaft. System des heutigen römischen Rechts, von Friedrich Carl von Savigny. B. 1-4, Berlin 1840 u. 41. Veit u. Comp.", in: Deutsche Jahrbücher für Wissenschaft und Kunst 4, S. 365f., 369f., 373f., 377-384, 383-387, 389-391, 393-399.

- (1842a): Der Socialismus und Communismus des heutigen Frankreichs. Ein Beitrag zur Zeitgeschichte. Leipzig: Otto Wigand.

- (1842b): „Zur Charakteristik der heutigen Rechtswissenschaft. Lehrbuch des gemeinen in Deutschland giltigen Rechts von Anselm Ritter von Feuerbach. Herausgeg. von Dr. C. J. A. Mittermaier, Gießen, 1840“, in: Deutsche Jabrbücher für Wissenschaft und Kunst (70), S. $277 \mathrm{ff}$.

- (1845a): „Das Corpus Iuris und die Idee des gemeinen deutschen Rechts“, in: Deutsche Vierteljahres Schrift (4), S. 293-344.

- (1845b): „Das Corpus Juris und die historische Schule in ihrem Verhältnis zur deutschen Rechtsentwicklung“, in: Deutsche Vierteljabres Schrift (2), S. 145-188.

- (1846): Geschichte des französischen Strafrechts und des Processe. Basel: Schweighauser.

- (1850): Geschichte der socialen Bewegung in Frankreich von 1789 bis auf unsere Tage. Erster Band: Der Begriff der Gesellschaft und die soziale Geschichte der Französischen Revolution bis zum Jahre 1830. Leipzig: Otto Wigand.

— (1852): System der Staatswissenschaft. 1. Band: System der Statistik, des Populationistik und der Volkswirtschaftslehre. Stuttgart, Tübingen: Cotta.

Steinthal, Heymann (1885): Allgemeine Ethik. Berlin: Reimer.

Stern, Jacques (1959): „Einleitung“, in: ders. (Hg.): Thibaut und Savigny. Ein programmatischer Rechtsstreit auf Grund ihrer Schriften Über die Notwendigkeit eines allgemeinen bürgerlichen Rechts für Deutschland und Vom Beruf unserer Zeit für Gesetzgebung und Rechtswissenschaft. mit den Nachtr. der Verf. und den Urteilen der Zeitgenossen. Hrsg. u. eingel. von Jacques Stern. Unveränd. fotomech. Nachdr. d. Ausg. 1914. Darmstadt: Wissenschaftliche Buchgesellschaft, S. 8-34.

Sternberg, Theodor (1904): Allgemeine Rechtslehre. Leipzig: Göschen.

- (1920): Einführung in die Rechtswissenschaft. Teil 1: Methoden- und Quellenlehre. 2. Aufl. Berlin, Leipzig: de Gruyter. 
— (1988): „Die Rechtsfindung [1927]“, in: ders.; Rehbinder, Manfred (Hg.): Zur Methodenfrage der Rechtswissenschaft und andere juristische Schriften. Berlin: Duncker \& Humblot, S. 19-52.

Stichweh, Rudolf (1992): „Motive und Begründungsstrategien für Wissenschaftlichkeit in der deutschen Jurisprudenz des 19. Jahrhunderts“, in: Rechtshistorisches Journal 11, S. 330-351.

Stiegler, Herwig (1988): „'Troubadour der Pandekten'. Savigny im Vexierspiegel Heinischer Satire“, in: Valentinitsch, Helfried (Hg.): Recht und Geschichte. Festschrift für Hermann Baltl zum 70. Geburtstag. Graz: Leykam, S. 503-523.

Stintzing, Johann August Roderich von (1862): Friedrich Carl von Savigny: Ein Beitrag zu seiner Würdigung. Berlin: Georg Reimer.

Stöckhardt, Heinrich Robert (1825): Die Wissenschaft des Rechtes oder das Naturrecht in Verbindung mit einer vergleichenden Critik der positiven Rechtsideen. Leipzig: Karl Heinrich Reclam.

Stoll, Heinrich (1974): „Begriff und Konstruktion in der Lehre der Interessenjurisprudenz (1931)“, in: Ellscheid, Günter; Hassemer, Winfried (Hg.): Interessenjurisprudenz. Darmstadt: Wissenschaftliche Buchgesellschaft, S. 153-210.

Stolleis, Michael (1989): „Die Entstehung des Interventionsstaates und das öffentliche Recht", in: Zeitschrift für neuere Rechtsgeschichte 11, S. 129-147.

- (1992): Geschichte des öffentlichen Rechts in Deutschland. Bd. 2: Staatsrechtslehre und Verwaltungswissenschaft, 1800 - 1914. München: Beck.

- (1996): „Öffentliches Recht und Privatrecht im Prozeß der Entstehung des modernen Staates“, in: Hoffmann-Riem, Wolfgang; Schmidt-Aßmann, Eberhard (Hg.): Öffentliches Recht und Privatrecht als wechselseitige Auffangordnungen. Ibre Funktionen als wechselseitige Auffangordnungen. Baden-Baden: Nomos, S. 41-61.

- (2001): Der Methodenstreit der Weimarer Staatsrechtslehre - ein abgeschlossenes Kapitel der Wissenschaftsgeschichte? Stuttgart: Steiner.

- (2002): Geschichte des öffentlichen Rechts in Deutschland. Bd. 3: Weimarer Republik und Nationalsozialismus. München: Beck.

- (2003): Geschichte des Sozialrechts in Deutschland. Ein Grundriss. Stuttgart: Lucius \& Lucius.

Stolterfoth, Paul (1890): Beiträge zur Beurtheilung des Entwurfs eines bürgerlichen Gesetzbuches für das Deutsche Reich. Leipzig: Veit.

Stölting, Erhard (1986): „Soziologie und Nationalökonomie. Die Wirkung des institutionellen Faktors“, in: Papcke, Sven (Hg.): Ordnung und Theorie. Beiträge zur Geschichte der Soziologie in Deutschland. Darmstadt: Wissenschaftliche Buchgesellschaft, S. 69-92.

Stone, Christopher D. (1974): Should trees have standing? Toward legal rights for natural objects. Los Altos, Calif: Kaufmann.

Stühler, Hans-Ulrich (1978): Die Diskussion um die Erneuerung der Rechtswissenschaft von 1780-1815. Berlin: Duncker \& Humblot.

Sturm, August (1910): Die psychologische Grundlage des Rechts. Ein Beitrag zur allgemeinen Rechtslehre und zum heutigen Friedensrecht unter Benutzung der vom Auswärtigen Amt zur Verfügung gestellten jüngsten Rechtsquellen. Hannover: Helwing. 
Šuber, Daniel (2007): Die soziologische Kritik der philosophischen Vernunft. Zum Verhältnis von Soziologie und Philosophie um 1900. Bielefeld: Transcript.

Sukale, Michael (2002): Max Weber, Leidenschaft und Disziplin. Leben, Werk, Zeitgenossen. Tübingen: Mohr Siebeck.

Swedberg, Richard (1998): Max Weber and the idea of economic sociology. Princeton, NJ: Princeton Univ. Press.

Szirtes, Artur (1916): Die Rechtswissenschaft, eine Kulturmacht. Zur Frage der gesellschaftlichen Vorbereitung der Gesetze. Hannover: Helwing.

Tadros, Victor (1998): „Between Governance and Discipline: The Law and Michel Foucault", in: Oxford Journal of Legal Studies 18 (1), S. 75-103.

Takebayashi, Shirō (2003): Die Entstehung der Kapitalismustheorie in der Gründungsphase der deutschen Soziologie. Von der historischen Nationalökonomie zur historischen Soziologie Werner Sombarts und Max Webers. Berlin: Duncker \& Humblot.

Takii, Kazuhiro (2014): „Savignynähe und Savignykritik. Entstehung und Tragweite der Staatswissenschaft Lorenz von Steins“, in: Koslowski, Stefan (Hg.): Lorenz von Stein und der Sozialstaat. Baden-Baden: Nomos, S. 42-63.

Tamanaha, Brian Z. (1995): „An Analytical Map of Social Scientific Approaches to the Concept of Law", in: Oxford Journal of Legal Studies 15 (4), S. 501-535.

- (2006): Law as a means to an end. Threat to the rule of law. Cambridge, New York: Cambridge University Press.

Tenbruck, Friedrich H. (1981): „Émile Durkheim oder die Geburt der Gesellschaft aus dem Geist der Soziologie“, in: Zeitschrift für Soziologie 10 (4), S. 333-350.

- (1984): Die unbewältigten Sozialwissenschaften oder Die Abschaffung des Menschen. Wien, Graz, Köln: Styria.

— (1989): „Abschied von der 'Wissenschaftslehre'?“, in: Weiss, Johannes (Hg.): Max Weber heute. Erträge und Probleme der Forschung. Frankfurt am Main: Suhrkamp, S. $90-115$.

- (1994): „Wie kann man die Geschichte der Sozialwissenschaften in den 20er Jahren schreiben?"“, in: Nörr, Knut Wolfgang; Schefold, Bertram; Tenbruck, Friedrich H. (Hg.): Geisteswissenschaften zwischen Kaiserreich und Republik. Zur Entwicklung von Nationalökonomie, Rechtswissenschaft und Sozialwissenschaft im 20. Jahrhundert. Stuttgart: Steiner, S. 23-46.

- (1999a): „Genesis der Methodologie Max Webers“, in: ders.; Homann, Harald (Hg.): Das Werk Max Webers. Gesammelte Aufsätze zu Max Weber. Tübingen: Mohr Siebeck, S. 1-58.

— (1999b): „Max Weber und Eduard Meyer“, in: ders.; Homann, Harald (Hg.): Das Werk Max Webers. Gesammelte Aufsätze zu Max Weber. Tübingen: Mohr Siebeck, S. 176-218.

Terrier, Jean (2017): „Law contra sociology. The critique of the social sciences, especially Durkheimian sociology, by Kelsen and Schmitt“, in: Journal of Classical Sociology 17 (4), S. 309-330.

Teubner, Gunther (1987): „Episodenverknüpfung. Zur Steigerung von Selbstreferenz im Recht“, in: Baecker, Dirk; Willke, Helmut (Hg.): Theorie als Passion. Niklas Lubmann zum 60. Geburtstag. Frankfurt am Main: Suhrkamp, S. 423-446. 
- (1996): „Globale Bukowina. Zur Emergenz eines transnationalen Rechtspluralismus“, in: Rechtshistorisches Journal (15), S. 255-290.

- (2006): „Elektronische Agenten und große Menschenaffen“, in: Zeitschrift für Rechtssoziologie 27 (1), S. 5-30.

- (2012): Verfassungsfragmente. Gesellschaftlicher Konstitutionalismus in der Globalisierung. Berlin: Suhrkamp.

- (2013): „The Project of Constitutional Sociology: Irritating Nation State Constitutionalism“, in: Transnational Legal Theory 4 (1), S. 44-58.

Teubner, Gunther; Willke, Helmut (1984): „Kontext und Autonomie: Gesellschaftliche Selbststeuerung durch reflexives Recht“, in: Zeitschrift für Rechtssoziologie 6 (2), S. 4-35.

Thibaut, Anton Friedrich Justus (1817): „Rezension: Blicke auf die juristische Praxis in Beziehung auf das künftige Gesetzbuch für Deutschland. 1817. 204 S. “, in: Heidelbergische Jahrbücher für Litteratur 10 (26), S. 401-406.

- (1838): „Ueber die sogenannte historische und nicht-historische Rechtsschule“, in: Archiv für die civilistische Praxis XXI, S. 391-419.

- (1840a): „Aus den Heidelbergischen Jahrbüchern der Literatur. 1815. No. 42. S. 657-61: Rezension zu Savigny ZgeschRw, Bd. 1. Einleitungsaufsatz“, in: ders. (Hg.): Ueber die Nothwendigkeit eines allgemeinen bürgerlichen Rechts für Deutschland. Neue Ausgabe. Abgedruckt nach der der in den Civilist. Abhandlungen des Verf. als XIX. Abhandl. vielvermehrten zweiten Bearbeitung dieser Schrift. Nebst Zugabe der darauf Bezug habenden Recensionen des Verf. aus den Heidelb. Jahrb. d. Liter. der Jahre 1814. 15. u. 16. Heidelberg: Mohr, S. 120-124.

- (1840b): „Rezensionen: Aus den Heidelbergischen Jahrbüchern der Literatur. 1814. No. 1. u. 2. S. 1-32. Ueber den Code Napoleon und dessen Einführung in Deutschland. Von August Wilhelm Rehberg (1814)“, in: ders. (Hg.): Ueber die Nothwendigkeit eines allgemeinen bürgerlichen Rechts für Deutschland. Neue Ausgabe. Heidelberg: Mohr, S. 55-88.

- (1840c): „Ueber die Nothwendigkeit eines allgemeinen bürgerlichen Rechts für Deutschland [2. Ausgabe 1814]“, in: ders. (Hg.): Ueber die Nothwendigkeit eines allgemeinen bürgerlichen Rechts für Deutschland. Heidelberg: Mohr, S. 1-54.

- (1959): „Über die Nothwendigkeit eines allgemeinen bürgerlichen Rechts für Deutschland [1814]", in: Stern, Jacques (Hg.): Thibaut und Savigny. Ein programmatischer Rechtsstreit auf Grund ihrer Schriften Über die Notwendigkeit eines allgemeinen bürgerlichen Rechts für Deutschland und Vom Beruf unserer Zeit für Gesetzgebung und Rechtswissenschaft. mit den Nachtr. der Verf. und den Urteilen der Zeitgenossen. Hrsg. u. eingel. von Jacques Stern. Unveränd. fotomech. Nachdr. d. Ausg. 1914. Darmstadt: Wissenschaftliche Buchgesellschaft, S. 35-68.

Thieme, Hans (1963): „Savigny und das deutsche Recht“, in: Zeitschrift der SavignyStiftung für Rechtsgeschichte / Germanistische Abteilung 80, S. 1-26.

Thomas, Anton (1803): Lebrbuch der natürlichen Rechtswissenschaft. Frankfurt am Main: J. C. Hermann.

Thon, August (1878): Rechtsnorm und subjectives Recht. Untersuchungen zur allgemeinen Rechtslehre. Weimar: Böhlau. 
Tönnies, Ferdinand (unbekannt): Exzerpt: Jhering. Geist des römischen Rechts. Schleswig-Holsteinische Landesbibliothek, Cb 54.45:11.

- (1880a): Notizbuch: Jhering: Der Zweck im Recht. Rezension (1880); zweiteilig (1. Teil). Schleswig-Holsteinische Landesbibliothek, Cb 54.41:17a.

- (1880b): Notizbuch: Jhering: Der Zweck im Recht. Rezension (1880); zweiteilig (2. Teil). Schleswig-Holsteinische Landesbibliothek, Cb 54.41:17b.

- (1880c): Notizbuch: Vortragsmanuskript "Die Erneuerung des Naturrechts I", 1880, dreiteilig (erster Teil). Schleswig-Holsteinische Landesbibliothek, Cb 54.41:64 I.

- (1880d): Notizbuch: Vortragsmanuskript "Die Erneuerung des Naturrechts II", 1880, dreiteilig (zweiter Teil). Schleswig-Holsteinische Landesbibliothek, Cb 54.41:64 II.

- (1880e): Notizbuch: Vortragsmanuskript "Die Erneuerung des Naturrechts III", 1880, dreiteilig (dritter Teil). Schleswig-Holsteinische Landesbibliothek, Cb 54.41:64 III.

- (1884): Exzerpt Jhering Zweck II. Schleswig-Holsteinische Landesbibliothek, Cb 54.41:30.

- (1887): Gemeinschaft und Gesellschaft. Abhandlung des Communismus und des Socialismus als empirischer Culturformen. Leipzig: Fues.

- (1896): Thomas Hobbes. Leben und Lebre. Stuttgart: Frommann.

- (1901): „Zur Theorie der Geschichte“, in: Archiv für systematische Philosophie 8, S. 1-38.

- (1906): Philosophische Terminologie in psychologisch-soziologischer Ansicht. Leipzig: Thomas.

— (1908): „Soziologie und Politik“, in: Zeitschrift für Politik 1, S. 219-229.

- (1909): Die Sitte. Frankfurt am Main: Ruetten \& Loening.

- (1911a): „Hobbes' Naturrecht“, in: Archiv für Rechts- und Wirtschaftsphilosophie 4 (3), S. 395-410.

— (1911b): „Soziologie und Rechtsphilosophie. Leitsätze“, in: Archiv für Rechts- und Wirtschaftsphilosophie 4 (4), S. 569-571.

- (1914): „Rechtsstaat und Wohlfahrtsstaat. Referat, erstattet auf dem III. Kongress der Internationalen Vereinigung für Rechts- und Wirtschaftsphilosophie“, in: Archiv für Rechts- und Wirtschaftsphilosophie 8 (1), S. 65-70.

— (1922): „Ferdinand Tönnies. Eutin (Holstein)“, in: Schmidt, Raymund (Hg.): Die Philosophie der Gegenwart in Selbstdarstellungen. Band 3. Leipzig: Felix Meiner, S. 199-234.

- (1925): „Die Anwendung der Deszendenztheorie auf Probleme der sozialen Entwicklung. Teil 1-6 [1905-1911]“, in: ders. (Hg.): Soziologische Studien und Kritiken. Band 1. Jena: Fischer, S. 133-329.

- (1926a): Das Eigentum. Wien, Leipzig: Braumüller.

— (1926b): „Die Aufgabe der Soziologie [1908]“, in: ders. (Hg.): Soziologische Studien und Kritiken. Band 2. Jena: Fischer, S. 123-124.

- (1926c): „Einteilung der Soziologie [1925]“, in: ders. (Hg.): Soziologische Studien und Kritiken. Band 2. Jena: Fischer, S. 430-443. 
- (1926d): „Entwicklung der Soziologie in Deutschland im 19. Jahrhundert [1908]“, in: ders. (Hg.): Soziologische Studien und Kritiken. Band 2. Jena: Fischer, S. $63-103$.

- (1926e): „Soziologie als Wissenschaft und die Deutsche Gesellschaft für Soziologie [1911]“, in: ders. (Hg.): Soziologische Studien und Kritiken. Band 2. Jena: Fischer, S. 144-149.

- (1926f): „Soziologie im System der Wissenschaften [1915/1916]“, in: ders. (Hg.): Soziologische Studien und Kritiken. Band 2. Jena: Fischer, S. 236-242.

- (1926g): „Wege und Ziele der Soziologie. Verhandlungen des Ersten Deutschen Soziologentages (Eröffnungsrede) [1910]“, in: ders. (Hg.): Soziologische Studien und Kritiken. Band 2. Jena: Fischer, S. 125-143.

— (1926h): „Zur Soziologie des demokratischen Staates [1923]“, in: ders. (Hg.): Soziologische Studien und Kritiken. Band 2. Jena: Fischer, S. 304-352.

— (1929): „Zweck und Mittel im sozialen Leben [1923]“, in: ders. (Hg.): Soziologische Studien und Kritiken. Band 3. Jena: Fischer, S. 1-39.

- (1931): Einführung in die Soziologie. Stuttgart: Enke.

- (1935): Geist der Neuzeit. Leipzig: Buske.

- (1979): Gemeinschaft und Gesellschaft. Grundbegriffe der reinen Soziologie. Neudr. 8. Aufl. von 1935. Darmstadt: Wissenschaftliche Buchgesellschaft.

- (1998): „Hegels Naturrecht. Zum Gedächtnis an Hegels Tod ( $\uparrow 14$. November 1831) [1932]“, in: ders.; Clausen, Lars (Hg.): 1932 - 1936. Geist der Neuzeit ; Schriften; Rezensionen. Berlin [u.a.]: de Gruyter, S. 247-265.

— (2000): „Individuum und Welt in der Neuzeit [1913]“, in: Mohr, Arno; Fechner, Rolf; Clausen, Lars (Hg.): Ferdinand Tönnies Gesamtausgabe: 1911-1915. Leitfaden einer Vorlesung über theoretische Nationalökonomie, Englische Weltpolitik in englischer Beleuchtung, Schriften, Rezensionen. Berlin, New York: de Gruyter, S. 299332.

- (2012a): „Gemeinschaft und Gesellschaft. Theorem der Kultur-Philosophie: Einleitung (Kapitel I-III) [Entwurf von 1880-1881]“, in: Lichtblau, Klaus; Tönnies, Ferdinand (Hg.): Soziologische Schriften. Studien zu Gemeinschaft und Gesellschaft. Wiesbaden: VS Verlag für Sozialwissenschaften, S. 27-58.

— (2012b): „Gemeinschaft und Gesellschaft. Vorrede zur ersten Auflage [1887]“, in: Lichtblau; Tönnies (Hg.): Soziologische Schriften. Studien zu Gemeinschaft und Gesellschaft, S. 59-69.

- (2012c): „Status und contractus. Eine sozialpolitische Betrachtung [1892]“, in: Lichtblau; Tönnies (Hg.): Soziologische Schriften. Studien zu Gemeinschaft und Gesellschaft, S. 71-78.

— (2012d): „Historismus und Rationalismus [1895]“, in: Lichtblau; Tönnies (Hg.): Soziologische Schriften. Studien zu Gemeinschaft und Gesellschaft, S. 79-100.

— (2012e): „Zur Einleitung in die Soziologie [1899]“, in: Lichtblau; Tönnies (Hg.): Soziologische Schriften. Studien zu Gemeinschaft und Gesellschaft, S. 101-110.

— (2012f): „Das Wesen der Soziologie [1907]“, in: Lichtblau; Tönnies (Hg.): Soziologische Schriften. Studien zu Gemeinschaft und Gesellschaft, S. 111-129. 
— (2012g): „Gemeinschaft und Individuum [1914]“, in: Lichtblau; Tönnies (Hg.): Soziologische Schriften. Studien zu Gemeinschaft und Gesellschaft, S. 203-211.

- (2012h): „Gemeinschaft und Gesellschaft. Vorrede der dritten Auflage“, in: Lichtblau; Tönnies (Hg.): Soziologische Schriften. Studien zu Gemeinschaft und Gesellschaft, S. 213-219.

— (2012i): „Der Begriff der Gemeinschaft [1919]“, in: Lichtblau; Tönnies (Hg.): Soziologische Schriften. Studien zu Gemeinschaft und Gesellschaft, S. 221-230.

— (2012j): „Gemeinschaft und Gesellschaft [1931]“, in: Lichtblau; Tönnies (Hg.): Soziologische Schriften. Studien zu Gemeinschaft und Gesellschaft, S. 231-255.

- (2012k): „Die Entstehung meiner Begriffe ,Gemeinschaft“ und ,Gesellschaft‘ [posthum]", in: Lichtblau; Tönnies (Hg.): Soziologische Schriften. Studien zu Gemeinschaft und Gesellschaft, S. 257-262.

— (2012l): „Mein Verhältnis zur Soziologie [1932]“, in: Lichtblau; Tönnies (Hg.): Soziologische Schriften. Studien zu Gemeinschaft und Gesellschaft, S. 263-280.

Tönnies, Ferdinand; Paulsen, Friedrich (Hg./ 1961): Briefwechsel 1876-1908. Herausgegeben von Olaf Klose, Eduard Georg Jacoby und Irma Fischer. Kiel: Hirt.

Tönnies, Sibylle (1987): „Die Erneuerung des Naturrechts durch die Unterscheidung zwischen Gemeinschaft und Gesellschaft", in: Rechtstheorie 18, S. 386-398.

Treiber, Hubert (1993): „Zur Genealogie einer 'science positive de la morale an Allemagne'“, in: Nietzsche-Studien 22 (1), S. 165-221.

- (1997): „Vom Nutzen und Nachteil juristischer Dogmatik“, in: Rechtshistorisches Journal 16, S. 411-452.

- (2014a): „Max Weber, Johannes von Kries und die kinetische Gastheorie“, in: Sociologia Internationalis 52 (2), S. 251.

- (2014b): „Zum Staatsverständnis bei Max Weber“, in: Sociologia Internationalis 52 (1), S. 1-40.

- (2016a): „Weder 'künstlerische Anschauung' noch 'Takt', sondern 'objektivierende Erkenntnis'. Zu einem vergessenen Schlüsselbegriff und kaum beachteten Autoren in Max Webers 'Wissenschaftslehre'“, in: Wagner, Gerhard; Härpfer, Claudius (Hg.): Max Webers vergessene Zeitgenossen. Beiträge zur Genese der Wissenschaftslehre. Wiesbaden: Harrassowitz, S. 93-116.

— (2016b): „Zur Frage nach der Vorbildfunktion Georg Jellineks für Max Webers Idealtypus“, in: Wagner, Gerhard; Härpfer, Claudius (Hg.): Max Webers vergessene Zeitgenossen. Beiträge zur Genese der Wissenschaftslehre. Wiesbaden: Harrassowitz, S. 145-160.

— (2017): Max Webers Rechtssoziologie - eine Einladung zur Lektüre. Wiesbaden: Harrassowitz.

Treiber, Hubert; Quensel, Bernhard K. (2002): „Das 'Ideal' konstruktiver Jurisprudenz als Methode: Zur 'logischen Struktur' von Max Webers Idealtypik“, in: Rechtstheorie 33, S. 91-124.

Treitschke, Heinrich von (1859): Die Gesellschaftswissenschaft. Ein kritischer Versuch. Leipzig: Melzer. 
Troeltsch, Ernst (1911): „Das stoisch-christliche Naturrecht und das moderne profane Naturrecht", in: Simmel, Georg (Hg.): Deutscher Soziologentag: Verhandlungen des Deutschen Soziologentages. 19. - 22. Okt. 1910 in Frankfurt a.M.; Reden und Vorträge von Georg Simmel [u.a.] und Debatten. Tübingen: Mohr, S. 166-192.

- (1922a): Der Historismus und seine Probleme. Band 1. Das logische Problem der Geschichtsphilosophie. Tübingen: Mohr.

- (1922b): „Die 'deutsche historische Schule'“, in: Die Dioskuren: Jahrbuch für Geisteswissenschaften 1, S. 178-207.

Turner, Stephen P. (1991): „Two Theorists of Action: Ihering and Weber“, in: Analyse \& Kritik 13, S. 46-60.

- (Hg./ 1993): Emile Durkheim. Sociologist and moralist. London [u.a.]: Routledge.

Turner, Stephen P.; Factor, Regis A. (1981): „Objective Possibility and Adequate Causation in Weber's Methodological Writing“, in: The Sociological Review 29 (1), S. 5-28.

- (1997): Max Weber. The lawyer as social thinker. London: Routledge.

Tyrell, Hartmann (1994): „Max Webers Soziologie - eine Soziologie ohne 'Gesellschaft'“, in: Wagner, Gerhard; Zipprian, Heinz (Hg.): Max Webers Wissenschaftslehre. Interpretation und Kritik. Frankfurt am Main: Suhrkamp, S. 390-414.

Unger, Joseph (1906): „Der Kampf um die Rechtswissenschaft“, in: Deutsche Juristenzeitung 11 (14), Sp. 781-787.

Valkhoff, Johan (1972): „Einige Wegbereiter der Rechtssoziologie in der Mitte des 19. Jahrhunderts: Dankwardt, Arnold, Leist“, in: ders. (Hg.): Recht, Mensch und Gesellschaft. Zur Transformation gesellschaftlicher Kräfte in Rechtsnormen. Berlin: Duncker \& Humblot, S. 24-47.

Valverde, Mariana (2006): „A New Entity in the History of Sexuality: The Respectable Same-Sex Couple“, in: Feminist Studies 32 (1), S. 155-162.

- (2007): „Theoretical and Methodological Issues in the Study of Legal Knowledge Practices“, in: Sarat, Austin; Douglas, Lawrence; Umphrey, Martha Merrill (Hg.): How law knows. Stanford, Calif.: Stanford University Press, S. 72-92.

- (2010): „Specters of Foucault in Law and Society Scholarship“, in: Annual Review of Law and Social Science 6 (1), S. 45-59.

Viehweg, Theodor (1970): „Rechtsdogmatik und Rechtszetetik bei Jhering“, in: Wieacker, Franz; Wollschläger, Christian (Hg.): Jherings Erbe. Göttinger Symposion zur 150. Wiederkehr des Geburtstags von Rudolf von Jhering. Göttingen: Vandenhoeck \& Ruprecht, S. 211-216.

Vierhaus, Felix (1888): Die Entstehungsgeschichte des Entwurfes eines Bürgerlichen Gesetzbuches für das Deutsche Reich. In Verbindung mit einer Uebersicht der privatrechtlichen Kodifikationsbestrebungen in Deutschland. Berlin, Leipzig: Guttentag.

- (1909): „Die Freirechtsschule und die heutige Rechtspflege“, in: Deutsche Juristen-Zeitung 14 (19), Sp. 1169-1175.

Vismann, Cornelia (2011): Medien der Rechtsprechung. Herausgegeben von Alexandra Kemmerer und Markus Krajewski. Frankfurt am Main: Fischer. 
Vogenauer, Stefan (2012): „Rechtsgeschichte und Rechtsvergleichung um 1900. Die Geschichte einer anderen 'Emanzipation durch Auseinanderdenken'“, in: Rabels Zeitschrift für ausländisches und internationales Privatrecht / The Rabel Journal of Comparative and International Private Law 76 (4), S. 1122-1154.

Vogl, Stefan (2003): Soziale Gesetzgebungspolitik, freie Rechtsfindung und soziologische Rechtswissenschaft bei Eugen Ehrlich. Baden-Baden: Nomos.

Vogt, Paul (1983): „Obligation and right: The Durkheimians and the sociology of law", in: Besnard, Philippe (Hg.): The Sociological Domain: the Durkheimians and the Founding of French Sociology. Cambridge, New York, Paris: Cambridge University Press, Editions de la Maison des sciences de l'homme, S. 177-198.

Vormbaum, Thomas (Hg./ 1997): Die Sozialdemokratie und die Entstehung des Bürgerlichen Gesetzbuches. Quellen aus der Sozialdemokratischen Partei und Presse. 2. Aufl. Baden-Baden: Nomos.

Wagner, Adolph (1892): Grundlegung der politischen Oekonomie. 3. Aufl. Erster Theil: Grundlagen der Volkswirthschaft. Erster Halbband (Einleitung und Buch 1-3). Leipzig: Winter.

Wagner, Gerhard (1987): Geltung und normativer Zwang. Eine Untersuchung zu den neukantianischen Grundlagen der Wissenschaftslehre Max Webers. Freiburg (Breisgau), München: Alber.

- (2014): „Der lange Schatten des Syllogismus. Zur Einheit der Wissenschaftslehre Max Webers“, in: Sociologia Internationalis 52 (2), S. 219-240.

Wagner, Gerhard; Härpfer, Claudius (2015): „Max Weber und die Naturwissenschaften“, in: Endreß, Martin; Lichtblau, Klaus; Moebius, Stephan (Hg.): Zyklos 1: Jahrbuch für Theorie und Geschichte der Soziologie. Wiesbaden: Springer, S. 169194.

Wagner, Gerhard; Zipprian, Heinz (1985): „Methodologie und Ontologie. Zum Problem kausaler Erklärung bei Max Weber“, in: Zeitschrift für Soziologie 14 (2), S. $115-130$.

- (1989): „Wertfreiheit. Eine Studie zu Max Webers kulturwissenschaftlichem Formalismus“, in: Zeitschrift für Soziologie 18 (1), S. 4-15.

- (Hg./ 1994a): Max Webers Wissenschaftslehre. Interpretation und Kritik. Frankfurt am Main: Suhrkamp.

— (1994b): „Zur Einführung“, in: dies. (Hg.): Max Webers Wissenschaftslehre. Interpretation und Kritik. Frankfurt am Main: Suhrkamp, S. 9-28.

Wagner, Peter (1990): Sozialwissenschaften und Staat. Frankreich, Italien, Deutschland 1870 - 1980. Frankfurt am Main, New York: Campus.

— (2000): „'An Entirely New Object of Consciousness, of Volitation, of Thought'. The Coming into Being and (almost) Passing Away of 'Society' as Scientific Object", in: Daston, Lorraine (Hg.): Biographies of scientific objects. Chicago: University of Chicago Press, S. 132-157.

- (2001): A history and theory of the social sciences. Not all that is solid melts into air. London, England, Thousand Oaks, Calif: SAGE.

Wagner-Hasel, Beate (2000): Der Stoff der Gaben. Kultur und Politik des Schenkens und Tauschens im archaischen Griechenland. Frankfurt, New York: Campus. 
Wallgärtner, Gisela (1991): Der soziologische Diskurs im Kaiserreich. Auswertung sozialwissenschaftlicher Zeitschriften. Münster [u.a.]: LIT.

Walther, Manfred (1989): „Hat der juristische Positivismus die deutschen Juristen im 'Dritten Reich' wehrlos gemacht? Zur Analyse und Kritik der Radbruch-These", in: Dreier, Ralf; Sellert, Wolfgang (Hg.): Recht und Justiz im "Dritten Reich". Frankfurt am Main: Suhrkamp, S. 323-354.

Wansleben, Leon (2008): „Geisteswissenschaften als epistemische Praktiken. Was kann die Wissenschaftssoziologie zur Zukunft der Geisteswissenschaften beitragen?“, in: Goschler, Constantin et al. (Hg.): Arts and figures. GeisteswissenschaftlerInnen im Beruf. Göttingen: Wallstein, S. 53-68.

Warnkönig, Ludwig August (1839): Rechtsphilosophie als Naturlehre des Rechts. Freiburg (Breisgau): Wagnersche Buchhandlung.

Weber, Max (1902): „Besprechung: Philipp Lotmar, Der Arbeitsvertrag. Nach dem Privatrecht des Deutschen Reiches. Bd 1. Leipzig 1902“, in: Archiv für soziale Gesetzgebung und Statistik 17, S. 723-734.

— (1920): „Vorbemerkung“, in: ders. (Hg.): Gesammelte Aufsätze zur Religionssoziologie. Band I. Tübingen: Mohr, S. 1-16.

- (1976): Wirtschaft und Gesellschaft. Grundriß der verstehenden Soziologie. Besorgt von Johannes Winckelmann. 5. Aufl. Studienausgabe. Tübingen: Mohr.

- (1988a): „Roscher und Knies und die logischen Probleme der historischen Nationalökonomie [1903-1906]“, in: ders.; Winckelmann, Johannes (Hg.): Gesammelte Aufsätze zur Wissenschaftslehre. 7. Aufl. Tübingen: Mohr, S. 1-145.

- (1988b): „Die 'Objektivität' sozialwissenschaftlicher und sozialpolitischer Erkenntnis [1904]“, in: ders.; Winckelmann (Hg.): Gesammelte Aufsätze zur Wissenschaftslehre. Tübingen: Mohr, S. 146-214.

- (1988c): „Kritische Studien auf dem Gebiet der kulturwissenschaftlichen Logik [1906]“, in: ders.; Winckelmann (Hg.): Gesammelte Aufsätze zur Wissenschaftslehre. Tübingen: Mohr, S. 215-290.

— (1988d): „R. Stammlers "Überwindung" der materialistischen Geschichtsauffassung [1907]“, in: ders.; Winckelmann (Hg.): Gesammelte Aufsätze zur Wissenschaftslehre. Tübingen: Mohr, S. 291-359.

— (1988e): „Nachtrag zu dem Aufsatz über R. Stammlers »Überwindung« der materialistischen Geschichtsauffassung [aus dem Nachlass]“, in: ders.; Winckelmann (Hg.): Gesammelte Aufsätze zur Wissenschaftslehre. Tübingen: Mohr, S. 360383.

— (1988f): „"Energetische" Kulturtheorien [1909]“, in: ders.; Winckelmann (Hg.): Gesammelte Aufsätze zur Wissenschaftslehre. Tübingen: Mohr, S. 400-426.

— (1988g): „Über einige Kategorien der verstehenden Soziologie [1913]“, in: ders.; Winckelmann (Hg.): Gesammelte Aufsätze zur Wissenschaftslehre. Tübingen: Mohr, S. 427-474.

- (1988h): „Die drei reinen Typen der legitimen Herrschaft“, in: ders.; Winckelmann (Hg.): Gesammelte Aufsätze zur Wissenschaftslehre. Tübingen: Mohr, S. 475488 . 
- (1988i): „Der Sinn der 'Wertfreiheit' der soziologischen und ökonomischen Wissenschaften [1918]“, in: ders.; Winckelmann (Hg.): Gesammelte Aufsätze zur Wissenschaftslehre. Tübingen: Mohr, S. 489-540.

- (1988j): „Soziologische Grundbegriffe [1921]“, in: ders.; Winckelmann (Hg.): Gesammelte Aufsätze zur Wissenschaftslehre. 7. Aufl.Tübingen: Mohr, S. 541-581.

- (1993): „'Römisches' und 'deutsches' Recht. in: Die christliche Welt. Evangelisch-Lutherische Gemeindeblatt für Gebildete aller Stände, Leipzig, Nr. 22 vom 30. Mai 1895, Sp. 521-525“, in: Mommsen, Wolfgang J. (Hg.): Landarbeiterfrage, Nationalstaat und Volkswirtschaftspolitik: Schriften und Reden 1892 - 1899. Max Weber Gesamtausgabe: Abt. 1, Bd. 4. Tübingen: Mohr Siebeck, S. 526-534.

- (1994): „Briefe 1909-1910“, in: Lepsius, M. Rainer; Mommsen, Wolfgang J. (Hg.): Briefe 1909-1910. Max Weber-Gesamtausgabe. Abteilung II: Briefe, Band 6. Tübingen: Mohr Siebeck, S. 13-765.

Weber, Max; Albrow, Martin (1975): „R. Stammler's 'Surmounting' of the Materialist Conception of History, Part 1", in: British Journal of Law and Society 2 (2), S. 129-152.

Weber, Max; Schluchter, Wolfgang; Schröder, Joachim (2011): Abriss der universalen Sozial- und Wirtschaftsgeschichte. Mit- und Nachschriften 1919/20. Tübingen: Mohr.

Weiß, Johannes (1981): Das Werk Max Webers in der marxistischen Rezeption und Kritik. Opladen: Westdeutscher Verlag.

- (1988): „Georg Simmel, Max Weber und die 'Soziologie'“, in: Rammstedt, Otthein (Hg.): Simmel und die frühen Soziologen. Nähe und Distanz zu Durkheim, Tönnies und Max Weber. Frankfurt am Main: Suhrkamp, S. 36-63.

- (1992): Max Webers Grundlegung der Soziologie. 2. Aufl. München, New York: Saur.

- (2010): „'Kultur ist ein Wertbegriff' - Über einen problematischen Grundsatz Max Webers“, in: Wohlrab-Sahr, Monika (Hg.): Kultursoziologie. Paradigmen, Methoden, Fragestellungen. Wiesbaden: VS Verlag für Sozialwissenschaften, S. 53-72.

— (2018): „Einleitung“, in: ders.; Frommer, Sabine (Hg.): Max Weber Gesamtausgabe. Verstehende Soziologie und Werturteilsfreibeit. Schriften und Reden 1908-1917. Abt. I Band 12. Tübingen: Mohr, S. 1-92.

Weiss, Manfred (2014): „Arbeitsrechtswissenschaft auf den Spuren Hugo Sinzheimers", in: Fachbereich Rechtswissenschaften der Goethe-Universität Frankfurt am Main (Hg.): 100 Jahre Rechtswissenschaft in Frankfurt. Erfahrungen, Herausforderungen, Erwartungen. Frankfurt: Klostermann, S. 577-590.

Whitman, James (1997): „Jhering parmis les Français“, in: Beaud, Olivier; Wachsmann, Patrick (Hg.): La science juridique française et la science juridique allemande de 1870 à 1918. Actes du colloque organisé à la Faculté de droit de Strasbourg, les 8 et 9 décembre 1995. Strasbourg: Presses universitaires de Strasbourg, S. 151-164.

Wieacker, Franz (1959): Gründer und Bewahrer: Rechtslehrer der neueren deutschen Privatrechtsgeschichte. Göttingen: Vandenhoeck \& Ruprecht.

- (1996): Privatrechtsgeschichte der Neuzeit: unter besonderer Berücksichtigung der deutschen Entwicklung. 2. Aufl. Göttingen: Vandenhoeck \& Ruprecht. 
Wiese, Leopold von (1957): „Gustav Rümelins Rede über den Begriff der Gesellschaft und einer Gesellschaftslehre", in: Zeitschrift für die gesamte Staatswissenschaft 113 (2), S. 350-355.

Wiethölter, Rudolf (1974): „Privatrecht als Gesellschaftstheorie? Bemerkungen zur Logik der ordnungspolitischen Rechtslehre“, in: Raiser, Ludwig; Baur, Fritz (Hg.): Funktionswandel der Privatrechtsinstitutionen. Festschrift für Ludwig Raiser zum 70. Geburtstag. Tübingen: Mohr, S. 645-695.

Wiley, Norbert (Hg./ 1987): The Marx-Weber Debate. Newbury Park, Calif.: Sage.

Wilhelm, Walter (1958): Zur juristischen Methodenlehre im 19. Jahrbundert. Die Herkunft der Methode Paul Labands aus der Privatrechtswissenschaft. Frankfurt am Main: Klostermann.

- (1979): „Private Freiheit und gesellschaftliche Grenzen des Eigentums in der Theorie der Pandektenwissenschaft", in: Coing, Helmut; Wilhelm, Walter (Hg.): Wissenschaft und Kodifikation des Privatrechts im 19. Jahrhundert. Band 4: Eigentum und industrielle Entwicklung, Wettbewerbsordnung und Wettbewerbsrecht. Frankfurt am Main: Klostermann, S. 19-39.

Wilmanns, Carl (1890): Die Reception des römischen Rechtes und die sociale Frage der Gegenwart. Berlin: Luckhardt.

Windscheid, Bernhard (1853): „Die Singularsuccession in Obligationen“, in: Kritische Ueberschau der deutschen Gesetzgebung und Rechtswissenschaft 1, S. 23-46.

- (1870): Lehrbuch des Pandektenrechts. Band 1. 3. Aufl. Düsseldorf: Julius Buddeus.

- (1904): „Die Aufgaben der Rechtswissenschaft. Leipziger Rektoratsrede vom 31. Oktober 1884“, in: Oertmann, Paul (Hg.): Bernhard Windscheid. Gesammelte Reden und Abhandlungen. Leipzig: Duncker \& Humblot, S. 100-125.

Wischmeyer, Thomas (2015): Zwecke im Recht des Verfassungsstaates. Geschichte und Theorie einer juristischen Denkfigur. Tübingen: Mohr Siebeck.

Wittkau-Horgby, Annette (1998): Materialismus. Entstehung und Wirkung in den Wissenschaften des 19. Jahrhunderts. Göttingen: Vandenhoeck \& Ruprecht.

Wolf, Erik (1926): „Besprechung Jerusalem, Franz Wilhelm: Soziologie des Rechts. I. Gesetzmäßigkeit und Kollektivität“, in: Jahrbücher für Nationalökonomie und Statistik 70 (125) (4), S. 374-376.

- (1963): Große Rechtsdenker der deutschen Geistesgeschichte. 4. Aufl. Tübingen: Mohr.

Wolff, Ernst (1914/15): „Freirechtsbewegung und Richteramt“, in: Die Tat. Sozialreligiöe Monatsschrift für deutsche Kultur 6 (4), S. 361-375.

Wrana, Daniel; Langer, Antje (2007): An den Rändern der Diskurse. Jenseits der Unterscheidung diskursiver und nicht-diskursiver Praktiken. [62 Absätze]. Forum Qualitative Sozialforschung / Forum: Qualitative Social Research [On-line Journal]. http://nbn-resolving.de/urn:nbn:de:0114-fqs0702206 (zuletzt geprüft am 16.01.2019).

Wrase, Michael (2006): „Rechtssoziologie und Law and Society - Die deutsche Rechtssoziologie zwischen Krise und Neuaufbruch“, in: Zeitschrift für Rechtssoziologie 27 (2), S. 289-312. 
- (2010): „Recht und soziale Praxis - Überlegungen für eine soziologische Rechtstheorie“, in: Cottier, Michelle; Estermann, Josef; Wrase, Michael (Hg.): Wie wirkt Recht? Baden-Baden: Nomos, S. 113-145.

Wrobel, Hans (1975): Die Kontroverse Thibaut-Savigny im Jahre 1814 und ibre Deutung in der Gegenwart. Bremen: Hochschulschrift.

Wunderlich, Agathon (1848): Das römische Recht der Gegenwart. Eine Pandektenvorlesung. Halle.

Wundt, Wilhelm (1892): Ethik. Eine Untersuchung Thatsachen und Gesetze des sittlichen Lebens. 2. Aufl. Stuttgart: Enke.

- (1918): Völkerpsychologie. Band 10: Das Recht. Leipzig: Kröner.

Würtenberger, Thomas (1991): Zeitgeist und Recht. 2. Aufl. Tübingen: Mohr.

Wurzel, Karl Georg (1904): Das juristische Denken. Wien: Perles.

Wüstendörfer, Hans (1913): „Die deutsche Rechtsprechung am Wendepunkt. Versuch einer positiven Methode soziologischer Rechtsfindung“, in: Archiv für die civilistische Praxis 110, S. 219-380.

- (1915): „Die beiden ersten deutschen Soziologentage und die Rechtswissenschaft", in: Archiv des öffentlichen Rechts 34, S. 399-430.

- (1916a): „Zur Hermeneutik der soziologischen Rechtsfindungstheorie“, in: Archiv für Rechts- und Wirtschaftsphilosophie 9 (2-3), S. 170-180, 289-320.

- (1916b): „Zur Hermeneutik der soziologischen Rechtsfindungstheorie. (Schluss. )“, in: Archiv für Rechts- und Wirtschaftsphilosophie 9 (4), S. 422-455.

Zeerleder, August (1896): „Privatrecht und soziales Recht“, in: ders. (Hg.): Kirche und Recht. Privatrecht und soziales Recht. 2 Vorträge, gehalten in Bern. Bern: Goepper \& Lehmann, S. 23-43.

Ziegert, Klaus A. (1979): „The Sociology behind Eugen Ehrlich's Sociology of Law", in: International Journal of the Sociology of Law 7 (3), S. 225-273.

Ziemann, Sascha (2009): Neukantianisches Strafrechtsdenken. Die Philosophie des Südwestdeutschen Neukantianismus und ihre Rezeption in der Strafrechtswissenschaft des frühen 20. Jahrbunderts. Baden-Baden: Nomos.

Zimmermann, Reinhard (2001): „Schuldrechtsmodernisierung?“, in: Ernst, Wolfgang; Zimmermann, Reinhard (Hg.): Zivilrechtswissenschaft und Schuldrechtsreform. Zum Diskussionsentwurf eines Schuldrechtsmodernisierungsgesetzes des Bundesministeriums der Justiz. Tübingen: Mohr Siebeck, S. 1-24.

Zitelmann, Ernst (1883): „Gewohnheitsrecht und Irrthum“, in: Archiv für die civilistische Praxis 66 (3), S. 323-468.

- (1889): Die Rechtsgeschäfte im Entwurf eines Bürgerlichen Gesetzbuches für das Deutsche Reich. Studien, Kritiken, Vorschläge. Erster Theil. Berlin: Guttentag.

- (1896): Die Gefahren des B.G.B für die Rechtswissenschaft. Rede zur Feier, des 27. Januar 1896, gehalten in der Aula der Universität zu Bonn. Bonn: Röhrscheid \& Ebbecke.

- (1903): Lücken im Recht. Rede, gehalten bei Antritt des Rektorats der Rheinischen Friedrich-Wilhelms-Universität zu Bonn am 18.10.1902. Leipzig: Duncker \& Humblot. 